\title{
Discurso y sociedad II Nuevas contribuciones al estudio de la lengua en un contexto social
}

José Luis Blas, Manuela Casanova, Mónica Velando, Javier Vellón (eds.) 


\section{COL·LECCIÓ «ESTUDIS FILOLÒGICS» Direcció: Lluís B. Meseguer}

1. Valoriana. Estudis sobre l'obra d'Enric Valor

2. La Escuela de Nueva York. John Ashbery y la nueva poética americana

3. Revisiones críticas del teatro alternativo británico 1968-1990

4. El discurs prefabricat. Estudis de fraseologia teòrica i aplicada

5. Discourse Analysis and Terminology in Languages for Specific Purposes

6. Methodology and New Technologies in Languages for Specific Purposes

7. Estudio toponímico del término municipal de Puertomingalvo (Teruel)

8. Language Learning in the Foreign Language Classroom

9. Estudios sobre lengua y sociedad

10. Oral Skills and Proposals for the Classroom

11. Aspectos empíricos de la traducción artesana y automática del verbo get

12. From Cha to Tea

13. Pragmatic Competence and Foreign Language Teaching

14. Tendencias actuales en los estudios filológicos anglonorteamericanos

15. Internet in language for specific purposes and foreign language teaching

16. Internet in linguistics, translation and literary studies

17. Linguistic studies in the academic and professional English

18. Computer-Mediated Lexicography in the Foreign Language Learning Context

19. Cognitive and discourse approaches to Metaphor and Metonymy

20. El Pensament de Salvador Dalí en el llindar dels anys trenta

21. La comparación con como en la Crónica Medieval: de Alfonso X a López de Ayala

22. Teaching and Learning the English Language from a Discourse Perspective

23. Discurso y sociedad. Contribuciones al estudio de la lengua en contexto social

24. Language @t Work: Language Learning, Discourse and Translation Studies in Internet

25. In-Roads of Language. Essays in English Studies

26. De unitate Speculorum: estudios de literatura comparada

27. El discurs prefabricat II. Fraseologia i Comunicació Social

28. Discurso y sociedad II. Nuevas contribuciones al estudio de la lengua en contexto social 
Col·lecció «Estudis filològics»

Núm. 28

\title{
DISCURSO Y SOCIEDAD II
}

\section{NUEVAS CONTRIBUCIONES \\ AL ESTUDIO DE LA LENGUA \\ EN CONTEXTO SOCIAL}

\author{
José Luis Blas Arroyo \\ Manuela Casanova Ávalos \\ Mónica Velando Casanova \\ JAVIER VELLÓN LAHOZ (EDS.)
}

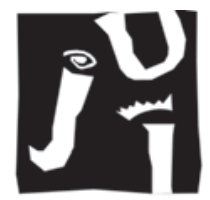

UNIVERSITAT

JAUME•I 
BIBLIOTECA DE LA UNIVERSITAT JAUME I. Dades catalogràfiques

DISCURSO Y SOCIEDAD II: nuevas contribuciones al estudio de la lengua en contexto social / José Luis Blas Arroyo, Manuela Casanova Ávalos, Mónica Velando Casanova, Javier Vellón Lahoz (eds.). —Castelló de la Plana: Publicacions de la Universitat Jaume I, D.L. 2008

p.; cm. - (Estudis filològics ; 28)

Bibliografía. æ Textos en castellà, català i anglès.

ISBN 978-84-16356-04-1

1. Sociolingüística. I. Blas Arroyo, José Luis, ed. lit. II. Casanova Ávalos, Manuela, ed. lit. III. Velando Casanova, Mónica, ed. lit. IV. Universitat Jaume I. Publicacions, ed. V. Sèrie.

$81^{\prime} 27$

Cap part d'aquesta publicació, incloent-hi el disseny de la coberta, no pot ser reproduïda, emmagatzemada, ni transmesa de cap manera, ni per cap mitjà (elèctric, químic, mecànic, òptic, de gravació o bé de fotocòpia) sense autorització prèvia de la marca editorial.

(C) Del text: els autors, 2008

(C) De la present edició: Publicacions de la Universitat Jaume I, 2008

Edita: Publicacions de la Universitat Jaume I. Servei de Comunicació i Publicacions Campus del Riu Sec. Edifici Rectorat i Serveis Centrals. 12071 Castelló de la Plana Tel. 9647288 19. Fax 964728832

http://sic.uji.es/publ_e-mail: publicacions@uji.es

ISBN 9978-84-16356-04-1

DOI http://dx.doi.org/10.6035/EstudisFilologics.2008.28

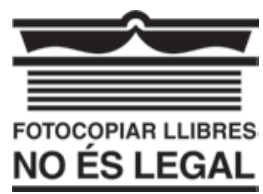




\section{ÍNDICE}

\section{Presentación}

JosÉ LuIs Blas ARROYo (Universitat Jaume I)

15

\section{Ponencias plenarias}

JosÉ LuIS Blas ARRoyo (Universitat Jaume I)

Aspectos estructurales y sociolingüísticos de una variedad de contacto:

el español de la Comunidad Valenciana

Lluís PAYRATó (Universitat de Barcelona)

Discurso, multimodalidad y plurilingüismo. Interrelaciones, interpretaciones y ejemplos

Teun A. van DiJK (Universitat Pompeu Fabra)

Racism and the press in Spain

\section{Sección I: Análisis del discurso: estrategias y tipologías}

Ángela Alameda (Universidad de Granada)

La prensa española ante la cuestión de Gibraltar: un análisis crítico del discurso de artículos editoriales

Cristina Aliagas, Carmen López, Soledad Aravena

(Universitat Pompeu Fabra)

Discurso y sociedad en las clases de lengua materna:

leer la ideología y comprender críticamente

Antonio Álvarez Platero, Ana Pitarch Gil, JoAn R. Monferrer Daudí (Universitat Jaume I)

Protocolos de comunicación en web: el portfolio europeo de las lenguas y los weblogs

Amparo Ayora del Olmo (Universitat Jaume I)

Análisis del discurso parlamentario español en el debate sobre el estado de la nación 2006 


\section{BEGOÑA BELLÉS-FoRTUÑo (Universitat Jaume I)}

Spoken academic discourse: the effects of students' participation in North-American and British lectures. A comparative study

EnRique Cámara Arenas (Universidad de Valladolid)

Atribución causal e interpretación: aplicaciones de la teoría de la covarianza al análisis del discurso

\section{Laura CAmargo Fernández (Universitat de les Illes Balears)}

Del enunciado a la enunciación: la representación de los aspectos no verbales del discurso en la interacción oral

PAul Danler (Universidad de Innsbruck)

Los objetivos sociodiscursivos de las distintas realizaciones argumentales en francés

$\mathrm{M}^{\mathrm{a}}$ Ángeles García CANElles (Universitat Jaume I)

El compromiso estético y social de la ironía romántica: «Poetisch leben»

M. Llü̈sa Gea VAlor (Universitat Jaume I)

'Great, brilliant, simply unputdownable!': exaggerated praise in online customers' reviews

Roberto Olaeta Rubio y Margarita Cundín Santos

(Universidad del País Vasco)

Expresiones eufemísticas en la prensa diaria

Pedro Tejada Tello (IES Vicent Castell i Domenech)

De los apodos y motes de toda la vida a los nicks del ciberhabla.

Hacia una caracterización lingüística de los chats a partir de los nicks ......235

Marisol Velasco Sacristán (Universidad de Valladolid)

Hacia una superación del sexismo semiótico en el discurso publicitario.......251

JAVIER VELLÓN LAHOZ (Universitat Jaume I)

El discurso del poder en el debate político: entre la autoridad y la legitimación. 


\section{Sección II: Estudios sobre (des)cortesía y construcción de la imagen en el discurso}

LidÓN BARBERÁ (Diario El Mundo), JAVIER Vellón (Universitat Jaume I) Imagen social e información en un conflicto urbano: el caso «Mestrets» ... 281

$\mathrm{M}^{\mathrm{a}}$ Ester Brenes PeÑa (Universidad de Sevilla)

Funciones estratégicas de la interrupción en los debates televisivos y su relación con la (des)cortesía verbal

Àngels CAmpos (Universidad Católica de Valencia), M.Josep Marín (Universitat Politècnica de València)

Qui som nosaltres i qui són els altres? Marques de persona en la campanya de L'Estatut de Catalunya

Andrea María Estrada (Universidad de Buenos Aires)

Evidencialidad y cortesía: ¿mentira o malentendido intercultural?

Ma Elena Gómez SÁNCHez (Universidad Europea de Madrid)

La configuración de la imagen pública: actividades de imagen en la entrevista política

Jolanta Kowalska ZapaseK (EOI Valencia)

Linguistic globalisation: the influence of English on national identities ...349

Nobuo Ignacio LóPez SAKo (Universidad de Granada)

Is «positive face» a universally valid concept?: toward a new model of face in politeness theory

Elvira MANero Richard (Universidad Católica San Antonio de Murcia)

¿Qué saben los hablantes sobre la cortesía lingüística? Algunos refranes españoles referidos a la cortesía

Mángeles Moreno LaRa (Universidad de La Rioja)

Metáfora y lenguaje político-periodístico: «Francia herida»

Manuel Padilla Cruz (Universidad de Sevilla)

On the (im)politeness of phatic utterances in the UK and USA

Paloma Tejada Caller (Universidad Complutense de Madrid)

Construcciones cambiantes de la identidad ajena: hetero-imagen inglesa en la Real Academia Española 
Alicia Vargas Amésquita (Universidad de Guadalajara, México)

Género y discurso teatral: la imagen de la madre-esposa en el teatro de la revolución mexicana (1904-1944)

\section{Sección III: Norma, usos y variación lingüística}

María Areta Lara (Universidad de Navarra)

Formulismo notarial y marcas de oralidad en declaraciones matrimoniales

de los siglos XVI-XVII: la expresión de la modalidad 443

María Luisa Arnal Purroy (Universidad de Zaragoza)

Niveles socioculturales y léxico dialectal en el vocabulario disponible de Aragón

Manuela Casanova Ávalos (Universitat Jaume I)

Anglicismos en el léxico disponible de Castellón

Bertha Chela-Flores (Universidad Simón Bolívar, Caracas)

Rasgos entonativos del español hablado en Venezuela: el enunciado declarativo

Joan Costa i Carreras (Universitat Pompeu Fabra)

El canvi lingüístic segons Pompeu Fabra (1891-1948)

Verónica Edeso Natalías (Universidad de Zaragoza)

Estudio de las formas ¿eh? y ¿no? en el discurso

M José García Folgado (Universitat de València), Mónica Velando Casanova (Universitat Jaume I)

Aportaciones del Diccionario Panhispánico de Dudas a la morfosintaxis del español

Astrid Huygens (Universidad de Gante)

El leísmo en Andalucía: una radiografía sociolingüística

FRANCESC LlOPIS RODRIGO (Universitat de València)

Disponibilitat lèxica del valencià: classificació dels fenòmens

de contacte lingüístic 
Josefina Prado Aragonés, María Victoria Galloso Camacho

(Universidad de Huelva)

La variable sexo en el léxico disponible de alumnos de primaria y bachillerato de Huelva: resultados cuantitativos

Ana Serradilla Castaño (Universidad Autónoma de Madrid)

Una diferencia sociolingüística en el uso de las fórmulas superlativas en español medieval

\section{Sección IV: Multilingüismo, interculturalidad y contacto de lenguas}

Raquel Casesnoves Ferrer (Universitat Pompeu Fabra)

DMLX: un programa informático para evaluar la revitalización y

proyectar tendencias de conocimiento y usos lingüísticos

Adela Costa, Consol Juan Asensio, Paulina Ribera Aragüete (Universitat de València)

El multilingüisme des del bilingüisme: les representacions dels estudiants de Magisteri envers la diversitat lingüística

CINZIA DI FRANCO

(Universidad Antonio de Nebrija de Madrid/Università degli Studi di Palermo)

La relación entre el aprendizaje del español como lengua extranjera y las actitudes lingüísticas

Dalila Fasla (Universidad de La Rioja)

El árabe como lengua fuente en los préstamos léxicos vigentes en francés magrebí

JAVIER GARCÍA GONZÁLEZ (Universidad Autónoma de Madrid)

Viejos problemas desde nuevos enfoques: los arabismos en el español medieval desde la perspectiva de la sociolingüística

Susana Gómez Martínez (Universidad de Valladolid)

Una nueva aproximación al concepto de orientación en el ámbito de aprendizaje y enseñanza de segundas lenguas y su aplicación en el marco universitario español 


\section{CRISTINA Illlamola (Universitat de Barcelona)}

La expresión de futuro en el español de Cataluña. Un posible caso de confluencia lingüística

Mercè Pujol Berché (Université de Lille 3)

El papel de la escuela ante la inmigración y la diversidad lingüística

Begoña Sarrionandia Gurtubay (Universidad del País Vasco)

Tipología de estrategias comunicativas entre hablantes euskaldunizados

LIDIA Usó VICIEDO (Universitat de Barcelona)

Creencias y modelos de representación sobre la enseñanza de la pronunciación en $\mathrm{E} / \mathrm{LE}$

Carmen Valero Garcés (Universidad de Alcalá de Henares)

Proyecto Universidad de Alcalá: Universidad para la inmigración

MARTA WichereK (Universidad Jaguelónica de Cracovia)

Los anglicismos en las lenguas española y polaca: un análisis contrastivo 773

$\mathrm{M}^{\mathrm{a}}$ ISABEl ANDÚGAR ANDREU (Universitat Jaume I)

Introducción de la fraseología en la clase de alemán 781 


\section{PRESENTACIÓN}


El presente libro contiene una selección de los trabajos presentados durante el III Congreso Internacional sobre Lengua y Sociedad, celebrado en la Universitat Jaume I de Castellón entre los días 19 y 21 de septiembre de 2006.

En la tercera edición de este congreso, que desde comienzos de la presente década se celebra periódicamente en la universidad castellonense, se concentraron más de ciento treinta actos académicos, repartidos entre ponencias, comunicaciones en diversas secciones, intervenciones en mesas redondas y paneles temáticos. Una cifra que representaba doblar, prácticamente, el nivel de participación alcanzado en la segunda convocatoria, en noviembre de 2004, y cuyas Actas (con el título de Discurso y Sociedad. Contribuciones al estudio de la lengua en contexto social) verían la luz un par de años más tarde. Y si la representación de especialistas resultó variada y profusa en los diferentes ámbitos temáticos abiertos al debate científico, no lo fue menos la procedencia de estos: casi dos centenares de participantes, llegados desde más de setenta universidades y otros centros de investigación repartidos por los cinco continentes.

Como tuvimos ocasión de destacar en el acto de presentación, el propósito que ha guiado siempre las diversas ediciones de este Congreso sobre Lengua y Sociedad ha sido permitir el intercambio de ideas, en un espacio autónomo de discusión, en torno a las implicaciones recíprocas entre dos realidades con las que convivimos a diario, el lenguaje y la sociedad. Así las cosas, la reunión científica que está detrás de las presentes Actas podría concebirse, en cierto modo, como un congreso de sociolingüística; y de hecho, así fue presentado en numerosos foros en los meses previos a su realización. Ahora bien, si aceptamos dicha adscripción disciplinaria, habría que matizar que, en todo caso, hablamos de una sociolingüística en su concepción más amplia, esto es, aquella en la que pueden verse incluidas tanto las investigaciones de orientación variacionista, como los temas adscritos comúnmente a la sociología del lenguaje o los modernos desarrollos de la sociolingüística interaccional. En suma, tanto los estudios sobre la estructura social, que tanta información han proporcionado a lo largo de las últimas décadas acerca de los hechos de variación y cambio en la lengua, como aquellos que parten, justamente, de la perspectiva inversa, esto es, donde son las lenguas como un todo, o sus variedades respectivas, las que nos permiten profundizar en el análisis de la sociedad. 
Con todo, el III Congreso Internacional sobre Lengua y Sociedad fue también un simposio en el que deseábamos que participaran -y así lo hicieron sobradamente-, otras áreas consolidadas de la investigación lingüística, y cuyas manifestaciones incluyen, en no pocas ocasiones, importantes revelaciones acerca de las implicaciones sociales del lenguaje. Este es el caso de algunos desarrollos del análisis del discurso, los estudios sobre las consecuencias lingüísticas y sociales del contacto de lenguas y culturas, o las investigaciones sociopragmáticas en torno a diversos principios y unidades del análisis interaccional. Asimismo, y con un espíritu de continuidad con respecto a convocatorias anteriores, tanto en el Congreso como en sus Actas hemos dado cabida también de forma monográfica a ciertas líneas y proyectos de investigación que han alcanzado un desarrollo particularmente intenso en los últimos años, como el análisis de la cortesía lingüística, o los estudios sobre disponibilidad léxica. Y todo ello, desde perspectivas tanto sincrónicas como diacrónicas.

Así pues, y tras el consiguiente proceso de selección a cargo de un comité científico integrado por destacados especialistas en los diferentes ámbitos de estudio, en este volumen presentamos un total de 53 trabajos, correspondientes a 3 ponencias y 50 de las comunicaciones presentadas durante el Congreso. Por su parte, estas últimas se ordenan en el libro de acuerdo con las siguientes agrupaciones temáticas: $a$ ) Análisis del discurso: tipologías y estrategias; $b$ ) Estudios sobre (des)cortesía y construcción de la imagen social; $c$ ) Norma, usos y variación lingüística; y $d$ ) Multilingüismo, interculturalidad y contacto de lenguas.

Junto a la diversidad temática, el lector encontrará también en estas páginas una muestra no menos significativa de diversidad lingüística. Los organizadores del Congreso, y editores del presente volumen, hemos querido contribuir, en la medida de nuestras posibilidades, a hacer realidad en un foro científico como el reseñado ese ideal del multilingüismo tantas veces proclamado a los cuatro vientos como ignorado en la práctica en las esferas educativas, administrativas, judiciales, etc. pero también en las académicas y científicas, donde casi siempre termina imponiéndose la dictadura de unas pocas lenguas, por no decir de una sola.

Tanto la organización del III Congreso Internacional sobre Lengua y Sociedad como la edición de las presentes Actas no hubiera sido posible sin la decisiva ayuda dispensada por diversas instituciones públicas y privadas, a las que es obligado recordar en estas palabras de presentación. En este sentido, queremos agradecer muy sinceramente las ayudas concedidas por algunas empresas con sede en Castellón, como TAU Cerámica y British Petroleum España, así como las contribuciones económicas de la Excma. Diputación de Castellón, la Fundación Mixta Bancaja-UJI, la Consejería de Cultura, Educación y Deporte de la Generalitat Valenciana (ADIF06/125) y el Ministerio de 
Educación y Ciencia (proyecto HUM2005-25425-E). Ahora bien, junto a esta ayuda material indispensable, queremos destacar también la entusiasta participación de numerosos alumnos, profesores y personal administrativo de la Facultad de Ciencias Humanas y Sociales de la Universitat Jaume I, cuya colaboración desinteresada hizo mucho más fácil el desarrollo del Congreso. Y cómo no, un agradecimiento muy especial a todos los congresistas, que durante tres días se dieron cita en la universidad castellonense para consolidar un congreso que, en su tercera edición, ha alcanzado ya plena madurez.

José Luis Blas ArRoyo

Presidente de la Comisión Organizadora 


\title{
ASPECTOS ESTRUCTURALES Y SOCIOLINGÜÍSTICOS DE UNA VARIEDAD DE CONTACTO: EL ESPAÑOL DE LA COMUNIDAD VALENCIANA
}

\author{
José Luis Blas Arroyo \\ Universitat Jaume I
}

\section{INTRODUCCIÓN}

Tos ejemplos (1) al (5) muestran algunas de las manifestaciones más caracUterísticas del contacto de lenguas que podemos encontrar en las comunidades de habla valencianas: ${ }^{1}$

(1) Deixa'm els horaris de trens Xavi, que li vull ensenyar una cosa. Mira Ana, es que este puente de la Constitución queremos ir a Madrid ida y vuelta y nos cuesta muy barato (Gómez Molina, 2000)

(2) i tu no saps els escándalos que ha armat quan era jove (Blas Arroyo, 2000)

(3) [...] mira Juan, mira lo que llevamos aquí, albondiguetas de carne $[\ldots] \mathrm{mm}$, esto, fideuà (Gómez Molina, 2000)

(4) Sólo le pido a la vida salut y felicidat. (Cscs-323) ${ }^{2}$

(5) [...] y luego viene San Antonio, que aquí al pueblo hacemos toros (CSCS-334)

El primero de los enunciados revela una de las modalidades del llamado cambio de código. Con este nombre se designa habitualmente en la bibliografía

1. Entre paréntesis figura el corpus o la obra de la que se extrae cada ejemplo. Las siglas CSCS corresponden al Corpus Sociolingüístico de Castellón, compilado por el Laboratorio de Sociolingüística de la UJI bajo la dirección del autor de estas páginas. El corpus, uno de los más amplios de su tipo en el mundo hispánico, se halla integrado por 305 entrevistas semidirigidas, de las cuales 225 han sido transcritas ya en el momento de redactar estas líneas, y clasificados sus informantes de acuerdo con criterios sociolingüísticos que aseguran la representatividad de los principales grupos que integran la sociedad castellonense. Por último, los ejemplos no identificados entre paréntesis corresponden a enunciados recopilados por el autor, en textos orales o escritos pero no publicados con antelación.

2. La cifra que aparece entre paréntesis corresponde al número de la entrevista de la que se ha extraído cada ejemplo en el Corpus Sociolingüístico de Castellón (CSCS). 
lingüística la alternancia por parte de un mismo hablante de fragmentos correspondientes a dos -o más- lenguas dentro de un mismo acto comunicativo, por razones diversas, que pueden ir desde la reproducción de citas en estilo directo, la existencia de modificaciones en el cuadro participativo de la interacción, la implicación del hablante en el mensaje o la mera plasmación en el habla de una entidad etnolingüística híbrida, como la que se ha descubierto en algunas comunidades hispanas de los Estados Unidos (Poplack, 1980; Torres, 1997). En el caso de (1) asistimos al cambio de lengua en función de la adscripción lingüística del interlocutor, uno de los motivos más frecuentes para la alternancia idiomática en las comarcas valencianohablantes de la Comunidad Valenciana. ${ }^{3}$ No en vano, en las conversaciones entre diversos participantes, muchos valencianohablantes cambian al castellano cuando se dirigen directamente a un interlocutor cuya historia conversacional identifican con esta última lengua, regresando al valenciano en la interlocución directa con los miembros de su mismo grupo etnolingüístico.

Con todo, estas manifestaciones del cambio de código deben distinguirse de otras que también singularizan el discurso bilingüe y en las que no deja de producirse en el fondo la misma alternancia de lenguas, si bien ahora con caracteres diferentes. A este respecto, nos referimos, por ejemplo, al llamado dualingüismo, modalidad que tiene lugar cuando en la conversación cada hablante mantiene su propia lengua. Aunque no tan extendida como en la vecina Cataluña, donde las pulsiones nacionalistas de uno y otro signo entre amplios sectores de la población propician la difusión creciente de este bilingüismo pasivo, no son tampoco excepcionales en tierras valencianas. El hecho de que la comprensión entre los hablantes de dos lenguas tan próximas se halle prácticamente asegurada, resulta un acicate para ese desenlace "no preferido" del principio de acomodación (Sachdev y Giles, 2004) cuando factores ideológicos y etnolingüísticos condicionan el desarrollo de las interacciones verbales.

Por su parte (2) es un ejemplo de lo que Poplack denomina préstamos ocasionales o espontáneos (nonce borrowing), inserciones léxicas de una segunda lengua, generalmente limitadas al ámbito de la palabra o la lexía compleja, y aisladas en el seno de un discurso producido íntegramente en otra lengua (Poplack, Sankoff y Miller, 1988). Pese a la ya larga polémica acerca del estatus tipológico de estos enunciados (véase un resumen actualizado en Muysken, 2004), algunos desarrollos metodológicos recientes, como el método comparatista, puesto

3. No así en las comarcas de la franja interior, que fueron reconquistadas fundamentalmente por aragoneses, de ahí que, históricamente, en ellas no se hable valenciano en la conversación cotidiana. Pese a ello, varios siglos de contacto intenso entre las dos comunidades idiomáticas han derivado en numerosos préstamos e influencias mutuas, que para el caso del español ha dado lugar al término despectivo de churro o habla churra (Román, 1998). 
en práctica por Poplack y sus colaboradores a partir de diferentes pares de lenguas en el mundo (Poplack y Malvar, 2007), demuestran fehacientemente su singularidad con respecto al cambio de código. El comportamiento gramatical de estos préstamos espontáneos es, en este sentido, similar al que ofrecen los préstamos consolidados -como sería el caso de fideuá [cat. fideuà] en (3)-, ya que cualitativa y cuantitativamente aparecen adaptados a la gramática de la L1 (Poplack, 1997), si bien se diferencian de estos por un menor grado de difusión social. Aunque la aplicación entre lenguas tipológicamente tan próximas como el castellano y el catalán puede entrañar algunas dificultades, nuestra propia puesta en práctica del método comparatista a partir de un corpus bilingüe valenciano nos permitió confirmar el mismo estatus para inserciones léxicas como las de (2) (Blas Arroyo, 2000).

Por último, los ejemplos (4) y (5) -y parcialmente el de (3)- afectan a niveles más profundos del análisis, como la fonología y la morfosintaxis, lo que supone una desviación con respecto a las normas monolingües estándares, y para los que inicialmente se ha reservado el nombre de interferencia lingüística desde la obra seminal de Uriel Weinreich (1953). Así, en (4) reproducimos el sonido particularmente tenso y sordo con que muchos valencianohablantes habituales realizan la consonante dental/-d/ en posición final de palabra, siguiendo los hábitos expresivos que impone la lengua catalana. La huella estructural de esta lengua también parece evidente en la inserción de un sufijo diminutivo como - eta $(s)$, característico del valenciano, junto a una base léxica española (albondig-), en (3). O en el empleo en (5) de la preposición $a$ en lugar de la preceptiva en en contextos estativos (esp. gen. “... aquí en el pueblo, hacemos toros"), así como en el calco de una expresión con el verbo comodín fer (fer bous; esp. hacer), particularmente funcional en lengua catalana.

\section{DIFERENCIAS DIALECTALES ENTRE LAS VARIEDADES DE CONTACTO}

Para los hablantes de las regiones donde el español convive con otras lenguas peninsulares, estos ejemplos resultan familiares, pero, por lo general, son pocos quienes conocen un origen que, lógicamente, no es otro que el calco de idénticas estructuras y rasgos procedentes de esas otras lenguas. De ahí que para muchos valencianos, enunciados como el de (5) no solo son perfectamente normales y aceptables, sino que al mismo tiempo encierran las variantes estadísticamente más probables en el habla común.

Muchos de estos fenómenos resultan corrientes también en otras regiones del ámbito lingüístico catalán, como Cataluña (Casanovas, 2001; Wesch, 1997; 
Sinner, 2004) o Baleares (Moll, 1961; Serrano, 1996). ${ }^{4}$ Sin embargo, no es descartable la existencia de diferencias dialectales y/o sociolingüísticas relevantes entre estas regiones, como han puesto de manifiesto los datos de algunos estudios recientes. Así, la confusión de las categorías adverbiales y prepositivas en el caso de bajo por abajo (debajo) (“... pero yo me pensaba que se había caído bajo de un puente" cscs-334), alcanza una difusión considerablemente más elevada en Valencia (Blas Arroyo, 1999) que en Barcelona (Sinner, 2004). Por el contrario, un fenómeno como la anteposición del artículo con nombre propio ("La Monse va y se come la estufa" CSCS-232), que en el español del resto de la península aparece claramente marcado desde el punto de vista sociolectal -y en buena medida también en las comarcas valencianasse ha advertido más homogéneamente difundido en tierras catalanas.

$\mathrm{Y}$ algo parecido sucede en otros paradigmas gramaticales, en los que las diferencias dialectales entre el catalán de Cataluña y el dialecto valenciano son decisivas para explicar la singularidad que alcanzan en uno $u$ otro territorio determinados hechos interferenciales. En la primera de estas comunidades históricas, por ejemplo, se han documentado empleos de ciertos conectores y marcadores discursivos que suponen un calco claro de idénticas unidades en el catalán de Cataluña (v. gr. "esta vez te lo presto; dile pero [cat. però] que es la última"; “...hoy no vendré, por eso") (Español 1996). Por el contrario, su extensión en la Comunidad Valenciana es mucho menor, lo que explicaría su rareza como fenómeno interferencial en estas tierras. Por otro lado, algunas diferencias en el paradigma preposicional entre los dialectos catalanes (Blas Arroyo, 1993; Casanovas, 2002), justifican la existencia de resultados interferenciales diferentes entre las hablas castellanas del Principado y las valencianas. Así, en estas últimas se ha documentado la sustitución de con por en en contextos circunstanciales ("el niño está en fiebre", "pártelo en el tenedor", "tortilla en patatas", Gómez Molina, 1986; Blas Arroyo, 1993), debido a la homofonía que esta última preposición presenta con la equivalente valenciana (en), a diferencia de la unidad característica del catalán oriental $(\mathrm{amb})$, mucho más dispar formalmente, y por lo tanto, un considerable freno para la interferencia. Y lo mismo sucede con otras diferencias pragma-gramaticales entre ambas variedades catalanas, de las cuales es generalmente la valenciana la que se halla más próxima al castellano. De ahí que fenómenos como la influencia en el español del esquema dual correspondiente a los pronombres demostrativos (aquest/aquell) del catalán oriental (Vann, 1998), frente a los tres grados del

4. Pese a ello, es muy poco lo que sabemos acerca del español hablado en las Islas. Afortunadamente, las cosas parecen estar cambiando en los últimos años con el inicio de algunos estudios sincrónicos y diacrónicos sobre estas variedades de contacto.

5. Esp. general: "Esta vez te lo presto, pero dile que es la última"; “... ahora bien (pero, sin embargo), hoy no vendré". 
valenciano (aquest, eixe, aquell) -coincidentes, pues, con los del castellano: este, ese, aquel-, o la diferente distribución de usos de los verbos ésser y estar, más alejados también de la norma española en las hablas catalanas norteñas que en las valencianas, dan lugar a desenlaces interlingüísticos también diferentes.

Ahora bien, incluso dentro de la misma Comunidad Valenciana, algunas diferencias dialectales permiten distinguir ciertos rasgos del español hablado en unas comarcas frente al de otras. Así, por ejemplo, la pervivencia de la articulación labiodental de /v/ en algunas regiones del interior se traslada en ocasiones al castellano hablado por valenciano-hablantes, a diferencia de la pronunciación labial impuesta ya -al igual que, desde hace siglos, en todo el castellano peninsular- por numerosos dialectos del catalán (Badia i Margarit, 1985: I, 75). Por otro lado, la procedencia heterogénea de los alumnos matriculados en las aulas universitarias castellonenses, donde el autor de estas páginas imparte clase, permite apreciar fácilmente tales diferencias, convertidas en ocasiones en auténticos estereotipos lingüísticos que singularizan ciertas hablas. Así ocurre con algunos elementos periféricos, como apelativos, marcadores discursivos y otros elementos reguladores del discurso, cuyo empleo varía de unas zonas a otras. Así, mientras que el marcador conclusivo " $y a u$ " de (6) es habitual en el castellano de las tierras valencianas en general, otros son característicos solo de determinadas variedades locales. Es el caso, por ejemplo, de otro marcador del mismo tipo, "y avant" ('ya está'), ampliamente utilizado en el área de Castellón, pero mucho más esporádico en otras áreas. Por su parte, el apelativo "nano" con que muchos jóvenes se dirigen a sus colegas y amigos representa una de las principales señas de identidad lingüística de los hablantes de la ciudad de Valencia y alrededores ${ }^{6}$ pero es inusual fuera de estas comarcas centrales. Finalmente, en otros casos las diferencias entre unas zonas y otras obedecen a variaciones formales, como sucede con la exclamación de sorpresa, que adopta la forma che (cat. Val: xé) en la ciudad de Valencia y en toda su área metropolitana, pero que en Castellón es cha (cat. CS: xá):

(6) Yo estudiaba el día de antes de memoria y au! (CSCS-217)

(7) [...] los estudios es más ir a la marcha de lo que estás haciendo y avant (CSCS-123)

(8) Y mi madre: "Manuela qué dices? "Y yo "chá (Val. Ché), mamá lo que estás oyendo que no, que no [...]" (CSCS-124)

(9) ¡Nano, nano, has visto qué golazo!

6. No obstante, en la mayoría de estas hablas el fenómeno presenta un característico perfil de age grading (Chambers, 1995), ya que caracteriza el habla juvenil, pero suele restringirse su uso en el paso a edades más avanzadas. 
Aunque manifestaciones del discurso bilingüe como el cambio de código o la práctica del bilingüismo pasivo en la Comunidad Valenciana merecerían una atención monográfica por sí solas, en las páginas que siguen nos ocuparemos preferentemente de los fenómenos que hemos situado en una escala más avanzada del proceso de integración lingüística, y que en la bibliografía especializada reciben nombres que van desde algunos ya mencionados, como interferencia, transferencia o préstamo (especialmente este último cuando se limita al nivel léxico), ${ }^{7}$ a otros más ocasionales, y a menudo sin límites definidos, como el de convergencia.

\section{FACTORES EN LA CONFIGURACIÓN DIALECTAL DEL ESPAÑOL EN LA COMUNIDAD VALENCIANA}

Otorgar al contacto con la lengua catalana toda la responsabilidad en la configuración del castellano hablado en la actualidad en la Comunidad Valenciana sería tan exagerado como inexacto. Por un lado, habría que tener presente otros hechos de contacto ajenos al influjo del catalán, como los que en la actualidad ejercen "a distancia" ciertas lenguas internacionales como el inglés, en lo que esta variedad de contacto coincide con otras peninsulares. Como es bien sabido, la influencia de la lengua inglesa se deja sentir en cada vez más ámbitos de la vida cotidiana, condicionando el español que se habla en las diferentes regiones españolas. Por mencionar un ejemplo, en la actualidad muchos jóvenes valencianos utilizan el anglicismo basket para referirse al deporte de la canasta, a diferencia de sus mayores, entre los que todavía es mayoritaria la variante española (baloncesto). Por otro lado, el hecho de que el catalán haya adoptado también este anglicismo para designar el deporte de la canasta contribuye a reforzar su presencia creciente en el castellano. Y ello por no hablar de la huella que el inglés ejerce en esferas como la informática, las telecomunicaciones, el desarrollo tecnológico y científico, etc. (Gómez Capuz, 2001; Gimeno y Gimeno, 2003).

Por otro lado, conviene traer a colación aquí otros hechos, menos conocidos, pero que revelan el mantenimiento de algunas isoglosas en las que se advierte una cierta continuidad pancrónica con el aragonés y, en general, las tradicionales variedades aragonesas del castellano. Particularmente, ello ocurre en el

7. Autores como Gómez Molina (2000) han propuesto la distinción entre estos dos conceptos en función del grado de integración lingüística y social. De este modo, considera interferencias aquellos rasgos que, con independencia del nivel al que pertenezcan, muestran un índice bajo de adaptación lingüística, al tiempo que encuentran un eco ocasional en la sociedad. Por el contrario, los préstamos -con independencia también del nivel lingüístico al que afecten- serían aquellas consecuencias del contacto de lenguas, diferentes del cambio de código, que han alcanzado un elevado índice de integración tanto en la matriz lingüística como en la social. 
léxico, como lo demuestra el empleo a un lado y otro de la actual frontera lingüística de términos y acepciones comunes tanto en las comunidades de habla valencianas como en las aragonesas, castellanas o murcianas. Estos son solo algunos ejemplos representativos (entre corchetes figura el significado en el español general): gemecar/chemecar ['lloriquear'], escampar ['separar'], esclafar ['aplastar'], embastar, encanar(se) ['pasmarse los niños el llanto'], horno ['comercio donde se vende pan'], molla ['miga del pan'], pancha ['panza'], paño ['tela'], socarrar ['quemar'], etc.

Ocasionalmente, dicho nexo se advierte también en otros niveles del análisis. Así sucede, por ejemplo, con el empleo en una amplia zona del este peninsular, que se extiende desde Aragón hasta Murcia, pasando por las comarcas valencianas, del sufijo diminutivo -ico, bien que limitado en las hablas de la Comunidad Valenciana algunos términos con valor afectivo (bonico/a), frente a su mayor funcionalidad en las dos primeras regiones mencionadas. Asimismo, la sustitución de cuanto por contra en esquemas comparativos ("contra más como, más adelgazo"), que algunos han caracterizado como valencianismo gramatical, es un rasgo que aparece también ampliamente difundido en otras regiones colindantes. Por otro lado, las comarcas del sur de la Comunidad reciben el influjo de otras variedades del español meridional, como el murciano, a través de rasgos tan reconocibles como la aspiración y/o elisión de /s/, ciertas afijaciones características del habla popular, (safrán, estijeras...), cambios de género (la calor, la helor...), o usos verbales idiosincrásicos ("en casarte, nos vamos") (Montoya, 1989: 116ss.).

Por otro lado, algunas hablas españolas de la Comunidad Valenciana presentan peculiaridades sin correlato en otras variedades de esta misma región histórica. Particularmente interesantes son, a este respecto, determinados elementos pragmático-discursivos que aparecen a menudo en la conversación, y que tienen un uso muy local, ajeno al habla de otras comarcas valencianas. Uno de estos es, por ejemplo, el empleo en Castellón de la fórmula conversacional muy bien con significados característicos, diferentes a los que dicha expresión cualitativa presenta en el español general. Como es sabido, muy bien puede ser empleado para mostrar la valoración positiva que nos merece la actuación del interlocutor ("lo has hecho muy bien, Pepe") o el acuerdo con lo dicho por este en una intervención previa ("Me parece muy bien"). Sin embargo, en las hablas castellonenses muy bien puede utilizarse también como elemento de confirmación, como en (10), donde un hablante valida un dato temporal de la historia que está narrando, tras un momento inicial de vacilación. Asimismo, la expresión puede funcionar en secuencias reactivas, como elemento de respuesta a una pregunta previa, como vemos en (11). El elemento común a estos valores $-\mathrm{y}$ otros que no detallamos aquí- consiste en la presencia de pausas o vacilaciones en el contexto previo, que revelan una cierta actividad cognitiva por parte del hablante, para precisar hechos 
o acontecimientos sobre los que inicialmente no posee una total seguridad. Muy bien actúa entonces como elemento de conformidad y aprobación, mediante el que se ratifica tan solo una de las alternativas referenciales que se ofrecen al interlocutor, al tiempo que se eliminan las demás (Blas Arroyo, en prensa:

(10) [éramos] muy pequeñitos, máximo cinco [...] eee [...] Muy bien cinco años. Pasamos la noche allí y :: al día siguiente (CSCS-2)

(11) A: $¿[\ldots]$ fuiste a ese colegio hasta que terminaste los estudios?

B: eee [...] muy bien, sí

El anterior es, como decimos, uno de los rasgos más característicos del español hablado en Castellón y más fácilmente reconocibles por hablantes ajenos a esta comunidad de habla. Como también lo es la estrategia discursiva utilizada por muchos castellonenses como respuesta a determinadas solicitudes de información. Dicha estrategia consiste en guiar a quien pregunta a través de la formulación secuenciada de cuestiones en forma negativa, que permiten señalar etapas diversas en la transferencia de la información y avanzar, de este modo, con mayor seguridad (Blas Arroyo, Boix, Gil y Tejada, 1992). Así, si un desconocido pregunta a un nativo de Castellón por la ubicación del instituto Ribalta es probable que, en lugar de la alternancia de enunciados imperativos y enunciativos esperable en otras hablas:

(12) siga recto y cuando llegue a X, tuerza a la derecha y allí verá Y. Coja la siguiente calle a la derecha $\mathrm{y}[\ldots]$

o alternativamente, preguntas aproximativas del tipo:

(13) ¿sabe usted dónde está el edificio de Correos [...]?

reciba esta otra:

(14) ¿(que) no hay una avenida ancha donde está el edificio de Correos $[\ldots]$ ?

que se completará a renglón seguido con esta otra, si la respuesta del interlocutor es afirmativa:

(15) ¿(que) no hay otro edificio grande un poco más adelante [...]? Pues ahí está

y así sucesivamente, hasta completar el acto informativo. 


\subsection{Vestigios del contacto en el español de la Comunidad Valenciana}

En los últimos tiempos se ha llamado la atención sobre el hecho de que en las variedades de contacto pueden haber hallado refugio variantes antiguas, ya desaparecidas en otros dialectos, lo que, a juicio de algunos investigadores, mermaría capacidad explicativa al contacto lingüístico. Así se ha señalado, por ejemplo, a propósito de algunos rasgos característicos del inglés hablado en Irlanda, tradicionalmente asociados al contacto con el gaélico, y sobre los que hoy se sabe que tuvieron también una cierta difusión en otros dialectos ingleses en épocas pasadas (Harris, 1991). Y lo mismo sucede en el ámbito hispánico con determinadas estructuras reflexivas, que singularizan en la actualidad el español hablado en México, y que tras justificarse durante algún tiempo por el contacto con las lenguas indígenas, se han visto también repartidas por todo el continente americano en siglos pretéritos (Sala, 1988).

Ahora bien, negar el origen interferencial de un fenómeno es una cosa y poner en duda la influencia del contacto como catalizador del mismo, otra bien distinta. De hecho, ambas circunstancias no son en absoluto incompatibles. Por ello, un análisis detallado de la realidad lingüística de estas comunidades bilingües muestra que precauciones como las esbozadas en párrafos anteriores, con ser plausibles y necesarias desde el punto de vista científico, no siempre hacen justicia a la importancia del factor interlingüístico en la configuración de las respectivas variedades del español. En el caso de las regiones del este peninsular, el contacto secular con el catalán tiene una influencia decisiva en la configuración panlectal de sus variedades, un contacto intensificado durante buena parte del siglo Xx por fenómenos como la inmigración interior masiva o la extensión de la diglosia y el proceso de sustitución lingüística. Tanto la antigüedad como la intensidad de dicho contacto, unidas a la proximidad de las dos lenguas, han favorecido numerosos procesos interferenciales y convergentes entre las dos lenguas.

Con todo, cabe aventurar que las condiciones específicas que presenta el contacto en las diferentes regiones del ámbito lingüístico catalán permitirían realizar predicciones acerca del proceso interferencial favorito en cada una de ellas. Así, en las comarcas donde el español conoce más restricciones funcionales es razonable pensar que habrá una mayor tendencia a la atomización de hechos de interferencia en el habla, especialmente en boca de bilingües con un dominio mucho mayor del catalán que del castellano. Por el contrario, en las zonas donde dicha lengua convive intensamente con el español -muchas de ellas en la misma Comunidad Valenciana- serán menos esperables las interferencias más "crudas" y más los hechos de integración y convergencia lingüística, capaces de alcanzar incluso a los castellanohablantes de la Comunidad. 
Aunque otras variedades monolingües puedan mostrar en ocasiones pulsiones internas paralelas en determinados paradigmas, no es menos cierto que en los dialectos de contacto se producen algunos hechos distribucionales difícilmente soslayables y que avalan, a nuestro juicio, la relevancia del contacto de lenguas. Los siguientes son algunos de ellos:

a) Las variantes vernáculas se extienden a contextos gramaticales $y / 0$ pragmáticos por lo general mucho más esporádicos o inéditos en los demás dialectos. Silva Corvalán (1994) recuerda, por ejemplo, cómo la omisión del complementante que en subordinadas completivas utilizadas por los hablantes de origen mejicano de la ciudad de Los Ángeles (“dijo Ø no lo quería ver”) supone ampliar dicha elisión -ya presente en el español general en algunos registros formales ("le agradecería Ø me dijera si puedo" [...])- a otros contextos adicionales. Ahora bien, una ampliación -hay que reconocer- donde la influencia del inglés parece indiscutible. Por nuestra parte (Blas Arroyo, 1993), hemos llamado la atención acerca de ciertos esquemas sintácticos en el español hablado en Valencia que presentan un notable grado de convergencia con el catalán -donde tampoco son normativos- y que suponen un desenlace de estas mismas características. Es el caso de enunciados como los de (16) y (17):

(16) Tengo el carné de conducir siete años (esp. gen. "Tengo el carné desde hace siete años")

(17) Vivo ya doce años en esta finca (esp. gen. "Llevo viviendo ya doce años en este edificio/vivo desde hace doce años en este edificio")

Se trata de construcciones nominales con valor circunstancial, y con el verbo en presente de indicativo, que denotan el tiempo transcurrido desde el inicio de una actividad o estado hasta el momento del habla, y que suponen una clara simplificación con respecto a las que prescriben las gramáticas y demás obras normativas del español. Aunque en la lengua hablada de otras regiones peninsulares no faltan ejemplos de economía lingüística que conducen a la elisión del nexo preposicional (desde), no nos consta la amplia difusión en ellas de esquemas sintácticos como el ejemplificado más arriba, y en el que, junto a la preposición, desaparece también el verbo fosilizado hacer. Bien es cierto que dichas construcciones simplificadas encuentran un importante apoyo estructural en la posibilidad que ofrece la lengua de omitir esos mismos sintagmas en otros contextos morfosintácticos, como: 
1) las perífrasis de gerundio ("llevo viviendo ya doce años en esta finca");

2) la subcategorización de ciertos verbos durativos ("llevo doce años...; "dura ya cinco años ese calvario"), con los que el circunstancial aparece -esta vez normativamente- mediante un sintagma nominal ("doce años [...] cinco años");

3) por no hablar de los mismos verbos afectados por el esquema de simplificación que nos ocupa (estar, vivir, tener...) en otros tiempos de la conjugación diferentes al presente ("estuvimos siete años en esa casa", "hemos tenido tres años ese problema"). ${ }^{8}$

Ahora bien, a nuestro juicio, la extensión alcanzada en las comunidades de habla valencianas, tanto en la matriz lingüística como en la social, del esquema ejemplificado en (16) y (17), encuentra en estas regiones bilingües un factor decisivo en el contacto con el catalán hablado en Valencia. No en vano, este último presenta con la misma intensidad idénticos modelos sintácticos, que, al igual que en castellano, tampoco son aceptados por la normativa ("Tinc el carnet set anys", "Viu ja dotze anys en aquesta finca").

b) Complementariamente, la difusión social de estas variantes vernáculas suele ser también más elevada que:

1) en otras variedades peninsulares del español, ya sea en la actualidad o en épocas pasadas; y

2) alcanza en muchos casos a los castellanohablantes (en el mejor de los casos, tan solo bilingües pasivos), que, como miembros de la comunidad de habla, adquieren idénticos hábitos expresivos que los valencianohablantes.

Pese a ello, algunos autores han puesto en duda la idea de que numerosos rasgos del dialecto español hablado en Cataluña puedan ser responsabilidad directa del contacto de lenguas, argumentando la existencia de esas mismas particularidades "catalanas" en el castellano de individuos que nunca han estado en contacto (Sinner, 2004: 31). Así, en las encuestas utilizadas por Carmen Hernández (1998: 11) para analizar la interferencia escrita en el español de los estudiantes universitarios de Barcelona, la investigadora catalana señala que muchos supuestos catalanismos no son tales, ya que son reconocidos también por estudiantes procedentes de otras

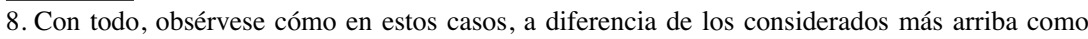
resultado de la convergencia con el catalán, el aspecto imperfectivo desaparece, por lo que el contexto semántico-pragmático es, pues, claramente diferente. 
regiones españolas. ${ }^{9}$ Ahora bien, con independencia de que no siempre las respuestas de este tipo hacen justicia acerca del "saber" lingüístico de los encuestados ${ }^{10} \mathrm{y}$ de que, por otro lado, los medios de comunicación actuales nos ponen a diario en contacto con rasgos lingüísticos de procedencias muy diversas,${ }^{11} \tan$ sólo podríamos invalidar la hipótesis de la influencia interferencial si comprobáramos patrones de difusión o evaluación social similares entre miembros de

9. Esta misma autora señala en otro lugar que determinadas fórmulas conversacionales, como las formas de saludo y despedida, son difícilmente atribuibles a los fenómenos de contacto (préstamos, interferencias o cambios de código, etc.) puesto que son muy conocidas y difundidas entre todos los hablantes. Ahora bien, que rutinas de despedida como agur en el País Vasco se hallen prácticamente generalizadas -particularmente en las zonas más vascófonas-y en menor medida, otras como adéu (déu), entre nosotros; o que fórmulas de saludo (bon dia, bona nit) sean cada vez más frecuentes en el discurso en español de las regiones del ámbito lingüístico catalán, no pueden invalidar su origen interferencial. De hecho, este es más que evidente en muchas ocasiones, como lo demuestra su empleo recurrente por parte de muchos monolingües castellanohablantes, que esperan obtener así un "beneficio" estratégico, bien sea mostrando indicios de acomodación emblemáticos con interlocutores que poseen una filiación etnolingüística más "políticamente correcta", bien sea por el temor a recibir una cierta sanción social ante el empleo de fórmulas no vernáculas. En el País Vasco, por ejemplo, nuestra experiencia personal nos impulsa a creer que el empleo de agur, se ve claramente condicionado por la adscripción lingüística y, sobre todo, ideológica del interlocutor. De manera que un castellanohablante utiliza mucho más frecuentemente esta fórmula (y otras, kaixo ['hola'], eskerri kasko ['gracias']) cuando se dirige a participantes de ideología nacionalista. Y aunque con límites mucho menos extremos, algo similar podemos observar en la Comunidad Valenciana en determinados ámbitos institucionales. Así, entre los profesores y alumnos de la Universitat Jaume I, donde el catalán aparece como única lengua oficial y donde está bien visto y prestigiado el empleo prioritario de esta lengua, se advierte una presión que impulsa al saludo -y demás fórmulas conversacionales- en catalán, aunque el resto de la interlocución tenga lugar en castellano. De este modo, muchos castellanohablantes cuando entran en una conserjería, en una reunión departamental o en cualquier otra dependencia universitaria -particularmente en las más institucionales-, se enfrentan a tres estrategias posibles ante el obligado saludo (lo contrario, llevaría también aparejadas las sanciones correspondientes): a) saludar en castellano (buenos días), fórmula minoritaria por la presión ambiental favorable al catalán; b) saludar en catalán (Bon dia, bona vespra(d)a, bona nit), acomodando la lengua, siquiera en estos pasajes periféricos de la conversación, a la lengua socialmente no marcada (Myers-Scotton, 1993) en ese ámbito; o c) saludar mediante fórmulas alternativas más "neutras", tanto desde el punto de vista interaccional como lingüístico (el caso de hola, por ejemplo, equivalente en las dos lenguas). Para otros ejemplos similares de empleo de elementos léxicos o expresivos de los que el hablante tiene plena conciencia sobre su origen catalán, como el caso del muy popular nen (“¿qué te pongo, nen?"), véase Sinner (2004: 99).

10. La fórmula "yo también lo he oído" es criticable. Por un lado, habría que determinar con qué frecuencia se ha escuchado y por otro lado, -y no menos importante- a quién. De hecho, la presencia en los medios de comunicación de individuos de diferentes procedencias, es un hecho determinante, que, por desgracia, no siempre se ha tenido en cuenta en el análisis de estos casos.

11. En España la presencia creciente de locutores y otros personajes célebres de la televisión procedentes de Cataluña y Valencia puede estar contribuyendo a la difusión de algunos de estos fenómenos característicos del español hablado en las regiones del ámbito lingüístico catalán. A propósito del imperativo ves que se menciona a continuación, Sinner (2004: 217) recoge diversos ejemplos a cargo de personajes tan célebres como Xavier Sardà ("Pero tú jves tocando!, en Crónicas Marcianas, Telecinco, 29-I-1998). Recientemente, hemos podido escucharlo también a un actor valenciano (Arturo Valls), que interpreta un papel destacado en dos de los programas de más éxito de la televisión española en el momento de escribir estas líneas (Cámera café y Caiga quien caiga). Otro rasgo vernáculo en su habla es, por ejemplo, la confusión bajo por abajo (están ahí bajo). 
comunidades de habla diferentes. Sin embargo, Sinner (2004) ha advertido recientemente acerca de la existencia de diferencias estadísticas significativas entre la muestra de hablantes autóctonos y otra de control, integrada por madrileños, en lo que al nivel de aceptabilidad de estos rasgos se refiere. A propósito, por ejemplo, del uso de ves como forma del imperativo del verbo ir, cuya formación podría explicarse tanto por analogía con otras formas de la segunda persona verbal (Seco, 1989), como por interferencia del catalán (vés) (Szigetvári, 1994), el lingüista alemán obtiene una variación regional claramente significativa: mientras que el valor medio de aceptabilidad intuitiva es de 3,85 en el grupo catalán (en una escala de 0 a 5), este desciende hasta un 1,9 en el madrileño.

En suma, un más que probable hecho de causación múltiple encuentra un eco diferente en comunidades lingüísticas también diferentes. Y si tales diferencias evaluativas se ven corroboradas por otras tantas del mismo signo en el uso real, habrá que conceder que el contacto de lenguas sí tiene un considerable peso explicativo.

c) Por último, la relevancia del contacto lingüístico puede mantenerse a salvo, con independencia de cuál pueda ser el origen de un fenómeno particular, si se comprueba la incidencia de factores externos, relacionados con el bilingüismo, como, entre otros: 1) la densidad etnolingüística en el seno de la comunidad de habla; 2) el tipo y grado de bilingüismo individual y/o social; 3 ) las actitudes de los hablantes hacia las lenguas en contacto, etc.

Los ejemplos disponibles en diversas regiones españolas avalan esta influencia, que algunos se han atrevido a situar, incluso, en un interesante plano simbólico. En su investigación acerca del fenómeno de la omisión de clíticos en el País Vasco (“¿Has comprado el vino? Sí, Ø he comprado”) Fernández Ulloa y Urrutia (1998) han advertido que la elipsis pronominal es significativamente más habitual en el habla de los euskaldunzaharras (hablantes con el vasco como L1) que en la de los euskaldunberris (hablantes con el vasco como L2) y erdaldunes (castellanohablantes exclusivos). Por su parte, Mendieta y Molina (1995) han observado que dicho fenómeno, para el que se ha visto una influencia del vasco (Oñederra, 2004), es mejor evaluado por los hablantes bilbaínos que por otra muestra de control compuesta por madrileños. Con todo, más significativa resulta aún la covariación que se observa entre la frecuencia de omisión del clítico y el grado de solidaridad con aquellos interlocutores que el hablante vincula como más ligados a la lengua y la cultura vascas.

En el español hablado en Cataluña, el sociolingüista norteamericano Robert Vann (1998) ha estudiado fenómenos de contacto de este mismo tipo, 
que trascienden el plano puramente gramatical, por sus particulares implicaciones pragmáticas y/o simbólicas. Así, rasgos que suponen un calco del catalán, como:

a) la confusión en la matriz de rasgos deícticos de pares verbales como ir/venir ("ya vengo" vs. Esp. gen. "ya voy") o traer/llevar ("Ya te los traigo a tu oficina" vs. Esp.gen. "Ya te los llevo a tu oficina"), o

b) la reducción del paradigma de los demostrativos a tan solo dos miembros ("Me gusta éste al lado mío, no éste detrás de ti" vs. Esp.gen. "Me gusta éste al lado mío, no ese detrás de ti"), sirven a muchos hablantes autóctonos no sólo como elementos deícticos en la conversación, sino también como marcadores de identidad etnolingüística en unos tiempos de cambios profundos en la sociedad catalana.

Por otro lado, determinadas actitudes idiosincrásicas hacia las lenguas en contacto justifican la recurrencia con que tienen lugar ciertos hechos de lo que podríamos denominar interferencia pragmática (Argente y Payrató, 1991). A los ya citados más arriba, añádase ahora la costumbre habitual en las poblaciones valencianas de acudir a la lengua autóctona para la expresión de tacos y demás expresiones malsonantes (collons), incluso modificadas para mitigar aún más su potencial fuerza agresiva (collins). Y lo mismo sucede con otros tabúes lingüísticos, como muestra el empleo habitual entre muchos hablantes -incluidos algunos castellanohablantes- del valencianismo pixar, en lugar del más "crudo" mear, o el demasiado formal orinar:

(18) ¡Collins tía!, ¿Y cuántas veces te ha pasado eso? (CSCs-143)

(19) ¡[..] Y se puso a pixar en medio (de) la calle, allí! (CSCs-175)

Interesante resulta también, en este mismo sentido, el distinto valor que los hablantes adjudican a determinadas fórmulas conversacionales paralelas en las dos lenguas. Así, para muchos valencianos la expresión de despedida adiós posee unas connotaciones temporales mucho más extremas que la equivalente catalana adéu (o su variante reducida déu), ${ }^{12}$ por lo que es habitual que los hablantes -especialmente los más jóvenes- elijan la fórmula catalana para despedirse, incluso cuando la conversación tiene lugar en castellano.

12. En el debate posterior a una de las comunicaciones presentadas en el III Congreso Internacional sobre Lengua y Sociedad, algunos congresistas asistentes con residencia en Cataluña subrayaron que, en ciudades como Barcelona, déu, es una fórmula de despedida que goza de una gran difusión social, especialmente entre los jóvenes de cualquier adscripción lingüística. 


\section{LOS GRADOS DE LA INTERFERENCIA LINGÜÍSTICA: CRITERIOS TEÓRICOS Y METODOLÓGICOS PARA DELIMITAR EL GRADO DE INTEGRACIÓN (SOCIO)LINGÜÍSTICA DE LOS FENÓMENOS DE CONTACTO EN EL HABLA}

Desde que Weinreich (1953) sentara las bases de los modernos estudios sobre el contacto de lenguas medio siglo atrás, los intentos de caracterización y clasificación del concepto interferencia han sido numerosos (para un resumen, véanse Payrató, 1985; Blas Arroyo, 1991; Sinner, 2004). Sin ánimo de ser exhaustivos, podríamos resumir diciendo que en los primeros ensayos, la interferencia lingüística se concebía como una desviación, y aplicado al aprendizaje de lenguas, como un "error" de actuación como consecuencia de la familiaridad con otro u otros idiomas por parte de los hablantes bilingües. ${ }^{13}$ No obstante, ya el propio Weinreich se vio obligado a reconocer la necesidad de distinguir entre fenómenos que ocurren de forma ocasional en el habla de esos hablantes bilingües y otros cuya difusión es considerablemente mayor, de forma que alcanzan a toda una comunidad de habla.

Estas diferencias entre lo que Weinreich denomina -desde la óptica estructuralista imperante en la época-, interferencias en el habla e interferencias en la lengua, sería reformulada más adelante por otros autores, entre los que destaca el canadiense William F. Mackey (1970), a partir del cual es frecuente distinguir entre hechos de interferencia y hechos de integración. ${ }^{14}$ Para Mackey la clave que permite diferenciar ambos reside en una cuestión de grado tanto en el plano lingüístico como en el plano social. Pese a ello, reconoce que no siempre resulta sencillo determinar cuándo hemos pasado de un grado a otro, y en la práctica, tan solo estudios empíricos solventes podrían ofrecernos una aproximación fiable (Mackey, 1970: 195).

Entre nosotros son ya varios los estudios que han acudido a esta distinción teórica en el examen del contacto entre español y catalán, tanto el que circula

13. Esta concepción de la interferencia es en parte responsable de la estigmatización del término. De ahí que desde muy pronto, numerosos lingüistas hayan intentado evitarlo, sustituyéndolo por otros (transferencia, simplificación...) que, pese a todo, no resuelven todos los problemas ya que no dan cuenta por completo de la complejidad estructural que puede entrañar la influencia interlingüística (vid. Payrató, 1985; Blas Arroyo, 1991, 2005).

14. Sin embargo, leyendo algunos trabajos sobre el tema en ocasiones da la impresión de que se olvida que los hechos de integración son también fenómenos que obedecen al contacto interlingüístico. Y de hecho es plausible suponer que muchos de ellos han comenzado en etapas previas como fenómenos, bien de interferencia ("en el habla"), bien de cambio de código, cuya difusión en la comunidad ha terminado siendo tan amplia que se han impuesto como préstamos consolidados. El caso de algunas fórmulas conversacionales como las reseñadas anteriormente es, a este respecto, representativo. 
en esta dirección (Gómez Molina, 1986; Payrató, 1985), como el que aquí más nos interesa, esto es, la potencial influencia de la lengua catalana sobre el castellano (Blas Arroyo, 1993; Wesch, 2002; Sinner, 2004). Aplicado al caso valenciano, el proceso de la integración lingüística supone la mayor o menor adaptación a las reglas morfo-fonológicas y gramaticales del castellano de los valencianismos. En este sentido podríamos distinguir inicialmente entre valencianismos “crudos” (collons! ['¡cojones'!], vete a fer la mà [expresión malsonante, equivalente a 'vete a la mierda'], ir a tota virolla ['a toda velocidad'], ser un tarator ['tarambana']...), de otros en los que se aprecia un mayor grado de adaptación a dichas reglas. Esto último es lo que podemos ver en el ejemplo (20), donde se observa la formación del gerundio de un lexema catalán mediante la adición del sufijo español correspondiente (-eando) en lugar del catalán $(-n t)$ :

\section{(20) ¿ya estáis dotoreando ['cotilleando'] otra vez?}

Pese a ello, el criterio de la adaptación lingüística presenta algunos problemas de envergadura como criterio determinante a la hora de distinguir entre fenómenos de interferencia y fenómenos de integración. Por un lado -y no es el menor-puede actuar de forma diferente a como lo hace el criterio de la integración social. Así, algunos de los valencianismos menos adaptados lingüísticamente al español figuran entre los préstamos más extendidos y por lo tanto, más "integrados" socialmente en la comunidad de habla. Pero además, el criterio de la integración lingüística resulta de difícil aplicación cuando se dan cita lenguas tan semejantes como las dos romances que aquí nos ocupan. ¿Hasta qué punto se hallan adaptados al castellano préstamos como moca $(d)$ or ['pañuelo'], arrapar ['arañar'], chopar [cat. xopar: empapar] o estar fava ['estar atontado'], ${ }^{15}$ cuya forma y pronunciación no difieren en lo esencial en las dos lenguas? Y las cosas se complican cuando desde el nivel léxico nos adentramos en la sintaxis. Sería posible admitir que la inserción de una partícula partitiva como de, característica de la sintaxis catalana en (21), figura en una posición baja del continuum de adaptación lingüística al español. Ahora bien, no podríamos decir lo mismo de la confusión de preposiciones que tiene lugar en (22), ya que la interferencia se cumple a través de una forma perfectamente "española" como es la preposición homófona (en) en ambas lenguas:

(21) [...] y a mí me ha gusta(d)o mucho de leer y de hacer mis cosas (CSCS-177)

(22) [...] el niño está en fiebre (esp. gen. con fiebre) ) (Blas Arroyo, 1993)

15. Obviamente nos referimos a la lengua oral y no a la escrita, donde, efectivamente, existen más diferencias gráficas, como las que aquí afectan a las grafías $b$ y $v$. 
Más determinante nos parece, pues, el criterio de la integración social para una eventual distinción entre grados diversos de la influencia linguiística. Pese a ello, no existe un consenso unánime en la bibliografía acerca de cuáles son los factores que priman para avanzar desde unos grados de integración a otros. A nuestro juicio, la frecuencia debe ser uno de los principales, aun reconociendo las dificultades metodológicas que implica la compilación de un corpus suficientemente amplio y representativo de la variedad de lengua empleada en una comunidad de habla, especialmente para el análisis de las variables menos recurrentes en el discurso (sintácticas, pragmáticas...). Con todo, los esfuerzos realizados en este sentido en los últimos tiempos, permiten ser optimistas acerca de la posible cuantificación de no pocas variables. De este modo, por ejemplo, el Corpus Sociolingüístico de Castellón nos ha permitido recientemente obtener más de 2.300 ocurrencias de variantes futúricas (ir a + infinitivo vs. -ré) para analizar la eventual influencia del catalán en los hábitos expresivos de la población castellonense, en la que el futuro sintético español (cantaré) muestra todavía una considerable vitalidad, como consecuencia de un más que probable proceso de convergencia con la lengua catalana (Blas Arroyo, 2007).

Por lo demás, la frecuencia no debería interpretarse en términos absolutos, esto es, cuantificando la presencia de una determinada variante en el discurso ${ }^{16}$ sino relativos, es decir, en relación con otras variantes alternativas. Así, por ejemplo, si una forma determinada (X) surge en un corpus con una frecuencia significativamente mayor que otras alternativas $(\mathrm{Y}, \mathrm{Z} \ldots)$, más habituales en otras variedades de la misma lengua, estaremos en condiciones de concluir que $\mathrm{X}$ muestra un grado de difusión amplio, y por lo tanto se halla en vías de integración en la comunidad de habla, si es que no lo está ya definitivamente. Esto último es lo que ocurre, por ejemplo, con numerosos usos dialectales del verbo hacer(se) (hacer(nos) un café, hacer algo en TV, hacer mala cara, hacer olor, etc.) que, como vimos anteriormente, compiten en la comunidad con variantes más frecuentes en otras hablas peninsulares (tomarse un café, poner/echar/haber algo en TV, tener mala cara, oler mal, etc.). Variación que se resuelve en estas variedades de contacto de forma claramente favorable a las formas vernáculas mencionadas, como han demostrado nuestros propios datos empíricos, correspondientes a la ciudad de Valencia (Blas Arroyo, 1993), donde cerca de un $80 \%$ de la muestra seleccionaba la variante interferencial. Por el contrario, la sustitución de bajo por abajo/debajo, característica también de diversas comunidades valencianas, presenta un mayor grado de variabilidad, y por tanto, un menor índice de integra-

16. Argumento que ha servido en ocasiones para poner en tela de juicio su validez; véase Kabatek, 2000; Sinner, 2004). 
ción social, tanto en la ciudad de Valencia (55\%; Blas Arroyo, 1993), como en las comarcas castellonenses, donde un examen provisional del CSCS permite advertir una considerable competencia entre la variante vernácula ("están ahí bajo") y la estándar ("están ahí abajo"). Y en el extremo opuesto, esto es, con un grado de integración social escaso se situaría en esta comunidad un fenómeno como el empleo de una partícula de con valor partitivo, a la que nos referíamos más arriba (12\% en Valencia; Blas Arroyo, 1993). No en vano, esta variante se encuentra marcada tanto desde el punto de vista etnolingüístico (prácticamente solo se detecta entre hablantes bilingües con un claro dominio del catalán sobre el español), como sociolectal (su presencia se halla favorecida entre los sociolectos bajos) y estilística (es mucho más previsible en contextos informales que formales). ${ }^{17}$

Más discutibles nos parecen, sin embargo, los criterios de la normatividad o aceptabilidad para dilucidar el grado de integración de un fenómeno determinado. Ya autores como Van Overbeke (1976: 113ss) y Schottmann (1977: 18-20) proponían que, para hablar de integración, es preciso que las variantes inicialmente interferenciales sean asumidas como correctas por la comunidad. A partir de un criterio de norma algo distinto, más recientemente Sinner (2004) ha basado también una parte significativa de sus principales conclusiones acerca del castellano hablado en Barcelona en los datos proporcionados por una muestra de hablantes, a través de sus juicios de aceptabilidad. A nuestro modo de ver, sin embargo, el empleo de este tipo de pruebas, con ser lícitas y necesarias para el análisis de esta clase de fenómenos, en el mejor de los casos solo pueden actuar como complemento de otros métodos (preferentemente el habla real extraída de entrevistas u otros procedimientos), bien con el propósito intrínseco de conocer las actitudes subjetivas de los miembros de la comunidad hacia las variantes vernáculas, bien con el objeto de analizar otros parámetros sociolingüísticos, como el índice de (in)seguridad lingüística de los hablantes, etc.

Entre los problemas que suscitan estas pruebas destacamos las siguientes. En primer lugar, hay que mencionar el hecho de que, a menudo, los hablantes tan solo son conscientes de los fenómenos más estereotipados, pese a que estos representan una parte reducida del conjunto de rasgos dialectales. Por otro

17. Junto con la frecuencia, otro criterio que permite vaticinar el grado de integración social de los fenómenos de contacto es su difusión entre hablantes monolingües (Haugen, 1950; Mougeon, et al., 1978) y, más excepcionalmente, en las áreas limítrofes con la comunidad de habla. Así ocurre con algunos rasgos característicos de estas variedades de contacto que aparecen también como fenómenos de adstrato tanto en las comarcas castellanohablantes de la Comunidad Valenciana (Montoya, 1989; Román, 1998), como en otros territorios colindantes (provincias de Teruel, Murcia, Albacete...). 
lado, aunque las pruebas se hallen correctamente diseñadas ${ }^{18}$ los informantes son conscientes de que se va a evaluar su juicio acerca de todos los enunciados que se les presentan, por lo que es muy posible que se sientan impelidos a aportar respuestas sobre cualquier estímulo lingüístico, sea del tipo que sea, e incluso cuando no estén seguros. Y es que, en definitiva, las actitudes -en ocasiones, además, inducidas y no reales- no tienen por qué corresponderse con la actuación. O dicho de otra manera, los hablantes hablan de una manera determinada, pero no siempre saben cómo hablan, y aun aceptando que ocasionalmente sean conscientes de ello, no tienen por qué tener una opinión formada. Por ello, resulta aventurado basar la hipótesis acerca de la integración de determinados fenómenos lingüísticos en función de esas respuestas.

\section{CONCLUSIONES}

Tras la revisión de diversas manifestaciones del contacto de lenguas que podemos advertir en el discurso bilingüe valenciano (cambio de código, bilingüismo pasivo, formas de la interferencia y la convergencia lingüísticas...), en las páginas iniciales de este artículo hemos mostrado algunas afinidades y divergencias entre las principales variedades de contacto del ámbito lingüístico catalán en el que se inserta el español de la Comunidad Valenciana. A este respecto, hemos visto cómo las diferencias estructurales y sociolingüísticas entre las diversas regiones de habla catalana explican la mayor o menor difusión de determinadas variantes vernáculas en dichas hablas.

Por otro lado, ciertos rasgos idiosincrásicos, así como otros fenómenos de contacto "a distancia", desempeñan también un papel relevante en la configuración dialectal de estas variedades. En este sentido sobresale, por un lado, la influencia creciente del inglés -en particular entre las generaciones más jóvenes y en tipos específicos de lenguaje-, así como, por otro, la existencia -advertida desde antiguo- de isoglosas comunes con las áreas limítrofes: tanto las hablas aragonesas en tierras castellonenses y valencianas, como las murcianas en el sur alicantino.

Ahora bien, sin descartar que el español de otras variedades peninsulares pueda mostrar desarrollos internos cualitativamente semejantes en algunas áreas del sistema lingüístico, ciertos datos distribucionales avalan el contacto directo e intenso con el catalán como el factor más relevante en la configuración dialectal del español hablado en la Comunidad Valenciana. Entre estos

$\overline{18 . \text { Se hace, }}$ por ejemplo, imprescindible alternar los ítems que contienen información valiosa para el analista con otros de control. 
destaca el hecho de que, por lo general, en estas hablas las variantes vernáculas se extienden a contextos lingüísticos y sociales más amplios que en otros dialectos monolingües. Por lo que se refiere a estos últimos, por ejemplo, no es baladí comprobar cómo la difusión social de estas variantes es considerablemente mayor que en otras variedades del español, de modo que alcanza a menudo a los miembros castellanohablantes de las comunidades de habla respectivas. Y ello tanto en el terreno de la actuación real como en el de las actitudes y reacciones subjetivas hacia los rasgos vernáculos. Por lo demás, la comprobación empírica, a través del análisis de corpus de habla oral suficientemente representativos, como el Corpus sociolingüístico de Castellón, al que se ha hecho referencia a menudo en estas páginas, permiten poner a prueba la hipótesis de la influencia interlingüística. En especial, si el estudio de hechos de variación advierte la incidencia significativa de factores externos relacionados con el bilingüismo, como la densidad etnolingüística en el seno de la comunidad de habla o el tipo y grado de bilingüismo individual y/o social en el que se desenvuelven los hablantes.

Para concluir, hemos revisado críticamente algunos de los criterios que más comúnmente aparecen citados en la bibliografía para explicar el grado que alcanza la interferencia lingüística en las distintas variedades de contacto. A este respecto, hemos defendido la prevalencia de los factores relacionados con la frecuencia relativa de las variantes en el discurso, en detrimento de otros parámetros no estructurales o de aquellos que miden el grado de adaptación lingüística a la lengua receptora. Las dificultades que conlleva guiarse por estos últimos en situaciones de contacto entre lenguas tan semejantes como, en este caso, el español y el catalán, merman su capacidad analítica, al tiempo que aumentan el crédito que otorgamos al criterio de la difusión social en el seno de la comunidad.

\section{REFERENCIAS BIBLIOGRÁFICAS}

Argente, J. y Ll. Payrató (1991): «Towards a Pragmatic Approach to the Study of Languages in Contact: Evidence from Language Contact Cases in Spain», Pragmatics, 1, 4, 465-480.

Badia i Margarit, A. (1985): Gramática Catalana, Vol. I, Madrid, Gredos.

Blas Arroyo, J. L. (1991): «Problemas teóricos en el estudio de la interferencia lingüística», Revista Española de Lingüística, 21.2: 265-289.

- (1993): La interferencia lingüística en Valencia (dirección catalán-español), Castellón, Universitat Jaume I.

- (1999): «Están ahí bajo: un caso de variación gramatical en una situación de contacto de lenguas», en Serrano, M. J. (ed.) (1999): Estudios de variación sintáctica, Frankfurt am Main, Vervuert, 173-196. 
- (2000): Gramáticas en contacto. Un modelo de análisis variacionista para la desambiguación de los fenómenos de contacto en el discurso bilingüe catalán-español, Munich, LINCOM Europa.

- (2005): Sociolingüística del español, Madrid, Cátedra.

- (2007) «El contacto de lenguas como factor de retención en procesos de variación y cambio lingüístico. Datos sobre el español en una comunidad bilingüe peninsular», Spanish in Context, 4, 2: 263-291.

- (en prensa): «Desde la cortesía a la marcación discursiva: el proceso de pragmaticalización de muy bien en una variedad peninsular», en BRAVO, D., A. Cordisco y N. Hernández Flores (eds.) (en prensa): Aportes pragmáticos, sociopragmáticos y socioculturales a los estudios de cortesía en español, Buenos Aires, Dunken.

Blas Arroyo, J. L., G. Boix, E. Gil, P. Tejada (1992): Variedades del castellano en Castellón, Castellón, Servicio de Publicaciones de la Excma. Diputación de Castellón.

Casanovas, M. (2001): Análisis cualitativo y cuantitativo de la morfosintaxis de una segunda lengua: el caso del español en contacto con el catalán, Lleida, Universitat de Lleida (tesis doctoral inédita).

- (2002): «Cuando el español es segunda lengua. Estudio cualitativo de las modificaciones del paradigma preposicional del español», Analecta Malacitana (versión electrónica), 15: 1-19.

Chambers, J. K. (1995): Sociolinguistic Theory, Oxford, Blackwell.

EsPaÑol, T. (1996): «Algunas insuficiencias de la clasificación de la interferencia lingüística», Pragmática y gramática del español hablado: actas del II Simposio sobre Análisis del Discurso Oral, [14-22 de noviembre de 1995], Valencia, Universidad de Valencia, 299-304.

Fernádez Ulloa, T., y H. UrRutia CÁrdenas (1998): «La duplicación y supresión del clítico de tercera persona: Chile y País Vasco» Actas del IV Congreso Internacional de Historia de la Lengua Española, vol. 1, Logroño, Universidad de La Rioja, 863-880.

Gimeno, F., y M. V. Gimeno (2003): El desplazamiento lingüístico del espanol por el inglés, Madrid, Cátedra.

Gomez CAPUZ, J. (2001): Anglicismos léxicos en el español coloquial: análisis semántico de los anglicismos y sus equivalentes españoles en un corpus de lengua hablada, Cádiz, Servicio de Publicaciones de la Universidad de Cádiz.

Gomez Molina, J. R. (1986): Estudio sociolingüístico de la comunidad de habla de Sagunto (Valencia), Valencia, Institució Alfons el Magnànim.

- (2000): «Transferencia y cambio de código en una comunidad bilingüe: área metropolitana de Valencia (I y II)» Contextos, 33-36: 309-360. 
HARRIS, J. (1991): «Conservatism versus substratal transfer in Irish English», en Trudgill, P. y J. K. Chambers (eds.) (1991): Dialects of English: Studies in Grammatical Variation, Londres and Nueva York, Longman, 191-212.

Haugen, E. (1950): «The analysis of linguistic borrowings», Language, 26: 210-231.

HERNÁNDEZ, C. (1998): Algunas cuestiones más sobre el contacto de lenguas: Estudio de la interferencia lingüística del catalán en el español de Catalu$\tilde{n} a$, Barcelona, Universitat de Barcelona (tesis doctoral inédita).

KABATEK, J. (2000): Os falantes como lingüistas. Tradición, innovació e interferencias no galego actual, Vigo, Xerais.

MACKeY, W. F. (1970): Bilinguisme et contact des langues, París, Klincksieck.

Mendieta, E. e I. Molina. (1995): «Orden de palabras y bilingüismo en el español del País Vasco», RLA. Romance Languages Annual, 7, 543-548.

Moll, F. (1961): «El castellano en Mallorca», Homenaje ofrecido a Dámaso Alonso, Vol. 2.

Montoya, B. (1989): La interferència al Sud de València, Valencia, Generalitat Valenciana.

MougeON, R. et al. (1978): «Le rôle de l'interférence dans l'emplois des prépositions en français et en anglais par des jeunes franco-ontariens bilingues», en PARADIS, M. (ed.) (1978): Aspects of bilingualism, Columbia, SC: Hornbeam.

Muysken, P. (2004): «Two Linguistic Systems in Contact: Grammar, Phonology and Lexicon», en Bhatia T. y W. C. RitchiE (eds.) (2004): The Handbook of Bilingualism, Oxford, Blackwell, 147-168.

Myers SCOtTON, C. (1993): Social Motivation for Code Switching. Evidence From Africa, Oxford, Clarendon Press.

OÑEDERRA, M. L. (2004): «El español en contacto con otras lenguas: españolvasco» en CANO, R. (coord.) (2004): Historia de la lengua española, Barcelona, Ariel, 1103-1115.

PAYRATó, Ll. (1985): La interferència lingüística (Comentaris i exemples catalá castellá), Barcelona, Curial-Publicacions de l'Abadia de Montserrat.

Poplack, S. (1980): «Sometimes I'll start a sentence in Spanish y termino en español: towards a typology of code-switching», Linguistics, 18 (7/8), 581-618.

- (1997b): «The sociolinguistic dynamics of apparent convergence», en GuY, G., J. BAugh y D. Schiffrin (eds.), (1997): Towards a Social Science of Language, Ámsterdam, Benjamins 285-309.

Poplack, S. H., E. Malvar, (2007): «Elucidating the transition period in linguistic change», Probus 19,1: 121-169. 
Poplack, S, D. Sankoff, Ch. Miller (1988): «The social correlates and linguistic processes of lexical borrowing and assimilation», Linguistics, 26, 47-104.

RoMAN, M. (1998): «El contacto lingüístico en la investigación diacrónica: la retención gramatical: Propuesta de análisis a través del español en una área de influencia catalana», en Mangado J. J., F. GonzÁlez, Cl. García TurZA (eds.) (1998): Actas del IV Congreso Internacional de Historia de la Lengua Española: La Rioja, 1-5 de abril de 1997, 833-846.

SACHDEV, I., H. GiLES (2004): «Bilingual accommodation» en BHATIA T. K. y W. C. RITCHIE (eds.) (2004): The handbook of bilingualism, Oxford, Blackwell, 353-378.

SALA, M. (1988): El problema de las lenguas en contacto, México, UNAM.

Schottmann, H. (1977): «Die Beschreibung der Interferenz», en Kolb, Helmut, LAUFFER, HARMut (eds.) Sprachliche Interferenz, Tübingen, Niemeyer.

SeCo, M. (1989): Gramática esencial del español: introducción al estudio de la lengua, Madrid, Espasa-Calpe.

SERRANO, M. C. (1996): «Interferencias léxicas y semánticas en una situación de contacto entre dos lenguas, catalán y castellano» en Pujol M., F. SIERRA (eds.) (1996): Las lenguas en la Europa Comunitaria II, Ámsterdam/ Atlanta, Diálogos Hispánicos, 375-394.

Silva-Corvalan, C. (1994): Language contact and change, Oxford, Oxford University Press.

SinNER, C. (2004): El castellano de Cataluña, Tübingen, Max Niemeyer Verlag. Torres, L. (1997): Puerto Rican Discourse: A Sociolinguistic Study of a New York Suburb, Mahwah, NJ, Lawrence Erlbaum.

VAN OBerbecke, M. (1976): Mecanismes de l'interférence linguistique, Madrid, Fragua.

VANN, R. (1998): «Aspects of Spanish Deictic Expressions in Barcelona: A Quantitative Examination», Language-Variation-and-Change, 10, 3: 263-288.

WeInReICH, U. (1953): Languages in contact. Findings and Problems, Nueva York, Publications of the Linguistic Circle of New York.

Wesch, A. (1997): «El castellano hablado de Barcelona y el influjo del catalán. Esbozo de un programa de investigación», Verba, 24, 287-312.

- (2002): «La investigación sobre variedades del español hablado en contacto con el catalán (particularmente en Cataluña y Baleares): estado de la cuestión y perspectivas para el futuro», Actas del V Congreso Internacional de Historia de la Lengua, Madrid, Gredos. 


\title{
DISCURSO, MULTIMODALIDAD Y PLURILINGÜISMO. INTERRELACIONES, INTERPRETACIONES Y EJEMPLOS ${ }^{1}$
}

\author{
Lluís Payrató \\ Universitat de Barcelona
}

\section{INTRODUCCIÓN}

$\mathbf{E}$ propósito de este texto es presentar una introducción teórica y panorámica de un conjunto de relaciones que se pueden establecer entre los tres términos y conceptos representados en su título. La primera parte de la exposición resume de manera muy sintética e introductoria algunas características fundamentales de la confluencia entre el estudio del discurso, de la multimodalidad comunicativa y del plurilingüismo; la segunda ejemplifica algunos de los puntos de contacto y de las repercusiones que se derivan de tener en cuenta nuevos factores en el análisis de determinados hechos comunicativos.

De los tres términos escogidos como palabras clave, parece evidente que el segundo, es decir multimodalidad, es el que exige de entrada una aclaración más detallada. En efecto, su uso es relativamente reciente, al menos en comparación con los dos restantes, y no muy diáfano, también en contraste con ellos. Sin embargo, su éxito no es discutible, y para muestra atengámonos a publicaciones tan recientes y misceláneas como LeVine y Scollon (ed.) (2004) y Ventola et al. (ed.) (2004), cuyas aportaciones además son suficientemente amplias y diversificadas para no provocar dudas sobre la utilidad del término y sobre la relevancia del campo de estudio que sugiere.

No costaría demasiado encontrar raíces de lo que representa el concepto de multimodalidad si buscáramos en la retórica, pero las acepciones actuales del término parecen más bien el fruto de dos tradiciones que, vistas en conjunto, no se excluyen aunque a menudo han vivido separadas: primero, la de la pragmática y el análisis del discurso, en el ámbito más lingüístico o de las ciencias del lenguaje; y, segundo, la de la llamada tan a menudo comunicación no verbal, en el ámbito de la semiótica y la teoría de la comunicación. En las dos tradiciones nos encontramos, y no por casualidad, con el intento más o menos

$\overline{1 .}$ Este trabajo se ha llevado a cabo en el marco del proyecto HUM2005-01936. Quisiera agradecer en especial al Dr. José Luis Blas su interés y su amabilidad a lo largo de todo el proceso que ha desembocado en este texto. 
explícito de solucionar ausencias muy explícitas: en el primer caso, la del análisis de elementos paralelos al uso lingüístico (o integrados en él); y, en el segundo, la del análisis de un conjunto de datos no definidos por su carácter negativo (no verbal) sino por su vertiente positiva (multimodalidad).

Con un término como discurso afirmamos un componente productivo, procesual, relativo a la creación de productos comunicativos; con el de plurilingüismo designamos una capacidad múltiple, que refleja una realidad en la que el monolingüismo queda como un reducto excepcional. De la misma manera, con multimodalidad destacamos de entrada el poliglotismo comunicativo al que se refiere Poggi (2006): somos políglotas comunicativamente hablando, si se admite el juego verbal. Se diga lo que se diga, lo decimos multimodalmente; se escriba lo que se escriba, lo escribimos multimodalmente. Tanto en el ámbito productivo (como origen) como en el ámbito en que se materializa o canaliza, la multiplicidad es también la norma y no la excepción. Lo mismo cabría decir de la recepción e interpretación de los productos, procesos que centrarán los comentarios de la segunda parte de este texto (v. el apartado 6).

\section{MODOS Y MEDIOS}

En concepciones estrictas, la multimodalidad suele hacer referencia a la diversidad de modos comunicativos de producción, reservándose el término $\mathrm{mul}$ timedialidad para los modos de canalización o reproducción (de acuerdo también con el uso corriente de un término como multimedia). En algunas concepciones muy particulares, por ejemplo la de Theo van Leeuwen (cf. Scollon y Levine, 2004: 2), su significado puede relacionarse incluso con el concepto de modalidad gramatical (y pragmática), precisamente otro representante destacado de la nómina de vocablos lingüísticos conflictivos o, por lo menos, polisémicos.

En concepciones más amplias, es decir, más generosas pero también inevitablemente más vagas, la multimodalidad se refiere tanto a modos como a medios, y ese parece hoy el uso mayoritario del término. Así, la multimodalidad se puede definir como una diversidad combinada o sincronizada de códigos, modos, fuentes, medios y canales comunicativos.

En la comunicación humana, entre las posibles combinaciones de modos (no) verbales y (no) vocales destacan, en principio, como fundamentales, la modalidad verbal (oral/escrita), la vocal y la gestual. Fernando Poyatos, a lo largo de su extensísima obra (v., entre otros trabajos, Poyatos, 1983, 1994, $2002,2004)$, se ha referido muy a menudo a esta trilogía o tripartición, y la ha concebido como un rasgo esencial de los sistemas comunicativos humanos, de su unidad (o coordinación) y de su diversidad (tridimensional). 


\section{AL LADO DEL LENGUAJE, MÁS ALLÁ DE LA VERBALIDAD}

La modalidad comunicativa que nos proporciona el lenguaje verbal es absolutamente única, en múltiples sentidos, en el reino de todas las especies animales, por mucho que en algunos casos se plantee un salto más cuantitativo que cualitativo entre los primates. El lenguaje verbal humano se estructura de una manera más que conocida como un enlace que transmite significados mediante sonidos y que permite descodificar sonidos como significados, tal como queda representado en el cuadro siguiente:

TABLA 1. Etapas del enlace entre el sonido y el significado.

\begin{tabular}{|c|}
\hline SONIIDO \\
Representación fonética \\
Sistema morfológico \\
Cadena sintáctica \\
Estructura textual \\
Intención pragmática \\
\$IGNIJIICADOO \\
\hline
\end{tabular}

La relación entre sonidos y significados se da en los dos sentidos, con unas proyecciones en muchos aspectos absolutamente automatizadas, pero al mismo tiempo también con componentes claramente inferenciales, es decir, no estrictamente codificados, y dependientes además siempre de aspectos contextuales.

Dando un paso más en esta línea argumentativa, ${ }^{2}$ la linguisticidad a que se refería Lyons (1972) incluye aspectos necesariamente no verbales (verbal en el sentido de palabra): son aspectos prosódicos o suprasegmentales (tono, acento y cantidad). Esta es la frontera más allá de la cual se suele hablar de paralenguaje o paralingüística: la vocalidad (no verbal, y ya no lingüística). Entre sus aspectos fundamentales, y aunque son susceptibles de ser presentados de distintas maneras, podemos hablar del ritmo de la elocución, de la intensidad y de las vocalizaciones.

Por otra parte, más allá de la verbalidad, pero ahora dentro del campo no vocal, nos encontramos con el fenómeno de la gestualidad, cuyas submodalidades pueden presentarse también de varias maneras. Se suelen distinguir, ya en detalle, la gesticulación manual, la gesticulación facial, la expresión de emociones (básicamente facial, también), la mirada o el contacto ocular, los movimientos de las cejas, los movimientos de la cabeza, las posturas y maneras (en el sentido de Poyatos), la proxémica y otros medios y canales como el tacto y el olfato.

2. Algunos de estos aspectos se comentan o analizan de manera más detallada en Payrató (2006, en prensa). Para todo lo referente al paralenguaje, v. Poyatos (2002), en especial el segundo volumen. 


\section{CATEGORÍAS GESTUALES}

Ekman \& Friesen (1969) establecieron una clasificación de los actos no verbales en cinco categorías, según los criterios de uso, origen y codificación: emblemas, adaptadores, ilustradores, reguladores y manifestaciones de estado de ánimo. McNeill $(1992,2000)$ ha establecido el "continuum de Kendon", tal como lo ha bautizado en homenaje a este analista, como una gradación de señales que van desde las que son más independientes del lenguaje verbal hasta las más dependientes:

(a) Signos manuales (propios de las lenguas de signos),

(b) Emblemas (o gestos emblemáticos, los gestos más lingüísticos de todos los que se producen, por ejemplo los de saludo o insulto),

(c) Pantomimas, como imitación de acciones de distinto tipo (por ejemplo, tocar el violín o conducir una moto),

(d) Gestos parecidos al lenguaje (en el sentido de que pueden ocupar un lugar o casilla paralelo al de una pieza de la cadena lingüística), y

(e) Gesticulación, o conjunto de gestos coverbales, que a diferencia de los emblemáticos o de las pantomimas no se dan en ausencia de habla paralela. Estos serían los menos lingüísticos, en principio, pero tanto McNeill (1985, 1992) como otros especialistas han defendido su carácter verbal con pruebas muy convincentes. Además, estos gestos tienen una función muy relevante en relación con la cohesión discursiva (cf. McNeill y Levy, 1993; Contento, 1998; McClave, 2000).

Aunque estamos lejos del establecimiento de categorías aceptadas unánimemente, las clasificaciones más habituales en la actualidad (v. Payrató, 2003 b) incluyen y analizan sobre todo los gestos emblemáticos (deícticos, icónicos, simbólicos...), los gestos coverbales (icónicos o metafóricos), los gestos interactivos (reguladores) y la expresión de estados de ánimo o emociones. La concreción de estas últimas, por ejemplo, nos llevaría a hablar, con el debate de fondo de su posible universalidad, de alegría, repugnancia/asco, tristeza, interés, rabia/odio, sorpresa y temor/miedo. Las denominadas "caras hablantes" (talking faces) han de incorporarlas para dar similitud a las simulaciones de la conducta humana.

En todos los casos anteriores la investigación sobre la gestualidad se presenta enraizada cada vez más con la de muchos aspectos lingüísticos o verbales, lo que justificaría el enfoque multimodal, pero también con una notable diversidad de perspectivas, tal como se apunta en el apartado siguiente. 


\section{LÍNEAS Y ENFOQUES DE LA INVESTIGACIÓN ACTUAL. METODOLOGÍA Y TÉCNICAS}

Los múltiples enfoques y marcos teóricos que hoy abordan la temática de la multimodalidad se pueden agrupar, con el evidente riesgo de la simplificación excesiva o del encasillamiento algo gratuito, en los cinco ámbitos siguientes:

En el psicolingüístico, con el consiguiente estudio de los procesos de producción y de recepción de señales multimodales (cf. Kendon, 1972, 2000, 2004; McNeill, 1992).

En el cognitivo, relacionado obviamente con el precedente y centrado en la capacidad mental humana para comunicarnos multimodalmente (sirvan como ejemplos específicos Levinson, 1992 o Alturo y Payrató, 2002, 2003 y Alturo, 2004; v. en conjunto McNeill (ed.), (2000).

En el pragmático, en el que tenemos en cuenta la dimensión de estos fenómenos en relación con los usuarios o interlocutores (valgan como ejemplos, entre otros muchos, Goodwin et al. 2002; Mora, 2004; como planteamientos generales, v. Arndt y Janney, 1987 y Kress y Van Leeuwen, 2001).

En el antropológico, como manifestación de la diversidad cultural humana, paralela, en el campo multimodal, de la diversidad lingüística (v. Haviland, 2000; Kendon, 2004).

En el computacional, prestando una atención especial a las posibilidades de simulación y automatización de las conductas multimodales, que en muchos casos ya son una realidad más avanzada de lo que solemos imaginar (v. Cassell et al. (ed.), 2000, como resumen, y el caso en particular ya citado más arriba de las caras o cabezas hablantes; cf. Massaro, 2001).

La investigación en estas líneas debe sustentarse lógicamente en bases de datos, archivos o corpus multimodales, cada vez de más fácil acceso. También se han simplificado mucho las técnicas de grabación, pero no puede decirse lo mismo de las de transcripción. Seguramente aquí nos encontramos con uno de los escollos más difíciles de sortear en la actualidad: extender en el seno de la comunidad científica técnicas de transcripción y anotación que actúen como estándares, y que en la medida de lo posible se emparejen con programas y sistemas de análisis a su vez también tan sencillos de manejar como sea factible: a ello se dedican programas como Elan, EXMARaLDA, Anvil o Transana, de los que se puede obtener rápida y clara información a través de Internet. Lamentablemente, no contamos con manuales dedicados a la metodología del análisis multimodal que cumplan una función análoga a la que en su momento cumplió la excelente recopilación de estudios de Scherer y Eckman (ed.) (1982) (cf. Goodwin, 1993; Payrató, 2003 b). 


\section{ANÁLISIS DE DATOS MULTIMODALES: MUESTRA DE INTERRELACIONES, INTERPRETACIONES Y EJEMPLOS}

¿Hasta qué punto una fotografía puede hacernos cambiar una interpretación inicial de un texto? ¿Hasta qué punto nuestra expresión facial actúa como un contexto o como verdadera parte del texto (o cotexto) verbal y comunicativo? ¿Nuestras citas verbales directas van acompañadas de citas multimodales también directas? ¿Nuestras capacidades gestuales o, en conjunto, todos los aspectos multimodales no verbales, son transversales a lo largo de las distintas lenguas que, como hablantes plurilingües, podemos utilizar? ¿Son interpretables los gestos propios de una cultura (y lengua) "vistos" desde otra lengua y cultura?

La concepción multimodal de la actividad lingüística en particular y de la comunicativa en general nos lleva a preguntas como las anteriores, o a muchas más que se podrían desglosar de las explicitadas o que resultarían complementarias. Por desgracia y, por ahora, parece mucho más fácil formular las preguntas que ensayar las respuestas, y no se trata de ningún tópico discursivo: muy buena parte de la investigación que necesitamos para contestarlas está por hacer. Sin duda tenemos pistas para avanzar respuestas provisionales, pero nos falta muchísima información para que estas respuestas puedan tener una base estadística e intercultural sólida. Basta para fundamentar esta afirmación una comparación transversal de varias de las obras básicas y más recientes sobre esta temática (Kress y van Leeuwen, 2001, LeVine y Scollon (ed.), 2004, Ventola et al. (ed.) 2004), de las recopilaciones de estudios sobre las relaciones entre oralidad y gestualidad (Santi et al. (ed.), 1998, Cavé et al. (ed.), 2001) o de las que plantean la posibilidad de analizar específicamente una modalidad, que luego se contrasta o compara con las restantes (v. por ejemplo Poggi, 2002, 2004, 2006). ${ }^{3}$

A las dificultades intrínsecas de obtener respuestas de una conducta poco analizada se añaden las que provienen de tópicos más bien infundados o por lo menos discutibles. Para empezar, se suele tender a pensar que el lenguaje verbal es mucho menos ambiguo que el no verbal, de manera que casi cualquier

3. De hecho, se pueden rastrear numerosos caminos que plantean, ya desde hace bastante tiempo, las interrelaciones y transversalidades que solo resultan evidentes cuando el análisis es multimodal. Son perfectos ejemplos de todo ello Bolinger (1983), sobre la relación entre entonación y gesto ( $c f$. Payà, 2004), Beattie (1981), que ya planteaba una síntesis entre los estudios lingüísticos y los de comunicación no verbal (cf. en el caso español Torrego (1971), un artículo casi olvidado o muy poco citado) y Arndt y Janney (1987), uno de los primeros intentos explícitos de análisis verbal, prosódico y cinésico de las opciones que seguimos en el habla ( $c f$. Payrató, 2006, donde se recogen algunos de sus ejemplos). Schegloff (1984) planteaba ya también las relaciones entre el gesto, el habla y el desarrollo de la conversación, en su caso desde la perspectiva etnometodológica, y Slama-Cazacu, entre gesto y sintaxis. 
gesto simbólico, por ejemplo el de encogerse de hombros, puede asociarse a significados muy diversos: desconocimiento "neutro" (paralelo a un enunciado como No lo sé, sin una modalización añadida), desconocimiento con desinterés (No lo sé ni me importa... ;Yo qué sé!), simplemente desgana (;Y a mi qué más me da!), etc. O bien, un gesto tan simple como el índice levantándose por encima del resto del puño cerrado puede ser una llamada de atención, puede marcar una demanda o solicitud de turno de habla, indicar una dirección o lugar (como deíctico), representar el número uno (y el adjunto concepto de victoria), etc.

Aparentemente, siguiendo el tópico, los elementos verbales no se verían afectados por esta polisemia, en términos semánticos, o por la multifuncionalidad, en términos pragmáticos, con el consiguiente riesgo de ambigüedad o mala interpretación. En realidad, si bien es cierto que las señales no verbales apuntadas no son monosémicas ni unifuncionales, debe recordarse que la interpretación de los actos comunicativos es siempre contextual, de manera que muchas interpretaciones se descartan inmediatamente por su irrelevancia mientras que otra(s) se prioriza(n). En las interacciones habituales, es una en particular la interpretación que se toma como prioritaria, y justamente por lo contrario que en el descarte anterior, es decir por su relevancia o pertinencia (entendido el concepto en los conocidos términos de la teoría de Sperber y Wilson, 1986).

Este mismo razonamiento es aplicable a los elementos verbales, que de hecho a menudo resultan, a su vez, igualmente polisémicos: como primer ejemplo (véase Payrató, 2003), la palabra diligencia, fuera de contexto, o en enunciados en apariencia tan simples como La diligencia era vital, admite interpretaciones acontextuales muy distintas (como documento, como virtud opuesta a la pereza, como vehículo de transporte...). Incluso el insulto más soez u ofensivo puede convertirse, como ya apuntara Leech (1983) gracias al principio pragmático de burla, en un elogio: hijo de puta es interpretable como alabanza cuando, en el contexto adecuado, alguien ha sobresalido por su ingenio, destreza, inteligencia... por ejemplo obteniendo una calificación muy alta en un examen, tras una jugada maestra, etc. En el caso inverso, magnífico (igual que el gesto emblemático de aplaudir) puede ser un calificativo para transmitir una desaprobación, una ironía o un sarcasmo, y nadie lo interpretaría en sentido literal en cualquier situación típica de un fiasco.

Si el uso lingüístico, oral o escrito, es ya de por sí multimodal, indefectiblemente, por contigüidad con otros códigos (vocales, gestuales, tipográficos), su combinación con otras modalidades en principio más lejanas aportará, como es lógico, numerosas y nuevas interpretaciones. Los fenómenos que nos encontramos son, básicamente, de confluencia o refuerzo (la situación esperable o no marcada, si nos atenemos a la coordinación de nuestra actividad comunicativa), o bien, como excepción, de contradicción o ambigüedad. En el primer caso sabemos que la "danza" gestual está sincronizada entre sus componentes (movimien- 
tos de la cabeza, de las cejas, de las manos, del cuerpo y expresiones faciales) y además casi siempre va acorde con el canal verbal. Pero a veces la oposición es manifiesta, como en el típico ejemplo de la mentira mal disimulada (en especial en los niños). Sea el caso que sea, la relevancia o pertinencia contextualizada, concebida en solitario o bien junto a principios de comunicabilidad e informatividad, es la base o el principio que nos permite llegar, a través de inferencias, a una interpretación adecuada (o al menos, a sabiendas que nunca podemos conocer con exactitud los propósitos o las motivaciones últimas del emisor o enunciador, a la que nos parece la más adecuada).

Cualquier proceso de interpretación multimodal de este tipo no está exento de posibles errores o desaciertos interpretativos, que son el equivalente en esta dimensión multimodal de los tradicionales y conocidos actos de habla infelices, si se admite el calco, o desafortunados. Como nuevo ejemplo, una foto de un avión que sobrevuela aparentemente a muy poca altura las cabezas de unos espectadores (v. ilustración 1) nos puede llevar a una interpretación más bien literal de un titular de prensa, en este caso el recogido bajo la foto en la edición del 17 de julio de 2006 del periódico El Punt: "Al Airbus le cuesta coger el vuelo"... puesto que, en una posible y primera hipótesis, necesita una pista muy larga, o tiene problemas para el despegue, etc. En realidad, el titular es metafórico y la fotografía es solo ilustrativa del aparato: la compañía que lo construye tiene problemas económicos, coger el vuelo (o despegar el vuelo, o simplemente despegar) es metafórico, se fundamenta en que el "arriba" económico es también lo deseable y positivo, y la fotografía no simboliza nada en particular sino que es puramente indexical.

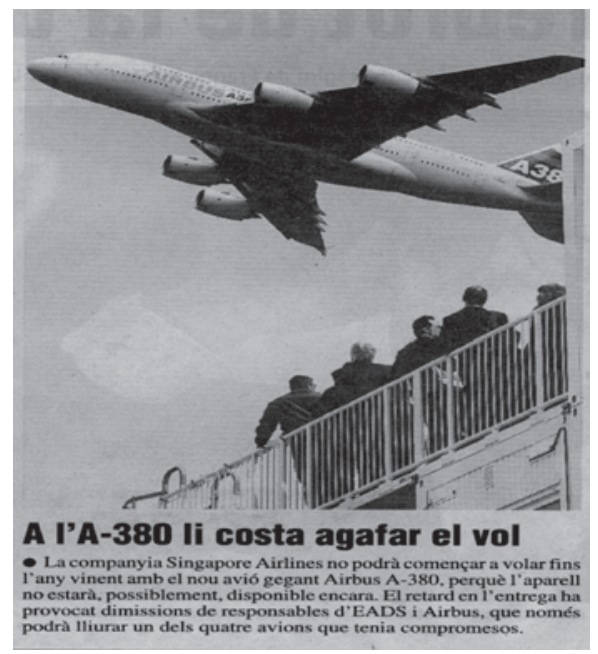

ILUSTRACIÓN 1. (El Punt 17/07/2006) 
Cambiando la modalidad de los ejemplos, muchos gestos emblemáticos crean problemas de comprensión interlingüística e intercultural. ${ }^{4}$ Nuestras traducciones suelen ser solo verbales, pero no gestuales, y de ahí que ya hace tiempo que se ha planteado en el dominio de la enseñanza de segundas lenguas la necesidad de añadir contenidos multimodales a los procesos de enseñanza y aprendizaje del código verbal. Incluso gestos tan aparentemente universales como los de afirmar o negar con la cabeza difieren en realidad en áreas como la europea; no digamos ya otros casos como los de emblemas tan particulares como los gestos de insulto (sexual, normalmente) o de apreciación (de la comida, de la actitud o conducta de otras personas, etc.). Morris et al. (1989) hicieron explícitas por primera vez, en el contexto europeo, muchas de estas aparentes paradojas cuando se parte del supuesto, todavía muy extendido en ámbitos corrientes, de la universalidad de las conductas no verbales y, en particular, de las gestuales.

Un último ejemplo, el de la polifonía multimodal (v. Payrató y Alturo, 2003; Alturo, 2004), permite hacerse cargo de la complejidad de las interrelaciones multimodales que pueden deparar actuaciones comunicativas también en apariencia, como en los ejemplos anteriores, muy sencillas. En este caso particular, que desvela una casuística muy compleja, tal como muestra Camargo (2004, 2006), encontramos diferentes combinaciones entre estilos de citación verbal y estilos de citación gestual. En concreto, por ejemplo, un estilo verbal directo o indirecto puede combinarse con un estilo gestual centrado en el narrador (que actúa como un observador externo) o centrado en los personajes (cuyos gestos reproduce, incorporándolos). Por tanto, cuatro combinaciones son posibles, cuyas repercusiones en lo que se refiere a los procesos interpretativos no están todavía muy claras, si bien McNeill (1992) ya apuntaba que las citas gestuales que podríamos llamar de estilo directo, por analogía con las lingüísticas, es decir, aquellas en las que el locutor adopta la perspectiva (¡y el cuerpo!) del personaje, se suelen corresponder con elementos básicos de la estructura narrativa y con construcciones gramaticales transitivas (mientras que en los casos de citación de estilo indirecto la correspondencia se daría predominantemente con elementos secundarios y con construcciones gramaticales de otros tipos). Como ejemplo final, en los proyectos Varcom y Pragmaestil, ${ }^{5}$ concebidos a partir de un corpus a la vez multimodal (verbal y audiovisual, es decir con transcripción verbal, sonido e imagen) y plurilingüe

4. V. sobre estos gestos y su relación con múltiples aspectos pragmáticos Payrató (1993, $2003 a$, 2004), y Kendon (1995, 1996, 1997) para cuestiones más generales. Meo-Zilio y Mejía (1980-83) recopilan un amplio repertorio de emblemas españoles e hispanoamericanos.

5. Para estos sucesivos proyectos, v. Payrató, 2002 y Payrató et al. (ed.), 2004. Más en particular para el corpus (Corpus Audiovisual Plurilingüe, CAP), v. Nogué y Payrató, 2006. 
(catalán, castellano e inglés), los análisis iniciales (y provisionales) parecen apuntar a ciertos estilos discursivos y gestuales distintos, al menos en las frecuencias de uso, entre una selección de hablantes cuya primera lengua es el catalán y otro grupo cuya primera lengua es el castellano. Otros análisis más detallados podrán indicar en el futuro hasta qué punto lo que parecen tendencias pueden confirmarse como rasgos realmente representativos y extrapolables a otros grupos de hablantes.

Cabe añadir, por último, que los principios de relevancia y comunicabilidad que subyacen en las interpretaciones apuntadas de los ejemplos deben combinarse, para evitar el riesgo de aumentar el porcentaje de desaciertos comunicativos y culturales, con el conocimiento del grado de variación de los usos, hábitos o patrones socioculturales: el mismo grado de variación del que ya somos al menos conscientes en la dimensión lingüística es imaginable (aunque por ahora no lo podamos constatar o probar con certeza) en las otras dimensiones multimodales: por tanto es esperable y lógico que encontremos diferencias en los diversos ámbitos generacionales, de género o sexo, geográficos, históricos, sociales y funcionales o estilísticos (v. Payrató, 2004).

\section{A MODO DE RESUMEN Y CONCLUSIÓN}

Van Leeuwen (2004) apunta, en un trabajo con un título muy explícito, diez razones por las que los lingüistas deberían interesarse por la comunicación visual. Quizá podrían reducirse... o quizá deberían ser más, pero en cualquier caso tienen mucho peso, y los cambios en los libros de texto de las últimas generaciones sirven de testimonio de que nos dirigimos a un destino en el que muy a menudo el texto aparece indisociablemente unido a la imagen. Y si la imagen siempre connota y si el texto denota, o si la palabra concreta o ancla lo que la imagen sugiere o evoca, es un último apunte de los tópicos o casi tópicos que los estudios deberán confirmar o desmentir.

Como conclusión, con vistas al futuro y teniendo muy presentes tanto el desarrollo científico como la nueva planificación académica, debe apuntarse que, en términos aún más amplios que los de la relación textoimagen, los estudios multimodales tienen un futuro prometedor. Y ello parece innegable, ya se lleven a cabo desde plataformas deliberadamente interdisciplinarias, desde una posición más (clásica) lingüística o desde otras perspectivas. Tienen asimismo una aplicación indiscutible, y cabe recordar también que el reciente y famoso Informe Pisa sobre la comprensión lectora incluye entre los textos, en especial entre los etiquetados como textos discontinuos (o documentos), una gran variedad de formatos, inclusive las ilustraciones. 
Esta exposición, en definitiva, ha tenido el modesto objetivo de mostrar que nuestros productos lingüísticos, si se admite la metáfora empresarial, son productos multimodales, y se combinan o entremezclan con otros productos que proceden de la misma factoría, que igualmente son multimodales, pero que no son verbales, no están hechos con palabras. La intención y el propósito de lo que se ha apuntado en estas líneas ha sido también argumentar que, sin menospreciar estrategias tradicionales que tienden a la separación o disgregación, a análisis segmentados por canales, debemos progresar en el análisis conjunto de los fenómenos comunicativos para poder explicar mejor su complejidad.

\section{REFERENCIAS BIBLIOGRÁFICAS}

Alturo, N. (2004): «Hipòtesis sobre la representació multimodal (verbal i gestual) dels esdeveniments», en PAYrató, Ll., N., Alturo, M. PAYÀ (ed.): Les fronteres del llenguatge. Lingüística $i$ comunicació no verbal. Barcelona: Universitat de Barcelona-PPU, 141-153.

Alturo, N., Ll. Payrató (2002): «La representación discursiva de las eventualidades. Gesticulación y habla», Comunicación en el Congreso de la Asociación Española de Lingüística Cognitiva, Valencia.

- (2003): «The cognitive processing of situations: evidence from multimodal discourse», Comunicación en el 8th International Cognitive Linguistics Conference, Logroño.

ARNDT, H., R. W. JANNEY (1987): InterGrammar. Toward an integrative model of verbal, prosodic and kinesic choices in speech, Berlín, Mouton de Gruyter.

Beattie, G. W. (1981): «Language and nonverbal communication -the essential synthesis?», Linguistics, 19, 1165-1183.

BOLINGER, D. (1983): «Intonation and Gesture», American Speech, 58, 156-74.

CAMARGO, L. (2004): La representación del discurso en la narración oral conversacional. Estudio sociopragmático, Madrid, Universidad de Alcalá. Tesis doctoral.

- (2006): «Las citas de paralenguaje y las citas de gestos en la conversación coloquial: del enunicado a la enunciación», Comunicación en el III Congreso Sobre Lengua y Sociedad, Universitat Jaume I, Castellón de la Plana, 20.09.06.

CAssell, J. et al. (eds.) (2000): Embodied conversational characters, Cambridge, MIT Press.

Cavé, C., I. Guaïtella, S. SANTi (eds.) (2001): Oralité et gestualité. Interactions et comportements multimodaux dans la communication, París, L'Harmattan. 
CONTENTO, S. (1998): «Forme et fonction du geste pour la cohésion discursive», en SANTi, S., et al. (eds.): Oralité et gestualité. París: L’Harmattan, 589-594.

EKMAN, P., W. V. FRIESEN (1969): «The repertoire of non verbal behavior: categories, origins, usage and coding”, Semiotica, 1, 49-97.

Goodwin, C. (1993): «Recording human interaction in natural settings», Pragmatics, 3, 181-209.

Goodwin, M. H., C. Goodwin, M. YAeguer-Dror (2002): «Multi-modality in girls' game disputes», Journal of Pragmatics, 34, 1621-1649.

HaVILAND, J. (2000): «Pointing, gesture spaces, and mental maps», en MCNeILl, D. (ed.): Language and gesture. Cambridge, Cambridge University Press, 13-46.

Kendon, A. (1972): «Some Relationships between Body Motion and Speech: An Analysis of an Example», en Siegman, A.W., B. Pope (eds.) (1972): Studies in Dyadic Communication, Nueva York, Pergamon, 177-210.

- (1995): «Gestures as illocutionary and discourse markers in Southern Italian conversation», Journal of Pragmatics, 23, 247-279.

- (1996): «An agenda for gestures studies», The Semiotic Review of Books, 7, 8-12. <http://www.univie.ac.at/Wissenschaftstheorie/srb/srb/gesture.html>

- (1997): «Gesture», Annu. Rev. Anthropol., 26, 109-128.

- (2000): «Language and gesture. Unity or duality?», en MCNeILL, D. (ed.): Language and gesture. Cambridge, Cambridge University Press, 47-63.

- (2004): Gesture: Visible action as utterance, Cambridge, Cambridge University Press.

Kress, G., T. van LeEuwen (2001): Multimodal discourse: The modes and media of contemporary communication, Londres, Arnold.

Leech, G. N. (1983): Principles of Pragmatics, Londres, Longman. [Trad. cast.: Principios de pragmática, Logroño, Universidad de la Rioja, 1998.]

LeVIne P., R. Scollon (eds.) (2004): Discourse and technology. Multimodal discourse analysis, Washington, Georgetown University Press.

LEVINSON, S. C. (1992): «Primer for the field investigation of spatial description and conception», Pragmatics, 2, 5-47.

LyONS, J. (1972): «Human language» en R. A. Hinde (ed.): Non-verbal communication, Cambridge, Cambridge University Press, 49-85.

Massaro, D. W. (2001): «Perceiving the many modalities of spoken language: Theories and data», en CAVÉ, C., I. GuaïTElla, S. SANTI (eds.): Oralité et gestualité. Interactions et comportements multimodaux dans la communication. París, L'Harmattan, 34-37.

McMlave, E. Z. (2000): «Linguistic functions of head movements in the context of speech», Journal of Pragmatics, 32, 855-878.

McNeILl, D. (1985): «So You Think Gestures Are Nonverbal?», Psychological Review, 92, 350-371. 
- (1992): Hand and Mind. What Gestures Reveal about Thought, Chicago, The University of Chicago Press.

- (ed.) (2000): Language and gesture, Cambridge, Cambridge University Press.

McNeIll, D., E. T. LeVy (1993): «Cohesion and gesture», Discourse Processes, 16, 363-386.

Meo-Zilio, G., S. Mejía (1980-3): Diccionario de gestos. España e Hispanoamérica. Bogotá, Instituto Caro y Cuervo, 2 vols., 1980 (I) y 1983 (II).

MorA, J. P. (2004): «De gestos, signos y palabras», en PAYRATó, LL. et al. (eds.): Les fronteres del llenguatge. Lingüística $i$ comunicació no verbal, Barcelona, Universitat de Barcelona-PPU, 47-55.

MorRIS, D. et al. (1979): Gestures, their origins and distribution, Londres, J. Cape. (Reimpr.: Triad/Granada, 1981).

Nogué, N., PAYRATó, L. (2006): «El corpus audiovisual plurilingüe de la Universitat de Barcelona (CAP)», Comunicación en el 3rd Freiburg Workshop on Romance Corpus Linguistics (Albert-Ludwigs-Universität), Friburg, (en prensa).

PAYÀ, M. (2004): «Interacció del grup tonal i el gest en el discurs: una aproximació d'anàlisi multimodal», en Payrató, Ll., Alturo, N., PAYÁ, M. (eds.): Les fronteres del lenguatge. Lingüística $i$ comunicació no verbal, Barceona, Universitat de Barcelona-PPU, 155-172.

PAYRATó, Ll. (1993): «A pragmatic view on autonomous gestures: A first repertoire of Catalan emblems», Journal of Pragmatics, 20, 193-216.

- (2002): «Variation, multimodal communication and multilingualism: The VARCOM project».<http://www.utexas.edu/coc/cms/International_House_of_Gestures>

- (2003 a): «What does 'the same gesture' mean? Emblematic gestures from some cognitive-linguistic theories», en Rector, M., I. Poggi, N. Trugo (eds.): Gestures: Meaning and Use, Porto, Ediçoes Universidade Fernando Pessoa, 73-81.

- (2003 b): «Nonverbal communication» en Verschueren, J., J. O. ÖSTMAN, J. Blommaert \& C. BulCAEN (eds.): Handbook of pragmatics, Ámsterdam, John Benjamins.

- (2003 c): Pragmàtica, discurs i llengua oral. Introducció a l'anàlisi funcional de textos, Barcelona, Editorial UOC.

- (2004): «Notes on pragmatic and social aspects of everyday gestures», en Posner, R., D. Müller (eds.): Semantics and Pragmatics of Everyday Gestures, Berlín, Weidler, 103-113.

- (2006): «Discurso oral y multimodalidad. Aspectos introductorios», Oralia, 9, 259-275. 
PAYrató, Ll., N. Alturo (2003): «Poliphony as a multimodal phenomenon», Comunicación en el 8th International Pragmatics Association Conference, Toronto.

Payrató, Ll., N. Alturo, M. PAyÀ (eds.) (2004): Les fronteres del llenguatge . Lingüística i comunicació no verbal, Barcelona, Universitat de Barcelona, PPU.

PoGGI, I. (2002): «Gesture, gaze and touch: Literal or indirect meaning», $<$ http://semioticon.com/virtuals/talks>

- (2004): «Lexicon and phonology of nonverbal communication systems», en Payrató, Ll., N. Alturo, M. PAyÀ (eds.): Les fronteres del llenguatge. Lingüística i comunicació no verbal. Barcelona, Universitat de Barcelona, PPU, 247-285.

- (2006): Le parole del corpo. Introduzione alla comunicazione multimodale, Roma, Carocci.

Poyatos, F. (1983): New Perspectives in Nonverbal Communication. Studies in Cultural Anthropology, Social Psychology, Linguistics, Literature and Semiotics, Oxford, Pergamon.

- (1994): La comunicación no verbal, Madrid, Istmo.

- (2002): Nonverbal communication across disciplines, Ámsterdam, John Benjamins.

- (2004): «Nuevas perspectivas lingüísticas en comunicación no verbal», en PAYRATÓ, Ll. et al. (eds.), 57-91.

SAnTi, S. et al. (eds.) (1998): Oralité et gestualité, París, L'Harmattan.

SCHEGLOFF, E. (1984): «On some gestures' relation to talk», en ATKInson, J. M., J. Heritage (eds.): Structures of Social Action. Studies in Conversation Analysis, Cambridge, Cambridge University Press, 266-298.

SCHERER, K. R. y P. EKMAN (eds.) (1982): Handbook of Methods in Nonverbal Behavior Research, Cambridge, Cambridge University Press.

Scollon, R., P. LeVine (2004): «Multimodal Discourse Analysis as the Confluence of Discourse and Technology», en LeVine, P., Scollon, R. (eds.): Discourse and technology. Multimodal discourse analysis. Eashington, Georgetown University Press, 1-6.

Slama-CAZACU, T. (1976): «Nonverbal components in message sequence: "Mixed syntax", en McCormack, W. C., S. A. Wurm (eds.) (1976): Language and Man: Anthropological Issues, La Haya, Mouton, 217-227.

SPERBER, D. y D. WiLSON (1986): Relevance: Communication and cognition, Oxford, Basil Blackwell (2a. ed., 1995). Trad. cast.: La relevancia, Madrid, Visor, 1994.

TORREGO, E. (1971): «Lingüística y cinésica», Revista de Filología Española, LIV, 145-159. 
Van Leeuwen, T. (2004): «Ten Reasons Why Linguists Should Pay Attention to Visual Communication», en LeVIne , P., Scollon, R. (ed.): Discourse and technology. Multimodal discourse analysis. Washington, Georgetown University Press, 7-19.

Ventola, E., C. Charles, M. Kaltenbacher (ed.) (2004): Perspectives on multimodality, Ámsterdam, John Benjamins. 


\title{
RACISM AND THE PRESS IN SPAIN
}

\author{
Teun A. van DiJK \\ Universitat Pompeu Fabra
}

\section{INTRODUCTION}

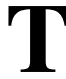

HE international conflict caused by the anti-Muslim cartoons of the Prophet Mohammed in the Danish newspaper Jyllands Posten has been widely covered in the world's press, also in Spain. Much of this coverage was framed in terms of the alleged clash of civilizations, between the West and the Muslim World, and more specifically as a struggle between 'our' freedom of the press, on the one hand, and 'their' fanatic religious intolerance, on the other hand. A few months earlier, the press covered the election of president Evo Morales as president of Bolivia, often in terms that showed little respect for this 'indio'. Also in 2005, the Spanish press dramatically portrayed the 'assault' of African migrants on the North African Spanish city of Melilla.

These three events will be examined in more detail in this paper in order to illustrate the way the Spanish quality press, and in particular El País, covers 'ethnic events' in general, and immigration in particular. I shall do so against the broader background of earlier work on European elite racism and the role of the press in the reproduction of ethnic inequality in society.

\section{ELITE RACISM AND ITS DENIAL}

If there is one social phenomenon that is often referred to, and even more often denied, but without much knowledge about what exactly it is, it is racism. If acknowledged at all, racism is typically attributed to others, to other countries, to other ('lower') classes, or considered to be a thing of the past. Against the daily experiences of its victims, European racism against nonWestern immigrants and ethnic minorities is seldom recognized by the political, media and academic elites. ${ }^{1}$

1. Back \& Solomos, 2000; Boxill, 2001; Bulmer \& Solomon, $1999 a, 1999$ b, 2004; Cashmore, 2003; Doane \& Bonilla-Silva, 2003; Essed, 1991; Essed \& Goldberg, 2002; Feagin, 2000; Feagin, Vera \& Batur, 2001; García Martínez, 2004; Goldberg, 1997, 2002; Goldberg \& Solomos, 2002; Lauren, 1998; Marable, 2002; Sears, Sidanius \& Bobo, 2000; Solomos \& Back, 1996; Solomos \& Wrench, 1993; Wieviorka, 1994, 1998. 
One of the reasons of this consistent and widespread negation is that racism is often associated with and limited to the Extreme Right, that is, with blatant prejudices and discrimination. The many more subtle, interpersonal as well as structural and institutional forms of everyday racism are usually ignored, and emphatically denied when they are attributed to the symbolic elites who control the access to public discourse.

Yet, if we assume that racism is not innate but learned, it must be learned during the social practices that have most impact on most people, that is, public discourse in general, and political and media discourse, in particular as well as on the everyday conversations that in turn are derived from this public discourse. Indeed, in most Western European countries most 'white' citizens do not have extensive personal and daily experiences with immigrants or ethnic minorities, and most information - as well as opinions - about them, hence, must be derived from the mass media, and learned from those who have access to the mass media. ${ }^{2}$

This argument is based on an empirically well-tested theory that defines European racism as a system of social power abuse, of domination of nonEuropean ethnic minority groups by an European ('white') ethnic majority (and in some countries, such as Guatemala, and the former Apartheid South-Africa).

This system of ethnic domination has two major dimensions, namely that of social cognition (prejudices, racist ideologies), on the one hand, ${ }^{3}$ and of social practices (discrimination, exclusion, etc.), on the other hand.$^{4}$ In order to be able to discriminate on ethnic grounds, one needs the relevant beliefs, categories, values and norms that define ethnic prejudices and ideologies. And in order to acquire such beliefs, one in turn needs to be exposed to racist discourses, which are themselves prominent social practices of the system of racist domination.

That is, racist practices, cognition and discourse are intimately related: we learn our prejudices largely through text and talk, first from our parents and friends, then from textbooks, television, and the newspaper, that is, from the symbolic elites: teachers, journalists, writers and politicians. The same is true, obviously, for our antiracist beliefs, ideologies and practices.

The question then is which of these discourses are dominant in society. Extensive international research of the last decade has unambiguously shown

2. For studies of racist discourse, see for detail, see Blommaert \& Verschueren, 1998; Jäger, 1992, 1998; Matouschek, Januschek \& Wodak, 1995; Reisigl \& Wodak, 2000, 2001; van Dijk, 1984, 1987 a , 1991, 1993, 2005; Wetherell \& Potter, 1992; Wodak, 1996; Wodak \& van Dijk, 2000).

3. Apostle, Glock, Piazza \& Suelze, 1983; Dovidio \& Gaertner, 1986; Hamilton, 1981; Pettigrew, 1982; Pickering, 2001; van Dijk, 1984, 1987 a, 1998).

4. Alvarez \& Lutterman, 1979; Banton, 1994; Britton, 2000; Cohn, 2000; Dovidio \& Gaertner, 1986; Essed, 1991; Flint, 2004). 
that the 'white' press in general is part of the problem of racism, rather than part of its solution. ${ }^{5}$

Whether more blatantly on the Right and especially in popular tabloids, or more subtly on the Left, all empirical research shows, among many other things, that non-European immigrants and minorities are systematically portrayed as a problem, and attributed many negative characteristics, of which violence, crime or cultural (religious, linguistic, etc.) deviance have been the main ones.

Moreover, the research shows that this bias is also due to the systematic discrimination of minority journalists: despite the presence of qualified minority journalists, newsrooms anywhere in Europe are nearly exclusively 'white', so that there is also lacking interest, knowledge and expertise to report about the ethnic communities in the first place.

In other words, the mass media play a prominent role in the coverage of ethnic affairs, and they do so in a way that promotes ethnic prejudices and, indirectly, discriminatory social practices based on such negative beliefs about the Others.

The media, however, are not alone. Much of their new and coverage is of politicians and political discourse, another 'elite' source of racism in society. Again, as is the case for the media, also the majority of the politicians are not blatantly racist, and indeed some are antiracist. However, as suggested above, much of their 'modern' racism is rather indirect, disguised and mitigated. Their discourse might be focusing on the 'problems' (rather than the challenges and possibilities) of the multicultural society, and is often limited to arguments that oppose further immigration - often in name of the 'people'.

\section{RACISM AND THE PRESS}

Let us examine some of the properties of the racism in the press, and then proceed to a more detailed account of the three events widely covered in the Spanish press: the 'assault' on Melilla, the election of Evo Morales and the affair of the Danish cartoons.

As suggested above, one of the conditioning elements of the prevailing racism of the European press is inherent bias in the processes of production. Newsgathering routines favor discourses of elite sources, and because the elite sources are predominantly white, the dominant discourse that is used as news, opinion and perspective defines a bias that is stacked against a definition of

5. Chávez, 2001; Cottle, 2000; Hartmann \& Husband, 1974; Jäger \& Link, 1993; Ruhrmann, 1995; Smitherman-Donaldson \& van Dijk, 1987; Ter Wal, 2002; van Dijk, 1991, 1995). 
events from the perspective of minority groups and their members. Minority sources, if consulted at all, are found less credible. Despite prevailing prejudices and ignorance, white journalists often think that white sources know more and are more 'objective' about ethnic groups and ethnic affairs than minority groups and their leaders and experts themselves. And because of widespread discrimination against minority journalists, alternative and expert views of ethnic minority communities and perspectives is scarce and often non-existent, even in the newsrooms of Europe's elite quality newspapers. Unlike US newspapers, European newspapers do not have equal opportunity policies to hire minority journalists.

It is not surprising that in such a production context, news and opinion about non-western immigrants, refugees, and minorities - and in general on ethnic affairs - is hardly unbiased. As is the case for all outgroups, the overall discursive strategy is to emphasize Our good things and Their bad things, and to de-emphasize (deny, ignore, mitigate) Our bad things and Their good things. Such polarization, expressing and reproducing underlying racist prejudices and ideologies, is implemented at all levels of media discourse.

In the press, for instance, this means that negative stories about Them are more frequent, bigger, more often on the front page, with bigger headlines, and so on. Besides such presentational and visual bias, we also find syntactic bias through the use of active sentences to emphasize Their negative actions and responsibilities, but passive sentences or nominalization (like 'discrimination') with hidden agents when We are responsible for negative actions against them (discrimination, racism, violence, etc.).

Most conspicuous is the biased selection of overall topics (semantic macrostructures). Analyses of many thousands of news and opinion articles in many research projects in many countries have consistently shown that - unlike our 'own' group - immigrants or minorities tend to be exclusively associated with negative topics and problems: immigration as invasion, abuse of identity papers, mafias, unemployment, violence, crime, drugs, illegality, cultural deviance, fanaticism, religious intolerance, backwardness, and so on.

At the same time, their obvious positive characteristics are systematically denied, ignored or underplayed: such as the immigrants' contributions to the economy (crucial in construction, agriculture, hotels, restaurants and domestic service), ethnic diversity and the arts, much needed correction of a very low autochthonous birthrate, and so on. Thus, whereas emphasis on problems is routine and daily, one seldom finds emphasis on the fact that Western Europe would economically collapse without the contributions of immigrants and minorities. 
Besides the racist biases in the definition of main topics, also expressed in the headlines, we find a host of more local properties of news and opinion articles that implement this ideological polarization in discourse. Thus, the problems and 'threats' of immigration are rhetorically enhanced by standard metaphors such as 'waves', and by the consistent number game of keeping count of how many thousands are arriving. That such numbers are not merely the expression of the usual rhetoric of exactness in the news may be concluded from the fact that these numbers are never given for all those who are leaving the country -as was the case for the millions of Spanish and Italian Gastarbeiter in the 1950s and 1960s in Northern Europe, or the political refugees from Latin America in the 1960 and 1970s.

The local discourse semantics of racist discourse is exhibited in the news, the editorials and the other opinion articles by more or less subtle meanings, such as negative descriptions of the Others, vague expressions for Our negative properties, and of course the usual play of negative presuppositions and other implications that indirectly state what hardly can be asserted explicitly about Them.

Consistent with the exclusion of minority journalists in the newsroom and the lacking access of other than white elite sources in the production process, is the biased pattern of citations in the news. Ethnic events are nearly exclusively defined by Our elites, and when those of the Others are incidentally given the floor, it is either because They are hardly representative (such as extremists) or because they happen to agree with Us. In any case, the Others are seldom speaking alone, and if they do have a different view on ethnic affairs than We do, their opinions are generally 'balanced' by one of Us. Of course Their accusations of racism tend not to be taken seriously, and hence are typically censored or played down - and always cited with conspicuous quotation marks, that is, not as a description of the facts, or as items of common knowledge, but as a controversial opinion.

In sum, both in the strategies of news production as well as in their discursive consequences in the news or the opinion articles themselves, we find a consistent pattern of racist bias, exclusion, and the overall polarization between Our good things and Their bad things. Whereas the prominent topics and headlines defining ethnic events and ethnic Others as a problem or as a threat are most conspicuous, more sophisticated discourse analysis has shown that such negativization extends to the subtle play of pronouns, demonstratives, active-passive syntax, implied meanings and the usual rhetorical means of emphasizing and de-emphasizing meaning.

Of course, the press is not homogeneous, and we may find differences between conservative, populist tabloids, on the one hand, or more liberal quality newspapers on the other hand. But the differences are more a question 
of style than of content. The quality press no less features news on problems and threats of immigration, illegality, crime and violence, and especially also alleged cultural threats. Most obvious, for instance, is that both on the Right as well as on the Left, and both in the tabloids as well as in the quality press, the denial of racism is standard. In fact, sometimes the denials on the Left are more vehement, because an 'accusation' of racism (and of sexism) is felt to be inconsistent with a progressive self-image. The same is true for the discrimination of minority journalists and minority sources in the production of news.

Also, the press is of course not alone in this discursive construction and reproduction of racism, and much of its discourses are rather closely imported from similar text and talk in politics, the bureaucracy, scholarship and other domains of symbolic power in society. Indeed, journalists not seldom blame others, such as politicians or the public at large, for their topics, style and other aspect of reporting - as if they were passive chroniclers of the discourses of the other power elites, or even of that of public sphere in general.

\section{THE SPANISH PRESS}

Unfortunately, most of the generalizations formulated above for the European press also apply to Spain and the Spanish press. It would be strange if this would not be the case. ${ }^{6}$

Yet, on the other hand, the Spanish press also has some particular properties that sets it apart from the rest of Europe.

First of all, there is not, properly speaking, a right-wing, popular tabloid press, as we know it from the UK, Germany, Denmark and other countries. On the contrary, most newspapers are definitely within the range of what usually would be called the quality press.

Secondly, the history of the Spanish press should also be seen against the light of the struggle against Franco's dictatorship, which promoted a strong democratic tradition since the early 1970s. This means that fascism, and more

6. For studies on immigration, racism and anti-semitism in Spain, see, e.g., the following books: Álvarez Chillida (2002); Aramburu Otazo, (2002); Bañón Hernández (1996, 2002); Barbadillo Griñan (1997); Calvo Buezas (1989, $1990 a, 1990$ b, 1993, 1995, 1997, 2000, 2001, 2003); Castiello (2002); Checa (2001); Colectivo IOE, (2001); Criado (2001); García Martínez (2004); García Martínez \& Sáez Carreras (1998); Gimeno Giménez (2001); Izquierdo (1996); Manzanos Bilbao (1999); Martín Rojo, Gómez Esteban, Arranz \& Gabilondo (1994); Martínez Vega (1997); Nash \& Marre (2001); Pajares (1998); Ruiz Olabúenaga, Ruiz Vieytez \& Vicente Torrado (1999); S.O.S. Racismo (2000, 2001, 2002, 2003, 2004); Solé (1995, 1996); van Dijk (2003). 
generally right-wing extremism, is outside of the consensus in Spain, especially under the symbolic elites. Unlike elsewhere in Europe there are no overtly racist parties, nor racist party publications. Various forms of radical conservatism survive in the Popular Party, in the hierarchy of the Catholic Church as well as in the Opus Dei movement, but so far this movement has not been associated with explicit racism.

Thirdly, Spain has a recent history of labor emigration, not only to the USA but also to Northern Europe, and the collective memory of these experiences, also among the symbolic elites, may have served as an antidote against blatant xenophobia against contemporary immigrant workers. This is more an explanatory hypothesis than an established fact, however, although it would be hard to prove such an assumption.

And finally, the debate in politics, education, the press and language in Spain is also strongly influenced by State and regional nationalisms. Conservative forces among these nationalist movements also have expressed themselves against immigration, e.g., for fear of losing linguistic and cultural identity, for instance in Catalonia.

These and other factors set the Spanish press apart from much of the press in Europe. However, as suggested, Spain has for decades been a member of the European Union, and its economic success has contributed to its rapid integration in the rest of Europe. The same causes have spawned unprecedented immigration, especially from Africa and Latin America - after earlier (largely pensioners') immigration from Northern Europe. This led to a strong increase of the immigrant population, from an insignificant percentage in the 1990s to close to $10 \%$ in large parts of the country in 2006. Compared with other EU countries, Spain now has by far the largest annual increase of immigrants.

As may be expected and predicted, fast non-European immigration has had its consequences also on the ethnic attitudes of large parts of the immigrant population. Although, again, not as strong as elsewhere in the EU, xenophobic and racist feelings have become widespread, and enacted in many forms of everyday discrimination and racist talk. As suggested, the Popular Party, led by former Prime Minister, José María Aznar, following the lead of the success of anti-immigrant politics on the Right in France, formulated and implemented anti-immigration policies. As elsewhere in the EU, these policies were accompanied by increasingly racist discourse associating immigration and immigrants with problems, illegality, crime, violence and cultural or religious threats.

Such political developments cannot be sustained without reproduction and help from the mass media. This means that national papers close to the Popular Party, such as $A B C$ and La Razón, often feature the same kind of topics 
formulating anti-immigration opinions. Regional newspapers, especially in the South, where African (including especially also Moroccan) workers are most conspicuous in intensive agriculture, might in this case be even more blatantly racist, typically so in more detailed coverage of 'foreign' crime, or their defense of xenophobic local politicians, for instance in the Voz de Almería.

The national prestige press, such as El País and El Mundo, as well as the regional quality press, such as La Vanguardia in Catalonia, comparable to the quality press elsewhere in the EU, are much less openly xenophobic.

Especially El País, backing the current socialist government of Luís Rodríguez Zapatero, has a rich tradition of high quality and progressive journalism that is largely inconsistent with explicit racism. Its strong opposition against the Popular Party and its earlier leader and Prime Minister Aznar also implied opposition against the latter's anti-immigration rhetoric.

As elsewhere in Europe for the center and center-left quality press, this does not mean that the coverage of immigration and minorities in El País is beyond critical analysis. As we shall see in more detail below, explicitly antiracist opinion articles may sit side by side with sensational coverage of the 'assault' of would-be African immigrants on the North-African Spanish cities of Ceuta and Melilla in 2005.

Similarly, during the cartoon affair in early 2006, El País, just like other EU newspapers, emphasized the freedom of the press and hence legitimatized anti-Muslim discourse, while again dramatically enhancing radical and violent Muslim protest around the world. Such biased reporting perhaps more clearly shows in what is not reported. Thus, although the occasion would have demanded it as context information, it did not publish background articles on racism in the EU press, nor detailed reports about racism and the situation of immigrants in Denmark - information that was relegated to that of a few letters to the editor and opinion articles of academic outsiders.

\section{RACISM AND THE SPANISH PRESS}

From the summary of some general properties of the Spanish press and its coverage of immigration, minorities and ethnic issues, we may expect few explicitly racist articles, but a clear European (Spanish, 'white') perspective on events. The few studies on racism in the Spanish press confirm this prediction. ${ }^{7}$ It is rare to find the explicit xenophobic sensationalism we may find in the British tabloid The Sun, or German Bild.

7. See, e.g. Bañón Hernández (1996, 2002); El-Madkouri Maataoui (2005); Prieto Ramos (2004); van Dijk (2003). 
Before we examine this general impression in more detail, let us summarize some earlier data. Unfortunately, the excellent press data of the Observatorio Permanente de la Inmigración (CIPIE) only go as far as 2000, and since immigration has doubled since then, and many more topics have become relevant we have no current general statistics of the press coverage. For the third trimester of 2000, the frequency data for a few newspaper are as follows, in Table 1:

TABLE 1. Frequencies of articles on immigration in four national and regional newspapers

368 El País

273 La Verdad (Murcia)

256 La Vanguardia (Barcelona)

$238 \mathrm{Abc}$

237 El Mundo

This means that after a steady increase of the coverage in the 1990s, the national and local newspapers in 2000 published on average about three articles per day on issues related to immigration, with El País at the top with 4 articles per day. The topics during these days may be summarized in Table 2:

TABLE 2. Topics in the 2000 Spanish newspaper coverage of immigration

15\% Legislation, the Immigration Law, etc.

23\% Border Control

$5 \%$ Daily life (work, housing, education)

$16 \%$ Crime, violence

$16 \%$ Solidarity, antiracism

$7 \%$ Europa

This simple frequency list shows that at least in 2000 - as was the case from the start - immigration coverage in Spain focuses first of all on the arrival of new immigrants (typically framed as illegal crossings from Africa in 'pateras'), on the one hand, and the question of papers and regularization on the other hand. Most likely a similar distribution is true today and for 2005, when the new regularization law of the new socialist government permitted millions of 'illegal' immigrants to legalize their situation $-\mathrm{a}$ topic prominently covered in the press, especially by pro-socialist newspaper $E l$ País. Note that the 'control de las fronteras' topics not only account for the harrowing experiences of the immigrants at sea, but also for the actions of the police. As is the case anywhere else, also in Spain there is scarce coverage of 
the everyday lives, the work and activities of minorities. On the other hand, less than elsewhere in Europe, and less than in the right-wing tabloids, is the limited (though not insignificant) coverage of 'ethnic' delinquency and violence. Part of the prominent topic of positive self-presentation is the collection of articles on solidarity with the immigrants.

\section{El País in 2005}

To get an impression of the coverage 5 years later, we did a search of the data base of El País, the paper that consistently publishes most on immigration topics. In 2005 El País published 5,791 articles featuring the words inmigrants, inmigration or the plural foreigners (we did not include the ambiguous singular Spanish expression 'extranjero', because this may also refer to 'abroad'; obviously, the plural may also refer to foreigners from Europe -whereas inmigrant in general only refers to non-European immigrants). This includes all articles on other topics in which these words are mentioned only in passing, but it confirms the general tendency observed in 2000 of some 4 articles per day, and in 2005 probably much more (some 15 articles per day at least mention these words). As suggested, these numbers include many articles in which immigrants are only briefly mentioned, but on the other hand do not include the articles that refer to immigrants only by their country of origin, such as Moroccans (mentioned in 1,481 articles, which of course includes reference to Moroccans in Morocco), Ecuadorians (mentioned in 327 articles). If we count all references to immigrants, foreigners, Africans, Moroccans, Ecuadorians, 'sin papeles', etc. El País may come close to 9,000 articles in $2005 .{ }^{8}$ In 2005 there are 701 articles in El País in which the notion of racism (or racist) appears, although many of these articles are about Europe or the rest of the world. In 228 articles racism is associated with immigration and in 346 articles with Spain - large part of which (97 articles) are about a racist incident in a football match and its consequences.

Headlines. In order to have an idea how many articles are actually largely on immigrants in El País, we examined the frequency of the words mentioned above in the headlines, which suggest that immigrants are a topic of the articles. The large amount of many thousands is now reduced to 983 for 2005, which means about 3 articles per day in all sections (also international or sports), and in all regional supplements together (viz., Catalonia, Madrid, Andalusia, Valencia, and Basque Country). Limiting this to national news only there remain 275 articles, less than

8. The search engine of El País does not allow to search more than a limited number of key words at the same time, so there is no way we can know the exact number, whereas accumulated separate searches are impossible because of much overlap: articles that use different words to refer to immigrants of various backgrounds. 
one article per day, whereas Catalonia, for instance, adds 95 articles to this, summing to 360 articles per year for the reader: one article per day. Obviously, there are articles on immigrants or immigration that do not mention this notion in the headline, so it is plausible that this number is higher. That many of the articles on immigration focus on illegal entry is obvious from the 92 articles that have 'patera' [the small boats used to cross the Straits of Gibraltar] in their headline - and 35 articles combine immigrants in the headline with the police.

A more detailed study of the headlines in the Catalan edition of JanuaryFebruary 2006 confirms these general tendencies: of 369 headlines, 85 are about any form or illegal entry, pateras, etc.; 38 about political reactions about irregular immigration; 10 about false papers; but also 19 articles about discrimination of immigrants. As is the case for the national coverage, and different from other countries, is the scant coverage, in El País, of crimes committed by immigrants. These topics rather tend to be covered by the conservative local press, such as the Voz de Almería, etc.

We specifically focused on the 70 articles in El Pais that had the word racism or racist in the headline, so as to see how the newspaper deals with racism as a main topic. First we see that many (20) articles on racism appear in the regional supplements, especially in Valencia, Andalusia, Madrid and Barcelona. Secondly, during 2005 it is especially the topic of racism in football that is covered - but nearly only in the sports section of the newspaper (in 22 of 70 articles). Only a few articles appear in the (national) sections on Society or Spain (e.g., protests against a racist disk jockey), and the same is true for international news. Actually, during the whole of 2005 there is not a single general news or opinion article in the national edition about racism in Spain. This confirms results of other studies as well as our own previous studies, namely that one of the topics that is most relevant for immigrants and minorities itself, but that is about Our bad things (in our own country, etc.), is typically excluded or backgrounded. If it occurs it is about racism in the past, in other countries, at the extreme right, or in other social classes (typically the 'uneducated' popular classes), or it is dealt with in euphemistic terms, such as 'prejudice' or even 'popular discontent'. The interest in the topic of racism in football confirms that it is rather something for 'another' section of the newspaper and for 'another' kind of readers and citizens. We have not found any reportages or background articles on elite racism, e.g., in government, the media, education, research, the police, business, and so on.

In other words, in Spain in 2005 the topic of racism is not found newsworthy or relevant for the readers, and hence probably not very prominent in the minds or worries of the (invariably white) Spanish journalists, reporters or editors. We see what the consequences are on the coverage of ethnic affairs of the homogeneously 'white' composition of the newsroom. 


\section{El Mundo}

The other major national newspaper El Mundo published 1,129 articles in 2005 with the notions of 'immigrant' or 'immigration', that is, still about 3 articles per day on average - following its own statistics. Only 219 articles actually deal with the topic as such (if we set the $95 \%$ relevance criterion of the newspaper). However, a search for extranjeros produce a frequency of 3,294 articles, so that we may assume that this is a term more used by El Mundo than the expression inmigrantes (this large number of articles on foreigners is reduced to 264 if we set the relevance criteria to $95 \%$. In other words, there are many articles that merely mention foreigners in passing and not as a main topic. Obviously, the term foreigners may also refer to other foreigners than immigrants, and in a search there it is impossible to make the distinction. Yet, as also is the case in the media in Holland and Germany, foreigners (buitenlanders, Ausländer) has become virtually synonymous with (non-European) immigrants. So, even when sometimes extranjeros is used to refer to European immigrants or tourists, it is likely that more than 4,000 articles at least briefly mention immigrants - that is, more than 10 articles per day. Many of these articles are about illegal immigration: 2,236 articles in 2005 feature the word patera, 104 of which also mention inmigrants o inmigration. Of the 1,129 that mention immigration, 247 also mention police, and 275 also the notion of illegality. In 2005 many of the articles (211) mention the process of regularization of undocumented immigrants (sin papeles -without papers). On the other hand, only 15 articles combine immigration with racism (of the 302 articles that only mention racism, many of which deal with the incidents of racist events in football and other sports). It is impossible to find out how many of these articles are mainly on these topics because the search engine of $E l$ Mundo does not allow searches of the headlines.

Unfortunately, we have no data from conservative $A b c$, whose search engine does not seem to produce reliable frequencies (all searches add up to the same frequency of 400 articles). ${ }^{9}$

9. More generally, it should be observed, for methodological reasons, that the search engines of the Spanish newspapers could be improved upon. First of all, they are all different, making access by readers and researchers more difficult. They often do not allow Boolean searches, or the use of abbreviations (like inmigra) to search for many forms of a word (inmigrante, inmigrantes, inmigración, etc.). Also, they are often very unreliable, producing the same frequencies when one adds a search term. It should therefore be recommended that all newspapers use a simple Googlelike search input of Boolean expressions, and all types of contents to be searched -headlines, bodies, different sections, etc. - (as is the case for the best of the engines, that of El País). Lacking in all media is a possible search of keywords. Now, with only a word-based search, many articles are found that have nothing or little to do with what is being searched. So, articles should be stored, like scientific articles or books, with keywords or 'subject terms', for instance in an xml framework. Thus, in our case, all articles should have had a keyword immigration or minorities, combined with some others, such as work, housing, etc. 
From these approximate statistics, we may first conclude about a prominent part of the national press that the topic of immigration and immigrants remains very prominent in the Spanish press, with at least some three articles each day — and possibly much more in El País. Also, much of this coverage still is about illegal entry, 'pateras', the police and other negative or stereotypical topics. Specific for 2005 is the extensive coverage of the regularization of undocumented immigrants. On the other hand, 'racism' is a concept that may appear at least once a day in the press, but hardly ever as a main topic, let alone about racism in Spain - except when there is a special incident, such as racist slogans during a prominent football match in 2005.

\section{La Vanguardia}

Looking at the regional press, in 2005 the conservative Catalan newspaper La Vanguardia published 2,499 articles with the words immigrant(s) or immigration, of which 418 in the headlines, that is, as main topic. Of these articles, 358 also talk about the police, 152 about illegals, and 31 about delinquents. If we add the vague term foreigners then there are 3,823 articles in 2005. In the same year La Vanguardia published 385 articles with the word racism or racists, of which only 60 also mentioned the word immigrant, 71 also mentioned Spain, and 30 both immigrant and Spain. In 65 articles we find both the word racism and football, as expected. In sum, it appears that when racism is being mentioned in the majority of cases it does not apply to Spain or immigrants in Spain. Also, of the 358 articles that mention the words racism or racist, only 33 have the words in their titles, thus defining it as a concept that is part of the main topic. Of these articles about racism, the majority is about other countries and about football incidents. Note that one of the few headlines about racism in Spain (but not about football) emphasizes that Spain is NOT racist:

El Observatorio ya no cree que España sea el país más racista (La Vanguardia, 21.5.2005)

The observatory no longer believes that Spain is the most racist country.

In sum, as is the case for the national quality press, we find that also $L a$ Vanguardia continues to publish many articles with the words immigrants or immigration (half the amount of El País), though only 418 in the headline, that is, as part of the main topic. Many of these articles also are about 'pateras' and the police. Although many articles (at least one a day, on average) mention the word racism, the concept seldom appears in the headlines as main topic, and it applies hardly ever as racism against immigrants in Spain. 


\section{Topics}

From the observations made above about the frequency of specific terms in the headlines, we have been able to draw some provisional conclusions on the relative frequencies of topics in the news and the opinion articles. These simple frequency counts seem to confirm that the major topics have not changed dramatically in the last years: 'illegal' entry and border control (pateras, etc.), political reactions to irregular immigration, papers and regularization, and then a variety of 'social' topics, such as work, housing, social services, as well as forms of protest of immigrants, discrimination of immigrants as well as solidarity with immigrants.

We have also seen that the topic of racism in Spain, and especially among the elites, is taboo in the press - and only covered for specific incidents (for instance racist calls during football matches). The contributions of the immigrants to the economy of the country are mentioned (e.g., for pensions, in construction, etc.) but only incidentally, as predicted by the theory: Their good things are de-emphasized. Similarly, we seldom read about the everyday lifes of immigrants, and virtually never about their elites (doctors, professors, $\mathrm{PhD}$ students), because such would be inconsistent with the stereotype of the typical immigrant as a poor worker.

\section{The 'assault' on Melilla}

After these more general remarks about the frequencies and topics of the coverage of immigrants in the Spanish press, let us examine some of this coverage in some more detail. We shall do this in the rest of this paper for the main quality paper, El País, because of its prominent position as the newspaper 'of reference' in the country, and because of its generally liberal, center-left, etc. policies and reporting, close to the socialist PSOE party (its slogan that it is an 'independent' morning paper is a form of well-known positive self-presentation that is inconsistent with its overtly biased reporting in favor of the PSOE - and its government - and against the Partido Popular and its earlier government and leaders). More generally in my work on racism and discourse, I have focused rather on 'our' discourses, that is, the discourses of the mainstream elites, rather than on extremist or very conservative newspapers, organizations, and so on. Indeed, the contribution of the 'ethnic definition' by our quality newspapers, e.g., because of their influence on the (other) elites, and primarily the politicians, is fundamental.

If there is one story that stood out in 2005, it is the attempt of African (mostly young male) migrants to enter the Spanish city of Melilla in North Africa by climbing over the fence that separates this city from Morocco. Here 
is a selection of the fragments from news reports between the end of August and October 2005.

(1) A las seis de la mañana de ayer se oyó un cuerno, y 250 subsaharianos surgieron de la maleza y se lanzaron al asalto de la valla que separa Melilla de Marruecos. Avanzaron en tres grupos de unas 80 personas cada uno. Portaban más de cien escaleras para salvar las alambradas. [...] Fue como un asalto medieval. "Es la primera ocasión en que los subsaharianos se muestran agresivos", relata el portavoz de la Guardia Civil. (El País, 27.8.05)

At six o'clock in the morning yesterday, a horn could be heard, and 250 'subsaharianos' [people from Africa South of the Sahara] emerged from the bushes and launched an assault against the fence that separates Melilla from Morocco. They advanced in three groups of each 80 persons. They carried more than 100 ladders to cross the barbed wire. [...] It was like a medieval assault. "This is the first time the 'subsaharianos' behave aggressively", says the spokesperson of the Guardia Civil.

(2) 300 inmigrantes logran entrar en Melilla en dos asaltos masivos a la valla en menos de 24 horas. (El País, 28.9.05)

300 immigrants manage to enter Melilla in two massive assaults in the fence in less than 24 hours.

(3) ¿Salto o asalto? Leo con sorpresa en su periódico y escucho en los telediarios de Telecinco y la Primera la noticia de que 70 inmigrantes subsaharianos intentan saltar la valla de Melilla, sin éxito y con resultado de varios heridos. La sorpresa no viene de la tentativa fallida, ni del número "masivo" que componía el grupo. No. La sorpresa viene de la expresión usada: asalto. Acudo al diccionario de María Moliner y compruebo que las principales acepciones de asaltar apuntan al ataque a una fortaleza o posición enemiga para penetrar en ella o tomarla; o bien "atacar a alguien, particularmente para robarle", o "penetrar violentamente en un sitio para robar". (Daniel Pelegrín Nicolás - Zaragoza). (El País, 23.9.05).

Jump or assault? It is with surprise that I read in your newspaper and that I hear on the news programs at Telecinco the first news item about 70 subSaharan immigrants who try to jump over the fence in Melilla, without success and with various people wounded as a result. My surprise is not caused by the failed attempt, nor by the "massive" number the group consisted of. No. My surprise was caused by the expression used: assault. I consult María Moliner's dictionary and realize that the main meanings of 'assault' refers to an attack of a fortress or a position of the enemy in order to penetrate it or to take it; or "to attack someone, especially to rob him" or "to penetrate a place violently in order to rob". 
As we see from these few examples from a huge coverage of weeks, the dominant definition of the event is in the military or criminal terms of 'assaults' that is, in terms of violence. After criticisms such as the Letter to the Editor cited in example (3), the word 'asalto' was sometimes replaced by the similar word 'salto' (jump), which has a less negative connotation. This sensationalist coverage of an 'international' assault on Spanish cities by black youths of course opens the Pandora box of well-known racial stereotypes, such as about the aggression and violence of black people. Note also the use of the metaphor in (1) about the 'medieval' character of the assault, because of the use of long ladders used to jump the high fence. As we know more generally from the association of time and the other (Fabian, 1983), the Others are often portrayed as living in another, past time - as also the common metaphor of being 'backward' (Spanish atrasado) suggests. The same is true for the use of a 'horn' to give the signal of the 'assault'. Thus, the African blacks are associated metaphorically with 'primitive' means (instruments 'we' used in 'our' Middle Ages). Throughout the coverage the aggression of the African men is being emphasized, as also a (police) source in example (2) suggests. Of course, in the primary coverage, only the police is the source of all news, and no African participants are (as yet) interviewed. This happens later, occasionally, in background victim-stories in weekly supplements, namely when the Africans have been forcefully removed by the Moroccan army and police and transported back to the desert (or sometimes sent home by plane). Notice finally the typical use of numbers in example (1), is a wellknown case of a rhetorical number game suggesting precision and objectivity and hence reliability and credibility of the news.

\section{Evo Morales}

The second topic in the 2005 coverage of El País that deserves critical analysis is the coverage of the election of president Evo Morales of Bolivia. Although not about immigrants or minorities in Spain, news and opinion about Morales shows surprising similarities with the coverage of minority leaders in Europe. More generally, it has often been observed that there are parallelisms between public discourses about non-European people residing in Europe as minorities, on the one hand, and the way Europeans speak and write about countries, cultures and people outside of Europe, on the other hand. In both cases they are groups that are dealt with as Others, and not only as essentially different from us, but especially as being inferior to us. Through the ages, and especially also since the conquest of the Americas, slavery and colonialism, Others have been systematically portrayed as less: less human, less smart, less beautiful, and so on. In contemporary discourse, such expressions of 
superiority focus specifically on technology, medicine, culture, religion and politics.

Until today the Third World is typically represented as less democratic than Europe - thus ignoring the recency and vast international destruction brought about by the fascist regimes in Germany, Italy, Spain, Portugal and Greece, colonialism until only a few decades ago by several European countries as well contemporary military hegemony and aggression by the USA and its allies.

This also applies to current media and political discourse on Latin American countries, even years after democratic elections. That is, despite changes and improvements in some media, also Latin America is still often covered by the well-known "Coups and Earthquakes" frame of international news (Rosenblum, 1981), although since the 1980s we might add a some more topics: "elections", "drugs" and of course "terrorism".

Thus, also Bolivia is covered much more intensely during open conflict and presidential elections and their aftermath, with the stereotypical label of the "poorest country of South America", but hardly with some background articles about why, and who is keeping Bolivia so poor, despite its resources (such as gas) - controlled by 'our' internationals.

The earlier coverage of Evo Morales, therefore, is consistent with these general principles: Less attention is being paid to what he has done and can do for the poorest of his country (and if such contributions are mentioned at all, they are disqualified as being 'populist' -which means democratic policies we do not like), than to his role as an opponent of the role of the multinationals and their local political protectors. For the same reason also Morales' association with Hugo Chávez of Venezuela, another pariah of Western politics and media, is enough to marginalize him and to brand him as another populist leader, instead as a respected, democratically elected president, who also has a heart for his people. His modest background and education, as well as his role as leader of the 'cocaleros' are further elements in a stereotypical portrayal as it characterized the quality press in the UE, also in El País.

Relevant for our discussion here is not only the typical superior and at times arrogant way the European media portray Third World countries and their leaders (if they portray them at all), but also the way Evo Morales was primarily defined as an 'indio'. Since the press loves to report 'historical events' and 'firsts', the election of the first indigenous president of his country (and one of the first in contemporary Latin America) provoked much special comments, descriptions, and a style of portrayal that does not characterize the description of 'white' (European) presidents, that is, of people more 'like Us' -though, as Latin-Americans, of course not quite like Us. 
The press description of Evo Morales as an 'indio' is generally found denigrating today in Latin America, also while generally used in racist talk and text associating indigenous people with many negative characteristics. In fact, several readers protested against this use, and El País' ombudsman (Defensor del Lector), Sebastián Serrano, dedicated a special item to this question on January 2nd, 2006. That this journalist usually defends the newspaper rather than the readers (and hence cannot possibly be compared to an ombudsman) is also very clear from his discussion, in which he basically concludes that such critique is another form of political correctness. This is the standard defense (blaming the victim or the accusers) of the symbolic elites (typically white males) when they are criticized for sexist or racist language use. And not surprisingly, the newspaper's reporters continued to use the term occasionally, even when the appropriate form (indigena) was used more often, as is the rule in the South American media - as any competent journalist reporting from and about Bolivia should know. Here is a passage of his article that is revealing and typical:

(4) Creo que utilizar preferentemente indígena es una opción razonable porque evita que algunas personas se puedan sentir ofendidas. No es posible obviar el dato de que este diario tiene cada vez más lectores latinoamericanos, sobre todo a través de Internet. Pero tampoco sería razonable prescindir totalmente del término indio. La redactora de Internacional, Maite Rico, enviada especial a las elecciones bolivianas y con amplia experiencia en América Latina, considera que la connotación negativa se la da a ese término el hablante o el lector. "No hay más que ver", añade, "la infinidad de documentos en los que se habla de pueblos indios: desde las declaraciones zapatistas, a la Agencia Internacional de Prensa India o el Parlamento Indio Americano. Yo uso más indígena, pero el debate me parece artificial". Para esta periodista, la actual "fiebre de corrección política empieza a ser asfixiante". (El País, 22.1.06).

I believe that it is a reasonable option to preferably use the expression 'indigena', because it avoids that some people may feel themselves offended. It is impossible to ignore the fact that this newspaper has more and more Latin American readers, especially through the Internet. But it is not reasonable either to totally abandon the term 'indio'. The international editor, Maite Rico, special envoy to the Bolivian elections and with extensive experiences in Latin America, thinks that the negative connotation of the term is given by the speaker or the reader. "One only has to see", she adds, "the enormous amount of documents in which mention is made of "pueblos indios": from the declarations of the Zapatistas, to the Agencia Internacional de Prensa India or the Parlamento Indio Americano. I use 'indigena' more, but the debate sounds artificial to me". For this journalist, the current "political correctness fever begins to be suffocating". 
This passage tells us something about the Defensor del Lector (DdL) and his norms and values, about the special envoy Maite Rico, as well as about the general policy of the newspaper - namely to send someone to Latin America who apparently has no idea (despite her experience praised by the Ombudsman) about norms in Latin America. First of all, the DdL accepts - after the critique of the readers - that the use of 'indígena' may be 'reasonable'. In other words, he does not agree that is imperative for a modern newspaper to follow the norm that one uses the designation preferred by the people referred to. Rather, he only seems to want to take into account that "algunas personas se pueden sentir ofendidas" (some people might feel offended), which contextually implies (a) that such persons may be oversensitive, and (b) that they are only few, which in turn implies (c) that most people or most Latin Americans or most 'indios' would not mind such use. More to the point from a commercial point of view, of course, is the argument that there are more and more readers from Latin America. That also people in Europe, Latin Americans or not, might feel that the newspaper is using racist denominators, and that in general, and for all readers and indigenous people it is just to use a correct name, is an argument that does not seem to hold. We see who this "Defensor" is actually defending, namely the journalist and the newspaper, and obviously not the readers.

The same is true for the reporter and her arguments. She first of all displays a fundamental ignorance about discourse and communication, when she claims that negative consequences are attributed by the speakers or the readers. She thereby ignores that word meanings change with their social context, and that if a word such as 'indio' in Latin America is more and more associated, socially and by indigenous peoples themselves, with negative stereotypes, she as a journalist should not only know this, but also act and write accordingly. If not, she is willingly using offensive language. Second, her argument that the notion of 'indio' is being used in many documents is incomplete and misleading. First of all, these uses are characteristic of the past, as is the case for labels such "Negroes" or "Colored People" in the USA and elsewhere. Secondly, where used today by indigenous peoples themselves, it is also as part of names of organizations, or in special contexts, as is also the case for the US organization NAACP (where the last letters denote "Colored People"). She should know that the preferred usage is "indigenous" or "original" throughout the Americas. And finally, the same journalist has no idea about ethnic relations and the requirements of multicultural societies when she deems the "debate artificial" - thus not taking seriously the arguments of indigenous peoples. One may wonder what the criteria of El País are to send this reporter to Latin America when she obviously shows so much ignorance and lack of respect for some basic social conditions. And finally, her 
description of "political correctness" as "asphyxiating" qualifies her not only as professionally incompetent but also as a conservative. And one may wonder whether she would accept traditional macho terms to refer to women, and would reject feminist critiques of such labels as equally "asphyxiating." Indeed, there must be a reason why she says that she herself prefers the (longer) term 'indígena'.

That the retrograde use of terms such as 'indio' is not limited to one journalist is obvious from the rest of the coverage of Evo Morales and his election. El Defensor (de El País) claims in his article that indigena is the preferred word of the newspaper, "while free of negative implication", but at the same time, having counted, found 16 uses of the term "indio". The very editorial of El País of January 5th, 2006, again speaks of "el primer indio eligido presidente", so these preferences are not very stable. Indeed, they are mere 'preferences', not fundamental rules of respect. A few days later, M. Á. Bastenier, reporting from various countries in Latin America around the days of the election of Morales, also uses the expression "indio aymara" in his column of January 8, 2006, as he does for "otro indio" Ollanta Humala, in Peru -also in a generally negative evaluation of 'populist' presidents in Latin America. And then again on December 21st, when dubbing Morales "el primer indio después de Benito Juarez” (the first Indian after Benito Juarez), and even "mestizo de indio" when referring in the same article to Lucio Gutiérrez of Ecuador. El País is apparently consistent, because it also referred to "el líder indio Evo Morales" (the Indian leader E. M.) in another editorial, accompanied by the negative verb catapultar. And so on for the reporters on the spot (Mabel Azcui, 11.12.05), and then even in a headline, Evo Morales, indio rebelde (E. M., rebel Indian) (December 17th, 2005). Writer Vargas Llosa, in his column against populist regimes on January 15th, is no less sociopolitically insensitive when he uses indio several times. In sum, El País does not seem to care very much whether or not they name indigenous peoples by the description they prefer. Indeed, imagine someone would accuse them of being politically (too) correct.

Of course, the old fashioned or provocative use of indio in the newspaper is merely one aspect of the coverage of Evo Morales and Bolivia. We already mentioned the consistently negative accounts of his association with Hugo Chávez and Fidel Castro - by the simple rule that the friends of my enemies are my enemies. This is, by itself, no problem - any newspaper and political commentator should of course evaluate politicians by their own standards. Remarkable only is that the negative accounts seem to focus on those presidents that seem to be more left of center, more anti-American, and more 'populist' if their first policy is to want to fight poverty. Indeed, comparatively little negative commentary has been lavished on all those (white, European) 
earlier presidents of the same countries, who were friendly with the USA and the multinationals, but contributed to the reproduction of poverty. But again, that is a political aspect of the coverage of Latin America, and not (always) an ethnic aspect, although it is not coincidental that the media opposition against Chávez, both in Venezuela, as well as outside, not only is a legitimate political critique, but also ethnic tinges, because also Chávez is not a white European.

Seemingly less relevant too is the way Evo Morales is portrayed. Not only are his indigenous roots and loyalties strongly emphasized, but as is often also the case for the (sexist) coverage of women politicians, there in extraordinary media interest in his clothes, and not only in the popular (populist?) European press. That Evo Morales prefers to dress in a colorful sweater and not in a traditional suit-with-tie, as most western politicians, is extensively covered and hence obviously important and relevant for the EU press. The references to his chompa (sweater) in El País range between the usual exotism in the account of ethnic others, on the one hand, and depreciative negative implications - as breaking the norms of international political etiquette - on the other hand, as we find in one of the Latin American columns of Bastenier:

(5) Morales $[\ldots]$ que va a los actos protocolarios ataviado con un jersey de la gama más modesta de Galerías Preciados (8.1.06).

Morales [...] who goes to official occasions dressed with a sweater of the cheapest kind from the Galerías Preciados.

The same is true for Vargas Llosa whose attacks on the "loony left" ("la izquierda boba") is also associated with "orgasmic enthusiasm" for the sweater of Morales (15.1.06). Javier Torrontegui is allowed to write a whole article (8.1.06), though in the less serious section "Gente", on the topic, apparently of major importance for the readers of El País. This is how that article begins:

(6) A la pregunta de cómo irá vestido el presidente electo de Bolivia Evo Morales el día de su toma de posesión como jefe de Estado, el senador Antoni Peredo ha respondido: "Cuidaremos de que lleve los calcetines nuevos". Así se ha visto en su propio ambiente la polémica suscitada por la indumentaria con la que el primer indio americano que llega a presidente ha afrontado el protocolo en su reciente visita institucional a España, donde acudió con una ropa que aquí se ha llamado informal a todas sus reuniones de trabajo, con el rey Juan Carlos, con el presidente del Gobierno, José Luis Rodríguez Zapatero, con los empresarios y con los especialistas en política internacional. Las críticas a la vestimenta que ha utilizado el líder boliviano han sido respondidas por éste con humildad, y en Bolivia se han visto como una señal de incultura. Evo Morales está acostumbrado. Y no sólo a eso. (8.1.06). 
To the question what clothes the president-elect of Bolivia Evo Morales will wear on the day of his inauguration as Head of State, senator Antoni Peredo replied: "We'll make sure he will be wearing new socks". It was thus how people in his own environment saw the controversy raised by the attire with which the first American Indian to become president faced the protocol during his recent official visit to Spain, when he was dressed in clothes that we would call informal during his work sessions, with King Juan Carlos, with Prime Minister José Luis Rodríguez Zapatero, with business leaders and with specialists of international politics. The criticisms about the clothes worn by the Bolivian leader were responded to by him with humbleness, and were seen in Bolivia as a sign of lacking education. Evo Morales is used to that. And not only to that.

To such commentary on his clothes, finally, are added negative comments on his Spanish pronunciation, also by Vargas Llosa, who incidentally never made it to the presidency of neighboring Peru, despite his undoubtedly posh Spanish accent. Here is how Vargas Llosa describes Morales, mixing dubious praise with many implied negative evaluations, and in the process also denying him his indio identity:

(7) Tampoco el señor Evo Morales es un indio, propiamente hablando, aunque naciera en una familia indígena muy pobre y fuera de niño pastor de llamas. Basta oírlo hablar su buen castellano de erres rotundas y sibilantes eses serranas, su astuta modestia ("me asusta un poco, señores, verme rodeado de tantos periodistas, ustedes perdonen"), sus estudiadas y sabias ambigüedades ("el capitalismo europeo es bueno, pues, pero el de los Estados Unidos no lo es"), para saber que don Evo es el emblemático criollo latinoamericano, vivo como una ardilla, trepador y latero, y con una vasta experiencia de manipulador de hombres y mujeres, adquirida en su larga trayectoria de dirigente cocalero y miembro de la aristocracia sindical. (15.1.02).

Mr. Evo Morales is not even an 'indio', properly speaking, although he was born in a very poor indigenous family, and although as a boy he was a shepherd of lamas. One only needs to hear him speak his good Spanish with round rolling $r$ 's of the mountains, his shrewd modesty ("it scares me a little, gentlemen, to see me among so many journalists, I beg your pardon"), his studies and wise ambiguities ("well, European capitalism is good, but that of the United States is not"), to know that Sir Evo is the typical Latin American, lively like a squirrel, a long-winded social climber with a vast experience as manipulator of men and women, acquired during his long career as leader of 'cocalero' [peasants who grow coca] and member of the union aristocracy.

From these various passages about the coverage of Evo Morales we might conclude that El País and its journalists and columnists simply do not 
like Evo Morales and his politics -as they also have shown for Hugo Chávez. However, this negative coverage is different from the negative coverage of other European (white) politicians they do not like. As is also shown by the 'joke' of the Spanish (conservative catholic) COPE radio journalist phoning Morales pretending to be Prime Minister Zapatero, we detect a lack of respect that is typical of sexism and racism -the other person is represented not only as a political or ethnic outgroup member, but also as inferior. The sociopolitical and conservative rejection of avoiding 'politically incorrect' denominations such as 'indio', further confirms this lack of what could be called 'interethnic correctness' of a leading newspaper as El País, a crucial condition for a newspaper in a multi-ethnic society in Europe.

\section{THE DANISH ANTI-MUSLIM CARTOONS}

Let us finally examine in some more detail some of the characteristics of the Spanish press coverage of the islamophobic cartoons published, in September 2005, in the conservative Danish newspaper Jyllands Posten, causing months later, in February 2006, vast international protests from Muslims and others around the globe.

The cartoon-affair of February 2006 in many respects reminds of the Rushdie-affair of 1989, when the Ayatollah Khomeini issued a 'fatwa' against writer Salman Rushdie for his book The Satanic Verses. Both in that affair, as well as in the current cartoon-affair, most of the symbolic elites who had access to the Western media not only vindicated the freedom of opinion and the press, but at the same time emphasized the religious intolerance, the fanaticism, and the backwardness of Islam and the Arab world. They thus continued a long tradition of Orientalism and anti-Arab racism, also in the mass media (Richardson, 2004; Said, 1979, 1981). Others in the debate, notably politicians and many scholars, emphasized that the freedom of the press should be exercised with responsibility and respect, and not be abused by insulting the icons of religious communities and thus exacerbate local and global ethnic tensions.

Conspicuously underreported in the cartoon affair, and also less emphasized in the many opinion articles, was the role of the affair and its coverage in the reproduction of racism - quite consistent with the general denial of elite racism by the press, as signaled above.

Also the Spanish press covered this affair extensively, not least because it construed the worldwide Muslim protests as an attack against the freedom of opinion in general, and as an attack on the freedom of the press, in particular. 
Many journalists and columnists thus represented the affair as a prime example of the alleged Huntingtonian "clash of civilizations", rather than as a straightforward case of racism in the press - a seemingly minor incident with a tremendous international consequences. As we shall see, the alternative definition of this affair, namely as a case of press racism, was found totally taboo and was never ever even mentioned in the media, anywhere, even by those who found the cartoons insensitive, or even an expression of islamophobia. Despite hundreds of articles on the case, and many opinions, especially by those who defended the allegedly attacked freedom of the press, no background articles appeared with analysis of the growing racism in Denmark, and the role of the conservative press and politicians in its production and reproduction. That story, which could be told in an article in Le Monde, could not be told in the Spanish press in general, and not even in leading El País.

As we have found before in earlier analysis of the coverage of racist events in the press, such events generally tend to be defined in terms of denials or mitigations, especially when the perpetrators are (more) like Us. As we have seen above, we might find articles on racism abroad, in the past, in popular neighborhoods or among right-wing extremists, but never in our own party, business, university or newspaper. Since journalists are the only professionals who control what appears in the press about themselves, it is hardly surprising that newspapers never publish about racism in their own newspaper. At most, and even then exceptionally, this may be the case for the coverage of racism of an extremist newspaper or TV station.

In sum, the coverage of the Danish cartoon-affair is quite consistent with a very solid tradition of reporting ethnic affairs in general and the role of the media in such affairs in particular. More specifically, and in line with historical, deep-rooted anti-Muslim sentiments among the European elites (Said, 1979, 1981), we find that in the same way as many Muslims viewed the cartoons as an insult of their prophet, many journalists and other elites took the affair as a test of the cherished value of the freedom of the press. That such freedom was not at all under attack and no one who could potentially limit it in Europe even hinted at such an attack, did not prevent journalists to associate international protests against islamophobic cartoons as such an attack. Let us see in some more detail how the Spanish press covered this affair.

The dominant topics in the coverage of the cartoon-affair are organized by the familiar overall polarization strategies of emphasizing Our good things and Their bad things: On the one hand, as we see in examples (9) and (10), a very prominent focus on the Freedom of Expression as a major, if not absolute, European or Western value: 
(8) El diario, el principal de Dinamarca, publicó los dibujos en nombre de la libertad de expresión, después de que el autor de un libro sobre Mahoma no hubiera podido encontrar ilustradores para su obra, por temor a represalias. (El País, 31.1.06).

The newspaper, the most important in Denmark, published the drawings in name of the freedom of expression, after an author of a book on Mohammed could not find illustrators for his work, out of fear of reprisals.

(9) "La libertad de expresión no es negociable" (Entrevista con redactor jefe de Jyllands Posten, El País, 1.2.06)

"The freedom of expression is not negotiable".

On the other hand, following the logic of polarization we find an emphasis on the topic of the violent protests, intolerance, fundamentalism and radicalism of the world of Islam, propagated by dictatorial regimes. More specifically, as we see, as is also the case for immigration, any form of 'outside' action relative to Europe is interpreted as another form of attack - in this case on one of the most important of 'our' values. As is generally the case for 'attacks' by outgroups, the ingroup shows that it is unified and shows solidarity with those of its members who are threatened, as we already saw in examples (9) and (10), and more explicitly in examples (11) and (12):

(10) La UE defiende la libertad de expresión. Los ministros de Exteriores de la Unión Europea mostraron ayer su solidaridad a sus colegas danés y sueco por las amenazas recibidas por sus gobiernos y sus empresas en varios países musulmanes [...](El País, 31.1.06).

The EU defends the freedom of expression. The Ministers of Foreign Affairs of the European Union showed yesterday their solidarity with their Danish and Swedish colleagues because of the threats received by their governments and businesses in several Muslim countries.

(11) Una decena de periódicos europeos han decidido reproducir las polémicas caricaturas de Mahoma publicadas inicialmente en el diario danés JyllandsPosten, que han provocado una reacción virulenta en el mundo islámico y una tormentosa crisis diplomática. Los diarios han decidido mostrar así la solidaridad con sus colegas daneses, que ayer sufrieron una nueva amenaza de bomba, y defender la libertad de expresión. (El País, 2.2.06).

A dozen European newspapers decided to reproduce the controversial cartoons of Mohammed originally published in the Danish daily Jyllands Posten, which led to violent reactions in the Muslim world and a deep diplomatic crisis. 
(12) La libertad de expresión es fundamento de la organización social de que se han dotado los países más progresivos del planeta, y Europa en particular. (Editorial, El País, 5.2.06).

The freedom of expression is the foundation of the social order with which the most progressive countries of the planet have endowed themselves.

These examples show clearly how the event of a (European) press insult against Muslims is constructed as an international conflict between Good and Evil, where We defend the basic values "of the most progressive countries on the planet" against "virulent" reactions and bomb-threats. That is, as is the case with one of the cartoons, the press thus associates, without much nuance, Muslims with radicalism and terrorism. At the same time, we witness the familiar move of all racist discourse, namely blaming the victim: those who were offended, and hence possibly would deserve our sympathy are transformed into the aggressor. Obviously, in such sympathetic coverage of their very own professional group, also the journalists of the Spanish quality press hardly show any discursive distance with respect to their Danish colleagues, and thus implicitly legitimate the publication of islamophobic cartoons in name of the freedom of the press.

Throughout the month of February 2006, thus, the coverage of the (violent) protests in the Muslim world remain a prominent topic -thus hammering home, and reproducing, the century old orientalist topos of the violent Muslim and Arab.

The polarization between our democracy and freedom, on the one hand, and their undemocratic fundamentalism is the main framework for the cognitive and discursive construction of this event. The tone of the coverage and the editorials in such a case may become explicitly paternalistic if not arrogantly superior, as in the following passage of an editorial in El País, in which the others are attributed not only violence and radicalism, but also being stupid and backward -as the euphemism "precario conocimiento" suggests:

(13) Si ciertos Estados árabes reclaman de las autoridades nacionales de los países acusados de blasfemar contra Mahoma una estentórea petición de excusas, debido arrepentimiento y garantía de que ello no volverá a suceder, es por su precario conocimiento de lo que es una sociedad abierta, donde la libertad incluye también caer en el error. (Editorial, El País, 5.2.06)

If certain Arab states loudly demand from the national authorities of the countries accused of having committed blasphemy against Mohammed an apology, sincere regrets and a guarantee that it won't happen again, this is 
because of their scarce knowledge of what an open society is, where freedom also includes committing errors.

We see that in Eurocentric and racist polarization, negative otherpresentation usually comes with positive self-presentation. Thus, we do not merely have a modest defense of what 'We' define as "Our" values, but at the same time a glorification of Our past -an ideological manifestation of Eurocentrism that is shared by some intellectuals from Latin America, such as El País columnist Vargas Llosa:

(14) [...] ¿Puede llegar a ocurrir lo mismo algún día en la Europa de Voltaire, la de las luces, la que instauró como un principio básico de la civilización el derecho de crítica, de irreverencia, no sólo ante los gobiernos, también ante los dioses, la libertad de expresión y la convivencia de diversos credos, costumbres e ideas en una sociedad abierta? (Vargas Llosa, El País, 12.2.06).

[...] Could this also happen one day in Voltaire's Europe of the Enlightenment, which established as a basic principle of civilization the right of critique, of irreverence, not only for the governments, but also for the gods, the freedom of expression and the coexistence of various creeds, customs and ideas in an open society?

Unfortunately, Vargas Llosa and other intellectuals seem to forget that the same Europe is also the Europe of, say, Napoleon, Stalin, Hitler and Milosevic, and the vastest genocides committed by humans, both inside as well as outside of Europe. With such brief fragments of the 'other' history of Europe in mind, the intellectuals, journalists and other symbolic elites might have been a bit less arrogant in their unrestrained self-glorification. That such critique against Eurocentric Muslim-bashing might become relevant is also prefigured in Vargas Llosa's own argument, when he discounts any 'leftist' critique of the USA or the West as a possible legitimization of Muslim wrath, in a passage that we should cite in full, because it is a prime example of well-known straw man fallacies in the rejection of counterarguments, by attributing positions (such as defending extremist Muslim attitudes) his opponents do not have at all:

(15) [...] Pero creo que la razón profunda es más grave y que buena parte del silencio de cierta izquierda ante este asunto se debe a que tiene serias dudas sobre cuál es la opción políticamente correcta en este caso. ¿Echarle la culpa de todo al pasado colonialista y racista del Occidente que por su política de humillación y saqueo de los países musulmanes creó el resentimiento y el odio que hoy se vuelven contra él? ¿Defender las actitudes de los extremistas musulmanes en nombre del multiculturalismo? ¿Demostrar, acogotando la sindéresis, que detrás de todo esto están las torvas garras de los Estados 
Unidos? ¿O, mejor, evitar pringarse en un asunto tan especioso y replegarse una vez más en lo seguro, lanzando las valientes arengas contra la guerra de Irak y la avidez de la Casa Blanca para apropiarse del codiciable oro negro del ocupado Irak y del pobre Irán, que se ve obligado a armarse de armas atómicas para no verse engullido por las trasnacionales? (Vargas Llosa, El País, 12.2.06).

[...] But I believe that the underlying reason is more serious and that large part of the silence of a certain left about this matter is due to the fact that it has serious doubts about what is politically correct in this case. Blame it all to the colonialist and racist history of the West, whose policies of looting and humiliation towards Muslim countries created the resentment and the hate that today turn against it? Defend the attitudes of extremist Muslims in name of multiculturalism? Show, ... that behind all this are the baleful claws of the United States? Or, rather, avoid to dirty their hands with such a specious affair and to withdraw again to the safety of addressing valiant speeches against the war in Iraq and the greed of the White House wanting to steal the black gold of occupied Iraq and of poor Iran, which has to arm itself with atomic weapons in order to avoid to be gobbled up by the multinationals.

Although the defense of the freedom of the press is of course a touchstone of journalistic ideologies -while the basis of media power- it may be formulated in slightly less radical terms. The same is true for the representation of Them. Thus, a first editorial of El País on the cartoon-affair may be interpreted as the official voice of Spain's 'newspaper of reference':

(16) [...] La libertad de prensa y la libertad de expresión no deben tener más cortapisas que las que fija la ley para todos los ciudadanos, y quien se sienta ofendido o injuriado tiene el derecho a acudir a los tribunales, la única instancia que debe resolver estos conflictos. [...] El fanatismo es una planta que crece en muchas religiones, pero el mundo islámico ofrece hoy una cosecha muy extensa. [...] Creer que sólo en el mundo islámico existe la intolerancia religiosa sería un ejercicio fatuo de autocomplacencia. Pero ignorar que el integrismo religioso se expande vertiginosamente entre los creyentes musulmanes sería ponerse una venda ante la realidad. (Editorial, El País, 1.2.06).

[...] The freedom of the press and the freedom of expression should not have other limitations than those established by law for all citizens, and who feels offended or insulted has the right to go to court, the only authority that should settle these conflicts. [...]. Fanatism is a plant that grows in many religions, but the Muslim word offers today a very large harvest. [...] To believe that religious intolerance only exists in the Muslim world, would be an exercise in fatuous smugness. But to ignore the vertiginous expansion of religious fundamentalism among Muslim believers would mean to be blind for reality. 
That is, freedom of the press is here not defined as absolute, but as limited by the law, and in principle its abuse might be sanctioned by the courts. In the same way, religious fanaticism is not limited to Islam -and hence condemned more generally. More specific examples of 'our' religion (say, from Opus Dei in Spain to religious fundamentalists in the USA backing Bush) are not given, following the general strategy that Our bad things are always ignored, denied or mitigated. Note the structure of the last part of this fragment, however. The assessment of the ubiquity of religious fanaticism is followed by a Pero in the next sentence, thus turning the assessment into an apparent concession and the whole argument into a well-known disclaimer. The thrust of the argument in this case should be sought in the second part of the disclaimer, namely that it is especially among Muslims that religious fundamentalism is expanding.

A critical assessment of religions, and especially of religious fundamentalism and fanaticism, is a consequent part progressive, atheist ideologies, and consistent with the positions of El País. However, when we examine the total coverage of the Western (quality and popular) press of Islam, and of for instance catholic and protestant fundamentalism in Europe and especially also in the USA, then it can hardly be denied that the balance is dramatically biased against Islam. Occasionally, the religious right in the USA is mentioned, and sometimes even cited as a background of Bush' international policies, and hence of his War on Terrorism (mainly waged against Muslims) and War in Iraq (a country of Muslims), but such is hardly the main story of anti-religious stances in the Western quality press. We can imagine that from a Muslim or Arabic perspective the protestant fundamentalists in the USA are indirectly guilty of much more violence in the world than Muslims -while immensely more powerful as one of the pillars of the administration of the most powerful State in the world. Of course, such arguments need and cannot all be spelled out in detail in an editorial, but at least briefly mentioning them more concretely, as in this example, would have made the slogan of El País as an 'independent' newspaper much more credible.

In the vein of the same religious values, those journalists covering the cartoon-affair in terms of the struggle between the (their) freedom of the press and Muslim radicalism, violence and threats, might have been more balanced if they had recalled more critically the fundamental flaws their own societies.

Of course, the old topos of the Arabs and Muslims as a threat had been given a new life in political, media and academic discourse since the September $11^{\text {th }}$ attacks on the World Trade Center, so the current coverage is in perfect synchrony with a more general Western hysteria about (Arab, Muslim) terrorism and Islamism. As predicted by the general thesis of the role of the elites in the reproduction of racism, such ideologies always are backed up by 'scientific' 
research, in this case in terms of the alarmist notion of the 'class of civilizations' by Huntington, a major topic that is often referred to, also in the press:

(17) [...] Parece que el mundo se empeña en darle la razón a Hungtinton [sic], o así lo pareciera si nos quedáramos con el estridente titular de la polémica. Van los daneses y hacen lo que ha hecho Europa desde que descubrió la carta de derechos fundamentales: ejercer su libre opinión y llevarla hasta los límites que su sistema legal le permite, un sistema legal que garantiza y protege esas mismas libertades. Además, y siguiendo una nutrida tradición de sátira religiosa, dan en el cogote a una de las grandes religiones monoteístas, quizá la menos acostumbrada a las querencias de la libertad. Y a partir de aquí, las hordas se levantan en grito, los actos de vandalismo callejero se convierten en una foto recurrente, desde el Mediterráneo hasta el Pacífico, y en los rincones del miedo, empiezan a proferirse amenazas de muerte. (Pilar Rahola, El País, 4.2.06).

[...] It seems as if the world absolutely wants to say that Hungtinton [sic] was right, or so it seems if we limit ourselves to the strident headlines of the controversy. Here are the Danes and they do what Europe has done since it discovered the Charter of the Fundamental Rights: to exercise the freedom of opinion to the ultimate limit of what its legal system allows, a legal system that guarantees and protects the same freedoms. Moreover, following a rich tradition of religious satire, they jump down the throat of one of the great monotheist religions, perhaps the one least accustomed to the basic principles of freedom. And from there the hordes raise their cry of protest, and the acts of street vandalism become a recurring photograph, from the Mediterranean to the Pacific, and in the corners of fear death threats begin to be made.

That this columnist of the quality newspaper El País (or the correctors) does not know how to spell foreign names is of course irrelevant here (though hardly exceptional in the Spanish press). However, that she has a very selective, self-serving memory of European history and at the same time emphasizes 'our' superiority over the 'hordes' of the outgroup, is more problematic. The familiar eurocentrist and racist schema is fully present here: We, the Europeans, invented the human rights, freedom, etc., whereas They, the backward 'hordes', are less used to the 'exigencies of freedom.' The concept of 'horde' implies and combines the notions of primitiveness and violence, historically associated with the Huns, who also came from the East. The further association of Them with those who threaten and cause fear completes this picture. The focus on our historical values as an European product of the Enlightenment, is not exclusive to this columnist and is another topos of Eurocentric discourse. As suggested above, this selective focus on Our (alleged) inventions of democracy obviously excludes any reminder of 
less democratic European inventions of the last two centuries, beginning with colonialism, also of the very same Muslim countries who are now defined as our enemies, and continuing with fascism (Germany, Italy, Greece, Portugal, Spain) and imperialism until quite recently, if not today -and in Spain the very recent dictatorship of Franco. Obviously, freedom of the press in Europe has hardly been permanent and ubiquitous in the last two centuries. And as a critical, leftist journalist from Spain, Pilar Rahola should be the first to remind the Spanish readers of the profoundly reactionary positions of the Catholic Church, its support of Franco and its permanent influence on Spanish society and its freedoms until today. In other words, the Eurocentric celebration of the freedom of the press could have been a bit more modest, and with an explicit reminder of our own undemocratic past. That the same critical journalist does not seem to realize that her defense of, or solidarity with her Danish and other colleagues -who are no more threatened by street demonstrations and violence in the Muslim world than the European freedom of the press- is a direct support of the even more explicitly racist Right in Europe, only testifies to the superficiality of her political judgment.

The same column as well as elsewhere, also in the very editorials of the same newspaper about the cartoon-affair, also feature two of the icons of Muslim threats and violence: Salman Rushdie and Theo van Gogh. These victims of Islamism are particularly attractive to the symbolic elites, because they are a writer and a film maker, that is, one of Us. Again, the representation is of course glaringly biased, in the sense that the multiple Muslim victims of the 'West' in general, and of Europe in particular, are not even known or mentioned, although quite readily Palestine comes to mind. Moreover, even the presupposed knowledge is biased, when Theo (of course, misspelled again!) van Gogh is generally represented, also in Spain, not only as a victim of Islamism, but also as a defender of human rights -a portrait that hardly corresponds to reality for those, especially women and immigrants, who happen to know his role as talk show host on Dutch TV. But of course, de mortuis nihil nisi bene. Here is how Ms. Rahola construes the facts:

(18) Como pasó con Salman Rushdie, condenado a muerte por ejercer libremente su profesión, y como pasó con Teo [sic] Van Gogh, asesinado por ello, otra vez nos damos de bruces con una lectura totalitaria del islam, no sólo incapaz de respetar los mecanismos de la libertad, sino abiertamente enemigo de su práctica. (Pilar Rahola, El País, 4.2.06).

As happened to Salman Rushdie, sentenced to death for having freely exercised his profession, and as happened to Teo [sic] van Gogh, assassinated by it, we again are confronted with a totalitarian interpretation of Islam, which not only is incapable to respect the mechanisms of freedom, but which is an open enemy of its practice. 


\section{DISSIDENT VIEWS}

Finally, what makes El País, a 'liberal' newspaper, is that besides the dominant presence of news article after news article on Muslim violence and intolerance, and after opinion article after opinion article defending the freedom of the press, we also find occasional articles of dissidents who have a different definition of the situation.

Much of these other voices barely reach the status of a letter to the editor, as is the case for a Danish journalist, former correspondent in Spain, who does tell a bit about what El País refuses to cover during the whole month: the prevalent and increasing racism and Islamophobia in Denmark, both in politics as well as in the conservative and popular media.

From Spain itself, only a select elite of those academic specialists who more generally have access to the newspaper are allowed to formulate a different point of view, as is first the case for Professor Gema Martín, a sociologist of the World of Islam and hence a specialist with a different and more detailed view of Islam and this affair than most journalists. The publication of the cartoons for her -and surely much of the coverage legitimating this publication in the name of the freedom of the press is thus evaluated as follows by her:

(19) Se transmite así un peligroso mensaje que estigmatiza y humilla a una parte muy importante de la humanidad. A partir de ahí la cuestión no es religiosa, es política, porque concierne a algo tan detestable como el racismo y la xenofobia. Y con respecto a esto sí que la libertad de expresión no puede ser un valor absoluto que, desprovisto de todo sentido de la responsabilidad, se convierta en el abuso de ese privilegio. (Gema Martín Muñoz, El País, 22.2.06)

Thus, a dangerous messages is sent that stigmatizes and humiliates a very important part of humanity. From then on the question is no longer religious, but political, because it concerns something as odious as racism and xenophobia. And with respect to that the freedom of expression can't be an absolute value that, without any sense of responsibility, becomes an abuse of that privilege.

We see that she is one of the few writers who actually dares to pronounce the hated R-word in this case, a judgment that of course the majority of journalists would energetically reject, as they have done nearly anonymously after each academic publication on racism in the Western press. She understand that as always power corrupts and that absolute power corrupts absolutely, as the saying goes, and that this also applies to the press if freedom is defined in 
terms of power -as being responsible to no one. She is also the one who locates the notion of threat or danger not with Muslims demonstrating in the streets, but rather with those who exacerbate ethnic tensions with provocation. Again, adequate balanced coverage in the quality newspaper would not just have included a detailed background article on racism in Denmark, but also a historical feature about the role of the media in the incitation of ethnic violence and racism in the past and the contemporary world. The role of the Serbian media in the genocide in Bosnia, and of the radio in the genocide of Rwanda, in the last few years would have been enough -without recalling the role of the German media in the victory of the Nazis and the attacks against the Jews in the 1930s, the Us media during segregation, the role of the South African press during Apartheid, and of all European media during colonialism: a long and so far untold story.

Enrique Calvo, another sociologist of the Complutense University, finally provides what has been missing in the coverage and the debate on the cartoons, namely a serious definition and analysis of what the freedom of the press really means:

(20) La libertad de opinión está para criticar al poder y a los poderosos, no para abusar de los débiles sometidos. Y si la prensa europea desea tomarse libertades escandalosas, que provoque a los amos de las multinacionales, en vez de hacerlo con sus siervos musulmanes. (Enrique Gil Calvo, El País, 17.2.06).

The freedom of opinion is to criticize the power and the powerful, not to abuse of those who are powerless. And when the European press wants to use its freedom to raise scandals, let it hassle its multinational masters, instead of doing so with its Muslim serfs.

The critique of the press in this case could not have been formulated more concisely. In this and similar debates on the freedom of speech it is often forgotten that this freedom is especially a privilege of the symbolic elites -and a right especially obtained in the struggle against political control of the press. That such a right is not carte blanche to abuse of this privilege to attack, misrepresent, insult, discriminate against all those without power, and without the power of access to the media, may be clear from the results of a host of critical publications on the representation of women, minorities, immigrants, refugees, in general, and of 'gitanos' and 'gitanas' in Spain, in particular. One may suppose that no journalist would vindicate the freedom of speech of Goebbels and his propaganda against the Jews -among others. That is, the freedom of speech is both precious, when used to fight those in power, and dangerous when excluding, ignoring or attacking those who will suffer more from the prejudices thus produced in society. 


\section{CONCLUSIONS}

Racism is a system of dominance, of power abuse, reproduced by social practices of discrimination and sustained by ideologies shared by dominant ethnic groups. Discourse is one of these social practices, and it is at the same time through discourse that racist ideologies and practices are learned and legitimated. Especially the various discourses of the 'symbolic elites', such as the politicians, the journalists, professors and writers, play a leading role in this reproduction process. They are the one whose power is defined by the preferential access to public discourse, and hence, indirectly to the minds of the people.

The media in general, and the press in particular, play a key role among the symbolic elite institutions. What most politicians and most scholars know about immigrants and minorities, they also see on TV or read in their newspapers, unless they are themselves engaged in research on the topic.

Indeed, such research shows time and again that the press is part of the problem of racism, rather than part of the solution. Newsrooms in Europe are generally white, and discrimination of minority journalists is widespread. Despite the presence of many highly qualified minority journalists, virtually no quality newspaper in Europe employs more than a token minority journalist, if any. Similarly, the process of news gathering and news production is systematically biased against non-elite and non-European sources, in favor of the ingroups own powerful institutions and spokespersons. Press releases and press conferences of minority groups, even on very relevant topics, tend to be ignored, in favor of 'own' experts -if at all, because in matters of ethnic coverage any white journalist will do. It is not surprising that news and opinions in the newspaper reflect these racist biases: A general focus on topics, style, and rhetoric that emphasize Our good things and Their bad things. Immigration is defined as an invasion, integration a threat to our culture, and their crime as prevalent. Whereas their contributions to our economy are ignored they are blamed for unemployment, and while Their religion is highlighted Ours is conveniently forgotten.

Application of these findings to the Spanish Press generally confirms these conclusions, but with some modifications. First, Spain has no right wing, explicitly racist tabloids as is the case in the UK and Germany -nor extremist right wing parties represented in Parliament, as elsewhere in Europe. That is, there is little public, official discourse that is blatantly racist, with some exceptions of more marginal individuals who may occasionally have access to the press because of their position. It should not be forgotten that one of the reasons of lacking extremist press and parties is precisely Spain's recent past of Franco's dictatorship -based on arch conservative, catholic forces who still 
have much influence in Spain today, for instance in organization of the Opus Dei, as well as in segments of the conservative Popular Party.

Despite the absence of openly racist media, this does not mean that the Spanish press, in its own way, does not also contribute to the quickly spreading racism and prejudices in Spanish society.

First of all, as is the case in the rest of Europe, newspapers barely hire minority journalists -so newsrooms are not diverse. Secondly, as elsewhere there is no routine of getting news and commentary on ethnic events from organizations of immigrants -who therefore are seldom cited.

The most conspicuous contribution to prevailing stereotypes and prejudices are undoubtedly the dominant topics of the coverage, such as the alarmist emphasis on border control and the 'invasion' of pateras from North Africa, immigration mafia, and as we have seen in the coverage of the 'assault' on Melilla, the repeated attempts of African youth to enter the country. The same is true for the extensive coverage of immigration policies, immigration laws, regularization, and so on-emphasizing the general opinion that immigrants and immigration are a serious problem, and not a boon for the country. Secondly, the emphasis on papeles conveys a dominant picture of immigrants who are not only sin papeles, but also 'illegal' -that is, one step removed from being criminal, while breaking the law. On the other hand, unlike the rest of the European press, there is -as yet- little emphasis on 'ethnic crime'. Thirdly, less prominently, but no doubt increasing are the stories about the actual presence of immigrants among 'us', and especially about their cultural differences and threats (typically religion, Islam, head scarves, etc.).

On the other hand, not topicalized, as is also the case elsewhere in Europe, is first of all the increase of racism, especially among the elites. Everyday discrimination, suffered by thousands of people, is barely covered. Racism of the press is a total taboo as a topic, for obvious reasons. We seldom see and hear about the everyday lifes of immigrants. Typically, whereas we daily read about our elites, we seldom read about theirs. Indeed, the basic stereotype is that immigrants are poor workers from Morocco or Ecuador -and not academics from Argentina or Chile, whose problems (such as the endless red tape to get their foreign titles recognized) are ignored in the press -of course in favor of autochthonous professionals.

As we have seen in the coverage of Bolivia's new president Evo Morales, even a quality newspaper like El País hardly manages to suppress its racist and Eurocentric superiority when describing Morales ethnic background and appearance -not to speak of its populist policies and contacts with Hugo Chávez.

The denial of (media) racism has been most clearly shown in the coverage, also in quality newspaper El País, of the affair of the Danish cartoons 
portraying Mohammed. Especially in this extensively covered affair, that is in the alleged threat of the interests (freedom) of the press itself, we see most clearly how the press represents ethnic events. Thus, all the positive things of 'our' democratic European values, ideologies, and system are highlighted, our own racism and xenophobia ignored or denied, and their violence, intolerance, threats, backwardness, etc, dramatically emphasized and generalized, as if all Muslims were rabid fundamentalists. Topics, topoi, lexical style, rhetoric, argumentation and so on are systematically biased in favor of such a deeply ideologically and historically based elite polarization between Us in Europe and the West, and Them Muslims and Arabs in the (Middle) East.

It is in this way, how the quality press reproduces racism, also in Spain and especially also among those who will need to give the good example, namely the other symbolic elites -that is, those who, literally, have everything to say in society, and hence have vast influence on the public at large.

\section{BIBLIOGRAPHICAL REFERENCES}

Álvarez, R., \& K. G. LutTERMAn (1979): Discrimination in organizations, San Francisco, Jossey-Bass.

Álvarez Chillida, G. (2002): El antisemitismo en España. La imagen del Judio (1812-2002), Madrid, Marcial Pons, Ediciones de Historia.

Apostle, R. A., C. Glock, T. Piazza \& M. Suelze (1983): The anatomy of racial attitudes, Berkeley, CA, University of California Press.

Aramburu OtAZU, M. (2002): Los otros y nosotros. Imágenes del inmigrante en Ciutat Vella de Barcelona, Madrid, Ministerio de Educación, Cultura y Deporte.

BACK, L. \& J. Lomos (eds.) (2000): Theories of Race and Racism. A reader, London, Routledge.

BAÑón HERNÁNDEZ, A. M. (1996): Racismo, discurso periodístico y didáctica de la lengua, Almería, Universidad de Almería, Servicio de Publicaciones.

- (2002): Discurso e inmigración. Propuestas para el análisis de un debate social, Prólogo de Teun A. van Dijk, Murcia, Universidad de Murcia.

Banton, M. P. (1994): Discrimination, Buckingham, Open University Press.

BARBADILLO GRIÑÁN, P. (1997): Extranjería, racismo y xenofobia en la Espana contemporánea, La evolución de los setenta a los noventa, Madrid, Centro de Investigaciones Sociológicas Siglo Veintiuno de Espana Editores.

Blommaert, J. \& J. Verschueren (1998): Debating diversity. Analysing the discourse of tolerance, New York, Routledge.

BoxILl, B. R. (ed.): (2001): Race and racism, Oxford (UK) New York, Oxford University Press. 
BritTon, N. J. (2000): Black justice? Race, criminal justice and identity, Stoke-on-Trent, Staffordshire, England, Trentham Books.

Bulmer, M. \& J. Solomos (eds.) (1999 a): Ethnic and racial studies today, London New York, Routledge.

- (1999 b): Racism, Oxford New York, Oxford University Press.

- (2004): Researching race and racism, London New York, Routledge.

Calvo Buezas, T. (1989): Los racistas son los otros. Gitanos, minorías y derechos humanos en los textos escolares, Madrid, Editorial Popular.

- (1990 a): El racismo que viene. Otros pueblos y culturas vistos por profesores y alumnos, Madrid, Tecnos Ilustre Colegio Nacional de Doctores y Licenciados en Ciencias Políticas y Sociología.

- (1990 b): ¿España racista? voces payas sobre los gitanos, Barcelona, Anthropos Editorial del Hombre.

- (1993): El crimen racista de Aravaca. Madrid (Spain), Editorial Popular Jóvenes Contra la Intolerancia.

- (1995): Crece el racismo, también la solidaridad los valores de la juventud en el umbral del siglo XXI, Cáceres, Tecnos Junta de Extremadura, Consejería de Cultura y Patrimonio.

- (1997): Racismo y solidaridad de españoles, portugueses y latinoamericanos. Los jóvenes ante otros pueblos y culturas, Madrid, Ediciones Libertarias.

- (2000): Inmigración y racismo. Así sienten los jóvenes del siglo XXI, Madrid, Cauce Editorials.

- (2001): Inmigración y universidad prejuicios racistas y valores solidarios, Madrid, Editorial Complutense.

- (2003): La escuela ante la inmigración y el racismo. Orientaciones de educación intercultural, Madrid, Editorial Popular.

CASHMORE, E. (2003): Encyclopedia of race and ethnic studies, London-New York, Routledge.

Castiello, C. (2002): Los desafíos de la educación intercultural, migraciones y curriculum, Universidad de Oviedo, Tesis Doctoral.

CHÁvez, L. R. (2001): Covering immigration. Popular images and the politics of the nation, Berkeley, CA, California University Press.

CHECA, F. (2001): El Ejido la ciudad-cortijo. Claves socioeconómicas del conflicto étnico, Barcelona, Icaria.

CoHn, S. (2000): Race and gender discrimination at work, Boulder, Colorado, Westview.

Colectivo IOE (2001): ¡No quieren ser menos! Exploración sobre la discriminación laboral de los inmigrantes en España, Madrid, Unión General de Trabajadores.

Cottle, S. (ed.) (2000): Ethnic Minorities and the Media, Buckingham, UK, Open University Press. 
Criado, M. J. (2001): La línea quebrada. Historias de vida de migrantes, Madrid, Consejo Económico y Social.

Doane, A. \& E. Bonilla-Silva (eds.) (2003): White out. The continuing significance of racism, New York, Routledge.

Dovidio, J. \& S. L. GaerTner (eds.) (1986): Prejudice, discrimination and racism, New York, Academic Press.

El-Madkouri MaAtaoui (2005): La imagen del Otro. Lo Árabe en la prensa española, Tesis de doctorado. Universidad Complutense, Departamento de Estudios Árabes e Islámicos.

EsSED, P. (1991): «Knowledge and resistance. Black women talk about racism in the Netherlands and the USA», Feminism and Psychology, 1(2): 201-219.

Essed, P., \& D. Goldberg (eds.) (2002): Race critical theories text and context, Malden, Mass, Blackwell Publishers.

FABIAN, J. (1983): Time and the other. How anthropology makes its object, New York, Columbia University Press.

Feagin, J. (2000): Racist America, Roots, current realities, and future reparations, New York, Routledge.

Feagin, J., H. Vera \& P. BAtUR (2001): White racism the basics, New York, Routledge.

FLINT, J. (2004): «Reconfiguring agency and responsibility in the governance of social housing in Scotland», Urban Studies, 41(1): 151-172.

García Martínez, A. (2004): La construcción sociocultural del racismo. Análisis y Perspectivas, Madrid, Dykinson.

García Martínez, A. \& J. SÁez Carreras (1998): Del racismo a la interculturalidad. Competencia de la educación, Madrid, Narcea.

Gimeno GimÉnez, L. (2001): Actitudes hacia la inmigración. Relación entre las investigaciones cualitativas y cuantitativas, Madrid, Centro de Investigaciones Sociológicas.

GoldBerg, D. (1997): Racial subjects. Writing on race in America, New York, Routledge.

- (2002): The racial state, Oxford, Blackwell.

GoldBerg, D. \& J. Solomos (ed.): (2002): A Companion to racial and ethnic studies, Malden, Mass, Blackwell.

HAMILTON, D. L. (1981): Cognitive processes in stereotyping and intergroup behavior, Hillsdale, N. J., L. Erlbaum Associates.

Hartmann, P. \& C. Husband (1974): Racism and the mass media. A study of the role of the mass media in the formation of white beliefs and attitudes in Britain, Totowa, N. J., Rowman \& Littlefield.

IZQUIERDO, A. (1996): La inmigración inesperada. La población extranjera en España (1991-1995).

JäGER, S. (1992): BrandSätze. Rassismus im Alltag. DISS-Studien, Duisburg, DIsS. 
- (1998): Der Spuk ist nicht vorbei völkisch-nationalistische Ideologeme im öffentlichen Diskurs der Gegenwart, Duisburg, Diss.

JäGER, S. \& J. Link (1993): Die vierte Gewalt. Rassismus und die Medien, Duisburg, Diss.

Lauren, P. (1988): Power and prejudice. The politics and diplomacy of racial discrimination, Boulder, Westview Press.

Manzanos BilbaO, C. (1999): El grito del otro, arqueología de la marginación racial, la discriminación social de las personas inmigrantes extracomunitarias desde sus vivencias y percepciones, Madrid, Tecnos.

MARABLE, M. (2002): The great wells of democracy the meaning of race in American life, New York, Basic Books.

Martín Rojo, L., C. Gómez Esteban, F. Arranz \& A. Gabilondo (eds.) (1994): Hablar y dejar hablar. Sobre racismo y xenofobia, Madrid, Universidad Autónoma de Madrid.

Martínez Veiga, U. (1997): La integración social de los inmigrantes extranjeros en España, Madrid, Editorial Trotta.

MatouscheK, B., F. JanuscheK, \& R. WodAK (1995): Notwendige Massnahmen gegen Fremde? Genese und Formen von rassistischen Diskursen der Differenz, Wien, Passagen Verlag.

NASH, M. \& D. MARRE (eds.) (2001): Multiculturalismos y género, Barcelona, Ediciones Bellaterra.

PAJARES, M. (1998): La inmigración en España. Retos y propuestas, Barcelona, Icaria.

Pettigrew, T. (1982): Prejudice, Belknap Press.

Pickering, M. (2001): Stereotyping. The politics of representation, Houndmills, Basingstoke, Hampshire New York, Palgrave.

Prieto Ramos, F. (2004): Media \& Migrants. A critical analysis of Spanish and Irish discourses on immigration, Oxford, P. Lang.

REISIGL, M. \& R. WODAK (eds.) (2000): The semiotics of racism. Approaches in critical discourse analysis, Wien, Passagen.

- (2001): Discourse and discrimination rhetorics of racism and antisemitism, London/New York, Routledge.

RICHARDSON, J. (2004): (Mis)Representing Islam. The racism and rhetoric of British broadsheet newspapers, Amsterdam, Benjamins.

Rosenblum, M. (1981): Coups and earthquakes. Reporting the world to America, New York, Harper and Row.

Ruhrmann, G. (ed.) (1995): Das Bild der Ausländer in der Öffentlichkeit. Eine theoretische und empirische Analyse zur Fremdenfeindlichkeit. (The image of foreigners in the public sphere. A theoretical and empirical analysis of xenophobia), Opladen, Leske. 
Ruiz Olabúenaga, J., E. Ruiz Vieytez \& T. Vicente Torrado (1999): Los inmigrantes irregulares en España. La vida por un sueño, Bilbao, Universidad de Deusto.

SOS RACISMO (2000): Informe anual 2000 sobre el racismo en el Estado español, Barcelona, Icaria Editorial.

SAID, E. W. (1979): Orientalism, New York, Vintage Books.

- (1981): Covering Islam, how the media and the experts determine how we see the rest of the world, New York, Pantheon.

Sears, D., J. Sidanius \& L. Bobo (eds.) (2000): Racialized politics, The debate about racism in America, Chicago, University of Chicago Press.

Smitherman-Donaldson, G. \& T. A. van DiJk (eds.) (1987): Discourse and discrimination, Detroit, MI, Wayne State University Press.

SolÉ, C. (1995): Discriminación racial en el mercado de trabajo, Madrid, Consejo Económico y Social.

- (ed.) (1996): Racismo, etnicidad y educación intercultural, Lleida, Edicions Universitat de Lleida.

Solomos, J., \& L. BACK (1996): Racism and society, New York, St. Martins Press.

Solomos, J. \& J. Wrench (eds.) (1993): Racism and migration in Western Europe, Oxford, Berg.

TER WAL, J. (ed.) (2002): Racism and cultural diversity in the mass media. An overview of research and examples of good practice in the EU Member States, 1995-2000, Vienna, European Monitoring Center on Racism and Xenophobia.

VAN Disk, T. A. (1984): Prejudice in discourse an analysis of ethnic prejudice in cognition and conversation, Amsterdam Philadelphia, J. Benjamins Co.

- (1987): Communicating racism, Ethnic prejudice in thought and talk, Newbury Park, CA, Sage Publications, Inc.

- (1991): Racism and the Press, London, Routledge.

- (1993): Elite discourse and racism, Newbury Park, CA, USA, Sage Publications.

- (1998): Ideology. A Multidisciplinary Approach, London, Sage.

- (2003): Dominación étnica y racismo discursivo en España y América Latina, Barcelona, Gedisa. (English version published by Benjamins, Amsterdam, 2005).

Wetherell, M. \& J. Potter (1992): Mapping the language of racism. Discourse and the legitimation of exploitation, New York, Columbia University Press

Wieviorka, M. (ed.) (1994): Racisme et xénophobie en Europe, une comparaison internationale, Paris, la Découverte.

- (1998): Le racisme. Une introduction, Paris, La Découverte. 
WodAK, R. (1996): Disorders of discourse, London, Longman.

WODAK, R. \& T. A. vAN DIJK (eds.) (2000): Racism at the Top. Parliamentary

Discourses on Ethnic Issues in Six European States, Klagenfurt, Austria, Drava Verlag. 


\section{SECCIÓN I ANÁLISIS DEL DISCURSO: ESTRATEGIAS Y TIPOLOGÍAS}




\title{
LA PRENSA ESPAÑOLA \\ ANTE LA CUESTIÓN DE GIBRALTAR: \\ UN ANÁLISIS CRÍTICO DEL DISCURSO \\ DE ARTÍCULOS EDITORIALES
}

\author{
Ángela Alameda \\ Universidad de Granada
}

\section{INTRODUCCIÓN}

$\mathbf{E}$ L origen de este estudio está en un interés por la comunidad de Gibraltar,

esa pequeña colonia inglesa al sur de la costa española, que está atravesando un momento crucial de su historia, cuando la cuestión de su identidad como pueblo y su futuro están en el foco de atención. Sin embargo, Gibraltar no es novedad, viene siendo un interesante galimatías histórico ya desde la invasión del Peñón por las tropas anglo-danesas en agosto de 1704 durante la Guerra de Sucesión española, hecho que convirtió a Gibraltar en territorio británico. Por tanto, desde hace más de trescientos años, en Gibraltar ondea la bandera inglesa a pesar de los repetidos intentos de la diplomacia española para recuperar el territorio perdido. Estos intentos, unos más violentos, otros a través de la diplomacia, se han sucedido sin éxito a lo largo de los años: desde el Gran Sitio que duró cuatro años (1779-1783), pasando por el cierre de la frontera con España desde 1969 a 1985, hasta las más recientes negociaciones entre los ministros de Exteriores español y británico.

Actualmente, el objetivo principal de ambos países es encontrar una solución para la situación de Gibraltar que ponga fin a su estatus colonial. Desde la ONU se les urge a llegar a un acuerdo en este sentido. La última tanda de negociaciones comenzó en julio de 2001 cuando los representantes británicos y españoles se comprometieron a llegar a un acuerdo antes del verano de 2002. Inmediatamente, las autoridades gibraltareñas, temerosas de una posible alianza que implicara un cambio de soberanía en la colonia y concretamente un cambio hacia la soberanía española, convocaron un referéndum para mostrar su oposición a una eventual solución de este tipo. La consulta popular tuvo lugar el 7 de noviembre de 2002, aunque sin validez reconocida tanto en España como en Gran Bretaña. El hecho fue descrito en la prensa gibraltareña y en otros medios como uno de los momentos más importantes de la reciente historia de Gibraltar al presentarse como un reconocimiento de la identidad pro- 
pia del pueblo gibraltareño que quiso hacer valer su voz a nivel internacional. Es precisamente en torno a este crucial momento histórico para la comunidad gibraltareña sobre el que gira este estudio.

Así pues, la presente investigación se acerca a la interesante y actual cuestión de Gibraltar desde una perspectiva filológica y discursiva, para intentar entender y descubrir cómo se percibe y representa la cuestión gibraltareña en el ámbito español. En la percepción que tenemos acerca de la identidad del pueblo gibraltareño, juega un papel muy importante la prensa como medio de difusión de ideas. De ahí que el corpus textual de este estudio esté extraído de artículos editoriales de la prensa española con la finalidad de descubrir la imagen de Gibraltar que discursivamente se construye y difunde a través de este medio de comunicación, influenciando y forjando la percepción que la sociedad española tiene de la identidad de este pueblo. El marco teórico al que se adscribe el presente análisis es el paradigma lingüístico denominado Análisis Crítico del Discurso (Critical Discourse Analysis o CDA), de raíces anglosajonas, ya que permite analizar el lenguaje con relación al amplio contexto social e histórico en que aparece con la finalidad de aportar una crítica social basada en la evidencia lingüística. En concreto, se ha seguido el modelo elaborado por la profesora Wodak y la Escuela Vienesa de Análisis del Discurso (denominado Discourse-historical approach) aplicado al contexto de la comunidad de Gibraltar. Este modelo ha permitido identificar las estrategias discursivas de referencia y predicación empleadas en la prensa española, lo cual ha sido especialmente relevante en el presente estudio ya que el modo con el que se hace referencia y se categoriza un grupo social influye en cómo la sociedad lo percibe, ya que contribuye a construir una determinada imagen de dicho grupo. Asimismo, se ha identificado la función de estas estrategias discursivas en la representación de la identidad nacional de este pueblo.

El análisis textual ha mostrado que la prensa española analizada, a través de sus artículos editoriales, construye una imagen de Gibraltar que se basa principalmente en referencias políticas, es decir, construyendo discursivamente un Gibraltar como una entidad política, con escasa referencia a su gente y por tanto escasa atención al lado humano de la cuestión. El análisis también ha puesto de manifiesto que son frecuentes las elecciones léxicas y los atributos negativos, así como varias metáforas, que representan a Gibraltar como un elemento anacrónico y como un problema. Esto junto a las referencias temporales de futuro y el énfasis en la discontinuidad se han identificado como estrategias discursivas de destrucción y transformación.

\section{CUESTIONES METODOLÓGICAS}

Por su singularidad histórica y social, la comunidad de Gibraltar ha sido objeto de variados estudios. Principalmente, Gibraltar ha sido del interés de his- 
toriadores, y no es de extrañar, ya que la evolución histórica de este pueblo es especialmente peculiar (Armangué, 1964; Hills, 1974; Finlayson, 1991; Morris y Haigh, 1992, entre otros). Se trata de autores tanto españoles, como británicos y gibraltareños que ofrecen visiones de la historia de Gibraltar desde ambos lados de la verja. Las obras de la última década (Sepúlveda, 2004; Oliva, 2004) reflejan el florecimiento de un sentimiento nacional gibraltareño y señalan el último referéndum de 2002 como uno de los hechos históricos que han favorecido su afianzamiento. Además, en estudios recientes Gibraltar ha cautivado la atención de lingüistas interesados por las peculiaridades comunicativas de la comunidad gibraltareña. Trabajos como los de Ballantine (1983), Kramer (1986), Moyer (1993), Kellermann (2001) y Fernández Martín (2002) son de carácter sociolingüístico y estudian aspectos como la educación, el bilingüismo o el cambio de código español-inglés en la Roca.

Sin embargo, esta revisión bibliográfica ha permitido constatar la escasez de estudios que, desde la disciplina del Análisis del Discurso, conecten los aspectos histórico-sociales con los discursivos, es decir, con un análisis textual del discurso sobre Gibraltar. Por este motivo, la presente investigación trata de cubrir este hueco y se acerca a la comunidad gibraltareña desde el paradigma lingüístico conocido como Análisis Crítico del Discurso. Esta aún joven corriente linguística se basa en la idea de que el lenguaje es un elemento central de la vida social y por tanto, analiza el discurso con referencia al amplio contexto social en el que este aparece. El análisis no se centra en el estudio de las estructuras lingüísticas per se, sino solamente en cuanto que su estudio ayuda a entender y desvelar los entresijos de una determinada situación social (Wodak, 2001: 2). De ahí que los analistas del CDA vayan con frecuencia más allá de la mera descripción e interpretación del discurso, para adentrarse en asuntos políticos o problemas sociales, en muchos casos con la intención de contribuir a la mejora de la sociedad (Coulthard y Caldas-Coulthard, 1996: xi; Fairclough, 2003: 209). De ahí se deduce que una característica fundamental del Análisis Crítico del Discurso es su orientación hacia el tratamiento de un hecho determinado (Meyer, 2001: 29). Es decir, la atención se centra en un problema o situación social, en lugar de dedicarse directamente al análisis de estructuras lingüísticas. Así, una vez que se ha identificado un asunto social, los analistas tratan de revelar/clarificar/desvelar a través de un análisis crítico del discurso las tensiones que subyacen casi de modo imperceptible en esa situación para hacerla más transparente y patente a todos los ojos. De este modo, el análisis discursivo crítico en torno a Gibraltar ha favorecido una lectura más profunda y, en consecuencia, un mejor entendimiento de los textos periodísticos analizados.

En concreto y dentro de la tradición del CDA, para el análisis discursivo del corpus textual se ha seguido el modelo desarrollado por Wodak en su Discourse- 
historical approach (Wodak, de Cillia, Reisigl y Liebhart, 1999; Reisigl y Wodak, 2001) (Modelo histórico-discursivo) ya que este modelo se elaboró a raíz de investigaciones acerca de la representación discursiva de la identidad nacional, en concreto en el contexto austriaco. Este modelo aboga por un amplio estudio de aspectos históricos y sociales de la comunidad que se investiga para poder llevar a cabo una adecuada interpretación crítica del discurso acerca de su identidad. Estas investigaciones llevaron a distinguir cuatro macro-estrategias discursivas: constructivas (para construir identidad nacional), justificadoras (para mantener y reproducir la identidad nacional), transformativas (para cambiar aspectos de esa identidad nacional) y destructivas (para desmontar la identidad nacional). Es decir, los discursos o narraciones acerca de un pueblo o comunidad cumplen la función de construir, justificar, transformar o destruir la identidad de ese pueblo. Estas macro-estrategias discursivas se concretan en el discurso en una serie de micro-estrategias y categorías lingüísticas que hay que analizar detenidamente.

Para la presente investigación y sobre la base de los resultados de una serie de estudios piloto (Alameda, 2005), se ha llevado a cabo un análisis de micro-estrategias discursivas de referencia y predicación. Las primeras se refieren al modo en que se nombra o refiere un actor social, en este caso Gibraltar; las segundas estrategias se centran en cómo ese actor social es representado, es decir, las cualidades que se le asignan en el discurso. Así, los elementos lingüísticos analizados incluyen elecciones léxicas, uso de pronombres, adjetivos, campos semánticos, metáforas y símiles para referirse y cualificar/describir a Gibraltar. El análisis de estos elementos lingüísticos y, por tanto, el examen de las estrategias de referencia y predicación, ha permitido identificar las estrategias discursivas predominantes en la prensa española para representar la identidad de Gibraltar (es decir, estrategias constructivas, transformativas, destructivas o de justificación). Además, siguiendo a Wodak (2001: 65), ha sido necesario un detallado estudio de la historia y otros aspectos sociolingüísticos de Gibraltar para así poder analizar e interpretar adecuadamente los textos seleccionados.

\section{DESCRIPCIÓN DEL CORPUS TEXTUAL}

El corpus textual consiste en artículos editoriales recogidos de la prensa española entre los meses de julio de 2001 y noviembre de 2002, es decir, desde el mes en que se relanzaron las negociaciones entre España y Gran Bretaña acerca del futuro de Gibraltar, hasta el mes en que se celebró el último referéndum. Como ya se ha indicado, se trata de un periodo crucial y de gran interés para el estudio de la comunidad de Gibraltar. Se han seleccionado cuatro periódicos de gran tirada y reconocido prestigio en España: El País, Abc, El Mundo y La Vanguardia. Estas publicaciones representan diferentes tenden- 
cias políticas y, por tanto, influyen sobre un amplio espectro de la sociedad española. Además, dentro del género periodístico se han analizado los editoriales, ya que se trata de artículos de opinión que reflejan la voz del periódico sobre temas relevantes para la comunidad y los lectores acuden a ellos en busca de guía e interpretación acerca de esos temas. De este modo son particularmente relevantes y cumplen una función esencial forjando la percepción que la sociedad se crea acerca de determinados temas. La tabla 1 recoge el número de artículos editoriales de la prensa española que tratan el tema de Gibraltar divididos por periódicos. En total se han analizado 56 editoriales.

TABLA 1. Número de editoriales sobre Gibraltar en la prensa española entre julio de 2001 y noviembre de 2002

\begin{tabular}{|c|c|}
\hline Periódico & Número de editoriales \\
\hline El País $(\mathrm{EP})$ & 18 \\
\hline Abc $(\mathrm{ABC})$ & 20 \\
\hline El Mundo $(\mathrm{EM})$ & 8 \\
\hline La Vanguardia $(\mathrm{LV})$ & 10 \\
\hline Total & $\mathbf{5 6}$ \\
\hline
\end{tabular}

Aunque a primera vista parezca un número reducido, 56 editoriales en los principales periódicos españoles a lo largo de dieciséis meses es un número considerable teniendo en cuenta, como han resaltado Armañanzas y Díaz (1996: 100), que solo los temas considerados de relevancia para la comunidad merecen estar reflejados y comentados por los editores de los periódicos. Además, un estudio de contenido muestra que los editores comentan el tema de Gibraltar tanto directamente, es decir, el artículo trata Gibraltar como su tema central, como indirectamente, es decir, hacen referencia a Gibraltar en artículos que tratan otros temas, como son la crisis hispano-marroquí en torno a Ceuta, Melilla y la Isla Perejil, la presidencia española de la UE o la crisis del petrolero Prestige. La proporción está bastante equilibrada: 30 artículos, un $53,6 \%$, trata el tema de Gibraltar directamente, y 26 , un $46,4 \%$, se refieren a Gibraltar de manera indirecta. Este análisis inicial pone de manifiesto que la cuestión de Gibraltar es un tema relevante para la sociedad española y, como tal, aparece reflejado frecuentemente en las páginas editoriales de sus principales periódicos. El alto número de editoriales que tratan Gibraltar en relación a otros temas refuerza esta interpretación, ya que el asunto de Gibraltar es tan candente que incluso se le hace referencia cuando se están comentando otros temas de interés. Conviene destacar, además, que esos otros temas de interés son en su mayor parte situaciones problemáticas o críticas en otros lugares. 
Por tanto, la prensa española asocia Gibraltar con escenarios conflictivos, cargando el asunto gibraltareño de tintes negativos.

\section{RESULTADOS}

En la prensa española analizada se han identificado cuatro estrategias predominantes para referirse a Gibraltar: como ente político, como comunidad, como territorio y como un tema de discusión. La más frecuente es la primera (42\%), es decir, las referencias a Gibraltar como una institución de carácter político e inmersa en actividades políticas. Para ello, los periódicos españoles emplean principalmente el nombre oficial, Gibraltar, aunque también aparecen con alta frecuencia sus nombres populares, el Peñón y la Roca. A esto hay que añadir las referencias a Gibraltar, no por su nombre, sino con referencia a su estatus político como colonia. Algunos ejemplos son: "formas de cooperación entre Gibraltar y su entorno" (EP 03/11/01), "la marcha de las negociaciones hispano-británicas sobre el futuro de Gibraltar" (Abc 29/5/02), "[España] adoptó una posición de dureza hacia el Peñón" (EP 27/7/01) y "la colonia revertiría a soberanía española” (EP 11/1/02). Así mismo, ayudan a construir esta imagen política de Gibraltar las referencias a las autoridades de la colonia. Normalmente se trata de usos metonímicos en los que las autoridades reemplazan a la institución que representan, como en "Caruana debía ser un miembro más de la delegación británica" (EM 18/11/01), en la que la invitación es a Gibraltar para que participe en las negociaciones. Sin embargo, este Gibraltar que la prensa española construye no es muy activo políticamente, sino que más bien se le representa cargado de carácter pasivo y como una posesión que puede pasar de una mano a otra. Lingüísticamente, esto se consigue a través de la aparición repetida de la palabra Gibraltar junto al término "soberanía", ya que este implica el estar bajo el control de algo/alguien. Expresiones como "soberanía de Gibraltar (Abc 10/11/01, EM 11/5/02, EP 19/11/01), "soberanía sobre Gibraltar" (EM 29/04/02), y "soberanía del Peñón” (EM 11/5/02, EP 27/7/01, LV 05/2/02) abundan en todos los editoriales analizados. Además, esta representación discursiva de Gibraltar se acentúa con la elección léxica de los nombres "Roca" o "Peñón" por sus mayores connotaciones materiales, así como elecciones léxicas como "retorno", "devolución" o "quedarse" que aparecen por ejemplo en "el retorno de Gibraltar a la soberanía española" (EP 27/7/01), "la devolución de la soberanía a España" (EP 19/11/01), "el Reino Unido se quedó con Gibraltar" (EP 21/11/01) y “en caso de cambiar de manos, el Peñón volvería a soberanía española" (EP 08/11/02). Por contraste, hay otras asociaciones léxicas que se construyen discursivamente como imposibles. Entre otros, lo ejemplifican expresiones como "soberanía gibraltareña" (Abc 10/11/01), "derecho de autodeterminación” (Abc 08/11/02) y 
"territorio independiente" que son calificados como "necesariamente excluida", "irreal" e "inviable".

En segundo lugar, la prensa española se refiere a Gibraltar como una comunidad o pueblo (26\%). Predomina el uso del gentilicio "gibraltareños". Es de destacar el escaso uso del gentilicio popular "llanitos". Este término, que según otras investigaciones posee mayores connotaciones afectivas (Kellermann, 1996: 74), es poco frecuente en los periódicos españoles, lo cual es indicativo de la escasa afectividad con que se refiere a la población gibraltareña desde la prensa española. Además, un análisis más detallado pone de manifiesto que una gran parte de estas referencias a Gibraltar como pueblo son en realidad usos metonímicos en los que el gentilicio reemplaza al país. Como por ejemplo, "la incorporación de los gibraltareños a las negociaciones" (Abc 20/11/01) y "los gibraltareños deben participar integrados en la delegación británica" (EP 10/11/01), ya que se trata realmente de Gibraltar como institución la que debe incorporarse a las negociaciones. Esto enfatiza la tendencia en la prensa española a representar a Gibraltar como entidad política.

En una proporción poco inferior a la anterior están las referencias a Gibraltar como un tema o asunto (23\%), como en "el otro gran frente de la acción exterior española es Gibraltar" (Abc 01/5/02). A Gibraltar se la representa como una "cuestión", "asunto", "proceso", "disputa", "conflicto", e incluso en términos jurídicos como "pleito" y "contencioso". Algunos ejemplos son: "su política hacia la cuestión gibraltareña" (EP 27/7/01), "el caso de Gibraltar" (LV 26/7/02), "desbloquear en breve el contencioso de Gibraltar" (LV 17/3/02), "Los estudiosos del tricentenario conflicto" (EM 11/5/02) y "si se resolviera esta disputa" (EP 11/1/02). Otras asociaciones léxicas que pertenecen a este campo semántico son "negociar sobre Gibraltar" (Abc 20/11/01), "conversaciones sobre Gibraltar" (Abc 04/2/02, EM 18/11/01, EP 21/7/02, LV 21/5/02), "diálogo sobre Gibraltar" (EP 27/7/01) y "hablar de Gibraltar" (LV 31/10/01). Estas estrategias de referencia sirven para construir discursivamente un Gibraltar como un tema o asunto a tratar, de modo que Gibraltar es "cosificado" y se elimina, o al menos se difumina, su realidad humana. Por último, con menor frecuencia, la prensa española también se refiere a Gibraltar como el territorio o lugar que esta ocupa $(8,4 \%)$, como en "empresas instaladas en Gibraltar" (EM 15/11/02) y "visita [de Jack Straw] a Gibraltar" (EP 21/5/02).

En cuanto a las estrategias de predicación identificadas en la prensa española, destacan los atributos y adjetivos que identifican a Gibraltar como algo anacrónico, enfatizando lo prolongado e inadecuado de su situación: "anacrónico y viejo" (Abc 10/11/01), "prolongado y anacrónico" (Abc 20/11/01), "histórico" (EP 03/11/01), "secular" (EP 03/11/01), "eterno" (EM 11/5/02), "tricentenario" (EM 29/4/02), entre otros. Como consecuencia, a Gibraltar se le atribuyen otras cualidades como "insostenible" (Abc 20/11/01) (EP 11/01/02), 
“estrambótica" (EM 04/6/02), "trasnochado" (EP 21/11/01), "incómodo" (Abc 27/6/02), y "espinoso" (Abc 11/7/02). Estas atribuciones son estrategias de representación negativa, que además se hacen más frecuentes en la prensa española a medida que pasan los meses y se percibe que el deseado acuerdo de co-soberanía hispano-británico no se va a firmar. En esta misma línea, las referencias temporales enfatizan la anacrónica situación de Gibraltar que contrasta con el moderno presente y que apuntan hacia una nueva realidad, un nuevo estatus, para Gibraltar. Sirvan como ejemplo las referencias de pasado: "durante tres siglos" (EM 11/5/02), "desde hace tres siglos" (EP 19/11/01)); así como las referencias que contrastan con el presente: "en la Europa del siglo XxI" (Abc 27/6/02), "en el mundo actual" (EP 11/1/02); y las que apuntan hacia un deseado futuro: "antes de acabar el año que viene" (EM 18/11/01), "en menos de un mes" (EP 27/4/02). Se trata, por tanto, de estrategias discursivas que enfatizan la discontinuidad (Wodak et al. 1999: 42).

En cuanto a otros recursos lingüísticos empleados, destaca la detallada elaboración de la metáfora que identifica la cuestión gibraltareña con un viaje, y uno particularmente largo con su inicio, paradas, obstáculos y final. Algunos ejemplos que lo ilustran son: "caminar paso a paso" (Abc 25/4/02), "proceso negociador en marcha" (EP 20/3/02), "España está abriendo eficaces vías de acuerdo" (LV 26/11/01), "dar este paso" (EP 03/11/01). Muy significativamente, y acentuando la representación negativa de Gibraltar en la prensa española, también se la identifica como un obstáculo en ese viaje. Así, Gibraltar es "una china en el zapato español" (EP 03/11/01). Además, a mediados de 2002, cuando ya quedó claro que no se llegaría a firmar ningún acuerdo, este viaje se convierte en un "viaje a ninguna parte" (EP 26/7/02), es decir, un viaje sin final. Por tanto, las negociaciones han puesto en marcha toda una compleja maquinaria para un largo viaje que finalmente no tiene un final feliz. La cuestión gibraltareña también se construye metafóricamente como una guerra y un juego. El contrincante es generalmente Gibraltar, pero también en algunos casos se identifica con Inglaterra como el país con el que hay que llegar a firmar el acuerdo. Ambas metáforas enfatizan el carácter belicoso de la cuestión gibraltareña con rivales que se enfrentan con visiones diferentes para solucionar la situación de la colonia.

Símiles y comparaciones son otros recursos lingüísticos empleados en los periódicos españoles para atribuir cualidades a Gibraltar. Las comparaciones con otros eventos que comparten características con la situación gibraltareña se pueden entender como formas de intertextualidad que sirven para enmarcar la situación y apoyar la línea argumentativa del editorial (Fairclough, 1992). Así, la situación de Gibraltar se compara a la de Hong Kong (Abc 20/5/02, EP 27/4/02, LV 26/7/02), el País Vasco (EM 11/5/02), Andorra y la isla Abu Musa (EP 11/1/02), las Maldivas (EP 20/3/02) e Irlanda del Norte (EP 19/11/01). Estas referencias cumplen diversas funciones ayudando a interpretar la situación de 
Gibraltar a través de los conocimientos generales de los lectores. Así, la prensa española establece relaciones de semejanza con aquellas situaciones en las que se ha llegado a un retorno del territorio colonizado, como es el caso de Hong Kong, mientras que se marcan las diferencias con casos como el de las Islas Maldivas, donde Gran Bretaña mantiene la soberanía. En la misma línea, los editoriales recurren a otros paralelismos que tienden a minimizar Gibraltar contribuyendo a su representación negativa. En ocasiones, se trata de cuantificadores $\mathrm{y}$ expresiones numéricas que establecen contrastes y enfatizan lo pequeña, y consecuentemente, trivial que Gibraltar es. Por ejemplo: "30.000 habitantes de su colonia [...] 370 millones de europeos" (Abc 20/5/02), "6 km² y 27.000 habitantes [...] $1.000 \mathrm{~km}^{2}$ y 6 millones de habitantes [Hong Kong]" (EM 29/04/02), "6,5 km² con 28.000 habitantes, la población de Lloret de Mar" (ЕM 08/11/02). A estas hay que añadir otras frecuentes elecciones léxicas que cumplen la misma función: "minúsculo territorio" (EM 04/6/02), "diminuta y díscola colonia" (Abc 08/11/02) y "pedacito de territorio" (EM 29/4/02), entre otras. Por el contrario, los atributos negativos se maximizan por medio de superlativos y otras elecciones léxicas, como en "Gibraltar tiene importantísimas ventajas fiscales" (EM 04/06/02), "contencioso tan prolongado" (Abc 25/4/02), "eterno bloqueo" (EM 11/5/02), y "la última colonia del continente europeo" (EP 03/11/01).

Por último, conviene llamar la atención sobre los juegos de palabras a los que recurre la prensa española en sus editoriales. Se encuentran expresiones como: "bien se merecería la Unión Europea que, durante la presidencia española de la misma, se quitara de la bota este Peñón que le impide caminar con normalidad" (EP 21/5/02), "algo más que una china en el zapato español" (EP 03/11/01) y "tropiezo en el Peñón” (LV 21/5/02). Estas expresiones juegan con el potencial semántico de los nombres populares de Gibraltar para activar en la mente de los lectores las connotaciones negativas de estos objetos especialmente en relación al proceso de caminar. De este modo, a Gibraltar se la vuelve a relacionar con algo incómodo y entorpecedor.

\section{CONCLUSIÓN}

Esta investigación ha servido para recalcar el papel tan relevante que la prensa tiene como modelador y forja de la opinión que la sociedad se crea sobre un determinado tema. A partir de la novedad que supone acercarse a la cuestión gibraltareña desde la disciplina del Análisis Crítico del Discurso y analizando el género periodístico, se han podido identificar los recursos lingüísticos y las estrategias discursivas empleadas en la prensa española para construir discursivamente la imagen de Gibraltar. 
Resumiendo, en la prensa española analizada, las estrategias de referencia y predicación, en concreto las elecciones léxicas, los atributos negativos y las metáforas, que representan discursivamente a Gibraltar como un elemento anacrónico, se pueden considerar estrategias discursivas de transformación, que apoyan la idea del cambio urgente de estatus para esta comunidad, a tono con la tendencia general de la política española. Sin embargo, en líneas generales son predominantes las estrategias discursivas que se pueden considerar destructivas con un gran énfasis en la representación negativa, las referencias temporales de futuro y en la discontinuidad. Además, destaca la construcción discursiva de Gibraltar como una entidad política, con escasa referencia a su gente $\mathrm{y}$, por tanto, mostrando un menor interés por el lado humano del conflicto.

\section{REFERENCIAS BIBLIOGRÁFICAS}

Alameda HernÁNDEZ, A. (2005): «Gibraltar, the outside view: a critical discourse analysis of the British press on the Gibraltar issue», en MARTínEZ-DuEÑAS ESPEJO, J. et al. (eds.) (2005): Towards an understanding of the English language: past, present and future, Granada, Editorial Universidad de Granada, 3-14.

Armañanzas, E. y J. Díaz Noci (1996): Periodismo y Argumentación. Géneros de Opinión, Bilbao, Servicio Editorial Universidad del País Vasco.

Armangué Rius, G. (1964): Gibraltar y los españoles, Madrid, Aguilar.

BALLANTINE, S. (1983): A study of the effects of English-medium education on initially monoglot Spanish-speaking Gibraltarian children, Tesis de Master, Gales, Universidad de Gales.

Coulthard, M. y C. CAldas-Coulthard (eds.) (1996): Texts and Practices: Readings in CDA, Londres, Routledge.

FaIRClough, N. (1992): Discourse and Social Change. Cambridge, Cambridge University Press.

FairClough, N. (2003): Analysing Discourse: Textual Analysis for Social Research, Londres, Routledge.

FERNÁNDEZ MARTín, C. (2002): Valoración de las actitudes lingüísticas en Gibraltar, Universidad de Cádiz, Cádiz. Tesis doctoral.

Finlayson, T. (1991): The Fortress Came First: The Story of the Civilian Population of Gibraltar During the Second World War, Grendon (Northants), Gibraltar Books.

HiLls, G. (1974): Rock of Contention: A History of Gibraltar, Londres, Hale. KellermanN, A. (1996): "When Gibraltarians speak, we're quite unique: constructing Gibraltarian identity with the help of English, Spanish and 
their respective local varieties», First International Conference on Sociolinguistics in Portugal, 73-78.

Kellermann, A. (2001): A New, New English. Language, Politics and Identity in Gibraltar. Heidelberg, Heidelberg Schriften zur Sprache und Kultur.

KrAMER, J. (1986): English and Spanish in Gibraltar, Hamburgo, Buske.

MEYER, M. (2001): «Between theory, method, and politics: positioning of the approaches to CDA», en WODAK, R. y M. MEYER (eds.) (2001): Methods of Critical Discourse Analysis, Londres, Sage Publications, 14-31.

Moyer, M. (1993): Analysis of Code-switching in Gibraltar, Universitat Autònoma de Barcelona, Barcelona. Tesis Doctoral.

Morris, D. y R. HAIGH (eds.) (1992): Britain, Spain and Gibraltar 1945-1990. The Eternal Triangle, Londres, Routledge.

OLIVA, F. (2004): The frontiers of doubt. The critique of the political system by a Gibraltarian sceptic, Cádiz, Editorial Acento.

ReISIGL, M. y R. WODAK (2001): Discourse and Discrimination. Rhetorics of Racism and Antisemitism, Londres, Routledge.

SEPÚlvedA, I. (2004): Gibraltar: la razón y la fuerza, Madrid, Alianza Editorial.

WODAK, R. (2001): «What CDA is about -a summary of its history, important concepts and developments», en WODAK, R. y M. MEYER (eds.) (2001): Methods of Critical Discourse Analysis, Londres, Sage Publications, 1-13.

WodAK, R. et al. (1999): The Discursive Construction of National Identity, Edinburgh University Press, Edimburgo. 


\title{
DISCURSO Y SOCIEDAD EN LAS CLASES DE LENGUA MATERNA: LEER LA IDEOLOGÍA Y COMPRENDER CRÍTICAMENTE
}

\author{
Cristina Aliagas \\ CARMEN LÓPEZ \\ SOLEDAd ARAVENa \\ Universitat Pompeu Fabra
}

\section{INTRODUCCIÓN: LA LITERACIDAD CRÍTICA EN LAS CLASES DE LENGUA MATERNA}

\footnotetext{
C
} OMPRENDER críticamente los discursos que generan las distintas prácticas sociales constituye una habilidad comunicativa básica para desenvolverse con destreza en la actual sociedad de la información y la comunicación. El concepto de literacidad crítica (Luke, 2000; Ames, 2002; Zavala, 2002; Cassany, 2006) sintetiza esta capacidad para manejar los discursos desde una perspectiva activa y profunda, al relacionar los textos con las intenciones e ideología subyacentes, con las representaciones sociales que estos vehiculan, con la comunidad discursiva a la que sirven y, por tanto, con el contexto sociocultural que les otorga sentido.

En el marco de la investigación sobre literacidad crítica, el presente trabajo persigue observar hasta qué punto en las clases de lengua materna los estudiantes pueden desarrollar un planteamiento crítico de la lectura y de su entorno a través de los textos y las actividades propuestas en los manuales utilizados. Teniendo en cuenta que la lectura es el medio de interacción de los estudiantes con su entorno social (Barton, Hamilton e Ivanic, 2000), trabajar la comprensión crítica de los discursos constituye un objetivo didáctico prioritario, aspecto que desarrollamos en el grupo de investigación sobre literacidad crítica de la Universitat Pompeu Fabra (proyecto HUM2004-03772/FILO). ${ }^{1}$

La literacidad (a menudo denominada alfabetización o alfabetismo), entendida como la enseñanza-aprendizaje de la lectura y la expresión escrita, es una empresa educativa bien desarrollada en las aulas, pero no tanto desde una perspectiva crítica. Dar cuenta de este componente crítico es precisamente el objeti-

1. Este proyecto, financiado por el MEC, está coordinado por el profesor Daniel Cassany. 
vo de nuestro trabajo, a través de las actividades que se proponen en las clases de lengua materna para relacionar lengua/discurso y sociedad, para leer la ideología subyacente en todo texto y comprender críticamente su contenido. En definitiva, nos interesa observar si las prácticas de lectura que presentan los manuales y su explotación por parte de los docentes contribuyen a formar lo que Lledó (1992: 110) ha denominado lectores "situados", "autobiográficos":

El lector "autobiográfico" [...] es un lector real, un hombre concreto que no solo se limita a gozar el "placer del texto", sino que "escribe" y nos cuenta en otro texto su experiencia con él, o se habla a sí mismo, desde los condicionamientos de su personal historia, el etéreo diálogo de su propia interpretación.?

Un enfoque crítico de la lectura, pues, frente a una lectura más convencional, implica tener en cuenta la experiencia y los conocimientos previos de quien interpreta el texto, su contexto sociocultural, sus intereses y representaciones sociales, y cómo interactúa el lector con el contexto de producción del texto y con su autor (sus intereses, sus puntos de vista, etc.). En definitiva, supone concebir la lectura como un proceso de interacción comunicativa, a modo de acicate para desarrollar la capacidad de razonamiento y la metacomprensión de los estudiantes, para suscitar el debate, para fomentar el "diálogo" con los textos, con uno mismo y con los demás.

La tarea de aprender a leer la ideología y comprender críticamente ha sido reivindicada por la Pedagogía Crítica (Freire, 1974; Giroux, 1990) y, en los estudios sobre el discurso, por el Análisis Crítico del Discurso (Fairclough, 1995; Van Dijk, 2003). Desde estos postulados, la literacidad crítica permite cuestionar las relaciones de poder en la sociedad actual, repensar los discursos $\mathrm{y}$ las identidades preestablecidas, y promover un desarrollo personal y social más justo; en definitiva, problematizar los valores sociales establecidos.

En el aula de lengua resulta difícil promover el cambio social si no es a través del crecimiento "lingüístico-comunicativo" del estudiante, esto es, del fomento en clase de una visión más compleja de los discursos y sus implicaciones a través de las herramientas lingüísticas. La competencia crítica en la "lectura" y la "escritura" de textos (la literacidad crítica) otorga al estudiante recursos adecuados para tomar conciencia de la ideología que hay detrás de cada texto, y promover su reflexión y discusión personal (sobre el contenido de los textos, pero también sobre la perspectiva adoptada en ellos).

El trabajo que los profesores de lengua podemos abordar de forma más eficaz se centra, por un lado, en ahondar en los elementos que definen la comunicación y, por el otro, en la selección lingüística que cada participante realiza

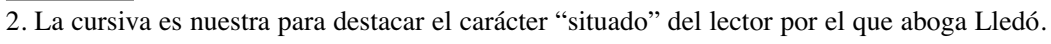


en función de sus intereses, de la situación y de los efectos que busca provocar. La reflexión, por lo tanto, sobre el contexto global (cultural) y local (situación espacio-temporal) en que se inscriben los discursos y el análisis de las unidades lingüísticas que les dan forma pueden fomentar la reacción discursiva ante estos textos por parte del alumno. De este modo, el estudiante, como individuo y ciudadano, contaría con instrumentos de argumentación y (auto)cuestionamiento para desarrollar opiniones personales con autonomía.

Esta concepción de lo que significa comprender "críticamente" un texto contrasta con el concepto que el término crítico presenta en algunos manuales de enseñanza, en los que se suele sobreutilizar con cierta impropiedad. Por ejemplo, se entiende a veces por comentario crítico el análisis de los rasgos propios del momento histórico y cultural de un texto, o la comprensión de las ideas principales y su relación con el tema de la lección, como ejemplifican las siguientes actividades de lectura:

Interpretación y juicio crítico [sobre El juego de hacer versos... de J. Gil de Biedma] ¿Qué nos enseña sobre la creación poética el poema de Jaime Gil de Biedma? Ponlo en relación con alguno de los aspectos presentados en esta unidad. (Bosque et al., 2002: 223)

Actividades de crítica

José Ortega y Gasset (1883-1955), en sus Ideas sobre la novela (1925), afirma que nunca leemos una narración extensa con el fin de conocer su argumento, sino por el placer de la demora, es decir, para disfrutar de su lenta presentación de acciones, lugares y personas:

Una narración somera no nos sabe: necesitamos que el autor se detenga y nos haga dar vueltas en torno a los personajes. Entonces, nos complacemos al sentirnos impregnados y como saturados de ellos y de su ambiente, al percibirlos como viejos amigos habituales de quienes lo sabemos todo y al presentarse nos revelan toda la riqueza de sus vidas.

Comenta y justifica estas líneas de Ortega de acuerdo con los datos contenidos en la unidad y con tu propia experiencia como lector de novelas. (Bosque et al., 2002: 271)

Estos ejercicios muestran que las actividades denominadas "críticas" en algunos libros de texto fomentan un tipo de lectura más instrumental que propiamente crítica, más centrada en los contenidos de tipo factual que en los procedimientos. Resumimos a continuación brevemente las conclusiones de un estudio previo sobre las propuestas de lectura que ofrecen algunos manuales de lengua y literatura, para contrastar estas conclusiones con la investigación que desarrollamos ahora. Como ha señalado Martín Peris (1996: 2), la relación entre materiales y práctica de aprendizaje está siempre mediatizada por la intervención activa del grupo de usuarios - profesorado y alumnado- que los interpreta cada vez que los utiliza. 


\section{ESTUDIO PREVIO Y METODOLOGÍA DE LA PRESENTE INVESTIGACIÓN}

En un estudio previo (Aliagas, Martí y López Ferrero, en prensa) observamos el escaso desarrollo de la lectura crítica en las propuestas didácticas de los manuales de lengua (catalana y castellana, de $1^{\circ}$ de Educación Secundaria Obligatoria (ESO) y $1^{\circ}$ de Bachillerato) más empleados en Cataluña. Tras este primer análisis, partimos de la hipótesis de que la consideración aislada de las propuestas de los libros de texto no es suficiente. Nuestro supuesto de partida es que los factores determinantes del desarrollo de un nivel de comprensión textual superior son la explotación que el profesorado hace de los materiales didácticos y el tipo de interacción generada en el aula.

Con este objetivo, presentamos el análisis de cuatro de las doce observaciones de las sesiones previstas en dos niveles educativos: seis de $1^{\circ}$ de ESO -tres de lengua castellana y tres de catalana-, y seis de $1^{\circ}$ de Bachillerato -tres de lengua castellana y tres de catalana. Hemos considerado dos etapas de enseñanza (el inicio de la Educación Secundaria Obligatoria y el inicio de la Postobligatoria) para poder graduar la extensión de la educación perspectiva crítica en el planteamiento de lectura en cada nivel, y también para poder establecer comparaciones en cuanto a progresión didáctica. A pesar de que en este trabajo solo analizamos cuatro clases (por lo tanto, se trata de un estudio no generalizable), a partir de los resultados obtenidos sí que se pueden apuntar tendencias que orientan sobre el tipo de prácticas lectoras que se realizan en dos etapas relevantes de aprendizaje.

Adoptamos una perspectiva ecológica (cfr. Edwards y Mercer, 1987; Van Lier, 2004) para la recolección de los datos en el planteamiento de cada clase. Este enfoque concibe la sesión de clase en el conjunto global (nivel holístico) del sistema de enseñanza en que se ubica y del proyecto curricular del centro que le da sentido. El aula (nivel émico), por lo tanto, constituye una parte de un todo (un organismo, de ahí lo ecológico) sin el cual no es posible interpretarla; al mismo tiempo, el conjunto educativo no se entiende sin las clases que lo concretan.

Desde esta perspectiva, pues, recogimos datos a nivel holístico (entrevistas con el docente sobre la planificación del aula y el sistema educativo) y émico (observación y triangulación de las observaciones anotadas manualmente en las clases). Esta metodología permitió detectar, analizar y también comparar los grados de planteamiento crítico de cada sesión promovidos por: 1) la propuesta del manual, 2) la planificación de la sesión del docente (sobre la propuesta del manual) y 3) el tipo de interacción generado en el aula. 
Para desarrollar estos objetivos específicos, utilizamos como instrumento de obtención de los datos una parrilla de observación ${ }^{3}$ de clases en la que anotamos de qué forma el profesor planteaba la sesión de lectura y cómo utilizaba el manual. Este instrumento perseguía sistematizar y unificar la recogida de datos, realizada por las tres autoras de este trabajo. Los elementos que cabe considerar en la observación responden a los aspectos que definen un planteamiento crítico del aprendizaje de la lectura (cfr. Cassany y Castellà, en prensa). De esta forma, fue posible triangular los resultados desde una base común de comparación.

\section{ANÁLISIS DE CUATRO CASOS Y DISCUSIÓN DE RESULTADOS}

Presentamos en la tabla 1 las cuatro clases analizadas para este estudio:

TABLA 1. Clases observadas

\begin{tabular}{|c|c|c|}
\hline Clase & Lengua y Literatura Catalana & Lengua y Literatura Castellana \\
\hline $\begin{array}{l}\text { 1) } \\
1^{\circ} \mathrm{ESO}\end{array}$ & $\begin{array}{l}\text { 1) IES Federica Montseny } \\
\text { (Badia del Vallès) } \\
\text { Fragmento de El cor de la ciutat } \\
\text { y una escena de Romeo y Julieta } \\
\quad \text { Guión televisivo y tragedia } \\
\text { La Galera (2001) Ed. Enciclopèdia } \\
\text { Catalana pp. 146-148 y pp. 132- } \\
134\end{array}$ & $\begin{array}{l}\text { 2) IES Josep Mestres i Busquets } \\
\text { (Viladecans) } \\
\text { Recuerdo de Mota del Cuervo } \\
\text { (adaptación de un fragmento de } \\
\text { Manolito Gafotas, de E. Lindo) } \\
\quad \text { Literatura juvenil } \\
\text { Códice (2002) Ed. Cruilla, pp. 60-61 }\end{array}$ \\
\hline $\begin{array}{l}\text { 2) } \\
1^{\circ} \mathrm{Bach} .\end{array}$ & $\begin{array}{l}\text { 3) IEs del Vallès (Sabadell) } \\
\text { El futbol, és a dir, tot, d'Agustí } \\
\text { Alcoberro } \\
\text { Artículo de opinión del periódi- } \\
\quad \text { co Avui } \\
\begin{array}{l}\text { Entre línies (2000) Ed. Teide, } \\
\text { pp. 138-141 }\end{array}\end{array}$ & $\begin{array}{l}\text { 4) IES Vila de Gràcia } \\
\text { (Barcelona) } \\
\text { La inteligencia creadora (frag- } \\
\text { mento de Teoría de la inteligencia } \\
\text { creadora, de J. A. Marina). } \\
\text { Fragmento de un ensayo } \\
\text { Lengua Castellana y Literatura } \\
\text { (2001) Ed. Teide, pp. 304-305 }\end{array}$ \\
\hline
\end{tabular}

3. La parrilla incluye una columna para analizar el discurso del profesor y la interacción aportada por los alumnos. Se abordan aspectos relacionados con 1) el contenido y las características lingüísticas del texto (resumen del contenido, estructura, cuestiones léxicas y de morfosintaxis), 2) la pragmática del texto (contextualización del texto, del autor y de la recepción, punto de vista e ideología del autor), 3) las formas de interacción en el aula (activación del conocimiento previo, generación de interrogantes, actividades de discusión e intercambio) y 4) el desarrollo de la perspectiva crítica (en qué medida se tienen en cuenta las reacciones y actitudes de los alumnos ante el texto leído, qué hacen los alumnos con el texto, cómo lo incorporan a su contexto cognitivo y sociocultural). 
Para cada asignatura (son clases de lengua materna, catalana o castellana), indicamos el nombre y población del Instituto de Secundaria, el curso $\left(1^{\circ}\right.$ ESO o $1^{\circ}$ Bachillerato), el tipo de lectura (género de discurso) trabajada en el aula $y$ el libro de texto en el que se incluye.

Una vez recogidos todos los datos (propuesta del manual, entrevista con el docente y notas de campo), procedimos a analizar cada una de las clases observadas que presentamos en este trabajo. El análisis detallado y sistemático aborda: 1) descripción del contexto en el que se impartieron las clases y características de los alumnos, 2) fecha y relación de la sesión con el examen de fin de trimestre o curso, 3) análisis de la propuesta didáctica, 4) objetivos de la actividad de lectura según el profesor (adquirir vocabulario, desarrollar habilidades de comprensión, desarrollar habilidades académicas para aprobar los exámenes/selectividad) y 5) tipo de interacción generada en el aula. Los resultados del análisis, que fueron triangulados con los profesores implicados en la entrevista posterior a la clase y después discutidos en el grupo de autoras, se sintetizan en la siguiente tabla 2 (en la que destacamos el tipo de ejercicios que, según la definición inicial que adoptamos, fomentan la comprensión crítica):

\section{TABLA 2. Resultados del análisis}

\begin{tabular}{|c|c|c|c|c|}
\hline Clase & $\begin{array}{c}\text { Justificación del } \\
\text { texto escogido }\end{array}$ & $\begin{array}{l}\text { Actividades del } \\
\text { manual }\end{array}$ & $\begin{array}{l}\text { Actividades del } \\
\text { profesor }\end{array}$ & $\begin{array}{c}\text { Actividades en la } \\
\text { interacción }\end{array}$ \\
\hline $\begin{array}{l}\text { 1) } \\
1^{\circ} \mathrm{ESO}\end{array}$ & $\begin{array}{l}\text { Adecuado a los } \\
\text { estudiantes; cono- } \\
\text { cimientos previos } \\
\text { sobre la serie de } \\
\text { televisión } \text { El cor } \\
\text { de la ciutat }\end{array}$ & $\begin{array}{l}\text { El cor de la ciutat } \\
\text { De comprensión } \\
\text { crítica: } 0 \\
\text { Otras actividades: } \\
3 \text { sobre tipología } \\
\text { textual; } 1 \text { sobre la } \\
\text { comprensión de las } \\
\text { ideas básicas } \\
\text { Romeo y Julieta } \\
\text { De comprensión } \\
\text { crítica: } 1 \text { [interpre- } \\
\text { tación dramática] } \\
\text { Otras actividades: } 2\end{array}$ & $\begin{array}{l}\text { El cor de la ciutat } \\
\text { Del libro de texto:1 } \\
\text { sobre la compren- } \\
\text { sión de las ideas } \\
\text { básicas } \\
\text { A iniciativa del pro- } \\
\text { fesor: } 3 \text { (1 sobre los } \\
\text { conocimientos pre- } \\
\text { vios; } 1 \text { léxico; y } 1 \\
\text { actividad crítica } \\
\text { (opinión acerca del } \\
\text { conflicto planteado) } \\
\text { Romeo y Julieta } \\
\text { Del libro de texto: } 1 \\
\text { actividad crítica } \\
\text { A iniciativa del pro- } \\
\text { fesor: "representar" } \\
\text { el texto escrito }\end{array}$ & $\begin{array}{l}\begin{array}{l}\text { Activación de } \\
\text { conocimientos pre- } \\
\text { vios }\end{array} \\
\begin{array}{l}\text { Lectura dramatiza- } \\
\text { da }\end{array} \\
\text { Aclaración del } \\
\text { contenido leído } \\
\text { Intercambio de } \\
\text { sinónimos } \\
\text { Negociación sobre } \\
\text { el contenido } \\
\text { semántico } \\
\text { Intercambio de } \\
\text { opiniones }\end{array}$ \\
\hline
\end{tabular}




\begin{tabular}{|c|c|c|c|c|}
\hline Clase & $\begin{array}{l}\text { Justificación del } \\
\text { texto escogido }\end{array}$ & $\begin{array}{l}\text { Actividades del } \\
\text { manual }\end{array}$ & $\begin{array}{l}\text { Actividades del } \\
\text { profesor }\end{array}$ & $\begin{array}{l}\text { Actividades en la } \\
\text { interacción }\end{array}$ \\
\hline $\begin{array}{l}\text { 2) } \\
1^{\circ} \text { ESO }\end{array}$ & $\begin{array}{l}\text { Adecuado a los } \\
\text { estudiantes; cono- } \\
\text { cimientos previos } \\
\text { sobre el personaje } \\
\\
\text { Romeo y Julieta } \\
\text { viene dado por el } \\
\text { tema La tragedia } \\
\text { del libro de texto }\end{array}$ & $\begin{array}{l}\text { De comprensión } \\
\text { crítica: } 0 \\
\text { Otras actividades: } \\
7 \text { sobre el género } \\
\text { narrativo }\end{array}$ & $\begin{array}{l}\text { Del libro de texto: } 6 \\
\text { A iniciativa del pro- } \\
\text { fesor: } 3 ; 1 \text { léxico; } 1 \\
\text { humor en el texto; } 1 \\
\text { actividad crítica: } \\
\text { creación de una } \\
\text { situación similar a } \\
\text { la del texto }\end{array}$ & $\begin{array}{l}\begin{array}{l}\text { Activación de conoci- } \\
\text { mientos previos }\end{array} \\
\text { Lectura en voz alta } \\
\text { Negociación del senti- } \\
\text { do figurado de las pala- } \\
\text { bras } \\
\text { Intercambio de expre- } \\
\text { siones coloquiales } \\
\text { Orientación para res- } \\
\text { ponder a las activida- } \\
\text { des }\end{array}$ \\
\hline $\begin{array}{l}3) \\
1^{\circ} \\
\text { Bach. }\end{array}$ & $\begin{array}{l}\text { Seguimiento del } \\
\text { programa del curso: } \\
\text { desarrollar habilida- } \\
\text { des de comprensión } \\
\text { lectora, en concreto, } \\
\text { la ironía. }\end{array}$ & $\begin{array}{l}\text { De comprensión } \\
\text { crítica: (1 para } \\
\text { reflexionar antes de } \\
\text { la lectura; } 1 \text { sobre } \\
\text { comprensión ideas } \\
\text { básicas; } 1 \text { de rela- } \\
\text { ción y reflexión; } 1 \\
\text { de detección de la } \\
\text { ironía; } 1 \text { de desarro- } \\
\text { llo de la opinión } \\
\text { personal sobre el } \\
\text { texto. } \\
\text { Otras actividades: } 2 \\
\text { sobre vocabulario } \\
\text { técnico-científico y } \\
\text { barbarismos/vulga- } \\
\text { rismos. }\end{array}$ & $\begin{array}{l}\text { Del libro de texto: } 5 \\
\text { de comprensión crí- } \\
\text { tica (4 en el aula -1 } \\
\text { en común, } 3 \text { en } \\
\text { parejas-, } 1 \text { como } \\
\text { deberes) } \\
\text { Iniciativas del pro- } \\
\text { fesor: } 1 \text { actividad } \\
\text { crítica: de discusión } \\
\text { previa a la lectura } \\
\text { del texto }\end{array}$ & $\begin{array}{l}\text { Discusión previa a la } \\
\text { lectura a partir de los } \\
\text { conocimientos previos } \\
\text { Orientación para la lec- } \\
\text { tura (diferentes niveles } \\
\text { de lectura: l. literal ver- } \\
\text { sus l. inferencial) y la } \\
\text { elaboración de las activi- } \\
\text { dades } \\
\text { Completar/Ampliar las } \\
\text { referencias históricas y } \\
\text { culturales } \\
\begin{array}{l}\text { Negociar las connotacio- } \\
\text { nes del léxico y el senti- } \\
\text { do del texto } \\
\text { Desarrollar habilidades } \\
\text { de escritura y argumen- } \\
\text { tación } \\
\text { Promover el intercambio } \\
\text { de ideas (discusión, acti- } \\
\text { vidades en parejas) }\end{array} \\
\text { Adquirir herramientas } \\
\text { para afrontar con éxito el } \\
\text { examen de Selectividad. }\end{array}$ \\
\hline
\end{tabular}




\begin{tabular}{|l|l|l|l|l|}
\hline Clase & $\begin{array}{l}\text { Justificación del } \\
\text { texto escogido }\end{array}$ & $\begin{array}{l}\text { Actividades del } \\
\text { manual }\end{array}$ & $\begin{array}{c}\text { Actividades del } \\
\text { profesor }\end{array}$ & $\begin{array}{c}\text { Actividades en la } \\
\text { interacción }\end{array}$ \\
\hline 4$)$ & $\begin{array}{l}\text { Interesante y de posi- } \\
\text { ble agrado de los } \\
1^{\circ} \text { EStudiantes }\end{array}$ & $\begin{array}{l}\text { De comprensión crí- } \\
\text { tica: } 2 \text {. Una de crea- } \\
\text { ción y otra sobre la } \\
\text { idea del receptor que } \\
\text { se expresa en el } \\
\text { texto. }\end{array}$ & $\begin{array}{l}\text { Del libro de texto: } \\
\text { las de análisis del } \\
\text { léxico, estructura } \\
\text { semántica y estructu- } \\
\text { ra argumentativa. }\end{array}$ & $\begin{array}{l}\text { Activación de conoci- } \\
\text { mientos previos }\end{array}$ \\
$\begin{array}{l}\text { Otras actividades: } \\
\text { Negociación del sentido } \\
\text { figurado de las palabras } \\
\text { semántica y enuncia- } \\
\text { tiva, aspectos léxi- } \\
\text { cos, estructura } \\
\text { argumentativa, gra- } \\
\text { mática, figuras retóri- } \\
\text { cas }\end{array}$ & $\begin{array}{l}\text { A iniciativa del pro- } \\
\text { fesor: subrayado de } \\
\text { palabras desconoci- } \\
\text { das. }\end{array}$ & $\begin{array}{l}\text { Lectura en voz alta } \\
\text { Aclarar el sentido de las } \\
\text { palabras }\end{array}$ \\
\hline
\end{tabular}

Después del análisis, respondimos a las siguientes preguntas de investigación, planteadas a partir de los objetivos que perseguimos:

\section{1. ¿Qué criterios sigue el profesor para seleccionar el texto? ¿Promueve la comprensión crítica?}

Los profesores de $1^{\circ}$ de ESO valoran de los textos que sean adecuados al nivel de comprensión de los alumnos, que estos tengan conocimientos previos sobre el propio texto y/o sobre sus personajes, y que los alumnos puedan establecer relaciones emotivas positivas con ese texto, como recurso para desarrollar el objetivo didáctico prioritario, que consiste en motivar su interés y el placer por la literatura, que se diviertan en contacto con los textos. En cambio, los profesores de $1^{\circ}$ de Bachillerato optan por textos cuyas características temáticas y lingüísticas favorezcan situaciones de intercambio como ejercicios de lectura, en los que los alumnos puedan desarrollar destrezas argumentativas y habili-dades académicas de lectura.

\section{2. ¿Qué actividades de comprensión lectora propone el manual sobre el texto escogido por el profesor? ¿Promueven la comprensión crítica?}

En los manuales de $1^{\circ}$ de ESO, la presencia de las actividades de comprensión lectora crítica es escasa, puesto que el objetivo didáctico principal se centra en comprobar la comprensión literal del contenido del texto y, sobre todo, desarrollar una actitud positiva de los alumnos para con la lectura y la literatura. En contraste, no se observa coincidencia en los dos manuales de Bachillerato analizados: en uno de los manuales, la lectura crítica es el objetivo prioritario, por 
lo que las actividades fomentan la discusión en el intercambio, la reflexión sobre la creación y la recepción durante el proceso de lectura, y, además, pone énfasis en la detección de la ideología de los textos; en el otro manual, en cambio, la comprensión profunda del texto se trabaja de manera fragmentaria e incompleta, por lo que el manual no es un soporte completo para que los alumnos acaben interpretando el texto en los parámetros de lectura crítica que proponemos. Sin embargo, es evidente que la gestión del manual y de la planificación del profesor podría completar los vacíos.

\subsection{El docente, ¿cómo explota las actividades propuestas por el manual? ¿Su gestión del texto y las actividades promueven la lectura crítica?}

Los docentes de $1^{\circ}$ de ESO completaron las actividades de comprensión propuestas por el manual con actividades de interacción en el aula. Se observa que el grado de perspectiva crítica en la planificación y el discurso del profesor es inversamente proporcional al grado de perspectiva crítica del manual de texto: es decir, cuanto "menos crítico" es el manual, más iniciativas críticas aparecen por parte del profesor, aunque se desarrollen superficialmente, en sintonía con el nivel de aprendizaje de esta etapa. Sin embargo, en el caso de los docentes de Bachillerato, se observa que uno, aunque siguiendo detalladamente la propuesta del manual (que ya incluye un planteamiento crítico bien elaborado), la desarrolla con un estilo muy libre y personal. En cambio, el otro profesor opta por un análisis clásico formal y pautado del texto; esta práctica puede caer en la contradicción de obstaculizar la autonomía y el desarrollo de la lectura crítica (que aceptaría la subjetividad en el comentario y la opinión personal de los alumnos), debido al exceso de pautas que seguir.

\section{4. ¿Qué tipo de habilidad de lectura crítica fomenta el profesor en la interacción en el aula con sus estudiantes?}

En las 4 sesiones analizadas, en ambos niveles educativos, observamos que el tipo de habilidad de lectura crítica que el profesor fomenta en la interacción en el aula con sus estudiantes aborda actividades sobre cuestiones básicas de lengua que, sin embargo, son el cimiento para promover un nivel complejo de lectura. Algunas de las actividades que la interacción posibilita durante la lectura en voz alta son las siguientes: el intercambio de sinónimos, la negociación sobre el contenido semántico o la aclaración del contenido leído; estas actividades se desarrollan sobre todo en $1^{\circ}$ ESO, aunque también en menor medida y menos sistemáticamente en Bachillerato. Estos ejercicios no pueden considerarse actividades que promuevan la comprensión crítica: son cuestiones básicas y necesarias para un nivel más complejo de lectura, eso sí, pero no desde una 
perspectiva crítica. Sin embargo, es pertinente destacar que la lectura en voz alta, según el objetivo perseguido, puede contribuir a una comprensión más o menos crítica: por ejemplo, como ejercicio académico de ejercitación oral incide menos en la perspectiva crítica, como actividad dramatizada promueve una interpretación más ajustada a la intención del autor.

Las actividades críticas que se fomentan en la interacción en ambos niveles tienen que ver sobre todo con:

- la activación de conocimientos previos;

- ofrecer y completar referentes culturales;

- negociar el sentido figurado de las palabras;

- intercambiar opiniones y

- negociar el sentido del texto.

Sin embargo, nuestra definición de lectura crítica conllevaría plantear más actividades que las observadas para leer la ideología y comprender críticamente, poco explotadas todavía en las aulas, como las siguientes:

- evaluar los procedimientos de construcción de sentido y estructuración semántica (jerarquización de la información, tematización, inferencias, generalizaciones, metáforas y otras figuras retóricas, etc.).

- evaluar la estructura argumentativa y la validez de los argumentos.

- interrogarse acerca de los propósitos lingüísticos del texto, las intenciones pragmáticas del autor, sus puntos de vista y los sesgos que puedan manifestarse en sus afirmaciones.

- indagar en las representaciones (de sucesos, objetos y personas mencionados) contenidas en los textos.

- tener en cuenta el contexto discursivo y sociocultural de los textos, así como sus condiciones y expectativas de recepción.

- elaborar discursos personales y alternativos a partir de los leídos, que representen las opiniones propias mediante el uso de todos los recursos lingüísticos disponibles.

\section{CONCLUSIONES}

En primer lugar, hay que destacar la escasez de actividades de comprensión crítica presente en los manuales, en ambos niveles educativos. En ellos encontramos principalmente actividades sobre la semántica global y local de los textos, tipología textual, y sobre aspectos léxicos y lingüísticos. Es decir, hay una preocupación evidente por el procesamiento de la información entendida desde un punto de vista cognitivo y textual, pero no se ve reflejada la dimensión social de la lectura, ni esta es entendida como práctica situada, histórica y cul- 
turalmente. En este sentido, los manuales se proponen la comprensión cabal del contenido de los textos, pero no promueven la lectura entre líneas ni el cuestionamiento del sentido que se les otorga.

Los docentes, por su parte, parecen desarrollar bien los objetivos de la comprensión lectora en sus perspectivas cognitiva y textual, ya sea siguiendo la secuencia de actividades presentes en el manual, ya sea proponiendo actividades propias de comprensión o haciendo una combinación de ambas. Se observa mayor apego al manual en Bachillerato y más independencia del mismo en la ESO. Como causa, planteamos la hipótesis de que en el programa y las sesiones de Bachillerato la presencia de los exámenes de Selectividad es más fuerte y, por tanto, condiciona los horizontes didácticos de los profesores. En cuanto a actividades de comprensión crítica, se presentan escasamente en las clases observadas, pero suelen ser actividades que requieren una integración global de los contenidos del texto, y, por lo tanto, bastante complejas (escribir otro texto, opinar justificadamente, representar el texto leído, etc.). Por otra parte, los profesores promueven activamente la interacción entre los estudiantes mediante preguntas acerca de la lectura, muchas de las cuales podrían ser trabajadas desde una perspectiva crítica. Sin embargo, la necesidad de abordar muchos aspectos en torno al texto y el escaso tiempo disponible hacen que la discusión no alcance los niveles de profundidad que requiere la comprensión crítica del texto por parte de los estudiantes.

Es interesante señalar que, si bien los profesores desarrollan ciertas actividades que tienen potencialidad de comprensión crítica, no suelen considerarla explícitamente como parte fundamental de los objetivos de su clase, tal como se desprende de las entrevistas previas y posteriores a las clases observadas. Es decir, no parece haber en ellos una particular conciencia crítica de la lectura que se manifieste y construya en su discurso pedagógico. Este es un aspecto que consideramos importante: aun cuando la comprensión crítica de los textos incluya muchas de las actividades que actualmente se desarrollan en las aulas, hace falta explicitación e intencionalidad de los objetivos de lectura crítica en las clases de lengua por parte de los docentes. En otras palabras, hace falta que los docentes contemplen explícitamente los objetivos de leer críticamente entre sus objetivos prioritarios en el momento de realizar actividades de lectura y que los incorporen en su discurso acerca de la misma.

Por último, la interacción entre los estudiantes y de estos con el profesor proporciona la instancia más fecunda para el acercamiento crítico a los textos ya que, en cierta medida, su sentido se negocia y se construye colectivamente; esta co-construcción del sentido posibilita las tomas de posición y los cuestionamientos espontáneos de los alumnos. Desgraciadamente, estos últimos son muy escasos debido a la enorme cantidad de contenidos que deben ser abordados en relación con la lectura. 


\section{REFERENCIAS BIBLIOGRÁFICAS}

Aliagas, C., F. Martí y C. LóPez Ferrero (en prensa): «Libros de texto y perspectiva crítica», comunicación presentada en las IV Jornadas de Desarrollo Humano y Educación, Fundación Infancia y Aprendizaje y Universidad de Alcalá, Alcalá de Henares, 6/9-9-2005.

Ames, P. (2002): Para ser iguales, para ser distintos. Educación, escritura y poder en el Perú, Lima, Instituto de Estudios Peruanos.

Barton, D., M. Hamilton y R. Ivanic (eds.) (2000): Situated Literacies. Reading and Writing in Context, Londres, Routledge, 7-15.

Bosque, I. et al. (2002): Lengua castellana y literatura. 1 Bachillerato, Madrid, Ed. Santillana ["Texto para el comentario"].

CASSANY, D. (2006): Tras las líneas: Sobre la lectura contemporánea, Barcelona, Anagrama.

CASSANY, D. y J. M. ${ }^{a}$ CASTEllà (en prensa): «Aproximación a la literacidad crítica», comunicación presentada en las IV Jornadas de Desarrollo Humano y Educación, Fundación Infancia y Aprendizaje y Universidad de Alcalá, Alcalá de Henares, 6/9-9-2005.

EDWARDS, D. y N. MERCER (1987): El conocimiento compartido. El desarrollo de la comprensión en el aula, Barcelona, Paidós/MEC, 1988.

FAIRCLOUgh, N. (1995): Critical discourse analysis. The critical study of language, Nueva York, Longman.

Freire, P. (1974): Pedagogía del oprimido, Buenos Aires, Siglo Veintiuno.

Giroux, H. (1990): Los profesores como intelectuales. Hacia una pedagogía crítica del aprendizaje, (Trad. de Isidro Arias), Barcelona.

LLEDÓ, E. (1992): El silencio de la escritura, Madrid, Centro de Estudios Constitucionales, $2^{\mathrm{a}}$ ed. corregida y aumentada.

Luke, A. (2000): «Critical Literacy in Australia», Journal of Adolescente and Adult Literacy, 43 (5): 448-461.

MARTín PeRIs, E. (1996): Las actividades de aprendizaje en los manuales de E/LE. Barcelona, Universitat de Barcelona. <http://www.sgci.mec.es/redele/ biblioteca/martin.shtml>

VAN LIER, L. (2004): «The ecology and semiotics of language learning: A sociocultural perspective», Boston, Kluwer Academic.

VAN DIJK, T. (2003): Ideología y discurso. Una introducción multidisciplinaria, Barcelona, Ariel (Lingüística).

Zavala, V. (2002): Desencuentros con la escritura. Escuela y comunidad en los Andes peruanos, Lima, Red para el desarrollo de las ciencias sociales en el Perú. 


\title{
PROTOCOLOS DE COMUNICACIÓN EN WEB: EL PORTFOLIO EUROPEO DE LAS LENGUAS Y LOS WEBLOGS
}

\author{
Antonio Álvarez Platero \\ Ana Pitarch Gil \\ JoAN R. MONFERrer DAUdí \\ Universitat Jaume I
}

\section{INTERNET: UNA RENOVACIÓN CONSTANTE DE LA SITUACIÓN COMUNICATIVA}

$\mathbf{L}$

A presente comunicación parte de las necesidades creadas a partir de la puesta en práctica del Portfolio electrónico en entorno web. Como profesores de idiomas que formamos parte del grupo de investigación gre-Lingua de la Universitat Jaume I, que trabaja principalmente en el desarrollo del Portfolio Europeo de las Lenguas (PEL), primero electrónico y posteriormente en web, hemos incorporado a nuestro proyecto el uso de las tecnologías de la información y comunicación, y en especial el uso de Internet y de algunas de sus herramientas popularizadas en los últimos años como los weblogs.

Todo ello con la intención de potenciar el aprendizaje colaborativo del alumno, ya que el dominio de las lenguas no se circunscribe al aprendizaje de reglas gramaticales, fonéticas, etc. (competencia lingüística), sino que, además, debe completarse con el control de normas sociales, culturales, textuales, etc. (competencias sociolingüística, textual y estratégica) difíciles de aprender en contextos aislados de comunicación. Internet nos ayuda a superar las barreras espacio-temporales que nos alejan de los escenarios habituales de comunicación, pudiendo comunicarnos tanto de manera sincrónica como asincrónica.

Las metodologías actuales de enseñanza y aprendizaje de lenguas se basan fundamentalmente en el modelo de enfoque comunicativo, también recomendado por la Unión Europea a través de la publicación del Marco común europeo de referencia para las lenguas: aprendizaje, enseñanza, evaluación (Consejo de Europa, 2001), de donde parte el Portfolio Europeo de las Lenguas. Internet nos ofrece la posibilidad de reproducir o de acercarnos a modelos de comunicación próximos a situaciones comunicativas reales que favorecen el aprendizaje de lenguas en entornos comunicativos cooperativos inimaginables hace pocos años. Consecuentemente, la integración de estos recursos didácti- 
co-pedagógicos abre nuevas posibilidades en el modelo de PEL en entorno web en el que trabajamos.

\subsection{Del constructivismo a las teorías de la comunicación}

El lenguaje como instrumento o medio para la adquisición de conocimiento cobra una importancia capital en algunas de las teorías psicológicas constructivistas desarrolladas en la segunda mitad del siglo $\mathrm{XX}$, que se encuentran en la base de la adquisición de conocimientos y del aprendizaje por parte del individuo.

A partir de los planteamientos de Vigotsky, autores como Gergen, Harré, Edwards o Potter han desarrollado el constructivismo vinculado al construccionismo social situando los procesos psicológicos en general en el uso del lenguaje y en las prácticas discursivas (Coll, 2001). La idea fundamental en este sentido es la negación de los procesos mentales y de la mente como propiedades individuales: si existen las encontramos en la interacción entre las personas, en las relaciones sociales, en las prácticas socioculturales.

A pesar de la importancia de los procesos sociales, no podemos olvidar las aportaciones individuales de las personas en los procesos de adquisición de conocimientos. Autores como Salomon señalan que es útil considerar los procesos mentales como una propiedad de las personas que actúan conjuntamente en entornos organizados culturalmente (Coll, 2001). Así pues, el aprendizaje es el resultado conjunto de las aportaciones individuales de las personas y de la dinámica de las relaciones sociales que se establecen colectivamente entre estas: los compañeros y los profesores.

Desde finales del siglo Xx los enfoques comunicativos que propugnan las teorías actuales de enseñanza y aprendizaje de lenguas, a partir de situaciones comunicativas, no hacen más que reproducir contextos de relación social, más o menos reales, para trabajar la respuesta del individuo en cada ámbito, teniendo en cuenta no solo los aspectos lingüísticos de la situación sino también el resto de elementos no lingüísticos (culturales, sociales, etc.) que intervienen en la comunicación, así como aquellos conceptos descritos por Jakobson (1960) en su conocido esquema de la comunicación (emisor, receptor, mensaje, canal, código, referente y contexto).

Finalmente, la introducción de las tecnologías de la información y la comunicación constituye un cambio muy significativo respecto a las situaciones comunicativas tradicionales. Así, la universalización de Internet y su imparable desarrollo posterior supera o hace tambalear conceptos básicos como los de espacio y tiempo, e incluso la clásica distinción de lengua oral y lengua escrita en los contextos tradicionales, creando a su vez una gran gama de registros lingüísticos propios de los nuevos canales y contextos (SMS, Messenger, blog, etc). 


\subsection{El lenguaje, elemento vertebrador de Internet}

Entre los nuevos recursos proporcionados por las TIC en los últimos años destacamos la aparición de Internet como producto informático, marcando un antes y un después en nuestro modus vivendi y modus operandi, sobre todo a partir de su universalización. Hoy en día no se concibe un ordenador, ya sea para uso personal o como instrumento de trabajo, sin conexión a Internet.

Los ordenadores, por su parte, como producto humano, se rigen por unas pautas y reglas de funcionamiento basadas, principalmente, en el lenguaje. Físicamente están construidos por materiales electrónicos diversos y exóticos, pero funcionan de acuerdo con pautas de comunicación. La interrelación persona-ordenador se da por medio de lenguajes. Los sistemas operativos que hacen que el aparato funcione están escritos en lenguajes de programación. Si queremos que la máquina realice alguna acción, hemos de comunicárselo.

Internet, como expresión de la interrelación de personas que se comunican por medio de ordenadores, ha logrado hacer transparente el proceso de comunicación: no son ordenadores poniéndose en contacto unos con otros por medio de una conexión de red, sino que tenemos la impresión de estar hablando con alguien, es decir, el ordenador funciona como un canal y no como un receptor. En este sentido, y por el hecho de poder poner en contacto a un universo de usuarios, Internet permite crear comunidades basadas casi esencialmente en la comunicación, agrupados por intereses, aficiones, etc., en muchas ocasiones entre personas desconocidas, aunque no tengamos esa sensación sino todo lo contrario.

Los usuarios hemos ido contactando de distintas formas y nos hemos agrupado en comunidades de acuerdo con intereses y/o aficiones comunes. Cada una de estas comunidades se rige y funciona de acuerdo con unas reglas, a veces no escritas, aceptadas por los miembros que la forman. Así pues, en el ambiente de la web, el proceso comunicativo es similar al que se puede dar en otros entornos: los elementos que intervienen son básicamente los mismos, puesto que la comunicación en la web es una traslación de la comunicación interpersonal anterior, si bien en otros contextos.

Desde un punto de vista pedagógico, Internet ofrece un gran número de posibilidades de explotación, algunas ya en marcha, pero la mayoría aún por explotar. Entre las actuales, presentamos a continuación aquellas que consideramos más relevantes como el PEL en web y los weblogs o blogs, creadores de comunidad. 


\section{LA NARRACIÓN EN EL E-PEL Y EN EL W-PEL}

\subsection{El PEL: El sistema electrónico y portfolio del usuario}

Desde el Consejo de Europa se ha impulsado y establecido oficialmente el modelo de Portfolio Europeo de las Lenguas (PEL), basado en las directrices del Marco Europeo Común de Referencia para las Lenguas (MECR). El PEL es un documento personal e individual, propiedad del aprendiz, no de las instituciones educativas. Ha sido pensado para fomentar el control y la autonomía del aprendiz a lo largo de su aprendizaje y «valora cualquier experiencia lingüística y la competencia intercultural del aprendiz, con independencia que su adquisición se haya producido dentro o fuera del sistema educativo o de un aprendizaje formal» (Consejo de Europa, 2004). El PEL consta de tres partes: el Pasaporte lingüístico, la Biografía lingüística y el Dossier.

El PEL cumple básicamente dos funciones: la informativa, al almacenar competencias y habilidades en lenguas del propietario con el propósito de complementar sus certificaciones y diplomas con información sobre su experiencia y competencia lingüística personal; y la pedagógica, pues guía a los aprendices en su proceso de aprendizaje y les ayuda a reflexionar, autoevaluarse y a asumir la responsabilidad de su proceso de aprendizaje, haciéndolos, en definitiva, más autónomos.

Tras dos años de experimentación del PEL en formato papel en la Escuela Oficial de Idiomas (EOI) de Castelló (Monferrer, Pitarch y Álvarez, 2005), somos conscientes de sus limitaciones: es difícil de manipular y de actualizar, tan solo puede almacenar una cantidad limitada de información y, sobre todo, es difícil que el alumnado lo sienta como suyo. Una propuesta de solución a estas dificultades es el Portfolio Electrónico de las Lenguas (e-PEL) para adultos. En la actualidad existen varias iniciativas de este tipo, pero dependen de los ordenadores donde se instala el programa, y son productos cerrados que no permiten la personalización por parte de las instituciones educativas ni de los usuarios.

Nuestro grupo de investigación gre-Lingua de la Universitat Jaume I de Castelló trabaja en una implementación web del PEL (Monferrer, Pitarch, Álvarez, 2006). El w-PEL en formato web nace con el objetivo de ser una herramienta útil en el proceso de aprendizaje de lenguas, especialmente allá donde el PEL convencional ha fracasado: facilitando el uso y el mantenimiento.

Una de sus características más destacables es que permite la personalización del sistema: por ejemplo, los formularios son sencillos de actualizar y modificar según futuras necesidades, tanto personales como pedagógicas o administrativas. El propietario del portfolio puede también personalizar los impresos, tanto en contenido como en dimensiones. Al estar basado en web, es más fácil para su propietario producir diferentes portfolios de muestra para 
distintos destinatarios: ofertas de puestos de trabajo, instituciones educativas, etc. Así se enfatiza el carácter informativo del PEL; por ejemplo, en la sección del Dossier, el usuario puede decidir si informar de su progresión o de su nivel actual en una o en varias lenguas, y en una o en varias destrezas, y decidir el periodo de tiempo del que desea mostrar su proceso de aprendizaje. Otra de sus ventajas es que permite a los alumnos crear grupos con los que compartir sus documentos y que estos sean accesibles vía web, así como seleccionar qué trabajos quiere que formen parte de los diferentes portfolios que pueda generar.

\subsection{La metáfora de la narración: el E-PEL /W-PEL}

Por su naturaleza, el PEL conforma un texto narrativo en el que el propietario, tras un trabajo previo y no espontáneo de reflexión y recopilación, muestra una información que desea difundir entre un número (escogido o no) de destinatarios con la finalidad de cumplir con las dos funciones, pedagógica e informativa, arriba mencionadas. Se trata de la narración de un proceso de aprendizaje en pasado, presente y futuro, en varias lenguas, aportando certificados, experiencias lingüísticas y un muestreo de sus mejores materiales. Explica y reflexiona sobre lo acontecido para pasar después a reflexionar sobre el punto del proceso de aprendizaje en que se encuentra en cada lengua $\mathrm{y}$, a partir de esta información, a plantearse nuevos retos para el futuro, a narrar (de nuevo) el camino a seguir en cada lengua.

En esta narración el emisor puede filtrar la información que desea transmitir, seleccionar los materiales a mostrar e influir así en la percepción que el receptor de esta información tenga sobre él. Sin embargo, el PEL tiene una estructura, una línea de trabajo y unas funciones prefijadas por el Consejo de Europa y está formado por unos impresos-guía que marcan el carácter de la información a transmitir, el metalenguaje a utilizar. Estos impresos rigen de tal manera el acto comunicativo que dejan al emisor un margen muy pequeño para manipular la imagen que pretende transmitir en la función pedagógica (el destinatario del PEL - o el mismo usuario- puede percibir el tipo de aprendiz de que se trata a través de las certificaciones, narraciones de experiencias lingüísticas o de las reflexiones y planes de futuro del propietario) o, con un margen mayor, la función informativa.

No obstante, aunque el w-PEL se basa en los formularios recomendados por el Consejo de Europa, estos pueden ser modificados según las necesidades de los propietarios, y ajustarse así a la intención comunicativa del emisor según el destinatario. Es decir, el propietario del PEL en su formato web puede decidir con antelación qué documentos y materiales del PEL desea mostrar según cada necesidad y a su vez, el receptor de la información, 
según se trate de su intención comunicativa -según sea un tutor, un compañero de aprendizaje o un posible empleador, por ejemplo- decide qué parte de la información le interesa recibir. De esta manera, el significado final del acto comunicativo queda en manos del destinatario. A su vez, también las instituciones pueden actualizar los formularios con mayor facilidad en los formatos electrónicos.

En cumplimiento de la función pedagógica, la narración expuesta en formato electrónico permite el análisis sincrónico y diacrónico del proceso de aprendizaje, tanto por parte del usuario como del tutor o de sus compañeros, siempre y cuando el propietario desee mostrárselo, incrementándose, así, las posibilidades de aprendizaje no solo autónomo o guiado, sino también colaborativo. En este sentido, el w-PEL ofrece más posibilidades de utilizar la red para crear nuevos lazos con otros aprendices del mismo idioma que estimulen el proceso de aprendizaje del propietario: desde la reflexión al planteamiento de nuevos objetivos a alcanzar o al intercambio de experiencias lingüísticas.

\subsection{Modelo de comunicación}

Hemos visto, pues, que el proceso de comunicación varía dependiendo del formato. Si la situación comunicativa de la que habla la Pragmática analiza qué comunico con quién, con qué intención y en qué circunstancias de lugar y tiempo, hemos visto que, en el formato web, la intención comunicativa ofrece mayor versatilidad, más posibilidades de adaptarse al receptor y a las circunstancias de lugar y tiempo.

El análisis de los modelos de comunicación de ambos formatos de portfolios según la teoría de la información (Jakobson, 1960) evidencia que el canal, junto con el contexto, determina el producto final, el número de destinatarios y los destinatarios a los que puede llegar el portfolio, así como la forma en la que llega, según la intención comunicativa. Además, el hecho de que se pueda utilizar en diferentes instituciones a lo largo de todo el proceso de aprendizaje facilita que el propietario lo identifique como algo propio, como documento acreditativo que le acompaña durante toda su experiencia de aprendizaje. 
TABLA 1

\begin{tabular}{|c|c|c|}
\hline Emisor & $\begin{array}{l}\text { PEL Formato tradicional (papel) } \\
\text { Propietario del PEL }\end{array}$ & $\begin{array}{l}\text { PEL Formato electrónico o web } \\
\text { Propietario del PEL }\end{array}$ \\
\hline Receptor/es & $\begin{array}{l}\text { Él mismo, compañeros, tutor, } \\
\text { departamentos de Recursos Huma- } \\
\text { nos, etc. }\end{array}$ & $\begin{array}{l}\text { Los mismos pero en mayor núme- } \\
\text { ro, en diferentes países, y simultá- } \\
\text { neamente quizás. }\end{array}$ \\
\hline Mensaje & $\begin{array}{l}\text { La reflexión, certificados, compila- } \\
\text { ción de experiencias lingüísticas } \\
\text { del propietario, planes de futuro y } \\
\text { mejores materiales realizados por } \\
\text { él. }\end{array}$ & $\begin{array}{l}\text { Los mismos pero con la posibilidad } \\
\text { de crear múltiples portfolios según } \\
\text { la intención comunicativa. }\end{array}$ \\
\hline $\begin{array}{l}\text { Contexto } \\
\text { Código }\end{array}$ & $\begin{array}{l}\text { Se realiza para y dentro del entorno } \\
\text { de una institución. Con el tiempo } \\
\text { puede quedar obsoleto, romperse, } \\
\text { perderse... }\end{array}$ & $\begin{array}{l}\text { Se puede simultanear su uso en } \\
\text { varias instituciones y durante un } \\
\text { tiempo mayor. Su resistencia y } \\
\text { actualización es mayor. }\end{array}$ \\
\hline \multirow[t]{2}{*}{ Canal } & $\begin{array}{l}\text { El lenguaje escogido por el propie- } \\
\text { tario. }\end{array}$ & $\begin{array}{l}\text { Se pueden generar en varios idiomas } \\
\text { según se quiera acceder a destinatarios } \\
\text { de toda Europa. }\end{array}$ \\
\hline & $\begin{array}{l}\text { Texto escrito en papel con archivo } \\
\text { de materiales en diferentes forma- } \\
\text { tos }\end{array}$ & Internet \\
\hline
\end{tabular}

En consecuencia hemos de distinguir varias fases trabajo según se trate de elaborar PEL en formato tradicional o electrónico/web.

TABLA 2

\begin{tabular}{|c|c|}
\hline Formato tradicional & Formato electrónico o web \\
\hline Trabajo de colección de materiales & Trabajo de archivo en soporte digital \\
\hline $\begin{array}{l}\text { Selección de los artefactos para el portfo- } \\
\text { lio muestrario final }\end{array}$ & $\begin{array}{l}\text { Enlace (web) a los artefactos que componen } \\
\text { el producto final que se quiere mostrar }\end{array}$ \\
\hline $\begin{array}{l}\text { Reflexión sobre formularios. Las posibi- } \\
\text { lidades narrativas o de personalizar los } \\
\text { impresos son limitadas. }\end{array}$ & $\begin{array}{l}\text { Narración más flexible y personal gracias } \\
\text { a que los formularios son dinámicos. }\end{array}$ \\
\hline $\begin{array}{l}\text { Proyección: hay menos libertad de actua- } \\
\text { ción y se siguen los impresos guía del PEL }\end{array}$ & $\begin{array}{l}\text { Planificación, se tiene más libertad de } \\
\text { construir el portfolio final, por lo tanto, se } \\
\text { ha de planificar qué es lo que se va a hacer }\end{array}$ \\
\hline
\end{tabular}




\begin{tabular}{|l|l|}
\hline Formato tradicional & Formato electrónico o web \\
$\begin{array}{l}\text { Publicación restringida, ya que hay que } \\
\text { entregar el producto completo a alguien. } \\
\text { El producto final es invariable. }\end{array}$ & $\begin{array}{l}\text { Publicación efectiva al hacer algo asequi- } \\
\text { ble a un gran público. } \\
\text { El w-PEL permite crear tipos de usuarios } \\
\text { finales, dar de alta a estos usuarios y que } \\
\text { puedan acceder al tipo de portfolio desti- } \\
\text { nado a ellos. }\end{array}$ \\
\hline
\end{tabular}

En conclusión, el w-PEL permite ajustarse en mayor grado a la intención comunicativa, a las necesidades y expectativas del receptor y a las diferentes circunstancias espacio-temporales, es decir, amplía la función informativa del PEL en soporte papel. Por lo que respecta a la función pedagógica, las posibilidades de reflexión aumentan en tanto que permite el análisis sincrónico y diacrónico del proceso de aprendizaje. Por todo ello, no solo fomenta el aprendizaje autónomo y guiado, como el PEL en otros formatos, sino que va más allá al facilitar el aprendizaje colaborativo.

\section{EL PROTOCOLO DE COMUNICACIÓN EN LA TERTULIA: EL WEBLOG}

\subsection{Definición de weblog}

Un weblog o blog es una página web que tiene su contenido clasificado en un orden temporal de más reciente a más antiguo. La palabra weblog quiere decir en inglés «libro de registro o bitácora de la red» y proviene de la idea del cuaderno de bitácora de los navíos, en los que los comandantes iban anotando los acontecimientos e impresiones durante las travesías. A partir de esa idea, los blogs (de we-blog) registran unas informaciones en orden cronológico inverso y permiten que otros usuarios de la red puedan comentar y participar, de esa manera, en la creación de contenidos.

Una de las características de los blogs es que se enlazan unos con otros, se citan para comentar las entradas de discusión, creando así un entramado de sitios web que comparten un interés común, aunque puede que no los mismos puntos de vista. Así se crea una comunidad.

\subsection{La metáfora de la tertulia y el blog}

La esencia y la filosofía del blog son tan antiguas como la humanidad; al menos, tan antiguas como la cultura occidental, puesto que, realmente, los 
blogs son una transposición o adaptación del foro griego en tiempos de Sócrates. Al igual que ocurre en los blogs actuales, Sócrates, como maestro, abría el tema y lo discutía con sus discípulos en el foro. El contenido real de las enseñanzas no partían de Sócrates, sino de las conclusiones de sus discípulos: aquí teníamos un primer ejemplo de creación colaborativa de conocimientos.

España también tiene una larga tradición de creación de contenidos colaborativos: las tertulias de los cafés, famosísimas, y muy definidoras del carácter del español. Al contrario que el foro griego, los temas de las tertulias han sido variadísimos: hemos tenido y tenemos tertulias taurinas, literarias, teatrales o de cualquier tipo, incluso tertulias de carácter general. Consustancial al carácter español, también en estas tertulias se ataca y desacredita sin piedad al contrincante, sobre todo si está ausente ese día.

Es difícil establecer una génesis clara de las tertulias españolas, aunque podrían tener su origen en las academias literarias del Siglo de Oro, en las reuniones de críticos después de las representaciones teatrales. El tipo de tertulias más documentado hasta el siglo xx es el de las literarias o artísticas y están íntimamente unidas al café, como centro de reunión.

En la actualidad son muy comunes las tertulias radiofónicas y televisivas que discuten principalmente la actualidad política.

También la web ha sido desde su origen un púlpito de expresión personal. Uno de los más reputados y antiguos profesores del MIT, Philip Greenspun, en su obra 'Philip and Alex's Guide to Web Publishing' (Greenspun, 1998), fue el primero en 1998 en ver las posibilidades de creación de contenidos en colaboración de la web, y ya daba a sus lectores la opción de hacer comentarios a cada capítulo del libro en línea, y ordenó cronológicamente los comentarios, aunque, al contrario que en los blogs, de más antiguo a más reciente. Greenspun insistía en que para fidelizar a los usuarios de una página web había que crear un sentimiento de comunidad con ellos y por eso lo primero que hizo fue darles voz.

Es en el siglo XXI cuando irrumpe con fuerza el blog, aunque antes había sitios de noticias que permitían a los usuarios enviar comentarios. En septiembre de 1997, Rob Malda creó "slashdot", un sitio web con estas características y que recogía ideas novedosas entonces: sitios interactivos, comunidades virtuales, noticias, weblogs, etc. Rob Malda logró sintetizar todos estos conceptos en "slashdot". En España existe el sitio Barrapunto (traducción del inglés slashdot), lanzado en 1999 con software de «slashdot», que es hoy día un centro de noticias de software libre y tecnología en español de la red.

Hasta ahora habíamos visto blogs fuertemente jerarquizados como "slashdot" o "Barrapunto", pero con la aparición de Blogger principalmente, hemos entrado en la época de la expresión personal, independiente de una infraestructura que marque las líneas ideológicas a seguir. Así, tener un blog personal es algo tan fácil como escribir y pulsar un botón y conseguir una publicación instantánea. 


\subsubsection{Proceso de comunicación}

Como en cualquier otro proceso de comunicación en el blog reconocemos unos elementos esenciales:

- el emisor, que aquí son los iniciadores del hilo, o los propietarios del sistema, o bien los administradores del sistema;

- el código, que es el conjunto de símbolos y signos que se combinan para hacer pasar el mensaje;

- el mensaje, que en este caso es el comentario mismo (en inglés "post" o "comment") y que, en conjunto con los demás, forma el corpus de la comunicación, que se va desarrollando dinámicamente y se construye y crece con los propios comentarios;

- el canal es Internet;

- las interferencias, que en este caso son los comentarios hirientes, fuera de tema o simplemente la mala expresión lingüística;

- la retroalimentación, que consiste en el hecho de que el receptor recibe el mensaje, lo descodifica y puede tener una actitud positiva, reavivando la discusión, o negativa, dando por terminado el tema;

- y el receptor, que es la comunidad de usuarios, porque rara vez se dirigen a un usuario en concreto, debido al anonimato que permite la red.

\subsubsection{Esquema temporal}

Como cualquier bitácora o registro, la primera información que aparece es la última en tener lugar y el flujo temporal va, pues, de lo más reciente a lo más antiguo. Los blogs permiten, generalmente, ordenar los comentarios por medio de filtros, que pueden ser temporales, por hilos (todos los comentarios sobre un tema están agrupados, cuando se cambia de tema o aspecto, se comienza un nuevo hilo y se representa gráficamente por medio de árboles), o por puntuación otorgada por los moderadores, que deciden qué comentarios son aptos y cuáles no, según qué se pretenda de la entrada en el blog.

\subsubsection{Objeto de la comunicación}

Según Rebecca Blood, la razón principal de la existencia de los blogs es la divulgación de temas de interés y, en el caso de que tengan éxito, serán referenciados por otros blogs, creándose enlaces a las noticias y discusiones allí tratadas (Blood, 2003), con lo cual las posibilidades de divulgación crecen exponencialmente.

La reflexión, también según Rebecca Blood, es otro de los objetivos comunicativos de los blogs: los propios usuarios/propietarios de blogs toman con- 
ciencia de cuáles son sus intereses y de que realmente profundizan en los temas, debido al proceso de reflexión que la inclusión de comentarios y el establecimiento de referencias con otros blogs produce en ellos (Blood, 2004). Muchos usuarios comentan que no eran conscientes de que tenían tanto interés por algo o de que realmente tenían ideas propias sobre un tema hasta que no lo vieron publicado en un blog (Blood, 2000).

Un blog recopila una cantidad ingente de información y los sitios más potentes tienen sistemas de clasificación para el acceso a los temas cerrados anteriormente: la publicación final documentada y clasificada temporalmente es otro objeto de comunicación.

\subsubsection{Agentes}

Los administradores, publicadores e iniciadores son las personas que pueden incluir entradas en un blog. En este caso es la misma situación que se daba en el foro socrático, pues Sócrates abría tema, era su responsabilidad como maestro, o, más de acuerdo con nuestra cultura de tertulias, las autoridades en la materia abrían los temas de tertulia en los cafés.

En muchos blogs hay sistemas de control de contenidos gestionados por los editores o moderadores que, en ocasiones, pueden confundirse con censores, pero que en la mayoría de los casos intentan solamente eliminar todos aquellos comentarios que intencionadamente insultan a los demás usuarios o quieren tergiversar el sentido primero de la conversación llevándolo a lugares no deseados para lesionar sus intereses. Normalmente, los editores o moderadores permiten acceder a estos comentarios, aunque los usuarios de la comunidad aprenden a evitarlos. Por ejemplo, en un blog sobre educación infantil, alguien podría intentar llevar el tema a cómo pervertir menores: los moderadores marcarán estos comentarios como fuera de tema y se dirigirán al pervertidor pidiéndole que abandone el sitio. Pero Internet es libre y tal usuario puede hacer o no caso, con lo cual, la marca de moderación/edición es la que advierte a los usuarios normales del contenido que va a encontrar en esos comentarios.

\section{CONCLUSIONES}

Los usuarios son el eje y la razón de ser de Internet, que en un principio nació como medio de comunicación y que evolucionó hasta convertirse, principalmente en un medio de publicación jerarquizado. La segunda generación de la web se centra en una mayor descentralización y no son ya los entes o instituciones los que pueden crear un contenido para ser consumido por el público, sino que es el mismo público el que crea los contenidos y el que establece 
canales de interrelación entre ellos. Como cualquier creación humana, partimos de experiencias conocidas en el devenir histórico y las adaptamos a nuevos medios y herramientas: la narración en el caso del w-PEL y la tertulia en el caso de los blogs.

\section{REFERENCIAS BIBLIOGRÁFICAS}

BloOD, REBECCA (2000): Weblogs: a history and perspective. Consultado el 30 de octubre de 2006. <http://www.rebeccablood.net/essays/weblog_history.html>.

- (2003): Weblogs and Journalism in the Age of Participatory Media. Consultado el 30 de octubre de 2006. <http://www.rebeccablood.net/essays/ weblogs_journalism.html>.

- (2004): Hammer, Nail: How Blogging Software Reshaped the Online Community. Consultado el 30 de octubre de 2006. <http://www.rebecca blood.net/essays/blog_software.html>.

Coll, C. (2001): «Constructivismo y educación: la concepción constructivista de la enseñanza y el aprendizaje», en Coll, C, J. PAlacios, A. MArChesi (comps.) (2001): Desarrollo psicológico y educación. Psicología de la educación escolar, Madrid, Alianza Editorial, 157-186.

CONSEJO DE EUROPA (2001): El Marco común europeo de referencia para las lenguas: aprendizaje, enseñanza, evaluación. Consultado el 30 de octubre de 2006. <http://cvc.cervantes.es/obref/marco/>.

Consejo de Europa (2004): The European Language Portfolio (ELP). Principles and Guidelines. Consultado el 30 de octubre de 2006. <http:// www.coe.int/t/dg4/linguistic/Source/Guidelines_EN.pdf>.

Greenspun, Philip (1998): Philip and Alex's Guide to Web Publishing. Consultado el 30 de octubre de 2006. <http://philip.greenspun.com/panda/>.

JAKOBSON, R. (1960): «Closing Statements: Linguistics and Poetics», en T. SЕвеок (1960): Style in Language, Cambridge Massachusetts, MIT Press, 350-377.

Monferrer, J., A. Pitarch, A. Álvarez (2006): El Portfolio Europeu de les Llengües electrònic (e-PEL) en format web, un repte profitós. Consultado el 30 de octubre de 2006. <http://espiral.xtec.net/jornada2006/je06_jmontferrer.pdf>.

- (2005): El portfolio electrónico, un instrumento integrador en el aprendizaje de lenguas a distancia. Consultado el 30 de octubre de 2006. $<$ http://www.upf.edu/bolonya/obolonya/titulac/upf/trad/docs/portf.pdf>. 


\title{
ANÁLISIS DEL DISCURSO \\ PARLAMENTARIO ESPAÑOL \\ EN EL DEBATE \\ SOBRE EL ESTADO DE LA NACIÓN 2006
}

\author{
Amparo Ayora del Olmo \\ Universitat Jaume I
}

\section{INTRODUCCIÓN}

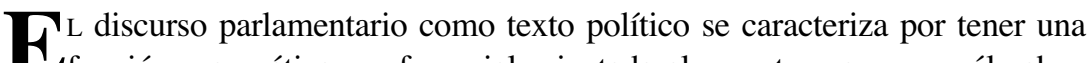
_función pragmática y referencial orientada al receptor ya que en él caben todos los ámbitos que constituyen la organización de la vida ciudadana. Aristóteles distingue tres tipos de textos oratorios, según se dirijan a un receptor espectador o árbitro y de que este último juzgue sobre hechos pasados o futuros. De aquí derivan tres tipos de discurso que pueden aparecer combinados: judicial -orientado al pasado-, deliberativo - proyectado hacia el futuro- y demostrativo. En general, el discurso parlamentario pertenece al género deliberativo, pues los receptores inmediatos son los diputados de la Cámara cualificados para tomar decisiones a través de sus votos, pero en el caso concreto del Debate sobre el estado de la Nación, que supone una evaluación del curso político hasta la fecha de su celebración, se presentan los tipos de discurso demostrativo y deliberativo a la hora de aprobar propuestas para el futuro. Se debe tener en cuenta la variedad de posibles receptores de los discursos parlamentarios, tanto dentro como fuera del hemiciclo. Para Albaladejo (1994: 7-16):

Los oradores no sólo se dirigen a los miembros de las asambleas políticas a los que intentan persuadir, sino también a aquellos otros receptores de sus discursos a los cuales intentan convencer influyendo en su opinión como miembros de la sociedad, en tanto en cuanto son miembros de la opinión pública.

Aparte de los miembros de la Cámara presentes en la sala asisten espectadores invitados. Otros posibles receptores son los espectadores que atienden las retransmisiones en directo por televisión o radio o posteriormente, a través de fragmentos grabados y difundidos en diversos medios de comunicación tanto audiovisuales (p. ej. vídeos en YouTube) como en prensa donde aparecen en versión transcrita tanto en formato físico, papel, como virtual. En Inter- 
net podemos acceder a versiones parciales o totales de esos discursos pronunciados en un contexto particular, donde, en ocasiones, figuran como enlace de hipertexto junto a artículos de opinión realizados por periodistas que pueden ejercer un efecto adicional en la recepción de esos textos o discursos. Otros canales que recogen la recepción de estos discursos son los chats, las páginas web o los blogs que se habilitan en la red, a veces simultáneamente a la retransmisión del debate. Es aquí donde puede haber una intención de influir en los receptores para persuadirlos de una determinada actitud política que, a más largo o más corto plazo, añade un componente deliberativo. Los discursos demostrativos tienden a la convicción ("hacer creer") y los deliberativos a la persuasión ("hacer actuar"), pero ambos conceptos no se excluyen entre sí.

\section{OBJETO, CORPUS Y METODOLOGÍA DE TRABAJO}

Esta comunicación pretende un análisis comparativo de los discursos parlamentarios del líder del partido en el Gobierno, José Luís Rodríguez Zapatero (ZP) y del líder de la oposición, Mariano Rajoy Brey (MR), en la primera sesión del Debate sobre el estado de la Nación de 2006. Nuestro análisis centra su atención en el género del discurso político según el tipo de receptor, -deliberativo, judicial o demostrativo-, siguiendo la terminología aristotélica, y en las estrategias utilizadas en los citados discursos parlamentarios con un fin pragmático. Aquí se pone de manifiesto cómo se intenta ejercer cierta influencia en el receptor a través de una determinada estructuración o disposición del contenido, de la utilización de algunas expresiones deícticas de carácter espacio-temporal y de diversos tropos o figuras retóricas, como la metáfora, la ironía y la metonimia, en un discurso enmarcado en el contexto específico del parlamento español caracterizado por un fuerte valor icónico.

Nuestro corpus de trabajo corresponde a la primera sesión (núm. 171) del Pleno del Congreso de la VIII Legislatura sobre el Debate en torno al estado de la Nación, ${ }^{1}$ celebrada el día 30 de mayo de 2006, en su versión trascrita en el Diario de Sesiones del Congreso de los Diputados y publicado en su página web http://www.congreso.es, desde donde ha sido obtenida en formato PDF. Se trata de transcripciones de los debates del Congreso de los Diputados donde figuran detalles como pausas, aplausos, risas, rumores o comentarios de los presentes, y no se consideran titubeos, muletillas o rasgos dialectales (p. ej. aspiraciones, ceceo, seseo, etc.). Cabe decir que el discurso del líder de la opo-

1. Comunicación del Gobierno para el Debate de política general en torno al estado de la Nación "BOCG. Congreso de los Diputados", serie D, número 394, de 26 de mayo de 2006. (Número de expediente 200/000003) 
sición está condicionado en parte por tener carácter de réplica a la intervención del presidente del Gobierno, y por disponer de un tiempo sensiblemente menor de acuerdo con el formato establecido de manera unánime por la Junta de Portavoces.

Partimos de un enfoque metodológico basado en la yuxtaposición de la Retórica clásica tradicional, que permite un análisis global del discurso, y las modernas teorías sobre el Análisis del Discurso (Van Dijk, 1999: 23-36), siguiendo la línea de los trabajos enmarcados en el proyecto de Análisis del Discurso Público Actual (ADPA) llevado a cabo por investigadores de la Universidad de La Coruña.

La Retórica clásica contempla tres operaciones retóricas principales en el discurso judicial, a saber, inventio -ideas contenidas en el texto-, dispositio -organización estructural de esas ideas- y elocutio -tropos y figuras de pensamiento y dicción. La estructura del discurso implica las dos primeras operaciones dando lugar al exordio -introducción o apertura-, narratio -descripción de los hechos-, argumentatio -confirmación o refutación-, y peroratio-final o cierre. Según Quintiliano (IV, 1 5-6) el discurso debe ser atento, dócil y benevolente con el auditorio (atentum, docile, benevolum).

Aquí partimos de la reinterpretación de la Retórica clásica² realizada por autores como Antonio García Berrio y Tomás Albaladejo Mayordomo que la incorporan a la actual Teoría del discurso más analítica, a la que confiere un enfoque de análisis global del cual carecía sin el complemento de ese poderoso mecanismo discursivo-retórico. Muy interesante para ilustrar esta reformulación teórica de la Retórica clásica es el trabajo de David Pujante (1998: 307-336), de la Universidad de Valladolid, centrado, precisamente, en el discurso político. Estudiamos, por tanto, los rasgos de retoricidad del discurso político desde un concepto moderno de retórica acorde con las actuales investigaciones sobre el discurso persuasivo en todas sus manifestaciones, teniendo en cuenta que las estrategias cambian con los tiempos, por influjo de causas externas como, por ejemplo, la fuerza mediática de la televisión, aspecto estudiado por David Pujante y Esperanza Morales (1996-97: 39-75). Cada época tiene unas metáforas, hipérboles, ironías, etc. características relacionadas con la cultura, las creencias y la ideología. Las tres partes de la retórica se complementan entre sí. La inventio supone interpretación del mundo, por tanto, ideología. ¿Por qué se habla de unos temas y no de otros? La dispositio y la elocutio sirven para dar énfasis o no a un determinado tema según el lugar que ocupe en la composición del texto y si está marcado mediante tropos y figu-

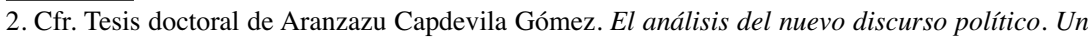
acercamiento al discurso persuasivo audiovisual leída en la Universitat Pompeu Fabra en 2002. <http://www.tdx.cesca.es/TESIS_UPF/AVAILABLE/TDX-1120103-113332/tacg1de1.pdf>. 
ras. Operaciones semánticas como las metáforas, que participan en la construcción del significado, pertenecen a la elocutio pero se relacionan también con la inventio. Recientes estudios sobre comunicación establecen los siguientes conceptos relacionados con la retórica: personaje retórico (el que dice el discurso), audiencia implícita (a quien se dedica el discurso), entendimiento del contexto (en nuestro caso el particular valor icónico de la Cámara) y las ausencias del texto.

Hay estructuras que caracterizan las estrategias concretas de un tipo determinado de discurso (político, pedagógico, publicitario, etc.). El discurso está marcado subjetivamente a través de indicadores de persona, espacio y tiempo y por las modalidades de la enunciación (duda, orden, posibilidad, actitud...). Esta relación entre los enunciados y las personas que lo usan e interpretan es la que implica a la pragmática en tanto en cuanto conlleva actuación (promesas, órdenes, amenazas...). En el contexto del discurso político las expresiones adverbiales espacio-temporales adquieren a veces valores simbólicos y pragmáticos, como los adverbios aquí, hoy... (Gelabert, 2006: 17-52). ${ }^{3}$ La deixis pronominal marca posiciones ideológicas mediante inclusiones y exclusiones del tipo nosotros, como las formas pronominales de $1^{a}$ persona que estudia Blas Arroyo (2000: 1-27) y (2003: 395-423). ${ }^{4}$ El discurso político (Quintrileo, 2005: 1-14) participa de rasgos del discurso judicial en cuanto se orienta al pasado, trata de ser atento dócil y benevolente con el auditorio, se utilizan fórmulas de tratamiento estereotipadas como «señorías», está marcado por un contrato conversacional muy rígido establecido por la Junta de Portavoces. Por otra parte podemos destacar su valor de discurso «cara a cara», el valor icónico del contexto (representa a la ciudadanía) la importancia de los deícticos espacio-temporales del tipo «aquí» y «ahora» o de los personales «nosotros» y «ustedes» con valor de exclusión y enfrentamiento, escaso margen de libertad en la elección de los temas a debatir, los alternativos cambios de voz del narrador en los turnos de palabra, presencia de un moderador, amplia repercusión en los medios y cierto nivel de ataque al adversario considerado "políticamente correcto" por la propia naturaleza del debate. La primera intervención de cada uno de los líderes responde a la lectura de un texto escrito previamente, y que será después trascrito en los boletines, a diferencia de las intervenciones en los turnos de réplica y dúplica que son menos previsibles.

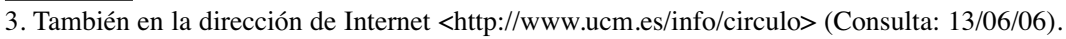

4. Señala las diferentes voces - profesional, personal, etc.- en los discursos preelectorales de Felipe González y José María Aznar emitidos por televisión en 1993. 


\section{CONTEXTO POLÍTICO Y ANÁLISIS DEL CORPUS}

La primera sesión del Debate sobre el estado de la Nación se produce el 30 de mayo de 2006, fechas previas al controvertido asunto de la votación del Estatuto de Autonomía de Cataluña (25 de junio de 2006), cuando todavía no se conocía el resultado de la baja participación en el referéndum pero de voluntad inequívoca de los votantes a favor de la reforma del texto. Por otra parte podemos considerar que el debate coincide con un período de cierta estabilidad política y de esperanza abierta para la ciudadanía tras el anuncio el 22 de marzo del alto el fuego de ETA. Entre los temas de mayor interés para la opinión pública destacan la inmigración, el posible diálogo con ETA y las reformas territoriales con el Estatuto catalán como protagonista.

Consideraremos en este punto las cuatro intervenciones de J. L. Rodríguez Zapatero (ZP), las tres réplicas de Mariano Rajoy (MR) y dos intervenciones del presidente de la Cámara de los Diputados, Manuel Marín (MM), en su papel de moderador.

\section{DISCURSO DE J. L. RODRÍGUEZ ZAPATERO (ZP)}

La primera intervención del presidente del Gobierno en esta sesión plenaria responde a los cánones que la Retórica clásica establecía para las distintas partes del discurso observando una estructura episódica que distribuye los distintos temas de la inventio en las partes fundamentales de la dispositio, a saber, -exordio, narratio (argumentatio) y peroratio. Los asuntos a tratar en el Debate político sobre el estado de la Nación limitan la inventio a los temas de la vida ciudadana que son responsabilidad del Gobierno (empleo, salud, derechos de los ciudadanos, política exterior, economía, etc.) por lo tanto están más o menos limitados a su campo de competencia. En el exordio se plantea una visión positiva de la España actual y las metas del Gobierno que resumen los temas que se van a desarrollar en el bloque narrativo: bienestar, derechos, seguridad y cooperación internacional. El bloque narrativo muestra una dispositio que construye la argumentación de los distintos asuntos por orden de impacto social. Se inicia con temas de carácter general (empleo, economía, educación, vivienda, salud...) quedando para el final los temas controvertidos de seguridad, inmigración, reforma de las autonomías y política exterior, todos ellos relacionados con la seguridad y la organización territorial que son los de mayor repercusión para los medios de comunicación en la actualidad, la reforma del Estatuto catalán y las posturas frente al terrorismo tanto nacional como internacional. En el bloque argumentativo podemos destacar el uso de datos estadísticos y fuentes, como la prensa internacional, para confirmar el cumplimiento de los compro- 
misos adquiridos en la sesión de investidura dos años antes y la valoración positiva de la política del Gobierno, y para refutar las profecías catastrofistas hechas por la oposición en anteriores sesiones. La peroratio o cierre resume la valoración positiva general de los asuntos básicos tratados y recurre a la captatio benevolentiae mostrando su actitud de aceptar críticas y de mejorar y con una alusión a las víctimas del terrorismo y al fin de la violencia, subrayando que confía en el apoyo de todos, expresión que adquiere relevancia dada la enfrentada postura de la oposición en este aspecto concreto. Con respecto a la elocutio cabe decir que en el discurso de ZP se evita el exceso de figuras retóricas de tipo metafórico, excepto repeticiones y paralelismos que abundan en estructuras bimembres y trimembres.

Sin embargo, la segunda intervención del presidente del Gobierno, en respuesta a las críticas del líder de la oposición, aparecen por primera vez metáforas, expresiones coloquiales y preguntas retóricas como "cantinela ahora más divertida", "estar como locos", "pasar de puntillas", "¿Quién le ha hecho ese discurso...?". También en la segunda intervención recurre ZP a la captatio benevolentiae con un agradecimiento a la ciudadanía y alusiones a términos positivos como "convivencia", "democracia" y "conciliación". Es importante destacar en la peroratio de esta segunda intervención la referencia al proceso electoral, ya que es un modo de recordatorio a los ciudadanos para el momento de votar. Por tanto, comprobamos la multiplicidad de receptores, por un lado la ciudadanía y por otro los miembros de la Cámara como explicita en alguna ocasión "Para información de la Cámara, le quiero decir que...". Esta alusión a la Cámara es reiterada a través de deícticos y adverbios espacio-temporales, como aquí y ahora. Algunas de estas expresiones adquieren valores simbólicos -y en muchos casos pragmáticos también- en el marco del discurso parlamentario, como reflejo de la importancia que las circunstancias físicas en las que se desarrollan los debates parlamentarios imprimen a este tipo de discurso. El contexto es un concepto clave para la pragmática y el análisis del discurso ya que permite la correcta interpretación de estos deícticos de lugar y de tiempo además de los personales que determinan las coordenadas espacio-temporales según la perspectiva del sujeto hablante. La forma no marcada de tratamiento en este contexto sería la fórmula perteneciente al lenguaje judicial "señorías", por tanto la personalización mediante usted y la adición del apellido del adversario resulta de mayor énfasis. Frente a estos usos agresivos, podemos notar el "ninguneo" que se ejerce con el partido en la oposición tratando de evitar llamarlo por su nombre ya que abundan formas del tipo "su grupo parlamentario" y otras semejantes. Cabe destacar el valor pragmático de la frase de ZP cargada de ironía: "Señor Rajoy... ¿Quién le ha hecho ese discurso?". Con ella no se desea conocer el autor del texto, sino poner en entredicho la situación de MR dentro de su partido. 


\section{DISCURSO DE MARIANO RAJOY (MR)}

El discurso del líder de la oposición ofrece abundantes figuras retóricas elocutivas y apenas se ajusta al esquema clásico en su estructura, estilo que se aproxima en su conjunto al de los mítines políticos y los debates electorales cara a cara, por la profusión de expresiones hiperbólicas, ironías, metáforas, usos del registro coloquial de la lengua como frases hechas y clichés y descalificaciones y valoración negativa de la acción del Gobierno en su conjunto.

La intervención de MR comienza sin exordio e introduce un bloque argumentativo relativo al tema que más preocupa a su partido, el diálogo con ETA, con abundancia de descalificaciones sobre la acción del gobierno como "poco preparado", "ineficiente", "irresponsable", "carece... no sabe... se equivoca", "insensatamente", "usted ha perdido", "ha fracasado", "no ha sido capaz de...", que son estrategias para minar la imagen (face) de su adversario, también con nombres y calificativos de tono humorístico y juegos de palabras: "tribulaciones", "frivolidades", "trompetería" ,"disparate", "absurdo", "trompetazo", "cabizbaja" , "errabunda", "usted hace oposiciones a volver a la oposición", "hace que se hace", "no saben gobernar y desgobiernan". Hay un uso amplio de metáforas del ámbito climatológico y de la navegación como "nubarrones", "tormenta", "manos que se aferran al timón del gobierno", "desbordar el dique", etc. Entre las expresiones coloquiales que tratan de acercar el discurso a la audiencia podemos citar "al alimón", "se nos cuelan", "se echa la siesta", "se ha colado de rondón", "estaban hasta el gorro", "sembrar cizaña", "cada equis tiempo" o "con gran pompa". Entre otras ironías encontramos: "El principal logro, la incertidumbre... la segunda conquista, la discordia". Todo ello está plagado de repeticiones, exclamaciones e interrogaciones retóricas. Entre las expresiones irónicas podemos citar "portentosa cifra", "Menos mal que conservamos el buen talante...", esta última con una alusión a la palabra "talante" que subraya la implicatura irónica ya que se ha convertido en icono del discurso de ZP y que repite en otras ocasiones: "el abanderado del talante...", "ha hecho usted una alusión de muy mal gusto y muy mal talante". En el aspecto de la dispositio MR argumenta que dedica mayor tiempo de su intervención al apartado de inmigración porque resume la actuación del gobierno. En su peroratio MR llega a plantear hasta 23 preguntas retóricas introducidas por la partícula ¿Por qué...?, 13 de ellas con reiteración de “¿Por qué no le dice usted a esta Cámara...? En algún caso la socarronería llega a niveles extremos como en la pregunta: “¿será por las zapatillas?, que es una implicatura al portal www.kelifinder.com. ${ }^{5}$ Hay en el dis-

5. Keli Finder es un servicio de información dirigido a los y las jóvenes para facilitar su acceso a la vivienda, proyecto del Consejo de la Juventud de España (CJE), que cuenta con la financiación del Ministerio de Vivienda, cuyo logotipo incluye unas zapatillas. 
curso profusión de exclamaciones: “todos... ¡Hermosa palabra!” En general, la agresión verbal que representa el uso de estas formas de discurso responde a una posición que se encuentra bajo ataque en un intento de negar la posición del otro manteniendo la propia e intentando derrotar al que ostenta el poder. En el uso de deícticos el discurso de la derecha tiende al uso de formas más personalizadas, yo y usted, frente a nosotros y ustedes que son los dos niveles habituales de tratamiento entre los participantes en el debate. Entre las innovaciones semánticas de MR destacamos el "efecto llamada" que ha provocado como respuesta el "efecto huída". Como los deícticos temporales pueden manipularse en este contexto, se hace necesaria a veces una explicación como: "¿Qué quiere decir hasta ahora? Exactamente hasta que llegó el señor Rodríguez Zapatero".

Cabe tener en cuenta que la intervención de MR actúa como respuesta a los temas ya introducidos por el presidente del Gobierno, que por el hecho de serlo disfruta de una situación de ventaja al intervenir en primer lugar y por disponer de mayor espacio de tiempo para su discurso. Precisamente este tema de los tiempos provocó una situación de protesta o desacuerdo que produjo un especial malestar y tensión que obligaron a intervenir al Sr. Marín, presidente de la Cámara. El comportamiento descortés (Blas Arroyo, 2001: 9-46) se ha convertido en norma, por tanto forma no marcada en el contexto del discurso político que presupone el uso de ciertos niveles de agresividad verbal.

Ciertos recursos que en principio pueden parecer de atenuación como "Lamento confesarlo pero..." lejos de atenuar subrayan la ironía de la crítica que prosigue a esa fórmula de cortesía. Una de las formas de agredir al adversario es no tomarle en serio y acusarle de mentir, como podemos ver en el siguiente ejemplo: "Pero hablemos en serio, Sr. presidente... Merece la pena tomarse en serio...", "Diga la verdad, señor presidente del Gobierno, porque si no corre el serio riesgo de que no lo podamos tomar en serio". Podemos considerar uso del registro coloquial, al que alude como "román paladino", al modo de Berceo, "en el qual suele el pueblo fablar a su veçino" (S. Dom. 1) como una estrategia de acercamiento popular y las interrupciones y el desacuerdo con el contrato conversacional como posiciones "a la defensiva" propias de quien no ostenta el poder. La abundancia de formas retóricas de intensificación de lo negativo funciona como estrategia de ataque a la imagen del interlocutor en el poder.

\section{PAPEL DEL MODERADOR SR. MANUEL MARÍN (MM)}

En la relación entre el moderador y el político sujeto del discurso (Bañón Hernández, 2005:10-19) podemos encontrar un tipo de comunicación manipu- 
latoria ya que se define por una estructura modal de tipo factitivo ("hacer hacer") y por una dimensión contractual (establecida, en este caso, por la Junta de Portavoces del Gobierno) por la que el destinatario no puede no aceptar el contrato propuesto (Lozano, Peña-Marín, Abril, 1989: 82). En este tipo de comunicación el sujeto destinador puede basarse en el poder (amenazar, intimidar -intercambio negativo- o tentar -intercambio positivo) o en el saber (provocar-imagen negativa- o seducir-imagen positiva). Por su parte, el destinatario manipulado puede estar moralizado por deber-hacer o querer-hacer y actúa por intimidación o provocación. El papel moderador de MM está moralizado por un "querer" y un "deber". El "poder hacer" causa satisfacción frente a la frustración del "no poder hacer". Las modalidades guardan estrecha relación con los actos discursivos ya que expresan el rol que adopta el hablante en la situación y las opciones de rol que asigna al oyente.

El Debate sobre el estado de la Nación de 2006 resulta especialmente interesante en cuanto a la intervención del moderador a causa de dos momentos puntuales de su desarrollo marcados por una cierta tensión provocada, en una ocasión por los gestos realizados por un diputado desde su escaño, destinados al Sr. Marín, y en otra por las protestas de MR en cuanto a la diferencia de tiempos de intervención del presidente del gobierno y del líder de la oposición. Ambas situaciones se tuvieron que resolver recurriendo a las reglas de cortesía disponibles para la salvaguarda de la imagen de las partes en desacuerdo. Con el uso del discurso se puede mitigar, o agravar la situación con reproches, desafíos, etc., se puede crear una obligación en el receptor con una alusión al mismo, todo ello desde usos determinados, como por ejemplo la cortesía, que establecen un marco diferente según las diversas funciones (distancia, desafío, deferencia...) de los verbos modales.

Ante los gestos del Sr. Matarí (vemos en este ejemplo la importancia del contexto), MM, con la distancia que ofrece el uso del condicional, del imperativo atenuado mediante "por favor", de las repeticiones y de la tercera persona reflexiva, como recursos de cortesía para resolver la tensión de la situación,

6. Los habituales del Congreso saben que los "diputados jabalíes" son, normalmente, el cuarteto popular formado por Juan José Matarí Ignacio Gil Lázaro, Juan Manuel Albendea y Neftalí Isasi y, por parte de la izquierda, los socialistas Teresa Cunillera y Mario Edo, y la apasionada Marisa Castro de Izquierda Unida. Ya a finales del siglo XIX, a los diputados más escandalosos y bulliciosos se les denominaba "diputados jabalíes". Eran los encargados de jalear en el Parlamento a los de su cuerda política y conseguir, con sus comentarios y machadas desde sus escaños, desestabilizar el discurso de sus contrarios. Contaba el fallecido Luis Carandell en uno de sus libros de crónicas parlamentarias que cinco de esos exaltados diputados, que se preciaban de su condición, se acercaron a saludar a Miguel de Unamuno en el pasillo del Congreso y le dijeron: "Don Miguel, aquí tiene usted a los cinco jabalíes de la Cámara", a lo que el escritor contestó sin inmutarse: "Imposible, los jabalíes van solos o en parejas. Los que van en piaras son los cerdos". <http://www.elsiglodeuropa.es/siglo/historico/politica/politica2003/553poli1.htm>. 
solicita "¿...sería capaz de interpretarme esos gestos hacia la presidencia?" "por favor, le ruego que... jamás he faltado al respeto a nadie, no me lo falte a mí. No me vuelva a hacer esos gestos, se lo ruego, por favor, le pido por favor que no me vuelva a hacer esos gestos. Gracias." Notemos en este ejemplo la importancia del contexto, ya que de no haber sido recogidos los citados gestos por una cámara o no hallarse el receptor presente en la Cámara, sólo podemos, como mucho, intuir o presuponer que se trata de algún gesto ofensivo. En nuestro caso no supimos que se trataba de un vulgarmente llamado "corte de mangas" hasta no leer, al día siguiente al debate, el artículo de Marco Schwartz en El Periódico de Aragón titulado "La ducha escocesa" que detallaba la escena.

En el caso de la protesta e interrupción (Blas Arroyo, 1998: 54-88) de MR se recurre a la repetición cortés y distante con valor de atenuación: "Sr. Rajoy, no ponga en esta situación al presidente...", "perdóneme, Sr. Rajoy", "discúlpeme, Sr. Rajoy", "Sr. Rajoy, lo lamento", "le ruego que... se lo ruego, por favor", "lo lamento profundamente, no quería decirlo”, “...perdóneme. Por favor, concluya... Por favor concluya, le ruego que concluya..." Se ve en esta estrategia de repeticiones el esfuerzo por resolver el conflicto y restablecer la armonía, un intento de negocio para el acuerdo, a pesar del cual fracasa el uso de las normas de cortesía, ya que se ha impuesto el desacuerdo sobre la conciliación cuando MM manifiesta: "Así de ninguna de las maneras... Así, no". A pesar de ello, MR asume la imposición del contrato conversacional que regula la Junta de Portavoces que ha votado los términos y duración de las intervenciones: "Entiendo... voy a aceptar las reglas del juego... porque no tengo otro remedio" y exclama con ironía hacia ZP "iQué suerte tiene usted!”. Vemos en este ejemplo la dimensión "manipulatoria" del papel del moderador ya que el receptor no puede "no aceptar" el contrato conversacional: "Las reglas que nos damos entre todos unánimemente están para cumplirse [...] esta es la decisión de la Junta de Portavoces". El conflicto está en su punto álgido: "Señor Rajoy, lo lamento. Creo que no nos estamos entendiendo". Emisor y receptor discrepan en la interpretación de la situación. MR dice en tercera persona refiriéndose a sí mismo: "al líder de la oposición [...] se le expulsa de la tribuna" y MM responde "yo no le expulso, le pido que termine". Sin embargo, el moderador hace una concesión final para restablecer la armonía mediante una deferencia: "Si me lo permite voy a ampliar a 8 minutos para que usted pueda terminar [...] feliz y contento y yo también." mientras MR interpreta negativamente la situación: "hoy se ha debatido aquí... con muy malos modos", "el poco tiempo del que dispongo, puro problema de poder", "así... no se puede hacer un Debate sobre el estado de la Nación". 


\section{CONCLUSIONES}

Nuestro análisis muestra los distintos estilos y estrategias utilizados en los discursos del presidente del Gobierno y del líder de la oposición. Tradicionalmente las intervenciones de los miembros del Partido Socialista han tendido a discursos ajustados a los cánones estructurales dictados por la Retórica Clásica. Desde las intervenciones del Sr. Aznar el discurso del Partido Popular ha tendido a un estilo de un tono más coloquial con la intención de llegar a un mayor número de público. Si bien esta estrategia discursiva resultó eficaz en anteriores ocasiones como ocurrió en debates entre el presidente Felipe González con José María Aznar en la oposición, no ha sido este el resultado del Debate sobre el estado de la Nación del año 2006 tras el cual la intervención de MR le ha hecho perder puntos en los estudios de opinión realizados con posterioridad a esa sesión plenaria, considerando como vencedor a ZP con un discurso más moderado y sobrio en su estructura retórica, que ha resultado de mayor modernidad y eficacia pragmática. La defensa argumentada y la capacidad de razonamiento y de persuasión del adversario utilizada en el discurso del presidente del Gobierno ha supuesto en la cultura actual una victoria ${ }^{7}$ frente al contraataque y el menoscabo de la imagen del interlocutor llevada a cabo por la oposición, estilo dialéctico que se considera como más agresivo, y es interpretado negativamente por la audiencia. Bien es cierto que estos usos que podemos considerar descorteses encuentran su justificación en el desequilibrio de poder entre el partido en el Gobierno y el partido en la oposición. La queja por la desigualdad de tiempos es una estrategia de interrupción usada por MR que pude ser valorado como un gesto descortés y despertar la simpatía del público por el interrumpido en tanto que agredido.

Hemos apreciado en nuestro estudio cómo a medida que transcurre la evolución del debate el inicial estilo contenido y moderado del presidente del Gobierno se "contamina" del estilo del adversario y va incrementando progresivamente los niveles de agresividad verbal en sus sucesivos turnos de réplica y dúplica al líder de la oposición de manera que se produce una aproximación a su estilo dialógico agresivo con el aumento de repeticiones, figuras y preguntas retóricas y mayor grado de personalización en el uso de deícticos. En cuanto al papel del moderador hemos destacado el uso de las reglas de cortesía como estrategia para atenuar las situaciones de conflicto.

7. Según las encuestas del Centro de Investigaciones Sociológicas (CIS) a la pregunta de quién cree usted que ganó el Debate sobre el estado de la Nación celebrado los días 30 y 31 de mayo de 2006, el 50,2\% de los encuestados respondió que Zapatero, frente al 14,3\%, que atribuyó la victoria a Rajoy. (El País Semanal, núm. 1.556, domingo 23 de julio de 2006 en <http://www.escolar.net/MT/archives/2006/05/> ¿Quién ha ganado el debate? Según elmundo.es, Rajoy arrasa a Zapatero. Según elpais.es, ZP congela a Rajoy. Mañana, más de lo mismo en los editoriales de sus diarios favoritos. Con esto de la política, el que pierde es porque lee el periódico equivocado. Mayo 30, 2006. 


\section{REFERENCIAS BIBLIOGRÁFICAS}

Albaladejo, T. (1994): «Sobre la posición comunicativa del receptor del discurso retórico», Castilla Estudios de Literatura, 19: 7-16.

BAÑón HeRnándeZ, A. M. (2005): «El Debate político. Una aproximación desde el análisis del discurso oral»Llengua, Societat $i$ Comunicació, Rev. Sociolingüística de la Universitat de Barcelona, Retòrica i Persuasió (juliol) 3: 10-19.

Blas Arroyo J. L. (2003): «Perdóneme que se lo diga, pero vuelve usted a faltar a la verdad, señor González: form and function of politic verbal behaviour in face-fo-face Spanish political debates, Discourse and Society, 14(4): 5-30.

- (2001): «No diga chorradas... La descortesía del debate político cara a cara: Una aproximación pragma-variacionista», Oralia. Análisis del discurso oral, 4: 9-45.

- (2000): «Mire usted Sr. González... Personal deixis in Spanish politicalelectoral debate», Journal of Pragmatics, 32: 1-27.

- (1998): «Pero no me interrumpa usted, haga el favor... Las interrupciones en el debate político-electoral», Mediterranean Language Review, 10: 54-88.

GELABERT, J. J. (2006): «La deixis espacio-temporal en el lenguaje parlamentario español contemporáneo», Universidad Complutense de Madrid, Círculo de Lingüística Aplicada a la Comunicación (clac), 26: 17-52.

Lozano, J., C. PeÑa-Marín y G. Abril (1989): Análisis del discurso, Madrid, Cátedra.

PujAnTE, D. (1998): «El discurso político como discurso retórico. Estado de la cuestión», Teoría/Crítica, 5, Universidad de Alicante.

Pujante, D. y E. Morales LóPez (1996): «El discurso político en la actual democracia española», Discurso (Revista de la UnAM, México, D. F.) 1996-97, 21/22.

Quintrileo, C. (2005): «El debate parlamentario como género discursivo. Una primera aproximación», Actas del VI Congreso ALED (Asociación Latinoamericana de Estudios del Discurso), Pontificia Universidad Católica de Chile, edición electrónica <http://www.congresoaled2005.puc.cl/ fset_actas.html> (Consulta 10/10/2006).

VAN DiJK, T. (1999): «El análisis crítico del discurso», Anthropos. 


\title{
SPOKEN ACADEMIC DISCOURSE: THE EFFECTS OF STUDENTS' PARTICIPATION IN NORTH-AMERICAN AND BRITISH LECTURES. A COMPARATIVE STUDY
}

\author{
BEGOÑa BELLÉS-FoRTUÑo \\ Universitat Jaume I
}

\section{INTRODUCTION: ENGLISH AS A LINGUA FRANCA}

$\mathbf{E}$ NGLISH as an international language has been coined a «lingua franca», and as such it has become the language of commerce, business and the academic world. The English language seems to be bound up in the phenomenon of globalism (Chew, 1999) with a growth in number of speakers, in domains of use, in economic and cultural power (Graddol, 1999).

English is adopting an international status and in the near future it will be mainly used as a second language fostering communication between non-native speakers in multilingual contexts. This phenomenon will also affect the ideological discourse about languages, linguistic competence and identity. Graddol (1999) argues about the authority of the discourse of the native speaker; he advances that with the emergence of «New Englishes» (an L2 speech community developing its own institutionalised variety of English, for example, former British colonial territories) together with the construction of a new Europe that places European citizens in a plurilingual context, it seems logical to question whether the authoritative norms of usage of the native speaker will prevail.

\subsection{English as the language of international academic exchange}

Graddol's (1999) considerations invite reflections towards to which extent academic discourses, and more concretely the lecture as the central instructional activity among higher education institutions, can be affected and challenged. We should bear in mind the international background (Benson, 1994: 182) of students and the important role lectures play for their learning process success. Although most of the tuition in English has been done in English speaking countries, such as Britain and the U.S. and it is also in these countries where academic discourse started to be analysed (Swales, 1990; 
Swales \& Malczewski, 2001; Mauranen, 2001; among others), we cannot deny that English is expanding to other countries as the result of internationalisation. Given also the internationalisation of university tuition mainly in Europe (e.g. Erasmus-Socrates programmes), and also in the United States (e.g. postgraduate education), academic discourse in English has become a priority in higher education institutions. Spoken academic discourse should be looked at as paramount for both students and faculty. Students attending a lecture need to listen and understand first to, on a second instance, take notes; faculty's academic life involves attending as well as presenting papers in conferences where English is used as the primary discourse language. All these are instances of oral academic genres which have been classified and some of their features analysed by some authors (Giménez, 2000; Bellés-Fortuño, 2004; BellésFortuño \& Fortanet, 2004; Fortanet, 2005). Fortanet (2005) aims at displaying a classification of oral genres «according to criteria of purpose, rather than to interaction between speaker and listener» and where the lecture is included within the category of Classroom genres together with the seminar, tutorial interview, students' presentation and oral exams. In general, classroom genres have aroused the interests of researchers, especially that of lectures, being one of the most important genres within spoken academic discourse. As Flowerdew (1994: 14) points out, lecture research:

[...] can indicate to teachers and course designers what linguistic and discoursal features learners need to be familiar with in order to understand a lecture and what, therefore, should be incorporated into ESL courses. In addition a knowledge of the linguistic/ discoursal structure of lectures will be of value to content lecturers in potentially enabling them to structure their own lectures in an optimally effective way.

\section{RESEARCH INTO LECTURE DISCOURSE}

Research into lecture discourse has primarily had effects on the what of teaching and learning, providing information about the linguistic and discoursal features of lectures. The study of linguistic and discoursal features of lectures have been of great help for both lecturers and learners in the learning process of content lectures. We will revise the different types of lectures classified by authors such as Goffman (1981) or Dudley-Evans and Johns (1981). Finally, we aim at presenting a thorough review of the role of Discourse Markers (henceforth DMs) have played in lectures by examining previous research on signalling devices (Cook, 1975; Murphy \& Candlin, 1979; Chaudron \& Richards, 1986). 


\subsection{Lecturing styles}

Several studies have identified a number of lecture styles. Morrison (1974, reported in Jordan, 1989: 153), studied science lectures and divided them into two kinds: i) formal and ii) informal. The former refers to «close spoken prose», and the latter is defined as «high informational content, but not necessarily in high formal register». This first classification, although somehow useful, is too simplistic. More complete classifications of lecture styles are those proposed by Goffman (1981), Dudley-Evans \& Johns (1981) and Dudley-Evans (1994). This last study points out that: «the key to the understanding of lectures is an appreciation of lecturers' individual styles» (Dudley-Evans, 1994: 148). Goffman (1981) talks about three «modes» of lectures, namely, «memorization», «aloud reading» and «fresh talk», whereas Dudley-Evans and Johns (1981:134) distinguish three styles:

reading style, «in which lecturers either read the lecture or deliver it as if they were reading it» (Dudley-Evans, 1994: 148). It is characterised by short tone groups, and narrowness of intonational range, in which falling tone predominates; although level tone may also occur.

the conversational style, «in which lecturers deliver the lecture from notes and in a relatively informal style with a certain amount of interaction with students» (Dudley-Evans, 1994: 148). It is characterised by longer tone groups and keysequences from high to low. When the lecturer is in «low-key» at the end of a key sentence, the speaker may markedly increase tempo and vowel reduction, and reduce intensity.

the rhetorical style, «in which the lecturers give a performance with jokes and digressions» (Dudley-Evans, 1994: 148). It is characterised by the wide intonational range. The lecturer often exploits high key, and a «boosted high key». There are frequent asides and digressions marked by key and temposhift, sometimes also by voice quantity-shift. (Dudley-Evans \& Johns, 1981: 134).

There is no written evidence about the frequency of use of lecture styles, but there seems to be a general agreement on identifying the informal conversational style -based on notes or handouts - as the predominant mode of lecture presentation not only for native, but also for non-native audiences (McDonough, 1978; DeCarrico and Nattinger, 1988; Dudley-Evans, 1994). Along this line, Frederick (1986) talks about a «participatory lecture» closer to discussion. More recent work (Benson, 1994) perceives a move towards a more interactive style of lecturing. This trend seems more predominant in the United States universities rather than in European ones; this fact may 
cause some problems for non-native speakers that have been trained in a much more traditional lecturing style, producing a default or precarious listening comprehension. Problems of cultural nature, role and status of university lecturers, degree of deference between lecturers and students or pure lecture content problems are the ones students may encounter. It is evident that the social norms of a lecture vary according to cultures, for example, in some Asian countries lecture attendance is regarded as more important than interaction; whereas in the United States the student who interacts whenever allowed is more appreciated than the mere spectator student (Benson, 1994).

\subsection{The role of discourse markers in lectures}

Following lecture discourse literature, many researchers have suggested that an understanding of the role of DMs and the relationships between different parts of the text is fundamental for the comprehension of lectures (Morrison, 1974; Coulthard and Montgomery, 1981; Chaudron and Richards, 1986).

One of the most cited classifications of DMs is the one by Chaudron \& Richards (1986). They propose a distinction between micro-markers (lowerorder DMs) and macro-markers (higher-order DMs). Micro-markers indicate links between sentences within the lecture, or function as fillers. They fill pauses giving listeners more time to process individual segments of a piece of discourse; they hence provide more opportunities for bottom-up processing. Macro-markers signal the macro-structure of a lecture through highlighting major information in the lecture and the sequencing or importance of that information. These discourse signals help top-down processing.

Chaudron and Richards classify micro-markers according to five semantic categories, namely, Segmentation, Temporal, Causal, Contrast, and Emphasis. Segmentation is understood as a semantic category including DMs which frame the segments of a discourse such as well or $O K$. Contrastive relationships among the discourse are represented by the Contrast category. Temporal and Causal categories embrace DMs of intersectional relations, whether temporal or causal links. Relative emphasis can be expressed with DMs such as of course, you see or in fact, all these under the semantic category of Emphasis. Table 1 below includes the micro-markers that have been taken into consideration by Chaudron and Richards (1986) and the categories established for their study.

TABLE 1. Chaudron and Richards'(1986) micro-markers classification 


\begin{tabular}{|l|l|l|l|l|}
\hline Segmentation & Temporal & Causal & Contrast & Emphasis \\
\hline Well & At the time & So & Both & Of course \\
\hline Ok & And & Then & But & You can see \\
\hline Now & After this & Because & Only & You see \\
\hline And & For the moment & & $\begin{array}{l}\text { On the other } \\
\text { hand }\end{array}$ & Actually \\
\hline Right & Eventually & & & Obviously \\
\hline All right & & & & Unbelievably \\
\hline & & & & As you know \\
\hline & & & & In fact \\
\hline & & & & \\
\hline
\end{tabular}

Regarding the classification of macro-markers, Chaudron and Richards (1986) did not distinguish any semantic category; however a list of those macro-markers contained in the lecture established for the development of their study was provided. The list included signals or metastatements about the major propositions within the lecture, or the important transition points in the lecture.

In The Effect of Discourse Markers in the Comprehension of Lectures (1986), Chaudron and Richards' findings show that macro-markers «are more conductive to successful recall of the lecture than micro-markers. Micromarkers do not aid the learner's retention of the lecture» (1986: 123). They claim two main reasons for these findings. On the one hand, micro-markers do not add enough content to make the subsequent information meaningful or salient. On the other hand, the quantity of the markers scattered probably results in making the entire lecture appear less well organized, notion already pointed out in Hiller et al. work (1969).

Another classification is the one provided by Murphy and Candlin (1979), they distinguish three types of discourse markers: i) markers, they include signalling devices such as well, right, now, providing a clearer discourse segmentation; ii) starters, for example, Well now, let's get on with, which establish links among discourse; and iii) metastatements, used to emphasise important information in the discourse as for example I want to mention three types of generator. On behalf of macro-markers and contrarily to Chaudron and Richards (1986) who did not distinguish categories for the macromarkers, Murphy and Candlin (1979) had previously developed some macromarkers divisions: Starter, to begin the discourse; Elicitation, which includes 
the words or expressions eliciting information; Accept, in order to show approval; Attitudinal, where the speaker takes positions about the discourse content; Informative, words used to emphasise important information; Comment, to express additional information; Aside, considered as an attempt to deviate from the ongoing discourse; Metastatement, which includes all the words and expressions used to strengthen and validate points in the discourse; and Conclusion, including final remarks.

A more recent study carried out by Morell (2001) examines the role of discourse markers and personal pronouns in the discourse of two lecture styles: an interactive (participatory) lecture and a non-interactive (explanatory) lecture. When analysing DMs she also makes the distinction between macro and micro-markers. In order to classify micro-markers she uses Chaudron and Richards (1986) taxonomy, but she adds a new category to the micro-markers classification: Elicitation, already present in Murphy and Candlin's (1979) classification of macro-markers, as seen above. Within the Elicitation semantic category we can find DMs that are used to elicit information from the students or to involve them in the discourse, for example, Anything else?. This new category was not found in Chaudron and Richards' classification as they analysed reading style lectures that do not include elicitation, whereas in a more interactive kind of lecture elicitation is required. On behalf of macro-markers, Morell (2001) categorises them according to some of the divisions cited by Murphy and Candlin (1979), disregarding three categories from the original classification, namely, Informative, Comment and Aside, since they were not relevant enough for her study.

\section{MODEL AND METHOD OF ANALYSIS}

As a point of departure for the study, the following research question was established: Is the American lecture corpus more interactive than the British lecture corpus? If so, does the degree of students' interaction affect the use of DMs?

For the development of the present study a combination of previous classifications of DMs was established. Micro-markers are categorised according to the semantic categories presented by Chaudron and Richards (1986). On the other hand, macro-markers are categorised according to the divisions proposed by Murphy and Candlin (1979) disregarding those divisions not taken into consideration by Morell (2001), that is, Informative, Comment and Aside. In this way, we restrict the scope of the present study and avoid getting misled by a myriad of categories.

To carry out the study we gathered a corpus with a total amount of twenty 
spoken monologic lecture transcripts. Ten North-American English lectures, constituting what we call corpus CA, and the rest ten British English lectures or the $\mathrm{CB}$. The North-American English lecture transcripts have been taken from the MICASE (Michigan Corpus of Academic Spoken English) (R.C. Simpson, S.L. Briggs, J. Ovens and J.M. Swales, 2002) available on the Net thanks to the English Language Institute at the University of Michigan (Ann Arbor, MI, USA). The MICASE is an on-line search engine containing a collection of transcripts of academic speech events recorded at the University of Michigan in Ann Arbor. It consists of a corpus of approximately 1,7 millions words transcribed from a variety of speech events that goes from February 1998 up to now. The British part of the corpus (CB) consists of ten lectures recorded at a British University and transcribed for the purpose of a doctoral thesis (Giménez, 2000) at the Universitat de València (Spain). As a result, the whole corpus consists of 20 monologic lectures recordings and transcripts from the field of Social Sciences: Sociology, Law and Business. As to participants, the students and teachers involved in the North-American English lectures and in the British English lectures are mostly native speakers of the language (NS).

Following the distinction between micro and macro markers proposed by Chaudron \& Richards (1986), we first conducted a search for micro-markers, continuing with macro-markers. Once the search finished, we took into consideration those DMs from each category with the highest number of occurrences. Along this line, a minimum of two and a maximum of four markers were fixed for each category; the reason was that, given the complexity and variety of DMs, it seemed necessary and methodical to centre the scope of the study and avoid getting lost in a myriad of DMs. An attempt to embrace too many DMs in a large corpus, like the one being used here, could have led us to a state of disorientation and could have interfered the aim of the current study. The DMs classification models (micro and macro-markers) for the present study can be seen in Tables 3 and 4 below.

TABLE 2. Micro-markers classification model for the present study

TABLE 3. Micro-markers classification model for the present study

\begin{tabular}{|l|l|l|l|l|l|}
\hline Segmentation & Temporal & Causal & Contrast & Emphasis & Elicitation \\
\hline Ok & And then & So $($ that $)$ & But & In fact & Why is that? \\
\hline And & After this & Because & Although & Of course & Anything else? \\
\hline Now & After that & Therefore & Unless & As you know & Anyone? \\
\hline Well & Eventually & & & & Why not? \\
\hline
\end{tabular}




\begin{tabular}{|l|l|l|l|l|l|}
\hline Starter & Elicitation & Accept & Attitudinal & Metastatement & Conclusion \\
\hline $\begin{array}{l}\text { Today I'm/we're } \\
\text { goig to talk } \\
\text { about, I'll/we'll } \\
\text { talk about }\end{array}$ & $\begin{array}{l}\text { (Wou think? } \text { yo } \\
\text { yight }\end{array}$ & $\begin{array}{l}\text { That's } \\
\text { rouink }\end{array}$ & Let me (lemme) & Finally \\
\hline To begin with & $\begin{array}{l}\text { Any } \\
\text { questions }\end{array}$ & Right & $\begin{array}{l}\text { I believe } \\
\text { that }\end{array}$ & $\begin{array}{l}\text { Let's try, go back, } \\
\text { find, focus... }\end{array}$ & $\begin{array}{l}\text { The last } \\
\text { thing }\end{array}$ \\
\hline The second thing & $\begin{array}{l}\text { How } \\
\text { about...? }\end{array}$ & Excellent & We believe & It says & $\begin{array}{l}\text { To end } \\
\text { up/with }\end{array}$ \\
\hline $\begin{array}{l}\text { Firstly, Secondly, } \\
\text { Thirdly }\end{array}$ & & & & $\begin{array}{l}\text { I wanna/want to } \\
\text { mention, } \\
\text { get back to, do... }\end{array}$ & \\
\hline
\end{tabular}

Regarding interaction in lectures, we had to establish the parameters to measure students' participation. The more students participate, the more interactive the lecture is believed. For this purpose we handled electronically both sub-corpora, $\mathrm{CA}$ and $\mathrm{CB}$, searching for students' interventions in the North-American and British lectures. The resulting data should establish if there is any close relationship between the use of micro and macro-markers and students' participation in lecture discourse. Eventually, we want to check if there is actually a trend towards a more interactive (participatory) style of lecturing in the North-American universities.

\section{RESULTS}

In this section, we aim at analysing the effects of students' participation in lecturing styles and the use of DMs in lectures. For this purpose we have taken into account the total number of students participating in the lectures, both in the $\mathrm{CA}$ and $\mathrm{CB}$. The more students intervene in the lecture, the more participatory the lecture can be considered.

As Table 4 below shows, the North-American corpus (CA) presents a higher number of students interventions (527), whereas the British Corpus (CB) has fewer students intervening in the lectures (249 interventions).

Comparing the number of students' interventions to the frequency rate of micro and macro-markers in the $\mathrm{CA}$ and $\mathrm{CB}$, we realise that the corpus with the highest number of students' interventions has the highest rate of micromarkers, as well as of macro-markers, that is, the North-American corpus (CA). Whereas the British lecture corpus (CB), not only shows fewer students' 
interventions but also the frequency rate of micro-and macro-markers used is lower.

Nevertheless, the most relevant difference is the one presented by the use of micro-markers in both sub-corpora. As said above, the North-American corpus (CA) seems to be more interactive than the British corpus, according to the number of students' interventions and it also shows a rate of $18.4 \%$ micromarkers, $3.7 \%$ points higher than the rate of micro-markers in Св. This difference is larger and more significant than that observed by macro-markers. Although the rate of macro-markers in CA is higher than in $\mathrm{CB}$, the span is only $0.6 \%$ higher in the CA than in the Св. The results can be observed in Table 4 below.

TABLE 4. Students' participation and DMs rate in the $C A$ and $C B$

\begin{tabular}{|l|c|c|}
\hline & CA & CB \\
\hline $\begin{array}{l}\text { Number of students' } \\
\text { interventions }\end{array}$ & 527 & 249 \\
\hline Micro-markers & $18.4 \% \%$ & $14.7 \% 00$ \\
\hline Macro-markers & $3.1 \% \%$ & $2.5 \% 00$ \\
\hline
\end{tabular}

\section{DISCUSSION AND CONCLUSION}

The purpose of the study is twofold: on the one hand, we wanted to check if as previous studies pointed out (Morell, 2000, 2001), a more participatory type of lecture uses a higher number of macro-markers than a non-interactive lecture. On the other hand, we wanted to corroborate whether the NorthAmerican style of lecturing tends to be more participatory than the European (British in this case) style of lecturing (Waggoner, 1984; Benson, 1994; Mason, 1994).

In order to measure the degree of interaction in a lecture, we took into consideration the number of students' interventions in each sub-corpus (CA and $\mathrm{CB}$ ). After the analysis of the two sub-corpora, we found that the CA showed a larger number of students' interaction, and therefore considered to a certain extent a more participatory type of lecture corpus. We observed that the $\mathrm{CA}$ also displayed a higher frequency rate of micro-markers, higher than the rate displayed in the Св (British corpus). Therefore, we could establish a link between the amount of students' interaction and the use of micro-markers, corroborating previous similar studies (Morell, 2000, 2001). The more participatory (interactive) a lecture is, the higher use of micro-markers in the 
lecture discourse.

However, the findings have shown that macro-markers were also more frequently used in the $\mathrm{CA}$, in spite of being more participatory, than in the $\mathrm{CB}$. This fact contradicts some results from previous studies (Morell, 2000, 2001). In her EFL Content Lectures: a discourse analysis of an interactive and a noninteractive style, Morell (2000: 76) found that «there is a substantial number of more macro-makers in the interactive lecture than in the non-interactive». Yet, the findings in the present study show that the CA, as the more participatory corpus, showed the highest frequency rate of both micro and macro-markers. Still, it has to be pointed out that the rate difference between $\mathrm{CA}$ and $\mathrm{CB}$ in relation to the use of macro-markers represents only $0.6 \%$, not a very relevant difference (see Table 4). Further research on this aspect should be carried out in order to confirm the higher or lower use of macro-markers related to students' participation in class. Peculiarities in both sub-corpora as well as discrepancies between the $\mathrm{CA}$ and $\mathrm{CB}$ may have led to these final figures regarding macro-markers and participation in lectures. A larger corpus would be necessary in order to generalise the above commented results.

As a conclusion, the findings derived from the present study attempted to shed some light on the spoken academic discourse field. However, it has to be mentioned that the study presents some limitations. Further research in the use of DMs comparing North-American and British lecture discourse using a larger lecture corpus seems to be necessary in order to be able to generalise the interpretations given. On the other hand, a deeper analysis of the effects of students' participation in lectures linked to the use of DMs should be carried out by means of a comparative analysis between a non-interactive and an interactive corpus, large enough to obtain reliable results.

\section{REFERENCES}

BELLÉs-FoRTUÑO, B. (2004): The spoken academic discourse of the social sciences. Discourse Markers within the university lecture genre, Unpublished MA Thesis, Castelló de la Plana, Universitat Jaume I.

Bellés-Fortuño, B. and I. Fortanet (2004): «Handouts in Conference Presentations», in Fortanet, I., J. C. Palmer and S. Posteguillo (eds.) (2004): Linguistic studies in academic and professional English, Castelló de la Plana, Publicacions de la Universitat Jaume I.

BeNSON, M. J. (1994): «Lecture listening in an ethnographic perspective», in FLOWERDEW, J. (ed.) (1994): Academic English: research perspectives, Cambridge University Press, Cambridge, 181-198.

Chaudron, C. and J. C. Richards (1986): «The effect of discourse markers 
on the comprehension of lectures», Applied Linguistics, 7/2: 113-127.

Chew, P. G. (1999): «Linguistic imperialism, globalism, and the English language», The AILA Review, 13: 37-47.

CoоK, J. R. S. (1975): A communicative approach to the analysis of extended monologue discourse and its relevance to the development of teaching materials for ESP, Unpublished M. Litt. Thesis, Edinburgh, University of Edinburgh.

Coulthard, M. and M. Montgomery (1981): «The structure of monologue», in Coulthard, M. and M. Montgomery (eds.) (1981): Studies in discourse analysis, London, Routledge and Kegan Paul, 31-39.

DeCArrico, J. and J. R. NAtTinger (1988): «Lexical phrases for the comprehension of academic lectures», English for Specific Purposes, 7: 91-102.

Dudley-Evans, A. (1994): «Variations in the discourse patterns favoured by different disciplines and their pedagogical implications», in FLOWERDEW, J. (ed.) (1994): Academic listening: research perspectives, Cambridge, Cambridge University Press, 146-158.

DudLEY-Evans, A. and T. JoHns (1981): «A team teaching approach to lecture comprehension for overseas students», in BRITISH CouncIL (ed.): The teaching of listening comprehension, ЕLT Documents Special, London, The British Council, 30-46.

Flowerdew, J. (ed.) (1994): Academic listening: research perspectives, Cambridge, Cambridge University Press.

FORTANET, I. (2005): «Honoris causa speeches: an approach to structure», Discourse Processes, 7/1: 31-51.

FREDERICK, P. J. (1986): «The lively lecture -8 variations», College Teaching, 34/2: 43-50.

GimÉNEZ, R. (2000): La repetición lingüística en el género de la clase magistral: El inglés académico oral en el ámbito de las Ciencias Sociales, Unpublished $\mathrm{PhD}$ Dissertation, València, Universitat de València.

Goffman, E. (1981): «The lecture», in GofFMan, E. (ed.) (1981): Forms of talk, Philadelphia, PA, University of Philadelphia Press, 162-195.

GRADDOL, D. (1999): «The decline of the native speaker», The AILA Review, 13: 57-68.

HILler, J. H., G. A. Fisher and W. KAESS (1969): «A computer investigation of verbal characteristics of effective classroom lecturing», American Educational Research Journal, 6: 661-675.

JoRDAN, R. R. (1989): «English for academic purposes (EAP)», Language Teaching, 22/3: 151-164. 
Mason, A. (1994): «By dint of: Student and lecturer perceptions of lecture comprehension strategies in first-term graduate study», in FlowerdEw, J. (ed.) (1994): Academic English: research perspectives, Cambridge, Cambridge University Press, 199-218.

Mauranen, A. (2001): "Reflexive Academic Talk: Observations from MICASE», in Simpson, R. C. and J. M. Swales (eds.) (2001): Corpus linguistics in North America, Ann Arbor, MI, The University of Michigan Press, 165-178.

McDonough, J. (1978): Listening to lectures, Oxford, Oxford University Press.

Morell, T. (2000): EFL Content Lectures: a discourse analysis of an interactive and a non-interactive style, Alicante, Imprenta Gamma.

- (2001): «The role of discourse markers and personal pronouns in lecture discourse», in Moreno, A. I. and V. Cowell (eds.) (2001): Perspectivas recientes sobre el discurso, León, Universidad de León (publicación en CDROM).

MORRISON, J. W. (1974): An investigation of problems in listening comprehension encountered by overseas students in the first year of postgraduate students in science at the University of Newcastle upon Tyne. Unpublished M. Ed. Thesis, Newcastle, University of Newcastle upon Tyne.

MurPhy, D. F. and C. N. CANDlin (1979): «Engineering lecture discourse and listening comprehension», Practical Papers in English Language Education, 2: 1-79.

SiMPSON, R. C. et al. (2002): MICASE (Michigan Corpus of Academic Spoken English), Ann Arbor, MI, USA.

SwAlES, J. M. (1990): Genre analysis: English in academic and research settings, Cambridge, Cambridge University Press.

Swales, J. M. and B. MALCZEWSKI (2001): «Discourse management and new episode flags in MICASE», in Simpson, R. and J. M. Swales (eds.) (2001): Corpus linguistics in North America, Ann Arbor, The University of Michigan Press, 145-164.

WAGGONER, M. (1984): «The new technologies versus the lecture tradition in higher education: is change possible?», Educational Technology, 24/3: 7-12. 


\title{
ATRIBUCIÓN CAUSAL E INTERPRETACIÓN: APLICACIONES DE LA TEORÍA DE LA COVARIANZA AL ANÁLISIS DEL DISCURSO
}

\author{
Enrique Cámara Arenas \\ Universidad de Valladolid
}

\section{ATRIBUCIÓN CAUSAL Y DISCURSO}

\begin{abstract}
Gupongamos por un instante que en el curso de una comunicación el ponente se queda sin palabras, guarda un molesto silencio mientras revuelve sus papeles desordenadamente y comienza a hablar con poca coherencia, incurriendo en toda suerte de contradicciones, interrupciones, etc. Es decir, supongamos por un instante que su contribución al congreso resulta un fracaso. Este evento -fracasar en una comunicación- podrá entenderse conforme a una multitud de recorridos interpretativos. Ante la pregunta de «ipor qué ha fracasado el ponente?», cualquier miembro del público podría dar varias respuestas. Consideremos por un momento tan solo dos posibles interpretaciones del fracaso:
\end{abstract}

Interpretación 1. El ponente se ha esforzado poco.

Interpretación 2. El ponente tiene una capacidad intelectual muy limitada.

Aquellos que optasen por la primera interpretación experimentarían probablemente una cierta indignación, que podría conducir a conductas más o menos hostiles hacia el ponente. Quienes optasen por la segunda, quizá pudieran experimentar además, o en lugar de indignación, algo de compasión, y adoptar consecuentemente una actitud paternalista hacia el investigador. Cualquier evento suele ser objeto de un sinfín de recorridos interpretativos, y dependiendo de los recorridos escogidos los eventos conducirán a unas u otras emociones, a unas u otras conductas.

La rama del saber que se interesa por el tipo de razonamientos que acabo de exponer es la denominada Psicología Social, ${ }^{1}$ cuyo objeto último consiste

1. Nuestro ejemplo es similar al que proponen Hewstone y Fincham (1996) para explicar los intereses de la Teoría de la Atribución, si bien ellos se refieren al fracaso en un examen. 
en «desarrollar teorías para explicar por qué y cómo actúa casi toda la gente la mayor parte del tiempo», así como «la forma en que la gente se ve influida por las situaciones y las relaciones sociales» (Worchel y Shebilske, 1998: 19). Dentro de la Psicología Social son los llamados teóricos de la Atribución Causal quienes se esfuerzan por diseñar modelos descriptivos de los procesos de interpretación de los eventos reales en términos de causas y efectos. Los teóricos fundamentales y fundadores de la Atribución son Heider (1958), Jones y Davis (1965), y Kelley, con su Teoría de la Covarianza (1967).

El discurso, en sí mismo «una forma de acción entre las personas» (Calsamiglia y Tusón, 1999: 15), constituye sin duda el tipo de eventos que promueve procesos de atribución causal en los oyentes. Frente a cualquier acto discursivo podemos plantearnos, y a menudo lo hacemos, toda una serie de preguntas de índole causal, cuya respuesta determinará en gran medida nuestras reacciones, actitudes y conductas. Nos preguntamos con frecuencia qué ha podido causar un discurso determinado (la contestación brusca de un amigo, por ejemplo), por qué el discurso posee tales o cuales propiedades formales, qué efecto persigue, cuál es la intención subyacente, cómo se ve afectado por el contexto concreto de enunciación, etc. Todas estas son precisamente el tipo de cuestiones que interesan al psicólogo social, si bien su interés no se circunscribe exclusivamente a la acción verbal. La afinidad que existe entre la Psicología Social y el Análisis del Discurso es tal que existe una Psicología Social Discursiva (Potter y Edwards, 2001) que emplea las técnicas propias del Análisis del Discurso con el fin de trascender lo puramente lingüístico y dilucidar cuestiones propiamente socio-psicológicas.

Dado el continuo desarrollo de la Psicología Social y los interesantes hallazgos de los teóricos de la Atribución, y dada la obvia afinidad existente entre la interpretación del discurso y los procesos de atribución de intenciones, causas y efectos, entiendo que no está de más que los lingüistas se beneficien del saber acumulado tras tantos años de Teoría de la Atribución. Y es precisamente el objetivo del presente trabajo indagar en una de las más conocidas teorías de la atribución, y plantear posibles aplicaciones al estudio de discursos de diversa índole.

\section{ACERCAMIENTOS PSICOLOGISTAS AL TEXTO LITERARIO}

En el terreno del lenguaje literario, que es el que mejor conozco, y concretamente en el ámbito de la teoría del personaje, la incorporación de una perspectiva socio-psicológica sería de gran ayuda. Sin embargo, en este terreno una poderosa tradición formalista que ha querido ver en el personaje un producto puramente estético se ha opuesto insistentemente y durante muchos años 
a cualquier forma de «psicologismo». Así, a principios del siglo pasado, el profesor A. C. Bradley fue duramente criticado por sus comentarios acerca de la complexión psicológica de personajes como Iago, de la obra Othello de Shakespeare. Con respecto al malvado personaje que consigue hundir la vida del héroe con su venenosa lengua, escribe Bradley: «This question Why? is the question about Iago» (1904: 181). Es decir, el análisis de Bradley consiste en averiguar por qué Iago se comporta como se comporta. Y esta no es otra, recordemos, que la pregunta que se hace continuamente el psicólogo social, «por qué y cómo actúa la gente la mayor parte del tiempo».

Con todo, Bradley no emplea más herramienta que su sentido común, y sin duda eso es en parte lo que dio lugar a la dura crítica que el autor recibiera más tarde de críticos como L. C. Knights (1933). Lo que sigue es un ejemplo del razonamiento de Bradley en el que el profesor de Oxford compara a dos malvados shakesperianos, Richard III y Iago, concluyendo que el segundo es más repelente que el primero; pero veamos por qué:

[Richard's] physical deformity, separating him from other men, seems to offer some excuse for his egoism. In spite of his egoism, too, he appears to us more than a mere individual, he is the representative of a family, the Fury of the House of York. Nor is he so negative as Iago: he has strong passions, he has admirations, and his conscience disturbs him (1904: 169).

Ciertas circunstancias que rodean al rey Richard sirven de atenuantes, lo que quiere decir que, en lugar de echarle toda la culpa al tirano, parte de sus malvadas acciones pueden achacarse a presiones externas, como su aislamiento por causa de la deformidad física, o su papel de representante de los intereses de una familia notable. En cualquier caso, Bradley practica aquí psicología social en toda regla, si bien no fundamenta sus argumentos en premisas de validez empíricamente comprobada, como harán más tarde los psicólogos sociales. El mismo párrafo que hemos citado podría reescribirse empleando los términos y conceptos de las teorías de la Atribución. Así, Jones y Davis podrían decir que en la medida en que los actos de Richard no son libremente escogidos, estos pierden su poder caracterizador (Jones y Davis, 1965: 223).

Años más tarde, Pfister en su obra Theory and Analysis of Drama (1977) sugiere, al tratar el tema de la caracterización, la idoneidad de incorporar al estudio de la caracterización los descubrimientos de la sociología y la psicología, y menciona a Goffman (1959) y a Watzlawick (1967). Pero al igual que Bradley, Pfister solo emplea su sentido común. Si bien, en ocasiones el estudioso alemán produce párrafos cargados de psicología lega:

A strong tendency towards monological speech can indicate egocentricity. The frequent interruption or cutting short of the speeches of the dialogue partner may 
reflect impatience or desire to dominate, and frequent use of maxims or abstract analysis of the situation often reflects dispassionate rationality (1977: 126).

The tendency to deceive or the ability to adapt one's own verbal characteristics to those of the dialogue partner and/or the situation (partner tactics) are also part of the broad tapestry of characteristic verbal behaviour (1977: 126).

En las dos citas, las reflexiones de Pfister son de orden socio-psicológico en tanto que en todos ellos una determinada conducta, en este caso verbal, se percibe como causada por un determinado rasgo psicológico.

Muchos años después de la publicación del citado trabajo de Pfister, Culpeper (2001) publica el que probablemente sea el más completo y ambicioso estudio de la caracterización por medio del lenguaje; y el autor no duda en incorporar a sus rutinas de análisis los conceptos de la Teoría de la Inferencia Correspondiente de Jones y Davis (1965), y de la Teoría de la Covarianza de Kelley (1967). Sin embargo, cuando lleva sus reflexiones teóricas al análisis de un discurso concreto (2001: 263-86), el papel que desempeñan estas teorías es poco o nada importante.

\section{LA TEORÍA DE LA COVARIANZA DE KELLEY (TC)}

La TC gira en torno a seis conceptos básicos: distintividad, consistencia, consenso, sujeto, circunstancias y estímulos. El presupuesto fundamental de esta teoría es que toda respuesta de un sujeto frente a un estímulo tiene su causa en uno de los siguientes factores:

1) Las propiedades del estímulo, de tal suerte que estas son suficientes para explicar la respuesta del sujeto: ej. un chiste bueno justifica por sí mismo la risa del sujeto $\rightarrow$ se ríe porque el chiste es bueno.

2) Las CIRCUNSTANCIAS en las que se halla el sujeto, en la medida en que estas permiten justificar la respuesta del sujeto al estímulo: ej. un chiste nada gracioso no justifica la risa, pero si quien lo cuenta es el jefe esto puede constituir la causa de la risa del subordinado $\rightarrow$ se ríe porque es el jefe quien cuenta el chiste.

3) La PERSONALIDAD del sujeto puede igualmente interpretarse como la causa de la respuesta del sujeto al estímulo: ej. un chiste nada gracioso puede hacer reír a alguien que tiene la risa muy fácil $\rightarrow$ se ríe porque a él todo le hace gracia.

Así, volviendo a un ejemplo anterior, la diferencia entre Richard III y Iago de acuerdo con Bradley (1904) es que las acciones de Richard pueden atribuirse causalmente a sus circunstancias, mientras que en el caso de Iago no parece quedar otro remedio que atribuírselas a su malévola personalidad. 
Para llegar a la conclusión de que las causas de un determinado evento, acción, discurso, declaración, etc. se encuentran en un estímulo, en las circunstancias del sujeto observado (o el sujeto enunciador), o en su personalidad, un observador realiza, de acuerdo con la teoría de Kelley (1967), un análisis de covarianza cuyas variables son la distintividad, la consistencia y el consenso.

La DISTINTIVIDAD tiene que ver con la especificidad de la respuesta con respecto al estímulo. Si el sujeto responde del modo R solamente ante el estímulo E y no ante otros estímulos, entonces la distintividad de su respuesta es alta. Si, por el contrario, el sujeto produce la respuesta $\mathrm{R}$ ante una gran diversidad de estímulos $\left(\mathrm{E}^{1}, \mathrm{E}^{2}, \mathrm{E}^{3}\right.$, etc.), la distintividad es baja. Así, la risa del individuo de risa fácil, que se ríe con cualquier chiste, posee una distintividad típicamente baja.

La CONSISTENCIA tiene que ver con la especificidad de la respuesta con respecto a las circunstancias. Si el sujeto responde del modo $\mathrm{R}$ ante el estímulo E en todo tiempo y lugar $\left(\mathrm{C}^{1}, \mathrm{C}^{2}, \mathrm{C}^{3}\right.$, etc. $)$, entonces la consistencia es alta. Pero si el sujeto produce la respuesta $\mathrm{R}$ ante el estímulo $\mathrm{E}$, en una ocasión concreta $\mathrm{C}$, y nunca antes ni después, entonces la consistencia de la risa es baja. Así, una película que jamás le hizo reír, hoy, «dadas las circunstancias» le parece muy graciosa, y todo ello constituye un evento de baja consistencia.

El CONSENSO tiene que ver con la especificidad de la respuesta con respecto al sujeto. Si el sujeto $\mathrm{S}$ es el único que responde del modo $\mathrm{R}$ ante el estímulo $\mathrm{E}$, entonces el consenso es bajo. Pero si todos los sujetos reaccionan exactamente igual ante el mismo estímulo, entonces el consenso es alto. Si todos los presentes $\left(\mathrm{S}^{1}, \mathrm{~S}^{2}, \mathrm{~S}^{3}\right.$, etc.) ríen por igual ante el mismo chiste, entonces el consenso es típicamente alto.

El análisis de un evento al que se quiera buscar causa, por ejemplo, un suspenso en un examen, se realiza conforme a las siguientes interrogantes:

1) Valoración de distintividad: ¿suele tener éxito en sus empresas, en la resolución de problemas?

2) Valoración de consistencia: ¿suspendía cuando sus circunstancias eran otras?

3) Valoración de consenso: ¿ha suspendido solo el sujeto? ¿han suspendido todos?

A cada una de estas preguntas el analista responde asignando el valor alto/a [ $\uparrow]$ o bajo/a $[\downarrow]$. Si el observador concluye que la distintividad es baja, la consistencia alta, y el consenso bajo, entonces la causa del suspenso está en el sujeto:

$[\uparrow \downarrow \uparrow]$ ATRIBUCIÓN AL SUJETO: el sujeto es inepto, perezoso, limitado, etc.

1. El sujeto suele fracasar en sus empresas, resolución de problemas, etc. 
2. El sujeto ha suspendido exámenes de este tipo también cuando sus circunstancias eran distintas.

3. El sujeto es el único que ha suspendido.

Si el observador decide que la distintividad es alta, la consistencia baja, y el consenso bajo, tenderá a concluir que la causa del suspenso está en las circunstancias:

$[\uparrow \downarrow \downarrow]$ ATRIBUCIÓN A LAS CIRCUNSTANCIAS: el sujeto ha tenido problemas, etc.

1. El sujeto no suele fracasar en sus empresas, resolución de problemas, etc.

2. El sujeto no ha suspendido un examen de este tipo cuando sus circunstancias eran distintas.

3. El sujeto es el único que ha suspendido.

Si el observador percibe que la distintividad, la consistencia y el consenso son altos, tenderá a concluir que la causa del suspenso está en el estímulo:

[ $\uparrow \uparrow]$ ATRIBUCión al estímulo: el examen era demasiado difícil, no se ajustaba al curso, etc.

1. El sujeto no suele fracasar en sus empresas, resolución de problemas, etc.

2. El sujeto ha suspendido exámenes de este tipo también cuando sus circunstancias eran distintas.

3. Los demás también han suspendido.

Hasta aquí nuestro resumen de la Teoría de la Covarianza de Kelley (1967). Ahora debemos plantearnos de qué modo estas intuiciones pueden resultarnos útiles a la hora de interpretar discursos.

\section{PROPUESTA DE APLICACIÓN}

\subsection{Tres tipos de aspectos significantes: de estímulo, circunstanciales y personales}

En principio la TC y el resto de las teorías de la atribución pueden guiar al analista a la hora de determinar qué aspectos sintácticos, semánticos o pragmáticos del discurso analizado pueden estar motivados por la presencia de un estímulo concreto. El argumento por el cual un determinado aspecto del discurso se vincula al estímulo se basa en la suposición de que la mayoría de los sujetos enunciadores en la mayoría de las circunstancias incorporarían a su 
discurso el mismo aspecto, y en la suposición de que no se trata de un aspecto característico de todos los discursos del sujeto en cuestión. Así, las declaraciones oficiales de todos los políticos y personajes públicos en los días siguientes al atentado del 11-S mostrarían un conjunto de aspectos idénticos, todos los cuales se podrían justificar a partir del estímulo.

El argumento por el cual un aspecto del discurso tiende a vincularse a las circunstancias se basa en la suposición de que ese determinado aspecto no se halla en la mayoría de los discursos conocidos del mismo enunciador, ni en la mayoría de los discursos de otros enunciadores, ni se repite en discursos posteriores. Así, en el estilo de ciertos escritores de determinadas épocas puede detectarse en ocasiones la huella de otros escritores recientemente leídos. El escritor imitado se convierte en una influencia exterior transitoria y por tanto circunstancial.

$\mathrm{El}$ argumento por el cual un determinado aspecto del discurso se vincula a la personalidad del sujeto enunciador se basa en la suposición de que ese aspecto se hace patente en la mayoría de los discursos conocidos del mismo enunciador, se mantiene consistentemente en diversos momentos y lugares, y es además un aspecto del que carecen la mayoría de los discursos de otros autores. Este sería el caso del genuino rasgo de estilo distintivo de un autor, que según la Teoría de la Atribución tenderíamos a convertir en la manifestación verbal a cualquier nivel de un aspecto permanente de la personalidad. La conocida licencia poética juanramoniana, por la cual toda $\langle\mathrm{g}>$ con sonido $/ \xi /$ se escribe con la letra $<j>$ (p. ej. jitana), constituye un ejemplo típico de rasgo de estilo genuino.

\subsection{La TC y los rasgos estilísticos}

Uno de los campos en los que la Teoría de la Covarianza puede resultar de gran utilidad es el del estudio de los «rasgos de estilo» característicos de ciertos escritores, ensayistas, políticos, creadores de publicidad. La TC no ofrece nada que no esté al alcance del sentido común -si lo hiciera inspiraría, en mi opinión, poca confianza como método de análisis. Pero tiene la virtud de ofrecernos un método de razonamiento por el que el analista podrá argumentar a favor de una u otra interpretación de determinados aspectos sobresalientes.

Todo aspecto llamativo o relativamente llamativo de un discurso puede ser descrito en términos de sintaxis, semántica o pragmática, pero la dinámica argumentativa de la TC permite además conferir cierta significación a cada uno de esos aspectos. Los tres tipos de aspectos significantes que hemos detectado en el epígrafe anterior se vienen a corresponder con lo que podríamos denominar tres tipos de rasgos estilísticos: 1) los rasgos que entendemos causados por el estímulo; 2) aquellos que entendemos causados por las circunstancias, 
y 3) los que entendemos causados por la personalidad del sujeto. Esta clasificación es de rango superior a cualquier clasificación meramente descriptiva, y pudiera perfectamente darse el caso de que rasgos formalmente equivalentes, o incluso idénticos, se interpretasen de distinto modo en distintos autores y distintas épocas. Así, el creador de un estilo personal presenta una serie de rasgos formales que en su caso se vinculan a su personalidad, pero en el caso de sus imitadores constituyen influencias circunstanciales que no indican nada, o no indican lo mismo, acerca de sus personalidades.

A los rasgos estilísticos vinculados al estímulo los denominaré rasgos TEMÁTICOS - por razones que enseguida quedarán claras; a los rasgos vinculados a las circunstancias los llamaré sencillamente CIRCUNSTANCIALES, y a los vinculados a la personalidad del sujeto enunciador los denominaré rasgos ESTILísTICOS PUROS.

\subsection{El tema como estímulo}

La aplicación de la TC al análisis del discurso plantea algunas dificultades. La TC funciona bien con ciertos casos típicos «de laboratorio» en los que nos encontramos con un sujeto (S) que reacciona (R) frente a un estímulo (E). Las tres variables están presentes: sujeto, reacción y estímulo. Sin embargo, cuando nos encontramos con un discurso, la existencia del sujeto enunciador y del estímulo son con frecuencia hipotéticas, y ninguno de los dos tiene por qué hallarse presente ni ser inmediatamente identificables. En muchos casos si opto por entender un poema, un relato, o la declaración de un político, como una respuesta a un estímulo concreto, soy yo como intérprete quien ha de proponer a manera de hipótesis cuál pudiera ser dicho estímulo. Ciertos géneros líricos, como la elegía o el panegírico, suelen hacer explícito el estímulo inicial, y lo mismo ocurre con ciertas declaraciones políticas. Aquí los rasgos temáticos se convierten en elementos definitorios de un género. Sin embargo, en muchos discursos la ausencia de un estímulo con respecto al cual entender la acción verbal como respuesta puede resultar un obstáculo importante.

Con todo, lo que tradicionalmente suele denominarse el tema de una composición podría quizá cumplir la función del estímulo. De ahí que en la medida en que los aspectos sintácticos, semánticos y pragmáticos se adapten convencionalmente a un tema, por ejemplo al tema de la muerte, el discurso deja de ser informativo con respecto a la personalidad del enunciador o de sus circunstancias. Por otro lado, un tratamiento poco consensuado del tema -piénsese en aquel «muero porque no muero» de San Juan de la Cruz- nos invita a indagar acerca de la personalidad del enunciador o de sus circunstancias. 


\subsection{El Análisis covariable de la evaluación}

Como ya hemos dicho, Culpeper (2001), en su estudio de la caracterización por medio del lenguaje, apenas hace un uso real de las teorías de la atribución, ni de la TC. En mi opinión, esto es así por dos motivos fundamentales. En primer lugar, porque los conceptos básicos de esta teoría deben adaptarse al ámbito del discurso, como yo he sugerido al igualar, por ejemplo, el tema al estímulo, o la atribución de sujeto al rasgo de estilo puro. Pero además, Culpeper (2001) solo considera relevantes aquellas conductas que él denomina reacciones. Como ya hemos visto, aunque estemos de acuerdo con que todo discurso es una acción verbal, decir que todo discurso es una reacción verbal solo aporta confusión.

Pueden existir acciones sumamente significativas en términos de atribución que no siempre se entienden como reacciones a un estímulo. Si el ponente con el que iniciamos nuestra presentación hubiera dado su charla con un sombrero de torero en la cabeza, semejante conducta estaría sin duda poco consensuada: la mayoría de la gente no presenta comunicaciones con un atuendo así. Un evento tan extravagante como el descrito lanzaría a los presentes con toda probabilidad a preguntarse por las causas del mismo. Conforme a la TC, una vez constatado el bajo consenso, las causas solo pueden ser dos: las circunstancias -ej. el sujeto está borracho, o ha perdido una apuesta, etc.- o la personalidad del sujeto -el sujeto es así, un rebelde, un loco, un extravagante narcisista, etc.

Noten que hemos operado de acuerdo con las directrices de la TC a partir de lo que yo denomino una ANOMALÍA CONSENSUAL, y sin que hayamos localizado un estímulo propiamente dicho. Lo que hemos localizado es un sujeto, un objeto -el sombrero de torero- y una peculiar MODALIDAD DE RELACIÓN entre ambos: vestir sombrero de torero en una comunicación.

Por medio del discurso, el sujeto enunciador como conciencia central del discurso se vincula conforme a ciertas modalidades de relación con todos los referentes aludidos, así como con todos los aspectos sintácticos, semánticos y pragmáticos del discurso. Una expresión del tipo «el temible cáncer» establece una modalidad de relación entre el sujeto enunciador y «el cáncer» que se puede considerar altamente consensuada: la mayoría de la gente teme esta enfermedad. Esta expresión resulta poco informativa con respecto al sujeto o sus circunstancias, y estilísticamente pobre. Sin embargo, expresiones del tipo «el ansiado cáncer»o «la dulce puñalada» resultan considerablemente menos consensuadas, y por lo tanto más propicias a dirigir nuestra atención al sujeto o a sus circunstancias.

En otras palabras, la TC en combinación con el estudio de los procesos de evaluación ${ }^{2}$ en el discurso puede constituir la base de un método de análisis y explicación de las propiedades estilísticas de cualquier tipo de discurso.

2. Uno de los trabajos más interesantes que conozco acerca del análisis de la evaluación es el de Susan Hunston y Geoff Thompson (2000). 


\subsection{La TC y la dimensión meta-metodológica}

Por último, quisiera apuntar que un objeto óptimo de investigación mediante los principios fundamentales de la TC seríamos nosotros mismos como analistas e intérpretes -e incluso como investigadores-, ya que el discurso es un estímulo ante el que reaccionamos interpretando de un modo u otro. Aquí la TC se muestra como una guía de introspección y autocrítica; invitándonos a considerar que nuestra interpretación puede verse afectada por nuestras circunstancias o por nuestra personalidad. Así, por ejemplo, puede ser que durante un tiempo un analista cualquiera insista en interpretar todos los poemas con los que tropieza como ilustraciones del esfuerzo del alma por lograr la disolución del «ego», al estar dicho analista bajo la influencia de algún tipo de literatura espiritual de corte oriental. O pudiera ser que este empecinamiento interpretativo perdurase en el tiempo, consistiendo así en un rasgo típico de una personalidad, supongamos, tendente al misticismo.

La prueba de la objetividad pudiera describirse vectorialmente como [ $\uparrow 0]$, es decir, mediante la alta distintividad de la respuesta, y su alta consistencia. En el terreno de la investigación, el hallazgo se caracteriza necesariamente por un enunciado objetivo y de bajo consenso: $[\uparrow \uparrow \downarrow]$; una situación que no acaba de coincidir con la típica atribución al estímulo [ $\uparrow \uparrow \uparrow]$. En el contexto del análisis e interpretación de textos estaríamos hablando del caso en el que un analista proporciona una interpretación novedosa y nada consensuada de un texto; pero que alcanza consistentemente los mismos resultados -aplicando, por ejemplo, métodos distintos, en momentos distintos; tratándose además de una interpretación no generalizable, sino aplicable exclusiva y distintivamente al texto concreto. En su búsqueda de la verdad, ni el investigador ni el intérprete debieran buscar el consenso, sino la distintividad y la consistencia, las cuales garantizan la especificidad del hallazgo, por un lado, y la solidez del argumento. Por lo demás, toda demostración de distintividad y consistencia constituye en sí misma un recurso retórico encaminado a promover el consenso o, dicho de otro modo, a persuadir. Los métodos interpretativos más convincentes nos convencen de la distintividad -interpretación no generalizable y solo válida para el texto concreto- y de la consistencia -resultados probados y contrastados por distintas vías- de una determinada lectura.

El recurso de acudir al consenso de las autoridades para argumentar a favor de una determinada interpretación constituye otro recurso de persuasión, si bien se trata de un recurso un tanto maquiavélico, especialmente cuando acudir a las autoridades exime de la responsabilidad de revisar la distintividad y la consistencia de una interpretación, y al mismo tiempo inhibe cualquier posibilidad de hallazgo - este es el escollo clásico con el que acaba tropezando tarde o temprano la tesis de muchos doctorandos. 
Al hilo de estas reflexiones, y para finalizar, quisiera apuntar que la TC sugiere dos tipos de subgéneros del trabajo investigador y de análisis de interpretación. El primero sería el del hallazgo, que requiere un bajo consenso como requisito indispensable. El segundo sería el de reforzamiento, que consiste en promover una tesis ya consensuada mediante la elaboración de argumentos alternativos. El tercero sería el de la profundización, que consistiría en aumentar la capacidad discriminatoria y aplicativa de una teoría ya consensuada. El aquí presentado es un trabajo perteneciente a este tercer subgénero.

Concluimos ya nuestras reflexiones, considerando satisfecho nuestro objetivo inicial de presentar la Teoría de la Covarianza de Kelley (1967) como un sistema capaz de clarificar importantes aspectos metodológicos y meta-metodológicos en el terreno de la interpretación. Esta teoría se centra en aspectos fundamentales de la cognición humana, de ahí que sus posibles aplicaciones parecen poder multiplicarse de forma sorprendente.

\section{REFERENCIAS BIBLIOGRÁFICAS}

Bradley, A. C. (1904): Shakespearean Tragedy: Lectures on Hamlet, Othello, King Lear, Macbeth, Londres, Macmillan.

Calsamiglia, H. y A. Tusón (1999): Las cosas del decir: Manual de análisis del discurso, Barcelona, Ariel.

CulPePER, J. (2001): Language \& Characterization: People in Plays \& Other Texts, Londres, Longman.

GofFMAn, E. (1959): La presentación de la persona en la vida cotidiana, Buenos Aires, Amorrortu.

HEIDER, F. (1958): The psychology of interpersonal relations, Nueva York, Wiley. Hewstone, M. y F. Fincham (1996): «Attribution Theory and Research: Basic Issues and Applications», en Hewstone, M., W. Stroebe y G. M. StePheson (eds.) (1996): Introduction to Social Psychology: A European Perspective, Oxford, Blackwells Publishers, 167-204.

Hunston, S. y G. Thompson (2000): Evaluation in Text: Authorial Stance and the Construction of Discourse, Oxford, Oxford University Press.

Jones, E. E. y K. E. DAvis (1965): «From Acts to Dispositions: The Attribution Process in Person Perception», en L. BERKOwITZ (ed.) (1965): Advances in Experimental Social Psychology, Nueva York, Academic Press, 219-266.

Kelley, H. H. (1967): «Attribution Theory in Social Psychology», en D. Levine (ed.) (1967): Nebraska Symposium on Motivation, Lincoln, University of Nebraska Press, 192-238.

KNIGHTS, L. C. (1933): Explorations: Essays in Criticism Mainly on the Literature of the Seventeenth Century, Londres, Chatto \& Windus. 
Pfister, M. (1977): The Theory and Analysis of Drama, Cambridge, Cambridge University Press.

PotTer, J. y D. Edwards (2001): «Discursive Social Psychology», en Robinson, P. E. y H. GiLes (eds.) (2001): The New Handbook of Language and Social Psychology, Nueva York, Wiley.

WatzlaWick, P., J. B. BAVELAS y D. D. JACKSON (1967): Teoría de la comunicación humana, Barcelona, Herder.

WorChel, S. y W. SHEBILSKe (1998): Psicología: Fundamentos y Aplicaciones, Madrid, Prentice Hall. 


\title{
DEL ENUNCIADO A LA ENUNCIACIÓN: LA REPRESENTACIÓN DE LOS ASPECTOS NO VERBALES DEL DISCURSO EN LA INTERACCIÓN ORAL
}

\author{
Laura Camargo Fernández \\ Universitat de les Illes Balears
}

\section{INTRODUCCIÓN}

$\mathbf{E}$ L trabajo que aquí presentamos tiene como principales objetivos explicar las peculiaridades de las citas de paralenguaje y gestos en el contexto de la interacción oral y presentar un avance de resultados procedente del estudio pragmático-cuantitativo de las citas no verbales encontradas en dos corpus de datos. El primero de estos corpus está formado por las grabaciones de las entrevistas semidirigidas realizadas en la ciudad de Cuenca para el ALeCMan ${ }^{1}$ y el segundo -que hemos denominado Corpus Espontáneo (CE)- lo componen diversas conversaciones recogidas por nosotros con grabadora oculta en situaciones de alta informalidad.

Las citas no verbales han sido tradicionalmente desatendidas en los estudios sobre la reflexividad lingüística, con la excepción de los trabajos realizados por Clark y Gerrig (1990) y Richard Cameron (1998), en los que se atiende a las citas que representan aspectos quinésicos y paralingüísticos del discurso. A pesar de la escasez de estudios sobre la materia, al analizar las manifestaciones de la reflexividad en el uso corriente del lenguaje llaman la atención dos circunstancias: 1) que en la interacción oral no es infrecuente que la representación de elementos no verbales acompañe a las diversas formas de representación del discurso, sumando así a la «estratificación de voces» o layering of voices (Günthner, 1999) una estratificación de rasgos paralingüísticos y quinésicos; y 2) que la aparición de estas unidades parece estar fuertemente condicionada por la situación comunicativa.

El marco teórico elegido para este estudio es la pragmática, pues las manifestaciones de la reflexividad lingüística, en general, y las citas, en particular, implican muchas de las principales preocupaciones de esta perspectiva, como

1. Atlas Lingüístico (y etnográfico) de Castilla-La Mancha. Dirigido por Pilar García Mouton y Francisco Moreno Fernández. Universidad de Alcalá. <http://www.uah.es/otrosweb/alecman>. 
son la producción e interpretación de actos comunicativos intencionales en contextos concretos, construidos desde el particular punto de vista del hablante. Citando las oportunas palabras de Reyes (2002: 46), que podemos aplicar al caso que nos ocupa: «[...] cualquier enunciado que, fuera de su uso, sea un sinsentido puede adquirir sentido en el contexto adecuado. No hay asteriscos en pragmática». En efecto, los acercamientos exclusivamente sintácticos al estudio de las citas han sido incapaces de dar cuenta de la complejidad del fenómeno por la sencilla razón de que toda cita acontece en el plano del discurso -entendido como un continuo verbal-paralingüístico-quinésico-, no de la oración (Reyes, 1994; Camargo, 2004 b). De hecho, las características que nos permiten distinguir diferentes tipos de citas se encuentran en el nivel textual más que en el sintáctico, pues incluso la orientación deíctica que diferencia el estilo directo del indirecto solo puede determinarse en el contexto más amplio del discurso. Asimismo, fenómenos reflexivos de naturaleza no verbal como los que se verán aquí dependen fuertemente del contexto conversacional inmediato y trascienden con claridad los límites oracionales. En cuanto a las técnicas de análisis, y dadas las posibilidades que ofrece para la cuantificación en relación con variables sociales y situacionales, recurriremos también a las herramientas propias de la sociolingüística.

\section{LA REFLEXIVIDAD LINGÜÍSTICA}

La capacidad reflexiva del lenguaje humano hace factible que los signos lingüísticos sean, a la vez, sujetos y objetos del discurso. Dicha capacidad de describirse a sí mismas es lo que más separa a las lenguas naturales de otros sistemas semióticos y gracias a ella el lenguaje puede volver sobre sí para describir, evocar, repetir, mejorar, matizar, criticar o negar lo dicho o lo pensado. Esta propiedad por la cual el lenguaje sirve para referirse al lenguaje mismo no existe en la comunicación animal y su manifestación completa es exclusiva del lenguaje humano (Lucy, 1993; Authier, 1995).

La actividad reflexiva ocupa gran parte de la materia de la que se componen nuestros discursos y gracias a ella podemos, entre otras cosas, citar pensamientos, enunciados o diálogos completos, acompañándolos de elementos no verbales que se dan de forma simultánea a nuestros discursos: el paralenguaje y los gestos. En efecto, citamos mucho más de lo que, a simple vista, podría parecer, y a menudo lo hacemos acompañando las representaciones verbales de elementos de naturaleza no verbal. Nuestros discursos cotidianos se componen, en gran medida, de lo que hemos oído decir, de lo que contamos que nos han dicho, de lo que nosotros mismos dijimos y de lo que podríamos decir; en definitiva, de instancias reflexivas en las que se habla sobre lo que se dice o puede decirse. 
Esta circunstancia nos lleva a concluir con Reyes (1993: 9) que lo realmente raro es encontrar textos sin alguna manifestación de dicha actividad reflexiva. ${ }^{2}$ Las formas de representación del discurso ${ }^{3}$ en las que nos centraremos son las que acontecen en el ámbito de la conversación, en donde -de acuerdo con los resultados de nuestros trabajos (Camargo, 2001 y $2004 a$ ) y confirmando las percepciones manifestadas por varios estudiosos de la conversación y del discurso oral (Tannen, 1989; Reyes, 1993 y 2002; Cameron, 1998; Briz, 1998)- las citas que aparecen son, esencialmente, directas.

Desde nuestro punto de vista, a la hora de estudiar cualquier tipo de cita, debe retomarse la idea aristotélica de que toda reproducción presupone un proceso productivo interno y es, por ello, más que la repetición de unos elementos dados. Como sagazmente han planteado Fludernik (1993: 17) y otras autoras (Tannen, 1989; Reyes, 1993), la representación del lenguaje por medio del lenguaje no suele ser ni completa ni literal, sino que es la reproducción de un tipo de discurso que se materializa en la utilización de un conjunto de formas más o menos estables y repetidas. Las limitaciones de la memoria y la utilización de expresiones vagas que nunca fueron utilizadas por la persona citada, las citas que expresan estados de ánimo o que sintetizan textos más largos, las autocorrecciones, los relanzamientos y la recurrencia a una serie de fórmulas fijas y típicas -entre otros factores- apuntan en la dirección de que lo que se reproduce es la idealización de una forma, más que la sustancia de una expresión concreta. De este modo, consideramos que toda cita es meramente un icono -en el sentido de Peirce (1932)-, una evocación, una tipificación, nunca una reproducción exacta. Esto es así porque, por un lado, se produce un desplazamiento contextual del discurso que conlleva, cuanto menos, la pérdida o la distorsión de idiosincrasias vocales y rasgos entonativos, y porque, por otro, al citar siempre seleccionamos dónde y en qué partes

2. La importancia de la reflexividad lingüística ha tenido eco en la comunidad lingüística internacional y ha propiciado, además de la proliferación de numerosos estudios sobre el tema, la creación del Groupe International et Interdisciplinaire d'Étude du Discours Rapporté, también llamado «Grupo Ci-Dit». Véase más información sobre este grupo y sobre bibliografía especializada en la página electrónica $<$ http://www.ci-dit.org $>$.

3. Preferimos el término representación del discurso en lugar de reproducción del discurso porque este puede dar lugar a error al sugerir versiones idénticas entre sí y no solo similares. Esta denominación es utilizada tanto por Reyes (1993 y 2002), quien sigue en lo esencial lo establecido por Fludernik (1993) en su magistral trabajo sobre la representación lingüística del habla y la conciencia, como por Authier (1995), otra de las voces más destacadas de los estudios sobre la reflexividad del lenguaje. Los términos representación y metarrepresentación son centrales también en los trabajos desarrollados en los últimos años dentro de la Teoría de la Relevancia. Las metarrepresentaciones son representaciones construidas sobre otra representación, sea esta pública, privada o abstracta ( $c f$. Wilson, 2000). Las citas son, por tanto, casos de metarrepresentación. 
de la reproducción ponemos el énfasis, emitiendo simultáneamente nuestro juicio y evaluación sobre las palabras citadas. La idea sobre las formas de representación del discurso que sostenemos es, en síntesis, opuesta a la desplegada en los estudios de narratología y en la tradición gramatical, en donde la cita directa se presenta como una reproducción verbatim de palabras pronunciadas y la cita indirecta como la transmisión de lo dicho desde el punto de vista del hablante. De este modo, se plantea una tesis antimimética sobre las formas de representación del discurso que resulta especialmente válida para el tipo de material oral, espontáneo y coloquial con el que trabajamos. ${ }^{4}$

\section{LAS CITAS EN LA CONVERSACIÓN}

Los resultados de nuestros análisis sobre las citas de dos grandes corpus revelan que las citas directas representan un porcentaje muy alto del total de las formas de representación del discurso que aparecen en la interacción oral. Son varios los autores que han insistido en la conveniencia de estudiar el habla como un modo de acción. De acuerdo con Mey (1993: 123), para estudiar el habla desde esta perspectiva es necesario dejar de observar unidades abstractas, como los speech acts, y prestar mayor atención a los acts of speech, pasando del estudio del enunciado al estudio de la enunciación. Al empezar a analizar las formas de representación del discurso en su uso real dentro de entrevistas y conversaciones (Camargo, $2004 a$ ), entendimos tempranamente la necesidad de tomar en consideración aspectos hasta entonces desatendidos dentro de los estudios sobre citas en español. Con la salvedad del trabajo de Cameron (1998) sobre los marcos de las citas directas -lingüísticas y no lingüísticas- dentro de un corpus de narraciones orales recogido en San Juan de Puerto Rico, es mínima la atención que se ha prestado en los estudios sobre la reflexividad lingüística a los elementos de los sistemas paralingüístico y quinésico. Dichos elementos constituyen, junto al habla, lo que Poyatos (1994: 130) ha denominado la «triple estructura básica de la comunicación». Consideramos con Cestero (2000: 43) que existe una estrecha relación entre actividades verbales y no verbales, y que dicha relación es manejada hábilmente por los participantes en cada conversación. Sien-

4. De nuestros dos conjuntos de datos, consideramos que hay habla espontánea en todo el Corpus Espontáneo y en algunas de las entrevistas del ALeCMan, especialmente en las de formalidad media y mínima. Entendemos que las formas del registro coloquial se dan, casi de manera exclusiva, en el corpus de conversaciones espontáneas. Briz (1996: 26-29) define el español coloquial como un registro, un nivel de habla, un uso determinado por la situación y las circunstancias de la comunicación, que es socialmente aceptado en situaciones cotidianas de comunicación y no vinculado a un nivel de lengua determinado, sino a las características de los usuarios. 
do así, y al igual que podemos volver reflexivamente sobre el discurso, podemos hacerlo con los elementos no verbales que lo acompañan.

El célebre artículo de Clark y Gerrig (1990) sobre las citas directas en la conversación constituye, por esta razón, un punto de partida teórico inexcusable para el análisis que presentamos. Al igual que había hecho tempranamente Goffman (1974) y entroncando con las ideas de Sperber y Wilson (1995) -quienes ya habían explicado que todo fenómeno natural o artificial puede utilizarse como representación de otro fenómeno con el que guarde parecido, avalando así la existencia de representaciones no lingüísticas-, estos autores incluyen la posibilidad de que el contenido de la cita sea una acción no verbal. De acuerdo con Clark y Gerrig (1990), las acciones pueden ser una onomatopeya, un ruido, un gesto, o una expresión sin contenido proposicional. Uno de los puntos más interesantes de su artículo es la explicación sobre las citas de aspectos no lingüísticos. Según afirman sus autores, «it is generally misleading to speak of internal structure of quotations as only linguistic [...] but many quotations depict noises, gestures, or other things with no linguistic structure at all» (Clark y Gerrig, 1990: 772). Clark y Gerrig (1990: 767) defienden la tesis de que las citas directas son un tipo de «demostración», es decir, elementos que ilustran algo mediante la ejemplificación y en donde los referentes no se describen, sino que se muestran a modo de ejemplos. Esto se traduce en una representación selectiva de los referentes de la acción que demuestran por parte de los hablantes, lo cual sitúa a quien construye las citas directas en una posición ventajosa, dado que la selección sobre las acciones que se van a representar depende, exclusivamente, de la intención de quien construye la cita. Cuando conversamos usamos las citas directas para traer ante los ojos de nuestro auditorio desde las palabras, el tono y el timbre de la voz de alguien, hasta su dialecto, su indignación, su duda, pasando por sus gestos faciales, el movimiento de las manos y los brazos, la postura que adoptó al responder o sus maneras de caminar. Lo que elijamos representar del conjunto de aspectos verbales y no verbales posibles depende de la experiencia que queramos que nuestro interlocutor tenga de las acciones demostradas. ${ }^{5}$ De acuerdo con Clark y Gerrig (1990: 775-789), estos son los distintos aspectos que pueden aparecer bajo la forma de cita directa dentro de la conversación. ${ }^{6}$

1. Peculiaridades físicas del modo de producción: timbre de voz (masculino, femenino, de niño), edad de la voz (de un adulto, de una chica, de un

5. En otro lugar, hemos estudiado la relación entre los materiales representados en las citas directas y la construcción y refuerzo de la imagen positiva de los hablantes ( $c f$. Camargo, 2006).

6. Presentamos un resumen adaptado del original en inglés de Clark y Gerrig (1990). 
viejo), cualidades de la voz (áspera, nasal), rasgos característicos de la forma de hablar (ceceo, tartamudeo), estado emocional (ira, sarcasmo, excitación), gestos que acompañan al acto de habla (señalar, sonreír, fruncir el ceño).

2. Lengua: la lengua propiamente dicha (inglés, español, japonés), el dialecto (inglés de Boston, español de Bogotá), un registro (formal, informal).

3. Actos lingüísticos: acto ilocutivo (interrogación, petición, promesa), contenido proposicional (la proposición expresada), acto locutivo (la oración), acto de la enunciación (enunciado emitido con dudas, con miedo, etc.).

4. Citas sin contenido proposicional: incluye expresiones como «esto y lo otro», «no sé qué», «tal y cual», que se dan frecuentemente dentro de las citas directas orales.

5. Citas no lingüísticas: citas de gestos, de paralenguaje, de movimientos, etc. Este tipo de demostraciones no son, normalmente, entendidas como parte del discurso, pero la teoría de Clark y Gerrig (1990) defiende que se puede citar cualquier cosa que se pueda demostrar, por lo que también estas deben ser consideradas citas.

6. Citas especializadas: citas que no vienen precedidas de un verbo dicen$d i$. Dentro de estas, Clark y Gerrig (1990) estudian el estilo indirecto libre, las citas de sonidos convencionales, las citas «incrustadas» o sin marco (embedded) y las citas mixtas, en las que el ED y EI se mezcla.

En lo relativo a la estructura de la cita directa, estamos de acuerdo con Reyes (1993 y 2002) en que el fenómeno no puede solo definirse en términos de sus rasgos conversacionales, sino que deben tomarse en consideración criterios sintácticos y pragmáticos. Entendemos, por tanto, que los requisitos para hablar de cita directa lingüística son:

Requisitos de la cita directa lingüística

(Reyes, 2002; Camargo, 2004 a)

- Que la cita conserve los deícticos (pronombres, demostrativos, verbos y adverbios) del enunciado que reproduce.

- Que el enunciado de la cita se refiera a otra representación (pasada, posible o imaginaria) de la que es icono fuerte y no a un estado de cosas del mundo.

Los criterios para hablar de citas no lingüísticas son, naturalmente, distintos, pero las bases para su definición son semejantes a las ya manejadas. Nuestra propuesta es la siguiente: 


\section{Requisitos de la cita directa no lingüística}

- Que los elementos paralingüísticos y quinésicos de la cita reproduzcan otros elementos no verbales.

- Que lo representado en la cita sea una versión icónica y aproximativa de un elemento no verbal (pasado, posible o imaginario).

\section{LAS CITAS NO LINGÜÍSTICAS EN LA CONVERSACIÓN}

No es el propósito de este trabajo estudiar la prosodia de las citas, esto es, todo lo relativo al delivery, a las peculiaridades físicas del modo de producción y los modificadores fónicos (tono, timbre, tipo de voz, intensidad) que aparecen en el punto número 1 de la relación anterior y que también pertenecen a los aspectos paralingüísticos (Poyatos, 1994). Tampoco vamos a detenernos a analizar lo relacionado con la lengua (punto número 2). En esta ocasión nos centraremos en las citas no lingüísticas, atendiendo al paralenguaje y los gestos, incluidos esos que Clark y Gerrig (1990) analizan como parte del modo de expresión y que se dan de forma simultánea a la emisión del enunciado.

Tenemos varios ejemplos en nuestros datos en los que las citas no siguen el esquema prototípico asociado al estilo directo: verbo de decir + objeto directo de acción lingüística. Hay citas que, además de no estar introducidas por un verbum dicendi, no representan una acción lingüística, sino una onomatopeya o un ruidito, referencial o no, que ilustra por aproximación el tipo de sonido que produce algo acerca de lo que se habla o que representa, a su vez, otros elementos paralingüísticos u otras onomatopeyas. Asimismo, tenemos casos en que lo que se cita es un gesto que el locutor atribuye a la persona cuyo enunciado cita imitando a la vez sus peculiaridades quinésicas. Veamos cómo son estas citas no lingüísticas.

\subsection{Las citas de paralenguaje}

Como han señalado Clark y Gerrig (1990: 781), en inglés las citas de paralenguaje vienen precedidas, normalmente, del verbo go, que funciona de forma idéntica a say cuando el objeto es una acción lingüística. Los resultados del estudio de Cameron (1998: 63) demostraron, sin embargo, que en español la estrategia más frecuente para introducir este tipo de citas es la ausencia de marco (freestanding quotations), seguida de cerca por la estrategia del «verbo de discurso directo» (verb of direct report). En los siguientes ejemplos procedentes de 
nuestros corpus, lo que se demuestra son uno de los sonidos habitualmente asociados a la risa («ija ja ja!»), los ruidos de un plato al caer («niu pa») y («plin»), como en (1), el del jadeo propio de la respiración entrecortada («ahh ahh ahh») y el de un disparo («ipa!») (2), el de la música disco («pum ta ta pum pum pum pum») (3) y dos formas en las que se representan onomatopeyas asociadas al acto de hablar («cucucucú» ${ }^{7}$ y «burururú») (4). ${ }^{8}$

(1)

13. [...] el caso es que luego nos empezamos a disfrazar de cosas de terror/ a: mí me metió una bolsa de plástico aquí atada con la cabeza así toda pintada// yo a ella la colgué de la puerta de la no sé qué/ y de repente tía estamos recogiendo la habitación y había/ encima de la tele// pero que imagínate/ la cama está aquí y la tele está allí// pues había un plato de comida/ y estábamos las dos partiéndonos el culo pero de "ija ja ja ja ja!" y hace el plato de la tele/ "ñiu pa”// nos quedamos mirando el plato/

14. qué fuerte esto

13. no nos vestimos y salimos echando hostias de la casa//

17. no/ yo no he entendido bien/ pero ¿cómo hace?

13. el plato: se cayó/ el plato se cayó pero no se cayó "plin"

14. que no se cayó porque estuviera inestable

13. no/ se cayó así ((gesto manual))

14. se cayó así ((gesto manual)) (risa $=14)$

(2)

14. y el sueño fue de/ "a:hh" esa sensación/ que me habían disparado de ver$\mathrm{dad} / / /$ o sea en las décimas de segundo en que la bala sale de la pistola y me atraviesa//

13. qué fuerte tía

14. mira/ yo me levanté medio llorando

17. y tú ¿cómo te sentiste todo esto?

14. o sea de- de la im- "ahh ahh ahh" no podía respirar y fue un sueño que ya ves no fue de:- fue de: que el tío se levantó rápido/ y me hizo “¡pa!”// ¿sabes? que fue décimas de segundo no fue más// ¡qué fuerte qué ma:1 lo pasé!

(3)

7. sí/ una se llama/ la discoteca Elipsis no yo la he visto/// yo me acuerdo que vi/ una que abrieron cuando yo era/ la única que había además era una cosa reducida pequeñita era una cosa/ tenía allí- pusieron/ digamos como una espe-

7. La motivación de esta onomatopeya puede encontrarse en la asociación entre hablar y los sonidos emitidos por las aves, que aparece en verbos y locuciones como cotorrear, cacarear, piar (en su acepción coloquial y figurada), soltar el mirlo, etc.

8. Las convenciones de transcripción son una adaptación ( $c f$. Camargo, 2004 a) de las utilizadas para la publicación de los corpus del Proyecto para el Estudio Sociolingüístico del Español de España y América (PRESEEA). <http://www.linguas.net/preseea>. 
cie de sótano de esas casas antiguas (m:) una pisteja central/ con unos taburetes unas mesejas para consumición y luego arriba/ otra doble- otra doble y enseguida empezó a practicarse la música del disco y tal y cual y "pum ta ta pum pum (risa $=0)$ pum pum"

(4)

8. hacía un frío// hacía un (?) te ponías tu abrigo te enfrascabas a la

0 . como en los pueblos ¿no?

8. justo lo único que en vez de la carretera de:1 pueblo te venías aquí y cogías a la amiga del brazo/ y hablabas y "cucucucucu" [...]

0. y Carretería sería donde os hacías los novios y todo ¿no?

8. todo todo// todo el mundo y allí habías echado el ojo a uno a otro "pues ese me ha mirado dos veces/ pues fíjate burururú" (risa $=0$ ) esto fue en el pasado// pero es un pueblo (risa $=0$ ) es bastante peor que un pueblo (?).

En cuanto a la estrategia introductora de esas citas de paralenguaje, hemos encontrado que, en efecto, la más común es la de la ausencia de marco introductor (freestanding quotations), seguida de la presencia del verbo hacer, marco habitual, también, de las citas de la citas de gestos que veremos ahora.

\subsection{Las citas de gestos}

Las citas de gestos son demostraciones en las que se representa una acción no verbal de tipo quinésico, pasada, posible o imaginaria. ¿Cómo ha sido posible inferir, en ausencia de imágenes, que los informantes habían producido un gesto? Dado que no trabajamos con grabaciones audiovisuales, es necesario explicar los criterios seguidos para determinar la presencia de gestos en nuestros corpora. El principal problema al que nos enfrentamos es que, contrariamente a lo que sucede en el Corpus Espontáneo, nosotros no participamos en las grabaciones del Atlas, en cuyas entrevistas, además, solo hemos encontrado dos citas de gestos. Siendo así, podría pensarse que hemos perdido datos. Sin embargo, como oportunamente planteó Cameron (1998: 55-56), existen otros recursos para determinar si el objeto de la demostración es un gesto o no. La estructura lingüística que más frecuentemente utilizaban los informantes de su corpus para enmarcar los gestos era la compuesta por un verbo -normalmente, hacer- más el adverbio así, segui$\mathrm{da}$, con un porcentaje menor, por la estrategia del sintagma nominal desnudo. En nuestras conversaciones, casi siempre e independientemente de la presencia del verbo, el adverbio así actúa como señal de la entrada en escena de un gesto. Aparte de esto, los comentarios de los narratarios sobre la acción física del narrador, así como la risa, actúan como indicadores de la realización de gestos por parte del hablante: 
(5)

5. no me puedo mirar en los espejos/// son manías/// voy a un sitio (risa = 5) (?) me compro algo pero como me vea en el espejo ya no me gusta

0 . no me digas

5. yo me tengo que ver así ((gesto con la cabeza mirándose el cuerpo)) “¡ay qué bien me queda!"// entonces/ me gusta

0. ¡ay! ¿de verda:d?

(6)

13. ponía dibujos así ((gesto manual)) (risa $=14)$ yo qué sé una cosa más rara (risa $=13) / /$ pero muy bien la verdad es que nos los pasamos muy bien 14. nos lo pasamos muy bien

(7)

13. y claro la tía/ se hacía la coleta/// "mira es que:/ no sé qué no sé cuántos que te he dicho que no" se la volvía a quitar hacía así con el pelo ((gesto manual y de la cabeza) $)($ risa $=$ todas $)$

(8)

14. fue/ este era el cua- el cuadro grande/// bueno este es el cuadro grande que te- que tengo yo en mi habitación ¿no?/ y yo/ de rodillas así ((gestos corporales)) (risa $=14)$ delante del cuadro/ entonces claro R con la cabeza (?) y el cuerpo así $(($ gestos corporales $)) / /$ y: $($ risa = todas $) / /$ pero así ¿eh?

La representación de gestos y paralenguaje cumple los criterios que consideramos indispensables para hablar de cita: que lo representado sea una versión icónica de otra representación que se refiera, en estos casos, a otro elemento no verbal (pasado, posible o imaginario) del que es icono y no a un estado de cosas del mundo.

\subsection{Aspectos cuantitativos}

El total de formas de representación del discurso analizadas en los dos corpus fue de 821, de las cuales 512 pertenecen al Atlas y 309 al Corpus Espontáneo. Como hemos adelantado, el porcentaje de citas directas es muy elevado en ambos corpus, pues alcanza un 78\% en el Corpus ALeCMan-Cuenca y un $96 \%$ en el CE. En cuanto a las citas no lingüísticas, los resultados del análisis factorial $^{9}$ mostraron que el factor más decisivo para su aparición es el tipo de entrevista, es decir, la situación comunicativa. Los datos apuntan en la dirección de que, en general, todas las informantes del Corpus Espontáneo se comportan de

9. Estos análisis forman parte del trabajo realizado para nuestra tesis doctoral (Camargo, $2004 a$ ). 
forman semejante a como lo hacen las mujeres en las entrevistas de formalidad media y, sobre todo, en las de formalidad mínima del Atlas. La tendencia es clara: la no presencia de la grabadora y la mayor espontaneidad en los usos lingüísticos de las informantes propicia la presencia de citas directas y de elementos propios de la dramatización de enunciados: las citas de paralenguaje, las citas de gestos y también los diálogos reconstruidos. Además, esto es totalmente independiente del nivel de instrucción de los informantes. En consonancia con lo anterior, cabe destacar que son varios los autores que han constatado que el uso de este tipo de dramatizaciones no es exclusivo de la clase trabajadora o de hablantes con un bajo nivel de instrucción, sino que es habitual de géneros tan sofisticados como los encuentros entre profesionales de la medicina o los discursos políticos (Lou Doubois, 1989: 354), en los cuales las estrategias de persuasión cobran especial importancia.

Es también interesante el resultado de las citas de paralenguaje al comparar los resultados obtenidos en el análisis factorial del Atlas y del CE, pues mientras que las citas paralingüísticas en este corpus aparecen acompañando a citas lingüísticas -como es común en los relatos dramatizados- las citas de elementos cuasi-léxicos en el Atlas surgen de forma aislada, como representación de ruido semejante, pero independientes de la representación dramatizada de enunciados. En cuanto a la cita gestual, hay que comentar el hecho de que en el Atlas solo aparecen 2 casos, ambos en las entrevistas de formalidad mínima, mientras que en el CE encontramos 23 casos. Contrariamente a lo que sucedía con la cita de paralenguaje, el análisis confirma que, cuando la cita de gestos aparece, lo hace en relación con otras citas directas y con la dramatización del discurso.

\section{CONCLUSIONES}

Las citas de elementos quinésicos y paralingüísticos ponen de relieve la capacidad de los hablantes para conceptualizar el contenido de sus discursos y comunicarse mediante formas icónicas y análogas, trayendo ante los ojos del auditorio una versión de la realidad filtrada por la expresividad y el punto de vista del hablante. Esta circunstancia viene a demostrar que el discurso oral es eminentemente multimodal (Payrató, 2006) y que en él se da una diversidad sincronizada de modos que comunican a diferentes niveles. El hecho de que se marquen las peculiaridades del modo de producción depende, en gran medida, de que el hablante tenga la intención y la ocasión de dramatizar sus enunciados, lo cual está íntimamente relacionado con la situación comunicativa. Clasificada como una de las funciones metapragmáticas del lenguaje (Silverstein, 1993; Lucy, 1993; Verschueren, 1999; Reyes, 2002), las distintas formas de representación del discurso que manejamos cotidianamente revelan, además, nuestra 
habilidad como hablantes para producir y clasificar actos comunicativos de acuerdo con las condiciones sociales y culturales del entorno, así como con las convenciones genéricas que los regulan. De esta forma, no utilizamos el mismo tipo de citas -ni entenderíamos como adecuado que alguien las usara -al narrar a nuestros círculo más cercano de amistades una anécdota extraordinaria, que al escribir una carta de recomendación.

Las formas de iconicidad fuerte (las «demostraciones», en el sentido de Clark y Gerrig (1990)) superan con mucho a las de iconicidad débil (cita indirecta y sus variantes) en nuestros dos corpus de datos. Esto puede guardar relación con el hecho de que las citas directas contribuyen más eficazmente a la comunicación efectiva de lo relatado, dado que la accesibilidad a los referentes es mayor al ofrecer una demostración detallada de las acciones de los protagonistas de la historia (sus palabras, sus sonidos, sus gestos). A esto hay que añadir el claro componente lúdico y persuasivo propio del relato dramatizado. Como se ha visto, la aparición de citas directas de elementos no lingüísticos está fuertemente condicionada por el tipo de auditorio y por la situación comunicativa: cuanto más informal y relajada sea esa situación, cuanta menos distancia social exista entre los interlocutores y menos cohibidos se encuentren ante el resto de participantes, mayor será su probabilidad de aparición y su frecuencia. De estas circunstancias deriva el hecho de que las citas de elementos quinésicos, por ejemplo, solo aparezcan en las conversaciones recogidas con grabadora oculta. Podemos concluir, por tanto y para terminar, que las citas no verbales son favorecidas por situaciones comunicativas en las que la interacción se parece menos a una entrevista y más a una conversación.

\section{REFERENCIAS BIBLIOGRÁFICAS}

AUTHIER, J. (1995): Ces mots qui ne vont pas de soi. Boucles réflexives et noncoïncidences $d u$ dire, II vols., París, Larousse.

BRIZ, A. (1996): El español coloquial: situación y uso, Madrid, Arco/Libros.

- (1998): El español coloquial en la conversación. Esbozo de pragmagramática, Barcelona, Ariel.

CAmargo, L. (2001): Diálogos en el interior de narraciones orales. Análisis sociolingüístico, Alcalá, Universidad de Alcalá, Memoria de Licenciatura.

- (2004 a): La representación del discurso en la narración oral conversacional. Estudio sociopragmático, Alcalá, Universidad de Alcalá, Tesis doctoral.

- (2004 b): «El estilo directo y el estilo indirecto. De las gramáticas del español al análisis del discurso y la pragmática», en VILLAYANDRE LLAMAZARES, M. (coord.) (2004): Actas del V Congreso de Lingüística General, vol. I, Madrid, Arco/Libros, 479-489. 
- (2006): «El diálogo reconstruido y la imagen positiva», en CASADO, M., R. GONZÁLEZ y Ma V. ROMERo GuALDA (eds.) (2006): Análisis del discurso: lengua, cultura, valores, vol. I, Madrid, Arco/Libros, 1241-1253.

CAMERON, R. (1998): «A variable syntax of speech, gesture, and sound effect: Direct quotations in Spanish», Language Variation and Change, 10: 43-83. CESTERO, A. M (2000): El intercambio de turnos de habla en la conversación. (Análisis sociolingüístico), Alcalá de Henares, Universidad de Alcalá.

Clark, H. y R. Gerrig (1990): «Quotations as demonstrations», Language, 66: 764-805.

FLUDERNIK, M. (1993): The Fictions of Language and the Languages of Fiction. The Linguistic Representation of Speech and Consciousness, Londres, Routledge.

García Mouton, P. y F. Moreno Fernández (dirs.): Atlas Lingüístico (y etnográfico) de Castilla-La Mancha, Universidad de Alcalá. <http://www. uah.es/otrosweb/alecman>.

GofFMAn, E. (1974): Frame Analysis: An essay on the organization of experience, Boston, Northeastern University Press.

GÜNTHNER, S. (1999): «Polyphony and the "Layering of Voices" in Reported Dialogues: An Analysis of the Use of Prosodic Devices in Everyday Reported Speech», Journal of Pragmatics, 31: 685-708.

Lou Dubois, B. (1989): «Pseudoquotation in current English communication: "Hey, she didn't really say it"», Language in Society, 18: 343-359.

LuCY, J. A. (1993): «Reflexive language and the human disciplines», en LuCY, J. A. (ed.) (1993): Reflexive Language. Reported speech and metapragmatics, Cambridge, Cambridge University Press, 9-32.

Mey, J. L. (1993): Pragmatics. An Introduction, Oxford, Blackwell.

Moreno Fernández, F. (coord.): Proyecto para el Estudio Sociolingüístico del Español de España y América (PRESEEA). <http://www.linguas.net/ preseea $>$. PAYRató, Ll. (2006): «Discurso oral y multimodalidad», Oralia, 9: 259-275. PeIRCE, Ch. S. [1932] 1987: Obra Lógico-Semiótica, Madrid, Taurus.

Poyatos, F. (1994): La comunicación no verbal, Vol II: Paralenguaje, kinésica e interacción, Madrid, Istmo.

REYES, G. (1993): Los procedimientos de cita: estilo directo y estilo indirecto, Madrid, Arco/Libros.

- (1994): «La cita en español: gramática y pragmática», en DEMONTE, V. (ed.) (1994): Gramática del español, México, El Colegio de México, 591-627.

- (2002): Metapragmática. Lenguaje sobre lenguaje, ficciones, figuras, Valladolid, Universidad de Valladolid.

SiLVERSTEIN, M. (1993): «Metapragmatic discourse and metapragmatic function», en LuCY, J. A. (ed.) (1993): Reflexive Language. Reported speech and metapragmatics, Cambridge, Cambridge University Press, 33-58. 
Sperber D. y D. Wilson (1995): Relevance. Communication and Cognition, $2^{a}$ ed. Oxford, Blackwell.

TANNEN, D. (1989): «"Oh talking voice that is so sweet”: constructing dialogue in conversation», en TANNEN, D. (ed.) (1989): Talking Voices. Repetition, Dialogue and Imagery in Conversational Discourse, Cambridge, Cambridge University Press, 98-133.

Verschueren, J. (1999): Understanding Pragmatics, Londres, Arnold.

WILSON, D. (2000): «Metarepresentation in Linguistic Communication», en SPERBER, D. (ed.) (2000): Metarepresentations. A Multidisciplinary Perspective, Oxford, Oxford University Press, 411-448. 


\title{
LOS OBJETIVOS SOCIODISCURSIVOS DE LAS DISTINTAS REALIZACIONES ARGUMENTALES EN FRANCÉS
}

\author{
Paul Danler \\ Universidad de Innsbruck
}

\section{DE LA PERSPECTIVIZACIÓN A LA FOCALIZACIÓN}

$\mathbf{P}$ RIMERO parece indispensable aclarar cómo usamos los términos perspectivización y focalización. En el nivel semántico, los functores verbales perspectivan o rigen cierto número de argumentos. Es decir, incluso sin contexto se puede averiguar cuántos y qué argumentos requiere el respectivo functor. Sin embargo, en ciertos casos, aunque más bien excepcionales, el functor no perspectiva solo los argumentos sino también las circunstancias, y eso en forma de modificadores. La calidad esencial o característica de perspectivar, es decir, de regir argumentos y/o modificadores, es inherente a cada functor verbal, y eso es lo que se denomina valencia verbal (Tesnière, ${ }^{2} 1965$; Helbig, 1992; Bossong, 1998; Ágel, 2000). A la hora de realizarse sintácticamente la estructura functor-argumento-modificador, los argumentos pasan a ser actantes mientras los modificadores se convierten en circunstanciales. Según el número de huecos del respectivo functor verbal para argumentos, y, dado el caso, también para modificadores, se suele diferenciar entre functores mono-, bi- y trivalentes. De eso se desprende que la valencia es una calidad sistémica del functor que constituye la base invariante del verbo en uso. Dicho de otra manera, el functor verbal predetermina en nuce la respectiva frase, puesto que este ya contiene los huecos que deben ser llenados por argumentos y/o modificadores a la hora de transponer la estructura functor-argumentomodificador en la respectiva estructura sintáctica, para asegurar la buena formación de la frase (Wotjak, 1996, 2001 y 2003). Se puede ilustrar lo que es la perspectivización a través de cualquier functor verbal. Al mirar, por ejemplo, los verbos franceses construire (construir), demander (preguntar, pedir) y souffrir (sufrir), resulta que las estructuras sintácticas establecidas por los respectivos functores son distintas las unas de las otras. Por un lado, estos functores no rigen el mismo número de argumentos, y por otro, los argumentos perspectivados por el respectivo functor son diferentes en lo concerniente a los casos semánticos. $\mathrm{Si}$, por el momento, prescindimos del caso excepcional de la genericidad, constatamos que el functor bivalente /construire/ perspectiva 
un primero y un segundo argumento, el functor trivalente /demander/ un primero, un segundo y un tercer argumento, ${ }^{1} \mathrm{y}$ el functor/souffrir/ perspectiva un primero y un tercer argumento.

En los siguientes ejemplos ficticios, todos los argumentos perspectivados en el nivel semántico se realizan actancialmente, es decir, se especifican en el nivel morfosintáctico, y es precisamente esta realización actancial de los argumentos perspectivados la que denominamos focalización (Langacker, 2002).

Nuestro primer ejemplo de focalización, para ilustrar el caso de construire, es a) Les victimes construisent le pont de pardon vers le tyran (Las víctimas construyen el puente de perdón hacia el tirano). Construire es bivalente. Les victimes desempeña el papel del primer actante y le pont, junto con los adyacentes, el del segundo. El verbo demander, en cambio, es trivalente y rige un primero, un segundo y un tercer actante. Por consiguiente, una frase como b) Le dictateur demande aux subordonnés de se résigner à la situation (El dictador pide a los subordinados que se resignen ante la situación) representa un ejemplo de focalización de los tres actantes de un verbo trivalente, ya que los tres argumentos son especificados lexemáticamente. Le dictateur es el primer actante, el complemento de infinitivo de se résigner, en la traducción al español una oración completiva, el segundo actante, y aux subordonnés es el tercer actante. Un tercer ejemplo para el functor/souffrir/, realizado por el respectivo verbo souffrir, que implica un hueco para el primer actante y otro para el tercero, es $c$ ) Les victimes souffrent d'injustice (Las víctimas sufren de/por la injusticia). En esta frase concreta les victimes es el primer actante y d'injustice el tercero.

Los argumentos perspectivados que quedan realizados a cero en el nivel léxico, por un lado, y los argumentos perspectivados que sí se realizan actancialmente, por otro, se distinguen los unos de los otros en lo concerniente al peso comunicativo. Para ilustrar eso, vamos a sacar tres enunciados de discursos pronunciados por Pétain entre 1940 y 1943 que derivan precisamente de los verbos arriba discutidos, y cuyos argumentos han sido realizados solo parcialmente.

\section{LA PERSPECTIVIZACIÓN SIN FOCALIZACIÓN}

Los tres verbos que constituyen el centro de los tres respectivos enunciados de Pétain son, como se ha dicho antes, construire, demander y souffrir (Busse y Dubost, ${ }^{2} 1983$ ). El programa estándar de la oración que depende del functor /construire/ es $x$ construit y que, sin embargo, refleja solo parcialmente la estructura del enunciado de Pétain:

$\overline{1 .}$ El segundo puede ser realizado por un complemento de infinitivo. 
(1) Renoncez à la haine, car elle ne crée rien; on ne construit que dans l'amour et dans la joie. (Pétain, 1941: 113)

(Renunciad a la hostilidad, ya que ella no crea nada; se construye solo en amor y alegría. $)^{2}$

El segundo argumento queda realizado a cero en el enunciado de Pétain. Es decir, Pétain no dice qué es lo que se construye solo en amor y alegría. Dicho de otro modo, el orador no hace explícito el referente y por lo tanto todo queda abierto.

Como hemos dicho arriba, el functor/demander/ establece el programa estándar de la frase $x$ demande y à $z$. Sin embargo, en francés el segundo argumento puede realizarse también a través de un complemento de infinitivo como en el enunciado siguiente:

(2) J'ai maintes fois demandé, et avec quelle insistance, d'établir entre vous l'accord des pensées. (Pétain, 1943 c: 319)

(He pedido varias veces, y con qué insistencia, que se llegue a un acuerdo de pensamiento entre vosotros.)

En este caso, es el tercer argumento el que el orador, consciente o inconscientemente, se abstiene de especificar. Es decir, Pétain no precisa a quién ha pedido que elabore un acuerdo de pensamiento entre los oyentes. Sin embargo, probablemente eso no suceda por casualidad (Růži čka, 1978). Por consiguiente, el motivo para no realizar este argumento puede resultar importante bajo el aspecto comunicativo.

En cuanto al tercer enunciado, hay que tener presente que el programa estándar de la frase que deriva del functor/souffrir/ es $x$ souffre de $y$. Sin embargo, el tercer enunciado tampoco lo refleja:

(3) Vous avez souffert, vous souffrirez encore. (Pétain, 1940 a: 66)

(Habéis sufrido y seguiréis sufriendo todavía.)

Otra vez es el tercer argumento el que, por cualquier motivo, queda realizado a cero. Dicho de otra manera, Pétain se abstiene de precisar de qué vienen sufriendo los oyentes así como de qué seguirán sufriendo.

La cuestión crucial que se plantea después de este breve vistazo a los pocos ejemplos arriba citados es el de la distribución del peso comunicativo en enuciados que contienen argumentos realizados a cero. Por lo menos dos conse-

2. Las citas originales han sido traducidas por el autor del ensayo. 
cuencias que resultan de tales construcciones parecen altamente significativas del punto de vista comunicativo-pragmático: por un lado, los argumentos realizados como actantes, o los modificadores especificados como circunstantes, adquieren el peso comunicativo de los argumentos realizados a cero. Por otro lado, sin embargo, los argumentos mismos realizados a cero pueden, bajo ciertas condiciones, tener mucho peso comunicativo. Las citas (1) y (2) ilustran el primer caso, mientras la cita (3) ejemplifica el segundo.

Con respecto a la primera cita, eso significa que el circunstante dans l'amour et dans la joie recibe el peso comunicativo esencial a costa del segundo argumento realizado a cero. En el segundo ejemplo, sin embargo, es, por un lado, el segundo actante, realizado por un complemento de infinitivo, y, por otro, el circunstante modal et avec quelle insistance, los que ganan mucho peso comunicativo gracias a la ausencia del tercer actante. En estos dos casos el peso comunicativo de los argumentos realizados a cero parece ser, de hecho, de mínimo a cero. No obstante, en contraste con las citas (1) y (2), en el enunciado (3), el mismo argumento realizado a cero que, hipotéticamente, está en la posición más remática, sigue teniendo el peso comunicativo central. El hecho de que el tercer argumento queda realizado a cero significa que el sufrimiento al que alude el orador puede, teóricamente, ser provocado por cualquier motivo. Además, no hay ningún otro actante o circunstante que podría llamar la atención del destinatario. Gracias a estas dos condiciones, incluso un argumento realizado a cero puede quedar con un peso comunicativo considerable.

En el apartado siguiente veremos de qué manera los argumentos perspectivados pueden ser realizados, y, puesto que el foco es un criterio central para el peso comunicativo, con qué medidas lexémicas y sintácticas se puede efectuar la puesta en foco de los argumentos ya realizados, es decir, ya focalizados.

\section{DE LA FOCALIZACIÓN A LA PUESTA EN FOCO}

Como hemos precisado arriba, entendemos por perspectivización la propiedad sistémica del verbo de regir cierto número de argumentos y, en el caso de que los haya, de modificadores. Una vez que los argumentos perspectivados hayan sido objeto de una realización concreta, el campo visual, abierto por los huecos inherentes al functor verbal, es reducido. Las posiciones argumentales para actantes han sido llenadas, con lo cual una situación ya mucho más concreta se va presentando. Ya no se perspectiva una constelación abstracta de argumentos, sino que se focaliza una constelación concreta de actantes. Los argumentos realizados o materializados como actantes focalizados pueden ser, 
además, enfatizados o puestos en foco mediante la realización actancial marcada, la serialización actancial marcada, y/o la realización actancial múltiple. Aquí, sin embargo, vamos a dedicarnos únicamente a la realización actancial marcada.

En principio, distinguimos entre cinco realizaciones actanciales formales a las que llamamos realización primaria, secundaria, terciaria, cuaternaria y quintenaria. Las vamos a ilustrar brevemente y solo de manera ejemplar por las respectivas variantes del primer actante, si bien este esquema vale también para los demás.

La variante morfológica como parte del verbo conjugado, que a menudo basta para indicar la persona en las llamadas lenguas pro-drop, es la realización primaria. Il pleut es llueve en español, piove en italiano y chove en portugués. Es decir, en español, italiano y portugués es exclusivamente la morfología verbal la que indica que la tercera persona singular es el primer actante. En francés, en cambio, la morfología verbal, que también indica la tercera persona singular, no es suficiente, ya que la buena formación de la frase requiere el respectivo pronombre clítico. La realización actancial mediante el pronombre clítico es la realización secundaria según nuestro esquema. La realización terciaria se efectúa por los pronombres tónicos, que en francés suelen aparecer juntos con los respectivos pronombres clíticos aunque eso no es siempre así. Por consiguiente, un enunciado como Moi, je pars alors qu'eux, ils restent (Yo parto/me voy mientras ellos se quedan) resulta común. La realización cuaternaria es la nominal y en la realización quintenaria los argumentos son especificados por oraciones u otras construcciones que sustituyen a oraciones, como el gerundio o el complemento de infinitivo. ${ }^{3}$

Después de esta breve introducción a los aspectos morfológicos de las distintas variantes de realizaciones actanciales, hay que aclarar qué realizaciones actanciales se consideran marcadas y bajo qué condiciones estas se presentan. En una fórmula algo reducida se puede decir que siempre cuando se usa una variante más alta que la comunicativamente necesaria, es decir, la segunda en vez de la primera, la tercera en vez de la segunda, etc., la realización es formalmente marcada. De ahí que haya motivos funcionales para marcar cierto constituyente, ya que marcar significa ipso facto poner en foco.

3. Los cinco tipos de realizaciones actanciales:

Realización primaria del primer actante: (Il) pleut. Llueve .

Realización secundaria del primer actante: $\underline{I l}$ pleut.

Realización terciaria del primer actante: $\underline{M o i}$, je ne viens pas. $\underline{Y o}$ no vengo.

Realización cuaternaria del primer actante: L'élève arrive. El alumno_está llegando.

Realización quintenaria del primer actante: Qui ne dit mot consent. Quien tienelencuentra a un amigo, tiene/encuentra un tesoro. 
A continuación, se discutirá el peso comunicativo de las variantes marcadas y de ese modo puestas en foco.

(4) Vous, vous avez attendu votre charte plus d'une année: mais la Charte n'est pas une création provisoire, et l'on ne devait pas l'improviser. (Pétain, 1943 b: 308)

(Vosotros habéis esperado vuestra carta desde hace más de un año: pero la Carta no es una creación provisoria y no se debe improvisar.)

En este enunciado es la realización terciaria del primer argumento, que en este caso es el vocativo o el nominativo de tratamiento, es decir, el primer vous, la que representa la realización actancial marcada. El motivo pragmático para enfatizar este constituyente sintáctico parece ser el objetivo de crear identidad de grupo. A pesar de ser sintácticamente innecesario, este constituyente sintáctico resulta altamente relevante desde la perspectiva comunicativa y por eso adquiere un peso comunicativo considerable. Como elemento más temático en este enunciado, vous sirve, más que nada, de medio de cohesión y coherencia, pero no introduce ninguna información nueva. El actante remático es votre charte, cuya contribución a la dinámica comunicativa resulta, precisamente gracias a su posición sintáctica, mayor que la del primer actante, aunque este aparece en tres niveles morfológicos, es decir, como realización primaria, secundaria y terciaria. No obstante, precisamente por la realización marcada del primer argumento, el peso comunicativo del primer actante no puede ser ignorado.

(5) Français, mes amis, libérez votre conscience des préjugés et des rancunes, vous comprendrez mieux alors ceux qui ont la charge douloureuse de vous conduire. (Pétain, 1943 a: 301)

(Franceses, mis amigos, liberad vuestra consciencia de los prejuicions y de los rencores, entonces entenderéis mejor a los que tienen la carga dolorosa de guiaros.)

En la cita número cinco, Pétain podría perfectamente obviar las realizaciones cuaternarias français y mes amis, sin quebrantar el principio de la buena formación de la frase. Al igual que en español, en el imperativo francés la realización primaria, es decir, morfológica, mediante la desinencia del verbo conjugado, es suficiente para indicar el primer actante. La referencia queda clara por el marco deíctico, construido discursivamente. Sin embargo, análogamente a la cita número cuatro, es la doble realización cuaternaria del primer argumento que, a pesar de ser sintácticamente innecesaria, conduce a la presunción de que este constituyente es altamente importante, por lo menos desde la perspec- 
tiva comunicativa. Otra vez, el primer actante como realización del vocativo o del nominativo de tratamiento es el constituyente sintáctico más temático. Sin embargo, gracias a su especificación marcada, es este el elemento que está en foco. El motivo extralingüístico para enfatizar de tal manera emocional a los destinatarios parece residir en el objetivo del orador de infundir un sentimiento de comunidad entre él mismo y los oyentes. Eso forma parte del patetismo retórico.

(6) Celui qui a pris en main les destinées de la France a le devoir de créer l'atmosphère la plus favorable à la sauvegarde des intérêts du pays. (Pétain, $1940 \mathrm{~b}$ : 95)

(El que ha tomado en mano los destinos de Francia tiene el deber de crear la atmósfera más favorable para la salvaguardia de los intereses de su país.)

En la cita número seis, el primer argumento es realizado por un pronombre demostrativo, forzosamente seguido por una subordinada relativa. ${ }^{4}$ Esta realización del primer argumento es marcada, ya que una realización cuaternaria bastaría. En función de lo que el orador quiere expresar o comunicar al público, este podría emplear términos como el presidente, el canciller, el subversivo, el dictador o también el tirano en vez de el que ha tomado en mano los destinos de Francia. De eso se desprende que el orador ha preferido la compleja realización quintenaria a una sencilla realización cuaternaria por motivos pragmáticos. Es, por un lado, el tamaño de tal realización quintenaria que supera el de cualquier realización cuartenaria y que hace que el respectivo actante quede por lo menos formalmente muy resaltado, puesto en foco. En lo concerniente al contenido, sin embargo, la realización quintenaria provee al orador de posibilidades adicionales que resultan altamente relevantes desde la perspectiva comunicativo-retórica. Es decir, esa realización permite al orador transmitir un concepto sin que este tenga que limitarse al significado de un significante concreto. En consecuencia, tal primer actante recibe un peso comunicativo considerable bajo el aspecto semántico-pragmático, ya que es el destinatario mismo el que puede y debe interpretar todos los aspectos explícitos e implícitos del concepto al que el emisor hace alusión mediante el actante realizado de manera frasal.

\section{CONCLUSIÓN}

El objetivo de este análisis no ha sido interpretar de manera detallada y global las citas sacadas de los varios discursos pronunciados por Pétain durante el

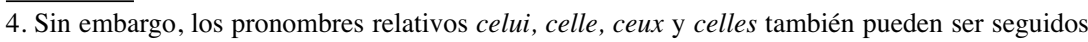
por -ci o -là u, ocasionalmente, incluso por el participio pasado. 
régimen de Vichy. En cambio, el objetivo declarado sí ha sido averiguar cómo se otorga un peso comunicativo particular a ciertos constituyentes sintácticos que, en realizaciones estándar, no tendrían un peso comunicativo tan marcado, y que sí lo tienen en las citas presentadas y discutidas.

\section{REFERENCIAS BIBLIOGRÁFICAS}

Ágel, V. (2000): Valenztheorie, Tübingen, Narr.

Bossong, G. (1998): «Éléments d'une typologie actancielle des langues romanes», en Feuillet, J. (ed.) (1998): Actance et Valence dans les Langues de l'Europe, Berlín, de Gruyter, 769-787.

Busse, W. y J.-P. Dubost ( $\left.{ }^{2} 1983\right)$ : Französisches Verblexikon, Stuttgart, Klett. Helbig, G. (1992): Probleme der Valenz- und Kasustheorie, Tübingen, Niemeyer.

LANGACKER, R. (2002): Foundations of Cognitive Grammar, Volume I, Stanford, Stanford University Press.

RŮZICKA, R. (1978): «Three Aspects of Valence», en ABRAHAM, W. (ed.)

(1978): Valence, Semantic Case, and Grammatical Relations, Amsterdam, Benjamins, 47-53.

TESNIÈRE, L. ( ${ }^{1965): ~ E ́ l e ́ m e n t s ~ d e ~ s y n t a x e ~ s t r u c t u r a l e, ~ P a r i ́ s, ~ K l i n c k s i e c k . ~}$

WOัTЈ̌AK, G. (1996): «Actants und circonstants. Tesnières Pionierleistungen in semantischer Sicht: Zu Funktoren, Argumenten und Modifikatoren», en GrÉCIANo, G. y H. Schumacher (eds.) (1996): Lucien Tesnière - Syntaxe structurale et opérations mentales, Tübingen, Niemeyer, 101-115.

— (2001): «Valenztheorie im Aufwind? Versuch einer Bilanz», en THIELEMAN, W. y K. WelKe (eds.): Valenztheorie. Einsichten und Ausblicke, Münster, Nodus, 27-64.

- (2003): «Zur Dekomposition der lexikalischen Bedeutung von Verben», en Cyrus, L. et al. (eds.) (2003): Sprache zwischen Theorie und Technologie, Wiesbaden, Dt. Univ.-Verlag, 315-332.

\section{DISCURSOS}

Barbas, J.-C. (ed.) (1989): Philippe Pétain. Discours aux Français. París: Albin Michel.

PÉTAIN, P. (1940 a): «Appel du 25 juin 1940», en Barbas, J.-C. (ed.) (1989: 63-66). - (1940 b): «Message du 30 octobre 1940», en BARBAS, J.-C. (ed.) (1989: 94-96).

- (1941): «Discours du 1r mars 1941», en BARBAS, J.-C. (ed.) (1989: 110-114).

- (1943 a): «Messages du 4 avril 1943», en BARBAS, J.-C. (ed.) (1989: 299-302). 
- (1943 b): «Message du 2 mai 1943», en BARBAS, J.-C. (ed.) (1989: 306-309).

- (1943 c): «Appel du 3 novembre 1943», en BARBAS, J. - C. (ed.) (1989: 318-319). 


\title{
EL COMPROMISO ESTÉTICO Y SOCIAL DE LA IRONÍA ROMÁNTICA: «POETISCH LEBEN»
}

\author{
Ma Ángeles García Canelles \\ Universitat Jaume I
}

\section{INTRODUCCIÓN}

I en el II Congreso de Lengua y Sociedad planteábamos la ironía socrática Ddesde su compromiso ético-social más allá de toda reflexión puramente dialéctica, en este III Congreso de Lengua y Sociedad analizaremos la interpretación que de ella hace el Romanticismo Temprano Alemán dentro de su propuesta de una nueva concepción de arte moderno, dando lugar a la acepción de ironía como principio literario. Desde esta perspectiva veremos cómo la ironía socrática, sin perder sus connotaciones trascendentales, se transforma en una ironía «urbana» que nace de la interrelación entre «Philosophie» y «Poesie» como concepto unitario e inherente a ambas y que está por encima de la mera figuración retórico-poética. Esta nueva acepción de ironía está basada en la armonización de elementos contrarios, adquiriendo así un carácter paradójico. En virtud de esta interrelación, la ironía romántica eleva a un todo universal la creación poética, al tiempo que poetiza la propia existencia y hace la «Poesie» más social y comunicativa, lo que justifica la máxima «poetisch leben» de Friedrich Schlegel, el padre de la ironía romántica.

En la acepción de ironía de este autor aparecen tres cuestiones a tener en cuenta para poder abordar la problemática de dicho concepto como principio literario. Primera: la ironía es autodeterminativa en la conducta y en la facultad creativa del sujeto. Segunda: la ironía imprime carácter y dota a la obra literaria de una estructura paradójica muy particular. Tercera: es significativa para la interrelación que la obra creada ha de tener con el entorno socio-cultural en el que se integra. Consecuentemente, la ironía así entendida va más allá del puro contenido irónico como forma de expresión.

Desde estos presupuestos de la ironía como principio literario planteados por Friedrich Schlegel demostraremos: primero, que la ironía romántica es una facultad especial de la creatividad artística, que constituye una fuerza impulsora que contribuye a la totalidad de la realidad estética, potenciando el arte a la universalidad; segundo, que la ironía romántica es fruto del ejercicio de la voluntad como arbitrium liberum del que la ejercita, como artista y como ser 
humano, cuyo único freno es la limitación impuesta consciente y responsablemente a sí mismo y a su propia obra; tercero, que la autoliberación del sujeto irónico solo se podrá lograr por medio del arte y no de la dialéctica puramente filosófica, diferenciándose así de la ironía socrática.

En nuestro análisis sobre la ironía romántica tomaremos como corpus los postulados estéticos de Friedrich Schlegel contenidos fundamentalmente en sus escritos teóricos y fragmentos aforísticos críticos escritos de 1794 a 1797 , considerados como su primera producción teórica, y publicados en 1797 en la revista Lyceum der schönen Künste, así como los publicados de 1798 a 1800 en la revista Athenäum, y los contenidos en los manuscritos conocidos como Marburger Handschriften escritos de 1797 a 1801.

\section{LA REFLEXIÓN SOBRE LA IRONÍA EN LOS POSTULADOS ESTÉTICOS DE FRIEDRICH SCHLEGEL}

Friedrich Schlegel ha profundizado en su teoría estética en la acepción de ironía como principio literario desde la perspectiva romántica. La idea que tiene de la ironía no es la de un ejercicio plácido y contemplativo en el que todos los presupuestos se aceptan claramente sin cuestionarlos, sino todo lo contrario. Schlegel descubre en la práctica irónica la necesidad vital de entrar en conflicto dialéctico con uno mismo, de pugnar y discernir entre lo estrictamente necesario y lo relativo, reconociendo en ello la facultad autoliberadora y autodeterminativa de la ironía. Pero la autoconfrontación, según sus planteamientos, va más allá de la polémica interna del sujeto con su yo. Se trata de una nueva cosmovisión estética desde la perspectiva de una poesía universal en la que filosofía y poesía están interactivamente relacionadas. Dicha cosmovisión, que, según Schlegel, solo puede darse a través del arte y no de la dialéctica puramente filosófica, es fruto de la conmoción interna de la propia conciencia crítica del artista. Esta se eleva por medio de la fantasía a un mundo en el que todo se relativiza y en el que la realidad cotidiana se convierte en fantasía, dando sentido a la propia existencia en ansiosa búsqueda de la perfección. La acepción de ironía propuesta por Friedrich Schlegel consiste en elevar a un todo universal la creación poética y poetizar la propia existencia y la sociedad. Ello supone una potenciación de la obra de arte a lo absoluto, en la que la ironía oscila en el centro de la interacción del artista y su obra, «explicándola y fijando sus límites a la par que tratando de abolirlos» (Ballart, 1994: 67). El contraste entre lo prosaico y lo poético a todos los niveles es lo que este autor intenta combinar armoniosamente, basando en él la estructura irónica.

Así pues, la ironía como principio literario no es en sí un concepto aislado. Está interrelacionado con determinados aspectos de la teoría estética del 
Romanticismo Temprano Alemán, como son su ideología filosófica y su peculiar forma de concebir el arte en todas sus dimensiones. Dicha teoría contempla la ironía desde dos perspectivas que no están totalmente diferenciadas: la ironía como síntesis de la reflexión estético-filosófica, por tanto entra dentro de las actitudes fundamentales del ser humano, y la ironía como principio literario, fruto de la reflexión puramente estético-poética. Ambas perspectivas se interaccionan en la reflexión sobre la ironía hecha por Friedrich Schlegel dando lugar a la llamada «romantische Ironie», también «künstlerische Ironie» (Solger, 1969: 125) o «dichterische Ironie» (Allemann, 1956: 28, 32). Sin embargo, dicho término como tal aparece explícito relativamente poco en su teoría, ya que para él el concepto de ironía queda implícito en el de «romantische Poesie» que define como «eigentlich die Poesie selbst, wie die idealische» (Schlegel, 1957: 180). Por tanto, entra de lleno en la reflexión sobre la organización interna del arte moderno de aquella época, como se podrá comprobar en este análisis.

En sus escritos sobre estética Schlegel no da una definición de ironía que pueda interpretarse únicamente como un recurso o forma determinada de concebir el arte en todas sus expresiones o como una estructura especial poéticoliteraria. En su planteamiento sobre ironía hay que intuir una interpretación diferenciadora del concepto, pero a la vez unitaria y homogénea en sí misma. Precisamente, es en la escisión conceptual entre la Antigüedad clásica y la Modernidad, donde se fundamenta la esencia de la ironía romántica. El sentido por la abstracción de la esencia crece en detrimento de la realidad finita, de la descomposición de la forma en aras de una realidad infinita. Con lo cual elementos opuestos como ideal-real, infinito-finito, objetivo-subjetivo, absolutorelativo, libre-arbitrario, entre otros, entran en conflicto dialéctico en la reflexión schlegeliana sobre la ironía.

En su obra Über das Studium der Griechischen Poesie Schlegel establece de forma velada la acepción de ironía como principio literario y la interconexión que esta tiene con el arte. Dentro de dicho contexto se puede analizar también una de las cuestiones más interesantes de esta teoría: si la ironía, tal y como la plantea Schlegel, es un principio exclusivo de objetividad o de subjetividad respectivamente. En este punto de la reflexión schlegeliana se puede interpretar, por una parte, que la ironía romántica es fruto de la evolución de la ironía clásica, resultado de la abstracción y pérdida de sustancia de lo trascendental en aras de una mayor absolutización y perfección estéticas. Ello implica una subjetivación del ideal clásico del arte griego. Dicha subjetivación es para algunos autores la característica principal y exclusiva de la ironía romántica (Hegel, 1970: II, 233; Kierkegaard, 1991: 216, 266), si bien no es la única, como tendremos ocasión de comprobar más adelante. Por otra parte, se podría pensar que dicho concepto lo analiza Schlegel solo desde una pers- 
pectiva puramente objetiva (Joachimi-Dege, 1907: 166), tal y como se desprende de sus últimos escritos. De estas dos posibles interpretaciones se deduce que el concepto de ironía ofrece más de una perspectiva de análisis.

\subsection{La ironía producto de la interrelación entre filosofía y poesía: El espíritu de la ironía socrática}

Es en los fragmentos aforísticos críticos y cuadernos de apuntes de 1797 donde Schlegel se cuestiona por primera vez el concepto de ironía en una discusión dialéctica desde un nuevo planteamiento, dotándolo de una determinada dimensión epistemológica. La problemática sobre la ironía aparece en dichos fragmentos dentro de un círculo de pensamientos y reflexiones en los que intenta definir determinados rasgos del espíritu socrático, y con ello una peculiar manera de expresión artística. En ellos se hace referencia a la ironía socrática propiamente como «zarte Gewebe der Sokratischen Muse» para designar una determinada forma de representación cuya «Leichtigkeit nicht selten die Frucht der größten Kunst und Anstrengung ist» (Minor, 1882: II, 133). Asimismo define la ironía socrática como «ein zartes, geflügeltes und heiliges Ding», producto de la inspiración, «auf die man anwenden könnte, was Plato vom Dichter sagt» (Ibid.: 131). En ese contexto hace referencia a unas condiciones internas especiales que caracterizan la ironía como actitud filosófica y a la vez como facultad artística. Dichas reflexiones apuntan hacia una fuerza autoimpulsiva e impulsora que se potencia en el interior del arte y de la creatividad artística del propio sujeto. Estas ideas están en conexión con el nuevo planteamiento sobre el arte y sus principios de organización interna expuestos en su obra Über das Studium der Griechischen Poesie.

La máxima exigencia de Schlegel, manifestada insistentemente en sus reflexiones sobre estética literaria y en especial sobre la ironía, es interrelacionar poesía y filosofía, como afirma en el Lyceums-Fragment 115: «Die ganze Geschichte der modernen Poesie ist ein fortlaufender Kommentar zu dem kurzen Text der Philosophie [...]; Poesie und Philosophie sollen vereinigt seyn.» (Ibid.: 200). Precisamente, de esta interrelación nace la ironía como concepto unitario e intrínseco en ambas: «Poesie und Philosophie sollen sich immer innigst durchdringen» (Schlegel, 1956: 171). Sin embargo, el componente de la ironía, la «Einbildungskraft», es un elemento, como afirma Schlegel, específicamente racional, no poético, ya que «bezieht sich nur auf Witz und Vernunft» (ibid.: 155). Dicho componente filosófico es lo que ha de hacer operativa la ironía en la poesía, lo cual posibilita que la filosofía pueda producir en el arte «absolute Liberalität» (ibid.: 37). De ahí que al definir la ironía socrática en el Lyceums-Fragment 42 establezca la filosofía como «die eigentliche Heimat der Ironie» (Minor, 1882: II, 188). Con ello concibe la iro- 
nía más allá de la mera figuración retórico-poética, elevándola a «erhabene Urbanität der Sokratischen Muse» (ibid.), pasando así a formar parte de las actitudes fundamentales del ser humano. Dicha ironía tiene también una importante significación implícita para la poesía: «Es gibt alte und moderne Gedichte, die durchgängig im Ganzen und überall den göttlichen Hauch der Ironie atmen.» (Ibid.)

En el mismo fragmento explicita el espíritu singular de la poesía antigua y moderna caracterizado por la ironía: «Es lebt in ihnen eine wirklich transcendentale Buffonerie. Im Innern, die Stimmung, welche alles übersieht, und sich über alles Bedingte unendlich erhebt [...] im Äußern, in der Ausführung die mimische Manier eines gewöhnlichen guten italiänischen Buffo.» (Ibid.: 189). El sentido de sublimación de esta formulación no es excluyente ni tiene por qué estar en contraposición con la manifestación bufonesca externa asignada a la ironía. Más bien habría de interpretarse como un elevado distanciamiento poético que justifica y hace necesaria en el artista la diferenciación de los dos comportamientos, el interno y el externo, expresados en dicho fragmento. De este modo, la escisión interna, la autosublimación y la destrucción de lo estrictamente «Bedingt» aparecen como características de la ironía en la obra de arte, y la bufonada como algo resultante de la relación ideal-real.

Con la comparación del comportamiento externo arbitrario al estilo de un «Buffo» parece que Schlegel asigna a la ironía la función de distorsionar el efecto ilusión tanto en el artista como en la obra de arte, originando con ello una destrucción de la ilusión o efecto antiilusión. Dicho efecto, característico de la ironía romántica, no se emplea sólo para distanciar, con el fin de despojar la obra de su forma concreta en aras de una potenciación absoluta del arte; se emplea, sobre todo, para dar un efecto aparentemente real a todo el contenido de dicha obra. Es por ello que al analizar el final del fragmento 42 algunos autores, en su intento de despojar la ironía de su característica de arbitrariedad subjetiva, interpretan dicha comparación solo como una expresión puramente metafórica, por tanto figurativa, negando así el efecto antiilusión (Walzel, 1938: 42; Immerwahr, 1951: 180). Según ellos, ha de ser así, pues no se comprendería que el espíritu socrático se identificara con la distorsión burlesca de la ilusión, como ocurre en la Commedia dell'Arte. Si ello fuera como sostienen estos autores, el contenido trascendental que Schlegel otorga a la poesía procedente de la ironía socrática no se entendería relacionado con dicha distorsión de la ilusión, tal y como aparece en el citado fragmento. Consecuentemente, habría que descartar también de la interpretación de dicho aforismo que la ironía sea un signo de arbitrariedad subjetiva. Sin embargo, como parece deducirse de la formulación de Schlegel, los términos «transcendental»y «Buffonerie» no son excluyentes, y, por lo tanto, no se contraponen ni han de interpretarse como un contrasentido. Es por ello que apa- 
recen combinados bajo la expresión «transcendentale Buffonerie». Asimismo, la relación de las expresiones «im Innern», «im Äußern» refleja el sentido que dará más adelante al término «transcendental» en el Athenäums-Fragment 22.

La idea de que la distorsión de la ilusión, o lo que es lo mismo el juego con la apariencia de realidad o simulatio, sea un acto subjetivo y arbitrario del sujeto creativo es algo que parece indiscutible, según se desprende del fragmento 42. Schlegel considera la ironía en este fragmento, por una parte, como un estado anímico del artista, por tanto, como una actitud interna, trascendental, y, por otra, como una conducta externa o comportamiento determinado por una peculiar forma de actuar cuya característica es la simulatio. De este modo, interpreta la expresión «die Manier des Buffo» de forma total y concreta, por tanto no figurativa, sino como signo característico del fenómeno ironía. En este aspecto externo le asigna, pues, un comportamiento eminentemente representativo, poético.

No parece técnicamente tan fácil separar la sabiduría interna trascendental de la actitud externa, cómica y simulada, bufonesca y naiv, tal y como aparece en el fragmento 42, ya que para Schlegel la «Ironie» y la «Bouffonerie» entran a formar parte de las «Kategorien des Komischen» (Schlegel, 1957: 212). En dicho fragmento se aprecia la clara interrelación que en un principio tiene la ironía romántica con la socrática. Esta relación se expresa por medio de una actitud existencial y trascendental del irónico ante la vida. No obstante, la negación de la esencia del yo, esto es, la «unendliche absolute Negativität» (Kierkegaard, 1991: 266) implícita en la ironía socrática la proyecta Schlegel no absolutamente desde el prisma ético-filosófico, sino, sobre todo, desde la perspectiva estética. En tanto que la ironía encierra lo negativo, al intentar superarlo se convierte ella misma en negación. Es el radicalismo moral y negativo de la ironía socrática lo que le impide apoyarse totalmente en los contenidos socráticos a la hora de justificar y potenciar su acepción de ironía como principio literario (Walser, 1981: 41). Dicha negación absoluta e infinita del ser, observada en la ironía socrática, irá volatilizándose en la acepción schlegeliana en aras de una mayor abstracción de la esencia estética. Así pues, la ironía romántica va perdiendo connotaciones filosóficas para ganar en aptitudes estéticas. De ahí que dicha negación intrínseca en la ironía encuentre en el humor su propia superación. En este fragmento 42 se puede apreciar claramente cómo la ironía socrática se transforma en ironía burguesa o urbana, símbolo de la época romántica.

En el Lyceums-Fragment 108 Schlegel intenta profundizar de nuevo en la caracterización de la ironía socrática: «Die Sokratische Ironie ist die einzige durchaus unwillkührliche, und doch durchaus besonnene Verstellung [...]. Sie soll niemanden täuschen, als die, welche sie für Täuschung halten.» (Minor, 1882: II, 198). En el primer párrafo aparece explícito el término «Verstellung», 
que se puede interpretar en el mismo sentido que se desprendía del contexto final del fragmento 42. La idea principal del fragmento 108 gira en torno a las condiciones intelectuales y a los componentes determinantes de la ironía: «In ihr soll alles Scherz und alles Ernst sein, alles treuherzig offen, und alles tief verstellt.» (Ibid.). Además de la interrelación de los términos opuestos «Scherz und Ernst» inherentes a la ironía, que expresan respectivamente los comportamientos externo e interno referidos en el fragmento 42 , aparecen otros elementos contrarios, articulados armónicamente, que forman parte de dichos componentes como «Naturphilosophie»y «Kunstphilosophie»(ibid.). Esta asociación de ambos conceptos refiere de nuevo a los presupuestos preliminares de la teoría estética de Schlegel basados en la síntesis combinatoria de la Antigüedad clásica y la Modernidad.

\subsection{El concepto «Paradox»: La paradoja como base de la estructura irónica}

El carácter paradójico que Schlegel otorga a la ironía hace que la conciba asimismo en el fragmento 108 como «die feyste aller Licenzen, denn durch sie setzt man sich über sich selbst weg; und doch auch die gesetzlichste, denn sie ist unbedingt nothwendig». De nuevo vuelve a relacionar aquí adjetivos antagónicos como «frei/gesetzlich», «unbedingt/notwendig» al referirse a la ironía como licencia, libre pero a la vez absolutamente necesaria. Se trata, pues, de una doble formulación que quiere potenciar por medio de la ironía un autoimpulso en el artista. Asimismo, el Lyceums-Fragment 87 abunda en la idea de libertad como condición intrínseca en el arte poético ( $c f$. ibid.: 195).

La síntesis armónica de elementos opuestos, lógica y natural para Schlegel, es una constante a lo largo de todo su planteamiento sobre estética, pero es en el Lyceums-Fragment 48, al hablar del carácter formal de dicha interrelación de contrarios como característica principal de la ironía, donde se eleva esta última a paradoja: «Ironie ist die Form des Paradoxen. Paradox ist alles was zugleich gut und groß ist». (Ibid.: 189). Entendiéndose por grande, según puntualiza posteriormente en el Athenäums-Fragment 419, «was zugleich Enthusiasmus und Genialität hat, was zugleich göttlich und vollendet ist» (ibid.: 282). En esta breve definición se puede apreciar claramente cómo Schlegel se aparta de la ironía socrática y concede a su propia acepción de ironía un marcado acento romántico, ya que para Sócrates lo grande y lo bueno eran incompatibles. Este aforismo refleja la misma idea que los anteriormente analizados: la caracterización de la ironía por medio de la relación paradójica dicotómica. Sin embargo, ya no lo hace como una mera adición de elementos contrarios, sino que va profundizando en la significación y en el origen de 
dicha interrelación. A partir de aquí insiste Schlegel en dicho carácter formal de la ironía: «Die Paradoxie ist für die Ironie die conditio sine qua non, die Seele, Quelle und Prinzip.» (1957: 114).

Como se desprende de los Lyceums-Fragmente 42, 87 y 108, la idea común es lograr la sublimación de uno mismo por medio de la libertad que concede la ironía como máxima expresión de aquel «freyen Aktus des Gemüts» (Minor, 1882: I, 98), propuesto ya en Über das Studium der Griechischen Poesie como primera condición de la estructura interna del arte y del comportamiento artístico, con lo cual se eleva a principio básico del arte. Dicho «Aktus» encuentra en los Lyceums-Fragmente una nueva orientación diferenciadora en la reflexión sobre la ironía. Este ha de servir al artista de actitud existencial para consigo mismo, permitiéndole su autoliberación y a su vez posibilitándole un distanciamiento de su propia obra. El sentido de dicha actitud es común para la ironía socrática y para la romántica.

$\mathrm{Al}$ analizar el Lyceums-Fragment 108 veíamos cómo Schlegel concede a la ironía el carácter de licencia más legítima y necesaria. Ello conduce no a una paradoja confusa y desconcertante, sino al núcleo de toda la cuestión filosófica que encierra el concepto de ironía romántica. La formulación del citado fragmento trasluce una idea fundamental del pensamiento filosófico de Fichte. Se trata del principio de subjetividad, esto es, de la libre autodeterminación del yo: «Ichheit ist in sich zurückgehende Tätigkeit des Ich, Subjekt-Objektivität.» (Fichte, 1924: 502). Fichte defiende la teoría del yo como sujeto absoluto, el «Ich». Sitúa a este en el centro de todo suceso, y a expensas de él se origina el mundo de la realidad, es decir, el otro yo, el «Nicht-Ich».

\subsection{Las condiciones de la comunicación artística entre el autor y su obra: Los conceptos «Selbstschöpfung», «Selbstvernichtung» $\mathbf{y}$ «Selbstbeschränkung»}

No hay que caer, sin embargo, en el error de afirmar que la ironía romántica nace únicamente de la interrelación de lo finito e infinito, de lo absoluto y relativo. Es fruto de una relación interactiva de elementos contrarios más amplia, base de la paradoja y condición indispensable que estructura la síntesis antitética que configura la ironía romántica. Esta síntesis de elementos contrarios se apoya asimismo en el principio fichtiano de subjetividad ( $c f$. Fichte, 1970: 23ss.): «Ironie ist Analyse der These und Antithese.» (Schlegel, 1957: 93). Dicha relación abre las posibilidades dialécticas sobre este concepto en el ámbito artístico y, consecuentemente, literario. Así, en el Lyceums-Fragment 37 (Minor, 1882: II, 187ss.) Schlegel establece las condiciones de la comunicación artística. En este fragmento aparecen nuevos conceptos determinantes para la acepción de ironía como principio literario, siempre dentro de una relación contrastiva: «Selbstbeschränkung»y «unbedingte Willkühr» están aquí interrelacionados y 
ambos opuestos a «Illiberalität». Del mismo modo que Schlegel en el fragmento 108 hablaba de libertad como algo necesario y legítimo, en el fragmento 37 califica la arbitrariedad de necesaria, absoluta y razonable. Estos calificativos hacen que la arbitrariedad haya de interpretarse en un sentido positivo y desde el punto de vista artístico como «Laune», y no como mero capricho, sino actuando de forma autónoma e independiente, esto es, libre, según su propia naturaleza. Dicho término lo circunscribe igualmente dentro del dualismo conceptual contrastivo: «Laune ist in der Mitte zwischen Freude und Schmerz, zugleich positiv und negativ.» (Schlegel, 1956: 167). Ello quiere decir que la arbitrariedad se ha de imponer sus propios límites, de ahí su relación antitética con «Illiberalität». Viene a ser, por tanto, una autodeterminación, libre pero a la vez necesaria y comprometida, resultado del arbitrium liberum y no del arbitrium brutum. ${ }^{1}$ Al dotar Schlegel la arbitrariedad de los adjetivos «unbedingt» y «notwendig» le exige la autolimitacion de su libertad. Si no estuviera limitada por estos calificativos, es decir, si no fuera esencial y necesaria, dicha autolimitación se convertiría en destrucción de la propia arbitrariedad. Ello implicaría la destrucción del yo libre, imprescindible para toda creatividad artística, convirtiéndose en mero capricho o subjetivismo negativo. ${ }^{2}$

El fragmento 37 plantea también los conceptos «Selbstschöpfung» y «Selbstvernichtung». Ambos están empleados como alternativa para la autodeterminación libre no solo del artista, sino también del ser humano. Juntos potencian la «Selbstbeschränkung», tal y como apunta también el LyceumsFragment 28: «Selbstbeschränkung, also ein Resultat von Selbstschöpfung und Selbstvernichtung.» (Minor, 1882: II, 186; $c f$. también Schlegel, 1957: 38). En el término «Selbstbeschränkung» está implícito el concepto de ironía como resultante de la interacción entre «Selbstschöpfung» y «Selbstvernichtung». Con dicho término Schlegel quiere expresar la libertad incondicional y a la vez necesariamente responsable que el artista, como tal y como ser humano, ha de tener para consigo mismo y ante cualquier vínculo demasiado fuerte que le una a lo creado por él. Para Schlegel, la autodeterminación del ser humano se realiza solo a través de la propia voluntad, sin que esta «weder

1. Friedrich Schlegel basa su acepción de arbitrariedad en la importante distinción que hace Kant de este concepto en su Transzendentale Dialektik: «Die Freiheit im praktischen Verstande ist die Unabhängigkeit der Willkür von der Nötigung durch Antribe der Sinnlichkeit. Denn eine Willkür ist sinnlich, sofern sie pathologisch (durch Bewegursachen der Sinnlichkeit) affiziert ist; sie heißt tierisch (arbitrium brutum), wenn sie pathologisch nezessitiert werden kann. Die menschliche Willkür ist zwar ein arbitrium sensitivum, aber nicht brutum, sondern liberum; weil Sinnlichkeit ihre Handlung nicht notwendig macht, sondern dem Menschen ein Vermögen beiwohnt, sich unabhängig von der Nötigung durch sinnliche Antriebe von selbst zu bestimmen.» (1913: II, 375).

2. Strohschneider-Kohrs (1977: 37) hace hincapié en el sentido estético objetivo de la ironía, reconociendo en ella el carácter positivo de la arbitrariedad. 
innern noch äußern Schranken unterworfen ist» (Minor, 1882: I, 13). En la exigencia de la autolimitación se manifiesta la negación del mundo, de la realidad misma. Es, por tanto, un elemento constituyente de la autodeterminación que presupone un elevado grado de distanciamiento, tanto de sí mismo como de su propia obra.

Los términos «Selbstschöpfung», «Selbstvernichtung» $\mathrm{y}$ «Selbstbeschränkung», que llevan implícitos los componentes de negación y de nihilismo, se traducen en los fragmentos 28 y 37 de una forma positiva, y son imprescindibles, según Schlegel, para la verdadera interpretación de la libertad creativa. La interacción de estos tres conceptos, expresa, como ninguna otra, la función más esencial y relevante de la ironía como principio literario, esto es, como agente potenciador del impulso creativo artístico. ${ }^{3}$

Al final del fragmento 37 Schlegel vuelve a referirse al concepto «Selbstbeschränkung» al hablar de posibles errores del artista y del escritor, siendo necesario establecer sus límites: «Man muß die Selbstbeschränkung nicht übertreiben». (Minor, 1882: II, 188). De este modo, el concepto «Selbstbeschränkung» lleva implícito el de «Selbstschöpfung» al considerar a este último como una primera fase en el proceso de creatividad, sujeto a una transformación cualitativa por medio de la voluntad, de la libertad y de la limitación. De ello se deriva que el verdadero fundamento de la interacción de ambos conceptos estriba no en la distorsión de la ilusión en sí misma ( $c f$. Immerwahr, 1951: 173), sino en trascender la fuerza creativa limitada. Así pues, podemos afirmar que la ironía es el resultado del «Moment der Negation» (Strohschneider-Kohrs, 1977: 36), es decir, una facultad que está determinada por la lucidez y la más elevada negación, representativas del nihilismo romántico.

\subsection{El concepto «transcendental» en la ironía: Propuesta de una metapoesía universal}

Si bien el concepto «transcendental» para Schlegel encierra el intento de relacionar lo filosófico y lo poético como máxima expresión del arte, dicho concepto se proyecta a través de la ironía solamente en el arte, y más concretamente en el literario. Actúa como fuerza impulsora de la autodesilusión por la propia obra, con el fin de independizar al sujeto de su creación artística. Dado que el romántico distorsiona o destruye la ilusión por medio de la ironía, como se indicaba en el Lyceums-Fragment 42, distorsiona también la forma concreta

3. Behler (1972: 68) define dicha función de la ironía derivada del oscilar entre «Selbstschöpfung» $\mathrm{y}$ «Selbstvernichtung», fruto de lo cual nace la «Selbstbeschränkung» como «Meisterung des künstlerischen Schaffensdranges». 
de la obra creada, potenciándola directamente a través del arte absoluto y único a lo universal e infinito. Es por ello que Schlegel pretende integrar este concepto en la misma dinámica de la vida al proclamar en el Athenäums-Fragment 116 la universalidad de la poesía a todos los ámbitos de la misma como máxima exigencia (Minor, 1882: II, 220): «Die romantische Poesie ist eine progressive Universalpoesie [...]. Sie will [...] und soll die Poesie lebendig und gesellig und das Leben und die Gesellschaft poetisch machen.»

En los siguientes apuntes se reafirma en dicho carácter universal de la poesía: «Die Materie der Poesie muß universell sein» (Schlegel, 1957: 164), «Individualität und Universalität [sind] die Agenten der Poesie.» (Ibid.: 166; $c f$. también ibid.: 163,84). Dicha universalidad de la poesía conlleva a su vez un carácter eminentemente social: «Das Volk muß leben und zwar Poesie leben» (ibid.: 201), «Das gesamte Leben und die gesamte Poesie sollen in Kontakt gesetzt werden; die ganze Poesie soll popularisiert werden und das ganze Leben poetisiert» (ibid.: 141ss.), «Poesie muß und kann ganz mit dem Leben verschmelzen.» (Ibid.: 163). De ahí que aludiera ya en el Lyceums-Fragment 108 a un «Lebenskunstsinn» (Minor, 1882: II, 198). Si el Athenäums-Fragment 22 emplea los términos «Ideales» y «Reales» para definir el concepto «transcendental» (ibid.: II, 207), en el Athenäums-Fragment 238 se sirve también de ellos para aplicar dicho término al ámbito poético, implicando totalmente en él su acepción de ironía al definir la poesía como «Transcendentalpoesie»: «Es gibt eine Poesie, deren Eins und Alles das Verhältnis des Idealen und des Realen ist, und die also nach der Analogie der philosophischen Kunstsprache Transcendentalpoesie heißen müßte.» (Ibid.: II, 242). En este aforismo, al definir la poesía romántica, Schlegel propone una poesía que contemple e integre lo objetivo, y que, por medio de la proyección del sujeto en el objeto, llegue a ser una «Poesie der Poesie» (ibid.), esto es, metapoesía, con lo cual está reconociendo implícitamente la ironía como agente potenciacior del propio arte poético. En el Athenäums-Fragment 388 eleva el término «transcendental» a la máxima potencia: «Transcendental ist was in der Höhe ist, sein soll und kann», diferenciándolo del término «transcendent», que define como «was in die Höhe will, und nicht kann oder nicht soll» (ibid:: 265). Cuando dice en el siguiente apunte «In der Transcendentalpoesie herrscht Ironie» (Schlegel, 1957: 86), vincula explícitamente la ironía a dicho concepto. De todas estas definiciones que interrelacionan la ironía con el concepto «trascendental» se desprende que esta es la expresión de una actitud existencial. Llegado a este punto de la reflexión sobre la ironía, esta ya no se cuestiona, pues, una determinada realidad en un momento determinado, sino toda la realidad histórica, cósmica, si se quiere, adquiriendo el carácter de «Weltironie» (Kierkegaard, 1991: 267) o «allgemeine Ironie der Welt» (Hegel, 1970: XVIII, 460). Con ello la subjetividad alcanza una nueva dimensión dentro de la misma subjetividad. 
Al aludir al «Weltgeist» (Minor, 1882: II, 325) de la poesía y de la filosofía, Schlegel está dotando implícitamente a la ironía de la universalidad que concede a ambas, y de una forma explícita cuando dice: «Die Ironie ist gleichsam die Epideixis der Unendlichkeit, der Universalität, von Sinn fürs Weltall.» (1957: 161). Y al propugnar para el arte la interrelación entre filosofía y poesía como condición sine qua non, y reconocer que «nur in ihnen kann auch das einzelne Werk die Welt umfassen» (Minor, 1882: II, 325), está proyectando el arte a lo universal y, consecuentemente, también la ironía. Ello implica totalmente a esta en el arte poético y, por consiguiente, la eleva a principio literario, a «künstlerische Ironie.» Con ello abstrae la ironía de su componente trascendental, puramente filosófico, y la absolutiza en su condición estéticopoética «zur Kunst gewordene Poesie» (ibid.: 355). Por tanto, esta es, ante todo, una facultad intelectual muy especial dentro del arte que agudiza y potencia las fuerzas creativas del espíritu que pugnan en conmoción interna, dando como resultado la autoliberación del sujeto.

A modo de conclusión podemos afirmar que de todo este análisis sobre la reflexión de la ironía en los postulados estéticos de Friedrich Schlegel hay que destacar tres ideas fundamentales: la dialéctica en el proceso creativo artístico, el elemento trascendental en la significación estética y la reflexión poética como facultad sintetizadora de la paradoja irónica, es decir, la armonización de elementos contrarios. Estas tres ideas vienen representadas respectivamente por tres conceptos que aparecen en sus postulados, de forma implícita unas veces y explícita otras: la «poetische/künstlerische Reflexion», «Transcendental-/Universalpoesie»y el concepto «Paradox». Asimismo, en el proceso creativo artístico, la ironía aparece siempre como el centro del equilibrio pendular en constante movimiento que oscila entre fuerzas positivas, es decir productivas, representadas por la «Selbstschöpfung», y fuerzas negativas, esto es, de autocontrol, representadas por la «Selbstbeschränkung» y la «Sebstvernichtung». Unas y otras se interaccionan en la reflexión poética por medio de la dialéctica, dando como resultado la «Selbsterhebung». Las dos funciones básicas de la ironía, esto es, como facultad de la libre autosublimación y como síntesis antitética, no se excluyen, sino que se complementan, haciendo de ella una conciencia que actualiza y potencia los principios fundamentales del arte.

\section{REFERENCIAS BIBLIOGRÁFICAS}

Allemann, B. (1956): Ironie und Dichtung, Pfüllingen, Günther Neske. BALLART, P. (1994): Eironeia. La figuración irónica en el discurso literario moderno, Barcelona, Sirmio: Quaderns Crema. 
BEHLER, E. (1972): Klassische Ironie, romantische Ironie, tragische Ironie, Darmstadt, Wissenschaftliche Buchgesellschaft.

Fichte, J. G. (1970): Grundlage der gesamten Wissenschaftslehre, Hamburgo, F. Meiner.

Hegel, F. (1970): Werke, 20 vols., Moldenhauer, E. y K. Michel (eds.), Fráncfort del Meno, Shurkamp.

IMMERWAHR, R. M. (1951): «The Subjectivity or Objectivity of Friedrich Schlegel's Poetic Irony», German Review, 25: 173-192.

Joachimi-Dege, M. (1907): Deutsche Shakespeare-Probleme im 18. Jahrhundert und im Zeitalter der Romantik, Leipzig, Haessel.

KANT, I. (1913): Werke, 4 vols., CASSIERER, E. (ed.), Fráncfort del Meno, Shurkamp.

KIERKEGAARD, S. (1991): Der Begriff der Ironie mit ständiger Rücksicht auf Sócrates, (traducción al alemán de E. HIRSCH), HirSCH, E. y H. GERDES (eds.), Gütersloh, GTB Siebenstern.

Schlegel, F. (1882): Prosaische Jungendschriften, 2 vols., Minor J. (ed.),Viena, F. Schöningh. (Citado: Minor).

- (1957): Literary Notebooks 1797-1801, EICHNER, H. (ed.), University of London, The Athlone Press.

Solger, K. F. (1969): Vorlesungen über Aesthetik, Heyse, K. W. (ed.), Darmstadt, Wissenschaftliche Buchgesellschaft.

STROHSCHNEIDER-KoHRS, I. (1977): Die romantische Ironie in Theorie und Gestaltung, Tubinga, Max Niemeyer.

Walser, M. (1981): Selbstbewußtsein und Ironie. Frankfurter Vorlesungen, Fráncfort del Meno, Shurkamp.

Walzel, O. (1938): «Methode? Ironie bei Friedrich Schlegel und bei Solger», Helicon, I: 153-182. 


\title{
'GREAT, BRILLIANT, SIMPLY \\ UNPUTDOWNABLE!': \\ EXAGGERATED PRAISE IN ONLINE \\ CUSTOMERS' REVIEWS
}

\author{
M. Lluïsa Gea VALOR \\ Universitat Jaume I
}

\section{INTRODUCTION}

$\mathbf{T}$

HERE is no doubt that online purchases have become relatively common and popular nowadays. Like many other products, books have also benefited from the boom of the online market, and most publishing and bookselling companies make use of the Internet to promote and sell their products. With this objective in mind, book blurbs and reviews are conspicuously displayed in order to attract the potential reader's attention and persuade him/her to eventually purchase the book (Bhatia, 2004; Gea Valor, 2005). In this scenario, a new tendency seems to be emerging: apart from official reviews and solicited opinions from experts, customers' reviews (CRs) are also offered. In effect, CR web sites constitute an open forum where readers of all backgrounds share their opinions on the books they have read, recommend them or dissuade others from reading them. In other words, customers are given here the opportunity to evaluate books.

The concept of evaluation has drawn much attention in recent years. Of particular interest is the research into evaluative language in academic discourse, especially in the genres of the research article and the book review (Hunston \& Thompson, 2000; Martin \& White, 2005; Salager-Meyer, 2006; Moreno \& Suárez, 2006). All these studies coincide in pointing at the elusive and complex nature of evaluation, and many have also explored related phenomena of paramount importance in academic discourse such as hedging (Hyland, 1996, 1998; Markkanen \& Schröder, 1997).

Taking this research into account, the present paper explores 50 online CRs offered by one of the most popular Internet bookstores: Amazon (<www.amazon.co.uk>). The main objective of this study is to examine the way readers word their evaluative comments, especially their positive ones. It is argued here that, in contrast with professional writers, ordinary readers are not subject to the pressures of the academia or the publishing industry so that 
their reviews will probably render more honest and emotional appraisal. Pragmatic factors such as the anonymity of the reviewer, the lack of any kind of relationship with the review and the characteristics of the target audience are also considered.

\section{THE STUDY}

The corpus of this study consists of 50 online CRs displayed by the wellknown online bookstore Amazon in its British version (<www.amazon.co.uk $>$ ). All the CRs analysed refer to the so-called 'Hot 100 Books' (Figure 1), defined by the company as «The 100 titles Amazon.co.uk customers couldn't live without in the last 24 hours. Updated hourly». Most of them are fictional bestsellers and their date of publication is quite recent: from November 2004 to March 2006. The latest search was performed on 20th March 2006.

Figure 1. Amazon 'Hot 100 Books' Web Page

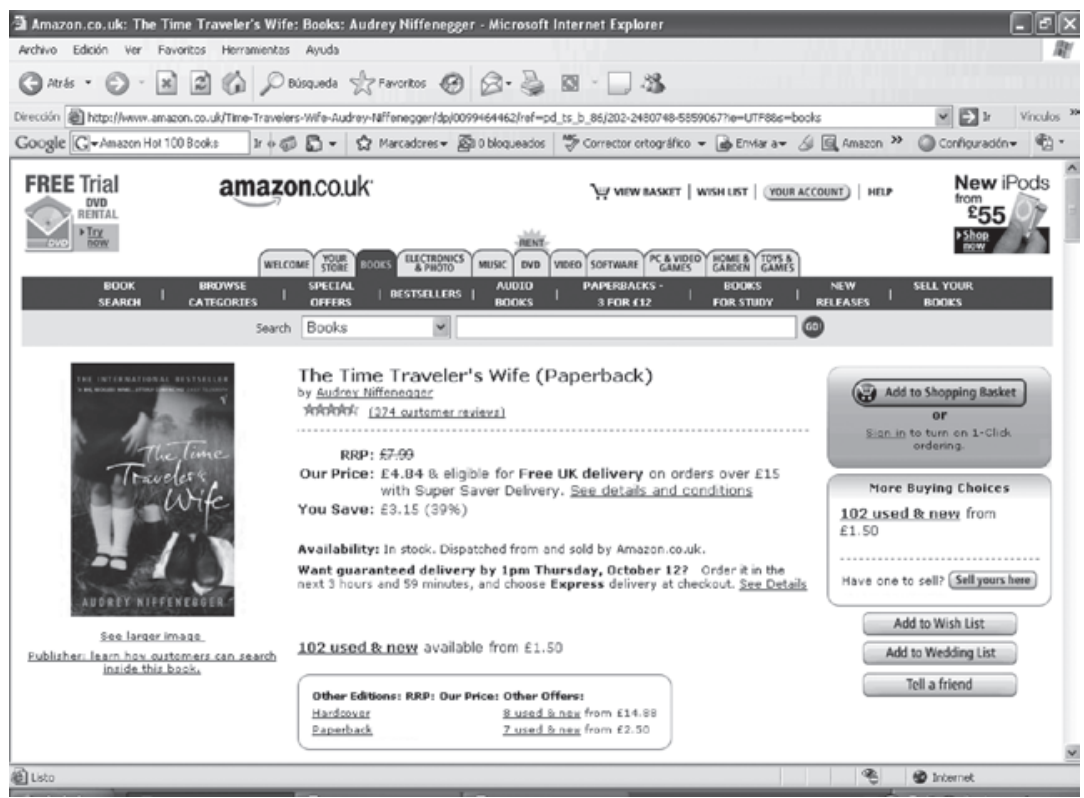

Since the main objective of this study is to explore the way readers word their praising evaluative comments, an initial larger corpus of Amazon CRs was analysed and classified into three main groups - utterly positive, balanced 
and utterly negative; only those in the first and second group, namely those containing absolutely positive and balanced evaluation, were focused on.

The starting hypothesis was that pragmatic factors such as the anonymous nature of the assessment rendered and the target audience - the general public, a non-specialist audience made up of other readers considered as peers - strongly influence the rhetoric of CRs so that the resulting discourse may be more informal, more direct and less hedged than solicited opinions from expert writers and reviewers.

\section{COMPLIMENTING}

\subsection{Emotional language}

The high emotional involvement of readers when appraising a book is reflected in the pervasive use of emotionally-charged intensifiers, emphatic devices and exclamatory clauses, as in these examples:

«I absolutely loved it. Wouldn't normally bother to write a review but I need to share this with someone: the book is that good! You MUST read it.» (CR11 on The Shadow of the Wind)

«I really enjoyed this book. The first essential for a good thriller is the setting and the various places in France were described with great skill. The test is... would you want to go there... and yes, I would. [...] I felt the book lived... I was there... it was a page turner and please don't compare it with the Da Vinci Code...» (CR1 on Labyrinth)

Closely related to the intense emotional charge of CRs is the exaggeration in the praise, which these examples illustrate:

«This is one of those books that grips you like no other. I couldn't put it down: life had to go on hold whilst this was in my hand.» (CR2 on The Shadow of the Wind) «The Last Templar is just fabulous and a rare creature: a book that just grabs you and charges ahead at a breathless pace, while at the same time giving you a wealth of fascinating information.» (CR6 on The Last Templar).

\subsection{Catchy headings, star rankings and cliché evaluations}

All CRs appear under a heading, usually a short catchy phrase, usually an adjective or an exclamation, which summarises and anticipates the tone of the ensuing review, and also serves to catch the reader's eye. In this sense, their function is similar to that fulfilled by blurbs. Examples: 
«Love it» (CR2 on Labyrinth)

«Brilliant!» (CR1 on Cell)

«Engrossing, absorbing, stunning» (CR7 o n The Shadow of the Wind)

«Sit back and get swept away!» (CR5 on The Last Templar)

«The Time of my Wife» (CR2 on The Time Traveler's Wife)

The use of stars - from one to five - in order to rank the book also aims to pique the reader's attention (Figure 2). In this sense, star ranking functions as a most expressive rhetorical device which conveys meaning in a direct and symbolic way.

FIGURE 2. Star rankings in CRs for K. Hosseini's The Kite Runner

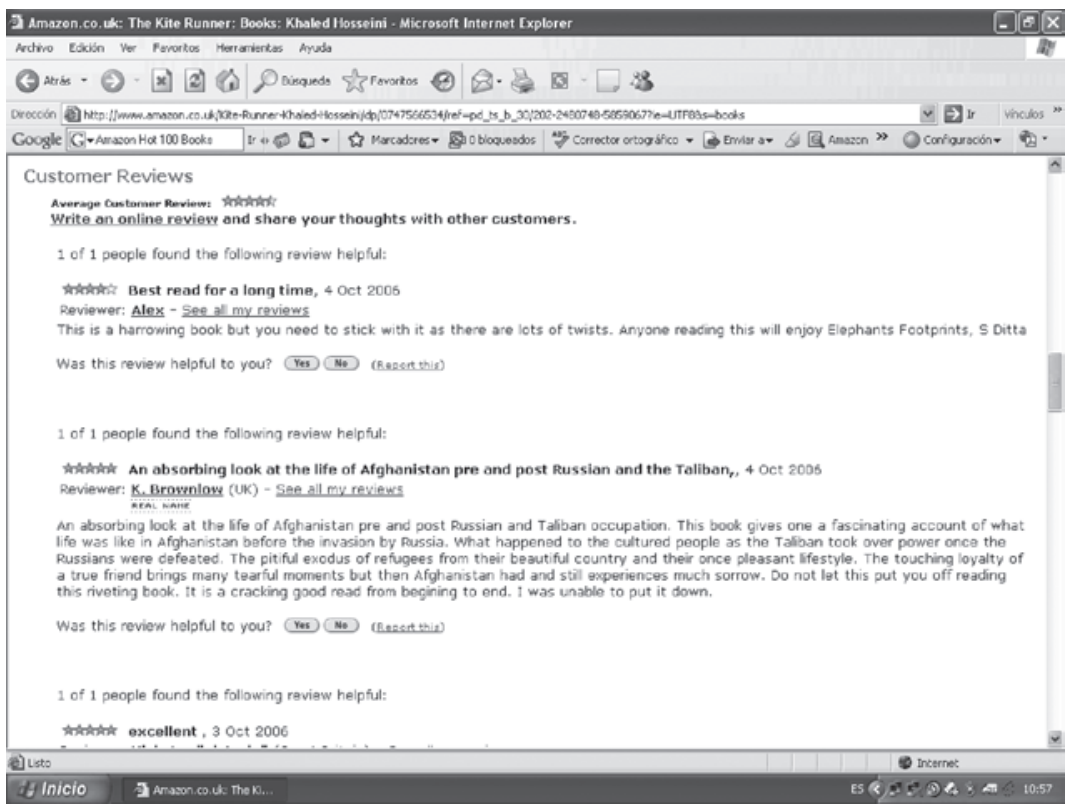

Finally, cliché positive comments are abundantly used in CRs. These highly conventionalised evaluative statements resemble official blurbs, as these examples show:

«Another page turner» (CR7 on False Impression)

«Simply unputdownable» (CR6 on The Last Templar)

«Fantastic read» (CR10 on The Kite Runner)

«Another masterpiece» (CR1 on Blue Shoes and Happiness) 


\title{
3.3. Balancing criticism with praise
}

While a previous study (Gea Valor, 2006) focused on the lack of mitigation and excessive straightforwardness of amateur reviewers in their negative assessment of books, the combination of criticism and praise to tone down the former appears to be a common strategy favoured by readers. Adversative and concessive constructions are the most typical syntactic realisations of this rhetorical practice so that the final resulting tone of the evaluation is positive. The following excerpts clearly illustrate this practice:

\begin{abstract}
«The only problem is that the beginning is a bit slow but once you get into it, it really picks up the pace.» (CR3 on The Last Templar)

«My one criticism would be that for me the book ended somewhat prematurely [...] however, despite my disappointment, the last section of the book still kept me captivated.» (CR4 on The Last Templar)

«Annie Proulx is an excellent writer, and even though I found it occasionally difficult to relate to her main characters [...], I can still understand the themes of longing, despair, disappointment, and yes, love, too.» (CR3 on Brokeback Mountain)

«A fascinating read, occasionally flawed, but full of rich ideas and characters. If only real science fiction writers could learn to colour their characters with a bit of motivation and emotion, too.» (CR8 on The Time Traveler's Wife) «It also surprised and disappointed me that there were no Jewish characters in the book, but maybe Nemirovsky felt that one of her earlier novels, David Golder, had said enough on the subject of Jews.» (CR1 on Suite Française)
\end{abstract}

\subsection{A sense of audience}

The prospective readership may be considered as one of the paramount factors in the pragmatics of the $\mathrm{CR}$ genre. This interesting feature is what I call 'a sense of audience', since many customers seem to rely on previous reviews in order to express their feelings about the book and also whether their expectations were rewarded or not. Examples:

«I have to say that I only bought this book because of the hype, but when I started to read it I could not put it down. It is a great story and although it is fictional, Dan Brown really makes you believe. It's a great book» (CR9 on The Da Vinci Code)

«I wasn't sure about picking this one up, but the other glowing reviews here made me take the plunge. Glad to report they weren't wrong. It's a cracker.» (CR5 on The Last Templar)

«I am glad to see so many praises by other readers» (CR1 on The Time Traveler's Wife) 


\subsection{Recommendations}

Directly related to audience awareness are the common recommendations to other readers, as these examples show:

«If you like lightweight pop fiction thrillers, check out the little known Tourist in the Yucatan, a Da Vinci Code for the Americas!» (CR7 on The Da Vinci Code) «If you like it you'll probably also enjoy Iain Pears' Instance of the Fingerpost, Caleb Carr's The Alienist, Charles Palliser's The Unburied \& Qunicunx and, of course, Eco's Name of the Rose.» (CR7 on The Dante Club)

As can be observed, the most frequent syntactic realisations of such recommending statements are conditional and imperative clauses, which clearly remind us of advertising discourse.

\section{IMPACT OF CUSTOMERS' REVIEWS ON OTHER READERS}

In order to complement and reinforce the results of this study, a small-scale survey was conducted among 20 individuals, all of whom are English language or literature teachers, and also avid readers. The questions relevant to this study were the following:

1) Have you ever used the Internet to find, browse or purchase books?

2) Do you take 'official' reviews in blurbs into consideration for your purchase?

3) Internet blurbs also offer customer's reviews (CRs). To what an extent would a CR influence your decision to buy a book?

As for the first question, most of the respondents recognised using the Internet as an effective tool to browse and purchase books. However, regarding the second and third questions, the responses were more varied. There was general agreement on the fact that the credibility of official reviews depends very much on the critic's authority and reputation, as well as that of the newspaper or magazine where the review has been published. At the same time, however, certain suspicion was shown as to where the loyalties of those critics remained, due to possible biased commitments with publishing houses, as the following sample answer suggests:

Not much. I believe they either 'choose' the good ones or the people who are asked to write a review on a certain book may feel kind of 'forced' to give a positive one. 
In this sense, CRs are generally perceived as more honest and sincere, since they have supposedly not been skewed or manipulated by editors. The fact that CRs appear online in an open forum may also contribute to this perception.

\section{CONCLUSIONS}

This preliminary study of the rhetoric of online CRs has focused on the way amateur reviewers compliment books. The results indicate that readers tend to praise the books they have enjoyed without any reserve, sometimes even excessively, although, contrary to initial expectations, some degree of hedging is also favoured in what can be interpreted as an attempt to balance the negative force of critical comments and render a general positive evaluation of the book.

\section{REFERENCES}

Bhatia, V. K. (2004): Worlds of Written Discourse. A Genre-Based View, London \& New York, Continuum.

Gea Valor, M. L. (2005): «Advertising books: A linguistic analysis of blurbs», Ibérica, 10: 41-62.

- (2006): «A preliminary approach to the rhetoric of online customers' reviews: Emotional involvement and negative evaluation», Proceedings of the 5th AELFE International Conference, 136-141.

Hunston, S. and G. Thompson (2000): Evaluation in Text: Authorial Stance and the Construction of Discourse, Oxford, Oxford University Press.

HYLAND, K. (1996): «Writing without conviction? Hedging in science research articles», Applied Linguistics, 17: 433-454.

- (1998): Hedging in Scientific Research Articles, Amsterdam, John Benjamins.

MarkKanen, R. and H. Schröder (eds.) (1997): Hedging and Discourse, Berlin-New York, Walter de Gruyter.

Martin, J. R. and P. R. R. White (2005): The Language of Evaluation: Appraisal in English, New York, Palgrave MacMillan.

Moreno, A. I. and L. SuÁrez (2006): «The role of evaluation in the rhetorical structure of literature academic book reviews», Proceedings of the 4th AELFE International Conference, 67-76.

SALAGER-MEYER, F. (2006): «¿Lo valiente quitará lo cortés? Critical voices in 19th and 20th century Spanish-English academic discourse», Proceedings of the 5th AELFE International Conference, 127-135. 


\title{
EXPRESIONES EUFEMÍSTICAS EN LA PRENSA DIARIA ${ }^{1}$
}

\author{
Roberto Olaeta Rubio \\ Margarita Cundín Santos \\ Universidad del País Vasco
}

$\mathbf{L}$

A expresión eufemística es un hecho de habla en el que influyen «valores

expresivos y socio-contextuales» (Guiraud, 1960: 30-33). Un vocablo no es eufemístico o disfemístico sino que en un determinado contexto adquiere un sentido eufemístico, que el hablante debe interpretar. No se puede hablar, en sentido estricto, de eufemismo o expresión eufemística sino de usos eufemísticos y disfemísticos de acuerdo con un contexto o una situación comunicativa concre$\mathrm{ta}^{2}$ lo que explica que el auge y la vigencia de muchas expresiones eufemísticas sean tan efímeros como la realidad social que las originó. Un ilimitado número de usos eufemísticos, cada día mayor, son creados ad hoc, de ahí la naturaleza efímera, inestable y vacilante de la mayoría de los usos eufemísticos que encontramos en la prensa diaria.

El estudio de algunos sustitutos eufemísticos con gran arraigo por su empleo frecuente en la prensa peninsular española en la última década (19962006) para evitar agravios étnicos, para referirse a los muertos en las guerras y al terrorismo, nos permitirán acercarnos al hecho eufemístico en el español peninsular moderno.

\section{EUFEMISMOS PARA EVITAR AGRAVIOS ÉTNICOS ${ }^{3}$}

Los medios de comunicación son un fiel reflejo del exceso de prejuicios que padecemos y la necesidad de ocultar la realidad; para ilustrarlo, solo tene-

1. Para ciertas precisiones terminológicas son interesantes, entre otros, los siguientes trabajos: Rabanales (1953), Senabre (1971), Casas Gómez (1986, 1995, 1996, 2005).

2. Los conceptos de eufemismo y disfemismo han sido claramente delimitados por Allan y Burridge (1991): «An euphemism is used as an alternative to a dispreferred expression, in order to avoid possible loss of face either one's own face or, through living offense, that of the audience, or of some third party. [...] A dysphemism is an expression with connotations that are offensive either about the denotatum or to the audience, or both, and it is substituted for a neutral or euphemistic expression for just that reason».

3. En este apartado, por motivos de limitaciones espaciales de los editores, solo haremos referencia a los sustitutos eufemísticos que se emplean para evitar los agravios étnicos contra las personas de raza negra, aunque en la prensa encontramos, a menudo, discursos racistas donde salen a la luz prejuicios contra los gitanos, los árabes, etc. 
mos que fijarnos en cómo han cambiado las designaciones referentes a aquellos grupos o realidades marcados socialmente, por ejemplo los negros, los homosexuales, los drogadictos... Lo negro se asocia con expresiones desfavorables; nuestra lengua está llena de clichés lingüísticos que corroboran esta afirmación: estar negro «estar enfadado», pintarlo negro «expresar el lado negativo de algo», tenerlo negro «tenerlo difícil», trabajar como un negro «trabajar mucho», verlo todo negro «adoptar una actitud pesimista», verse negro «tener dificultades», pasarlas negras «pasar necesidades», tener la negra «tener mala suerte». Lo negro, como color que señala la melancolía, el pesimismo, la aflicción o el infortunio, se encuentra constantemente en el lenguaje cotidiano. Por esto no debe extrañar que, al identificar lo negro como generador de atributos de carácter negativo (mala suerte, ilegalidad, pesimismo, deshonestidad...), se trate de evitar por todos medios este uso como referente de individuos.

Esto no es un hecho arbitrario; desde antiguo, simbólicamente este color es entendido muy a menudo en su aspecto frío y negativo. Corominas y Pascual (1981: s.v. negro) documentan, desde los primeros testimonios de nuestra lengua, los usos figurados de esta voz: la acepción «funesto» se nota ya en Berceo; asimismo, añaden que como sustantivo es ya antigua su sustitución eufemística por moreno. Para Chevalier y Gheerbrant (1993) lo negro expresa la pasividad absoluta, el estado de muerte. Es, pues, el color del luto, del duelo sin esperanza. ${ }^{4}$ En lenguaje del blasón, el color negro se denomina sable (del latín SABULUM «arena») lo que expresa sus afinidades con la tierra estéril. El sable del blasón significa prudencia, sabiduría y constancia en las tristezas y adversidades. El negro se asocia con la ausencia de color, de toda luz, provoca el caos, la nada, las tinieblas, la angustia, la tristeza. Para la Biblia, antes que fuera la luz, la tierra era informe y vacía, las tinieblas recubrían la faz del abismo. Para la mitología grecolatina, el estado primordial del mundo es el caos. El caos engendró la noche.

4. Udo Becker (1996: 228) manifiesta respecto a este color: «El negro aparece con frecuencia bajo los aspectos de lo no diferenciado, lo abismal, para describir las tinieblas, el caos primitivo, la muerte. [...] Es el color del mal, de ahí la expresión magia negra. [...] Desde el punto de vista psicoanalítico las personas y los animales negros de los sueños significan los instintos, las tendencias del inconsciente».

Por su parte, Juan-Eduardo Cirlot $\left(1985^{6}: 324\right)$ compila en su diccionario el sentido de negro aplicado al sustantivo hombre: «La imagen del hombre negro alude siempre a la parte inferior humana, al magma pasional. Este hecho psicológico, comprobado en su empirismo por los analistas, tiene un paralelo -u origen- en la doctrina simbólica tradicional, para la cual las razas negras son hijas de las tinieblas, mientras que el hombre blanco es hijo del sol o de la montaña blanca polar. Naturalmente, también puede tratarse de una mujer negra, [...], la que posee el mismo sentido de inferioridad que en el caso del hombre negro o del "etíope"». 
El Diccionario de Autoridades, s. v. negro registra las acepciones «moreno o que le falta la blancura que le corresponde», «se toma figuradamente por triste y melancólico», «se toma también por infeliz, infausto y desgraciado», «se llama asimismo al Etíope, porque tiene ese color», «en la Germanía vale astuto y taimado». Pero, caben destacar las expresiones recogidas en este diccionario boda de negros «expresión, que por modo de apodo, se aplica a cualquier función en que hay mucha bulla, confusión, grita y algazara», y no somos negros «frase con que se nota al que trata a otro mal de palabra, u obra con superioridad, previniéndole no debe juzgarle esclavo, porque regularmente lo son los negros».

Visto el significado simbólico de este color y sus connotaciones negativas, no es extraño que se intente encontrar sustitutos eufemísticos cuando se hace referencia a las personas de raza negra. ${ }^{5}$

Beatriz Varela (1992) ofrece un buen número de expresiones utilizadas en el habla popular para referirse a los negros (charolitos, tizones, morenos, chocolates...). El carácter irónico de estas expresiones es manifiesto: cuando un concepto es tabuizado, genera gran número de sinónimos en torno a él. Ahora bien, toda esta riqueza sinonímica contrasta con el lenguaje culto empleado dentro de un estilo de habla formal: las expresiones son escasas y sus connotaciones más positivas: gente o personas de color, afroamericanos (solo en Estados Unidos), morenos, trigueños, subsaharianos...

A pesar de la clara intención eufemística de estos usos, estas expresiones no son útiles como forma sustitutiva. Gente o personas de color posee un carácter neutro, ambiguo e impreciso, ¿acaso los blancos son incoloros? Afroamericano evoca el origen africano de los antepasados de estas personas y alberga referencias étnicas positivas. Sin embargo, su uso solo es aplicable en el contexto norteamericano. Alvar Ezquerra (2003: 12) compila esta entrada y aduce 'de los negros de América del Norte', pero además registra negroamericano 'de los negros norteamericanos'. Recoge asimismo otras voces como afroantillano 'de los negros de origen antillano'; afrobahiano 'de los negros de Bahía (estado de Brasil)'; afrobrasileño 'de los negros de Brasil'; afrocaribeño 'negro de un país del Caribe' y 'de los negros del Caribe'. En muchos países de América (Argentina, Colombia, Chile...) la denominación general para referirse a estas personas es la de afrodescendientes, que no hemos documentado en ninguno de los diccionarios consultados.

5. El mismo diccionario académico corrobora estos sentidos simbólicos en las acepciones: «7. adj. Clandestino, ilegal. Dinero negro; 8. adj. Dicho de ciertos ritos y actividades: Que invocan la ayuda o la presencia del demonio o del poder maligno. Magia, misa negra; 9. adj. Muy sucio; 10. adj. Dicho de la novela o del cine: Que se desarrolla en un ambiente criminal y violento; 12. adj. Sumamente triste y melancólico; 13. adj. Infeliz, infausto y desventurado; 15. adj. coloq. Muy enfadado o irritado. Estaba, se puso negro». 
Moreno se usa para designar al negro, al árabe, al mestizo. Se refiere de modo genérico a cualquier raza no completamente blanca. Además pensamos que ha perdido parte de su valor eufemístico y que a menudo tiende a convertirse en un insulto de tipo racista. ${ }^{6}$ El Diccionario de Autoridades, s.v. moreno comenta: «llaman también al hombre negro atezado, por suavizar la voz negro, que es la que le corresponde. Quev. Amistad llaman al amancebamiento, trato a la usura, burla a la estafa... valiente al desvergonzado, cortesano al vagabundo, al negro moreno».

Rubén Darío Julio a propósito de la sustitución del tratamiento negro por el tratamiento moreno aduce (1987: 66-67):

Los hispanohablantes blancos tuvieron que admitir su error, pero al no poder despojarse de su complejo de superioridad, en vez de cambiar su actitud frente al negro, cambiaron negro por moreno. Es más fácil sustituir un vocablo que dejar un hábito. El término moreno se convierte así en un eufemismo, innecesario si no existiera el complejo de culpa: de que se es injusto con la raza negra; de que el negro se ofende si se le dice negro, porque el vocablo porta una tremenda carga negativa, depositada en él por los blancos, a veces no tan blancos como lo suponen. El sólo hecho de emplear una fórmula eufemística es una confesión de la negatividad subyacente al término negro.

En la vigésima segunda edición del DRAE se puede leer en la quinta acepción de la entrada moreno y con la marca coloquial «dicho de una persona: negra».

Subsaharianos está usado de manera imprecisa, ya que presupone que todas las personas que han nacido o viven al sur del Sáhara son de raza negra. Directamente relacionados con noticias sobre inmigrantes subsaharianos, encontramos los calificativos sin papeles, indocumentados e ilegales.

La expresión sin papeles hace referencia a un ciudadano extranjero que se halla en España sin la documentación o los requisitos que las leyes en materia de extranjería disponen a tal efecto. En este sentido, esta denominación es sinónima de los adjetivos indocumentado e ilegal, sentido que no figura en ninguna de las acepciones del diccionario académico. El término sin papeles apareció en Francia en los años setenta con las primeras movilizaciones de los

6. Moreno es voz derivada de moro, del lat. MAurus. Según Corominas y Pascual (1991: s.v. moro) «es una de las palabras más importantes y antiguas, entre las que tienen el sufijo más bien raro-ENUS; pero ante la aplicación sorprendente de una terminación prerromana a una raíz romance, y ante testimonios mozárabes de los ss. XI y XIII sería lícito sospechar que el derivado *MAURINUS se cambiara en maureno y moreno por la misma pronunciación arabizada [...]». En el siguiente párrafo, estos autores comentan la expresión andar a morena «pelearse», donde afloran algunos prejuicios: «frase para amenazar con pelea [...] quizá por el carácter peleante de la raza negra o más bien de los moros, que son morenos $[\ldots]$. 
inmigrantes en situación irregular. Efectivamente, entre 1972 y 1973, numerosas huelgas de hambre colectivas tuvieron lugar en toda Francia para la obtención de la carta de residencia y contra las leyes de inmigración. Es en esa época cuando apareció el término sans-papiers, utilizado en las organizaciones de izquierda que apoyaban los movimientos de los inmigrantes. Antes se hablaba de trabajador inmigrante. Su utilización, de origen periodístico, evita el uso de un término más despectivo como clandestino y no tiene la connotación del concepto de irregularidad y de ilegalidad.

En nuestro país existen numerosas voces para designar a los negros, entre ellas se oyen betún, conguito, negrata, ${ }^{7}$ es decir, denominaciones del habla coloquial, familiar, con sentido peyorativo, que se emplean cuando se pretende menospreciar el valor de un objeto o persona.

En cuanto al español en la vigésima edición del DRAE aparece la entrada negrear ${ }^{8}$ y la tercera acepción reza «insultar a alguien tratándolo de negro», además se dice que es voz de Panamá; en la vigésima primera edición se mantiene la acepción y se extiende su uso a Perú. En la vigésima segunda edición, las acepciones son diferentes y se dice que es voz propia de Colombia, Panamá, Perú y Venezuela con el significado de «menospreciar, tener en menos», y añade el ejemplo: te negrearon; no te invitaron a la fiesta. Según las noticias que aporta Rubén Darío Julio (1987: 73) en Colombia se mantiene como insulto.

En la prensa, cuando el adjetivo negro se refiere a la raza, etnia, no hay duda a la hora de utilizar este adjetivo y se hace con toda normalidad («El cáncer no discrimina a negros, asiáticos, indoamericanos u otras minorías» (El País, 12-05-02); «La mortandad infantil entre los blancos es de 13 de cada mil niños y entre los negros de 60 por cada mil» (El Mundo, 10-05-96). ${ }^{9}$

7. Pharies (2002: 114-115) refiere que tradicionalmente, las palabras españolas terminadas en -ata se dividían en varias categorías: latinismos que representan la forma femenina de sustantivos y adjetivos en -atus; latinismos provenientes de sustantivos latinos cuya terminación no corresponde a -atus, -ata; numerosos italianismos; y palabras de origen diverso. Recientemente, este sufijo ha cobrado nueva vida en el lenguaje juvenil. Es frecuente oír fumata, sociata, drogata, negrata... Sanmartín Sáez (1998: 93) asevera que el origen del sufijo en este uso se documenta primero en el argot de los delincuentes y luego se extiende al lenguaje juvenil. Para Camus y Miranda (1996: 273) se trata de un sufijo epiceno de unos setenta sustantivos (entre ellos negrata «negro») «cuya evidente relación formal se ve reforzada por el hecho de pertenecer a una misma variante sociolingüística de tipo jergal».

8. Corominas y Pascual, s.v. negro registran el derivado negrear y añaden: «popularmente negrear, *nigriar, podría venir el alav. y rioj. nidrio "amoratado", "harto de comida o bebida"».

9. Para no desviarnos de nuestro tema, dejamos el ejemplo tal y como se ha recogido de la prensa y no entramos a valorar la confusión del periodista entre mortandad y mortalidad, término que debería haberse empleado en este caso. 


\section{EUFEMISMOS REFERIDOS A LA GUERRA}

El fenómeno de la guerra es uno de los elementos a partir del cual se generan gran cantidad de eufemismos, sobre todo por el trato cercano con la muerte y el derramamiento de sangre. Entre los eufemismos más utilizados para designar a las personas muertas en la guerra destacan caídos y bajas. Las tropas sufren importantes bajas, las bombas y minas sin explotar causan bajas, las municiones de racimo provocan bajas civiles... Estados Unidos honrará a los caídos en Irak; héroes caídos en combate; periodistas caídos en Irak... Son numerosos los ejemplos que podemos encontrar en la prensa.

El término caído para referirse a una persona muerta violentamente se documenta desde antiguo. Procede del latín CAEDERE, verbo al que se le atribuye comúnmente el significado de «cortar». Según Uría (1997: 287) una explicación precisa del significado de este verbo no debe limitarse al significado de «cortar», o de «abatir cortando»; es primario el significado de «golpear» respecto al de «cortar». Comenta este autor:

De hecho, es posible que, en el origen, CAEDERE no sea más que un causativo de CADERE, lo que equivaldría a decir que su significado era 'hacer caer': es lógico que en el vocabulario técnico de los campesinos adquiera, al aplicarse a los árboles, el significado de 'hacer caer cortando' y, de ahí, 'cortar'. Pero en el lenguaje común y en referencia a entes animados, el sentido contextual adquirido sería 'hacer caer golpeando', de donde 'golpear'.

Originariamente, el sentido que adopta el verbo caer en el lenguaje militar es el de «abatir de un golpe» y era muy probable que el hecho de abatir se llevara a cabo con un instrumento cortante, dadas las armas con las que se combatía. Así pues, el significado básico del que surgió el sentido de morir fue el de «matar golpeando». No debemos olvidar que uno de los verbos más usados en latín para referirse al hecho de matar es OCCIDERE, verbo formado sobre CAEDERE. Precisamente, derivado de OCCIDERE tenemos el sustantivo OCCASUS (ocaso) con el sentido de «ocultarse el sol, caer el día», es decir la muerte del día. La posibilidad de utilizar el verbo caer como metáfora con el sentido de «caer en combate» es muy común. ${ }^{10}$ Dicho empleo es frecuente en las narraciones bélicas y artículos periodísticos, donde el contexto está lo suficientemente claro como para permitir que un verbo como caer pueda designar única y exclusivamente el hecho de la muerte.

El sustantivo baja con el significado de «muerte o inutilización de un hombre producida en la lucha» solo se aplica en el lenguaje militar y tiene gran éxito

10. Este verbo, además de usarse en español para designar la muerte en combate, se emplea en griego $\pi \iota \pi \tau \omega$, en francés tomber, en alemán fallen y en inglés fall. 
en la prensa como sustituto eufemístico de «muerto en el combate». Los diccionarios generales de la lengua registran como primera acepción del vocablo femenino baja el sentido de «cese o abandono de una persona en un cuerpo, en una profesión o en una asociación legalmente reconocida» y posteriormente «muerte o desaparición en combate de una persona». Todas las locuciones y modismos que se emplean en nuestro idioma con la voz baja están relacionados con la idea de abandono de algo: causar baja «dejar de pertenecer a una asociación, a un grupo, etc.»; dar de baja a alguien «declararlo enfermo, lo que conlleva al cese temporal en el trabajo» o «registrar que ha dejado de dedicarse a una actividad». Podríamos seguir con más ejemplos, pero consideramos que es suficiente para corroborar que el uso de esta voz con el significado de «muerte en el combate» está relacionado con la idea de abandono, dejación, en este caso de la vida.

Entre las designaciones básicas para referirse a la privación violenta de la vida destacamos acabar con. El verbo acabar como sustituto eufemístico de «morir, fallecer» lo encontramos en el Diccionario de Autoridades (I: 31). En este mismo diccionario se recoge la expresión acabar con alguno, e indica «es matarle o perseguirle, hasta perderle y arruinarle». Cuervo, s.v. acabar, señala: «5. Poner fin, destruir, consumir, apurar. Dícese tanto de lo físico como de lo moral. 6. Matar; primariamente se dice del que ya está herido, luego del que sucumbe al número, y por fin representa la acción lenta de las causas que traen la muerte. 9. Morir, perecer (intrans.)». Corominas y Pascual (1991: s.v. acabar) recogen este verbo como derivado del sustantivo cabo del latín CAPUT «cabeza» y de ahí procede la acepción castellana «extremo de una cosa». Acabar es «propiamente hacer algo hasta el cabo», es decir, hasta el fin.

La mayoría de diccionarios recogen la expresión acabar con algo o alguien «destruirlo, aniquilarlo». Es fácil establecer una relación entre este verbo y el hecho de matar. Acabar es alcanzar el punto final de algo, y el fin de la vida es la muerte.

Otros sustitutos aplicados al campo de matar pertenecen fundamentalmente a los ámbitos semánticos de la privación: eliminar, suprimir, quitar de en medio. Se trata de sustitutos con los que se pretende lograr cierta atenuación en la comunicación de la referencia real. Los hablantes aprecian claramente el valor de privación que existe en estos verbos y esto permite atribuirles un cierto valor eufemístico, si bien es cierto que han sido pronunciados por soldados que relataban sus experiencias a los periodistas, en un ambiente informal, coloquial.

El DRAE s.v. eliminar compila la acepción «matar, asesinar» y la única información que facilita es que se trata de un verbo transitivo. Los diccionarios de uso también recogen este sentido. El diccionario Clave en la 3. acepción nos informa de que con el sentido de matar o asesinar es voz coloquial y 
el Diccionario Salamanca en la 4. a acepción «matar una persona a otra» aduce que se trata de un eufemismo. Parece clara la extensión de este verbo con el significado de matar, pero no precisamente en el campo de batalla. El contexto en el que se produzca este hecho violento no es relevante para determinar su sentido: eliminar es privar a alguien de su vida. El DRAE no recoge el sentido de «matar» en la entrada suprimir («tr. Hacer cesar, hacer desaparecer. Suprimir un empleo, un impuesto, una pensión»).

De manera similar, encontramos el uso del verbo liquidar, que originariamente significaba hacer líquido algo consistente. Se trata de un derivado del sustantivo licor (procedente del latín LIQUOR, -ORIS «fluidez, liquidez», «líquido») que en la octava acepción del DRAE y con la marca vulgar, se define como «desembarazarse de alguien, matándolo». Liquidar significa literalmente «Poner término a algo o a un estado de cosas» $\mathrm{y}$ «Gastar totalmente algo, especialmente dinero, en poco tiempo» (acepciones 4 y 5 ). En este caso se alude a terminar con la vida de una persona empleando una metáfora que reduce la carga negativa del acto o al menos le otorga un aire informal. Parece claro que, por extensión del significado de esta acepción, se ha llegado al sentido metafórico de matar que tiene hoy.

Estos verbos son aceptables socialmente hablando porque consiguen ocultar el lado más crudo del objeto tabú. A pesar de que se han lexicalizado y han perdido su ambigüedad original sirven de sustitutos eufemísticos porque pertenecen al campo léxico de la privación y el hablante los asocia con la privación de la vida.

Un caso diferente lo constituye el verbo neutralizar, que se usa con el sentido de matar hablando de rivales políticos en una situación de conflicto. La acepción más próxima que recoge el DRAE es la que figura con el número 3 «tr. Anular, controlar o disminuir la efectividad de algo o de alguien considerados peligrosos», donde veladamente se hace alusión a la idea de matar. La diferencia en el uso de este verbo o los mencionados en los párrafos anteriores estriba, en primer lugar, en su aspecto diafásico. Suprimir, eliminar, quitar de en medio se pronuncian en situaciones coloquiales y de familiaridad, $\mathrm{y}$, en segundo lugar, son verbos que se han lexicalizado y en cierta manera han dejado de ejercer su función de nombrar indirectamente al objeto tabú. Cuando esto ocurre, los hablantes buscan un nuevo sustituto eufemístico para no recurrir a voces inapropiadas, bien porque son malsonantes o porque dejan a la vista crudas realidades. Por eso, en los medios de comunicación, se recurre a la utilización de otro término, neutralizar, al que se le otorga un sentido nuevo y así se puede seguir refiriéndose al objeto innombrable. El sentido de neutralizar es más ambiguo que el de abatir, ejecutar, matar y de ahí su éxito en la prensa. De hecho las acepciones que recogen los diccionarios no tienen nada que ver con la idea de matar. 
Entre las expresiones más populares, recogidas de boca de soldados, destacan las siguientes: achicharrar, freír, asar, dar matarile... Nosotros las consideramos sustitutos eufemísticos porque, al igual que eliminar o suprimir, ocultan la realidad interdicta. Como derivado del verbo matar surge la locución dar matarile a alguien que denota cierto juego fónico. El uso de achicharrar con el sentido de «disparar sobre una persona y acribillarla» obedece a un sentido figurado del verbo achicharrar en su primera acepción del DRAE «Freír, cocer, asar o tostar un alimento, hasta que tome sabor a quemado». Es decir, la persona queda sin vida, figuradamente frita, por la acción de las balas. Achicharrar es verbo derivado del sustantivo chicharrón «residuo de las pellas del cerdo, después de derretida la manteca» (Corominas y Pascual, s.v. chicharrón). Se trata de una raíz onomatopéyica $\mathrm{CHICH}$ - imitadora del ruido del chicharrón al freírse. Achicharrar, antes chicharrar [Quevedo], «abrasar» procede de la misma onomatopeya. El sentido figurado de matar es evidente.

En la macroestructura freír, el DRAE recoge el sentido de «acribillar» con la marca coloquial y aduce como ejemplo Lo frieron a balazos, a tiros. Seco, Andrés y Ramos (1999) s.v. freír recogen tres acepciones con la marca coloquial y los sentidos de «quemar o achicharrar algo o a alguien»; «acosar o molestar insistentemente con algo», y, finalmente, «acribillar a balazos». En estos casos se comprueba que estos sustitutos eufemísticos destacan un aspecto de un concepto en términos de otro: matar es freír, asar, achicharrar... Es decir la conceptualización de matar en términos de las diferentes maneras de preparar los alimentos. Además no debemos olvidar que las metáforas culinarias son frecuentes en la vida diaria: cocerse «emborracharse», quedarse frito «quedarse dormido», tener frito a alguien «estar harto», tener achicharrado a alguien «molestar», hervirle a alguien la sangre «enfadarse»...

En el extremo opuesto, encontramos la necesidad de impactar, de llamar la atención del lector con la realidad más cruda. De ahí que en los titulares de las noticias los sustitutos eufemísticos escaseen y los términos elegidos no oculten la realidad interdicta: se emplean los verbos matar, ejecutar, abatir...

\section{EUFEMISMOS RELACIONADOS CON EL TERRORISMO}

Si se analiza el lenguaje empleado en las noticias sobre terrorismo, enseguida nos percatamos de que hay una invasión de términos que son propios del discurso militar. En este trabajo dejaremos a un lado estas expresiones, y solo haremos referencia a algunas palabras y sintagmas utilizados frecuentemente y sometidos a interdicción.

Sin duda alguna, uno de los sintagmas más extendidos mediáticamente es kale borroka y su correspondiente en español violencia callejera. Efectivamen- 
te, en la sección destinada al Defensor del lector del diario El País, los lectores se cuestionan acerca de la idoneidad o no de estas expresiones. ${ }^{11}$ El sustantivo borroka, en los diccionarios bilingües (Elhuyar, Hiztegia 3000) se define como «pelea, lucha, combate, enfrentamiento». Sarasola (1997) señala «Norbaitek edo talde batek beste norbaiti edo talde bati garaitzeko, buru egiteko edo zerbait lortzeko egiten duen indarrezko ahalegina» (Lucha que una persona o un grupo hace contra alguien o contra un grupo para vencerle o para lograr algo).

Las cuatro palabras están estrechamente relacionadas con el mundo militar. Se refieren a acciones en las que intervienen fuerzas militares y tienen connotaciones positivas; lucha, combate, enfrentamiento son lemas que llevan implícita la idea de defensa de unos ideales, de una causa justa y, como bien refleja el DRAE en la acepción cuarta de la entrada lucha, se trata de resistir a una fuerza hostil para alcanzar algún objetivo. Las personas que acuñaron esta expresión, movidos por su ideología política, trataron de evidenciar el derecho que les asiste de defenderse contra lo que consideran una fuerza invasora.

La traducción al español más habitual y de mayor difusión es violencia callejera. Esta expresión ha sido objeto de duras críticas por algunos sectores de la población, por considerarla demasiado genérica y no reflejar con nitidez la dura realidad. En efecto, el DRAE define el término violencia como «f. Acción violenta o contra el natural modo de proceder», microestructura que da lugar a las más variadas interpretaciones. Alvar Ezquerra (2003: 1334) la compila entre sus páginas como «Conjunto de acciones violentas llevadas a cabo, en plena calle, por grupos pequeños de jóvenes de ideología radical contra las cosas o las personas».

El problema de fondo es el significado de la expresión. Lo que en euskera tiene connotaciones positivas es una realidad sujeta a interdicción en castellano, por eso, no es apropiada la expresión genérica violencia callejera. En algunos medios se puede leer terrorismo callejero e, incluso hace algún tiempo se hablaba de terrorismo de baja intensidad, como si de una magnitud física se tratara. En definitiva, el sustantivo borroka «lucha, pelea, combate» tiene una serie de implicaciones culturales que conllevan a entender los destrozos y altercados ocasionados como algo noble, como acciones de justicia y de prestigio para sus protagonistas. En español, por el contrario, se entiende como el resultado de acciones totalmente negativas, dañinas y perjudiciales, fruto de la irracionalidad. Esta inadecuación entre las expresiones en euskera y castellano se extiende al lenguaje periodístico que es usado como seña de identidad de la propia postura ideológica del periódico de que se trate.

Respecto a la manera de referirse a los terroristas, en la prensa se encuentra una variada gama de sinónimos. Si se trata de prensa ideológicamente próxima

11. Defensor del lector, ¿'Borroka’ o terrorismo?, El País, 16-04-2000. 
al mundo de la denominada izquierda aberzale encontramos: activistas, militantes, luchadores, gudaris... Por el contrario, los periódicos de ámbito nacional se hacen eco de una variada gama de voces que, a menudo, se acompañan del adjetivo etarras: asesinos, terroristas, matones, pistoleros... En general, el terrorista es el que domina o se impone por medio del terror. Se observa que es la situación pragmática no solo la que suscita, sino también la que justifica estos empleos sinonímicos de naturaleza eufemística. Un activista es, según el DRAE, «Agitador político, miembro que en un grupo o partido interviene activamente en la propaganda o practica la acción directa». ¿A qué se refiere el diccionario académico con «practica la acción directa»? Militante es «la persona que practica la milicia», es decir, relacionado con el arte de hacer la guerra. Luchador designa a la persona que lucha, esto es, la que combate a una fuerza hostil. Comprobamos, pues, que tanto activista, como militante o luchador son sustantivos que no tienen nada que ver con la imposición del terror, sino con la práctica militar.

Entre los partidarios de ETA, se llama en ocasiones gudaris a los miembros de esta organización. Es voz vasca procedente de guda «guerra» y el sufijo ari que indica oficio. Los gudaris eran los miembros del Ejército Vasco (Eusko Gudarostea) en la Guerra Civil Española. ${ }^{12}$ Es uno de los sustantivos más extendidos entre los simpatizantes del mundo aberzale. Alvar Ezquerra (2003) lo recoge en su diccionario con el significado de «soldado del ejército vasco durante la Guerra Civil Española». Sarasola, s.v. lo define como «gerra egiten duena (el que hace la guerra)», «soldadua, berezk. Eusko Gudarosteko soldadua (soldado, principalmente, soldado de Eusko Gudarostea)».

En la otra cara de la moneda encontramos las designaciones extendidas en los medios de comunicación de ámbito nacional: asesinos, matones, pistoleros, etarras... Todos estos sustitutos encierran la idea de matar a alguien con premeditación y alevosía, pero en el caso de pistolero se añade además un rasgo fundamental: el uso de la pistola mercenariamente (DRAE, s.v. pistolero «Hombre que utiliza de ordinario la pistola para atracar, asaltar, o, mercenariamente, realizar atentados personales»). Matón es voz relacionada con el verbo matar y por asimilación fónica se utiliza con el mismo sentido que pistolero o asesino; sin embargo, el DRAE define matón como «m. coloq. Hombre jactancioso y pendenciero, que procura intimidar a los demás», y ya en el Diccionario de Autoridades podemos leer: «MATón. f.m. Guapetón, espadachín y pendenciero, que afecta valentía y quiere poner miedo. Lat. Sicarius». Es decir, que el término matón no conlleva el rasgo pertinente de matar, sí el de infundir o causar miedo.

12. Eusko Gudarostea fue la denominación utilizada por el ejército nacionalista vasco durante la guerra civil, que luchó en el frente del Norte contra las tropas de Franco. 
Etarra es un término formado sobre las siglas ETA (Euskadi eta Askatasuna) y el sufijo que indica procedencia y sirve para la formación de gentilicios -darra, -tarra. En el DEA se define como «de la organización terrorista ETA». En ocasiones, se usa como elemento formativo de sustantivos compuestos, sobre todo, con las voces asesino y pistolero: pistoleros etarras, asesinos etarras.

\section{CONCLUSIONES}

Los rodeos eufemísticos son muy empleados por la prensa para hacer más apacible la cruda realidad con la que se encuentran a diario los ciudadanos cuando leen las páginas de cualquier periódico. Si neutralizar puede funcionar como un uso eufemístico para matar o matanza es precisamente por su carácter ambiguo y polisémico. La realidad es la misma, pero no el efecto que produce. Efectivamente, nos encontramos ante un procedimiento de creación léxica de gran éxito entre los trabajadores de los medios de comunicación quienes recurren a diversos procedimientos de creación eufemística: 1) la simbología: se trata de voces asociadas con expresiones desfavorables y que simbólicamente se entienden por su aspecto negativo; 2) la existencia de estos sustitutos eufemísticos ya en latín o en determinados lenguajes especializados, donde única y exclusivamente pueden designar un concepto; 3) otros eufemismos se crean por asociación de ideas, es decir, pertenecen a un ámbito semántico concreto, los hablantes aceptan la relación entre un objeto tabú y el sustituto eufemístico básico y a partir de ahí los términos emparentados con el que toman como básico se pueden usar para hablar del objeto tabuizado; 4) la utilización de un término al que se le otorga un nuevo sentido; 5) finalmente, las implicaciones culturales e ideológicas que acompañan a muchos términos y que conllevan a entenderlos de manera totalmente opuesta según quien acuñe la expresión.

\section{REFERENCIAS BIBLIOGRÁFICAS}

AlLAN K. y K. BuRRIDGE (1991): Euphemism and dysphemism: language used as shield and weapon, Oxford, Oxford University.

Alvar EzQuerra, M. (2003): Nuevo diccionario de voces de uso actual, Madrid, Arco Libros.

BECKER, U. (1996): Enciclopedia de los símbolos, Barcelona, Robinbook, SL. CAmus, B. y A. Miranda (1996): «En favor de una morfología paradigmática: las formaciones españolas en -ata», Revista Española de Lingüística, 26: 271-300. 
Casas Gómez, M. (1986): La interdicción lingüística. Mecanismos del eufemismo y disfemismo, Cádiz, Universidad de Cádiz.

- (1995): «Sinonimia y eufemismo», Quaderni di Semántica 16: 17-46.

- (1996): «El poder mágico de la palabra», Trivium. Anuario de Estudios Humanísticos, 8. In memoriam Prof. José Luis Millán Chivite, 29-52.

- (2005): «Precisiones conceptuales en el ámbito de la interdicción lingüística», Palabras, norma y discurso. En memoria de Fernando Lázaro Carreter, Salamanca, Universidad de Salamanca.

Chevalier, J. y A. Gheerbrant (1993): Diccionario de los símbolos, Barcelona, Herder.

CiRLot, J.-E. (1985'): Diccionario de símbolos, Barcelona, Labor.

Clave (2002): Diccionario de uso del español actual, Clave, Madrid, SM.

Corominas, J. y J. A. Pascual (1991): Diccionario crítico etimológico castellano e hispánico, (6 vols.) Madrid, Gredos (3. ${ }^{a}$ reimpresión).

Cuervo, R. J. (1886-1893): Diccionario de construcción y régimen de la lengua castellana, Instituto Caro y Cuervo, Santafé de Bogotá (1994, 1. ${ }^{a}$ reimpresión).

Guiraud, P. (1960): La semántica, México, Fondo de Cultura Económica.

JULIO, R. D. (1987): «Racismo lingüístico», Lingüística y Literatura, n. ${ }^{\circ}$ 11-12, Universidad de Antioquia, Colombia.

Moliner, M. (1998): Diccionario de uso del español, Madrid, Gredos.

PHARIES, D. (2002): Diccionario etimológico de los sufijos españoles, Madrid, Gredos.

Rabanales, A. (1953): Introducción al estudio del español de Chile. Determinación del concepto de chilenismo, Santiago de Chile, Editorial Universitaria.

- (1958): «Recursos lingüísticos en el español de Chile de expresión de la afectividad», Separata del Boletín de Filología de la Universidad de Chile, tomo X, Instituto de Filología, Universidad de Chile.

Real Academia Española (1990): Diccionario de Autoridades, Madrid, Gredos.

- (1984): Diccionario de la lengua española, Madrid, Espasa-Calpe.

- (1992): Diccionario de la lengua española, Madrid, Espasa-Calpe.

- (2001): Diccionario de la lengua española, Madrid, Espasa-Calpe.

SANMARTín SÁEZ, J. (1998): «Lenguaje y cultura marginal. El argot de la delincuencia», Cuadernos de Filología, anejo 25, Valencia, Universitat de València.

Sarasola, I. (1997): Euskal Hiztegia, San Sebastián, Fundación Kutxa.

Seco, M., O. Andrés y G. Ramos (1999): Diccionario del español actual (DEA), Madrid, Aguilar.

Senabre, R. (1971): «El eufemismo como fenómeno lingüístico», Boletín de la Real Academia Española, 51: 175-189. 
Universidad de Salamanca (1996): Diccionario Salamanca de la lengua española, Madrid, Santillana.

URÍA, J. (1997): Tabú y eufemismo en latín, Ámsterdam, A. M. Hakkert.

VV.AA. (2002): Hiztegia 3000 euskara - gaztelania / gaztelania - euskara, Adorez hiztegiak.

VAREla, B. (1992): El español cubano-americano, Nueva York, Senda Nueva de Ediciones.

Viceconsejería de Política Lingüística del Gobierno Vasco (1999): Diccionario Elhuyar, Gobierno Vasco. 


\title{
DE LOS APODOS Y MOTES DE TODA \\ LA VIDA A LOS NICKS DEL CIBERHABLA. \\ HACIA UNA CARACTERIZACIÓN \\ LINGÜÍSTICA DE LOS CHATS \\ A PARTIR DE LOS NICKS
}

\author{
Pedro Tejada Tello \\ IES Vicent Castell i Doménech
}

\section{INTRODUCCIÓN}

Tos proponemos un análisis de una manifestación concreta del ciberhabla, 1 el chat, centrándonos en los apodos o nicks que los usuarios crean para interactuar. El focalizar nuestra atención en el nick se debe a varios motivos:

1) Se trata de un requisito indispensable y decisivo para abrir, propiciar o truncar este tipo de comunicación mediante ordenador.

2) Es marca catafórica, es decir, anticipadora de rasgos idiosincrásicos de los participantes en la comunicación.

3) Es marca sintetizadora de las principales características lingüísticas de los chats.

\section{MARCO TEÓRICO-METODOLÓGICO}

Puesto que los nicks forman parte indispensable de una peculiar forma de comunicación, nuestro estudio adopta como marco teórico la perspectiva pragmática, que considera siempre los hechos lingüísticos sin separarlos del contexto en que surgen y donde deben ser interpretados. Por ello, en nuestro análisis hemos considerado los nicks en el contexto en el que surgen y para el que surgen: en un marco singular, que Crystal (2002) ha llamado «un genuino "tercer medio"», «suma de habla + escritura + otras propiedades que ofrece el medio electrónico» y cuyas producciones muchos estudiosos, como Yus (2001), consideran textos escritos oralizados, que incorporan vías compensatorias de la ausencia de canal auditivo-vocal. Este marco electrónico diferente del marco real nos permitirá además distinguir el nick del apodo tradicional.

Por otra parte, el desarrollo de la pragmática en las últimas tres décadas ha fructificado en diferentes perspectivas y teorías que nos han resultado útiles 
para los objetivos de nuestro trabajo. Así, el principio de cooperación de Grice (1975), la teoría de la relevancia de Sperber y Wilson (1986), y los estudios de cortesía lingüística -Leech (1983), Brown y Levinson (1987), Haverkate (1994), Bravo y Briz (2004)-, entre otros aspectos, nos permiten caracterizar los nicks, y por extensión el chat, así como ampliar los criterios de clasificación de los nicks, hasta ahora muy estrechos.

En lo que respecta a nuestro corpus, indicaremos que está formado por 1.000 nicks, recogidos en dos portales españoles de Internet, <www.ya.com> y <www.terra.es>, en sus respectivos canales de chat «\#amigos más de 40» (en este tipo de canales es mayor el número de usuarios y también mayor la variedad de nicks que en otros canales temáticos). Los datos se recogieron entre febrero y julio de este año, en días no consecutivos, normalmente entre las 10 y las 12 de la noche (en el canal de Terra suele haber a esas horas una media de 2.500 usuarios conectados). Hicimos la selección de nicks al azar, aunque un buen número de ellos corresponden a usuarios que solían repetir los nicks durante varias sesiones.

\section{LOS APODOS TRADICIONALES}

Resulta inconcebible una sociedad en la que los seres humanos estuvieran desprovistos de nombres. «Nadie, ya sea de baja o elevada condición esté sin nombre una vez que ha venido al mundo», podemos leer en la Odisea. (Ullmann, 1980: 81) En el siglo II a.C. el gramático Dionisio el Tracio hablaba ya del nombre propio como «aquel que significa un ser individual, tal como "Homero", "Sócrates"» (Ullmann, 1980: 83). Esta definición, retomada posteriormente por otros autores, no tomaba en cuenta que muchas personas, diversas y distantes y no emparentadas entre sí, podían tener el mismo nombre (Ullmann, 1980: 83). Por ese motivo junto a los nombres surgieron los apellidos. La función del apellido es la de servir de complemento al nombre de pila para evitar confusiones. Seguramente, uno de los recursos más antiguos en este sentido fue añadir al nombre de nacimiento algún apodo o mote. Apodo (de apodar) lo define el DRAE como «nombre que suele darse a una persona, tomado de sus defectos corporales o de alguna otra circunstancia». Y mote (procedente del prov. o fr. mot, palabra, dicho) como «sobrenombre que se da a una persona por una cualidad o condición suya». Alias (del latín alias) es «apodo o sobrenombre». Hoy, sobre todo en las zonas rurales, aún está muy arraigado el hábito de designar a una persona por su apodo. Apodo que, además, suele ser hereditario. Como indican Faure et al. (2005: XVII) «esta costumbre nos ayuda a entender cómo se hicieron hereditarios los segundos nombres o apellidos». La fijación de los apellidos 
comienza con la difusión del uso de la documentación legal y notarial a partir de la Edad Media. ${ }^{1}$ Los apellidos actuales en España derivan de diferentes sobrenombres que, como hemos indicado, el uso convirtió en hereditarios.

Se suele decir que en la actualidad el uso y la costumbre de apodar o mantener los apodos se ha circunscrito a ámbitos rurales. Se citan los casos de pueblos que han optado por la publicación de sus apodos en el listín telefónico, en lugar de sus apellidos, para facilitar la localización de sus habitantes. ${ }^{2}$ En Internet existen páginas web en las que se relacionan los motes de los vecinos de tal o cual pueblo, en un intento de preservarlos del olvido. ${ }^{3}$ Sin embargo, no es cierto que la costumbre de apodar esté desapareciendo, ni de que sea un hábito exclusivamente rural, pues la encontramos actualmente en muy diferentes ámbitos y estratos sociales: en el académico (apodos de los alumnos a los profesores o a sus propios compañeros), en el militar (frecuentemente en el ejército los soldados son designados, como en la Antigüedad, por su oficio, lugar de procedencia, rasgos físicos...), en el deportivo (conocida es la costumbre sudamericana de apodar a los futbolistas («El Pelusa» [Maradona], «El Piojo López»), en el cultural (cantantes flamencos como «Camarón de la Isla» o cantantes de hip-hop como «Eminem») y en el mundo de la marginalidad y la delincuencia («El Vaquilla»).

\section{LOS APODOS Y LOS NICKS}

Esta costumbre del apodo se ha convertido en un requisito indispensable en la actualidad para interactuar en alguno de los géneros de Internet. Es necesario poseer un apodo, un alias o un nick (del inglés nickname «apodo») para

1. Notarios y escribanos junto al nombre de pila del interesado hacían constar el nombre de su padre, su apodo, profesión, título o procedencia. También la documentación eclesiástica medieval, cuyo vehículo de expresión era el latín, desde el siglo IX, solía presentar el individuo más el nombre del padre en forma genitiva: Antonio filius Petri («Antonio hijo de Pedro») o el nombre de nacimiento del individuo más su título nobiliario o grado eclesiástico: Franciscus monacus («Francisco monje») o Bernardus baronus («Bernardo barón») (ejemplos tomados de Faure et al., 2005:XVIII).

2. En Cedillo (Cáceres). La idea surgió porque en el pueblo, a pesar de tener sólo 600 habitantes, hay varias personas con los mismos nombres y apellidos, y residentes en la misma calle. Como indica Texeira (2006): «Dos Gonzalo Faustino Riscado que residen en la calle Comandante Carrillo. Sin embargo, uno aparece como Gonzalo Cultuvio. Problema solucionado.»

3. Algunos apodos de Valbona (Teruel): <www.upv.es/\%7Efizquier/la_carroncha/numero2/motes. html>; de Tubilla del Lago (Burgos): <www.tubilladellago.com/apodos/html>; de Lopera y Pegalajar (Jaén): <personal.telefonica.terra.es/web/sierra-magina/articulos/apodo_en_los_pueblos_de_lopera_y.htm>; en Munera (Albacete): <www.munera.es/ocio_arch/apod_arch/apod. $h t m>$. Estos serían algunos ejemplos de páginas web que hemos elegido al azar. 
poder intervenir en una sesión de chat. ${ }^{4}$ Sin embargo, las diferencias entre estos apodos tradicionales y los nicks son muy claras y las vamos a señalar. (En adelante, nos referiremos a los apodos en entornos reales como apodos simplemente, y a los que aparecen en entornos virtuales como nicks.) En primer término existe una divergencia muy marcada en cuanto a la asignación del sobrenombre. Normalmente quien lleva el apodo es porque ha sido «bautizado» de nuevo por un determinado grupo o comunidad. Por el contrario, el nick es elegido voluntariamente por el propio usuario. Y esta elección, como veremos después, resulta fundamental para el éxito de la sesión de ciberhabla que se dispone a realizar. Pero además esta elección en muchos casos responde a una perspectiva muy alejada de la que prima en la creación de los apodos tradicionales. $\mathrm{Si}$, como indicábamos antes, el apodo muchas veces está basado en los defectos corporales de las personas y, añadamos ahora, suele ser burlesco o satírico (también referido a aspectos etopéyicos de la persona), en el nick por el contrario solemos encontrar la mayoría de las veces la hiperbolización de cualidades agradables (<supermimosa $>$, <RESALÁ $>$, <muyguapo $>$ ), aunque también hay quien se menosprecia o ridiculiza ( $<$ Pardilla $>,<$ MUJER-PERVER$\mathrm{SA}>,<$ Feissim-ooO $>$, <escritoramala $>$, <eNERGUMENo $>$, <Dómine_Cabra $>$ ). En segundo lugar, como hemos indicado más arriba, el apodo se convierte en muchos casos en una denominación permanente. Dura años, muchos años porque llega a hacerse hereditario. Por el contrario, la propia naturaleza del chat (en la que ahondaremos más abajo) hace que un nick sea efímero. Puede durar lo que dura una sesión o incluso menos, porque el usuario puede cambiar de nicks cuantas veces quiera. $\mathrm{O}$ puede usarlo intermitentemente, cuando le apetezca o se conecte. ${ }^{5}$ En tercer lugar, el apodo, como el nombre propio, cumple una función referencial. Todo el mundo sabe quién es "El Pelusa" (Maradona) o en la pandilla de adolescentes nadie se confundirá al referirse a "El Gafitas"

4. Definimos aquí algunos conceptos básicos: CHAT: La conversación virtual por Internet, popularmente conocida como chat (tomada del término inglés «charlar»), la definió Mayans (2002: 19) como «aplicación informática -software- que, haciendo uso de la conexión a Internet, permite la comunicación escrita inmediata y simultánea de múltiples usuarios». CANALES: «los servicios que hospedan los chats organizan a sus usuarios en un número indeterminado de subsecciones llamadas canales» (Ibid., 20). SESIÓN: «conexión a un servidor a través de la conexión de Internet. Así, una sesión de Chat significa conectarse a ese determinado servidor y hacer uso de él. Una sesión de Chat puede durar quince minutos o prolongarse durante muchas horas. Es un término más descriptivo que analítico, ya que sus parámetros concretos no están definidos.» (Ibid., 30, nota 9). NICK o NICKNAME: «significa en inglés, nombre de guerra, es decir, pseudónimo o apodo» (Ibid., 31, nota 10). Es indispensable poseer un nick para poder chatear, y muchos usuarios al elegirlo optan por registrarlo que, para Mayans (Ibid., 31) «es establecer algo así como unos derechos exclusivos sobre el apodo o nick que se haya escogido [...] Registrar un nick es algo así como legalizarlo, como inscribirlo en un registro civil local».

5. Sobre algunas experiencias de usuarios con sus nicks véase Mayans (2002: 200-202). 
o a "El Jirafa". Sin embargo, nicks como <chanel> o <ALIKANTYNO > no dejan de ser formas de enmascaramiento de la verdadera identidad de los usuarios.

\section{LA INTERACCIÓN MEDIANTE EL TEXTO ESCRITO ORALIZADO}

La mayoría de analistas de las producciones textuales de los chats han destacado que el rasgo más esencial de la conversación virtual es el carácter oral de los textos escritos que intercambian los usuarios de Internet. De ahí que, por ejemplo, Yus (2001: 139) ha propuesto denominar el lenguaje del chat como texto escrito oralizado. Se trataría, por tanto, de «un híbrido que oscila entre ambos planos [oral/escrito]». Mayans (2002: 42-43) presenta el chat como un «género confuso»,

el más inorgánico y espontáneo de los registros escritos [...] próximo, desprovisto de convenciones y reglas gramaticales o, al menos, de la obligación de su cumplimiento. La tradicional caracterización distante del texto escrito se diluye ante la poca elaboración de las frases y lo instantáneo de su llegada al o a los receptor/es [...] el sistema de argumentación es más similar al de una conversación oral: el contenido se improvisa más, se distribuye fragmentado.

Sin embargo, esta oralización del texto escrito no implica, como remarca Mayans, que se realice «una mera transcripción de una conversación oral» (2002: 43), pues al tratarse de intervenciones tecleadas existe «una reflexividad, distanciamiento y estructuración muy superiores a las del registro oral» (2002: 43). Al tratarse de textos escritos que el usuario vive, sin embargo, como enunciados orales, deben buscarse vías que compensen la ausencia de un canal auditivo-vocal en el chat (Yus, 2001: 112). Como han destacado diversos estudiosos (Reid, 1994: 31-32; Ruedenberg et al., 1994; Jaffe et al., 1995; todos ellos citados por Yus, 2001: 113-114) los usuarios recurren a innovaciones tipográficas, como variaciones intencionadas en la ortografía (vgr. dialecto visual), el uso estratégico de las mayúsculas, las sustituciones léxicas (pistas metalingüísticas de connotación paraverbal, por ejemplo escribir «hmmmm»), los marcadores gramaticales (como el uso repetido de las exclamaciones), y las composiciones icónicas (o emoti-conos).

Pero en esta interacción textual que es el chat quedan todavía algunos elementos por perfilar. La siguiente definición de Mayans (2002: 95) nos resulta especialmente útil en este sentido: «El chat es un género (1) eminentemente dramático en su realización, (2) televisivo en cuanto a sus estructuras formales y (3) lúdico en cuanto a sus disposiciones y estrategias por parte de los usuarios». Dramático en este caso viene referido a que los usuarios se con- 
vierten en actores y público de una representación que ellos mismos van elaborando con sus intervenciones. En cuanto se abre la pantalla del chat vemos un constante fluir de intervenciones. A un lado de la misma una lista de usuarios, nicks, que vienen a constituirse en el «dramatis personae» de la performance (así llama Mayans a esta actuación colectiva) «con todo el sentido que el verbo to perform tiene en inglés, hacer algo, y no sólo decirlo o pensarlo. Realizarlo» (2002: 54). Siguiendo al mismo estudioso, «los personajes que pueblan un chat son roles. Roles construidos mediante acumulación escénica de características. Roles propios del usuario, que realiza a través de ellos, un trabajo de exteriorización y dramatización de sus propias fantasías y/o realidades, una narración vehemente del propio self» (2002: 220). Y en este rol, como veremos después, la elección del nick puede ser muy importante.

Por otra parte, la relación del chat con la televisión es evidente y se manifiesta especialmente en dos aspectos. El primero de ellos el soporte o formato: la pantalla. El segundo tiene que ver con los contenidos y la expresión. Como destaca Mayans (2002: 144) es enorme «la importancia de los referentes mediáticos -especialmente televisivos- en los chats [...] la mitología pro-

pia de la mayoría de los usuarios de los chats proviene del medio televisivo». Incluso la expresión (onomatopeyas, frases hechas, chistes...) puede ir muy influida por el lenguaje televisivo (y del cómic).

Por último, el componente lúdico. El quebrantamiento de las normas ortográficas, las innovaciones tipográficas además de contribuir al aspecto de discurso hablado del chat también se relacionan con una intención lúdica $\mathrm{y}$, a veces, estética por parte de los usuarios.

Todos estos aspectos están también presentes en los nicks y más tarde los señalaremos y ejemplificaremos.

\section{TIPOLOGÍA DE LOS NICKS}

Hasta donde nosotros conocemos, las clasificaciones tipológicas de nicks se han establecido atendiendo fundamentalmente a criterios semánticos, señalando los contenidos y motivos a los que los nicks remiten. Dos de estas clasificaciones, la de Bechar-Israeli (1995) y Cammany (1997) -recogidas por Yus (2001: 77-78)-, sobre todo la primera, realizan una seriación que puede resultar excesiva (y, por tanto, poco operativa), pues al ser innumerables los posibles referentes de los nicks, intentar recogerlos todos se traduce en una prolija lista de categorizaciones. Las dos clasificaciones coinciden en señalar que son claramente mayoritarios los nicks referidos a características personales (de los 260 nicks recogidos por Bechar-Israeli, más del 50\% realizan indicaciones personales), es decir, carácter, aspecto físico, profesión, aficiones, 
localidad, etc. En el caso de nuestro corpus el porcentaje es de un $51 \%$, y todas las categorías apuntadas por Bechar-Israeli están presentes en él: (1) apodos relacionados con la literatura, personajes de cine y TV: $\langle$ KAVAFIS $>,<$ MAGUILA $>$, $<$ Audrey Hepburn>; (2) apodos relacionados con la flora y la fauna: <gataraña $>$, <lobitagatuna $>$, <petunia >; (3) apodos referidos a gente famosa: <elvispresley $>,<$ a-Luz_Casal $>$; (4) apodos relacionados con objetos de diferente naturaleza: $<$ AUDI $>,<$ torres 10>, <TROZO $>$; (5) apodos sobre las cualidades de las personas: el carácter $<$ supermimoso $>$, aspecto físico $<$ tetona $18>$, estado de ánimo <contenta-42>, profesión <abogada-50 $>$ o pasatiempos $<$ kanviofotos- >; (6) apodos indicando afiliación a algún lugar: <kantabrucaaa >, <castellonenca>; (7) apodos que sitúan a la persona en algún tramo de edad $<$ JovencitaMadrid>, <maduratractiva>; (8) apodos que indican relación con otra persona: <tunena>, <Tu_gatita>; (9) apodos sobre tecnología y el uso de programas de ordenador: <nacho-msn>; (10) apodos que efectúan una metacomunicación sobre la anonimia de Internet: <nick>, <ANONIMA44>; (11) apodos que el usuario utiliza para jugar con el lenguaje y las conversaciones tipográficas: <donzipote>, <tortuga_huga>; (12) apodos basados en la onomatopeya: <ñamñam>; (13) apodos relacionados con el sexo: <poyyita_jugosa>; (14) apodos provocativos: <jodemos $>$.

Sin embargo, este acercamiento nos parece incompleto porque consideramos que un nick informa de mucho más, sobre todo de las intenciones comunicativas de los usuarios. En las siguientes páginas proponemos otros criterios analíticos.

\subsection{Clasificación morfológica}

Podemos hablar de nicks simples (formados por una sola palabra: <AMADA>, $<$ Domus $>$, <eliot_> ), frente a nicks compuestos (formados por más de una: <carpediem $>,<$ cocoloco $>,<$ Dómine_Cabra $>$ ). Son más habituales los segundos. Entre las categorías morfológicas más empleadas, tanto para los simples como para los compuestos, se encuentran los sustantivos ( $<$ frutos $>,<$ kamelia $>,<$ malizia $>$ ) y los adjetivos ( $<$ navarrica $>$, $<$ provocativa $>$, $<$ INCULTA $>$ ), frecuentemente combinados ( $<$ Poetaseductor $>$, $<$ ViudAlegre $>,<$ MUJER-PERVERSA $>$ ). Las implicaciones semánticas y pragmáticas de esta abundancia de sustantivos y adjetivos son claras: interés de los usuarios por indicar ciertas señas de identidad. Además de las combinaciones de sustantivos y adjetivos pueden aparecer adverbios y numerales que amplían aún más estas caracterizaciones: <lescarolina42>, <mujersumisa35>, <MUYDOTADOCAMP. 


\subsection{Consideración de toda una serie de implicaciones pragmáticas}

\subsubsection{Interés o no del usuario por entrar en el juego de la creatividad lingüistica de Internet, de las jergas, de las nuevas convenciones lingüísticas, ortográficas, tipográficas, etc.}

Este criterio nos permite diferenciar diversos perfiles de usuarios: el novato que elige como nick <RODRIGO>, frente al experimentado que escoge <enmatojado> (en la jerga de los chats, «enmatojarse» o «irse a los matojos» es «hablar en privado dos personas, ignorando la conversación general») o el experimentado que crea neologismos como <asturdanonina>. Como señala Crystal (2002: 82): «El ritmo al que se han acuñado nuevos términos y se han introducido variaciones humorísticas sobre los vocablos establecidos no tiene parangón en el lenguaje contemporáneo». Siguiendo los procedimientos básicos que ofrece el español para la formación de palabras, encontramos en los chats los siguientes neologismos para los nicks:

-Por composición: encontramos tanto ortográficos (<abrildonosti>, $<$ asturcasado $>$, <asturmartes $>$ ) como sintagmáticos ( $<$ CHICA-LINDA $>$, <cultaguay $>$, <desnudito_cam>). La imposibilidad de incluir en el nick espacios en blanco, hace que muchos usuarios opten por fundir los dos vocablos en uno sin guión (ortográficos) -los más recurrentes- o los unan con un guión alto o bajo (sintagmáticos). Dentro de estas formas compositivas de la variedad ortográfica, destacan aquellas en las que una parte de una palabra se ensambla a otra (muchas veces completa). Crystal (2002: 99) destaca términos como netiquette, internauta, infonet... En los chats estudiados es especialmente recurrente el procedimiento cuando se trata de mostrar la inclinación sexual de los usuarios: <bisexalicantino $>,<$ bisexemilio $>,<$ mariales $>$, $<$ lesbiardiente $>,<$ LesMiriam $>$. No solamente pueden fundirse dos palabras, sino que pueden aparecer como una sola palabra, oraciones y frases comprimidas (en inglés, por ejemplo, whois, whowhere...). En nuestra indagación hemos encontrado nicks como $<$ lesbuscasada $>$, <Laquebuscas $>$, $<$ kanviofotos - - $>$. A veces, se utilizan guiones para separar las palabras: $<$ Me_Caes_bien $>,<$ Kiero_SUMISA $>$.

- Por derivación: al igual que en chats de habla inglesa se puede recurrir a prefijos como@-, cyber-, hyper-o e-, en nuestro corpus se hallan nicks como $<$ Ciberfrigida $>$ o $<$ CiberSumiso33 $>$. Pero en los chats españoles estudiados nos ha llamado la atención un tipo de prefijación de nuevo cuño: la realizada con $a(A)$ seguida de un número variable de guiones y unido a cualquier término: <a---ana43zgz>, <A-ANAIS-ANAIS >, <a--astrólogo >, <A-CON-AFECTO $>$, etc. En estos casos no se trata de prefijos que añadan a la palabra base el contenido "oposición, negación o privación" (como en amoral), sino que la consecuencia pragmática es otra: el interés del usuario por aparecer en el lis- 
tado de nicks entre los primeros -téngase en cuenta que en las horas que nosotros realizamos la recogida de datos había conectados unos 2.500 usuarios-, puesto que los alias se ordenan alfabéticamente. Esta opción sin duda implica el deseo del usuario de ser visto antes que otros y que, por tanto, sus posibilidades de interactuar puedan ser mayores. Nos encontramos, por tanto, ante un recurso morfo-pragmático, pero no el único. ${ }^{6}$ También existe un nuevo tipo de sufijos, que podríamos denominar meta-comunicativos, ya que informan de la posibilidad de comunicarse e interactuar por otras vías, igualmente en la Red. Así, es muy frecuente el sufijo -cam (abreviación de webcam), indicador de que el usuario cuenta con uno de esos aparatos: <Butanerocam $>$, <MUYDOTADOCAM> o con un servicio de mensajería instantánea $-m s n$ : <amiga46msn>, $<$ nacho-msn $>$.

- Acronimia: si en Internet son habituales acrónimos como HTML (Hypertext Markup Language) y FAQ (Frequently Asked Questions), encontramos algunos acrónimos en nicks como TKM ("te kiero mucho"), pero es un procedimiento raro para estos usos.

- Otras formaciones más extrañas se dan por las combinaciones de letras y números: <KL_50>, $<\mathrm{A}^{\wedge} \mathrm{Z}>$, <alfa1999>, <KIs02>.

Debemos destacar que todos estos recursos de creatividad lingüística son habituales en Internet y vienen también expresados por los propios nicks. Entre estos recursos tenemos que resaltar también aquellos que vienen motivados por la falta de cualidades vocales (no verbales) del texto escrito y que se usan para darle cierto aire de oralidad (recuérdese que consideramos las producciones del chat como textos escritos oralizados). Nos parece importante, a este respecto, la siguiente cita de Yus (2001: 142) referida a la actitud de los hablantes en un chat y que consideramos aplicable también en concreto a los nicks:

En el chat, los usuarios hacen constantes hipótesis sobre la accesibilidad de los interlocutores a un contexto en el que el procesamiento del enunciado será óptimo en su equilibrio de interés y esfuerzo de procesamiento. Normalmente, las desviaciones tipográficas y ortográficas obligarán a un esfuerzo suplementario de procesamiento, que puede verse compensado [...] por impresiones obtenidas por el destinatario en forma de implicaturas débiles (generadas en sensa-

6. Este recurso (prefijación con $a$-) lo hemos encontrado en algunos diarios, en su sección de anuncios por palabras, subsección "contactos", (por ejemplo en La Verdad de Murcia) y puesto que todavía no es habitual en toda la prensa nacional, creemos que es una clara influencia de los recursos de los chats en ese tipo de textos de los diarios. En una de las sesiones en las que tomamos datos, sobre 2.750 conectados, contabilizamos 120 nicks que empezaban por $a$ - más uno o varios guiones; que empezaran por $a$ (sin guión) 458. Esto confirma la relevancia que los usuarios dan a colocar sus nicks al principio de la lista. 
ciones como la manifestación mutua de compartir el dominio de una jerga, un incremento en la sociabilidad por el aumento de connotaciones orales en el texto, o el efectismo humorístico que a menudo se origina en los intercambios conversacionales del chat).

Los casos de modificación textual en el chat que propone Yus (2001: 142147) son en buena medida asumidos y reflejados por los nicks:

I) Faltas de ortografía (voluntarias o involuntarias): <adabuena $>$, $<$ aLUZinada>.

II) Grafía fonética y dialecto visual: existen varias estrategias de oralización del texto según estudió Androutsopulos (2000: 521-522):

- (orto) grafía fonética: <Brus_Guilis>

- (orto) grafía coloquial: <toifumailla>

- (orto) grafía regiolectal (dialecto visual): <Algoxidá><apacionada>

- (orto) grafía prosódica: mediante repeticiones de letras (<alexxxxxxxx XXss $>,<$ marrrrrr $>$ ) o mediante mayúsculas (<COSITADULCE $>$ )

- (orto) grafía interlingüística: <aa-piterpán>

- (orto) grafía homofónica: sustituciones léxicas $(<\mathrm{pk} 2>)$ y sustituciones grafémicas (<ALIKANTYNO>, <anparo>, <wason>)

- abreviaciones, acrónimos, truncamientos: <camxtucam>.

Como indica Yus (2001: 145) existe una marcada vertiente lúdica en todos estos usos.

\subsubsection{Interés o no del usuario en cumplir las máximas conversacionales de Grice}

Es bien sabido que las ideas de Grice constituyen el punto de partida de la concepción de la pragmática más extendida en nuestros días. El principio de cooperación («Haga que su contribución a la conversación sea, en cada momento, la requerida por el propósito o la dirección del intercambio comunicativo en el que está usted involucrado») se desarrolla en normas de menor rango, que denomina categorías y son cuatro: calidad, relevancia, cantidad y manera, que, a su vez, subdividió en máximas. Para simplificar nos referiremos solamente y en sentido general a las cuatro máximas (que llamaremos del mismo modo). Como indica Crystal (2002: 66-74) en el ciberhabla muy frecuentemente se quebranta el cumplimiento de estas máximas. Un nick, en concreto, puede cumplir al mismo tiempo las cuatro, alguna de ellas o ninguna. La primera -de calidades imposible saber a priori si se cumple, pues la propia naturaleza del chat invita en muchos casos a la mentira y al subterfugio. Nicks como <HERMOSísIMO>, $<$ culta-guay>, <enrrollada> sólo varias sesiones de chat o la utilización de otros 
medios (fotografías, trato real,...) podrán confirmar si esos nicks son contribuciones verdaderas o no. La segunda máxima -la relevancia- siguiendo a Crystal (2002: 74) en Internet tiene más que ver con factores de tipo social. Si el fin del chat es conversar, sin duda, esos mismos nicks que acabamos de citar serían relevantes. Otros aún más como <acariciameamor $>$, <acompáñame $>$ o < hablamos $>$. La máxima de cantidad también la cumplen a la perfección algunos nicks al aprovechar totalmente el número de caracteres permitido, creando contribuciones muy informativas: <jovbuscamadura $>,<$ megustarialigar $>,<$ mimaridonoesta $>$. Todos los nicks anteriores responden perfectamente a la máxima de manera. Otros, sin embargo, conscientemente optan por no ser claros: $\left\langle\mathrm{A}^{\wedge} \mathrm{Z}\right\rangle,\langle\mathrm{ZXZXZX}\rangle$, $<$ vcr3 $>$ (si bien estos casos son raros).

\subsubsection{Relacionado con lo anterior, nicks que apelan a la cortesía o no (descorteses o neutros)}

Si por cortesía se entiende «un conjunto de normas sociales, establecidas por cada sociedad, que regulan el comportamiento adecuado de sus miembros, prohibiendo algunas formas de conducta y favoreciendo otras» (Escandell, 2006: 142), podemos considerar que en un listado de nicks, gente desconocida que se presenta como <NOESTOYPARATI $>$, <pezoneserectos $>$ y $<$ alamierda $>$ está atentando contra las más elementales normas de cortesía (y más teniendo en cuenta que se trata de un canal llamado <\#amigos más de 40> y no de un canal de cibersexo). ${ }^{7}$ Pero además de un «conjunto de normas sociales», la cortesía «es un conjunto de estrategias conversacionales» pensada para evitar o mitigar los conflictos que pueden originarse entre los objetivos del hablante y los del destinatario. Con la cortesía se busca «mantener las buenas relaciones» entre ambos (Escandell, 2006: 145).

Por otra parte, la cortesía y el principio de cooperación (forma de asegurar una transmisión de información eficaz) no siempre se conjugan. Como indica Escandell (2006) existe una diferencia clara motivada por el tipo de discurso y por sus objetivos prioritarios (Escandell, 2006: 147). Y la misma estudiosa habla de intercambio interaccional - «cuando lo que importa es el mantenimiento de las relaciones sociales, y vence la cortesía» (Escandell, 2006: 147) frente a un intercambio transaccional, («cuando lo importante es la transmisión eficaz de información, y tienen prioridad los principios conversacionales») (Escandell, 2006: 147).

7. La mayoría de chats para la preservación de la netiquette marcan claramente la prohibición de realizar manifestaciones que puedan herir la sensibilidad de los usuarios (insultos, palabras procaces, tacos...). De hecho, Terra censura determinadas palabras malsonantes, cosa que no ocurre, paradójicamente, con la elección de nicks. 
En el listado de nicks o usuarios de los canales que analizamos, encontramos que la mayoría de ellos constituyen enunciados dispuestos alfabéticamente y que semejan en cierta forma las páginas de contactos o anuncios por palabras de diarios o revistas (con un mayor constreñimiento para los nicks como sabemos). De hecho son muchos los nicks que comienzan con el verbo buscar, abreviado o combinado de variadas formas. Al tratarse de nicks en los que prevalece el cumplimiento de las máximas de Grice sobre otras consideraciones, podemos decir que con ellos el hablante (usuario) busca un intercambio transaccional. ¿Serán nicks como $<$ BuscoSexxo $>$, $<$ BUXKOTETONAS $>$, $<$ BuscoPecho120 $>$ descorteses? Dependerá sin duda de la opinión del resto de usuarios y de sus fines al entrar en ese canal. Quienes se identifiquen abiertamente con los intereses expresados por esos nicks no los considerarán descorteses. Por el contrario, quienes se vean agredidos al leer esos nicks los considerarán descorteses y rehusarán la interacción. En el extremo opuesto pueden encontrarse nicks como <megustarialigar>, $<$ a-CON-AFECTO> en los que prima la cortesía, aunque alguna máxima de Grice sea incumplida.

Aunque no es el propósito de este trabajo ahondar excesivamente en el tema de la cortesía en los chats, ni de aplicar las diferentes teorías existentes (resumidas por Escandell, 2006: 148-58), podríamos a partir de nuestro corpus esbozar qué procedimientos emplean los usuarios al crear sus nicks para mostrar sus estrategias corteses (la cortesía es un conjunto de estrategias que determina la elección de ciertas formas lingüísticas). Si bien podemos considerar inferior cuantitativamente los nicks que evidencian cortesía o descortesía, frente a los que no indican ni uno ni otro valor (neutros), ciertamente los usuarios indican con sus nicks su deseo de distanciarse del destinatario (o de un tipo de destinatarios): $<$ Solocultos $>$, $<$ no-tontos $>$, $<$ nosalidos $>,<$ NOESTOYPARATI $>$ (que puede ser una manera también de defenderse de posibles agresiones).

Otros nicks marcan claramente un deseo de entablar un trato amistoso: $<$ hola-soy-ane $>,<$ Me_Caes_bien $>,<$ foryou $>,<$ amiga_si_kieres $>$. O declarar un clima de respeto y educación en la interacción: <educada $>$, <buenasNoCHES $>$.

Un número considerable de nicks tienen en común la sufijación mediante diminutivos. El diminutivo en su relación con la cortesía en los chats ha sido ya estudiado entre otros por Mariottini (2006), quien en su trabajo concluía

que los diminutivos representan una estrategia indispensable para modular la fuerza elocutiva de un acto de habla y para contextualizar una interacción en el plan de cercanía y distancia comunicativa en los chats. A nivel pragmático, y desde el punto de vista de la cortesía lingüística, cumplen un rol fundamental, dado que atenúan el conflicto local (excepto si se emplean con valor sarcásti- 
co) para alcanzar la cooperación global en una modalidad de interacción que no permite emplear estrategias que los usuarios no tecleen en la pantalla.

En su estudio de los chats españoles indica que el diminutivum puerile es empleado con una función primordial, la fática, con el fin de abrir y cerrar la interacción. La estudiosa se refiere únicamente al saludo (adiosito) y al nick que es manipulado durante el diálogo (<sirena $>$ pasa a ser $<$ sirenita $>$ ), pero no se fija o al menos no remarca los nicks que ya aparecen en el listado con el diminutivo. Consideramos que los valores que Mariottini establece a partir de su análisis del uso de los diminutivos en el chat (cercanía, familiaridad, afecto entre los interlocutores) y la función pragmático-comunicativa conocida como ironía (del hablante hacia otro o hacia sí mismo), están contenidos ya en los propios nicks: <marguita $>$, <casadita $>,<$ Tu_gatita $>,<$ DULCECITA $>$, <abogadita $>$ (más frecuentes en femenino, pocos en masculino), $<\mathrm{a}---$ Yogurin>, <cazurrin>. En estos casos aparte de cortesía debería hablarse también del intento de seducir o de instar a ser "pinchado". Quizá como reacción burlesca a esta proliferación de diminutivos en los nicks, encontramos sufijos ponderativos, aumentativos y superlativos: <EMBARAZADísIMA $>$, $<$ deseadísima $>,<$ canariona44>, <amorosísimo $>$.

\subsubsection{Nicks indicativos de carácter lúdico y humorístico}

Las vías y géneros que se integran en Internet son en gran medida una invitación al juego, a la diversión y al humor. Queremos destacar ahora un grupo de nicks en los que sus usuarios destacan su sentido del humor y el empleo ingenioso de diferentes recursos lingüísticos. En nuestro corpus aparecen nicks creados a partir de calambures: <paka-cagarse>, <aitor-tilla>; juegos de palabras: $<$ Miss_LaBoReS $>$, $<$ PENElopez $>$; rimas jocosas: $<$ AnitA_DiNaMiTa $>$, <cocoloco $>$, <tortuga_huga $>$; paráfrasis, rupturas de frases hechas y clichés: <bellasinbestia>, <elcidchateador $>,<$ ElPeneFactor $>$, <donzipote>; uso insólito de palabras, flexiones agramaticales: <ALCACHOFO>; expresiones coloquiales y vulgares <FEI-DE-COJONES $>$, <Hostiaquefeosoy $>$; transcripciones, más o menos, fonéticas de términos en inglés, de personajes famosos: $<$ Brus_Guilis $>$; la televisión, la publicidad y el cine sirven de inspiración a nicks como <busco-a-jacks $>$, <donlimpio $>$, $<$ Dabadabaduuuuu $>,<$ MAGUILA $>$, $<$ PELOPICOPATA $>$ o $<$ Fornicator $>$ (este clara paráfrasis por la interferencia entre "fornicador" y títulos de películas como Terminator o Gladiator); otros nicks son frases ocurrentes basadas en anécdotas reales del momento: <piloto-derajoy $>$ (aunque también las hay serias y solidarias, como $<$ Duelo_por_Valencia>, tras el trágico accidente de metro). 


\section{CONCLUSIONES}

Como apunta Crystal (2002) la revolución de Internet es fundamentalmente lingüística, y en uno de los medios que acoge, el chat, se ha producido buena parte de esta revolución. Al tratarse de un nuevo entorno, la forma de apodar, de designar cambia: frente al apodo tradicional el nick nace por autoasignación (la mayoría de veces autoidentificativa y no peyorativa), su pervivencia depende también de la voluntad de su creador-usuario y es una forma de enmascaramiento o preservación de su identidad real.

El nick resulta fundamental en la forma de comunicación llamada chat, pues abre, posibilita o trunca la interacción textual (función fática del lenguaje). Y esto es posible porque además se constituye en marca catafórica, anticipadora de muy diferentes rasgos: del rol que el usuario quiere jugar en esa performance que es cada sesión del chat; la intención informativa que subyace a la ostensión (principio de relevancia). Dicha información puede ser muy variada: señas de identidad, experiencia del usuario en el chat, proposiciones del usuario a los posibles receptores (las de tipo sexual son las más frecuentes en estos canales estudiados), etc.

El nick en definitiva es elemento sintetizador, aglutinador, de las principales características lingüísticas de los chats: carácter lúdico y humorístico, creatividad lingüística -neologismos variados, modificaciones textuales para suplir la falta de cualidades vocales (no verbales) en el texto (faltas de ortografía, grafía fonética, grafía coloquial, grafía prosódica, etc.)-, incumplimiento frecuente de las máximas de Grice y de la cortesía, favoreciendo los intercambios transaccionales sobre otras consideraciones. Aunque los usuarios pueden desarrollar sus propias estrategias corteses (como la sufijación mediante diminutivos en sus nicks).

\section{REFERENCIAS BIBLIOGRÁFICAS}

Androutsopoulos, J. K. (2000): «Non-standard spellings in media texts: The case of German fanzines», Journal of Sociolinguistics, 4, 4, pp. 514-533.

Bravo, D. y A. Briz (2004): Pragmática sociocultural. Estudios sobre el discurso de cortesía en español, Barcelona, Ariel.

Brown, P. y S. Levinson (1987): Politeness: Some Universals in Language Usage, Cambridge, Cambridge University Press.

CRYSTAL, D. (2002): El lenguaje e Internet, Madrid, Akal Cambridge.

ESCANDELL, M. V. (2006): Introducción a la pragmática, Barcelona, Ariel.

FAURe, R., M. A. Ribes y A. García (2005): Diccionario de apellidos españoles, Madrid, Espasa-Calpe, XI-LII. 
Grice, P. (1975): «Logic and Conversation» en Cole, P. y J. Morgan (eds.) (1975): Syntax and Semantics. Vol. 3: Speech Acts. Nueva York, Academic Press, 41-58.

Haverkate, H. (1994): La cortesía verbal. Estudio pragmalingüístico, Madrid, Gredos.

LEECH, G. (1983): Principles of Pragmatics, Londres, Longman.

MariotTini, L. (2006): «El uso de los diminutivos y su relación con la cortesía lingüística en los chats. Análisis contrastivo de las comunidades virtuales españolas e italianas», Cultura, Lenguaje y Representación / Culture, Language and Representation, 3: 103-131.

Mayans i Planells, J. (2002): Género chat o cómo la etnografía puso un pie en el ciberespacio, Barcelona, GEDISA.

SPERBER, D. y D. WILSON (1986): Relevance. Communication and Cognition, Oxford, Blackwell.

TeXeIRA, A. (2006): «Llámeme mejor por mi apodo», <www.elmundo.es/su plementos/cronica/2006/550/1147557615.html>.

Ullmann, S. (1980): Semántica. Introducción a la ciencia del significado, Madrid, Aguilar.

Yus, F. (2001): Ciberpragmática. El uso del lenguaje en Internet, Barcelona, Ariel. 


\title{
HACIA UNA SUPERACIÓN \\ DEL SEXISMO SEMIÓTICO \\ EN EL DISCURSO PUBLICITARIO ${ }^{1}$
}

\author{
Marisol Velasco Sacristán \\ Universidad de Valladolid
}

\section{INTRODUCCIÓN}

$\mathbf{L}$

A viabilidad y conveniencia de una reforma linguística es uno de los

temas de debate más conocidos de los movimientos feministas y postfeministas en pro de la igualdad de los sexos. Estos, basándose en el determinismo lingüístico, encuentran en el lenguaje el marco idóneo con el que intentar demoler el estado patriarcal y androcéntrico de la sociedad, apoyándose para ello en la hipótesis conocida como hipótesis de Sapir-Whorf. Hoy en día es, sin embargo, grande la incertidumbre que se cierne sobre el valor y eficacia de estos intentos de reforma. Con frecuencia se alude a la opinión tradicional de que no puede haber una reforma lingüística sin que cambien antes las condiciones sociales que dieron lugar al uso discriminatorio del lenguaje (Frank, 1985: 27). Esta opinión rejuvenece, de nuevo, la polémica clásica que se cierne sobre la mencionada hipótesis: ¿se puede cambiar la sociedad para que cambie la lengua?, ¿puede la reforma lingüística contribuir a la reforma social? Para comprender a fondo esta polémica es necesario, en principio, remontarse al debate original sobre la relación entre el lenguaje y la realidad, en el que se distinguen tres posturas claras (Pauwels, 1998: 81-86):

1. No hay ninguna relación entre el lenguaje y la realidad. $(L R)$. Esta postura es la que sostienen los que defienden, explícita e implícitamente, la inexistencia del sexismo en el lenguaje. En definitiva, si el lenguaje y la realidad no están relacionados, no se puede probar que una variable extralingüística como es el sexo influya en la categoría gramatical del género (Mackay y Fulkerson, 1979; Mackay, 1980 y 1983).

2. Existe algún tipo de relación entre el lenguaje y la realidad. En esta postura se contemplan dos posibilidades:

1. Comunicación elaborada dentro del marco del proyecto «INFOGÉNERO: Sistema bilingüe inglésespañol de información y gestión del conocimiento en el campo de los estereotipos de género», financiado por el Ministerio de Trabajo y Asuntos Sociales (I+D+I 27/01). 
2.1. El lenguaje refleja la realidad ( $L \Leftarrow R$ ). Las estructuras lingüísticas están influidas e inspiradas por la realidad no lingüística. Se acogen a esta aproximación numerosos lingüistas y antropólogos que estudian el lenguaje en la cultura y la sociedad, tales como Labov (1972), Miller y Swift (1980) y Milroy (1980).

2.2. El lenguaje influye o determina la realidad $(L \Rightarrow R)$. Esta postura abona la idea de fondo de la hipótesis de Sapir-Whorf. Su hipótesis se desglosa en dos variantes: la teoría de la relatividad lingüística y la teoría del determinismo lingüístico (Hellinger, 1990). La primera defiende que existen diferencias lingüísticas debido a diferentes concepciones del mundo, por lo que las lenguas codifican la realidad de forma diferente. Sin embargo, queda claro, por ejemplo, que la traducción no sería posible si se radicalizara esta teoría. La teoría del determinismo lingüístico, por otra parte, evolucionó hacia las dos posturas conocidas como radical y moderada del determinismo lingüístico. De este modo, «the 'strong' version of the hypothesis posits that language determines thought whereas the 'weak' version takes the view that language helps construct thought» (Pauwels, 1998: 83). La versión radical parece descartada hoy en día por ser demasiado drástica y por existir ejemplos que la invalidan (i.e. figuras retóricas con valor cognitivo que se reflejan en el lenguaje y no viceversa). La versión moderada, sin embargo, ha tenido una gran acogida por parte de sociólogos y lingüistas, especialmente aquellos que estudian la conexión entre el lenguaje y el género (Fuertes Olivera, 1992; García Meseguer, 1994 y 1996).

3. Existe una relación mutua entre el lenguaje y la realidad $(L \Leftrightarrow R)$. El lenguaje no solo refleja la realidad, sino que también ayuda a construirla. Se la conoce como postura interaccionista (Pauwels, 1989 y 1993) y en ella tienen cabida investigaciones sobre el lenguaje y la estructura social que beben de las fuentes de la teoría crítica y del análisis del discurso. Se trata, en definitiva, de una posición dialéctica entre el lenguaje, el individuo y la sociedad (Graddol y Swann, 1989; Pauwels, 1998).

En el discurso publicitario es precisamente este último tipo de relación, de interacción entre el lenguaje y la realidad, el que es más adecuado. Creemos, en este sentido, que la publicidad crea y refleja la realidad $(\mathrm{L} \Leftrightarrow \mathrm{R})$. Por un lado, se refleja la realidad cuando se aportan mensajes denotativos de carácter referencial que tienden hacia la información objetiva casi siempre sobre el producto o servicio anunciado; por otro lado, se construye la realidad cuando surgen creaciones léxicas con las que designar a una realidad no existente previamente o no nombrada con anterioridad. 
En nuestra opinión, y a diferencia de las premisas del determinismo lingüístico creemos que se trata de cambiar el uso lingüístico, y con ello la valoración sociocultural en la que descansa el lenguaje, pero no de modificar, sin más, el sistema lingüístico. Defendemos, por ello, que toda reforma ha de iniciarse con un llamamiento a la concienciación social ante aquellos recursos discriminatorios por razón de sexo. Por ello, a continuación presentamos un recorrido por varios ejes de caracterización de lo que hemos denominado «sexismo semiótico» ilustrando su presencia en la muestra objeto de investigación en esta comunicación.

\section{EL SEXISMO SEMIÓTICO Y SU PRESENCIA EN LA MUESTRA DE ANUNCIOS COMERCIALES ANALIZADOS}

En el discurso publicitario es frecuente encontrarse con recursos discriminatorios por razón de sexo. El rasgo más sobresaliente de estos es, sin duda, su carácter sincrético, que no se limita exclusivamente a lo verbal. Resulta conveniente, por ello, denominar a este tipo de sexismo «semiótico», puesto que tiene lugar en diferentes códigos y medios de naturaleza verbal y no verbal (Velasco Sacristán, 2003).

Podemos afirmar que se incurre en sexismo cuando se emplean recursos que debido a su forma o fondo muestran que el sexo es para los hombres o las mujeres un factor de discriminación, entendiéndose esta última como aquella actitud que pone de relieve una relación de desigualdad, subordinación, dependencia o inferioridad (Velasco Sacristán, 2003).

Probablemente sea el «sexismo verbal» el que ha contado con un mayor número de análisis, puesto que a menudo se ha considerado que la discriminación es «a verbal act, through which reality is defined in such a way that one person by reason of sex or color is superior to some other person» (TroemelPloetz, 1982: 268). Hay que precisar, no obstante, que el sexismo es algo más. En realidad, el sexismo lingüístico es consecuencia del sexismo social, que tiene lugar cuando la discriminación se debe al fondo, y no a su forma (García Meseguer, 1996: 2 de 10). El plano de la lengua (sexismo lingüístico) y el plano de la realidad (sexismo social) no deben confundirse, pese a que están inextricablemente unidos. García Meseguer (1994: 26) emplea un hermoso símil para describir esta interrelación especial: «sexismo social y sexismo linguístico se enlazan como dos serpientes que se devoran mutuamente por la cola. Diacrónicamente el primero es causa del segundo, pero el segundo contribuye a reforzar el primero, ya que el lenguaje conforma en parte la mentalidad de los hablantes». Una misma situación de la realidad, sexista o no, puede describirse con un mensaje sexista o no (García Meseguer, 1994: 24), 
lo que implica que la relación entre el lenguaje y la realidad es bidireccional $(\mathrm{L} \Leftrightarrow \mathrm{R})$, como defendíamos antes.

Por ello, creemos que no se ha de acusar a la lengua, como sistema de signos, de ser sexista, sino al uso que se hace de ella. Ello viene a corroborar el origen pragmático del sexismo. El sexismo pragmático es, en efecto, un tipo de sexismo semiótico que tiene lugar cuando se emite un mensaje que debido a su fondo (significado) y función discrimina a uno de los dos sexos (Velasco Sacristán y Fuertes Olivera, 2002). El sexismo semiótico es, por otro lado, un tipo de sexismo social que se localiza en el nivel implícito del lenguaje y que puede adoptar formas no exclusivamente verbales (Velasco Sacristán y Fuertes Olivera, 2002).

El sexismo en el componente verbal y no verbal del lenguaje publicitario viene caracterizado por una serie de rasgos, prácticas y áreas observables, como veremos e ilustraremos a continuación en la muestra textual manejada aquí.

Por un lado, los rasgos y prácticas incluyen:

- La invisibilidad de las mujeres

- La asimetría en la representación de los sexos

- La estereotipización de sexos

- La inferioridad o trivialización de las mujeres

En lo que se refiere a las áreas de uso y estructura del lenguaje que necesitan atención y examen por su contribución al sexismo verbal y no verbal, hay que hablar de:

La referencia genérica a las personas, mediante nombres, pronombres, expresiones idiomáticas y otras construcciones: los términos que se refieren a los hombres pueden ser genéricos o específicos mientras que los femeninos son únicamente específicos.

\section{EJEMPLOS:}

[1] - «First man, then machine» (eslogan), (ilustración de un dibujo de un hombre y fotografía del producto), abril 1999, [automóvil Joy Machine de Honda].

[2] - «Some men have a device that can tell if you're turned on» (titular), (fotografía de un detector de antenas sin licencia), noviembre 1999, [TV Licensing].

[3] - «Man in gorilla suit» (titular), (fotografía de un hombre o mujer disfrazado/a de gorila), febrero 2000, [cámara fotográfica Olympus C-2000Z].

[4] - «Allure makes the man» (titular), (entrepreneur) (subtitular), (fotografía de un hombre y el producto), junio 1999, [perfume Allure Homme de Chanel]: uso específico. 
La terminología para referirse a las ocupaciones, profesiones, oficios y otras actividades de hombres y mujeres (apellidos y títulos honoríficos) marcan dependencia, sumisión o subordinación de las mujeres respecto de los hombres.

\section{EJEMPLOS:}

[5] - «The newspapers that always pull in the best young female professionals» (eslogan), (fotografía de una mujer tirando de una cuerda y el producto), agosto 1999, [editorial de prensa Evening Standard de Metro-London].

[6] - «Gina Gallo» (titular), «Wines from the family of Ernest \& Julio Gallo» (eslogan), (fotografía de Gina, de los viñedos, botellas de los vinos y de Ernest y Julio), julio 1999, [vinos Ernest \& Julio Gallo].

Estereotipización de los dos sexos:

\section{EJEMPLOS:}

[7] - «As light as your shadow» (titular), (fotografía de una mujer desnuda y el producto), septiembre 1999, [reloj Swatch Skin].

[8] - «Get the figure you're always dreamed of» (titular), (fotografía de una mujer con buen tipo y del producto), octubre 1999, [coche Megane de Renault].

\section{FIGURA 1}

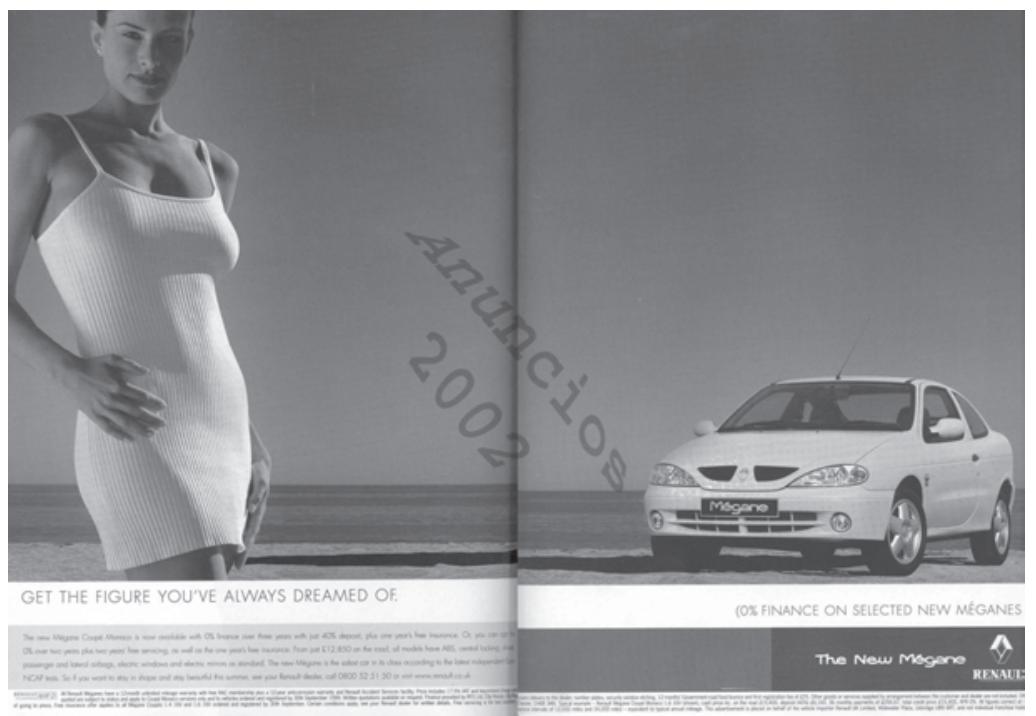


[9] - «I can't cook/who cares?» (eslogan), (fotografía de una conocida modelo con el producto), enero 1999, [sujetadores Wonderbra].

\section{FIGURA 2}

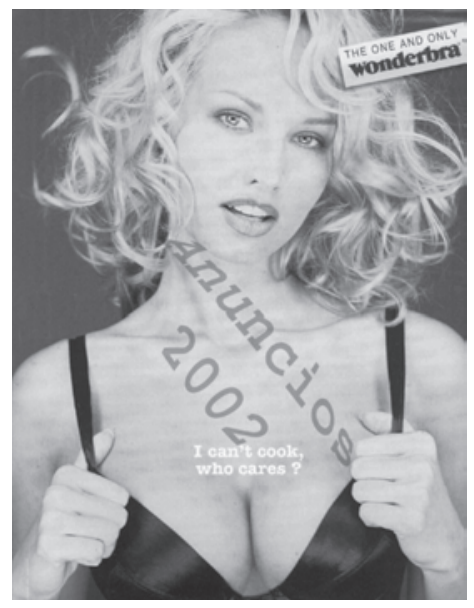

[10] - «Lesson No. 30 - To lift his spirit» (eslogan), (fotografía de una mujer que lleva el producto), octubre 1999, [lencería Aubade de Lingerie Française].

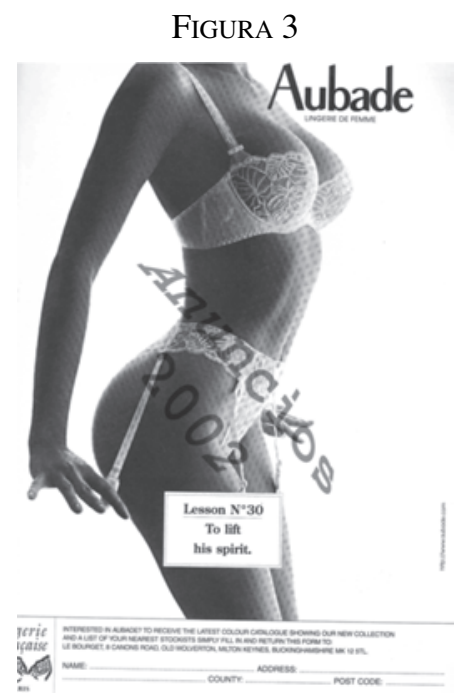


Inferioridad o trivialización de las mujeres: derogación semántica del término femenino, metáforas referentes al sexo y uso de términos despectivos y piropos obscenos.

\section{EJEMPLOS:}

[11] - «How does a guy in Bath set up a romance with a woman in Edinburgh?» (titular), (fotografía de un hombre junto a una mujer y el producto), enero 1999, [teléfono inalámbrico Philips Onis]: las connotaciones positivas de «guy» referido contrastan con las de «woman» que con frecuencia se equipara a prostituta, dando lugar a «duales aparentes».

[12] - «Beautiful things are happening at ES every Friday» (eslogan), (fotografía de dos modelos conocidas), abril 1999, [suplemento $E S$ del periódico Evening Standard]: cosificación de la mujer.

\section{FIGURA 4}

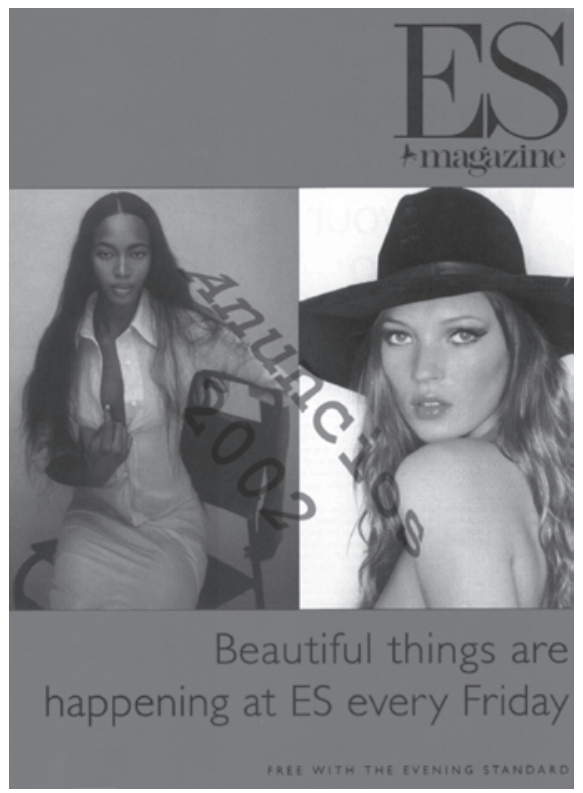

[13]- «Isn't it nice to have Options?» (eslogan), (fotografía de seis bragas y el producto), marzo 1999, [chocolatinas Options Chocolate \& Mint]: mujer como comida. 
FIGURA 5

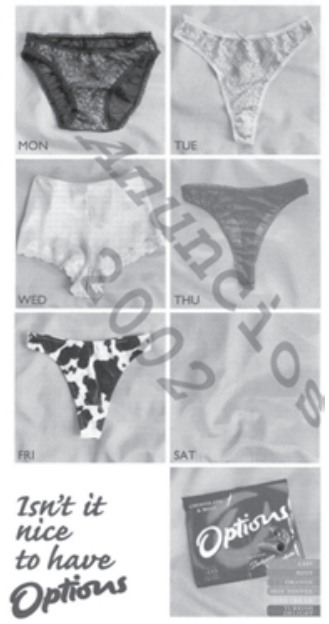

[14] - «Exquisite... isn’t she?» (titular) (fotografía de una mujer en ropa interior), septiembre 1999, [lencería Eva de Naturana]: mujer como comida.

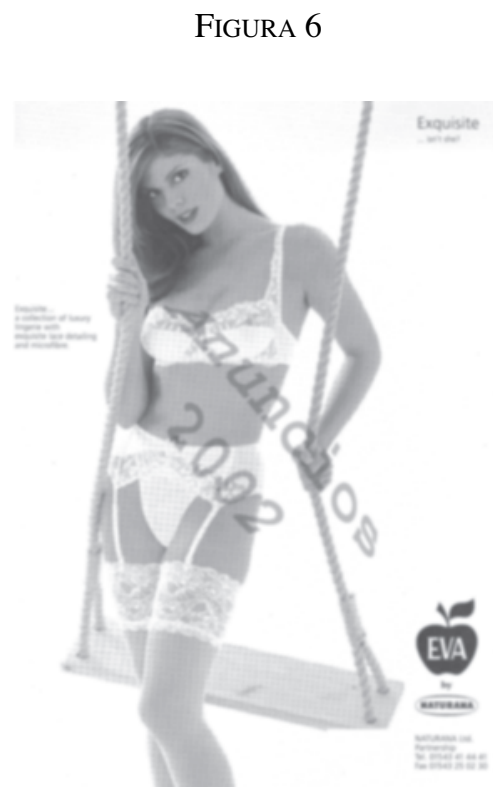




\section{HACIA UNA SUPERACIÓN DEL SEXISMO PUBLICITARIO}

Dada la interacción entre la lengua y la sociedad, parece lógico suponer que una reforma lingüística tendrá más éxito si viene avalada por un contexto social no sexista que fomente valores y actitudes a favor de un uso neutral de la lengua que no discrimine por razón de sexo (Romaine, 1984: 131).

Además, y como señalábamos antes, el lenguaje como sistema de signos no es culpable de desencadenar actitudes de discriminación; el culpable, si de buscar culpables se trata, es el uso que se hace del mismo, por lo que consideramos que lo que hay que reformar es dicho uso, con el objeto de acelerar una reforma social, necesaria y apremiante (Romaine, 1984: 125).

Existe constancia de un interés temprano por una reforma lingüística en inglés (Baron, 1986: 217). Desde entonces, se han sucedido múltiples propuestas de reforma en la lengua inglesa. Las diferentes propuestas que surgieron desde la izquierda se perfilan desde dos frentes: (1) un enfoque liberal moderado, que puede apreciarse en el manual de propuestas anti-sexistas de Miller y Swift (1981), cargado de directrices para los comunicadores públicos y (2) la tradición radical, con autores como Smith (1978), que intenta derrocar la visión machista de los discursos públicos de los que se ve excluida la mujer (Goddard y Patterson, 2000: 73-76).

Los medios de comunicación son muy proclives a la proliferación del sexismo (Fasold et al., 1990; Talbot, 1995). Los intentos por llevar a cabo una reforma lingüística en los mismos han sido múltiples, y los frutos que los mismos han deparado parecen constatar cambios sustanciales sobre todo en lo referente a la terminología profesional neutra y el uso de genéricos no sexistas (i. e. «businessperson», etc.).

Por otro lado, varias son las etapas que se inscriben en toda reforma lingüística: en primer lugar se impone una identificación y documentación de las prácticas sexistas del uso lingüístico. Esta etapa ha de dar paso a una planificación lingüística, en la que se han de seleccionar y evaluar alternativas ante las formas evidenciadas. Aquí es necesario considerar las limitaciones generales de las nuevas propuestas, caracterizar la transición de la etapa anterior a la nueva y evaluar estos cambios lingüísticos, examinando los efectos que pueden producir tanto en la estructura lingüística como en los factores de actuación. El tercer paso supone la puesta en funcionamiento de este cambio, y la posterior valoración de su efectividad (Fuertes Olivera, 1992: 4; Pauwels, 1998: 94191).

Una identificación (véase apartado anterior), análisis y denuncia de los recursos semióticos sexistas puede constituir el primer paso de una potencial reforma del sexismo semiótico en el discurso publicitario. 


\section{CONCLUSIONES}

Digamos, a modo de conclusión, que las etapas arriba especificadas son viables para una potencial propuesta de reforma en el discurso publicitario. El modelo de identificación, análisis y denuncia de los recursos semióticos evidenciados en British Cosmopolitan puede constituir el primer paso de esta potencial reforma, puesto que esperamos sirva para despertar la conciencia de la sociedad contemporánea, que movilizada de forma colectiva pueda poner en alerta a los organismos encargados de luchar contra el sexismo en la publicidad. Estos habrán de concretar una serie de medidas institucionales encaminadas a erradicar el sexismo semiótico que opera en el discurso publicitario.

Nuestro pequeño estudio en esta comunicación pretende así plantear un modelo viable no solo para la identificación y análisis de recursos semióticos que pueden ser sexistas sino también ofrecer, en definitiva, un pórtico sobre el que modelar una futura implementación que erradique el sexismo semiótico presente en la publicidad.

\section{REFERENCIAS BIBLIOGRÁFICAS}

BARON, D. (1986): Grammar and Gender, Yale, Yale University.

FRANK, F.W. (1985): «Language planning and sexual equality: guidelines for nonsexist usage», en Hellinger, M. (ed.) (1985): «Feminist linguistics and linguistic Relativity. Working Paper on Language», Gender and Sexism 1 (1): 27-37.

Fuertes Olivera, P. A. (1992): Mujer, lenguaje y sociedad: Los estereotipos de género en inglés y en español, Ayuntamiento de Alcalá de Henares, Madrid.

GARCÍA MESEguer, A. (1994): ¿Es sexista la lengua española? ¿Una investigación sobre el género gramatical?, Buenos Aires, Paidós. Publicación en html: $<\mathrm{http}$ ://europa.eu.int/comm/solt/bulletins/puntoycoma /45/psyc456.htm>.

Hellinger, M. (1990): Kontrastive feministiche linguistik. Mechanismen sprachlicher Diskriminierung im Englischen und Deutschen, Ismaning, Hueber.

Labov, W. (1972): Sociolinguistic Patterns, Filadelfia, University of Pennsylvania Press.

MaCKAY, D. G. (1980): «Language, Thought, and Social Attitudes», en GILES, H., W. P. Robinson y P. SMith (eds.) (1980): Language: Social Psychological Perspectives, Pergamon, Oxford, 89-96.

- (1983): «Prescriptive Grammar and the Pronoun Problem», en Thorne, B., C. Kramarae y N. Henley (eds.) (1983): Language, Gender and Society, Rowley, Massachusetts, Newbury House, 38-53. 
MackAy, D. G. y D. G. FulKerson (1979): «On the comprehension and production of pronouns», Journal of Verbal Learning and Verbal Behavior.

MILER, C. y K. SWIFT (1980): The Handbook of NonSexist Writing: for Writers, Editors and Speakers, Nueva York, Lippincott y Crowell.

Milroy, L. (1980): Language and Society Networks, Oxford, Basil Blackwell.

PAuwels, A. (1989): «Some thoughts on gender, inequality and language reform», Vox 3: 78-84.

- (1998): Women Changing Language, Londres y Nueva York, Longman.

Romaine, S. (1984): Language in Society. An Introduction to Sociolinguistics, Nueva York, Oxford University Press.

Sмiтh, D. E. (1978): «A peculiar eclipsing: Women's exclusion from man's culture», Women's Studies International Quatterly, 1: 281-296.

TALBOT, M. (1995): «A synthetic sisterhood: False friends in a teenage magazine», en HALL, K. y M. Bucholtz (eds.) (1995): Gender Articulated: Language and the Socially Constructed Self, Londres, Routledge, 143-165.

Troemel-Ploetz, S. (1989): Gender Voices, Oxford, Blackwell and Open University.

Trudgill, P. (1972): Sociolinguistics. An Introduction, Harsmondsworth, Penguin.

Velasco SACRISTÁn, M. (2003): «Propuesta, diseño y aplicación de un modelo de análisis de las metáfora de género en la publicidad impresa en lengua inglesa», Tesis doctoral. Publicación en html: <http://wwwlib.umil com/dissertations $>$.

Velasco Sacristán, M. y P. A. Fuertes Olivera (2002): «Sexismo semiótico de las metáforas de género en la publicidad impresa española», Mujeres, Hombres y Medios de Comunicación, Valladolid, Editorial Junta de Castilla y León, 375-380. 


\title{
EL DISCURSO DEL PODER EN EL DEBATE POLÍTICO: ENTRE LA AUTORIDAD Y LA LEGITIMACIÓN
}

\author{
JAVIER VELLÓN LAHOZ \\ Universitat Jaume I
}

$\mathbf{E}$ L análisis de los textos políticos posee una gran relevancia en toda metodología que aspire a superar los límites de la hermenéutica, como es el caso del Análisis Crítico del Discurso (ACD). El presente trabajo se centra en dos intervenciones del ex presidente del gobierno, José $\mathrm{M}^{\mathrm{a}}$ Aznar: la primera, una conferencia en el Palacio Euskalduna de Bilbao, el 8/2/00, con el título «España: libertad, pluralidad y Constitución» (PE, a partir de ahora); la segunda, en un acto organizado por la Cámara de Comercio de Barcelona, el 26/11/03, tras las elecciones catalanas (ССВ).

La selección de esta tipología discursiva, así como los ejemplos citados, obedece a una serie de factores que se irán desgranando a lo largo del artículo, basados en criterios interpretativos proporcionados por el ACD para actuar sobre las prácticas textuales de dimensión social.

\section{EL MODELO DE DISCURSO}

La práctica textual objeto del trabajo responde a lo que Fairclough (1992: 72-73) denominó la «concepción tridimensional del discurso», esto es, un procedimiento globalizador e integrador, abierto a una visión multidisciplinar que observa «la forma en que las prácticas discursivas fluyen cada vez más cruzando los lindes entre lenguaje y cultura» (Fairclough, 1998: 50).

Por una parte, en cuanto a textos, se incluyen en una tipología considerada por Igualada (2003: 993) como «formas ritualizadas», que condicionan el tipo de comunicación así como las relaciones entre el emisor y los diferentes niveles de recepción, y con shifters que canalizan las implicaciones con el contexto determinando el sentido performativo. Esta primera dimensión justifica la perspectiva de una lingüística crítica, de índole semántico-pragmática (en la línea de lo establecido por la obra de Halliday), que propone un modelo dialógico, según la teoría de Ducrot (1986), en el cual las microes- 
tructuras superficiales dependen de estructuras subyacentes de naturaleza cognitiva.

La segunda dimensión corresponde a la práctica discursiva, es decir, a la producción, distribución y recepción del texto. Resulta interesante constatar, en este caso, las estrategias persuasivas, especialmente las relacionadas con las diversas implicaciones de las estancias de emisión y destinatario. Por una parte, el texto incluye, en su desarrollo, su propia interpretación, a través de un metatexto que ofrece las claves no solo de su lectura, sino de las posibles lecturas que sobre él puedan realizarse. Se refleja así la vocación conversacional, propia del discurso contemporáneo (Fairclough, 1992: 200), en un movimiento de aproximación que atañe a las instancias discursivas, por el que el emisor se muestra en el acto ilocutivo, utilizando incluso la categoría pragmática de los atenuantes (Briz, 2002: 87), lo que se vincula tanto con la modalidad de recepción del acto político ante un foro determinado, como con el diálogo interdiscursivo con el segundo destinatario, la producción periodística. Baste recordar, como indica van Dijk (1990: 67), que el periodista, a la hora de reelaborar los textos-fuentes cuenta con unos esquemas previos incluidos en el propio original. Veamos algunas de estas tácticas discursivas en CCB:

\begin{abstract}
A mí me gusta ser lo más preciso en mis apreciaciones y, por lo tanto, me gusta que, cuando se formulan cuestiones [...] se planteen cuestiones sobre datos reales, no sobre prejuicios o no sobre datos que no responden a la realidad. Y yo les quiero decir lo que son unos datos que forman parte de un mensaje político [...], con el cual se estará de acuerdo o no, pero lo que no se puede discutir, en mi opinión, es el dato.
\end{abstract}

La tercera dimensión es la práctica social, puesto que la finalidad de estos discursos es «incitar a hacer», como señala Otaola (2003: 1037). En la sociedad contemporánea, definida como la de la comunicación, el verdadero poder se ejerce sobre el control, manipulación y difusión de la información (así lo explica Flaquer (1998: 280ss.)). Las elites políticas pugnan no solo por la vigilancia de los flujos informativos, sino por imponer unos plazos y unos ritmos a las cuestiones sometidas al debate social.

En los textos citados, José $\mathrm{M}^{\mathrm{a}}$ Aznar compagina la actitud conversacional, dialogante, aproximativa, con su dimensión institucional, en un proceso de autolegitimación que tiene como destinatarios tanto a los ciudadanos como a sus adversarios políticos y a las clases hegemónicas representadas por los asistentes a las conferencias. Y todo ello por medio de la repercusión de sus palabras a través de los medios de comunicación.

Esta nueva modalidad del diálogo político ha generado un complejo discurso, en el que se ven implicados tanto la clase política, que ha desarrollado 
estrategias para utilizar el marco informativo actual, como los grupos mediáticos, cada vez más concentrados en una industria globalizadora del entretenimiento, en la que se entremezclan los factores económicos, los espectaculares, los intereses de mercado, y todo ello en un universo saturado de información, en el que la virtualización modaliza la reproducción simbólica de lo que Habermas denominaba «el mundo de la vida».

El texto, en el marco discursivo citado, no solo es un instrumento para el debate político, sino que adquiere un valor económico. Su interés se mide por su capacidad de actuación como mecanismo de intervención social, por lo que, más allá de la aparente espontaneidad conversacional propia de este género oral, se inscribe en programas muy elaborados que la teoría de la comunicación denomina «laboratorios de publicidad política». En este orden discursivo, la presencia de ciertas referencias conceptuales activa un estudiado proceso de implicaturas, que los propios medios de comunicación han contribuido a fijar en el imaginario colectivo. Sin ánimo de ser exhaustivo, en PE expresiones como «realidad plural de España», «articular y vertebrar España», «ámbito propio de decisión», «reforma constitucional», «márketing político», forman parte de una estrategia global de confrontación sobre la que se articula el tejido significante de la textualidad, asumiendo una relevancia decisiva en la identificación de los diferentes sujetos inscritos en la alocución.

\section{EL CONTEXTO COMO MARCO DE PRODUCCIÓN DISCURSIVA: LOS AGENTES DEL DEBATE}

La elección de las dos intervenciones nombradas del ex presidente del Gobierno se debe a su vinculación con uno de los temas más ilustrativos del debate político nacional: la vertebración del modelo de Estado, el papel de las comunidades autónomas y los límites de la Constitución.

En esta compleja -y casi siempre violenta- confrontación intervienen tres agentes sociopolíticos, sobre los que se construye el sistema de referencias y las estrategias de legitimación en las dos conferencias citadas:

- Por una parte, el gobierno central del PP, que se presenta como garantía de continuidad de lo que se considera el pacto constitucional que, en realidad, es una lectura particular de la Carta Magna. Desde los intereses del presente artículo, lo primordial es la estrategia discursiva cuyo fin es situarse como sujeto de un proceso de legitimación, enmarcado en el referente de objetivización institucional representado por la Constitución.

- En segundo lugar, los que serán tratados como «exogrupos», esto es, las propuestas de los llamados nacionalistas (sobre todo, los catalanes y vas- 
cos, lugares donde se desarrollan las intervenciones de José $\mathrm{M}^{\mathrm{a}}$ Aznar). Como es bien sabido, dos hechos estaban contribuyendo a agudizar la tensión de las controversias en torno al tema: la presentación del denominado «plan Ibarretxe» y los resultados de las elecciones catalanas, con el triunfo de las opciones favorables a un nuevo marco político de convivencia. - Finalmente, la oposición estatal, el PSOE, sumido en un proceso de redefinición a partir de las dinámicas generadas desde las agrupaciones autonómicas, proclives a cambios en el programa socialista que favorezcan las tesis nacionalistas frente a los sectores más estatalistas. Su presencia en el discurso es también sintomática, y, en gran medida, coincide con los planteamientos esbozados para el grupo anterior.

\section{PRESENCIA DISCURSIVA DEL EMISOR}

El discurso de autolegitimación, como fase previa en la estrategia argumentativa, se sustenta sobre la dialéctica entre la posición social y la posición discursiva del emisor, esto es, sobre la fijación del criterio de autoridad, tanto en los mecanismos internos de la textualidad como en las implicaciones contextuales.

El mensaje ha de construir la «imagen» (face) del productor del acto de habla, noción desarrollada por la pragmática anglosajona para definir las tipologías comunicativas en torno a conceptos como la modalidad ilocutoria, la cortesía verbal, en definitiva, para la interacción pragmática que algunos autores han trasladado a la descripción del discurso político (Blas, 2001: 18ss.).

En los dos textos objeto de estudio, el sujeto enunciador se presenta, en primer lugar, y como táctica inicial de cortesía contextual, próximo a la recepción: «Me considero ya, por lo tanto, de hecho y de derecho, uno más de los 'asediados'» (la conferencia fue organizada por la Sociedad El Sitio (PE)); «hoy tengo la oportunidad de estar aquí con todos ustedes y, por lo tanto, de devolverles la visita» (ССB).

Hasta aquí, lo que correspondería al inicio de un texto ritualizado, escasamente significativo para el análisis (la captatio benevolentiae clásica). A partir de este momento, y a lo largo de la intervención, la figura del «yo» cobra un protagonismo determinante, arropándose con las prerrogativas institucionales en un proceso gradual de fijación del estatuto social y discursivo de autolegitimación:

- Referencias históricas cargadas de sentido político: «es para mí del máximo interés histórico que el anterior jefe de Gobierno que habló en El Sitio fuese don Manuel Azaña en 1934, hablando de grandezas y miserias de la política». (PE) 
- El ámbito generacional: «somos españoles privilegiados; españoles que hemos sido capaces de sincronizar [...] en una empresa constitucional». (PE) - Representación del sujeto institucional y sociopolítico en su dimensión internacional:

Muy agradecido que [este acto] lo celebremos en este salón, en el cual recordaba haber estado también [...] con ocasión de la Presidencia española de la UE. ( $\mathrm{CCB})$

Yo quiero sumarme a las manifestaciones de la Comisión Europea, como por el Presidente del Banco Central Europeo [...] (СCB)

Me importa destacar esto [...] estamos discutiendo el borrador del tratado constitucional europeo. ( $\mathrm{CCB})$

- Representación del sujeto institucional en la dimensión interna:

Gracias a esas iniciativas, España es una economía hoy más estable, más dinámica y más próspera. ( $\mathrm{CCB})$

Desde 1996 nosotros hemos avanzado en la consolidación del modelo autonómico. (PE)

Como Gobierno, nosotros no cooperamos con personas o con partidos; como Gobierno, cooperamos con instituciones. (ССB)

Un párrafo especialmente ilustrativo de este tipo de fijación discursiva del sujeto enunciador es el siguiente: «Pues bien, yo creo que la tarea principal de los dirigentes $[\ldots] \gg(\mathrm{CCB})$

De la categoría genérica se pasa al colectivo 'nosotros', todo ello enmarcado por la forma declarativa «yo creo», que propone una secuencia sintetizante, introducida por el conector conclusivo «pues bien».

Efectivamente, tras la determinación del sujeto enunciador como referencia de verdad objetivable, el «yo» textual, omnipresente (aparece abriendo el $40 \%$ de los párrafos en ambos parlamentos), formando estructura con los llamados verbos performativos y los de pensamiento («creo, soy consciente, deseo, tengo que desear, insisto, estoy convencido, quiero dejar constancia [...]»), constituye un singular refuerzo de lo que se denominan «indicadores de fuerza» (Lo Cascio, 1998: 49), explicitando el tipo de acto que el emisor está produciendo.

Se genera así un férreo control discursivo de los mecanismos argumentales por parte del sujeto, en correspondencia a la univocidad de un ideario en abierta confrontación con sus oponentes. Frente a la insistencia determinativa 
de la autorrepresentación, veremos en el siguiente apartado la exclusión del contrario, también en el ámbito del propio dominio textual.

El procedimiento de inclusión deíctica, a través del plural de primera persona, o bien de los «activadores de generidad» (Hernanz, 1990), tiene como fin la constitución del endogrupo, integrado por los que topológicamente forman el centro del discurso y, a la vez, son la referencia del argumento cuantitativo, es decir, tras la consolidación de la función discursiva del sujeto se da el paso al «discurso del nosotros» (Wodak y Matouschek, 1998: 79). Veámoslo en ejemplos de PE: «los españoles podemos sentirnos [...]»; «los ciudadanos saben reconocer mucho mejor que alguno de sus dirigentes»; «tengo la convicción de que no van por ahí las aspiraciones mayoritarias de la sociedad vasca»; «yo, como muchos otros, me mantengo [...]»; «mi empeño va dirigido al reencuentro de los vascos [...]»; «los ciudadanos del País Vasco no quieren ir por este camino $[\ldots]$; ; «todos los que se reconocen y actúan como demócratas»; «futuro de paz y libertad que haremos entre todos».

El núcleo temático de la exposición, la Constitución, aparece como marca de cohesión argumental, aglutinadora de referencias personales, en cuanto que representa el concepto de «nación plural». Se activa así el tópico de la cooperación y de la solidaridad en torno a dicha noción, con lo que contribuye a formalizar los indicadores de legitimación.

El espacio del centro discursivo y argumental queda constituido así, en un proceso de concentración en torno a la Carta Magna, en el que se ven implicados los «ciudadanos», «los españoles» y «la mayor parte del pueblo vasco», lo que enfatiza no solo la credibilidad del sujeto, sino que se presenta como exponente de un grupo homogéneo, cuantitativamente determinante, y sobre el que se gestiona la legitimidad moral y política de la objetividad. Es el resto, los otros, los que quedan (auto)excluidos en su práctica ideológica y, también, como veremos, de las instancias del discurso.

\section{DEFINICIÓN DEL EXOGRUPO}

Tras la clara identificación del centro generador del discurso, tanto desde la perspectiva textual como de la ideológico-referencial, ambas intervenciones desplazan al grupo opositor (el exogrupo, en sus diversas manifestaciones) a la periferia discursiva, en su dimensión topológica y como instancia del tejido textual. Se entabla así una dialéctica entre el discurso insitucionalizado, garantía de autoridad legitimadora de una práctica política y social, y lo que Bordieu (1985: 90ss.) denomina los «discursos regionalistas», alejados del núcleo productor de imágenes socializadas, de los focos de intervención mediática y desvinculados de la trama discursiva. 
La CCB, aun observando un objetivo político, debía apuntar hacia temas de índole económica. Tras una primera parte laudatoria de la labor propia en este campo, en el contexto de la escena europea, apoyada en todo tipo de datos, el entonces presidente del Gobierno incide en la situación política e institucional. Y lo hace desde una estructura textual basada en la oposición entre las nociones de estabilidad y de inestabilidad, que a partir de aquí se convertirán en focos temáticos en torno a los cuales se genera una estrategia argumental que distribuye la acción de los agentes: el marco de la estabilidad es el resultado de la intervención del poder cohesionado, firmemente institucionalizado («todos los catalanes y todos los españoles nos beneficiamos hoy de un marco institucional estable, de una situación más favorable de nuestra economía y de una sociedad más dinámica»); frente a él, los responsables de la inestabilidad son los que no tienen voz, los que no han asumido responsabilidades:

No debe haber gobernantes que jueguen a sembrar incertidumbres [...]

Yo solo tengo que desear que la inestabilidad parlamentaria, si es que la hay [...] Porque quiero decir que ustedes [...] serán los primeros y los principales perjudicados si hay inestabilidad.

Una vez se limita el ámbito de los que generan beneficios y el de los que siembran dudas, son los primeros, dirigidos por la figura del emisor, los que adoptan un estilo burocratizado, formalista, una modalidad legalista, con terminología jurídica y efectos eufemísticos, estableciendo la necesidad del pacto institucional y también las condiciones. Desde el centro discursivo se marca el programa de actuaciones: «se puede cooperar, se pueden coordinar actuaciones... defendiendo que las relaciones entre naciones, como las relaciones entre los gobiernos e instituciones, deben basarse [...] en el respeto a las normas».

Esta posición del emisor institucionalizado, que desde su posición como referente de autoridad, cobra protagonismo frente al «otro», e impone las condiciones, es uno de los recursos discursivos más evidentes en ambas intervenciones. De hecho, la posición generadora de la argumentación, convertida en centro del consenso colectivo y, por ello, de la verdad objetiva, propugna unas pautas interpretativas según las cuales el resto de planteamientos se han alejado de su situación, por lo que deben revisar sus idearios.

En PE la cohesión de los párrafos centrales se organiza en torno al prefijo «re», vinculado morfológicamente a formas verbales que, desde las directrices de la semántica léxica, seleccionan una estructura argumental muy significativa en el contexto del discurso político. Así se habla de «reencuentro con el Estatuto», «retorno al sentido común», «retomar la trayectoria», «replantearse una política equivocada», «restablecer las exigencias democráticas». 
Siguiendo los principios señalados por Pinker (1989: 70ss.) y Jackendoff (1990: 43ss.), puede considerarse que los verbos y nominalizaciones citados actualizan la existencia de un agente (identificado aquí con los que se muestran ajenos a la actitud del emisor), cuyo tema, objeto o movimiento debe desarrollarse en una trayectoria de regreso hacia posiciones anteriores, ahora convertidas en centrales como focos espaciales donde se localiza la fuente léxico-semántica (traslación microestructural de la fuente ideológica).

A la conformación discursiva del exogrupo contribuye, a su vez, la táctica de la exclusión u ocultación textual, bien a través de la indeterminación, la impersonalización o, incluso, por medio de estímulos ostensivos que plantean la conferencia como contestación a la agresión de un programa sociopolítico, cuando, en realidad, responde a una lectura interesada, fragmentaria y, por ello, manipulada del discurso ausente. Además, como se expuso en el apartado anterior, en el marco erigido por la omnipresencia del «yo» como eje discursivo.

En ССв la estrategia de la impersonalización no adopta la tonalidad beligerante de PE. Frente a la apología de los aciertos económicos del Gobierno, basados en la coherencia y la previsibilidad, los resultados electorales catalanes representan la incertidumbre. Puesto que tales resultados han traído un panorama complejo en el que la capacidad de decisión del partido de Aznar es muy limitada, este recurre a la indeterminación genérica: «No debe haber gobernantes que $[\ldots]$...

A continuación, esa misma ambigüedad referencial se plasma en el terreno institucional: «nosotros [como gobierno] cooperaremos con instituciones [...]».

Ante la firmeza, consistencia discursiva e ideológica, del sujeto institucional, en la que se implica a los ciudadanos y a los poderes económicos, son los oponentes, excluidos y despersonalizados, los que deben integrarse en el ámbito de la vida pública, proponiendo a sus electores lo que el emisor ya les ha concedido. Como indica Alcaide (2002: 8), «al dejar en suspenso al sujeto nocional de la acción, se provoca una ambigüedad querida».

En el caso de PE, la plasmación discursiva del grupo opositor adopta una estrategia de mayor calado político. En un primer momento, la impersonalidad nocional propone una lectura genérica de todos aquellos que se oponen a la «norma fundamental»: «creo que quienes hablan de reformas constitucionales evitan deliberadamente el debate político de fondo y lo hacen con frivolidad asombrosa». El sujeto se sitúa en el espacio emotivo apelando a los ciudadanos como entidad próxima a su plano discursivo, frente a la lejanía de los dirigentes, marcada por la estudiada indeterminación nocional, en una confrontación con profundas implicaciones ideológicas: «Los ciudadanos saben reconocer mucho mejor que alguno de sus dirigentes [...]».

A partir de aquí, y una vez fijadas las posiciones discursivas, la conferencia se adentra en una espiral de imputaciones, en la que la estructura dialogal 
subyacente solo activa el ideario del sujeto proyectando hacia el exogrupo valores de la negatividad:

- Primero en una respuesta al supuesto planteamiento programático de los oponentes: «Yo no creo en políticas de apaciguamiento [...]».

- A continuación, presentando al contrario como peligro para la democracia: «Hoy el desafío principal que los sistemas democráticos [...]».

La delimitación discursiva del exogrupo se desliza gradualmente al terreno de la violencia política (ETA):

Desbordar o deslegitimar los espacios de acuerdo no solo es, para mí, una irresponsabilidad, sino que es un fraude a los ciudadanos, porque lejos de acercarnos a la paz, reafirma en los terroristas la idea de que la violencia o su amenaza va a permitirles conseguir el precio político que nos exigen.

El párrafo anterior refleja la estrategia discursiva con toda nitidez: de la impersonalización marcada por dos infinitivos, cuya estructura argumentativa negativa (señalada por la prefijación) desvirtúa la acción de los agentes, a la identificación del endogrupo (yo-los ciudadanos-nosotros), en un diseño topológico que remarca la distancia de los referentes discursivos. A partir de esta fijación de posiciones, el sujeto opositor comienza a tomar forma nocional («el nacionalismo vasco»), como entidad que actúa ajena a los principios de la sensibilidad social. El «yo» reafirmado frente a la abstracción personalizada representa la conclusión más idónea en la escenificación del conflicto:

Comprendo que algunos vean en la globalización un motivo de temor. Yo prefiero considerarla como lo que es... Comprendo que para algunos su objetivo sea una comunidad cerrada, monolingüe, refractaria. Para mí, el futuro lo protagonizarán las sociedades abiertas, capaces de integrar... y abiertas a la cooperación.

\section{ESTRUCTURAS SINTÁCTICAS Y ESQUEMAS SEMÁNTICOS}

El estilo sintáctico-semántico del texto viene condicionado por la modalidad discursiva, vinculada, a su vez, con el contexto y con la finalidad perseguida. En principio sería previsible el dominio de los procedimientos propios de la argumentación, concretamente los pertenecientes al ámbito del debate político (Fuentes y Alcaide, 2002: 231ss.). Sin embargo, puede observarse que el desarrollo de ambas conferencias adopta una perspectiva de carácter autolegitimador y, a la vez, beligerante, síntoma de los modelos actuales en el discurso político.

En primer lugar, y como rasgo identificador de la estrategia discursiva, el estilo explicativo, definido por el principio de la causalidad, deja paso a un 
esquema atributivo, en la modelización de la actuación del oponente, lo que revela la tendencia a la transferencia de la legitimidad personal al discurso que, en definitiva, responde a la maniobra de apropiación del discurso dominante (la referencia objetivable) por parte de las instancias del poder y la consecuente exclusión, por la vía de la desacreditación, de los grupos situados en la periferia.

La presencia de adverbios ceroargumentales, con valor intensivo (López y Morant, 2002) («lo deseo fervientemente y fundamentalmente pensando en Cataluña», «pienso modestamente»), por una parte, y la adjetivización, en algunos casos matizada por el morfema de grado, («[estas ideas] confusas y disparatadas y completamente distantes de nuestra realidad social», «frivolidad asombrosa»), atribuida a la actividad del exogrupo, son ilustrativas de esta fijación por reafirmar la presencia discursiva del sujeto generador de referencias argumentales y deformar al oponente.

En esta misma línea resulta sugerente observar la presencia de estructuras contrastivas en el nivel léxico, con términos con una sobrecarga expresiva por su propia caracterización morfológica, con una prefijación y sufijación valorativa argumentalmente determinante sobre la actuación negativa, disgregadora del exogrupo («irresponsabilidad», «deslealtad», «descrédito», «ruptura»), frente a la actividad cooperativa, identitaria, socializante del emisor («convivencia», «perfeccionamiento», «pluralidad», «cooperación»), y también en el nivel sintáctico-semántico. El siguiente ejemplo de PE es ilustrativo:

Ocurre que la visión cotidiana del incendio, del destrozo, del amedrentamiento o de la violencia extrema que acaba con vidas humanas inocentes repugna a todos, salvo, naturalmente, a la minoría que lo celebra y lo instiga.

Las implicaciones semánticas iniciales seleccionan un predicado argumental claramente negativo; en esa ubicación se sitúa, sin embargo, a «la minoría que lo celebra y lo instiga». Este último verbo impone un argumento interno, por el que se activan las presuposiciones en torno al agente de la acción identificado con el adversario político, máxime cuando en el párrafo anterior al citado se identificaba a los que defienden ideas nacionalistas con los que «conducen a la intolerancia, a la coacción y a la violencia». De esta manera se establece una relación entre los roles sintácticos y los sociales, tal como Ribas (2002: 48) ha observado en su estudio sobre los discursos de los grupos parlamentarios en lo concerniente al tema de la inmigración.

Otros recursos contribuyen a caracterizar las instancias discursivas. Entre ellos cabe destacar las estructuras condicionales del tipo: «La Constitución se puede reformar, pero más allá de esto [...] hay que saber el qué, el cómo [...]». El vínculo argumental entre la prótasis y la apódosis queda determinado por la 
garantía del sujeto, en cuanto que es el elegido para establecer las normas de veracidad, el potencial de realidad de las proposiciones.

En similares términos actúan las fórmulas categóricas atributivas, una constante a lo largo del texto sobre las que se construye el esquema argumentativoexplicativo: «Esa es la España de la Constitución», «Esos son los datos que hay», «Cataluña es la comunidad [...]». En este sentido es relevante el uso en PE de una forma paralelística en torno a «Son la Constitución y el Estatuto los que [...]» (repetida cuatro veces, consecutivamente).

La insistencia en el uso de verbos declarativos (Levin, 1993: 182) en primera persona como marco de las cláusulas oracionales («Yo creo [...]», «Yo estoy convencido $[\ldots] »$, «Yo solo tengo que desear $[\ldots] »)$, incluyendo reiteraciones con un valor rítmico propio de la oralidad, enfatiza las diferencias de estatutos en el discurso, reafirmando el dominio discursivo del sujeto de la enunciación, atribuyéndole la función de inductor temático y controlando la posición izquierda de la cláusula (Hidalgo, 2003: 130).

La autoridad institucional, y su correlato en el sujeto discursivo, también se despliega en las estructuras consecutivas, en cuanto que desde dicho ámbito enunciativo se señalan las pautas interpretativas, además de optar por los espacios temáticos sobre los que gravitan las suposiciones causativas: «Yo creo que de la historia reciente del País Vasco podemos sacar la conclusión [...]»; «Alguna conclusión habría que sacar del hecho de que $[\ldots]$ ».

Finalmente, cabe resaltar la especial incidencia de la morfología verbal en la trama discursiva objeto de comentario. Tomando como base el valor deíctico de la temporalidad verbal (Rojo, 1990: 17-45) y la dimensión discursiva del modo y del aspecto (Gutiérrez, 1998: 275-306), puede determinarse el desarrollo interno de la argumentación a través de la síntesis entre las citadas categorías.

Por una parte, la deixis de proximidad, determinada por el presente, se convierte en ambas conferencias en el tiempo absoluto de referencia, con fórmulas -morfología verbal, adverbios situacionales, marcas deícticas espacialesque actúan como indicadores de fuerza, al explicitar la actividad del emisor como productor del discurso: «Yo estoy convencido, y además lo veo, de que hoy la marca España [...]»; «muchos de ellos [ejemplos] están nacidos aquí, en Cataluña, muchos de ellos pertenecen a esta Cámara de Comercio y algunos de ellos están aquí sentados hoy».

El proceso verbal conductor de la identidad verbal fija los límites temporales, «mientras el aspecto asumirá el desarrollo interno inherente al proceso verbal, proceso que nos indicará el inicio, el desarrollo o el final de la noción interna temporal» (López, 1989: 386). Así, el aspecto como entidad discursiva, textualmente actualizada a través de las formas marcadas de la conjugación y una utilización estratégica de los adverbios focalizadores (Fernández y Miguel, 1999: 97-128), presenta una acción concluida, en el 
presente, resultado de una fase previa. Esto es especialmente relevante en $\mathrm{CCB}$, puesto que aquí el desarrollo argumental adopta un estilo cronológico -como recurso explicativo de la actividad del sujeto-, en el que la situación actual de Cataluña es el resultado de la política llevada a cabo por el partido gobernante: «se ha hecho realidad una vieja ambición [...]», «esas inversiones han pasado de representar [...]», «ha sido así para todos y ha sido así también para Cataluña».

La noción de modo también cumple una función significativa en la organización discursiva de las categorías verbales. En la $\mathrm{CCB}$, la parte conclusiva está modalizada a partir de la presencia reiterada de perífrasis modales de obligación («debe ser», «debemos tener», «debemos asumir»), con una evidente proyección futura. El papel institucional del sujeto se abre aquí al sentido participativo de la colectividad, planteado desde el tamiz subjetivo que envuelve las formas marcadas modalmente.

Por su parte, en PE, las perífrasis aspectuales, de tipo reiterativo («vuelvo a expresar»), que gradúan el valor intensivo de la presencia del emisor, se combinan con la modalidad imperativa («habría que [...]», «el nacionalismo tiene que aceptar», «es preciso acabar», «el nacionalismo tiene que retomar $[\ldots] »)$, aplicadas a un agente concreto, el exogrupo, y estratégicamente situadas para regir sintáctica y argumentalmente el desarrollo de párrafos y cláusulas.

\section{CONCLUSIÓN}

El discurso de legitimación, y su implicación en el debate político, puede convertirse en una manifestación de violencia dialéctica en cuanto que se sigue una estrategia de autoafirmación ideológica acompañada de la marginación, cuando no eliminación del adversario.

En el caso que nos ocupa, las conferencias del entonces presidente del gobierno, José $\mathrm{M}^{\mathrm{a}}$ Aznar se realizaron en dos foros con características especiales dado el contexto en el que se hallan: en PE, en el corazón del País Vasco, lugar donde se desarrolló, en la anterior legislatura, un agrio debate político, con claras derivaciones hacia la violencia de todo género; en $\mathrm{CCB}$, tras unas elecciones en las que las opciones nacionalistas pasaron a convertirse en árbitros de la situación.

La singularidad de este género textual reside en los mecanismos que lo generan y su funcionalidad: como oralización de un esquema prefijado según los tópicos argumentales y formales de un discurso político global, y como procedimiento de intervención en la vida pública, a través de un receptor inmediato (el público asistente, perteneciente a sectores sociales identificados) y, sobre todo, de la presencia de los medios de comunicación, a quien se diri- 
gen ciertos gestos semánticos, ajustados a las directrices de la comunicación mediática, con el objeto de su difusión social.

La proyección de la propia imagen del sujeto, reforzada por su carácter institucional, es el estadio previo a su conversión en referente de la verdad objetivable, asumiendo el valor de los intereses colectivos. La presencia obsesiva del «yo», como agente organizador de las microestructuras y como instancia decisiva del discurso, constituye el eje sobre el que se fundamenta la identidad del endogrupo.

El exogrupo, por su parte, queda alejado del centro temático del discurso y también del registro organizativo de los esquemas sintáctico-semánticos. Oculto tras los mecanismos de la impersonalidad o de la alusión genérica, está relegado a la función de objeto pasivo en la alocución del sujeto institucional o de interlocutor de un esquema dialógico implícito, en el que sus planteamientos son sometidos a un proceso deslegitimador.

Aupado a la condición de intérprete único de los intereses globales de verdad, el sujeto de la enunciación domina todos los resortes de la producción discursiva, tanto en sus aspectos argumentales como en los marcos formales. Los esquemas sintáctico-semánticos reproducen esta situación de privilegio, tanto en la vertiente léxica, como a través de los mecanismos morfológicos y pragmáticos, al tiempo que relegan al oponente a los márgenes de los esquemas conceptuales.

El discurso político y el de la violencia se integran en un proceso de implicaturas, por el que el contrario aparece como coartada intelectual de todo tipo de actos delictivos (terrorismo, incluido). La apropiación de los ejes generadores de la identidad social (ley, libertad, cooperación, individuo, globalización, etc.) representa una estrategia discursiva cuyo fin es el control de los resortes normativos de los que dimanan las coordenadas éticas de la comunidad. Desde esta posición de dominio, el control de la gestión social del discurso oficial (el cómo, cuándo y dónde de su producción y difusión) se convierte en un acto impositivo, cercano a la violencia discursiva, exponente de la legitimación y reproducción del ejercicio del poder.

\section{REFERENCIAS BIBLIOGRÁFICAS}

AlCAide, E. R. (2002): «Estructuras impersonales y argumentación», en Veiga, A., M. González y M. Souto (eds.) (2002): Léxico y gramática, Lugo, Tris Tram, 7-18.

BLAS, J. L. (2001): «'No diga chorradas...' . La descortesía en el debate político cara a cara. Una aproximación pragma-variacionista», Oralia, 4: 9-45. BRIZ, A. (2002): «La atenuación en una conversación polémica», en BLAS, J. L. 
et al. (eds.) (2002): Estudios sobre lengua y sociedad, Castellón, Universitat Jaume I, 87-103.

BouRdieu, P. (1985): ¿Qué significa hablar? Economía de los intercambios lingüísticos, Madrid, Akal.

DiJK, T. A. VAN (1990): La noticia como discurso. Comprensión, estructura y producción de la información, Barcelona, Paidós.

Ducrot, O. (1986): El decir y lo dicho. Polifonía de la enunciación, Barcelona, Paidós.

Faircclough, N. (1992): Discourse and social change, Cambridge, Polity Press.

- (1998): «Propuestas para un nuevo programa de investigación del Análisis Crítico del Discurso», en Rojo, L. M. y R. WhitTAKer (eds.) (1998): Poder-decir o El Poder de los discursos, Madrid, Arrecife-UAM, 35-53.

FERNÁNDEZ, M. y E. DE Miguel (1999): «Relaciones entre el léxico y la sintaxis: adverbios de foco y delimitadores aspectuales», Verba, 26: 97-128.

FLAQUER, Ll. (1998): «L'impacte de les noves tecnologies sobre la llengua i les seues dimensions pública i privada», en Mollà, T. (ed.) (1998): La política lingüística a la societat de la informació, Alzira, Bromera, 277-297.

Fowler, R. (1991): Language in the News. Discourse and ideology in the Press, Londres, Routledge.

Fuentes, C. y E. R. AlCAIDE (2002): Mecanismos lingüísticos de la persuasión, Madrid, Arco/Libros.

GuTIÉRREZ, Mª L. (1998): «Sistema y discurso en las formas verbales del pasado», Revista Española de Lingüística, 28, 2: 275-306.

HERNANZ, M. L. (1990): «En torno a sujetos arbitrarios de segunda persona del singular», en DEMONTE, V. y B. GAZA (eds.) (1990): Estudios de lingüística de España y México, México, UNAM, 151-178.

HidALGO, R. (2003): «Orden de palabras y conversación: la tematización sintáctica como introductor de temas discursivos en el español hablado», en GIRón, J. L. et al. (eds.) (2003): Estudios ofrecidos a José Jesús de Bustos Tovar, Madrid, Universidad Complutense-Instituto de Estudios Almerienses, 125-134.

IguAladA, D. A. (2003): «Rituales: el discurso de investidura», en GIRÓN, J. L. et al. (eds.) (2003): Estudios ofrecidos a José Jesús de Bustos Tovar, Madrid, Universidad Complutense-Instituto de Estudios Almerienses, 991-1002.

JACKENDOFF, R. (1990): Semantic Structures, Cambridge-Massachussets-Londres, The MIT Press.

Levin, B. (1993): English Verb Classes and Alternations, Chicago-Londres, The University of Chicago Press.

Lo CAscio, V. (1998): Gramática de la argumentación, Madrid, Alianza.

LóPEZ, A. y R. Morant (2002): «L'adverbi», en SolÀ, J. et al. (dir.) (2002): 
Gramàtica del català contemporani, Barcelona, Empúries, vol. 2, 17991852.

LÓPEZ, C. (1989): «La organización enunciativa del discurso», Revista Española de Lingüística, 19, 2: 377-387.

OtaOla, C. (2003): «El verbo y las expresiones directivas en el discurso político», en GiRÓN, J. L. et al. (eds.) (2003): Estudios ofrecidos a José Jesús de Bustos Tovar, Madrid, Universidad Complutense-Instituto de Estudios Almerienses, 1033-1053.

PINKER, S. (1989): Learnability and cognition. The acquisition of Argument Structure, Cambridge, The Mit Press.

Ribas, M. (2002): «Discurs públic dominant i cognició social», en UbaLdina, C. y M. Ribas (eds.) (2002): Anàlisi del discurs polític. Producció, mediació i recepció, Barcelona, Universitat Pompeu Fabra, 39-57.

RoJo, G. (1990): «Relaciones entre temporalidad y aspecto en el verbo español», Tiempo y aspecto en español, Madrid, Cátedra, 17-45.

WodAK, R. y B. MatouscheK (1998): «'Se trata de gente que con sólo mirarla se adivina su origen': análisis crítico del discurso y el estudio del neoracismo en la Austria contemporánea», en Rojo, L. M. y R. WHITTAKER (eds.) (1998): Poder-decir o El poder de los discursos, Madrid, ArrecifeUAM, 55-92. 


\section{SECCIÓN II ESTUDIOS SOBRE (DES)CORTESÍA Y CONSTRUCCIÓN DE LA IMAGEN EN EL DISCURSO}




\title{
IMAGEN SOCIAL E INFORMACIÓN EN UN CONFLICTO URBANO: EL CASO «MESTRETS»
}

\author{
LIDÓN BARBERÁ \\ Diario El Mundo - Castellón al Día \\ JAVIER VeLLÓN \\ Universitat Jaume I
}

\section{INTRODUCCIÓN: ORDEN SOCIAL Y ORDEN MEDIÁTICO}

$\mathbf{L}$ A labor de los medios de comunicación se ha definido tradicionalmente como factor que hace posible la transmisión de información entre las fuentes y la sociedad. Dicho concepto resulta claramente insuficiente en la denominada «sociedad de la información», cuyo sistema sociopolítico exige una comunicación constante y fluida entre los agentes del orden comunitario (Saperas, 2002: 123).

Un análisis que pretenda englobar la totalidad de los procesos de interacción comunicativa en el ámbito social debe atender no sólo al contenido de los mensajes, sino a los modelos de textualización de la realidad, convertidos en exponente no sólo significativo sino también ideológico en la transmisión informativa.

El presente trabajo pretende analizar un triángulo comunicativo formado por tres factores: la Administración (en este caso la municipal, ante todo), una representación de los llamados «Nuevos Movimientos Sociales», el grupo Mestrets enfrentado al Ayuntamiento de Castellón por una cuestión de urbanismo que será detallada más tarde, y, finalmente, los medios de comunicación locales (la prensa escrita, concretamente).

El objetivo es estudiar las estrategias de acceso de los agentes sociales a la lógica del discurso mediático, especialmente de los grupos no institucionales, alejados inicialmente de las rutinas que canalizan los vínculos entre la realidad y los centros periodísticos. A partir de ahí, el eje de la investigación se centra en la propia dinámica de los medios, que se actualiza a través de los mecanismos que textualizan las interacciones comunicativas de los sujetos sociales, cuyo fin es modelizar una imagen de cara a la opinión pública, referente último del sistema democrático. 


\section{MOVIMIENTOS SOCIALES: EL CASO 'MESTRETS'}

Los vecinos de Mestrets irrumpen en la escena mediática castellonense solo unos meses después de las elecciones municipales de 2003 y se convierten en el principal movimiento reivindicativo de todo el mandato.

El conflicto surge precisamente cuando el Ayuntamiento anuncia, en plena campaña electoral de 2003, la construcción de 6.000 nuevas viviendas, la mitad protegidas, en la zona noroeste de la ciudad. Poco después, los propios vecinos denuncian que la construcción de estos bloques de pisos supondrá la demolición de las viviendas unifamiliares que cumplían con los requisitos legales para convertirse en núcleo urbano consolidado y evitar así cualquier derribo.

A partir de ese momento se abre una clara lucha entre los vecinos y el Ayuntamiento. Mientras los primeros defienden la convivencia de ambas formas de edificación, el consistorio rechaza completamente esta posibilidad, que considera incompatible y acusa a los vecinos no solo de intentar frenar el desarrollo de la ciudad, sino también de oponerse al interés social.

La tramitación del expediente urbanístico marca el ritmo de todo el proceso, ya que los vecinos actúan a medida que la Administración da nuevos pasos para consolidar la actuación.

Como sucede con el resto de asociaciones integradas en la plataforma «Abusos Urbanísticos No», las reclamaciones de Mestrets se enmarcan en los llamados «Nuevos Movimientos Sociales», que cambian las tradicionales reivindicaciones de clase por otras vinculadas con su identidad o con sus formas de vida. Según recogen Johnston, Laraña y Gusfeld (1994: 9), los nuevos movimientos trascienden de clase social y su orientación es pragmática, con diversidad ideológica en su interior.

\section{LA GESTIÓN DE LA COMUNICACIÓN SOCIAL}

El conflicto planteado en las líneas precedentes traslada al escenario de la comunicación un sistema de interacciones propio de los grandes conflictos urbanos en la sociedad de la información.

En su diseño básico, se trata de un diálogo entre los dos agentes sociales a través de los medios de comunicación, siguiendo un proceso que, al hacerse público, involucra como destinatario último de la negociación a la sociedad en su conjunto, asumida en su faceta de opinión sobre la que planea la imagen de los sujetos.

La función del medio es, pues, gestionar los estímulos informativos, integrándolos en su práctica discursiva, lo que conlleva una implicación de los 
sectores socioeconómicos y profesionales que participan en la producción y difusión de dichos medios y, a la vez, la aceptación por parte de los contendientes de las normas que franquean el acceso al discurso informativo.

En el caso de la Administración, en cuanto a discurso público dominante, con un valor performativo, pues de sus actos se desprenden modificaciones del orden social, los canales con los flujos informativos están perfectamente ritualizados a través de distintos tipos de convocatorias, ruedas de prensa, entrevistas, notas oficiales, además de las fórmulas más personales e informales desarrolladas diariamente en las redacciones.

En el caso del colectivo afectado, su irrupción en los medios revela las claves de las pautas informativas en la sociedad actual, sobre todo cuando afectan a grupos, más o menos homogéneos, no sólo alejados del discurso informativo dominante, sino enfrentados a la imagen oficial del poder en los medios.

Por una parte, existe una tendencia a seguir las pautas establecidas, abriendo canales con la prensa, a través de portavoces que responden normativamente al discurso oficial. Por otra, ante el desequilibrio de fuerzas, y su traducción cualitativa y cuantitativa en la presencia en los medios, estos colectivos han optado por formas alternativas de acceso a la información (irrupción en plenos, manifestaciones, etc.), de las que se hablará en el siguiente apartado.

Lo más relevante es que también a través de sus protestas, verbalizadas y visualizadas (las fotografías de sus pancartas) por los medios, puede seguirse el proceso de interacción comunicativa, con la doble dirección en la categoría de la recepción. En la pancarta desplegada en el pleno municipal del 29.4.04 -«En nombre del bien común, ¿por qué nos robáis nuestras tierras?»-, reproducida en todos los medios locales el colectivo responde al argumento del Ayuntamiento (Fabra: «Gracias a esta actuación, se consigue equilibrar el precio del mercado y facilitar a los jóvenes y familias con mayores dificultades para poder acceder a una casa el acceso a la primera vivienda» (El Mundo, 26.2.03).

\section{EL ACCESO A LA INFORMACIÓN Y EL DISCURSO PERIODÍSTICO}

El proceso informativo del caso Mestrets, en su desarrollo cronológico, es sintomático de los parámetros que rigen la gestión de la información por parte de los medios, a la vez que desvela las relaciones entre la textualidad y sus tipologías, por una parte, y la dimensión exacta del discurso periodístico como lenguaje social, sometido a factores e intereses muy heterogéneos.

Antes de analizar las vías de acceso y el tratamiento informativo del conflicto comentado, convendría precisar las peculiaridades de uno de los fenómenos más relevantes de la sociedad actual en el terreno de la comunicación: 
la incidencia cada vez más notable de los medios locales. Esta incidencia, que puede ser relativa en ámbitos donde es difícil competir con los generalistas, puede actuar «com a correctiu de la desigualtat en els intercanvis comunicatius» (Gómez y Dolç, 1998: 87-95).

Efectivamente, la proximidad de los medios locales respecto a los hechos que relatan conlleva una serie de condicionantes que determinan no sólo la perspectiva, más o menos humana o impersonal, de la información, sino también una cierta imagen contradictoria alejada de la homogeneidad de intereses que domina la narración y organización del discurso periodístico en lo medios nacionales:

-La proximidad real con los acontecimientos impide una despersonalización de los sujetos implicados, de manera que no se habla de simples funciones narrativas en un enunciado, sino que las experiencias humanas, emocionales, están presentes en un discurso, el de la noticia, cuya objetividad se actualiza, ante todo, en la asepsia impersonal.

-Esta estrategia basada en la lógica de la comunicación local, rompe con las tendencias generales de los grandes grupos mediáticos, que otorgan una cierta autonomía a sus terminales locales para ubicarse en un mercado publicitario cada vez más localizado en las instituciones de proximidad.

Frente a esta constatación, no es menos cierto que como empresas, los medios de comunicación están sometidos a los imperativos del mercado, lo que se traduce en necesidades de financiación que condicionan la gestión de la información.

Por una parte, la Administración, a través de la publicidad institucional, sin olvidar los beneficios indirectos (calidad y priorización de la información estatal, por ejemplo) que pueden generarse a través de una sintonía concreta con el poder. Por otra, las empresas que bien por su implicación en el accionariado, bien por las promociones publicitarias, pueden tener intereses concretos (en el caso que nos ocupa, las constructoras son, sin duda, parte interesada en el conflicto y no son ajenas a la implantación de los medios locales). Por supuesto los partidos políticos y demás agentes sociales también constituyen grupos de presión sobre los periódicos, por su influencia en los sectores económicos y en los centros de poder, además de ser focos generadores de noticias.

Esta realidad explica que si bien los géneros informativos de los medios han dedicado una atención prioritaria al conflicto de Mestrets, en la parte argumentativa del periódico, la que le compromete ideológicamente de un modo directo -editoriales, sueltos-, se ha preferido obviar el tema o contemporizar.

En cualquier caso, los primeros testimonios periodísticos sobre el tema reproducen una visión parcial del problema, dando preeminencia absoluta al 
discurso aportado por la Administración, lo que refleja cómo se vertebran las dinámicas informativas en la sociedad.

Desde el punto de vista del discurso informativo, esta tendencia inicial se observa en la estricta objetividad informativa, reflejo de un lenguaje institucionalizado en torno al sentido impositivo del registro administrativo, así como en la interacción de formas y géneros textuales que puede observarse en el ejemplo 1 (Mediterráneo, 18.11.03), en el que la información del PAI -en la parte izquierda- queda enmarcada por otra noticia, que perceptiva y semánticamente determina una relación de causalidad respecto a la anterior, lo que queda confirmado por la columna de opinión que reafirma, desde la óptica argumental, la macroproposición que sustenta toda la heterogeneidad textual de la plana.

\section{ESTRATEGIAS DE TEXTUALIZACIÓN}

\subsection{Estrategias superestructurales}

La organización discursiva de la materia informativa tiene una primera manifestación en la disposición secuencial del texto. Como recuerda Fuentes Rodríguez (2000), este puede ser de carácter homogéneo -constituido por un solo tipo de secuencias- o, como en el caso del discurso periodístico, formado por una multiplicidad de géneros, modalidades, además de por la interacción entre códigos semiológicos, visuales y verbales, que determinan su dimensión perceptivo-comunicativa.

Este planteamiento discursivo determina el primer nivel del análisis a la hora de valorar el acceso de la materia a su textualización informativa, convertida así en un lenguaje social ajustado al ritual informativo impuesto por el medio.

En el caso que nos ocupa, la opción del colectivo Mestrets por protestas alternativas a los canales institucionales, con fórmulas como la irrupción en los plenos municipales, la organización de manifestaciones lúdicas, aparición en actos oficiales, participación en procesiones cívicas, presencia constante ante los considerados promotores del problema, ha posibilitado su irrupción en los flujos informativos desde una perspectiva no convencional: la ruptura con lo establecido y el dominio del orden visual.

Los estudiosos de los movimientos sociales urbanos de la modernidad (Laraña y Gusfield, 1994: 112) insisten en la importancia de lo que denominan «dramaturgias» como «procedimiento fundamental para la difusión de los nuevos significados de los que son portadores los movimientos», asumiendo así la lógica de la sociedad de la información, según la cual «una audiencia de masas actúa como observadora» de los actos. 
La presencia visual de los afectados, con su componente teatral (pancartas, disfraces, ruptura de los significados espaciales, etc.), es un mecanismo clave para textualizar su protesta, trasladando al discurso periodístico la estrategia de confrontación de la realidad y la pugna por la imagen social de los contendientes ante la opinión pública.

La comparación entre los ejemplos 2 y 3 (dos planas de $E l$ Mundo del 4.2.05 y 15.12.04, respectivamente) son ilustrativas. Mientras en la primera el dominio verbal del titular («Moliner premia el "pacifismo" de Mestrets con la promesa de un "acuerdo seguro"»), focalizando la atención en la Administración como tema de la oración, se reproduce en la secuencia visual, en el 3, la fotografía prioriza la acción del colectivo, tal como se transmitía a través de un titular dominado semántica y perceptivamente por su preeminencia.

Otro aspecto de las estrategias superestructurales se refiere a la dinamización de la organización informativa de los acontecimientos a través de los géneros textuales.

En el caso que nos ocupa, el paso de un género netamente informativo como la noticia, con sus limitaciones macroestructurales y semántico-cognitivas, al reportaje supone la transición entre una textualidad basada en el EXPONER (Bronckart, 2004: 87ss.) a otra basada en el CONTAR, con lo que ello implica en el orden no sólo de la actividad verbal, sino de la práctica discursiva y de su estatuto en el ámbito de la comunicación.

El ejemplo 4 ( $E l$ Mundo, 27.6.04) tanto en el orden lingüístico como en el perceptivo-visual, del acceso del colectivo Mestrets a formas discursivas del lenguaje periodístico que amplían las posibilidades emotivo-argumentativas de su causa en la rutina informativa de los medios. El paso al reportaje garantiza, como puede verse, el dominio de los resortes visuales, el control de los núcleos macroproposicionales, incluyendo el control de los titulares por el estilo directo, así como de la polarización argumentativa.

El cambio cualitativo que supone ya no solo el acceso sino también el protagonismo en la dinámica textual también se observa en la estrategia desarrollada en el ejemplo 5 (Levante, 25.5.04), en el que un género tan impactante -visual y argumentativamente- como la viñeta enmarca, subjetivamente a favor de los afectados, la textualidad informativa, componiendo así una imagen heterogénea de la práctica periodística que refleja, en el nivel de discurso mediático, la pugna de intereses que se está desarrollando.

\subsection{Estrategias macroestructurales}

El análisis macroestructural se centra en la organización del texto, en su vertiente informativa y persuasiva, en el caso concreto del periodístico, pues como indica van Dijk (1998: 230), ello supone estudiar cómo se plantea la 
información, qué se considera relevante, cómo se dispone y cómo se almacena en la memoria del destinatario.

\subsubsection{Acceso a los titulares}

El acceso a la preeminencia perceptivo-comunicativa del titular es una de las claves para evaluar la situación del proceso informativo, ya que, según señala van Dijk (2001: 61,70), el titular «expresa una macroproposición temática» que interactúa con las categorías cognitivas del receptor, estableciendo una dinámica presuposicional con el contexto.

La forma más evidente de determinar la presencia en los encabezamientos visualmente dominantes es a través del control sintáctico-perceptivo de la unidad oracional, convirtiendo a los agentes sociales en figuras de la secuencia perceptivo-informativa (Gutiérrez, 2004: 37ss.), lo que supone acceder al estatuto dominante del mensaje. La agentividad, como argumento externo de la acción verbal, se observa en los siguientes titulares en los que la presencia de Mestrets es sintomática: «El Camí Els Mestrets levanta la voz» (Mediterráneo, 30.5.04); «Afectados por el PAI Els Mestrets rechazan las oferta de A. Fabra» (Heraldo, 8.5.04).

Otra forma de escenificar oracionalmente la presencia de los afectados es situando a la Administración como «marco oracional» (López García, 1994: 197) en sentido negativo, es decir, formalizar una imagen perceptual a través de un esquema lingüístico-funcional en el que la actuación -positiva- del agente -Mestrets- tiene como entorno referencial la negativa de su oponente: «Els Mestrets protesta ante el consistorio por el "desarrollo destructivo del PP”» (Levante, 12.6.05).

De manera paralela, la ubicación sintáctica del Ayuntamiento como figura puede adoptar una imagen negativa al estar determinada por un verbo que desarrolla una estructura argumental desfavorable: «Gimeno expulsa otra vez a los vecinos de Els Mestrets del pleno que modifica el PGOU» (Levante, 25.6.04); «El PP aprueba en solitario el PAI Mestrets con pitos y cacerolada» (Heraldo, 25.6.04).

Finalmente, la estructura perceptivo-comunicativa del titular puede reflejar una lectura política de los acontecimientos, concediendo el privilegio sintáctico-semántico, además de visual, a los agentes de la oposición, que pasan a adquirir una preeminencia informativa reproducida por la organización del mensaje: «PSPV y Bloc rechazan las VPO de Mestrets por la falta de acuerdo con los expropiados» (El Mundo, 25.6.04).

\subsubsection{Organización cohesiva}

La organización cohesiva del material textual informativo, así como las estrategias tematizadoras reflejan la incidencia del colectivo Mestrets en el espa- 
cio de la comunicación periodística. El conjunto de mecanismos discursivos que establece las relaciones entre las diferentes unidades informativas revela, a su vez, el modelo estructural que posibilita un determinado desarrollo de los contenidos temáticos.

En los textos 6, 7, 8 y 9, correspondientes a la noticia sobre un mismo acontecimiento (25.6.04) -uno de los puntos álgidos informativos del conflicto-, se observa la gradación macroestructural de las secuencias en el proceso de comunicación:

-El primer -y en algún caso, segundo- párrafo ofrece la descripción del hecho que motiva la noticia. El periódico Levante es el que más modaliza la información al establecer desde el inicio un responsable, lo que considera más relevante que los acontecimientos en sí: «El PP hizo valer ayer su mayoría absoluta en el Ayuntamiento de Castelló[...]».

-El segundo párrafo -o tercero, en otros casos- se centra ya en los vecinos y en el hecho violento del desalojo por parte del alcalde, elemento informativo clave que ha catalizado el interés textual por encima del evento administrativo, la aprobación de la modificación del PGOU.

De este modo, la estructura externa de yuxtaposición de los acontecimientos se asienta sobre un modelo semántico de orden causal, capaz de visualizar a través de la organización cohesiva los ejes del enfrentamiento: Situación de soledad política del equipo de gobierno + Acción represiva contra ciudadanos $=$ Consecuencias, acción reivindicativa de los afectados.

La ordenación sintáctica del proceso informativo presenta un mapa del conflicto donde cada parte implicada aparece ante la opinión pública con una imagen marcada por un componente emotivo favorable a los vecinos. El resultado es que Mestrets logró situarse en el centro del debate político municipal, como uno de los motivos informativos de mayor trascendencia para la opinión pública local.Así se muestra en la ordenación sintáctico-perceptual del siguiente titular: «El ejecutivo local recalificará la zona de viviendas de 'els Mestrets' con la oposición del PSPV» (Levante, 22.6.04). Ayuntamiento (PP) $\Rightarrow$ Mestrets $\Leftarrow$ Oposición.

\subsubsection{Implicaturas}

Uno de los mecanismos privilegiados para observar el acceso a los flujos informativos es la capacidad de generar un contexto de referencias que actúa como implicatura discursiva en el proceso interpretativo por parte del receptor, es decir, el texto activa un registro inferencial, entendido como «operación mental por la que se evalúan las intenciones» (Yus, 1997: 108).

Nos situamos así, en el entorno de lo que Habermas (1984: 267) denomina «acciones intencionales» que vertebran dos tipos de referencias: «referen- 
cias a la representación cognitiva de la realidad que el agente considera válida y la actitud subjetiva que el agente pone en relación con esa representación de la realidad». De esta manera, se produce un espacio informativo que se convierte en garantía para la interpretación alusiva de todo tipo de noticias vinculadas, interesadamente, explícita o implícitamente -en este caso, el salto cognitivo necesitará de soportes semánticos más consistentes-, con el hecho nuclear, en este caso, el conflicto de Mestrets, convertido en «información pertinente o relevante» (Gutiérrez Ordóñez, 2002: 135) de todo un ciclo informativo.

El caso de Mestrets ha logrado tal relevancia informativa, que la coherencia temática de numerosos textos periodísticos locales solo puede establecerse a partir de un proceso inferencial que remite a su problemática y a su plasmación, y continuidad, en los medios.

Tal es el caso de la noticia-reportaje de El Mundo (22.10.04) cuyo titular ya es suficientemente ilustrativo: «El Ayuntamiento paraliza tres PAI para evitar más crispación vecinal». La referencia a Mestrets resulta evidente, convertidos así en sujetos activos de la gestión municipal, desde el punto de vista de la interpretación informativa.

Más emocional es la noticia del Heraldo (28.6.04), enmarcada semántica y visualmente por una fotografía de las protestas del colectivo, con una pancarta cuyo mensaje actúa directamente sobre el resto del texto: «No abuséis del poder». El titular que sitúa la información en el interés perceptivo del destinatario es elocuente: «Un estudio asocia la patología del acoso laboral a la de los afectados por la LRAU». El subtitular, desarrolla los síntomas de la enfermedad psicológica asociándola al caso concreto de los afectados por el PAI Mestrets.

\subsection{Estrategias microestructurales: significados locales}

a) El léxico es uno de los capítulos determinantes en el proceso de acceso de la información a la textualidad, así como un factor básico para establecer las líneas modalizadoras del contenido.

Un primer capítulo relevante lo forman los verbos adscritos como argumento al sujeto Mestrets, del tipo «denuncian», «exigen», «protestan», «rechazan», «levantan la voz», convirtiéndolos en agentes de un proceso que, en primera instancia, tiene una dimensión verbal, una interacción comunicativa, expresada por verbos de lengua, cuya referencialidad argumental se agota en sí misma.

El paso siguiente en el enfrentamiento lo reflejan verbos como «frenar» («Mestrets frena la tasación del IVVSA alegando falta de respeto hacia sus casas», El Mundo, 15.12.04), que representa un salto cualitativo de la estrategia del colectivo, expresada a través de un predicado de mayor complejidad 
construido en torno a un verbo que precisa ser desarrollado por un argumento interno para exponer el contenido completo de su información.

Las categorías nominales son, asimismo, esclarecedoras del sesgo informativo del conflicto. Los sujetos son definidos siempre como los «afectados» $\mathrm{y}$ «vecinos»; sus hogares son aludidos como «massets», término local próximo a la memoria colectiva de la sociedad castellonense, por lo que el vocablo adquiere resonancias afectivas importantes. Las acciones sobre ellos son caracterizadas como «expropiación», «derribo», «pérdida», y las más concretas de la alcaldía frente a sus protestas en los plenos como «expulsión», «realojo», «rechazo».

La selección léxica, por tanto, define las líneas generales del planteamiento informativo, tal como ya se apreciaba en el nivel macroestructural, aportando un componente afectivo a la acción del grupo de vecinos, como puede apreciarse en el primer párrafo de la noticia publicada por el Heraldo (8.5.04), en la que la adjetivización domina la parte perceptualmente relevante del texto, condicionando así su lectura posterior:

Indignados, enfadados y con más ganas de seguir luchando por lo suyo que nunca. No hay otras palabras para describir el estado de ánimo de los propietarios afectador por el futuro $[\ldots]$

b) Identificación de los agentes. El colectivo Mestrets aparece siempre como un grupo compacto, a veces matizado con expresiones como «vecinos», «propietarios de [...]». Lo más relevante, sin embargo, es que en los textos periodísticos el nombre propio, con su carácter deíctico (Cuenca, 1996: 105106), se ha convertido en señal singularizadora de un contenido informativo privilegiado, asociado a unos valores sociocomunicativos determinados, capaz de activar la memoria discursiva del lector.

Se cumple así una de las claves pragmáticas de la comunicación, especialmente la periodística, la máxima de la economía y su consecuencia, la elipsis (Ducrot, 1984: 25): la mención del nombre obtiene un gran rendimiento, consiguiendo un elevado número de efectos contextuales a cambio de un mínimo esfuerzo de procesamiento, como señalan Sperber y Wilson (1986: 80ss.).

En cuanto a las instituciones, existe una tendencia a pasar de lo genérico impersonalizado, presente en los primeros tiempos («pleno», «equipo de gobierno», «Ayuntamiento», «Corporación municipal»), a formas de expresión más singularizadoras y lesivas para la imagen pública de los implicados, siguiendo el proceso descrito anteriormente, el que lleva de la objetividad inicial a la toma de postura y el componente afectivo de la información. Así, por una parte se personifica a través de un nombre propio, para mantener un equilibrio conceptual con la alusión constante al colectivo Mestrets: primero Fabra, luego Moliner, los concejales de urbanismo. En cierta medida, este 
recurso metonímico, consistente en señalar a un responsable en representación de un equipo, proviene de los mensajes de los propios afectados, quienes, inicialmente, adoptaron una visión personalista del problema.

En una fase más combativa y reivindicativa, tanto los afectados como los medios, comienzan a adoptar un criterio designativo más explícitamente político, al abandonar las referencias generales e institucionales, adoptando en su lugar términos que acusan directamente al partido político (PP): «El PP aprueba en solitario el PAI Mestrets con pitos y caceroladas» (Heraldo, 25.8.04). Frente a ello, otros textos difuminan el impacto sobre la imagen pública del grupo político fijando como sujetos de la acción a entidades administrativas, cuyo carácter impersonal contrasta con la estrategia anterior: «El Consell afirma que el $80 \%$ de los vecinos de Mestrets acepta una unifamiliar a precio de VPO» (Las Provincias, 15.2.06), «El Ivvsa anuncia un pacto con vecinos de Mestrets» (Heraldo, 30.11.05), «Urbanismo aprueba los proyectos del plan que desalojará a 40 familias de Els Mestrets» (Levante, 23.5.06), «Territorio aprueba el informe favorable para la urbanización de Els Mestrets» (Las Provincias, 27.7.05).

c) Autorreferencia y variedad lingüística. El modo con el que el sujeto se muestra en el enunciado es uno de los mecanismos que refleja «la estructura lingüística de poder en los textos» (Wodak, 2003: 24), señalando la «postura discursiva» (Jäger, 2003: 84), esto es, la ubicación desde la que participan en el discurso los individuos, grupos o instituciones.

A partir de las citas abiertas, el despliegue del estilo directo que permite incorporar las voces de los agentes -con las reservas propias de todo proceso de descontextualización, como advierten Calsamiglia y Tusón (2004: 152)-, puede valorarse el modelo de autorreferencia de los sujetos implicados en el conflicto descrito.

En el caso de los afectados, el tramo de las referencias personales se reduce a las formas más explícitas de la personalización, a través de la primera persona, singular o plural, según el afectado asuma una representatividad de mayor o menor rango. La impersonalización apenas se reduce a fórmulas apoyadas en una segunda persona, capaces de activar la genericidad (Hernanz, 1990): «son un robo porque te quitan tu casa y te obligan...» (Levante, 23.5.06).

Esta limitación deíctica es el síntoma de una de las características de este movimiento vecinal: su carácter circunscrito a una reivindicación concreta, sin planteamientos globalizadores que apunten hacia una corriente organizada de mayor alcance, de índole política, ecológica o social.

En lo que respecta a la Administración, el amplio espectro referencial refleja su control de los mecanismos discursivos mediáticos, transmisores de la imagen pública, como reflejo de su carácter hegemónico y de constituir una estructura de poder consolidada socialmente. 
Las fórmulas iniciales de autorreferencia tienen una dimensión genérica, cuya función es convertir al interlocutor en un sujeto institucional, portavoz del discurso dominante del poder sociopolítico, con la legitimidad y peso objetivo que ello implica. La impersonalidad sintáctica es uno de los mecanismos privilegiados para proyectar dicha imagen: «Se ha previsto su restauración [...]» (Mediterráneo, 22.5.06), «Hay que crear suelo...»(Levante, 4.5.06). Como también lo es la impersonalidad semántica, bien en su variante pasivorefleja («Desde el Ayuntamiento se tomarán las medidas...» (Mediterráneo, 10.6.04), bien convirtiendo en argumento externo del verbo a una unidad léxica de carácter instrumental o impositivo «la actuación urbanística cumplirá uno de los objetivos [...]» (Levante, 23.5.06).

Sin abandonar la $3^{\text {a }}$ persona, un recurso argumentativo de carácter coercitivo en torno a la presencia del sujeto del enunciado es el que plantea la actuación del Ayuntamiento como un ente que proyecta su acción sobre el conjunto social, en una transición metafórica que se traduce en el dominio sintáctico de la construcción oracional: «Esta actuación es importante para la ciudad» (A. Fabra, Levante, 4.5 .06). En esta línea, se singulariza la supuesta situación privilegiada de Mestrets frente al colectivo, a través del operador existencial (Brucart y Rigau, 2002: 1562): «Tienen unas condiciones que no ha recibido nadie...» (Moliner, Heraldo, 19.6.05).

El paso al «discurso del nosotros» (Wodak y Matouschek, 1998: 79) profundiza en el carácter impositivo de la institución, tomada ya no como una entidad suprapersonal, sino como un colectivo de intereses enfrentado al «nosotros» vecinal, en el que puede implicarse también el lector como partícipe del bien social y del imperio de la ley: «No vamos a frenar...» (A. Fabra, Mediterráneo, 17.2.06), «Vamos a asumir por escrito los compromisos...» (Moliner, Las Provincias, 27.7.05). En algún caso, incluso, el «nosotros» refirma la dimensión de todo el aparato estatal, insistiendo así en un grado mayor de legitimidad: "Tanto el IVVSA como el Ayuntamiento tenemos la misma voluntad...» (A. Fabra, Heraldo, 4.5.04).

Finalmente, los representantes de la Administración pueden considerar efectivo el uso del «yo», no solo para personalizar la información, sino para adoptar un talante conciliador, dialogante, opuesto o complementario de la vertiente impositiva comentada: «Tienen mi palabra [...] y yo podré comprometerme [...]» (Moliner, Heraldo, 19.6.05).

Esta última fórmula puede venir acompañada de un cambio de registro como recurso para marcar la transición a formas expresivas marcadas por la cercanía socio-afectiva respecto a los destinatarios, puesto que, como señala Fowler (1991: 37), el registro lingüístico «is the meaning potencial that is accessible in a given social context»: «Quiero que sepan que en sus reivindicaciones estaré con ellos $[\ldots]$ moveremos ficha $[\ldots]$ se está mareando demasiado la perdiz» (A. Fabra, Levante, 4.5.04). 


\section{CONCLUSIÓN}

El análisis del acceso a las rutinas informativas por parte de los movimientos sociales enfrentados al poder constituido supone una valoración del papel de los medios en la sociedad actual, así como un estudio de los mecanismos discursivos que determinan la gestión textual de los acontecimientos públicos.

En el caso concreto de los medios locales, el papel institucional del medio de comunicación, implicado en la lógica de mercado en las sociedades capitalistas, y en los debates ideológicos y políticos de la democracia, se ve compensado por los imperativos de la proximidad de los hechos, que, en ciertos niveles del periódico -los más alejados de los géneros vinculados al control socioeconómico del medio- puede decantarse por una información que no solo atienda a los grupos alternativos, sino que, incluso, les ofrezca cobertura.

El análisis del discurso periodístico, en sus diferentes niveles, permite observar cómo la disposición perceptual de los mecanismos semióticos implicados en la información, la organización macroestructural, la selección de modalidades y tipologías textuales, así como los elementos microestructurales, contribuyen a ofrecer una imagen del conflicto que, en general, se decanta hacia la posición defendida por Mestrets, como grupo alternativo a la política institucional.

El resultado es una comunicación diversa y heterogénea, por la cual, mientras los textos vinculados con la información, la noticia, el reportaje, se muestran permeables a las exigencias informativas del grupo vecinal, las variedades discursivas más próximas al medio como institución social, política y económica, permanecen al margen cuando no en una neutralidad que no comprometa su posición ante agentes implicados, directa o indirectamente, en el problema, mostrando así la dependencia económica y de intereses ideológicos entre los diferentes tipos de empresas y el poder.

\section{REFERENCIAS BIBLIOGRÁFICAS}

Bronckart, J.-P. (2004): Actividad verbal, textos y discursos. Por un interaccionismo socio-discursivo, Madrid, Fundación Infancia y Aprendizaje.

BRUCART, J. M. y G. RigaU (2002): «La quantificació», en Solà, J. et al. (eds.) (2002): Gramàtica del català contemporani, Barcelona, Empúries, vol. 2, 1519-1589.

Calsamiglia, H. y A. Tusón (2004): Las cosas del decir. Manual de análisis del discurso, Barcelona, Ariel.

CuencA, Ma J. (1996): Sintaxi fonamental, Barcelona, Empúries.

Ducrot, O. (1984): El decir y lo dicho. Polifonía de la enunciación, Barcelona, Paidós. 
Fowler, R. (1991): Language in the News. Discourse and ideology in the Press, Londres, Routledge.

Fuentes Rodríguez, C. (2000): Lingüística, Pragmática y Análisis del Discurso, Madrid, Arco Libros.

GómEZ, J.-Ll. y M. Dolç (1998): «Ciutat, política lingüística i política comunicativa», en Mollà, T. (ed.) (1998): La política lingüística a la societat de la informació, Alzira, Bromera, 65-104.

GutiérReZ OrdóñEZ, S. (2002): De pragmática y semántica, Madrid, Arco Libros.

GutiÉrrez, M. A. (2004): Perfiles comunicativos en los elementos de la oración simple, Madrid, Iberoamericana-Vervuert.

HABERMAS, J. (1984): Teoría de la acción comunicativa: complementos y estudios previos, Madrid, Cátedra.

Hernanz, M. L. (1990): «En torno a sujetos arbitrarios de $2^{a}$ persona del singular», en DemONTE. V. y B. GAZA (eds.) (1990): Estudios de lingüística de España y México, México, UnAM, 151-178.

JÄGER, S. (2003): «Discurso y conocimiento: aspectos teóricos y metodológicos de la crítica del discurso y del análisis de dispositivos», en WoDAK, R. y M. MEYER (comp.) (2003): Métodos de análisis crítico del discurso, Barcelona, Gedisa, 61-99.

JoHNSTON, H., E. LARAÑa y J. GUSFIELD, (eds.) (1994): Los nuevos movimientos sociales. De la ideología a la identidad, Madrid, Centro de Investigaciones Sociológicas.

LÓPEZ GARCíA, A. (1994): «Categorías y funciones en la percepción de la oración», en HERNÁNDEZ, F. (ed.) (1994): Perspectivas sobre la oración, Zaragoza, Universidad de Zaragoza, 185-204.

- (1996): Escritura e información. La estructura del lenguaje periodístico, Madrid, Cátedra.

SAPERAS, E. (2002): «La premsa i la televisió com a actors polítics: sobre l'anàlisi de la mediació política i de la recepció de la comunicació política», en Ubaldina, C. y M. Ribas (eds.) (2002): Anàlisi del discurs polític. Producció, mediació i recepció, Barcelona, Universitat Pompeu Fabra, 123-133.

Sperber, D. y D. WiLSON (1986): Relevance: Communication and Cognition, Oxford, Blackwell.

TARRow, S. (2004): El poder en movimiento. Madrid, Alianza.

VAN DiJK, T. A. (1998): Texto y contexto (Semántica y pragmática del discurso), Madrid, Cátedra.

- (2001): La noticia como discurso. Comprensión, estructura y producción de la información, Barcelona, Paidós.

WoDAK, R. (2003): «De qué trata el análisis crítico del discurso (ACD). Resumen de su historia, sus conceptos fundamentales y sus desarrollos», en 
Wodak, R. y M. Meyer (comp.) (2003): Métodos de análisis crítico del discurso, Barcelona, Gedisa, 17-33.

WodAK, R. y B. MATOUSCHECK (1998): «Se trata de gente que con solo mirarla se adivina su origen: análisis crítico del discurso y el estudio del neoracismo en la Austria contemporánea», en MARTín, L. y R. WHITTAKER (eds.) (1998): Poder-decir o El poder de los discursos, Madrid, Arrecife, 55-92.

Yus, F. (1997): Cooperación y relevancia. Dos aproximaciones pragmáticas a la interpretación, Alicante, Universidad de Alicante.

La actividad urbanística en la Comunidad Valenciana, principales preocupaciones de los ciudadanos. Síndic de Greuges, Alicante, noviembre de 2004. 


\section{APÉNDICE DE IMÁGENES COMENTADAS}

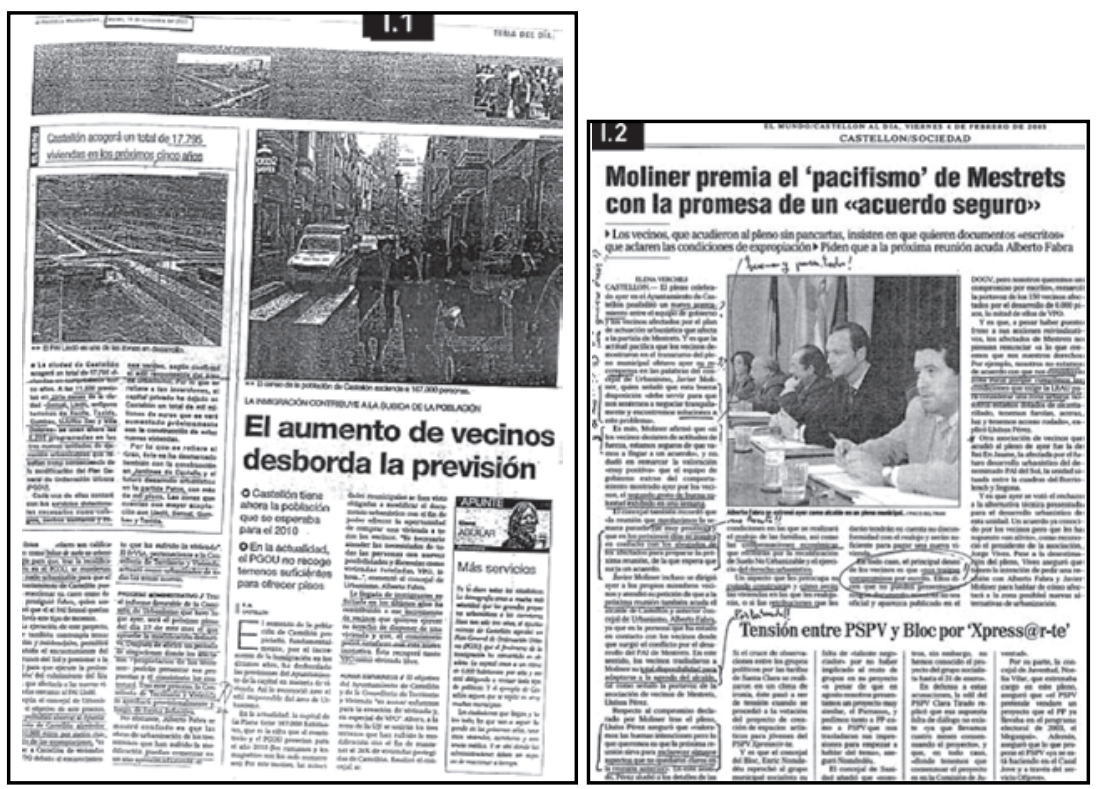

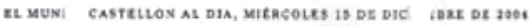
CASTELLON/SOCIEDAD

\section{'Mestrets' frena la tasación del IVVSA alegando falta de respeto hacia sus casas}

Los afectados han solicitado una entrevista al presidente de la Generalitat y anuncian nuevas movilizaciones en contra del Ayuntamiento

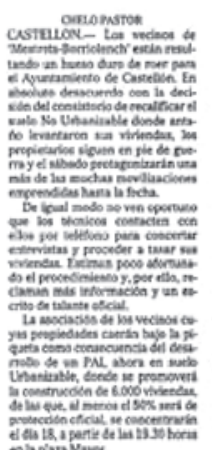
entarian Noyes.
Eat rrabse revindicatis, que

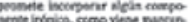

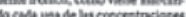

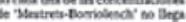

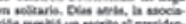

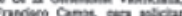
shadih No st la primm nis

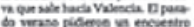

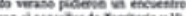

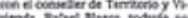
veredis Let vecimos lanertas cou do

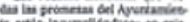

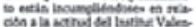

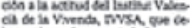
bes nelers las propedides gers.

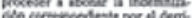

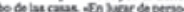

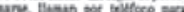
cendar y varier las viventes.

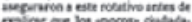
colicar que be spomit chatala. nos out hin redtubs eatas burra.

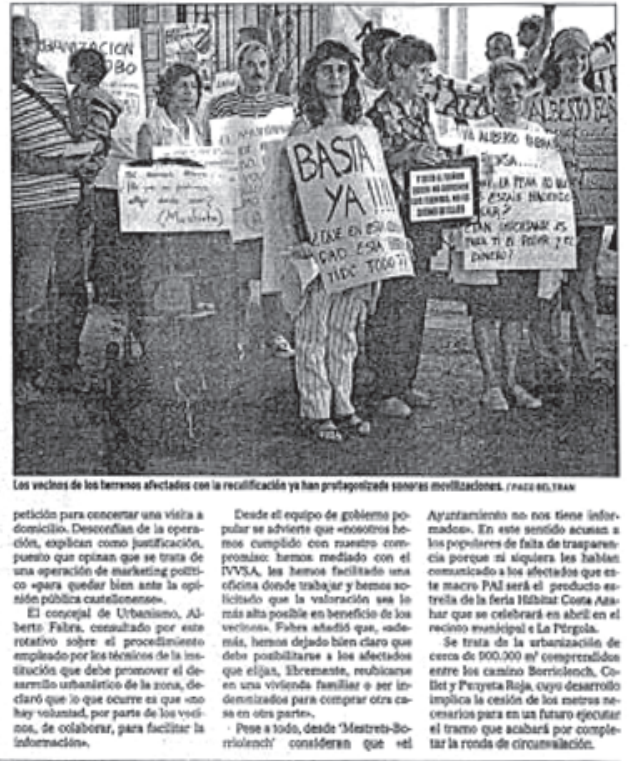




\section{APÉNDICE DE IMÁGENES COMENTADAS}
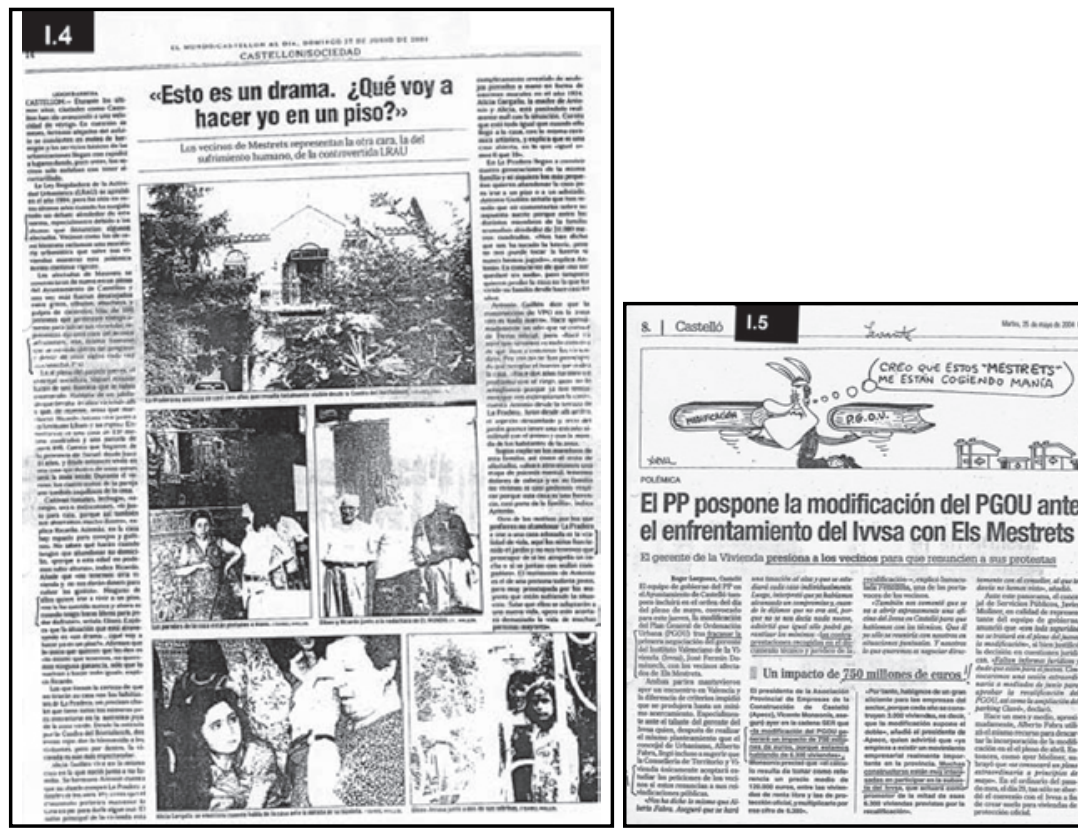

El PP pospone la modificación del PGOU ante el enfrentamiento del Ivvsa con Els Mestrets

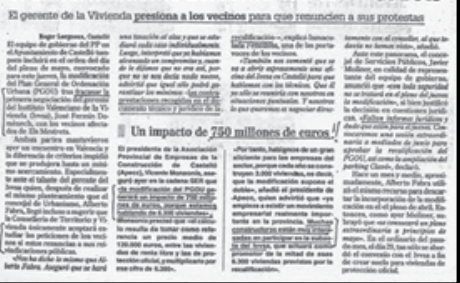

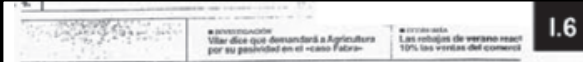

\begin{tabular}{|l|l|l|}
\hline Capital & 1.7 & $=$ \\
\hline
\end{tabular}

Gimeno expulsa otra vez a los vecinos ae Els Mestrets del pleno que modifica el PGOU

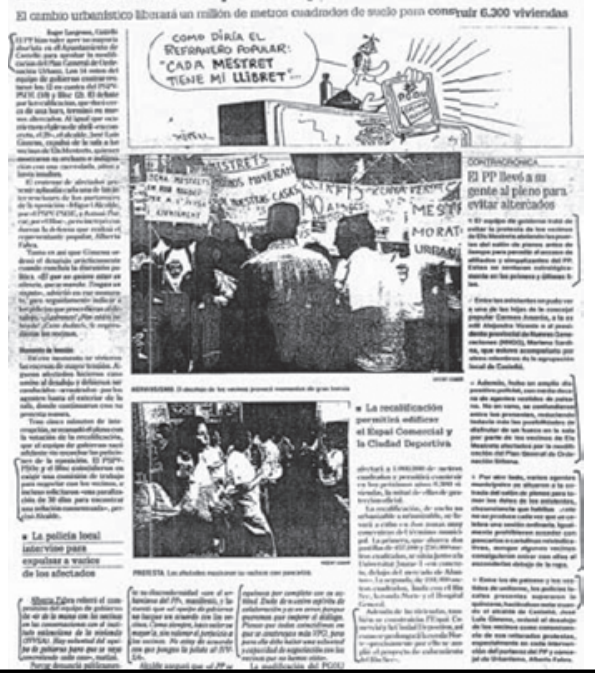

\section{EI PP aprueba en solitario el PAI Mestrets con pitos y cacerolada}

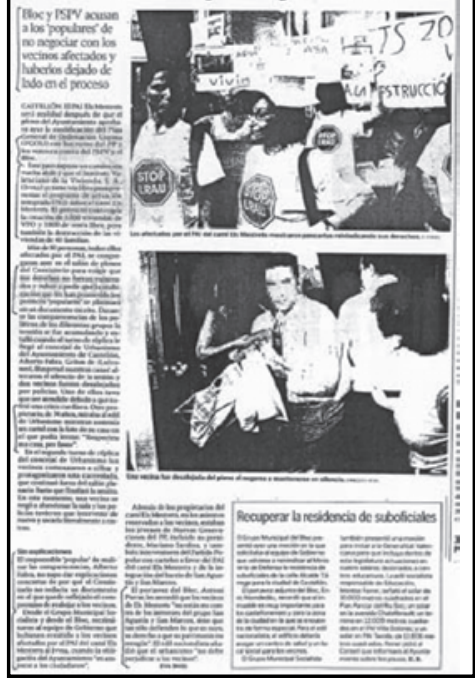




\section{APÉNDICE DE IMÁGENES COMENTADAS}
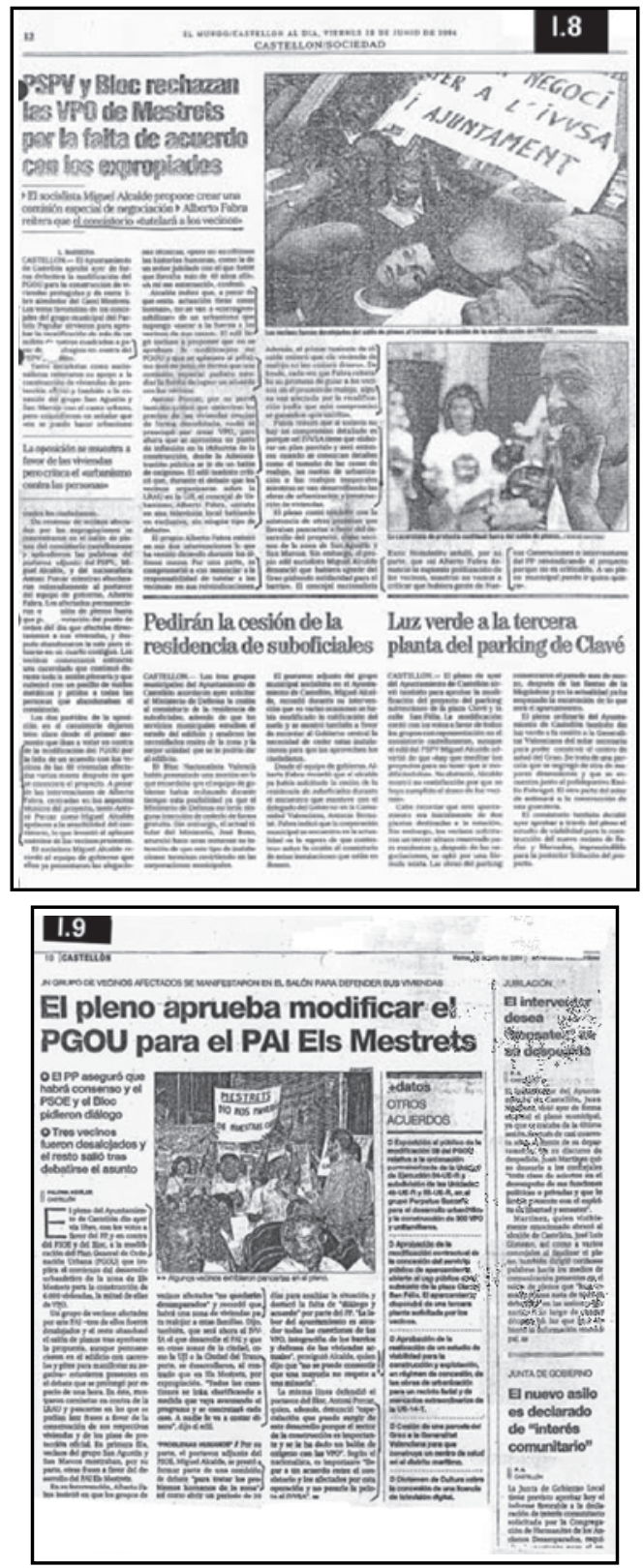


\title{
FUNCIONES ESTRATÉGICAS DE LA INTERRUPCIÓN EN LOS DEBATES TELEVISIVOS Y SU RELACIÓN CON LA (DES)CORTESÍA VERBAL ${ }^{1}$
}

\author{
Ma Ester Brenes PeÑa \\ Universidad de Sevilla
}

\section{INTRODUCCIÓN}

T As primeras investigaciones sobre la estructura de la conversación llevaron Aa cabo una caracterización ideal de estas interacciones. Sacks, Schegloff y Jefferson (1974), por ejemplo, consideran que la conversación está regida por el principio de «un hablante por vez», por lo que cada interlocutor dispone de un turno propio y el tránsito de un interlocutor a otro se explica a partir de un sistema de toma de turnos.

Así pues, desde esta perspectiva, las interrupciones se consideran transgresiones descorteses del sistema que reflejan relaciones de poder social. El objetivo de nuestra investigación será, no obstante, analizar, en el discurso de los debates televisivos, si las interrupciones pueden considerarse en todas las ocasiones como un acto de amenaza de la imagen del interlocutor interrumpido o si, por el contrario, deben tenerse en cuenta otros factores a la hora de determinar el grado de (des)cortesía y agresividad que conlleva esta estrategia conversacional.

\section{LA INTERRUPCIÓN. DEFINICIÓN Y DELIMITACIÓN}

Actualmente, existen posturas y opiniones divergentes en torno al concepto y a la delimitación de las instancias interruptivas. Por lo tanto, en primer lugar, antes de poder llevar a cabo el análisis del funcionamiento de dichas estrategias conversacionales en nuestro corpus, debemos definir qué entendemos exactamente por interrupción.

En el estudio realizado por West and Zimmermann (1983: 114) ya se diferenciaba entre overlaps, «those simultaneities occurring within the first or last syllable

1. Este estudio se inserta dentro del Proyecto de Excelencia La violencia verbal y sus consecuencias sociales, subvencionado por la Junta de Andalucía, 2006-08. 
of unittypes», shallow interruptions, «simultaneities occurring within the second or second to last syllable or between first and second or next- to- last and last syllable of unit types» $\mathrm{y}$ deep interruptions, «those onset of simultaneity more than two syllables away from the beginning or end of a unit type». Consideramos, no obstante, que se trata de una diferenciación demasiado formal, centrada únicamente en el aspecto estructural. Así pues, coincidimos con la crítica que Tabolt (1992: 459) realiza a esta teoría, ya que, como ella misma señala: «interactuants define interruptions not by counting syllables but functionally [...]. We need to look at discoursal activity, which means more than counting syllables».

Fant (1996), por otra parte, tomando como base el hecho de que los hablantes españoles afirman sentirse interrumpidos sólo en el caso de que no hayan podido terminar la expresión de un pensamiento antes de que un nuevo hablante comience a hablar, diferencia entre dos tipos de entrecruzamiento: entrecruzamientos interruptivos y no interruptivos.

Nosotros, sin embargo, obviando la distinción realizada por algunos autores entre encabalgamiento e interrupción, ${ }^{2}$ debido a la dificultad de dilucidar hasta qué punto responden a una falta de cálculo por parte del interlocutor, consideraremos en nuestro análisis que desde el mismo momento en el que un segundo hablante se entromete en el discurso del interlocutor que posee el turno de habla, existe una interrupción. Es decir, la interrupción puede producirse tras un enunciado completo (interrupción suave) o fragmentando un enunciado (interrupción abrupta), con sobreposición o sin ella, pero en todos los casos en los que a pesar de que un interlocutor está hablando o existen indicios de que desea continuar hablando, un segundo hablante intenta tomar el turno de habla para emitir un determinado mensaje, nos encontraremos ante un proceso interruptivo.

Por otra parte, en nuestro estudio consideraremos a la interrupción como una estrategia conversacional que los hablantes pueden utilizar con fines diversos, según los factores contextuales que influyan en el proceso de comunicación. Por consiguiente, para poder llevar a cabo un análisis adecuado de los procesos interruptivos deberemos observar detenidamente las finalidades con las que las instancias interruptivas son emitidas. Además, si seguimos la terminología de Bañón (1997), en nuestro estudio nos centramos en microinterrupción ${ }^{3}$ endógena y, preferentemente, en aquellos casos en los que tanto el acto interruptor como el interrumpido son fundamentalmente lingüísticos.

2. Blas Arroyo (1998) diferencia entre encabalgamiento, solapamiento producido por el hablante debido a que este intuye que el anterior interlocutor ha concluido el turno de habla, e interrupción, que se diferencia del anterior, entre otros rasgos, por conllevar una vulneración del sistema de turnos.

3. Microinterrupción: afecta a un turno conversacional sin repercutir sobre la continuidad de la interacción. 


\section{OBJETO DE ESTUDIO. LOS DEBATES TELEVISIVOS}

Como ya hemos comentado, vamos a focalizar nuestro análisis en el género comunicativo de los debates televisivos, interacciones orales basadas en la polémica, en el enfrentamiento de opiniones, valoraciones y argumentos divergentes de, al menos, dos personas, sobre cualquier tema de más o menos interés social.

El corpus utilizado en nuestro estudio, lo constituyen, por lo tanto, debates televisivos que giran en torno a diferentes temas, ya sean temas relativos a la prensa rosa, como es el caso de a tu lado o TNT, o temas de mayor alcance político y/o social, como los tratados en el programa Mejor lo Hablamos.

Como es lógico, en la estructura conversacional de este tipo de situaciones comunicativas caracterizadas por la defensa de posiciones dispares, la aparición de interrupciones puede verse motivada por la competitividad en el uso del turno de habla, por la necesidad de disponer más del uso de la palabra para poder llevar a cabo la argumentación y defensa de la propia postura. Pero, como vamos a ver más detenidamente, no es esta la única causa que motiva la aparición de instancias interruptivas en este tipo de situaciones comunicativas.

\section{PRINCIPALES TEORÍAS EN TORNO A LOS FENÓMENOS DE LA (DES)CORTESÍA Y AGRESIVIDAD VERBAL}

El principal objetivo de nuestro estudio es analizar la relación de la interrupción con los fenómenos de la (des)cortesía y agresividad verbal, comprobar si se puede afirmar o no la existencia de una correspondencia biunívoca entre las interrupciones y los FTAs. ${ }^{4}$ Para ello, nos basaremos en la reformulación que propone Bravo (2003) del modelo de Brown y Levinson sobre el análisis de la (des)cortesía lingüística ([1978] 1987).

El objetivo de la teoría de Brown y Levinson ([1978] 1987), como bien indica el título de su obra, Politeness. Some Universals In Language Use, era el de diseñar una teoría universal del uso cortés, es decir, dilucidar los principios corteses reguladores de las relaciones sociales entre individuos que están presentes en todas las culturas y que son, por tanto, universales. Así pues, apoyándose en el concepto de face de Goffman (1967) y de su afirmación de que la conversación es potencialmente conflictiva, defienden la universalidad de la cortesía verbal como estrategia reguladora del equilibrio interactivo, como estrategia destinada a evitar o atenuar las amenazas a la imagen social, principalmente a la imagen negativa, que se producen en toda interacción y que ponen en peligro la armonía del intercambio verbal y, en consecuencia, de las relaciones sociales.

4. Face Threatening Acts (actos de amenaza de la imagen). 
Sin embargo, esta teoría está siendo actualmente muy criticada, debido principalmente al hecho de que su carácter marcadamente etnocentrista impide explicar la variación tanto cultural como contextual del principio cortés. Desde esta perspectiva, Bravo (2003) propone la sustitución de los conceptos de imagen negativa y positiva por los de imagen de autonomía, definida como el deseo del individuo de verse y ser visto como alguien con contorno propio dentro del grupo, e imagen de afiliación, referida a la finalidad del individuo de verse y ser visto por las características que lo identifican con su grupo. Dichas categorías, a diferencia de los conceptos de imagen negativa e imagen positiva de Brown y Levinson, no contienen descripciones específicas sobre la imagen ni sobre los comportamientos comunicativos que supuestamente implican, sino que son categorías abiertas que permiten la incorporación de las características específicas que presenta cada comunidad cultural.

En nuestro análisis, además, también tendremos en cuenta que, si nos adentramos en la interacción concreta, la imagen del interlocutor se relaciona con otro factor social, el rol, el cual se determina por la actividad de una persona de acuerdo con su posición social y a la concreta situación en que se encuentra. Así pues, uno de los objetivos de nuestro estudio será investigar la relación que puede existir entre los procesos interruptivos y cada una de estas imágenes y del rol desempañado por el hablante.

\section{FUNCIONES ESTRATÉGICAS DE LA INTERRUPCIÓN Y SU RELACIÓN CON LA (DES)CORTESÍA VERBAL}

Con respecto a la interpretación de la interrupción en relación con la (des)cortesía y agresividad lingüística, algunos estudios de investigadores como Haverkate (1994) o Tannen (1987) ya han afirmado la necesidad de relativizar la máxima conversacional de «no interrumpas al que está hablando», pues no todas las comunidades lingüísticas observan la máxima de la misma manera o en la misma medida. Haverkate (1994), por ejemplo, señala que los hablantes de español, en general, no consideran descortés hablar al mismo tiempo que otra persona, por lo que son más tolerantes con respecto a las violaciones de la máxima que los holandeses.

A pesar de ello, la interrupción se ha caracterizado, en general, sin tener en cuenta el contexto comunicativo en el que se producen, como un acto que, además de violar la estructura conversacional, impide que el interlocutor que está hablando concluya la emisión de su mensaje y alcance su objetivo comunicativo. La interrupción, por tanto, se ha calificado como un acto que amenaza la imagen social negativa del interlocutor interrumpido, ya que no respeta sus deseos de poseer libertad de acción y de no verse sometido por ninguna otra instancia emisora. 
En este sentido, en el análisis de nuestro corpus, hemos podido observar cómo los mismos interlocutores consideran la interrupción como una muestra de descortesía y de mala educación, de ahí que pidan disculpas por ello, como puede observarse en el siguiente fragmento:

MARIO ARnAUd: § Bien, y la cuestión es, miren ustedes $\S^{5}$

CARMen Hermosín: $\S$ es que eso está ya en el código penal, perdona, lo que pasa es que no se cumple y nadie, [nadie echa mano del código penal,perdón, que tenías tú la palabra]

(Mejor lo Hablamos, 15/3/06)

Sin embargo, debemos tener en cuenta que la (des)cortesía y la agresividad verbal, como fenómenos sociopragmáticos que son, se constituyen a partir del contexto comunicativo, por lo que su relación con respecto a las interrupciones necesita ser analizada en cada intercambio verbal concreto, y no de una forma abstracta y aislada de la situación comunicativa. Así pues, aunque en todos los casos implique la violación de una máxima conversacional, de un derecho de los hablantes, debemos tener en cuenta que el grado de (des)cortesía y agresividad verbal que puede conllevar una interrupción no es el mismo en todas las ocasiones, sino que para poder determinarlo debemos tener en cuenta varios factores que inciden en el proceso comunicativo. De hecho, ya Kerbrat (1992: 178) realizó una clasificación de las interrupciones según la mayor o menor legitimidad que poseen en el contexto en el que son realizadas.

En general, podemos afirmar que el proceso interruptivo se considera menos descortés y agresivo si el turno interruptor se presenta con atenuantes cualitativos -referidos al mismo hecho de interrumpir-o cuantitativos -referidos al tiempo que el propio hablante quiere hacer pensar que durará su interrupción o al número de temas que se prevé tratar. Así pues, es evidente que el primero de los siguientes ejemplos, en el que no observamos ningún tipo de de atenuadores, la interrupción llevada a cabo es mucho más descortés y agresiva que en los otros dos ejemplos siguientes, en los que se utilizan atenuadores cuantitativos y cualitativos respectivamente:

CARMEN HeRmosín: § no los conductores dicho así dicho en general, [hay algunos conductores]

Luis VILlamil: [no así dicho] en general. Yo cada vez que habla el señor Pere Navarro yo no sé si apagar la televisión o exactamente qué tengo que hacer

(Mejor lo Hablamos, 15/3/06)

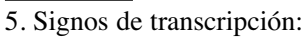

$\S$ sucesión inmediata, sin pausa apreciable, entre dos emisiones de distintos participantes; [ lugar donde se inicia un solapamiento o superposición; ] final del habla simultánea. 
JUDD: yo sí, yo quiero decir algo. Yo quería decir que bueno, ahora se está comparando un accidente con el otro. Noemí casi se muere. Llega a pasar un coche o se da un golpe en la cabeza y casi se muere. Eh, simplemente pido que Raquel entiendo que está colaborando en un programa, pero ya está, se ha acabao, son dos años, [pero ya está, basta]

MiLA: [no, no, Judd], escucha un segundo, es que hay que ser claro ya (...)

(A tu lado, 18/5/06)

$\mathrm{M}^{\mathrm{a}}$ ÁNGELES MADERO: [yo] lo explico muy claro cada vez que hablo en cualquier medio [hay que diferenciar lo que es un accidente de una imprudencia y la imprudencia la hace el conductor con todas las de la ley]

MARIO ARNAUD: [no, no, no, perdón, no, no, no si me permite, si me permite], y tengo aquí las actas del Congreso, ¿eh?, las tengo aquí. Son tres supuestos lo que se han planteado últimamente tanto por el Director General de Tráfico como por el defensor del pueblo

(Mejor lo Hablamos, 15/3/06)

Además, podemos considerar menos abrupta la interrupción si dicha atenuación se sitúa en posición inicial de turno, como ocurre en los casos anteriores, ya que cuando aparece en una posición no inicial parece concederse más importancia al hecho de conseguir el turno de habla que al suavizar este acto.

Otro elemento general que debe tenerse en cuenta es que la interrupción es menos descortés y agresiva si se produce cuando el primer interlocutor ha terminado de expresar un pensamiento completo, como ocurre en el primero de estos ejemplos, en contraste con el segundo de ellos:

Carmen Hermosín: es que la medicación también es una droga. Bajo los efectos de algunas drogas, aunque sean curativas, como son las medicinas, pues no se puede conducir. Si te tomas un relajante muscular, [te tomas un relajante muscular y a la media hora pues no ves nada $\left.\downarrow^{6}\right]$

Marcos García Montes: [en las propias instrucciones viene, en las propias instrucciones viene] Carmen, en las propias instrucciones viene que no se puede conducir cuando se toma antiestamínicos, hipnóticos, etc., etc.

(Mejor lo Hablamos, 15/3/06)

RAQUel Bollo: [pues] mira, he trabajado y tengo mi contrato y he tenido nómina. [Es más, y quiero dar un dato]

ALBert CASTILLón: [y tenía un despacho a su nombre], a nombre de Mayte Muñoz, en Puerto Banús

(A tu lado, 19/5/06)

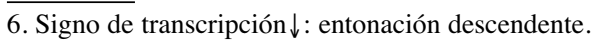


Ahora bien, aparte de estos factores generales, para poder interpretar adecuadamente el grado de (des)cortesía y agresividad de las instancias interruptivas, debemos atender también al rol desempeñado por el hablante responsable de la interrupción. Como señala Blas Arroyo (1998), en el caso concreto del género de los debates, las interrupciones llevadas a cabo por el moderador, principalmente con el objetivo de controlar la estructura del debate, no se consideran tan (des)corteses y agresivas como las realizadas por parte del resto de los participantes en el mismo, debido al superior estatus que posee dentro del proceso comunicativo, como puede observarse en el siguiente fragmento:

MaRio ARNAUd: [...] Pero yo voy a dar un dato, muy breve $\S$

MODERADORA: $\S$ un datito que voy a dar yo antes $\S$

MARIO ARNAUD: $\S$ perfecto $\S$

MODERADORA: § que es sumamente importante, porque Patricia ha estado preguntando en la calle algo que hemos estado hablando aquí. A mí ya saben ustedes que me gusta contrastar entre la opinión del público, la de ustedes y la de la calle [...]

(Mejor lo Hablamos, 15/3/06)

Este hecho, el que una interrupción, en idéntico contexto interlocutivo, pueda ser interpretada de una manera más o menos (des)cortés según la función y el rol que posea la persona interruptora en el proceso comunicativo, implica que la relación de la interrupción con respecto a la (des)cortesía y agresividad no pueda ser de ninguna manera constante ni biunívoca.

No obstante, la noción de la interrupción como muestra de descortesía y mala educación está tan arraigada en los hablantes que hasta el moderador del debate puede llegar a pedir disculpas por ello:

Moderadora: doce y cuarto casi de la noche. Continuamos en el debate Mejor lo Hablamos y vamos a empezar a hablar de algo fundamental que solamente se hace en Andalucía que son las intervenciones en el Hospital Carlos $\langle<\ldots\rangle^{7}$ de Málaga para hacer la reasignación sexual, el cambio de sexo y las intervenciones. Pero antes, y de la Seguridad Social también, quiero que concluya la discusión que tenían entre Fernando y Miguel porque lo he cortado. Fernando, me va a perdonar usted. Además, le pido perdón públicamente, pero ya sabe que el papel de moderador es así.

(Mejor lo Hablamos, 22/6/06)

Por otra parte, si nos centramos en las intervenciones llevadas a cabo por los participantes en el debate, que poseen todos el mismo estatus, podemos señalar que los procesos interruptivos no sólo reflejan relaciones de poder o

$\overline{7 . \text { Signo de }}$ transcripción $<<\ldots .>>$ : fragmento indescifrable. 
dominancia, sino que se pueden utilizar para configurar la imagen del hablante como un interlocutor seguro de sí mismo, de la postura defendida y de su argumentación. En el debate Mejor lo Hablamos emitido el día 22/6/06, se observa claramente que entre los participantes que defienden la nueva ley sobre la transexualidad, Carla Antonelli es la más agresiva, la que más interrupciones lleva a cabo con el objetivo de contraargumentar las razones esgrimidas por los defensores de la posición contraria. De ahí que los interlocutores se dirijan precisamente a ella:

MARINA CASTAÑo: [...] pero un instante, yo quiero preguntarle algo de nuevo a Carla Carla Antonelli: la tenéis tomada [conmigo]

Marina CASTAÑo: [no, no, no], es que eres muy expresiva y [...]

(Mejor lo Hablamos, 22/6/06)

Como señala Hernández (2004), el receptor de los actos comunicativos en el plano del efecto social es tanto el destinatario como el hablante. La interrupción, en relación con la (des)cortesía y agresividad verbal, se emplea para atacar la imagen social del hablante interrumpido, pero también para crear una determinada imagen del hablante que hace uso de ella.

Además, debemos tener en cuenta que en una situación comunicativa como la de los debates televisivos, marcada por la tensión y el enfrentamiento de posturas radicalmente opuestas, la interrupción no es una mera transgresión de una máxima conversacional sino una estrategia al servicio de la dimensión argumentativa de estas interacciones, así como de los fenómenos de la (des)cortesía y agresividad verbal. Mediante una interrupción se puede tensionar o distender el clima de estos enfrentamientos comunicativos, según se coopere o no con la imagen social y la postura defendida por el hablante interrumpido. Por lo tanto, en relación con las categorías de imagen de autonomía y de afiliación, podemos considerar que la interrupción que conlleva un proceso de afiliación entre los interlocutores, es mucho menos descortés y agresiva que aquella que supone desafiliación entre ellos. Así, a veces las instancias interruptivas pueden ser motivadas por el deseo del hablante de apoyar la argumentación que el otro interlocutor está realizando, para insistir o reforzar la postura del hablante que en ese momento posee el turno de habla. En el siguiente fragmento, por ejemplo, observamos cómo se interrumpen entre sí varios interlocutores que coinciden en realzar la fuerza y el coraje de Isabel Pantoja, artista que se entrega a su trabajo y a su público a pesar de la delicada situación personal por la que está pasando:

PABLO: hombre, yo supongo que Isabel lo estará pasando como lo pasaría cualquier mujer o lo estará pasando cualquier mujer de los imputados que ahora mismo o las personas que están encarceladas dentro del proceso de la operación Malaya. Induda- 
blemente, bien, no, con esa presión que supone además pues ser quién es, pues una grande como es Isabel Pantoja, y el seguimiento continuo que tiene por parte de los medios de comunicación. Evidentemente, el momento no tiene que ser nada bueno para ella. Eh, yo de lo que conozco a Isabel siempre la he visto como una mujer fuerte, y supongo que seguirá entregándose a su público de la misma forma, quizás con más ahínco si es posible, y se refugiará en su trabajo y [en su familia]

CRISTINA: [de hecho] no ha anulado las galas, que se había especulado con que iba a anular las galas que tenía todo este verano. Ya su representante María ha confirmado que Isabel $[<<\ldots>>]$

RAQUEL Bollo: [no, es que ni siquiera] ni siquiera anuló la primera, cuando se ha dicho que anuló la televisión [la televisión no fue $=^{8}$ ]

CRISTINA: [no, la tiene aplazada]

RAQUEL BOLLO: $=$ anulada, fue cambiada.

(A tu lado, 24/7/06)

En este mismo sentido, podemos ver cómo en otras ocasiones la causa que determina la aparición de una interrupción es el deseo de subrayar un término que el hablante considera fundamental en la argumentación que está llevando a cabo el primer interlocutor, por lo que el efecto de la misma sería también de afiliación entre ambos interlocutores:

LUIS VILLAMIL: los países que tiene en Europa menos accidentes tienen una estructura conjunta de cosas, de formación, de estado de las carreteras, de señalización y de unas administraciones me va a perdonar dado que usted pertenece a ese mundo, porque si no, a mí me debería explicar usted cómo hacen en Alemania para tener muchísimos más coches, mucha más población, hacen muchos más kilómetros al año, tiene la velocidad ilimitada en [autopistas =]

Marcos García Montes: [Ilimitada]

LUIS VILLAMIL: = ilimitada y tienen un tercio menos de accidentes $[\ldots]$

(Mejor lo Hablamos, 15/3/06)

Dentro de estas interrupciones que refuerzan los lazos existentes entre los hablantes, podemos situar también el caso observado en el siguiente fragmento, en el que la moderadora, desviándose un poco de sus funciones, interrumpe a uno de los participantes en el debate para destacar la exclusividad del dato que está aportando, hecho que, lógicamente, beneficia al programa:

Albert Castillón: [...] eso que veis ahora es la firma de Roca $\S$ MODERADORA: $\S$ que es la primera vez que se ve su firma, [¿no?]

ALbert CASTILLón: [fijaos] es la primera vez que se ve su firma. Es curioso [...]

(A tu lado, 19/5/06)

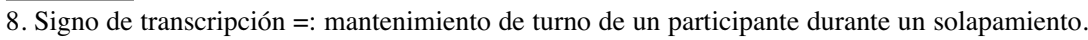


Este hecho se destaca, además, en los subtitulares del programa, en los que se puede observar:

«Los documentos "Maras" están firmados por Roca, algo inusual»

En el otro extremo, tenemos aquellas interrupciones motivadas por el deseo de contraargumentar las declaraciones que el primer interlocutor está emitiendo. Se trata, por tanto, de un tipo de interrupción mucho más descortés y agresiva, pues, además de la máxima de «no interrumpas al que está hablando», el interlocutor también transgrede la máxima de acuerdo señalada por Leech (1983) y que consiste en minimizar el desacuerdo y maximizar el acuerdo con el otro. La circunstancia más agresiva, en este sentido, se produce cuando uno de los dos interlocutores intenta, gracias a la emisión de continuas interrupciones, controlar la conversación evitando que el mensaje de la otra persona llegue a la audiencia. En el siguiente fragmento podemos observar cómo el mecanismo de la interrupción, utilizado para contraargumentar, se convierte en un elemento fundamental de la batalla dialéctica que mantienen ambos interlocutores.

ANTONIO DAVID: vale, bueno, esto es un tema, como Enrique ya manifestó en un programa de televisión hace algunos meses, él me catalogó como uno de sus enemigos, eh, no sé si tendrá los motivos oportunos, pero bueno, yo, en definitiva, esto, Enrique, lo hemos hablao tú y yo por activa y por pasiva, privadamente, en muchas conversaciones que [hemos tenido]

ENRIQUE DEL POZO: [no, no]

ANTONIO DAVID: = y que [tendrás mala memoria, tendrás mala memoria, bueno, voy a terminar de dar las explicaciones $=]$

ENRIQUE DEL Pozo: [yo contigo no he hablao nunca de este tema, no, perdone, yo contigo no he hablao nunca de este tema],

ANTONIO DAVID: = y si no, si se te han olvidao [ahora te las]

ENRIQUe DEL Pozo: [no, no, yo tengo] una memoria maravillosa $\S$

ANTONIO DAVID: § bueno, chico, déjame hablar, venga, [que te pones muy pesao =] ENRIQUE DEL POZO: [bueno, pero no mientas]

ANTONIO DAVID: = mira, vamos a ver, el tema este se lo expliqué a Enrique hace mucho tiempo

(A tu lado, 18/5/06)

También podemos considerar bastante agresivas aquellas interrupciones utilizadas para señalar o precisar un error que ha cometido el otro interlocutor, pues en estas ocasiones se viola también la máxima de aprobación señalada por Leech (1983):

Consuelo Berlanga: pero vamos a ver, los que estáis al otro lao, os comento, está demostrado y hay estudios psicológicos que dicen que ir a mayor velocidad de 150 , que es lo que dice la ley, te produce es una especie de borrachera de velocidad que ellos lo llaman cataclismo perceptivo § 
ALICIA FERNÁNDEZ: $§$ sensorial $\S$

Consuelo Berlanga: $\S$ eso, [que ya =]

ALICIA FERnÁNDEZ: [cataclismo sensorial]

CONSUElo BERLANGa: = que resulta que ya no sabes ni a qué velocidad vas, ni a qué distancia tienes que guardar $\S$

(Mejor lo Hablamos, 15/3/06)

En este caso podríamos pensar que se trata de una interrupción que pretende ser colaboradora, es decir, que tiene como objetivo el precisar o corregir la enunciación llevada a cabo por el anterior hablante. Sin embargo, debemos tener en cuenta que estas dos interlocutoras, Consuelo Berlanga y Alicia Fernández, mantienen posturas enfrentadas en el debate, por lo que el objetivo de la hablante interruptora no es el de ayudar a la interrumpida en su enunciación sino el de demostrar que no domina el tema del que está hablando. En este sentido, si además tenemos en cuenta el rol desempañado por los interlocutores, la descortesía y agresividad de este tipo de interrupción aumenta considerablemente cuando el interlocutor interrumpido es el moderador:

MODERADORA: bueno, hemos visto que se traslada de cárcel desde Salamanca hasta Valdemoro $§$

RAMÓN BERMEJO: § de Topas a Valdemoro exactamente

MODERADORA: ¿cuál es la causa de este [traslado?]

(A tu lado, 18/5/06)

En los casos en los que la interrupción desafiliativa se utiliza para poner en entredicho no ya la argumentación del contrario, sino la pertinencia del tema que está tratando, también se realiza claramente un acto que descalifica claramente la imagen del interlocutor, pues se pone en entredicho su capacidad intelectual:

LIDIA LozANO: [vamos a ver, Nuria Bermúdez por dinero], Sonia Moldes por arreglarle la vida, porque Sonia Moldes le niega, pero bien que hicieron petición de mano y además [en la puerta de su casa]

Mila XimÉNez: [yo no creo que Sonia Moldes] y Nuria Bermúdez sean ahora el tema, [perdona que te diga]

LIDIA LoZANo: [no, no, no, perdona], perdona un momento, oye Mila, uno de los temas que [creo convenientes y aquí $=$ ]

LUCÍA RIAÑO: $[<<\ldots>>]$

LidiA LoZANO: = perdona Lucía, es que en este tema, ¿esta señora se casó a cambio de dinero con Rodríguez Menéndez? Es lo que quiero decir

(A tu lado, 18/5/06)

Además de esta relación de las interrupciones con las imágenes de autonomía y afiliación, debemos tener en cuenta que dichas estrategias conversa- 
cionales pueden estar causadas, en ocasiones, por el deseo del hablante interruptor de delimitar el turno de habla del hablante interrumpido. En el género del debate, monopolizar el turno de habla supone, especialmente, un abuso y una violación del sistema de turnos. En este sentido, en el debate Mejor lo Hablamos emitido el día 13/5/06, se observa claramente cómo uno de los participantes, Mario Arnaud en concreto, intenta monopolizar la interacción. De hecho, otro de los participantes en el debate llega a afirmar:

\section{Marcos García MonTeS: aquí está Mario y cinco más}

Por lo tanto, las interrupciones utilizadas por Adela Utrera en este caso en concreto para señalar a Mario Arnaud la necesidad de no mantener indefinidamente el turno y respetar su regulación, pueden ser consideradas menos descorteses y agresivas:

Mario ARnAUD: [permíteme, no, no, permíteme =]

ADEla UtRera: [es que no ha hablao el muchacho en toa la noche]

MARIO ARNAUD: =no, no, perdóname, perdóname [...]

\section{CONCLUSIONES}

Este sucinto análisis nos demuestra, por consiguiente, que los procesos interruptivos pueden estar motivados por múltiples factores, por lo que constituye una gran simpleza considerarlas solo como transgresiones descorteses de una máxima conversacional que reflejan relaciones de poder. La principal conclusión que podemos extraer de nuestro análisis es, por tanto, la necesidad de estudiar la lengua no en sí misma y por sí misma, sino atendiendo a todos y cada uno de los elementos contextuales que intervienen e influyen en el proceso de comunicación. Así pues, aunque es cierto que los procesos interruptivos conllevan en todas las ocasiones un cierto grado de descortesía, ya que suponen la violación de una máxima conversacional, de un derecho de los hablantes, no podemos afirmar que este valor sea el mismo en todos los casos.

No se puede hablar sin más de la existencia de una correspondencia unívoca entre interrupción y FTA sin tener en cuenta todos estos factores que dependen, en última instancia, de la situación concreta en la que se produce la comunicación. Hay que tener en cuenta el contexto comunicativo para poder determinar los distintos valores que pueden aparecer asociados a las instancias interruptivas, así como el grado de (des)cortesía y agresividad que conlleva esta violación del sistema de alternancia turnal. El grado de cortesía, descor- 
tesía e incluso agresividad que poseen las interrupciones en una situación comunicativa determinada depende de cuál sea la función comunicativa y estatus de la persona que lleva a cabo la interrupción, de si dicha interrupción va acompañada o no de atenuadores cualitativos o cuantitativos, de su relación con la imagen de autonomía y de afiliación o de su uso como demarcador de turnos conversacionales demasiados extensos.

Todo ello nos conduce a intentar adoptar una cierta flexibilidad y una perspectiva más global en la interpretación de la transición entre turnos conversacionales en general y de la interrupción en particular, así como a relativizar su correspondencia con la (des)cortesía y la agresividad verbal.

\section{REFERENCIAS BIBLIOGRÁFICAS}

BaÑón HeRnández, A. M. (1997): La interrupción conversacional. Propuestas para su análisis pragmalingüístico, Málaga, Analecta Malacitana.

Blas Arroyo, J. L. (1998): ""Pero no me interrumpa usted, haga el favor..." Las interrupciones en el debate político-electoral», Mediterranean Language Review, 10: 54-88.

Brown, P. y S. Levinson (1987): Politeness. Some Universals in Language Use, Cambridge, CuP. Originalmente publicado como «Universals in language usage: Politeness phenomena», en Goody, E. N. (ed.) (1978): Question and Politeness. Strategies in Social Interaction, Cambridge, UK.

Cestero MANCERA, A. M. (1994): «Intercambios de turnos de habla en la conversación en Lengua Española», Revista Española de Lingüística, 24, 1: 77-99.

CordisCO, A. (2003): «Afiliación y desafiliación: contexto sociocultural en el análisis de la interrupción y de sus consecuencias sociales en la interacción», en Bravo, D. (ed.) (2003): Actas del Primer Coloquio Edice (ed. electrónica): <http: www.primercoloqio.edice.org/Actas/actas.htm>, 149-163.

FANT, L. (1996): «Regulación conversacional en la negociación: una comparación entre pautas mexicanas y peninsulares», en KOTSCHI, T., W. OESTERREICHER y K. ZIMMERMANN (eds.) (1996): El español hablado y la cultura oral en España e Hispanoamérica, Vervuert-Iberoamericana, Frankfurt am Main-Madrid, 147-185.

Goffman, E. (1967): Interaction Ritual: Essays on Face-to-face Behavior, Garden City, NY: Anchor/Doubleday.

GoldBerG, J. A. (1990): «Interrupting the discourse on interruptions. An analysis in terms of relationally neutral, power- and rapport-oriented acts», Journal of Pragmatics, 14: 886-903.

HaVerkate, H. (1994): La cortesía verbal. Estudio pragmalingüístico, Madrid, Gredos. 
HERNÁNDEZ FloRES, N. (2004): «La cortesía como búsqueda del equilibrio de la imagen social», en Bravo, D. y A. BrIz (eds.) (2004): Pragmática sociocultural: estudios sobre el discurso de cortesía en español, Barcelona, Ariel, 95-108.

- (2005): «Cortesía y oscilación de la imagen social en un debate televisivo», en Murillo, J. (ed.) (2005): Actas del II Coloquio Edice (ed. electrónica): <http: www.edice.org/2coloquio/2coloquio.EDICE.pdf>, 37-54.

Kerbrat Orecchioni, C. (1992): Les Interactions Verbales II, París, Armand Collin.

LEECH, G. N. (1983): Principles of pragmatics, Londres, Longman.

MAKRI-TSILIPALOU, M. (1994): «Interruption revisited: affiliative vs. disaffiliative intervention», Journal of Pragmatics, 2: 401- 426.

MuRATA, K. (1994): «Intrusive or co-operative? A cross-cultural study of interruption», Journal of Pragmatics, 21: 385-400.

SACKS, H., E. SCHEGLOFF y G. JEFFERSON, (1974): «A simplest systematics for the organization of turn taking for conversation», Language, 50 (4): 696-735.

TABOLT, M. (1992): «I wish you'd stop interrupting me!: Interruptions and asymmetries in speakers-rights in equal encounters», Journal of Pragmatics, 18: $451-466$.

TANNEN, D. (1987): «Repetition in conversation: Toward a poetics of Talk», Language, 7, 3: 574-605.

WeSt, C. Y. y D. H. ZimMERMAN (1987): «Small insults: A study of interruptions in cross-sex conversations between unacquainted persons», en THORNE, B., C. Kramarae y N. Henley (eds.) (1987): Language gender and Society, Cambridge, MA: Newbury House, 103-117. 


\title{
QUI SOM NOSALTRES I QUI SÓN ELS ALTRES? MARQUES DE PERSONA \\ EN LA CAMPANYA DE L'ESTATUT DE CATALUNYA
}

\author{
Àngels CAMPos \\ Universidad Católica de Valencia \\ MARIA JoSEP MARÍn \\ Universitat Politècnica de València
}

\section{INTRODUCCIÓ}

$\mathrm{A}_{\mathrm{L}}^{\mathrm{L}}$ treball que presentem analitza els textos que els principals partits Colítics catalans (Convergència i Unió, ciu; Partit dels Socialistes Catalans, PSC; Esquerra Republicana de Catalunya, ERC; Partit Popular de Catalunya, PPC i Iniciativa per Catalunya-Els Verds, ICV) van incloure en les corresponents pàgines web per tal de demanar als ciutadans de Catalunya el vot a favor o en contra en el referèndum sobre el nou Estatut d'autonomia, celebrat el 18 de juny de 2006. Hi estudiem, d'una banda, les marques textuals mitjançant les quals els partits fan referència a 'nosaltres': totes aquelles persones, grups o institucions que, d'acord amb la ideologia política de cada partit, defensen els interessos de Catalunya i els seus ciutadans. D'una altra, les marques que es relacionen amb 'els altres': totes aquelles persones, grups polítics o institucions que, segons cada partit, representen o podrien representar una amenaça per als interessos de Catalunya i els seus ciutadans. Més específicament, ens centrem en els elements gramaticals lligats a la primera persona del plural (desinències verbals, pronoms personals i possessius) $i$ en els sintagmes nominals que tenen referents extratextuals vinculats a 'nosaltres' o 'els altres'.

Els textos estudiats són les síntesis que contenen els principals arguments dels diversos grups polítics sobre la conveniència de votar «sí» $\mathrm{O}$ «no» al nou Estatut. Es tracta de documents que poden variar quant a l'extensió (852 mots, el d'ERC; 1.690, el corresponent a ICV; 1.006, el del PSC; 1.890 , el text de CIU i 3.018 paraules, el del PPC), però que es poden considerar discursos paral-lels: es tracta de textos expositivoargumentatius, escrits amb una finalitat comuna (obtenir el vot dels ciutadans), on l'emissor és el partit polític, un subjecte col·lectiu que, com a tal, quan adopta discursivament la primera persona, 
apareix només en plural. De fet, aquest és un dels trets gramaticals característic dels textos objecte d'estudi, que es distancien així d'altres gèneres polítics com ara el debat i, sobretot, l'entrevista, en què l'ús de la primera del singular és molt abundant. Des del punt de vista del contingut, els temes que hi destaquen són: la conveniència o no de l'Estatut entès globalment, la nació catalana, les relacions amb l'Estat, les competències autonòmiques i els assumptes econòmics.

Per descriure breument el context polític en què es produeixen els documents analitzats, cal tenir en compte que la Comunitat Autònoma de Catalunya està dirigida políticament des de 2003 pel tripartit, un govern nascut del pacte del Tinell entre el partits d'esquerra: PSC (no definit com a nacionalista), ICV (no definit com a nacionalista) i ERC (nacionalista), presidit pel socialista Pasqual Maragall. El pacte ha deixat en l'oposició els dos partits de dretes, CIU (partit nacionalista, que havia governat Catalunya des de l'arribada de la democràcia) i PPC (no nacionalista). A l'Estat espanyol, governa el Partit Socialista Obrer Espanyol (PSOE).

En aquestes circumstàncies, els ciutadans catalans han de votar un text modificat respecte del que es va aprovar al Parlament català, amb el vot a favor de tots els partits excepte el PPC. En efecte, el que ha estat aprovat pel Parlament espanyol i se sotmet a votació és la modificació d'aquell text original, realitzada a partir de les negociacions obertes entre els diferents grups polítics, després de ser aprovat amb esmenes, i novament amb els vots en contra del PP, pel Congrés dels Diputats. Aquest procés de negociació ha fet créixer de manera molt considerable el protagonisme de CIU, mentre que ERC, oposat a una reforma que considera insuficient, finalment s'ha desvinculat del Govern català. Així les coses, durant la campanya, PSC, CIU i ICV demanen el vot favorable per al nou text; ERC i PPC reclamen el no per a l'Estatut.'

La metodologia que hem seguit ha consistit a identificar les marques que analitzem i introduir-les en una base de dades, on hem tingut en compte diversos aspectes en relació amb cada marca. Es tracta de la categoria gramatical que presenta, la funció sintàctica que realitza, el referent extratextual a què fa referència i el context o context textual en què apareix que, a més d'indicarnos si la marca s'alinea amb 'nosaltres' o 'els altres', ens informa sobre el tema tractat.

La perspectiva adoptada ens situa dins del marc teòric traçat per autors com van Dijk (2003: 58), per a qui una de les característiques fonamentals dels discurs polític, com a discurs ideològic, és emfasitzar els aspectes positius del 'nosaltres' destacant, al mateix temps, els aspectes negatius de 'els altres'. En

$\overline{1 .}$ Amb una participació del 49,42\% dels ciutadans catalans, el 18 de juny se celebra el referèndum sobre el nou Estatut català. El sí s'imposa sobre el no, amb un 73,9\% dels vots emesos. 
aquesta línia de recerca, el nostre treball connecta també amb l'estudi, ja clàssic, de Wilson (1990) o el més recent de Gelabert (2004), que, entre altres aspectes, han posat en relleu la importància que la utilització dels pronoms de primera persona té en el discurs polític.

\section{2. 'NOSALTRES' I 'ELS ALTRES'}

Des del punt de vista polític, el nou Estatut de Catalunya determinarà les relacions entre la Comunitat autònoma de Catalunya i l'Estat espanyol. Dins d'aquest marc, tots els partits, en demanar el vot afirmatiu o negatiu, proclamen defensar els interessos de Catalunya i dels ciutadans catalans, 'nosaltres', davant les possibles amenaces de 'els altres', qualsevol element, intern o extern, que puga posar en perill aquests interessos. En aquest apartat presentem, en primer lloc, les manifestacions textuals i els referents extratextuals relacionats amb 'nosaltres' i, a continuació, els referits a 'els altres'.

\subsection{Manifestacions textuals i referents extratextuals de 'nosaltres'}

Entre les marques mitjançant les quals es manifesta el 'nosaltres', hem estudiat, per una part, els díctics personals, és a dir, desinències verbals, pronoms personals i possessius de 1a persona del plural; per altra part, hem analitzat aquells sintagmes nominals que es refereixen a 'nosaltres' i que, de fet, podrien ser parafrasejats per díctics de 1a persona.

En conjunt, les marques díctiques, que es vehiculen sobretot mitjançant desinències verbals, corresponen majoritàriament al tipus de nosaltres que anomenem generalitzador (Campos, Marín i Cuenca, 2004), un plural que inclou l'emissor, el receptor i una 3a persona no present en la situació comunicativa $(1):^{2}$

(1) Pagant el mateix que els països més avançats d'Europa TENIM menys prestacions socials que Extremadura. (ERC)

2. També hi hem trobat alguns exemples aillats de desinències de 1a persona en les quals l'emissor selecciona i hi incorpora un receptor i una 3 a persona amb característiques ideològiques afins a ell. L'emissor utilitza aquestes marques de caràcter més restrictiu per a remetre al seu partit polític o a persones de la seua ideologia política, generalment ciutadans catalans d'esquerra, ja que aquesta marca només és utilitzada per ICV (i):

(i) La gent d'esquerres no ens PODEM conformar amb el que TENIM. La gent d'esquerres i ecologista no PODEM deixar passar l'oportunitat de fer un salt històric cap a una Catalunya més justa socialment i més sostenible. (ICV)

Com podem apreciar, en aquests casos, les desinències verbals es reforcen mitjançant l'ús d'un sintagma nominal que concreta el referent extratextual. 
Segons mostra l'exemple (1), la desinència verbal de 1a personal del plural és generalitzadora $\mathrm{i}$, per tant, fa referència al partit polític que emet el missatge, en aquest cas ERC, i a tots els ciutadans catalans, tant a aquells que, com a receptors, llegiran el missatge com a aquells que no el llegiran.

Pel que fa als sintagmes nominals (SN) vinculats a 'nosaltres', hi hem inclòs tots aquells sintagmes nominals que s'haurien pogut expressar mitjançant un díctic lligat a la 1a persona del plural, com ocorre en 'Generalitat' i 'ciutadans de Catalunya' en (2):

(2) El nou Estatut dóna capacitat a LA GENERALITAT per treballar en aquells àmbits que més preocupen als CIUTADANS DE CATALUNYA, com ara l'ocupació, la seguretat, la immigració i els permisos de treball dels treballadors estrangers. (PSC)

En aquests casos, l'ús del sintagma nominal concreta el referent extratextual, que seria molt més general i ambigu si s'emprara un element díctic, perquè, com afirma Wilson (1990: 48) «forms like 'we' [...] become ambiguous in actual productions».

Des del punt de vista formal, hem trobat SN el nucli dels quals pot ser: un nom comú (com ara catalans o ciutadans); un nom comú utilitzat en els textos com a propi, en el sentit que té una referència extradiscursiva única (com, per exemple, Generalitat); o un nom propi (com ara Catalunya). ${ }^{4}$ L'exemple (3) mostra aquest darrer cas:

(3) CATALUNYA seguirà sent solidària, de forma justa i transparent. (ICV)

$\mathrm{Si}$ atenem als referents extratextuals de 'nosaltres', comprovarem que s'agrupen majoritàriament entorn a tres realitats: Catalunya, Espanya i ideologies afins a l'emissor. Aquestes categories es poden concretar més, partint de la proposta de Fernández Sebastià (2002: 1). De fet, podem realitzar una classificació més detallada de cadascuna d'aquestes realitats, atenent a una gradació de més individual a més institucional que es concreta de manera següent: els ciutadans catalans, la Comunitat Autònoma i el Govern/la Generalitat de Catalunya, d'una

3. L'exemple (2) es podria parafrasejar utilitzant díctics de primera persona, segons mostrem en

(ii): El nou Estatut ENS dóna capacitat per treballar en aquells àmbits que més ENS preocupen, com ara l'ocupació, la seguretat, la immigració i els permisos de treball dels treballadors estrangers.

4. Catalans, ciutadans, Generalitat i Catalunya són els SNs més utilitzats en els textos que hem estudiat. Més aïlladament, com a marques de 'nosaltres', hi trobem altres SNs com espanyols, Espanya o Estat, el nom o les sigles d'alguns dels partits (el Partit Popular, ICV i CIU) i denominacions que al-ludeixen a aspectes ideològics o socials dels ciutadans com ara les persones d'esquerres o els treballadors i les treballadores. 
banda; els ciutadans espanyols, Espanya i el Govern espanyol, d'altra; i, finalment, ciutadans amb ideologia pròxima, partits polítics afins i moviments ideològics propers. Aquest agrupament permet de destacar, respectivament, els col-lectius humans, els territoris i grups polítics, o les institucions i els corrents ideològics. En l'exemple (2), es focalitzava en els ciutadans catalans. Fixemnos, en canvi, en els exemples (4), (5) i (6):

(4) Fort augment de les inversions de l'Estat en matèria d'infraestructures a CATALUNYA, amb el compromís que durant set anys s'equiparin a la participació relativa del PIB català en el PIB espanyol. (PSC)

(5) La proposta de redacció del nou Estatut opta per una relació bilateral entre Catalunya i Espanya en la qual L'ESTAT és anul-lat en la seva capacitat per representar els interessos dels catalans i catalanes. (PPC)

(6) Des del CATALANISME D'ESQueRres no és comprensible un rebuig a l'Estatut quan suposa un pas més en el camí de redreçament nacional iniciat ara fa cent anys. (ICV)

Observem que mentre que, en (4), el SN Catalunya remet a la comunitat autònoma, focalitzant, per tant, en el territori, en (5), L'Estat fa referència al govern central, destacant-ne el pes institucional. L'últim exemple, el (6), apunta al corrent ideològic a què pertany el partit emissor.

\subsection{Manifestacions textuals i referents extratextuals de 'els altres'}

A diferència del que s'esdevé amb les marques de 'nosaltres', la manifestació textual de 'els altres' es fa únicament mitjançant SN, que poden tenir com a nucli un nom comú (els actors, la dreta, els partits catalans, els socialistes, el legislador, els sectors reaccionaris...), un nom comú utilitzat com a propi (l'Estat, el Govern, la Generalitat, el president de la Generalitat...), o un nom propi, on trobem topònims, antropònims o noms de partits concrets (Espanya, Madrid, Bono, Carod-Rovira, Ibarra, Guerra, el PP, el PSOE...). Hi presentem un exemple on el nucli és el nom comú / propi Estat:

(7) Aquests són els guanys més destacables que incorpora el text i que justifiquen un 'sí' contundent el dia del referèndum: [...] Blindatge de les competències exclusives per evitar la intromissió de L'ESTAT. (CIU)

Quant als referents extratextuals, els SN de 'els altres' es poden agrupar entorn a dues realitats: l'Estat espanyol i ideologies oposades, que alhora, tal com ocorria amb 'nosaltres', es poden concretar més per focalitzar, en el cas 
de l'Estat espanyol, en les persones (els espanyols), en el territori (Espanya) o en les institucions (Govern espanyol); o bé, si es remet a ideologies contràries, per focalitzar en els polítics adversaris, en els partits polítics rivals o en els moviments ideològics contraris, en una gradació de més concret (polítics) a més abstracte (moviments ideològics). Els exemples (8) i (9) ens serveixen per il-lustrar els dos tipus de referents extratextuals de 'els altres':

(8) Les retallades han fet desaparèixer de l'Estatut: L'Agència Tributària Catalana per a recaptar tots els impostos i evitar que se'ls quedi MADRID. (ERC)

(9) Les discussions internes entre els membres del tripartit o entre el PSC i el PSOE i entre institucions governades pels mateixos partits han paralitzat la construcció d'infraestructures vitals pel desenvolupament econòmic i la competitivitat catalana. (PPC)

Segons podem comprovar, l'exemple de (8) presenta Madrid com a adversari. Es tracta d'un nom propi que fa referència a l'Estat espanyol i, en especial, s'usa per a fer referència al Govern espanyol, de manera que ressalta l'aspecte institucional. En (9), l'amenaça està constituïda per dos partits polítics (PSC i PSOE), que són els rivals directes del grup polític emissor, el PPC.

\section{RESULTATS GLOBALS}

En aquest apartat, presentem i analitzem els resultats globals de la nostra investigació. Ens centrem, per tant, en les marques ('nosaltres' o 'els altres') més utilitzades pels diferents grups polítics, tenint en compte el nombre total de paraules de cadascun dels textos.

Pel que fa a la quantitat de marques de 'nosaltres', ERC és el partit que empra més marques d'aquest tipus (6\%) sobre el total de paraules. En l'altre extrem, PPC és el que menys marques relatives a 'nosaltres' fa servir $(2,2 \%)$. Aquestes dades poden relacionar-se amb el caràcter nacionalista i no nacionalista d'aquestes dues formacions: ERC tendeix a accentuar la ideologia nacionalista atorgant predomini a 'nosaltres' ('els catalans'), mentre que el PPC la minimitza.

$\mathrm{Si}$ ens fixem en les referències a 'els altres', els textos del PSC $(0,1 \%)$ i CIU $(0,8 \%)$ són els que menys marques de 'els altres' inclouen. Per contra, ERC $(1,6 \%)$ i PPC $(1,3 \%)$ en fan un ús comparativament destacable. D'acord amb aquests resultats, la minva de l'ús de referències a 'els altres' sembla estar relacionada amb el protagonisme dels partits en la negociació i el sentit del vot que propugnen. Així els dos partits que demanen el sí i, a més, tenen un paper clau en la negociació (PSC i CIU) minimitzen aquestes marques i, per tant, la confrontació. 
La conclusió anterior es reforça si comparem els percentatges de 'nosaltres' $i$ 'els altres' considerant ara el nombre total de marques que utilitza cada partit. La dada més remarcable és que tots els partits fan més referències a 'nosaltres' que no pas a 'els altres', cosa lògica en un referèndum autonòmic on tots volen deixar clar que defensen els interessos de Catalunya i els catalans. No obstant això, cal remarcar que el PPC tendeix a acostar els resultats entre l'ús de 'nosaltres' $(61,9 \%)$ i 'els altres' $(38,1 \%)$; mentre que el PSC ocuparia la posició contrària, ja que fa servir pràcticament de manera exclusiva les referències a 'nosaltres' $(97,4 \%)$.

\section{RESULTATS DE LES REFERÈNCIES A 'NOSALTRES'}

En aquesta secció, presentem les dades obtingudes a partir de l'anàlisi del 'nosaltres' en els textos de cada partit. En primer lloc, mostrem els resultats pel que fa a la manifestació gramatical del 'nosaltres' dins dels textos (taula 1). Posteriorment, exposem les dades relatives al referent extratextual concret a què remeten aquestes marques (taula 2 ).

La taula 1 mostra que, en general, en els textos estudiats, apareixen més SN relacionats amb el 'nosaltres' (68\%) que no díctics de 1a persona del plural (32\%). De fet, si analitzem les dades per partits, veurem que la majoria expliciten el referent discursivament mitjançant diversos SN. Hi destaca especialment CIU, que utilitza SN en el 84,4\% de casos vinculats al 'nosaltres'. En canvi, ERC és l'únic partit que empra més marques de primera persona del plural $(52,9 \%)$ que no SN $(47,1 \%)$ en aquesta funció. ICV és el partit que més s'aproxima a ERC en l'ús de primera persona del plural $(60,5 \%)$.

TAUla 1. Manifestació de 'nosaltres' mitjançant diferents marques gramaticals

\begin{tabular}{|c|c|c|c|}
\hline $\begin{array}{c}\text { Partit } \\
\text { polític }\end{array}$ & $\begin{array}{c}\text { Díctics } \\
\text { personals }\end{array}$ & $\begin{array}{c}\text { Sintagmes nomi- } \\
\text { nals }\end{array}$ & $\begin{array}{c}\text { TOTAL de } \\
\text { 'nosaltres' }\end{array}$ \\
\hline ERC & $27(52,9 \%)$ & $24(47,1 \%)$ & $\mathbf{5 1 ( 1 0 0 \% )}$ \\
\hline ICV & $32(39,5 \%)$ & $49(60,5 \%)$ & $\mathbf{8 1}(\mathbf{1 0 0 \%})$ \\
\hline PSC & $10(26,3 \%)$ & $28(73,7 \%)$ & $\mathbf{3 8}(\mathbf{1 0 0 \%})$ \\
\hline CIU & $12(15,6 \%)$ & $65(84,4 \%)$ & $\mathbf{7 7}(\mathbf{1 0 0 \%})$ \\
\hline PPC & $19(29,2 \%)$ & $46(70,8 \%)$ & $\mathbf{6 5 ( 1 0 0 \% )}$ \\
\hline TOTAL & $\mathbf{1 0 0}(\mathbf{3 2 \%})$ & $\mathbf{2 1 2 ( 6 8 \% )}$ & $\mathbf{3 1 2 ( 1 0 0 \% )}$ \\
\hline
\end{tabular}

Les dades semblen indicar que els partits situats ideològicament més a l'esquerra es refereixen al 'nosaltres' de manera poc precisa, mentre que els partits de centre i dreta ho fan de manera més concreta, mitjançant SNs. 
Si observem la taula 2, el referent extratextual més utilitzat globalment és 'els catalans' $(42,4 \%)$, seguit a distància de 'Govern català' $(24,6 \%)$ i 'Comunitat autònoma' $(19,9 \%)$. La tendència general, doncs, és identificar 'nosaltres' amb Catalunya, en especial com a col-lectiu humà ('els catalans') i, en menor mesura, com a institució i com a territori (§2.1).

TAULA 2. Referent extratextual de 'nosaltres' per partits

\begin{tabular}{|c|c|c|c|c|c|c|}
\hline & ERC & ICV & PSC & CIU & PPC & TOTAL \\
\hline Els espanyols & - & - & - & - & $2(3,1 \%)$ & $\mathbf{2}(\mathbf{0 , 6 \%})$ \\
\hline Estat espanyol & - & $1(1,2 \%)$ & - & - & $6(9,2 \%)$ & $\mathbf{7}(\mathbf{2 , 2 \%})$ \\
\hline Govern espanyol & - & - & - & - & $5(7,7 \%)$ & $\mathbf{5}(\mathbf{1 , 6 \%})$ \\
\hline Els catalans & $33(64,7 \%)$ & $36(44,4 \%)$ & $17(44,8 \%)$ & $15(19,5 \%)$ & $31(47,7 \%)$ & $\mathbf{1 3 2}(\mathbf{4 2 , 4 \%})$ \\
\hline Comunitat autònoma & $12(23,6 \%)$ & $14(17,3 \%)$ & $7(18,4 \%)$ & $21(27,3 \%)$ & $8(12,3 \%)$ & $\mathbf{6 2}(\mathbf{1 9 , 9 \%})$ \\
\hline Govern català & $6(11,7 \%)$ & $10(12,4 \%)$ & $14(36,8 \%)$ & $40(51,9 \%)$ & $7(10,8 \%)$ & $\mathbf{7 7}(\mathbf{2 4 , 6 \%})$ \\
\hline Classe política & - & $5(6,2 \%)$ & - & - & - & $\mathbf{5 ( 1 , 6 \% )}$ \\
\hline $\begin{array}{c}\text { El mateix partit i } \\
\text { partits afins }\end{array}$ & - & $2(2,4 \%)$ & - & $1(1,3 \%)$ & $6(9,2 \%)$ & $\mathbf{9}(\mathbf{2 , 9 \%})$ \\
\hline $\begin{array}{c}\text { Pers. de la mateixa } \\
\text { ideologia }\end{array}$ & - & $13(16,1 \%)$ & - & - & - & $\mathbf{1 3}(\mathbf{4 , 2 \%})$ \\
\hline TOTAL & $\mathbf{5 1}(\mathbf{1 0 0 \% )}$ & $\mathbf{8 1}(\mathbf{1 0 0 \% )}$ & $\mathbf{3 8}(\mathbf{1 0 0 \% )}$ & $\mathbf{7 7}(\mathbf{1 0 0 \%})$ & $\mathbf{6 5}(\mathbf{1 0 0 \% )}$ & $\mathbf{3 1 2}(\mathbf{1 0 0 \% )}$ \\
\hline
\end{tabular}

Per partits, tots, excepte CIU, identifiquen 'nosaltres' amb 'els catalans'. Hi destaca per damunt de la resta ERC, amb un $64,7 \%$. En l'extrem contrari, CIU és el grup que menys referència extratextual fa al col-lectiu humà, ja que prefereix centrar-se en Catalunya com a institució (51,9\% dels casos). En aquest sentit, es podria pensar, per una part, que aquest partit encara se sent govern, ja que ho ha estat durant més de tres dècades; per una altra, que és conscient del fet que l'expressió lingüística pot transformar la realitat. ${ }^{5}$ El segueix el PSC, segons és lògic, atès que és el partit majoritari en el govern. En qualsevol cas, cal destacar que es tracta dels grups polítics amb més pes específic en la negociació de l'Estatut.

D'altra banda, un altre resultat destacat és la diversitat de referents extratextuals del grup ICV. Convé remarcar que és l'únic partit, a més del PP, que fa servir el 'nosaltres' per referir-se al 'Govern espanyol', fet que s'explica perquè no és un partit nacionalista i perquè el Govern espanyol és de centreesquerra i ja ha defensat en el Parlament espanyol l'Estatut per al qual ICV

5. Des d'aquest punt de vista, Fernández Sebastián (2002: 1) afirma que «El lenguaje, además de un "registro" más o menos fiel del mundo, es un factor y un instrumento esencial del cambio social y político, y muchas veces los cambios lingüísticos preceden y en cierta manera estructuran las transformaciones en el terreno fáctico e institucional». 
demana el vot afirmatiu. Igualment, destaquen les marques referides a persones d'ideologia afí $(16,1 \%)$, resultat que podria interpretar-se com un afany d'arribar a tots els votants d'esquerra.

Per últim, resulta interessant el fet que el PP és l'únic grup que vincula el 'nosaltres' a 'els espanyols' i també el que més referències fa a si mateix, al Partit Popular de Catalunya. Probablement, es tracta d'una manifestació discursiva de la situació d'aïllament en què aquesta formació es troba: és l'únic partit que ha votat sempre en contra des de l'inici del procés del nou Estatut, en alguns casos en solitari; i tot i que, a l'igual com ERC, demana el no per al nou Estatut, els motius d'uns i d'altres són radicalment oposats.

\section{RESULTATS DE LES REFERÈNCIES A 'ELS ALTRES'}

En aquest apartat, exposarem els resultats quant al referent extratextual que s'oculta sota el genèric 'els altres'. A partir de la taula 3 , podrem descobrir qui constitueix una amenaça per a cadascun dels partits polítics catalans. La columna de totals d'aquesta taula mostra que les marques textuals de 'els altres' solen fer referència sobretot a partits d'ideologia contrària $(44,2 \%) \mathrm{i}$, en menor mesura, al govern espanyol $(28,4 \%)$.

TAULA 3. Referent extratextual de 'els altres' en els diferents partits

\begin{tabular}{|c|c|c|c|c|c|c|}
\hline & ERC & ICV & PSC & CIU & PPC & TOTAL \\
\hline Estat espanyol & - & $1(4,2 \%)$ & - & - & - & $\mathbf{1}(\mathbf{1 , 1 \%})$ \\
\hline $\begin{array}{c}\text { Altres Comunitats } \\
\text { autònomes }\end{array}$ & - & $1(4,2 \%)$ & - & - & - & $\mathbf{1}(\mathbf{1 , 1 \%})$ \\
\hline Govern espanyol & $5(35,7 \%)$ & $7(29,1 \%)$ & $1(100 \%)$ & $14(87,5 \%)$ & - & $\mathbf{2 7}(\mathbf{2 8 , 4 \%})$ \\
\hline $\begin{array}{c}\text { Ideologies con- } \\
\text { tràries }\end{array}$ & $2(14,3 \%)$ & $6(25 \%)$ & - & - & - & $\mathbf{8}(\mathbf{8 , 4 \%})$ \\
\hline Els altres partits & $3(21,4 \%)$ & $7(29,1 \%)$ & - & - & $32(80 \%)$ & $\mathbf{4 2}(\mathbf{4 4 , 2 \%})$ \\
\hline $\begin{array}{c}\text { Polítics d'ideologia } \\
\text { oposada }\end{array}$ & $4(28,6 \%)$ & $2(8,4 \%)$ & - & $2(12,5 \%)$ & $7(17,5 \%)$ & $\mathbf{1 5}(\mathbf{1 5 , 7 \%})$ \\
\hline Legisladors & - & $2(3,1 \%)$ & - & - & $1(2,5 \%)$ & $\mathbf{1}(\mathbf{1 , 1 \%})$ \\
\hline TOTAL & $\mathbf{1 4}(\mathbf{1 0 0 \%})$ & $\mathbf{2 4}(\mathbf{1 0 0 \%})$ & $\mathbf{1 ( 1 0 0 \% )}$ & $\mathbf{1 6}(\mathbf{1 0 0 \%})$ & $\mathbf{4 0}(\mathbf{1 0 0 \%})$ & $\mathbf{9 5}(\mathbf{1 0 0 \%})$ \\
\hline
\end{tabular}

Per partits, CIU i PPC tendeixen a unificar l'adversari i centrar-lo, en el cas de CIU, en el govern espanyol i, en el cas del PPC, en les persones o formacions que representen ideologies oposades a la seua. Per contra, en els textos d'ICV i ERC, s'observa la tendència contrària, que consisteix en la diversificació de l'adversari. Aquests resultats semblen indicar una certa coincidència d'estratègia discursiva entre els partits de dretes. 
Pel que fa als referents concrets, tots els partits, tret de PPC, apunten a l'Estat espanyol com a principal amenaça. Per contra, per al PPC, el perill més important, el constitueixen els altres partits (80\%), sobretot el tripartit. En aquest sentit, es produeix una certa coincidència amb l'altre partit que demana el no per al nou Estatut (ERC), que també ofereix percentatges destacables en la referència a altres partits $(21,4 \%)$ i a polítics concrets d'altres ideologies $(28,6 \%)$. Aquestes dades podrien apuntar al fet que les formacions que defensen el no utilitzen l'atac com a estratègia argumentativa i, per això, insisteixen molt en la referència als altres grups polítics i els presenten com un perill per a la identitat.

\section{ANÀLISI GLOBAL I CONCLUSIONS}

Els textos analitzats, en els quals les cinc principals forces polítiques de Catalunya resumeixen els arguments per votar sí o no al nou Estatut d'autonomia, evidencien que els elements discursius són reflex d'una situació extralingüística determinada i alhora constitueixen un indicador de la imatge que els diferents grups volen oferir. De fet, hem comprovat que l'ús de les marques analitzades (referides a 'nosaltres' i a 'els altres') es relaciona, en alguns casos, amb la ideologia política; però, en la majoria de casos, depèn del sentit del vot que es demana i sobretot de la participació que els diversos partits han tingut en el procés de negociació.

Les marques referides a 'nosaltres', en tots els partits polítics, són molt més abundants que no pas l'ús de marques referides a 'els altres', la qual cosa indica que tots els grups polítics, independentment de la seua ideologia, volen demostrar que, amb el vot que demanen, defensen els interessos de Catalunya i dels seus ciutadans. En aquest sentit, hem observat que els partits que demanen el vot negatiu per al nou Estatut (ERC i PPC) augmenten l'ús de marques de 'els altres' i, d'aquesta manera, manifesten textualment la confrontació política, que els altres partits intenten minimitzar.

Des del punt de vista gramatical, el fet que, globalment, s'utilitzen de manera majoritària els SN i no tant els díctics aporta precisió en la identificació del referent extratextual, ja que permet focalitzar, en cada cas, sobre els ciutadans, el territori o les institucions. Aquest afany de precisió és més abundant en els textos dels partits de centre-dreta, mentre que els partits més a l'esquerra fan un ús més elevat de díctics.

Quant al referent extratextual de 'nosaltres', el més destacat és 'els catalans', la qual cosa confirma la intenció dels partits de demostrar preocupació pels interessos dels ciutadans. Per contra, 'els altres' remeten a 'l'Estat espanyol' en la majoria de partits, per als quals pot representar un entrebanc davant dels 
interessos catalans. En aquest sentit, els dos partits més de dretes s'aparten de l'esquema general, tot i que per motius diversos. Així, ciU utilitza les marques de 'nosaltres' per a remetre, majoritàriament, al 'govern català', atès que se senten protagonistes de la negociació, han estat en el poder durant molts anys i aspiren a recuperar-lo pròximament. El llenguatge s'utilitzaria, per tant, com un element previ al canvi, mitjançant el qual s'intenta transformar la realitat. Pel que fa al PPC, usa les marques de 'els altres' per a referir-se a ideologies oposades i sobretot per a criticar la gestió del tripartit, l'equip de govern de la Generalitat; d'aquesta manera, l'atac als rivals més directes constitueix la principal arma argumentativa. Es tracta d'una estratègia que, en certa manera, també manifesta una posició d'aïllament polític.

En síntesi, l'anàlisi dels textos mostra que tant l'ús de les marques analitzades com el referent extratextual de 'nosaltres' i de 'els altres' sembla vinculat al protagonisme de cada partit en el procés de negociació del nou Estatut i al sentit del vot demanat, més que no pas a la ideologia de cada formació política.

\section{REFERÈNCIES BIBLIOGRÀFIQUES}

CAMpos, A., M. J. Marín i M. J. Cuenca (2004): «Las marcas de primera persona en el debate electoral» en SoAReS DA SiLva, A et al. (eds.) (2004): Linguagem, cultura e cogniçao: Estudos de Linguística Cognitiva, Coimbra, Almedina, vol. II: 279-298.

Chilton, P. (2004): Analysing Political Discourse. Theory and Practice, Londres, Routledge.

FERnÁNDEZ SebASTIÁn, J. (2002): «Estado, nación y patria en el lenguaje político español. Datos lexicométricos y notas para una historia conceptual» [<www.ejercito.mde.es/IHYCM/revista/patria/07-javier-fernandez.html $>$ ].

Gelabert, J. (2004): Pronominal and Spatio-temporal deixis in Contemporary Spanish Political Discourse: a Corpus-based Pragmatic Analysis, Universitat de Pensilvània. Tesi doctoral.

Marín, M. J. i A. CAmpos (2005): «El discurso de José María Aznar antes y después del 11M: las marcas de primera persona en la entrevista política», Estudios de Lingüística, 19: 319-333.

Souchard, M. et al. (1997): Le Pen. Les mots: Analyse d'un discours d'extrême droite, París, Le Monde.

VAN DiJK, T. A. (1999): Ideología. Una aproximación multidisciplinaria, Barcelona / Buenos Aires, Gedisa.

- (2003): Ideología y discurso, Barcelona, Ariel.

Wilson, J. (1990): Politically Speaking. The Pragmatic Analysis of Political Language, Oxford, Blackwell. 


\title{
EVIDENCIALIDAD Y CORTESÍA: ¿MENTIRA O MALENTENDIDO INTERCULTURAL?
}

\author{
Andrea María Estrada \\ Universidad de Buenos Aires
}

\section{MARCO GENERAL DE LA INVESTIGACIÓN}

\subsection{Antecedentes}

$\mathbf{T}$ ANTO la lógica modal como los estudios linguísticos se han ocupado de estudiar la relación de las proposiciones con categorías tales como la verdad (modalidad alética), el deber (modalidad deóntica) y el saber (modalidad epistémica). La modalidad epistémica es la expresión de la subjetividad del hablante en relación con el ámbito de la posibilidad y, en tanto señala el grado de certeza del locutor frente a su enunciado, se relaciona con otra categoría, la evidencialidad,' que indica la forma en que el locutor ha obtenido el conocimiento: de modo directo -ha sido testigo presencial-, o de modo indirecto, es decir, mediante inferencias o basado en el discurso de terceros.

Para ejemplificar de algún modo esta categoría semántica, vamos a suponer que estoy hablando con un alumno sobre literatura argentina y que este me pide una opinión sobre el cuento de Borges Funes, el memorioso. Paradójicamente solo recuerdo que Funes es un personaje que, como consecuencia de que no puede olvidar ningún detalle -hasta el más insignificante-, tampoco está habilitado para pensar. Obviamente, intuyo dos cosas: que el relato debe ser profundo y hasta fundacional y que, además, no conviene que se note que no lo he leído: «Mi imagen de profesora puede verse seriamente amenazada, si no conozco al dedillo la obra de Borges», pienso. Y es por esta razón que, en las circunstancias planteadas, no puedo dar una opinión cabal -a pesar de que tengo una somera idea de su contenido-porque desconozco las causas por las que el alumno me ha hecho la pregunta: si para ponerme en un aprieto, o para saber realmente mi opinión. Puedo responder, entonces con los siguientes enunciados:

1. Cada lengua codifica la evidencialidad de diferente modo: las lenguas amerindias o sufijales lo hacen mediante morfemas y, como en el español, la categoría está escasamente codificada en la morfología, existen otros recursos -tanto gramaticales como lexicales- para señalar la forma en que el locutor ha accedido a la fuente de conocimiento. 
(1) Tengo entendido que el cuento es interesante...

(2) Según dicen, el cuento sería interesantísimo. Pero a mí me parece que es muy complejo.

En (1) el locutor indica mediante la expresión «Tengo entendido...» que puede haber obtenido el conocimiento a partir de inferencias, por ejemplo deducir que el cuento es interesante a partir de la lectura de otros relatos de Borges. En (2), en cambio, el conocimiento es «de oídas»-de allí el uso tanto de «Según dicen» como del evidencial de rumor «sería», muy utilizado en el discurso periodístico- que aluden a una fuente verbal en la que se delega la evaluación del cuento de Borges. De ese modo, el locutor se distancia de su enunciado y atenúa su grado de responsabilidad con respecto al juicio emitido.

Pero supongamos ahora que enuncio:

(3) A mí Borges me fascina. Y ese cuento en especial es fabuloso. Realmente lo encuentro muy interesante.

En este caso, el modo en que se presenta la evaluación difiere del de los enunciados anteriores, porque mientras (1) y (2) indican que el acceso a la fuente es indirecta -inferencial o citativa-, es decir que el locutor emite un juicio valorativo a partir de inferencias que pueden provenir del hecho de que sólo ha leído referencias sobre el relato en cuestión (indicios externos) o bien porque alguien, un colega por ejemplo, le ha contado el argumento (fuente verbal), en cambio en (3), el locutor señala que su opinión se basa en la lectura efectiva del cuento. Y esa es la razón por la que puede emitir un juicio asertivo. Por el contrario, en los enunciados (1) y (2) el locutor no ha efectuado la lectura y entonces no puede mostrarse tan seguro. ${ }^{2}$

El modo en que el locutor ha adquirido el conocimiento condiciona entonces de tal forma la confiabilidad hacia sus enunciados, que le permite adoptar distintos grados de adhesión frente a ellos, mostrándose ante su interlocutor más o menos sincero. Así, el tratamiento de la evidencialidad encuentra una conexión natural con el tema de la mentira como delito discursivo, ya que un hablante inserto en nuestra cultura sólo podrá dar fe de aquello que ha visto con sus propios ojos. ${ }^{3}$

2. Prueba de ello, es que en este último caso la pregunta del alumno será del tipo ¿Cree/le parece que el libro es interesante?, mientras que si presupone que efectivamente el cuento ha sido leído, estará habilitado para preguntar: ¿Encuentra interesante el libro?

3. Parto de la premisa de que esta categoría en español no se restringe a las marcas de distanciamiento del locutor frente al contenido que transmite su enunciado y que, por lo tanto, no debe ser identificada con precaución epistemológica. 
En el presente trabajo, me propongo contribuir a los estudios de cortesía, para lo cual analizo el comportamiento del ítem lexical encontrar como evidencial de acceso sensorial directo en enunciados del tipo del presentado en (3) «Encuentro el relato muy interesante» $o$ «Lo encuentro muy interesante». Mi hipótesis es que los distintos grados de adhesión del locutor frente a sus enunciados no solo le permiten mostrarse ante su interlocutor más o menos sincero, sino también más o menos cortés. Y que al ser el comportamiento cortés un fenómeno específico de cada cultura, la interrelación entre los parámetros de sinceridad y de cortesía puede devenir en malentendidos interculturales.

\section{LA MENTIRA}

Los estudios lingüísticos nos permiten abordar de dos modos diferentes el tema de la mentira: desde el punto de vista vericondicional o desde el punto de vista argumentativo. Así, para el primero, la noción de verdad/falsedad está asociada a la capacidad descriptiva de la lengua y a su función primordialmente informativa. Por el contrario, desde una perspectiva no representacionista de la lengua, por ejemplo desde la TAL (Teoría de la Argumentación en la Lengua) de Ducrot $(1980,1984)$, el sentido no se reduce a las condiciones de verdad y entonces el valor informativo de la lengua aparece como derivado del valor argumentativo, en tanto las palabras no describen los objetos en sí mismos sino que indican posibles continuaciones discursivas. Pero veamos con más detalle estas posibilidades.

\subsection{La mentira como delito discursivo}

Según Searle (1983) la sinceridad se relaciona con el estado mental o intencional del hablante asertivo: es sincero quien emite una aserción que describe una determinada realidad extralingüística a la que considera verdadera. Por oposición, la mentira, entonces, se define como la insinceridad del hablante asertivo cuyo acto locutivo describe un estado de cosas contrario a su estado intencional. Al mentir, el hablante tiene una representación determinada de la realidad, pero manifiesta otra distinta para su interlocutor.

Por su parte, para Grice (1985), la mentira viola la máxima de calidad: «No digas aquello de lo cual no tienes pruebas suficientes». Dicha violación es transparente, cuando el efecto no es engañar al interlocutor sino producir determinados efectos retóricos. Tal es el caso de la metáfora, en la cual la máxima de calidad es violada explícitamente con el fin de activar una implicatura y comunicar otra cosa diferente de la expresada. Por el contrario, el hablante mentiroso, en tanto debe evitar que lo descubran, no puede expresar abiertamente su 
insinceridad, puesto que la mentira dejaría de ser efectiva y produciría una contradicción del tipo de la denominada paradoja de Moore: «Son las tres y media, pero no lo creo»o «Deme lumbre, pero no quiero que lo haga». Sin embargo, el interlocutor, en tanto no perciba señales que le hagan pensar lo contrario, siempre presupondrá la sinceridad del hablante (Haverkate, 1984).

\subsection{La mentira como argumentación}

Para abordar el tema de la mentira desde la perspectiva argumentativa, retomaré el ejemplo inaugural referido a Borges, quien también inaugura, según los críticos, un modo de hacer literatura.

Supongamos ahora que logro que la conversación sobre Borges se derive hacia el cuento Pierre Menard, autor del Quijote, obviamente, porque en este caso sí lo he leído. En este texto, que alude de modo magistral a los procedimientos de lectura, escritura e interpretación, Pierre Menard se propone escribir nuevamente el Quijote y, para ello, no encuentra mejor solución que copiarlo «palabra por palabra y línea por línea». Entonces, como lo he leído puedo emitir un juicio contundente y polémico que además me permitirá mostrar mis conocimientos cuando tenga que justificar mi opinión. Enuncio:

(4) «Pierre Menard, autor del Quijote» es el cuento de Borges más famoso, pero yo lo encuentro delirante.

El locutor de (4) señala con el uso de encuentro que su juicio se basa en la lectura efectiva del relato y, será sincero si la condición de «acceso visual directo a la fuente de conocimiento» se cumple efectivamente. Por el contrario, si no lo ha leído no estará habilitado para enunciar (4) sin caer en la mentira.

Pero imaginemos la siguiente situación: he leído el cuento pero no lo entiendo y, por lo tanto, no puedo ser contundente puesto que corro el riesgo de tener que justificar mi apreciación. Puedo enunciar entonces:

(5) Si bien «Pierre Menard, autor del Quijote» es el cuento de Borges más famoso, yo creo que es delirante.

(6) «Pierre Menard, autor del Quijote» es el cuento de Borges más famoso, pero dicen que es delirante.

En los enunciados (5) y (6) el locutor se distancia del punto de vista puesto en escena por su discurso: al decir «creo» atenúa la fuerza de su juicio y con el evidencial citativo «dicen» señala que el conocimiento fue adquirido de oídas, lo que lo cubre de posibles críticas ante la opinión contraria del interlo- 
cutor. Es por ello que, si el cuento no fuera en realidad «delirante» sino todo lo contrario, algo así como «claro» o «comprensible» el locutor que enunciara (5) y (6) nunca podría ser tildado de mentiroso, mientras que sí podría serlo el locutor que se hiciera plenamente responsable del punto de vista reflejado en su enunciado diciendo Lo encuentro delirante.

Por otra parte, el juicio personal e inédito del locutor basado en el conocimiento de la cosa en sí misma puede ser directo, como en los ejemplos que he dado, o mediatizado. Supongamos que, al igual que en el caso de Funes el memorioso conozco Pierre Menard, autor del Quijote, su argumento y su estructura como si lo hubiera leído, aunque en realidad nunca lo hice. En rigor de verdad, no podríamos decir, si el locutor enunciara «Lo encuentro delirante» que está incurriendo en una mentira, pero sí, que el verbo encontrar ha perdido su matiz endofórico, en tanto el locutor sólo mantiene el aspecto informativo de la cosa aprehendida y no el contenido afectivo que todo aprendizaje conlleva. ${ }^{4}$

Veamos, para aclarar este punto, otra situación. Imaginemos que continúo la charla con mi alumno sobre literatura argentina. En esta ocasión, le manifiesto que entre la poesía y la narrativa de Borges, prefiero la primera porque la encuentro llana, formalmente perfecta y despojada de todo el aparato teórico necesario para disfrutar de su prosa. Sin embargo, mi opinión queda descalificada porque mi alumno considera que no está sustentada por la lectura de la obra completa de Borges. Utilizo, entonces, el siguiente enunciado en el que descalifico la actitud de mi alumno, del mismo modo que él lo ha hecho con mi opinión. Le digo:

(7) ¿Sabes qué? Encuentro tu postura muy soberbia.

La inclusión del evidencial en (7) se justifica porque el locutor está viendo a su interlocutor y puede «dar fe» de su postura a la que califica de «soberbia». Sin embargo, a lo que realmente alude el enunciado no es a la «postura» en cuanto a posición física, por ejemplo -y Cortázar seguramente la describiría con más talento- poner las manos en la cintura, echar levemente la cabeza hacia un lado orientando el mentón hacia arriba para hacer finalmente un gesto con la boca. A lo que realmente se refiere el locutor de (7) es a la actitud de su interlocutor que no necesariamente tiene por qué manifestarse en el plano físico.

4. Por otra parte, este es el origen de muchos errores y malentendidos que suelen propagarse en los distintos ámbitos de la vida, cuando los hablantes no exigen ninguna verificación sobre ellos. En nuestra vida de relación, por ejemplo, sucede cuando conocemos a alguien de quien nos han hablado muy mal y al tiempo de tratarlo nos damos cuenta de que nada de lo dicho se corresponde con la realidad. En el ámbito académico, sucede cuando los alumnos (y no solo ellos) repiten los apuntes de los profesores sin acudir a las fuentes, exponiéndose a tergiversar teorías o a incorporar errores insalvables. 


\section{MENTIRA Y MALENTENDIDO INTERCULTURAL}

La cortesía no es un fenómeno universal sino culturalmente específico, puesto que cada cultura cuenta con diferentes sets de conocimientos para las relaciones sociales, eventos y situaciones. Imaginemos el siguiente diálogo. A es de origen alemán y $\mathrm{B}$ es argentino. Se han conocido hace relativamente poco tiempo y, luego de tomar un café juntos, se despiden de la siguiente manera:

(8) A (alemán): La pasé muy bien. Hasta pronto.

B (argentino): Chau. Te llamo.

Luego de este diálogo, el hablante A espera el llamado de B durante los siguientes días y como esto no sucede, interpreta el enunciado como una promesa incumplida y siente que su amigo le ha mentido. De hecho, enunciados del tipo Te llamo, Nos vemos en el dialecto del español rioplatense no significan que el llamado se vaya a producir en breve o que los hablantes tengan que verse efectivamente; se trata en realidad de fórmulas convencionales de cortesía habituales entre los porteños. La cortesía se entiende, entonces (Escandell Vidal, 1996), como la interacción entre variadas formas lingüísticas, significados sociales, estrategias interaccionales y expectativas sobre comportamientos verbales y no verbales. El malentendido intercultural de (8) se produce porque el hablante alemán desconoce el set de conocimientos específicos para las relaciones sociales, eventos y situaciones que rigen para la cultura del emisor. El hablante A malinterpreta una emisión clave en la situación de despedida y entonces selecciona un frame $e^{5}$ incorrecto que deriva en lo que metafóricamente resulta «la actuación de diferentes escenas».

Pero veamos ahora con un ejemplo artificial, en el que señalamos puntos extremos, cómo se relaciona la cortesía con el caso del verbo encontrar evidencial. Supongamos para ello que cumplo años y recibo regalos de todo tipo: libros, ropa, adornos. Pero hay un obsequio que encuentro particularmente horrible: es una cartera del llamado «cuero ecológico», un eufemismo del marketing contemporáneo para disimular el más ordinario de los plásticos.

5. El contexto (Sperber y Wilson, 1994) es un mecanismo cognitivo interno que permite clasificar una emisión como cortés o no, independientemente del contexto real, puesto que el proceso de comprensión discursiva se basa en la capacidad de relacionar las representaciones transmitidas por las emisiones, con una secuencia estereotipada de acciones, eventos y experiencias, es decir, con un frame específico. De este modo, el contexto no es algo externo y dado, sino interno y seleccionado en el momento de la interpretación, lo que permite evaluar una emisión como cortés o no, independientemente de la situación real en la que haya sido emitida. 
El set de conocimientos corteses presupuestos para la situación de agradecimiento señala que el hablante debe abrir el regalo, destacar sus virtudes en forma pública y ponérselo o exponerlo, de acuerdo con el tipo de obsequio en cuestión. Es por ello, que entre otras muchas opciones el hablante podría enunciar (9):

(9) ¡Uy! ¡Qué buena que está! En serio, la encuentro espectacular. Muchas gracias.

En (9) el locutor elige asimilarse a un punto de vista asertivo que no deja lugar para interpretar que el regalo ha sido mal recibido, sino todo lo contrario, que le ha gustado mucho. Así, el locutor tiene ante sus ojos -y ante la vista de todos- las pruebas que sustentan su evaluación. Pero sucede que en realidad la cartera es tan ordinaria que si efectivamente el hablante enunciara (9), incurriría desde el punto de vista representativo de la lengua en una mentira, en tanto el enunciado describiría un estado de cosas contrario al estado intencional. Podría elegir entonces (10) y decir:

(10) Mmmm... Está buena, pero es un poco grande... y marrón ya tengo... Mirá, la verdad es que la encuentro poco ponible. Mejor la cambio.

Si el hablante enunciara (10) sería veraz, pero a cambio de la sinceridad, incurriría en un comportamiento descortés. De hecho, (9) habilita discursos del tipo Por lo tanto voy a usarla, mientras que (10) orienta hacia No la usaré.

Pero supongamos que la persona que ha recibido la cartera pertenece a otra cultura (la oriental, por ejemplo, donde incluso el que obsequia debe minimizar la importancia de su regalo) y no hace ningún comentario sobre el objeto en cuestión, es decir no enuncia ningún tipo de juicio de valor.

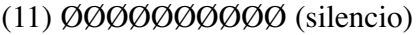

No hay duda de que su reticencia sería percibida como anómala en el contexto del agradecimiento ya que, como señalé anteriormente, el frame específico para el agradecimiento de regalos en situación informal en Buenos Aires orienta hacia la realización de un juicio personal ante el obsequio ofrecido y, en el caso de que se trate de una prenda, incluso hacia su exposición pública o su prueba. Si algunos de estos comportamientos previstos no se llevan a cabo es porque probablemente existe alguna razón para que el hablante se desvíe de las expectativas usuales o bien porque desconoce el frame específico para dicha situación. Y si esto sucede, el interlocutor estará entonces habilitado para inferir algo distinto de lo frecuente: para la situación de agradecimiento, por ejemplo, que su regalo no ha sido bien recibido. 


\section{CONCLUSIONES}

En el presente trabajo he intentado demostrar el modo en que se interrelacionan los parámetros entre mentira y cortesía sobre el supuesto de que el modo en que el locutor ha adquirido la información condiciona el grado de asertividad de sus enunciados. Para ello, me he detenido en el comportamiento del evidencial encontrar que, en tanto marcador de acceso sensorial directo, resulta un recurso válido mediante el cual el locutor puede mostrarse sincero. Sin embargo, tal como he señalado a lo largo de esta ponencia, los hablantes actúan en sociedad de acuerdo con el modo en que han representado interiormente el contexto social. Pero como las relaciones interpersonales también se asocian a un set de conocimiento específico, que guía las expectativas sobre el modo en que el locutor interactúa con el oyente en diversas situaciones, cualquier comportamiento que se desvíe de lo esperado puede ser malinterpretado. De allí que en la situación de despedida planteada más arriba, el hablante haya intentado, al decir Te llamo, ser sincero y cortés, pero su enunciado haya sido malinterpretado por un interlocutor ajeno a su cultura como una mentira o, al menos, como una promesa no cumplida, es decir, como una descortesía. Del mismo modo, en el segundo ejemplo -la situación de agradecimiento- el hablante extranjero se ha mostrado reticente no porque intentara ser insincero ni descortés.

Pero ¿qué sucedería en esta situación con un hablante perteneciente a nuestro medio? Es probable que se hallara en la siguiente encrucijada: utilizar un evidencial sensorial para ser cortés como en (9) pero incurrir en una mentira (en caso de no gustarle el obsequio), o decir la verdad, también con el mismo recurso evidencial -como en (10)- y ser descortés. Si en cambio, guardara silencio para no mentir o tener que manifestar abiertamente que la cartera no le gusta, su reticencia sería percibida no solo como una descortesía, sino como un juicio negativo equivalente a haber proferido efectivamente un enunciado del tipo: «Mirá, mucho no me gusta. Para ser sincero, la encuentro espantosa».

Entonces ante esta encrucijada y para evitar ser malinterpretado, quizás lo mejor sea hacer prevalecer la cortesía y seguir el consejo del aeda ciego, para quien las evidencias visuales resultaban por fuerza poco importantes: porque por algo Borges escribe en Fragmentos de un Evangelio apócrifo (Elogio de la sombra, 1969): «No exageres el culto de la verdad; no ha un hombre que al cabo de un día, no haya mentido con razón muchas veces». 


\section{REFERENCIAS BIBLIOGRÁFICAS}

Borges, J. L. (1974): Obras completas. 1923-1972, Buenos Aires, Emecé editores. Ducrot, O. et al. (1980): Les mots du discours, París, Les editions de Minuit. - (1984): El decir y lo dicho: polifonía de la enunciación, Barcelona, Paidós. EsCANDELL VIDAL, V. (1996): «Towards a cognitive approach to politeness», en Jaszczolt, K. y K. Turner (eds.) (1996): Contrastive Semantics and Pragmatics (Vol. II: Discourse Strategies), Oxford, Pergamon, 629-650.

Grice, H. P. (1985): «Logic and conversation», en Cole, P. y J. L. Morgan (eds.) (1985): Syntax and Semantics: Volume 3. Speech Acts, Nueva York, Academic Press, 41-58.

HAVERKATE, H. (1984): «La sinceridad del hablante retórico: una investigación pragmalingüística», en GARRIDO Gallardo, M. A. (ed.) (1984): Teoría semiótica, lenguajes y textos hispánicos, Madrid, CSIC, 261-267.

SeArle, J. (1983): Actos de habla, Madrid, Cátedra.

SPERBER, D. y D. WILSON (1994): La relevancia. Comunicación y procesos cognitivos, Madrid, Visor. 


\title{
LA CONFIGURACIÓN \\ DE LA IMAGEN PÚBLICA: \\ ACTIVIDADES DE IMAGEN \\ EN LA ENTREVISTA POLÍTICA
}

\author{
Ma Elena Gómez SánChez \\ Universidad Europea de Madrid
}

\section{INTRODUCCIÓN}

$\mathbf{E}$ L objetivo de este trabajo es poner de relieve algunas actividades de ima-

gen presentes en distintas entrevistas políticas publicadas en la prensa española e hispanoamericana. En este tipo de entrevistas, las actividades de cortesía o descortesía directamente dirigidas a un interlocutor (en este caso, el entrevistador) son más bien escasas, sobre todo si las comparamos con las actividades de autoimagen realizadas (entendiendo tales actividades de autoimagen como aquellas que tienen una repercusión -positiva o negativa- sobre la imagen del hablante, pero que no tienen un efecto sobre la imagen del interlocutor. Cfr. Haverkate, 2001; Hernández Flores, 2006). ${ }^{1}$ Sin embargo, y aunque en el momento de realizar la entrevista el locutor «ciudadanía» no esté presente, esto no significa que el político olvide que es precisamente a los ciudadanos a quienes se dirige y que, por tanto, debe aparecer ante ellos con la imagen pública que considere más oportuna. Así pues, desde nuestro punto de vista, la ausencia «física» del alocutor/interlocutor «ciudadano» (o del alocutor/interlocutor «otro representante político», por señalar otro ejemplo posible) no implica la inexistencia de estrategias de cortesía y descortesía dirigidas a esos destinatarios «no visibles», sino que, en nuestra opinión, tales estrategias aparecen integradas dentro de las actividades de autoimagen que los entrevistados llevan a cabo. Dicho de otro modo, lo cortés y lo descortés se hace presente en las respuestas de los políticos entrevistados al hablar de las medidas propuestas o desarrolladas por su partido, de sus apoyos y oponentes, de su percepción de la ciudadanía, etc. Por tanto, con este trabajo pretendemos mostrar la relevancia que tales manifestaciones de cortesía y descortesía (no dirigidas directamente al interlocutor, sino referidas a terceros

1. Para Chen (2001: 88), la autocortesía se refiere a los casos «en los que la necesidad de proteger y reforzar la propia imagen influye en lo que se dice y la forma en que se dice» [trad. nues- 
y subyacentes en las respuestas ofrecidas) tienen en la configuración del discurso político.

El corpus con el que trabajamos está formado por varias entrevistas realizadas a altos representantes políticos españoles e hispanoamericanos del momento actual. ${ }^{2}$ Por razones de espacio, en este trabajo tan solo vamos a utilizar dos de esas entrevistas, y vamos a centrarnos exclusivamente en los siguientes aspectos:

a) actividades claramente identificadas como descorteses y dirigidas al interlocutor.

b) actividades de autoimagen llevadas a cabo por el entrevistado en las que, en nuestra opinión, también se hacen patentes muestras de descortesía, aunque dirigidas a terceros, y análisis del modo en que esta forma de actuar contribuye a configurar el discurso político del entrevistado.

Las conclusiones que obtengamos nos permitirán poner de manifiesto cómo estas actividades ayudan a definir la imagen pública de algunos representantes de la vida política actual.

\section{LA CONSTRUCCIÓN LINGÜÍSTICA DE LA IMAGEN EN LA ACTIVIDAD POLÍTICA}

En la prensa, la publicación de entrevistas de carácter político es algo habitual. Para Albaladejo (1999: 391), «políticos, ciudadanos cuya actividad propia no es la política y periodistas [...] coinciden en la finalidad de influir en los lectores a propósito de decisiones o de actitudes futuras que vayan a adoptar éstos en relación con asuntos de índole política». En la misma línea incide Mellizo (1990: 136), quien señala:

El líder no habla por hablar. Está buscando partidarios. [...] Por eso intenta poner en todo cuanto dice un poco de emoción, de sabiduría o de habilidad. Llega un momento, entonces, en que ya ni importa el sentido verdadero de los vocablos, sino su efecto acústico, su capacidad de producir impactos psicológicos sobre los oyentes, su energía para suscitar rayos polémicos y su sutileza para arbitrar disculpas. ${ }^{3}$

2. Este trabajo se enmarca dentro de un estudio más amplio sobre cortesía en la prensa española e hispanoamericana y forma parte del proyecto de investigación Norma, discurso y español «panhispánico» en los medios de comunicación, dirigido por la Dra. Ana M. ${ }^{a}$ Vigara Tauste (UCM), y cuya referencia es HUM2005-00956/FILO (Plan Nacional de I+D+I).

3. Por otra parte, conviene tener presente que esta «búsqueda de eco», por parte de los emisores políticos, en los oyentes o lectores puede hacerse de modo que el compromiso real del emisor con respecto a aquello que dice sea solo relativo, recurriendo, para ello, a términos generales y vaguedades ( $c f r$. Chanell, 1994: 34-38). 
También Pérez (2003: 15) hace hincapié en este aspecto cuando indica, como una de las intenciones del discurso político, la de «su esfuerzo por hacer comprensibles conceptos complejos e incomprensibles conceptos sencillos», que explica del siguiente modo:

En el primer caso, se busca acercar a las entendederas populares la jerga técnico-política cuando esta expresa algo provechoso para los intereses del partido implicado, y este esfuerzo es loable. En caso contrario, cuando la realidad no conviene ser conocida, se recurre al circunloquio, la impenetrable expresión y el lenguaje críptico. ${ }^{4}$

No muy diferente es la opinión de López y Santiago (2000: 91):

El discurso político es un acto de habla pragmático, interactivo, movido por el afán de poder, que aprovecha al máximo la fuerza del lenguaje y todas las circunstancias que se dan en el acto de habla, tanto las lingüísticas como las paralingüísticas y las extralingüísticas. Es un acto de habla en el que el hablante y los oyentes comparten el contexto de una manera muy especial y bien definida, por cuanto que el primero aspira al poder de la gobernación de los segundos y éstos, por su parte, son los jueces que con su voto ratifican el cumplimiento de las aspiraciones del orador.

En el caso de las entrevistas políticas que se publican en la prensa, hay que tener en cuenta, además, que si bien la dinámica del propio acto comunicativo requiere cierta improvisación por parte del entrevistado (pues debe contestar a las preguntas en un tiempo «razonable»), también le permite cierto margen para la reflexión y la selección de los términos que considere más adecuados a sus propósitos.

\section{ACTIVIDADES DE IMAGEN EN LA ENTREVISTA POLÍTICA. AUTOIMAGEN Y DESCORTESÍA}

Como hemos señalado en la introducción, es raro encontrar en las entrevistas realizadas a dirigentes políticos claras muestras de cortesía o descortesía

4. Evidentemente, la claridad puede relacionarse con una de las máximas de cooperación de Grice, la de modalidad (también llamada de manera o perspicuidad), que incluye el hablar evitando la oscuridad y la ambigüedad. Como señala Alvar (1991: 36): «La oscuridad indiscriminada no permite la comprensión; la oscuridad impresa crea la ambigüedad. Si en cualquier tipo de lenguaje son defectos inadmisibles, mucho más debieran serlo para quienes deben granjearse la benevolencia de quienes los escuchan. Para facilitar las cosas, en latín llamaban a esto perspicuitas». 
dirigidas directamente al interlocutor, esto es, al periodista. Es obvio que entrevistador y entrevistado desempeñan distintos roles y que no se encuentran en un mismo plano social, por lo que no es esperable encontrar muestras de solidaridad (o, por el contrario, de descortesía) que sí resultarían posibles (y, por tanto, no especialmente marcadas) en el caso de interlocutores que pertenecieran a un mismo grupo social o que estuvieran unidos por lazos (profesión, edad, familiaridad, etc.) que les confirieran unos rasgos de identidad a partir de los cuales establecer un intercambio comunicativo entre iguales. Por ello, en el caso de la entrevista periodística (teniendo en cuenta los roles establecidos y el peso que la distancia social puede tener para la selección de enunciados corteses o descorteses por parte de los interlocutores), las muestras de cortesía o descortesía (especialmente estas últimas) que se apartan de lo esperado resultan especialmente llamativas. Podemos ejemplificarlo con los intercambios siguientes, tomados de una entrevista de M. ${ }^{a}$ Antonia Iglesias al político español Manuel Fraga y publicada en El País Semanal el 30 de abril de 2006:

TABLA 1

\begin{tabular}{|c|c|c|}
\hline Ejemplo & Actividad descortés & Actividad de autoimagen \\
\hline $\begin{array}{l}M .^{a} A . I .: \text { Siempre me he } \\
\text { preguntado [...] si nunca } \\
\text { tuvo un sentimiento de } \\
\text { repugnancia, de duda de } \\
\text { conciencia, de tentación de } \\
\text { no permanecer en aquella } \\
\text { complicidad con la dicta- } \\
\text { dora franquista. } \\
M . F .: \text {;Yo lo de mi compli- } \\
\text { cidad con la dictadura no se } \\
\text { lo voy a consentir de nin- } \\
\text { guna manera! }\end{array}$ & $\begin{array}{l}\text { Asunción de que el entre- } \\
\text { vistado colaboró con la } \\
\text { dictadura. } \\
\text { Prohibir al interlocutor } \\
\text { pensar o decir algo, coar- } \\
\text { tando así su libertad de } \\
\text { acción. }\end{array}$ & $\begin{array}{l}\text { Defenderse de una grave } \\
\text { acusación. }\end{array}$ \\
\hline $\begin{array}{l}M .^{a} A . I .: \text { Pero su carácter, } \\
\text { señor Fraga... ¡Cuánto le } \\
\text { han perjudicado a usted } \\
\text { sus prontos, sus reacciones } \\
\text { airadas, ese inapelable «no } \\
\text { tengo nada más que decir» } \\
\text { que ha dejado a tanta } \\
\text { gente petrificada. [...] }\end{array}$ & $\begin{array}{l}\text { Insinuación de mal carác- } \\
\text { ter. }\end{array}$ & \\
\hline
\end{tabular}




\begin{tabular}{|c|c|c|}
\hline Ejemplo & Actividad descortés & Actividad de autoimagen \\
\hline 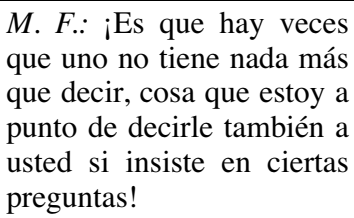 & $\begin{array}{l}\text { Negarse a cooperar en el } \\
\text { avance de la conversación, } \\
\text { con amenaza al interlocu- } \\
\text { tor de pasar a comportarse } \\
\text { de ese modo. }\end{array}$ & $\begin{array}{l}\text { Justificación de por qué se } \\
\text { actúa así. }\end{array}$ \\
\hline $\begin{array}{l}M .^{a} A . \text { I.: Pienso que sería } \\
\text { cicatero, y un tanto misera- } \\
\text { ble, no reconocer que usted } \\
\text { situó a Galicia en el mapa, } \\
\text { que siempre habrá un antes } \\
\text { y un después de Fraga y } \\
\text { que los gallegos se lo } \\
\text { deben. Pero usted cometió } \\
\text { un error que... } \\
M . F . \text { Errores habré come- } \\
\text { tido muchos, como todo ser } \\
\text { humano. Pero no sé en cuál } \\
\text { ha preferido fijarse usted, } \\
\text { que a veces parece usted un } \\
\text { fiscal y no una periodista. }\end{array}$ & $\begin{array}{l}\text { Previo reconocimiento a la } \\
\text { imagen del entrevistado } \\
\text { (actividad de cortesía), hay } \\
\text { un comienzo de acusación } \\
\text { de haberse equivocado en } \\
\text { algún aspecto concreto. }\end{array}$ & $\begin{array}{l}\text { Admitir la «no infalibili- } \\
\text { dad» de sus actuaciones. }\end{array}$ \\
\hline
\end{tabular}

Encontrar respuestas que, como estas, tengan un carácter descortés tan marcado no es en absoluto habitual, por lo que creemos oportuno analizarlas un poco más pormenorizadamente. En primer lugar, cabe decir que esas muestras de descortesía responden a ciertas «provocaciones» por parte de la entrevistadora (acusación de complicidad con la dictadura, de difícil carácter, de comisión de errores) que se constituyen en ataques a la imagen del entrevistado (o, al menos, así lo percibe él). Al margen de que la periodista se exceda o no en su papel de entrevistadora al incluir en las preguntas sus propios comentarios, no cabe duda de que este hecho incomoda a su entrevistado, que llega a sentirse «fiscalizado» (esto es, acusado y, por tanto, atacado en su imagen). En segundo lugar, cabe señalar que tales respuestas descorteses se enmarcan en la construcción de los rasgos que el entrevistado quiere poner de manifiesto acerca de sí mismo: de una parte, defenderse de una acusación de complicidad con la dictadura franquista; de otra, justificar reacciones previas (muy comentadas y discutidas) propias de un mal carácter y que pueden suponer una pérdida de imagen (y que son exactamente iguales a la que en ese momento está teniendo) y, por último, admitir la comisión de errores, «como todo ser humano», en lo que supone una actividad de autoimagen, con la que el político quiere indicar que no se considera ningún ser excepcional. 
En su análisis del lenguaje político, Chilton y Schäffner (2000: 310-311) señalan lo siguiente:

[...] por un lado, está el conjunto de relaciones entre el emisor, el destinatario y los terceros que escuchan u observan; y, por el otro, está el conjunto de actores políticos pertenecientes al universo político del hablante y las relaciones existentes entre ellos, a los que este hace referencia o presupone, aunque no se dirija necesariamente a ellos. Estas relaciones se encuentran nítidamente mediadas por pronombres, que dibujan un «espacio» político o social en donde las personas y los grupos ocupan una «posición».

En la segunda de las entrevistas que vamos a presentar aquí, la realizada al ex ministro de economía argentino Roberto Lavagna el 2 de junio de 2006 y publicada en la versión electrónica del diario La Nación, la descortesía no se dirige al entrevistador, aunque este sí es el destinatario de dos preguntas de carácter retórico (de las que nos ocupamos a continuación) que el político «devuelve» y que también forman parte de las actividades de autoimagen realizadas por el entrevistado:

- ¿Usted se considera opositor?

- Por supuesto que no. ¿Por qué debería serlo?

De la respuesta se deduce que adjudicarse el rol de opositor se consideraría negativo, por lo que se rechaza de forma enfática y, además, se vuelve la pregunta contra el periodista. Ahora bien, en tanto que realmente no se espera que este responda, se trata más bien de una acusación velada (es decir, «si usted cree que soy un opositor, tendrá que darme una justificación de por qué piensa así»). La diferencia de posición social y de roles jugados a la que antes hemos hecho referencia hace que en una entrevista «al uso» no sea el periodista quien responda cuestiones, por lo que en realidad podríamos considerar tal respuesta como un acto de defensa de la imagen por parte de Lavagna. Igual sucede en el siguiente ejemplo:

- Pero usted sabía la lectura política que se le iba a dar a la reunión.

- Sí, pero, ¿por qué nos tiene que llamar la atención en una sociedad plural, en la que uno habla con todo el mundo que está dentro del sistema democrático?

En este caso, al margen de la pregunta retórica (y al igual que sucede en otros momentos de la entrevista, como posteriormente analizaremos), encontramos un uso irónico del pronombre de primera persona (nos), pues lo que da a entender el entrevistado es precisamente que a él no le llama en absoluto su 
atención su propio comportamiento, y que lo que le sorprende (independientemente de la «sinceridad» que haya en tal sorpresa) es que sí resulte curioso para otros.

Más allá de estas muestras de «inversión» (ficticia) de roles, vamos a analizar pormenorizadamente a continuación cómo el recurso a estrategias corteses y/o descorteses sirve para configurar la imagen que el político quiere dar de sí mismo, y cómo lo va a hacer, precisamente, por contraposición a otros políticos. En el diálogo, el ex ministro está visiblemente molesto (y así lo hace notar el periodista en la introducción a la entrevista) con las críticas que en días anteriores se han vertido hacia él desde el Gobierno. En la entrevista, Lavagna pone de manifiesto que las críticas que está recibiendo no son una manifestación de lo que sería comportamiento verbal políticamente correcto (en el sentido que Watts (2003) da a esta expresión) ${ }^{5}$ y, por tanto, esperable: «no, porque es equivocada la idea de que son críticas desde la oposición». El ex ministro se defiende de esas críticas y no pretende suavizar el conflicto, sino reforzar su punto de vista, mediante las siguientes actividades de imagen y recursos lingüísticos:

TABLA 2

\begin{tabular}{|c|c|c|c|c|}
\hline Declaración & $\begin{array}{l}\text { Actividad de } \\
\text { autoimagen }\end{array}$ & $\begin{array}{c}\text { Actividad de } \\
\text { descortesía } \\
\text { implícita en lo } \\
\text { manifestado }\end{array}$ & $\begin{array}{c}\text { Recursos } \\
\text { lingüísticos }\end{array}$ & $\begin{array}{l}\text { Qué podría } \\
\text { inferir la } \\
\text { audiencia }\end{array}$ \\
\hline $\begin{array}{l}\text { «Todo esto me } \\
\text { parece bastante } \\
\text { lamentable. Yo } \\
\text { creí, en serio, } \\
\text { como dijo el } \\
\text { Presidente, que } \\
\text { éramos } \\
\text { plurales, pero } \\
\text { ahora parece } \\
\text { que tan } \\
\text { plurales no } \\
\text { somos». }\end{array}$ & $\begin{array}{l}\text { Se presenta } \\
\text { como una } \\
\text { persona que } \\
\text { confía en los } \\
\text { demás y que } \\
\text { cree lo que le } \\
\text { dicen. La } \\
\text { actividad se } \\
\text { repite más } \\
\text { adelante: «Esto } \\
\text { es una muestra } \\
\text { en contra, } \\
\text { evidentemente, } \\
\text { pero sigo } \\
\text { creyendo». }\end{array}$ & $\begin{array}{l}\text { Acusaciones } \\
\text { veladas (contra } \\
\text { personas que el } \\
\text { entrevistado no } \\
\text { identifica) de } \\
\text { falta de } \\
\text { independencia } \\
\text { política. }\end{array}$ & $\begin{array}{l}\text { - Predicado } \\
\text { doxástico: «yo } \\
\text { creí». } \\
\text { - Intensificador: } \\
\text { «en serio». } \\
\text { - Uso irónico } \\
\text { de la } 1^{a} \text { persona } \\
\text { de plural: } \\
\text { «parece que tan } \\
\text { plurales no } \\
\text { somos». }\end{array}$ & $\begin{array}{l}\text { «Me siento } \\
\text { engañado. } \\
\text { (Ellos) no son } \\
\text { plurales ni } \\
\text { permiten voces } \\
\text { diferentes». }\end{array}$ \\
\hline
\end{tabular}

5. Para Watts (2003: 19), el comportamiento político (politic behaviour) es el comportamiento «lingüístico y no lingüístico, que los participantes consideran apropiado para la interacción social que se lleva a cabo» [trad. nuestra]. 


\begin{tabular}{|c|c|c|c|c|}
\hline Declaración & $\begin{array}{l}\text { Actividad de } \\
\text { autoimagen }\end{array}$ & $\begin{array}{c}\text { Actividad de } \\
\text { descortesía } \\
\text { implícita en lo } \\
\text { manifestado }\end{array}$ & $\begin{array}{c}\text { Recursos } \\
\text { lingüísticos }\end{array}$ & $\begin{array}{l}\text { Qué podría } \\
\text { inferir la } \\
\text { audiencia }\end{array}$ \\
\hline $\begin{array}{l}\text { «Y también me } \\
\text { parece } \\
\text { lamentable que } \\
\text { aparezca para } \\
\text { criticarme toda } \\
\text { una comparsa, } \\
\text { simultáneamen- } \\
\text { te, reúne a la } \\
\text { Biblia y al } \\
\text { calefón». }\end{array}$ & $\begin{array}{l}\text { Al mostrarse } \\
\text { atónito ante } \\
\text { una situación } \\
\text { que no tiene } \\
\text { lógica } \\
\text { implícitamente } \\
\text { se da a } \\
\text { entender que la } \\
\text { persona en } \\
\text { cuestión sí se } \\
\text { rige por } \\
\text { criterios } \\
\text { lógicos. }\end{array}$ & $\begin{array}{l}\text { Acusación a } \\
\text { sus oponentes } \\
\text { de comportarse } \\
\text { como } \\
\text { marionetas, sin } \\
\text { criterio en su } \\
\text { actuación. }\end{array}$ & \begin{tabular}{|l|} 
- Predicado \\
doxástico: «me \\
parece \\
lamentable \\
que...». \\
- Empleo de \\
términos \\
descalificadores: \\
«comparsa» \\
- Recurso a \\
frases hechas \\
que dan idea de \\
escaso \\
conocimiento \\
por parte de \\
quien actúa así: \\
«mezclar la \\
Biblia con el \\
calefón».
\end{tabular} & $\begin{array}{l}\text { «Sus críticas } \\
\text { no tienen } \\
\text { fundamento». }\end{array}$ \\
\hline $\begin{array}{l}\text { «Yo tengo mi } \\
\text { diagnóstico, } \\
\text { que traté de } \\
\text { marcar. Que } \\
\text { eso dé lugar a } \\
\text { esta reacción } \\
\text { en comparsa } \\
\text { me parece } \\
\text { lamentable. Es } \\
\text { querer imponer } \\
\text { un pensamiento } \\
\text { único. Y eso no } \\
\text { le va a hacer } \\
\text { bien a la } \\
\text { economía } \\
\text { argentina». }\end{array}$ & $\begin{array}{l}\text { - Imagen de } \\
\text { autonomía. } \\
\text { - Apelación a } \\
\text { un «bien } \\
\text { superior» (la } \\
\text { situación de la } \\
\text { economía } \\
\text { argentina) que, } \\
\text { se supone, } \\
\text { incumbe a } \\
\text { todos ellos, y } \\
\text { que, al } \\
\text { preocuparle, le } \\
\text { legitima para } \\
\text { opinar de } \\
\text { forma distinta. }\end{array}$ & \begin{tabular}{|l} 
Nueva \\
acusación de \\
«reacción en \\
comparsa», sin \\
criterio por \\
parte de sus \\
oponentes. \\
Acusación de \\
que quien \\
detenta el \\
poder rechaza \\
formas de \\
pensar distintas \\
de la oficial (lo \\
cual es \\
contrario a un \\
planteamiento \\
democrático).
\end{tabular} & \begin{tabular}{|l|} 
- Verbos \\
volitivos: «traté \\
de marcar». \\
-Despersonali- \\
zación en la \\
acusación más \\
grave («Es \\
querer imponer \\
un pensamiento \\
único»).
\end{tabular} & $\begin{array}{l}\text { «Aunque } \\
\text { puedan ser } \\
\text { acertadas, las } \\
\text { opiniones } \\
\text { distintas de la } \\
\text { oficial no son } \\
\text { bienvenidas». }\end{array}$ \\
\hline
\end{tabular}




\begin{tabular}{|c|c|c|c|c|}
\hline Declaración & $\begin{array}{l}\text { Actividad de } \\
\text { autoimagen }\end{array}$ & $\begin{array}{l}\text { Actividad de } \\
\text { descortesía } \\
\text { implícita en lo } \\
\text { manifestado }\end{array}$ & $\begin{array}{c}\text { Recursos } \\
\text { lingüísticos }\end{array}$ & $\begin{array}{l}\text { Qué podría } \\
\text { inferir la } \\
\text { audiencia }\end{array}$ \\
\hline $\begin{array}{l}\text { «Es como que } \\
\text { alguien tocó un } \\
\text { botón y salen } \\
\text { todos, como } \\
\text { digo, } \\
\text { mezclando la } \\
\text { Biblia con el } \\
\text { calefón». (La } \\
\text { imagen «como } \\
\text { que alguien } \\
\text { tocó un botón» } \\
\text { se repite tres } \\
\text { veces a lo } \\
\text { largo de la } \\
\text { entrevista). }\end{array}$ & $\begin{array}{l}\text { Al mostrar de } \\
\text { nuevo su falta } \\
\text { de } \\
\text { comprensión } \\
\text { ante una } \\
\text { reacción } \\
\text { ilógica, se } \\
\text { presenta a sí } \\
\text { mismo, por } \\
\text { contraste, } \\
\text { como alguien } \\
\text { que actúa } \\
\text { guiado por la } \\
\text { lógica. }\end{array}$ & $\begin{array}{l}\text { No piensan por } \\
\text { sí mismos. }\end{array}$ & $\begin{array}{l}\text { Metáfora y } \\
\text { frase hecha. }\end{array}$ & $\begin{array}{l}\text { «Las personas } \\
\text { lógicas, con } \\
\text { criterio, no } \\
\text { actuamos así». }\end{array}$ \\
\hline $\begin{array}{l}\text { «Ahora, acá } \\
\text { hay alguien } \\
\text { que emite un } \\
\text { mensaje y } \\
\text { alguien que lo } \\
\text { recibe. Si el } \\
\text { que lo recibe lo } \\
\text { decodifica mal, } \\
\text { yo no puedo } \\
\text { hacer nada». }\end{array}$ & $\begin{array}{l}\text { Exculpación de } \\
\text { las reacciones } \\
\text { que sus } \\
\text { declaraciones } \\
\text { han generado, } \\
\text { poniendo así su } \\
\text { imagen a salvo. }\end{array}$ & $\begin{array}{l}\text { Acusación de } \\
\text { error (debido a } \\
\text { deficiencias en } \\
\text { la } \\
\text { comprensión) } \\
\text { por parte de } \\
\text { quien recibe el } \\
\text { mensaje. }\end{array}$ & $\begin{array}{l}\text { En primer } \\
\text { lugar, un aserto } \\
\text { que presenta el } \\
\text { dato como algo } \\
\text { puramente } \\
\text { objetivo. En } \\
\text { segundo lugar, } \\
\text { una } \\
\text { condicional } \\
\text { que da idea de } \\
\text { irresolubilidad. }\end{array}$ & $\begin{array}{l}\text { «Yo no tengo } \\
\text { la culpa si } \\
\text { ellos, por falta } \\
\text { de inteligencia } \\
\text { o } \\
\text { conocimiento, } \\
\text { no entendieron } \\
\text { lo que quise } \\
\text { decir». }\end{array}$ \\
\hline $\begin{array}{l}\text { «[...] el } \\
\text { gobierno de } \\
\text { Venezuela hizo } \\
\text { un excelente } \\
\text { negocio con las } \\
\text { colocaciones de } \\
\text { la Argentina. A } \\
\text { la Argentina } \\
\text { también le vino } \\
\text { bien, pero } \\
\text { Venezuela no } \\
\text { nos regaló } \\
\text { nada, a ver si } \\
\text { creemos que } \\
\text { nos regaló } \\
\text { algo». }\end{array}$ & $\begin{array}{l}\text { Persona que } \\
\text { conoce los } \\
\text { asuntos en } \\
\text { profundidad, } \\
\text { que no se queda } \\
\text { en la superficie } \\
\text { y a la que no se } \\
\text { puede engañar } \\
\text { fácilmente. }\end{array}$ & $\begin{array}{l}\text { Minimiza y } \\
\text { ridiculiza la } \\
\text { capacidad de } \\
\text { análisis de los } \\
\text { otros } \\
\text { (fundamental- } \\
\text { mente, sus } \\
\text { opositores } \\
\text { políticos, pero } \\
\text { también la parte } \\
\text { de la audiencia } \\
\text { que les } \\
\text { creyera). }\end{array}$ & $\begin{array}{l}\text { - Concesión } \\
\text { inicial («a la } \\
\text { Argentina } \\
\text { también le vino } \\
\text { bien») seguida } \\
\text { de adversativa } \\
\text { (pero). } \\
\text { - Uso irónico } \\
\text { de la primera } \\
\text { persona del } \\
\text { plural. }\end{array}$ & $\begin{array}{l}\text { «No se crean } \\
\text { ustedes todo lo } \\
\text { que les han } \\
\text { contado, } \\
\text { háganme caso a } \\
\text { mí, que } \\
\text { conozco bien el } \\
\text { asunto». }\end{array}$ \\
\hline
\end{tabular}




\begin{tabular}{|c|c|c|c|c|}
\hline Declaración & $\begin{array}{l}\text { Actividad de } \\
\text { autoimagen }\end{array}$ & $\begin{array}{c}\text { Actividad de } \\
\text { descortesía } \\
\text { implícita en lo } \\
\text { manifestado }\end{array}$ & $\begin{array}{l}\text { Recursos } \\
\text { lingüísticos }\end{array}$ & $\begin{array}{l}\text { Qué podría } \\
\text { inferir la } \\
\text { audiencia }\end{array}$ \\
\hline $\begin{array}{l}\text { «Una sociedad } \\
\text { que funciona } \\
\text { sobre la base de } \\
\text { enojos funciona } \\
\text { mal. El que se } \\
\text { enoja, que se } \\
\text { enoje. Y eso } \\
\text { vale para } \\
\text { Kirchner, para } \\
\text { Lavagna, para } \\
\text { todos. Una } \\
\text { sociedad } \\
\text { civilizada no } \\
\text { funciona sobre } \\
\text { la base de } \\
\text { enojos». }\end{array}$ & $\begin{array}{l}\text { - No pretende } \\
\text { un tratamiento } \\
\text { especial, al } \\
\text { contrario, } \\
\text { quiere que la } \\
\text { audiencia le } \\
\text { juzgue con los } \\
\text { mismos } \\
\text { parámetros que } \\
\text { él utiliza para } \\
\text { los demás. } \\
\text { - Uso de } \\
\text { planteamientos } \\
\text { generalistas, } \\
\text { difíciles de } \\
\text { rebatir o poner } \\
\text { en duda, y que } \\
\text { buscan la } \\
\text { complicidad } \\
\text { con el lector. }\end{array}$ & \begin{tabular}{|l|} 
Acusación \\
indirecta de \\
actuar \\
impulsivamen- \\
te (lo que es \\
poco apropiado \\
para el rol de \\
político).
\end{tabular} & \begin{tabular}{|l|} 
Asertos, que \\
presentan los \\
hechos como \\
algo objetivo. \\
La referencia a \\
sí mismo en el \\
discurso \\
«objetivándose» \\
como si se \\
tratara de \\
«otro», de una \\
tercera \\
persona. \\
Curiosamente, \\
y a pesar de \\
esta estrategia \\
«distanciadora» \\
de sí mismo, \\
aquí sí que se \\
incluye \\
sinceramente \\
en el «grupo».
\end{tabular} & \begin{tabular}{|l}
$\ll$ El gobierno \\
debe actuar de \\
forma lógica, y \\
no movido por \\
impulsos. Por \\
tanto, no se \\
está \\
comportando \\
bien». \\
«(El propio) \\
Lavagna no \\
habla \\
exclusivamente \\
motivado por \\
un enfado, sino \\
que actúa de \\
acuerdo con un \\
criterio \\
racional».
\end{tabular} \\
\hline $\begin{array}{l}\text { (Per.) - «en } \\
\text { una entrevista } \\
\text { con Perfil, } \\
\text { analizó que el } \\
\text { Presidente se } \\
\text { cerró sobre su } \\
\text { grupo. Es eso } \\
\text { malo?» } \\
\text { - «Él cree que } \\
\text { no, yo creo que } \\
\text { sí. El sentido } \\
\text { común indica } \\
\text { que de una } \\
\text { provincia de } \\
\text { 200.000 } \\
\text { habitantes es } \\
\text { difícil que } \\
\text { salga toda la } \\
\text { materia gris } \\
\text { que necesita la } \\
\text { Argentina». }\end{array}$ & $\begin{array}{l}\text { - Imagen de } \\
\text { autonomía } \\
\text { frente a imagen } \\
\text { de afiliación } \\
\text { «irracional». } \\
\text { - Aunque cree } \\
\text { llevar razón } \\
\text { (apela al } \\
\text { «sentido } \\
\text { común») } \\
\text { admite (al } \\
\text { menos } \\
\text { aparentemente), } \\
\text { que haya } \\
\text { formas de } \\
\text { pensar distinta } \\
\text { a la suya. }\end{array}$ & \begin{tabular}{|l|} 
Acusación de \\
falta de sentido \\
común, pues el \\
hablante apela \\
a éste para \\
defender su \\
postura, \\
mientras que la \\
persona a la \\
que se refiere \\
opina lo \\
contrario.
\end{tabular} & \begin{tabular}{|l|} 
Ironía al \\
mostrar disenso \\
y al señalar (de \\
forma \\
eufemística) \\
criterios de \\
«cercanía»en \\
la selección de \\
altos cargos: \\
«El sentido \\
común indica \\
que de una \\
provincia de \\
200.000 \\
habitantes es \\
difícil que \\
salga toda la \\
materia gris \\
que necesita la \\
Argentina».
\end{tabular} & \begin{tabular}{|l|} 
«La selección \\
de los altos \\
cargos se debe \\
más a \\
cuestiones \\
personales que \\
a cuestiones de \\
valía \\
profesional».
\end{tabular} \\
\hline
\end{tabular}


Así pues, el análisis detallado de las respuestas de Lavagna nos permite poner de manifiesto cómo, a través de sus declaraciones, el ex ministro construye un discurso político en el que defiende su propia imagen y minusvalora a sus oponentes, pero sin necesidad de lanzarse «a tumba abierta» contra ellos. En lugar de ser abiertamente descortés con sus opositores o atacarles de forma descarnada, opta por una estrategia más refinada en la que (casi) todo se hace de forma velada, mediante el recurso a imágenes, condicionales, ironías, generalizaciones... y en la que, en otro orden de cosas, incluso salva (al menos, aparentemente) la imagen del presidente Kirchner en la primera de las ocasiones en las que se refiere expresamente a él. ${ }^{6}$

Además, al sacar a la luz lo que sería esperable que un lector atento dedujera de las palabras de Lavagna se pone de manifiesto la distancia entre lo que este realmente «dice» y lo que, de forma subyacente, «puede querer decir», y se revela cómo esa distancia queda cubierta precisamente por las estrategias que el ex ministro desarrolla para defender (y potenciar) su propia imagen y atacar y minusvalorar la actuación del Gobierno. ${ }^{7}$ En otras palabras, se muestra como la sutilidad e «indirección» (en algunos casos) empleadas, sin rebajar en modo alguno el grado de crítica, ayudan a defender la propia imagen quizá de forma más efectiva que si el entrevistado se enzarzara en una confrontación más abierta (por ejemplo, con acusaciones más personales) y que podría resultar más dañina también para su propia imagen. Con sus declaraciones, el ex ministro apela a la solidaridad y a la comprensión de los lectores, pero sin solicitarla de forma expresa. Al presentarse como una persona que cree a los demás (lo que, de algún modo, lleva implícita la idea de que es justo que, en correspondencia, también le crean a él) y mostrarse como un individuo que actúa con lógica, con criterios fundados y con independencia política (aspectos que, generalmente, son valorados positivamente por los ciudadanos), está dando de sí mismo una imagen sólida, fuerte, pero no agresiva (lo que podría, llevado al extremo, provocar el rechazo de la ciudadanía) que contrasta claramente con la imagen de «marionetas» que está ofreciendo de quienes le critican.

6. En la segunda ocasión, aunque la acusación velada sea la de actuar impulsivamente, lo que Lavagna dice es que se debe aplicar igual criterio a todos (Kirchner, él mismo, otros), de modo que, al situarse en el mismo plano, cabe decir -por segunda vez- que al menos aparentemente tampoco se puede considerar que el ex ministro se refiera al presidente de modo descortés.

7. Las estrategias de descortesía que hemos encontrado en nuestro análisis no son muy diferentes de las que Blas Arroyo (2001) señala para los debates cara a cara («asocia directamente al interlocutor con intenciones, hechos, etc. negativos, dile que miente, muéstrate despectivo, formula contrastes desventajosos para el interlocutor, acúsale de contradictorio»). La diferencia radica en que, como venimos diciendo, todo ello se dirige a un alocutor no presente en el momento de la enunciación. 


\section{CONCLUSIONES}

En este trabajo hemos estudiado dos tipos de actividades de imagen presentes en las entrevistas políticas publicadas en la prensa: las que el hablante realiza dirigidas a su propia imagen y las que tienen como destinatario un interlocutor (o alocutor) y están relacionadas con la descortesía. Nuestro propósito ha sido poner de manifiesto cómo, al margen de posibles actividades puntuales $-\mathrm{y}$, por ello, casi anecdóticas- de (des)cortesía que el entrevistado dirige al interlocutor/entrevistador, en las respuestas del político (en las que se tiene presente, como alocutor, a un destinatario muy variado -otros políticos, la ciudadanía en su conjunto-) se ponen en juego diversas estrategias (entre ellas, las de [des]cortesía) para, por un lado, «integrar» a dicho alocutor en su discurso y, por otro, contribuir significativamente -si bien no siempre explícitamente- a la elaboración de su propia imagen.

\section{REFERENCIAS BIBLIOGRÁFICAS}

Albaladejo, T. (1999): «El texto político de escritura periodística: la configuración retórica de su comunicación», en GARRIDO MEDINA, J. (ed.) (1999): La lengua y los medios de comunicación I. Actas del Congreso Internacional celebrado en la Universidad Complutense de Madrid en 1996, Madrid, Universidad Complutense de Madrid, 390-396.

Alvar, M. (1991): «Lenguaje político: el debate sobre el estado de la nación (1989)», Lingüística Española Actual, XIII/1: 5-46.

Blas ArRoyo, J. L. (2001): «"No diga chorradas...” La descortesía en el debate político cara a cara. Una aproximación pragma-variacionista», Oralia, 4: $9-45$.

Channell, J. (1994): Vague Language, Oxford, Oxford University.

CHEN, R. (2001): «Self-politeness: A proposal», Journal of Pragmatics, 33: 87-106.

Chilton, P. y C. SchäffNer (2000): «Discurso y Política», en VAn Dijk, T. A. (comp.) (2000): El discurso como interacción social. Estudios del discurso: introducción multidisciplinaria. Volumen 2 [1997], trad. José Ángel Álvarez et al., Barcelona, Gedisa, 297-329.

Haverkate, H. (2001): «Cortesía y descortesía en los diálogos del Quijote. Análisis de la representación de las imágenes positiva y negativa de los protagonistas», Oralia, 4: 129-148.

HERNÁNDEZ Flores, N. (2006): «Actividades de autoimagen, cortesía y descortesía: tipos de actividades de imagen en un debate televisivo», en BLAS Arroyo, J. L., M. Casanova y M. Velando (eds.) (2006): Discurso y 
sociedad. Contribuciones al estudio de la lengua en contexto social, Castellón, Universitat Jaume I, 637-648.

López Eire, A. y J. DE SANTIAGo Guervós (2000): Retórica y comunicación política, Madrid, Cátedra.

Mellizo, F. (1990): «Del lenguaje y la política», en García Domínguez, P. y A. Gómez Font (comps.) (1990): El idioma español en las agencias de prensa, Madrid, Fundación Germán Sánchez Ruipérez, 133-144.

PÉREZ GarCÍA, D. (2003): Técnicas de comunicación política. El lenguaje de los partidos, Madrid, Tecnos.

WatTs, R. J. (2003): Politeness, Cambridge, Cambridge University Press. 


\title{
LINGUISTIC GLOBALISATION: THE INFLUENCE OF ENGLISH ON NATIONAL IDENTITIES
}

\author{
Jolanta Kowalska ZaPaSeK \\ EOI Valencia
}

\section{$\mathbf{T}$} HE extension of multinational companies all over the world -backed mostly by the American and British economies-, along with the technological advances, have inevitably had a strong impact on social transformation, often referred to as globalisation and defined by Fairclough (2004: 380) as: 'restructuring of relations between the economic, political and social domains'. The term globalisation often provokes strong reactions, and it is either praised or feared, or even condemned, since along with new opportunities, sometimes it also brings undesirable change. Nevertheless, globalisation is not solely a factor present in the economy, it is a process that influences our lives in many aspects, including that of communication and language.

In this sense, the dominance of the English language and consequently, the British and American cultures -each time becoming more and more evident in the unified Europe-, suggests that language may have 'a more significant role in the current socio-cultural changes than it had in the past' (Fairclough \& Thomas, 2004: 385). Therefore, the main question of this research paper is to what extent is our language and national identity affected by the phenomenon called globalisation.

\section{INTRODUCTION}

Globalisation can be understood as 'an umbrella term for a complex series of economic, social, technological, cultural and political changes seen as increasing interdependence, integration and interaction between people and companies in disparate locations' (Wikipedia, 2006). The term globalisation is used to refer to these collective changes as a process, or else as the origin of turbulent change. The different uses comprise:

- Economically and socially positive: as an instrument of commerce; one which brings an increased standard of living to developing countries and additional wealth to First World and Third World countries. 
- Economically, socially, and ecologically negative: as an instrument of 'corporate imperialism'; one which steps on over the human rights of developing societies, claims to fetch prosperity, yet often merely amounts to plundering and exploiting. Negative effects include cultural integration via cultural imperialism, the export of artificial desires, and the destruction or inhibition of authentic local and global community, ecology and cultures.

While being a complex and many-sided range of phenomena, globalisation can be broken down into separate aspects: industrial, financial, informational and last but not least cultural, which refers to the growth of cross-cultural contacts. Nevertheless, the cultural aspect often boils down to cultural imperialism, i.e. the practice of promoting, distinguishing, separating, artificially injecting of the culture or language of one nation in another. It is usually the case that the former is a large, economically or militarily powerful nation and the latter is a smaller, less affluent one. Cultural imperialism can take the form of an active, formal policy or a common approach.

In this sense, the influence of Anglo-Saxon way of living on the rest of the world is more than evident in its omnipresent presence in the 21 st century. Then, the American culture is often despised and idolised by turns, precisely because of its all-pervasive strength that must have an impact on how its production is viewed abroad. The economic and technological dominance of the United States, the transmission of the culture, life style and behaviours of the Anglo-Saxon world through multiple channels reach all social classes, from literature to press, from television programmes to music, from advertising to fashion. Consequently, as the language used is an integral part of the cultural identity, English, as the prevailing language all over the world, has acquired a function of lingua franca.

\section{GLOBALISATION AND ADVERTISING}

Nowadays, the acceleration and growth of consumerism that has accompanied globalisation has led a number of theorists to argue that social life is becoming increasingly commodified, with many social objects and processes taking on new values and significances. In this sense, consumerisms embodies an attractive idea especially for modern people since sometimes they feel disoriented, unsatisfied with their job or unemployed altogether, and consequently they look for a new style and an identity that advertisers exploit and offer to them.

In other words, sometimes people suffer from an identity crisis and if advertisers can promise not only a good product but also an accompanying 
identity, then they represent a powerful strategy (Goatly, 2000). As Faigley suggests (1992: 12): «The desire to consume is predicated on the lack of a stable identity. Purchasing and using a consumer object is temporary and unstable attempt to occupy an imagined identity provoked by an image». There's a practice which suggests that by buying a product you are adopting a certain lifestyle. Thus, advertisements encourage consumption, appeal to value systems, and suggest that by buying a product people can solve their problem, choose their identities, acquire a lifestyle.

Being aware of that, international commercial companies try to conquer world-wide markets. It is enough to watch the satellite broadcast television channels for a day to see the same campaigns shown in several languages. In the same way, consulting various weekly or monthly editions of the same magazine enables you to come across the same translated advertisements again and again. However, initially, in order to preserve a balance between the significance of the brand and sensitivity to the culture of the consumers around the world, the authors of advertisements may try to adjust their message to the consumers they are targeting. This implies that a translation must be to some extent adapted to each country.

Depending on the country, the translation of the original message into the languages of the foreign consumers does not bring any change to the communication in terms of the brand image. That happens when the message is transmitted between two very similar culturally countries (e.g. western European countries). However, when there are more differences between two countries involved in this type of communication (at religious level, as far traditions, ethnic attitudes, the spirit of community, and purchasing habits, etc. are concerned), the cultural dimension offers other group of parameters determining the environment in which the translator of advertising operates.

In this sense, we may say that some aspects of culture can create a problem in international advertising. Yet, the very nature of advertising (its omnipresence, usually aggressive forms of reaching consumers, characterised by visual and audio attractiveness or appealing texts, and so forth), facilitates its constant conquer of what we understand by social aspects culture, be it of an ethnically similar country or of a totally different one. In this way, diverse cultural factors transmitted along with advertisements, slowly gain place in our society and eventually replace some of our old values.

\section{ADVERTISING AS A DISCOURSE TYPE}

As Dimter (1985) points out, there are hundreds of types of discourses divided and categorised by a society and it is part of a person's cultural 
competence to recognise them. Some discourses are lessons, other conversations, stories, letters or brochures, just to mention a few of them, and there are many ways of classifying them. For example, discourses can be categorised by text, function, participants, substance or by combination of these factors. What is important, however, is the fact that a given text type is directed to a specific discourse community and if it is to be recognised by the members of this community, it must possess certain characteristics. In this sense we can say that advertising is one of discourse types and among other things it is distinguished from other discourses by its function, i.e. it always persuades people to buy or do something, for example to give their support to some organisation.

Advertisements have flooded our everyday life and their ubiquitous presence has become a natural element in sight. We can find them in all places and in different forms, on the streets, in our places of work, in the radio, on television, in magazines, newspapers and so forth. While some of them have blended with our environment and we pay no attention to them, unless they are particularly funny or irritating, the others, such as the ones in the radio and on television normally do not let us indifferent.

Each type of advertisements have their forms of presentation -they are various combinations of image, music and language which are changing constantly- in order to catch our attention. Thus advertisements in paper form are usually texts, shorter or longer ones. They may be accompanied by pictures -shocking, because of their visual aspect (e.g. bursting images of, normally, young people full of life and happiness thanks to the product in question)- or lacking them (white, or black pages with only some text on them). In this type of advertisements sometimes the message is transmitted through text solely, being the images a decorative element, on other occasions, it is grounded on the mixture of images and text.

While some studies of advertising have concentrated on the influence it has on receivers or addressees within a society (Rotzoll, 1990; O'Barr, 1994; Fowles, 1996; Zeff and Aronson, 1999; Cannon, 2000), others have focused on the aspects of image and sound in advertising (Feliu, 1983; Patti \& Moriarty, 1990). Even so, advertisements represent a type of discourse that arises from new technologies and is responsible for new kinds of relationships between producer and receiver.

\section{ASPECTS OF ADVERTISEMENTS}

Advertising as a discourse type can be distinguished from other discourses by its function. Still, what has to be kept in mind is the fact that not all advertisements influence all receivers in the same way. Some of them having 
as a function to persuade a certain audience to buy something, may have different influence on another audience for which the product in question is absolutely irrelevant. Moreover, the understanding of a message depends not only on language, but on factors such as context, the mutual knowledge of producer and receiver, kind of society and situation, the medium, different types of communication evolved and their relationship to each other.

Consequently, describing advertising as a discourse then is a very complete and difficult task, since we have to take into account all the factors and the effects they cause on each other. In advertising the following elements interact with one another:

- Substance: the physical material that carries the text (as well as music and images).

- Paralanguage: behaviour that accompanies language and is meaningful, e.g. gestures, facial expressions, type of letters used, etc.

- Situation: the properties and relations of people and objects as perceived by participants.

- Co-text: text which precedes and follows the piece of text which is under analysis.

- Intertext: text that participants recognise as belonging to other discourse, but which is associated with the text analysed.

- Participants: described as senders, addressers, addressees and receivers with their knowledge, beliefs, attitudes and feelings.

- Functions: what is the role of the text concerning the senders or receivers.

- The already gained knowledge of thousands of earlier advertisements.

Senders or transmitters address their messages (here advertisements) to the receivers who normally belong to the same socio-cultural background. If that is not the case, the authors of advertisements try to adjust their message to the culture in question. While preparing a message, the following factors are taken into account (Cantó, 1993): education and traditions, values and attitudes, social organisation, economy, technology, politics, legal system, language and religion. The transmitters also base their textual competence on the previous advertisements, which turned out to be successful.

\section{METHODOLOGY}

We maintain our present study on the hypothesis that the discourse of advertising is based on a determined use of language which transmits a 
particular communicative target. The set of the features we expect to find in a text, can be regarded as special choices from among the options available in the discourse types which the text draws upon. Our approach is established on the co-occurrence of a number of linguistic features underlying functional dimensions. We assume that if a group of features consistently co-occur in a text, those features define the dimension. In addition, many authors have proposed a big number of distinctions, and that proves that there is no ideal pattern of text interpretation. Therefore, we are going to reduce the range of this analysis to a limited number of linguistic features.

Another aspect that is considered essential in the explanation of a text is context -understood as all properties of the social situation which are relevant to the production or reception of a discourse. Nevertheless, we must distinguish between local and global context. The first refers to the setting, participants and their communicative roles, intentions, and purposes. The latter being relevant to the participants recognised as members constituting a specific target audience. Subsequently, we have chosen the following parameters comprising the contextual and linguistic situation. As for the contextual situation, the aspects taken into account will be those of the tenor of discourse (participants), mode (channel) and field (topic).

\subsection{Participants}

The following factors should be necessarily included here:

1. Addressee: an individual, who is familiar with the Internet and related technology. Someone who looks for specific information on-line and is aware of the technological advances that his/her country has overcome. In spite of the gap, that may economically and culturally separate his/her country from another one, he/she has a positive attitude towards the foreign influence.

2. Addresser: who does not have to be only one individual, it is a group of people responsible for the creation of an advert in all its form (text, music, images, cultural connotations, translation (if required), etc.).

3. Audience: that is a group of people to whom the advertisement is not addressed directly, but still they might be influenced by it. This model is what Fairclough (1989: 62) calls «synthetic personalisation», that is treating a mass audience as though they were individual being directly addressed. When describing advertisements, Fairclough refers to «conversation of public discourse», meaning that ads are in general public discourses, so that they have a mass and an undetermined audience. 
All the participants are familiar with advertisements. Even if they are formally incapable of defining them, they realise that advertisements exist to sell, therefore the advertisements which are short -to save space, and omit direct appeal, what sometimes makes the advertisement more difficult to comprehend- are anyway recognised by the participants as advertisements.

\subsection{Channel}

The Internet is considered the channel of transmission of the messages, as for the mode, the choice is between image, music and language. However, since the object of this study are written advertisements, our primary concern will be the language.

\subsection{Message content}

1. Vocabulary: neologisms.

2. Grammar:

- Modes: imperative.

- Pronouns: you, we, I.

\subsection{Corpus}

For the purpose of this analysis we have chosen the advertisements from different web pages (in Polish and Spanish). ${ }^{1}$ We mainly took into account the written message, though we did not totally ignore other elements that mingle with the text -such as colours, images, and sounds-, in order to give the message a more persuasive form.

The thirty (in each language) samples analysed in this paper relate to the same product (e.g. airlines, jobs, IT technology, etc.) but are advertised in different languages.

\subsection{Analysis and findings}

\subsubsection{Polish advertisements}

5.5.1.1. The imperatives and pronoun 'you'

Polish airlines LOT

1. See the appendix. 
The main web page for LOT is very similar to any airline all over the world. On the top there's a map of the world and a plane that takes off from one destination to another. On the top left hand-side there is the company's logo, below it there's the scroll menu which takes you to: travel planning, customers programmes, information about LOT, contact details, customer programmes. The main body of the page is occupied with the flight details and the section to book a flight. Just below there is some important information related to before and after the flight, on board and at the airport. On the right-hand-side there are promotions and best offers.

Apart from the basic information, the page includes some extra elements linked to offers for businesses, news and miles and more programme. If you click on that icon, the text immediately appears in English (though the previous page was in Polish). There is no translation for miles and more title of the section. Probably, the authors of the page assume that the reader has travelled before and is well familiar with the term.

The motto of a new LOT advertising campaign is 'You're under our wing'. In this way, the campaign aims at remodelling the brand image and implementing the communications strategy: 'We follow requirements of our passenger'. The campaign was inspired by LOT logo which features a crane. In order to complete the platform, the crane was now joined by other nice birds. The related TV spot uses stop motion animation technique.

As for the text, what struck us was the use of the pronoun 'you'. On the one hand, there is 'you', formal, used in the same way as 'usted' in Spanish, e.g.:

1. Biorąc pod uwagę Państwa życzenia, oczekiwania i wymagania...' (Taking into account your wishes, expectations and demands; Teniendo en cuenta sus (de ustedes) deseos, expectativas y exigencias...).

2. 'Jeśli są Państwo zainteresowani umieszczeniem reklamy...' (If you are interested in posting an advert...; Si ustedes desean insertar un anuncio...).

On the other hand, in some texts the serious and traditional 'you' ('usted') pronoun was substituted by a straightforward 'you', informal, ('tú'), for example:

'Liczne korzyści dla Twojej firmy'. (Many advantages for your company; Muchas ventajas para tu empresa).

'Zapisz się do programu Miles \& More'. (Register in the Miles \& More programme; Apúntate en el programa Miles \& More).

'Zarejestruj się do promocji i zdobądź podwójne mile!' (Register and get double miles; Apúntate y recibe el doble de millas). ${ }^{2}$

2. The subject is not used with the imperatives. 
What is interesting here is the fact that in spite of the tendency towards clear-cut, informal forms ('tú' instead of 'usted'), the possessive adjective was written in block letters ('Twój'), and that's a plain indication of the propensity of maintaining the old, more traditional forms.

\subsubsection{Language 'blend', neologisms and other uses of English words in Polish}

Polish language cannot sustain its pure forms in the 20th and 21st centuries. It is a perfectly normal process if we take into account the fact that languages are in a steady contact, what naturally make them borrow from each other. Since Poland is a smaller, less affluent country, then it is more prone to foreign influences. Thus while reading text on Polish web pages we can come across sentences such as:

1. '...popularna w całym świecie sieć fast foodów McDonalds...' (popular all over the world McDonalds fast food net'...) - 'fast food' was not translated, though it was declined.

2. '...przełom w monitoringu audycji radiowych...' (...breakthrough in the monitoring of radio programmes).

3. 'Dodawanie providera do bazy danych hot spots'. (Adding data to the hot spots provider data base.).

4. 'Zamów newsa!' (Order a piece of news!).

5. 'Big tasty bekon' (Big tasty bacon); 'Dla najmlodszych happy meal' (Happy meal for the youngest ones), -these adverts come from the McDonalds's page and they are a blend of Polish and English words.

In some cases it is indispensable to use a foreign word which will gain a slightly Polish form (e.g. English: 'log in', Polish: 'logowanie'). That is a consequence of the fact that the new technologies products have over flooded the Polish market so quickly that it is impossible to keep up their pace linguistically. Nonetheless, now and again even when there is a perfect translation for a strange word, the tendency is to use an English one in order to sound more straightforward, less traditional, in short, 'cool'. This predisposition can be observed especially when it comes to IT products and everything what is related to the Internet, and that refers either to the adverts translated from a foreign producer or created by someone from the Polish market (see table 1).

1. Loan words from English, or formal neologisms that are installed in the language either because they are necessary, or because the word in English seems to 'sound better' (e.g. cash flow, joint venture). 
TABLE 1

\begin{tabular}{|l|c|c|c|c|}
\hline \multicolumn{5}{|c|}{ ENGLISH IN ADVERTISEMENTS } \\
\hline Out of 60 adverts altogether & Polish (30) & Spanish (30) & \% Polish & \%Spanish \\
\hline Neologisms (xenisms) 1 & 20 & 14 & 66 & 46 \\
\hline Calques & 23 & 15 & 76 & 50 \\
\hline English words mixed with... & 18 & 9 & 60 & 30 \\
\hline
\end{tabular}

However, when other products are promoted, sometimes the Polish advertisers are inclined to preserve more traditional values, such as picturesque images of Polish landscapes when advertising mineral water (<www.kazimierska.pl/ index.php?ID=578>), or places of interest, hotels, etc. Still, the creators of adverts take the advantage of the opportunities that the new technologies bid them to convey their message in a more modern and persuasive tone.

\subsubsection{Spanish advertisements}

\subsubsection{The neutral forms and pronoun 'you'}

\section{Spanish airlines Iberia}

The main web page for Iberia is comparable to other airline companies. On the top there is the company's logo, proudly flaunting the Spanish national colours in a form of a B blotted with a small crown. The main part of the page is occupied by offers, which have sort of in-your-face display and definitely more aggressive if we compare it with the LOT web page.

On the top left hand-side, there are flight details and the section to book a flight. Below it there's a scroll menu which takes you to more offers (hotels, rent a car, etc.) and below it there are icons with the reference to: travel planning, customers programmes, contact details, etc.

Compared to the Polish texts, Spanish ones usually decline the use of the pronoun 'usted' in favour of more straightforward pronoun 'you' ('tú'), they animate inanimate objects (e.g. hotels) or employ more neutral forms, such as passive sentences. For instance:

1. 'Ubicado en el corazón histórico del centro de la ciudad,' (Situated in the heart of the historic centre of the town,) - passive voice.

2. 'El Carlton Hotel pone especial atención para dar confort...' (The Carlton Hotel offers a special attention to give comfort...) - animation of the 'hotel'. 
3. 'El hotel ofrece tecnología moderna de última generación para asegurarte una estancia agradable.' (The hotel offers you the last generation modern technology to assure you a pleasant stay.) - animation of the 'hotel'.

4. 'Tus sueños de libertad hechos realidad, un acogedor espacio...' (Your dreams of freedom came true, a cosy place...).

5. '...guiarán tus pasos hacia las habitaciones...' (...will lead your steps to the rooms...).

6. 'Disfruta de tu estancia.' (Enjoy your stay.).

As for the neologisms used in Spanish texts, there were some examples, still, they were not as broadly exploited as in Polish (see Table 1). The situation was more evident as for the products related to mobiles, computer technology, etc. (e.g. 'roaming'; 'componentes wireless'; pack: navega y habla'; 'Internet Gateways and Sistemas de Control').

\section{CONCLUSIONS}

The purpose of this paper was to tackle the concept of globalisation, viewed through the advertisements as one of the discourse types. Our modest findings indicate that nowadays the influence of a powerful country such as the United States can be well observed in many aspects of our social life (job announcements, adverts of sales of different types of products, leisure time activities, etc.). That development is already having different consequences on the linguistic situation of different countries. The functional potential of a language is the result of historical processes concerning both, the language and socio-economic and cultural circumstances of its speech community. Nevertheless, the higher the level of communication between different countries the more visible changes can be observed in the less dominant cultures, even if there is still a humble desire on their part to preserve their own identity.

While this paper concentrates on some aspects of neologisms (false loans, xenisms) -that are a clear indicator of the presence of the English language in other languages-, it does not fully explore other consequences of the influence of one language on the other, such as: false friends and calques, which could be a subject of a further research study. Moreover, other characteristics of the language used in this type of discourse type, such as persuasive force of the vocabulary used, sentence form, etc., could also be a focus of an extra analysis. Besides, for the length limits, this paper does not sufficiently concentrate either on the characteristics of image or of sound used in advertisements, other very important elements, which undoubtedly, along with the vocabulary used, build up to a very powerful tool in the hands of the creators of advertising. 


\section{APPENDIX}

\section{Web pages consulted:}

$<$ http://www.buisness.pl>

$<$ http://www. franchising.info.pl $>$

$<\mathrm{http}: / /$ krapkowice.net>

$<$ http://hot.spots.pl/showspot.php>

$<$ http://manager.money.pl/artykul>

$<\mathrm{http}: / /$ www.ingbank.pl>

$<$ http://www.iberia.com/OneToOne/v3/home.do>

$<$ http://www.hotelesib.com/site/viajes $>$

$<$ http://www.lot.pl>

\section{REFERENCES}

AAvV (2006): Wikipedia. The Free Encyclopedia (<http://en.wikipedia.org/wiki>).

CANNON, J. (ed.) (2000): Advertising and Identity in Europe: the I of the Beholder, Bristol, Intellect.

CANTÓ, C. (1993): «Estandarización versus localización», MK, marketing y ventas, 66: 40-47.

DimTeR, M. (1985): «On Text Classification», in Dijk, T. A. van (ed.) (1985): Discourse and Literature, Oxford, Oxford University Press, 215-246.

FAIGLEY, L. (1992): Fragments of Rationality, University of Pittsburgh Press, Pittsburgh.

FAIRClough, N. (1989): Language and Power, London, Longman.

FAIrClough, N. and P. Thomas (2004): «The Globalisation of Discourse and the Discourse of Globalisation», in Grant D. et al. (eds.) (2004): The Sage Handbook of Organizational Discourse, London, Sage, 379-396.

Feliu García, E. (1983): «Publicidad y connotación: el mensaje de inferencia», Estudios de lingüística, 1: 113-125.

Fowles, J. (1996): Advertising and Popular Culture, Thousand Oaks (CA): Sage Publications.

GoAtLy, A. (2000): Critical reading and writing, London, Routledge.

O'BARr, W. (1994): Culture and the Ad: Exploring Otherness in the World of Advertising, Boulder (CO), Westview.

Patti, CH. and S. Moriarty (1990): The Making of Effective Advertising, Englewood Cliffs (NJ), Prentice Hall.

Rotzoll, K. B. (1990): Advertising in Contemporary Society: Perspectives Toward Understanding, Cincinnati ( $\mathrm{OH})$, South Western College Publishing. ZeFF, R. and D. Aronson (1999): Advertising on the Internet, New York, John Wiley and Sons. 


\title{
IS «POSITIVE FACE» A UNIVERSALLY VALID CONCEPT?: TOWARD A NEW MODEL OF FACE IN POLITENESS THEORY
}

\author{
Nobuo Ignacio López SAKo \\ Universidad de Granada
}

\section{INTRODUCTION}

\begin{abstract}
A CCORDING to Brown \& Levinson (1987 [1978], henceforth B\&L), the need to «save face» is behind all polite behavior, either verbal or nonverbal. They define face as «the public self-image that every [adult] member [of society] wants to claim for himself [sic]» (1987: 61). Their notion of face is partly taken from Goffman (1967) and partly from the English folk term, as used in expressions such as «losing face», related to the feelings of embarrassment and humiliation.
\end{abstract}

In addition to this general definition, $B \& L$ propose that the claimed public self-image has two aspects: «the basic claim to territories, personal preserves, rights to non-distraction - i.e. to freedom of action and freedom of imposition» (Ibid.), labelled «negative face», and «the positive consistent self-image or "personality" (crucially including the desire that this self-image be appreciated and approved of) claimed by interactants» (Ibid.), called «positive face». These two aspects being vulnerable in interaction, people try to cooperate in maintaining each other's face by letting the other participants know that one is taking face concerns into consideration (B\&L, 1987: 61).

Although they allow for certain variation among cultures regarding the exact limits of both negative and positive face, they assume that the mutual knowledge of and concern for face are universal. (Ibid.: 62)

So far, the criticism against B\&L's notion of face has focused mainly on its negative aspect (Y. Matsumoto, 1988; Nwoye, 1992; Gu, 1990; Mao, 1994; De Kadt, 1998; Koutlaki, 2002), leaving positive face almost untouched. ${ }^{1}$ This paper argues, however, that the very argument used to reject the universality of negative face can be employed against the notion of positive face: it is suggested that this aspect of face is also individualistic and egocentric («centripetal», in Mao's terms) and therefore equally inapplicable in cultures where collectivistic and group values outweigh personal ones.

1. But see Mao (1994) and Pizziconi (2003) for some comments. See also below for further details. 
If both aspects of B\&L's face are inappropriate to account for non-Western cultures, should we abandon the «face-view» (Fraser, 1990) of politeness? My position is not to reject B\&L's definition altogether, as I consider it is still valid for individualistic cultures, but to expand the notion to include «centrifugal orientations» (Mao, 1994) of face. To achieve this goal, the notions of «self» in the Japanese culture are explored and then related to face, following TingToomey and Kurogi's (1998: 188) suggestion that «[f]ace is, fundamentally, a "social self" construction issue» and depends on how «self» is conceptualized.

Drawing from previous studies conducted in the field of Japanese anthropology, psychology and sociolinguistics, it is suggested that individual's private (inner) self has little bearing on the social aspect of self, and therefore face, in Japan. A proposal is then made of a Dual Face Construct that would integrate both Western and non-Western face concerns in one single framework.

\section{AN ETHNOCENTRIC VIEW OF FACE}

\subsection{Focus on negative face}

The critics' basic argument against negative face (Y. Matsumoto, 1988; Ide, 1989; Gu, 1990; Nwoye, 1992; Mao, 1994; De Kadt, 1998; Koutlaki, 2002) is that, in many cultures, people do not act politely because they want to be undisturbed and free to act without any kind of imposition from others (i.e, B\&L's negative politeness), but because they consider it socially appropriate to act that way. That is, they claim that it is not the individual's internal desires but the external social conventions and norms that dictate the use of polite expressions (vid. Bravo, 1999; Bargiela-Chiappini, 2003, for a somewhat different view).

Y. Matsumoto (1988: 404) argues that the central notion of face in Brown and Levinson's theory seems alien to Japanese, and adds that it is the notion of negative face that sounds most problematic:

What is most alien to Japanese culture in the notion of face, as attributed to the model person, is the concept of negative face wants as the desire to be unimpeded in one's action. Postulating as one of the two aspects of the Model Person's 'face', the desire to be unimpeded, presupposes that the basic unit of society is the individual. With such an assumption, however, it is almost impossible to understand behaviour in the Japanese culture.

Similarly, Ide (1989: 241) concedes that face is plausibly regarded as the key to interaction in a Western society where individualism is assumed to be 
the basis of all exchanges, but believes that in societies where group membership is a key element, face (as defined by B\&L) cannot be the basis of interaction.

Mao (1994: 460) regards «respect of the community» encapsulated in the expression miànzi («image») as more relevant in Chinese society than negative face, and sees no relation between the English and the Chinese expressions:

When one obtains miànzi in Chinese, one wins recognition not so much of one's claim to freedom of action as of one's claim to the respect or prestige of the community. This recognition may or may not be deserved. Whatever freedom accrues to such recognition is of secondary consideration.

Koutlaki (2002) tries to apply their model to the Persian culture and concludes that their «view of offers and thanks [as being threatening to the addressee's negative face] is not universally valid» (Koutlaki, 2002: 1734) because in Persian culture «interdependence is the norm in social relationships» (Ibid.).

In the African context, Nwoye (1992) argues for the need to incorporate the additional category of «group face» to account for the collectivist and egalitarian Igbo society, which would refer to «the individual's desire to behave in conformity with culturally expected norms of behavior that are institutionalised and sanctioned by society» (Nwoye, 1992: 313). De Kadt (1998: 181) underscores the importance given in the Zulu culture to the respect interactants pay to each other taking into account their relative status and position in the social hierarchy, and concludes that «the assumption underpinning [B\&L's] category of negative politeness, that S[peaker] has a want that his action be unimpeded by others [negative face], is as questionable for Zulu as for the languages of the Far East» (De Kadt, 1998: 175).

Evidence of the straight inapplicability of B\&L's notion of negative face in the South American context is given by Placencia (1996), who argues that Ecuadorian's motivation for politeness is not based on face concerns as understood by $\mathrm{B} \& \mathrm{~L}$, but on the principle of reciprocity regarding mutual benefits, the sense of honor and social embarrassment, and the norms of deference depending on the social status of the interactants. According to Placencia (1996), the main face want for Ecuadorians is the ideal social identity, rather than the ideal individual identity.

2. See also Bravo (1999: 159). 


\subsection{Positive face revisited}

Compared to the vast amount of criticism against the notion of negative face, its positive aspect has received little attention. Most comments have been made in passing. Y. Matsumoto (1988), for example, mentions both positive and negative aspects as problematic in Japanese, but only elaborates on the latter. Furthermore, she implicitly seems to accept its positive side when describing «negative face oriented strategies addressed to positive face wants» (Y. Matsumoto, 1988: 408, my emphasis).

Mao (1994) points out that the Chinese expression liăn resembles positive face only in the fact that both concepts refer to the individual's desire to be liked and approved of by others, but that the similarities end there, as liăn is more socially oriented, and refers to the respect of the group toward the group member. Koutlaki (2002) compares positive face and the Persian word

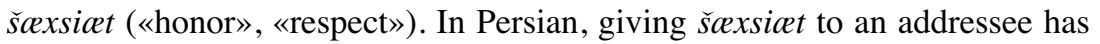
to do with society's injunctions about paying face, and also with group face wants. This means that individual and group values are equally important. As B\&L's construct is based on individual and not group values, Koutlaki finds B\&L's notion inappropriate in the Iranian context.

As far as I know, apart from these brief mentions, no direct revision has been made of B\&L's positive face. So far, the fact that the assumptions underlying the definition of negative face which make it inappropriate for some cultures are also present in the definition of positive face has been overlooked. In order to address this issue, it is worth repeating its definition here:

Positive face: the positive consistent self-image or 'personality' (crucially including the desire that this self-image be appreciated and approved of) claimed by interactants. (B\&L, 1987: 61)

Some scholars have interpreted this definition as the individual's desire to merge, to belong to a group, to be accepted. Pizziconi (2003: 1474), for example, regards positive face as «a want of approval and appreciation», whereas O'Driscoll (1996: 4) argues for the universality of positive wants, consisting in «the need to come together, make contact and identify with others; to have ties; to belong; to merge».

While I agree with both scholars on the universal need of approval and appreciation, the first question we should ask is whether B\&L's definition actually states that. I regard Pizziconi and O'Driscoll's restatement a somewhat free interpretation of B\&L's definition. My argument is that $B \& L$ are more specific and equally biased toward the individual when defining 
positive face. According to B\&L, what constitutes positive face is the desire that one's «personality» be accepted and even liked by relevant others. «Personality» is defined by the Oxford Dictionary of English as «the combination of characteristics or qualities that form an individual's distinctive character» (my emphasis). It refers to one's inner qualities which make each and every individual different from others. This means that what B\&L claim is not just the desire to belong, but that the sense of belongingness is achieved when others accept, approve, and maybe share, one's idiosyncrasies and personal characteristics; it is the accommodation of others to oneself that is expected and desired. This is further emphasized in the restatement of the definition of face as wants:

Positive face: the want of every member that his [sic] wants be desirable to at least some others. (B\&L, 1987: 62)

What is a key issue here is the individual's disposition toward social relations. The assumption is that the individual comes first. The desire to merge and to belong is built upon others accepting one's views, likes and dislikes, and so on. Self-affirmation, the building of one's «self-image», is a pre-requisite for claiming others' acknowledgment. Clearly, from this perspective, positive face also has a «centripetal» orientation, as Mao (1994) would put it. Thus, the same argument used to deny the universal applicability of negative face can be raised against positive face.

In collectivistic societies, however, the sense of belongingness can be experienced by mutually acknowledging and recognising each other's group membership, without resorting to personality. According to Mao (1994), the Chinese liăn shares with positive face the desire for approval but differs with the latter in that it is more socially oriented. Y. Matsumoto (1988) argues that the expression doozo yoroshiku onegai shimasu ('I ask you to please treat me well/take care of me'), although impositive to negative face in B\&L's sense, in Japan is rather viewed as a «relation-acknowledging device» (1988: 409), mutual acknowledgment and interdependence being more relevant (Ibid.: 410). In the above example, the speaker displays deference toward the addressee by recognizing the latter's position to give protection and care toward the speaker, a role reserved for people of higher social rank. This way, the speaker is paying tribute to the addressee's want of appreciation, but crucially not involving his/her personality.

Koutlaki (2002: 1743) explains how important proper behavior is in Persian culture in order to be accepted as a competent member of society. To

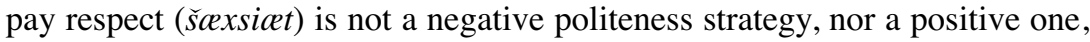
but a consideration of the wants of the group. Nwoye (1992) points out that in 
Igbo society there is a strong sense of hospitality and suggests that the notion of «group face» should be added to account for this group or other-oriented behavior.

In the Japanese and Persian cases, it is the individual's accommodation to others or to the group that is assumed. The sense of belongingness is achieved via others' recognition of one's proper behavior. In the case of the Igbo culture, it is a sense of mutual attachment, belongingness and care that is highlighted. «Personality» and the selfish want that others want one's want have no place here. Positive face in B\&L's sense cannot account for these ways of merging and coming together.

Does it mean, then, that face concerns are completely alien to these societies? Not necessarily. I argue that it is possible to articulate a more complex face construct that may account for the so-called Western and nonWestern ways of behavior. Inspired by Mao's (1994) suggestion that face has opposite orientations - «centripetal» vs. «centrifugal»- in Anglo-American and Chinese cultures, an attempt is made to integrate both «orientations» in a more comprehensive and overarching concept of face.

\section{THE DUAL FACE CONSTRUCT}

Face is a social-psychological construct: it is related to one's feelings, emotions, self-construal, and actualized in social interaction (Singelis, 1994). It refers to how self is presented to others. It is «a 'social self' construction issue [and] [s]ocial self is tied closely with the conceptualization of 'personal self' phenomenon in different cultures» (Ting-Toomey and Kurogi, 1998: 188). Therefore, how self is conceptualized should inform about what constitutes face. In this sense, we should acknowledge that face is a human quality and therefore universal, but the contents of face may vary cross-culturally:

In some cultures, the «social self» (i.e. the «public self») is expected to be closely aligned with the «personal self» (i.e. the «private self»). In other cultures, the «social self» is expected to engage in optimal role performance, regardless of what the inner «personal self» is experiencing at that interaction moment.

From this perspective, B\&L's model of face may represent an equation between personal self (PS) and social self (SS), as it is the individual's personal wants for autonomy and/or others' acceptance of one's personality that is at stake:

B\&L's face: $P S \neq$ SS 
The question is whether this model of face is applicable to the Japanese and other cultures. An analysis of Japanese construal of «self» or selfawareness suggests it is not. Drawing from Lebra's (1992) conceptualization of Japanese self, an alternative non-Western view is proposed. This face-type will then be integrated in a Dual Face Construct, including B\&L's model, which seems to be valid for Western societies. Due to lack of space, only a brief outline of what might constitute this alternative view of face will be presented here.

\subsection{Interactional vs. inner self}

According to anthropologist Lebra (1992: 105), self-awareness is a product of social participation and cultural representation. Maynard (1997: 41) suggests that for the Japanese, «[s]elf is not rigid, stable, constant, and standing alone. It is a changing, forming, fluid awareness based on social relationships, and it bears meaning in relation to one's thought, to other people, and to contexts».

Lebra (1992) distinguishes three levels or dimensions of self-awareness, each one flowing into the other: the interactional self; the inner self, and the boundless self. The boundless self refers to the transcendental self in which the state of no-self (mushin, muga) is reached. It is a state of passivity and nonassertiveness, where the self is free from cultural and social ties. Thus, it has little or no relevance for face and it will not be discussed here.

The distinction between interactional and inner self, however, is of crucial importance. Lebra (1992: 106) defines the interactional self as the awareness of self at the surface level as perceived through social interaction and is interdependent with others. It has two orientations: the presentational self and the empathetic self. The presentational self is the surface layer of self and is metaphorically localized on the person's face. Related aspects of this side of self are honor, self-esteem, reputation and dignity. It is upheld in everyday life including routine behavior, status attainment, enactment of protocols, prominent achievement, conformity, distinction, etc. Crucial to this aspect of self is the role played by the seken (society, the world), which acts as audience, always watching and judging one's behavior. Consequently, «self here consists of continuous reflexivity between performance by self and sanctions by the audience» (Lebra, 1992: 106).

The empathetic self is the intimacy-seeking part of the interactional self. It involves the awareness of self as a group or network member, or a partner to a relationship. Values such as love, trust, fellowship, support, cooperation, solidarity, interdependence and sociability are salient. This is the aspect of self that is relevant and shown toward miuchi (fellow insiders), as opposed to tanin 
(outsiders), seken being part of the latter. This aspect of the interactional self is related to the feeling of fusion, synergy, «interchangeability of self and other» (Lebra, 1992: 109), and mutual attachment. While mismanagement of the presentational self brings shame, inappropriate handling of empathetic self brings loneliness.

As opposed to the interactional self, the inner self in the Japanese tradition is free, spontaneous and even asocial. It is the reservoir of truthfulness and purity, where the true kokoro (heart, mind) belongs. This true kokoro is kept hidden, because «the inner part, when coupled with the socially contextualized presentational self, tends to be encapsulated and remains uncommunicated or ungestured» (Lebra, 1992: 115). «Real» truth is, therefore, inexpressible.

Evidence of this dichotomy is provided by Matsumoto (1996), who demonstrated that the Japanese hide their true emotions in public. According to Matsumoto, core emotions (fear, happiness, sadness, contempt, anger, surprise, disgust) are universal, and are associated with certain expressive behavior. Emotions are expressed through the face, which is defined as «image» or «reputation». Face must be constantly maintained in in-group situations, if one does not want to face shame and even isolation. Although the facial expressions of the seven basic emotions are universal, the Japanese may not always display these emotions or may conceal some of them depending on the social context and the dictates of their culture.

An experiment using Japanese and American informants showed that the Japanese individuals changed their facial expression depending on whether they knew they were observed or not. When alone, they showed disgust, fear, anger or surprise to some intense, stress-inducing stimuli, the same as Americans. But when there was a higher-status person in front, they just smiled, while the Americans did not change their expressions. This leads Matsumoto (1996: 51) to conclude that

[w] hen display rules are not of consequence, the Japanese will exhibit exactly the same facial expressions of emotion as will people of any other culture. Yet when the social situation calls for the use of display rules, the Japanese will modify their expressions in order to be socially appropriate. In Japan, display rules serve to assure that the correct emotions are shown in the appropriate circumstances, and little deviance is tolerated.

It can be argued then that only the interactional self, with its two aspects, is relevant for face, and that the inner (= private) self has little or no bearing on it. That is, the private self will have little influence on social self, and hence, on face. As the locus of this type of face is the relationship with others and is based on the reflexivity between self and the audience, I will use the 
term relational to refer to this type of face, as opposed to B\&L's, which can be labelled «egocentric». In «relational face», the private/personal/inner self will be detached from the social self:

Relational face: PS $\neq$ ss

An example that illustrates the relational orientation of Japanese face, as opposed to the Western egocentric view, can be found in self-introduction greetings:

$\begin{array}{ll}\text { 1. Doozo yoroshiku onegai shimasu (Japanese) } & \\ \text { Please well HON-ask for to do-POL } & \\ \text { 'I ask you to please (treat me) well' } & \\ \text { 2. Nice to meet you. } & \text { (English) } \\ \text { 3. Encantado de conocerle. } & \text { (Spanish) }\end{array}$

(I'm) very happy to meet you.

These formulae express the interlocutors' will to start a new relationship. However, it is interesting to note that, while in both (2) and (3) it is the personal feelings of the speaker that are expressed to the interlocutor, in (1) a request to be treated fairly and nicely is made. As Matsumoto (1988: 410) points out, it is a device to express mutual acknowledgment and interdependence. In (2) and (3), the focus is on inner opinions and personal evaluations; in (3), on the establishment of a relationship.

Further evidence for the interactional nature of self in social relations in the Japanese culture is provided by the sheer amount of first person personal pronouns (Maynard, 1997) and «the lack of the exact equivalent of "I" which would serve as the fixed point of self» (Lebra, 1992: 111). Depending on the social context (in-group vs. out-group, public vs. private situation, etc.), the speaker may refer to him/herself with terms such as ore, boku, watashi, watakushi, watakushidomo. The equivalent of the term «self» in Japanese, jibun, is also based on a relational view, literally meaning «one's part or piece».

\subsection{Face and self-construal}

The dichotomy between egocentric vs. relational face is also related to the social-psychological constructs of independent and interdependent selfconstrual. According to Markus and Kitayama (1991), the construals inform about how people conceive themselves in terms of their relative autonomy or connection with others. 
The independent individual perceives him or herself as an autonomous entity, with unique internal attributes, and his/her behavior is primarily a consequence of these attributes, rather than out of consideration for the thoughts and feelings of others. In the interdependent self-construal, the self is viewed in relation to others and is «influenced by a pervasive attentiveness to the relevant others in the social context» (Markus and Kitayama, 1991: 225, original emphasis). While the independent selves view themselves as separate from others, the interdependent selves construe themselves in connection with and less differentiated from others. This way, relevant others participate actively in the definition of the interdependent self. In many situations, the interdependent self gives less importance to his or her own opinions, abilities, and traits, as well as to his or her autonomy. Thus, Markus and Kitayama's interdependent self-construal is closely related to Lebra's interactional self, whereas the independent self-construal lies behind B\&L's definition of selfimage.

\subsection{Face types, wants and interactional strategies}

B\&L defined the two face subtypes -negative face and positive face- in terms of wants. The former referred to the want for autonomy and personal space, whereas the latter had to do with the acceptance of one's personality. I suggest that, following Lebra's argument that interactional self has two orientations -the presentational self and the empathetic self-, «relational face» can also be divided into two subtypes: the «presentational face» and the «empathetic face».

The «presentational face» is related to the sense of honor, self-esteem, reputation and dignity, and should be activated in non-familiar, formal situations. It is more or less equivalent to what Spencer-Oatey (2000) calls identity face. The «empathetic face», on the other hand, is defined as the want for mutual attachment, care and love, and becomes relevant in situations (and/or cultures) where the mutual trust and knowledge, and the sense of group-belongingness is high. Crucially, it is based on the expectation of others' love and care, of one being accepted as an in-group member. It is a sense of abandonment and trust and has nothing to do with one's «personality».

Finally, I suggest that both B\&L's «egocentric face» and «relational face» subtypes can be related to avoidance and approach interactional strategies. B\&L's negative face calls for avoidance strategies -what B\&L call negative politeness strategies- and positive face is redressed by the use of approach strategies -positive politeness strategies (B\&L, 1987: 101ff.). Similarly, when 
the presentational face is at stake, avoidance strategies should be preferred, whereas approach strategies would be used to avoid threatening empathetic face. Table 1 summarizes all the aspects of face discussed so far:

TABLe 1. Dual Face Construct

\begin{tabular}{|c|c|c|c|c|}
\hline \multicolumn{5}{|c|}{ FACE } \\
\hline $\begin{array}{c}\text { Face } \\
\text { orientation }\end{array}$ & \multicolumn{2}{|c|}{ CENTRIPETAL } & \multicolumn{2}{|c|}{ CENTRIFUGAL } \\
\hline $\begin{array}{c}\text { Type of } \\
\text { face }\end{array}$ & \multicolumn{2}{|c|}{ EGOCENTRIC } & \multicolumn{2}{|c|}{ RELATIONAL } \\
\hline $\begin{array}{c}\mathrm{PS} / \mathrm{SS} \\
\text { relationship }\end{array}$ & \multicolumn{2}{|c|}{$\mathrm{PS}=\mathrm{SS}$} & \multicolumn{2}{|c|}{$\mathrm{PS} \neq \mathrm{SS}$} \\
\hline $\begin{array}{l}\text { Face sub- } \\
\text { type }\end{array}$ & NEGATIVE & POSITIVE & PRESENTATIONAL & EMPATHETIC \\
\hline $\begin{array}{c}\text { Type of } \\
\text { want }\end{array}$ & AUTONOMY & $\begin{array}{l}\text { ACCEPTANCE } \\
\text { OF ONE'S } \\
\text { PERSONALITY }\end{array}$ & $\begin{array}{c}\text { RESPECT } \\
\text { ESTEEM } \\
\text { HONOR }\end{array}$ & $\begin{array}{c}\text { MUTUAL } \\
\text { ATTACHMENT } \\
\text { LOVE, CARE }\end{array}$ \\
\hline $\begin{array}{l}\text { Type of } \\
\text { interactional } \\
\text { relationship }\end{array}$ & INDEPENDENCE & INDEPENDENCE & INDEPENDENCE & INDEPENDENCE \\
\hline $\begin{array}{c}\text { Type of } \\
\text { interactional } \\
\text { strategy }\end{array}$ & AVOIDANCE & AVOIDANCE & AVOIDANCE & AVOIDANCE \\
\hline & & $\searrow_{\text {Linguistic }}^{7}$ & tion of strategies & 支 \\
\hline
\end{tabular}

\section{CONCLUDING REMARKS}

This paper has aimed to, on one hand, draw attention on the fact that B\&L's notion of positive face is as individualistic and «ego» centered as its negative counterpart, which made the whole concept -and not only partiallyinappropriate to account for the so-called non-Western collectivistic cultures, such as Japanese, Chinese, Persian, Igbo or Zulu. However, instead of rejecting the face-view of politeness, an attempt has been made to elaborate the non-Western counterpart and include both in a more comprehensive, allencompassing face model: the Dual Face Construct. This face model is divided into two face types: «egocentric» (B\&L's face) and «relational» -related to Markus and Kitayama's (1991) independent and interdependent self-construals -each one consisting of two further subtypes: negative and 
positive face, on one hand, and presentational and empathetic, on the other. Each face sub-type is related to a specific kind of interactional want: autonomy, acceptance of personality, self-esteem and mutual attachment. It is finally suggested that avoidance interactional strategies mitigate threats to both negative and presentational face, whereas approach strategies are used to anoint positive and empathetic face. This being a work in process, further research is needed to delve into the relationships between face-subtypes and interactional strategies, as well as between the latter and their linguistic realization.

\section{BIBLIOGRAPHICAL REFERENCES}

BARGIELA-ChIAPPINI, F. (2003): «Face and politeness: new (insights) for old (concepts)», Journal of Pragmatics, 35: 1453-1469.

Bravo, D. (1999): «¿Imagen "positiva” vs. imagen "negativa”?: Pragmática socio-cultural y componentes de FACE», Oralia, 2: 155-184.

Brown, P. and S. C. Levinson (1987 [1978]): Politeness: Some universals in language usage, Cambridge, Cambridge University Press.

DE KADT, E. (1998): «The concept of face and its applicability to the Zulu language», Journal of Pragmatics, 29: 173-191.

FraSER, B. (1990): «Perspectives on politeness», Journal of Pragmatics, 14: 219-236.

GofFMAN, E. (1967): Interaction ritual: Essays on face-to-face behavior, New York, Pantheon.

Grice, H. P. (1975 [1967]): «Logic and conversation», in Cole, P. and J. L. Morgan (eds.) (1975 [1967]): Syntax and semantics, Vol.3: Speech acts, New York, Academic Press, 41-58.

Gu, Y. (1990): «Politeness phenomena in modern Chinese», Journal of Pragmatics, 14: 237-257.

IDE, S. (1989): «Formal forms and discernment: Two neglected aspects of universals of linguistic politeness», Multilingua, 8(2/3): 223-248.

KoUTLAKI, S. A. (2002): «Offers and expressions of thanks as face enhancing acts: tæ'rof in Persian», Journal of Pragmatics, 34: 1733-1756.

LEBRA, T. S. (1992): «Self in Japanese culture», in RosenbERGER, N. R. (ed.) (1992): Japanese sense of self, Cambridge/New York/Melbourne, Cambridge University Press, 105-120.

MaO, L. R. (1994): «Beyond politeness theory: 'Face' revisited and renewed», Journal of Pragmatics, 21: 451-486.

MARKUS, H. R. and S. KitAYAMA (1991): «Culture and the self: Implications for cognition, emotion, and motivation», Psychological Review, 98(2): 224-253. 
Matsumoto, D. (1996): Unmasking Japan: Myths and realities about the emotions of the Japanese, Stanford (Calif.), Stanford University Press.

Matsumoto, Y. (1988): «Reexamination of the universality of face: Politeness phenomena in Japanese», Journal of Pragmatics, 12: 403-426.

MAYNARD, S. K. (1997): Japanese communication: Language and thought in context, Honolulu, University of Hawai Press.

Nwoye, O. G. (1992): «Linguistic politeness and socio-cultural variations of the notion of face», Journal of Pragmatics, 18: 309-328.

O'DRISCOLL, J. (1996): «About face: A defence and elaboration of universal dualism», Journal of Pragmatics, 25: 1-32.

PizZiconi, B. (2003): «Re-examining politeness, face and the Japanese language», Journal of Pragmatics, 35: 1471-1506.

Placencia, M. (1996): «Politeness in Ecuadorian Spanish», Multilingua, 15(1): 13-34.

Singelis, T. M. (1994): «The measurement of independent and interdependent self-construals», Personality and Social Psychology Bulletin, 20: 580-591.

Spencer-OAtey, H. (2000): «Rapport management: A framework for analysis», in SPENCER-OATEY, H. (ed.) (2000): Culturally speaking: Managing rapport in talk across cultures, London/New York, Continuum, 11-46.

Ting-Toomey, S. and A. Kurogi (1998): «Facework competence in intercultural conflict: An updated face-negotiation theory», International Journal of Intercultural Relations, 22(2): 187-225. 


\title{
¿QUÉ SABEN LOS HABLANTES SOBRE LA CORTESÍA LINGÜÍSTICA? ALGUNOS REFRANES ESPAÑOLES REFERIDOS A LA CORTESÍA
}

\author{
Elvira Manero Richard \\ Universidad Católica San Antonio de Murcia
}

$\mathbf{L}$

OS refranes que se estudian en estas páginas pertenecen a lo que puede denominarse -de acuerdo con la teoría general del hablar de Coseriu- ${ }^{1}$ metalenguaje del discurso, en relación con el nivel individual del hablar. En particular, se trata de expresiones que se integran en el discurso metalingüístico o aquel sector del metalenguaje donde se conciben aquellos textos referidos al lenguaje. Así, estos refranes pertenecen al metalenguaje del discurso en tanto que se producen y comprueban en el plano del discurso y, además, porque son unidades con naturaleza textual.

En este ámbito, es posible analizar el saber lingüístico intuitivo que albergan estos textos paremiológicos. El interés para el lingüista de tal análisis, realizado desde la etnolingüística y el análisis del discurso, reside fundamentalmente en la naturaleza comunitaria y tradicional del conocimiento que recogen dichas paremias.

Por otra parte, estos refranes se han extraído de un corpus de refranes metalingüísticos, de casi tres mil entradas, realizado a partir de varios refraneros del siglo $\mathrm{XX} .{ }^{2}$ El estudio de dicho corpus ha permitido observar la existencia de numerosas expresiones centradas en valorar la cortesía en los intercambios verbales. Este hecho se une a la propia intuición de que unos textos tradicionales como son los refranes, tan estrechamente ligados a la cultura y, por tanto, a la sociedad en la que surgen, no podían dejar de ocuparse de la vertiente social de la comunicación, en relación con la cual se entiende el uso de la cortesía.

Aunque las expresiones estudiadas se refieren a la cortesía en general, es posible advertir que la conciben desde diferentes puntos de vista. Por ello, trataré de exponer cuáles son los tipos de cortesía que los hablantes distinguen a través del refranero, independientemente de si tal concepción coincide o no con las clases de cortesía que señala la lingüística científica. Solo cuando sea

1. Esta teoría es conocida y se halla expuesta, entre otros lugares, en Coseriu, 1992: 80-92.

2. Estos refraneros se ofrecen en la bibliografía final del artículo. El corpus al que me refiero ha sido elaborado por mí misma para una investigación más amplia sobre el refranero español de contenido metalingüístico (cfr. Manero Richard, 2000, $2005 a$ y 2005 b). 
necesario acudiré a algún aspecto teórico sobre cortesía lingüística y únicamente en las conclusiones tendré en cuenta, a grandes rasgos, alguna correlación entre conocimiento ingenuo y científico sobre cortesía al hablar. Así pues, me interesa ofrecer estrictamente la visión que los hablantes poseen sobre este aspecto de la comunicación.

Los apartados en los que divido este trabajo se establecen según el tipo de cortesía valorada en cada caso y, en segundo lugar, según el contenido descriptivo o prescriptivo del refrán, pues es posible diferenciar dos grandes grupos de expresiones. ${ }^{3}$ Así, se distinguen refranes de contenido descriptivo o que se presentan como actos asertivos (con modalidad declarativa) (por ejemplo, Quien calla, otorga), y refranes de contenido prescriptivo o actos directivos ${ }^{4}$ (de modalidad imperativa), esto es, refranes que se presentan como normas de comportamiento (entre otros, No reprendas a otro el vicio que hay en ti propio).

\section{REFRANES REFERIDOS A FÓRMULAS DE TRATAMIENTO}

Únicamente un refrán descriptivo del corpus se detiene en el uso del tratamiento de respeto entre interlocutores: Cuando en mi casa me llaman con crian$z a$, mala va la danza. Con crianza quiere decir "con cortesía", según indica el DRAE (s.v. crianza).

Este refrán revela los conocimientos que poseen los hablantes acerca de la interpretación pragmática convencional asociada al uso de la cortesía en contexto y, concretamente, a un tipo de cortesía entendida como aquel principio regulador de la distancia social: lo que Leech (1983: 83) llamó cortesía relativa.

Los hablantes aludidos por este refrán están habituados a un tratamiento familiar en sus intercambios verbales (esta información se presupone en el significado de en mi casa). Entonces, el uso de la cortesía lingüística en este contexto puede considerarse como la forma que tiene el hablante de marcar la distancia con su interlocutor y, en consecuencia, como indicio de su enfado con él. La ruptura de expectativas que sufre el destinatario de este discurso genera la interpretación descrita. No encontramos, por tanto, en este refrán una denuncia de un uso inadecuado de esta estrategia verbal. Antes al contrario, se describe aquí un uso adecuado (y, por tanto, eficaz) de la cortesía con la intención de implicar un significado que el destinatario infiere sin dificultades.

3. Esta división se basa en el tipo de acto de habla que constituye el refrán, como texto que es. Según Corpas (1996: 228), «las paremias constituyen fundamentalmente actos de habla informativos y actitudinales, en la terminología de Raerch et al. (1984); es decir, asertivos y directivos en la terminología de Searle».

4. Actos asertivos y directivos, en la terminología de Searle (1979 y 1980). 


\section{REFRANES REFERIDOS A LO CORTÉS EN GENERAL}

Aunque los siguientes refranes no determinan expresamente el tipo de cortesía que valoran, esta puede entenderse en ellos de dos maneras: en primer lugar, como aquello que se dice, en relación tanto con la forma como con el contenido del discurso, para agradar al destinatario y, manteniendo una relación cordial con él, conseguir el éxito del objetivo perseguido al hablar gentilmente. En segundo lugar, se trata de aquella cortesía referida, en palabras de Escandell-Vidal (1996: 136), al «conjunto de normas sociales, establecidas por cada sociedad, que regulan el comportamiento adecuado de sus miembros». En este marco se conciben, por ejemplo, algunas normas que exigen respeto a los turnos de habla, que serán descritas más adelante, y también la cortesía entendida como lo que se dice evitando el uso de términos malsonantes. Este último sentido responde a una de las acepciones de la expresión hablar mal, utilizada por diversos refranes y recogida en el DUE (s.v. hablar) como "blasfemar o decir palabras groseras", y en el DEA (s.v. hablar) como «Con abundancia de palabras malsonantes».

No se han distinguido dos grupos para cada uno de estos dos sentidos de hablar con cortesía, puesto que algunas expresiones, buenas palabras, buen decir, bien decir, etc., presentan un significado muy amplio y resulta difícil determinar si se refieren a uno u otro tipos. De hecho, en varios refranes se puede interpretar la cortesía en ambos sentidos. Cuando sea posible establecer la distinción, especifico el sentido del refrán en su correspondiente subapartado.

En otras ocasiones, la mención se presenta más clara, dulce hablar, palabras blandas (centradas, además de en otros rasgos, esencialmente en la cortesía), o se encuentra explícita: palabras de cortesía.

\subsection{Refranes de contenido descriptivo}

Los refranes de contenido descriptivo relativos a la cortesía se reparten, en su mayoría, entre juicios que valoran positivamente el uso de cortesía lingüística y otros que juzgan de forma negativa recurrir a esta estrategia.

\subsubsection{Refranes que enjuician positivamente el uso de la cortesía al hablar}

\subsubsection{En general}

En este grupo, encontramos refranes que valoran la cortesía de manera general, esto es, que no especifican la razón que fundamenta el juicio positivo que estas expresiones realizan. 
Algunos de estos refranes se refieren al primer tipo de cortesía comentada, es decir, a aquella que se manifiesta especialmente en un tipo de contenido concreto: 'palabras en que se dicen cosas agradables para el interlocutor'. Se trata de expresiones que juzgan positivamente dirigir buenas palabras a los interlocutores: Aunque otra sea tu mente, de buenas palabras págase la gente; El buen decir no cuesta más que la necedad; No hay cosa más barata que las buenas palabras; Buenas palabras no cuestan nada.

Otros refranes parecen apuntar, a través de la locución hablar bien, a un hablar cortés, sin groserías ni malsonancias, y acorde con las normas sociales de buena educación al hablar. El refranero considera que este hablar es poco costoso: El hablar bien no cuesta argén; El hablar bien no cuesta dinero; El hablar bien poco cuesta; Hablar bien no cuesta dinero; En hablar bien, nada se pierde. Apoyando esta interpretación, está el hecho de que hablar bien va acompañado, en algunas de estas expresiones, de un acto (verbal o no) cortés, como es agradecer: ${ }^{5}$ Agradecer y bien hablar son de mucho loar; Bien hablar y agradecer, en mucho se han de tener.

\subsubsection{En función de los efectos perlocutivos positivos para el hablante}

En segundo lugar, otros juicios positivos que el refranero realiza sobre la cortesía se basan en las implicaciones positivas para el hablante que recurre a ella.

En la serie de refranes que sigue es clara la referencia a aquel tipo de cortesía, ya citada, en la que el hablante se expresa para agradar al interlocutor. Decir aquello que no ofende (utilizar, así, el lenguaje cuidadosamente) protege la imagen positiva del emisor ante su receptor: ${ }^{6}$ Buena palabra es media paga; Buenas palabras no cuestan cobre y valen más que plata; Buenas palabras valen mucho y no cuestan nada; Cortesía de lengua vale mucho y poco cuesta; Palabra cortés, vale mucho y no cuesta res; Honra de palabra, vale mucho y no cuesta nada; La buena palabra a los amigos agrada y a los ene-

5. Lo explica Haverkate (1994: 82), a propósito de la cortesía verbal relacionada con actos expresivos: «[...] agradecer, felicitar y dar el pésame son actos corteses, porque sirven para apoyar o reforzar la imagen positiva del interlocutor». Sobre el acto de habla agradecer y el beneficio que redunda en el hablante que lo emite, véase Haverkate (1994: 93-97).

6. La teoría sobre la cortesía expuesta por Brown y Levinson (1987), cuya pretensión es explicar el funcionamiento de la cortesía en las lenguas, presenta, como uno de sus conceptos fundamentales, el de imagen pública: cada hablante tiene y reclama para sí una cierta imagen pública o prestigio que pretende conservar. De la necesidad de proteger esta imagen surge el empleo de la cortesía verbal. Este concepto presenta dos vertientes: una imagen negativa (deseo de tener libertad de acción, de no sufrir imposiciones de los demás), y otra positiva (deseo de ser apreciado por los demás, y de que otros compartan los mismos deseos). Esta última es la imagen que pretende mantener el emisor al que se refieren los refranes de este grupo. 
migos aplaca; Bien hablar y hacerse agradable, cuesta poco y mucho vale; Cortesía y bien hablar cien puertas nos abrirán; El hablar bien te abrirá puertas cien.

\subsubsection{En función de la consecución de la finalidad del discurso}

En tercer lugar, el refranero valora positivamente la cortesía por considerarla un instrumento lingüístico eficaz para conseguir la finalidad perseguida con el discurso. Algunos refranes formulan este hecho de manera general, como Arte para lograr es el dulce hablar y Con buenas palabras y mejores hechos, conquistarás el mundo entero. En cambio, otros especifican la finalidad del hablante: actuar sobre el destinatario de la manera perseguida por él (calmarlo, atraerlo a su terreno, mejorar, en definitiva, las relaciones con el interlocutor): Buenas palabras al más airado calman; Buenas palabras las fieras amansan; Buenas palabras, las peñas quebrantan; Palabras buenas quebrantan las peñas; Buen ejemplo y buenas razones avasallan los corazones; Con buenas palabras, el siervo a su amo manda; Del traidor harás leal con bien hablar.

En algunos de estos refranes, las expresiones palabras blandas, palabras suaves y palabras melosas hacen referencia al discurso cortés cuyo contenido es tanto 'palabras en que se dicen cosas agradables al interlocutor' como 'palabras de cariño al interlocutor', acompañadas, entre otros rasgos, de un tono suave y dulce: El buen mercado saca el dinero del bolsón; y las palabras blandas, roban el corazón; La palabra blanda rompe la ira; Palabra blanda, la ira quebranta; Palabras blandas, ¿a quién no ablandan?; Palabras blandas rinden armas; Palabras blandas te pondrán en andas; Palabritas mansas, ¿a quién no engañan?; Las palabras suaves, de los corazones son llaves; Palabras suaves, del corazón son llaves; Palabra suave, llegar al alma sabe; No todo se alcanza a punta de lanza; con palabritas melosas se consiguen las más de las cosas.

\subsubsection{Refranes que enjuician negativamente la cortesía al hablar}

Son varios los criterios que fundamentan el juicio negativo sobre la cortesía en el hablar.

\subsubsection{En función de los efectos perlocutivos negativos}

El primero tiene que ver con los efectos perlocutivos negativos para el hablante. En concreto, el refranero juzga que hablar cortésmente, en el sentido de hablar con urbanidad, es decir, respetando las normas sociales del "deber 
ser”, no aporta beneficios prácticos. Se presenta así la cortesía como un recurso improductivo o ineficaz: Buenas palabras no hacen buen caldo; Con las buenas palabras nadie come; Buenas palabras, cantar de cigarra. En estas expresiones, la ineficacia no ha de entenderse desde el punto de vista comunicativo y social, pues, como sabemos, la cortesía tiene funciones prácticas más que reconocidas en la interacción comunicativa. Antes bien, se habla en ellos de improductividad en la obtención de beneficios materiales, lo que difiere de los juicios positivos que acaban de comentarse, basados en la eficacia de esta estrategia para mantener o mejorar relaciones sociales (cfr. 2.1.1.3.).

\subsubsection{Por lo que manifiesta generalmente del hablante un tipo de cortesía}

Algunos juicios negativos responden a una concepción peyorativa, señalada por Leech (1983: 83), que los hablantes ingenuos asumen habitualmente respecto de la cortesía y que asocia esta a una actitud insincera en el hablante: Boquita de miel, corazoncito de hiel; En los labios la miel, y en el corazón la hiel; Miel en las palabras, y hiel en el alma; Palabras melositas, palabras falsitas; Palabritas confitadas, entrañitas dañadas; Palabritas azucaradas, palabritas endemoniadas; Hay lenguas almibaradas, que debían estar cortadas; Palabras melositas, tan falsas como bonitas; Palabras mansas, y entrañas falsas; Palabras untadas de miel, por dentro llevan la hiel.

El tipo de cortesía que juzgan estos refranes tiene que ver, una vez más, con el contenido del discurso ('palabras en que se dicen cosas agradables para el interlocutor') y otros aspectos, como el tono (suave, apacible, dulce), la intención (zalamera), etc. El hablante intenta fundamentalmente actuar sobre el destinatario utilizando una cortesía favorecedora del hablante. Los términos miel, meloso y azucarado, utilizados por estos refranes, tienen en común el sema 'dulce', que es definido por el DRAE (s.v. dulce), en su quinta acepción, de este modo: «Naturalmente afable, complaciente, dócil». Los tres adjetivos con los que el DRAE define este lexema apoyan la intención del hablante de actuar sobre el destinatario.

\subsubsection{Refranes que enjuician negativamente la descortesía}

Finalmente, encontramos un tercer grupo de refranes descriptivos que denuncia ser descortés al hablar. En este grupo, la descortesía se traduce en un hablar malsonante, grosero y maleducado, poco gentil, en definitiva. El juicio en tales expresiones se plantea en términos generales: Palabras locas, pedos de boca y Unos por el culo estercolan, y otros por la boca, o bien en función de los efectos perlocutivos negativos para el hablante: Quien mal habla, se condena; Al deslenguado, nunca le falta pleito mal parado; El deslenguado, por otras lenguas es castigado; Hombre deslenguado, caballo desbocado. 
Deslenguado se recoge en los diccionarios con varios significados, todos ellos aplicados a la acción lingüística. El hablante deslenguado es, según los diccionarios manejados (DRAE, DUE, DEA), "grosero" al hablar, esto es, "malhablado" en relación con lo que se considera maleducado verbalmente en una comunidad. El hablante al que se juzga ha perdido la vergüenza que le llevaría a respetar las normas sociales de cortesía.

\subsection{Refranes de contenido prescriptivo}

Aunque no son muy numerosos en el corpus, destacan aquellos refranes prescriptivos referidos, en un sentido amplio, al primer tipo de cortesía señalada, esto es, aquella que se concreta en lo que se dice, en relación tanto con la forma como con el contenido del discurso, para agradar al destinatario y conseguir, así, el éxito del objetivo perseguido o los efectos buscados con la enunciación.

El primero de los refranes de este grupo, A quien reza por la calle, hablalle bien y no fialle, prescribe el uso de cortesía verbal (sin concretar el tipo de cortesía) y especifica el contexto (por la calle) y el tipo de interlocutor: alguien que gruñe o refunfuña (según la sexta acepción de rezar que recoge el DRAE). La cautela que debe adoptarse ante este tipo de interlocutor se traduce en no prestarle nada (no fialle), norma no lingüística, y en dirigirse a él con palabras corteses, a fin de no granjearse la antipatía de alguien a quien se cree poco cuerdo.

Los otros dos refranes normativos de este grupo son Miel en la boca y guarda la bolsa y su variante Miel en tu boca y nudo en tu bolsa. La explicación que la Academia ofrecía para ellos en la XVIII edición del Diccionario la recogen Campos y Barella en su Diccionario de refranes (s.v. miel, 2287): ${ }^{8}$ «Aconseja que, ya que uno no dé lo que le pidan, se excuse con buenas palabras». Se recomienda, por tanto, responder cortésmente (norma) a una petición y en ningún caso satisfacerla (guarda la bolsa).

\section{REFRANES REFERIDOS A NORMAS DE CORTESÍA SOCIAL CONCRETAS MANIFESTADAS A TRAVÉS DEL LENGUAJE}

Frente al grupo anterior, donde no se establecía en qué consisten exactamente las normas de cortesía correspondientes a la comunidad de habla espa-

7. DRAE (s.v. deslenguado): adj. Desvergonzado, desbocado, mal hablado. DUE (s.v. deslenguado): 2. adj. Calumniador, difamador o malhablado. DEA (s.v. deslenguado): 2 [Pers.] de lenguaje grosero o desvergonzado.

8. La cita de un refrán o comentario procedente del Diccionario de refranes de Campos y Barella se realiza especificando la voz bajo la que se encuentra el refrán o comentario y el número de entrada del refrán en el diccionario de estas autoras. 
ñola, los refranes que ahora se comentan, tanto descriptivos como normativos, se refieren a determinadas normas sociales que se manifiestan en el hablar. Parece lógico que los refranes anteriores, menos determinados en este sentido, constituyan el grupo más numeroso, toda vez que las estrategias lingüísticas de la finalidad interaccional son parte de la competencia pragmática de los hablantes. Quizá lo más relevante entonces para el refranero sea juzgar la cortesía de manera general o establecer con claridad en qué circunstancias comunicativas es necesario poner en práctica estas estrategias.

\subsection{Refranes de contenido descriptivo}

El primer refrán de este grupo, El burro del aceitero siempre se nombra primero, denuncia expresamente el incumplimiento de una norma de cortesía social. El refranero considera descortés, en el sentido de poco gentil y educado, un tipo muy concreto de actuación verbal: en una enumeración de personas, entre las que se encuentra el propio emisor, este debe nombrarse el último por educación.

Por otra parte, lo descrito en los otros dos refranes que completan este apartado afecta, en la comunidad de habla española, a los turnos de habla ${ }^{9}$ cuando uno de los interlocutores es un niño. Esta norma de cortesía social consiste en que el niño únicamente ha de hablar cuando se le insta a hacerlo: El mozo bien criado, no habla sino cuando es preguntado; Niño bien criado, no habla si no es preguntado. Tusón (1997: 82) explica esta norma de comportamiento respecto de la adquisición de la competencia comunicativa y Haverkate (1994: 64) se refiere a ella como manifestación de la cortesía verbal.

\subsection{Refranes de contenido prescriptivo}

Muy relacionados con estas últimas expresiones descriptivas se encuentran los dos refranes prescriptivos Calla y escucharás; escucha y hablarás y Oye primero y habla postrero, ya que sus normas tienen que ver también con la propia forma de desarrollarse el intercambio verbal. Específicamente, estos refranes instan a los interlocutores a respetar los turnos de habla en los que se reparten sus intervenciones en la interacción comunicativa y, por tanto, a no

9. Los turnos de habla o de palabra constituyen el sistema de organización de las interacciones conversacionales. Son las unidades con las que se construye una conversación (cfr. Sacks et al., 1974). Tusón Valls (1997: 55) se refiere a ellos en estos términos: «Desde el punto de vista formal, si algo caracteriza a la conversación es precisamente el hecho de ser un texto a varias voces que se organiza a partir de la alternancia de turnos, es decir, a través de la sucesión de intervenciones a cargo de diferentes hablantes». 
interrumpir al que está hablando, acción que, en palabras de Haverkate (1994: 64), amenaza potencialmente el espacio intencional del interlocutor. Se entiende, pues, que el hablante no debe expresar su opinión sin saber primero lo que su interlocutor le quiere decir.

\section{REFRANES SOBRE TIPOS DE TEXTO O ACTOS DE HABLA INTRÍNSECAMENTE CORTESES O DESCORTESES}

En el último grupo de refranes referido a la cortesía, se observa la existencia de numerosas valoraciones positivas o negativas basadas en la consideración de ciertas tradiciones textuales como actos inherentemente corteses o descorteses. De sobra es conocido -lo señalan, por ejemplo, Haverkate (1994: 77) o Leech (1983: 83) - que existen actos de habla intrínsecamente corteses (agradecer, felicitar, saludar, ofrecer, invitar, alabar, etc.) o descorteses (entre otros, preguntar, pedir u ordenar), o acciones que apoyan la cortesía o que entran en conflicto con ella, en tanto que refuerzan la imagen positiva del emisor o la perjudican. Se trata, a diferencia del tipo de cortesía valorada en el refrán del apartado 1, de lo que Leech (1983: 83) denominó cortesía absoluta, pues esta se concibe como una característica propia de algunos actos, como los citados.

\subsection{Refranes de contenido descriptivo}

Entre los refranes descriptivos, se valoran positivamente la disculpa y la excusa, por ser actos que solventan comportamientos negativos de los hablantes: Para poco es la boca que disculpa no topa o Triste es la boca que no sabe excusa. Del mismo modo, el consejo siempre es juzgado de forma positiva por el refranero, lo cual es coherente con el tipo de acto de habla que constituye: Un buen consejo no tiene precio; Un buen consejo no merece menosprecio; etc. De acuerdo con Haverkate (1994: 148), el consejo es un acto de habla exhortativo no impositivo, en el que el hablante procura conseguir que el oyente realice el acto exhortado primariamente en beneficio de sí mismo.

En otros refranes, el juicio negativo sobre ciertos tipos de texto tiene que ver con la imagen del emisor ante su receptor, perjudicada por el uso de géneros intrínsecamente descorteses, como el ruego o la petición. Por eso el refranero califica a los emisores de estos actos como pordioseros o apestados: Quien pedir suele, mal huele; Quien pide, apesta, y huele bien el que da o presta; Dar es de caballeros; y pedir, de pordioseros; Lo muy rogado, a caro precio es comprado, etc. 


\subsection{Refranes de contenido prescriptivo}

En cuanto a los refranes prescriptivos de este apartado, se observa en el corpus la existencia de diversas expresiones que prescriben o aconsejan enunciar determinados tipos de texto. Entre las razones que fundamentan estas normas encontramos que la realización de ciertos actos de habla corteses redunda en beneficio del interlocutor $y$, por tanto, refuerza su imagen positiva ante el receptor. Por eso, el refranero suele recomendar la enunciación de actos como el saludo, en La palabra de Dios [el saludo] a nadie se le niega, o la alabanza, en Cierra tu puerta, y alaba a tu vecino o Cierra tu puerta, y loa a tus vecinos. Aunque es frecuente que el refranero juzgue negativamente la alabanza por ser con frecuencia insincera (Alabanzas y regalos, tratos malos), alabar es un acto de habla cuya enunciación ideal (sincera) se aconseja siempre en los refranes.

\section{CONCLUSIONES}

Como ha podido comprobarse, los hablantes identifican intuitivamente la cortesía con lo que socialmente se considera educado en el hablar. Así, aquellos refranes donde la cortesía se concibe como lo que se dice para agradar al interlocutor apuntan a lo que, desde el punto de vista social, es amable y gentil para el resto de individuos de la comunidad. Por lo que respecta a aquellas expresiones que especifican normas referentes, por ejemplo, a los turnos de habla, no hay que olvidar que estas valoran o aconsejan el respeto a determinadas normas sociales manifestadas en la comunicación, lo que se traduce igualmente en una cuestión de urbanidad en el hablar. Por otra parte, expresarse evitando utilizar términos malsonantes, hecho al que se refieren otros refranes analizados, no es sino una denuncia de la grosería y, por tanto, una valoración del respeto y el trato educado hacia los demás hablantes.

Se demuestra, en esta línea, que en la lingüística de los hablantes se encuentra la percepción de algo que ya ha señalado la lingüística teórica, por ejemplo, Brown y Levinson: la cortesía es un instrumento de control interno, que hace posibles las buenas relaciones sociales controlando la agresividad de los miembros de la comunidad: La palabra blanda rompe la ira; Buenas palabras al más airado calman; Buenas palabras y buenos modales todas las partes abren; Buenas palabras y buenos modos dan gusto a todos, etc. Esto es lo que valora y aconseja el refranero: el uso de la lengua para mantener la buena relación entre los miembros de una comunidad lingüística. De ahí que, en la mayor parte de los refranes, se valore la eficacia del uso de la cortesía como estrategia comunicativa con una finalidad social. El refranero transmite la idea 
de lo poderosa que resulta, tanto comunicativa como socialmente, esta estrategia verbal: Arte para lograr es el dulce hablar. Esta idea ha sido señalada, por ejemplo, por Escandell (1996: 135): «[...] lo utilizamos [el lenguaje] cuando pretendemos determinados objetivos, especialmente aquellos cuya consecución depende más o menos directamente de otras personas». Se trata, en fin, de actuar sobre el destinatario de la manera perseguida por el hablante.

Del mismo modo, los hablantes perciben, por un lado, que existe un tipo de cortesía que regula la distancia social, reflejada en Cuando en mi casa me llaman con crianza, mala va la danza; y, por otro, perciben también que existe lo que la lingüística ha denominado «imagen pública» del hablante, es decir, un prestigio que hay que conservar. Los hablantes son conscientes de que la lengua ayuda a preservar esta imagen y, por eso, juzgan positivamente los actos de habla considerados por la lingüística teórica como intrínsecamente corteses, pues son estos los que protegen la imagen del emisor ante el receptor: Para poco es la boca que disculpa no topa; y rechazan los descorteses, por ser aquellos que amenazan la imagen positiva del hablante: Quien pedir suele, mal huele.

Con todo, los hablantes también juzgan negativamente la cortesía en dos sentidos. El primero se basa en su ineficacia en la obtención de bienes materiales, de beneficios que no son comunicativos y sociales. El segundo tiene que ver con una concepción peyorativa sobre la cortesía que hemos señalado en algunos refranes que asocian este término con formas de comportamiento humano aparentemente gentiles, pero en el fondo insinceras.

En definitiva, que el refranero atienda al buen funcionamiento de los intercambios comunicativos entre los hablantes y que tenga en cuenta muchos de los elementos pragmáticos que determinan el hablar (emisor, receptor, finalidad, contexto, etc.) demuestra que los refranes transmiten una concepción pragmática del hablar, ${ }^{10}$ esto es, que conciben el hablar en su dimensión funcional o atienden a cómo se usa efectivamente el lenguaje en el seno de una comunidad lingüística, en este caso, en lo que atañe a las relaciones entre los miembros de esa comunidad. A esta conclusión han llegado otros estudios descriptivos centrados en la concepción intuitiva que sobre el lenguaje está presente en diversas manifestaciones de la lengua española. Tales estudios, al igual que este, forman parte del proyecto Lo metalingüístico en español, desarrollado en la Universidad de Navarra y la Universidad de La Coruña. ${ }^{11}$

10. Se considera pragmático, siguiendo a Vilarnovo y Sánchez (1992: 42), todo enfoque de la lingüística que, por un lado, concibe el hablar como acción comunicativa y, por otro, tiene en cuenta el contexto general de enunciación del discurso, en el que se encuentran todos los elementos pragmáticos que se citan a continuación. 


\section{REFERENCIAS BIBLIOGRÁFICAS}

Álvarez, N. et al. (2006): «Lo metalingüístico en español», en CASADO Velarde, M., R. GonzÁlez Ruiz y M ${ }^{\mathrm{a}}$ V. Romero (eds.) (2006): Actas del I Congreso Internacional "Análisis del discurso: lengua, cultura, valores”, Madrid, Arco/Libros, vol. II, 2423-2432.

AZNÁREZ MAUlEón, M. (2004): La fraseología metalingüística con verbos de lengua en español actual, Universidad de Navarra, Tesis doctoral inédita.

AZnÁREZ MAUlEón, M. et al. (2002): «Tres calas (más) en el metalenguaje del español», Anuario de Estudios Filológicos, XvI: 17-33.

Brown, P. y S. Levinson (1987): Politeness: some universals in language use, Cambridge, Cambridge University Press.

Corpas Pastor, G. (1996): Manual de fraseología española, Madrid, Gredos. Coseriu, E. (1992): Competencia lingüística. Elementos de una teoría del hablar, Madrid, Gredos.

EsCANDELL-VIDAL, M ${ }^{\mathrm{a}}$ V. (1996): Introducción a la pragmática, Barcelona, Ariel.

GONZÁLEZ RUIZ, R. (2004): «Lo metalingüístico en español», en GonZÁLEZ Calvo J. M. et al. (eds.) (2004): Actas de las VII Jornadas de Metodología y Didáctica de la Lengua Española: Las Unidades Fraseológicas, Cáceres, Universidad de Extremadura, 313-325.

GonzÁlez Ruiz, R. y Ó. LouReda LAMAs (2001-2002): «Nuevos estudios sobre lo metalingüístico en español», Cuadernos de Investigación Filológica, XXVIII: 251-268.

- (2005): «Algunos estudios recientes sobre lo metalingüístico en español», Verba: Anuario gallego de filoloxia, 32: 351-369.

HaVerkate, H. (1994): La cortesía verbal. Estudio pragmalingüístico, Madrid, Gredos.

LeECH, G. (1983): Principles of Pragmatics, Londres/New York, Longman.

Loureda Lamas, Ó. (2003 a): Los nombres de los tipos de texto. El campo léxico 'lo que se dice' en español actual, Pamplona, Eunsa.

- (2003 b): «El metalenguaje de la lengua y los tipos de discurso. El campo léxico de los actos de habla», en MuÑoz NúÑEZ, $M^{a}$ D. et al. (eds.) (2003):

11. Me refiero sobre todo a dos trabajos descriptivos: dos sobre el léxico metalingüístico (Loureda, $2003 a$ y $2003 b$ ) y otro sobre una parcela de la fraseología metalingüística en español (Aznárez Mauleón, 2004). Además, los resultados científicos del grupo investigador se exponen, entre otros lugares, en Aznárez Mauleón, González Ruiz, Loureda y Manero Richard (2002), González Ruiz (2004), González Ruiz y Loureda (2001-2002 y 2005) y Álvarez, González Ruiz, Loureda y Manero (2006). El proyecto Lo metalingüístico en español ha disfrutado de la beca del Ministerio de Ciencia y Tecnología (referencia BBF 2002-00801) y se ha desarrollado de 2002 a 2005. 
Actas del IV Congreso de Lingüística General, Cádiz, Universidad de Cádiz/Universidad de Alcalá, vol. III, 1653-1661.

MANERo RichaRd, E. (2000): «La lingüística implícita en el refranero español de contenido metalingüístico», RILCE, 16/2: 343-361.

- (2005 a): Aproximación a un estudio del refrán. El refranero español de contenido metalingüístico, Universidad de Navarra, Tesis doctoral inédita.

- (2005 b): «Un caso especial de fenómeno polifónico de la lengua: el refrán», en CASADO VelaRde, M. et al. (eds.) (2005): Estudios sobre lo metalingüístico en español, Frankfurt am Main, Peter Lang, 93-115.

SACKS, H., A. Schegloff y G. JEFFERSON (1974): «A simplest systematics for the organization of turn-taking for conversation», Language, 50/4: 696-735. Searle, J. (1979): Expression and Meaning. Studies in the Theory of Speech Acts, Cambridge, Cambridge University Press.

- (1980): Actos de habla: ensayos de filosofía del lenguaje, Madrid, Cátedra. Tusón Valls, A. (1997): Análisis de la conversación, Barcelona, Ariel.

Vilarnovo CaAmaño, A y J. F. SÁnchez (1992): Discurso, tipos de texto y comunicación, Pamplona, Eunsa.

\section{DICCIONARIOS}

Due Moliner, Ma (1998): Diccionario de uso del español, Madrid, Gredos, $2^{\mathrm{a}}$ ed.

Drae Real Academia Española (2001): Diccionario de la lengua españo$l a$, Madrid, Espasa-Calpe, $22^{\mathrm{a}}$ ed.

Dea Seco, M., O. Andrés y G. Ramos (1999): Diccionario del español actual, Madrid, Aguilar.

\section{REFRANEROS DESPOJADOS}

Campos, J. y A. Barella (1996): Diccionario de refranes, Madrid, EspasaCalpe, $3^{\mathrm{a}}$ ed.

RodríGuez MARÍN, F. (1926): Más de 21.000 refranes castellanos no contenidos en la copiosa colección del maestro Gonzalo Correas, Madrid, Tip. de la "Revista de Archivos, Bibliotecas y Museos".

- (1930): 12.000 refranes más no contenidos en la colección del maestro Gonzalo Correas ni en "Más de 21.000 refranes castellanos", Madrid, Tip. de la "Revista de Archivos, Bibliotecas y Museos".

- (1934): Los 6.666 refranes de mi última rebusca, Madrid, Bermejo impresor

- (1941): Todavía 10.700 refranes más, Madrid, Prensa Española. 


\title{
METÁFORA Y LENGUAJE POLÍTICO- PERIODÍSTICO: «FRANCIA HERIDA»
}

\author{
Mángeles Moreno Lara \\ Universidad de La Rioja
}

\section{INTRODUCCIÓN}

L A teoría de la metáfora conceptual (Lakoff y Johnson, 1980) se basa en la noción de correspondencias entre conceptos de diferentes dominios. Grady $(1997,1999)$ ofrece un análisis alternativo de conceptualización metafórica más básico que implica un tipo de correspondencias que surgen a través de correlaciones experienciales. Son las llamadas metáforas primarias o de correlación. Desde esta perspectiva, el trabajo que presentamos tiene como objetivo el estudio de dos metáforas que describieron figuradamente las diez noches de violencia vivida en Clichy-sous-Bois. Estas metáforas son LA SOCIEDAD ES UN CUERPO (PMC) ${ }^{1}$ y EL ESTADO ES UNA PERSONA (Chilton, 1996; Kövecses, 1994; Lakoff, 1991). Los ejemplos analizados han sido extraídos del periódico Le Monde del 8 de noviembre de 2005 y de la revista Le Nouvel Observateur del 10-16 de noviembre de 2005. El resultado obtenido sugiere que LA SOCIEDAD ES UN CUERPO y EL ESTADO ES UNA PERSONA están motivadas por dos metáforas de tipo correlacional: UNA ORGANIZACIÓN ABSTRACTA ES UNA ESTRUCTURA FÍSICA (Grady, 1997) y EL DAÑO (no físico) ES DAÑO FÍSICO (PMC). Por otra parte, las metáforas: LOS OBJETIVOS SON DESTINOS y LOS ESTADOS SON LUGARES clasificadas como primarias por Lakoff y Johnson (1999: 45ss.), han sido objeto de nuestro interés, ya que nos han ofrecido datos sobre conceptualización de víctima y de gobierno político. Otros mecanismos conceptuales como la metonimia e interacción de modelos conceptuales han completado nuestro estudio. En este sentido hemos seguido la propuesta de (Ruiz de Mendoza, 1999; Ruiz de Mendoza y Otal, 2002; Ruiz de Mendoza y Díez, 2002 y 2004) y hemos seleccionado algunos ejemplos de interacción cuyos efectos comunicativos y cognitivos son importantes. En efecto, las expresiones metonímicas de tipo meta-en-fuente revelan que aunque son la periferia y su población los principales damnificados, el daño afecta de un modo global a la sociedad y al Estado francés. Finalmente, hemos tenido en cuenta otras nociones relacionadas con el papel de la proyección conceptual en la derivación de significado como

1. Página de la Metáfora Conceptual [en línea] Universidad de Berkeley (PMC en adelante). 
el Principio de generación de Correspondencias (Ruiz de Mendoza, 2005, en preparación) y el valor performativo de la metáfora (Sweetser, 2000).

Antes de comenzar nuestro análisis queremos presentar brevemente algunas nociones relativas a mecanismos conceptuales que han constituido la base de nuestro estudio.

\subsection{Algunos postulados teóricos}

Tipos de metonimia. Ruiz de Mendoza (2000) establece dos tipos de metonimia, de fuente-en-meta y de meta-en-fuente. Observamos los ejemplos siguientes extraídos del periódico Le Monde del 8 de noviembre de 2005:

(1) La gauche et la droite portent des responsabilités dans cette déchirure du pacte républicain dans les banlieues (LM 8.11.05: 2) ${ }^{2}$

(2) Cette France blessée qui paie [...] la facture de nos conservatismes (LM 8.11.05: 2)

Los términos izquierda y derecha de (1) van asociados a los dos partidos políticos que se han sucedido en Francia desde 1990; podemos decir que las nociones de ideología, partido y escaño que ocupan los políticos en el Parlamento son subdominios de persona que actúan como dominio inclusivo o dominio matriz (Ruiz de Mendoza y Díez, 2002). En (2) se trata de un ejemplo de la metonimia PAís POR CIUDADANOS; en la expresión, Francia, el dominio matriz, representa uno de sus subdominios, los ciudadanos de Clichy-sous-Bois. En (1) la metonimia proyecta un subdominio en su correspondiente dominio matriz y en (2), el dominio matriz resalta uno de sus subdominios. Ruiz de Mendoza y Díez, (2002: 518ss.) denominan ambos procesos conceptuales expansión de dominio (1) y reducción de dominio (2) respectivamente, cuyos efectos cognitivos y comunicativos son relevantes como veremos en el estudio detallado de algunos ejemplos de nuestro corpus.

Subescenas y escenas experienciales. Grady y Johnson (2002) en su análisis de proyección conceptual, han añadido dos unidades de experiencia que llaman subescena y escena primaria. Estos elementos conceptuales intervienen muy particularmente en la explicación de aspectos lingüísticos y de estruc-

2. Las convenciones utilizadas en la composición de las entradas han sido las siguientes: Expresión metafórica: cursiva. Publicación: Nombre del periódico o de la revista en abreviatura: Le Monde (LM), Le Nouvel Observateur (NO), seguido de la fecha, el mes, el año (las dos últimas cifras), dos puntos y la página. Se añade (T) si se trata de titulares. 
tura conceptual ya que sirven de base experiencial en la formación de metáforas primarias o de tipo correlacional.

Principio de Generación de Correspondencias. Ruiz de Mendoza (2005, en preparación) lo define de este modo: «Una vez identificado un sistema de correspondencias, se deben generar todas las posibles correspondencias entre los dominios fuente y meta. Esto puede suponer la utilización de proyecciones adicionales, algunas de ellas de tipo metonímico».

Performatividad. Este término tiene su origen en el campo filosófico y lingüístico (Austin, 1962; Searle, 1969, 1983, 1989), según el cual, la aparente descripción de un acto de habla se plantea como el modo de hacer algo diciéndolo. Sweetser (2000), desde este enfoque, analiza la performatividad como un modo de relacionar los dominios conceptuales y la realidad. Aunque su estudio se basa en lo mágico y lo ritual, su aplicación en el análisis metafórico del lenguaje político-periodístico es interesante ya que evidencia cómo los políticos y los periodistas intentan con sus enunciados influir en la realidad política (Moreno, 2004).

\section{ANÁLISIS DE ALGUNOS MODELOS CONCEPTUALES}

\subsection{La sociedad es un cuerpo}

Le Monde en su ejemplar del 8 de noviembre de 2005 mostraba un editorial que titulaba Fracture urbaine. Presentamos un extracto del mismo en el que el empleo de la metáfora LA SOCIEDAD ES UN CUERPO nos permite poner en correspondencia nuestro conocimiento sobre un cuerpo herido y dolorido con el razonamiento lógico de un problema sociológico y político.

Pour guérir «cette France blessée», qui paie par le chômage et l'exclusion la facture de nos conservatismes, le futur président prescrivait cinq remèdes sous la forme d'engagements [...]. La gauche et la droite portent des responsabilités dans cette déchirure du pacte républicain dans les banlieues [...]. Il y a deux ans, le 21 octobre 2003 à Vincennes, M. Chirac a ressucité la fracture sociale en évocant la nécessité de réconquerir les territoires perdus de la republique. «Ces difficultés, ces drames, cette fracture sociale qui menace de s'élargir en une fracture urbaine, ethnique et parfois mème réligieuse, ne sont pas des fatalités assurait-il. (El entrecomillado es del autor del editorial; la cursiva es mía y distingue una expresión metafórica). 
Analizamos a continuación algunos ejemplos del texto:

(3) «Cette France blessée», qui paie par le chômage et l'exclusion la facture de nos conservatismes (LM 8.11.05: 2)

Cette France blessée es una realización lingüística de la metáfora LA SOCIEDAD ES UN CUERPO en cuyo dominio fuente se desarrolla una metonimia de tipo meta-en-fuente como hemos descrito en (2). De acuerdo con Ruiz de Mendoza y Díez (2002), en este tipo de operación el lector accede globalmente al dominio matriz y debe determinar el subdominio relevante. El nombre del país, Francia, representa uno de sus subdominios, los habitantes de Clichysous-Bois. Por otra parte, LA SOCIEDAD ES UN CUERPO interacciona con la metáfora EL DAÑO (no físico) ES DAÑO FÍSICO (PMC) ya que el paro y la exclusión se entienden figuradamente como lesiones físicas que sufre la ciudadanía. De este modo, la proyección metonímica y las inferencias que resultan de la proyección metafórica nos permiten comprender el daño vivido por la ciudadanía de la periferia de París. En el mismo párrafo, la expresión Qui paie la facture de nos conservatismes es un ejemplo de la metáfora LAS IDEAS SON MERCANCÍAS que es un caso específico de LAS IDEAS SON OBJETOS (Lakoff, 1991). En el contexto político, el término mercancías encuentra su correspondencia en el dominio meta en las medidas sociales y de empleo de un gobierno conservador. En el ejemplo que analizamos a continuación dos términos, desgarro y fractura que conforman el dominio conceptual de cuerpo humano nos permiten analizar la base experiencial de las metáforas UNA ENTIDAD POLÍTICA ES UNA PERSONA Y LA SOCIEDAD ES UN CUERPO.

(4) La gauche et la droite portent des responsabilités dans cette déchirure $d u$ pacte républicain dans les banlieues [...]. «Ces difficultés, ces drames, cette fracture sociale qui menace de s'élargir en une fracture urbaine, ethnique et parfois même religieuse, ne sont pas des fatalités assurait-il [...]. (LM 8.11.05: 2)

El término déchirure, en francés como su equivalente en español, se utilizan con el sentido físico de romper o separar violentamente en varias partes un objeto, un papel, un vestido, y por extensión pueden referirse al cuerpo humano para designar un desgarro del tejido muscular o una herida. En la déchirure du pacte republicain de (4), en el dominio meta, una entidad política, el pacto republicano francés se manifiesta metafóricamente como una estructura física que se rompe o como un cuerpo humano que sufre un desgarro muscular. En el dominio meta, los valores democráticos que representan el modelo de régimen republicano francés han sido lesionados por las medidas políticas sociales y de empleo erróneas. El rasgo principal de "daño violento" subyace 
a los dominios fuente y meta, podemos, por ello, considerar la expresión como un ejemplo en el que interaccionan dos metáforas correlacionales: UNA ORGANIZACIÓN ABSTRACTA ES UNA ESTRUCTURA FÍSICA, (Grady, 1997) y EL DAÑO (no físico) ES DAÑO FÍSICO (PMC). Con respecto al término fracture que completa el párrafo (4), su empleo puede utilizarse con un sentido físico, referido a una estructura física como la corteza terrestre, a un hueso corporal o puede emplearse con un significado moral, como el que observamos en el ejemplo (5), extraído de Le Petit Robert:

(5) Tous à droite comme à gauche ont dénoncé la fracture sociale, stigmatisée (PR: 1119)

De este modo, podemos aplicar un doble nivel de descripción y decir, en primer lugar, que la expresión la fracture sociale, urbaine, réligieuse de (4) es una realización lingüística de una metáfora primaria UNA ORGANIZACIÓN ABSTRACTA ES UNA ESTRUCTURA FíSICA, ya que, y de acuerdo con el contexto, la sociedad de Clichy-sous-Bois es figuradamente una estructura física que se está rompiendo y al igual que como ocurre con un edificio, la fractura se extiende y daña a todo el conjunto. En segundo lugar, podemos explicar la expresión como un ejemplo de la metáfora de nivel más específico LA SOCIEDAD ES UN CUERPO, en cuyo dominio fuente, el daño físico corporal se proyecta sobre el daño social. Ofrecemos a continuación dos ejemplos, uno de ellos motivado por la metáfora EL ESTADO ES UNA PERSONA:

(6) L'état paralysée par les corporativismes [...], il a aussi accepté le désespoir des cités. (NO 10.11.05: 65)

(7) L'administration, tetanisée, nous a demandé de leur parler mais sans citer le nom de Sarkozy et sans donner la moindre position personnelle! (NO 10.11.05: 76)

En l'administration tétanisée de (7), una entidad política está conceptualizada como un cuerpo infectado gravemente. La subescena física de un órgano afectado por el tétanos se correlaciona con la contractura física de ese órgano vital. Esta relación de causa y efecto que existe en el mundo físico conforma la representación cognitiva de tensión, rigidez e inmovilidad del Estado francés que se proyecta en el dominio meta de la metáfora. Por otra parte, la expresión le désespoir des cités de (6) es un ejemplo de la metáfora LA SOCIEDAD ES UN CUERPO, motivada por una metonimia de tipo meta-en-fuente: los suburbios o dominio matriz se proyecta sobre uno de los subdominios, los ciudadanos que los habitan.

En el texto del editorial de Le Monde, ciertas expresiones relativas a la práctica política y a la información mediática actúan figuradamente como 
prácticas médicas. Observamos los ejemplos siguientes, dos de ellos extraídos de Le Nouvel Observateur del 10-16 de noviembre 2005:

(8) [Chirac] prescrivait cinq remèdes sous la forme d'engagements [...] Là encore le diagnostic était juste (LM 8.11.05:2)

(9) CNN et Al Jazire auscultent nos banlieues. (NO 10.11.05: 63)

(10) On va réanimer une loi inventée quand commençait cette guerre qui balaierait la IV République (NO 10.11.05: 63)

Los términos Chirac prescrivait cinq remèdes y Le diagnostic était juste, referidos al presidente francés y que leemos en (8), describen al político como un profesional de la medicina. En (9) el extrarradio francés se interpreta figuradamente como una persona enferma. En su información explícita se trata de un ejemplo de la metáfora LA CIUDAD ES UN CUERPO ya que existe una proyección conceptual del dominio físico de reconocimiento médico al cognitivo de investigación de un acontecimiento social. En el dominio fuente, la acción física de exploración mediante el oído y acompañada de instrumentos adecuados, tiene su correspondencia, en el dominio meta, en la grabación por parte de los medios de comunicación de las escenas de violencia de coches y de casas incendiadas en el extrarradio de París y captadas por lo periodistas de las televisiones extranjeras. Por otra parte, si consideramos que la parte más relevante del dominio fuente del término auscultar se pone en relación con el que ha sido el objetivo principal de las cámaras extranjeras, es decir, la captación de las imágenes de violencia y fuego de las calles para presentarlas en la cabecera de los programas informativos y de los periódicos, su empleo metafórico tiene un significado añadido, ya que el analista francés expresa intencionadamente, el diferente tratamiento del asunto que ha recibido por parte de los periodistas franceses que han sido más prudentes en sus boletines de noticias. En este sentido hablamos del valor performativo de la metáfora (véase NO 16.11.05: 74).

En el ejemplo siguiente, la metáfora LA SOCIEDAD ES UN CUERPO concurre con dos correspondencias específicas de la metáfora compleja LAS ACTIVIDADES CON OBJETIVOS SON VIAJES (Lakoff y Johnson, 1999) que nos aportan datos relativos a niveles de conceptualización y derivación de significado.

(11) Les banlieues ont mal aux jeunes? La République, elle se cherche un père. Jacques Chirac est absent. Personne ne tient la barre (NO 10.11.05: 66)

Les banlieues ont mal aux jeunes es un ejemplo de la metáfora LA SOcIEDAD ES UN CUERPO, en cuyo dominio fuente, las zonas periféricas de las grandes ciudades se describen figuradamente como cuerpos que padecen el dolor 
producido por uno de sus órganos. Este conocimiento sobre el cuerpo físico enfermo, encuentra su correspondencia en el dominio meta de la realidad social y nos permite razonar sobre los incendios y la violencia desatada por los jóvenes en las calles y edificios. Podemos considerar esta misma expresión como un caso de proyección metonímica de reducción de dominio, si, además del daño físico que sufre la ciudad, el periodista quiere comunicar el daño que sufren los ciudadanos. En este caso, debemos resaltar del dominio matriz que representan las ciudades de la periferia, el subdominio más representativo del contexto, es decir, las familias y los habitantes que los habitan. De este modo, dos operaciones conceptuales nos han permitido comprender el daño urbano y el daño social respectivamente y se adecuan al Principio de Generación de Correspondencias (Ruiz de Mendoza, 2005).

El párrafo (11) se completa con dos expresiones metafóricas: La République, elle se cherche un père y Personne ne tient la barre. La primera es un ejemplo de LA SOCIEDAD ES UNA FAMILIA. Lakoff (1996: 153ss.) considera que un modelo particular del concepto de familia interviene en la concepción de otros dominios como por ejemplo el gobierno en una sociedad. En (11) la figura del padre se proyecta en la figura de mayor autoridad que conduce una organización social/política, la guía y la protege. La segunda expresión, Personne ne tient la barre, es una realización lingüística de la metáfora de nivel específico LA POLíTICA ES UN VIAJE. En la expresión, el estado francés es, en sentido figurado, un barco que navega sin rumbo. En el dominio meta, la ausencia del presidente francés en los momentos críticos ralentiza las vías de pacificación y de búsqueda de solución a la violencia. Los dominios fuente de viaje y familia comparten con el dominio meta de la política una estructura conceptual relevante en la que se incluyen objetivos, metas, dificultades, medios y (como se describe en las expresiones mencionadas) la presencia de un "guía". En el caso de la política, esta figura se pone en correspondencia con el gobierno en general o el presidente en particular. Desde el punto de vista conceptual podemos decir que las metáforas LA SOCIEDAD ES UNA FAMILIA Y LA POLÍTICA ES UN VIAJE son casos específicos de la metáfora compleja LAS ACTIVIDADES CON OBJETIVOS SON VIAJES, ya que cualquier tipo de actividad con objetivos puede ser descrita como un viaje con un destino y ambas comparten la estructura conceptual de la metáfora LOS OBJETIVOS SON DESTINOS, clasificada por Lakoff y Johnson, a partir de los trabajos de Grady (1997), como una metáfora primaria (Lakoff y Johnson, 1999: 45). La proyección metafórica de las expresiones La République, elle se cherche un père y Personne ne tient la barre resaltan explícitamente el papel relevante del conductor-guía e inferimos (implícitamente) que su actuación es imprescindible para la consecución del objetivo político. 


\subsection{Los estados son lugares}

De acuerdo con Lakoff y Johnson (1999: 52), la escena primaria de la metáfora LOS ESTADOS SON LUGARES asocia dos tipos de experiencias, un estado psicológico y la presencia de un lugar determinado. En los ejemplos siguientes, esta metáfora primaria interacciona con el modelo proposicional de guerra y describe figuradamente el concepto de víctima.

(12) On promène la torche dans la soute à poudre. Dans certaines circonstances des mots sont des balles ou des coktails Molotov (NO 10.11.05: 65)

(13) Aujourd'hui on vit dans un monde où certains n'ont aucune chance de s'en sortir, vu l'endroit où ils vivent. Voilà pour ce qu'il appelle «la poudrière structurelle» (NO 10.11.05: 80)

Podemos clasificar las expresiones On promène la torche dans la soute à poudre y des mots sont des balles ou des coktails Molotov de (12) como realizaciones lingüísticas de la metáfora LAS PALABRAS SON ARMAS ya que lo que se dice hace referencia a los términos ofensivos con los que el ministro Sarkozy se dirigió a los jóvenes de Clichy-sous-Bois. Por otra parte, los términos la soute à poudre de (12) y la poudrière de (13) son ejemplos de la metáfora primaria LOS ESTADOS SON LUGARES (Lakoff y Johnson, 1999), si observamos que en la proyección metafórica, los términos la soute à poudre y poudrière encuentran su correspondencia en el estado exasperado de los habitantes de los suburbios de la capital francesa. De acuerdo con la propuesta de Grady y Johnson (2002) sobre motivación experiencial, la subescena experiencial de las expresiones la soute à poudre y la poudrière structurelle, muestran un lugar, un polvorín (en cuyo interior se guarda la pólvora). La subescena compleja revela la interrelación de dicho lugar con el estado de las personas y con el tipo de segregación en la que viven y es esta segunda subescena la que encuentra su correspondencia en el dominio meta de las dos expresiones metafóricas; la poudrière structurelle refleja además la disparidad económica social y religiosa que existe en Clichy-sous-Bois. Finalmente podemos incluir una proyección metonímica y considerar la soute à poudre y la poudrière structurelle como ejemplos de reducción de dominio ya que el dominio matriz de lugar comprende la subescena experiencial de estado de segregación de las personas que habitan Clichy-sous-Bois. 


\section{CONCLUSIONES}

Hemos ofrecido un estudio del empleo de algunos modelos conceptuales en la descripción que ciertos analistas políticos realizaron de la semana de violencia vivida en Clichy-sous-Bois. En primer lugar, las metáforas LA SOCIEDAD ES UN CUERPO Y EL ESTADO ES UNA PERSONA logran estructurar en su conjunto la idea de daño político y social expresado por los periodistas y políticos franceses. El análisis de nuestros ejemplos sugiere que estas metáforas de nivel cultural están motivadas por una metáfora de tipo correlacional: UNA ORGANIZACIÓN ABSTRACTA ES UNA ESTRUCTURA FísICA (Grady, 1997). Dos metáforas clasificadas como primarias, LOS ESTADOS SON LUGARES y LOS OBJETIVOS SON DESTINOS (Lakoff y Johnson, 1999), han sido igualmente objeto de interés, ya que nos han ofrecido datos sobre niveles de descripción, proyección conceptual y motivación metonímica de metáfora primaria. Finalmente, algunos ejemplos nos han ofrecido datos sobre mecanismos conceptuales relacionados con los procesos de derivación de significado como expansión y reducción de dominio (Ruiz de Mendoza y Díez, 2002 y 2004), Principio de Generación de Correspondencias (Ruiz de Mendoza, 2005) y valor performativo de la metáfora (Sweetser, 2000).

\section{BIBLIOGRAFÍA}

Austin, J. L. (1962): How to Do Things with Words, Oxford, Oxford University. Chilton, P. (1996): Security Metaphors: Cold War Discourse from Containment to Common House, Nueva York, Peter Lang.

Chilton, P. y C. SchäFfNer (1997): «Discourse and politics», en van DiJK, T. A. (ed.) (1997): Discourse as Social Interaction. Discourse Studies, vol. II, Londres, Sage Publications, 206-230.

Conceptual Metaphor Home Page [en línea], University of Berkeley, 24 marzo 1995. Disponible en: <http://cogsci.berkeley.edu/metaphors> GRADY, P. (1997): «THEORIES ARE BUILDINGS revisited», Cognitive Linguistics, 8-4: 267-290.

GRADY, P. (1999): «A typology of motivation for conceptual metaphor: correlation vs. resemblance», en GIBBS, R. y G. STEEN (eds.) (1999): Metaphor in Cognitive Linguistics, Ámsterdam, Filadelfia, John Benjamins, 79-101.

Grady, P. y C. Johnson (2002): «Converging evidence for the notions of subscene and primary scene», en DiRven, R. y R. PöRINGS (eds.) (2002): Metaphor and Metonymy in Comparison and Contrast, 533-553.

KöVECSES, Z. (1994): «Tocqueville's passionate "beast": a linguistic analysis of the concept of American democracy», Metaphor and Symbolic Activity, 9-2: 113-133. 
- (2005): Metaphor in Culture. Universality and Variation, Cambridge, Cambridge University Press.

LAKOFF, G. (1991): «Metaphors and war: the metaphor system used to justify war in the Gulf», Lentz Peace Research, 23: 25-29.

- (1993): «The contemporary theory of metaphor», en ORTONY, A. (ed.) (1993): Metaphor and Thought, $2^{\mathrm{a}}$ ed., Cambridge, Cambridge University Press, 202-251.

- (1996): Moral Politics. What conservatives know that liberals don't, Chicago y Londres, University of Chicago Press.

LAKoff, G. y M. Johnson (1980): Metaphors We Live by, Chicago, University of Chicago Press.

- (1999): Philosophy in the flesh: The embodied mind and its challenge to Western thought, Nueva York, Basic Books.

Moreno, A. (2004): La Metáfora Conceptual y el Lenguaje Político Periodístico: Configuración, Interacciones y Niveles de Descripción [en línea], Universidad de La Rioja. Disponible en <http://publicaciones. unirioja.es/ tesis/tesis28.shtml>.

Ruiz de Mendoza, F. J. (1998): «On the nature of blending as a cognitive phenomenon», Journal of pragmatics, 30-3: 259-274.

- (1999): Introducción a la Teoría Cognitiva de la Metonimia, Granada, Método Ediciones.

- (2000): «The role of mappings and domains in understanding metonymy», en Barcelona, A. (ed.) (2000): Metonymy and Metaphor at the Crossroads, Berlín, Mouton de Gruyter, 109-132.

- (2004): «High-level action metonymies in English and Spanish», Jezikoslovlje 4; Número especial: PANTHER, K.-U. y L. THORNBURG (eds.): How Universal are Conceptual Metonymies?, Facultad de Educación de la Universidad J. Strossmayer, Osijek, Croacia, 121-138.

RuIZ DE MENDOZA, F. J. (2005 en preparación): «Construing meaning through conceptual mappings», en FUerTes, P. (ed.): Lengua y Sociedad: Aportaciones recientes en Lingüística Cognitiva, Lingüística del Corpus, Lenguajes de Especialidad y Lenguas en Contacto, Universidad de Valladolid.

Ruiz de Mendoza, F. J. y J. L. Otal (2002): Metonymy, Grammar and Communication, Granada, Comares.

Ruiz de Mendoza, F. J. y O. I. Díez Velasco (2002): «Patterns of conceptual interaction», en DiRven, R. y R. PÖRINGS (eds.) (2002): Metaphor and Metonymy in Comparison and Contrast, Berlín, Nueva York, Mouton de Gruyter, 489-531.

Searle, J. (1969): Speech Acts. An Essay in the Philosophy of Language, Cambridge, Cambridge University Press. 
- (1983): Intentionality. An Essay in the Philosophy of Mind, Cambridge, Cambridge University Press.

- (1989): «How performatives work», Linguistics and philosophy, 12: 525-558.

SweEtser, E. (2000): «Blended spaces and performativity», Cognitive Linguistics, 11, 3-4: 305-333. 


\title{
ON THE (IM)POLITENESS OF PHATIC UTTERANCES IN THE UK AND USA
}

\author{
Manuel Padilla Cruz \\ Universidad de Sevilla
}

\section{INTRODUCTION}

I $\mathrm{N}$ the extant literature on phatic communication, there have been some attempts to explain the reasons why phatic utterances are used and evaluated as (im)polite in the UK and USA. These have been based on the assumption that interlocutors abide by some conversational maxims. Thus, Leech (1983) has argued that phatic utterances are motivated by the operation of a phatic maxim that prompts individuals to avoid silence. Similarly, Schneider (1988) has postulated the existence of a supermaxim of politesse and another of friendliness which condition the specific type of phatic token participants may resort to. Accordingly, judgements about (im)politeness arise as a consequence of the interlocutors' (non-)observance of such maxims.

However, the type of phatic utterances used in these two countries is influenced by contextual factors, such as the interlocutors' social identity and relationships. These are determined, among others, by the sociological variables power (P) and social distance (D) (Laver, 1974, 1975, 1981; Brown and Levinson, 1978, 1987), which define their social roles and the politeness system (Scollon and Scollon, 1983, 1995) within which interaction takes place. Therefore, the aim of this paper will be to suggest a different approach to the (im)politeness of phatic utterances. It will be argued that judgements about the (im)politeness of such utterances are a consequence of the interlocutors' perception of a specific politeness system and the (in)adequacy of the type of phatic utterance selected for the existing politeness system. In order to do so, I will start by reviewing the extant maxim-based proposals about the (im)politeness of phatic utterances.

\section{CONVERSATIONAL MAXIMS AND PHATIC UTTERANCES}

Traditionally, phatic utterances have been described as obvious or trivial utterances (Malinowski, 1923; Abercrombie, 1956, 1998; Turner, 1973; Leech, 1974; Hudson, 1980; Edmondson and House, 1981) which do not 
transmit enough information. For this reason, they have been regarded as deviations from a supposedly accepted way of speaking that meets the standards of authentic and efficient conversation established by Grice's (1975) cooperative principle and its maxims of quantity, quality, relation and manner (Coupland, Coupland and Robinson, 1992: 211; Coupland, 2000: 7-8; Coupland and Ylänne-McEwen, 2000: 179; Holmes, 2000: 39; McCarthy, 2000: 84; Tracy and Naughton, 2000: 64). Nevertheless, the usage of phatic utterances may be due to the operation of additional interactive principles, which justify their adequacy in specific communicative circumstances. This has been Leech's (1983) and Schneider's (1988) viewpoint, whose respective works I discuss in the following two subsections.

\subsection{The phatic maxim}

Leech (1983) believes that phatic utterances violate the quantity maxim of the cooperative principle (Grice, 1975) because they do not convey information that satisfies the hearer's expectations. He attributes that violation to the operation of further conversational principles. Among those principles, he thinks that his politeness principle and its six maxims -tact, generosity, approbation, modesty, agreement and sympathy ${ }^{1}$ play a crucial role, as they explain certain aspects of communication that cannot be satisfactorily accounted for by the cooperative principle (Grice, 1975) alone. However, in addition to those maxims, he argues that a new maxim is necessary in order to justify why individuals do not always offer the expected amount of information: the phatic maxim.

Therefore, Leech (1983: 141) suggests that the occurrence of phatic utterances can be explained as a result of the interlocutor's observance of this new maxim. He formulates it both in a negative form - «Avoid silence»- and in a positive form -«Keep talking». These formulations imply that phatic utterances appear in conversations as a consequence of the necessity that interlocutors feel to avoid silence, for they would interpret taciturnity negatively in certain cases. This would be the reason why interlocutors deal with apparently irrelevant topics, such as the weather, or resort to utterances with low informative content, platitudes or compliments. ${ }^{2}$

Nevertheless, Leech (1983: 142) also warns that this maxim could be redundant, since its effects may also be due to the maxims of sympathy and agreement. He is also aware of the inadequacy of describing phatic

1. See Leech (1983: 132) for a more detailed explanation about these maxims.

2. See Wolfson and Manes (1980), Manes and Wolfson (1981) or Boyle (2000), among many others, for some comments on the phatic value of compliments. 
communion as a linguistic behaviour exclusively aimed at avoiding silence, as it creates agreement between interlocutors by mentioning common ground and experience. In fact, phatic utterances may fulfil this function because of the selection of uncontroversial topics and their emphasis on the interlocutors' attitudes, so they allow the speaker to show and intensify her interest in the hearer and offer him additional information about her.

\subsection{The supermaxims of politesse and friendliness}

Like Leech (1983), Schneider (1988) also assumes that the aim of phatic communion is not the efficient transmission of information, but rather the accomplishment of its social function, so it must be regulated by maxims of a social nature. Based on Lakoff's $(1973,1977)$ rules of politeness ${ }^{3}$ and Leech's (1983) politeness principle, he developed a series of more specific interactive principles governing the usage of phatic utterances, the most important of which is «Be polite».

Regarding the (im)politeness of phatic utterances, Schneider (1988) thinks that it depends on two aspects of interaction, which coincide with Brown and Levinson's $(1978,1987)$ notions of negative and positive face, respectively. ${ }^{4}$ The first aspect is politesse or formality, which he understands as «[...] a reaction to the psychological pressure exerted by social norms» (Schneider, 1988: 158). Politesse is related to the distant style deriving from Lakoff's $(1973,1977)$ first rule of politeness - «Do not impose, keep the social distance»- and its immediate consequence is the usage of utterances alluding to aspects of the communicative situation. The second aspect is friendliness, which is associated with the deferent style deriving from Lakoff's $(1973,1977)$ second rule of politeness -«Offer options to the hearer»- instead of the style of comradeship emanating from her third rule - «Make the hearer feel good, be friendly». Therefore, friendliness is manifested in the usage of phatic utterances referring to the interlocutors.

These two interactive aspects lead Schneider (1988: 158) to propose two supermaxims governing phatic utterances: «Avoid offence», which regulates polite or formal behaviour, and «Be friendly», which regulates friendly behaviour. They can be paraphrased as «Avoid everything negative» and «Make your interlocutor feel good». In turn, each of these supermaxims is

3. See Lakoff (1973: 298) for the initial version and Lakoff (1977: 88) for the final version of the rules of formality, hesitancy and equality or camaraderie.

4. See Brown and Levinson $(1978,1987)$ for a definition of these two concepts.

5. However, the formulation of these two supermaxims could appear misleading because Schneider (1988) states that friendliness matches the deferent style emanating from Lakoff's $(1973,1977)$ second rule of politeness but formulates that supermaxim like Lakoff's (1973, 1977) third rule of politeness. 
articulated in a series of four more specific maxims referring to different dimensions of interaction-discourse, person, union and emotion- as shown in the following table:

TABLE 1

\begin{tabular}{|l|l|l|}
\hline & \multicolumn{1}{|c|}{ Politesse } & \multicolumn{1}{c|}{ Friendliness } \\
\hline Discourse & Avoid silencie & Say something nice \\
\hline Person & Avoid curiosity & Show interest in the hearer \\
\hline Union & Avoid conflict & Create ties of union \\
\hline Emotion & Avoid pessimism & Be optimistic \\
\hline
\end{tabular}

As can be seen, the maxims of friendliness complement those of politesse to a certain extent. «Avoid silence» implies that an individual should say something, although not necessarily that what he says has to be nice or inoffensive. Hence, Schneider (1988: 159) points out that this maxim does not oblige an individual to make another feel good. Likewise, "Avoid curiosity» excludes the usage of personal topics, while «Show interest» presupposes that interlocutors will resort to them, but without dealing with very intimate or taboo ones. Finally, the maxim of union of politesse prompts interlocutors to avoid disagreement, while the same maxim of friendliness urges them to seek agreement and a positive evaluation from the other interlocutor.

Finally, Schneider (1988: 285) argues that these two supermaxims and their respective maxims account for the more offensive or defensive usage of phatic utterances. Nonetheless, the application of one supermaxim or the other depends on contextual factors. Hence, the supermaxim of politesse is normally associated with those situations in which two strangers or distant individuals have to interact, while the supermaxim of friendliness is related to what the author calls "social events". For this reason, he concludes that politesse leads interlocutors to avoid silence, which can be experienced as embarrassing, whereas friendliness favours social contact.

\subsection{Some problems}

Although Schneider's (1988) proposal is more elaborated than Leech's (1983), both works share some problems, as these authors do not mention where their respective maxims come from, if they are universal or culturespecific, how interlocutors get to know them or if they even are aware of their existence. From my point of view, these two proposals capture some additional sociocultural motivations internalised by interlocutors as a 
consequence of their process of socialisation, which lead them to behave in a particular way. In other words, these proposals imply the existence of a cultural knowledge that conditions interlocutors' linguistic behaviour, so that, if they abide by the maxims suggested, their behaviour is evaluated as polite.

Nevertheless, the existing vast literature on politeness has shown that evaluations about the (im)politeness of linguistic acts also depend crucially on sociological variables, such as power or social distance (Brown and Levinson, 1978, 1987). ${ }^{6}$ As mentioned above, these variables define the interlocutors' social identity and relationships, and determine what is permitted or expected from them in certain circumstances. Therefore, any attempt at accounting for the (im)politeness of phatic utterances must also include considerations about such factors and their influence on the usage of those utterances. For this reason, in the next section I suggest a new approach to this issue.

\section{A NEW APPROACH TO THE (IM)POLITENESS OF PHATIC UTTERANCES}

The approach that I propose in this paper is based on a new integrative conception of linguistic politeness and on previous work on phatic utterances (Laver, 1974, 1975, 1981). For this reason, firstly I discuss each of these issues in the following two subsections and then I introduce this new approach.

\subsection{A new conception of politeness}

Among the many definitions and approaches to linguistic politeness, ${ }^{7}$ there is a widely accepted one that considers it a strategic behaviour aimed at avoiding interpersonal conflict (Lakoff, 1973, 1977; Brown and Levinson, 1978, 1987; Fraser, 1990; Kasper, 1990, 1998; Thomas, 1995). In addition to this view, politeness has also been identified with the adequacy or appropriateness of certain linguistic acts to a specific context (Fraser and Nolen, 1981; Zimmin, 1981; Fraser, 1990; Meier, 1995; Escandell Vidal, 1996, 1998; Jary, $1998 a, 1998$ b).

Following Garcés Conejos (1995) and Bou Franch and Garcés Conejos (2003), politeness can also be defined as the linguistic encoding of social interaction or, in other words, as the communication of information about the

6. See Garcés Conejos (1995), Bou Franch and Garcés Conejos (2003) or Padilla Cruz (2006), among many others, for some comments on the importance of other contextual variables, such as affect (A).

7. See Eelen (2001) for a review. 
interlocutors' social relationship. Regardless of whether such behaviour is aimed at avoiding interpersonal conflict or any threat to their faces, it must be understood as the result of a rational process in which individuals take into account the social context in which they are interacting and select the linguistic form that best fits that context. But such rational behaviour should not exclusively be understood as a process of adequation to a specific predetermined social context. Individuals have interactive goals, such as the establishment, maintenance or redefinition of their social relationships. For this reason, their linguistic behaviour will not only necessarily have to be adapted to the existing social context they perceive, but may also be aimed at matching other goals, such as modifying and/or redefining their social relationships.

As aforementioned, the extant literature on politeness has stressed the role of power and social distance, among other sociological variables, in the assessment of the adequacy or appropriateness of linguistic acts (Brown and Levinson, 1978, 1987). Therefore, being polite consists, in part, in the correct evaluation of those parameters, so that individuals may fit their linguistic behaviour to the values that they achieve. Concerning the (im)politeness of phatic utterances, the work by Laver $(1974,1975,1981)$ is pioneering in that he has linked the usage of such utterances to the values that those parameters achieve.

\subsection{Sociological variables and phatic utterances}

In his work on phatic communion, Laver $(1974,1975,1981)$ distinguished a group of utterances with neutral reference -i.e. utterances alluding to or describing the weather or features of the setting where they are produced (1, $2)^{8}$ and another with personal reference -i.e. utterances about the speaker (self-oriented) $(3,4)$ or the hearer (other-oriented) $(5,6)$ :

(1) Great match yesterday!

(2) Nice day.

(3) I like a cup of tea before going to work.

(4) Hot work this.

(5) That looks like hard work.

(6) Your house is so beautiful!

8. In turn, these utterances can be further subdivided in groups depending on whether they refer to a past, present or future event (Laver, 1975: 223, 1981: 301-302). 
However, his most important contribution was to relate the usage of each type of phatic utterance in the United Kingdom and in the United States to the participants' social roles and relationship. Such relationships are defined by their social status and distance or, what is the same, their power and social distance. In Scollon and Scollon's $(1983,1995)$ terms, these variables define the politeness system in which they interact.

According to Laver $(1974,1975,1981)$, firstly, if participants have a solidarity relationship, i.e. a solidarity politeness system [-P, -D] (Scollon and Scollon, 1983, 1995), they may select both neutral and personal phatic tokens, regardless of whether these are self- or other-oriented. Secondly, if participants have a relationship characterised by no power difference but a significant social distance between them, i.e. a deference politeness system [-P, +D] (Scollon and Scollon, 1983, 1995), the rule appears to be that participants should avoid personal utterances and choose neutral ones. Finally, if participants have a non-solidarity relationship and there is a power difference between them, i.e. a hierarchical politeness system $[+\mathrm{P},+/-\mathrm{D}]$, there seem to be two tendencies. On the one hand, if the speaker has less power than the hearer, she may address the hearer using a self-oriented phatic utterance. On the other hand, if the speaker has more power than the hearer, she may use an other-oriented phatic utterance.

When individuals follow these patterns, their behaviour may be evaluated as polite. However, if they do not do so, the effects that they can achieve may be more complex, as «[...] such contraventions have special significance for indexical attitudes about the status relationship between the two speakers, and sometimes about the solidarity factor of their relationship» (Laver, 1975: 224).

Hence, in a hierarchical politeness system, when the more powerful individual addresses the inferior by means of a self-oriented phatic token, she may be understood as offering the other a temporal relationship of solidarity in which the power difference is cancelled. However, if the less powerful individual addresses the superior by means of an other-oriented phatic token, the hearer may think that she is invading his psychological space without his previous permission to do so. Likewise, in a deference politeness system, the usage of a self-oriented phatic utterance by means of the speaker may be perceived as a momentary invitation to establish a solidarity-based relationship. On the contrary, the speaker's usage of an other-oriented utterance may be felt as a brusque attempt to establish a solidarity relationship with the hearer. Therefore, when the linguistic behaviour of the speaker is perceived as an invasion of the hearer's psychological space or as if forcing the establishment of a solidarity relationship, her behaviour may be interpreted as impolite. 


\subsection{Phatic utterances, politeness systems and (im)politeness}

As has been observed, the (im)politeness of linguistic behaviour depends partially on its (in)adequacy to a perceived social context. Therefore, I believe that judgements about the (im)politeness may arise as a result of evaluating the (in)adequacy of linguistic behaviour to the politeness systems within which interlocutors are interacting (Padilla Cruz, $2004 a$, 2006). The reason why this is so is that politeness systems can be said to set the basis of a sort of Conversational Contract (Fraser and Nolen, 1981; Fraser, 1990) containing the rights and obligations allowed to individuals in particular circumstances. Some of these rights and obligations will be related to what interlocutors are expected or permitted to do as regards their linguistic contributions. In fact, concerning phatic utterances in the UK and USA, as Laver $(1974,1975,1981)$ has shown, politeness systems restrict the type of utterances that interlocutors may use, so that some types are permitted in some circumstances, and hence regarded as polite or adequate, whereas others are excluded and considered impolite or inadequate.

As Fraser and Nolen explained, «To be polite is to abide by the rules of the conversational relationship. A speaker becomes impolite just in case where he violates one or more of the contractual terms» (1981: 96). When individuals perceive the existence of a certain type of politeness system, they will access knowledge about what they are allowed to say or should avoid, i.e. knowledge about their rights and obligations related to their linguistic behaviour. Such knowledge must be constituted by the cultural metarepresentations (Sperber, 1996) that they have acquired through their process of socialisation as a consequence of having grown up within a particular sociocultural group, and will condition their linguistic behaviour by providing them with information about what they can or cannot say.

To illustrate this, consider the case of an employee addressing his employer. In that situation, assumptions such as (7a) and (7b) may be manifest ${ }^{9}$ to the employee. Similarly, he may access an assumption such as (8), which will be part of his cultural knowledge and make him infer the conclusion (9) referring to the type of relationship existing between him and his employer. Finally, the employee may also access another cultural assumption (10) about the kind of phatic utterance that he is expected to use to begin a conversation:

(7) a. I'm an employee at company X.

b. I'm going to talk to the general manager of the company.

9. In relevance-theoretic terms, an assumption is manifest to an individual when he has a mental representation of it (Sperber and Wilson, 1995: 39). 
(8) The general manager of a company is normally a powerful person because he can make decisions about the company, its employees, etc.

(9) There is a hierarchical relationship between my hearer and myself because he has more power than me.

(10) In a hierarchical relationship, the convention is that I must use a selforiented phatic utterance to begin a conversation because my interlocutor has more power than me.

Thus, if the employee's intention is to be perceived as polite, he will have to abide by the rules established for the hierarchical politeness system in which he is going to interact and select accordingly the type of phatic utterance permitted or expected in that system. If he does not do so, he will be contravening those rules and will run the risk of being regarded impolite.

Nonetheless, for hearers to make judgements about the (im)politeness of linguistic behaviour, they must also possess similar cultural metarepresentations about the different politeness systems within which their interaction may take place, as well as the kind of linguistic contributions interlocutors may resort to depending on the existence of a specific politeness system (Padilla Cruz, $2004 a$, $2004 b, 2004 c$ ). Those cultural metarepresentations must intervene in the inferential processes occurring in verbal comprehension by relating to other contextual assumptions manifest to interlocutors, thus yielding cognitive effects (Sperber and Wilson, 1986, 1995) ${ }^{10}$ referring to the (in)adequacy of the usage of specific utterances and, therefore, to their (im)politeness.

Accordingly, in the case of the previous hierarchical politeness system, if the employee uses a self-oriented phatic utterance (11) in a mutual cognitive environment ${ }^{11}$ in which assumptions such as those in (12) are manifest to both interlocutors, the employer can combine them with some of his cultural metarepresentations about interaction in the specific politeness system that he perceives (13). The interaction of those assumptions with his cultural metarepresentations could make him derive contextual implications such as those in (14) about the employee's behaviour:

(11) I am having a hard week of work.

10. According to Sperber and Wilson $(1986,1995: 108)$, there are three kinds of cognitive effects: strengthening of previously held information, contradiction and rejection of previously held information, and contextual implications, which are assumptions that can only be obtained through the joint interaction of newly received information and old information.

11. The relevance-theoretic notion of mutual cognitive environment alludes to the whole set of assumptions that are manifest to interlocutors (Sperber and Wilson, 1995: 41). 
(12) a. Employee $e_{x}$ has said that he is having a hard week of work.

b. Employee $e_{x}$ has spoken about himself.

(13) a. We do not know each other well enough.

b. The general manager of a company normally has more power in the company than one of his employees.

c. Two individuals who are socially distant do not talk about very personal topics.

d. A way to show concern for an individual's status is to avoid very personal topics.

e. Not very personal topics are adequate in a hierarchical relationship.

(14) a. Employee 's behaviour is adequate.

b. Employee ${ }_{x}$ does not want to impinge on me or make me feel embarrased.

c. Employee ${ }_{x}$ has attempted to behave politely.

As has been seen in this example, if the phatic utterances interlocutors resort to correspond to those included in their cultural metarepresentations about linguistic behaviour in a specific politeness system as adequate for that system, their behaviour will be evaluated as polite. On the contrary, if they use phatic utterances that are not permitted in a particular politeness system, their behaviour may be considered impolite.

However, the derivation of cognitive effects about the (im)politeness of specific utterances may require a certain degree of cognitive effort from the hearer, since he will have to expand his interpretive context by accessing and including in it cultural metarepresentations about politeness systems and interaction in them. In the case of phatic utterances, which may apparently seem irrelevant because of the triviality of their propositional context, the hearer will only expand it if such utterances generate enough expectations of relevance to guarantee the derivation of those effects at the exchange of an unnecessary amount of cognitive effort (Sperber and Wilson, 1986, 1995; Padilla Cruz, $2004 a$ ).

\section{CONCLUSION}

The (im)politeness of utterances whose informative load does not meet certain communicative standards, such as those reflected in Grice's (1975) 
cooperative principle, has been accounted for by the existence of additional interactive principles. Nevertheless, in this paper I have developed a new approach to the (im)politeness of such utterances in the UK and USA that hinges on the interlocutors' perception of the social context in which they are interacting and their cultural knowledge about the linguistic behaviour acceptable in that context. Accordingly, interlocutors store information about their social relationships and the type of linguistic contributions expected or permitted, which constitutes a sort of conversational contract essential for interaction. That knowledge may influence their linguistic behaviour, so that «[...] being polite constitutes operating within the then-current terms and conditions of the CC [conversational contract]» (Fraser, 1990: 233). Therefore, the (im)politeness of phatic utterances in the UK and USA can be determined as a consequence of their (in)adequacy to a set of cultural metarepresentations extended throughout the members of particular socio-cultural groups. Thus, interlocutors may conclude that phatic utterances are (im)polite when they check to see if they correspond to the type of utterances considered correct for a specific social relationship.

\section{BIBLIOGRAPHICAL REFERENCES}

Abercrombie, D. (1956): Problems and Principles, London, Longman.

- (1998): «Phatic Communion» in MeY, J. L. (ed.) (1998): Concise Encyclopaedia of Pragmatics, Oxford, Elsevier, 672-673.

Bou Franch, P. y P. Garcés Conejos (2003): «Teaching Linguistic Politeness: A Methodological Proposal», IRAL, 41: 1-22.

Boyle, R. (2000): «"You Worked with Elizabeth Taylor!" Phatic Functions and Implicit Compliments», Applied Linguistics, 21: 26-46.

Brown, P. y S. C. Levinson (1978): «Universals of Language Usage: Politeness Phenomena» in Goody, E. (ed.) (1980): Questions and Politeness, Cambridge, Cambridge University Press, 56-324.

- (1987): Politeness. Some Universals in Language Usage, Cambridge, Cambridge University Press.

Coupland, J. (ed.) (2000): Small Talk, Harlow, Pearson Education Limited.

Coupland, J., N. Coupland y J. D. Robinson (1992): «How Are You?

Negotiating Phatic Communion», Language in Society, 21: 207-230.

Coupland, N. y V. YLÄNNE-McEwEN (2000): «Talk about the Weather: Small Talk, Leisure Talk and the Travel Industry» in CouPLAND, J. (ed.) (2000): Small Talk, Harlow, Pearson Education Limited, 163-182.

Edmondson, W. y J. House (1981): Let's Talk and Talk about It. A Pedagogic Interactional Grammar of English, München, Urban \& Schwarzenberg. 
Eelen, G. (2001): A Critique of Politeness Theories, Manchester, St. Jerome Publishing.

Escandell Vidal, M. V. (1996): «Towards a Cognitive Approach to Politeness», Language Sciences, 18: 629-650.

- (1998): «Politeness: A Relevant Issue for Relevance Theory», Revista Alicantina de Estudios Ingleses, 11: 45-57.

Fraser, B. (1990): «Perspectives on Politeness», Journal of Pragmatics, 14: 219-236.

Fraser, B. and W. Nolen (1981): «The association of Deference with Linguistic Form», International Journal of the Sociology of Language, 27: 93-109.

Garcés Conejos, P. (1995): «Revisión crítica de algunos de los postulados de la teoría de la cortesía lingüística propugnada por Brown y Levinson», Quaderns de Filologia: Estudis Lingüístics, 1: 43-61.

Grice, H. P. (1975): «Logic and conversation» in Cole, P.; J. Morgan (eds.) (1975): Syntax and Semantics, Vol. 3: Speech Acts, New York, Academic Press, 41-59.

Holmes, J. (2000): «Doing Collegiality and Keeping Control at Work: Small Talk in Government Departments» in Coupland, J. (ed.) (2000): Small Talk, Harlow, Pearson Education Limited, 32-61.

Hudson, R. A. (1980): Sociolinguistics, Cambridge, Cambridge University Press.

JARY, M. (1998 a): «Is Relevance Theory Asocial?», Revista Alicantina de Estudios Ingleses, 11: 157-169.

- (1998 b): «Relevance Theory and the Communication of Politeness», Journal of Pragmatics, 30: 1-19.

KASPER, G. (1990): «Linguistic Politeness: Current Research Issues», Journal of Pragmatics, 14: 193-218.

- (1998): «Politeness» in Mey, J. L. (ed.) (1998): Concise Encyclopaedia of Pragmatics, Oxford, Elsevier, 677-684.

LAKOFF, R. T. (1973): «The Logic of Politeness; or, Minding Your P's and q's», Papers from the Ninth Regional Meeting, Chicago, IL, Chicago Linguistic Society, 292-305.

- (1977): «What You Can Do with Words: Politeness, Pragmatics, and Performatives» in Rogers, A. et al. (eds.) (1977): Proceedings of the Texas Conference on Performatives, Presuppositions, and Implicatures, Arlington, TX, Center for Applied Linguistics, 79-105.

LAVER, J. (1974): «Communicative Functions of Phatic Communion», Work in Progress, 7: 1-17.

- (1975): «Communicative Functions of Phatic Communion» in Kendon, A., R. M. HARRIS y M. R. KEY (eds.) (1975): Organisation of Behaviour in Face-to-face Interaction, The Hague, Mouton, 215-238. 
- (1981): «Linguistic Routines and Politeness in Greeting and Parting» in Coulmas, F. (ed.) (1981): Conversational Routine. Explorations in Standardized Communication Situations and Prepatterned Speech, The Hague, Mouton, 289-304.

LeECH, G. (1974): Semantics, Harmondsworth, Penguin.

- (1983): Principles of Pragmatics, London, Longman.

Malinowski, B. K. (1923): «The Problem of Meaning in Primitive Languages» in Ogden, C. K. y I. A. Richards (eds.) (1923): The Meaning of Meaning. A Study of the Influence of Language upon Thought and of the Science of Symbolism, New York, Harcourt, Brace \& Company, INC, 451-510.

MANEs, J. y N. Wolfson (1981): «The Compliment Formula» in Coulmas, F. (ed.) (1981): Conversational Routine. Explorations in Standardized Communication Situations and Prepatterned Speech, The Hague, Mouton, 115-132.

McCarthy, M. (2000): «Mutually Captive Audiences: Small Talk and the Genre of Close-Contact Service Encounters» in CouPLAND, J. (ed.) (2000): Small Talk, Harlow, Pearson Education Limited, 84-109.

MeIER, A. J. (1995): «Passages of Politeness», Journal of Pragmatics, 24: 381-392.

Padilla CRUZ, M. (2004 a): Aproximación pragmática a los enunciados fáticos: enfoque social y cognitivo, University of Seville, $\mathrm{PhD}$ Thesis.

- (2004 b): «On the Social Importance of Phatic Utterances: Some Considerations for a Relevance-Theoretic Approach» in GARCÉs CONEJOS, P. et al. (eds.) (2004): Current Trends in Intercultural, Cognitive and Social Pragmatics, Seville, Intercultural Pragmatics Research Group, 199-216.

- (2004 c): «Phatic Utterances and Cultural Knowledge: Some Remarks for a New Relevance-Theoretic Approach to Phatic Communication» in Celada, A. R., D. Pastor García y P. J. Pardo García (eds.) (2004): Actas del XXVII Congreso Internacional de AEDEAN, Salamanca, Editorial Ambos Mundos, CD ROM edition.

- (2006): «Hacia una nueva definición de la cortesía» in Blas Arroyo, J. L., M. Casanova Ávalos y M. Velando Casanova (eds.) (2006): Discurso y sociedad: contribuciones al estudio de la lengua en contexto social, Castellón de la Plana, Universitat Jaume I, 699-710.

SchneIDer, K. P. (1988): Small Talk. Analysing Phatic Discourse, Marburg, Hitzeroth.

SCOLlON, R. y S. W. SCOLlON (1983): «Face in Interethnic Communication» in Richards, J. C. y R. W. SchmidT (eds.) (1983): Language and Communication, London, Longman, 156-190.

- (1995): Intercultural Communication. A Discourse Approach, Cambridge, Blackwell. 
SPERber, D. (1996): Explaining Culture. A Naturalistic Approach, Oxford, Blackwell.

SPERBER, D. y D. WiLSON (1986): Relevance. Communication and Cognition, Oxford, Blackwell.

- (1995): Relevance. Communication and Cognition, 2nd edition, Oxford, Blackwell.

Thomas, J. (1995): Meaning in Interaction: An Introduction to Pragmatics, London, Longman.

Tracy, K. y J. M. NAughton (2000): «Institutional Identity-Work: a Better Lens» in Coupland, J. (ed.) (2000): Small Talk, Harlow, Pearson Education Limited, 62-83.

TURNER, R. (1973): Stylistics, Harmondsworth, Penguin.

Wolfson, N. y J. MANES (1980): «The Compliment as a Social Strategy», Papers in Linguistics, 13: 391-410.

Zimmin, S. (1981): «Sex and Politeness: Factors in First and Second Language Use», International Journal of the Sociology of Language, 27: 35-58. 


\title{
CONSTRUCCIONES CAMBIANTES \\ DE LA IDENTIDAD AJENA: \\ HETERO-IMAGEN INGLESA \\ EN LA REAL ACADEMIA ESPAÑOLA
}

\author{
Paloma Tejada Caller \\ Universidad Complutense de Madrid
}

\section{INTRODUCCIÓN}

$\mathbf{E}$ $\mathrm{N}$ el presente artículo pretendemos acercarnos a la imagen que de Estados Unidos, de su lengua, su literatura y su cultura se transmite en España a través de los discursos pronunciados por académicos españoles en la ceremonia de ingreso en la Real Academia Española (RAE). Con ello profundizaremos en el papel que desempeñan las instituciones en la construcción de formas de identidad cultural y en la naturaleza ideológica del discurso lingüístico. De manera más concreta, a partir de la firma de los acuerdos bilaterales de los años cincuenta, los Estados Unidos saltan en España a la escena política, social y cultural; con ello, la alteridad que representa lo inglés en nuestro país ya no se ciñe a lo británico, sino que se amplía e incluso se ve empañada por lo americano. La actitud de los académicos cambia y con ello lo hace también la hetero-imagen global que elaboran, consciente o inconscientemente, sobre la identidad 'inglesa' y la que, por tanto, transmiten a la sociedad con mayor o menor grado de éxito.

Los datos proceden de los discursos de ingreso en la RAE del periodo comprendido entre 1950-2002. En total, 81 discursos de ingreso (y otros tantos de contestación). Debemos reseñar que la extensión de las referencias no es homogénea y oscila entre la mera anécdota, incluso la mera cita de nombres o frases, al uso del inglés como prueba argumental o como tema secundario de la exposición. Ninguno de los discursos está dedicado al inglés, como sería de esperar, ya que los futuros académicos eligen convencionalmente temas de interés nacional. De los 93 autores (a pesar de que las ocasiones son 162), sólo 25 hacen referencia a temas norteamericanos. ${ }^{1}$

1. En las citas mencionaremos las páginas de los discursos editados únicamente en papel. No lo haremos, sin embargo, en aquellos discursos que están informatizados y a disposición del usuario a través de la página web de la RAE. 
Las preguntas concretas que sostienen este estudio son las siguientes: ¿qué imagen de la lengua y la identidad 'anglosajona' (en el sentido más laxo de la palabra) proyectan estos intelectuales españoles de la segunda mitad del siglo xx, una vez que Estados Unidos entra en la escena política e intelectual española?, ¿es distinta de la que se había construido con anterioridad en foros similares?, ¿por qué hacen referencia a lo americano las autoridades lingüísticas españolas?, ¿para qué lo hacen?, ¿qué rasgos, hechos, escenarios, lugares y personas clave se seleccionan para la elaboración de la imagen? La imagen que se construye, ¿sirve para reforzar una ideología concreta?, ¿se utiliza la referencia a Estados Unidos, su lengua y su cultura, para construir determinada identidad española, o de la lengua española?, ¿qué grado de influencia y de calado tienen estas imágenes elaboradas en ámbitos institucionales?

\section{PINCELADAS SOBRE EL MARCO TEÓRICO: LA NOCIÓN DE ALTERIDAD}

En los últimos tiempos, desde hace unos treinta años, la noción de alteridad se ha erigido en categoría fundamental de la experiencia como perspectiva esencial para la reflexión sobre el pensamiento humano, la cultura y la relación entre individuo y sociedad. La dialéctica entre lo propio y lo ajeno, el modo en que los individuos y grupos son percibidos y representados o el grado con que determinadas comunidades comprenden al otro van adquiriendo progresivamente mayor atención. (Corbey \& Leerssen, 1991: x; Woolard, 1998; Koerner, 2002: 1).

La noción de identidad no puede tomarse ya apriorísticamente como algo fijo, homogéneo, objetivable. En la investigación sobre identidades de segunda mitad del siglo xx la noción tradicional de existencia se ha sustituido por la de percepción o representación. El inglés, los americanos son, en definitiva, lo que se diga de ellos y, en consecuencia, lo que se piensa de ellos. De ahí que no se trate de ver en nuestro caso cómo son la lengua inglesa o los americanos, sino cómo se les percibe o se les representa a través de imágenes necesariamente selectivas y múltiples.

Este proceso de representación es fundamental en tanto que social, ya que las imágenes pueden y suelen pasar a formar parte del acervo simbólico de una comunidad, de su cultura, sus creencias, opiniones y actitudes. Y llega un momento en que las imágenes, en tanto que elementos culturales, ya no sólo se articulan argumentativamente, sino que se diluyen en sentimientos deshilvanados, en sensaciones que organizan nuestras posteriores reacciones socioculturales (Voestermans, 1991: 220-23). 
Hay que tener en cuenta también que las imágenes del otro, de lo americano y del inglés como lengua en nuestro caso, varían con el tiempo. Lejos de ser estáticas, revelan una naturaleza dinámica, determinada histórica y culturalmente, de acuerdo con las circunstancias de quienes diseñan la imagen y de las relaciones que se establecen en cada momento entre observadores y observados.

En este proceso de elaboración de imágenes, de representación de identidades propia o ajena debemos considerar detenidamente la intervención de los agentes, de las llamadas 'voces'. Es decir, las imágenes tienen diseñadores. De hecho, los valores y presupuestos culturales del autor de la imagen suelen aparecer inevitablemente en el retrato. Sin embargo, aunque en todo encuentro cultural hay mediadores, caracterizados cada uno por un sinfín de intereses particulares, prácticos o ideológicos, no todos ellos ejercen similar nivel de influencia en la configuración social de las imágenes ajenas. Resulta claro que existe una evidente interdependencia entre la construcción de imágenes y el poder establecido y que las representaciones que nos hacemos deben mucho a instituciones socialmente relevantes (Grew, 1986: 39; Engler, 2000: 344; Porter 2001: 121). De ahí que para nuestros fines nos interese más la voz institucional y que queramos destacar el marco que proporciona la RAE. Desde el siglo XIX la Academia resulta relevante en tanto que institución filológica avalada por el Estado. Y podemos afirmar que hasta nuestros días mantiene en amplios círculos su influencia didáctica y social, aunque ahora -a diferencia de lo que ocurría en el siglo XIX-comparta su poder con la Universidad y los medios de comunicación.

Por último, hemos de tener en cuenta que el discurso público de científicos e intelectuales con frecuencia se ve tintado de prejuicios y opiniones. Desde la institución -y probablemente también desde la RAE-, sin embargo, lo que se consigue es trasponer estos puntos de vista de lo privado a lo público y legitimarlos, confiriéndoles el peso de la autoridad y cargarlos con ello de mayor convencimiento, prestigio y efectividad.

\section{ESTADOS UNIDOS EN LA REAL ACADEMIA ESPAÑOLA}

Tras este brevísimo excurso teórico que nos sirve de marco, y antes de centrarnos en los datos concretos, conviene dedicar un breve apunte al contexto histórico y, más concretamente, al papel que representan las lenguas y culturas extranjeras en el contexto español del momento.

\subsection{Lo extranjero en la cultura española: entre el miedo y la atracción}

El acuerdo de los historiadores confirma que en la época que nos ocupa y desde finales del siglo anterior, el estudio de la cultura y la lengua españolas 
llegó a ser la obsesión de intelectuales (y de regímenes dictatoriales), que por razones distintas temieron y rechazaron los valores de las culturas no hispanas. En los años cuarenta la ideología oficial aconsejaba desarrollar los «fundamentos ideales de la Hispanidad, base de la cultura auténtica española y del sentido tradicional y católico de nuestro pensamiento imperial» e impulsar el «desarrollo de una cultura propia y original». Por ello el uso de idiomas extranjeros en carteles públicos era interpretado como presencia de «modas con apariencia de vasallaje o subordinación colonial» y exigía leyes con las que «desarraigar los vicios del lenguaje» (Monterrey, 2003: 73-79). Y por ello también la historiografía convencional de la época concentraba esfuerzos para ofrecer una visión unitaria de España en la que sobresalieran Castilla, los Reyes Católicos, el Renacimiento, la presencia española en América, el Siglo de Oro, la mística y la tradición y de la que quedaran apartados el siglo XVIII y los exiliados de los siglos siguientes (Julià, 2003 y Fusi, 2003). España se encontraba centrada y cerrada sobre sí misma. Sólo a partir de los años cincuenta, y con medio siglo de retraso frente a lo que ocurría en Europa, esta España ensimismada empezó a negociar un nuevo rumbo a través de los acuerdos suscritos con Estados Unidos y, como veremos, lo hace en medio de un clima que rezumaba a la vez miedo y atracción, aunque el hecho se ensalzara en distintos foros con oficial entusiasmo. ${ }^{2}$

\subsection{Voces: la 'generación de 1956 '}

Los académicos que entre 1950 y 2000 mencionan temas, personas, lugares, relacionados con ESTADOS UNIDOS son los siguientes: Alvarado (1982), Areilza (1987), Bousoño (1980), Buero (1972), Calvo Sotelo (1987 en su contestación a Areilza), Cebrián (1997), Cela (1977 en contestación a Torrente), Colino (1972), Delibes (1975), Díaz Plaja (1967), Enterría (1994), Fernán Gómez (2000), García de la Concha (1992), García Yebra (1985), Goytisolo (1995), Gullón (1990), Lapesa (1984 en contestación a Ayala, y 1972 en contestación a Lázaro), Lorenzo (1981), Marías (1965), Martínez Campos (1950), Montes (1978), Nieva (1990), Prados Arrarte (1982), Rico (1998 en su contestación a Matute), Sáinz Rodríguez (1979), Torrente (1977) y Zamora Vicente (1967). Como se ve, se trata de un grupo aparentemente heterogéneo, de quienes aquí haremos más bien

2. Baste como ejemplo el siguiente texto extraído del corpus: «A Washington llega Areilza el año 1954 como embajador... Eisenhower se encuentra, el año 1954, en la plenitud de su popularidad y de sus facultades mentales... Su estancia en Washington se produce en los años decisivos para las relaciones entre España y los Estados Unidos... Areilza emerge por derecho propio y su sede se convierte en un centro social... por el que desfilan... los grandes dioses del Senado y del Congreso, de la Banca, y de la high life norteamericana.» (Calvo Sotelo contesta a Areilza: 42-43). 
una caracterización social y profesional válida para todos en tanto que académicos, sin entrar en excesivos detalles de sus biografías individuales.

Los académicos que intervienen en este periodo de 1950-2002 son representativos en su mayoría de la llamada «generación de 1956» en su vertiente más moderada. Tal como lo define Santos Julià (2003: 158ss.), este es un grupo de intereses convergentes y, por tanto, amplio y diverso, heredero de una larga tradición liberal y de su conciencia crítica. Lo componían intelectuales deseosos de seguir una política de olvido y reconciliación, que mantenían los ojos puestos en Europa (regida entonces por gobiernos moderados), y vivían alentados por los cambios que parecían vislumbrarse a partir de los acuerdos firmados con Estados Unidos en 1953. De este grupo surge lo que va a ser la cultura dominante en las décadas que nos ocupan, definida por una doble oposición que la enfrentaba de un lado al amplio páramo de la cultura oficial, católica, y de masas y, de otro, a la minoritaria cultura de radicales y vanguardistas, que siempre quedaron excluidos del establishment. En este conjunto de liberales moderados, representantes de la cultura hegemónica, que no nacional, se integra gente muy diversa: profesionales, intelectuales pertenecientes al establishment liberal junto a otros de pasado falangista; creadores individuales, renovadores e independientes, escritores reconocidos, poco radicales y creadores de nuevas corrientes artísticas; y una representación de universitarios y profesores, más nutrida a partir de la década de los ochenta. En todas las épocas aparecen entre nuestras voces personas estrechamente vinculadas con la derecha oficial y tradicional y como contrapunto reconoceremos algunos nombres del exilio y una escasísima vanguardia.

Junto a esta caracterización ideológica, debemos destacar el hecho de que muchos de los académicos que hacen referencia a lo americano han estado en contacto con Estados Unidos por diversas razones. Si nos restringimos a los datos que encontramos en los propios discursos a partir de 1953 en que se firman los acuerdos con aquel país, son muchos los futuros académicos que entran en contacto con ese territorio, sus gentes, sus vanguardias, sus preocupaciones socio-políticas. Martínez Campos realiza allí cursos militares; Areilza es enviado como embajador en 1954. Sin embargo, es la Universidad el ámbito a través del cual nuestros actores entran a menudo en contacto con aquel país: Marías, Delibes, Ayala, Lorenzo, Zamora, todos pasan por distintas instituciones durante más o menos tiempo; y Gullón es nombre destacado por su contribución al hispanismo norteamericano.

Por último, son muchos los que se aproximan al inglés a través de la cultura escrita. A partir de mediados de los sesenta nuestros académicos dan signos de lo que será a partir de entonces una irrenunciable dependencia intelectual; a través de los discursos asistiremos a diálogos científicos mantenidos a distancia con intelectuales anglosajones de las más diversas ramas del saber. En el 
último tercio del siglo Xx los nombres que confieren autoridad a lo dicho en las más diversas materias (linguiística, literatura, antropología, biología, ciencias de la tierra, historia del derecho, economía, sociología o geografía) son angloparlantes y en muchos casos estadounidenses.

\subsection{Temas y elementos seleccionados en la imagen: el doble trazado}

En términos generales y tomando en consideración el conjunto de las referencias a lo anglosajón que aparecen en el corpus de académicos entre los años 1950 y 2000 , hay que decir que la descripción de la identidad de tal lengua y de su comunidad de hablantes responde en buena medida al estereotipo y a la propia imagen elaborada y exportada por los ingleses desde el siglo XIX, que -en opinión de la mayoría- realza la larga tradición y flexibilidad de sus instituciones, el talante empírico de sus habitantes, sus virtudes negociadoras, su naturaleza individualista, amante de la libertad, tolerante, democrática e introvertida; la presencia de Shakespeare como icono cultural y la generalización de esta identidad inglesa a todos los británicos. El esquema reproduce en buena parte además lo dicho por los académicos de la RAE en el siglo XIX (cf. Tejada, 2005), aunque las funciones del estereotipo sean distintas en un momento histórico y en otro.

Sin embargo, lo que nos interesa y queremos destacar en este trabajo es la nueva imagen de lo inglés que aparece diseñada e inducida por los nuevos tiempos. Y dejando al margen otras cuestiones particulares, ${ }^{3}$ en semejante representación despunta el trazo americano, que emerge con fuerza.

Es decir, la mayor diferencia temática que hallamos en la elaboración de esta imagen de lo inglés frente a la proyectada en el siglo XIX viene dada por el hecho de que Estados Unidos irrumpe en la escena de nuestros académicos a partir de la firma de los acuerdos bilaterales de los años cincuenta. Desde este momento podemos decir que la alteridad que representa lo inglés, lo anglosajón, ya no se ciñe a lo británico, sino que se amplía e incluso se ve empañada por lo americano. En la segunda mitad del siglo Xx lo inglés representa a un grupo nuevo de personas y rasgos. De acuerdo con la retórica de construcción de identidad, lo inglés ya no equivale a ninguna visión (reducida y esquematizada) de lo británico, como en el siglo XIX, sino que el estereotipo integra (en términos igualmente esquemáticos y reducidos) lo británico y lo americano.

Más concretamente, la ampliación de rasgos que implica la consideración de Estados Unidos genera una imagen anglosajona de doble trazado, estructu-

3. La mayor parte de las veces los nuevos temas que perfilan la imagen obtenida del inglés refuerzan la relación de lo inglés con España y enfatizan la vuelta a las edades Media y Renacentista, aunque esto quede fuera del ámbito de nuestro estudio. 
ralmente más disociada que la que advertíamos en el siglo XIX: $a$ ) por un lado con trazo amable se recoge una imagen más estereotipada, y convencional, circunscrita a lo británico en términos literarios y culturales, cuyas innovaciones resultan poco vigorosas, menos atractivas o relevantes que en el siglo XIX; $b$ ) por otro, la imagen americana, nos perturba a través de fuertes pinceladas, disonantes entre la innovación y la amenaza. Estados Unidos se distingue como modelo de innovación, más atractivo que el atenuado inglés. Pero junto a ello brota lo ajeno con formas amenazantes, de rivalidad y competitividad; (re)surge la imagen del inglés como imperio avasallador, atemorizante, algo que no ocurría en la representación del siglo XIX. El hecho de que los Estados Unidos irrumpan en la escena pública, intelectual y social española hace cambiar radicalmente la actitud de los académicos y la hetero-imagen global de lo inglés que, por tanto, se transmite. Incluso diremos que esto termina imponiendo un tono negativo sobre la representación de la identidad inglesa en sí y de la propia lengua. Para corroborar lo dicho con cierto detalle, procederemos a un breve análisis de las referencias obtenidas del corpus, distinguiendo algo groseramente aquellas relativas a la literatura, la cultura o la lengua en sí.

En literatura el canon de modernidad que representa en España lo inglés y que caracterizó la imagen trazada por los académicos en el siglo XIX también viene dado ahora esencialmente por lo americano. Sobre la stream of consciousness de Joyce o los momentos mágicos que Carroll representa para la imaginación, en la imagen destaca el ojo cinematográfico de Dos Passos, la alegoría de Eliot y la vanguardia rupturista del Living Theatre, según aparece en los discursos de Goytisolo, Lapesa en contestación a Ayala: 55, Zamora Vicente: 115, García de la Concha, Buero: 54, Nieva: 17, o Bousoño en su contestación a Nieva: 44. Basten como ejemplo los siguientes textos:

El siglo XX nos ha enseñado un mundo en el que no tienen cabida tan seguras actitudes, sino que resulta el dominio total del absurdo... Vivimos en el imperio de lo discontinuo, lo revolucionario. Y es precisamente hacia 1920 cuando Europa comienza a vivir estas irregularidades o nuevos puntos de intelección... (No es una simple casualidad que se titule precisamente 1919 un libro capital en la nueva visión del mundo. Me refiero a la novela de John Dos Passos). (Zamora Vicente: 115)

Bajo la impronta del Living Theatre de Grotouski, de Brook, Roy Hart, Lavelli y otros, los escenarios se pueblan de alaridos báquicos, de audaces ritmos corporales, de torsos desnudos y cabellos encrespados... (Buero: 54)

En la imagen, y a través de las palabras de Goytisolo, Torrente: 20 (en cita), Cela en contestación a Torrente: 45, Ansón o Díaz Plaja: 127, aparecen también 
Faulkner, Beckett, Ezra Pound, Whitman, esencialmente como modelos de los que son deudores determinados autores hispanos, ya sea Rubén Darío o Lorca. A ellos se añade Henry James, como maestro de la novela, que junto con Poe y Wilde se consideran ya clásicos en su género:

Un modo de narrar que, parafraseando a Ezra Pound, se hubiera ajustado a su fórmula secreta: la música, lo más cerca posible de la danza; la poesía, lo más cerca posible de la música; y la novela, lo más cerca posible de la poesía. (Goytisolo)

y no sería justo olvidar que uno de los grandes poemas de su libro cenital Poeta en Nueva York se titula 'Oda a Walt Whitman', cuya efigie física evoca... (Díaz Plaja: 127)

Es en los temas relativos a la cultura donde Estados Unidos ofrece los trazos más contradictorios de la imagen; la novedad que supone el contacto con Estados Unidos es objeto a la vez de alabanza y rechazo. De nuestros académicos, unos descubren elementos positivos en el carácter democrático de sus ciudadanos (Martínez Campos citado por Estrada Arnáiz), en la modélica Declaración Americana, en su defensa de los derechos individuales (Enterría nota $40 \mathrm{c} 2$, nota $12 \mathrm{c} 2$ ), en la condición de pueblo menos lastrado por el peso de una larga tradición cultural y en la generosidad que despliega con los creadores cinematográficos (Goytisolo) o en el impulso que ofrece a la vanguardia (Nieva: 16). Así lo vemos en algunos de estos textos:

La tesis central de Jellinek es que la idea de recoger legislativamente los derechos innatos, inalienables y sagrados no es de origen político, sino religioso, y se origina en las colonias de los protestantes puritanos ingleses y holandeses que se establecen en América en el siglo XVII, a partir del congregacionismo de Roger Williams desde 1640, y que se plasmará por vez primera en la Royal Charter de Rhode Island de 1663, que consagra la libertad religiosa o de conciencia, matriz de los demás derechos fundamentales (de opinión, de prensa, de reunión). Es, pues, en el pensamiento protestante anglosajón donde la idea surge, y sus raíces estarían, añade Jellinek, para mayor irritación de sus contradictores franceses, en el Derecho germánico. (Enterría nota 12/c2)

No me parece casual que el cine fuese a encontrar el caldo de cultivo más adecuado en la sociedad industrial más desarrollada de la época, que era a la vez, por lo joven, la sociedad menos lastrada por el peso de una larga tradición cultural: los Estados Unidos de Norteamérica. Y similarmente, por la sociedad que, en un intento de hacer realidad la utopía, creía encontrarse en parecidas circunstancias: la Rusia de los soviets. Fue verdaderamente en Estados Unidos y en la Unión Soviética donde el cine, aunque todavía mudo, llegó a convertir- 
se en una nueva forma de arte, gracias, en buena medida, a la aportación de gran número de europeos que encontraban en esos países y muy especialmente en Estados Unidos las facilidades creadoras que, por uno u otro motivo, sus propios países parecían negarles. (Goytisolo)

Digamos... que en estos momentos lo que es vanguardia en Estados Unidos es vanguardia forzada y sumisa en Europa... La única especie de vanguardia que el viejo continente exporta ya a Estados Unidos es el joven rock inglés y algunas insinuaciones de la moda. Un teatro 'happening' y apenas explícito ya verbalmente fue concebido por Samuel Beckett. Pero desde la aparición en Europa del Living Theatre... hasta la del joven director Bob Willson, ha ido formándose la idea de un teatro menos deudor de la tradición humorística... En todo caso, como el impulso inicial... nos vino de Estados Unidos, cabe pensar que por una suerte de flojera de su identidad, en Europa nos identificamos bien a la novedad caliente americana (Nieva: 16$)$

Son también muchos los académicos que se refieren al cine norteamericano y se muestran atraídos por él, por la fascinación que ejercía. Conviene recordar, quizá, que el cine (determinadas películas) se había convertido en España en parte de la cultura de masas, de ahí quizá también la mayor extensión de las referencias a este arte norteamericano. Autores como Fernán Gómez (23-24), Nieva (17), o Mingote rememoran esos primeros tiempos del cinematógrafo, a Chaplin y otros actores cómicos y películas como Mogambo o El ladrón de bicicletas.

Sin embargo, como contrapunto y en claro contraste con el reconocimiento de estos valores de la sociedad norteamericana, otras voces presentan la novedad estadounidense como un mundo de pesadilla, devastador de la naturaleza (Delibes: 27, 44, 45, 47-8), poblado de grandes edificios, vastas empresas, grandes avenidas, automóviles arrolladores y estridentes (Martínez Campos: 46) y por una sociedad de excesivo consumo (Delibes: 23), perseguidora de la felicidad capitalista (Cebrián), y creadora de Hollywood, el gran enemigo de la palabra (en palabras de Wilde recogidas por Fernán Gómez: 23), un Hollywood que se convierte en epítome del dominio americano del espectáculo (Cebrián).

[Martínez Campos contrasta Japón y Estados Unidos:] [...]El inmenso Pacífico mediaba entre el primitivo cochecillo de tracción humana... que pululaba por las calles de Tokio, y el automóvil deslizándose, arrollador y estridente, por las grandes avenidas neoyorquinas, donde la inquietud de la vida se palpa y el ánimo se enerva (Martínez Campos: 46)

En Hanford, estado de Washington... hay enterrados 124 tanques de acero y hormigón, ... los cuales contienen más de 200 millones de litros de desechos radiactivos... (Delibes: 27) 
Por último, en este repaso al corpus, haremos referencia a temas más específicamente lingüísticos y a la notable transformación que sufre la imagen del inglés creada por la Academia a partir del contacto con Estados Unidos. Para apreciar semejante alteración hemos de recordar, con todo, que desde el siglo XIX el inglés se representaba como lengua histórica y culturalmente importante, de vocabulario rico, pronunciación difícil y caprichosa y naturaleza esencialmente económica, reflejo del pragmatismo de sus hablantes y de otras notas de su carácter (cf. Tejada, 2005).

Sin embargo, a partir de 1950 la consideración del inglés como nueva realidad, como lengua del potencial americano, induce a enfatizar su naturaleza universal en tanto que "geolengua" o lengua imperial, que -contra el deseo colectivo- compite con el español. Así, en nuestro corpus, la lengua inglesa recibe adjetivos hasta ahora desconocidos, como los de "arrolladora", "invasora", "dominante", "prepotente" o "avasalladora". El inglés emerge como rival del español (incluso en número aspiramos a superarla) y amenaza de su integridad, como confirman estas citas:

El Inglés y el Portugués, las dos lenguas europeas que comparten con la nuestra el mayor grado de universalidad. (Sáinz Rodríguez: 11)

De las llamadas "lenguas de cultura de Europa", es la nuestra la que desbordará, con mucho, en importancia numérica en esos años [2010-2020] a las demás. Y entre ellas, incluso a la prepotente y avasalladora lengua inglesa que hoy domina en número los medios informáticos del mundo entero. (Areilza: 22)

Reflejo tácito de esta rivalidad, en la nueva imagen lingüística se observa además la nostalgia de los académicos por recuperar un pasado más puro, lo cual les obliga a insistir sobre el neologismo y a incidir reiteradamente sobre temas relativos a traducciones, modas y mercancías venidas de fuera, algo que no ocurría en el siglo XIX. El tratamiento del neologismo, cifrado mayoritariamente en términos de anglicismos españoles, resulta más apasionado que científico. El fenómeno lingüístico se trata sistemáticamente en términos de advertencias, aclaraciones y abucheos ridiculizantes en algunos casos; determinados usos lingüísticos se tachan de "absurdos", "superfluos", "viciosos", "injustificados" e "innecesarios" frente a los "correctos" y "necesarios"; unos atentan contra nuestra "gloriosa y venerable tradición", otros muestran "naturaleza inestable", algunos más implican admitir un "espíritu de derrota”, y

4. Sáinz Rodríguez: 11, Areilza: 21-22, 27-30, Calvo Sotelo en contestación a Areilza: 51. 
todos representan, en definitiva, una "angliparla". En el corpus seleccionado, molestan las traducciones, la prensa, los mass-media, los ordenadores y su ritmo atropellado y mecánico. Sólo ocasionalmente se nos ofrecen consideraciones asépticas y bienintencionadas en torno a estas cuestiones léxicas, y rara vez se concede al inglés la iniciativa de la creación. ${ }^{6}$

La disgregación del lenguaje técnico económico parece así cada vez más grave, si cada país de lengua española utiliza sus modismos o traduce a su manera las voces británicas o norteamericanas. ¡Peligra por ello la unidad de nuestra lengua, amenazada de dispersión, como ocurrió en su día al latín! Por otra parte, la inclusión de vocablos ingleses como si el español no pudiera expresarlos dentro de su peculiar estructura, disponiendo a más de ello de fuentes originarias como serían el latín y el griego, responde a un espíritu de derrota de una lengua incapaz de mantenerse a la altura de los tiempos presentes... (Prados Arrarte: 12)

Las continuas traducciones, algunas incluso divulgadas por editoras oficiales, con los frecuentes cursos y cursillos de nuestro personal joven en los Estados Unidos, constituye cultivo apropiado para la proliferación de este imperio del solecismo que invade y ahoga lo auténtico y preciso. (Julio Guillén: 40)

En la segunda mitad del siglo xx la imagen del inglés americano elaborada por los académicos destaca también su condición de lengua "trasplantada" a Estados Unidos. Más allá de consideraciones sociolingüísticas o geográficas asépticas que nos invitan a reflexionar sobre cuestiones de hibridación y variación dialectal (Marías: 20, Lorenzo), el inglés en Estados Unidos se ofrece como víctima modificada y degradada de la desmembración. El inglés ha iniciado un camino de separación que debe servir de repelente y de advertencia al español desplegado en América (Areilza: 15, 25 y Sáinz Rodríguez: 11). En palabras de este último:

El Inglés y el Portugués, las dos lenguas europeas que comparten con la nuestra el mayor grado de universalidad, han visto crearse una verdadera división

5. Observamos con curiosidad que este término, utilizado por Laín en 1982 en contestación a Alvarado, lo retoma años después el hijo de este último en otro artículo de corte similar al de los discursos aquí reseñados. «...[L]os anglicismos en nuestra lengua son... algo incomprensible, extraño y fascinante, a modo de "divinas palabras" cuyo misterio subyuga a los papanatas... Sirvan por lo menos los neohelenismos para librar a nuestra hermosa lengua (y a otras de nuestro entorno europeo) de la angliparla, de modo que sigan siendo lo que son, y no se conviertan en un pidgin.» (Boletín de la Real Academia Española, 1999).

6. Junto a los autores que se citan, el anglicismo atrae el comentario de autores como Areilza, García Yebra, Guillén, Alvarado, Palacios, Guillén, Lorenzo, Pascual, Cebrián, Fernán Gómez o Bosque. 
entre el inglés y el portugués de las naciones originarias y los países que con ellas utilizan ambos idiomas: Norteamérica y Brasil. La conocida frase atribuida a Bernard Shaw de que Norteamérica e Inglaterra son dos pueblos separados por la misma lengua es reveladora de un hecho que nadie ignora: la tendencia de los Estados Unidos a independizarse del inglés y a crear el americano. Notorias son las dificultades que ha tenido Portugal con el Brasil por motivos semejantes. Pues a España le amenazaba un peligro igual; hubo un momento en el país de más tendencia europeizante, donde la Argentina se inició un gran momento en defensa de una lengua independiente... Las relaciones de nuestra Academia con las academias hermanas han requerido un tacto, una diplomacia y un talento que jamás agradeceremos los españoles bastante... [El Estado] ha contemplado todo este esfuerzo sin prestarle ayuda ni solidarizarse con él.

Por su parte, esta presencia del inglés en Estados Unidos ofrece una vertiente de las lenguas aparentemente desconocida: la de "acicate empresarial". Frente al competidor natural que es el inglés, el español debe descubrir para sí el 'inmenso mercado potencial' que supone la 'industria de la lengua', según recomendación de Areilza (21).

Indudablemente, América no sólo introduce novedades empresariales en el ámbito lingüístico. Hay discursos en que se destacan también nuevos temas y nuevas corrientes de pensamiento, iniciados en Estados Unidos: el feminismo, la vinculación de lengua e ideología y cultura, temas sociolingüísticos experimentados por la presencia del español en América, teorías lingüísticas como el generativismo chomskiano o el anterior distribucionalismo salen a la palestra en nuestros discursos. ${ }^{7}$ De nuevo, la novedad será cantada más honestamente por los miembros más profundamente liberales o intelectuales del grupo.

\section{FUNCIONES DE LA IMAGEN}

Tras esta somera exposición del análisis de las referencias que ofrece el corpus llega el momento de recapitular y apuntar razones por las que se utilizan estas referencias a EEUU; es decir, de interpretar la función simbólica a la que sirven. Como sabemos, lo ajeno es indisoluble de la propia identidad y las heteroimágenes no se entienden si no es en el seno de una dialéctica que incluye la auto-imagen. Ello nos servirá también como conclusión al presente trabajo.

Como punto destacado del estudio podemos afirmar que Europa -y "lo inglés" en su debida proporción- ha dejado de representar la imagen de la democracia, la modernidad y el progreso. Hasta cierto punto podríamos pen-

7. Cf. Enterría, Colino (27, 28, 32), Lorenzo, Lapesa en contestación a Lázaro: 136. 
sar que Estados Unidos adoptaría ahora este papel y es cierto que en alguna medida lo hace. Sin embargo, el tema de la modernidad y de la innovación que supone Estados Unidos exige mayor comentario.

El corpus ratifica que en la RAE del siglo XX la imagen norteamericana sirve como escaparate de innovación, pero hemos visto que la innovación no se interpreta, según lo hizo en otra época, ni como modelo incuestionable, ni como espacio de aprendizaje y experimentación, ni como pauta de normalidad que marque las metas a conseguir. Todo esto pertenece al siglo XIX, un tiempo caracterizado por la fascinación, el optimismo de la revolución burguesa del siglo XIX, la confianza en el progreso de la humanidad y los cantos al cosmopolitismo. En el siglo Xx la modernidad se interpreta en buena medida en términos de advertencia. Los académicos no proyectan a sus colegas y a la sociedad en general una imagen anglosajona que sirva como negociación de futuro, sino como frontera que no debe cruzarse. Es más, con la incorporación de Estados Unidos a la representación, la imagen de lo inglés y sobre todo del inglés no se utiliza para reforzar o crear objetivos comunes entre dos comunidades, sino para destacar intereses rivales. Se lanza así con la nueva imagen una expresión de desconfianza, típica de situaciones en que el desarrollo de las comunidades observadora y observada es desigual (Porter, 2001). Parece que España retoma la nostalgia provocada por el ocaso de su imperio, la pérdida de las colonias y el miedo a la competencia en Latinoamérica. Aparece con intensidad el prejuicio contra lo exterior y metafóricamente se proyecta la alteridad como amenaza y al otro como adversario, muy de acuerdo con el momento histórico de los cincuenta. La hetero-imagen, en realidad, se utiliza para reforzar la autoestima española, una autoestima y una obsesión por lo español que en la RAE (y en buena parte de España o de los españoles) sigue latiendo en los años 70 y 80 .

A la luz del corpus analizado observamos igualmente que los rasgos referentes a Estados Unidos no proceden tanto de un estereotipo intertextual, ni, contra lo que parece, de la observación directa de la comunidad retratada. Los discursos filtran prejuicios y opiniones particulares de muy distinto componente, sedimentados a través del tiempo y los proyectan como cliché relativo a la alteridad americana.

Resulta, por último, significativo, que los rasgos referentes a Estados Unidos terminan en buena medida empañando metonímicamente la idea de inglesidad en sí. Hoy, veinte o treinta años después son muchos quienes desde diversos sectores siguen percibiendo y retratando al inglés como 'la modernidad amenazante'. Este estereotipo, al que han contribuido los académicos, forma ya parte de la tradición narrativa de la lengua en España. 


\section{REFERENCIAS BIBLIOGRÁFICAS}

ANDERSON, B. (1991): Imagined communities, Londres, Verso.

BAILEY, R. (1992): Images of English. A cultural history of the language, Cambridge, CUP.

BOERnER, P. (ed.) (1986): Concepts of national identity: An interdisciplinary dialogue, Baden-Baden, Nomos.

CORBEY, R. \& J. LEERSSEN (1991): «Studying alterity: backgrounds and perspectives», en CORBEY \& LEERSSEN (eds.): VI-XIX.

- (eds.) (1991): Alterity, identity, image. Selves and others in society and scholarship, Ámsterdam, Rodopi.

Del GiUdice, L. \& G. PorTer (eds.) (2001): Imagined states: nationalism, utopia, and longing in oral cultures, Logan, UT: Utah State UP.

ENGLER, B. (2000): «Englishness and English Estudies», en ENGLER, B. y F. HAAS (eds.) (2000): Contributions towards the history of a discipline, Leicester, England, 335-348.

Fusi, J. P. (2003): «La cultura», en SANTOS, J. et al. (eds.) (1986): 443-595.

GREw, R. (1986): «The construction of national identity», en P. BOERNER (ed.) (2003): 3144.

JuLIÀ S. et al. (eds) (2003): La España del siglo XX, Madrid, Marcial Pons.

Hillman, K. (2001): Diccionario enciclopédico de sociología, Barcelona, Herder.

KOERNER, E. F. K. (2000): «Ideology in 19th and 20th century study of language: a neglected aspect of linguistic historiography», Indogermanische Forschungen, 105: 1-26.

MonTERREY, T. (2003): «Los estudios ingleses en España (1900-1950): legislación curricular», Atlantis, 25.1: 63-80.

PORTER, G. (2001): «'Who talks of my nation?': the role of Wales, Scotland, and Ireland in constructing 'Englishness'», en Del GiUdice, L. \& Porter, (eds.) (2001): 10135.

TejadA, P. (2005): «English Consciousness in $19^{\text {th }}$ c Spain», en C. Butler (ed.) (2005): The Dynamics of Language Use, Ámsterdam, John Benjamins: 369-92.

Voestermans, P. (1991): «Alterity/identity: a deficient image of culture», en CORBEY \& LEERSSEN (eds.): 219-249.

WODAK, R. (1999): «The discursive construction of national identities», Discourse and Society, 10-2: 149-173.

- et al. (eds.) (2000): The discursive construction of national identity. Edimburgo UP.

WoOLARD, K. (1998): «Introduction: Language ideology as a field of inquiry», en SchielfFelin B., K. WoOlard y P. KROSKRITY (eds.) (1998): Language ideologies, Nueva York, Oxfo University, 3-47.

$<$ www.rae.es> y discursos depositados en los fondos de la Biblioteca de la RAE. 


\title{
GÉNERO Y DISCURSO TEATRAL: LA IMAGEN DE LA MADRE-ESPOSA EN EL TEATRO DE LA REVOLUCIÓN MEXICANA (1904-1944)
}

\author{
Alicia Vargas Amésquita \\ Universidad de Guadalajara, México
}

$\mathbf{L}$

A Literatura, como manifestación cultural, ha sido frecuentemente usada por la Historia, la Antropología, la Sociología, la Linguística o la Etnología, entre otras, para tratar de dilucidar prácticas sociales y discursivas del pasado, sobre las que se tiene poca o ninguna información de primera mano. En este caso, nos valdremos de ella, en particular del texto teatral, ${ }^{1}$ para estudiar la construcción discursiva que se hizo en las primeras décadas del siglo Xx, de una de las imágenes arquetípicas que más peso tiene sobre la identidad femenina en México actual, ${ }^{2}$ la de la madre-esposa.

Basándonos en el Análisis Crítico del Discurso (ACD), perspectiva que propone estudiar el discurso desde una postura analítica y política, presentaremos una breve descripción de algunos recursos y procesos discursivos y semióticos sobresalientes de la representación de esta imagen de mujer, e intentaremos mostrar cómo el discurso literario también interviene en el sostenimiento de un determinado orden de cosas a través de la reproducción, transmisión y perpetuación (o cuestionamiento) de unas determinadas visiones del mundo y sus agentes sociales, en este caso, las formas especiales de concebir a la mujer y los roles socialmente legitimados de su ser-hacer dentro de una sociedad conservadora-patriarcal, como lo es la mexicana; y que redundan en una colocación desventajosa y una participación poco trascendente dentro de la sociedad.

Para el análisis hemos utilizado herramientas afines al ACD, las cuales nos han permitido valorar diversos aspectos de la construcción discursiva de la madre-esposa como actor social, entre las que ahora resaltaremos:

1. Debemos recordar que, aunque la finalidad última del teatro escrito es la escenificación, donde nuevos emisores dan nuevos sentidos al texto escrito y lo lanzan a un receptor colectivo, convirtiéndolo en espectáculo; también es válido el estudio del texto dramático, como texto literario en sí mismo y como objeto de análisis discursivo y social. (cfr. Toro, 1987).

2. Para una revisión de este aspecto, revisar Lagarde (2001). 
1. las formas de tratamiento y designación, como una manera de detectar su influencia en su percepción y proyección sociales;

2. las descripciones físicas y la atribución de rasgos de carácter ético moral, que sirven para anclarlas a un estereotipo de madre-esposa acuñado desde lo social, y

3. las funciones o roles asignados a ese estereotipo que intervienen en la configuración de su competencia modal y su agentividad.

Para este trabajo, se seleccionaron veinticinco obras de teatro que abordan de una u otra forma la Revolución Mexicana (1910-1920) en cualquiera de sus tres estadios: prerrevolucionario, revolucionario y posrevolucionario. La elección de este corpus responde a que este período se significa como el de más cambios sociales y políticos dentro del México contemporáneo y el que supuestamente permitió la proyección de la mujer hacia el ámbito público. De esta creencia son resultado, por ejemplo, las figuras mitificadas de la soldadera y la Adelita. Por otro lado, hay que indicar que solo se tomaron en cuenta aquellos textos escritos por varones, dada la poca producción femenina al respecto; y porque esto denota que, dentro de la literatura, la imagen femenina se ha construido, entonces, desde una visión masculina.

Una prueba de la relativa importancia que cobra la participación de la mujer en el movimiento armado es que en la casi totalidad de las obras de teatro que hemos estudiado, la imagen de mujer que predomina es la de la madre-esposa, es decir, mujeres desempeñando los roles más tradicionales de nuestra cultura y representadas con los atributos que igualmente dan continuidad a una visión conservadora de su identidad. Solo debemos recordar que en la tradición occidental, la maternidad ha sido entendida como una noción esencial de lo femenino, natural y universal, el objetivo único de la mujer y su realización absoluta, hasta el punto que se creía, y me atrevo a afirmar que se sigue creyendo, que no logra su plenitud y compleción sino cuando alcanza la categoría de MADRE. Históricamente asociados, feminidad y maternidad se han convertido en una parte medular de la identidad de la mujer: se es más mujer cuando se es madre; y, por el contrario, la mujer que no ha podido engendrar hijos es una mujer mutilada, incompleta.

Esto ha permitido mantener la visión de una identidad femenina que ancla a las mujeres en roles específicos como la maternidad -y por ende la crianza de los hijos-, las responsabilidades domésticas que incluyen el cuidado del hogar y de la familia, las labores de socialización, etc. Esta construcción social de la maternidad va a otorgar un alto valor simbólico al acto de procreación y cuidado de los hijos, para asegurar un control de los roles femeninos. Por eso, la maternidad se halla articulada entorno a conceptos altamente conservadores como la pureza, la virtud, la abnegación, el sacrifico, la generosidad, el servi- 
cio, la entrega incondicional, el desprendimiento, la devoción hacia el cuidado y satisfacción de las necesidades del marido y de los hijos, y otros tantos que la han convertido en el baluarte moral, el sostén y guía de la familia y de la sociedad (Fuller, 2006).

Sin embargo, el rol de madre aparece normalmente asociado a un segundo rol, el de ESPOSA, entendido como previo y necesario para una "buena" ejecución y valoración social de la maternidad. Este rol tiene que estar legitimado, evidentemente, a través del vínculo matrimonial, que dentro de una sociedad conservadora-católica como la mexicana, equivale al matrimonio religioso. En los textos analizados, la madre-esposa que cumple con los requisitos socio-religiosos de su definición, como categoría y estereotipo, es mostrada de acuerdo con las expectativas sociales de la época:

- una mujer preocupada por el buen funcionamiento de su hogar, y por tanto, consagrada a sus funciones domésticas y de educadora de los hijos, en particular, y de atención y cuidado de la familia, en general;

- una mujer que delega en el hombre las responsabilidades financieras y públicas de la relación, respetando su rol de proveedor, protector y representante familiar de cara a la sociedad;

- una mujer que ofrece seguridad, atención, guía, solidaridad moral, confort y protección a un nivel privado-doméstico;

- una mujer decente que protege la honra propia, la del marido y de los hijos, luchando contra los que buscan mancillarla, y

- una mujer que busca la armonía familiar y que por ello se asume como la mediadora natural entre las necesidades de los hijos y las exigencias del padre-marido.

Los dos primeros aspectos de la representación de la madre-esposa están correlacionados, ya que solo se entiende su dedicación al ámbito doméstico y familiar si existe la manutención y protección financiera masculina. Desde este punto de vista, en la concepción más tradicional de la relación matrimonial, el varón es visto como el proveedor principal y necesario del hogar; y la mujer, como la receptora y hasta cierto punto administradora de los bienes aportados por él. ${ }^{3}$ Esta mutua responsabilidad se da por sentada en los textos analizados, al grado de que, por ejemplo, la realización de las actividades domésticas es

3. La tradición católica mantiene en la práctica ritual y discursiva esta distribución de responsabilidades entre los esposos, concretándolas en el contrato simbólico del intercambio de las "arras" durante el rito matrimonial, las cuales representan los bienes que van a compartir. La transferencia de la práctica discursiva y ritual a la práctica social, solo se entiende si consideramos lo fuertemente vinculadas que están vida y religión, en sociedades tan conservadoras como la mexicana. 
una cotidianidad de la actuación femenina, al igual que las encaminadas al cuidado y formación de los hijos. Así, al ser la madre-esposa la responsable doméstica, queda recluida en el ámbito privado del hogar y el padre-marido, en cambio, tiene el privilegio público de representatividad externa de la familia. Aquí debemos resaltar el hecho de que en ningún momento se representan mujeres faltando a su responsabilidad de "amas de casa", lo que demuestra una determinación social tan efectiva que, ni siquiera en el mundo permisivo de la ficción, se puede plantear la no existencia o el incumplimiento de estas ocupaciones. La fuerte asociación entre mujer y trabajo doméstico a nivel de las prácticas sociales, es la causa de que, a nivel de la práctica discursiva que nos ocupa y en el corpus elegido, las labores hogareñas aparezcan como meras acciones de ambientación, lo que prácticamente las hace invisibles para los lectores ya que son intrascendentes para las acciones fundamentales de la obra dramática.

Entonces, lo que prima en la definición y categorización de la mujer como madre-esposa y como actor social, es, definitivamente, su pertenencia a un grupo familiar representado públicamente por un varón reconocido en el entorno social. En este sentido, las formas de su designación están determinadas por las relaciones de parentesco que se tengan con un varón. Tomemos, por ejemplo, el caso de El Gesticulador, de Rodolfo Usigli. En ella se habla de «el profesor César Rubio», por un lado; y de «Elena, su esposa», por el otro. Esta sistemática de representación en la que el varón es designado formalmente, es decir, anteponiendo el título y acompañando el nombre con el apellido, y la mujer de manera informal solo especificada por su vínculo relacional con el varón, será la forma recurrente en el resto de obras de teatro. Esta manera de designar a la madre-esposa la hace aparecer siempre como dependiente del marido, sin posibilidad de acceder al espacio público si no es a través de él.

También, en relación con las formas de tratamiento de la madre-esposa, ya en la interacciones ficcionalizadas de cara a lo público, hay que resaltar que influye notablemente la responsabilidad que tiene la mujer de resguardar el prestigio social de la familia, la cual, en las obras, depende tanto de la actuación social y pública del varón, como la de la esposa. Así, las obras reproducen un orden social que limita la actuación femenina a una serie de códigos y normas morales que regulan su vida desde todos los puntos de vista, pero que pone especial énfasis en lo sexual y que le impone la obligación de la decencia como un medio de preservar la buena imagen social de la familia. Por eso, más que ninguna otra categoría femenina, a la madre-esposa se la presenta como la que más cuida las formas de relacionarse con los varones externos al entorno familiar. Siempre mantiene una distancia respetuosa y su trato queda dentro de los límites de la más estricta formalidad, que se manifiestan principalmente a través del uso del «usted» en las interacciones y de los sustantivos de tratamiento formal, que van del consabido «señor» $\mathrm{y}$ «señora», pasando por 
el «don»y «doña». En los casos más extremos, la mujer queda mediatizada por el marido, quien hablará por ella en la interacción con otros varones, interviniendo sólo en momentos muy puntuales.

Otro aspecto sobresaliente de su representación tiene que ver con los atributos físicos asignados en las descripciones. A pesar de que la función materna está estrechamente relacionada con la función de esposa, este último rol no implica la representación de las mujeres como actores sociales con una sensualidad y sexualidad activa. La esposa que es madre termina siendo una simple compañera, una camarada del marido y se vuelca enteramente en sus labores maternales y de cuidado de la familia. La representación de una mujermadre-esposa que encuentra natural la incompatibilidad entre la satisfacción de sus necesidades femeninas y su rol materno, será la tónica de los textos. ${ }^{4}$

Entonces, la mujer, para ser madre, antes tiene que dejar de pensarse en su función biológico-reproductiva de hembra: después del acto de engendramiento, durante el embarazo y ya en ejercicio pleno de la maternidad posterior al parto, la mujer aparece des-sexuada, requisito indispensable para cumplir con la exigencia de la pureza.

De esta manera, se pasa de ser una joven bellamente femenina a ser una mujer maternalmente femenina. Este aspecto aparece marcado en nuestros textos de varias formas, tanto en el plano de la descripción física de los personajes, como en el del tópico conversacional.

La descripción es especialmente ilustradora: para resaltar esa pérdida de la sexualidad y sensualidad de las mujeres que son madres, suelen presentarse como mujeres regordetas, vestidas con ropa seria y colores oscuros que las hacen lucir sobrias; o también, como ancianas ajadas, enfermas y cariñosas, la típica «cabecita blanca» que será presentada casi simultáneamente en el cine mexicano (Ayala, 1993; Monsiváis y Bonfil, 1994). Para acentuar aún más la des-sensualización de la madre, las vamos a encontrar representadas de manera paralela a mujeres jóvenes que no tienen hijos y cuya descripción resalta sus cuerpos sinuosos marcados sugerentemente por la ropa, sus rostros hermosos, sus figuras atractivas y sus actitudes coquetas, incluso provocativas, que subrayan semióticamente lo que se ha dejado atrás con la maternidad.

Así encontramos, por ejemplo, las descripciones de María e Inés en San Miguel de las Espinas, la primera «es una vieja de pelo gris y rasgos enérgicos»; y la otra «es una joven delgada, morena y de pelo lacio» (p. 50). O las descripciones, por un lado, de Meche, la madre de Trapos viejos: «Mujer de treinta y cuatro años, bastante guapa, aunque un poco gruesa» (p. 746); y, por el otro, las jóvenes de la historia: Carola, veinte años, «morena, alta, delgada y voluptuosa»; y Carmen, diecinueve años, «rubia cenicienta, mediana de cuerpo; pero con

4. Este aspecto también ha sido observado por Wodak y Schultz (1987: 13). 
cierta picardía en el movimiento» (p. 751). O la de la madre de Linda, en la obra del mismo nombre, «viste un traje negro, que le cubre cuello y brazos. En su rostro está pintada la energía. Una cadena, con una cruz de oro, cuelga sobre su pecho» (p. 464); mientras que de Linda no hay que decir mucho más: es linda.

Junto a esta semiótica de los cuerpos y del vestido, está el hecho de que las madres nunca aparecen en una interacción de tipo amoroso, y en los pocos casos en los que es representada, se rechaza totalmente el cortejo y se preconiza la entrega total a los hijos y la pérdida del ejercicio de la sexualidad femenina como símbolo del valor materno.

Ahora, si nos centramos en las responsabilidades asignadas a las mujeres en su rol de madres y esposas, tenemos que la principal preocupación de la madreesposa debe ser y es siempre la crianza de los hijos pero sin descuidar la atención del marido. Socialmente se ha determinado que la mujer sea la encargada de la educación y la formación moral y religiosa de los hijos, de su bienestar físico y emocional. La responsabilidad de cuidar del hijo es asentada desde el momento mismo de la concepción. Desde ese instante se vislumbran las obligaciones que se adquieren con la maternidad y se tendrá que empezar a demostrar la cualidad de madre cuidando al hijo nonato. Esta responsabilidad de la madre sobre los hijos se fundamenta en una visión del vínculo materno como un vínculo sagrado, irrompible e inviolable: «El lugar de un niño está siempre junto a su madre» (p. 218), dice Clara en Fugitivos. Así, madre e hijo establecen una relación en la que una no puede ser entendida sin el otro y viceversa. Entonces, el vínculo madre-hijo se convierte en una simbiosis social y culturalmente inmutable e inalterable a lo largo del tiempo, a través de la cual la mujer reafirma sus aspiraciones y el hijo recibe apoyo y guía incondicional. Dice Doña Julia, la protagonista de Las Madres:

Yo estoy esperando a mi hijo. Lo espero hoy [...] ... lo espero cada día que vuelve del colegio; lo espero cada año escolar que termina, lo espero cuando tenga quince y cuando tenga diez y ocho y cuando tenga veinte años. Y lo espero cuando sea hombre y se case y tenga hijos. Tenemos una cita para toda la vida. (p. 590)

Es una unión tan fuerte que solo es rota por actos extremos, ya sea actos achacados a los hijos, que implican desobediencia o deshonra familiar (de carácter sexual o criminal); o, por actos cuya responsabilidad recae en la madre: madres que abandonan a los hijos o a la familia, principalmente.

Estos aspectos son claramente ubicados en la representación que se hace de la madre en las obras estudiadas, las cuales refuerzan una imagen anclada en lo sociocultural. Madres responsables del bienestar físico y moral de los hijos y preocupadas por protegerlos, incluso por encima de la seguridad propia. Pero, sobre todo, son madres que dirigen, aconsejan, ordenan y sancionan 
las acciones de los hijos de una u otra manera. ${ }^{5}$ Esta línea de actuación inherente al rol materno es claramente localizable en los textos analizados: sobre los hijos menores de edad que deben ser formados como buenos ciudadanos, pero sobre todo, como buenos cristianos; $y$, sobre los hijos mayores, que deben ser vigilados para que perseveren en lo aprendido en la infancia y no dejen el «buen camino».

De ahí que se observe que las mutuas obligaciones entre madre-hijo -la de la madre de educar y la del hijo de obedecerla y respetarla- siempre están vigentes, sin importar, por ejemplo, que los hijos sean mayores, o que ya estén separados de la familia materna para formar un hogar propio. De manera permanente, las madres consideran a los hijos como niños que tienen que ser supervisados, corregidos o animados en sus actuaciones cotidianas, privadas en el caso de las hijas; públicas en el caso de los hijos varones. No obstante, los aspectos de la vida sobre los que se ejerce la dirección pasan de los típicos en la formación de un niño (creación de hábitos de comportamiento e higiene -en el sentido amplio del término), a un ámbito más elevado que tiene que ver con la realización y proyección de los hijos en la sociedad. Ya no habrá órdenes del tipo «anda a tu casa», «lávate las manos», «no tardes», «pórtate bien», «cómete todo», «no salgas», etc.; sino que hay un desplazamiento de lo práctico-cotidiano a lo ético-moral, social y psicológico.

DoÑa PudenCiana. ¿Discutir? Con la religión no te metas, hijo; con la religión, no. Te traerá desgracia en esta vida y en la otra.

[...]

¡Por favor, Monche, deja nuestras creencias intactas! Causaste ya bastante daño. No rebases la copa. Huye la compañía y el ejemplo de esos herejes. Respeta el dogma, defiende a la Iglesia. ¡Teme a Dios!

$[\ldots]$

(Estallando.) ¡Hereje! ¡Hereje! ¡Demonio tentador! No te mezcles en los asuntos eclesiásticos. Deja las conciencias en paz. Ocúpate de intereses terrenales; pero, repito, no colmes la paciencia de Dios Nuestro Señor. (Trapos viejos, pp. 770-771).

La trasformación de las estrategias discursivas del control es quizás más evidente en las interacciones entre madres e hijos adolescentes, quienes tienen que sufrir el control de las dos facetas de la vida: una ya totalmente desarrollada, la de los hábitos propiamente adquiridos en la infancia; y otra incipiente todavía, la del control de la libido a través de la moral y la de la ejecución

5. Ya ha sido observado en estudios sobre las relaciones entre madres e hijos, la normalidad en el uso de exhortaciones, órdenes y consejos directos e indirectos sobre cómo deben comportarse y actuar los hijos en varios aspectos de su vida (Wodak y Schultz, 1986; Rich, 1979; Chodorow, 1978; Castresana, 1993; Walters, 1992). 
de los actos propios de la edad adulta, como sería la toma de decisiones. Veamos un ejemplo tomado de Las madres:

Doña Pudenciana. Vamos, José. ¿Qué buscas?

PEPE. Nada, mamá.

DoÑa CATA. Ya te conozco: has de estar buscando a la Rosita esa. Si sale como su madre...

PEPE. Hombre, mamá...

DoÑa CATA. Todavía no te pinta el bozo y ya quieres andar de faldas. Como tu padre, que en paz goce. [...] ¡Muchacho fodongo este! ¡Mocos de membrillo! (p. 570)

Pragmáticamente, esta responsabilidad se manifiesta en la gran cantidad de actos directivos que van cambiando, adecuándose a la edad y género de los hijos: de los actos ilocutivos directos que predominaban en la infancia, se pasa a macroactos de habla directivos-indirectos, ejecutados en elaboradas secuencias donde lo que se pone en juego es la habilidad materna para dirigir a los hijos adultos, intentando que no sea evidente esa sanción sobre su proceder, a menos que la cerrazón del hijo requiera una dirección categórica.

De esta forma, la madre se convierte en la continuadora de la institución y en la instructora connaturalizada de las disposiciones sociales que crean las diferencias de género, sobre todo aquellos rituales y signos que tienden a acentuar en cada agente, varón o mujer, los signos exteriores de diferenciación sexual conformes con su definición social, o a estimular las prácticas adecuadas para su sexo, a la vez que impiden o dificultan los comportamientos inadecuados (Bourdieu, 1998: 39-40).

Otra de las funciones asignadas a la madre-esposa desde la representación y que va de acuerdo con su percepción social tradicional, es la de servir de mediadora entre los miembros de la familia, específicamente entre el padre y los hijos. Esta calidad de mediación, de intercesión -¿por qué no decirlo así?-, tiene como claro referente, en la cultura occidental, la figura de la Virgen María. En otras palabras, si la Virgen desempeña el rol de intercesora entre el Dios Padre para lograr el perdón de los pecados de los hombres, sus hijos, la madre establecerá esa misma dinámica, pero trasladada al contexto familiar. Se convierte, de esta forma, en la mediadora natural entre el padre, que ejerce el control público de la familia, y los hijos, que estarán supeditados, al igual que la esposa, a las decisiones paternas. Entonces, a la dureza paternal, se opondrá la comprensión materna.

La mediación materna implica de alguna manera controlar los actos de los hijos y formarlos en las maneras adecuadas de gestionar con el padre la información, los permisos, las opiniones, etc. En los textos, padres e hijos son pues- 
tos en intercambios comunicativos, que requieren la intervención mediadora de la madre para evitar que sean foco de conflictos familiares. Lo más común es que se trate de interacciones en las que los hijos desacreditan al padre como el legítimo ejecutor de la autoridad familiar. En estos casos, la madre-esposa interviene para mitigar o reconducir las actuaciones de los hijos, usando estrategias discursivas que tiene como fin reprocharles su proceder, o, en última instancia, justificar la actuación paterna. En El gesticulador y Fugitivos, de Usigli, y en ...Y la mujer hizo al hombre, de Alejandro Galindo, encontramos una buena cantidad de ejemplos que ilustran esta mediación. Solo por citar algunos, veamos los siguientes:

CÉSAR. ¿No cuentas los años que perdiste en la Universidad?

Miguel. (Mirándolo.) Son menos que los que tú has perdido en ella.

ELENA. (Con reproche.) Miguel. (ELG: 505)

DoÑa REMEDIOS. Hija; has sido cruel e irrespetuosa con tu padre. Apenas si lo puedo creer de ti... (MUJ: 853)

Esta actitud mediadora de la madre, también está vinculada a su función como guía y protectora de los hijos y como observadora solidaria en las actuaciones del marido. Al igual que en otras funciones maternas, la mediación se asume como una inherente a la madre y ella lo ejecutará como tal; si no lo hace, se le recordará cuál es su deber.

Finalmente, retomemos la circunscripción de la madre-esposa al ámbito privado del hogar, que, como ya apuntábamos antes, trae como consecuencia que su agentividad -lingüística y sociológica $-{ }^{6}$ se limite a aspectos relacionados con lo doméstico y con la maternidad. Por eso encontramos a mujeres limpiando, cocinando, consolando a los hijos y al marido, reconfortándolos y ofreciendo un apoyo incondicional.

Si observamos la agentividad verbal, vemos que se repite esa sujeción de la madre-esposa a la figura dominante del marido, quien ostenta el control del entorno de la familia. Por eso, las esposas dependerán de la aprobación del marido para ejercer su participación en tanto en la esfera privada como en la pública, ya sea en la toma de decisiones o en la exposición de la propia opinión.

De esta forma, no queda sino reconocer una asimetría de poder entre hombres y mujeres en ambos espacios; ya que, aunque suele pensarse que la mujer es más agentiva en los espacios privados, esa agentividad queda a otros niveles, no al de las decisiones que atañen a la familia como conjunto. Se ha

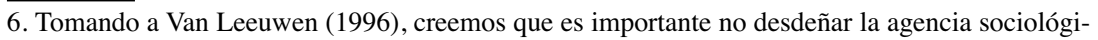
ca, ya que muchos actores sociales que aparecen agentivos desde el punto de vista lingüístico, son pacientes sociológicamente hablando. La agentividad refiere a esa «capacidad para actuar libre y autónomamente» (Cameron, 2001: 125). 
dicho con respecto a la pasividad femenina que está en relación con una tendencia a evitar la responsabilidad en las acciones porque no se sienten autónomas y autocontroladas (Martín, 1997 b: 3). Yo diría que más bien responde a que se han asumido roles que socialmente están tipificados para ser menos agentivos, y cuya asunción no ha pasado por una evaluación crítica del ser y el hacer. Los atributos socioculturales de los roles que desempeñamos pesan sobre nuestras estructuras cognitivas, y muchas veces terminamos aceptándolos como normales o como parte de nuestro ser-hacer. Las mujeres en su rol de madres y esposas, en tanto que miembros de una categoría de género que socialmente tiene acotados los espacios de actuación, tanto verbal como material, verá prácticamente circunscrita su agentividad al espacio privado del hogar; a ejercerla sobre aquéllos que dependen de ella, como los hijos o la servidumbre en caso de que la hubiera y limitada a aquellos tópicos que el varón quiera cederle o que le lleguen estipulados de lo social: las decisiones sobre la administración del hogar, la preparación de alimentos, la limpieza de la casa, la educación de los hijos y, sobre todo, de las hijas; la mediación para conciliar los intereses entre los diferentes miembros de la familia, exigir al marido el cumplimiento de sus responsabilidades morales y materiales para con la familia, etc.

Así, la agentividad de la madre esposa no hace sino reforzar la asimetría entre los géneros, en una clara desventaja para la mujer, a quien se le atribuyen actos que tienen una injerencia prácticamente nula en las acciones trascendentes representadas en las obras. Además, encontramos que el trabajo doméstico, visto como una actividad de poco prestigio y totalmente subordinada, es representado como incumbencia exclusiva de las mujeres, con un fin de integración y protección de la familia.

Podemos concluir, entonces, que la construcción discursiva que se hace de la madre-esposa se corresponde con la construcción de una identidad femenina que está pendiente de la tradición y los códigos morales y sociales vigentes en ese período, manteniendo una visión conservadora de su ser-hacer que difícilmente se corresponde con la realidad social detectada en estudios de vida cotidiana de la época.

\section{REFERENCIAS BIBLIOGRÁFICAS}

Ayala Blanco, J. (1993): La aventura del cine mexicano en la época de oro y después, México, Grijalbo.

Bourdieu, P. (1998): La domination masculine, París, Éditions du Seuil (tr. de JORDÁ, J. (2000): La dominación masculina, España, Anagrama.

CAMERon, D. (2001): Working with spoken discourse, Gran Bretaña, Sage. 
Cantón, W. (comp.) (1982): Teatro de la Revolución Mexicana, México, Aguilar.

Castresana, A. (1993): Catálogo de virtudes femeninas: de la debilidad histórica de ser mujer versus la dignidad del ser esposa y madre, Madrid, Tecnos.

Chodorow, N. (1978): The reproduction of mothering: Psychoanalysis and the sociology of gender, Berckewley, CA, Univ. of California Press.

FULLER, N. (2006): Identidad femenina y maternidad; una relación incómo$d a$, Pontificia Universidad Católica de Perú, en http://www.demus.org. pe/aborto/index/mater.htm, consultada en junio de 2006.

Lagarde, M. (2001): Los cautiverios de la mujer: De madresposas, putas, presas, monjas y locas, México, UNAM.

MagaÑa Esquivel, A. (comp.) (1956): Teatro mexicano del siglo XX, vol. 2, México, FCE.

- (1970 a): Teatro mexicano del siglo XX, vol. 4, México, FCE.

- (1970 b): Teatro mexicano del siglo XX, vol. 5, México, FCE.

MARTín Rojo, L. (1996): «Lenguaje y género. Descripción y explicación de la diferencia», Signos. Teoría y práctica de la educación, 16: 6-17.

- (1997 a): «El orden social de los discursos», Discursos, 21-22: 1-37.

- $(1997 b)$ : «The politics of gender: agency and self-reference in women's discourse», en Blommaert, J. y Ch. Bulcaen (eds.) (1997): Political Linguistics, Ámsterdam, John Benjamins, 231-254.

- (2001): «New developments in Discourse Analysis: discourse as social practice», en Folia linguistica. Critical discourse analysis in postmodern societies, XXXV/1-2: 41-78.

- (2003): «El análisis crítico del discurso. Fronteras y exclusión social en los discursos racistas», en Í̃̃̃GUEZ, L. (ed.) (2003), Análisis del discurso. Manual para las ciencias sociales, Barcelona, UOC, 157-191.

Monsivárs, C. y C. BonfiL (1994): A través del espejo. El cine mexicano y su público, México, Ediciones El Milagro / Instituto Mexicano de Cinematografía.

MonteVERDE, F. (comp.) (1956): Teatro mexicano del siglo XX, vol. 1, México, FCE.

Pavis, P. (1980): Dictionnaire du Théâtre. Termes et concepts de l'analyse théâtrale, París, Éditions Sociales (tr. de DE ToRO, F. (1980): Diccionario del teatro: dramaturgia, estética y semiología, Barcelona, Paidós, 1990).

Rich, A. (1976): Of woman born, N. Y., Bantam (tr. de G. AdElstein, Nacemos de mujer: la maternidad como experiencia e institución. Madrid, Cátedra (1996).

Río, M. (1993): Perfil del teatro de la Revolución Mexicana, Nueva York, Peter Lang ( $2^{\mathrm{a}}$ ed. Perfil y muestra del teatro de la Revolución Mexicana, México, FCE, 1997).

Toro, F. (1987): Semiótica del teatro: del texto a la puesta en escena, Buenos Aires, Galerna. 
VAN DIJK, T. (1980): The structures and functions of discourse: an interdisciplinary introduction to textlinguistics and discourse studies, Text of lectures given at the University of Puerto Rico at Río Piedras, University of Amsterdam, Unpublished ms. 1978, (tr. de GANN, M. y M. MUR (1980): Estructuras y funciones del discurso: una introducción interdisciplinaria a la lingüística del texto y a los estudios del discurso (nueva edición aumentada), México, Siglo XXI).

- (1987): «La pragmática de la comunicación literaria», en MAYORAL A. (comp.) (1987): Pragmática de la comunicación literaria, Madrid, Visor Libros, 171-194.

- (1993): «Principles of critical discourse analysis», en VAN DIJK, T. (ed.) (1993): Discourse and Society, vol. 4, $\mathrm{n}^{\circ}$ 2, Londres, Sage, 249-283.

- (2001): «Critical discourse analysis», en SCHIFfrin, D., D. TANnen y H. HAmiLton (eds.) (2001): The handbook of discourse analysis, Gran Bretaña, Blackwell Publishers, 352-371.

- (2003): Ideología y discurso, Barcelona, Ariel.

VAN LEEUWEN, T. (1996): «The representation of social actors», en CALDASCoulthard, C. y M. Coulthard (eds.) (1996): Texts and practices. Readings in critical discourse analysis, Londres / Nueva York, Routledge, 32-70.

Vershueren, J. (1999): Understanding Pragmatics, Londres / Nueva York, Arnold Publishers, (tr. de BAENA, E. y M. LACORTE (1999): Para entender la Pragmática, Madrid, Gredos).

WALTERS, S. D. (1992): Lives together / worlds apart: mothers and daughts in popular culture, CA, University of California Press.

WODAK, R. (1997): «Introduction: some important issues in the research of gender and discourse», en Gender and discourse, Londres, Sage Publications, 1-20.

- (2000): «¿La sociolingüística necesita una teoría social? Nuevas perspectivas en el análisis crítico del discurso», Revista iberoamericana de discurso y sociedad: lenguaje en contexto desde una perspectiva crítica $y$ multidisciplinaria, Barcelona, Gedisa, vol. 2 (3): 123-147.

WodAK, R. y M. SchUlz (1987): The language of love and guilt: Mootherdaughter relationships from a cross-cultural perspective, Amsterdam/ Philadelphia, John Benjamins. 


\section{SECCIÓN III \\ NORMA, USOS \\ Y VARIACIÓN LINGÜÍSTICA}




\title{
FORMULISMO NOTARIAL Y MARCAS DE ORALIDAD EN DECLARACIONES MATRIMONIALES DE LOS SIGLOS XVI-XVII: LA EXPRESIÓN DE LA MODALIDAD*
}

\author{
María Areta Lara \\ Universidad de Navarra
}

\section{INTRODUCCIÓN}

$\mathbf{E}$ L interés por el estudio de la lengua oral no solo resulta atractivo para los investigadores del ámbito sincrónico, sino también para los que centran su atención en el estudio diacrónico de la lengua, a pesar de que, como es evidente, el acercamiento a la lengua oral se hace mucho más intrincado conforme se mira hacia atrás en el tiempo, pues, como afirma Cano (2002: 279), nunca podremos «presenciar» un coloquio del siglo XVI, pero tampoco podemos conformarnos con pensar que los textos más realistas de la literatura de épocas pasadas reflejan la lengua que se hablaba entonces. ${ }^{1}$

Hasta hace pocos años no se había descubierto la valía de muchos documentos de carácter jurídico como las cartas, los testamentos, las declaraciones, ${ }^{2}$ etc. No obstante, no todas las fuentes documentales resultan adecuadas para rastrear vestigios de la lengua oral de otros siglos. ${ }^{3}$ En cambio, entre la diversidad de la tipología documental notarial las declaraciones de litigantes y testigos constituyen una fuente muy útil para el estudio de la lengua oral; así lo atestiguan las palabras de Cano (2002: 281):

\footnotetext{
* Este estudio ha sido posible gracias al proyecto Teoría y Análisis de los Discursos. Estrategias persuasivas y de interpretación, perteneciente al PIUNA (Proyecto de Investigación de la Universidad de Navarra).

1. Así lo explica también González Ollé (1999: 219): «No se puede trazar la historia de la lingüística sin el concurso de los textos literarios, aunque el conocimiento de éstos nunca resulte suficiente para trazar aquélla».

2. Destacan los trabajos pioneros en el ámbito diacrónico de Eberenz (1998 y 2003), quien se ha centrado en analizar actas de la Inquisición; Cano, que ha estudiado distintos tipos textuales como cartas de emigrantes españoles a Indias (1996) y declaraciones de documentos indianos (1998), y Oesterreicher (1996), quien ha establecido una tipología de textos en los que se pueden rastrear muestras de lo hablado en lo escrito.

3. Entre la documentación jurídica, la real y la notarial están sujetas a unos modos de decir plagados de formulismos y giros propios del estilo notarial, por lo que este tipo de textos no resulta apropiado para constatar la presencia de lo oral en lo escrito.
} 
Quizá la reproducción más aproximada que podamos hallar los historiadores es la que quedó plasmada en las actas de procesos, en las que figuran declaraciones de actuantes en un proceso judicial. Tales declaraciones son, en principio, la transcripción de enunciados orales realmente emitidos; adoptan la forma de intercambio (se produjeron en secuencias de preguntas y respuestas); y suelen incluir a su vez, en discurso directo o indirecto, la reproducción de otros actos de habla. Las actas de la Inquisición, o las relaciones de tantos procesos guardados en los Archivos (como el de Indias), son un magnífico campo para el objetivo que pretendemos, muy poco transitado hasta el momento [...] Finalmente, no olvidemos que la transcripción fue hecha por un escribano, o un notario, formados en un estilo de escritura fuertemente estereotipado, y que, en todo caso, sirvieron como «filtro».

Entre las posibilidades que ofrece el análisis de este tipo textual, he considerado interesante constatar el carácter híbrido de las declaraciones prestando atención a los elementos lingüísticos que aportan un valor modal al texto, en la medida que, como se verá más adelante, el análisis de algunos de estos elementos que expresan la actitud del hablante revela, por un lado, la huella del escribano que actúa como un «filtro» (Cano, 2002) por el que pasan las palabras de los declarantes, y, por otro, pone de manifiesto también la espontaneidad en la que se fraguan las declaraciones de los testigos.

\section{EL CORPUS: DECLARACIONES MATRIMONIALES DE FINES DEL SIGLO XVI}

Así, con el apoyo de las palabras de Cano arriba citadas y tras varios estudios que han ratificado la idoneidad del corpus escogido, ${ }^{4}$ he tomado como base para este análisis varias declaraciones de litigantes y testigos contenidas en siete procesos matrimoniales navarros de finales del siglo XVI. ${ }^{5}$

$\mathrm{Al}$ analizar la naturaleza discursiva del tipo de texto declaración, se observa que se halla a medio camino entre la oralidad y la escritura; ${ }^{6}$ pues es oral en cuanto al modo de realización, en tanto que hay una persona que declara, pero, en lo que al modo de transmisión se refiere, el escribano transcribe las palabras de los declarantes adaptándolas, en cierto modo, al nuevo medio y a las formas propias del discurso escrito. Así pues, tomando la metáfora del «doble filtro perspectivista $\gg^{7}$ de Eberenz (1998: 244), se puede afirmar que las declaraciones

4. Para un estudio más detallado, véase Areta (2007 b).

5. Estos procesos se encuentran almacenados en el Archivo Diocesano de Pamplona. Aprovecho estas líneas para agradecer a D. José Luis Sales, archivero de la diócesis, la ayuda que me brindó.

6. Véase Areta (2007a).

7. «Los hechos apuntados en los documentos han pasado por un doble filtro perspectivista: los relata el testigo desde su punto de vista personal, y este relato queda a su vez alterado por el escribano que lo consigna por escrito». 
conjugan dos modos discursivos radicalmente opuestos: el de la declaración espontánea de los testigos y el del discurso formulario del documento oficial.

Como se verá a continuación en el análisis de la huella del sujeto enunciador en las declaraciones, el estilo estereotipado de la prosa notarial hace que, en proporción, los rastros de la producción oral primigenia sean escasos.

Este hecho se advierte de manera notable al estudiar los elementos lingüísticos que expresan la actitud del declarante, a pesar de que, en principio, dado que manifiestan la subjetividad del hablante, podrían parecer menos «vulnerables» a la influencia del notario.

\section{LA EXPRESIÓN DE LA MODALIDAD EN LAS DECLARACIONES}

Antes de adentrarnos en el análisis del carácter oral o «escritural» de los elementos que manifiestan la actitud del hablante en el corpus estudiado, considero necesario recordar -al menos someramente- qué se entiende por modalidad.

Los autores que han abordado el estudio de la modalidad desde el plano de la Lingüística parecen no ponerse de acuerdo a la hora de establecer una definición. Como señala Otaola (1988: 99), la raíz del problema está en que no hay unanimidad entre los estudiosos acerca de los elementos que aportan valor modal a un texto. Para algunos, la modalidad se identifica exclusivamente con el modo verbal, mientras que otros autores advierten de la capacidad de expresar modalidad a través de diferentes medios lingüísticos. ${ }^{8}$ A este respecto cabe destacar la aportación de Bally (apud Otaola, 1988: 100) para quien la modalidad es «la forma lingüística de un juicio intelectual, de un juicio afectivo o de una voluntad que un sujeto pensante enuncia a propósito de un percepción o de una representación del espíritu».

Es evidente, por tanto, que en el concepto de modalidad desempeña un papel primordial la relación que se establece entre tres elementos de la comunicación: hablante-oyente-enunciado.

Dado que el estudio de la modalidad puede adquirir orientaciones diversas, el enfoque que he adoptado -siguiendo a Otaola (1988)- para el análisis de aquellos elementos del corpus que expresan un valor modal se basará fundamentalmente en la teoría de la enunciación, pues considero que la distinción

8. López Rivera (2002: 66) rescata en su obra la tesis modal de Sánchez de las Brozas (1587: cap. XIII), quien señala que no solo debe ser tenido en cuenta el modo como atributo natural de los verbos, en tanto en cuanto puede explicarse por el ablativo o por los adverbios.

Como se verá más adelante, la expresión de la modalidad puede adoptar formas muy diversas como adjetivos, locuciones adverbiales, verbos, etc. 
entre modalidad del enunciado y modalidad de la enunciación refleja de manera clara las relaciones entre:

$$
\begin{aligned}
& \text { Hablante }- \text { oyente } \rightarrow \text { en la modalidad de la enunciación } \\
& \text { Hablante }- \text { enunciado } \rightarrow \text { en la modalidad del enunciado }
\end{aligned}
$$

Esta autora afirma que la modalidad de la enunciación viene dada por todos aquellos elementos lingüísticos que manifiestan la actitud del hablante hacia el oyente (Otaola, 1988: 101). Asimismo, destaca tres modalidades que determinan la forma lingüística del enunciado: modalidad declarativa, interrogativa e imperativa a través de las cuales se percibe la relación interpersonal entre hablante y oyente. ${ }^{9}$

Por otra parte, en la modalidad del enunciado -que es la que va a centrar nuestra atención- se expresa la actitud del hablante ante el enunciado (Otaola, 1988: 102-103)..$^{10}$ Dentro de este tipo se puede establecer una subdivisión entre modalidad lógica, que caracteriza en términos de real, contingente e irreal la manera en que el hablante presenta el enunciado, y modalidad apreciativa, que indica el modo en que el sujeto juzga el enunciado con relación a juicios apreciativos o subjetivos.

Una vez establecidos los criterios básicos para analizar los indicios de modalidad en los textos estudiados, me dispongo ahora a realizar un análisis de los medios de expresión de la modalidad indicando, en la medida de lo posible, la acción que ejerce el escribano.

Como se ha descrito en las líneas anteriores, en un primer acercamiento a los textos se descubre que los escribanos, en un afán de fidelidad al testimonio de los declarantes - del discurso directo (de la oralidad) al indirecto-, recogían por escrito marcas modales (adverbios, verbos, adjetivos, etc.) que teñían de subjetividad las declaraciones de los testigos. No obstante, y tras analizar varios testimonios, se comprueba que la mayoría de estos mecanismos que evidencia la actitud del hablante, al pasar por el tamiz del notario, quedan fijados como expresiones formularias -por tanto, propias de la escritura-, y otros, en cambio, mantienen en cierto sentido la huella oral.

A continuación vamos a clasificar y analizar estos elementos que manifiestan la actitud del hablante en función del grado de ${\text { oralidad-}-« e s c r i t u r a l i d a d{ }^{11}}^{11}$ que presentan..$^{12}$

9. Casi todos los testimonios estudiados corresponden a reproducciones indirectas de declaraciones de testigos. Como se puede deducir de la palabra declaración, la modalidad de la enunciación que impera en este tipo de texto es la declarativa.

10. Esta modalidad se corresponde con la definición propugnada por Bally.

11 Término acuñado por W. Oesterreicher.

12 Para un estudio más detallado de la presencia de rasgos orales en estas mismas declaraciones véase Areta $b$. 


\subsection{Características de la prosa notarial en indicadores de modalidad}

$\mathrm{Si}$, como es sabido, el estilo de los textos jurídicos se caracteriza por su conservadurismo y por el afán de exactitud, no es extraño encontrar en las declaraciones expresiones formularias y coordinaciones sinonímicas con el fin de lograr este objetivo. Asimismo, la repetición constante de algunas expresiones es un indicio de que dicha expresión está normalizada dentro de la prosa notarial.

\subsubsection{Indicadores de certeza}

Es frecuente encontrar expresiones con el verbo saber, que indica un alto grado de certeza, reforzadas además por otros elementos -como los adjetivos cierto y harto- que enfatizan el valor de seguridad inherente a este verbo:

(1) Y este dixo que sabe de cierto saber por aberse allado presente al punto que se casaron en la dicha yglesia...13

(2) Dixo esta que depone que sabe de cierto (sic) sabe de cierto saber ${ }^{14}$ que puede haber catorze años, poco más o menos, que casaron.

(3) Y por esta caussa save esta testigo de muy harto saber, que el dicho Joanes de Yelz tiene catorze o quinze años que dicho tiene y no más.

Se ha apuntado antes que el modo verbal ayuda a caracterizar por procedimientos gramaticales la actitud del hablante. ${ }^{15}$ Como es sabido, el verbo saber, que pertenece al conjunto de los verbos modales según algunos autores ${ }^{16}$ sirve para manifestar que el juicio del hablante hacia el enunciado que pronuncia es de certeza, pues el significado léxico de este verbo es «seguridad, certeza»; sin embargo, es reseñable ver la diferencia modal entre los siguientes testimonios:

13. Los testimonios que sirven de base para este estudio proceden de siete procesos matrimoniales almacenados en el Archivo Diocesano de Pamplona. Estos documentos no habían sido analizados antes, por lo que fue necesario transcribirlos.

Dado que el propósito de estas transcripciones no es paleográfico, los textos han sufrido varias modificaciones. Por un lado se han actualizado las mayúsculas así como la puntuación del texto para facilitar su lectura y comprensión. Por otro, se han mantenido las grafías originarias por el interés lingüístico que éstas encierran. Finalmente, las abreviaturas se han resuelto utilizando la cursiva.

14. Utilizo la negrita para destacar las expresiones que se analizan en cada momento.

15. M. Casado (1972) habla de distintas formas de expresar la modalidad; por un lado están los medios léxicos, a través de adjetivos, adverbios, locuciones adverbiales, verbos modales, etc. y por otro los medios gramaticales, modo y tiempo.

16. Más adelante se hará hincapié en este aspecto. 
(4) Y este dixo que sabe de cierto saber por aberse allado presente.

(5) Y que conoce a las partes litigantes y no es deudo ni pariente de ninguna d'ellas, que sepa.

En el primer caso el escribano muestra con el verbo saber en indicativo que el testigo está completamente seguro de sus palabras; en cambio, en el segundo, el significado léxico de certeza de este verbo se ve superado por el sentido incierto del subjuntivo que caracteriza el juicio del declarante. ${ }^{17} \mathrm{R}$. J. Cuervo (s. v. saber) recoge la locución «que yo sepa» y señala que se trata de una «expresión correctiva o restrictiva con que se hace una salvedad a algo que se acaba de afirmar».

En el siguiente testimonio la fórmula «sabe de cierto saber» aparece en coordinación sinonímica con otra expresión que es muy frecuente en los textos de carácter notarial «sabe y se acuerda»:

(6) Y entiende ser así verdad porque quando esta testigo parió solía traer al dicho Joanes a braços su madre, niño de poca edad; y que el dicho su hijo d'esta testigo tenga la hedad que dicho tiene lo save de çierto saber y se acuerda d'ello porque quando morió su marido d'esta testigo y padre del dicho su hijo, que abrá ya diez años justos, tenía tres años y pocos días más el dicho su hijo.

(7) Y save y se acuerda que a lo que cree y entiende el mes de abril antes de aquel mismo año o en la comarca del dicho mes naçió, o a lo menos se bautizó, el dicho Joanes de Yelz a la iglesia del dicho lugar.

También encontramos esta expresión formularia en sentido negativo, esto es, para expresar incertidumbre:

(8) Fue preguntada si se acuerda por qué palabras el dicho abbad los casó, es a saber, si fueron de presente o de futuro; dixo que no lo sabe ny se acuerda, mas de que los casó como casó a sus dichos padres.

Además de estos testimonios que prueban el carácter formulario y reiterativo de estas expresiones con saber, es interesante prestar atención a las coordinaciones sinonímicas «es cossa pública y notoria», ${ }^{18}$ «es cossa cierta y verdadera» que son una constante en los textos de carácter jurídico-administrativo:

17. «La subjetividad, con toda la vaguedad que el término supone, es quizá la forma más adecuada, por menos comprometida, de denominar el valor del subjuntivo español que, pese a ciertas diferencias, recoge el carácter del subjuntivo latino como catalizador de la subjetividad del hablante» (Bassols apud Jiménez Juliá, 1989: 202).

18. Esta expresión se encuentra en múltiples textos jurídicos en el banco de datos CORDE de la Real 
(9) A la segunda pregunta dixo este testigo que save ser cossa muy pública y notoria que la dicha noche que así se cassaron los dichos Joanes de Yelz y Luzía de Ybero, y aún después en un año, dormieron juntos en una cama como marido y muger [...] Y en efeto, aunque este testigo no lo bio ocularmente es cosa çierta y notoria que durmieron juntos y en una cama y después an bivido juntos en un una cassa y messa.

(10) A la quarta pregunta dixo este testigo que dize lo que dicho tiene. Y que es cossa çierta y verdadera que el dicho Joanes de Yelz, después que conplió los dichos catorze años, y aún al presente quiere consentir y passar por el dicho cassamiento, como este testigo lo a oydo dezir del mismo Joanes de Yelz.

Tras hallar numerosos testimonios en los que aparecen estas expresiones, se puede afirmar que el empleo de estas fórmulas al comienzo de cada respuesta de los declarantes es un indicio claro de que se trata de fórmulas recurrentes en la prosa notarial que revelan la huella del escribano.

\subsubsection{Indicadores de incertidumbre}

La expresión más frecuente en la prosa jurídico-administrativa, en general, y en los testimonios estudiados, en particular, para expresar inseguridad es «poco más o menos». ${ }^{19}$

(11) Y un día miércoles, que era de labor, que no se acuerda aora qué día era mas de que puede aver tres meses, poco más o menos, que fue cuando fenecieron en el mismo día los padres del dicho Miguel de Ynduráyn.

(12) Dixo que no tiene padres y él es el heredero de la cassa y bienes que ellos dexaron en el dicho lugar de Rípodas, y que de año y medio, poco más o menos, a esta parte conoçe de vista y conbersaçión a la dicha Catalina de Orbayz.

(13) Y le reçevió juramento en forma de derecho en manos de mí el dicho not $a$ rio de que diría verdad de lo que supiese de lo que fuese preguntado, el qual, a la fuerça del dicho juramento respondió que sí jurava y amén que diría verdad y ser de hedad de dieciséis años, poco más o menos.

Autoridades (s. v. menos) recoge esta expresión adverbial y la define como «con poca diferencia». Otra fórmula frecuente para expresar la incertidumbre, también característica del estilo notarial, es la coordinación sinonímica «a lo que cree y entiende» y su variante «a lo que cree y sus mayores le diçen»:

19. Cabe señalar que el uso de esta expresión está más ligado hoy a la lengua oral que a la escrita. 
(14) Dixo que a lo que crehe y sus mayores le dizen tiene dieciocho años, poco más o menos.

(15) A la segunda pregunta dixo este testigo que lo que d'ella save es que este testigo tiene un hijo suyo y de María Martín, su muger, llamado Joanico, el qual, al presente tiene catorze años y aún, a lo que cree, no los tiene cumplidos.

(16) Y save y se acuerda que a lo que cree y entiende el mes de abril antes de aquel mismo año o en la comarca del dicho mes naçió, o a lo menos se bautizó, el dicho Joanes de Yelz a la iglesia del dicho lugar.

En definitiva, a través de los testimonios estudiados se ha comprobado que tras muchos de los elementos que reflejan la subjetividad del hablante se descubren también algunos de los rasgos más característicos de la prosa de los escribanos como el empleo de expresiones formularias, recurrentes en todos los documentos analizados, y coordinaciones sinonímicas que hacen patente el afán de exactitud del estilo notarial y que ponen de manifiesto la mano del notario.

\subsection{Indicadores de modalidad cercanos a la lengua oral}

Es normal que cuando los testigos son llamados a declarar en un juicio, conscientes del imperativo legal de fidelidad a la verdad que toda declaración implica, asuman la importancia que su declaración puede tener para el desarrollo del juicio y traten, por todos los medios, de recordar lo ocurrido. No obstante, muchas veces, cuando ha pasado un tiempo de los sucesos en cuestión, éstos vacilan en sus declaraciones y el escribano -como fiel reproductor- transcribe los vaivenes que los declarantes sufren en la memoria. Estas vacilaciones reflejan la espontaneidad que envuelve a la declaración. Son varias las expresiones que revelan esos titubeos de la memoria. Veamos algunos casos:

- Como: Los testimonios encontrados atestiguan que el uso de como ante expresiones numéricas imprimía borrosidad y vaguedad al conjunto, como ocurre todavía hoy. ${ }^{20}$ Quizá este uso era frecuente en la lengua oral y esto hizo que trascendiera también a la lengua escrita:

(17) Y estuvieron sin venir a la compañía como dos oras de tiempo más o menos.

(18) Pasando algunos días, como un mes de tiempo.

20.Véase L. Santos Río (2003: 258). 
(19) A estado esta [...] sirviendo de criada en la casa que llaman del abbad viejo, y salió d'ella que puede haber como un mes.

- Tal: Al igual que hoy, los casos hallados muestran que en esta época era también usual utilizar el adjetivo tal o un tal aplicado a un nombre propio para señalar que esa persona era desconocida y, al mismo tiempo, manifestar la inseguridad o desconocimiento de su nombre. ${ }^{21}$ Este uso aparece registrado en el Diccionario de Autoridades (s. v. tal): «Se usa asimismo para demostrar un sujeto no conocido». ${ }^{22}$

(20) Y así fueron este que declara y el dicho doctor y tal de Eliçondo y otros tres cuyos nombres no se acuerda a casa de un escribano real.

(21) Porque esta testigo la dixo que se dezía que ella se cassaba o quería cassar con tal de Elizondo [...] Y también ha dicho a esta declarante una tal Baptista.

- Cosa de: Autoridades (s. v. cosa) señala que significa «lo mismo que cerca de o poco más o menos»; no obstante, a diferencia de lo que ocurría con la fórmula «poco más o menos», únicamente se halla un testimonio entre todos los documentos estudiados. Esta singularidad en el uso puede apoyar la hipótesis de que se trate de una expresión propia de la lengua oral que ha trascendido a la escritura. ${ }^{23}$

(22) Se salieron y apartaron de la compañía el dicho Domingo de Sola y la dicha Graciana de Asiayn y se fueron assí juntos y se metieron entre las biñas [...] donde estuvieron por espacio de dos oras. Al cabo de las quales, más o menos, volvieron otra vez al carro. Y a la mañana se volvieron cossa de una ora u dos antes del día.

A parte de ser un lexema muy presente en la lengua oral, la capacidad extensiva del sustantivo cosa hace que aparezca también formando parte de expresiones que hemos calificado como características de la prosa notarial - «es cosa pública y notoria»; no obstante, es importante señalar que el estilo notarial parece anteponer la estructura neutra «es público y notorio» a «es cosa pública y notoria». Esta preferencia puede revelar un interés por parte de la

21. Por la frecuencia con que aparece esta forma, se podría pensar que se trata de un uso propio de la lengua escrita.

22. Testimonio de Autoridades: «Después la tal, que así la tal se nombra, te seguirá con paso más ligero, que al cuerpo sigue la importuna sombra».

23. Conviene recordar que uno de los rasgos que caracteriza a la lengua oral frente a la escrita es la espontaneidad o falta de planificación. 
prosa de los notarios por desvincularse del sustantivo cosa, dado que este lexema -por la amplitud de su significado- ha estado siempre más ligado a la lengua oral que a la escrita. ${ }^{24}$

Además de estos elementos -de posible adscripción oral- que revelan la inseguridad del hablante ante el enunciado, encontramos otros testimonios, en estilo directo, en los que la huella oral se hace más patente.

Al hablar de la modalidad hemos visto que no hay acuerdo entre los especialistas a la hora de cifrar los elementos que aportan valor modal a un texto. Sin embargo, de lo que parece no haber duda es de la existencia de ciertos verbos modales, a pesar de que algunos autores proponen unas nóminas más amplias que otros. ${ }^{25}$

En el siguiente fragmento encontramos varios testimonios -en estilo directo- en los que se aprecia el valor modal de querer ${ }^{26}$ que es el verbo de modalidad, que aparece junto a casar, verbo del dictum: «iMás querríais vos casar con ella que no que casse Eliçondo!», «Yo no puedo sustentar el fausto d'ella, que soy pobre moço, pero no querría se cassase con el dicho Eliçondo ympidido»:

(23) Y ottro testigo deuda de la dicha Yribas dize que por todos santos húltimos passados en su cassa, como en burlas, dixo al acusado: ¿En qué anáys estorbando que no se casse Eliçondo con Yribas? Y que el acussado les respondió que si lo hazía hera por ser Eliçondo hombre ympidido y querer él no se casase con él. Y que dicho testigo que es el 1 (sic) le respondió: ¡Más querríais vos casar con ella que no que casse Eliçondo! Y que le respondió el acusado: Ella dize que quiere entrar monja. ¡Por mí, cásese con Eliçondo que a mí no se me da nada! Y el dicho testigo le dixo: Pues, ¿por qué lo estorbáys? Y el acusado le dixo: Yo no puedo sustentar el fausto d'ella, que soy pobre moço, pero no querría se cassase con el dicho Eliçondo ympidido.

Entre las expresiones con querer destaca la estructura comparativa de carácter volitivo «más querríais vos... que...» que aparece en boca de la testigo y que, a mi modo de ver, puede equipararse con una expresión muy frecuente en la lengua oral actual «iqué más quisieras!».

Asimismo, conviene prestar atención al modo verbal, pues se trata de otra forma lingüística capaz de expresar modalidad, en la medida que refleja la actitud del hablante hacia el oyente (modalidad de enunciación). La mayoría de los

24. Sería muy difícil averiguar si las expresiones con cosa surgieron primero en el ámbito jurídico para pasar luego al popular, o viceversa.

25. Como señala Otaola (1988: 111), Alcina, Blecua y Carbona conciben como modales únicamente dos o tres verbos: poder, deber, soler. Otros, como Gili Gaya, la RAE, Alonso y Henríquez Ureña añaden a la lista saber, querer y los sinónimos de todos ellos.

26. Querer expresa modalidad apreciativa, es un verbo de voluntad. 
testimonios encontrados se hallan en estilo indirecto y responden a una modalidad declarativa clara; no obstante, entre los escasos testimonios en estilo directo, podemos encontrar otros tipos de modalidad como la imperativa. Como es sabido, el imperativo es la única forma verbal marcada exclusivamente por la modalidad yusiva, que responde a la función conativa o apelativa.

Volviendo al fragmento arriba citado, se comprueba que el acusado, molesto por el tono irónico e incitante con el que se dirige a él la testigo, acaba adoptando una actitud defensiva: «¡Por mí, cásese con Elizondo, que a mí no se me da nada!» donde la modalidad impresiva se hace patente a través del imperativo cásese.

En cuanto a «no se me da nada» Autoridades (s. v. dar) señala: «frase con que se explica el ningún cuidado que causa alguna cosa»; cabría encuadrar esta expresión dentro de la modalidad apreciativa, puesto que caracteriza la manera en que el sujeto sitúa el enunciado con relación a juicios subjetivos, en concreto, de indiferencia. Por otro lado, «no se me da nada» podría hallar su parangón en la lengua coloquial actual con locuciones del tipo «ia mí qué me importa!» o «por mí, que se case, me da absolutamente igual».

\section{A MODO DE CONCLUSIÓN}

A pesar de que, como se ha visto, es fácil identificar los rasgos que caracterizan el estilo notarial resulta, en cambio, muy complicado adscribir ciertos usos como propios de la lengua oral. No obstante, el valor expresivo y el carácter espontáneo de algunas de las marcas modales analizadas revela, en cierto sentido, la huella de la reproducción oral primigenia en la que se produjeron las declaraciones.

Si se me permite la comparación, el estudio que ahora concluyo no es sino una pequeña pieza del enorme «puzle» que constituye el estudio de la oralidad desde la perspectiva diacrónica. Como ya he indicado en las líneas anteriores, me he centrado en estudiar las huellas de oralidad y la influencia del formulismo notarial en algunas expresiones de modalidad, pero el panorama y las posibilidades de análisis son inmensas a la par que necesarias.

\section{REFERENCIAS BIBLIOGRÁFICAS}

Areta Lara, M. (2007 a): «Oralidad y escritura en el tipo de texto declaración (siglos XVI y XVII)», en FernándeZ AlCALDE, M. y A. LóPeZ SERENA (eds.): Cuatrocientos años de la lengua del Quijote. Estudios de historiografía e historia de la lengua española, Sevilla, Universidad de Sevilla, Secretariado de Publicaciones, 177-188. 
- (2007 b): «Reflexiones sobre la presencia de lo oral en declaraciones matrimoniales de finales del siglo XVI», en CORTES RodRíGUEZ, L. et al. (coords.): Discurso y oralidad. Homenaje al profesor José Jesús de Bustos Tovar, Grupo Ilse, Almería, Arco/Libros, vol. 2, 317-331.

Cano Aguilar, R. (1996): «Lenguaje espontáneo y retórica epistolar en cartas de emigrantes españoles a Indias», en Kotschi, T., W. Oesterreicher y K. ZiMMERMANN (eds.) (1996): El español hablado y la cultura oral en España e Hispanoamérica, Fráncfort - Madrid, Vervuert-Iberoamericana, 375-404.

- (1998): «Presencia de lo oral en lo escrito: transcripción de las declaraciones en documentos indianos del siglo XVI», en OESTERREICHER, W., E. STOLL y A. WeSCH (eds.) (1998): Competencia escrita, tradiciones discursivas y variedades lingüisticas. Aspectos del español europeo y americano en los siglos XVI y XVII, Tübingen, Gunter Narr Verlag, 219-242.

- (2002): «El español coloquial: enfoques y perspectivas de análisis», en ECHENIQUE, Ma $\mathrm{M}^{\mathrm{a}}$ T. y J. SÁNCHEZ (eds.) (2002): Actas del V Congreso Internacional de Historia de la Lengua Española I, Valencia, Gredos, 279-284.

Casado Velarde, M. (1972): Estudio de los verbos de modalidad en La Familia de Pascual Duarte, resumen de Tesis de Licenciatura defendida en 1972 en la Universidad de Sevilla.

Cuervo, R. J. (1872): Diccionario de construcción y régimen de la lengua castellana, Santafé de Bogotá, Instituto Caro y Cuervo.

EBERENZ, R. (1998): «La reproducción del discurso oral en las actas de la Inquisición», en OesterReicher, W., E. STOLl y A. Wesch (eds.) (1998): Competencia escrita, tradiciones discursivas y variedades lingüísticas. Aspectos del español europeo y americano en los siglos XVI y XVII, Tübingen, Gunter Narr Verlag, 243-266.

- (2003): «En busca de la palabra viva sobre la representación de la lengua hablada en las actas de la Inquisición», en El mundo como escritura. Estudios sobre Cervantes y su época, Analecta Malcitana, anejo XLVIII, Málaga, Universidad de Málaga, 59-77.

GoNZÁLEZ OlLÉ, F. (1999): «Orígenes de un tópico lingüístico: alabanza de la lengua cortesana y menosprecio de la lengua aldeana», Boletín de la Real Academia Española, LXXIX: 197-219.

JiMÉNEZ JULIÁ, T. (1989): «Modalidad, modo verbal y modus causal en español», Verba, 16: 175-214.

LÓPEZ RIVERA, J. J. (2002): El modo: la categoría gramatical y la cuestión modal, colección Lucus Lingua, Anexos de Moenia, 12, Universidad de Santiago de Compostela.

OesterReicher, W. (1996): «Lo hablado en lo escrito. Reflexiones metodológicas y aproximación a una tipología», en KoTSCHI, T., W. OESTERREICHER 
y K. Zimmermann (eds.), El español hablado y la cultura oral en España e Hispanoamérica, Fráncfort-Madrid, Vervuert-Iberoamericana, 317-339. Otaola Olano, C. (1988): «La modalidad (con especial referencia a la lengua española)», Revista de Filología Española, 68: 97-117.

Real Academia Española, (1726): Diccionario de Autoridades, Madrid, Gredos, 2002.

- Banco de datos (CORDE), Corpus diacrónico del español, <http://www.rae.es>. SÁNCHEZ DE LAS BROZAS, F. (1587): Minerva seu de causis linguae latinae, Salmanticae, versión española sobre el original latino de RIVERA CÁRENAS F. (1976): Minerva o de la propiedad de la lengua latina, Madrid, Cátedra.

Santos Río, L. (2003): Diccionario de partículas, Salamaca, Luso - Española de ediciones. 


\title{
NIVELES SOCIOCULTURALES Y LÉXICO DIALECTAL EN EL VOCABULARIO DISPONIBLE DE ARAGÓN*
}

\author{
María Luisa Arnal Purroy \\ Universidad de Zaragoza
}

\section{INTRODUCCIÓN}

D ENTRO del campo de la disponibilidad léxica, ${ }^{1}$ el estudio de la relación entre los factores sociales y el léxico disponible se revela como una importante vía de análisis, pues permite mostrar diferencias cuantitativas y cualitativas entre los diversos grupos establecidos y aportar, en definitiva, información empírica para conocer la estratificación social del léxico (Samper, 2006).

De los diversos condicionantes sociales que se tienen en cuenta en los estudios de disponibilidad adscritos al llamado Proyecto panhispánico del léxico disponible, nos ocupamos en esta contribución del «nivel sociocultural», factor que consideraremos en relación con un determinado conjunto del vocabulario disponible: el de los dialectalismos o regionalismos aportados por los informantes de Aragón.

El corpus del que partimos está constituido por los términos dialectales presentes en el inventario aragonés de disponibilidad léxica, que se publicó en el libro Léxico disponible de Aragón (cf. Arnal et al., 2004). Como se explica en ese volumen, se trata de un conjunto de 150.284 palabras (respuestas), que corresponden a 9.741 vocablos (palabras diferentes), obtenidos de una muestra formada por 417 estudiantes de $2^{\circ}$ de Bachillerato (o COU), de ambos sexos

* La autora es miembro del grupo de investigación ARALEX (Léxico de Aragón), reconocido por el Gobierno de Aragón.

1. No está de más recordar que la disponibilidad léxica busca el léxico potencial del hablante, es decir, el que forma parte de su lexicón mental y, por lo tanto, puede ser utilizado cuando la comunicación gira en torno a un determinado tema. Para una cabal explicación del concepto de léxico disponible, su origen, desarrollo y aplicaciones, remitimos, entre otros, al trabajo de Samper, Bellón y Samper Hernández (2003). Asimismo, las ya numerosas contribuciones basadas en esta fructífera línea de investigación en el ámbito hispanohablante, así como el estado de los diferentes proyectos que, a ambos lados del Atlántico, se ocupan del léxico disponible, se encuentran en la página electrónica <www.dispolex.com> que atienden José Antonio Bartol y Natividad Hernández Muñoz desde la Universidad de Salamanca. 
y diferentes niveles socioculturales, pertenecientes a 28 centros de enseñanza, públicos y privados, de las tres provincias aragonesas. ${ }^{2}$

En cuanto al factor «nivel sociocultural», es preciso explicar que se trata de una variable postestratificada que -al igual que hacen Blas Arroyo y Casanova (2003: 25), entre otros- hemos obtenido con arreglo al nivel de estudios de los padres de cada alumno, parámetro a partir del cual establecimos cuatro subgrupos: 1 . bajo, 2 . medio, 3 . medio-alto y 4 . alto; ${ }^{3}$ así pues, lo que denominamos «nivel sociocultural» ha de entenderse en realidad como «el entorno sociocultural en el que se desenvuelven los alumnos en sus respectivos dominios familiares» (Blas Arroyo y Casanova, 2003: 25). Según esta variable, la muestra aragonesa queda estratificada como aparece en el siguiente cuadro:

CUADRO 1. Estratificación de la muestra aragonesa según el «nivel sociocultural»

\begin{tabular}{|c|l|c|c|}
\hline \multicolumn{1}{|c|}{ Variable social } & $\mathbf{N}^{\mathbf{0}}$ de informantes & Proporción \\
\hline \multirow{3}{*}{ Nivel sociocultural } & bajo & 90 & $22 \%$ \\
\cline { 2 - 4 } & medio & 144 & $34 \%$ \\
\cline { 2 - 4 } & medio-alto & 129 & $31 \%$ \\
\cline { 2 - 4 } & alto & 54 & $13 \%$ \\
\hline
\end{tabular}

Por otra parte, con respecto a los regionalismos aportados por los sujetos de la muestra, tomamos en consideración los resultados del trabajo «Los dialectalismos en el léxico disponible de los jóvenes aragoneses» (cf. Arnal,

2. Las encuestas se realizaron en los propios centros de enseñanza, durante los cursos 1998-99 y 1999-00; de acuerdo con la metodología habitual de la disponibilidad léxica, se trata de pruebas asociativas en las que se presentan al estudiante, a modo de estímulo, unas áreas temáticas -los llamados «centros de interés»- en torno a las que tiene que responder por escrito cuantas palabras asocie con las mismas. El tiempo de respuesta fue de dos minutos para cada centro de interés. Los considerados en Aragón son los 16 comunes a todas las investigaciones del Proyecto panhispánico más el ámbito de Los colores: 01. Partes del cuerpo (CUE), 02 La ropa (ROP), 03. Partes de la casa (sin los muebles) (CAS), 04. Los muebles de la casa (MUE), 05. Alimentos y bebidas (ALI), 06. Objetos colocados en la mesa para la comida (MES), 07. La cocina y sus utensilios (COC), 08. La escuela: muebles y materiales (ESC), 09. Iluminación, calefacción y medios de airear un recinto (ILU), 10. La ciudad (CIU), 11. El campo (CAM), 12. Medios de transporte (TRA), 13. Trabajos del campo y del jardín (TRC), 14. Los animales (ANI), 15. Juegos y distracciones (JUE), 16. Profesiones y oficios (PRO) y 17. Los colores (COL).

3. Según se explica en Arnal et al. (2004: 19-20), aunque también contrastamos en cada caso la profesión de los progenitores, estos cuatro grupos socioculturales resultan de aplicar sendos cortes en el sumatorio de los valores numéricos otorgados a los estudios del padre y a los estudios de la madre. Recordemos que la mayoría de los investigadores que integran el Proyecto panhispánico se ha basado en dos indicadores, el nivel de estudios y la ocupación de los padres, siguiendo la propuesta que aplicaron Samper y Hernández Cabrera para Gran Canaria (vid. Samper, Bellón y Samper Hernández, 2003: 76). 
2007), en el que, además de exponer con detalle los criterios utilizados para atribuir o no carácter dialectal a una voz, se analizan -entre otros aspectos y con carácter general- la densidad de los dialectalismos según los centros de interés, su grado de disponibilidad o la situación del término dialectal en relación con el estándar equivalente. Por lo que ahora nos interesa, el análisis realizado ha permitido establecer una nómina de 280 términos dialectales, que representan el 2,87\% de léxico disponible, si bien se trata de un conjunto poco disponible, puesto que prácticamente la mitad de los regionalismos ha sido actualizada por tan solo un informante y en posiciones muy retrasadas de los listados. Conviene señalar, asimismo, que se han incluido entre los dialectalismos los casos que responden a la interferencia del catalán (recordemos que la denominada «franja oriental de Aragón» es de habla catalana y está presente en nuestra muestra mediante tres centros de enseñanza de esa área lingüística, como también lo está, por otra parte, el área altoaragonesa en la que todavía perviven variedades vernáculas, continuadoras del «dialecto histórico» aragonés).

Como se expone en el citado estudio, esos 280 dialectalismos ofrecen una distribución marcadamente desigual según los 17 centros de interés considerados. En el cuadro 2 presentamos el porcentaje de vocablos dialectales en cada uno de los centros de interés, que ordenamos de mayor a menor densidad de regionalismos. Aparecen resaltados también los seis centros cuya proporción de voces dialectales es superior a la media del 2,87\%.

Cuadro 2. Densidad de dialectalismos según los centros de interés

\begin{tabular}{|l|c|c|c|}
\hline Centros de interés & $\begin{array}{c}\text { Número de } \\
\text { vocablos }\end{array}$ & $\begin{array}{c}\text { Número de } \\
\text { dialectalismos }\end{array}$ & $\begin{array}{c}\text { Porcentaje de } \\
\text { dialectalismos }\end{array}$ \\
\hline 13. TRC & 547 & 44 & $8,04 \%$ \\
\hline 11. CAM & 1224 & 77 & $6,29 \%$ \\
\hline 03. CAS & 346 & 17 & $4,91 \%$ \\
\hline 07. COC & 520 & 25 & $4,81 \%$ \\
\hline 05. ALI & 649 & 27 & $4,16 \%$ \\
\hline 14. ANI & 542 & 19 & $3,51 \%$ \\
\hline 09. ILU & 442 & 10 & $2,26 \%$ \\
\hline 15. JUE & 894 & 18 & $2,01 \%$ \\
\hline 06. MES & 324 & 6 & $1,85 \%$ \\
\hline 12. TRA & 403 & 6 & $1,49 \%$ \\
\hline
\end{tabular}




\begin{tabular}{|l|c|c|c|}
\hline Centros de interés & $\begin{array}{c}\text { Número de } \\
\text { vocablos }\end{array}$ & $\begin{array}{c}\text { Número de } \\
\text { dialectalismos }\end{array}$ & $\begin{array}{c}\text { Porcentaje de } \\
\text { dialectalismos }\end{array}$ \\
\hline 04. MUE & 363 & 5 & $1,38 \%$ \\
\hline 08. ESC & 669 & 9 & $1,35 \%$ \\
\hline 16. PRO & 761 & 6 & $0,79 \%$ \\
\hline 17. COL & 380 & 3 & $0,79 \%$ \\
\hline 02. ROP & 332 & 2 & $0,60 \%$ \\
\hline 01. CUE & 356 & 2 & $0,56 \%$ \\
\hline 10. CIU & 989 & 4 & $0,40 \%$ \\
\hline
\end{tabular}

Nuestro propósito es ahora poner en relación esos resultados generales sobre los dialectalismos con el parámetro sociocultural. Partimos de la hipótesis de que este factor sociológico covariará en mayor o menor medida con la cantidad y cualidad de los términos dialectales aportados. ${ }^{4}$ En concreto, queremos comprobar si, como nos enseñan las aportaciones dialectológicas y sociolingüísticas, son los informantes de nivel sociocultural bajo los que muestran la mayor proporción de términos dialectales; y, asimismo, si es este grupo social, frente a los de niveles altos, el que ha evocado las voces regionales con mayor grado de «dialectalidad» o diferenciación diatópica.

\section{LOS DIALECTALISMOS Y EL NIVEL SOCIOCULTURAL}

Bien se sabe que la Dialectología tradicional, con el objeto de recopilar la mayor cantidad de elementos vernáculos o dialectales posible, buscaba los informantes entre los individuos de nivel sociocultural bajo, pues en ellos podía encontrarse más y mejor conservado ese patrimonio lingüístico tradicional. ${ }^{5}$ Igualmente, desde la Sociolingüística, como ha recordado Blas Arroyo (2005: 218-219), los resultados de las investigaciones variacionistas sobre el español muestran de forma recurrente que las variantes vernáculas (los dialectalismos, en nuestro caso) suelen aparecer con más frecuencia en el habla de los indivi-

4. Merece la pena señalar que, en las investigaciones de disponibilidad léxica, el nivel sociocultural se ha revelado como una de las variables sociales que mayor incidencia tiene en el léxico disponible, y ello pese a que se trata de un factor indirecto, dado que responde a parámetros no de los informantes sino de sus padres (cf. Blas Arroyo y Casanova, 2003: 25-26; Samper, Bellón y Samper Hernández, 2003: 78-79; Samper, 2006: 114-115).

5. Sirva como botón de muestra el reciente trabajo, de carecer exploratorio, de Borrego y Fernández Juncal (2002: 299) en el que, dado que lo que pretenden es detectar la presencia de léxico dialectal, todos sus informantes tienen un nivel de estudios bajo. 
duos de los niveles sociales bajos, mientras que las variantes estándares se hallan asociadas en mayor medida al habla de los sociolectos elevados. ${ }^{6}$ También en el ámbito de la disponibilidad léxica, en el único trabajo que sepamos dedicado específicamente a esta cuestión, Samper y Hernández Cabrera (2006) han comprobado que los dialectalismos canarios están muy propiciados por los estudiantes del nivel sociocultural bajo, siendo el sociolecto alto el grupo que menos favorece, con diferencia, la presencia de los regionalismos. Dados estos resultados previos, cabe esperar que este mismo patrón se reproduzca cuando nos enfrentamos con los dialectalismos presentes en el léxico disponible de Aragón.

\subsection{Análisis cuantitativo}

Y, efectivamente, desde una perspectiva meramente cuantitativa, tal como se refleja en el cuadro 3, la mayor cantidad de respuestas dialectales tiene lugar en el grupo sociocultural bajo, con un promedio $(3,53)$ que casi duplica al que presenta el alto $(1,87)$. El patrón de estratificación es aquí lineal: el número de respuestas dialectales desciende progresivamente a medida que nos acercamos a los estratos más altos del espectro.

CUADRo 3. Cantidad de respuestas dialectales y promedio según el NSC

\begin{tabular}{|l|c|c|c|}
\hline Nivel sociocultural & $\begin{array}{c}\mathbf{N}^{\mathbf{o}} \text { de } \\
\text { informantes }\end{array}$ & $\begin{array}{c}\mathbf{N}^{\mathbf{0}} \text { de respuestas } \\
\text { dialectales }\end{array}$ & $\begin{array}{c}\text { Promedio de } \\
\text { respuestas dialectales }\end{array}$ \\
\hline 1. Bajo & 90 & 318 & 3,53 \\
\hline 2. Medio & 144 & 456 & 3,17 \\
\hline 3. Medio-alto & 129 & 337 & 2,61 \\
\hline 4. Alto & 54 & 101 & 1,87 \\
\hline
\end{tabular}

$\mathrm{Si}$ atendemos ahora a los vocablos dialectales aportados, es decir, no ya a las respuestas sino a las palabras diferentes a las que remiten, los resultados son similares, según se muestra en el cuadro 4. Se observa en él que el grupo bajo duplica al alto en la proporción de dialectalismos, si bien la estratificación no es lineal, pues el grupo sociocultural medio se halla más acorde con el bajo, superando incluso -aunque muy ligeramente- el porcentaje de vocablos dialectales.

6. Resulta asimismo ilustrativo al respecto el ejemplo que comenta López Morales (2004: 152153) sobre el conocimiento y uso de indigenismos en Puerto Rico en relación con los niveles socioculturales alto y bajo: son los hablantes del estrato bajo quienes más indigenismos conocen y usan. 
CUADro 4. Densidad de dialectalismos según el NSC

\begin{tabular}{|c|c|c|c|}
\hline Nivel sociocultural & $\begin{array}{c}\mathrm{N}^{\circ} \mathrm{de} \\
\text { vocablos }\end{array}$ & $\begin{array}{c}\mathrm{N}^{\mathrm{o}} \text { de } \\
\text { dialectalismos }\end{array}$ & $\begin{array}{c}\text { Promedio de } \\
\text { respuestas dialectales }\end{array}$ \\
\hline 1. Bajo & 4843 & 127 & $2,62 \%$ \\
\hline 2. Medio & 5983 & 164 & $2,74 \%$ \\
\hline 3. Medio-alto & 6063 & 131 & $2,16 \%$ \\
\hline 4. Alto & 4097 & 46 & $1,12 \%$ \\
\hline
\end{tabular}

Interesa también examinar si esta misma distribución social tiene lugar cuando ponemos en relación los niveles socioculturales con los centros de interés particulares. Nos atenemos a los seis que muestran la mayor densidad de dialectalismos (véase el cuadro 2). Los resultados, que aparecen expuestos en el cuadro 5 , no son ahora tan claros.

CUADRO 5. Densidad de dialectalismos según el NSC en los centros de interés con mayor proporción de voces dialectales

\begin{tabular}{|c|c|c|c|c|c|c|}
\hline Nivel sociocultural & TRC & CAM & CAS & COC & ALI & ANI \\
\hline 1. Bajo & $9,91 \%$ & $4,79 \%$ & $3,65 \%$ & $4,48 \%$ & $3,33 \%$ & $3,34 \%$ \\
\hline 2. Medio & $10,36 \%$ & $6,78 \%$ & $4,46 \%$ & $4,93 \%$ & $2,93 \%$ & $2,96 \%$ \\
\hline 3. Medio-alto & $6,48 \%$ & $5,87 \%$ & $3,14 \%$ & $2,87 \%$ & $2,51 \%$ & $2,89 \%$ \\
\hline 4. Alto & $2,60 \%$ & $1,91 \%$ & $3,40 \%$ & $1,68 \%$ & $2,67 \%$ & $1,50 \%$ \\
\hline
\end{tabular}

Si nos fijamos, en primer lugar, en los dos grupos extremos, es cierto que, de acuerdo con la tendencia general, el grupo sociocultural bajo ofrece en las seis áreas temáticas mayor proporción de dialectalismos que el grupo alto, pero hay diferencias dignas de consideración entre unos y otros ámbitos temáticos:

La diferencia más acusada aparece en Trabajos del campo y del jardín (TRC): nada menos que 7,31 puntos a favor del sociolecto bajo, con una densidad de dialectalismos que casi cuatriplica la obtenida por el grupo alto.

No son tan llamativas las diferencias en los centros El campo (CAM), La coci$n a(\mathrm{COC})$ y Los animales (ANI), aunque siguen siendo diferencias relevantes.

En cambio, las distancias entre ambos grupos socioculturales se acortan significativamente en el centro de interés Los alimentos (ALI) -la diferencia es tan solo de 0,66 puntos- y, de manera señalada, en Partes de la casa (CAS), donde los resultados se hallan muy próximos (3,65\% en el sociolecto bajo y 3,40\% en el alto).

Pensamos que estos datos son muy reveladores, pues muestran que la evocación de dialectalismos por parte de unos u otros grupos socioculturales está 
marcadamente asociada al ámbito conceptual al que remiten tales dialectalismos. Es decir, parecen reflejar diferencias cognitivas no desdeñables entre ambas submuestras. Así, los informantes pertenecientes al sociolecto bajo revelan -como tendremos ocasión de observar más adelante- un mayor conocimiento de las actividades agrícolas, en las que, efectivamente, recae buena parte del léxico dialectal, tan apegado -y no solo en la comunidad aragonesa- a las formas de vida tradicionales. Sin embargo, los dialectalismos aportados en los centros de interés Los alimentos y Partes de la casa se distribuyen de manera más equitativa entre los distintos grupos socioculturales quizá porque se trata de ámbitos conceptuales menos "terruñeros", menos especializados, y quizá también porque tanto la comida "tradicional" y "típica" como la casa "tradicional" y "típica" -y en lo tradicional y lo típico se hallan los dialectalismoshan cobrado en nuestros días notable valor y prestigio.

Se observa, por otro lado, que los grupos socioculturales medio y medioalto dibujan patrones muy desiguales según el campo temático de que se trate. En los seis centros de interés considerados, el grupo medio muestra resultados muy cercanos al bajo y en cuatro casos incluso los supera. Por su parte, el nivel medio-alto se aleja claramente del alto en tres casos (TRC, CAM y ANI), en los que va más acorde con los resultados de los niveles medio y bajo; llama la atención, asimismo, que en dos centros de interés (CAS y ALI), precisamente aquellos en que los resultados de los grupos bajo y alto están más próximos, sea este nivel sociocultural el que ofrece la menor proporción de dialectalismos de todos, por debajo del nivel alto.

\subsection{Análisis cualitativo}

Además de los aspectos cuantitativos comentados, para tener un conocimiento más ajustado de la relación entre léxico dialectal y nivel sociocultural del hablante, conviene atender a varias cuestiones de índole cualitativa. Limitándonos a los dos niveles socioculturales extremos y a los seis centros de interés con mayor densidad de dialectalismos, merece la pena examinar al respecto qué términos dialectales están presentes en uno de ambos grupos y ausentes en el otro, sea con carácter privativo o no. ${ }^{7}$ Es lo que aparece en el cuadro 6, en el que se destacan los vocablos privativos de uno u otro grupo.

7. Es necesario advertir, según hacen Samper y Hernández Cabrera (2006), que hay que actuar con cautela «a la hora de extraer conclusiones sobre la ausencia de ciertos vocablos en las listas de disponibilidad de determinados grupos», principalmente porque, como dicen ambos autores, «estamos ante un léxico que se obtiene sobre la base de pruebas asociativas y no a partir de preguntas, directas o indirectas, que busquen el significante correspondiente a un determinado significado que se le aporta al informante». 
CUADRO 6. Dialectalismos presentes en el NSC bajo o en el NSC alto en los seis centros de interés con mayor proporción de voces dialectales

\begin{tabular}{|c|c|c|c|c|c|c|}
\hline & TRC & CAM & CAS & COC & ALI & ANI \\
\hline $\begin{array}{l}\text { NSC } \\
\text { bajo }\end{array}$ & $\begin{array}{l}\text { aclarecer } \\
\text { despollizar } \\
\text { echar fiemo } \\
\text { empeltar } \\
\text { enfiemar } \\
\text { esbozar } \\
\text { esbrinar } \\
\text { esclarecer } \\
\text { espedregar } \\
\text { esporgar } \\
\text { jarmentar } \\
\text { molonar } \\
\text { pajentar } \\
\text { rollar } \\
\text { rosegar } \\
\text { susular } \\
\text { tallar árboles } \\
\text { triar } \\
\text { tozar } \\
\text { tronzar }\end{array}$ & \begin{tabular}{|l} 
abrevador \\
ajado \\
aladro \\
alfalce \\
aliaga \\
astral \\
carrasca \\
cerecero \\
espedregadora \\
fiemo \\
jada \\
jadeta \\
junta \\
manzanera \\
manzanero \\
mas \\
masico \\
molonadora \\
ordio \\
perera \\
plegamans \\
rabosa \\
ruello \\
torre
\end{tabular} & $\begin{array}{l}\text { alcobilla } \\
\text { cubierto } \\
\text { reposte }\end{array}$ & $\begin{array}{l}\text { arpeta } \\
\text { baldoseta } \\
\text { escorredera } \\
\text { escorredora } \\
\text { esparto } \\
\text { paella } \\
\text { tape } \\
\text { tortera } \\
\text { topí }\end{array}$ & $\begin{array}{l}\text { apatusco } \\
\text { bróquil } \\
\text { chupico } \\
\text { esquerola } \\
\text { lomillo dulce } \\
\text { rabaneta } \\
\text { síndria }\end{array}$ & $\begin{array}{l}\text { bucardo } \\
\text { choto } \\
\text { cocullada } \\
\text { perdigacho } \\
\text { plegamanos } \\
\text { verderol }\end{array}$ \\
\hline $\begin{array}{l}\text { NSC } \\
\text { alto }\end{array}$ & $\begin{array}{l}\text { aplanar } \\
\text { escoscar } \\
\text { remoldar }\end{array}$ & $\begin{array}{l}\text { aliagar } \\
\text { arañón } \\
\text { galacho } \\
\text { rebollón } \\
\text { ruejo } \\
\text { sarrio }\end{array}$ & $\begin{array}{l}\text { cadiera } \\
\text { fogaril } \\
\text { tendedor }\end{array}$ & & \begin{tabular}{|l} 
alberge \\
bisalto \\
judía pocha \\
magra
\end{tabular} & \\
\hline
\end{tabular}

Los datos expuestos en el cuadro precedente ${ }^{8}$ muestran, aparte de las evidentes diferencias numéricas a las que ya nos hemos referido, algunas diferencias cualitativas que revelan que los dialectalismos más claramente aragoneses, los

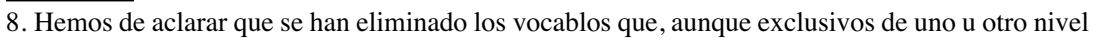
sociocultural en un determinado centro de interés, aparecen en el grupo contrario en otro centro de interés. Por ejemplo, en el área temática CAM eliminamos cardelina (solo en el NSC bajo), dado que ese dialectalismo ha sido actualizado también por el NSC alto en el centro ANI. 
más marcados diatópicamente se dan preferentemente en el grupo sociocultural bajo. Así, por ejemplo, términos que conservan rasgos fonéticos propios del dialecto histórico aragonés (ruello 'rodillo', tallar 'cortar', cocullada 'cogujada') o el resultado velar $[\mathrm{x}]$ de tipo «seudodialectal»9 (jarmentar 'sarmentar', pajentar 'apacentar', jada 'azada', jadeta 'azadilla'), los que muestran el sufijo -era, característico del aragonés para formar nombres de árboles (manzanera 'manzano', perera 'peral'), los que manifiestan la interferencia del catalán (empeltar 'injertar', paella 'sartén', topí 'puchero', síndria 'sandía', etc.) o incluso algún caso de "dialectalización" como chupico 'chupito', ejemplos todos ellos de voces con marcado grado de dialectalidad, aparecen en los alumnos de nivel sociocultural bajo pero están ausentes en los pertenecientes al entorno sociocultural más culto. Este grupo tiende, en cambio, a evocar dialectalismos cuyo carácter dialectal aragonés resulta menos evidente y, en algún caso, hasta dudoso (obsérvese en el cuadro 6: aplanar 'allanar', aliagar 'aulagar', ruejo 'rodillo'-cf. ruello en el grupo bajo-, sarrio 'gamuza pirenaica', tendedor 'tendedero', judía pocha 'judía blanca temprana' o magra 'loncha de jamón', casi todos sin marcación diatópica en los diccionarios de lengua); asimismo, el grupo alto muestra cierta tendencia hacia los términos que, siendo claramente dialectales, carecen de equivalente en el español estándar o este es raramente usado -incluso desconocido- en Aragón: es el caso de galacho 'brazo de río', cadiera 'banco con respaldo situado en la cocina', bisalto 'especie de guisante que se come con la vaina' y quizá remoldar 'podar o limpiar un olivo', sin voz estándar equivalente, así como de arañón 'endrina' y rebollón 'níscalo'. El hecho de que estos dialectalismos sean apoyados por el grupo sociocultural alto permite deducir que gozan de prestigio en las comunidades de habla implicadas. Es preciso puntualizar, con todo, que de los dieciséis vocablos dialectales presentes en el nivel alto (y ausentes en el bajo) únicamente cadiera, remoldar y aplanar figuran entre los más disponibles -posiciones 1-200- en los listados aragoneses (cf. Arnal, 2007).

Cuando atendemos, precisamente, a los dialectalismos más disponibles y que han sido actualizados por los cuatro grupos socioculturales en los que hemos estratificado la muestra, llegamos también a resultados concordantes con los obtenidos en el caso anterior. Véanse los datos que se exponen en el cuadro siguiente. ${ }^{10}$

9. Téngase en cuenta que el resultado propiamente dialectal aragonés es el sonido prepalatal fricativo sordo -grafía $x$-, hoy mantenido en las hablas vernáculas del Alto Aragón.

10. En relación con las cifras que aparecen indicando la posición o rango de cada vocablo, recordemos que han de interpretarse en el sentido de que cuanto más se aproximen a la unidad mayor es su grado de disponibilidad; así, por ejemplo, falsa (en la posición 81 en el NSC bajo y en la 108 en el NSC alto) es un término dialectal que se halla más disponible en los alumnos del nivel sociocultural bajo que en los del nivel alto. 
CuAdro 7. Los dialectalismos más disponibles presentes en los cuatro grupos socioculturales. Posición que ocupan en los NSC extremos

\begin{tabular}{|c|c|c|c|}
\hline \multirow[b]{2}{*}{ Centro de interés } & \multirow[b]{2}{*}{ Dialectalismos } & \multicolumn{2}{|c|}{$\begin{array}{c}\text { Posición } \\
\text { (disponibilidad) }\end{array}$} \\
\hline & & NSC alto & NSC bajo \\
\hline ROP & maripí & 92 & 90 \\
\hline CAS & $\begin{array}{l}\text { falsa } \\
\text { patio }\end{array}$ & $\begin{array}{r}108 \\
31\end{array}$ & $\begin{array}{l}81 \\
27\end{array}$ \\
\hline MUE & cocinilla & 62 & 79 \\
\hline ALI & $\begin{array}{l}\text { canalón } \\
\text { oliva } \\
\text { ternasco }\end{array}$ & $\begin{array}{l}324 \\
123 \\
166\end{array}$ & $\begin{array}{l}110 \\
121 \\
103\end{array}$ \\
\hline MES & plato plano & 131 & 42 \\
\hline $\mathrm{COC}$ & $\begin{array}{l}\text { cocinilla } \\
\text { fregadera } \\
\text { rasera }\end{array}$ & $\begin{array}{l}57 \\
41 \\
21\end{array}$ & $\begin{array}{l}22 \\
24 \\
29\end{array}$ \\
\hline ESC & sacaminas & 104 & 139 \\
\hline ANI & tocino & 106 & 97 \\
\hline JUE & maquineta & 94 & 39 \\
\hline PRO & pescatero & 44 & 51 \\
\hline
\end{tabular}

En efecto, según se refleja en el cuadro 7, de esos quince dialectalismos que cabe considerar como pertenecientes a la norma aragonesa, aquellos que, por distintas razones, resultan menos marcados desde el punto de vista diatópico son apoyados abiertamente -con alguna excepción que en seguida comentaremospor los informantes del entorno familiar más culto o muestran, en todo caso, posiciones muy próximas en los dos grupos socioculturales extremos; obsérvense los rangos de disponibilidad de rasera 'espumadera' 21 alto/29 bajo, sacaminas 'sacapuntas' 104/139, pescatero 'pescadero' 44/51, patio 'zaguán' 31/27 y oliva 'aceituna' 123/121. ${ }^{11}$ Frente a estos dialectalismos, los que presentan, en cierta medida, mayor grado de dialectalidad o de diferenciación con respecto al español estándar que los anteriores son propiciados con claridad por el grupo sociocultural bajo; se trata de falsa 'desván' 108 alto/81 bajo, canalón 'canelón' -variante no exenta de connotaciones vulgares- 324/110, plato plano 'plato

11. Podría añadirse cocinilla 'cocina, aparato para cocinar', aunque solo es propiciada por el grupo alto cuando aparece en el centro de interés MUE (62/79); en el centro de interés COC, en cambio, ocurre lo contrario (57/22). 
llano' 131/42, ${ }^{12}$ fregadera 'fregadero' 41/24, tocino 'cerdo' 106/97 y maquineta 'máquina tragaperrras' o 'pequeño aparato electrónico para jugar' 94/39. Las únicas excepciones a la interpretación expuesta vienen dadas por el término específicamente aragonés -zaragozano, en concreto- maripí 'bamba, zapatilla deportiva', que muestra una disponibilidad similar (92/90) en los dos grupos socioculturales que consideramos, y por la voz ternasco 'cordero lechal' propiciada en este caso por el nivel bajo (166/103), frente a lo que cabría esperar dado que es un término ampliamente difundido en la geografía peninsular y, por tanto, de dialectalidad más diluida.

\section{CONCLUSIONES}

De acuerdo con nuestras expectativas iniciales, el análisis realizado ha permitido comprobar que las diferencias socioculturales de los alumnos, o más precisamente, el entorno familiar más o menos culto en el que se desenvuelven incide de manera significativa en la cantidad y la cualidad de los dialectalismos aportados por los preuniversitarios aragoneses.

Desde una perspectiva cuantitativa, los dialectalismos son claramente propiciados por el grupo sociocultural bajo, con valores que duplican aproximadamente los obtenidos por el nivel alto. Nuestros resultados concuerdan, por tanto, con los que Samper y Hernández Cabrera (2006) obtienen sobre los canarismos y confirman, asimismo, las conclusiones a las que se ha llegado tanto desde la Dialectología tradicional como desde la Sociolingüística variacionista.

Estos resultados cuantitativos generales quedan matizados, no obstante, tras el análisis detallado de los centros de interés, que ha puesto de manifiesto que la mayor o menor presencia de dialectalismos en unos u otros grupos socioculturales está marcadamente asociada al ámbito conceptual al que remiten tales dialectalismos, con diferencias francamente relevantes que van desde el centro Trabajos del campo y del jardín, en el que las distancias cuantitativas entre el nivel bajo y el alto son muy acusadas, hasta el centro de interés Partes de la casa, donde ambos grupos extremos ofrecen cifras similares. Los dos niveles intermedios muestran, en general, un comportamiento más acorde con el grupo inferior que con el más alto del espectro.

Asimismo, el análisis cualitativo -limitado a los dos grupos extremos de la pirámide sociocultural- ha mostrado que las voces regionales con mayor

12. Cabe pensar que el adjetivo plano muestra el mantenimiento, sin palatalizar, del grupo consonántico $\mathrm{pl}$ - inicial característico del aragonés, aunque no se puede afirmar con total seguridad, puesto que plato plano se localiza también en zonas alejadas de la aragonesa (aparece, por ejemplo, en el léxico disponible de Ávila, donde tiene un alto índice de disponibilidad (Bartol, 2003: 140)). 
grado de dialectalidad se hallan asociadas preferentemente al nivel sociocultural bajo. Si hablamos en términos de prestigio, parece razonable deducir que este lo ostentan los regionalismos menos marcados diatópicamente, así como los aragonesismos que carecen de equivalente en el español estándar, en tanto que son los que de modo preferente han aportado los alumnos del nivel alto: patio, rasera, cadiera o galacho se encuentran así en mejores condiciones de pervivencia que fregadera, fiemo, jada o perera.

\section{REFERENCIAS BIBLIOGRÁFICAS}

Arnal, M. L. (2007): «Los dialectalismos en el léxico disponible de los jóvenes aragoneses», en ARNAL, M. L. (ed.) (2005): Estudios sobre disponibilidad léxica en los jóvenes aragoneses, Zaragoza, Institución Fernando el Católico, 17-49.

ARnal, M. L. (coord.), R. CASTAÑER et al. (2004): Léxico disponible de Aragón, Zaragoza, Libros Pórtico.

BARTOL, J. A. (2003): «Léxico disponible y norma lingüística», en Moreno FERNÁNDEZ, F. et al. (eds.) (2003): Lengua, variación y contexto. Estudios dedicados a Humberto López Morales, Madrid, Arco/Libros, I, 127-143.

Blas Arroyo, J. L. (2005): Sociolingüística del español. Desarrollos y perspectivas en el estudio de la lengua española en contexto social, Madrid, Cátedra.

Blas Arroyo, J. L. y M. Casanova (2003): «La influencia de la red educativa y del entorno sociocultural en la disponibilidad léxica. Estudio de las comunidades de habla castellonenses», en SÁNCHEZ Miret, F. (ed.) (2003): Actas del XXIII Congreso Internacional de Lingüística y Filología Románica, Tübingen, Max Niemeyer, V, 17-33.

BORREGO, J. y C. FERNÁNDEZ JUNCAL (2002): «Léxico disponible: aplicaciones a los estudios dialectales», en MuÑoz, M. D. et al. (eds.), Actas del II Congreso de Lingüística General, Cádiz, Universidad de Cádiz, II, 297-306.

LóPez Morales, H. (2004): Sociolingüística, Madrid, Gredos, $3^{\text {a }}$ ed. aumentada.

SAMPER, J. A. (2006): «Disponibilidad léxica y sociolingüística», en Blas Arroyo, J. L., M. Casanova y M. Velando (eds.) (2006): Discurso y sociedad. Contribuciones al estudio de la lengua en contexto social, Castellón de la Plana, Publicacions de la Universitat Jaume I, 99-120.

SAMPer, J. A. y C. E. Hernández CABrera (2006): «Densidad de dialectalismos y condicionantes sociales en el léxico disponible de Gran Canaria», en Sedano, M. et al. (comps.) (2006): Haciendo lingüística. Homenaje a Paola Bentivoglio, Caracas, Universidad Central de Venezuela, 537-553. 
SAMPer, J. A., J. J. Bellón y M. SAMPer Hernández (2003): «El proyecto de estudio de la disponibilidad léxica en español», en Ávila, R. et al., Pautas y pistas en el análisis del léxico hispano (americano), Madrid-Fráncfort, Iberoamericana-Vervuert, 27-140. 


\title{
ANGLICISMOS EN EL LÉXICO DISPONIBLE DE CASTELLÓN
}

\author{
Manuela Casanova Ávalos \\ Universitat Jaume I
}

\section{INTRODUCCIÓN}

$\mathbf{E}$ L objetivo fundamental de este trabajo es analizar los anglicismos que aparecen en el Léxico disponible de Castellón, ver qué grado de implantación poseen en el léxico de los preuniversitarios de esta provincia. Ya sabemos la fuerza que tienen estos vocablos y lo rápidamente que se expanden gracias sobre todo a los medios de comunicación y la inmediatez de estos. Se realizará un estudio desde un punto de vista cuantitativo que nos permitirá determinar en qué campo léxico prevalecen los términos provenientes del inglés. Al mismo tiempo se cotejará el porcentaje de anglicismos obtenidos en Castellón con otros estudios similares, en concreto con el léxico disponible de Zamora (Bartol, 1998), Cádiz (González y Orellana, en prensa), como provincias españolas, y fuera de España trabajaremos con el léxico de Puerto Rico (López Morales, 1999) y la República Dominicana (Alba, 1996).

Se considera anglicismo, toda palabra o vocablo que deriva directamente del inglés o que haya penetrado en el español a través de ella aunque su procedencia sea otra lengua, actuando el inglés como puro intermediario.

\section{ASPECTOS METODOLÓGICOS}

Para el análisis del presente trabajo se ha utilizado el corpus léxico procedente del Diccionario del Léxico disponible de la provincia de Castellón. Debemos entender por léxico disponible aquellos vocablos que están listos para ser actualizados en cualquier momento si la situación comunicativa lo requiere. ${ }^{1}$ Así pues, se trabaja con un léxico vivo y espontáneo como comenta Alba (1996: 854).

La muestra del estudio la componen 354 estudiantes del antiguo COU (Curso de Orientación Universitaria) y de $2^{\circ}$ de Bachillerato LOGSE. Los datos

1. López Morales (1983: 213) define así el concepto de léxico disponible: «caudal léxico utilizable en una situación comunicativa dada». 
fueron recogidos a través de unas encuestas pasadas a los alumnos durante los cursos académicos 1998-99 y 1999-2000. Se trata de unas pruebas de carácter asociativo. A los informantes se les propone unos temas, llamados en disponibilidad léxica «centros de interés», y deben contestar durante dos minutos todos aquellos vocablos que les vengan a la mente relacionados con el campo semántico propuesto.

La mayoría de los estudios ${ }^{2}$ de disponibilidad léxica analizan 16 centros de interés, los que ya estudió Gougenheim en 1964, con pequeñas variaciones en la enunciación de los mismos.

En nuestro estudio hemos analizado esos 16 centros de interés más el campo denominado «Los colores», como lo hacen Gómez Molina y Gómez Devís en Valencia, Mateo García en Almería, Benítez en Madrid... Quedan enunciados de la siguiente forma:

01. Partes del cuerpo

02. La ropa

03. Partes de la casa (sin muebles)

04. Los muebles de la casa

05. Alimentos y bebidas

06. Objetos colocados en la mesa para la comida

07. La cocina y sus utensilios

08. La escuela: muebles y materiales

09. Iluminación, calefacción y medios para airear un recinto

10. La ciudad

11. El campo

12. Medios de transporte

13. Trabajos del campo y del jardín

14. Los animales

15. Juegos y distracciones

16. Profesiones y oficios

17. Los colores

\section{ANÁLISIS DE LOS ANGLICISMOS. RESULTADOS}

Como datos generales podemos decir que la cantidad de palabras recogidas en las encuestas asciende a 121.792, de las cuales 9.215 son vocablos o

2. Todos los incluidos en el macroproyecto de disponibilidad léxica dirigido por Humberto López Morales, en el que están inmersos los trabajos realizados en España y en Hispanoamérica, cuyo objetivo es obtener el léxico disponible del español. 
palabras diferentes y de ellos 327 son anglicismos, que representa un porcentaje de $3,54 \%$.

Estos resultados globales distribuidos en los diferentes campos de interés dan como resultado el siguiente cuadro:

\section{CUADRO 1. Anglicismos diferenciados por centros de interés en el léxico disponible de Castellón}

\begin{tabular}{|l|c|c|c|}
\hline \multicolumn{1}{|c|}{ Centro de interés } & $\mathbf{N}^{0}$ de vocablos & $\mathbf{N}^{\mathbf{0}}$ anglicismos & Densidad \\
\hline 1. Partes del cuerpo & 271 & 0 & \\
\hline 2. La ropa & 312 & 24 & $7,69 \%$ \\
\hline 3. Partes de la casa & 307 & 12 & $3,84 \%$ \\
\hline 4. Muebles de la casa & 303 & 6 & $1,98 \%$ \\
\hline 5. Alimentos y bebidas & 607 & 20 & $3,29 \%$ \\
\hline 6. Objetos colocados en la mesa & 317 & 3 & $0,94 \%$ \\
\hline 7. La cocina y sus utensilios & 502 & 8 & $1,59 \%$ \\
\hline 8. La escuela: muebles y materiales & 623 & 26 & $4,17 \%$ \\
\hline 9. Iluminación, calefacción y medios... & 479 & 12 & $2,5 \%$ \\
\hline 10. La ciudad & 949 & 49 & $5,16 \%$ \\
\hline 11. El campo & 1060 & 10 & $0,94 \%$ \\
\hline 12. Medios de transporte & 344 & 42 & $12,20 \%$ \\
\hline 13. Trabajos del campo y del jardín & 704 & 2 & $0,28 \%$ \\
\hline 14. Los animales & 447 & 5 & $1,11 \%$ \\
\hline 15. Juegos y distracciones & 908 & 83 & $9,14 \%$ \\
\hline 16. Profesiones y oficios & 732 & 22 & $3,00 \%$ \\
\hline 17. Los colores & 350 & 3 & $0,85 \%$ \\
\hline
\end{tabular}

Analizando los datos que aparecen en el cuadro 1 se puede llegar a una serie de primeras conclusiones. Vemos cómo ciertos centros de interés están más afectados por los anglicismos, su penetración es mayor en la lengua de nuestros jóvenes, como en los campos 12,15 y 2. Le siguen otros centros con una densidad media viendo la globalidad como el 8, 16 y 5 , y centros de interés donde la penetración es poca, el 3, 11 y 7 o más bien escasa como el 14, 4, 17 y el 6. No observamos anglicismos en el campo 1. Partes del cuerpo.

Especifiquemos un poco más. Si observamos el número de vocablos procedentes del inglés vemos cómo los campos semánticos propensos a la entra- 
da de anglicismos son el 15, 10 y 12; seguidos por el 8, 2 y el 16. A continuación se quedarían los centros de interés con un número de palabras que van desde ocho a doce vocablos como los campos 3,11, 7, 4 y 14. Y por último, los centros con escasa o nula incidencia: 6,17 y 13 .

El orden de mayor a menor se establecería de la siguiente manera: 15, 10, $12,8,2,16,5,9$ junto con $3,11,7,4,14,17$ coincidiendo con 6,13 , 1 , en este último no se recoge ningún anglicismo, tal como sucede en los trabajos consultados.

Los resultados parecen bastante lógicos puesto que los centros que presentan mayor cantidad de anglicismos corresponde a áreas léxicas abiertas a la continua incorporación de léxico, son campos semánticos dominados por el prestigio social y económico del mundo anglosajón. No sucede lo mismo con los centros de interés con escasa o nula penetración de anglicismos. Son campos cerrados lexicológicamente hablando. Como muy bien dice Orlando Alba (1996: 856): «Es posible inventar o crear nuevos juegos y modernos medios de transporte o prendas de vestir, pero no se puede hacer lo mismo con las partes del cuerpo ni con los animales».

$\mathrm{Si}$ continuamos comentando los grupos que se pueden establecer en los diferentes centros de interés, el orden de mayor a menor de estos cambia si lo que tenemos en cuenta es la densidad, el porcentaje que representan los anglicismos en el número de vocablos ${ }^{3}$ por campo léxico. Siguiendo con esos cuatro grupos que hemos establecido, observamos cómo estos cambian el orden. En el primer grupo formado por una incidencia alta de anglicismos estarían los campos 12,15 y 2 . Centros con incidencia media: $10,8,3,6,5$ y 16 . Con escasa penetración de anglicismos los campos 9, 4, 7 y 14 y con casi nula incidencia el 6 (junto con el 11), 17 y 13.

El orden que estableceríamos de mayor a menor sería: 12 , 15, 2, 10, 8, 3, $5,16,9,4,7,14,6,11,17,13,1$.

La gran diferencia está en la consideración del centro 2. La ropa, que cambia del segundo al primer grupo analizando la densidad.

Algo similar ocurre si observamos los datos de otros estudios de disponibilidad léxica. No contamos con el centro 17. Los colores porque no aparece en los trabajos que utilizamos para el cotejo. Primero veremos los totales (Cuadro 2) y luego la especificación por centros de interés (Cuadro 3). En este aparecen en las diferentes casillas el número de anglicismos encontrado en cada centro de interés y la densidad que supone expresado en el porcentaje.

3. Entiéndase por vocablo cada una de las entradas distintas que se producen en las encuestas, bien sea una palabra aislada o un sintagma. 
CuAdro 2. Anglicismos totales en las sintopías estudiadas

\begin{tabular}{|l|r|r|r|r|r|}
\hline & Castellón & \multicolumn{1}{c|}{ Zamora } & Cádiz & Puerto Rico & Rep. Dominicana \\
\hline $\mathbf{N}^{\mathbf{0}}$ vocablos & 9.215 & 4.978 & 6.655 & 7.311 & 6.393 \\
\hline Anglicismos & 327 & 96 & 203 & 444 & 308 \\
\hline Densidad \% & $3,54 \%$ & $1,92 \%$ & $3,05 \%$ & $6,07 \%$ & $6,06 \%$ \\
\hline
\end{tabular}

CUADRO 3. Comparación de anglicismos por centro de interés en las sintopías del español estudiadas

\begin{tabular}{|c|c|c|c|c|c|c|c|c|c|c|}
\hline \multirow[t]{2}{*}{$\begin{array}{l}\text { Centro } \\
\text { de interés }\end{array}$} & \multicolumn{2}{|c|}{ Castellón } & \multicolumn{2}{|c|}{ Zamora } & \multicolumn{2}{|c|}{ Cádiz } & \multicolumn{2}{|c|}{ Puerto Rico } & \multicolumn{2}{|c|}{$\begin{array}{l}\text { República } \\
\text { Dominicana }\end{array}$} \\
\hline & Angl. & $\%$ & Angl. & $\%$ & Angl. & $\%$ & Angl. & $\%$ & Angl. & $\%$ \\
\hline $\begin{array}{l}\text { 1. Partes del } \\
\text { cuerpo }\end{array}$ & 0 & & 0 & & 0 & & 0 & & 0 & \\
\hline 2. La ropa & 24 & $7,69 \%$ & 8 & $4,18 \%$ & 23 & $9,05 \%$ & 37 & $17,37 \%$ & 40 & $16,06 \%$ \\
\hline 3. Partes de la casa & 12 & $3,84 \%$ & 4 & $2,29 \%$ & 4 & $2,12 \%$ & 14 & $8,23 \%$ & 13 & $4,43 \%$ \\
\hline $\begin{array}{l}\text { 4. Muebles de la } \\
\text { casa }\end{array}$ & 6 & $1,98 \%$ & 1 & $0,46 \%$ & 2 & $1,29 \%$ & 26 & $10,61 \%$ & 34 & $10,75 \%$ \\
\hline $\begin{array}{l}\text { 5. Alimentos y } \\
\text { bebidas }\end{array}$ & 20 & $3,29 \%$ & 4 & $1,13 \%$ & 16 & $3,21 \%$ & 43 & $8,95 \%$ & 20 & $5,00 \%$ \\
\hline $\begin{array}{l}\text { 6. Objetos coloc. } \\
\text { en la mesa }\end{array}$ & 3 & $0,94 \%$ & 0 & & 3 & $1,33 \%$ & 5 & $2,67 \%$ & 4 & $1,70 \%$ \\
\hline $\begin{array}{l}\text { 7. La cocina y sus } \\
\text { utensilios }\end{array}$ & 8 & $1,59 \%$ & 3 & $0,93 \%$ & 8 & $2,11 \%$ & 22 & $7,16 \%$ & 16 & $4,04 \%$ \\
\hline 8. La escuela... & 26 & $4,17 \%$ & 2 & $0,65 \%$ & 16 & $3,49 \%$ & 23 & $9,54 \%$ & 19 & $6,18 \%$ \\
\hline $\begin{array}{l}\text { 9. Iluminación, } \\
\text { calefacción... }\end{array}$ & 12 & $2,5 \%$ & 4 & $1,52 \%$ & 1 & $0,62 \%$ & 34 & $11,68 \%$ & 26 & $7,34 \%$ \\
\hline 10. La ciudad & 49 & $5,16 \%$ & 11 & $2,22 \%$ & 26 & $3,48 \%$ & 50 & $7,20 \%$ & 36 & $4,97 \%$ \\
\hline 11. El campo & 10 & $0,94 \%$ & 3 & $0,55 \%$ & 7 & $0,74 \%$ & 1 & 0 & 9 & $1,22 \%$ \\
\hline $\begin{array}{l}\text { 12. Medios de } \\
\text { transporte }\end{array}$ & 42 & $12,20 \%$ & 11 & $5,3 \%$ & 26 & $11,87 \%$ & 38 & $23,31 \%$ & 32 & $18,93 \%$ \\
\hline $\begin{array}{l}\text { 13. Trabajos del } \\
\text { campo }\end{array}$ & 2 & $0,28 \%$ & 0 & & 0 & & 2 & $0,43 \%$ & 0 & \\
\hline 14. Los animales & 5 & $1,11 \%$ & 3 & $0,95 \%$ & 8 & $1,56 \%$ & 6 & $2,23 \%$ & 3 & $0,90 \%$ \\
\hline $\begin{array}{l}15 \text { Juegos y } \\
\text { distracciones }\end{array}$ & 83 & $9,14 \%$ & 40 & $8,35 \%$ & 53 & $7,54 \%$ & 115 & $20,98 \%$ & 116 & $17,23 \%$ \\
\hline $\begin{array}{l}\text { 16. Profesiones y } \\
\text { oficios }\end{array}$ & 22 & $3,00 \%$ & 2 & $0,44 \%$ & 10 & $1,82 \%$ & 28 & $5,20 \%$ & 20 & $3,10 \%$ \\
\hline
\end{tabular}


Observando detenidamente las cifras contenidas en el cuadro 2 vemos que hay bastante diferencia entre un trabajo y otro. El número de anglicismos de 388 y 444 de la República Dominicana y Puerto Rico respectivamente difieren de las cifras de Zamora y Cádiz (96 y 203 respectivamente), sobre todo con Zamora. Castellón se quedaría en una zona intermedia entre esos dos grupos con 327 anglicismos. Estas diferencias cuantitativas pueden estribar en el número de informantes que representan cada zona geográfica: Zamora: 100; Castellón: 354; Cádiz: 400; República Dominicana: 347 y Puerto Rico: 558.

Las cifras similares de Castellón y República Dominicana quizá expliquen la cifra también similar de los anglicismos encontrados: 327 y 388 respectivamente. Superados indudablemente por esta última debido, evidentemente, a la cercanía de la nación con los Estados Unidos, país exportador de léxico a todas las partes del mundo, gracias a que es una potencia político-social, científica y, sobre todo, económica. Esto también explicaría la mayor cantidad de anglicismos en Puerto Rico.

Si nos fijamos en los porcentajes globales, Puerto Rico $(6,07 \%)$ y República Dominicana $(6,06 \%)$ se acercan entre ellas y se separan del resto de los estudios españoles, donde Cádiz $(3,02 \%)$ y Castellón $(3,54 \%)$ se aproximan mucho más entre ellas y se alejan de Zamora $(1,92 \%)$.

Pero creo que la razón más importante de las divergencias se debe a la estandarización y procesamiento de los datos extraídos en las encuestas. Aunque todos los estudios inmersos en el Proyecto Panhispánico del léxico disponible del español comparten la misma metodología, siempre hay diferencias derivadas, por ejemplo, de los objetivos primarios que se pretenden alcanzar en los análisis o por opiniones personales a la hora de enfrentarse con un trabajo de investigación.

Otra causa es la consideración del concepto de anglicismo. Alba (1996: 854) sigue de cerca el concepto de anglicismo propuesto por López Morales y lo especifica así: «Se han considerado anglicismos no solo los términos de origen inglés (los aceptados por la Academia como bisté, club, suéter, y los no aceptados aún, como clóset, jeans, jeep), sino también palabras cuyo étimo mediato procede de otras lenguas pero que han entrado al español a través del inglés como cafetería, mocasín, televisión».

López Morales (1999: 150-151) trabaja con préstamos, calcos y extranjerismos. Así lo hace también González y Orellana (en prensa) en su análisis de los anglicismos en Cádiz. En el estudio sobre Castellón he seguido ese mismo concepto amplio de anglicismo; no obstante me he enfrentado a decisiones difíciles en algunos vocablos. Para intentar solucionar el problema he consultado los diccionarios y manuales de anglicismos a mi alcance: Alfaro (1970), Lorenzo (1996), Pratt (1980), Gómez Capuz (2000)4 y Rodríguez y A. Lillo (1997). Por supuesto

4. Gómez Capuz (2000:10) va a tener en cuenta los anglicismos patentes, los híbridos, las creaciones y pseudoanglicismos y los que llama anglicismos pragmáticos integrales. 
el DRAE, en su vigésima segunda edición. La consulta de todos ellos me ha ayudado a decidir qué vocablos incluir. Ha tenido mucho peso la opinión de la Academia. Por eso he decido aportar un listado de lo que he llamado "anglicismos problemáticos" (ver anexo 2), vocablos en los que los distintos investigadores no se ponen de acuerdo y la academia o bien no expone su origen o bien da una procedencia distinta al mundo anglosajón.

Pero vayamos a los cotejos. Si manejamos los datos de Puerto Rico y la República Dominicana sobresalen los centros 15, 12, 2 y 10. Hay diferencias en el campo 4. Los muebles donde la República Dominicana marca 8 anglicismos más que Puerto Rico. En cambio, esta excede a la República Dominicana en 23 vocablos en el campo 5. Alimentos. Si nos fijamos en las densidades se acercan enormemente en el grado de influencia de la lengua inglesa. Así en el mencionado centro 4. Muebles con 8 anglicismos de diferencia, el porcentaje es en ambos estudios de $10 \%$, y en el campo 5. Alimentos sí hay diferencia, 8,95\% de Puerto Rico frente al 5\% de la República Dominicana.

Si comparamos Castellón y Cádiz, que son lo léxicos de España más similares en esta comparativa, se vuelven a establecer los mismo grupos con los mismos centros de interés, enunciados más arriba. Cabría resaltar el campo 8 . Escuela con 26 anglicismos de Castellón frente a 16 de Cádiz (4,17\% y 3,49\% respectivamente), el centro 10. La ciudad con 49 anglicismos de la primera frente a los 26 vocablos de Cádiz $(5,16 \%$ y $3,48 \%$ respectivamente) y el campo 15. Juegos donde hay una diferencia de 30 palabras: 83 en Castellón y 53 en Cádiz $(9,14 \%$ y 7,54\%).

A pesar de las diferencias cuantitativas, a grandes rasgos las conclusiones son las mismas: se pueden establecer los cuatro grupos en la clasificación de la incidencia de los anglicismos: 1 . Centros con mayor número de vocablos procedentes del inglés: $15,10,2,12 ; 2$. Centros de interés con una densidad media: $3,5,8,16$; 3. Centros con una densidad baja: 14,9 , 7; y, por último, 4. Campos semánticos con escasa o nula incidencia de anglicismos: 11, 6, 4, 1 .

Llama la atención Zamora por su poca penetración de anglicismos, no ya solo frente a Puerto Rico y la República Dominicana, sino también frente a las otras provincias españolas. Bartol (1998: 123) en sus conclusiones no llega a comentar ninguna razón al respecto. Quizá se deba, me aventuro a decir, a que Zamora es una provincia del interior de España, de una zona rural, mientras que Cádiz y Castellón son provincias costeras y turísticas. Es un poco peliaguda esta afirmación porque hoy en día los medios de comunicación (prensa periódica, radio, televisión, Internet) llegan a todas partes y estos son los mayores difusores de los extranjerismos, ${ }^{5}$ unas veces con mayor fortuna que

5. Otros conductos de penetración de los anglicismos son: industria, comercio, ciencia, deportes, viajes, relaciones internacionales, cinematografía, etc. 
otras. Si observamos un trabajo similar del mismo autor sobre los extranjerismos en el Léxico disponible de Soria (Bartol, 2005), podemos comprobar que el número de anglicismos en Soria es mayor que en Zamora ${ }^{6}$ y la situación geográfica es la misma poco más o menos. Creo que los motivos habría que buscarlos, como se ha apuntado anteriormente, en los diferentes criterios de edición de los materiales y en el concepto de anglicismo con el que se trabaje.

Las cifras de Soria y Córdoba ${ }^{7}$ que ofrece Bartol en el trabajo mencionado se acercan bastante a las de Castellón y Cádiz. Se llega a las mismas conclusiones al dividir los centros de interés en tres grupos: el primero lo formarán los centros con mayor incidencia de anglicismos, es decir, donde el porcentaje de anglicismos es significativo; un segundo grupo formado por los centros con un incidencia media, es decir, aquellos en los que el porcentaje es escaso; y un tercer grupo formado por los campos con nula incidencia, o dicho de otra manera, cuando el porcentaje de anglicismos es insignificante. Coinciden los campos y los grupos en las cuatro provincias aproximadamente: Castellón, Cádiz, Soria y Córdoba.

Para matizar estas afirmaciones sería conveniente realizar un análisis cualitativo del léxico disponible de las regiones mencionadas, y así obtener una idea más exacta de la penetración de los anglicismos en el léxico de los jóvenes. Y además se tendría que acotar el estudio a las cien primeras palabras que son las verdaderamente disponibles. Faltaría analizar, pues, el rango o posición de todos esos anglicismos que aparecen en los listados de los diccionarios de léxico disponible. Por otro lado sería interesante ver el grado de convergencia de los diferentes léxicos teniendo en cuenta las variables sociales aplicadas en los trabajos de disponibilidad léxica, ${ }^{8}$ es decir, analizar la incidencia de los anglicismos teniendo en cuenta las variables observadas, tanto lingüísticas como extralingüísticas. Y asimismo, convendría estudiar los equivalentes españoles de los anglicismos trabajados con los que alternan. Esto permitiría tratar cuestiones de vitalidad, uso y frecuencia y el fenómeno de especialización semántica.

6. En Soria también el número de informantes es de 100.

7. La provincia de Córdoba es estudiada por Bellón Fernández (2003).

8. Las variables estudiadas en el Léxico disponible de Castellón son: el sexo; el tipo de centro educativo: público o privado; ubicación del centro: rural o urbano (coincide con la residencia de los padres); nivel de estudio de los padres: estudios primarios, estudios elementales, estudios secundarios y estudios superiores; lengua materna: valenciano, castellano y ambas. 


\section{CONCLUSIONES}

Tras realizar un estudio cuantitativo de los anglicismos del léxico disponible de Castellón y la comparación de los datos con otras zonas dialectales, Cádiz, Zamora, Puerto Rico y República Dominicana, se llega a las siguientes conclusiones:

1. El número de anglicismos registrado en Castellón es de 327, lo que representa un 3,54\% del total del léxico disponible de la provincia, 9.215 palabras. Es un porcentaje bajo que no supone ningún peligro a la lengua española como auguran los puristas de la lengua. Lo mismo podríamos decir de los otros léxicos estudiados, aunque la densidad de anglicismos sea mayor en la República Dominicana y Puerto Rico (6,06\% y 6,07\% respectivamente).

2. La mayor o menor presencia de anglicismos está motivada o condicionada por los campos semánticos que se han propuesto en la encuesta, con relevantes diferencias entre ellos. Podríamos decir que hay áreas semánticas que por su estatus de léxico abierto a las innovaciones favorecen la penetración de anglicismos, mientras que otras áreas niegan esa entrada, justamente por lo contrario, por ser campos cerrados.

Si tenemos en cuenta el índice de densidad de anglicismos, podemos establecer cuatro grupos, como ya se ha adelantado a lo largo del texto:

a) Centros con alta densidad de anglicismos: 15. Juegos y distracciones, 12. Medios de transporte y 2. La ropa.

b) Centros de densidad media: 10. La ciudad, 16. Profesiones y oficios, 8. La escuela. 5. Alimentos y bebidas y 3. Partes de la casa.

c) Centros de baja densidad: 4. Muebles, 7. La cocina y sus utensilios, 9. Iluminación, calefacción y medios para airear un recinto y 14. Los animales.

d) Centros de escasa o nula incidencia (promedios inferiores al 1\%): 6. Objetos colocados en la mesa, 13. Trabajos del campo y del jardín, 11. El campo, y 1. Partes del cuerpo.

3 . El centro de interés 1. Partes del cuerpo no registra ningún anglicismo en los trabajos de disponibilidad léxica consultados. Tampoco ofrecen anglicismos en el campo 13. Trabajos del campo y del jardín los estudios de la República Dominicana, Cádiz y Zamora. Puerto Rico y Castellón registran dos cada uno, pero en este último léxico en posiciones tan altas $(545,565)$ que no merecen ser tenidos en cuenta.

4. Los países sudamericanos superan a los españoles en campos semánticos como el 15, 12, y el 2, que forman el primer grupo de centros fuertemente influenciados por la cultura anglosajona. Se formarían los mismos grupos 
con los mismos campos semánticos enunciados anteriormente. Llama la atención como el centro 4. Muebles de la casa aparece en la República Dominicana y Puerto Rico con densidades del 10,75\% y $10,61 \%$ frente a la baja densidad de anglicismos de las provincias españolas.

Podríamos afirmar que los centros de interés de mayor penetración o permeabilidad de anglicismos coinciden en todos los trabajos estudiados. ${ }^{9}$ Alba (1996: 860) nos comenta: «Finalmente, la gran diferencia de permeabilidad frente al anglicismo que presentan unos centros de interés con respecto a otros parece constituir un rasgo universal del léxico hispánico, determinado, entre otras razones, por la naturaleza semántica del campo. La comparación con investigaciones similares llevadas a cabo en otras zonas del mundo hispanohablante confirma el hecho de que no solamente los campos más susceptibles, sino también los más reacios a la influencia del inglés son, en todas partes, los mismos».

5. Castellón se acerca más a Cádiz en los porcentajes de densidad de anglicismos que a los países sudamericanos, más influenciados estos por la cercanía de la cultura anglosajona, y a su vez se aleja de Zamora, con poca incidencia del léxico procedente de la lengua inglesa, quizá por las razones esgrimidas anteriormente. Aun así, Zamora también coincide en el orden de incidencia de anglicismos formando los mismos grupos.

\section{REFERENCIAS BIBLIOGRÁFICAS}

Alba, O. (1996): «Densidad de anglicismos en el léxico disponible de la República Dominicana», Actas del XI Congreso Internacional de la ALFAL, Universidad de Las Palmas de Gran Canaria, 853-865.

Alfaro, R. J. (1970): Diccionario de anglicismos, Madrid, Gredos.

BARTOL, J. A. (1998): «Anglicismos en el español de finales de siglo. Anglicismos en el léxico disponible de dos regiones hispanas», en CONRAD, K. y $\mathrm{M}^{\mathrm{a}}$ D. DE LA CALLE (eds.) (1988): Visiones salmantinas, 1898-1998, Universidad de Salamanca y Ohio Wesleyan University, 97-124.

- (2005): «Extranjerismos disponibles. Su integración y vitalidad en una comunidad de habla (Provincia de Soria, España)», Spanish in Context, 2:2, 203-229.

Bellón FeRnÁNDEZ, J. J. (2003): Léxico disponible de la provincia de Córdoba, Las Palmas de Gran Canaria, tesis doctoral.

CARrera DE la Red, F. y W. E. Bradley (2004): «Extranjerismos en el léxico disponible de Cantabria», en Milka Villayandre Llamazares (ed.)

9. Carrera y Bradley (2004: 541) en su artículo sobre Cantabria también afirman que los centros con mayor incidencia de vocablos ingleses son La ropa, Alimentos y bebidas, Medios de transporte y Juegos y distracciones. 
(2004): Actas del V Congreso de Lingüística General, León, Arco/Libros, tomo I.

GonzÁlez Martínez, A. y P. Orellana (en prensa): «Anglicismos en el léxico de la provincia de Cádiz», Linguiística española actual.

Gómez CAPUZ, J. (2000): Anglicismos léxicos en el español coloquial, Cádiz, Universidad de Cádiz.

HuyKe, I. (1978): «Índices de densidad léxica: anglicismos en la zona metropolitana de San Juan», en LóPEZ Morales, H. (ed.) (1978): Corrientes actuales de la Dialectología del Caribe hispánico, San Juan, Editorial Universitaria, 144-163.

LóPez Morales, H. (1983): «Lingüística estadística», en LóPEZ Morales, H. (coord.): Introducción a la lingüística actual, Madrid, Playor.

- (1999): «Anglicismos en el léxico disponible de Puerto Rico», en OrTIZ LÓPEZ, L. A. (ed.) (1999): El Caribe hispánico: perspectivas lingüísticas actuales. Homenaje a Manuel Alvar Nazario, Madrid, Vervuert Iberoamericana, $147-170$.

LORENZO, E. (1996): Anglicismos hispánicos, Madrid, Gredos.

RodríGUez, F y A. LILlo (1997): Nuevo diccionario de anglicismos, Madrid, Gredos.

PRAT, C. (1980): El anglicismo en el español peninsular contemporáneo, Madrid, Gredos. 


\section{ANEXO I. ANGLICISMOS EN EL LÉXICO DISPONIBLE DE CASTELLÓN}

Como he dicho anteriormente se trabaja con un concepto amplio de anglicismo. Se entenderá por tal, toda palabra procedente directa o indirectamente de la lengua inglesa. Se abordarán los préstamos y los calcos.

Las marcas registradas y comerciales aparecen en los listados con mayúscula y asterisco porque así se lematizan en el diccionario del Léxico disponible de Castellón. Pero solo se han incluido las que son muy comunes (tienen un alto índice de disponibilidad) que muchos investigadores consideran lexicalizadas, como Gómez (2000), Pratt (1980), Lorenzo (1996) y también lo incluyen los estudios de anglicismos en léxicos disponibles consultados: Cádiz, Zamora, Puerto Rico y República Dominicana, con el objetivo de facilitar las comparaciones.

Cuando un vocablo aparece especificado con algún tipo de complemento del nombre, no se ha contado como entradas distintas y por tanto no se ha contabilizado como un anglicismo diferente, puesto que la palabra objeto de estudio es la misma. Por ejemplo, bloc aunque aparece modificada en bloc de anillas, bloc de notas, bloc de dibujo solo se ha marcado una vez en los listados de anglicismos. Siempre que aparecen especificaciones o modificaciones quedan aclaradas en notas a pie de página contando sus empleos.

En los diferentes cuadros $N^{o}$. se refiere a la posición en la que ha sido nombrada la palabra, la siguiente columna hace referencia al índice de disponibilidad, la frecuencia relativa indica el número de veces que aparece esa palabra respecto al total de palabras; \% aparición da el porcentaje de sujetos que han anotado ese vocablo, y, por último, la frecuencia acumulada señala la suma de las frecuencias relativas de las palabras que la preceden.

\section{Partes del cuerpo}

No se dan anglicismos.

02. La ropa

\begin{tabular}{|l|l|c|c|c|c|}
\hline $\mathbf{N}^{\mathbf{o}}$ & \multicolumn{1}{|c|}{ Palabra } & $\begin{array}{c}\text { Disponi- } \\
\text { bilidad }\end{array}$ & $\begin{array}{c}\text { Frecuencia } \\
\text { relativa }\end{array}$ & $\begin{array}{c}\text { \% } \\
\text { Aparición }\end{array}$ & $\begin{array}{c}\text { Frecuencia } \\
\text { acumulada }\end{array}$ \\
\hline 7 & jersey $^{10}$ & 0,45409 & $2,817 \%$ & $64,407 \%$ & $24,534 \%$ \\
\hline 19 & suéter $^{10}$ & 0,18791 & $1,235 \%$ & $28,249 \%$ & $51,402 \%$ \\
\hline
\end{tabular}

10. Jersey aparece modificado en otras entradas, cada una con un solo empleo, como: «jersey de cuello alto», «jersey grueso», «jersey de manga corta» y «jersey de lana». 


\begin{tabular}{|l|l|c|c|c|c|}
\hline $\mathbf{N}^{\mathbf{0}}$ & \multicolumn{1}{|c|}{ Palabra } & $\begin{array}{c}\text { Disponi- } \\
\text { bilidad }\end{array}$ & $\begin{array}{c}\text { Frecuencia } \\
\text { relativa }\end{array}$ & $\begin{array}{c}\text { \% } \\
\text { Aparición }\end{array}$ & $\begin{array}{c}\text { Frecuencia } \\
\text { acumulada }\end{array}$ \\
\hline 26 & bermudas & 0,13066 & $1,149 \%$ & $26,271 \%$ & $60,754 \%$ \\
\hline 30 & pijama & 0,11674 & $1,371 \%$ & $31,356 \%$ & $65,756 \%$ \\
\hline 32 & biquini & 0,10512 & $1,186 \%$ & $27,119 \%$ & $67,868 \%$ \\
\hline 36 & polo & 0,09280 & $0,741 \%$ & $16,949 \%$ & $71,537 \%$ \\
\hline 37 & top & 0,08766 & $0,828 \%$ & $18,927 \%$ & $72,365 \%$ \\
\hline 39 & anorak ${ }^{11}$ & 0,08406 & $0,815 \%$ & $18,644 \%$ & $73,884 \%$ \\
\hline 40 & minifalda & 0,08235 & $0,729 \%$ & $16,667 \%$ & $74,613 \%$ \\
\hline 41 & short & 0,08232 & $0,754 \%$ & $17,232 \%$ & $75,367 \%$ \\
\hline 48 & body ${ }^{12}$ & 0,06509 & $0,704 \%$ & $16,102 \%$ & $80,691 \%$ \\
\hline 51 & panty & 0,05273 & $0,506 \%$ & $11,582 \%$ & $82,334 \%$ \\
\hline 65 & slip & 0,03115 & $0,247 \%$ & $5,650 \%$ & $87,732 \%$ \\
\hline 73 & esmoquin & 0,02146 & $0,247 \%$ & $5,650 \%$ & $89,708 \%$ \\
\hline 94 & pareo & 0,01351 & $0,161 \%$ & $3,672 \%$ & $93,107 \%$ \\
\hline 112 & boxer & 0,00807 & $0,074 \%$ & $1,695 \%$ & $95,060 \%$ \\
\hline 113 & jeans & 0,00734 & $0,037 \%$ & $0,847 \%$ & $95,097 \%$ \\
\hline 208 & Wonderbra* & 0,00196 & $0,025 \%$ & $0,565 \%$ & $98,570 \%$ \\
\hline 209 & leggings & 0,00193 & $0,012 \%$ & $0,282 \%$ & $98,582 \%$ \\
\hline 213 & nailon & 0,00181 & $0,012 \%$ & $0,282 \%$ & $98,643 \%$ \\
\hline 229 & blazer & 0,00149 & $0,012 \%$ & $0,282 \%$ & $98,913 \%$ \\
\hline 235 & pulóver & 0,00123 & $0,012 \%$ & $0,282 \%$ & $98,998 \%$ \\
\hline 275 & cárdigan & 0,00095 & $0,012 \%$ & $0,282 \%$ & $99,504 \%$ \\
\hline 288 & poliester & 0,00079 & $0,012 \%$ & $0,282 \%$ & $99,673 \%$ \\
\hline
\end{tabular}

\section{Partes de la casa(sin los muebles)}

\begin{tabular}{|l|l|c|c|c|c|}
\hline $\mathbf{N}^{\mathbf{0}}$ & \multicolumn{1}{|c|}{ Palabra } & $\begin{array}{c}\text { Disponi- } \\
\text { bilidad }\end{array}$ & $\begin{array}{c}\text { Frecuencia } \\
\text { relativa }\end{array}$ & $\begin{array}{c}\% \\
\text { Aparición }\end{array}$ & $\begin{array}{c}\text { Frecuencia } \\
\text { acumulada }\end{array}$ \\
\hline 28 & hall & 0,09356 & $0,881 \%$ & $14,689 \%$ & $71,665 \%$ \\
\hline 38 & váter $^{13}$ & 0,05345 & $0,508 \%$ & $8,475 \%$ & $79,506 \%$ \\
\hline
\end{tabular}

11. Este vocablo está recogido como anglicismo por Pratt (1980) y Lorenzo (1996). Este último nos dice que es un término de difícil vía de penetración. Procede de otras lenguas pero quien lo ha expandido es el inglés.

12. La palabra body viene matizada por «body interior» $\mathrm{y}$ «body deportivo», un uso cada uno.

13. El vocablo váter tiene otro empleo en «váter pequeño». 


\begin{tabular}{|l|l|c|c|c|c|}
\hline $\mathbf{N}^{\mathbf{0}}$ & \multicolumn{1}{|c|}{ Palabra } & $\begin{array}{c}\text { Disponi- } \\
\text { bilidad }\end{array}$ & $\begin{array}{c}\text { Frecuencia } \\
\text { relativa }\end{array}$ & $\begin{array}{c}\% \\
\text { Aparición }\end{array}$ & $\begin{array}{c}\text { Frecuencia } \\
\text { acumulada }\end{array}$ \\
\hline 63 & WC & 0,01826 & $0,152 \%$ & $2,542 \%$ & $88,364 \%$ \\
\hline 84 & office & 0,01049 & $0,102 \%$ & $1,695 \%$ & $92,138 \%$ \\
\hline 93 & pista de tenis & 0,00886 & $0,136 \%$ & $2,260 \%$ & $93,124 \%$ \\
\hline 162 & jacuzzi $^{14}$ & 0,00261 & $0,034 \%$ & $0,565 \%$ & $97,017 \%$ \\
\hline 217 & sala de ping-pong & 0,00156 & $0,017 \%$ & $0,282 \%$ & $98,394 \%$ \\
\hline 219 & bar & 0,00156 & $0,017 \%$ & $0,282 \%$ & $98,428 \%$ \\
\hline 231 & pista de básquet & 0,00127 & $0,051 \%$ & $0,847 \%$ & $98,700 \%$ \\
\hline 232 & parking & 0,00125 & $0,017 \%$ & $0,282 \%$ & $98,717 \%$ \\
\hline 237 & minigolf & 0,00117 & $0,051 \%$ & $0,847 \%$ & $98,836 \%$ \\
\hline 259 & cancha de tenis & 0,00100 & $0,017 \%$ & $0,282 \%$ & $99,210 \%$ \\
\hline
\end{tabular}

\section{Los muebles de la casa}

\begin{tabular}{|l|l|c|c|c|c|}
\hline $\mathbf{N}^{\mathbf{0}}$ & \multicolumn{1}{|c|}{ Palabra } & $\begin{array}{c}\text { Disponi- } \\
\text { bilidad }\end{array}$ & $\begin{array}{c}\text { Frecuencia } \\
\text { relativa }\end{array}$ & $\begin{array}{c}\text { \% } \\
\text { Aparición }\end{array}$ & $\begin{array}{c}\text { Frecuencia } \\
\text { acumulada }\end{array}$ \\
\hline 22 & mueble bar & 0,06909 & $0,895 \%$ & $12,994 \%$ & $65,129 \%$ \\
\hline 61 & váter $^{15}$ & 0,02113 & $0,311 \%$ & $4,520 \%$ & $84,907 \%$ \\
\hline 68 & vídeo & 0,01793 & $0,214 \%$ & $3,107 \%$ & $86,501 \%$ \\
\hline 164 & bar & 0,00267 & $0,039 \%$ & $0,565 \%$ & $96,860 \%$ \\
\hline 194 & láser disk & 0,00210 & $0,019 \%$ & $0,282 \%$ & $97,689 \%$ \\
\hline 276 & sandwichera & 0,00086 & $0,019 \%$ & $0,282 \%$ & $99,427 \%$ \\
\hline
\end{tabular}

05. Alimentos y bebidas ${ }^{16}$

\begin{tabular}{|l|l|c|c|c|c|}
\hline $\mathbf{N}^{\mathbf{0}}$ & \multicolumn{1}{|c|}{ Palabra } & $\begin{array}{c}\text { Disponi- } \\
\text { bilidad }\end{array}$ & $\begin{array}{c}\text { Frecuencia } \\
\text { relativa }\end{array}$ & $\begin{array}{c}\% \\
\text { Aparición }\end{array}$ & $\begin{array}{c}\text { Frecuencia } \\
\text { acumulada }\end{array}$ \\
\hline 3 & whisky $^{17}$ & 0,36806 & $2,093 \%$ & $55,650 \%$ & $7,587 \%$ \\
\hline
\end{tabular}

14. Este vocablo no está en el DRAE (2001), sí lo recoge el Diccionario Panhispánico de dudas (2005) así como Lorenzo (1996).

15. Váter está inmerso en dos sintagmas: «taza de váter» (1 empleo) y «mueble de váter» (1 empleo).

16. No hemos recogido Coca-cola* en el cómputo de anglicismo porque la mayoría de autores trabajados no lo hacen. Si lo incluye Gómez (2000: 90), reconociendo que es una marca registrada de procedencia norteamericana pero que revela una «perfecta aclimatación de este anglicismo a la vida española», yo diría que al resto del mundo. Hay que decir que en el Léxico disponible de Castellón ocupa el cuarto lugar con un índice de disponibilidad de 0.34356 y con un empleo de 163 informantes. Lorenzo (1996) lo admitiría pero no está recogido en Pratt (1980).

17. Este vocablo lo encontramos también en «crema de whisky», con dos empleos. 


\begin{tabular}{|l|l|c|c|c|c|}
\hline $\mathbf{N}^{\mathbf{0}}$ & \multicolumn{1}{|c|}{ Palabra } & $\begin{array}{c}\text { Disponi- } \\
\text { bilidad }\end{array}$ & $\begin{array}{c}\text { Frecuencia } \\
\text { relativa }\end{array}$ & $\begin{array}{c}\text { \% } \\
\text { Aparición }\end{array}$ & $\begin{array}{c}\text { Frecuencia } \\
\text { acumulada }\end{array}$ \\
\hline 39 & hamburguesa & 0,09205 & $0,744 \%$ & $19,774 \%$ & $49,315 \%$ \\
\hline 49 & ron $^{18}$ & 0,07609 & $0,478 \%$ & $12,712 \%$ & $55,679 \%$ \\
\hline 74 & kiwi $^{19}$ & 0,04914 & $0,425 \%$ & $11,299 \%$ & $67,196 \%$ \\
\hline 77 & jamón de York & 0,04751 & $0,404 \%$ & $10,734 \%$ & $68,376 \%$ \\
\hline 156 & sándwich & 0,01680 & $0,128 \%$ & $3,390 \%$ & $85,497 \%$ \\
\hline 157 & brandy & 0,01659 & $0,138 \%$ & $3,672 \%$ & $85,635 \%$ \\
\hline 172 & beicon & 0,01412 & $0,106 \%$ & $2,825 \%$ & $87,431 \%$ \\
\hline 174 & Donut* & 0,01344 & $0,106 \%$ & $2,825 \%$ & $87,696 \%$ \\
\hline 178 & ponche & 0,01296 & $0,096 \%$ & $2,542 \%$ & $88,122 \%$ \\
\hline 244 & ketchup & 0,00679 & $0,053 \%$ & $1,412 \%$ & $93,139 \%$ \\
\hline 254 & chóped & 0,00588 & $0,064 \%$ & $1,695 \%$ & $93,639 \%$ \\
\hline 299 & bourbon & 0,00395 & $0,021 \%$ & $0,565 \%$ & $95,389 \%$ \\
\hline 331 & frankfurt & 0,00317 & $0,032 \%$ & $0,847 \%$ & $96,279 \%$ \\
\hline 381 & gin & 0,00224 & $0,011 \%$ & $0,282 \%$ & $97,197 \%$ \\
\hline 414 & bistec & 0,00189 & $0,011 \%$ & $0,282 \%$ & $97,702 \%$ \\
\hline 418 & mango & 0,00184 & $0,021 \%$ & $0,565 \%$ & $97,766 \%$ \\
\hline 456 & rosbif & 0,00142 & $0,011 \%$ & $0,282 \%$ & $98,315 \%$ \\
\hline 508 & pudin & 0,00113 & $0,011 \%$ & $0,282 \%$ & $98,977 \%$ \\
\hline
\end{tabular}

06. Objetos colocados en la mesa para comer

\begin{tabular}{|l|l|c|c|c|c|}
\hline $\mathbf{N}^{\mathbf{0}}$ & \multicolumn{1}{|c|}{ Palabra } & $\begin{array}{c}\text { Disponi- } \\
\text { bilidad }\end{array}$ & $\begin{array}{c}\text { Frecuencia } \\
\text { relativa }\end{array}$ & $\begin{array}{c}\% \\
\text { Aparición }\end{array}$ & $\begin{array}{c}\text { Frecuencia } \\
\text { acumulada }\end{array}$ \\
\hline 65 & bol & 0,01794 & $0,303 \%$ & $4,520 \%$ & $86,068 \%$ \\
\hline 143 & ketchup & 0,00395 & $0,038 \%$ & $0,565 \%$ & $95,726 \%$ \\
\hline 285 & mando del vídeo & 0,00096 & $0,019 \%$ & $0,282 \%$ & $99,412 \%$ \\
\hline
\end{tabular}

18. Encontramos la especificación «ron blanco» y «ron negro» con un uso cada uno.

19. Kiwi aparece también en «licor de kivi» con un solo empleo. 
07. La cocina y sus utensilios

\begin{tabular}{|l|l|c|c|c|c|}
\hline $\mathbf{N}^{\mathbf{0}}$ & \multicolumn{1}{|c|}{ Palabra } & $\begin{array}{c}\text { Disponi- } \\
\text { bilidad }\end{array}$ & $\begin{array}{c}\text { Frecuencia } \\
\text { relativa }\end{array}$ & $\begin{array}{c}\% \\
\text { Aparición }\end{array}$ & $\begin{array}{c}\text { Frecuencia } \\
\text { acumulada }\end{array}$ \\
\hline 1 & (horno) microondas & 0,49741 & $3,961 \%$ & $74,011 \%$ & $3,961 \%$ \\
\hline 33 & sandwichera & 0,09151 & $1,013 \%$ & $18,927 \%$ & $57,249 \%$ \\
\hline 83 & bol & 0,02256 & $0,242 \%$ & $4,520 \%$ & $79,519 \%$ \\
\hline 96 & robot (de cocina) & 0,01852 & $0,181 \%$ & $3,390 \%$ & $82,663 \%$ \\
\hline 118 & grill & 0,01310 & $0,166 \%$ & $3,107 \%$ & $86,609 \%$ \\
\hline 267 & Tupper(ware)* & 0,00250 & $0,030 \%$ & $0,565 \%$ & $95,938 \%$ \\
\hline 473 & vídeo & 0,00065 & $0,015 \%$ & $0,282 \%$ & $99,523 \%$ \\
\hline 494 & Spontex* & 0,00046 & $0,015 \%$ & $0,282 \%$ & $99,838 \%$ \\
\hline
\end{tabular}

08. La escuela (muebles y materiales)

\begin{tabular}{|c|c|c|c|c|c|}
\hline $\mathbf{N}^{\mathbf{o}}$ & Palabra & $\begin{array}{l}\text { Disponi- } \\
\text { bilidad }\end{array}$ & $\begin{array}{c}\text { Frecuencia } \\
\text { relativa }\end{array}$ & $\begin{array}{c}\% \\
\text { Aparición }\end{array}$ & $\begin{array}{l}\text { Frecuencia } \\
\text { acumulada }\end{array}$ \\
\hline 12 & carpeta $^{20}$ & 0,24304 & $2,300 \%$ & $54,520 \%$ & $37,091 \%$ \\
\hline 40 & vídeo $^{21}$ & 0,06826 & $0,560 \%$ & $13,277 \%$ & $66,115 \%$ \\
\hline 61 & bloc $^{22}$ & 0,03499 & $0,298 \%$ & $7,062 \%$ & $75,515 \%$ \\
\hline 64 & clip & 0,03193 & $0,381 \%$ & $9,040 \%$ & $76,539 \%$ \\
\hline 101 & panel $^{23}$ & 0,01513 & $0,131 \%$ & $3,107 \%$ & $84,189 \%$ \\
\hline 110 & póster & 0,01323 & $0,131 \%$ & $3,107 \%$ & $85,476 \%$ \\
\hline 143 & escáner & 0,00818 & $0,071 \%$ & $1,695 \%$ & $89,023 \%$ \\
\hline 182 & bar $^{24}$ & 0,00555 & $0,060 \%$ & $1,412 \%$ & $91,937 \%$ \\
\hline 220 & váter $^{25}$ & 0,00356 & $0,048 \%$ & $1,130 \%$ & $93,723 \%$ \\
\hline 299 & fax & 0,00210 & $0,024 \%$ & $0,565 \%$ & $95,619 \%$ \\
\hline 326 & WC & 0,00183 & $0,012 \%$ & $0,282 \%$ & $96,111 \%$ \\
\hline 333 & red de voleibol & 0,00174 & $0,024 \%$ & $0,565 \%$ & $96,231 \%$ \\
\hline 346 & hall & 0,00165 & $0,024 \%$ & $0,565 \%$ & $96,459 \%$ \\
\hline
\end{tabular}

20. Encontramos este vocablo modificado por «de anillas» con 4 empleos.

21. Este vocablo lo vemos empleado una sola vez en los siguientes sintagmas: «máquina de vídeo», «cinta de vídeo» y «sala de vídeo».

22. La palabra bloc aparece también en los sintagmas «bloc de notas» ( 3 empleos), en «bloc de dibujo» (2 empleos) y «bloc de anillas» ( 3 empleos).

23. Panel viene modificado por «de anuncios», «informativo» $\mathrm{y}$ «de corcho» (4 empleos).

24. El vocablo bar aparece en dos usos más: «mesa de bar», «silla de bar».

25. Aparece también en «papel de váter» con dos empleos. 


\begin{tabular}{|l|l|c|c|c|c|}
\hline $\mathbf{N}^{\mathbf{0}}$ & \multicolumn{1}{|c|}{ Palabra } & $\begin{array}{c}\text { Disponi- } \\
\text { bilidad }\end{array}$ & $\begin{array}{c}\text { Frecuencia } \\
\text { relativa }\end{array}$ & $\begin{array}{c}\% \\
\text { Aparición }\end{array}$ & $\begin{array}{c}\text { Frecuencia } \\
\text { acumulada }\end{array}$ \\
\hline 393 & disquete & 0,00132 & $0,024 \%$ & $0,565 \%$ & $97,191 \%$ \\
\hline 400 & CD & 0,00126 & $0,012 \%$ & $0,282 \%$ & $97,275 \%$ \\
\hline 415 & cúter & 0,00118 & $0,012 \%$ & $0,282 \%$ & $97,491 \%$ \\
\hline 422 & Kleenex* & 0,00118 & $0,012 \%$ & $0,282 \%$ & $97,575 \%$ \\
\hline 423 & cómic & 0,00118 & $0,012 \%$ & $0,282 \%$ & $97,587 \%$ \\
\hline 443 & subcarpeta & 0,00111 & $0,012 \%$ & $0,282 \%$ & $97,851 \%$ \\
\hline 486 & póster de David & 0,00092 & $0,012 \%$ & $0,282 \%$ & $98,391 \%$ \\
\hline 519 & láser & 0,00087 & $0,012 \%$ & $0,282 \%$ & $98,787 \%$ \\
\hline 523 & aro de básquet & 0,00081 & $0,012 \%$ & $0,282 \%$ & $98,835 \%$ \\
\hline 536 & campo de fútbol ${ }^{26}$ & 0,00081 & $0,012 \%$ & $0,282 \%$ & $98,991 \%$ \\
\hline 542 & pista de tenis & 0,00077 & $0,012 \%$ & $0,282 \%$ & $99,075 \%$ \\
\hline 577 & barra de bar & 0,00068 & $0,012 \%$ & $0,282 \%$ & $99,495 \%$ \\
\hline 616 & bafle & 0,00047 & $0,012 \%$ & $0,282 \%$ & $99,963 \%$ \\
\hline
\end{tabular}

09. Iluminación, calefacción y medios para airear un recinto

\begin{tabular}{|c|c|c|c|c|c|}
\hline $\mathbf{N}^{\mathbf{o}}$ & Palabra & $\begin{array}{l}\text { Disponi- } \\
\text { bilidad }\end{array}$ & $\begin{array}{c}\text { Frecuencia } \\
\text { relativa }\end{array}$ & $\begin{array}{c}\% \\
\text { Aparición }\end{array}$ & $\begin{array}{l}\text { Frecuencia } \\
\text { acumulada }\end{array}$ \\
\hline 2 & aire acondicionado & 0,53261 & $5,837 \%$ & $77,119 \%$ & $11,439 \%$ \\
\hline 69 & láser & 0,01230 & $0,150 \%$ & $1,977 \%$ & $82,704 \%$ \\
\hline 79 & gasoil $^{27}$ & 0,01046 & $0,128 \%$ & $1,695 \%$ & $84,136 \%$ \\
\hline 87 & flash & 0,00908 & $0,150 \%$ & $1,977 \%$ & $85,336 \%$ \\
\hline 114 & Camping gas* & 0,00652 & $0,107 \%$ & $1,412 \%$ & $88,161 \%$ \\
\hline 151 & gasolina $^{28}$ & 0,00438 & $0,043 \%$ & $0,565 \%$ & $90,817 \%$ \\
\hline 159 & gasóleo $^{29}$ & 0,00402 & $0,043 \%$ & $0,565 \%$ & $91,288 \%$ \\
\hline 313 & farol de camping & 0,00169 & $0,021 \%$ & $0,282 \%$ & $96,334 \%$ \\
\hline 377 & spray & 0,00121 & $0,021 \%$ & $0,282 \%$ & $97,788 \%$ \\
\hline 390 & cámara de vídeo & 0,00111 & $0,021 \%$ & $0,282 \%$ & $98,061 \%$ \\
\hline
\end{tabular}

26. También encontramos «pista de fútbol» (un empleo) que no es muy usual.

27. Lo mismo decimos de gasoil, que aparece en los sintagmas: «calefacción de gasoil» (4 empleos), «estufa de gasoil» (2 empleos).

28. La palabra gasolina aparece también acompañando a «calefacción de gasolina» (1 empleo) y «lámpara de gasolina» (1 empleo).

29. También en este caso encontramos una especificación: «caldera de gasóleo» (1 empleo). 


\begin{tabular}{|l|l|c|c|c|c|}
\hline $\mathbf{N}^{\mathbf{0}}$ & \multicolumn{1}{|c|}{ Palabra } & $\begin{array}{c}\text { Disponi- } \\
\text { bilidad }\end{array}$ & $\begin{array}{c}\text { Frecuencia } \\
\text { relativa }\end{array}$ & $\begin{array}{c}\% \\
\text { Aparición }\end{array}$ & $\begin{array}{c}\text { Frecuencia } \\
\text { acumulada }\end{array}$ \\
\hline 392 & vatio & 0,00111 & $0,021 \%$ & $0,282 \%$ & $98,103 \%$ \\
\hline 411 & voltio & 0,00102 & $0,021 \%$ & $0,282 \%$ & $98,502 \%$ \\
\hline
\end{tabular}

10. La ciudad

\begin{tabular}{|l|l|c|c|c|c|}
\hline $\mathbf{N}^{\mathbf{0}}$ & \multicolumn{1}{|c|}{ Palabra } & $\begin{array}{c}\text { Disponi- } \\
\text { bilidad }\end{array}$ & $\begin{array}{c}\text { Frecuencia } \\
\text { relativa }\end{array}$ & $\begin{array}{c}\text { \% } \\
\text { Aparición }\end{array}$ & $\begin{array}{c}\text { Frecuencia } \\
\text { acumulada }\end{array}$ \\
\hline 10 & bar & 0,24033 & $1,714 \%$ & $42,373 \%$ & $21,397 \%$ \\
\hline 35 & pub & 0,11484 & $0,926 \%$ & $22,881 \%$ & $50,301 \%$ \\
\hline 39 & rascacielos & 0,10397 & $0,652 \%$ & $16,102 \%$ & $53,377 \%$ \\
\hline 40 & paso de cebra & 0,10289 & $0,697 \%$ & $17,232 \%$ & $54,074 \%$ \\
\hline 49 & tráfico & 0,07094 & $0,446 \%$ & $11,017 \%$ & $59,332 \%$ \\
\hline 56 & parking & 0,06091 & $0,446 \%$ & $11,017 \%$ & $62,612 \%$ \\
\hline 57 & señal de tráfico ${ }^{30}$ & 0,05937 & $0,423 \%$ & $10,452 \%$ & $63,035 \%$ \\
\hline 107 & apartamento & 0,02261 & $0,126 \%$ & $3,107 \%$ & $76,066 \%$ \\
\hline 120 & aparcamiento & 0,01946 & $0,137 \%$ & $3,390 \%$ & $78,192 \%$ \\
\hline 121 & estrés & 0,01921 & $0,137 \%$ & $3,390 \%$ & $78,329 \%$ \\
\hline 129 & gasolinera & 0,01721 & $0,149 \%$ & $3,672 \%$ & $79,415 \%$ \\
\hline 130 & tranvía & 0,01717 & $0,137 \%$ & $3,390 \%$ & $79,552 \%$ \\
\hline 179 & club & 0,01014 & $0,057 \%$ & $1,412 \%$ & $84,286 \%$ \\
\hline 198 & pista de tenis & 0,00869 & $0,057 \%$ & $1,412 \%$ & $85,566 \%$ \\
\hline 209 & sex shop & 0,00755 & $0,046 \%$ & $1,130 \%$ & $86,253 \%$ \\
\hline 232 & bingo & 0,00668 & $0,069 \%$ & $1,695 \%$ & $87,523 \%$ \\
\hline 254 & sidecar & 0,00572 & $0,046 \%$ & $1,130 \%$ & $88,542 \%$ \\
\hline 263 & estadio de fútbol ${ }^{31}$ & 0,00539 & $0,057 \%$ & $1,412 \%$ & $88,931 \%$ \\
\hline 267 & turista & 0,00527 & $0,034 \%$ & $0,847 \%$ & $89,067 \%$ \\
\hline 275 & puticlub & 0,00499 & $0,046 \%$ & $1,130 \%$ & $89,387 \%$ \\
\hline 278 & videoclub & 0,00492 & $0,034 \%$ & $0,847 \%$ & $89,501 \%$ \\
\hline
\end{tabular}

30. Otra forma de denominar este concepto es «paleta de tráfico» con un empleo. El vocablo tráfico el DRAE nos dice que viene del italiano, pero Pratt (1980), Alfaro (1964), Lorenzo (1996) y

Gómez (2000) lo incluyen como anglicismo penetrado en nuestra lengua a través del francés.

31. Vemos asimismo «equipo de fútbol» con un uso. 


\begin{tabular}{|l|l|c|c|c|c|}
\hline $\mathbf{N}^{\mathbf{0}}$ & \multicolumn{1}{|c|}{ Palabra } & $\begin{array}{c}\text { Disponi- } \\
\text { bilidad }\end{array}$ & $\begin{array}{c}\text { Frecuencia } \\
\text { relativa }\end{array}$ & $\begin{array}{c}\% \\
\text { Aparición }\end{array}$ & $\begin{array}{c}\text { Frecuencia } \\
\text { acumulada }\end{array}$ \\
\hline 283 & túnel & 0,00484 & $0,046 \%$ & $1,130 \%$ & $89,650 \%$ \\
\hline 291 & stop & 0,00456 & $0,023 \%$ & $0,565 \%$ & $89,878 \%$ \\
\hline 308 & yonqui & 0,00423 & $0,023 \%$ & $0,565 \%$ & $90,414 \%$ \\
\hline 318 & boutique & 0,00410 & $0,034 \%$ & $0,847 \%$ & $90,722 \%$ \\
\hline 328 & hamburguesería & 0,00400 & $0,034 \%$ & $0,847 \%$ & $91,086 \%$ \\
\hline 330 & zona residencial & 0,00391 & $0,023 \%$ & $0,565 \%$ & $91,132 \%$ \\
\hline 345 & bungalow & 0,00371 & $0,023 \%$ & $0,565 \%$ & $91,577 \%$ \\
\hline 348 & fútbol & 0,00370 & $0,034 \%$ & $0,847 \%$ & $91,691 \%$ \\
\hline 380 & graffiti & 0,00319 & $0,023 \%$ & $0,565 \%$ & $92,493 \%$ \\
\hline 382 & club nocturno & 0,00316 & $0,023 \%$ & $0,565 \%$ & $92,539 \%$ \\
\hline 392 & salón de belleza & 0,00291 & $0,023 \%$ & $0,565 \%$ & $92,813 \%$ \\
\hline 432 & drogadicto & 0,00257 & $0,023 \%$ & $0,565 \%$ & $93,608 \%$ \\
\hline 450 & tráiler & 0,00252 & $0,023 \%$ & $0,565 \%$ & $93,937 \%$ \\
\hline 458 & señal de stop & 0,00245 & $0,011 \%$ & $0,282 \%$ & $94,084 \%$ \\
\hline 461 & zombi & 0,00245 & $0,011 \%$ & $0,282 \%$ & $94,117 \%$ \\
\hline 526 & trolebús & 0,00212 & $0,011 \%$ & $0,282 \%$ & $94,928 \%$ \\
\hline 529 & campo de básquet ${ }^{32}$ & 0,00212 & $0,011 \%$ & $0,282 \%$ & $94,961 \%$ \\
\hline 543 & váter & 0,00202 & $0,011 \%$ & $0,282 \%$ & $95,151 \%$ \\
\hline 548 & campo de fútbol sala & 0,00202 & $0,011 \%$ & $0,282 \%$ & $95,218 \%$ \\
\hline 559 & turismo & 0,00193 & $0,011 \%$ & $0,282 \%$ & $95,351 \%$ \\
\hline 613 & campo de golf & 0,00167 & $0,011 \%$ & $0,282 \%$ & $96,017 \%$ \\
\hline 627 & frankfurt & 0,00167 & $0,011 \%$ & $0,282 \%$ & $96,183 \%$ \\
\hline 706 & videojuegos & 0,00138 & $0,011 \%$ & $0,282 \%$ & $97,064 \%$ \\
\hline 902 & parada de hippys & 0,00085 & $0,011 \%$ & $0,282 \%$ & $99,268 \%$ \\
\hline 908 & parlamento & 0,00085 & $0,011 \%$ & $0,282 \%$ & $99,334 \%$ \\
\hline 923 & campo de hockey & 0,00077 & $0,011 \%$ & $0,282 \%$ & $99,499 \%$ \\
\hline 928 & motel & 0,00070 & $0,011 \%$ & $0,282 \%$ & $99,554 \%$ \\
\hline 942 & camping & 0,00061 & $0,011 \%$ & $0,282 \%$ & $99,708 \%$ \\
\hline
\end{tabular}

32. Básquet aparece con tres sustantivos: «campo de básquet», «cancha de básquet», «pista de básquet» con un empleo cada uno. 
11. El campo

\begin{tabular}{|l|l|c|c|c|c|}
\hline $\mathbf{N}^{\mathbf{0}}$ & \multicolumn{1}{|c|}{ Palabra } & $\begin{array}{c}\text { Disponi- } \\
\text { bilidad }\end{array}$ & $\begin{array}{c}\text { Frecuencia } \\
\text { relativa }\end{array}$ & $\begin{array}{c}\% \\
\text { Aparición }\end{array}$ & $\begin{array}{c}\text { Frecuencia } \\
\text { acumulada }\end{array}$ \\
\hline 291 & bar & 0,00686 & $0,067 \%$ & $1,412 \%$ & $82,858 \%$ \\
\hline 302 & camping & 0,00642 & $0,067 \%$ & $1,412 \%$ & $83,557 \%$ \\
\hline 306 & picnic & 0,00632 & $0,067 \%$ & $1,412 \%$ & $83,799 \%$ \\
\hline 387 & turista & 0,00443 & $0,040 \%$ & $0,847 \%$ & $87,717 \%$ \\
\hline 428 & kiwi & 0,00359 & $0,027 \%$ & $0,565 \%$ & $89,247 \%$ \\
\hline 476 & relax & 0,00292 & $0,027 \%$ & $0,565 \%$ & $90,700 \%$ \\
\hline 527 & fútbol & 0,00250 & $0,013 \%$ & $0,282 \%$ & $91,848 \%$ \\
\hline 555 & tenis & 0,00236 & $0,013 \%$ & $0,282 \%$ & $92,446 \%$ \\
\hline 882 & mandril & 0,00107 & $0,013 \%$ & $0,282 \%$ & $97,534 \%$ \\
\hline 975 & pub & 0,00079 & $0,013 \%$ & $0,282 \%$ & $98,757 \%$ \\
\hline
\end{tabular}

\section{Medios de transporte}

\begin{tabular}{|l|l|c|c|c|c|}
\hline $\mathbf{N}^{\mathbf{0}}$ & \multicolumn{1}{|c|}{ Palabra } & $\begin{array}{c}\text { Disponi- } \\
\text { bilidad }\end{array}$ & $\begin{array}{c}\text { Frecuencia } \\
\text { relativa }\end{array}$ & $\begin{array}{c}\% \\
\text { Aparición }\end{array}$ & $\begin{array}{c}\text { Frecuencia } \\
\text { acumulada }\end{array}$ \\
\hline 14 & tranvía & 0,21481 & $1,934 \%$ & $37,288 \%$ & $49,048 \%$ \\
\hline 31 & yate & 0,07464 & $0,879 \%$ & $16,949 \%$ & $73,922 \%$ \\
\hline 34 & sidecar $^{33}$ & 0,05666 & $0,615 \%$ & $11,864 \%$ & $75,753 \%$ \\
\hline 39 & tráiler & 0,04038 & $0,410 \%$ & $7,910 \%$ & $78,448 \%$ \\
\hline 46 & tándem & 0,03257 & $0,366 \%$ & $7,062 \%$ & $81,729 \%$ \\
\hline 57 & turismo & 0,02208 & $0,161 \%$ & $3,107 \%$ & $85,216 \%$ \\
\hline 59 & tabla de surf & 0,02074 & $0,278 \%$ & $5,367 \%$ & $85,758 \%$ \\
\hline 63 & trolebús & 0,01843 & $0,176 \%$ & $3,390 \%$ & $86,461 \%$ \\
\hline 69 & ferry & 0,01626 & $0,190 \%$ & $3,672 \%$ & $87,721 \%$ \\
\hline 73 & todoterreno & 0,01580 & $0,161 \%$ & $3,107 \%$ & $88,438 \%$ \\
\hline 76 & jet ${ }^{34}$ & 0,01386 & $0,146 \%$ & $2,825 \%$ & $88,950 \%$ \\
\hline 78 & zodiac & 0,01339 & $0,190 \%$ & $3,672 \%$ & $89,286 \%$ \\
\hline 85 & Concorde & 0,01237 & $0,146 \%$ & $2,825 \%$ & $90,369 \%$ \\
\hline 90 & tanque & 0,01148 & $0,161 \%$ & $3,107 \%$ & $91,101 \%$ \\
\hline
\end{tabular}

33. Este vocablo aparece también en «moto con sidecar» con un empleo.

34. Lo vemos modificado por «privado», un solo informante. 


\begin{tabular}{|l|l|c|c|c|c|}
\hline $\mathbf{N}^{\mathbf{0}}$ & \multicolumn{1}{|c|}{ Palabra } & $\begin{array}{c}\text { Disponi- } \\
\text { bilidad }\end{array}$ & $\begin{array}{c}\text { Frecuencia } \\
\text { relativa }\end{array}$ & $\begin{array}{c}\text { \% } \\
\text { Aparición }\end{array}$ & $\begin{array}{c}\text { Frecuencia } \\
\text { acumulada }\end{array}$ \\
\hline 92 & bote $^{35}$ & 0,01044 & $0,161 \%$ & $3,107 \%$ & $91,350 \%$ \\
\hline 99 & mountain bike & 0,00923 & $0,073 \%$ & $1,412 \%$ & $92,126 \%$ \\
\hline 101 & autostop & 0,00869 & $0,103 \%$ & $1,977 \%$ & $92,346 \%$ \\
\hline 106 & kart & 0,00780 & $0,088 \%$ & $1,695 \%$ & $92,932 \%$ \\
\hline 107 & crucero & 0,00767 & $0,103 \%$ & $1,977 \%$ & $93,035 \%$ \\
\hline 115 & monorraíl & 0,00659 & $0,073 \%$ & $1,412 \%$ & $93,782 \%$ \\
\hline 126 & vagón & 0,00550 & $0,044 \%$ & $0,847 \%$ & $94,529 \%$ \\
\hline 128 & tabla de windsurf & 0,00545 & $0,073 \%$ & $1,412 \%$ & $94,675 \%$ \\
\hline 129 & snowboard & 0,00538 & $0,059 \%$ & $1,130 \%$ & $94,734 \%$ \\
\hline 134 & hovercraft & 0,00452 & $0,073 \%$ & $1,412 \%$ & $95,027 \%$ \\
\hline 138 & boeing & 0,00437 & $0,044 \%$ & $0,847 \%$ & $95,188 \%$ \\
\hline 141 & jeep & 0,00425 & $0,044 \%$ & $0,847 \%$ & $95,320 \%$ \\
\hline 143 & windsurf & 0,00417 & $0,073 \%$ & $1,412 \%$ & $95,466 \%$ \\
\hline 148 & catamarán & 0,00400 & $0,059 \%$ & $1,130 \%$ & $95,730 \%$ \\
\hline 159 & moto de cross & 0,00345 & $0,029 \%$ & $0,565 \%$ & $96,214 \%$ \\
\hline 162 & skate & 0,00333 & $0,059 \%$ & $1,130 \%$ & $96,346 \%$ \\
\hline 193 & poni & 0,00249 & $0,044 \%$ & $0,847 \%$ & $97,312 \%$ \\
\hline 194 & jumbo & 0,00248 & $0,029 \%$ & $0,565 \%$ & $97,341 \%$ \\
\hline 203 & skateboard & 0,00231 & $0,029 \%$ & $0,565 \%$ & $97,605 \%$ \\
\hline 204 & vagoneta & 0,00229 & $0,015 \%$ & $0,282 \%$ & $97,620 \%$ \\
\hline 209 & container & 0,00229 & $0,015 \%$ & $0,282 \%$ & $97,709 \%$ \\
\hline 230 & jet privado & 0,00186 & $0,015 \%$ & $0,282 \%$ & $98,136 \%$ \\
\hline 239 & quad & 0,00171 & $0,029 \%$ & $0,565 \%$ & $98,313 \%$ \\
\hline 248 & surfing & 0,00156 & $0,029 \%$ & $0,565 \%$ & $98,504 \%$ \\
\hline 267 & kayak & 0,00131 & $0,015 \%$ & $0,282 \%$ & $98,831 \%$ \\
\hline 278 & vuelo chárter & 0,00122 & $0,015 \%$ & $0,282 \%$ & $99,010 \%$ \\
\hline 288 & gasolina ${ }^{36}$ & 0,00106 & $0,015 \%$ & $0,282 \%$ & $99,188 \%$ \\
\hline 303 & scooter & 0,00086 & $0,015 \%$ & $0,282 \%$ & $99,413 \%$ \\
\hline
\end{tabular}

35. Otro uso que aparece es bote modificado por «salvavidas».

36. Aparece también en el sintagma «monopatín de gasolina» con un empleo. 


\begin{tabular}{|c|l|c|c|c|c|}
\hline $\mathbf{N}^{\mathbf{0}}$ & \multicolumn{1}{|c|}{ Palabra } & $\begin{array}{c}\text { Disponi- } \\
\text { bilidad }\end{array}$ & $\begin{array}{c}\text { Frecuencia } \\
\text { relativa }\end{array}$ & $\begin{array}{c}\% \\
\text { Aparición }\end{array}$ & $\begin{array}{c}\text { Frecuencia } \\
\text { acumulada }\end{array}$ \\
\hline 306 & moto con sidecar & 0,00086 & $0,015 \%$ & $0,282 \%$ & $99,458 \%$ \\
\hline 319 & footing & 0,00075 & $0,015 \%$ & $0,282 \%$ & $99,653 \%$ \\
\hline
\end{tabular}

\section{Trabajos del campo y del jardín}

\begin{tabular}{|c|l|c|c|c|c|}
\hline $\mathbf{N}^{\mathbf{0}}$ & \multicolumn{1}{|c|}{ Palabra } & $\begin{array}{c}\text { Disponi- } \\
\text { bilidad }\end{array}$ & $\begin{array}{c}\text { Frecuencia } \\
\text { relativa }\end{array}$ & $\begin{array}{c}\% \\
\text { Aparición }\end{array}$ & $\begin{array}{c}\text { Frecuencia } \\
\text { acumulada }\end{array}$ \\
\hline 545 & cowboy & 0,00135 & $0,025 \%$ & $0,282 \%$ & $96,027 \%$ \\
\hline 565 & sembrar kiwis & 0,00124 & $0,025 \%$ & $0,282 \%$ & $96,552 \%$ \\
\hline
\end{tabular}

\section{Los animales}

\begin{tabular}{|l|l|c|c|c|c|}
\hline $\mathbf{N}^{\mathbf{0}}$ & \multicolumn{1}{|c|}{ Palabra } & $\begin{array}{c}\text { Disponi- } \\
\text { bilidad }\end{array}$ & $\begin{array}{c}\text { Frecuencia } \\
\text { relativa }\end{array}$ & $\begin{array}{c}\% \\
\text { Aparición }\end{array}$ & $\begin{array}{c}\text { Frecuencia } \\
\text { acumulada }\end{array}$ \\
\hline 50 & hámster & 0,08423 & $0,557 \%$ & $15,819 \%$ & $63,308 \%$ \\
\hline 134 & poni (pony) & 0,01676 & $0,149 \%$ & $4,237 \%$ & $90,345 \%$ \\
\hline 141 & kivi & 0,01444 & $0,099 \%$ & $2,825 \%$ & $91,120 \%$ \\
\hline 157 & mandril & 0,01107 & $0,090 \%$ & $2,542 \%$ & $92,780 \%$ \\
\hline 279 & husky siberiano & 0,00254 & $0,010 \%$ & $0,282 \%$ & $98,105 \%$ \\
\hline
\end{tabular}

\section{Juegos y distracciones}

\begin{tabular}{|l|l|c|c|c|c|}
\hline $\mathbf{N}^{\circ}$ & Palabra & $\begin{array}{c}\text { Disponi- } \\
\text { bilidad }\end{array}$ & $\begin{array}{c}\text { Frecuencia } \\
\text { relativa }\end{array}$ & $\begin{array}{c}\% \\
\text { Aparición }\end{array}$ & $\begin{array}{c}\text { Frecuencia } \\
\text { acumulada }\end{array}$ \\
\hline 2 & fútbol $^{37}$ & 0,44770 & $3,527 \%$ & $68,644 \%$ & $6,952 \%$ \\
\hline 7 & tenis & 0,20488 & $1,887 \%$ & $36,723 \%$ & $17,316 \%$ \\
\hline 10 & Trivial* & 0,18431 & $1,466 \%$ & $28,531 \%$ & $22,091 \%$ \\
\hline 16 & Monopoly* & 0,12574 & $1,001 \%$ & $19,492 \%$ & $30,015 \%$ \\
\hline 20 & voleibol & 0,11177 & $1,103 \%$ & $21,469 \%$ & $34,297 \%$ \\
\hline 23 & póquer & 0,10437 & $0,842 \%$ & $16,384 \%$ & $37,055 \%$ \\
\hline 27 & bingo & 0,09194 & $0,740 \%$ & $14,407 \%$ & $40,291 \%$ \\
\hline 31 & videojuego & 0,07417 & $0,624 \%$ & $12,147 \%$ & $43,498 \%$ \\
\hline 44 & básquet & 0,05260 & $0,493 \%$ & $9,605 \%$ & $51,350 \%$ \\
\hline
\end{tabular}

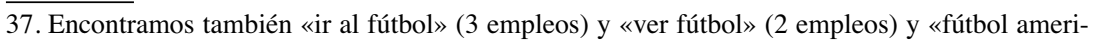
cano» (4 empleos). 


\begin{tabular}{|l|l|c|c|c|c|}
\hline $\mathbf{N}^{\mathbf{0}}$ & Palabra & $\begin{array}{c}\text { Disponi- } \\
\text { bilidad }\end{array}$ & $\begin{array}{c}\text { Frecuencia } \\
\text { relativa }\end{array}$ & $\begin{array}{c}\% \\
\text { Aparición }\end{array}$ & $\begin{array}{c}\text { Frecuencia } \\
\text { acumulada }\end{array}$ \\
\hline 52 & golf & 0,04388 & $0,450 \%$ & $8,757 \%$ & $54,585 \%$ \\
\hline 56 & (juegos de) rol & 0,04305 & $0,319 \%$ & $6,215 \%$ & $56,151 \%$ \\
\hline 59 & béisbol & 0,03936 & $0,363 \%$ & $7,062 \%$ & $57,370 \%$ \\
\hline 60 & futbolín & 0,03802 & $0,377 \%$ & $7,345 \%$ & $57,747 \%$ \\
\hline 62 & pimpón & 0,03721 & $0,392 \%$ & $7,627 \%$ & $58,516 \%$ \\
\hline 67 & hockey ${ }^{38}$ & 0,03410 & $0,406 \%$ & $7,910 \%$ & $60,214 \%$ \\
\hline 81 & puzle & 0,02374 & $0,247 \%$ & $4,802 \%$ & $64,176 \%$ \\
\hline 98 & aeróbic & 0,02060 & $0,232 \%$ & $4,520 \%$ & $68,385 \%$ \\
\hline 99 & squash & 0,02059 & $0,247 \%$ & $4,802 \%$ & $68,632 \%$ \\
\hline 102 & waterpolo & 0,02027 & $0,203 \%$ & $3,955 \%$ & $69,169 \%$ \\
\hline 103 & rugby & 0,01985 & $0,218 \%$ & $4,237 \%$ & $69,387 \%$ \\
\hline 108 & fútbol sala & 0,01925 & $0,189 \%$ & $3,672 \%$ & $70,302 \%$ \\
\hline 120 & puenting & 0,01749 & $0,232 \%$ & $4,520 \%$ & $72,596 \%$ \\
\hline 123 & futbito & 0,01692 & $0,203 \%$ & $3,955 \%$ & $73,090 \%$ \\
\hline 133 & footing & 0,01489 & $0,174 \%$ & $3,390 \%$ & $74,585 \%$ \\
\hline 149 & pub & 0,01203 & $0,116 \%$ & $2,260 \%$ & $76,780 \%$ \\
\hline 150 & vídeo 39 & 0,01179 & $0,116 \%$ & $2,260 \%$ & $76,896 \%$ \\
\hline 178 & black jack & 0,00966 & $0,102 \%$ & $1,977 \%$ & $79,760 \%$ \\
\hline 183 & Internet & 0,00949 & $0,087 \%$ & $1,695 \%$ & $80,182 \%$ \\
\hline 190 & bar & 0,00912 & $0,102 \%$ & $1,977 \%$ & $80,953 \%$ \\
\hline 193 & cómic 40 & 0,00899 & $0,087 \%$ & $1,695 \%$ & $81,200 \%$ \\
\hline 201 & bádminton & 0,00867 & $0,102 \%$ & $1,977 \%$ & $81,956 \%$ \\
\hline 221 & rafting & 0,00691 & $0,087 \%$ & $1,695 \%$ & $83,671 \%$ \\
\hline 229 & strip póquer & 0,00630 & $0,044 \%$ & $0,847 \%$ & $84,195 \%$ \\
\hline 232 & paddle & 0,00616 & $0,073 \%$ & $1,412 \%$ & $84,399 \%$ \\
\hline 242 & frontenis & 0,00563 & $0,073 \%$ & $1,412 \%$ & $85,040 \%$ \\
\hline 247 & polo & 0,00550 & $0,044 \%$ & $0,847 \%$ & $85,405 \%$ \\
\hline
\end{tabular}

38. Observamos el vocablo hockey en sus diferentes variantes de juego: «hockey sobre hielo»

( 2 empleos), «hockey sobre patines» (2 empleos), y «hockey sobre hierba» (un empleo).

39. Vemos esta palabra también en «películas de vídeo» con 4 usos.

40. El vocablo cómic aparece en el sintagma «leer un cómic» con un solo empleo. 


\begin{tabular}{|c|c|c|c|c|c|}
\hline $\mathbf{N}^{0}$ & Palabra & $\begin{array}{l}\text { Disponi- } \\
\text { bilidad }\end{array}$ & $\begin{array}{c}\text { Frecuencia } \\
\text { relativa }\end{array}$ & $\begin{array}{c}\% \% \\
\text { Aparición }\end{array}$ & $\begin{array}{l}\text { Frecuencia } \\
\text { acumulada }\end{array}$ \\
\hline 251 & surf & 0,00528 & $0,073 \%$ & $1,412 \%$ & $85,681 \%$ \\
\hline 261 & boxeo & 0,00497 & $0,073 \%$ & $1,412 \%$ & $86,249 \%$ \\
\hline 280 & tenis de mesa & 0,00457 & $0,058 \%$ & $1,130 \%$ & $87,211 \%$ \\
\hline 312 & rappel & 0,00372 & $0,058 \%$ & $1,130 \%$ & $88,654 \%$ \\
\hline 323 & motocross & 0,00360 & $0,044 \%$ & $0,847 \%$ & $89,121 \%$ \\
\hline 327 & tobogán & 0,00352 & $0,029 \%$ & $0,565 \%$ & $89,310 \%$ \\
\hline 328 & voley playa & 0,00348 & $0,044 \%$ & $0,847 \%$ & $89,354 \%$ \\
\hline 387 & ir de camping & 0,00267 & $0,029 \%$ & $0,565 \%$ & $91,254 \%$ \\
\hline 397 & mountain bike & 0,00261 & $0,029 \%$ & $0,565 \%$ & $91,460 \%$ \\
\hline 398 & zapping & 0,00260 & $0,029 \%$ & $0,565 \%$ & $91,489 \%$ \\
\hline 418 & top model & 0,00246 & $0,015 \%$ & $0,282 \%$ & $91,916 \%$ \\
\hline 419 & fin de semana & 0,00246 & $0,015 \%$ & $0,282 \%$ & $91,931 \%$ \\
\hline 432 & windsurf & 0,00229 & $0,029 \%$ & $0,565 \%$ & $92,323 \%$ \\
\hline 458 & club & 0,00214 & $0,015 \%$ & $0,282 \%$ & $92,812 \%$ \\
\hline 467 & póquer-strip & 0,00214 & $0,015 \%$ & $0,282 \%$ & $92,947 \%$ \\
\hline 476 & trial & 0,00206 & $0,029 \%$ & $0,565 \%$ & $93,224 \%$ \\
\hline 486 & bate & 0,00199 & $0,015 \%$ & $0,282 \%$ & $93,430 \%$ \\
\hline 501 & Disney* world & 0,00186 & $0,015 \%$ & $0,282 \%$ & $93,754 \%$ \\
\hline 512 & jogging & 0,00186 & $0,015 \%$ & $0,282 \%$ & $93,919 \%$ \\
\hline 519 & test & 0,00186 & $0,015 \%$ & $0,282 \%$ & $94,024 \%$ \\
\hline 24 & oír el CD & 0,00182 & $0,029 \%$ & $0,565 \%$ & $94,141 \%$ \\
\hline 547 & PC fútbol & 0,00173 & $0,015 \%$ & $0,282 \%$ & $94,612 \%$ \\
\hline 551 & ir de picnic & 0,00173 & $0,015 \%$ & $0,282 \%$ & $94,672 \%$ \\
\hline 553 & walkie talkie & 0,00173 & $0,015 \%$ & $0,282 \%$ & $94,702 \%$ \\
\hline 564 & trekking & 0,00162 & $0,015 \%$ & $0,282 \%$ & $94,909 \%$ \\
\hline 66 & fútbol playa & 0,00162 & $0,015 \%$ & $0,282 \%$ & $94,939 \%$ \\
\hline 593 & kung-fu & 0,00151 & $0,015 \%$ & $0,282 \%$ & $95,428 \%$ \\
\hline 599 & surfear & 0,00151 & $0,015 \%$ & $0,282 \%$ & $95,518 \%$ \\
\hline 613 & ver videoclips & 0,00141 & $0,015 \%$ & $0,282 \%$ & $95,770 \%$ \\
\hline 637 & gymkhana & 0,00133 & $0,029 \%$ & $0,565 \%$ & $96,172 \%$ \\
\hline
\end{tabular}




\begin{tabular}{|l|l|c|c|c|c|}
\hline $\mathbf{N}^{\mathbf{0}}$ & \multicolumn{1}{|c|}{ Palabra } & $\begin{array}{c}\text { Disponi- } \\
\text { bilidad }\end{array}$ & $\begin{array}{c}\text { Frecuencia } \\
\text { relativa }\end{array}$ & $\begin{array}{c}\text { \% } \\
\text { Aparición }\end{array}$ & $\begin{array}{c}\text { Frecuencia } \\
\text { acumulada }\end{array}$ \\
\hline 657 & sex-shop & 0,00131 & $0,015 \%$ & $0,282 \%$ & $96,472 \%$ \\
\hline 668 & surfing & 0,00122 & $0,015 \%$ & $0,282 \%$ & $96,651 \%$ \\
\hline 681 & minigolf & 0,00114 & $0,015 \%$ & $0,282 \%$ & $96,846 \%$ \\
\hline 705 & karting & 0,00106 & $0,015 \%$ & $0,282 \%$ & $97,220 \%$ \\
\hline 728 & fitness & 0,00099 & $0,015 \%$ & $0,282 \%$ & $97,565 \%$ \\
\hline 736 & libro de ciencia ficción & 0,00099 & $0,015 \%$ & $0,282 \%$ & $97,685 \%$ \\
\hline 749 & hacer test & 0,00093 & $0,015 \%$ & $0,282 \%$ & $97,880 \%$ \\
\hline 811 & rally & 0,00075 & $0,015 \%$ & $0,282 \%$ & $98,810 \%$ \\
\hline 847 & backgammon & 0,00065 & $0,015 \%$ & $0,282 \%$ & $99,350 \%$ \\
\hline 857 & chatear & 0,00065 & $0,015 \%$ & $0,282 \%$ & $99,500 \%$ \\
\hline 860 & Hula hop* & 0,00065 & $0,015 \%$ & $0,282 \%$ & $99,545 \%$ \\
\hline 864 & snow & 0,00061 & $0,015 \%$ & $0,282 \%$ & $99,605 \%$ \\
\hline 872 & handball & 0,00061 & $0,015 \%$ & $0,282 \%$ & $99,725 \%$ \\
\hline 873 & rock and roll & 0,00061 & $0,015 \%$ & $0,282 \%$ & $99,740 \%$ \\
\hline 877 & skate & 0,00057 & $0,015 \%$ & $0,282 \%$ & $99,800 \%$ \\
\hline 892 & cross & 0,00049 & $0,015 \%$ & $0,282 \%$ & $100,025 \%$ \\
\hline 896 & full contact & 0,00049 & $0,015 \%$ & $0,282 \%$ & $100,085 \%$ \\
\hline
\end{tabular}

\section{Profesiones y oficios}

\begin{tabular}{|l|l|c|c|c|c|}
\hline $\mathbf{N}^{\mathbf{0}}$ & \multicolumn{1}{|c|}{ Palabra } & $\begin{array}{c}\text { Disponi- } \\
\text { bilidad }\end{array}$ & $\begin{array}{c}\text { Frecuencia } \\
\text { relativa }\end{array}$ & $\begin{array}{c}\% \\
\text { Aparición }\end{array}$ & $\begin{array}{c}\text { Frecuencia } \\
\text { acumulada }\end{array}$ \\
\hline 29 & futbolista & 0,10724 & $0,987 \%$ & $22,599 \%$ & $38,742 \%$ \\
\hline 119 & científico & 0,01980 & $0,197 \%$ & $4,520 \%$ & $75,990 \%$ \\
\hline 143 & relaciones públicas & 0,01545 & $0,148 \%$ & $3,390 \%$ & $79,901 \%$ \\
\hline 147 & tenista & 0,01521 & $0,185 \%$ & $4,237 \%$ & $80,542 \%$ \\
\hline 173 & jugador de fútbol & 0,01101 & $0,111 \%$ & $2,542 \%$ & $83,946 \%$ \\
\hline 186 & barman & 0,00959 & $0,136 \%$ & $3,107 \%$ & $85,205 \%$ \\
\hline 249 & detective ${ }^{41}$ & 0,00566 & $0,074 \%$ & $1,695 \%$ & $89,631 \%$ \\
\hline 268 & disc-jockey & 0,00528 & $0,062 \%$ & $1,412 \%$ & $90,593 \%$ \\
\hline 279 & golfista & 0,00497 & $0,074 \%$ & $1,695 \%$ & $91,235 \%$ \\
\hline
\end{tabular}

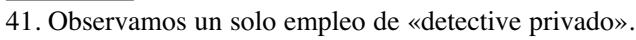




\begin{tabular}{|l|l|c|c|c|c|}
\hline $\mathbf{N}^{\mathbf{0}}$ & \multicolumn{1}{|c|}{ Palabra } & $\begin{array}{c}\text { Disponi- } \\
\text { bilidad }\end{array}$ & $\begin{array}{c}\text { Frecuencia } \\
\text { relativa }\end{array}$ & $\begin{array}{c}\% \\
\text { Aparición }\end{array}$ & $\begin{array}{c}\text { Frecuencia } \\
\text { acumulada }\end{array}$ \\
\hline 296 & mánager & 0,00454 & $0,062 \%$ & $1,412 \%$ & $92,025 \%$ \\
\hline 377 & turismo & 0,00263 & $0,012 \%$ & $0,282 \%$ & $94,649 \%$ \\
\hline 468 & conductor de trolebús & 0,00184 & $0,012 \%$ & $0,282 \%$ & $96,419 \%$ \\
\hline 480 & boxeador & 0,00171 & $0,037 \%$ & $0,847 \%$ & $96,666 \%$ \\
\hline 482 & gánster & 0,00171 & $0,012 \%$ & $0,282 \%$ & $96,690 \%$ \\
\hline 567 & bróker ${ }^{42}$ & 0,00128 & $0,012 \%$ & $0,282 \%$ & $97,866 \%$ \\
\hline 573 & showman & 0,00121 & $0,025 \%$ & $0,565 \%$ & $97,964 \%$ \\
\hline 576 & jugador de béisbol & 0,00119 & $0,012 \%$ & $0,282 \%$ & $98,013 \%$ \\
\hline 648 & striptease & 0,00083 & $0,012 \%$ & $0,282 \%$ & $98,903 \%$ \\
\hline 652 & jugador de golf & 0,00083 & $0,012 \%$ & $0,282 \%$ & $98,951 \%$ \\
\hline 672 & baby-sitter & 0,00067 & $0,012 \%$ & $0,282 \%$ & $99,191 \%$ \\
\hline 709 & jugador de básquet & 0,00047 & $0,012 \%$ & $0,282 \%$ & $99,635 \%$ \\
\hline 718 & linier ${ }^{43}$ & 0,00044 & $0,012 \%$ & $0,282 \%$ & $99,743 \%$ \\
\hline
\end{tabular}

17. Los colores

\begin{tabular}{|l|l|c|c|c|c|}
\hline $\mathbf{N}^{\mathbf{0}}$ & \multicolumn{1}{|c|}{ Palabra } & $\begin{array}{c}\text { Disponi- } \\
\text { bilidad }\end{array}$ & $\begin{array}{c}\text { Frecuencia } \\
\text { relativa }\end{array}$ & $\begin{array}{c}\% \\
\text { Aparición }\end{array}$ & $\begin{array}{c}\text { Frecuencia } \\
\text { acumulada }\end{array}$ \\
\hline 76 & cian $^{44}$ & 0,01566 & $0,128 \%$ & $2,542 \%$ & $89,948 \%$ \\
\hline 183 & camel & 0,00328 & $0,028 \%$ & $0,565 \%$ & $97,165 \%$ \\
\hline 283 & rojo láser & 0,00149 & $0,014 \%$ & $0,282 \%$ & $99,028 \%$ \\
\hline
\end{tabular}

42. Aparece también «broker de bolsa» con un solo empleo.

43. Este vocablo tiene un origen dudoso. Lo admite como anglicismo el DRAE y Lorenzo (1996: 65 y 274); no así Pratt (1980). Hay quien dice que viene del francés.

44. Cian aparece también en «azul cian» con un solo empleo. 


\section{ANEXO II. ANGLICISMOS PROBLEMÁTICOS}

En este apartado recogemos los vocablos problemáticos. Aquellos que algunos estudiosos los incluyen como anglicismos y otros no. La Academia no los menciona como tales.

\section{La ropa}

\begin{tabular}{|l|l|c|c|c|c|}
\hline $\mathbf{N}^{\mathbf{0}}$ & \multicolumn{1}{|c|}{ Palabra } & $\begin{array}{c}\text { Disponi- } \\
\text { bilidad }\end{array}$ & $\begin{array}{c}\text { Frecuencia } \\
\text { relativa }\end{array}$ & $\begin{array}{c}\% \\
\text { Aparición }\end{array}$ & $\begin{array}{c}\text { Frecuencia } \\
\text { acumulada }\end{array}$ \\
\hline 91 & parka & 0,01390 & $0,148 \%$ & $3,390 \%$ & $92,662 \%$ \\
\hline 99 & frac & 0,01139 & $0,124 \%$ & $2,825 \%$ & $93,813 \%$ \\
\hline 238 & niqui & 0,00123 & $0,012 \%$ & $0,282 \%$ & $99,034 \%$ \\
\hline 294 & kimono & 0,00074 & $0,012 \%$ & $0,282 \%$ & $99,745 \%$ \\
\hline
\end{tabular}

03. Partes de la casa

\begin{tabular}{|c|c|c|c|c|c|}
\hline $\mathbf{N}^{\mathbf{0}}$ & Palabra & $\begin{array}{c}\text { Disponi- } \\
\text { bilidad }\end{array}$ & $\begin{array}{c}\text { Frecuencia } \\
\text { relativa }\end{array}$ & $\begin{array}{c}\% \\
\text { Aparición }\end{array}$ & $\begin{array}{c}\text { Frecuencia } \\
\text { acumulada }\end{array}$ \\
\hline 276 & sala de televisión & 0,00086 & $0,017 \%$ & $0,282 \%$ & $99,499 \%$ \\
\hline
\end{tabular}

04. Los muebles de la casa

\begin{tabular}{|l|l|c|c|c|c|}
\hline $\mathbf{N}^{\mathbf{0}}$ & \multicolumn{1}{|c|}{ Palabra } & $\begin{array}{c}\text { Disponi- } \\
\text { bilidad }\end{array}$ & $\begin{array}{c}\text { Frecuencia } \\
\text { relativa }\end{array}$ & $\begin{array}{c}\% \\
\text { Aparición }\end{array}$ & $\begin{array}{c}\text { Frecuencia } \\
\text { acumulada }\end{array}$ \\
\hline 69 & televisor $^{45}$ & 0,01789 & $0,253 \%$ & $3,672 \%$ & $86,754 \%$ \\
\hline
\end{tabular}

\section{Comidas y bebidas}

\begin{tabular}{|l|l|c|c|c|c|}
\hline $\mathbf{N}^{\mathbf{0}}$ & \multicolumn{1}{|c|}{ Palabra } & $\begin{array}{c}\text { Disponi- } \\
\text { bilidad }\end{array}$ & $\begin{array}{c}\text { Frecuencia } \\
\text { relativa }\end{array}$ & $\begin{array}{c}\% \\
\text { Aparición }\end{array}$ & $\begin{array}{c}\text { Frecuencia } \\
\text { acumulada }\end{array}$ \\
\hline 241 & soda & 0,00700 & $0,043 \%$ & $1,130 \%$ & $92,979 \%$ \\
\hline 231 & bíter $^{46}$ & 0,00749 & $0,043 \%$ & $1,130 \%$ & $92,436 \%$ \\
\hline 543 & soja & 0,00089 & $0,011 \%$ & $0,282 \%$ & $99,372 \%$ \\
\hline
\end{tabular}

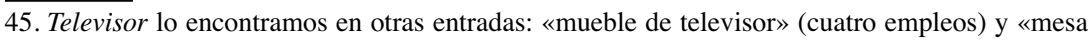
de televisor» (un solo empleo).

46. Bíter va modificada por «sin alcohol» $\mathrm{y} « \mathrm{kas} * »$ con un uso cada una. 
07. La cocina y sus utensilios

\begin{tabular}{|c|l|c|c|c|c|}
\hline $\mathbf{N}^{\mathbf{0}}$ & \multicolumn{1}{|c|}{ Palabra } & $\begin{array}{c}\text { Disponi- } \\
\text { bilidad }\end{array}$ & $\begin{array}{c}\text { Frecuencia } \\
\text { relativa }\end{array}$ & $\begin{array}{c}\% \\
\text { Aparición }\end{array}$ & $\begin{array}{c}\text { Frecuencia } \\
\text { acumulada }\end{array}$ \\
\hline 133 & detergente & 0,00907 & $0,151 \%$ & $2,825 \%$ & $88,545 \%$ \\
\hline 170 & refrigerador & 0,00582 & $0,045 \%$ & $0,847 \%$ & $91,693 \%$ \\
\hline
\end{tabular}

08. La escuela (muebles y materiales)

\begin{tabular}{|c|c|c|c|c|c|}
\hline $\mathbf{N}^{\mathbf{0}}$ & Palabra & $\begin{array}{c}\text { Disponi- } \\
\text { bilidad }\end{array}$ & $\begin{array}{c}\text { Frecuencia } \\
\text { relativa }\end{array}$ & $\begin{array}{c}\% \\
\text { Aparición }\end{array}$ & $\begin{array}{c}\text { Frecuencia } \\
\text { acumulada }\end{array}$ \\
\hline 113 & (pluma) estilográfica & 0,01246 & $0,095 \%$ & $2,260 \%$ & $85,893 \%$ \\
\hline
\end{tabular}

09. Calefacción, iluminación y medios para airear un recinto

\begin{tabular}{|l|l|c|c|c|c|}
\hline $\mathbf{N}^{\mathbf{0}}$ & \multicolumn{1}{|c|}{ Palabra } & $\begin{array}{c}\text { Disponi- } \\
\text { bilidad }\end{array}$ & $\begin{array}{c}\text { Frecuencia } \\
\text { relativa }\end{array}$ & $\begin{array}{c}\% \\
\text { Aparición }\end{array}$ & $\begin{array}{c}\text { Frecuencia } \\
\text { acumulada }\end{array}$ \\
\hline 71 & refrigerador & 0,01211 & $0,150 \%$ & $1,977 \%$ & $83,025 \%$ \\
\hline 168 & batería & 0,00366 & $0,064 \%$ & $0,847 \%$ & $91,759 \%$ \\
\hline
\end{tabular}

10. La ciudad

\begin{tabular}{|l|l|c|c|c|c|}
\hline $\mathbf{N}^{\mathbf{0}}$ & \multicolumn{1}{|c|}{ Palabra } & $\begin{array}{c}\text { Disponi- } \\
\text { bilidad }\end{array}$ & $\begin{array}{c}\text { Frecuencia } \\
\text { relativa }\end{array}$ & $\begin{array}{c}\% \\
\text { Aparición }\end{array}$ & $\begin{array}{c}\text { Frecuencia } \\
\text { acumulada }\end{array}$ \\
\hline 279 & dúplex & 0,00490 & $0,034 \%$ & $0,847 \%$ & $89,535 \%$ \\
\hline 64 & cafetería & 0,04807 & $0,354 \%$ & $8,757 \%$ & $65,629 \%$ \\
\hline 219 & limusina & 0,00730 & $0,046 \%$ & $1,130 \%$ & $86,814 \%$ \\
\hline 247 & autocar & 0,00605 & $0,034 \%$ & $0,847 \%$ & $88,233 \%$ \\
\hline 730 & televisión & 0,00131 & $0,011 \%$ & $0,282 \%$ & $97,352 \%$ \\
\hline
\end{tabular}

12. Medios de transporte

\begin{tabular}{|l|l|c|c|c|c|}
\hline $\mathbf{N}^{\mathbf{0}}$ & \multicolumn{1}{|c|}{ Palabra } & $\begin{array}{c}\text { Disponi- } \\
\text { bilidad }\end{array}$ & $\begin{array}{c}\text { Frecuencia } \\
\text { relativa }\end{array}$ & $\begin{array}{c}\% \\
\text { Aparición }\end{array}$ & $\begin{array}{c}\text { Frecuencia } \\
\text { acumulada }\end{array}$ \\
\hline 24 & tractor & 0,11461 & $1,216 \%$ & $23,446 \%$ & $66,496 \%$ \\
\hline 33 & minibús & 0,05769 & $0,571 \%$ & $11,017 \%$ & $75,138 \%$ \\
\hline 41 & limusina & 0,03849 & $0,381 \%$ & $7,345 \%$ & $79,356 \%$ \\
\hline 42 & esquí & 0,03463 & $0,498 \%$ & $9,605 \%$ & $79,854 \%$ \\
\hline 48 & caravana & 0,02927 & $0,322 \%$ & $6,215 \%$ & $82,432 \%$ \\
\hline
\end{tabular}




\begin{tabular}{|l|l|c|c|c|c|}
\hline $\mathbf{N}^{\mathbf{*}}$ & \multicolumn{1}{|c|}{ Palabra } & $\begin{array}{c}\text { Disponi- } \\
\text { bilidad }\end{array}$ & $\begin{array}{c}\text { Frecuencia } \\
\text { relativa }\end{array}$ & $\begin{array}{c}\text { \% } \\
\text { Aparición }\end{array}$ & $\begin{array}{c}\text { Frecuencia } \\
\text { acumulada }\end{array}$ \\
\hline 62 & autocar & 0,01883 & $0,161 \%$ & $3,107 \%$ & $86,285 \%$ \\
\hline 64 & reactor & 0,01809 & $0,220 \%$ & $4,237 \%$ & $86,681 \%$ \\
\hline 77 & hidroavión & 0,01356 & $0,146 \%$ & $2,825 \%$ & $89,096 \%$ \\
\hline 84 & portaaviones & 0,01258 & $0,161 \%$ & $3,107 \%$ & $90,223 \%$ \\
\hline 95 & ultraligero & 0,00966 & $0,117 \%$ & $2,260 \%$ & $91,731 \%$ \\
\hline 136 & (auto)bús articulado & 0,00439 & $0,044 \%$ & $0,847 \%$ & $95,100 \%$ \\
\hline 198 & aeronave & 0,00244 & $0,044 \%$ & $0,847 \%$ & $97,430 \%$ \\
\hline 217 & rompehielos & 0,00206 & $0,029 \%$ & $0,565 \%$ & $97,913 \%$ \\
\hline
\end{tabular}

15. Juegos y distracciones

\begin{tabular}{|l|l|c|c|c|c|}
\hline $\mathbf{N}^{\mathbf{0}}$ & \multicolumn{1}{|c|}{ Palabra } & $\begin{array}{c}\text { Disponi- } \\
\text { bilidad }\end{array}$ & $\begin{array}{c}\text { Frecuencia } \\
\text { relativa }\end{array}$ & $\begin{array}{c}\% \\
\text { Aparición }\end{array}$ & $\begin{array}{c}\text { Frecuencia } \\
\text { acumulada }\end{array}$ \\
\hline 17 & tele(visión) $^{47}$ & 0,12519 & $1,074 \%$ & $20,904 \%$ & $31,089 \%$ \\
\hline
\end{tabular}

16. Profesiones y oficios

\begin{tabular}{|c|c|c|c|c|c|}
\hline $\mathbf{N}^{\mathbf{0}}$ & Palabra & $\begin{array}{c}\text { Disponi- } \\
\text { bilidad }\end{array}$ & $\begin{array}{c}\text { Frecuencia } \\
\text { relativa }\end{array}$ & $\begin{array}{c}\% \\
\text { Aparición }\end{array}$ & $\begin{array}{c}\text { Frecuencia } \\
\text { acumulada }\end{array}$ \\
\hline 285 & gogó & 0,00484 & $0,062 \%$ & $1,412 \%$ & $91,482 \%$ \\
\hline
\end{tabular}

47. Televisión también aparece en los sintagmas: «Ver tele(visión)» con 81 empleos y «mirar la tele(visión)» con 17 usos. 


\title{
RASGOS ENTONATIVOS DEL ESPAÑOL HABLADO EN VENEZUELA: EL ENUNCIADO DECLARATIVO
}

\author{
Bertha Chela-Flores \\ Universidad Simón Bolivar, Caracas
}

\section{INTRODUCCIÓN}

$\mathbf{E}$ L propósito de este trabajo es describir la configuración entonativa del enunciado declarativo del español hablado en Venezuela en tres de sus lectos: el patrón entonativo general no marcado, que corresponde en su configuración no solamente a hablantes de Venezuela, sino también a hablantes del Centro y Sur de América, México y España; el patrón entonativo marcado, característico de la segunda ciudad en importancia de Venezuela, Maracaibo, donde las variantes entonativas difieren de forma más notoria del patrón general del español hablado en el resto del país; y por último, el patrón entonativo marcado, característico de un grupo profesional específico: locutores venezolanos de noticias de radio y televisión.

Aunque en ambos contextos marcados los patrones entonativos se alejan del patrón general del español, proponemos que las configuraciones entonativas del dialecto de Maracaibo son aceptadas por la población como naturales y/o parte de la evolución normal de las lenguas naturales, mientras que las variantes entonativas en el habla de locutores de noticias de radio y televisión no se aceptan de igual manera. Se sugiere que en la formación de estos últimos se debe incluir el estudio y análisis de los patrones entonativos generales del español.

Para poder apreciar las diferencias entonativas de los enunciados declarativos en los tres lectos, el análisis da cuenta no sólo del comportamiento melódico del inicio y final de la frase entonativa como solía hacerse en descripciones tradicionales de la entonación del español (por ejemplo, Navarro, 1944; Delattre et al., 1962; Kvavik, 1974; Quilis, 1987), sino que se describen las variaciones tonales del tonema y pretonema que existen en el interior de la frase, como se ha sugerido en trabajos más recientes (por ejemplo, Chela Flores, 1994; B. Chela Flores y G. Chela Flores 1994; Chela-Flores y Sosa, 1999; Sosa, 1999). Dentro del concepto del núcleo o tonema incluimos todo el contorno terminal del grupo melódico, es decir, tanto el último acento tonal como los tonos de juntura. El pretonema, también llamado «cabeza» (head) del grupo melódico en los estudios entonativos de la tradición 
británica, lo constituye el conjunto de sílabas métricamente fuertes asociadas a acentos tonales que se encuentran antes del núcleo.

La representación fonética de los diferentes patrones entonacionales es la frecuencia fundamental (F0), que consideramos el resultado de las reglas de implementación fonética aplicada a las estructuras tonales subyacentes. Los valores numéricos de la frecuencia fundamental y los gráficos resultantes, de los cuales hemos extraído las unidades discretas entonacionales, han sido obtenidos por medio de un CSL (Computerized Speech Lab), de Kay Elemetrics, que representa la señal digitalizada en la pantalla de un monitor y de allí se analizan aquellas cualidades acústicas que caracterizan la curva entonacional.

\section{RASGOS ENTONATIVOS NO MARCADOS}

Los enunciados declarativos son los que expresan un hecho determinado o una aseveración. A estos se les atribuye, en el patrón general del español, una configuración melódica descendente con mayor o menor pendiente, como por ejemplo el de la Figura 1, que corresponde a un hablante masculino de Venezuela:

\section{FIGURA 1. Enunciado declarativo La marcha de anoche duraba tres horas}

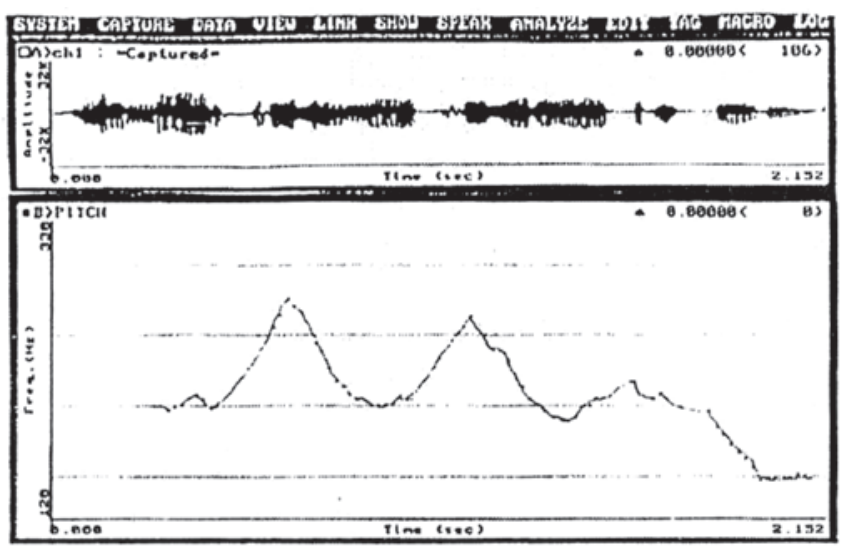

Como podemos observar, el descenso de la curva melódica no es suave y se realiza como en rebotes. Asimismo, las sílabas acentuadas tienen una configuración más baja, (como en las sílabas «mar» en marcha y «no» en anoche de

1. Por la poca claridad de la impresión y errores por ruido, el contorno entonativo original en todas las figuras que presentamos en este trabajo se han repasado a mano. 
la Figura 1), mientras que las postónicas tiene una posición más alta. Además se encontró que por regla general, el núcleo o tonema en el enunciado declarativo no marcado (por ejemplo, horas en la Figura 1), coincide con el punto más bajo de la curva entonativa y no con la cima o pico. Esta muestra de la Figura 1 responde en su configuración a cientos de enunciados analizados de conversaciones espontáneas grabadas de hablantes nativos de nuestro corpus y de muestras del Caribe, Centro y Sur América, México y España (ver por ejemplo, Sosa, 1999), donde se puede apreciar que el comportamiento melódico del fragmento prenuclear de la configuración en los enunciados no marcados demuestra una extraordinaria regularidad en el pretonema, lo cual hemos podido corroborar en las muestras de nuestro corpus.

\section{RASGOS ENTONATIVOS MARCADOS DEL HABLA DE MARACAIBO}

Las variantes entonativas marcadas del enunciado declarativo que presentamos en este trabajo (y reportadas previamente en Chela Flores, 1994; Chela Flores y Sosa, 1999) proceden de tres informantes masculinos que responden en su configuración a ciento once enunciados analizados de otros informantes. El corpus utilizado proviene de un material de estudios que consiste en grabaciones espontáneas de media hora de ochenta hablantes de Maracaibo clasificados según su nivel socio-económico y según la edad y el sexo (Chela Flores y Gelman, 1988). La configuración entonativa en estas muestras difiere del patrón general del español tanto en el pretonema como en el tonema. La Figura 2 es un ejemplo de estas muestras:

FIGURA 2. Enunciado declarativo No tienen buena presencia

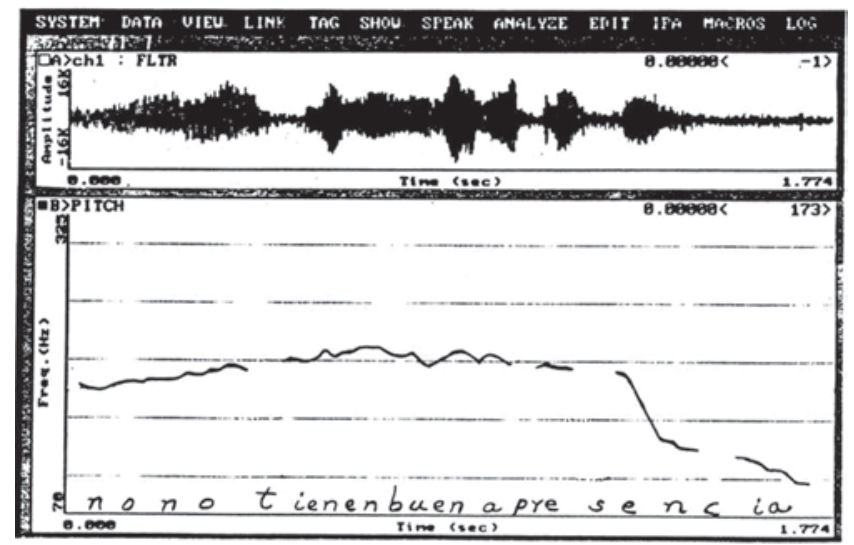


En este enunciado se puede observar claramente el comportamiento melódico marcado de esta configuración entonativa en la suspensión de la declinación y la falta de acción de escalonamiento descendente presente en el patrón general entonativo, ejemplificado en la Figura 1. Esta suspensión de la declinación puede ser mucho más marcada, como la que se muestra en la Figura 3 , donde el pretonema se mantiene casi a la misma altura hasta la última sílaba inacentuada anterior al núcleo:

\section{FIGURA 3. Enunciado declarativo Este mes saqué diecinueve}

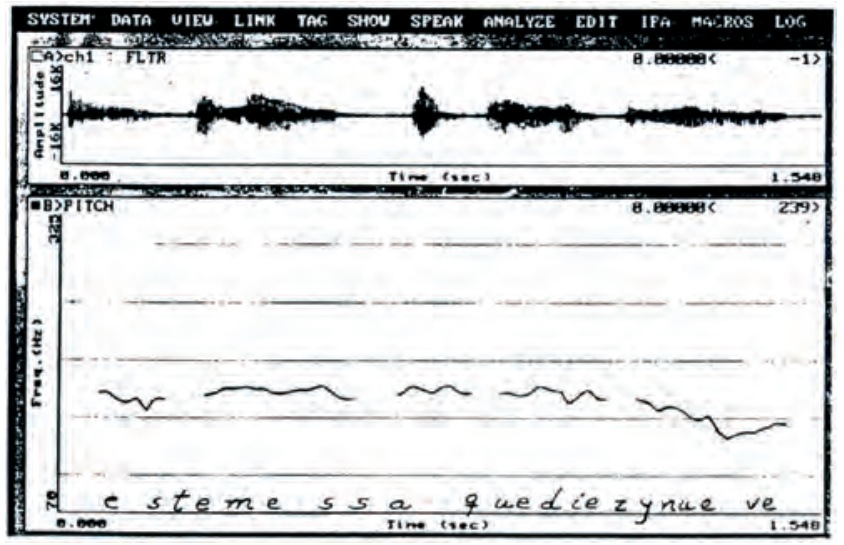

Lo notorio de las variantes entonativas de las Figuras 2 y 3 es la falta de variación melódica pretonemática en forma de subidas y descensos, característica de las configuraciones entonativas no marcadas en el enunciado declarativo del español general. Por otra parte, el movimiento desde la última vocal tónica hasta el final del fundamental suele ser lento en las configuraciones marcadas en el habla de Maracaibo, ya que la vocal tónica tiene un aumento considerable de duración: por ejemplo, el diptongo «ue» de la palabra nueve, en la última sílaba tónica de la configuración en la Figura 3 dura 0,1317 msegs., el promedio de los segmentos vocálicos en el pretonema es de 0,0551 msegs.

Otra variante de la configuración entonativa del enunciado declarativo en el habla de Maracaibo se manifiesta por un movimiento de ascenso-descenso en su parte final. Esta llamada entonación circunfleja se ha registrado en el habla de México, Puerto Rico y Madrid como una de las formas del enunciado declarativo con sentido completo (Quilis, 1987) y en el habla del Centro y Sur América por Sosa (1999). El ascenso y descenso que caracteriza el tonema en esta variante de la configuración entonativa se realiza en algunos casos a la misma altura de la cima en el inicio del grupo melódico, como podemos observar en la Figura 4: 
FIgURA 4. Enunciado declarativo No me queda tiempo

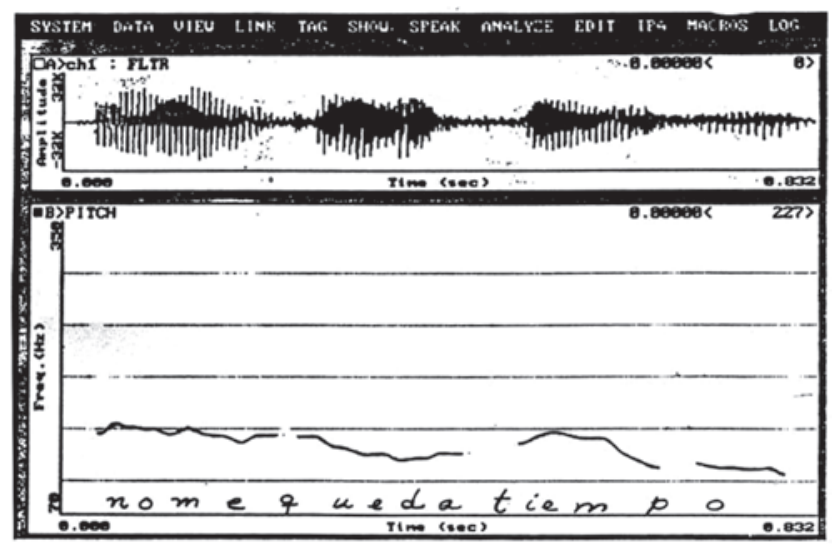

Lo que hace esta variante diferente a la entonación circunfleja en otros dialectos es, de nuevo, el movimiento lento de la inflexión por el aumento considerable de duración $(0,1004$ msegs $)$ del segmento vocálico en la última sílaba tónica «tiem» de la palabra tiempo.

La inflexión circunfleja puede ser mucho más pronunciada en este dialecto, como se muestra en la Figura 5, realizándose el ascenso-descenso a un nivel más alto que el movimiento del pretonema:

\section{FiguRa 5. Enunciado declarativo Parrita es prácticamente hermano mío}

SYSTEM DAT́ UIEU LINK TAG SHOU SPEAK AMAL.yZE EDIT IPA MACROS LOG

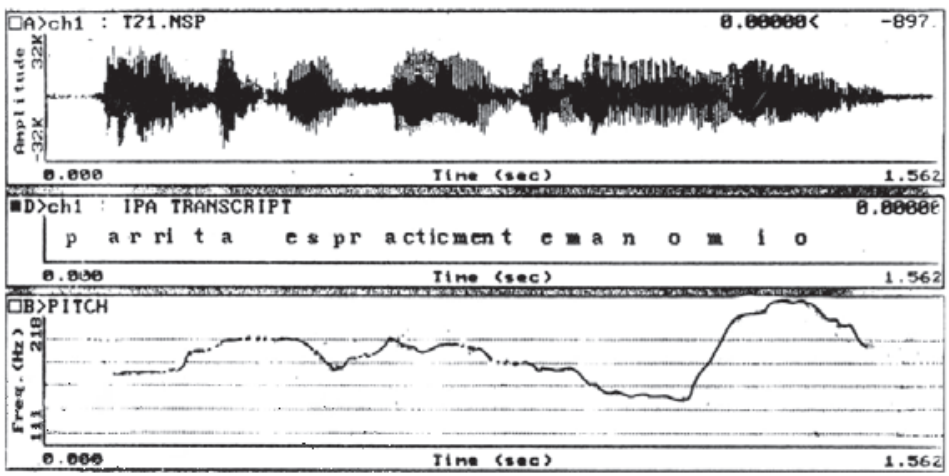

El ascenso en esta configuración es más pronunciado $(55 \mathrm{~Hz})$ y el fundamental termina con un movimiento descendente que alcanza un nivel más alto 
que el del cuerpo del grupo melódico. De nuevo, el movimiento de esta inflexión circunfleja es lento por el aumento considerable de duración de la sílaba tónica en la palabra mío, que abarca toda la inflexión. La duración de esta sílaba es de 0,1938 msegs. La variación melódica pretonemática en estos dos enunciados (Figura 4 y 5) se diferencia de las otras variaciones entonativas marcadas por el descenso que se produce en el pretonema antes del ascensodescenso en su parte final, acentuando la inflexión circunfleja. En el enunciado de la Figura 4, el ascenso desde el punto más bajo a la cima es de $22 \mathrm{~Hz}$, mientras que el ascenso en el enunciado de la Figura 5 alcanza $55 \mathrm{~Hz}$.

La variante entonativa de la Figura 5 también se puede presentar con un ascenso mantenido importante en el pretonema antes de la inflexión circunfleja del fonema, en vez de una declinación o suspensión de la declinación. La configuración en la Figura 6 es un ejemplo de esta variante:

\section{FIGURA 6. Enunciado declarativo Y el abuelo mío tenía real}

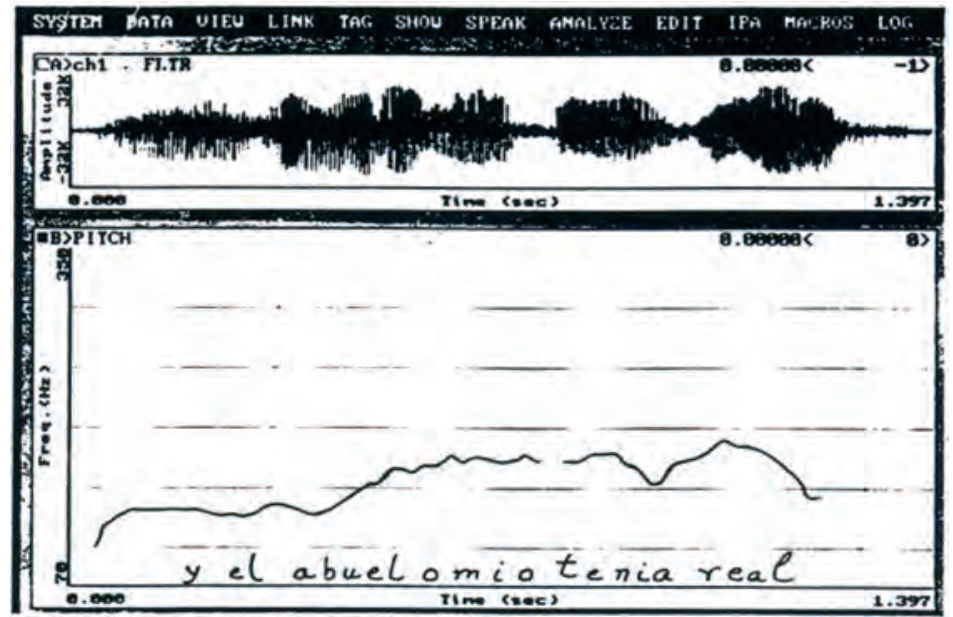

El ascenso en esta configuración se mantiene hasta el final del cuerpo y luego presenta un movimiento circunflejo del fundamental cuya cima se sitúa sobre el último segmento vocálico. El movimiento del fundamental de la primera sílaba tónica a su punto más alto es de $55 \mathrm{~Hz}$. El final se encuentra a una frecuencia más alta que la del resto del enunciado y el fundamental termina más alto que el nivel del cuerpo. De nuevo, el movimiento circunflejo final es lento por la duración del segmento vocálico en la palabra real, es decir, 0,0686 msegs. para la vocal «e» y 0,1685 msegs. para la vocal «a». 


\section{RASGOS ENTONATIVOS MARCADOS DEL HABLA DE LOCUTORES DE RADIO Y TELEVISIÓN}

Las variantes entonativas del enunciado declarativo, encontradas en algunos de los locutores de noticias de radio y televisión de nuestro corpus, difieren del patrón general del español descrito en la sección 2, tanto en el pretonema como en el núcleo o tonema. La configuración entonativa de la Figura 7, es un fragmento de un enunciado declarativo en una emisión informativa de un locutor venezolano de noticias de televisión:

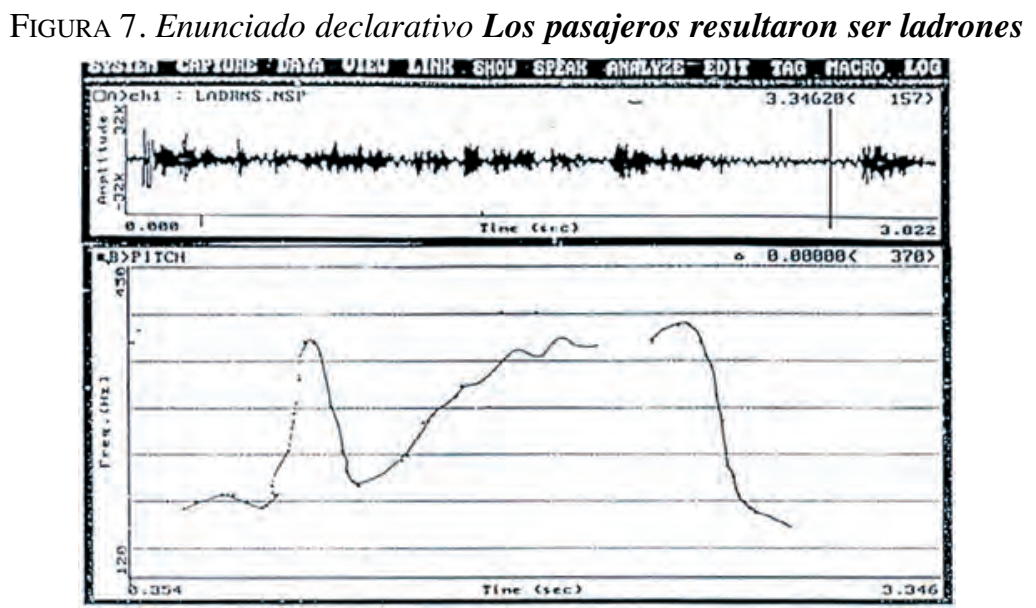

Como en las otras muestras discutidas anteriormente, esta configuración entonativa responde en su configuración a un gran número de enunciados analizados de locutores de radio y televisión de Venezuela: El pretonema se inicia con una acción de escalonamiento al principio de la frase con «Los pasajeros» pero, a diferencia de la configuración entonativa del patrón no marcado (Figura 1), se suspende la declinación en la siguiente parte de la frase «resultaron ser», y se mantiene el pretonema casi a la misma altura del primer pico vocálico; y aquí, en la última sílaba acentuada en la palabra «ser» hay una pausa anterior al núcleo o tonema.

En lo que respecta el tonema de la Figura 7, la palabra ladrones tiene el pico más alto de la configuración entonativa; por otra parte, la cima no se ubica en la sílaba acentuada «dro» del núcleo, sino en la sílaba anterior «la», a pesar de que la sílaba acentuada «dro» es de mayor duración, como podemos observar (Figura 8) en el análisis hecho de la duración de las sílabas de este primer fragmento: ${ }^{2}$

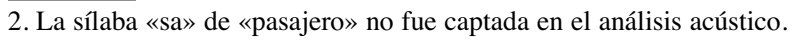




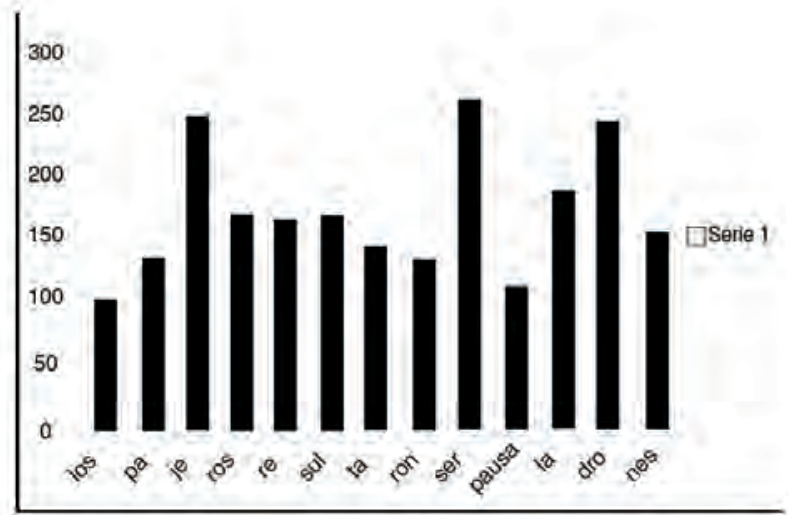

El patrón entonativo de la Figura 7 fue utilizado por el locutor en nuestro corpus, de forma recurrente, en las siguientes unidades entonativas (4.1) de la misma emisión informativa:

\subsection{Los pasajeros resultaron ser ladrones/ luego pensaban matarlos / más adelante chocaron...}

Al igual que en la configuración entonativa de la Figura 7, la cima tonal más alta en los dos últimos grupos entonativos de la emisión 4.1 fue colocada en la sílaba pretónica del tonema, en las palabras matarlos y chocaron respectivamente, como se muestra en las Figuras 9 y 10 :

FIGURA 9. Enunciado declarativo Luego pensaban matarlos

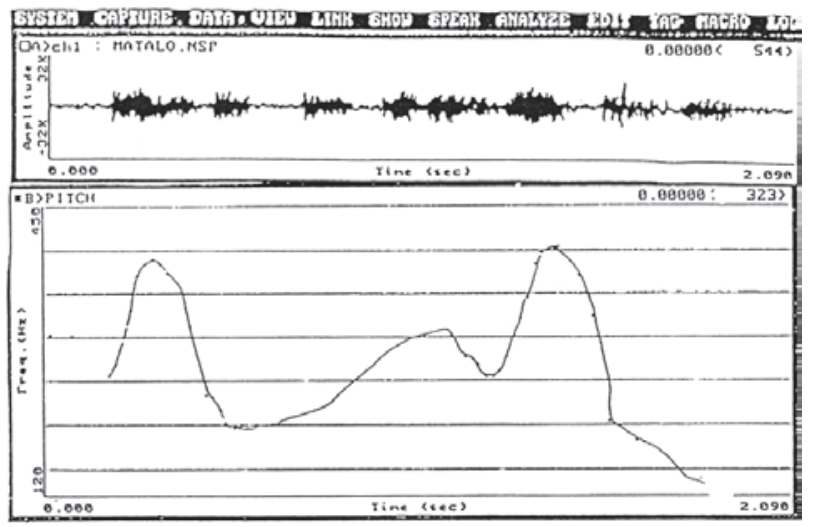


FIGURA 10. Enunciado declarativo Más adelante chocaron

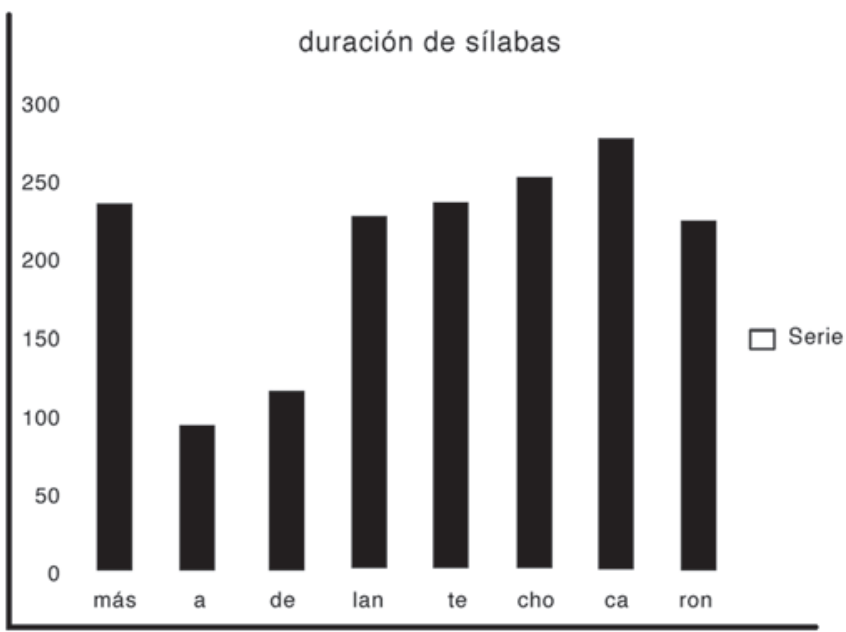

Y al igual que en la configuración entonativa de la Figura 7, las sílabas pretónicas en los dos últimos grupos entonativos de la emisión 4.1 es donde se coloca la cima más alta siendo éstas de menor duración que la tónica, como se muestra en las Figuras 11 y 12:

FIGURA 11. Duración de sílabas en ...luego pensaban matarlos...

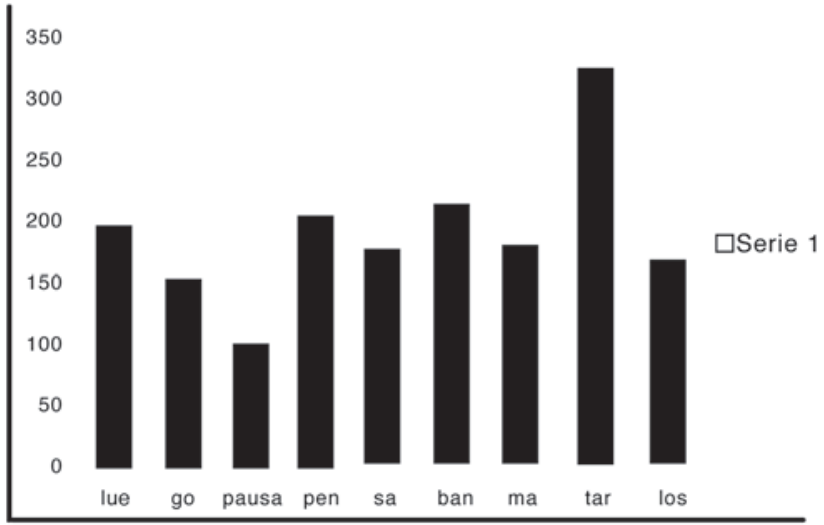




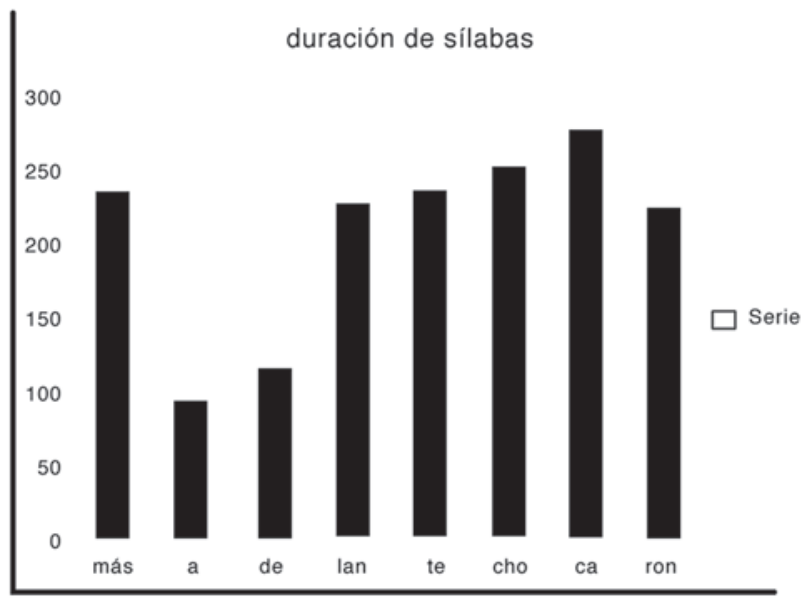

Otra irregularidad entonativa que presenta el primer grupo tonal del fragmento de emisión de noticia 4.1: «Los pasajeros resultaron ser ladrones», es darle a la palabra prenuclear «ser» la mayor duración, mayor aún que el núcleo (Figura 8), sin tener ésta la mayor importancia gramatical o semántica dentro del enunciado. Por la pausa que se ha colocado después del verbo «ser», el locutor ha hecho de este enunciado dos unidades entonativas: Los pasajeros resultaron ser / ladrones.

\section{CONSIDERACIONES FINALES}

Aunque realmente no hay criterios lingüísticos que den a una determinada manera de hablar más validez que a otra, hay ciertos cambios que la población percibe como naturales y/o parte de la evolución normal de las lenguas naturales, y hay otros cambios que no son aceptados de igual manera. Pensamos que las variantes fonético-fonológicas de un «geolecto», ${ }^{3}$ tal como las variantes entonativas del español hablado en Maracaibo y descritas en la sección (3), son aceptadas como naturales dentro del español hablado en Venezuela y en el mundo, por el hecho de que se considera natural que «toda lengua que se habla en puntos geográficos distintos siempre tiene más de un lecto» (Guitart, 2004: 5).

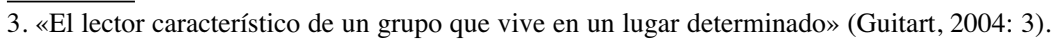


Sin embargo, aunque no se puede hablar de una norma mejor o peor en cuanto a pronunciación se refiere, hay ciertas situaciones comunicativas donde las variantes fonético-fonológicas, que se alejan del patrón general del idioma, no son aceptadas de igual manera por la población, como se aceptan las de un geolecto. Tal es el caso del lecto característico de locutores de noticias de radio y televisión. En un estudio experimental, Rodero (2001) comprobó que variantes de ritmo y segmentación del mensaje, que se alejan de los patrones generales no marcados del español en el habla de locutores radiofónicos se consideraba como un defecto bastante desagradable para el oyente.

Los rasgos entonativos marcados que hemos encontrado en el habla de locutores de noticias de radio y televisión venezolanos podrían ser producto de un deseo inconsciente del locutor de diferenciarse del público receptor de las noticias, de hacer su emisión no sólo más precisa en la pronunciación, sino también más resaltante y atractiva. Es importante indicar que estos rasgos marcados en la pronunciación los produce el locutor durante la emisión de noticias y no durante situaciones radiales o televisivas más espontáneas como las entrevistas; hemos constatado en nuestro corpus que en su rol de entrevistador el locutor mantiene los procesos articulatorios naturales, pero al pasar a la emisión de noticias, el mismo hablante presenta irregularidades segmentales, rítmicas, fonosintácticas y entonativas y hemos sugerido que estas diferencias podrían ser producto quizás de una mayor consciencia fonético-fonológica en situaciones menos espontáneas como la lectura de noticias (Chela Flores et al., 2002).

En la entrevista, hay una interacción inmediata entre el locutor y el entrevistado, y por ende hay un estímulo lingüístico y contextual que mantiene al hablante, (en la mayoría de los casos, inconscientemente) dentro de los patrones normales del español, es decir, prevalecen los procesos articulatorios naturales del habla. En la emisión de noticias, los locutores generalmente están más concentrados en la forma en que se dice algo y no en su contenido, sobre todo porque se lee un mensaje prefabricado. Cuando se está más concentrado en la forma en que se dice algo, se comienza a analizar la pronunciación, es decir, a cuestionarse si la articulación de los sonidos es la correcta y/o a esmerarse por una «buena» pronunciación, sin tener realmente claras sus implicaciones. Si el locutor de noticias no tiene acceso consciente a los patrones normales del español, podría no tener tampoco la capacidad de manejar estos aspectos de una manera aceptable en el momento en que intentan hacer su emisión más atractiva; podría llegar a crear un código propio, inaceptable dentro del español estándar.

Se ha dicho (Bialystok, 1982) que aunque el conocimiento adquirido en forma no analítica es estructurado (por ejemplo, la adquisición del sistema fonológico de nuestro idioma nativo) las representaciones mentales de ese conocimiento no incluyen el acceso a esas estructuras, y por consiguiente no 
estamos en capacidad de hacer transformaciones y operaciones con ese conocimiento. Si el locutor de noticias no tiene acceso consciente a los fenómenos fonológicos estructurados del español, los cuales utiliza en situaciones comunicativas cotidianas, no tendrá tampoco la capacidad de transformar estos aspectos de una manera aceptable al crear un código propio para hacer su emisión radial o televisiva más atractiva.

La emisión 4.1 descrita en la sección (4) puede hacerse más precisa, resaltante y atractiva para el público manteniendo los rasgos entonativos básicos del patrón general del español. El primer fragmento de esta emisión fue leído por dos fonetistas, a los que se les pidió que pusieran el mayor énfasis posible para hacer destacar el mensaje. Se les explicó que lo tenían que leer como si estuvieran dando la noticia por televisión. Las Figuras 13 y 14 corresponden a la lectura de esta frase por un fonetista masculino y otro femenino respectivamente:

FIGURA 13. Enunciado Los pasajeros resultaron ser ladrones leído por un fonetista masculino

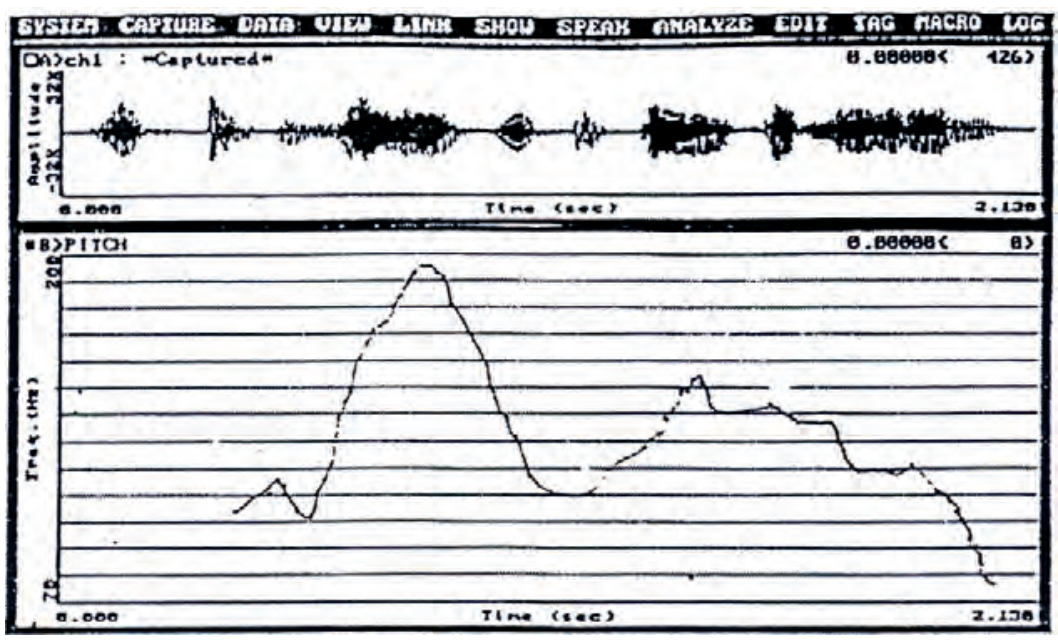


FIGURA 14. Enunciado Los pasajeros resultaron ser ladrones leído por un fonetista femenino

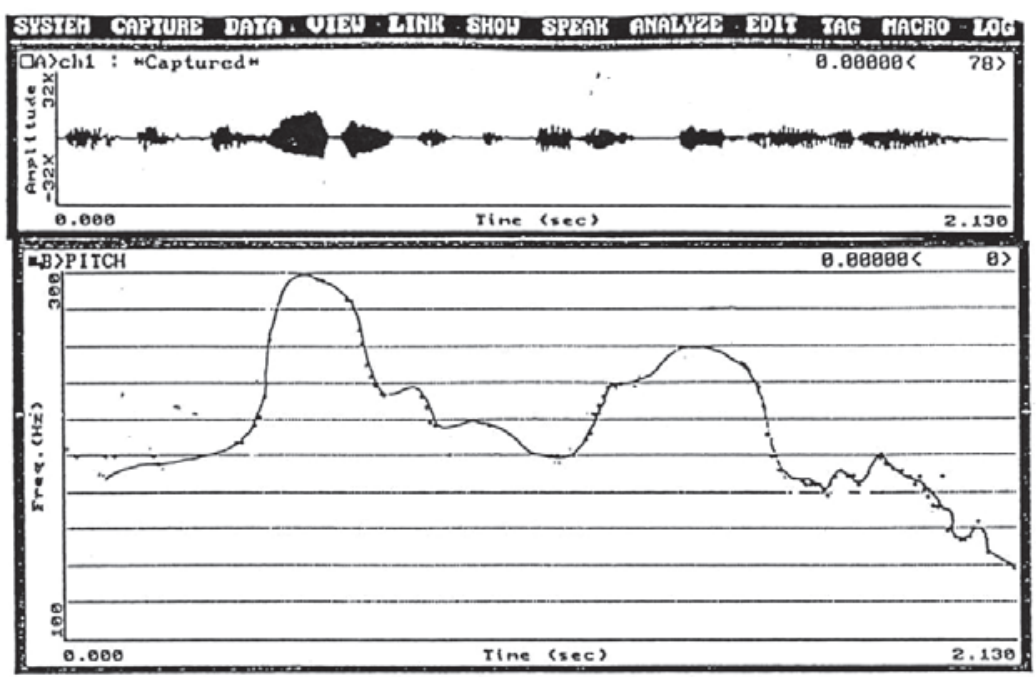

Como podemos observar, en ambas lecturas del enunciado declarativo Los pasajeros resultaron ser ladrones, los fonetistas mantienen los rasgos entonativos básicos del patrón normal del español, reflejados en la Figura 1: un escalonamiento descendente donde la palabra de mayor prominencia «ladrones» coincide con el punto más bajo de la curva entonativa y no con la cima o pico, como fue producido por el locutor en nuestra muestra (Figura 7). El enunciado en cuestión se hizo más resaltante, tanto en el caso del fonetista masculino como en el femenino, por medio de un registro más alto del patrón básico no marcado. Especialistas en la materia han analizado y descrito el comportamiento melódico del habla emocional, o de exclamación en el español y lo han caracterizado como un registro más alto de la configuración entonativa no marcada del enunciado declarativo, con un mayor ascenso y descenso del escalonamiento de la configuración, es decir, con picos más elevados, registros más altos y escalonamientos descendentes más marcados (Sosa, 1999). Si en la formación del locutor de radio y televisión se introduce el estudio y análisis de los patrones entonativos del español, tanto el comportamiento melódico del inicio y final de la frase entonativa como las variaciones tonales que existen en el interior de la frase, hay más probabilidades que las variaciones que se lleven a cabo para hacer las emisiones más atractivas, se hagan dentro de los procesos naturales de la lengua. 


\section{REFERENCIAS BIBLIOGRÁFICAS}

BialystoK, E. (1982): «On the relationship between knowing and using linguistic forms», Applied Linguistics, 3, 3: 181-206.

Chela Flores, B. (1994): «Entonación dialectal del enunciado declarativo de una región de Venezuela», Lexis, 18, 1: 55-68.

Chela Flores, B. y G. Chela flores (1994): Hacia un estudio fonetológico del español hablado en Venezuela, Caracas, Fondo Editorial Tropykos.

Chela Flores, B., G. Chela flores e I. Palencia (2002): Habla Pública: de lo pragmático a lo fónico, Caracas, Fondo Editorial Tropykos.

Chela Flores, B. y J. Gelman (1988): El Habla de Maracaibo: Materiales para su estudio, Maracaibo, CONDES, Universidad del Zulia.

Chela Flores, B. y J. M. Sosa (1999): «La representación subyacente de la entonación dialectal del "maracucho"», Oralia, 2: 71-81.

Delattre, P., C. Olsen y E. Poenack (1962): «A comparative study of declarative intonation in American English and Spanish», Hispania, XLV: 233-241.

GuITART, J. (2004): Sonido y sentido: Teoría y práctica de la pronunciación del español contemporáneo, Washington D.C., Georgetown University Press.

KVAVIK, K. (1974): «An analysis of sentence initial and final intonation data in two Spanish dialects», Journal of Phonetics, 2: 181-191.

NAVArRo Tomás, T. (1944): Manual de entonación española, Nueva York, Hispanic Institute on the United States.

Quilis, A. (1987): «Entonación dialectal hispánica», Actas del I Congreso Internacional sobre el Español de América, en LóPEZ MORALES, H. y M. Vaquero (eds.) (1987): San Juan Puerto Rico, Academia Puertorriqueña de la Lengua Española, 117-164.

Rodero Anton, E. (2001): «Los principales errores que debe evitar todo locutor de informativos radiofónicos: un estudio práctico», Reinventar la Radio, Actas de las XV Jornadas Internacionales de Comunicación, Pamplona, 29-34.

SosA, J. M. (1999): La entonación del español, Madrid, Cátedra. 


\title{
EL CANVI LINGÜÍSTIC SEGONS POMPEU FABRA (1891-1948)
}

\author{
Joan Costa I CARreras \\ Universitat Pompeu Fabra
}

\section{INTRODUCCIÓ}

$\mathbf{L}$ A informació que presentem s'ha extret de la nostra tesi doctoral (Costa, 2006). Atès que Fabra no va deixar cap obra general de reflexió sobre la sintaxi, el canvi, la variació i la codificació, l'objectiu principal de la nostra tesi va ser buidar la terminologia de Fabra relativa a aquests aspectes, amb la intenció de reconstruir a partir d'aquest buidatge les seves concepcions. La hipòtesi subjacent és que per establir la normativa sintàctica, Fabra havia de tenir una concepció d'aquests quatre aspectes. El buidatge es va fer en tot els textos que va escriure $\mathrm{i}$ en aquell moment eren accessibles des del diccionari (1932) fins als cursos universitaris (1933-1936) que es conserven mecanografiats, passant per les cartes que se'n conserven.

El que presentem, doncs, en aquesta comunicació són els principals resultats d'aquesta recerca pel que fa a la concepció fabriana del canvi sintàctic. ${ }^{1}$ Tal com ja hem dit, ens vam valer de la classificació de la interferència establerta per Payrató (1985) -que vam modificar arran del nostre buidatge-i dels factors que Labov (1983) estableix com a determinants en la seva teoria del canvi lingüístic.

\section{L'APARAT TEÒRIC UTILITZAT PER BUIDAR LA TERMINOLOGIA}

\subsection{La classificació de la interferència adoptada per Payrató $(\mathbf{1 9 8 5})^{2}$}

Payrató (1985: 58) defineix la interferència en sentit ampli com segueix: «canvi lingüístic (= una innovació, una pèrdua, una substitució) que té lloc en una llengua $\mathrm{A}$ (o registre), i que és motivat directament per una llengua $\mathrm{B}$ (o d'un altre registre de la mateixa llengua $[\ldots]) »$.

1. Qui estigui interessat a ampliar la informació, pot consultar el capítol 3 i l'epígraf 9.3 de Costa, 2006.

2. Per veure la discussió en detall, es pot consultar Costa (2006: § 3.1) 
A les pàg. 77-79 en fa la presentació següent i a les pàg. 90-91 dóna exemples de cada cas d'interferència gramatical en català:

a) Subestimació d'una distinció (o sots-diferenciació, o hipodiferenciació)

b) Sobreestimació d'una distinció (o sobrediferenciació, o hiperdiferenciació)

c) Reinterpretació d'una distinció

d) Substitució

e) Importació

f) Pèrdua

Atès que no sempre va ser fàcil decidir en quin tipus classificàvem un canvi, vam triar el tipus que explica d'una manera més general cada canvi analitzat. No és fàcil perquè aquests tipus, tal com els presenta Payrató, només fan referència a una de les variants en concurrència en el procés general de canvi lingüístic, mentre que el procés comporta gairebé sempre més d'un tipus concret de canvi, que s'esdevenen, l'un en la variant en procés de substitució i l'altre en la variant diguem-ne emergent. (I encara, de vegades, la nova situació respon a un altre dels tipus de Payrató.)

D'aquestes observacions, doncs, es desprèn que la tipologia de Payrató forneix una base per a la descripció del canvi sintàctic, sempre que es tingui en compte que el canvi és un procés de substitució, amb dues variants -de vegades, més- en concurrència, i que quasi sempre aquest procés és fruit de la interacció de més d'un dels tipus payratonians.

A banda d'aquests sis tipus de canvi, Fabra parla d'un altre cas de canvi sintàctic: el que vam anomenar «addició». No és previst en la tipologia de Payrató, ja que ell presenta únicament tipus d'interferència interlingüística; l'addició que descobrim en Fabra, en canvi, és en general un fenomen endogen, consistent a crear noves unitats a partir d'unitats ja existents. Classifiquem com a tals els canvis següents:

- El sorgiment de la forma «híbrida» an: a la «Conversa filològica» del $13 / 3 / 1923$ (§ 9.3.2.15).

- el quin, format sobre el qual: a la «Conversa filològica» del 25/1/1923 (§ 9.3.2.15).

- Creació del conjunt els hi amb valor datiu: a la «Conversa filològica» del 29/9/1923 (\$ 9.3.2.15).

- Formació del conjunt el què, a partir de el que i què: a la «Conversa filològica» del 1/4/1925 (§ 9.3.2.18).

\subsection{La teoria del canvi lingüístic de Labov (1983)}

Labov forneix una teoria general del canvi que l'analitza com un procés en el qual cal descriure les fases i els aspectes següents: l'origen del canvi, els factors interns (propis de l'estructura lingüística) i externs (fenòmens socials, 
polítics o econòmics) que hi influeixen, les resistències al canvi, la fase d'alternança en el procés de canvi, la direcció del canvi i les conseqüències que té en l'estructura i en l'ús de la llengua.

Per a la nostra anàlisi, ens va ser especialment útil la distinció laboviana entre el canvi «des de dalt» (introduït conscientment per les classes altes) i el canvi «des de baix» (introduït inconscientment per les classes baixes), pel que fa a l'origen del canvi. Pel que fa a la distinció entre factors interns i externs, ens va caldre establir una categoria intermèdia: la dels factors que vam tipificar com a «externs i psicolingüístics». En serien exemples la lectura habitual en castellà, la lectura habitual dels diaris catalans, les traduccions mecàniques, el bilingüisme, la descastellanització i la llengua escrita general. Són pràctiques dels catalanoparlants que tenen una vessant externa, ja que tenen a veure amb tendències socials i actuacions polítiques; però aquestes tendències i actuacions tenen unes conseqüències psicolingüístiques en els parlants: la lectura habitual en castellà, la lectura habitual dels diaris catalans molt castellanitzats, les traduccions mecàniques plenes de calcs, el bilingüisme i la llengua escrita general molt castellanitzada reforcen les interferències en la competència i l'actuació dels parlants; la descastellanització, en canvi, introdueix alternatives a les formes denunciades com a interferències, amb la consegüent fase d'inseguretat lingüística.

\section{LES PRINCIPALS CONCEPCIONS DE POMPEU FABRA SOBRE EL CANVI LINGÜÍSTIC}

Hem exposat les bases teòriques que vam fer servir per buidar la terminologia sobre el canvi, bases que arran del buidatge vam haver d'adaptar: la tipologia payratoniana amb el procés d' «addició» i la teoria laboviana amb els factors «externs i psicolingüístics».

\subsection{La concepció fabriana de la sintaxi}

Per buscar la concepció fabriana del canvi sintàctic, primer vam establir la concepció que tenia de la sintaxi. Quin és l'àmbit del canvi sintàctic segons Fabra? Al § 2.4.2 de Costa, 2006, vam arribar a la conclusió següent sobre la concepció fabriana de la sintaxi:

Fabra defineix explícitament la sintaxi com l'àmbit de les funcions i les relacions dels (grups de) mots dins la frase. El terme relacions n'inclou tres més, el lligam, l'ordre i l'estructura, també bàsics pel lingüista de Gràcia. I aquests tres termes, el Mestre sovint els vehicula amb la unitat construcció -definida 
al D[iccionari] G[eneral de la] L[lengua] C[atalana] com l'«arranjament sintàctic»-, el terme que més utilitza.

Per tant, el que presentem és l'anàlisi de les unitats de significació especialitzades que tenen a veure amb la transformació de les funcions i de les relacions -de lligam, d'ordre i d'estructura- dels (grups de) mots dins la frase.

\subsection{La classificació de 102 casos de canvi sintàctic}

Tal com ja hem dit un dels principals resultats obtinguts en la nostra tesi (Costa, 2006: § 3.4.2.1), és la classificació segons la tipologia del canvi adoptada dels 102 casos de canvi sintàctic que hem considerat que Fabra tractava. Atès l'espai de què disposem, oferim un parell d'exemples de cada tipus. El detall és el següent:

\begin{tabular}{|l|l|}
\hline Sobreestimació d'una distinció & 40 \\
\hline Substitució & 17 \\
\hline Subestimació & 14 \\
\hline Importació & 13 \\
\hline Pèrdua & 11 \\
\hline Addició d'una forma & 4 \\
\hline Reinterpretació d'una distinció & 3 \\
\hline Total & $\mathbf{1 0 2}$ \\
\hline
\end{tabular}

Els exemples de cada tipus són els següents: ${ }^{3}$

a) Casos que classifiquem com a casos de sobreestimació:

- L'ús prepositiu de baix: al text «L'obra de depuració de la llengua catalana», de 1924 (§ 9.3.1.1.9) i la «Conversa filològica» del 30/11/1919 (§ 9.3.2.12).

- L'adquisició pels mots com mai de la modalitat negativa: a «L'obra de depuració de la llengua catalana», de 1924 (§ 9.3.1.1.9) i la «Conversa filològica» del 14/12/1919 (\$ 9.3.2.12).

b) Casos que classifiquem com a casos de substitució:

— L’ús de davant de per davant: text del 28/1/1920 (§ 9.3.2.13).

$\overline{3 .}$ Donem les referències d'un text de cada tipus (pertinent i discrecionalment pertinent). 
- L'ús causal pel temporal de la locució tota vegada que: a «L'obra de depuració de la llengua catalana», de 1924 (§ 9.3.1.1.9), i a la «Conversa filològica» del 5/2/1920 (§ 9.3.2.13).

c) Casos que classifiquem com a casos de subestimació:

- L'eliminació de la preposició per a: 21/1/1920 (§ 9.3.2.13).

- La pèrdua de la preposició en per designar el terme d'un moviment: al Recull de les lliçons del curs de català superior, de 1933-1934 (§ 9.3. 1.1.13) i a la «Conversa filològica» del 23/1/1920 (§ 9.3.2.13).

d) Casos que classifiquem com a casos d'importació:

- lo qual: a la «Conversa filològica» del 29/12/1919 (§ 9.3.2.12).

— La reintroducció d'arcaismes: a la «Conversa filològica» del 18/11/1919 (§ 9.3.2.12).

e) Casos que classifiquem com a casos de pèrdua:

- damunt preposició: en el curs del 1933-1934 (§ 9.3.1.1.13) i a la «Conversa filològica» del 18/10/1925 (§ 9.3.2.18).

- sens (conservat només en locucions fossilitzades): a la «Conversa filològica» del 6/2/1927 (§ 9.3.2.20).

Pel que fa als casos d'addició, ja els hem donat més amunt (La classificació de la interferència adoptada per Payrató (1985)).

\subsection{La definició fabriana de calc}

En el curs del buidatge, vam poder deduir una definició d'un tipus de castellanisme sintàctic, un tipus de calc, que vam reformular com segueix: «Identificació amb les significacions d'un mot gramatical castellà de les significacions d'un mot gramatical català que afecta l'estructura de la proposició en català».

El fragment que ens ho va permetre és al text «L'obra de depuració de la llengua catalana», de 1924 (p. 155-156; § 9.3.1.1.9), en què posa els exemples de bajo/baix-sota, nada/res-gens, pues/doncs i a/en: «aquesta identificació de significacions entre els mots catalans i els mots espanyols és sobretot deplorable quan afecta els mots gramaticals; sovint aquesta identificació afecta ja l'estructura de la proposició, constitueix ja un castellanisme sintàctic.»

\subsection{La definició fabriana de canvi lingüístic}

En la «Conversa filològica» del 30/12/1924 (§ 9.3.2.16), Fabra ofereix el que podríem anomenar procés general de canvi per interferència, en parlar de l'ús de la forma se'l dono: 
Més que un mot, una construcció forastera, pot penetrar en la llengua sense que ens en [sic] adonem. [...] llegint tots els dies i gairebé exclusivament en una llengua en què és usat se significant $a$ ell sempre que el complement directe és lo, la, los o las, l'associació entre el mot se i aquella significació s'estableix talment en la nostra pensa, que en traduir d'aquella llengua pot no semblar-nos estrangera i esmunyir-se inadvertidament en la nostra traducció, i pot així mateix no sobtar-nos quan la trobem acceptada en un text català. Des d'aquest moment, el se amb la valor de $l i \mathrm{o} h i$, perilla de produir-se espontàniament.

Hi hauria les fases següents:

a) Una primera fase, que podríem anomenar «exposició a la nova forma».

b) Una segona fase, que podríem anomenar «acceptació creixent». En aquesta fase, hi hauria un primer moment d' «acceptació passiva»: no sonaria estranya «en les traduccions del castellà»; posteriorment, no sonaria estranya «en textos catalans».

c) Després vindria la fase de «producció espontània».

\subsection{El procés de canvi segons Fabra}

Pel que fa a la descripció de la fase d'alternança en el procés de canvi, Fabra a la «Conversa filològica» del 15/9/1925 (§ 9.3.2.18), planteja de la manera següient la situació prototípica de les transferències entre català i castellà:

Bilingües, s'esdevé sovint que ens són igualment familiars dues construccions, dues formes o dues paraules, l'una catalana i l'altra espanyola; i, quan això s'esdevé, no és rar que les usem indistintament dins la pròpia llengua i dins la llengua forastera; de vegades usarem la catalana en espanyol, sobretot parlant; però, més freqüentment encara, usarem l'espanyola en català, sobretot escrivint. I si la concurrència de les dues construccions, de les dues formes o de les dues paraules ha d'acabar amb el triomf de l'una d'elles, generalment serà aquesta la manllevada a la llengua forastera. Per això convé tant de destriar ben bé ço que és català de ço que és castellà: de moment, millorarà, així, el nostre català; i de retop el nostre castellà, i evitarem la pèrdua de la construcció, forma o paraula catalana $[$ sic $]$.

El catalanoparlant transfereix estructures i formes catalanes al castellà quan parla aquesta llengua i transfereix estructures i formes castellanes al català quan escriu en aquesta llengua. El primer cas és el que Payrató anomena interferència: el parlant d'una llengua trasllada formes de la seva llengua en aprendre'n una altra; el segon, donat el bilingüisme dels catalanoparlants, també s'hi pot considerar. D'això es dedueix el que el mateix Fabra ja diu: en el seu temps, la interferència del castellà en el català es dóna sobretot en la llengua escrita. 


\subsection{Fabra, precursor en l'ús de la unitat interferència?}

En els textos fabrians es dedueix un ús particular de la unitat interferència. Arran de la lectura dels textos buidats, ens va caldre distingir entre la «interferència en sentit estricte» $\mathrm{i}$ el «moment secundari» de la interferència. La primera consisteix en un canvi lingüistic degut a la transferència d'una forma o d'una distinció, o a la supressió d'una forma en virtut del domini que té el parlant d'una segona llengua. $\mathrm{El}$ «moment secundari» de la interferència consisteix en la situació en què el parlant, en aquest cas del català, arriba a no reconèixer com a pròpies les formes genuïnes. Són els següents:

a) Quan certs parlants no reconeixen com a genuí l'ús dels mots res, gens, ningú, etc., en oracions condicionals: text del 14/12/1919 (§ 9.3.2.12).

b) Quan certs parlants no reconeixen com a genuí l'ús de davant com a preposició (davant la casa): text del 28/1/1920 (§ 9.3.2.13).

c) Quan certs parlants no reconeixen com a genuí l'ús de la preposició de davant de l'infinitiu subjecte o complement directe: text del 5/2-11?/1925 (§ 9.3.2.18).

d) Quan certs parlants no reconeixen com a genuí l'ús de qual com a relatiu, text del 25/1/1923 ( 9 9.3.2.15).

e) Quan certs parlants no reconeixen com a genuí l'ús de venir com a «desplaçament cap a la segona persona del discurs»: text del 15/7/1920 (§ 9.3.2.13).

No cal dir que el fet que Fabra usés en els anys 30 la unitat interferència aplicada a la linguística va despertar la nostra curiositat sobre l'origen d'aquest ús. En els textos fabrians trobem al·lusions a la noció d'interferència -com a transferència del parlant de L1 d'una forma de la L2 en escriure la L1 i com a transferència del parlant de L1 d'una forma de la L1 en parlar la L2.

Però, quan Fabra usa la unitat interferència, no ho fa com a «canvi lingüístic», sinó com a «influència d'una llengua en una altra», a la conferència «El català a l'escola primària», de 1933 (§ 9.3.1.1.12):

P. 5: que [sic] passa quan l'infant català va a una escola i per contra de fer la seva instrucció en català la fa en castellà? Compreneu com ha d'ésser funesta la interferència de $[s i c]$ una segona llengua quan s'està, podríem dir, en el moment, en mig camí de l'aprenentatge de la pròpia.

P. 8: que l'aprenentatge de l'infant català no es trobi pertorbat per la interferència d'una llengua forastera $[\ldots]$

4. Com que l'anotació manuscrita de la data alterna per a la consignació dels mesos la numeració aràbiga i la romana, davant la notació amb dos pals, no queda clar si és el mes de febrer (el 2) o de novembre (1'11). 
Malgrat això, al seu diccionari, de l'any 1932 (§ 9.3.1.1.11), només defineix interferència com a unitat de significació de la física.

L'ús de la unitat interferència en un text de l'any 1933 no deixa de ser rellevant si tenim en compte que Payrató (1985: 218) situa al 1936 la primera referència d'aquesta unitat de significació en un text europeu i en un de català: «Per acabar, un detall curiós - i valuós. Dalmau (1936) intuí perfectament ja l'ús que es podria fer de la noció i el terme interferència [...]»

Payrató diu que Dalmau l'usa tres vegades, i en nota a peu de plana afegeix: «6. Delfí Dalmau publicà aquesta obra, Poliglotisme passiu, el 1936, el mateix any, doncs, en què Sandfeld presentà la comunicació «Problèmes d'interférences linguistiques» al Quart Congrés Internacional de Lingüistes (Copenhague) [...]»

Abans (1985:48), Payrató afirma que és Sandfeld (1936) qui «comença a fer servir el terme interferència». Per tant, la transcripció de la conferència de 1933 s'avança 3 anys a la primera referència trobada per Payrató (1985), la qual cosa concorda amb la següent afirmació de Lamuela i Murgades (1984: 50-51): «Fabra fou també un gran estudiós, avant la lettre, de la interferència lingüística; entesa aquesta [...] com el procés d'influenciament exercit per part d'una llengua sociopolíticament dominadora damunt una llengua sòcio-políticament dominada».

\subsection{Proposta d'anàlisi del procés de canvi lingüístic}

En comentar la tipologia de Payrató (1985) sobre la interferència, ja hem observat que es fa evident que en el procés de canvi hi ha una variant emergent $i$ una variant tradicional: la classificació en un tipus o en un altre depèn en quina de les dues variants ens fixem.

Després del buidatge dels textos fabrians, cal concloure, des d'una perspectiva general de l'anàlisi del canvi sintàctic que, per donar compte de tota la complexitat del procés de canvi, caldria descriure quina era la situació de partida (una sola forma, dues formes en una relació determinada, etc.), què li passa a la variant emergent (és una importació interlingüística o intralingüística, és un mot que canvia de significat o de funcions, etc.), què li passa a la tradicional (desapareix, canvia de significat o de funcions, queda en una nova relació respecte a altres formes, etc.) i quina és la relació final entre les dues variants (l'emergent substitueix la tradicional, l'emergent provoca una nova relació amb la tradicional, etc.).

\section{A TALL DE CONCLUSIÓ}

En aquest text hem presentat uns quants resultats que vam obtenir en la nostra recerca sobre la concepció que Pompeu Fabra té del canvi sintàctic en particular i lingüístic en general. 
No havent deixat aquest lingüista cap obra general de reflexió, ens va semblar útil fer un buidatge de la seva terminologia, ja que aquest aspecte de la llengua s'agrupa en xarxes conceptuals i permet veure, doncs, l'organització de les matèries.

Els resultats del nostre buidatge permeten veure com Fabra va haver de tractar sistemàticament amb el canvi sintàctic (en vam recollir 102 casos), que tenia una idea clara del procés de canvi, que va arribar a definir el calc sintàctic, que tenia clara la noció d'interferència i que va fer servir aquesta unitat tres anys abans dels primers testimonis europeus i catalans recollits per Payrató (1985). També hem presentat, arran del procés de canvi explicat per Fabra, la que creiem que és la perspectiva adequada per analitzar el canvi lingüístic.

\section{REFERÈNCIES BIBLIOGRÀFIQUES}

Costa, J. (2006): Norma i variació sintàctiques: la concepció de Pompeu Fabra (1891-1948). <http://www.tdx.cesca.es/TDX-0116106-120523>. ISBN: 84-689-6585-5. Dipòsit legal: GI-1560-2005. 16/01/2006. [Treball actualment (setembre 2006) en premsa.]

«FABRA / Converses filològiques» [s. 1l.: s. n., s. a.]. [Capsa amb aquesta indicació conservada a la biblioteca del Seminari de Romàniques de la Universitat de Barcelona. La capsa conté 881 fulls, amuntegats, sense cap data general, numerats amb converses retallades i enganxades o mecanografiades. Hi ha també una carpeta, mida quartilla, amb un exlibris d'Artur Martorell (portada: «Converses filològiques»; full 3: «Cuaderno para uso de Converses filològiques»). Conté 263 converses numerades en llapis amb un ordre no cronològic; retallades i enganxades. Segons comunicació personal de Rafel, és el material de base per a l'edició de les converses de Barcino]

Dalmau, D. (1936): Poliglotisme passiu, Barcelona, Publicacions de "La Revista".

FABRA, P. (1919-1924): «Converses filològiques». V. RAFEL I FONTANALS (1983-1984).

- (1924): «L'obra de depuració del català». Reproduït per VALLVERDÚ (1980: 149-165).

— (1927-1928): «Converses filològiques». V. «Fabra / Converses filològiques».

- (1933): «El català a l'escola primària»: Manuscrit 2804 de la Biblioteca de Catalunya.

- (1933-1934): V. GaLtÉs I TORRES (1988).

Galtés i TORRes, P. (1988): Recull de les lliçons del curs de català superior 1933-1934 pel mestre En Pompeu Fabra. Pere Galtés i Torres, professor de català, Barcelona, Impremta Guinart. 
Labov, W. (1983): Modelos sociolingüísticos, Madrid, Cátedra.

Lamuela, X. i J. Murgades (1984): Teoria de la llengua literària segons Fabra, Barcelona, Quaderns Crema.

Payrató, Ll. (1985): La interferència lingüística. Comentaris i exemples català-castellà, Barcelona, Curial / Abadia de Montserrat.

Rafel i Fontanals, J. (ed.) (1983): Pompeu Fabra. Converses filològiques I. Edició crítica a cura de Joaquim Rafel i Fontanals, Barcelona, Edhasa.

- (1984): Pompeu Fabra. Converses filològiques II. Edició crítica a cura de Joaquim Rafel i Fontanals, Barcelona, Edhasa.

SANDFELD, K. (1936): «Problèmes d'interférences linguistiques», A: Actes du Quatrième Congrès International des Linguistes, Copenhague, 1938, 59-61. Vallverdú, F. (cur.) (1980): Pompeu Fabra. La llengua catalana i la seva normalització, Barcelona, Edicions 62. (Les Millors Obres de Literatura Catalana; 28). 


\title{
ESTUDIO DE LAS FORMAS ¿EH? Y ¿NO? EN EL DISCURSO
}

\author{
Verónica Edeso Natalías \\ Universidad de Zaragoza
}

\section{INTRODUCCIÓN}

$\mathbf{E}$ L objeto de este trabajo consiste en determinar las diferencias existentes entre el empleo de las formas ¿eh? y ¿no? en el discurso, en su forma interrogativa y con entonación generalmente ascendente.

Partimos de la lingüística sistémica de Halliday (1970) para situar estos elementos dentro del ámbito interpersonal, en el que «language serves to establish and maintain social relations» (Halliday, 1970: 143).

Dentro del ámbito interpersonal, consideramos que ¿ $e h$ ? y ¿no? son elementos linguísticos que nos ayudan en el buen desarrollo de la conversación y, como tales, los incluimos dentro de los procedimientos de validación interlocutiva señalados por Kerbrat-Orecchioni (1996: 4-5):

Pour qu'il y ait échange communicatif, il ne suffit pas que deux locuteurs (ou plus) parlent alternativement; encore faut-il qu'ils se parlent, c'est-à-dire qu'ils soient tous deux «engagés» dans l'échange, et qu'ils produisent des signes de cet engagement mutual, en recourant à divers procédés de validation interlocutoire.

El distinto comportamiento de ¿eh? y ¿no? en sus diferentes usos nos permite concluir que en algunos casos constituyen enunciados (Hidalgo, 1997), mientras que en otros, la imposibilidad de aparecer de forma autónoma nos lleva a considerarlos como constituyentes extra-clausales (Dik, 1989, 1997).

Para determinar las diferencias entre el empleo de ¿eh? y ¿no? nos basamos en un corpus de ejemplos obtenidos de El Jarama (1956), de algunas conversaciones extraídas de La conversación coloquial (Briz et al., 1995), del Corpus de Referencia del Español Actual de la Real Academia Española y de nuestra competencia lingüística como hablantes de español.'

1. En lo que respecta a los ejemplos, cuando provienen de El Jarama citamos como J, y como B cuando los hemos obtenido de la obra de Briz El español coloquial (1995). Cuando el ejemplo proviene de nuestra competencia lingüística como hablantes de español, no añadimos ninguna referencia. Finalmente, cuando lo hemos obtenido del CREA añadimos el título y páginas de la obra a la que corresponde. 
Diferenciamos, principalmente, dos usos de las formas ¿eh? y ¿no? en el discurso: 1) como elementos inquisitivos, cuando con ellos se espera una respuesta por parte del interlocutor, y 2) como elementos implicativos, cuando a través de su empleo no se espera una respuesta, sino que lo que se pretende es atraer al interlocutor hacia el punto de vista del hablante. ${ }^{2}$

Pasamos a estudiar, partiendo del marco teórico expuesto previamente, las diferencias de empleo entre las formas ¿eh? y ¿no?.

\section{2. ¿EH? Y ¿NO?, ELEMENTOS CON VALOR INQUISITIVO}

Consideramos que ¿eh? y ¿no? presentan un valor inquisitivo cuando el hablante efectúa una petición de información a través de su empleo y espera obtener una respuesta por parte del interlocutor. ${ }^{3}$

Partimos de la clasificación propuesta por Escandell Vidal (1999) para diferenciar, en este uso, dos empleos de ¿eh? y ¿no?: 1) como interrogativos marcados -apéndice comprobativo- y 2) como interrogativos neutros - pregunta.

\section{1. ¿Eh? y ¿no? como interrogativos marcados}

¿Eh? y ¿no? constituyen interrogativos marcados cuando orientan interpretativamente los enunciados (Escandell Vidal, 1999). A nuestro juicio, esto sucede cuando funcionan como apéndices comprobativos.

Las formas ¿eh? y ¿no? han sido tradicionalmente consideradas como apéndices comprobativos pero, ¿qué se entiende como tal? Para Ortega $(1985),{ }^{4}$ los apéndices comprobativos son elementos modalizadores de cuerpo fónico reducido de los que se sirve el hablante para conseguir del oyente cierta corroboración.

Por su parte, Blas Arroyo (1995), que se encarga del estudio de la interjección $e h$, considera que, en estos casos, estamos ante un marcador discursivo con el que se solicita la confirmación de que la información ha sido asimilada por el interlocutor. Para él (ibíd.: 99) eh «funciona como una especie de comprobativo».

2. A pesar de que estudiamos algunos de los usos de ¿eh? y ¿no? en su forma interrogativa, hemos de señalar que interrogación no equivale siempre a pregunta (Escandell Vidal, 1999: 3931).

3. Respuesta que no ha de ser obligatoriamente verbal, como señala Escandell Vidal (1999: 3934) «(...) decir que la fórmula admite una solución no supone afirmar que la pide explícitamente o que la respuesta deba ser, necesariamente de naturaleza verbal».

4. En su artículo, Ortega (1985) ofrece el estudio de algunas formas consideradas tradicionalmente como apéndices comprobativos, tales como ¿no?, ¿sí?, ¿verdad?, ¿no es esto?, ¿no es eso?, ¿no es así?, ¿no es verdad?, ¿es verdad?, ¿es mentira?, ¿miento?, ¿no cree(-s)?, ¿no creen (-éis)?, ¿de acuerdo? y ¿vale?. 
Para Martín Zorraquino y Portolés (1999), los apéndices comprobativos son unidades que indican (ibíd.: 4188) «el deseo del hablante de contar con el interlocutor, buscando su cooperación, su comprensión, su complicidad, etc.». Fuentes Rodríguez (1990) se aparta un poco de estas posturas y considera que, más que una corroboración, lo que ella denomina «apéndices con valor apelativo» son apoyos del discurso que apelan al oyente para que escuche al locutor y para que colabore con él en la creación del enunciado, postura que comparte, asimismo, Alcaide Lara (1993).

Consideramos que ¿eh? y ¿no? funcionan como apéndices comprobativos cuando con estos elementos se pretende confirmar el segmento del discurso al que remiten:

(1) Más bien, que nos ponga la espuela, como es su obligación, que hay que irse marchando -miró a los carniceros. ¿Eh? (J: 297)

(2) Intentó cogerle la mano por encima de la mesa pero él la retiró a tiempo. -Estás celoso, ¿eh? (CREA, Los aires difíciles, Almudena Grandes, 2002, párrafo 183)

(3) La idea parece buena hasta que él mismo se da cuenta de qué tipo de fotos guarda. Una con una raqueta: esa no la ponemos, ¿eh?' (CREA, prensa, El País de las Tentaciones, 14/02/2003)

El objetivo de los apéndices comprobativos consiste, efectivamente, en «comprobar» si se cuenta con la aprobación del destinatario, de ahí que aparezcan en enunciados en los que se muestran diferentes grados de incertidumbre del emisor.

El uso de las formas ¿eh? y ¿no? como apéndices comprobativos se diferencia de su empleo como interrogativos neutros en las posibilidades de elección de la respuesta: como apéndices, la respuesta se encuentra orientada; mientras que, cuando con ellos se efectúa una pregunta neutra la respuesta es, como veremos, abierta.

¿Eh? y ¿no? pueden funcionar como apéndices comprobativos cuando el hablante presenta cierta inseguridad ante lo que enuncia y, de este modo, la pone de manifiesto. ${ }^{6}$ A través de su empleo, el hablante pretende confirmar lo que ha

5. Adviértase que, en los ejemplos que aquí proponemos, ¿eh? admite ser sustituido por otros apéndices comprobativos, tales como ¿no? y ¿verdad?.

6. Para Ortega (1985) la diferencia entre seleccionar un enunciado interrogativo, uno enunciativo acabado con un apéndice y uno dubitativo radica en el grado máximo o medio de incertidumbre que exista en el hablante. Es decir, el hablante escogerá un enunciado como ¿tuviste tiempo de verla? cuando su grado de incertidumbre es máximo; tuviste tiempo de verla, ¿no?, cuando su grado de incertidumbre es medio y, finalmente, quizá tuviste tiempo de verla, cuando su grado de incertidumbre es menor (ejs. de Ortega, 1985: 243). 
dicho previamente. Como señala Ortega (1985: 244), pretende «ratificar algo sobre lo que ya ha establecido ciertas previsiones [...]». Pero, como ya hemos señalado, aunque ¿eh? y ¿no? pueden funcionar como apéndices comprobativos, existen diferencias entre ellos.

Creemos que la principal diferencia entre ambas formas consiste en que, con ¿no?, las posibilidades de elección de respuesta del destinatario son más reducidas que con $¿ e h ?$, forma con la que el locutor no sólo pregunta, sino que también efectúa una llamada de atención al destinatario:

(4) Al final encontró el camino, ¿eh?

(5) Al final encontró el camino, ¿no?

Adviértase que, a través de los enunciados con ¿eh? se efectúa una pregunta, no obstante, con ¿no? no se pregunta realmente, ya que los enunciados parecen contener la respuesta en sí mismos.

La presencia de ¿no? indica una expectativa previa por parte del hablante. Éste espera que el interlocutor cierre la pregunta con una respuesta que cumpla con sus expectativas, el destinatario no tiene posibilidad de elección ya que el hablante sólo pretende confirmar un supuesto previo.

La diferencia entre el empleo de ¿¿h? y ¿no? como apéndices comprobativos radica, por tanto, en que con $i e h ?$ se inducen dos procesos interpretativos diferentes e igual de válidos:

1) El contenido que se interroga incluye la negación

2) El contenido que se interroga excluye la negación

Por el contrario, con ¿no? sólo se deja abierta una posibilidad, aquella que coincide con el supuesto previo del hablante.

Con el empleo de ¿eh? el locutor permite elegir al destinatario la respuesta. El interlocutor puede interpretar dos posibles expectativas. Como consecuencia, ¿eh? constituye un elemento más cortés que ¿no? -no impongas tu voluntad al destinatario, propón opciones. ${ }^{7}$ Por el contrario, con ¿no? se excluye directamente una de las dos posibilidades, dejando sólo cabida a una expectativa del locutor que éste desea corroborar. No hay, por tanto, elección posible. No se proponen opciones al interlocutor sino que se impone una única opción posible. Se trata, por ello, de un elemento menos cortés que ¿eh?

Formalmente, no existe diferencia entre ellos, pues tanto ¿eh? como ¿no? aparecen al final del enunciado como medio de ratificar $u$ orientar sobre el

7. Entre los autores que se han encargado de la cortesía, Leech (1983) ya indica, al formular la máxima de tacto, que resulta más cortés -o educado-, aumentar el grado de elegibilidad del destinatario sin imponer la voluntad del hablante. 
contenido del mismo. Presentan independencia respecto de éste, de hecho el enunciado previo al que remiten no ha de presentar necesariamente contorno interrogativo y suelen encontrarse separados de él mediante coma, pero, a pesar de esta aparente independencia, no pueden entenderse sin su presencia. Consideramos, por ello, que en estos casos las formas de las que nos ocupamos son, partiendo de la terminología de Dik $(1989,1997)$, constituyentes extra-clausales, es decir:

A variety of expressions which can be analysed neither as clauses nor as fragments of clauses. These expressions may stand on their own, or precede, follow, and even interrupt a clause, being more loosely associated with it than those constituents which belong to the clause proper. These expressions will here be called extra-clausal constituents (ECCS). (Dik, 1997: 379).

Para Dik (1997) los constituyentes extra-clausales pueden desempeñar diferentes funciones. Los usos de ¿eh? y ¿no? de los que nos ocupamos aquí se incluirían dentro de lo que él denomina interaction management, ya que se trata de elementos que (ibíd.: 384) «[...] play a role in strategies for getting A's [addresse's] attention and securing his willingness to participate in the discourse event».

La diferencia que hemos señalado entre el empleo de ¿eh? y ¿no? se hace todavía más patente si acompañan a un acto directivo:

(6) Me ayudarás mañana, ¿eh?

(7) Me ayudarás mañana, ¿no?

Y a enunciados cuyo contenido proposicional implican un determinado comportamiento por parte del interlocutor:

(8) Vendrás a cenar, ¿eh?

(9) Vendrás a cenar, ¿no?

Adviértase que con ¿eh? se admiten dos respuestas por parte del interlocutor -sí o no-, mientras que con ¿no? existe una expectativa por parte del locutor que orienta hacia la respuesta afirmativa. ${ }^{8}$ Puesto que se impone -o se intenta imponer- la voluntad del locutor, el empleo de ¿no? como apéndice comprobativo es menos cortés que el de ¿eh?, con el cual, a pesar de efectuarse una pre-

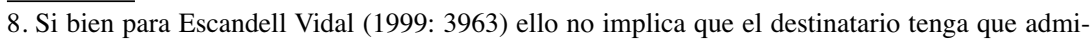
tir, necesariamente, la respuesta que el locutor le propone. 
gunta orientada, se permite elegir (aunque sea entre un conjunto reducido de posibilidades: sí o no).

\section{2. ¿Eh? y ¿no? como interrogativos neutros (pregunta)}

Según Escandell Vidal (1999) una interrogación es neutra cuando no contiene indicadores que orienten interpretativamente el enunciado. Consideramos que ¿eh? y ¿no? constituyen interrogaciones neutras cuando no orientan la respuesta del interlocutor. Dentro de las interrogaciones neutras se incluyen las preguntas, es decir las peticiones de información a través de las cuales se espera una respuesta por parte del interlocutor:

(10) Sería necesario que yo me subiera para arriba, para avisarlos a todos los otros. ¿Eh?, ¿qué decís? (J: 292)

(11) Sería necesario que yo me subiera para arriba, para avisarlos a todos los otros. ¿No? ¿qué decís?

Sin embargo, en los ejemplos presentados, ¿tenemos realmente interrogaciones neutras? Como puede observarse, ¿no? parece orientar la respuesta del interlocutor (como sucede cuando funciona como apéndice comprobativo), lo cual no sucede con $¿ \mathrm{eh}$ ?. Esto nos lleva a considerar que, a diferencia de $¿ e h ?, ~ ¿ n o ?$ no puede constituir interrogaciones neutras, ya que siempre orienta argumentativamente los enunciados hacia una respuesta preferida del locutor.'

Como elementos con valor inquisitivo existe otra diferencia entre el empleo de ¿eh? y ¿no?. Adviértase que, como apéndices comprobativos, son utilizados por el locutor. No obstante, como señala Kany (1969: 468-469), ¿eh? puede utilizarse, asimismo, por el interlocutor cuando quiere que se le repita determinada información:

(12) $\mathrm{M}:(. ..) /{ }^{\circ}\left(\right.$ me llamó Roberto ¿se ha enterado de lo el ascensor? ${ }^{\circ}$

A: $i$ eh?

S: ¿el ascensor? (B: 132)

(13) El otro llenó el vaso; «lo que bebemos todos», murmuraba al dejarlo sobre el mostrador.

-¿Eh?, ¿cómo dice? No lo he oído, Señor Mauricio; ¿decía usted? (J: 158)

En estos casos el interlocutor solicita que se le repita algo que no ha oído o no ha entendido correctamente. Al no existir una expectativa previa, constituye una

9. Ya señala Escandell Vidal (1999: 3961) que «la presencia de la negación en los enunciados interrogativos restringe formalmente sus posibilidades interpretativas». 
pregunta neutra. Utilizada por el locutor, ¿eh? puede constituir una interrogación orientada (apéndice), o neutra (pregunta). Por el contrario, utilizada por el interlocutor, ¿eh? constituye siempre una interrogación neutra, ya que simplemente equivale a ¿qué?, cualquier respuesta es válida, ya que no existe ninguna expectativa hacia la misma. Adviértase que no es posible la conmutación por ¿no?:

(14) M: $[\ldots] /{ }^{\circ}\left(\right.$ me llamó Roberto ¿¿se ha enterado de lo el ascensor? ${ }^{\circ}$ *A: ¿no?

S: ¿el ascensor?

(15) El otro llenó el vaso; «lo que bebemos todos», murmuraba al dejarlo sobre el mostrador.

* ¿¿No?, ¿cómo dice? No lo he oído, Señor Mauricio; ¿decía usted?

Lo cual no hace sino confirmar el hecho de que ¿no? siempre orienta la respuesta del interlocutor, por eso no admite aparecer en este tipo de interrogaciones, precisamente porque no son orientadas, sino neutras.

¿Eh? equivale en estos casos a ¿qué? y, como elemento lingüístico a través del que se solicita una información, puede acompañarse de otros elementos que comparten este valor interrogativo y que resultan, en este empleo, equivalentes tales como ¿qué?, ¿cómo?, ¿qué dices?, ¿puede repetir?, etc.:

(16) [Imaginemos que un hablante A está hablando por el móvil, pasa por un sitio con poca cobertura, de manera que deja de oír lo que dice su interlocutor, podría reaccionar del modo que sigue]

A: ¿Qué?, ¿cómo dices?, ¿eh?, no te oigo... ¿puedes repetir?

También a veces la interjección ¿eh? puede utilizarse como una falsa petición de información cuando el hablante ha dicho algo que no ha sido del agrado del oyente y éste muestra, de este modo, su disconformidad: ${ }^{10}$

(17) A: Es que eres muy egoísta por no dejarme los apuntes

$B:$ ¿Ehh?, ¿pero qué dices?, ¡si te los llevo dejando todo el curso!

En estos casos, con ¿eh? no se solicita una repetición de la información, sino que muestra el desacuerdo del interlocutor ante la intervención previa.

10. En este sentido, ya señala De Luna (1996: 111) que la interjección ¿eh? con función interrogativa puede utilizarse no sólo para pedir que se repita una información que no se ha oído, sino también para que se repita una información que no se ha querido entender, según ella (ibíd.), «quizá porque tiene algo de provocativo o amenazante»:

Inf. $B$ - No, idiota

Inf. A - ¿Eh? (XXI, 399) (ej. 59 de Carmen de Luna, 1996: 112) 
También se produce este empleo cuando el locutor desea que el interlocutor rectifique lo que ha dicho previamente. De este modo, se finge que no se ha entendido lo que éste ha dicho para que reflexione y lo rectifique en la intervención siguiente:

(18) A: ¿Este fin de semana nos iremos a la playa?

$B:$ ¿Ehh?

[A reflexiona y recuerda que $B$ le ha dicho que este fin de semana tiene mucho trabajo, con lo que se da cuenta de que no pueden ir a la playa, ante lo que responde]

A: nada, nada, que se me había olvidado que tenías mucho trabajo.

Este empleo es tan abundante que, a veces, resulta contraproducente ya que, en muchas ocasiones, el interlocutor desea que se le repita una información que no ha oído, sin embargo, el hablante infiere, incorrectamente, que algo de lo que ha dicho resulta inoportuno de modo que, automáticamente, lo rectifica:

(19) A: ¿Mañana iremos al cine?

B: ¿Eh?

[Ante la respuesta de $B, A$ infiere que $B$ no quiere ir al cine, no que no ha oído lo que le acaba de decir, ante lo que responde]

A: Bueno, lo que quieras, si no quieres ir no pasa nada ${ }^{I I}$

¿Eh? no puede sustituirse por ¿no? en ninguno de estos casos. Adviértase que, a diferencia de lo que sucede cuando es utilizado como apéndice comprobativo, cuando es empleada por el interlocutor constituye, por sí mismo, un turno de palabra. No depende de una predicación anterior. Posee, en suma, autosuficiencia comunicativa. No se trata, por tanto, de un constituyente extra-clausal. En estos casos, constituye un enunciado (Hidalgo, 1997). ${ }^{12}$

11. Este empleo es muy significativo cuando el profesor pregunta a un alumno en clase. Si el profesor no entiende bien la respuesta y pregunta con un ¿eh?, el alumno tiende a cambiarla al inferir que la respuesta previa es incorrecta:

A: ¿Cuál es el sujeto de la oración?

B: María

A: ¿Eh?

[B piensa que el profesor no ha querido oír la respuesta porque es incorrecta y vuelve a preguntarle para darle la oportunidad de rectificar, ante lo que contesta]

B: Juan, que me he equivocado.

12. Según Hidalgo (1997), podemos hablar de enunciado cuando tenemos un conjunto unitario de elementos agrupados en torno a una curva melódica que constituyen una secuencia comunicativa mínima. Un enunciado, además, ha de producirse en un contexto comunicativo real, por un hablante específico con una intención comunicativa. Por último, señala Hidalgo (ibíd:: 26) que el enunciado «debe poseer sentido (autosuficiencia semántica)». 
Podemos concluir que ¿eh? y ¿no? pueden funcionar, ambos, como elementos inquisitivos. No obstante existen, entre ellos, algunas diferencias.

¿Eh? y ¿no? pueden constituir interrogaciones marcadas cuando se utilizan como apéndices comprobativos a través de los cuales el locutor pretende confirmar determinada información. En este uso se diferencian en que ¿eh? es más cortés que ¿no?, ya que permite al interlocutor la posibilidad de elegir entre dos opciones posibles. Mientras que ¿no? sólo parece dejar cabida a que se responda con la expectativa previa del locutor.

Solamente ¿eh? puede constituir interrogaciones neutras, preguntas abiertas en las que se espera una respuesta. En estos casos puede utilizarse bien por el locutor, bien por el interlocutor, que indica que no ha recibido correctamente determinada información previa. En el primer caso se trata de un constituyente extra-clausal, ya que carece de autosuficiencia comunicativa, mientras que en el segundo caso se trata de un enunciado, ya que sí que presenta independencia.

\section{3. ¿EH? Y $₫ N O ?$, ELEMENTOS CON VALOR IMPLICATIVO}

Como ya hemos señalado en la introducción, creemos que ¿eh? y ¿no? pueden presentar también un valor implicativo en la comunicación cuando su entonación es interrogativa. En estos casos no se pretende obtener una respuesta por parte del oyente (Blas Arroyo, 1995), sino implicarlo en las palabras del hablante y lograr, de este modo, que éste comparta su punto de vista: ${ }^{13}$

(20) M: $[\ldots] /$ / cada uno tiene que de- llevar $\neq /$ dentro de lo elegante $\neq / / / j$ eh? // y ponerlo $\neq / /(())$ / hágase esto y verá cómo / se gana // (...) (B: 143)

(21) Lo primero es eso. ¿Eh, Luci?, como se ponga burro lo expulsamos, ¿qué te parece? (J: 134)

(22) Mira, es verdad esto que dice Petra, ¿eh, Felipe? Es necesario una pequeña necesidad para el futuro (J: 166)

¿Eh? y ¿no? constituyen, como elementos implicativos, preguntas retóricas, ya que con su empleo no se persigue una respuesta por parte del interlocutor, sino implicarlo en una situación o ganar su complicidad. El objetivo de ganar el favor del interlocutor provoca que ¿eh? y ¿no? con valor implicativo

13. Otros autores ya han dado cuenta de este valor en relación con la interjección ¿eh?, es el caso de Beinhauer (1973: 81), que lo ha denominado eh sugestivo, Martínez Álvarez (1990), Alcaide Lara (1993) o Haverkate (1994), entre otros. 
aparezcan frecuentemente en discusiones -como medio de introducir al interlocutor en los argumentos del locutor-, así como en intervenciones que resultan demasiado extensas para evitar que decaiga la atención del interlocutor al intentar que éste comparta el punto de vista del hablante.

¿Eh? y ¿no? pueden funcionar como elementos implicativos, no obstante, presentan diferencias. Así, ¿eh?, acepta cualquier posición y no es extraño que aparezca en medio de una estructura sintácticamente equivalente:

(23) ¿Ves cómo son?, ¿eh?, ¿ves cómo son?

(24) ¿Pero tú lo ves normal esto?, ¿eh?, ¿tú lo ves normal?

(25) Que no, ¿eh?, que no puede ser.

No es el caso de ¿no? que, en ocasiones, resulta extraño en este empleo ya que no suele aceptar la posición intermedia entre dos estructuras equivalentes:

(26) ?¿Ves cómo son?, ¿no?, ¿ves cómo son?

(27) ?¿Pero tú lo ves normal esto?, ¿no?, ¿tú lo ves normal?

(28) ? Que no, ¿no?, que no puede ser.

A nuestro juicio, si bien ¿eh? y ¿no? pueden funcionar casi en todos los casos de forma semejante como implicativos, el hecho de que ¿eh? sea más frecuente que ¿no? y de que admita todas las combinaciones y posiciones posibles se debe a las características que ya hemos señalado en su empleo como inquisitivo: resulta mucho más cortés que ¿no?.

De este modo, ¿eh? puede entenderse como una llamada de atención al interlocutor para que comparta el punto de vista del hablante, mientras que ino? supone, más que una invitación, una imposición de este punto de vista. La existencia de opciones en el primer caso, frente a la imposición de una opción determinada en el segundo, convierte a ¿eh? en un elemento más cortés que $¿ n o ?^{14}$

En este uso, tanto ¿eh? como ¿no? carecen de autosuficiencia comunicativa, ello nos lleva a considerarlos constituyentes extra-clausales, como en su empleo como apéndices comprobativos, ya que no se entienden sin la presencia del enunciado al que remiten.

14. Escandell Vidal (1999: 3985) denomina «interrogativas retóricas» a aquellas interrogativas que contienen algún marcador relacionado con la negación, ya que considera que estos enunciados «[...] tratan de hacer admitir al destinatario la presuposición que contienen» y que en ellos el emisor (ibíd.) «[...] favorece explícitamente una determinada opción». 
De este modo, ¿eh? y ¿no? pueden funcionar, asimismo, como implicativos cuando con su empleo se intenta que el interlocutor comparta la postura del hablante. Como sucedía en su empleo como inquisitivos, ¿eh? resulta más cortés que ¿no?, ya que con este último no se proponen opciones, sino que se impone la del locutor.

\section{CONCLUSIONES}

¿Eh? y ¿no? con contorno interrogativo pueden utilizarse en el discurso con dos valores: 1) como elementos inquisitivos y 2) como elementos implicativos. Si bien en la mayoría de ocasiones podemos conmutar uno por otro, presentan una diferencia fundamental: ¿eh? resulta más cortés que ¿no?, con ¿eh? se permite elegir la respuesta al interlocutor ya que no supone una expectativa previa por parte del hablante.

A nuestro juicio ello se debe a la propia naturaleza de los elementos que analizamos. Adviértase que ¿eh? ha sido definido, a lo largo de la tradición gramatical, como una interjección apelativa (Beinhauer, 1973; Seco, 1989; Alarcos, 1994; Haverkate, 1994, entre otros). Parece, al menos en principio, que ¿eh? es un elemento de llamada -o de llamada de atención. Aunque en determinados usos ¿eh? admite el contorno interrogativo, sigue constituyendo, fundamentalmente, una llamada al interlocutor, se trata de un elemento abierto, una petición de información. Por el contrario, ¿no?, no constituye una simple llamada, su significado no contiene esa posibilidad-como sucede con ¿eh?. Con ¿no? no se pretende llamar la atención del destinatario, sino orientar su respuesta hacia una opción determinada. El hecho de que con ¿eh? se permita elegir al interlocutor, y de que con ¿no? simplemente se intente corroborar una expectativa previa del locutor, provoca que el empleo de ¿eh? resulte más cortés que el de ¿no?.

En conclusión, creemos que las diferencias de comportamiento observables entre estos dos elementos lingüísticos radican, esencialmente, en que ¿eh? mantiene, en todos sus usos, un valor de llamada o interaccional, mientras que ¿no? indica, más que una simple idea de llamada, una orientación determinada de la actitud del interlocutor, una certeza por parte del locutor que condiciona la respuesta o adhesión solicitada y que restringe las posibilidades reales de elección, lo cual la convierte en un elemento menos cortés que ¿eh?.

\section{REFERENCIAS BIBLIOGRÁFICAS}

Alarcos Llorach, E. (1994): Gramática de la lengua española, Madrid, Espasa-Calpe. 
AlCAide LARA, E. (1993): «Anotaciones sobre algunos usos de la interjección en el habla urbana de Sevilla», Sociolingüística andaluza 8. Estudios sobre el enunciado oral: 215-235.

Beinhauer, W. (1930): El español coloquial, $2^{\mathrm{a}}$ ed., Madrid, Gredos, 1973.

Blas ArRoyo, J. L. (1995): «La interjección como marcador discursivo: el caso de eh», Anuario de Lingüística Hispánica XI: 81-117.

BRIz, A. (y grupo Val. Es. Co.) (1995): La conversación coloquial (materiales para su estudio), Valencia, Universitat de València.

Diк, S. C. (1989): The Theory of Functional Grammar. Part I: The Structure of the Clause, Dordrecht-Holland/Providence RI - USA, Foris Publications.

- (1997): The Theory of Functional Grammar. Part 2: Complex and Derived Constructions, Berlín-Nueva York, Mouton de Gruyter.

EsCANDELL VIDAL, M. V. (1999): «Los enunciados interrogativos. Aspectos semánticos y pragmáticos» en BosQue, I. y V. Demonte (eds.) (1999): Gramática descriptiva de la lengua española, vol. 3, Madrid, EspasaCalpe, 3929-3991.

Fuentes Rodríguez, C. (1990): «Apéndices con valor apelativo», Sociolingüística andaluza, 5: 171-196.

HaLLIDAY, M. A. K. (1970): «Language structure and language function» en New horizons in linguistics, Great Britain, Penguin Books, 140-165.

HAVERKATE, H. (1994): La cortesía verbal, estudio pragmalingüístico, Madrid, Gredos.

HidAlgo, A. (1997): La entonación coloquial. Función demarcativa y unidades de habla, Anejo $\mathrm{n}^{\circ}$ XXI de la revista Cuadernos de Filología, València, Universitat de València.

KanY, C. E. (1969): Sintaxis hispanoamericana, Madrid, Gredos.

Kerbrat-Orecchioni, C. (1996) : La Conversation, Seuil, Editions du Seuil.

LeECH, G. (1983): Principles of Pragmatics, Nueva York, Longman.

LuNA, C. DE (1996): «Cualidades gramaticales y funcionales de las interjecciones españolas», en Kotschi, T., W. OESTERREICHER y K. ZIMMERMANN (eds.) (1996): El español hablado y la cultura oral en España e Hispanoamérica, Madrid / Fráncfort, Biblioteca Ibero-Americana, Vervuert, 95-116.

Martínez Álvarez, J. (1990): Las interjecciones, Logroño, Consejería de Educación, Cultura y Deportes de la Comunidad Autónoma de la Rioja.

Martín Zorraquino, Mª . A. y J. Portolés LÁZARo (1999): «Los marcadores del discurso» en BosQue, I. y V. Demonte (eds.) (1999): Gramática descriptiva de la lengua española, vol. 3, Madrid, Espasa-Calpe, 4051-4213.

ORTEGA, J. (1985): «Apéndices modalizadores en español: los "comprobativos"», en Estudios románicos dedicados el profesor Andrés Soria Ortega, 239-255. 
SÁnCHEZ Ferlosio, R. (1956): El Jarama, Barcelona, Destino.

SECO, M. (1972): Gramática esencial del español. Introducción al estudio de la lengua, $2^{\mathrm{a}}$ ed., Madrid, Espasa-Calpe, 1989. 


\title{
APORTACIONES \\ DEL DICCIONARIO PANHISPÁNICO \\ DE DUDAS A LA MORFOSINTAXIS \\ DEL ESPAÑOL
}

\author{
Ma José García Folgado \\ Universitat de València \\ Mónica Velando Casanova \\ Universitat Jaume I
}

\section{INTRODUCCIÓN}

$\mathbf{L}$

A aparición del Diccionario panhispánico de dudas a finales de 2005 ha supuesto un importante hito en el mundo de la norma académica de la lengua, puesto que la creación de un nuevo diccionario que diera respuesta a los problemas diarios en el uso del español era ya muy necesaria. Con él se resuelven las dudas más habituales del uso del español en los distintos niveles de análisis lingüístico (fonográfico, morfológico, sintáctico y léxico-semántico).

Pese a su carácter normativo, el nuevo diccionario de dudas propone soluciones y recomendaciones basadas en la realidad lingüística actual y, dada la conciencia de la naturaleza cambiante de una norma fundada en una lengua «viva», acostumbran a aparecer, en lugar de los calificativos correcto o incorrecto, expresiones del tipo Se desaconseja por desusado...; No es normal hoy $y$ debe evitarse...; No es propio del habla culta...; Esta es la forma mayoritaria y preferible, aunque también se usa... que conjugan los criterios de vigencia, de extensión y de frecuencia en el uso general culto. Asimismo, abundan apreciaciones sobre la norma española y americana -dada la colaboración conjunta en su elaboración entre la Real Academia Española y la Asociación de Academias de la Lengua Española, hecho que implica abarcar el uso del español en los distintos lugares en que se habla-, y suele ser habitual la alusión al nivel de lengua al que pertenecen los usos comentados (lengua escrita/oral, lengua literaria/corriente, lengua formal/informal, lengua culta/popular, etc.). ${ }^{1}$ Se comprueba, entonces, la «modernidad» del tratamiento de la norma por parte de este diccionario.

1. Para esta cuestión, véase el apartado introductorio «Qué es el Diccionario panhispánico de dudas» del propio diccionario (2005: XIII-XVI). 
Ante el interés despertado por esta obra y la ausencia casi total de estudios sobre ella, con la excepción del artículo de Martínez de Sousa (2006), nos ha parecido relevante tratar algunas novedades de este diccionario en el marco del III Congreso Internacional sobre Lengua y Sociedad. Nos hemos centrado en las aportaciones morfosintácticas presentes en este diccionario, ${ }^{2}$ a partir de un exhaustivo cotejo con manuales de español correcto, tales como el de Estrella Montolío (2000) o el de Gómez Torrego (2002). El objetivo ha sido descubrir los cambios en la normativa vigente, los criterios utilizados y, finalmente, la correspondencia o no con el uso real por parte de los hablantes.

\section{SUSTANTIVO: GÉNERO Y NÚMERO}

En líneas generales, por lo que respecta al género, la tendencia seguida por el Panhispánico ha sido la de mantener la misma variación genérica que el diccionario de 2001, si bien son interesantes las observaciones incluidas en el nuevo diccionario en torno al uso habitual de estas voces, su extensión geográfica e, incluso, las afirmaciones tajantes sobre el uso incorrecto de los femeninos con la terminación en -o (*la abogado).

Sin embargo, a la vista de los resultados obtenidos, podemos realizar algunas observaciones: por un lado, el nuevo diccionario de dudas se resiste a registrar únicamente como variables -prefiere incluirlos como variables y como comunes- aquellos sustantivos que presentan una forma femenina específica plenamente consolidada (clienta, jefa, sirvienta, etc.) e, incluso, aquellos que hasta ahora se recogían en los diccionarios solo con variación formal (aprendiz/a, bedel/a, cacique/cacica, comediante/a, etc.); y, por otro lado, con un carácter innovador recoge nuevos femeninos profesionales hasta ahora no considerados (alguacila, jenízara, la chef, la faquir, etc.). Con todo, esperamos que estas modificaciones con respecto a los diccionarios académicos anteriores se hayan realizado con la voluntad de responder al uso real de estas voces. ${ }^{3}$

En lo referente a la formación del plural, se observan, asimismo, dos modificaciones importantes de la normativa anterior.

Por una parte, la regla general de formación del plural de las voces terminadas en $-i$ o en $-u$ tónicas era adoptar la terminación -es -salvo contadas

2. Se han revisado las siguientes cuestiones morfosintácticas: género y número gramaticales, grado del adjetivo, determinantes, pronombres, régimen verbal, adverbios, conjunciones y preposiciones. En el presente trabajo, solo se tratan aquellos aspectos de los analizados que presentan alguna diferencia con respecto a la normativa anterior.

3. Un estudio exhaustivo sobre las novedades del Panhispánico con respecto al género gramatical se recoge en Velando (2006). 
excepciones como gachís, popurrís, pipís, mis, sis, cañís, gilís, recibís y travestís-, pese a que estas palabras acostumbraban a hacer también el plural en - $s$ en el uso general (tabús, bambús, iglús, etc.), lo que hasta entonces no estaba legitimado normativamente. La novedad del Panhispánico es admitir para estas palabras terminadas en $-i$ o en $-u$ tónicas las dos formas de plural, una con -es y otra con - $s$, con la pertinente matización de la preferencia en la lengua culta por la primera (bisturíes o bisturís, tabúes o tabús, etc.).

Por otra parte, en lo concerniente a la pluralización de los latinismos, aunque tradicionalmente se recomendaba mantenerlos invariables, muchos de ellos se han acomodado ya, en el uso mayoritario, a las reglas de formación del plural en castellano: dependiendo de su terminación, hacen el plural con $-s$, o -es, o se quedan invariables (ratios, pluses, lapsus, déficits, ítems, etc.). Como excepción, la nueva normativa deja sin variación los latinismos terminados en - $r$ procedentes de formas verbales (exequátur, cónfer, etc.) y las locuciones latinas. En general, se aconseja usar con preferencia, cuando existan, la variantes hispanizadas de los latinismos y, consecuentemente, también sus plurales (currículos, podios, etc.). Asimismo, se rechazan los plurales latinos en -a (córpora, currícula, etc.).

\section{ADJETIVO: EL GRADO}

Se observa en el Panhispánico una tendencia a la aceptación de las formas más coloquiales en la formación del superlativo, muchas de ellas hasta ahora censuradas, ${ }^{4}$ frente a las cultas de procedencia latina. Estos son los casos de muchos adjetivos que tienen en su raíz los diptongos ie o ue, en los que junto a las formas sin diptongar que conservan la raíz del adjetivo latino correspondiente, como ocurre en certísimo, fortísimo, novísimo, ternísimo o valentísimo, se presentan las que incorporan la raíz española del adjetivo, como ciertísimo, fuertísimo, nuevísimo, tiernísimo o valientísimo, igualmente válidas. Junto a estos, otros superlativos que proceden directamente del latín, como amicísimo, crudelísimo, sacratísimo y simplicísimo, alternan con las formas que incorporan la raíz española del adjetivo, como amiguísimo, cruelísimo, sagradísimo y simplísimo, igualmente válidas y a menudo más frecuentes en el uso.

4. Gómez Torrego (2002: 200-201) registraba como correctas las siguientes formas coloquiales de superlativo: ciertísimo, nuevísimo, tiernísimo, amiguísimo y simplísimo, y, como vulgares e incorrectas, fuertísimo, cruelísimo, sagradísimo y valientísimo. Finalmente, con respecto a calientísimo, este autor la censuraba, mientras que el Panhispánico dice de ella que es una forma comúnmente usada en algunos países de América, pero ajena a la norma culta de otras zonas del ámbito hispánico. 


\section{VERBO}

En primer lugar, se observan cambios de acentuación en algunas formas verbales. Así, verbos como adecuar y licuar, que en el uso culto se acentúan preferentemente como averiguar (adecuan), pasan a poderse acentuar como actuar (adecúa), por ser hoy frecuente esta acentuación, hasta ahora censurada.

Pero donde mayores cambios se registran es en el régimen sintáctico de algunos verbos. Como ya ha sido demostrado por autores como Lázaro Carreter (1997: 219-221 y 510-512) o Martín Zorraquino (2001), actualmente existe en el español una marcada tendencia a modificar el régimen de muchos verbos. Se convierten, por ejemplo, construcciones tradicionalmente pronominales (entrenarse, alinearse, clasificarse, calentarse, adherirse a, etc.) en intransitivas no pronominales (entrenar, alinear, clasificar, calentar, adherir $a$, etc.); pasan a construcción transitiva, con complemento directo, giros que rigen un complemento preposicional (incautar algo por incautarse de algo; enterarse que... por enterarse de que...); se introduce la preposición de (dequeísmo) en giros transitivos (pensar de que... por pensar que...; creer de que... por creer que...); etc.

\subsection{Verbos indebidamente transitivados}

La nómina de verbos indebidamente transitivados - utilizados como transitivos, con un complemento directo, cuando no lo son-, recogida por Gómez Torrego (2002) es bastante amplia. De entre ellos, el Panhispánico acepta el uso transitivo de apelar («Anunció que apelará la sentencia», Clarín [Arg.] 28.2.97), callar («Ve a Leonardo y va a hablar, pero lo calla un gesto de él», Wolff Balsa [Chile 1984]), estallar («Andrés seguía ahí dirimiendo el asunto de unos obreros que querían estallar una huelga», Mastretta Vida [Méx. 1990]), jugar («Es empleado bancario y juega fútbol», Bryce Vida [Perú 1981]), obsequiar («Su Majestad [...] LE obsequiaría un juego de trajes de gala», Paz Sombras [Méx. 1983]), pelear («Pelearon cada voto hasta el último minuto», LpzAlba Relevo [Esp. 2002]), recurrir («Podemos recurrir la sentencia», A. Millán Oportunidad [Esp. 1991]), repercutir («La empresa ha de soportar dichos pagos sin poder trasladar ni repercutir su importe al público», $A b c$ [Esp.] 15.6.89) y transitar («Betancur también ha transitado ese camino», Alape Paz [Col. 1985]).

En algún caso simplemente se indica que se admite tanto la construcción intransitiva como la transitiva (recurrir), pero la norma general es justificar la aceptación del uso transitivo por su extensión en los últimos tiempos (callar, apelar). Con todo, también se incluye el uso transitivo, aunque sea menos frecuente -aspecto que se señala-, de algunos verbos, tales como estallar ${ }^{5}$ y transitar. Una última razón para la admisión del régimen transitivo en verbos que lo rechazaban es su extensión de uso en América: este es el caso de obsequiar, 
pelear y jugar. Finalmente, con respecto a repercutir, su uso como transitivo se admite solo en el lenguaje económico, tal y como se recoge en el Panhispánico.

\subsection{Verbos indebidamente intransitivados}

Junto a los verbos indebidamente transitivados, también se observa una tendencia generalizada a utilizar verbos transitivos como intransitivos. De entre los recogidos por Gómez Torrego (2002), el Panhispánico registra como correctos los usos intransitivos de abdicar -con un complemento con de: «Los diputados abdican DE su tarea de control» (Mundo [Esp.] 3.3.96), si bien sigue siendo incorrecto introducir este complemento con $a:{ }^{*} \ll \mathrm{El}$ riesgo es que puede uno traicionarse y abdicar A su propia vocación» (Proceso [Méx.] 3.11.96)-, atravesar («Los cables de la luz que atraviesan POR la avenida», Ferré Batalla [P. Rico 1993]), debatir («Rajoy acepta debatir SOBRE un nuevo modelo de televisión», País [Esp.] 30.10.02), entrenar («Actualmente entreno entre cuatro y seis horas diarias», Cambio 16 [Esp.] 4.6.90) y suspender (se aceptan las construcciones suspender [a alguien] EN una prueba o materia, suspender [una prueba o materia] a alguien y suspender alguien [una prueba o materia]). En la mayoría de estos casos, el verbo aparece en el diccionario con la construcción transitiva y la intransitiva, sin necesidad de un comentario adicional (abdicar, atravesar y suspender); en un par de ocasiones se apela al criterio del uso actual para aceptar el nuevo régimen verbal (debatir y entrenar).

\subsection{Otros verbos con problemas normativos}

Finalmente, hallamos dos verbos (incautarse y simpatizar) que también presentan algunas modificaciones en su régimen ya aceptadas por el Panhispánico. Con respecto al primero, dada la extensión del empleo de este verbo como transitivo (incautar), por influjo de verbos sinónimos como confiscar o decomisar, hoy es frecuente y se considera válido este uso como transitivo: «Les incautaron tres dosis de cocaína» (Mundo [Esp.] 5.10.95), cuando hasta ahora solo se admitía como intransitivo pronominal (incautarse). Con respecto a simpatizar, el Panhispánico registra como correcta la construcción con un complemento indirecto: «Me simpatiza tu mujer» (Rovinski Herencia [C. Rica 1993]), que se trata de un uso coloquial del español de algunas áreas americanas, para el que el español general prefiere verbos como agradar, gustar o complacer.

5. El Panhispánico acepta el uso transitivo de estallar, pero, sin embargo, pese a su extensión de uso, censura la construcción transitiva del verbo explotar $(* \ll$ Los desconocidos [...] explotaron un artefacto en las oficinas administrativas», Universal [Ven.] 9/10/96). 


\subsection{Perífrasis verbales}

-Deber + infinitivo / Deber de + infinitivo: la novedad del Panhispánico consiste en matizar para la perífrasis deber de + infinitivo, la cual denota probabilidad o suposición, que, con este sentido, la lengua culta admite también el uso sin preposición: «Marianita, su hija, debe tener unos veinte años» (V. Llosa Fiesta [Perú 2000]). Gómez Torrego (2002: 450), sin embargo, admitía la omisión de la preposición de en los casos de posibilidad (Deben (de) estar desnudos) en la lengua oral (¡nunca en la escrita!).

-Estar siendo + participio: construcción que a menudo ha sido considerada un calco censurable del inglés, pero que es perfectamente posible y correcta en español, aunque sea menos frecuente que las construcciones activas o que la pasiva refleja: «John Polidori tuvo la inquietante certeza de que estaba siendo observado» (Andahazi Piadosas [Arg. 1999]); «Era evidente que estaba siendo acosado y atacado por el otro» (Guelbenzu Río [Esp. 1981]). ${ }^{6}$

\section{NUMERALES: CARDINALES Y ORDINALES}

\subsection{Cardinales (porcentaje y concordancia)}

En lo concerniente a la expresión de los porcentajes, ha de utilizarse siempre la fórmula por ciento: «En un noventa por ciento se trataba de cartas enviadas a los periódicos» (Cano Abismo [Col. 1991]), como ya se documentaba. Pero, cuando el porcentaje expresa totalidad, son igualmente válidas las expresiones ciento por ciento (preferida en América), cien por ciento y cien por cien (preferida en España), ${ }^{7}$ si bien hasta ahora era preferible decir (el) cien por cien (mejor que ciento por ciento) cuando el significado era el de 'totalmente' y, si se trataba de un porcentaje, se decía el ciento por ciento: «Este mueble es cien por cien (= totalmente) de madera de roble»; «Gano el ciento por ciento más en esta empresa» (Gómez Torrego, 2002: 285).

Con respecto a la concordancia, en los numerales compuestos que preceden al cardinal mil lo habitual era la forma apocopada (un), al entenderse la concor-

6. De hecho, Gómez Torrego ya se hacía eco de su extensión, sobre todo en el español de América, y comentaba que si el sistema justificaba dicha construcción y, además, esta se encontraba muy extendida en el español actual, no había razones para proscribirla.

7. Como ejemplos de estos usos, el Panhispánico registra los siguientes: «A cada gambeteador se le exige el ciento por ciento de eficacia» (Cappa Intimidad [Arg. 1996]); «Utilizar este recurso natural en el cien por ciento de los casos es una necesidad imperiosa» (Mendoza Niñez [Perú 1994]); «El calor es pegajoso, la humedad del cien por cien» (Sierra Regreso [Esp. 1995]). 
dancia no con el sustantivo femenino sino con mil (veintiún mil pesetas y no *veintiuna mil pesetas). Esta solución ya fue criticada por Gómez Torrego (2002: 284) porque las formas consideradas incorrectas están muy extendidas en el uso culto del español de hoy, incluso se pueden considerar formas compuestas (veintiún mil / veintiuna mil). En estos casos, el Panhispánico ha optado, siguiendo el criterio del gramático, por considerar la concordancia de género como opcional: veintiún mil toneladas o veintiuna mil toneladas.

\subsection{Ordinales}

El Panhispánico se muestra innovador por lo que respecta a los ordinales. Pese a la tradicional censura de *decimoprimero y $*$ decimosegundo, cuyas formas correctas eran respectivamente undécimo y duodécimo, el nuevo diccionario incluye dos formas: las etimológicas simples undécimo y duodécimo, que son las preferidas en el uso culto, y las compuestas decimoprimero y decimosegun$d o$, creadas modernamente por analogía con la forma que adoptan los ordinales del resto de las series (vigesimoprimero, vigesimosegundo, trigésimo primero, trigésimo segundo, etc.).

Por otro lado, en relación con la ortografía de los ordinales compuestos, el Panhispánico muestra su preferencia por la grafía simple (decimotercero, decimocuarto, vigesimoprimero, vigesimoctavo, etc.), aunque también se pueden escribir en dos palabras, siendo ambos componentes variables (vigésima primera, vigésimos primeros, vigésimas primeras). Gómez Torrego (2002: 287) consideraba más habitual la escritura de estos ordinales compuestos en dos palabras.

\section{ADVERBIO}

\subsection{Fuera-afuera / dentro-adentro / abajo-arriba-debajo / adelante-delante / atrás-detrás}

En cuanto a la distribución de las variantes fuera-afuera, dentro-adentro, abajo-arriba-debajo, adelante-delante, atrás-detrás, la norma general era que, en estos casos, si el adverbio acompañaba a un verbo de movimiento, eran correctas las formas con $a$ - y $\sin a$ - (vete fuera, vete afuera); si el adverbio acompañaba a un verbo que no expresara movimiento o fuera seguido de un complemento introducido por la preposición de, las formas elegidas eran las de $\sin a$ - (quédate dentro, está fuera de la clase, detrás estarás más cómoda) (Montolío, 2000: 99-101).

El Panhispánico registra el uso de afuera y fuera, adentro y dentro con verbos de movimiento, pero incluye además el empleo de afuera y adentro sin idea 
de movimiento, con los sentidos respectivos de 'en el exterior del sitio en que se está o de que se habla' y 'en la parte interior', aunque ello es más frecuente en América que en España: «Se oyeron sonidos afuera» (Belli Mujer [Nic. 1992]); «Ya estás adentro y eres incapaz de salir» (Volpi Días [Méx. 1994]). ${ }^{8}$

Por otro lado, el uso de dentro y fuera exige en el español de España un complemento con de, explícito o implícito, lo que es infrecuente con adentro y afuera. Sin embargo, las combinaciones adentro de y afuera de son normales en el español de América, por lo que deben considerarse correctas (Gómez Torrego, 2002: 558-559). Aun así, el Panhispánico recomienda evitar este uso en el habla esmerada, pese a afirmar que en el español de América, en registros coloquiales o populares, no es infrecuente que afuera y adentro vayan seguidos de un complemento con $d e .^{9}$

\subsection{Cuestiones relativas a la ortografía}

El adverbio relativo de lugar adonde tradicionalmente se podía escribir de dos maneras según la presencia o ausencia de su antecedente: adonde cuando su antecedente estaba explícito y a donde cuando estaba implícito. Sin embargo, ya advertía Gómez Torrego (2002: 560, nota 370) la conveniencia de evitar esta regla, que solía exigir al que escribía conocimientos gramaticales. La opción tomada ha sido la de admitir como correcto el empleo indistinto de ambas formas: «Esperamos nerviosos el mediodía en el lugar a donde hemos sido conducidos» (Laín Descargo [Esp. 1976]); «Vaya a donde quiera, descanse» (Andrade Dios [Arg. 1993]).

Asimismo, el adverbio interrogativo o exclamativo adónde solo podía escribirse en una palabra; no se admitía *a dónde. Sin embargo, el nuevo diccionario no considera que haya razones suficientes para censurar la escritura de este adverbio en dos palabras, documentada desde siempre en todo tipo de textos. Así pues, son igualmente aceptables las grafías adónde y a dónde: «¿Y adónde llegaremos?»(Ocampo Cornelia [Arg. 1988]; «Esas seducciones, ¿qué significaban, a dónde conducían?» (Edwards Anfitrión [Chile 1987]).

Problemas ortográficos presentaba también la escritura de asimismo, con una doble posibilidad, conjunta (asimismo) o separada (así mismo) para un mismo significado ('también'). Se siguen aceptando las dos, pero se prefiere la grafía simple, cuando antes la preferida era la grafía en dos palabras -que

8. En España, con verbos de estado o de no movimiento, es más frecuente el uso de dentro y fuera que el de adentro y afuera.

9. Lo mismo ocurre con arriba de y abajo de, que, pese a estar ampliamente documentados en el español popular y culto de zonas de América (en España, en zonas rurales), el Panhispánico recomienda evitar su uso en el habla esmerada. 
tenía también el significado de 'de este modo', lo que provoca mayores dificultades ortográficas.

Con respecto a enseguida, hoy es mayoritaria y preferible su escritura en una sola palabra, aunque también es válida la grafía en seguida. Sin embargo, Gómez Torrego (2002: 581-582) matizaba la preferencia de la RAE, en este caso, por la escritura en dos palabras.

\subsection{Locuciones adverbiales}

Las locuciones a campo través, a campo traviesa, a campo travieso, campo a través y campo a traviesa, que significan 'dejando el camino y atravesando el campo', se registran en el Panhispánico todas como válidas, pero se matiza que las preferidas en el uso son campo a través y a campo traviesa, y que la forma a campo travieso está en desuso. Asimismo, son incorrectas las fórmulas $* a$ campo a través y * a campo atraviesa. En cuanto a la corrección, se sigue el mismo criterio, pero, en cuanto a las preferencias, Gómez Torrego (2002: 584) comentaba que la RAE prefería las formas con las preposición $a$ al principio de las locuciones (a campo través, a campo traviesa, a campo travieso).

Algo similar ocurre con de estampida y de estampía ('repentinamente, sin preparación ni anuncio alguno'). Durante largo tiempo se prefirió la forma de estampía, tal como señala Gómez Torrego (2002: 585). Actualmente, la lengua culta opta claramente por la forma de estampida, pese a que durante mucho tiempo solo se consideró válida la variante de estampía, la cual continúa documentándose.

Por su parte, de seguida, con el significado de 'inmediatamente, enseguida', especialmente frecuente entre hablantes catalanes -esta misma locución existe en catalán-, sigue admitiéndose (ya en el DRAE de 2001 se registraba con este significado), pese a la recomendación de Gómez Torrego (2002: 584-585) de evitarla por no pertenecer a la lengua culta.

Las locuciones de pie y de pies, sinónimas de en pie, se consideraban igualmente válidas, aunque de pies se registraba como menos culta (Gómez Torrego, 2002: 590). El Panhispánico censura la forma de pies, normal en etapas anteriores del español, por sentirse hoy como vulgar, por lo que debe evitarse en el habla culta.

\section{PREPOSICIONES}

7.1. $A$

Durante largo tiempo la secuencia a por fue considerada incorrecta. Ya Gómez Torrego (2002: 661) insistía en que, pese a ser desconocida en Améri- 
ca, no debiera censurarse, por su uso frecuente en España -sobre todo en el registro periodístico-, por su papel desambiguador y por la existencia de otras agrupaciones preposicionales aceptadas (de por). Finalmente, el Panhispánico se hace eco de la presencia de esta construcción en España, aunque en la norma culta goza de preferencia el empleo de por, y la acepta por existir en la lengua otras agrupaciones preposicionales, como para con, de entre, por entre, tras de, de por, etc., perfectamente normales.

Algunos empleos incorrectos de $a$ por otra preposición, documentados por Gómez Torrego (2002: 667-670), se incluyen en el nuevo diccionario de dudas como correctos. Son los casos de *colaborar a algo (con alguien) $\rightarrow$ colaborar en algo con alguien y *hacer mención a algo / a alguien $\rightarrow$ hacer mención de algo / de alguien. El Panhispánico acepta que, para el verbo colaborar, el asunto en el que se colabore se exprese con un complemento introducido por en o, raramente, a; la construcción hacer mención requiere un complemento introducido por de o por $a$, este último menos recomendable, aunque también válido.

Por otra parte, las construcciones sentarse a y sentarse en son igualmente válidas si bien con un matiz significativo distinto: la primera indica 'alrededor de la mesa, normalmente para comer' y la segunda se refiere a 'encima de la mesa' (Gómez Torrego, 2002: 674). El Panhispánico reconoce que, en sentido recto, sentarse en la mesa significa 'acomodarse encima de ella', pero, dada su extensión de uso, esta expresión funciona también como equivalente de sentarse a la mesa. Es más, cuando el sustantivo mesa lleva elementos especificativos lo normal es usar la preposición en: Se sentó en la mesa del fondo y pidió el menú.

Se siguen aceptando las locuciones en relación con y con relación a ('a propósito de' y 'en comparación con'). Sin embargo, pese a su uso frecuente en la lengua culta de América, se sigue censurando el empleo de *en relación $a$, resultado del cruce entre ambas..$^{10}$

\subsection{De}

Algunos de los usos incorrectos de la preposición de documentados por Gómez Torrego (2002: 698), al igual que ocurre con los de la preposición $a$, se incluyen en el nuevo diccionario de dudas como correctos. Así, por ejemplo: *mucho gusto de saludarle $\rightarrow$ mucho gusto en saludarle, *puede hacerse acreedor de algo $\rightarrow$ puede hacerse acreedor a algo y *quedó de venir a vernos $\rightarrow$ quedó en venir a vernos. El Panhispánico acepta las secuencias mucho gusto en y mucho gusto de, aunque se explicita que en la lengua culta es mucho más frecuente la primera; acreedor/a se construye con un complemen-

10. Gómez Torrego (2002: 672-673) ya insistía en este uso frecuente de en relación a, razón que debiera favorecer su aceptación. 
to introducido por $a$ o de; y quedar(se), con el sentido de 'acordar', se construye hoy normalmente con un complemento introducido por $e n$, pero aún pervive, especialmente en países americanos como México o Colombia, el uso clásico con de.

Respecto de y respecto a son locuciones igualmente válidas, aunque se considera más culta, pero menos frecuente, respecto de (Gómez Torrego, 2002: 702). El Panhispánico registra ambas locuciones y simplemente comenta que respecto $a$ es actualmente más frecuente.

\subsection{En}

Algunos de los usos incorrectos documentados por Gómez Torrego (2002: 705-706) de la preposición en se registran en el Panhispánico como correctos:

a) *Te veré el lunes en la tarde: con esta preposición en delante del complento de tiempo relativo a una parte del día es de uso frecuente en Hispanoamérica (en España es un arcaísmo), por lo que se recoge en el nuevo diccionario de dudas, junto a la preposición más habitual por.

b) Con el significado de 'en apoyo de algo o alguien' se emplea a favor de; con el de 'en beneficio de alguien', pueden usarse a favor de y en favor de. Sin embargo, el Panhispánico añade que, por influjo de la expresión antónima en contra, a veces, especialmente en América, se sustituye la preposición $a$ por en y se dice en favor (de), y resulta admisible cuando el complemento con de está explícito: «Una refutación y un alegato en favor de la reapertura de relaciones con el régimen dominicano» (V. Llosa Fiesta [Perú 2000]).

c) *Estar en la expectativa $\rightarrow$ Estar a la expectativa. Sin embargo, es ya muy normal la expresión estar en expectativa (de destino), sobre todo en el lenguaje administrativo. Con el significado de 'espera', el Panhispánico incluye, sin ningún otro comentario, las construcciones a la expectativa o en expectativa: «La nación entera está a la expectativa de los resultados que de este diálogo puedan desprenderse» (Prensa [Nic.] 30.6.97); «En Pamplona recalaron don Carlos y Conchita, en expectativa de mejores tiempos» (Laín Descargo [Esp. 1976]).

d) * Interesarse en $\rightarrow$ Interesarse por. Según el Panhispánico, se construye con por o, menos frecuentemente, en: «Se interesó POR los estudios de los niños» (Chavarría Rojo [Ur. 2002]); «Me interesé EN aquella anciana de cabellos blancos» (Pinto Despertar [C. Rica 1994]).

\subsection{Entre}

El uso de entre por cuanto delante de más y menos ha sido hasta el momento censurado por parte de la Real Academia (Gómez Torrego, 2002: 708). Sin 
embargo, el nuevo diccionario de dudas admite su uso (únicamente) en México y el área centroamericana, por ser normal entre hablantes de todos los niveles: «Entre más vieja estoy menos entiendo la vida» (Elizondo Setenta [Méx. 1987]).

\subsection{Por}

La eliminación de la preposición por en los sintagmas *ayer noche, *ayer tarde y *ayer mañana era hasta ahora considerada una grave incorrección (Gómez Torrego, 2002: 713). El Panhispánico coincide en afirmar que el adverbio ayer lleva a menudo un complemento introducido por una preposición que ciñe la referencia temporal a una parte concreta del día; pero discrepa al aceptar la posibilidad de usar expresiones más breves, ya existentes en el español clásico, en las que tarde y noche, funcionando como adverbios, se posponen directamente a ayer: «Fidel Castro llegó ayer tarde a Santiago» (Tiempo [Col.] 11.11.96); «Ayer noche estuve limpiando este sitio» (Cohen Muerte [Esp. 1993]). En cambio, no ha prosperado la expresión reducida ayer mañana, tal vez debido a que el término mañana es polisémico, tal y como se comenta en el Panhispánico.

\subsection{Sobre}

Hemos registrado dos casos en los que el antiguo empleo incorrecto de la preposición sobre ha sido ya aceptado.

Por una parte, el verbo disparar, según Gómez Torrego (2002: 719), se construía con un complemento introducido por contra y no por sobre: *Los delicuentes dispararon sobre el director del banco (correcto: ... contra el director...). Sin embargo, el Panhispánico acepta que este verbo lleve un complemento preposicional introducido por contra o sobre, que exprese el objetivo del disparo.

Por otra parte, dada la generalización del empleo del verbo debatir como intransitivo, con un complemento introducido por sobre, el nuevo diccionario de dudas consiente en aceptarlo, si bien matiza que la lengua culta prefiere su empleo como transitivo (véase lo dicho en el apartado de «verbos indebidamente intransitivados»).

\subsection{Locuciones preposicionales}

Bastantes novedades incluye el Panhispánico con respecto a algunas locuciones preposicionales. De este modo, acepta el uso -desaconsejado por Gómez Torrego (2002: 723)- de a falta de con complementos temporales ( $« \mathrm{El}$ conjunto andaluz [...] empató a falta de un minuto para el final del partido», 
D. Navarra [Esp.] 3.1.01), puesto que entre las acepciones de faltar se encuentra la de 'tener que transcurrir el tiempo que se indica para que se realice algo' (Falta una hora para que llegue el tren). Asimismo, la locución a bordo, válida referida a barcos o aviones pero no a automóviles (*Alguien iba a bordo de un automóvil) (Gómez Torrego, 2002: 723), pasa a extender su ámbito de aplicación a cualquier medio de transporte, por lo que ejemplos como «El dentista ayudó a subir a bordo el sillón portátil» (Sepúlveda Viejo [Chile 1989]) o «La espera en el coche o a bordo de un taxi» (Marías Corazón [Esp. 1992]) ya se registran como correctos.

La locución conforme a, que no debía emplearse sin a (*Conforme lo expuesto) (Gómez Torrego, 2002: 724), en el nuevo diccionario de dudas se incluye tanto con la preposición como sin ella, uso este último que no se censura.

De cara a con los significados 'con vistas a', 'con miras a', 'para', 'ante' y 'respecto de' ya era aceptada por Gómez Torrego (2002: 725), si bien se prefería no abusar de dicha locución preposicional. En el Panhispánico se registran todos los sentidos que adquiere la expresión, pero se rechazan algunos de ellos: no se recomienda el empleo de (de) cara a con el sentido de 'ante', aunque sea frecuente en el lenguaje periodístico, y tampoco debe emplearse con el sentido de 'en relación con'.

Gómez Torrego (2002: 726) recomendaba utilizar en lugar de en orden a ('para o con el fin de') los sustitutos para, con el fin de, con objeto de o con el propósito de. Sin embargo, este sentido, según documenta el Panhispánico, ya existía en el español clásico y es, por tanto, admisible, aunque modernamente pueda estar influido por el inglés in order to: «Les interesa sobremanera alcanzar algún tipo de colaboración en orden a potenciar sus respectivas cuotas de mercado» (Abc [Esp.] 6.10.97).

Finalmente, las formas anteriormente a y posteriormente $a$, ambas censuradas por Gómez Torrego (2002: 723 y 727), se incluyen sin ningún problema en el nuevo diccionario de dudas, como puede comprobarse en las entradas de posterior y anterior: en ellas, se desaconseja el uso de estas voces con valor adverbial, como meros sinónimos de después o de posteriormente y de antes o de anteriormente, respectivamente; en su lugar se recomienda decir después de eso o posteriormente a eso y antes de eso o anteriormente a eso.

\section{CONCLUSIONES}

Cuando iniciamos esta investigación, partimos de la presuposición de que posiblemente el nuevo diccionario de dudas repetiría una vez más la norma preestablecida. Por ello, consultamos unas cuantas entradas de este dicciona- 
rio (el número, el grado y algún verbo), que tiraron por tierra nuestra hipótesis inicial. A través de nuestro trabajo, hemos podido constatar que hay un gran número de modificaciones en las cuestiones de normativa de la morfosintaxis del español.

Como primera conclusión, podemos afirmar que el nuevo diccionario se muestra flexible a la hora de aceptar usos ya extendidos e integra tanto los de la norma española como los de la americana. Así, por ejemplo, la pluralización de los latinismos según las reglas generales de formación del plural en castellano, la admisión del interrogativo a dónde, la validez de las expresiones ciento por ciento, cien por ciento y cien por cien, la aceptación de decimoprimero y decimosegundo, o la inclusión como correctas de formas de superlativo tales como fuertísimo, cruelísimo, sagradísimo, valientísimo y calientísimo -si bien se exceptúan algunas voces como *noblísimo o *fielísimo, que continúan considerándose incorrectas.

Un capítulo importante lo componen los regímenes verbales. Como ya hemos visto, se amplían para algunos verbos sus usos sintácticos a partir de motivos como, entre otros, la extensión del uso en los últimos tiempos, o su frecuencia en América, o su presencia en algún campo del saber. En algunas ocasiones, simplemente se introduce el régimen antes censurado sin dar ninguna explicación. Sin embargo, pese a su habitual uso, entre los verbos indebidamente transitivados siguen presentes cesar (*Han cesado al director), dimitir (*Han dimitido al director), explotar (*El niño explotó el globo) y luchar (*Lucha todos los balones). Y entre los verbos indebidamente intransitivados se sigue incluyendo rehusar (*Rehusé a/de hacer eso). Algo similar ocurre con las preposiciones: muchos antiguos usos censurados pasan a considerarse correctos. Así, se acepta Mucho gusto de saludarle, pero, sin embargo, se proscribe el empleo de en relación a, de uso habitual.

Con respecto a lo dicho, comprobamos que, si bien se puede hablar de un «espíritu abierto» por parte del nuevo diccionario, conviene tener en cuenta que no todos los usos habituales han sido incluidos como correctos. Y, en algunas ocasiones, nos planteamos -por supuesto, desde un plano subjetivo- hasta qué punto se ha llegado, al registrar, incluso, secuencias que, desde nuestra visión como hablantes, no responden a un uso real generalizado. Nos referimos, por ejemplo, a construcciones como de seguida (en lugar de enseguida) o conforme lo expuesto (en lugar de conforme a). Y, por otra parte, tampoco terminamos de entender las modificaciones con relación a las preferencias formales: asimismo frente a así mismo con el significado de 'también' (antes era al revés); enseguida frente a en seguida (antes era al revés); a campo travieso, registrada por la RAE como una de las formas preferidas para el significado de 'atravesando el campo' pasa ahora a considerarse en desuso; de estampía, única forma válida durante mucho tiempo, se sitúa detrás de su 
correspondiente forma de estampida; etc. Confiamos en que todo ello, en definitiva, responda a la realidad lingüística de uso.

A partir de estas observaciones, no hemos querido dejar este trabajo en un plano puramente descriptivo, por lo que hemos ahondado en los usos morfosintácticos admitidos por el Panhispánico, haciendo un cotejo con los datos que ofrece el CREA, por una parte, y los que hemos extraído a partir de una encuesta sobre usos reales que se ha pasado a 34 alumnos de la Facultad de Ciencias Humanas de la Universitat Jaume I, por otra parte.

Sin pasar a ofrecer datos estadísticos -pues eso sería otra investigación-, queremos dejar constancia, en primer lugar, de que los nuevos usos aceptados por el Panhispánico se registran todos ellos en el CREA, si bien su frecuencia de aparición, salvo en contadas excepciones -el plural de los latinismos y las locuciones adverbiales excepto de seguida- es siempre menor que los usos considerados cultos -se ha realizado la búsqueda en todos los textos del CREA, tanto escritos como orales.

En segundo lugar, a partir de los datos ofrecidos por las encuestas, se concluye que la mayor parte de los nuevos usos incluidos en el Panhispánico -dejando aparte los americanos- responden a la realidad lingüística diaria: los alumnos vacilan a la hora de añadir $-s$ o -es para formar el plural; pluralizan los latinismos siguiendo las normas generales del castellano; utilizan como transitivos los verbos apelar, callar, recurrir y repercutir -incluso explotar, pese a que todavía no se ha aceptado-, y como intransitivos abdicar, entrenar y suspender; emplean la perífrasis deber + infinitivo tanto para el significado de obligación como de posibilidad; prefieren decir veintiuna mil toneladas a veintiún mil toneladas; vacilan ante $a$ donde y adonde, y para la pregunta optan por a dónde; escriben asimismo y enseguida -esta última la prefieren a de seguida-; en cuanto a las preposiciones, seleccionan las recientes formas aceptadas (a por, hacer mención a, sentarse en y acreedor de) y alguna censurada como en relación a. Sin embargo, se muestran reacios a utilizar formas como calientísimo, fuertísimo o nuevísimo, así como decimoprimero o decimosegundo; finalmente, de las locuciones preposicionales los datos mayoritarios responden a los antiguos usos (se evitan construcciones como a falta de, a bordo de, conforme, de cara a, en orden a, posteriormente a).

Pese a las observaciones realizadas, no podemos dejar de afirmar que el esfuerzo llevado a cabo por parte de los participantes en el proyecto de la elaboración del Diccionario panhispánico de dudas ha sido, sin lugar a dudas, digno de elogiar, no solo por la inclusión de un buen número de voces utilizadas actualmente y hasta ahora censuradas, sino también por las correspondientes explicaciones para cada una de las entradas del nivel de lengua al que pertenecen los usos incluidos. 


\section{REFERENCIAS BIBLIOGRÁFICAS}

Gómez Torrego, L. (2002): Nuevo manual de español correcto, Madrid, Arco Libros, 2 volúmenes.

LÁzaro CARreter, F. (1997): El dardo en la palabra, Barcelona, Galaxia Gutenberg, Círculo de lectores.

MARTÍN ZORRAQUINO, $\mathrm{M}^{\mathrm{a}} \mathrm{A}$. (2001): «El neoespañol y los principios que fundamentan la lengua estándar o consagrada», en II Congreso Internacional de la Lengua Española, <http://cvc.cervantes.es/obref/congresos/valladolid/>.

Martínez de Sousa, J. (2006): «El Diccionario panhispánico de dudas ¿cumple con su deber?», La palabra y su escritura, Gijón, Ediciones Trea, 183-199.

Montolío, E. (2000) (coord.): Manual práctico de escritura académica en español, Barcelona, Ariel.

Seco, M. (1998): Diccionario de dudas y dificultades de la lengua española, Madrid, Espasa Calpe, 10. a edición.

Real ACAdemia Española: Corpus de Referencia del Español Actual, crea. En <http://www.rae.es.>.

- (2001): Diccionario de la lengua española. En http://www.rae.es. Avance de la 23. a edición.

Real Academia Española y Asociación de Academias de la Lengua ESPAÑOla (2005): Diccionario panhispánico de dudas, Madrid, Santillana.

Velando, M. (2006): «El tratamiento del género gramatical en el Diccionario panhispánico de dudas: entre la tradición y la novedad», Hesperia. Anuario de Filología Hispánica, Ix: 225-242. 


\title{
EL LEÍSMO EN ANDALUCÍA: \\ UNA RADIOGRAFÍA SOCIOLINGÜÍSTICA
}

\author{
Astrid Huygens \\ Universidad de Gante
}

\section{INTRODUCCIÓN}

$\mathbf{E}$ $\mathrm{N}$ el presente artículo trataré un fenómeno lingüístico que intriga y divide a los investigadores de la lengua española desde hace más de cuatro siglos: ${ }^{1}$ el leísmo. Comúnmente se habla de leísmo cuando la forma dativa aparece en la posición de objeto directo. Dado que etimológicamente es el pronombre acusativo el que representa esta función, la gramática tradicional califica las formas de «le(s)» de «transgresiones» (Alcina Franch y Blecua, 1975: 607) o «desajustes» (RAE, 1973: 205). Como foco contagioso de estas «alteraciones del estado originario» (Gil y Gaya [1941], 1948: 207) se suele indicar la región de las dos Castillas. A pesar de la agresiva expansión quedarían algunas zonas exentas del contagio, llamadas no leístas. Se trataría, entre otras, de Aragón, las Islas Canarias, la mayor parte de América y, finalmente, Andalucía. Con este trabajo pretendo demostrar que la oposición entre zonas leístas y zonas no leístas no es tan nítida como sugieren las gramáticas. De los datos del corpus se aprecia que si, en vez de examinar exclusivamente el comportamiento pronominal de las frases prototípicamente transitivas directas, tal como hacen los autores antes mencionados, se examinara otro tipo de construcción, como los verbos psicológicos, Andalucía también se calificaría de zona leísta.

Por otra parte, no hay que olvidar la gran presión que ejerce, por su prestigio y consiguiente omnipresencia en los medios de comunicación, la variedad madrileña, sobre todo en las generaciones jóvenes. Del corpus se desprende, primero, que los jóvenes son más sensibles al leísmo que las personas de 35 años y más. Esto corrobora las observaciones de Cano Aguilar y González (2000: 95). En segundo lugar se aprecia, que dentro de la categoría de los jóve-

1. «Ya en los siglos XVI y XVII los primeros gramáticos de la lengua española no se ponían de acuerdo al intentar describir las reglas conforme a las cuales se empleaban estos clíticos. El asunto ha seguido ocupando a las principales figuras de la gramática hasta el presente, pero la falta de acuerdo en las explicaciones propuestas revela que el leísmo, así como las confusiones asociadas, el laísmo y el loísmo, pese al interés que siempre han suscitado, son fenómenos complejos que todavía estamos lejos de comprender plenamente ni en su génesis histórica ni en su funcionamiento actual» (Fernández Ordóñez, 1993: 63). 
nes, los que provienen de Sevilla capital son más leístas que los que viven en los pueblos de la Sierra Norte de Sevilla. También se observa que las personas que no han seguido más que estudios primarios son más reticentes respecto de la forma dativa que los que tienen formación secundaria y superior, y, finalmente, que los hombres emplean más «le» que las mujeres.

Los resultados se basan en el análisis de un cuestionario lingüístico sometido $^{2}$ en noviembre del año 2005 a 249 informantes sevillanos, hombres y mujeres, de distinta edad (15-34 años, 35-55 años, +55 años), procedencia geográfica (Sierra Norte, pueblos alrededor de Sevilla, Sevilla capital, otras provincias andaluzas) y nivel de instrucción (estudios primarios, estudios secundarios, estudios superiores). Cada cuestionario está compuesto por 89 frases sacadas de novelas y periódicos españoles. Las 89 frases equivalen a un total de 176 blancos. De estos 176 hay 37 (o un $21,02 \%$ ) que investigan el leísmo con verbos psicológicos.

\section{LOS VERBOS PSICOLÓGICOS: DEFINICIÓN Y TIPOLOGÍA}

Por verbos psicológicos entendemos, conforme a Melis (1999: 50), aquellos verbos que «[...] denotan un proceso de afectación psicológica en el que figuran el ser animado que sufre el proceso, conocido como "el experimentante", y la entidad externa que suscita el proceso en el experimentante, a la que llamaré aquí el "estímulo".» Quiere esto decir que tanto «María le tiene miedo a Óscar», como «María teme a Óscar» y «Óscar le terroriza a María» se definen como construcciones psicológicas. En las últimas dos construcciones el sentimiento que le afecta al experimentante va incorporado en el verbo mismo («temer» «temor»; «terrorizar» «terror»), en la primera se expresa en un argumento sintáctico suplementario («miedo»). El presente trabajo se limita al estudio de las últimas dos construcciones.

Éstas se suelen dividir, de acuerdo con Ruwet (1993: 96), ${ }^{3}$ en tres subcategorías, según la posición gramatical ocupada por el experimentante -la de sujeto («temer»), la de objeto directo («preocupar») o la de objeto indirecto («gustar»). En español la frontera entre objeto directo y objeto indirecto muchas veces es borrosa, entre otras cosas por la existencia de fenómenos como el leísmo y el acusativo preposicional, por lo que resulta más adecuado discernir

2. Agradezco sinceramente al profesor Manuel Marín de la Universidad de Sevilla por su ayuda y útiles consejos durante este trabajo.

3. «Les $\Psi$ se répartissent presque tous dans trois classes principales, selon la position syntaxique du NP désignant l'être humain (ou assimilé: animal, dieu, diable, fantôme, etc.) qui est "le siège de l'émotion" (en anglais: experiencer)». 
tan sólo dos grupos, conforme a Bouchard (1995: 6): los verbos con sujet expérienciel, o sea los verbos cuyo experimentante desempeña la función gramatical de sujeto, y los verbos con objet expérienciel cuyo experimentante ocupa la posición de objeto -directo o indirecto.

La segunda categoría (con el experimentante en la posición gramatical del objeto) se suele dividir en dos subcategorías, que varían según el criterio utilizado. Fernández Ordóñez (1999: 1323) se basa, por ejemplo, en el criterio de la agentividad, y opone una estructura agentiva a una estructura no agentiva. Bouchard (1995: 280) hace la misma distinción, pero habla respectivamente de lectura agentiva y lectura psicológica, produciéndose esta última cuando el estímulo es un concepto, es decir «an element in the semantic field of mental space». Autoras como Vázquez Rosas (1995: 211-212) y Di Tullio (1997: 255), al contrario, utilizan un criterio aspectual, y hablan de estructuras incoativas frente a estructuras estativas o resultativas. Finalmente, Melis (1999: 50) trabaja desde un punto de vista más bien pragmático, distinguiendo una «construcción transitiva básica que muestra un sujeto preverbal» $\mathrm{y}$ una «construcción de voz inversa con [...] sujeto posverbal». Mientras esta disminuiría el papel del estímulo en el evento emocional, aquella acentuaría la participación del mismo. De las distintas interpretaciones se aprecia que la segunda categoría (con el experimentante en la posición gramatical del objeto) es la más estudiada en la literatura sobre los verbos psicológicos en español. Esto explica por qué acerca del comportamiento pronominal de los verbos psicológicos con sujeto experimentante se ha escrito poco, mientras que el de los verbos con objeto experimentante se presta a discusión. La hipótesis más aceptada, sin embargo, es la de Fernández Ordóñez (1999: 1324) según la cual el pronombre acusativo se asociaría con estímulos animados y el dativo con estímulos inanimados. Whitley (1995: 577-578) añade que más que la agentividad real del estímulo es la percepción de la misma por el locutor que determina la selección pronominal: «At any rate, the casting of objects for "transitive" psych verbs like preocupar and sorprender may reflect speaker perception of roles rather than fixed case assignment».

\section{LEÍSMO EN ANDALUCÍA}

Antes de comprobar si -tal como pretende Fernández Ordóñez- las estructuras agentivas seleccionan menos leísmo que las no agentivas, conviene preci-

4. «Cuando el sujeto es inanimado o una oración, el objeto suele pronominalizarse en dativo, y cuando el sujeto es animado, y encierra mayores posibilidades de ser concebido como agente, el objeto tiende a pronominalizarse en acusativo. Sin embargo, la selección de caso depende de la interpretación que el hablante quiera otorgar a la oración. Si el sujeto animado no se concibe como agente, el dativo es posible [...], y si un sujeto inanimado u oracional puede concebirse como causa del proceso que afecta al experimentante, podemos encontrar el acusativo». 
sar lo que entendemos por agentividad. Aunque Fernández Ordóñez (1999) no proporciona ninguna definición, de los ejemplos que cita se deduce con facilidad que para ella el sujeto de la estructura agentiva es necesariamente animado y de preferencia también volitivo. ${ }^{5}$ Sin embargo, en el corpus se hallan frases como (43c) con sujeto inanimado que, a mi ver, difícilmente se pueden considerar como no agentivas, ya que son frases en las que ocurre algo:

(43c) $-i$ Por eso viaja usted en una camioneta blindada? La camioneta blindada es para protegerlo a usted -dijo Pizarro con ironía. A mí me cuidan mis muchachos, los que vienen atrás y los que van adelante. Pero a usted no lo cuida nadie, y no vaya a ser. La pregunta lo había irritado, se enderezó en el asiento.

Sería una contradicción in terminis no atribuirle una lectura agentiva a una frase que describe una acción. El sujeto («la pregunta») no es animado, ni volitivo. Sólo es causativo, es decir que produce, dentro de los límites de la predicación, un efecto en otro argumento verbal. La agentividad es, pues, un concepto multicomponente, tal como opina también Dowty (1991: 572). A su ver, el agente prototípico es volitivo (se implica deliberadamente en la acción descrita por el verbo), intencional (dirige su atención hacia el otro argumento verbal), causativo (produce un efecto en el otro argumento verbal) y dinámico (gasta energía en la realización de la acción).

Estos dos papeles ocupan un lugar central en el principio de la selección de argumentos, que determina qué argumento desempeña qué función gramatical. Según Dowty (1991: 576), el sujeto de la frase es el argumento que más propiedades del proto-agente exhibe, mientras que el objeto directo es el argumento que más rasgos del proto-paciente reúne. Este esquema, sin embargo, se ve trastocado en cuanto quepa duda acerca de la distribución de los argumentos. Es el caso cuando el agente es menos agentivo de lo normal, o cuando el paciente no es tan pasivo como suele ser. La reducción de la distancia entre agente y paciente puede llevar a una confusión entre ambos papeles, y por lo tanto, entre sus respectivas formas. Un ejemplo de una construcción con distribución ambigua lo constituyen los verbos psicológicos, como observa Primus (1999: 44). ${ }^{6}$

5. Aunque habla de estructuras no agentivas, está claro que en realidad no se refiere tanto a las características semánticas de los argumentos, sino más bien al aspecto estático de la frase.

6. «The Argument Selection Principle [...] predicts that verbs such as build, write, murder, eat and wash in their literal meaning are the most stable ones with respect to their argument pattern accross languages [...]. By contrast, experiencer-stimulus verbs select fewer Proto-Role properties for their arguments and are accordingly less stable with respect to their argument pattern accross languages and very often also within one language.» 
Los ejemplos (3b), (50b) y (56a) nos permiten comprobar la validez de la teoría de Dowty. En los tres casos se trata de verbos psicológicos con sujeto experimentante. Los verbos de esta categoría suelen clasificarse ${ }^{7}$ como estados. Contrariamente a los de la segunda clase, adoptan una estructura transitiva básica en la que el experimentante coincide con el sujeto/agente, y no con el objeto/paciente. El experimentante suele ser no activo, pero L. Di Desidero (1992: 32-39) demuestra que algunos verbos de esta clase, concretamente los que expresan un sentimiento positivo, pasan algunas de las pruebas sintácticas desarrolladas por Lakoff (1966) para distinguir los verbos estáticos de los no estáticos. Señala que en algunos contextos admiten, por ejemplo, el imperativo, ${ }^{8}$ el adverbio de manera ${ }^{9}$ y la sustitución mediante el verbo «hacer». ${ }^{10}$ Esta idea se confirma, entre otros, por Rifón (1997: 253) quien opina que «no se puede establecer una diferenciación dicotómica» entre la dinamicidad y la estatividad. Las frases (3a), (50b) y (56a) representan situaciones que requieren cada vez más esfuerzo por parte del experimentante, hasta tal punto que el último («aguantar») muchas veces ya no se incluye entre los verbos psicológicos. Cano Aguilar (1981: 204) apunta, por ejemplo, que «aguantar» y «soportar» «se prestan más a una interpretación donde el sujeto no es totalmente pasivo». ${ }^{11}$ Según la teoría de Dowty tendría que apreciarse, pues, cada vez menos leísmo. La tabla (1) recoge los recuentos:

Los resultados confirman la hipótesis de Dowty: con «querer» el verbo selecciona el pronombre dativo en un 63\% de los casos, pero este porcentaje disminuye a medida que el experimentante se vuelve más agentivo. Es el caso con «adorar», verbo que expresa un sentimiento mucho más intenso que «querer», hasta tal punto que muchas veces se comporta como sinónimo del verbo activo «reverenciar». Y es aún más el caso con «aguantar», por las razones que expliqué antes.

El alto porcentaje de leísmo con «querer» demuestra que el leísmo está lejos de estar ausente en Sevilla. De ahí que la tradicional descripción de Andalucía como zona no leísta sea incorrecta. La selección pronominal por

7. En la clasificación aspectual de Vendler (1967).

8. «Love your sister, will you, she's all you've got».

9. «She loved him well but reluctantly».

10. «I loved him anyway, although my parents told me not to do so».

11. Vanhoe (2004: 100-101) afina esta idea al comparar las frases (111a) «Pedro siempre ha soportado el comportamiento de su hermano» y (111b) «Pedro siempre ha detestado el comportamiento de su hermano»: «En (111b), Pedro tiene una emoción que en general, no puede controlar. En el primer ejemplo, en cambio, la interpretación más natural es que Pedro siempre ha soportado el comportamiento de su hermano, porque siempre ha hecho un esfuerzo para soportarlo; quizás sea esta la razón por la que con estos verbos, el imperativo no es totalmente excluido (podemos mandar a alguien hacer un esfuerzo para conseguir algo).» 
parte de los habitantes de esta zona se rige por los mismos mecanismos que los de zonas consideradas como leístas, al menos en lo que se refiere a los contextos menos prototípicos.

TABLA 1

\begin{tabular}{|c|c|c|c|c|c|c|c|c|c|c|c|c|c|}
\hline \multirow{2}{*}{ 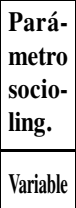 } & \multirow{2}{*}{$\begin{array}{c}\varnothing \\
\varnothing\end{array}$} & \multicolumn{2}{|c|}{ Sexo } & \multicolumn{3}{|c|}{ Edad } & \multicolumn{3}{|c|}{ Formación } & \multicolumn{4}{|c|}{ Lugar de residencia } \\
\hline & & Masc. & Fem. & $15-34$ & $35-55$ & $>55$ & Prim & Sec & Sup & $\mathrm{Sn}^{1}$ & Pbl & $\mathrm{Se}$ & And \\
\hline \multicolumn{14}{|c|}{$\begin{array}{l}\text { Frase 3b: El padre Ernesto acompaña al padre Enrique hasta el paradero del autobús y decide caminar un rato por } \\
\text { las calles cercanas. Es un hombre delgado, de uno setenta y cinco de estatura [...]. La gente que asiste a su parro- } \\
\text { quia lo respeta y lo quiere. }\end{array}$} \\
\hline \multirow{2}{*}{ Le } & (153) & (61) & (90) & (71) & (76) & (6) & (28) & (69) & (56) & (56) & (13) & (61) & (12) \\
\hline & $63 \%$ & $69 \%$ & $60 \%$ & $62 \%$ & $64 \%$ & $60 \%$ & $67 \%$ & $62 \%$ & $64 \%$ & $62 \%$ & $52 \%$ & $67 \%$ & $57 \%$ \\
\hline \multirow{2}{*}{ Lo } & (89) & (28) & (61) & (43) & (42) & (4) & (14) & (43) & (31) & (35) & (12) & (33) & (9) \\
\hline & $37 \%$ & $31 \%$ & $40 \%$ & $38 \%$ & $36 \%$ & $40 \%$ & $33 \%$ & $38 \%$ & $36 \%$ & $38 \%$ & $48 \%$ & $33 \%$ & $43 \%$ \\
\hline Total & $(242)$ & (89) & (151) & (114) & (118) & (10) & (42) & (112) & (87) & (91) & (25) & (91) & (21) \\
\hline
\end{tabular}

Frase 50b: Algún tiempo después de esto, creo que fue en el año 85, Salas destituyó a Pepe Oneto como director de Cambio 16 y lo puso en la calle. Paloma, su mujer, que lo adora y lo cuida, trabajaba como funcionaria en la oficina del portavoz del Gobierno desde su fundación, en tiempos de la UCD.

\begin{tabular}{|c|c|c|c|c|c|c|c|c|c|c|c|c|c|}
\hline Le & $(112)$ & $(46)$ & $(66)$ & $(59)$ & $(47)$ & $(6)$ & $(17)$ & $(54)$ & $(40)$ & $(42)$ & $(10)$ & $(44)$ & $(8)$ \\
& $48 \%$ & $55 \%$ & $45 \%$ & $54 \%$ & $41 \%$ & $55 \%$ & $41 \%$ & $49 \%$ & $49 \%$ & $47 \%$ & $43 \%$ & $51 \%$ & $38 \%$ \\
\hline \multirow{2}{*}{ Lo } & $(122)$ & $(38)$ & $(82)$ & $(50)$ & $(67)$ & $(5)$ & $(24)$ & $(56)$ & $(42)$ & $(48)$ & $(13)$ & $(43)$ & $(13)$ \\
& $52 \%$ & $45 \%$ & $55 \%$ & $46 \%$ & $59 \%$ & $45 \%$ & $59 \%$ & $51 \%$ & $51 \%$ & $53 \%$ & $57 \%$ & $49 \%$ & $62 \%$ \\
\hline \multirow{2}{*}{ Total } & $(234)$ & $(84)$ & $(148)$ & $(109)$ & $(114)$ & $(11)$ & $(41)$ & $(110)$ & $(82)$ & $(90)$ & $(23)$ & $(87)$ & $(21)$ \\
\hline
\end{tabular}

Frase 56a: -¿Sabéis una cosa? -añadió la mayor soltando el delantal y encendiendo un cigarrillo. Me voy a separar de Alfredo. No le aguanto más. Como respondiendo al mensaje, se oyó la voz de Alfredo: - ¡iEse café!! ¿Viene o no viene? -¿Lo veis? No le aguanto. Es mandón, egoísta, ordinario, prepotente, desconsiderado y además ronca.

\begin{tabular}{|c|c|c|c|c|c|c|c|c|c|c|c|c|c|}
\hline Le & $(48)$ & $(20)$ & $(27)$ & $(31)$ & $(15)$ & $(2)$ & $(6)$ & $(26)$ & $(16)$ & $(21)$ & $(3)$ & $(22)$ & $(1)$ \\
& $20 \%$ & $22 \%$ & $18 \%$ & $27 \%$ & $13 \%$ & $18 \%$ & $14 \%$ & $23 \%$ & $18 \%$ & $23 \%$ & $12 \%$ & $24 \%$ & $5 \%$ \\
\hline \multirow{2}{*}{ Lo } & $(196)$ & $(70)$ & $(125)$ & $(84)$ & $(103)$ & $(9)$ & $(36)$ & $(88)$ & $(71)$ & $(69)$ & $(22)$ & $(71)$ & $(21)$ \\
& $80 \%$ & $78 \%$ & $82 \%$ & $73 \%$ & $87 \%$ & $82 \%$ & $86 \%$ & $77 \%$ & $82 \%$ & $77 \%$ & $88 \%$ & $76 \%$ & $95 \%$ \\
\hline Total & $(244)$ & $(90)$ & $(152)$ & $(115)$ & $(118)$ & $(11)$ & $(42)$ & $(114)$ & $(87)$ & $(90)$ & $(25)$ & $(93)$ & $(22)$ \\
\hline
\end{tabular}

1. $\mathrm{Sn}=$ Sierra norte; $\mathrm{Pbl}=$ pueblos alrededor de Sevilla; $\mathrm{Se}=$ Sevilla capital; And = otras provincias andaluzas. 
Obsérvese por lo demás que, en las tres frases, los hombres utilizan más leísmo que las mujeres, y que el leísmo de los informantes residentes en Sevilla capital es un poco más elevado que el promedio, mientras que el de los informantes de la Sierra Norte siempre es un poco más bajo, salvo en el ejemplo 56a. Esta excepción se podría deber a que muchos de los informantes ${ }^{12}$ serranos pertenecen a la categoría más joven, que como se nota, con «aguantar» resulta ser mucho más sensible al leísmo que las categorías mayores. Esto podría demostrar que en situaciones parecidas a las prototípicamente transitivas directas los jóvenes provenientes de zonas tradicionalmente consideradas como no leístas usan cada vez más el leísmo. ${ }^{13}$ En lo que sigue, se examinarán con más detalle las preferencias pronominales de los distintos grupos encuestados.

\section{UNA RADIOGRAFÍA SOCIOLINGÜÍSTICA}

\subsection{El sexo}

La variación lingüística patrocinada por el sexo siempre ha llamado la atención de los investigadores. Numerosos son los estudios que demuestran que las mujeres hablan de otro modo que los hombres: pronuncian las palabras de otra manera, ${ }^{14}$ emplean otros afijos ${ }^{15}$ y su léxico es distinto. ${ }^{16}$ La variación gramatical entre ambos sexos sería, en cambio, más bien rara. Veamos si esto también vale para el leísmo.

La tabla 2 reproduce los resultados, ordenados según la posición gramatical del experimentante y el aspecto del proceso verbal, conforme a la clasificación de Vázquez Rosas (1995) y Di Tullio (1997): ${ }^{17}$

Repárese en la discrepancia entre las frases con objeto experimentante y lectura estática por una parte y las frases con objeto experimentante y lectura no estática y las frases con sujeto experimentante por otra. Con aquellas las mujeres encuestadas (155 en total) emplean más leísmo que los hombres encuestados (94 en total), mientras que con estas es al revés: en las frases con objeto experimentante y lectura no estática los informantes masculinos utilizan un $4 \%$ más de leísmo que las mujeres, y en las frases con sujeto experimentante la diferencia es de más de un $10 \%$.

12. Concretamente se trata de 43 de los 94 informantes, o sea de un $45,74 \%$.

13. Cf. Cano Aguilar y González (2000: 95).

14. Cf., entre otros, Salvador (1952), Fontanella de Weimberg (1973), etc.

15. Cf., entre otros, Bodine (1975).

16. Cf., entre otros, Cappell (1966).

17. Cf. supra. 
TABLA 2

\begin{tabular}{|c|c|c|c|c|c|c|c|c|c|c|c|c|}
\hline \multirow{3}{*}{ Total } & \multirow{2}{*}{\multicolumn{3}{|c|}{ Total }} & \multirow{2}{*}{\multicolumn{3}{|c|}{$\begin{array}{l}\text { Sujeto experimentante } \\
\text { (Lectura estática) }\end{array}$}} & \multicolumn{6}{|c|}{ Objeto experimentante } \\
\hline & & & & & & & \multicolumn{3}{|c|}{ Lectura estática } & \multicolumn{3}{|c|}{ Lectura no estática } \\
\hline & Total & Masc. & Fem. & Total & Masc. & Fem. & Total & Masc. & Fem. & Total & Masc. & Fem. \\
\hline Le & $72,88 \%$ & $76,05 \%$ & $71,05 \%$ & $51,03 \%$ & $57,49 \%$ & $46,98 \%$ & $95,60 \%$ & $95,50 \%$ & $95,74 \%$ & $71,54 \%$ & $74,64 \%$ & $70,06 \%$ \\
\hline Lo & $27,12 \%$ & $23,95 \%$ & $28,95 \%$ & $48,97 \%$ & $42,51 \%$ & $53,02 \%$ & $4,40 \%$ & $4,50 \%$ & $4,26 \%$ & $28,46 \%$ & $25,36 \%$ & $29,94 \%$ \\
\hline Total & $100 \%$ & $100 \%$ & $100 \%$ & $100 \%$ & $100 \%$ & $100 \%$ & $100 \%$ & $100 \%$ & $100 \%$ & $100 \%$ & $100 \%$ & $100 \%$ \\
\hline
\end{tabular}

Que la discrepancia sea más alta en estas frases que en las demás no ha de extrañar: presentan el esquema transitivo básico, y son, por ende, más sensibles a eventuales mecanismos de diferenciación lingüística (in casu el uso de «le» en vez de «lo») por parte de ciertos grupos (in casu los hombres). Cuanto menos prototípica la frase, más su forma parece estar gramaticalizada y menos los locutores se sienten autorizados a darle un toque personal, como si temieran cometer un error. Es probablemente por esta misma razón que los casos de variación lingüística se producen con más frecuencia en el campo léxico y fonético que en el sintáctico.

Que las mujeres seleccionen menos leísmo que los hombres se debería, según López Morales (1993?: 126), a que siempre se ha esperado que la conducta social de las mujeres, y por consiguiente también su habla, fuera más correcta que la de los hombres.

\subsection{La edad}

En su estudio dedicado a las hablas andaluzas Cano Aguilar y González (2000: 95) observan que entre los jóvenes andaluces el leísmo se extiende. Los porcentajes representados en la tabla 3 confirman esta tendencia:

TABLA 3

\begin{tabular}{|c|c|c|c|c|c|c|c|c|c|c|c|c|c|c|c|c|}
\hline & \multirow{2}{*}{\multicolumn{4}{|c|}{ Total }} & \multirow{2}{*}{\multicolumn{4}{|c|}{$\begin{array}{l}\text { Sujeto experimentante } \\
\text { (Lectura estática) }\end{array}$}} & \multicolumn{8}{|c|}{ Objeto experimentante } \\
\hline & & & & & & & & & \multicolumn{4}{|c|}{ Lectura estática } & \multicolumn{4}{|c|}{ Lectura no estática } \\
\hline & Total & $15-34$ & $35-55$ & $>55$ & Total & $15-34$ & $35-55$ & $>55$ & Total & $15-34$ & $35-55$ & $>55$ & Total & $15-34$ & $35-55$ & $>55$ \\
\hline Le & $\begin{array}{c}72,88 \\
\%\end{array}$ & $\begin{array}{c}75,30 \\
\%\end{array}$ & $\begin{array}{c}70,97 \\
\%\end{array}$ & $\begin{array}{c}73,07 \\
\%\end{array}$ & $\begin{array}{c}51,03 \\
\%\end{array}$ & $\begin{array}{c}55,17 \\
\%\end{array}$ & $\begin{array}{c}48,17 \\
\%\end{array}$ & $\begin{array}{c}47,05 \\
\%\end{array}$ & $\begin{array}{c}95,60 \\
\%\end{array}$ & $\begin{array}{c}95,45 \\
\%\end{array}$ & $\begin{array}{c}95,68 \\
\%\end{array}$ & $\begin{array}{c}96,45 \\
\%\end{array}$ & $\begin{array}{c}71,54 \\
\%\end{array}$ & $\begin{array}{c}75,27 \\
\%\end{array}$ & $\begin{array}{c}67,90 \\
\%\end{array}$ & $\begin{array}{c}77,24 \\
\%\end{array}$ \\
\hline Lo & $\begin{array}{c}27,12 \\
\%\end{array}$ & $\begin{array}{c}24,70 \\
\%\end{array}$ & $\begin{array}{c}29,03 \\
\%\end{array}$ & $\begin{array}{c}26,93 \\
\%\end{array}$ & $\begin{array}{c}48,97 \\
\%\end{array}$ & $\begin{array}{c}44,83 \\
\%\end{array}$ & $\begin{array}{c}51,83 \\
\%\end{array}$ & $\begin{array}{c}52,95 \\
\%\end{array}$ & $\begin{array}{c}4,40 \\
\%\end{array}$ & $\begin{array}{c}4,55 \\
\%\end{array}$ & $\begin{array}{c}4,32 \\
\%\end{array}$ & $\begin{array}{c}3,55 \\
\%\end{array}$ & $\begin{array}{c}28,46 \\
\%\end{array}$ & $\begin{array}{c}24,73 \\
\%\end{array}$ & $\begin{array}{c}32,10 \\
\%\end{array}$ & $\begin{array}{c}22,76 \\
\%\end{array}$ \\
\hline Total & $100 \%$ & $100 \%$ & $100 \%$ & $100 \%$ & $100 \%$ & $100 \%$ & $100 \%$ & $100 \%$ & $100 \%$ & $100 \%$ & $100 \%$ & $100 \%$ & $100 \%$ & $100 \%$ & $100 \%$ & $100 \%$ \\
\hline
\end{tabular}

Globalmente, los jóvenes entre 15 y 34 años (118 en total) utilizan más o menos un 5\% más de leísmo que los informantes entre 35 y 55 años (120 en 
total). En las frases con sujeto experimentante y en las frases no estáticas con objeto experimentante este porcentaje sube, probablemente por las razones que cité en el párrafo anterior. A primera vista los datos de la generación mayor contradicen la tendencia observada. Tienen que tomarse, sin embargo, con cautela dado que representan tan sólo a 11 informantes.

Como posibles causas de la expansión dativa entre los jóvenes, se podrían citar el alto índice de escolaridad, la influencia por los medios de comunicación y lo que López Morales (1993?: 115) llama la sensibilidad de esta generación «a las formas prestigiadas por esta comunidad». Pero el prestigio del habla castellana, aunque atestiguado y ponderado por distintos autores, ${ }^{18}$ nos deja, a la hora de definir su impacto en el uso pronominal andaluz, ante una inexplorada laguna cuya orilla la definen el papel importantísimo de Castilla en la Reconquista, ${ }^{19}$ la presencia de la corte en sus ciudades ${ }^{20}$ y los autores famosos provenientes de esta región, ${ }^{21}$ por una parte, y la aparición de medios de comunicación de marcada índole regionalista ${ }^{22}$ y la reivindicación de los propios dialectos como signos de identidad, señalada, entre otros, por KleinAndreu (2000: 26) ${ }^{23}$ por otra parte.

Otro tanto vale para los medios de comunicación cuya influencia en el uso pronominal de los jóvenes andaluces es igual de difícil de medir. En el cuestionario les pedí a los informantes que indicaran el número de horas que veían la televisión cada día por término medio. La tabla 4 exhibe los promedios:

TABLA 4

\begin{tabular}{|c|c|c|c|c|c|c|c|c|c|c|c|c|c|c|c|c|}
\hline & $0 \mathrm{~h}$ & $0,25 \mathrm{~h}$ & $0,50 \mathrm{~h}$ & $1 \mathrm{~h}$ & $1,25 \mathrm{~h}$ & $1,50 \mathrm{~h}$ & $2 \mathrm{~h}$ & $2,5 \mathrm{~h}$ & $3 \mathrm{~h}$ & $4 \mathrm{~h}$ & $5 \mathrm{~h}$ & $6 \mathrm{~h}$ & $7 \mathrm{~h}$ & $8 \mathrm{~h}$ & 1 & promedio \\
\hline $\begin{array}{l}15- \\
34\end{array}$ & & 2 & 4 & 19 & 1 & 5 & 35 & 1 & 16 & 20 & 10 & 1 & 3 & I & 1 & $\begin{array}{c}2,61 \\
\text { horas/día }\end{array}$ \\
\hline $\begin{array}{l}35- \\
55\end{array}$ & 2 & 1 & 2 & 24 & 1 & 2 & 34 & 1 & 25 & 21 & 5 & 2 & 1 & 1 & 1 & $\begin{array}{c}2,56 \\
\text { horas/día }\end{array}$ \\
\hline$>55$ & 1 & 1 & 1 & 1 & 1 & 1 & 4 & 1 & 1 & 3 & 1 & 1 & 1 & 1 & I & $\begin{array}{c}2,68 \\
\text { horas/día }\end{array}$ \\
\hline
\end{tabular}

18. Cf., entre otros, Alcina Franch y Blecua (1975: 607).

19. Cf., entre otros, Cano Aguilar (1992: 205).

20. Respectivamente Toledo, Madrid, Valladolid, y otra vez Madrid.

21. Cf., entre otros, Cervantes, Lope de Vega, Quevedo, Calderón de la Barca, etc.

22. Así en Sevilla emiten, junto a las cadenas nacionales TVE 1, La 2, Tele 5 y Antena 3, las cadenas regionales Canal Sur, Canal Sur 2, Onda Giralda, Canal 47 y Tele Sevilla.

23. «Por otra parte, también se ha constatado la influencia del llamado "prestigio encubierto" o "solidaridad", en favorecer la mantención de características locales, en contra de las más generales (Trudgill, 1972, citado en Milroy, 1980: 194). Parecería que, en general, la "solidaridad local"ha de afectar más al habla que a la escritura, ya que el habla se dirige más comunmente que la escritura justamente a personas locales (de la misma cultura, grupo social, e incluso íntimos).» 
Las tres generaciones ven igual de horas de televisión por día, lo cual demuestra que el papel de la televisión en la expansión del leísmo es reducido, por no decir nulo. Esto no quita para que para los jóvenes la televisión haya formado parte de su vida desde siempre, mientras que la mayoría de los informantes de 35 años y más haya crecido sin televisión. ${ }^{24}$ Es decir que en el período crucial, en que su habla se iba forjando, el acceso a la televisión que tenían era reducido o incluso inexistente, según la edad del informante. La influencia de la televisión en el uso pronominal debería examinarse, pues, diacrónicamente y no sincrónicamente.

Finalmente, el impacto del nivel de formación del locutor en su uso pronominal se investiga en el párrafo siguiente.

\subsection{El nivel de formación}

Los recuentos recogidos en la tabla 5 demuestran claramente que cuanto más alto es el nivel de instrucción del encuestado, más ocurrencias de «le» se cuen$\tan$. Fíjese en que son otra vez las frases estáticas con sujeto experimentante y las frases no estáticas con objeto experimentante las que mayores discrepancias entre los estratos más extremos (estudios primarios / estudios superiores) exhiben, respectivamente un $9 \%$ y un $18 \%$ :

TABLA 5

\begin{tabular}{|c|c|c|c|c|c|c|c|c|c|c|c|c|c|c|c|c|}
\hline & \multirow{2}{*}{\multicolumn{4}{|c|}{ Total }} & \multirow{2}{*}{\multicolumn{4}{|c|}{$\begin{array}{l}\text { Sujeto experimentante } \\
\text { (Lectura estática) }\end{array}$}} & \multicolumn{8}{|c|}{ Objeto experimentante } \\
\hline & & & & & & & & & \multicolumn{4}{|c|}{ Lectura estática } & \multicolumn{4}{|c|}{ Lectura no estática } \\
\hline & Total & Prim. & Sec. & Sup. & Total & Prim. & Sec. & Sup. & Total & Prim. & Sec. & Sup. & Total & Prim. & Sec. & Sup. \\
\hline $\mathrm{Le}$ & $\begin{array}{c}72,88 \\
\%\end{array}$ & $\begin{array}{c}67,55 \\
\%\end{array}$ & $\begin{array}{c}73,17 \\
\%\end{array}$ & $\begin{array}{c}76,00 \\
\%\end{array}$ & $\begin{array}{c}51,03 \\
\%\end{array}$ & $\begin{array}{c}44,21 \\
\%\end{array}$ & $\begin{array}{c}52,04 \\
\%\end{array}$ & $\begin{array}{c}53,48 \\
\%\end{array}$ & $\begin{array}{c}95,60 \\
\%\end{array}$ & $\begin{array}{c}94,96 \\
\%\end{array}$ & $\begin{array}{c}95,31 \\
\%\end{array}$ & $\begin{array}{c}96,43 \\
\%\end{array}$ & $\begin{array}{c}71,54 \\
\%\end{array}$ & $\begin{array}{c}61,04 \\
\%\end{array}$ & $\begin{array}{c}71,55 \\
\%\end{array}$ & $\begin{array}{c}79,36 \\
\%\end{array}$ \\
\hline Lo & $\begin{array}{c}27,12 \\
\%\end{array}$ & $\begin{array}{c}32,45 \\
\%\end{array}$ & $\begin{array}{c}26,83 \\
\%\end{array}$ & $\begin{array}{c}24,00 \\
\%\end{array}$ & $\begin{array}{c}48,97 \\
\%\end{array}$ & $\begin{array}{c}55,79 \\
\%\end{array}$ & $\begin{array}{c}47,96 \\
\%\end{array}$ & $\begin{array}{c}46,52 \\
\%\end{array}$ & $\begin{array}{c}4,40 \\
\%\end{array}$ & $\begin{array}{c}5,04 \\
\%\end{array}$ & $\begin{array}{c}4,69 \\
\%\end{array}$ & $\begin{array}{c}3,57 \\
\%\end{array}$ & $\begin{array}{c}28,46 \\
\%\end{array}$ & $\begin{array}{c}38,96 \\
\%\end{array}$ & $\begin{array}{c}28,45 \\
\%\end{array}$ & $\begin{array}{c}20,64 \\
\%\end{array}$ \\
\hline Total & $100 \%$ & $100 \%$ & $100 \%$ & $100 \%$ & $100 \%$ & $100 \%$ & $100 \%$ & $100 \%$ & $100 \%$ & $100 \%$ & $100 \%$ & $100 \%$ & $100 \%$ & $100 \%$ & $100 \%$ & $100 \%$ \\
\hline
\end{tabular}

Son los jóvenes los que más formación tienen. De los 118 encuestados, 116 (o un $98,31 \%$ ) han seguido estudios secundarios (72 o un 61,02\%) o superiores (44 o un 37,29\%). Entre los 120 informantes de entre 35 y 55 años, 41 (o un 34,17\%) no han seguido más que estudios primarios, 40 (o un $33,33 \%$ ) han seguido estudios secundarios y 39 (o un $32,50 \%$ ) han seguido estudios superiores. Esto corrobora la hipótesis formulada en el párrafo anterior, según la que un alto índice de instrucción favorece el uso del pronom-

24. La televisión se introdujo en España en 1956 y generalizó en la década de los años 60 y 70. 
bre dativo donde, etimológicamente, se usaría una forma acusativa. Esto se explicaría por un contacto prolongado con los autores clásicos ${ }^{25} \mathrm{y}$, ante todo, con la lengua estándar, que, como se sabe, admite el leísmo masculino de persona ${ }^{26}$ por una parte, $y$, por otra, se basa fundamentalmente en el castellano, donde «las innovaciones se observan con mayor intensidad», ${ }^{27}$ sobre todo en las construcciones prototípicamente transitivas directas.

\subsection{El lugar de residencia}

La última variable sociolingüística investigada en este artículo es el impacto del lugar de residencia del sevillano en su uso pronominal. Concretamente, se averiguarán eventuales diferencias entre pueblo y ciudad. Si es cierto, como pretende Fernández Ramírez (1987: 51), que «el leísmo irradia de Madrid», es de esperar que los índices de leísmo en las ciudades sean más elevados que en los pueblos.

En el corpus se distinguen dos tipos de pueblos. Por una parte están los pueblos de la Sierra Norte de Sevilla, que se encuentran a unos 80 kilómetros de Sevilla capital: ${ }^{28}$ se trata de Cazalla de la Sierra y los pueblos vecinos Alanís y Constantina. Por otra parte están los pueblos que se encuentran a una distancia máxima de 30 kilómetros de Sevilla capital, y que son mucho más grandes que aquellos: se trata, entre otros, de Osuna, Brenes y Camas. Conforme a la hipótesis de Fernández Ramírez antes citada, tendría que haber más leísmo en estos pueblos que en aquellos. La tabla 6 representa los respectivos porcentajes:

25. Cf. Cuervo (1970: 493): « [...] pero la influencia de la capital por una parte y la de la literatura por otra, hacen que los loístas de nación al hablar o escribir esmeradamente usen el le con más o menos frecuencia, lo mismo que se valen de tantas otras voces y giros comunes en los libros, pero ajenos del habla familiar.»

26. Cf. RAE (1973: 424): «La Academia Española, teniendo en cuenta el origen etimológico de estas formas y la práctica más autorizada entre los escritores modernos, recomienda para el uso culto y literario la siguiente norma general: $l o$, para el acusativo masculino; $l a$, acusativo femenino; le, dativo de ambos géneros, y además como acusativo masculino de persona, pero no de cosa; [...] Así, pues, tratándose de un hombre podemos decir indistintamente No lo conozco o No le conozco; pero si se trata de una mujer, solo podemos decir No la conozco; hablando de un libro, Lo tengo en casa.»

27. Cf. Klein-Andreu (2000: 9).

28. 704.158 habitantes según la página web del Instituto de Estadística de Andalucía (datos de 2005). Le doy las gracias al Prof. Dr. R. Verdonk de la Universidad de Amberes por haberme indicado este sitio web. Según este mismo sitio web Cazalla de la Sierra tiene 5.161 habitantes, Alanís 1.937, Constantina 6.826, Osuna 17.431, Brenes 11.412 y Camas 25.769. 
TABLA 6

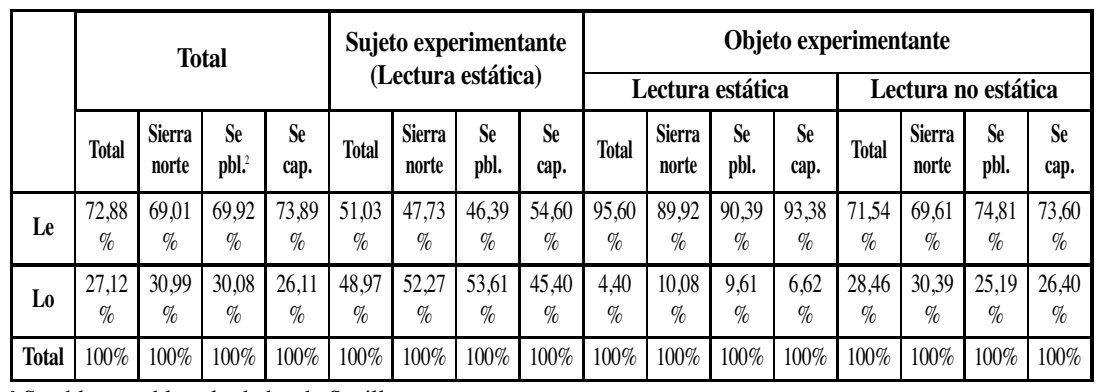

${ }^{2}$ Se pbl. = pueblos alrededor de Sevilla.

Los resultados provenientes de la Sierra Norte (94 informantes) y Sevilla capital (94 informantes) confirman la hipótesis. Los de los pueblos alrededor de Sevilla (25 informantes), en cambio, no encajan, salvo en el caso de las frases estáticas con objeto experimentante, o sea en las frases que, tal como vimos en el párrafo dedicado a la variable del sexo, toleran poca variación personal. Lo que resalta ante todo es que con las frases no estáticas, los pueblerinos de Camas, Brenes y Osuna seleccionan incluso más leísmo que los habitantes de Sevilla capital, como si se trataran de copiar el habla sevillana con demasiado fervor y entusiasmo, quizá porque opinan, con Bourdieu (1992: 120-121) y López Morales (1993: 116), que esto «los favorecerá en su vida laboral y social en general». ${ }^{29}$ Sin embargo, si esto es así, no queda muy claro por qué, con las frases con sujeto experimentante, no se aplica esta estrategia. Repárese en que el número de informantes de esta región es mucho más reducido que en las otras dos zonas. Quizá sea esta la clave de este comportamiento vacilante y poco coherente.

\section{CONCLUSIÓN}

En el cuestionario lingüístico sometido en noviembre del año 2005 a 249 informantes sevillanos, salieron 21 verbos psicológicos con referentes masculinos singulares. Estos 21 verbos seleccionan el pronombre dativo en un 72,88\% de los casos, lo que nos autoriza a desechar la etiqueta de «no leísta» para el habla andaluza. Dentro de estos 21 verbos se distinguen 3 categorías: las que seleccionan el leísmo en más o menos un 50\% de los casos, las que exhiben porcentajes entorno al 70\%, y las que son casi exclusivamente dativas. Cada uno de estos cor-

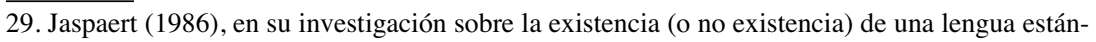
dar flamenca, observa comportamientos similares. 
tes refleja la clasificación de los verbos psicológicos de las autoras Vázquez Rozas (1995: 211-212) y Di Tullio (1997: 255): los verbos con sujeto experimentante, los verbos con objeto experimentante con lectura estática y los verbos con objeto experimentante con lectura no estática. La primera y la tercera categoría son las que más variación, según las distintas variables (sexo, edad, formación y lugar de residencia), exhiben. El uso pronominal de la segunda categoría, en cambio, es similar en las tres categorías: la discrepancia máxima respecto al promedio de 95,60\% que se observa es de un 5,68\% (menos de leísmo en los pueblos de la Sierra Norte). La tercera categoría (con lectura no estática) es la que más variación exhibe, en la categoría de los informantes con instrucción primaria, que seleccionan un $10,50 \%$ menos de leísmo que el promedio de $71,54 \%$. Es la categoría que, en lo referente a las características del agente, más se acerca a la frase prototípica. Antes vimos que cuanto más prototípica la frase, más los locutores se atreven a darle un toque personal, mediante el cual pretenden identificarse con o diferenciarse de otros grupos sociales.

En cuanto a las preferencias pronominales de los distintos grupos examinados, vimos que son los hombres entre 15 y 34 años con formación superior y residentes en Sevilla capital los que más favorecen el uso del pronombre dativo, y que son las mujeres entre 35 y 55 años con formación primaria y residentes en la Sierra Norte las que más reticentes son respecto al leísmo. El factor que, globalmente, más favorece el leísmo en la provincia de Sevilla es el sexo masculino del informante $(+3,17 \%)$, inmediatamente seguido por la formación superior del mismo $(+3,12 \%)$. Los factores que menos favorecen el uso dativo en esta zona son la instrucción primaria $(-5,17 \%)$ y la residencia en la Sierra Norte $(-3,87 \%)$. Investigacines futuras tendrán que afinar estas conclusiones.

\section{REFERENCIAS BIBLIOGRÁFICAS}

Alcina Franch, J. y J. Blecua (1975): Gramática española, Barcelona, Ariel. Bello, A. y R. Cuervo (1970): Gramática de la lengua castellana, Buenos Aires, Editorial Sopena Argentina.

Bodine, A. (1975) «Sex differentiation in language», en THORNE, B. y N. HeNLEY (eds.) (1975): Language and sex: difference and dominance, Rowlay, Mass., Newbury House, 130-151.

BouCHARD. D. (1995): «Les verbes psychologiques», Langue Française, 105: 6-15.

Bourdieu, P. y L. Wacquant (1992): Réponses, París, Seuil.

Cano Aguilar, R. (1981): Estructuras sintácticas transitivas en el español actual. Madrid, Gredos. 
- (1992²): El español a través de los tiempos, Madrid, Arco.

CANo Aguilar, R. y Ma D. GonzÁlez CANTOS (2000): Las hablas andaluzas, Sevilla, Consejería de Educación y Ciencia.

CAPpell, A. (1966): Studies in socio-linguistics, The Hague, Mouton.

Di Desidero, L. (1992): «On the stativity of the FEAR verbs of psychological state», Northwestern Univ. Working Papers in Linguistics, 4: 31-40.

Di TulLIO, Á. (1997): «Alternancia acusativo-dativo en verbos psicológicos del español», en RuFFINO, G. (ed.) (1997): Atti del XXI Congresso di Linguistica e Filologia Romanza Vol II, Tübingen, Max Niemeyer Verlag, 255-261.

DowTY, D. (1991): «Thematic protoroles and argument selection», Language, $67 / 3,547-619$.

FERNÁNDEZ ORDóÑEZ, I. (1993): «Leísmo, laísmo y loísmo: estado de la cuestión», en FERnÁNDEZ SORIANO, O. (ed.) (1993): Los pronombres átonos, Madrid, Taurus, 63-96.

- (1999): «Leísmo, laísmo y loísmo», en Bosque, I. y V. Demonte (eds.) (1999): Gramática descriptiva de la lengua española I, Madrid, Real Academia Española/Espasa Calpe, 1317-1393.

FERNÁNDEZ RAmíREZ, S. (1987?): Gramática española: 3.2. El pronombre, Madrid, Arco.

FonTANELla DE WEINBERG, M. (1973): «Comportamiento ante -s de hablantes femeninos y masculinos del español bonarense», Romance Philology, 27: 50-58.

Gili Gaya, S. (1948²): Curso superior de sintaxis española. Barcelona, Spes. JASPAERT, K. (1986): Statuut en structuur van standaardtalig Vlaanderen, Leuven, Universitaire Pers Leuven.

KleIN-ANDReu, F. (2000): Variación actual y evolución histórica: los clíticos $l e / s, l a / s, l o / s$, Múnich, Lincom Europa.

LAKoff, G. (1966): Stative Adjectives and Verbs in English, NSF-Report 17, Harvard Computational Laboratory.

LóPez Morales, H. (1993) Sociolingüística, Madrid, Gredos.

Melis, C. (1999): «Variación actual con los verbos de emoción», Español actual, 71, 49-62.

PRIMUS, B. (1999): Cases and Thematic Roles, Tübingen, Niemeyer.

REAl ACADEMIA EsPaÑola (1973): Esbozo de una nueva gramática de la lengua española, Madrid, Espasa Calpe.

RIFÓN, A. (1997): «Sobre la oposición verbal 'dinamicidad'/ 'estatividad' en español», Romanistik in Geschichte und Gegenwart, 3.2, 241-254.

RUwET, N. (1993): «Les verbes dits psychologiques: trois théories et quelques questions», Recherches linguistiques de Vincennes, 22, 95-124.

- (1994): «Etre ou ne pas être un verbe de sentiment», Langue française, 103: 45-55. 
SALVAdOR, G. (1952): «Fonética masculina y fonética femenina en el habla de Vertientes y Tarifa, (Granada)», Orbis, 1: 19-24.

SECo, M. (1967): Manual de gramática española, Madrid, Aguilar.

VANHOE, H. (2004): Aspectos de la sintaxis de los verbos psicológicos en español. Un análisis léxico funcional, Fráncfort del Meno, Peter Lang.

VÁzQUEZ RozAs, V. (1995): El complemento indirecto en español, Santiago de Compostela, Universidade de Santiago de Compostela.

Vendler, Z. (1967): Linguistics in Philosophy, Ithaca/Nueva York, Cornell University Press.

Whitley, S. (1995): «Gustar and other Psych Verbs: A problem in Transitivity», Hispania, 78-3, 573-585. 


\title{
DISPONIBILITAT LÈXICA DEL VALENCIÀ: \\ CLASSIFICACIÓ DELS FENÒMENS DE CONTACTE LINGÜÍSTIC
}

\author{
Francesc Llopis Rodrigo \\ Universitat de València
}

\section{INTRODUCCIÓ}

\begin{abstract}
QUESTA comunicació forma part de les investigacions dutes a terme pel A grup lexval (Análisis léxico del castellano y del valenciano en la comunidad bilingüe de Valencia), de la Universitat de València.

El que pretenem en aquest treball és mostrar l'elevat nombre de transferències que apareixen als tests de disponibilitat lèxica, principalment del castellà. De tots els centres d'interés, sols mostrarem tres estímuls, a tall d'exemple, per qüestió d'espai, després de comentar la classificació feta dels fenòmens de contacte lingüístic tenint en compte la metodologia emprada en aquest estudi del lèxic.
\end{abstract}

\section{EL TEST DE DISPONIBILITAT}

\subsection{Selecció de la mostra}

Pel que fa a la selecció d'informants, aquesta ha estat condicionada pels criteris sociolingüístics emprats en comunitats de parla bilingües. Així, hem procurat respectar els dos criteris bàsics de qualsevol mostreig: representatiu (població estudiantil, tipus d'ensenyament, programes d'educació...) i exhaustiu (proporcionalitat). L'enquesta s'ha dut a terme en 24 centres, tant públics com privats, on han participat els alumnes de $2 \mathrm{n}$ de batxillerat ${ }^{1}$ durant els cursos acadèmic 2002/2003 i 2003/04.

En la següent figura es pot veure la distribució desigual quant a les diferents comarques. Aquesta respon a les peculiaritats de la dinàmica econòmica i demogràfica de la població estudiada.

1. La gran part dels estudis de disponibilitat léxica s'han fet a partir de les mostres de xiquets o adolescents. Gougenheim (1956, 1964); Mackey (1971); López Morales (1973); Azurmendi (1983); Murillo Rojas (1993); Murillo Rojas i Sánchez Corrales (2002); Valencia (1994 a, 1994 b, 1998 a) i Marta Samper (2003). 


\section{FIGURA 1}

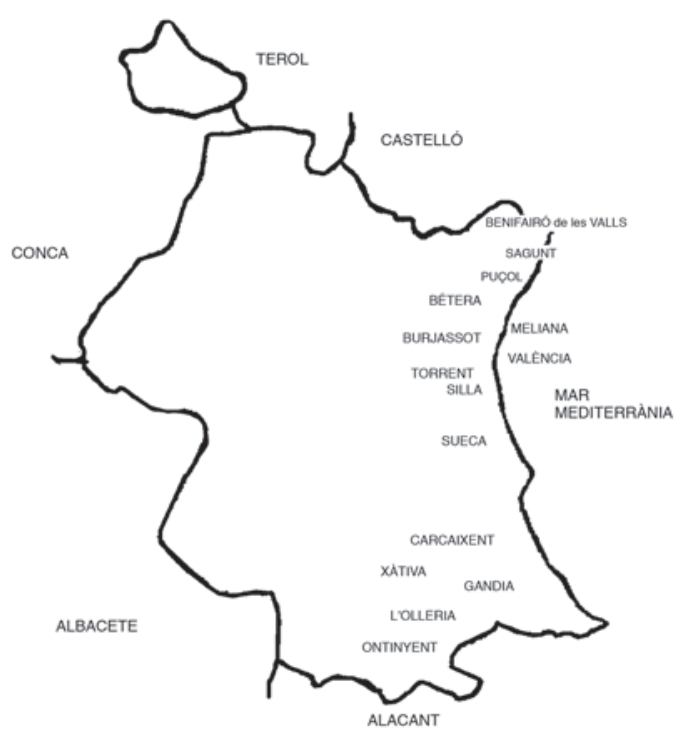

La població objecte d'anàlisi ha estat els estudiants preuniversitaris de la província de València distribuïts en les comarques valencianoparlants: Camp de Morvedre (Sagunt i Benifairó de les Valls), Camp de Túria (Bétera), l'Horta (Puçol, Meliana, Burjassot, València, Torrent i Silla), Ribera Alta (Carcaixent), Ribera Baixa (Sueca), la Costera (Xàtiva), la Safor (Gandia) i la Vall d'Albaida (Ontinyent i l'Olleria).

La grandària de la mostra, ${ }^{2} 464$ informants, ve determinada després d'aplicar la fórmula de Garret (1980: 270) per a una mostra aleatòria simple. Aquest mostreig suposa un nivell de confiança al voltant del $95 \%$ en els resultats obtinguts, amb un nivell de significació estadística inferior o igual a 0,05 i amb un error d'estimació en la distribució de la mostra de $+/-0,03$; en altres paraules, que hi ha un nivell de precisió entre el 92,0\% i el 98,0\% amb el total de la població.

A continuació mostrem la proporcionalitat de la mostra d'acord amb les variables preses. La disposició de les variables que componen la mostra ha estat la següient:

2. En la fórmula $N=\frac{p q}{\sigma_{p}^{2}}$ s'han assignat iguals percentatges d'ocurrència a $p$ i $q$; ço és, un $50 \%$. I sigma és el resultat de la divisió de D (desviació 1,96 o nivell de significació 0,05 ) entre l'errada d'estimació de la distribució del mostreig, que en el nostre cas és del +/- 0,05. Per aconseguir aquests valors són necessaris almenys 417 informants. 
- Sexe: home, 195 informants (42\%); dona, 269 (58\%)

- Tipus d'ensenyament: ensenyament públic, 297 (64\%); ensenyament privat, $167(58 \%)$

- Llengua habitual: monolingüe, 211 (45\%); bilingüe, 253 (55\%)

- Nivell sociocultural: alt, 83 (18\%); mitjà, 229 (49\%); baix, 152 (33\%)

- Lloc de residència: València ciutat, 159 (34\%); àrea metropolitana, 109 (23\%); semiurbà, 119 (26\%); rural, 77 (17\%)

- Llengua materna: monolingüe, 195 (42\%); bilingüe, 269 (58\%)

- Programa d'ensenyament bilingüe: programa d'ensenyament en valencià (PEV), 114 (25\%); programa d'incorporació progressiva, 350 (75\%)

- Comunitat de parla: València ciutat, 159 (32\%); l'Horta, Camp de Morvedre i Camp de Túria, 179 (34\%); les Riberes, la Safor, la Costera i la Vall d'Albaida, $135(34 \%)$

\subsection{Obtenció del corpus}

Pel que fa a la prova associativa, on realment s'actualitza el material lèxic, està dissenyada en disset àrees temàtiques, les quals corresponen als següents camps lèxics objecte d'estudi:

01. El cos humà

02. La roba

03. Parts de la casa (sense mobles)

04. Els mobles de la casa

05. Menjars i begudes

06. Objectes col'locats a taula per menjar

07. La cuina i els seus utensilis

08. L'escola: mobles i material (institut o col·legi)

09. Il·luminació, calefacció i ventilació

10. La ciutat

11. El camp

12. Mitjans de transport

13. Treballs del camp i del jardí

14. Els animals

15. Jocs i distraccions

16. Professions i oficis

17. Colors

Cal assenyalar que tots els informants han rebut en iniciar el test una sèrie de consignes generals: que no es preocupen per l'ortografia; que escriguen totes les paraules que els vinguen a la ment relacionades amb el tema indicat; que si acaben la columna poden seguir per darrere del full; i si en algun 
moment no recorden el mot en valencià, però sí en castellà, poden escriure'l en castellà. I en començar cada centre d'interés han escoltat altres indicacions particulars. ${ }^{3}$

\section{FENÒMENS DE LLENGÜES EN CONTACTE}

La presentació de les classificacions de fenòmens de contacte lingüístic l'hem feta seguint el següent ordre: oferim, en primer lloc, l'actualització d'alguns doblets més significatius (estantería/prestatgeria; ternera/vedella) i serà l'índex de disponibilitat el que ens informarà del processament lingüístic (priming) en la fluència semàntica conjunta. Quan una etiqueta categorial (concepte) està formada per dos significants podem observar en quina llengua s'activa la facilitació semàntica en l'evocació del lèxic disponible; així doncs, serà l'estudi particular de cada subjecte el que ens informarà de com està organitzat el seu lexicó.

A continuació hem classificat les transferències lèxiques en interferències, préstecs integrats, préstecs en vies d'integració i compostos híbrids. Les interferències, produccions agramaticals en les dues llengües, responen a un fet puntual, esporàdic, producte probablement del nonce-borrowing i tenen una freqüència molt baixa (igual al 5\% o menor); per això es consideren fenòmens de parla. Més problemàtic resulta establir la diferència entre préstecs en vies d'integració (lingüística i social) i préstecs integrats. Per a la seua classificació hem tingut en compte tant la flexió lingüística (gènere i nombre), com el grau d'integració social. S'han considerat préstecs en vies d'integració aquells

3. Indicacions:

1. Parts del cos humà: internes i externes

2. Roba, calcer, complements...

3. Parts de la casa: dins i fora

4. Mobles i també ornaments

5. Aliments i begudes: tot tipus

6. Objectes col-locats a taula per menjar (i per a beure): no poseu noms d'aliments

7. La cuina i els seus utensilis: també electrodomèstics

8. L'escola (institut o col·legi): mobles, materials, persones, dependències

9. Il·luminació, calefacció i ventilació (mitjans naturals i artificials)

10. La ciutat: imagineu que passegeu i tot el que veieu

11. El camp: imagineu que passegeu i tot el que veieu

12. Mitjans de transport de terra, aire i aigua

13. Treballs del camp i del jardí , per tant verbs, substantius...

14. Animals domèstics i salvatges; de terra, aire i aigua

15. Jocs, distraccions, entreteniments, diversions, aficions

16. Professions i oficis de tota classe, manuals, especialitzats, carreres...

17. Colors: paraules simples i compostes 
que tenen una freqüència de mencions entre $6 \%$ i $15 \%$ i préstecs integrats quan la frequiència d'aparició és superior al 15\%. Quant als compostos híbrids, es produeixen quan els parlants activen un element del sintagma en una llengua i l'altre element en l'altre codi idiomàtic.

Si considerem la transferència com un procés que respon al continuum interferència $\rightarrow$ préstec en vies d'integració $\rightarrow$ préstec integrat, els trets delimitadors són els diferents graus d'integració lingüística -adaptació fonològica, morfològica i sintàctica- i d'integració social -freqüència d'ús, homogeneïtat i nivell d'acceptació. Donades les limitacions del test de disponibilitat lèxica, és possible que els criteris establerts per a la catalogació dels fenòmens anteriors -freqüència d'ús- condicionen la classificació de certs vocables, ja que seria necessari un estudi més exhaustiu per a una taxonomia sociolingüística.

Finalment, s'han assenyalat les substitucions de codi, mots normatius en altres llengües que els informants han actualitzat molt poques vegades, bé per desconeixement, o bé per no recordar la seua traducció valenciana (cajón, cirujano) i, els canvis de codi (sushi, stripper). S'ha d'assenyalar que moltes de les unitats lèxiques catalogades com a substitució de codi, podrien ser classificades com a préstecs en vies d'integració o consolidats, però ateses les característiques de la metodologia duta a terme per a la recollida del corpus, les hem classificades com a substitució de codi tant per la baixa frequiència obtinguda en els inventaris lèxics com perquè, al nostre parer, són fruit d'un oblit o desconeixement en la llengua base del test de disponibilitat. Però també s'han actualitzat algunes unitats lèxiques que han de classificar-se com a «canvi de codi», ja que l'informant desconeix el vocable tant en castellà com en valencià.

És obvi que una conseqüència del contacte lingüístic i del bilingüisme social, presents en l'àrea territorial objecte d'estudi, són les transferències, especialment, lèxiques.

\section{CLASSIFICACIÓ DELS FENÒMENS DE CONTACTE LINGÜÍSTIC}

\section{Els mobles}

\section{Doblets}

Estantería $(0,24003)$ / prestageria $(0,10318)$

Lámpara $(0,12144)$ - llàmpara $(0,03801)$ - làmpares $(0,01786)$ / làmpada $(0,00432)$

Mecedora $(0,05384)$ / gronxador $(0,01916)$

Taburet $(0,03345) /$ tamboret $(0,00240)$ 


\section{Interferència}

Candelabre, alfombres, tendeder, silles, colxó, lampareta, clavijes, zapater, horn, lavavajilles, grif, encristalat, cepill, flexe, cenicers, trisill, maceter, roper, podi, lavader, felput, lavavaixelles, arcó, paraigüero, microondes

\section{Préstec en vies d'integració}

Taburet, alfombra, llàmpara, despensa, secadora, cobert

\section{Préstec consolidat}

Silló, estantería, lámpara, mesita, mecedora, comedor

\section{Compostos híbrids}

Armari empotrat**, mesita de nit**, taula camilla, sofá cama, armari roper, mesa d'ordinador, moble de comedor, taula d'ordenador, ropero de paret, mesita de llit, mármol de cuina, taula de comedor, moble de recibidor, centre de mesa, armari ropero, mesa d'estudi, lampareta de peu, mesa de jardí, armari de cristal, moble d'ordenador, escala de madera, taula de cristal, moldura finestra, moldura porta, tauleta de cristal, caixó de cuberts

\section{Substitució de codi}

Lavadora, almohada, sillón, ventana, horno, mesa comedor, cabezal, zapatero, calentador, sábana, tostadora, altillo, enchufe, rinconera, cajón, sandwichera, cuco, papelera, secador, taza, batidora, freidora, exprimidor, banco, dormilona, parabán, corcho, desván, comodín, camarera, chimenea, escritorio, diván, bandeja, tablero, tabla de planchar, manivela, armario, alfeizar, foco, toallero, balancín, galán de noche, grifo, escalera, puerta, cesta, revistero, cerradura, botellero, encendedor, jaula, portalámpara, espejo, caucho, macetero, órgano, vela, joyero, bombilla, cama nido, frutero, mantel, microondas, alacena, lavavajillas, silla, pila, perchero, mesa, cama, puf, baúl, ropero, recibidor, encimera, tresillo, mesa camilla, florero, ordenador

\section{Canvi de codi}

Play station, chaise-longe, boucherie, home cinema

\section{Menjars i begudes}

\section{Doblets}

Ternera $(0,06688)$ / vedella $(0,01724)$

Ron $(0,04137) /$ rom $(0,00081)$

Galleta $(0,03432)$ / galeta $(0,04486)$

Fiambre $(0,02004)$ / companatge $(0,00316)$

\section{Interferència}

Jamó, albòndigues, hervid, solomill, pepí, alubies, llenguat, lentejes, calabací, acelgues, uves, cebolles, lenguat, bocadill, chipiró, llubina, costilles, morcilles, 
almendres, setes, osobuc, palomites, ràban, lom, habes, aceitunes, orégan, almejes, pases, morcó, llevadura, navajes, judions, golosines, pat, pimient, judies, chuletes, guisant, mejilló, saltxitxó, boqueró, pescat, melocotó

\section{Préstec en vies d'integració}

Ternera, tomata, sangría, puchero, gaseosa, galleta

\section{Préstec consolidat}

Ron, tortilla, mero, pechuga, fiambre

\section{Compostos híbrids}

Suc de melocotó, vi tinto, suc de fresa, jamón serrà, batut de fresa, arròs a l'horn, vi tint, zum de taronja, arròs amb bogavant, suc de tomate, potaje de cigrons, pierna de corder, suc de fruta, carn de cordero, lates de conserva, carn de cerdo, pa de sándwich, anques de granota, zumo de taronja, aigua en cloro, bocadillo blanc i negre, vi amb gaseosa, pa de molde, pa tostat

\section{Substitució de codi}

Sirope, costilla, chupito, hueva, margarita, mojito, rosquito, bollería, pimienta, tarta de trufa, níspero, paletilla, ensaladilla, guisante, lluvia, sorbete, ciruela, miel, san jacobo, jamón serrano, pescado, albaricoque, granizado de limón, aguacate, bocadillo tortilla, caramelo, alubia, turrón, embutido, pata de cerdo, bonito, mostaza, gusanito, fruto seco, rollito de primavera, emparedado, conejo, refresco, papilla, jurel, pepito, ajo, trigo, dorada, rollo, paleta, brote de soja, cebada, roquefort, canela, golosina, hojaldre, orujo, lechuga, atún, manzana, zanahoria, yogur, lenteja, lomo, cordero, cerdo, lubina, mermelada, fruta, , manteca, bocadillo, lenguado, merluza, salchicha, sandía, sándwich, jamón york, flan, solomillo, zumo, plátano, besugo

\section{Canvi de codi}

Whisky, sushi

\section{Professions}

\section{Doblets}

Abogat $(0,09338)$ - abogado $(0,00553) /$ advocat $(0,15892)$

Carpinter $(0,06142)$ - carpintero $(0,00363) /$ fuster $(0,08245)$

Albañil $(0,03623)$ / obrer $(0,16585)$ - paleta $(0,00359)$

\section{Interferència}

Cristaler, azafat, pàrroc, boticari, pasteler, bedell, cociner, botons, torer, noviller, cirujàn, camiller, bailarí, artesan, pereós, cerrajer, neurocirujà, marmolistes, cetrer, papeler, tesorer, llimpiador, parat, empolló, tenient, llavander, rentacristals, carretiller, zapater, carceler, cirujà, dependient, fruter, peluquer, verduler, camarer, peó 


\section{Préstec en vies d'integració}

Basurer, mèdic, panader, albañil, barrender, enfermera, enfermer, carpinter

\section{Préstec consolidat}

Abogat, ingenier

\section{Compostos híbrids}

Ingenier de camins*, ingenier industrial *, ingenier de telecomunicacions $*$, ingenier químic*, ingenier agrònom**, ingenier informàtic*, ingenier mecànic*, ingenier textil*, ingenier tècnic*, ingenier aeronàutic*, ingenier d'electricitat, dona de l'hogar, testigo de juici, ingenier tecnològic, ingenier electrònic*, ingenier tècnic agrònom*, ingenier agrícola*, ingenier tècnic forestal*, ingenier de robòtica, ingenier forestal, ingenier tècnic aliments, ingenier d'obres públiques*, jefe d'estudis, treballador d'almacén, medio ambient, capità de barc, recollidor de basura, recaptador d'hacienda, encargat almacén, dona de la llimpieza, licenciat en algo, vendedor ambulant, venedor de golosines, ingenier tècnic tèxtil*

\section{Substitució de codi}

Niñera, go go, barrendero, piloto, abogado, cirujano, butanero, dependiente, banquero, limpiador, concejal, camionero, camarera, carpintero, polero, bombero, chacha, madero, ingeniero, vagabundo, corredor de seguros, marmolista, panadero, bailarín, maestra, pedagogo, cocinero, maricón, segurata, cámara, embajador, capataz agrícola, veterinario, pastelero, capataz, modelo, banderillero, almacenista, capataz de obra, obrero, cajera, lechero, cosedor, paro, secuestrador, autobusero, teniente, marino, teniente coronel, baloncestista, podólogo, hacienda, inspector de hacienda, agrónomo industrial, obispo, secretario, picolo, guardián, pizzero, cajero, cantante, mendigo, controlador aéreo, famoso, tendero, médico, político, intérprete, actriz, otorrinolaringólogo, científico, guardaespaldas, músico, alquiler, DVD, canguro, fotógrafo, corredor de bolsa, psicopedagogo, ganadero, bordadora, feriante, bedel, cristalero, limpiacristales, timador, peluquería, árbitro, paparazzi, basurero, deportista, chulo, camello, cura, chapero, ingenieria, celador, azafata, fontanero, psicólogo, esthéticienne, camarero, vendedor, peluquera, enfermeria, juez

\section{Canvi de codi}

Stripper, boy, disc-jockey

* Préstec en vies d'integració.

** Préstec consolidat.

\section{CONCLUSIONS}

$\mathrm{Al}$ centre d'interés dels "Mobles", trobem un nombre prou considerable de préstecs, dotze, sis en vies d'integració i sis consolidats, i amb un nombre d'ac- 
tualitzacions per part dels parlants molt elevat. El percentatge de transferències és del 30,37\%.

En l'estímul "Menjars i begudes", el percentatge dels fenòmens de contacte lingüístic és el segon menor després de 'La ciutat', amb un 20,66\% sobre el total de 842 vocables, ${ }^{4}$ malgrat haver-hi un nombre bastant considerable de préstecs en vies d'integració. Cal assenyalar el fort grau d'integració del mot anglès whisky (xenisme per a alguns lingüistes).

En el centre d'interés "Professions i oficis" trobem un 20,80\% de transferències sobre el total dels vocables d'aquest estímul, cosa que representa el tercer centre amb menor grau d'elements forans. En el grup dels compostos híbrids trobem bastants préstecs en vies d'integració (ingenier de camins, ingenier industrial, ingenier de telecomunicacions).

A grans trets podem assenyalar, per una banda, que el grau de transferències en aquests centres d'interés és molt elevat, i arriba a la quarta part en "Els mobles". D'altra banda, el nombre de préstecs als centres "Menjars i begudes" i "Professions i oficis", a pesar de tenir un grau de transferències menor (pel nombre de vocables total actualitzats), el nombre de préstecs també és important.

Concloem que la castellanització de la varietat estàndard del valencià està molt arrelada en el lèxic dels estudiants i per tant cal ressaltar la necessitat urgent i compromesa d'una planificació lingüística coherent del català parlat a València.

\section{REFERÈNCIES BIBLIOGRÀFIQUES}

Alba, O. (1995): Léxico disponible de la República Dominicana, Santo Domingo, Pontificia Universidad Católica 'Madre y Maestra'.

Alcover, A. i F. B. Moll (1988): Diccionari Català-Valencià-Balear, Palma de Mallorca, Moll.

Aavv, (1995): Diccionari de la Llengua catalana, Fundació Enciclopèdia Catalana.

AZURMENDI, M. J. (1983): Elaboración de un modelo para la descripción sociolingüística del bilingüismo y su aplicación parcial en la comarca de San Sebastián, San Sebastián, Ediciones de la Caja de Ahorros Provincial de Guipúzcoa.

Blas Arroyo, J. L. (1993): La interferencia lingüística en Valencia. Estudio sociolingüístico, Castelló de la Plana, Universitat Jaume I.

Bruguera, J. (1985): Història del Lèxic Català, Barcelona, Enciclopèdia Catalana, Biblioteca Universitària.

4. Per vocable s'entén els mots diferents actualitzats pels informants. 
Carcedo, A. (2001): Léxico disponible de Asturias, Universidad de Turku, Publicaciones del Dpto. de Lengua Española, Monografías, vol. I.

CASANova, E. (2004): «Del lèxic col-loquial al lèxic estàndard: el cas valencià», en CABANES (coord.): El lèxic: perspectives $i$ intervencions. El valencià al segle XXI, Alcoi, Aitana edicions-CAM.

Clyne, M. (1967): Transference and triggering, la Haia, Nijhoff.

Colón, G. (1976): El Léxico catalán en la Romania, Madrid, Gredos.

Institut d'Estudis Catalans (1995): Diccionari de la Llengua Catalana, (1995): Barcelona-Mallorca-València.

Generalitat Valenciana I Bromera (1996): Diccionari Valencià, IIFV.

ECHEVERRÍA, M. (1991): «Crecimiento de la disponibilidad léxica en estudiantes chilenos de nivel básico y medio», en LóPEZ Morales, H. (ed.) (1991): La enseñanza del español como lengua materna, Actas del II Seminario Internacional sobre Aportes de la lingüística a la enseñanza del español como lengua materna, Universidad de Puerto Rico, 61-78.

ETXEBARRía, M. (1995): El bilingüismo en el Estado Español, Bilbao, Ediciones FBV.

- (1996): «Disponibilidad léxica en escolares del País Vasco. Variación sociolingüística y modelos de enseñanza bilingüe», Revista Española de Lingüística, 26: 301-325.

Galloso, V. (2002): El léxico de los estudiantes preuniversitarios en el distrito universitario de Salamanca, Ediciones Universidad de Salamanca.

Garret, H. E. (1973): Estadística en Psicología y Educación, Buenos Aires, Paidós (1980, 2a edició).

Gómez Devís, B. (1995): Disponibilitat lèxica del valencià en la ciutat de València i àrea metropolitana, (inèdit), Generalitat Valenciana, Pla EVA, València.

Gómez Devís, B. i F. Llopis Rodrigo (2006): «La disponibilitat lèxica a València: criteris d'edició», en Blas Arroyo, J. L., M. Casanova y M. Velando (eds.) (2006): Discurso y Sociedad. Contribuciones al estudio de la lengua en contexto social, Castelló de la Plana, Universitat Jaume I, 779-789.

Gómez Molina, J. R. (1986): Estudio sociolingüístico de la comunidad de habla de Sagunto (Valencia), València, Institució Alfons el Magnànim.

- (1999-2000): «Transferencia y cambio de código en una comunidad bilingüe: Área metropolitana de Valencia», Contextos, XVII-XVIII/33-36: 31-87.

- (2000): «Consecuencias del contacto de lenguas», en BRIZ, A., GruPO VAL.Es.Co (eds.) (2000): ¿Cómo se comenta un texto coloquial?, Barcelona, Ariel, 287-313.

- (2002 a): «Préstamos léxicos del castellano en el valenciano central: inserción, evaluación y actualización», en ECHENIQUE, M. T. y J. SÁNCHEZ (eds.) 
(2002): Actas del V Congreso Internacional de Historia de la Lengua Española, Madrid, Gredos, 1739-1765.

- (2002 b): «Norma i ús en el valencià central (nivell lèxic)», Treballs de Sociolingüística Catalana, 16: 5-23.

Gómez Molina J. R. i B. Gómez Devís (2004): La disponibilidad léxica de los estudiantes preuniversitarios valencianos. Estudio de estratificación sociolingüística, Universitat de València.

GONZÁLEZ, A. (2002): La disponibilidad léxica de los alumnos preuniversitarios en la provincia de Cádiz, Servicio de Publicaciones de la Universidad de Cádiz.

Gosjean, F. (1981): Life with two languages. An introduction to Bilingualism, Cambridge, Harvard University Press.

GougenHeIM, G., et al. (1956): L'élaboration du francais élémentaire (I degré). Étude sur l'établissement d'un vocabulaire et d'une grammaire de base, París, Didier.

- (1964): L'élaboration du francais fondamental (I degré). Étude sur l'élaboration d'un vocabulaire et d'une grammaire de base, París, Didier.

GUILBERT, L. (1975): La créativé lexicale, París, Larousse.

Hasselmo, N. (1969): «How can me measure the effects wich one language may have on the other in the speech bilinguals», en KeLLY, L. G. (ed.) (1969): Description and Measurement of bilingualis, Toronto, 122-141.

Haugen, E. (1953): The Norwegian Language in America, Filadèlfia, The University of Pennsylvania Press.

Hernández, N. (2002): El léxico disponible de los estudiantes conquenses. Del análisis sociolingüístico a la reflexión metodológica, Trabajo de grado, Universidad de Salamanca.

Llobera i ArAmon, J. (1968): El català bàsic, Barcelona, Teide.

Llopis Rodrigo, F. (1997): El lèxic del valencià central (inèdit), Generalitat Valenciana, Pla EVA, València.

- (2005): «Transferències lèxiques en una comunitat de llengües en contacte», Lenguaje y Textos, 68, Univerdidade A Coruña.

LóPeZ DEL CASTILlo, Ll. (1984): Llengua standard i nivells de llenguatge, Barcelona, Laia.

López Morales, H. (1973): Disponibilidad léxica de los escolares de San Juan, MS.

- (1999): Léxico disponible de Puerto Rico, Madrid, Arco Libros.

MACKeY, W. F. (1971): Le vocabulaire disponible du Francais, (2 vols.), París, Didier.

- (1976): Bilingualism et Contact des Langues, París, Editions Klinckieck.

MARí I. (1992): Un horitzó per a la llengua. Aspectes de la planificació lingüística, Barcelona, Empúries. 
Mateo, M. V. (1998): Disponibilidad léxica en el cou almeriense. Estudio de estratificación social, Almería, Universidad de Almería.

Mollà, D. i altres (1986): Estudi sociològic sobre la problemàtica sociolingüística a la Comunitat Valenciana, València, Generalitat Valenciana, Conselleria de Cultura, Educació i Ciència.

Moreno, F., J. E. Moreno i A. J. García de las Heras (1995): «Cálculo de disponibilidad léxica. El programa Lexidisp», Lingüística, ALFAL, 7: 243-249.

MuRILlo, M. i V. M. SÁNCHEZ (2002): Léxico básico de los niños preescolares costarricenses, Editorial de la Universidad de Costa Rica.

NinYoles, S. R. (1996): Sociologia de la ciutat de València, València, Germania.

PAYRATÓ, Ll. (1985): La interferència lingüística, Abadia de Montserrat.

SAMPER HernÁNDEZ, M. (2003): «Léxico disponible y 'nivel educativo' en escolares de Gran Canaria: datos cuantitativos», Documentos de Español Actual 5: 105-125.

SAmper Padilla, J. A. (1998): «Criterios de edición del léxico disponible: sugerencias», Lingüística 10, ALFAL: 311-333.

SAMPeR, J. A., J. J. Bellón i M. SAMPer (2003): «El Proyecto de estudio de la disponibilidad léxica en español», en WotjaK, G. (2003): Pautas y pistas en el análisis del léxico hispano(americano), Madrid, Iberoamericana-Vervuert, 27-140.

SERRANO, M. I. (2006): «Consecuencias del contacto de lenguas en Lérida: interferencias detectadas en las encuestas de disponibilidad léxica», en Blas Arroyo, J. L., M. Casanova i M. Velando (eds.) (2006): Discurso y Sociedad. Contribuciones al estudio de la lengua en contexto social. Castelló de la Plana, Universitat Jaume I, 811-829.

Valencia, A. (1994a): El léxico de los estudiantes de $4^{o}$ año de Educación Media. Centro de interés 'Procesos mentales', Santiago de Chile, Serie Documentos de Estudio, 26, CPEIP.

- (1994b): «Disponibilidad léxica en educación Media: III y IV», en $X$ Encuentro en torno a la Admisión Universitaria, Santiago de Chile, Talleres Divest, 5-31.

- (1998): «Aspectos sociolingüísticos del léxico estudiantil de la Región Metropolitana», en Bernales, M. i C. Contreras (eds.) (1998): Por los Caminos del Lenguaje, Temuco: Ediciones de la Universidad de La Frontera, 39-45.

Weinreich, U. (1953): Languages in Contact. Findings and Problems. The Hague, Mouton. Trad. cat. (1996): Llengües en contacte, Alzira, Bromera. 


\title{
LA VARIABLE SEXO EN EL LÉXICO DISPONIBLE DE ALUMNOS DE PRIMARIA Y BACHILLERATO DE HUELVA: RESULTADOS CUANTITATIVOS
}

\author{
Josefina Prado Aragonés \\ Ma Victoria Galloso Camacho \\ Universidad de Huelva
}

D ESDE los fundamentos de la sociolingüística, uno de los factores sociales que muestran una mayor influencia sobre la variación lingüística de una comunidad de habla es el sexo; partiendo de esta premisa, el objeto de esta comunicación es analizar la incidencia de esta variable social en el comportamiento léxico de adolescentes de dos niveles educativos en la provincia de Huelva, el último curso de Educación Primaria y Bachillerato, contrastando los resultados cuantitativos obtenidos en cada uno de los dos sociolectos, hombre y mujer, a partir de sendas investigaciones sobre el léxico disponible del alumnado de estas etapas.

Revisaremos igualmente la pertinencia de este factor sociolingüístico en los resultados de distintas investigaciones de disponibilidad léxica, enmarcadas en el Proyecto Panhispánico, que dirige el Profesor Humberto López Morales, y los contrastaremos con los obtenidos en la muestra de Huelva, para sacar conclusiones que nos permitan demostrar hasta qué punto la variable sexo puede ser significativa en los repertorios de disponibilidad léxica.

\section{ASPECTOS METODOLÓGICOS}

La investigación sobre el léxico disponible llevada a cabo en la provincia de Huelva se enmarca en el Proyecto Panhispánico de disponibilidad léxica y, por tanto, la metodología con la que se ha llevado a cabo sigue la misma estructura que dicho proyecto. Esta metodología también ha sido la misma para los niveles de Primaria y de Bachillerato:

1. El mismo número de informantes que constituyen la muestra, 220 en cada nivel, procedentes de 11 centros educativos de Huelva y provincia, seleccionados según parámetros sociolingüísticos de representatividad. De estos informantes, en el nivel de Primaria 105 son chicas, frente a 
115 chicos; y en el nivel de Bachillerato, 131 chicas, frente a 89 chicos. Aunque somos conscientes de que lo ideal hubiese sido la igualdad en el número de informantes de cada uno de los sexos, esto ha sido imposible conseguirlo, dado que en estas investigaciones no hay una preestratificación previa y la selección de los grupos en cada centro y el número de veinte encuestas en cada uno de ellos es aleatoria.

2. La misma encuesta cerrada, constituida por una prueba asociativa de varias hojas, con idénticos centros de interés, 16 en total, que los encuestados cumplimentaron escribiendo todas las palabras que les vinieron a su mente durante los dos minutos, cronometrados por el encuestador, de que disponían para rellenar cada uno de ellos.

3. Unas variables sociolingüísticas iguales, que son: sexo (hombre/mujer), ubicación geográfica del centro (urbano/rural), tipo de centro (público/privado) y nivel sociocultural de los padres (analfabeto/prima$\mathrm{rio} /$ elemental/superior).

4. Criterios de edición similares, que son, en términos generales, los consensuados entre los investigadores del Proyecto Panhispánico (Samper, 1998), con el fin de favorecer la comparación entre los resultados de los distintos niveles educativos investigados y éstos con los de otras zonas investigadas.

\section{RESULTADOS CUANTITATIVOS GLOBALES DEL LÉXICO DISPONIBLE DE HUELVA}

A la hora de valorar los resultados globales en cuanto a la producción léxica en los dos niveles investigados, partimos de la hipótesis inicial de que el periodo de formación seguido por los alumnos desde el final de la etapa de Primaria hasta el periodo previo a su ingreso en la universidad, es decir, $2^{\circ}$ curso de Bachillerato o Preuniversitario, y el periodo de socialización en el que estos alumnos están inmersos durante estos años inciden positivamente en un evidente incremento de su léxico disponible.

Presentamos a continuación los resultados globales en cada uno de los dos niveles investigados:

TABLA 1. Datos globales por niveles educativos

\begin{tabular}{|l|c|c|c|c|}
\hline & $\begin{array}{c}\text { Total de unidades } \\
\text { léxicas }\end{array}$ & $\begin{array}{c}\text { Palabras } \\
\text { diferentes }\end{array}$ & $\begin{array}{c}\text { Promedio de } \\
\text { palabras de cada } \\
\text { informante }\end{array}$ & $\begin{array}{c}\text { Promedio de } \\
\text { vocablos diferentes } \\
\text { por cada centro }\end{array}$ \\
\hline Primaria & 47.236 & 5.719 & 222,35 & 357,43 \\
\hline Bachillerato & 70.656 & 7.714 & 321,16 & 482,31 \\
\hline
\end{tabular}


GRÁFICO 1. Total de palabras por centro de interés y nivel

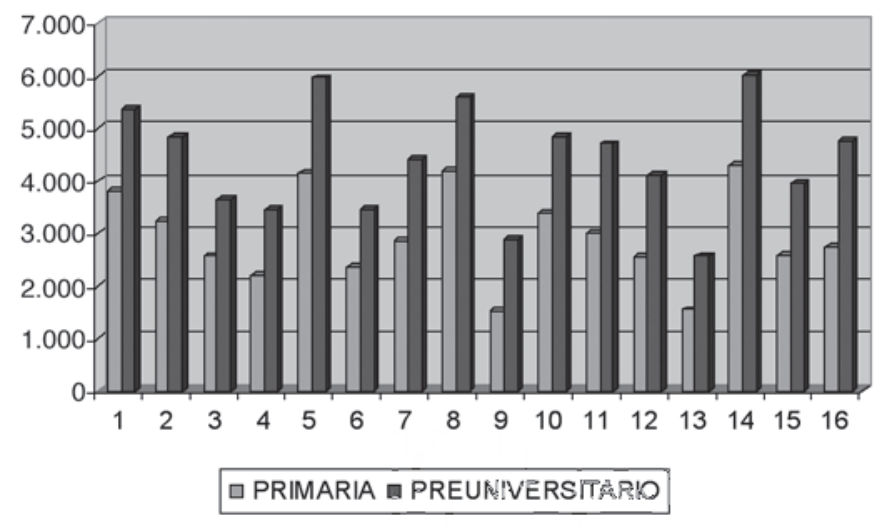

GRÁFICO 2. Total de palabras diferentes por centro de interés y nivel

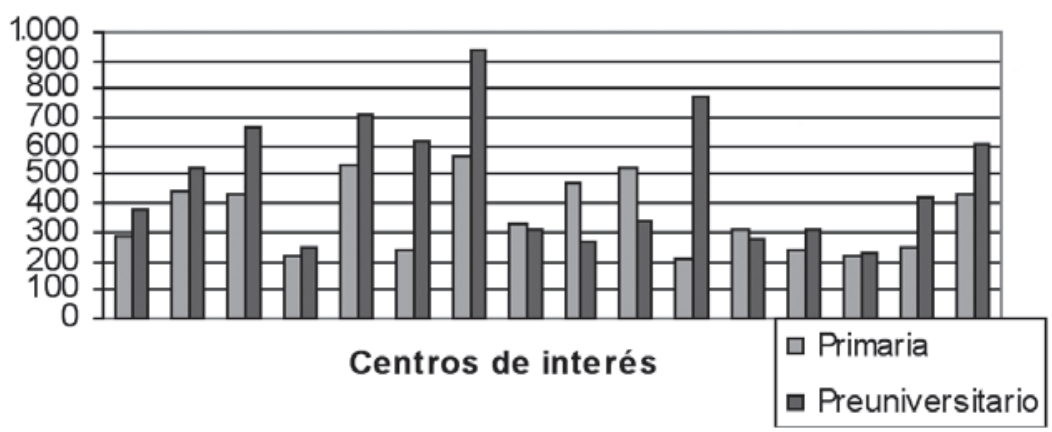

Como puede observarse, en términos generales, la producción léxica del nivel de Bachillerato es bastante superior a la de Primaria. Los resultados obtenidos nos indican que la media global del número de respuestas por sujeto en Primaria es de 13,42, siendo la media global de dichas respuestas en Bachillerato de 20,06 respuestas por sujeto. Por consiguiente, los alumnos de $2^{\circ}$ de Bachillerato poseen un 49,6\% más de promedio de total de unidades léxicas disponibles, un 34,9\% más de palabras diferentes, un 44,3\% más de palabras cada informante, e igualmente, un $34,9 \%$ más de vocablos diferentes por centros de interés, que los alumnos de $6^{\circ}$ de Primaria. 


\section{LA VARIABLE SOCIAL SEXO EN LAS INVESTIGACIONES DE DISPONIBILIDAD LÉXICA}

Aunque la influencia del factor sexo resultará más significativa en el análisis cualitativo del léxico, los datos que arrojan los análisis estadísticos aplicados en las más recientes investigaciones de disponibilidad léxica ponen de manifiesto que se trata de un factor que parece influir en el comportamiento léxico de los individuos y, por tanto, puede resultar un dato pertinente para esta investigación.

Esta afirmación difiere de lo que se ha obtenido en los estudios de disponibilidad léxica iniciales, en los que se siguió un criterio general de observación de valores absolutos de promedio de palabras disponibles para establecer las diferencias léxicas por razón de sexo. De esta manera, los pioneros en investigaciones de disponibilidad léxica, Gougenheim y sus colaboradores (1956), en su estudio sobre el Français Élémentaire, no encuentran diferencias léxicas apreciables entre los sexos.

Respecto a las primeras investigaciones hispanas, que siguieron el criterio de mera observación descriptiva de promedio de palabras disponibles al analizar la incidencia del factor sexo en la disponibilidad léxica y, a partir de las consideraciones de Galloso (2003: 93), podemos distinguir dos grupos de investigaciones en cuanto a los resultados obtenidos:

En las investigaciones hispanoamericanas, las mujeres aventajan a los hombres en casi todos los centros de interés en el estudio de Echeverría (1987) en Chile, quien concluye que el sexo no influye notablemente en el promedio de respuestas, aunque en general el grupo femenino presenta una ligera ventaja que se hace mayor en los centros de interés 02 . La ropa, 05. Alimentos y bebidas y 07. La cocina y sus utensilios; por su parte, Alba (1995), en la República Dominicana, considera que el sexo no ejerce una influencia muy evidente en el comportamiento de los sujetos, pero añade que parece tener alguna significación la sistematicidad con que las mujeres sobrepasan a los hombres en todos los centros de interés, excepto en 09. Iluminación y aire acondicionado donde coinciden, y destaca la diferencia más significativa en favor de las mujeres, con una explicación justificada culturalmente en centros como 04 . Los muebles de la casa, 05. Alimentos y 07. La cocina y sus utensilios. Igualmente, en Chile, Valencia y Echeverría (1999) demuestran la superioridad de las mujeres en doce centros y los hombres en seis; sin embargo, en las investigaciones de López Morales (1979) y Ruiz Bastos (1987), los chicos tienen una mayor productividad léxica que las chicas.

En las investigaciones españolas hay también claras diferencias: así, hay una diferencia a favor de las mujeres en las llevadas a cabo por Samper y Hernández (1997) en Las Palmas de Gran Canaria, aunque con diferencias poco 
relevantes; en Soria, también los resultados de Bartol (2004) demuestran una ligera superioridad de las chicas frente a los chicos en el número de vocablos producidos en quince de los dieciséis centros, salvo en el 12. Medios de transporte; igualmente, en Asturias, en la investigación de Carcedo (2001: 65), las mujeres superan a los hombres en once centros de interés y éstos sólo en cinco, evidenciando este investigador que los resultados «parecen confirmar la debilidad discriminatoria de este factor social»; por el contrario, en las investigaciones de Benítez (1992) y también en las de Bellón (2003) la ventaja se muestra a favor de los hombres.

Recientemente, algunos investigadores, conscientes de las limitaciones del análisis descriptivo para determinar la incidencia de los distintos factores sociales en los resultados de disponibilidad léxica, han considerado oportuno completar estas observaciones con análisis estadísticos, capaces de demostrar si las diferencias evidenciadas eran fruto del azar o de factores sociales.

Las investigaciones pioneras en la utilización del programa estadístico SPSS, en diferentes versiones, para determinar la incidencia y significación estadística de factores sociales en la disponibilidad léxica de hablantes españoles han sido, en primer lugar, las de Galloso (2003), quien, tras aplicar la prueba estadística, señala una ligera inclinación en Salamanca a favor de los hombres, que superan a las mujeres en once de los dieciséis centros de interés; y en Zamora, donde la distancia entre hombres y mujeres es aún mayor a favor de éstos; mientras que en Ávila se presenta una igualación entre ambos sexos. No obstante, esta investigadora afirma que, a pesar de las diferencias cuantitativas observadas, estos datos de forma aislada no tienen una gran importancia en el conjunto del léxico disponible, pues no pueden demostrar hasta qué punto es significativa estadísticamente la variable sexo; las investigaciones de Gómez Molina y Gómez Devís (2004) ponen de manifiesto que el factor sexo sí que ejerce un efecto diferenciador y destacan en su investigación llevada a cabo en Valencia la clara superioridad en la producción léxica de las mujeres frente a los hombres en quince centros de interés, de los diecisiete propuestos por ellos, y sólo éstos las superan en dos áreas temáticas y con una mínima diferencia; en las de Hernández (2006), en el análisis cuantitativo del léxico disponible de Castilla-La Mancha, se destaca una diferencia a favor de los hombres en doce de los dieciséis centros de interés y se pone de manifiesto que la diferencia en los promedios de respuestas de los hombres y de las mujeres es estadísticamente significativa a favor de los hombres, de manera que, según esta investigadora (ibídem: 325), «las divergencias en el número de palabras de los varones y de las mujeres no se deben al azar o a causas accidentales, sino a relaciones de causalidad relacionadas con el factor sexo»; sin embargo, en el reciente estudio sobre el léxico disponible de estudiantes malagueños realizado por Ávila (2006), tras aplicar pruebas estadísticas similares, 
afirma que «el factor sexo no parece condicionar la mayor o menor producción léxica», pues, en esta provincia, la media de palabras obtenida para hombres y mujeres es prácticamente la misma.

De lo expuesto anteriormente se desprende que no hay unanimidad en el predominio de disponibilidad léxica de un sexo sobre otro.

\section{LA VARIABLE SEXO EN LA DISPONIBILIDAD LÉXICA DE HUELVA}

Veamos ahora los resultados de la producción léxica de Huelva por niveles educativos y sexo.

En primer lugar, analizaremos los resultados del nivel de $6^{\circ}$ curso de Primaria con centros de interés y sexo:

TABla 2. Promedio de palabras disponibles por sujeto de acuerdo con el sexo en sexto de Primaria

\begin{tabular}{|l|l|c|c|}
\hline & \multicolumn{1}{|c|}{ Centros de interés } & Mujeres & Hombres \\
\hline 01 & Partes del cuerpo & 17 & 17 \\
\hline 02 & La ropa & 16 & 14 \\
\hline 03 & Partes de la casa sin los muebles & 11 & 12 \\
\hline 04 & Muebles de la casa & 11 & 9 \\
\hline 05 & Alimentos y bebidas & 20 & 18 \\
\hline 06 & Objetos colocados en la mesa para la comida & 11 & 10 \\
\hline 07 & La cocina y sus utensilios & 13 & 13 \\
\hline 08 & La escuela & 19 & 19 \\
\hline 09 & Calefacción e iluminación & 9 & 8 \\
\hline 10 & La ciudad & 16 & 15 \\
\hline 11 & El campo & 13 & 14 \\
\hline 12 & Medios de transporte & 11 & 12 \\
\hline 13 & Trabajos del campo y del jardín & 7 & 7 \\
\hline 14 & Animales & 20 & 19 \\
\hline 15 & Juegos y diversiones & 12 & 11 \\
\hline 16 & Profesiones & 13 & 12 \\
\hline Total de palabras por sexo & $\mathbf{2 1 9}$ & $\mathbf{2 1 0}$ \\
\hline Total de media & $\mathbf{1 4}$ & $\mathbf{1 3}$ \\
\hline
\end{tabular}


GRÁfICO 3. Promedio de palabras disponibles por sujeto de acuerdo con el sexo en sexto de Primaria

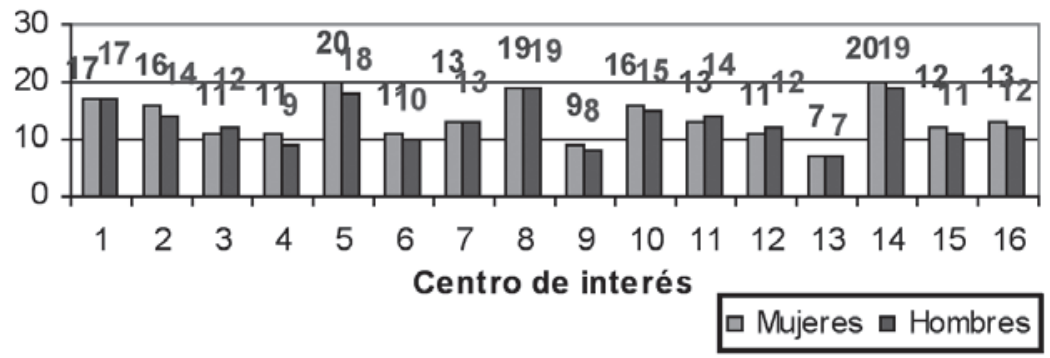

Como puede observarse, en el promedio global de palabras disponibles en el nivel de Primaria las mujeres superan a los hombres en 9 palabras, lo que supone un $1,04 \%$ más de producción léxica. Los centros de interés más rentables léxicamente en ambos sexos, con un promedio de 20 o más unidades léxicas producidas son el 05. Alimentos y bebidas y el 14. Animales; y los menos rentables, con un promedio inferior a 10 unidades léxicas, son el 09. Calefacción e iluminación y el 13. Trabajos del campo y del jardín, en el que coinciden el número de unidades producidas en ambos sexos. El promedio por centro de interés de las mujeres supera al de los hombres, excepto en los campos 03. Partes de la casa (sin muebles), 11. El campo y 12. Medios de transporte, en los que los hombres aventajan en una palabra a las mujeres; y los dos sexos coinciden en cuatro centros de interés, 01. Partes del cuerpo, 07. La cocina y sus utensilios, 08. La escuela y 13. Trabajos del campo y del jardín; mientras que en los centros 02. Ropa, 04. Muebles de la casa y 05. Alimentos $y$ bebidas las chicas aventajan en dos palabras a los chicos; y en una palabra también éstas, en los centros 06. Objetos colocados en la mesa para la comida, 09. Calefacción e iluminación, 10. La ciudad, 14. Animales, 15. Juegos y diversiones y 16. Profesiones.

Frente a los resultados anteriores, en los obtenidos en el nivel de $2^{\circ}$ de Bachillerato por sexos (Prado y Galloso, 2005), los hombres superan a las mujeres. 
TABLA 3. Promedio de palabras disponibles por sujeto de acuerdo con el sexo en Bachillerato

\begin{tabular}{|l|l|c|c|}
\hline & \multicolumn{1}{|c|}{ Centros de interés } & Mujeres & Hombres \\
\hline 01 & Partes del cuerpo & 24 & 26 \\
\hline 02 & La ropa & 22 & 22 \\
\hline 03 & Partes de la casa sin los muebles & 16 & 18 \\
\hline 04 & Muebles de la casa & 16 & 16 \\
\hline 05 & Alimentos y bebidas & 28 & 26 \\
\hline 06 & Objetos colocados en la mesa para la comida & 15 & 17 \\
\hline 07 & La cocina y sus utensilios & 19 & 22 \\
\hline 08 & La escuela & 25 & 26 \\
\hline 09 & Calefacción e iluminación & 13 & 14 \\
\hline 10 & La ciudad & 22 & 22 \\
\hline 1 & El campo & 22 & 20 \\
\hline 12 & Medios de transporte & 18 & 20 \\
\hline 13 & Trabajos del campo y del jardín & 12 & 12 \\
\hline 14 & Animales & 27 & 28 \\
\hline 15 & Juegos y diversiones & 19 & 18 \\
\hline 16 & Profesiones & 22 & 21 \\
\hline Total & & $\mathbf{3 2 0}$ & $\mathbf{3 2 8}$ \\
\hline
\end{tabular}

GráfICo 4. Promedio de palabras disponibles por sujeto de acuerdo con el sexo en Bachillerato

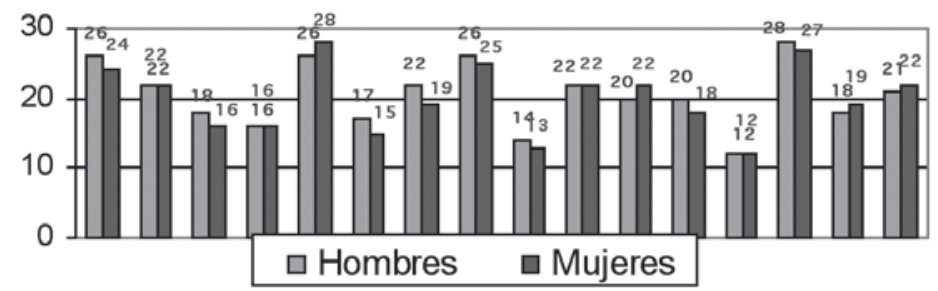

Como se desprende de estos resultados, en el promedio global de palabras disponibles en $2^{\circ}$ de Bachillerato los hombres superan a las mujeres en 8 palabras, lo que significa un 1,03\% más. Los centros de interés más renta- 
bles léxicamente en ambos sexos, con un promedio de 25 o más unidades léxicas producidas son el 05. Alimentos y bebidas, el 08. La escuela y el 14. Animales; y los menos rentables, con un promedio de palabras producidas inferior a 15 unidades léxicas, son el 09. Calefacción e iluminación y el 13. Trabajos del campo y del jardín. En cuanto a centros de interés, el promedio indica que los hombres superan a las mujeres en tres palabras en el centro 07. La cocina y sus utensilios; dos en 01. Partes del cuerpo, 03. La casa sin los muebles, 06. Objetos colocados en la mesa para la comida y 12. Medios de transporte; y una en el 08. La escuela, 09. Calefacción e iluminación y 14. Animales. Por el contrario, en los campos 05, Alimentos y bebidas, 11. El campo, 15. Juegos $y$ diversiones y 16. Profesiones, las mujeres aventajan en una o dos palabras a los varones; y los dos sexos coinciden en los centros 02. La ropa, 04. La casa con los muebles, 10. La ciudad y 13. Trabajos del campo y del jardín.

Comparemos a continuación ambos sexos en ambos niveles:

TABLA 4. Promedio de palabras disponibles por sexo y niveles

\begin{tabular}{|l|l|c|c|c|c|}
\hline \multicolumn{1}{|c|}{ Centros de interés } & $\begin{array}{c}\text { Mujeres } \\
\text { Primaria }\end{array}$ & $\begin{array}{c}\text { Mujeres } \\
\text { Bachiller }\end{array}$ & $\begin{array}{c}\text { Hombres } \\
\text { Primaria }\end{array}$ & $\begin{array}{c}\text { Hombres } \\
\text { Bachiller }\end{array}$ \\
\hline 01 & Partes del cuerpo & 17 & 24 & 17 & 26 \\
\hline 02 & La ropa & 16 & 22 & 14 & 22 \\
\hline 03 & Partes de la casa sin los muebles & 11 & 16 & 12 & 18 \\
\hline 04 & Muebles de la casa & 11 & 16 & 9 & 16 \\
\hline 05 & Alimentos y bebidas & 20 & 28 & 18 & 26 \\
\hline 06 & $\begin{array}{l}\text { Objetos colocados en la mesa para } \\
\text { la comida }\end{array}$ & 11 & 15 & 10 & 17 \\
\hline 07 & La cocina y sus utensilios & 13 & 19 & 13 & 22 \\
\hline 08 & La escuela & 19 & 25 & 19 & 26 \\
\hline 09 & Calefacción e iluminación & 9 & 13 & 8 & 14 \\
\hline 10 & La ciudad & 16 & 22 & 15 & 22 \\
\hline 11 & El campo & 13 & 22 & 14 & 20 \\
\hline 12 & Medios de transporte & 11 & 18 & 12 & 20 \\
\hline 13 & Trabajos del campo y del jardín & 7 & 12 & 7 & 12 \\
\hline 14 & Animales & 20 & 27 & 19 & 28 \\
\hline 15 & Juegos y diversiones & 12 & 19 & 11 & 18 \\
\hline 16 & Profesiones & $\mathbf{2 1 9}$ & $\mathbf{3 2 0}$ & $\mathbf{2 1 0}$ & $\mathbf{3 2 8}$ \\
\hline $\begin{array}{l}\text { Total de palabras disponibles } \\
\text { por sexo }\end{array}$ & $\mathbf{2 0}$ & $\mathbf{1 3}$ & $\mathbf{2 1}$ \\
\hline Total de media & 22 & 12 & 21 \\
\hline
\end{tabular}


Contrastando ambos niveles y sexos en cada uno de ellos, los resultados generales por centros de interés nos evidencian que las mujeres del nivel de Bachillerato producen un promedio de $46,1 \%$ más de vocablos o palabras diferentes que las chicas de Primaria, y los hombres de Bachillerato un 56,2\% más que los chicos de Primaria. Asimismo, los centros de mayor rentabilidad léxica son los mismos en ambos niveles y sexos, el 05. Alimentos y bebidas, el 08. La escuela y el 14. Animales; e igualmente, los menos rentables en ambos niveles y sexos son el 09. Calefacción e iluminación y el 13. Trabajos del campo y del jardín, siendo también este último el de menor rentabilidad léxica.

En cuanto a los resultados obtenidos por centros de interés en las mujeres de ambos niveles, frente a los hombres, tan sólo hay coincidencia en la superioridad numérica, en tres centros de interés, el 05. Alimentos y bebidas, común en otras muchas investigaciones hispánicas, el 15. Juegos y diversiones y el 16. Profesiones; mientras que los hombres coinciden en su ventaja léxica frente a las mujeres en el centro 03. Partes de la casa sin muebles y en el 12. Medios de transporte.

\subsection{Estudios exploratorios por niveles y sexo del léxico disponible de Huelva, aplicando el programa estadístico SPSS}

Realizado el test de Levenne para contrastar la hipótesis de igualdad de varianzas entre ambos sexos, por niveles educativos, obtenemos los siguientes resultados:

1. En el nivel de Primaria se obtiene una significación del 0,402, que es mayor que la estipulada teóricamente del 0,05 , por consiguiente, se acepta la hipótesis de igualdad de varianzas. Por tanto, teniendo en cuenta que las varianzas en ambos sexos son iguales, de los dos contrastes realizados para la igualdad de medias, consideraremos el que tiene como valor del estadístico t-student $=-3,478$, con una significación del $0,001(<0,05)$, por lo que rechazamos la igualdad de medias con una confianza del $99 \%$.

2. En el nivel de Bachillerato, realizado el test de Levenne para contrastar la hipótesis nula de igualdad de varianzas entre ambos sexos, se obtiene una significación del 0,001 , que es menor que la estipulada teóricamente del 0,05 , por consiguiente, se rechaza la hipótesis de igualdad de varianzas. Por tanto, teniendo en cuenta que las varianzas en ambos grupos son distintas, de los dos contrastes realizados para la igualdad de medias, consideraremos el que tiene como valor del estadístico t-student $=-4,183$ con una significación del $0(<0,05)$, por lo que también rechazamos la igualdad de medias con una confianza del $99 \%$. 
3. Tras observar los resultados obtenidos tras las pruebas estadísticas, concluimos que existen diferencias significativas entre hombres y mujeres (diferencias no debidas al azar) en el número de respuestas producidas por los informantes, a favor de las mujeres en Primaria y de los hombres en Bachillerato.

\section{CONCLUSIONES}

1. En la investigación llevada a cabo en la provincia de Huelva para la obtención de la disponibilidad léxica en el alumnado de $6^{\circ}$ de Primaria y $2^{\circ}$ de Bachillerato, en términos generales, los resultados obtenidos nos indican que la media global del número de respuestas por sujeto en Primaria es de 13,42, siendo la media global de dichas respuestas en Bachillerato de 20,1 respuestas por sujeto, lo que significa que los alumnos de $2^{\circ}$ de Bachillerato poseen un $49,6 \%$ más de promedio de total de unidades léxicas disponibles, un 34,9\% más de palabras diferentes, un 44,3\% más de palabras cada informante, e igualmente, un 34,9\% más de vocablos diferentes por centros de interés, que los alumnos de $6^{\circ}$ de Primaria, lo que parece confirmar nuestra hipótesis inicial de que el periodo de formación seguido por los alumnos desde el final de la etapa de Primaria hasta el periodo previo a su ingreso en la universidad, $2^{\circ}$ de Bachillerato, junto con el periodo de socialización en el que estos alumnos están inmersos durante estos años, incide positivamente en un evidente incremento de disponibilidad léxica.

2. En cuanto a si es significativa la incidencia del factor sexo en la disponibilidad léxica, en las investigaciones llevadas a cabo hasta el momento en el mundo hispánico en el nivel preuniversitario, no hay unanimidad en el predominio léxico de un sexo sobre otro y la diferencia a favor de uno u otro, siempre poco importante numéricamente y aparentemente poco significativa, ha dependido de la sintopía investigada.

3. A este respecto, en la investigación de disponibilidad léxica llevada a cabo en la provincia de Huelva, si bien en términos generales es clara la superioridad numérica en la producción léxica del nivel de Bachillerato sobre el de Primaria, la mayor producción léxica en ambos niveles no coincide en el mismo sexo, pues, mientras que en Primaria las chicas aventajan a los chicos en 9 palabras, en Bachillerato son los chicos quienes aventajan a las chicas en 8 palabras de promedio.

4. En cuanto a los centros de interés, no encontramos que dicha superioridad por sexos se produzca en los mismos centros de interés, aunque las chicas de ambos niveles aventajan a los chicos en tres centros de inte- 
rés, el 05. Alimentos y bebidas, común en otras muchas investigaciones hispánicas, el 15. Juegos y diversiones y el 16. Profesiones; mientras que los hombres coinciden en su ventaja léxica frente a las mujeres en el centro 03. Partes de la casa sin muebles y en el 12. Medios de transporte. Respecto a los centros de mayor rentabilidad léxica, hay coincidencia en ambos niveles y sexos, siendo el 05. Alimentos y bebidas, el 08. La escuela y el 14. Animales los más rentables; e igualmente, los menos rentables en ambos niveles y sexos son el 09. Calefacción e iluminación y el 13. Trabajos del campo y del jardín, siendo también este último el de menor rentabilidad léxica de todos.

5. Pese a estas escasas diferencias numéricas, y tras la aplicación de las pruebas estadísticas SPSS a los resultados obtenidos en la investigación de disponibilidad léxica de Huelva, una vez realizado el test de Levenne en todos los centros de interés para contrastar la hipótesis nula de igualdad de varianzas entre ambos sexos, el resultado ha sido el valor del estadístico t-student $=-3,478$, con una significación del 0,001 $(<0,05)$ en Primaria; y el valor del estadístico t-student $=-3,478$, con una significación del 0,001 $(<0,05)$ en Bachillerato; por ello, podemos concluir que en ambos niveles existen diferencias significativas entre hombres y mujeres (diferencias no debidas al azar) en el número de respuestas producidas según sexo, a favor de las mujeres en Primaria y de los hombres en Bachillerato.

6. Por último, consideramos que en relación con la variable social sexo, los datos que hemos presentado no tienen una gran relevancia en el conjunto del léxico disponible del hablante hispano, aunque hayamos encontrado diferencias cuantitativas significativas como las que acabamos de señalar. $\mathrm{Y}$ hacemos esta afirmación teniendo en cuenta que tan sólo con estos resultados aislados no podemos demostrar hasta qué punto es significativa la variable sexo en sentido estricto, pues sería necesario que todas y cada una de las investigaciones del Proyecto Panhispánico aplicasen los programas estadísticos adecuados para obtener sus conclusiones, como se está llevando a la práctica en las investigaciones más recientes.

\section{REFERENCIAS BIBLIOGRÁFICAS}

Alba, O. (1995): Léxico disponible de la República Dominicana, Santiago de los Caballeros, Pontificia Universidad Católica Madre y Maestra.

Ávila, A. M. (2006): Léxico disponible de los estudiantes preuniversitarios de Málaga, Málaga, Universidad de Málaga.

BARTOL, J. A. (2004): Léxico disponible de Soria. Estudio y diccionario, Burgos, Fundación Instituto Castellano-Leonés de la Lengua. 
Bellón, J. J. (2003): Léxico disponible de la provincia de Córdoba, tesis doctoral (inédita), Universidad de las Palmas de Gran Canaria.

Benítez PÉREZ, P. (1992): «Disponibilidad léxica en la zona metropolitana de Madrid», Boletín de la Academia Puertorriqueña de la Lengua Española, 1,1: 71-102.

Carcedo A. (2001): Léxico disponible de Asturias, Turku, Departamento de español de la Universidad de Turku.

ECHEVERRÍA, M. (1987): «Disponibilidad léxica en Educación Media. Resultados cuantitativos», Revista de Lingüística Teórica y Aplicada, 25: 55-115.

Galloso Camacho, M ${ }^{a}$ V. (2003): El léxico disponible de Ávila, Salamanca y Zamora, Burgos, Fundación Instituto Castellano-Leonés de la Lengua.

Gómez Molina, J. R. y Mª B. Gómez Devís» (2004): Disponibilidad léxica de los estudiantes preuniversitarios valencianos. Estudio y estratificación sociolingüística, Valencia, Universitat de València.

Gougenheim G., R. Michéa y A. Sauvageot (1956): L'élaboration du Français Fondamental, París, Didier.

HERNÁNDEZ, N. (2006): Hacia una teoría cognitiva integrada de la disponibilidad léxica: el léxico disponible de los estudiantes castellano-manchegos, Salamanca, Ediciones Universidad de Salamanca, versión digital.

LóPEZ Morales, H. (1979): «Disponibilidad léxica y estratificación socioeconómica», en Dialectología y Sociolingüística. Temas puertorriqueños, Madrid, Hispanova, 173-181.

Prado, J. y M ${ }^{\mathrm{a}}$ V. Galloso (2005): El léxico disponible de Huelva. Nivel preuniversitario, Huelva, Universidad de Huelva.

Ruiz Basto, A. (1987): Disponibilidad léxica en seis centros de interés en alumnos de primer ingreso en el Colegio de Ciencias y Humanidades, Plantel de Naucalpan, México, Universidad Autónoma de México.

SAMPER, J. A. (1998): «Criterios de edición del léxico disponible», Lingüística, 10: 311-333.

SAMPER, J. A. y C. E. HeRnÁNDEZ (1997): «El estudio de la disponibilidad léxica en Gran Canaria: datos iniciales y variación sociolingüística», en Contribuciones al estudio de la lingüística hispánica, Homenaje al profesor Ramón Trujillo, Montesinos, Santa Cruz de Tenerife, vol. II: 229-239.

VALENCIA, A. y M. ECHEVERría (1999): Disponibilidad léxica en estudiantes chilenos, Santiago de Chile, Universidad de Concepción. 


\title{
UNA DIFERENCIA SOCIOLINGÜÍSTICA EN EL USO DE LAS FÓRMULAS SUPERLATIVAS EN ESPAÑOL MEDIEVAL*
}

\author{
ana Serradilla Castaño \\ Universidad Autónoma de Madrid
}

\begin{abstract}
A L estudiar los cambios que en el nivel morfológico o en el sintáctico sufre el castellano a lo largo del periodo medieval, nos encontramos habitualmente con afirmaciones de carácter general que no tienen en cuenta la variación lingüística existente en cada época. Así, pocas veces prestamos atención a las diferencias que pueden surgir según el texto que estemos analizando sea una crónica, un texto jurídico, una obra literaria, etc. Estamos acostumbrados a observar las diferencias en el nivel diatópico pero en muchas ocasiones nos olvidamos de las diferencias diastráticas. La dificultad para atender a estas diferencias se basa en primer lugar en que, obviamente, solo contamos con un tipo de material, el escrito, y, por otro lado, en que sabemos que la escritura estaba aún al alcance de pocos hablantes y que, por tanto, habrá niveles de lengua que se nos escapen. Pese a esto, está claro que los textos medievales presentan un diferente grado de latinismo, así como que hay textos que reflejan en mayor medida el habla popular que otros. Dos trabajos muy recientes como son los de Penny (2004) y de Moreno (2005) nos presentan una visión de los cambios lingüísticos que tiene muy en cuenta la variación existente durante estos siglos y es en esta línea en la que se inscribe la comunicación que ahora presento.
\end{abstract}

Sabido es para los estudiosos de la morfología y la sintaxis histórica del español cómo en el paso del latín a las lenguas romances desaparece el superlativo sintético latino (eloquentissimus) a favor de una serie de fórmulas perifrásticas, algunas de las cuales tienen su base en el latín popular (bene, multu... + adjetivo). El uso de una u otra expresión en español antiguo (bien, mucho, muy, asaz, harto, fuert, sobra...) no es, sin embargo, un hecho arbitra-

* Este trabajo se inscribe en el marco de un proyecto investigador de carácter más amplio que llevamos a cabo un grupo de profesores de la Universidad Autónoma de Madrid: Vieja y nueva sintaxis: la emergencia de la norma sintáctica del castellano, financiado por el Ministerio de Educacióon y Ciencia. Este grupo dirigido por Javier Elvira y formado también por Inés Fernández Ordóñez, Javier García, Santiago U. Sánchez y Jacinto González está analizando, desde diferentes perspectivas, la naturaleza del cambio lingüístico, así como el conjunto de fenómenos sujetos a variación gramatical en el español. 
rio. En el estudio de diversos textos medievales he podido observar que la elección de una u otra forma tiene que ver con el tipo de texto ante el que nos encontramos, con la variedad geográfica y con el tipo de adjetivo al que acompaña el adverbio superlativo.

En este breve estudio dejaré de lado la variación diatópica y me centraré en la diversidad diastrática, que nos permitirá establecer una diferenciación en el uso de las fórmulas perifrásticas dependiendo del tipo de texto y del tipo de adjetivo que presenta una modificación en su grado. Así, por ejemplo, en $E l$ Cid no se documenta la forma asaz, de origen culto, y, sin embargo, una perífrasis de carácter popular como es bien + adjetivo se utiliza con notable frecuencia. Asimismo, quiero llamar la atención sobre el hecho de que los pocos casos que en la época medieval aparecen de superlativos sintéticos se incluyen en obras de marcado carácter latinizante.

El objetivo último, pues, de este estudio es demostrar cómo ya en español antiguo la diversidad sociolingüística determina la utilización de las fórmulas perifrásticas que sustituyeron al superlativo sintético latino y cómo en esta época va a estar la base de lo que luego será también una diferencia en el español clásico y moderno. ${ }^{1}$

Me gustaría destacar que el corpus en el que se asienta este trabajo es muy amplio ya que para la búsqueda de ejemplos he contado con el CORDE, así como con la base ADMYTE, entre otras fuentes; dadas las limitaciones de espacio, mostraré solo algunos ejemplos ilustrativos, que nos permiten ratificar la hipótesis de partida. En primer lugar, haré referencia a los usos encontrados del superlativo sintético y, a continuación, iré analizando las diversas fórmulas superlativas que aparecen en los distintos textos medievales.

\section{CONSTITUCIONES SINTÉTICAS Y CONSTRUCCIONES ANALÍTICAS}

Como ya señalé en Serradilla (2005), el superlativo desinencial latino desapareció en el tránsito a las lenguas romances y fue sustituido por formaciones perifrásticas. Solo por vía culta se reintroduce más tarde en italiano, portugués y español. En la península ibérica la datación más antigua corresponde a Berceo: del mi fijo duçisimo amas eran sus tias (Duelo, 20). Poco después, Sancho IV en Castigos e documentos habla del «altísimo rey»; no obstante, era una forma prácticamente desconocida que Nebrija, de hecho, no menciona en su Gramáti$c a$, por no sentirla del idioma. Solo en el siglo XV, en textos de marcado carác-

1. Sobre la diferencia en el uso de fórmulas superlativas en español clásico puede consultarse Serradilla (2004) y sobre la variación social en el español de algunas regiones en la actualidad son interesantes los datos y reflexiones incluidos en Salvador Salvador (1987) o en Arjona (1991). 
ter latinizante pueden observarse ya algunos usos del superlativo en -ísimo, aunque es de destacar que en la obra de autores como Mena o Santillana su presencia es aún muy esporádica (de este último: en grandisimas cadenas en Cantares $y$ Decires). Realmente, hemos de esperar al siguiente siglo para que esta forma empiece a consolidarse en nuestra lengua, aunque todavía en esta época está muy presente su uso latinizante o italianizante (recuérdese que empieza a introducirse a través de traducciones del italiano, véase la traducción de Boscán de El Cortesano de Castiglione). ${ }^{2}$ Su introducción se da básicamente en un registro culto y al convertirse en una diferencia significativa de la lengua culta frente a la popular se convierte también en una pieza clave cuando se quiere imitar o parodiar la lengua culta, por parte de los personajes populares, como puede verse en autores como Cervantes o Quevedo.

Pero volvamos a la época medieval con ejemplos como los siguientes, recogidos en el corpus elaborado por Company para su Sintaxis histórica (2006):

1. Mirando y contemplando, muy alta señora mía, con atento acatamiento y ojos circunspectos, los aferes caridosos y diligentes actos y los ejercicios de continuo y servicios por cabo devotos que a nuestro Señor y a la Santísima Virgen y Castísima Madre suya ofresce vuestra devotísima humildat, especialmente y sobre todo en las solemnísimas fiestas (H. 1450. Juan López de Salamanca (h. 1385-1479). [Vida de la Virgen], ed. de L. G. A. Getino, Madrid, 1924.)

2. el cual acumulase y juntase las devotísimas y santísimas historias que comprenden toda la vida de Nuestra Señora. (H. 1450. Juan López de Salamanca (h. 1385-1479). [Vida de la Virgen], ed. de L. G. A. Getino, Madrid, 1924.)

3. Lucena a su señora. Y pensara que, sin screvirte, mi suavíssima señora, conoscieras de mí la mucha gana que tengo de servirte. ( $1^{\mathrm{a}}$ ed., Salamanca, h. 1495-1497. Luis de Lucena, Repetición de amores, ed. de J. Ornstein, Chapel Hill, 1954.)

Se trata de dos textos del siglo XV momento en el que el esfuerzo latinizante es más evidente. Son ejemplos, como digo, esporádicos: uno de ellos, de carácter religioso y, por tanto, con clara influencia latina, y el otro de corte amoroso y laudatorio a la dama, en el que el lenguaje presenta también una gran complejidad formal. Obsérvese que en todos los casos estamos ante epítetos que se anteponen al nombre al que se refieren. Quiero llamar también la atención sobre un documento jurídico aragonés del siglo XV, donde excepcionalmente encontramos este uso. En este tipo de texto, salvo en las fórmulas

2. Un estudio básico sobre el uso del superlativo en esta obra es el de Morreale (1955). También en Serradilla (2004) profundizo en la evolución del superlativo sintético en español clásico. 
fijadas, donde son habituales los latinismos, suele aparecer un lenguaje más cercano a la lengua popular:

4. Clamado, conuocado e congregado capitol de nos, los sozdean, canonges e capitol de la seu de la ciudat de Jacca... pora fazer et desenbargar los afferes et negocios de aquel, yes a saber et costumbrado plegar se... todos ensemble concordes et alguno de nos no discrepant, attendientes et considerantes la grandissima diminucion, destruction et danyo... de las heredades de aquella et encara otras folgan et no se troba qui las spleyte, mayorment las trehuderas, et van en ruyna et albaix... a causa de las mortaldades, piedras, geladas... Damos un campo con tiras de vites... (1465, Jaca. Concesión de un campo, ed. de M. Alvar, Documentos... 354). ${ }^{3}$

Pasemos ya, una vez anotada la mínima presencia de la construcción sintética, a analizar el uso de las fórmulas perifrásticas.

\section{ANÁLISIS DE LOS DATOS}

Recordemos las expresiones que constituían junto al adjetivo fórmulas perifrásticas para expresar el máximo grado en español medieval: mисho, muy, bien, asaz, además, harto, sobre (sobra), tan (tanto) y fuerte. En principio, el uso de una u otra forma no trae consigo diferencias semánticas relevantes, por lo que la elección depende de otros factores: estilísticos, sociales, cronológicos o geográficos; pero maticemos esta afirmación.

El uso de much $(o)$ + adjetivo para expresar el superlativo absoluto en la época medieval es general hasta el siglo XV. Se observa en todo tipo de textos y ante todo tipo de adjetivos. En los manuales de gramática histórica se viene repitiendo que en castellano existían, por una cuestión de fonética sintáctica, variantes como mucho, much (ante vocal) y muy, muyt (ante consonante) pero la realidad es que hay muchas vacilaciones y, a partir del siglo XIII, no se cumple esta regla y encontramos casos de mucho + consonante o muy + vocal:

5. Desto fue el hermitaño mucho marauillado e dixole asy: (Zifar, p.107)

6. Salieron de Alcoçer avna priessa much estrana. (Cid, 587)

7. Delo que auien fecho mucho Repisos son; (Cid, 3569)

8. fazié una tal vida non mucho ordenada, pero dicié sus oras en manera (Berceo, Los Milagros de Nuestra Señora)

3. En todo caso, es significativo que el adjetivo que aquí aparece, grande, es también el que un siglo después en El Lazarillo o en las obras de Santa Teresa, textos de carácter popular, aparecerá con la forma de superlativo sintético con mayor frecuencia. Se trata, de hecho, de un adjetivo que tiende a ser graduado (Serradilla, 2004). Obsérvese que también se da la anteposición. 
9. el precio del pan sera mediano. ny mucho karo. ny mucho rafez. \& andaran mucho por mar. (1259, Alfonso X, Libro de las Cruces)

Aunque desde el principio esta fórmula compite con muy + adjetivo, que gana claramente la partida, no es hasta el siglo XV cuando la expresión que estamos analizando pasa a ser cada vez más extraña, pese a esto, todavía varios siglos después encontramos ejemplos esporádicos de su uso:

10. Este cavallero ordenó en metros los proverbios que comiençan: «Fijo mío, mucho amado, etc.», (Fernando del Pulgar, Claros varones de Castilla)

11. que dizque fue cosa ${ }^{39}$ mucho admirable. (1529, Ciudad de México: Fragmento de una carta autógrafa de fray Juan de Zumárraga al emperador Carlos V, refiriéndole lo sucedido en la ciudad de México durante el viaje de Hernán Cortés a las Higueras)

12. la $/{ }^{16}$ cual es amiga mucho de la dicha Bastida que $/{ }^{17}$ me lo dijo- $(1692$, Ciudad de México. Denuncia autógrafa de don Diego Martín Pinzón Dávila Galindo contra un fraile agustino...)

En este caso estamos ante una construcción que va desapareciendo, desbancada por otras más productivas. No se observa en su uso una diferenciación diastrática ni diatópica en la época medieval, diferencias que, como señalan Menéndez Pidal (1944: 238) y Fernández Ramírez (1988: 60), sí son observables en los restos de su uso en épocas posteriores; así, el primer autor localiza esta construcción en zonas de Soria y Álava donde, en los primeros años del siglo XX se mantenía esta construcción incluso por parte de las personas cultas, mientras que Fernández Ramírez la considera ya solo como uso vulgar de algunas regiones españolas. En todo caso, es una estructura en franco retroceso desde el siglo XV, que solo ha pervivido de forma esporádica.

En el caso de muy + adjetivo, considero que no es preciso insistir pues su uso está generalizado desde la época de orígenes y es, sin duda alguna, la fórmula más utilizada en todas las épocas del idioma y en todo tipo de textos.
13. Assiniestro dexan Atineza, una peña muy fuert (Cid, 2691)
14. Que era un omne muy pobre (Cal.p. 96)
15. e fallolo que era bueno e muy enfrenado e muy valiente, (Zifar, p. 55)
16. al muy prepotente don Juan el segundo (Mena: Lab.)

Tampoco parece haber diferencias sociolingüísticas significativas en el uso de tan + adjetivo como perífrasis de superlativo absoluto. Se trata de una forma poco usada con este valor, ya que lo normal es que aparezca en construcciones comparativas o consecutivas; solo cuando desaparece el segundo término de la correlación se observa claramente el valor superlativo; salvo en 
El Cid, donde es muy frecuente, la lengua medieval suele valerse de otros recursos para expresar el superlativo de los adjetivos.

\section{7 Ffablo myo Çid bien \& tan mesurado: \\ 18. 630 Vino posar sobre Alcoçer, en vn tan fuerte logar; \\ 19. 1588 Fizo vna corrida esta fue tan estraña. \\ 20. 2843 Vinieron a SantEsteuan de Gormaz, vn castiello tan fuert,}

Antes de comenzar a analizar otras fórmulas, haré un brevísimo comentario en torno a dos expresiones: fuert y sobre, cuyo uso obedece únicamente a razones geográficas -solo se encuentran en textos aragoneses y riojanos- y no rebasa el límite de la época medieval. En francés fort sigue equivaliendo a «muy» y fue forma muy utilizada, sobre todo entre los siglos XVI y XVIII; en la actualidad, se mantiene como forma culta y arcaica, como señala Lago Alonso (1965-67: 52).

En la época medieval, se usaba sobre todo en aragonés y en la lengua hablada en zonas cercanas, y después del siglo XIII tiende a desaparecer.

21. Fue en la abadia el baron assentado, con la fazienda pobre era fuert enbargado. (Berceo, Sto. Domingo, 215 b)

22. et por alexandre grant esquiuada(da)s et fuert Jnstruydas en armas et en cauallos, (1377-1396, Fernández de Heredia: Historia Eutropio)

Tampoco sobre/sobra tiene una alta frecuencia de uso en la época medieval

23. fue luego por las tierras sobra grand el roído; (1230, Berceo: Vida de San Millán de la Cogolla)

Aunque se encuentra algún ejemplo todavía en el siglo XV:

24. E las espuelas sangrientas de la sangre del cavallo non los podian fazer llegar al sañudo puerco, que mayor era el temor por la vision que la dolor por las feridas e sobre mayor quel pungimiento de las espuelas. (Enrique de Villena: Los doce trabajos de Hércules)

Respecto a además, 'en demasía', 'en exceso', 'demasiado', lo he localizado únicamente en textos de prosa histórica. Véanse, en este sentido, los siguientes ejemplos extraídos del CORDE y de ADMYTE:

25. En Affrica a un mont muy alto ademas e quel dizien otrossi el mont Athlant $(P C G)$

26. Este alhaçan fallo la tierra muy asosegada \& mucho en paz ca el padre la tenje muy ademas apremjada \& sin bolliçio ninguno (Crónica de Veinte Reyes fol 22v (ADMYTE)) 
27. E Quando esto dixieron al rey fue muy sannudo ademas (Gran Conquista de Ultramar fol. 154r (ADMYTE))

28. ech seteno enla generacion de caym. fue omne malo ademas. Otrossi este enoc seteno enla generation (1275, Alfonso X, General Estoria I)

29. Et por ende es bona pora los omnes ademas gruessos que quieren enmagrecer ayna $(1250$, Lapidario $)$

Con este valor no lo he encontrado en otro tipo de textos y llama la atención cómo siglos después, cuando ya su significado más extendido era el actual, Cervantes retoma este uso al contar la historia de don Quijote:

30. Pensativo además iba don Quijote por su camino adelante, considerando la mala burla que le habían hecho los encantadores, (Quijote: cap. XI, $2^{\mathrm{a}}$ parte)

Me detendré ahora en el uso de bien, que semánticamente presenta en el español antiguo el mismo valor que muy, solo en épocas posteriores irá adquiriendo nuevos valores (como el totalizador) e irá diferenciándose su comportamiento sintáctico (posibilidad de aparecer focalizado). Sí quiero destacar, sin embargo, que desde los orígenes del idioma esta fórmula, empleada ya en latín vulgar, es una forma popular. Su carácter más coloquial, sobre todo a partir de la época clásica, es el que provoca que cada vez su aparición en textos literarios vaya siendo menor hasta llegar a la época actual donde aparece básicamente en la lengua oral y en textos que muestran un registro coloquial. ${ }^{4}$

En el Cid se documenta frecuentemente:

31. 1290 Bien entendido es de letras \& mucho acordado

32. 2195 Quando uos nos casaredes bien seremos Ricas.

y también en otras obras como Calila e Dimna:

33. p. 265. Et el can guardólo quanto pudo, ca era bien nodrido.

En El Libro del caballero Zifar no parece utilizarse bien como estructura superlativa salvo en el siguiente ejemplo, donde es más que probable que presente un valor modal y no un valor superlativo:

34. p. 54. E entre todos los otros paresçia bien armado e muy fermoso e muy valiente. (i?)

4. Me refiero únicamente al español estándar. En algunos países americanos como Ecuador su uso está extendidísimo en todos los grupos socioculturales y en todos los registros (información aportada por la profesora Marleen Haboud). Salvador Salvador (1987) y Arjona (1991), sin embargo, apuntan también en sus trabajos a la mínima frecuencia de uso en los sociolectos cultos y en los contextos formales. Sobre el uso de esta expresión en español actual profundizo en Serradilla (2007). 
En una cala realizada en El Conde Lucanor ${ }^{5}$ sólo he localizado el siguiente ejemplo, lo que era de esperar dado el tono culto que impera en las obras de D. Juan Manuel. Obsérvese que, en todo caso, bien aparece con un adjetivo de uso común:

35. Et desnuyóse et tomó un cubo de agua bien caliente, et una grand maga de madero. (Cap. XLIII)

Una vez entrados en los siglos XV y XVI, no parece que se use frecuentemente en los textos escritos esta perífrasis de superlativo; aunque he encontrado todavía varios ejemplos, estos aparecen únicamente en cartas o en textos históricos pero no en textos literarios:

36. E caso que de la parte de los griegos oviese asaz caualleros e gentiles omnes e de grand esfuerço e ardjmento e bien valientes por sus personas, (Corónica Troyana)

37. Y siguiendo su jornada el dicho capitan, con mucha gente, nabios y bastimentos $/^{6}$ que don Hernando le dio, que fue bien costosa, (1529, ciudad de México: Fragmento de una carta autógrafa de fray Juan de Zumárraga al emperador Carlos V, refiriéndole lo sucedido en la ciudad de México durante el viaje de Hernán Cortés a las Hibueras)

En El Quijote seguimos encontrando ejemplos de este uso y destaca el hecho de que aparezcan sobre todo en boca de Sancho: -replicó Sancho-, que vuesa merced se queja de bien pocas cosas. (Quijote, $2^{\mathrm{a}}$ parte)

$\mathrm{Si}$ en los textos del siglo XV y en los clásicos hemos podido observar que su uso es menos frecuente que en los textos medievales, no por ello podemos aventurarnos a afirmar que su frecuencia de uso real desciende, ya que es muy posible que, como avanzaba, esta fórmula esté comenzando a especializarse en la lengua oral y en un registro más coloquial que pocas veces llega a la escritura. Así, las amadas no serán ya «bien fermosas» sino «muy/asaz hermosas», por poner solo un ejemplo. De hecho esta construcción no parece haber estado nunca en declive en la lengua conversacional (más en la vulgar que en la culta) y sigue siendo muy productiva en el español actual. En este caso parece evidente que el tipo de texto y los registros que en él aparezcan serán determinantes a la hora de usar esta construcción.

Una situación bien distinta es la que se da en el caso de asaz. Entra como provenzalismo, del antiguo assatz 'suficientemente' y este del latín vulgar AD SATIS (lat. SATIS 'suficientemente'). Corominas cita a Berceo como primera documentación. Podía aparecer antepuesto o pospuesto y los ejemplos, ante todo tipo de adjetivo, son muy abundantes:

5. Ejemplos XV a XXI y XXXIII a XLV. 
38. Gran Conquista de Ultramar, fol. 13v: es assaz alto

39. Gran Conquista de Ultramar, fol. 16r: era assaz de buen cuerpo

40. Gran Conquista de Ultramar, fol. 150r: tomol q<ua>nto leuaua assí quel non dexo si non un Roçin malo assaz.

41. Apolonio, fol. 48r: Entiendo q<ue $>$ me dizes buen conseio Asaz

42. Apolonio, fol. 51r: Tres dema $<\mathrm{n}>$ das tengo $\mathrm{q}<\mathrm{ue}>$ son assaz rafeçes

43. Cancionero de Baena, fol. 49r: asaz bastante so yo

44. Cancionero de Baena, fol. 135v: entre los poetas. assaz rradycantes

45. Libro de Marco Polo, fol. 70v: et son assaz fuertes

46. Libro de Marco Polo, fol. 88r: et han çiudades villas et castiellos fuertes assaz

47. Los que vienen por tierra, tan luengo camino andan con ellos, que cuando acá llegan son mansos assaz (J. Manuel, Caza, 4, apud. Cuervo)

48. Fernand Sanches Calauera, comendador de la orden de Calatraua, conpuso asaz buenos dezires. (Marqués de Santillana, Prohemio al Condestable de Portugal)

49. que a Vuestra Merced assaz es notorio, (Diego de Valera, Epistola)

Desde su introducción y hasta la época clásica, la presencia de esta fórmula superlativa es muy frecuente en textos muy diversos. No obstante, decía Martinell (1992: 1261): «Asaz, presente en Alfonso X, Berceo, Juan Manuel y Rojas cede en el siglo XVI frente a harto, tanto cede ante tan delante de adjetivos, del mismo modo que cómo retrocede ante qué y mucho ante mиу».

Efectivamente, a partir de esta época, unas formas parecen decaer en beneficio de otras, pero como veremos más adelante, asaz es forma, aunque cuestionada, frecuente en el español clásico y, de hecho, llega hasta el español moderno.

50. Sosegad los pensamientos, que asaz ásperos tormentos, por cierto, le tengo dado. (1514, Lucas Fernández, Auto de la Pasión)

51. puesto que la madera es feble o floja, e vana asaz. E lo que los indios quieren hacer más blanco, (1535-1557, Gonzalo Fernández de Oviedo, Historia general y natural de las Indias)

52. Assaz de desdichada es la persona que a las dos de la tarde no se ha desayunado. (El Quijote)

Valdés lo rechazaba y decía: «llevo cuidado de usar los mejores vocablos que hallo, dexando siempre los que no son tales; y assí no digo acucia, sino diligencia; [...]. No asaz, sino harto; no adufre, sino pandero» (Valdés, Diálogo de la lengua, p. 194).

Para Corominas y Pascual (1980-1981), desde principios del siglo XVI pertenece al estilo elevado y con frecuencia es pedante pero 
no puede asegurarse que siempre tuviera ese matiz en la Edad Media, aunque es posible dado el origen extranjero del vocablo, ajeno al espontáneo lenguaje del Cid, donde se halla únicamente mucho. Cuando se sintió la necesidad de distinguir los dos matices, al elaborarse más el lenguaje literario, se echó mano del extranjerismo asaz o se creó harto con los recursos internos del idioma.

Efectivamente, asaz no se usa en el Cid y, aunque tiene el mismo valor superlativo que muy, mucho o bien, que sí aparecen en esta obra, se observa una mayor frecuencia de uso en obras históricas, religiosas o en la poesía cancioneril del siglo $\mathrm{XV} .{ }^{6}$ En la actualidad su uso se restringe a registros cultos; dato que empieza ya a perfilarse, aunque aún no de forma tan evidente, en los textos medievales analizados.?

Como decía Valdés, asaz es sustituido por harto, que se usa no solo en los registros cultos. ${ }^{8}$ Se trata en este caso de una fórmula creada en el siglo XV con un recurso ya existente en la lengua y no de un préstamo culto, por lo que su uso se va a extender en el siguiente siglo a todos los niveles. En la época medieval los ejemplos no son aún muy frecuentes, como era de esperar en una forma de reciente introducción, pero empieza a verse cada vez más a medida que avanza el siglo Xv; así, aunque hay ejemplos de la primera mitad, la mayor parte de los ejemplos encontrados pertenece a los últimos años del siglo:

53. farto es notorio a los hombres (1438, Corb.)

54. sy el pecado tal de forniçio contynúa, mientra más yrá más se arrepentyrá. E ¿non es farto enxienplo notorio e palpable al que quisyere consyderar en este vill e suzio pecado, que quanto es el ardor e el fuego al su comienço de lo cometer e poner por obra, tanto e mucho es más el arrepentymiento, súvito él acabado, quel'viene al que le ha cometydo? (1438, Corb.)

55 . \& vino se a seuilla \& su flota tanbien farto enojado por la perdida de tantos (1443-1454, Martínez de Toledo, Atalaya corónicas)

56. \& dende saldra vna fontayna \& nasçera vn arroyo harto grande que al tienpo a venir sera muy provechoso (1489, Anónimo, Historia de la linda Melosita)

57. Y este Balán por quien me preguntáis quedó harto mançebo cuando su padre murió, (1482-1492, Rodríguez de Montalvo: Amadís de Gaula, libros I y II)

6. De hecho, en La Celestina tampoco es forma muy frecuente y lo encontramos únicamente acompañando a nombres, verbos o adverbios: asaz veces, asaz tiempo, cosas he visto asaz, asaz. bien. No parece, pues, una fórmula utilizada normalmente en el diálogo.

7. He realizado una encuesta entre mis alumnos a lo largo de los últimos seis cursos y, aunque todos conocen este uso, ninguno utiliza esta perífrasis superlativa ni en la lengua escrita, ni en la lengua oral formal. En la conversación solo aparece cuando se quiere imitar un estilo pedante o arcaico. Se confirman, pues, las palabras con las que Corominas y Pascual (1980-1991) se referían a la situación existente ya en el español clásico.

8. Véase Serradilla (2004) respecto al frecuente uso de harto + adjetivo en la obra de Santa Teresa. 
58. Y esta gente farto mansa, y por la gana de aver de nuestras cosas, (14921493, Diario del primer viaje de Colón)

59. SEMPRONIO. Ya no temas, Pármeno, que harto desviados estamos; en sintiendo bollicio, $(1499$, Celes.)

Estamos ante una fórmula cada vez más utilizada pues viene a rellenar el hueco que ha dejado $a s a z$, que ha pasado a restringir su uso a registros más cultos.

\section{CONCLUSIONES}

A la vista de los datos expuestos, podemos concluir, en primer lugar, que las pocas apariciones de superlativo desinencial en la época medieval obedecen a un esfuerzo latinizante $y$, por otro lado, que, aunque la similitud semántica entre las diversas perífrasis sea casi absoluta, la elección de una u otra forma tiene que ver con el tipo de texto en el que se inscriban y el registro de lengua que se utilice, criterio que seguirá presente también en los siglos posteriores; así, bien acompaña, sobre todo, a adjetivos patrimoniales en textos populares, situación que, por ejemplo, sabrá explotar en su momento Cervantes poniéndolo en boca de los personajes más incultos. Este uso característico de bien será el que determine su ausencia en la mayor parte de los textos que presentan un código elaborado, ausencia que, sin embargo, no sería tal en la lengua cotidiana pues ha llegado al español actual también básicamente en el mismo contexto. Por su parte, $a s a z$, que entra como préstamo, pertenece básicamente al registro culto y así seguirá hasta nuestros días; en el mismo registro culto encontramos la forma además, que solo se documenta en la prosa histórica y que también es recogida por Cervantes como marca de un estilo concreto. Diferente es el caso de harto, poco documentado aún en la época medieval pero que luego será una forma muy utilizada en todos los contextos, hasta llegar a la situación actual en la que su frecuencia de uso en la lengua oral es mínima salvo en fórmulas semifosilizadas como harto sabido, harto conocido, harto difícil... y ha quedado relegada, como arcaísmo, a la escritura formal.

Muchas de las fórmulas analizadas han ido desapareciendo sustituidas por otras más productivas, de carácter más general. Así, expresiones de uso restringido en la época medieval solo han pervivido a nivel dialectal en hablantes poco influidos por la norma (fuert, sobre o incluso mucho, que desaparece muy pronto en la lengua estándar sustituido definitivamente por la forma más extendida muy).

Obsérvese que en el ámbito de la superlación absoluta ha tenido lugar un proceso de gramaticalización, que lleva a la reducción del paradigma; sin 
embargo, la intensificación se ha valido de una serie de recursos casi ilimitada a lo largo de nuestra historia lingüística, por lo que cada día distintos grupos de hablantes van creando fórmulas más expresivas para referirse a la cualidad en su más alto grado. Se trata de un proceso creativo que está teniendo lugar en nuestros días, como lo ha estado a lo largo de toda la historia, con la creación de nuevas fórmulas y la recuperación de expresiones de otra categoría a las que se les otorga una nueva función. De los procedimientos usados en español actual tendremos que hablar, sin embargo, en otro momento, pues es un tema que escapa de los límites que me había propuesto en este trabajo.

\section{REFERENCIAS BIBLIOGRÁFICAS}

ArJona, M. (1991): «El adverbio muy y otros intensificadores», Estudios sintácticos sobre el habla popular mexicana, México, UNAM, 65-84.

COMPANy COMPANy, C. (ed.) (2006): Sintaxis histórica de la lengua española, vol. I. La frase verbal, México, FCE-UNAM.

Corominas, J. y J. A. PASCuAl (1980-1991): Diccionario crítico etimológico castellano e hispánico, Madrid, Gredos.

Correa, J. A. (1978): «Estudios de la gradación adjetiva en latín», Actas del V Congreso Español de Estudios Clásicos, Madrid, Sociedad Española de estudios Clásicos, 535-539.

FERNÁNDEZ RAMíREZ, S. (1986): Gramática española, vol. 3.1. El nombre, (vol. preparado por José Polo), Madrid, Arco/Libros (en especial pp. 57-68).

GARCÍA ARRIBAS, I. (1978): «Formas de comparación perifrásticas y anómalas en la Mulomedicina Chironis y en Vegecio», Actas del V Congreso Español de Estudios Clásicos, Madrid, Sociedad Española de estudios Clásicos, 131-135.

Lago Alonso, J. (1965-67): «Consideraciones sobre la idea de superlativo en francés y en español», en Alarcos LloRACH, E. (ed.) (1965-67): Homenaje al profesor Alarcos García, 2, Valladolid, Universidad de Valladolid, 49-61.

MARTinell, E. (1992): «Estilística en la gradación del adjetivo», Actas del $X$ Congreso de la Asociación Internacional de Hispanistas, Barcelona, Universidad de Barcelona, 1253-1263.

MEnÉndez PidAl, R. (1944): Cantar de Mio Cid. Texto, gramática y vocabulario, Madrid, Espasa-Calpe, 1976, ${ }^{5}$ vols. III, IV y v de las Obras completas de R. Menéndez Pidal.

Moreno Fernández, F. (2005): Historia social de las lenguas de España, Barcelona, Ariel.

Morreale, M. (1955): «El superlativo en -issimo y la versión castellana del Cortesano», RFE, XXXIX: 46-60. 
Penny, R. J. (2004): Variación y cambio en español, Madrid, Gredos (versión española de J. Sánchez Méndez).

SAlVADOR SALVADOR, F. (1987): «La gradación adjetiva en el habla popular de Ciudad de México», en Vaquero de Ramírez, Mª T. y H. LóPez Morales (eds.) (1987): Actas del I Congreso Internacional del español de América, San Juan de Puerto Rico, Academia Puertorriqueña de la Lengua Española, 419-430.

Serradilla Castaño, A. (2004): «Superlativos cultos y populares en español clásico», Edad de Oro, XXIII: 95-133.

- (2005): «Evolución de la expresión del grado superlativo absoluto en el adjetivo: las perífrasis sustitutivas del superlativo sintético en español antiguo», Cauce, 28: 357-385.

- (2006): «El proceso de gramaticalización en las perífrasis de superlativo absoluto», en DE Bustos Tovar, J. J. y J. L. GiRÓn Alconchel (eds.) (2006): Actas del VI Congreso de Historia de la lengua, Madrid, Arco/Libros, 1123-1134.

- (2007): «BIEN + adjetivo como perífrasis de superlativo en español. Particularidades semánticas y sintácticas», Verba, 33: 215-233. 


\section{SECCIÓN IV MULTILINGÜISMO, INTERCULTURALIDAD Y CONTACTO DE LENGUAS}




\title{
DMLX: UN PROGRAMA INFORMÁTICO PARA EVALUAR LA REVITALIZACIÓN Y PROYECTAR TENDENCIAS DE CONOCIMIENTO Y USOS LINGÜÍSTICOS ${ }^{1}$
}

\author{
Raquel Casesnoves Ferrer \\ Universitat Pompeu Fabra
}

\section{LA REVITALIZACIÓN LINGÜÍSTICA}

$\mathbf{L}$ A desintegración de los imperios coloniales, la democratización de países Aanteriormente regidos por dictaduras o la lenta descomposición de los gobiernos centralizados propician una reacción social que aspira a revitalizar las tradiciones culturales locales y regionales y, muy especialmente, la lengua en la que se expresan esos pueblos. La historia moderna está repleta de sociedades cuyas lenguas han sido reemplazadas por la lengua de unos colonizadores, de una gran metrópoli o de una lengua extranjera, de manera forzosa y gradual o paulatinamente por medio de procesos sociales, económicos y demográficos más lentos y apenas perceptibles in situ. La reacción natural de estos pueblos y comunidades, una vez desaparecida la causa elemental que provocó el cambio de lengua, supone el intentar frenar e invertir, tanto como sea posible, este cambio.

Las medidas que se ponen en marcha pueden ir desde la legislación del uso de la lengua en ámbitos administrativos oficiales, en los medios de comunicación públicos y privados, en los comercios, pasando por la regulación e intervención en el sistema educativo, hasta la promoción y fomento, por medio de campañas de concienciación social, de la transmisión y de los usos privados de la lengua histórica. La actual mezcla de fuerzas y medidas que favorecen y perjudican la revitalización lingüística, así como su receptividad por parte de la población, varía enormemente de una comunidad bilingüe a otra.

Los resultados de la revitalización lingüística han sido tan diferentes como las causas que los provocaron. El ejemplo típico de un caso de verdadero éxito

1. Este proyecto de investigación ha sido parcialmente subvencionado por el programa de ayudas Marie-Curie International Reintegration Grants (IRG) y colaboran además el profesor David Sankoff y Qian Zhu de la Universidad de Ottawa y la profesora M. Teresa Turell de la Universitat Pompeu Fabra. 
es la revitalización del hebreo en Israel, donde la diversidad de lenguas y la necesidad de comprenderse entre los judíos de la diáspora favorecería la aceptación y completa restauración del hebreo como lengua franca y oficial del nuevo estado de Israel (Bobaljik et al., 1996; Spolsky, 2004). El caso contrario, de rotundo fracaso, lo encontramos en las infructuosas tentativas por revitalizar diversas lenguas indígenas que han acabado por desaparecer o que se encuentran en vías de extinción (Batibo, 2005; Martí et al., 2005) o en el más próximo del gaélico irlandés, que a pesar de ser la primera lengua oficial del estado de Irlanda no ha conseguido desplazar el uso mayoritario del inglés (Carnie, 1996; Slomanson, 1996).

Resulta prácticamente imposible predecir si un programa de revitalización tendrá éxito o no, así como determinar la causa principal que motiva un resultado u otro (Grenoble y Whaley, 2006). Extremadamente difícil es, también, prever cómo los factores sociales y políticos afectarán a estos programas puesto que todos ellos interactúan sobre el fondo de procesos demográficos que pueden llegar a tener efectos mucho más drásticos que cualquier iniciativa social o medida política y jurídica.

La compleja casuística que impera en el terreno de la revitalización lingüística no debe hacernos olvidar, sin embargo, que la razón última que motiva cualquier proceso de restauración implica hacer frente a las fuerzas que provocaron y motivan el cambio de lengua. Si pensamos que son pocas las regiones del mundo donde no encontramos al menos alguna tentativa de revitalizar una lengua entonces debemos concluir que no hay rincón del mundo en que una lengua no esté en proceso de sustitución o de extinción.

De organismos internacionales, como la UNESCO, procede uno de los estudios más completos y recientes sobre las lenguas amenazadas (Unesco, 2003). En este trabajo se recogen los factores que se deben considerar para determinar el grado de vitalidad de una lengua: la transmisión intergeneracional de la lengua, el número absoluto de hablantes, la proporción de hablantes en relación con el total de población, el uso de la lengua en diferentes ámbitos y su capacidad de adaptación a los nuevos dominios, el material didáctico existente para enseñar la lengua, la política lingüística institucional y gubernamental (incluyendo estatus y usos oficiales), las actitudes lingüísticas de los miembros de la comunidad y la cantidad y la calidad de la documentación disponible sobre la lengua. A esta lista de factores de tipo social, político y demográfico podríamos añadir otros como el prestigio de la lengua a nivel internacional o el grado de atracción o integración lingüística de los inmigrantes, etc. Pero además de considerar todos estos factores que operan simultáneamente, hemos de tener en cuenta también los procesos demográficos básicos (natalidad, mortalidad y movimiento migratorio) que a veces pueden llegar a tener efectos más drásticos que cualquier acción social, política o jurídica. 
La multiplicidad de factores a tener en cuenta pone de manifiesto la tarea tan compleja a la que se enfrenta la ejecución, planificación y evaluación de cualquier proceso de revitalización.

\section{LA NORMALIZACIÓN LINGÜÍSTICA EN ESPAÑA}

El concepto de normalización, específico al contexto español, fue puesto en circulación por los sociolingüistas catalanes a principios de la década de los 80 , adoptado posteriormente como modelo de planificación en los territorios de habla catalana pero también vasca y gallega y ampliamente difundido hoy en día en el ámbito social y político. En efecto, las leyes que regulan el uso de las lenguas «propias» ${ }^{2}$ en las seis comunidades oficialmente bilingües (Cataluña, Valencia, Baleares, País Vasco, Navarra y Galicia) son «Leyes de Normalización Lingüística», una expresión manejada y empleada por políticos, académicos, periodistas y por la sociedad en general. No entraremos a discutir la necesidad de un término como el de normalización cuando a nivel internacional se viene utilizando el de planificación porque ya existe abundante bibliografía sobre el tema ( $c f$. , entre otros, Branchadell, 1987; Bañeres y Romaní, 1994; Vallverdú, 1998) y, sobre todo, porque es un debate desfasado y pueril que se aleja de nuestros intereses. Convengamos en que la restauración de la democracia, tras 40 años de dictadura franquista (1939-1975), propició la puesta en marcha de diferentes programas de normalización lingüística cuyo objetivo primordial era frenar e invertir la tendencia al monolingüismo español.

Los objetivos concretos de cada programa pueden variar de una comunidad a otra, entre otras causas según el grado de vitalidad que la lengua propia ostentaba en el momento en que se inició el proceso de su normalización. Los resultados a corto plazo serán también diferentes pero, por lo que al conocimiento y uso de la lengua se refiere, las tendencias de cambio nos pueden ayudar a vislumbrar si la población es más o menos competente que antes y si el número de hablantes aumenta o, a pesar de los esfuerzos por revitalizar la lengua, decrece.

La evaluación periódica y continua de la normalización lingüística es necesaria para poder así comprobar los efectos de las medidas que se están aplican-

2. El término lengua propia, como el de normalización, es reciente, carente de tradición lingüística y de uso restringido al Estado español. Aparece empleado en las leyes que regulan los derechos y deberes lingüísticos, como la Constitución española, los Estatutos de Autonomía y las Leyes de Normalización. Según la Declaración Universal de los Derechos Lingüísticos la denominación de «lengua propia» hace referencia al idioma de la comunidad históricamente establecido en ese territorio. El doblete «lengua oficial»-«lengua propia» sirve para diferenciar el castellano, oficial en todo el Estado español, del vasco, catalán y gallego que además de ser oficiales en seis comunidades autónomas también son lenguas propias en sus respectivos territorios. 
do, su correcta ejecución e implementación. Pero evaluar los programas de normalización resulta ser una tarea tan ardua y compleja como necesaria, puesto que los factores que intervienen en su desarrollo son múltiples y muy variados, como ya hemos apuntado más arriba.

En este artículo presentamos, primero, un programa de proyecciones demolingüísticas, llamado DMLX, concebido y diseñado como una herramienta, eficaz, que nos debería ayudar a evaluar objetivamente los programas de normalización además de a predecir la relativa importancia que tienen los procesos demográficos y lingüísticos en la vitalidad de las lenguas a corto y largo plazo. Luego, un estudio comparativo de los cambios «reales» en la habilidad para hablar catalán, vasco y gallego que han tenido lugar ente 1991 y 2001 (datos basados en los censos lingüísticos), contrastados con los cambios previstos por DMLX. En último lugar, siguiendo los resultados del análisis, deberíamos ser capaces de hacer una primera y aproximada evaluación del progreso de la normalización en cada una de las comunidades.

\section{DMLX: PROGRAMA DE PROYECCIONES DEMOLINGÜÍSTICAS}

Las proyecciones demolingüísticas son técnicamente difíciles porque a los movimientos demográficos básicos (natural y migratorio) que intervienen en las proyecciones de población hemos de añadir los cambios que se producen en los procesos lingüísticos pertinentes en la normalización lingüística: la transmisión intergeneracional de la lengua, la adquisición y aprendizaje de la lengua propia en la escuela y la integración lingüística de los inmigrantes.

Las proyecciones demográficas implican cohortes definidas por la edad, el género y el lugar de residencia, y cada cohorte gana o pierde individuos debido a los nacimientos, las defunciones y las migraciones locales o internas e internacionales. Al incorporar la dimensión lingüística, los individuos no solo cambiarán de una cohorte a otra a lo largo de su vida por estos tres procesos demográficos básicos (natalidad, mortalidad y movimiento migratorio), sino también por los cambios que se puedan producir en el nivel de conocimiento o habilidad lingüística e incluso en el uso de la(s) lengua(s). Cuando realicemos proyecciones demolingüísticas tendremos en cuenta:

a) la dimensión de la transmisión intergeneracional de la lengua, asignando los recién nacidos, en las buenas proporciones, a las categorías lingüísticas que representarán su eventual nivel de competencia lingüística: si aprenderá a hablar la lengua propia, si solo será capaz de entenderla o incluso, aunque en proporciones muy bajas, si no llegará tampoco a comprenderla. 
b) la dimensión de la escolarización, cambiando una proporción determinada de individuos de una categoría lingüística a otra debido a la adquisición de la lengua propia en la escuela.

c) la dimensión de la integración lingüística, incorporando parte de los inmigrantes de diversa procedencia a las diferentes categorías lingüísticas, según el nivel de conocimiento y uso eventual.

El programa DMLX incorpora estas dimensiones a las proyecciones demográficas para prever así, a corto y largo plazo, los futuros niveles de competencia y uso lingüístico de la población.

\subsection{La transmisión intergeneracional de la lengua}

La mejor estimación de conjunto de la tasa de transmisión intergeneracional disponible actualmente consiste en la proporción de niños y niñas entre 0-4 años con capacidad oral en la lengua propia. La tasa de transmisión varía de una comunidad a otra ( $c f$. Gráfico 1), siendo Cataluña la comunidad que ostenta el nivel más alto de transmisión (entre el 50\% en 1991 y el 30\% en 2001) y Navarra el más bajo (alrededor del 25\% los dos años censales).

GráfICO 1. Proporción de niños y niñas entre 0-4 años con capacidad para entender y hablar la lengua propia. Censos 1991 y 2001

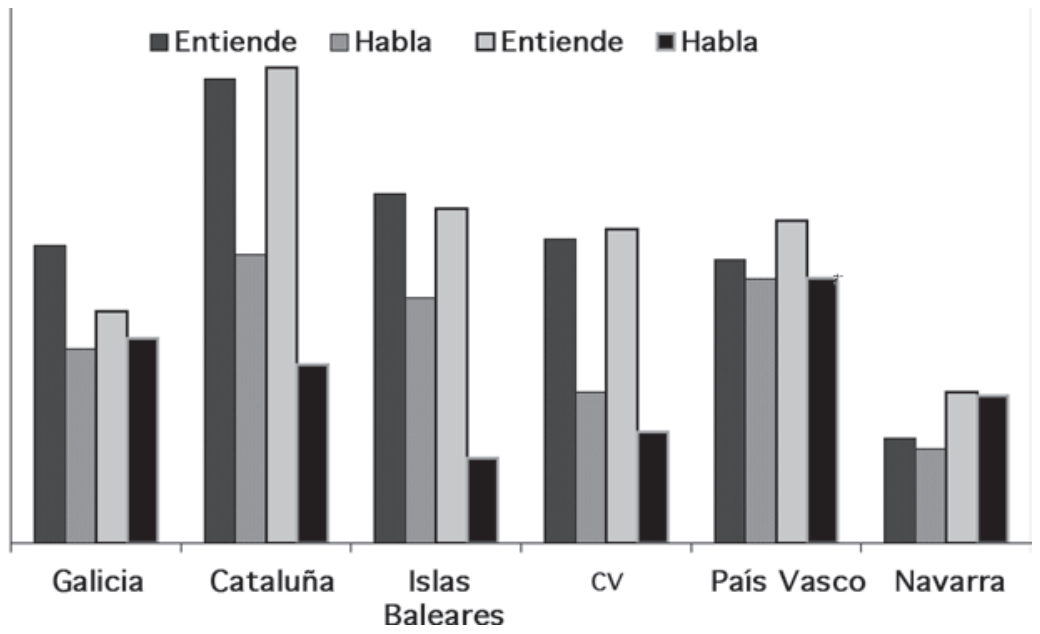

El retroceso de la capacidad para hablar que se produce en una década es general a todas las comunidades. Ahora bien, la enorme diferencia que separa 
los dos años en Cataluña y las Islas Baleares resulta bastante sospechoso y nos hace dudar de la fiabilidad de los datos. Y, en efecto, a la gran fluctuación característica del primer grupo de edad parece que se añaden problemas técnicos tanto en la recogida de datos censales como en su posterior tratamiento. ${ }^{3}$

Los enormes sesgos en la estimación de la transmisión tienen, sin embargo, poco efecto en las proyecciones demolingüísticas, puesto que se compensan con la estimación de la adquisición en la escolarización: la subestimación de la transmisión se verá compensada por los valores sobrestimados de la escolarización.

La tasa de transmisión varía también al interior de la comunidad y su nivel depende del grado de competencia media que tiene la población de la comarca o zona en la que se reside. Dicha dependencia, más o menos lineal en todas las comunidades, viene ilustrada en el Gráfico 2.

GRÁFICO 2. Variación interna de la tasa de transmisión en las comunidades bilingües: 1991 y 2001
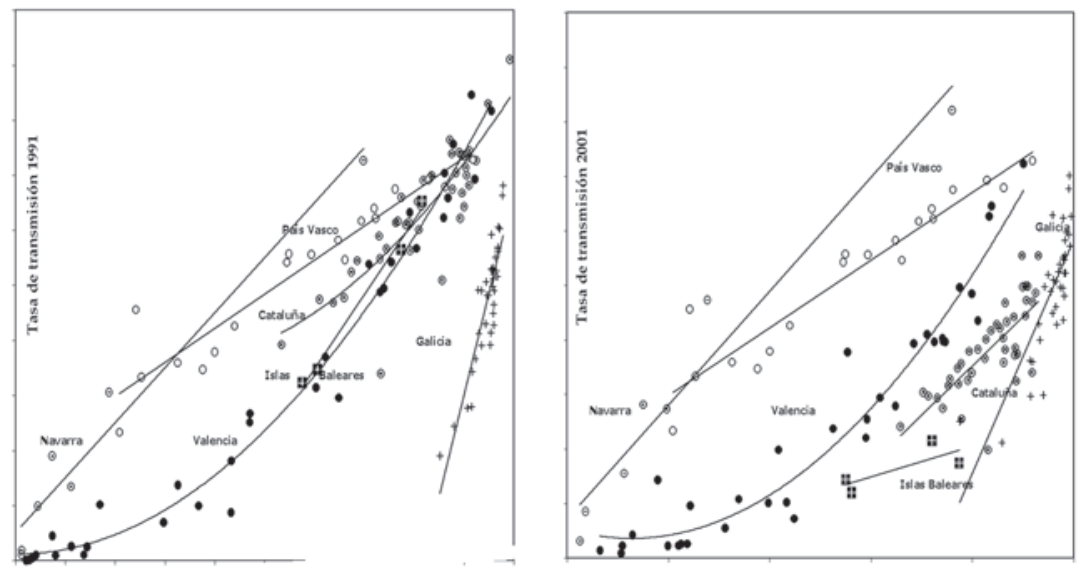

Asumiendo la hipótesis de que la función lineal es una característica estable de la comunidad, mientras que los niveles de competencia evolucionan con el tiempo, hemos incorporado la fórmula de la línea de regresión en el programa. Esto nos permitirá recalcular anualmente las tasas de transmisión de cada comarca, en función de la competencia media que ostente la comarca ese año.

3. La tasa de inexhaustividad, es decir, el porcentaje de población de la que no se llegó a obtener la información censal fuera por el motivo que fuera, alcanza el $12 \%$ en Cataluña y asciende hasta el 23\% en las Islas Baleares (Xarxa CRISCAT, 2004). 


\subsection{La adquisición de la lengua durante la escolarizazión}

Los niveles de competencia de la población escolar ( $c f$. Tabla 1) muestran un aumento rápido y acelerado de la adquisición de la lengua entre los 5 y 9 años, comparado con el nivel del grupo de 0-4 años, un incremento un poco menor durante los cinco años siguientes (entre los 10 y 14) y una nivelación de la competencia al acabar la escolarización (15-19). Estos cambios son comunes a todas las comunidades, excepto en Navarra.

TABLA 1. Nivel de competencia de la población escolar en las comunidades oficialmente bilingües. Censo 2001

\begin{tabular}{|c|c|c|c|c|c|c|}
\hline Edad & Galicia & Cataluña & $\begin{array}{c}\text { Islas } \\
\text { Baleares }\end{array}$ & $\begin{array}{c}\text { Comunidad } \\
\text { Valenciana }\end{array}$ & País Vasco & Navarra \\
\hline $\mathbf{0 - 4}$ & 37,0 & 32,3 & 15,4 & 20,1 & 48,0 & 26,7 \\
\hline $\mathbf{5 - 9}$ & 86,1 & 79,8 & 63,6 & 42,2 & 90,2 & 39,3 \\
\hline $\mathbf{1 0 - 1 4}$ & 88,7 & 92,1 & 80,1 & 63,1 & 92,4 & 33,9 \\
\hline $\mathbf{1 5 - 1 9}$ & 90,8 & 91,9 & 79,0 & 66,4 & 88,6 & 26,3 \\
\hline
\end{tabular}

El programa DMLX incorpora, de momento y a pesar de los diferentes niveles de aprendizaje según la edad, una única tasa de escolarización resultante de la diferencia existente entre el nivel de competencia del grupo de 15-19 años y el de 5-9 dividido por 10. Dicha tasa se calcula anualmente.

\subsection{La integración lingüística de los inmigrantes}

Entre la población adulta el nivel de habilidad para hablar la lengua propia va o descendiendo paulatinamente o bien se mantiene en general estable (Gráfico 3). Esta tendencia al declive, comparado especialmente con el nivel de competencia de los jóvenes, tendría dos causas fundamentales: el efecto, todavía visible, del período de dictadura franquista y, posiblemente, de la inmigración reciente. 
GRÁFICO 3. Nivel de capacidad para hablar la lengua propia de la población adulta en las seis comunidades bilingües. Censo 2001

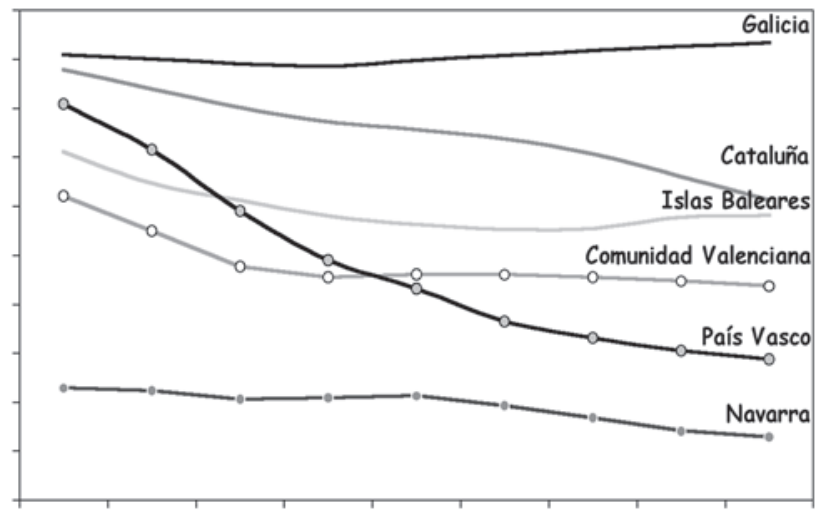

A pesar de que resulta evidente que el nivel de competencia varía según el origen o lugar de nacimiento (en la propia Comunidad, en el resto de España o en el extranjero) el programa no mantiene separadas las cohortes de acuerdo a esta variable. En su lugar, hemos de calcular previamente una tasa de competencia según el origen de la población e incluirla como parámetro en el input.

\section{LA EVOLUCIÓN DE LA HABILIDAD PARA HABLAR LA LENGUA PROPIA: EL CAMBIO «REAL» FRENTE AL CAMBIO PREVISTO}

Para poder llevar a cabo este estudio comparativo elaboramos una base de datos en la que se recogía toda la información necesaria para poder realizar proyecciones en cada una de las comunidades autónomas:

- nivel de conocimiento para comprender, hablar, leer y escribir la lengua propia según la comarca de residencia, la edad y el género

- movimiento intramigratorio (desplazamientos de población de una comarca a otra dentro de la comunidad)

- inmigración: población inmigrante según lugar de procedencia (de otra zona de España donde se hable también la misma lengua histórica; del resto de España y del extranjero)

- emigración: población que deja la comunidad para instalarse en otra región de España ${ }^{4}$

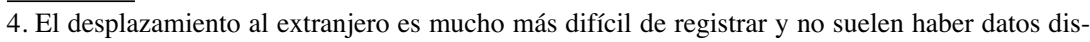
ponibles. 
- natalidad: número de nacidos el año censal según la edad de la madre

- mortalidad: número de defunciones producidas ese año según la edad y el género del individuo

Nos basamos en las estadísticas sobre el movimiento natural y migratorio de la población de cada comunidad, así como en los resultados de los censos de 1991 y 2001, información generalmente disponible en la página web de los diferentes institutos de estadística autonómicos (véase el apartado de referencias bibliográficas para las direcciones electrónicas concretas).

El programa DMLX utiliza todos estos datos para construir una población inicial y para calcular las tasas de los diferentes procesos lingüísticos y demográficos implicados en las proyecciones. A continuación ilustramos los resultados de la capacidad para hablar la lengua propia de esa población inicial en 1991, el cambio previsto por DMLX al cabo de 10 años y la evolución «real» o documentada en el censo de 2001.

En Cataluña, tal y como ilustra el gráfico 4, el programa DMLX subestima el nivel de conocimiento de la población adulta, es decir que los resultados del censo de 2001 son más positivos, mientras que sobrestima el del primer grupo de edad, entre 0 y 4 años (el nivel tendría que ser más alto de lo que era ese año según el censo). Sin embargo, la caída espectacular del nivel de transmisión en 10 años no solo no tiene ninguna explicación sino que tampoco existe conocimiento alguno de este nuevo fenómeno y, por lo tanto, debemos atribuirla a los errores censales ya comentados.

GRÁFICO 4. Contraste de la evolución «real» y prevista para hablar catalán en Cataluña

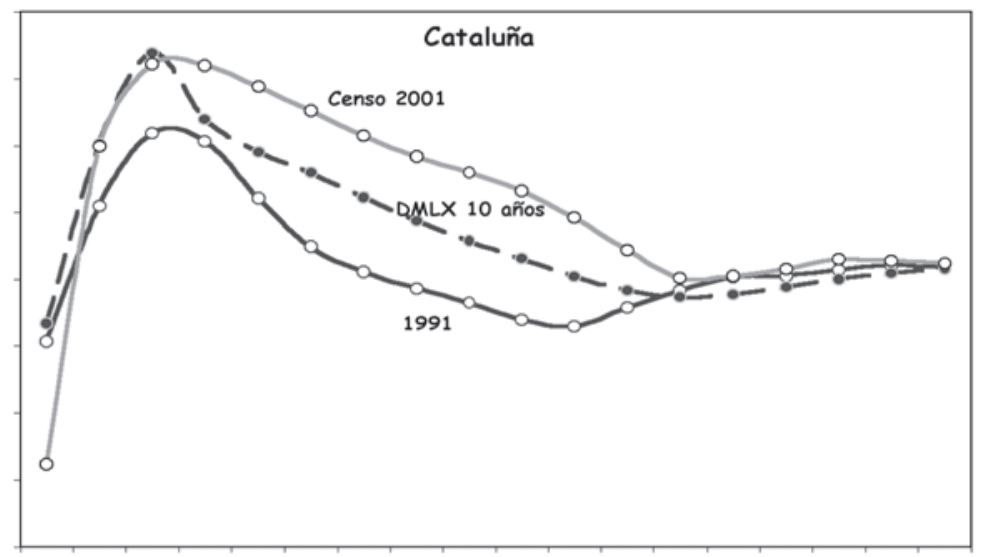


En Valencia, al contrario de lo que sucede en Cataluña, el conocimiento de la población infantil y adolescente (hasta los 14 años) así como de los más mayores era más bajo en el año 2001 de lo que había previsto el programa. Esta diferencia, ¿es el reflejo de un problema metodológico censal o responde a un cambio real?

GRÁFICO 5. Contraste de la evolución «real» y prevista para hablar catalán en Valencia

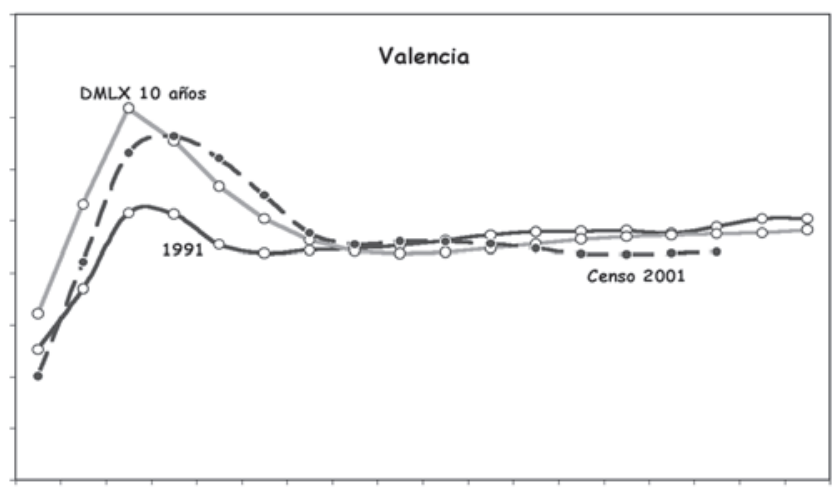

El descenso del nivel de competencia oral es general a toda la población balear. Esa pérdida de conocimiento ya estaba prevista por el programa, pero los resultados del censo de 2001 ilustran bien que el grado de retroceso documentado supera con creces lo vaticinado. Y, de nuevo, debemos preguntarnos la causa de esta divergencia.

GRÁFICO 6. Contraste de la evolución «real» y prevista para hablar catalán en las Islas Baleares

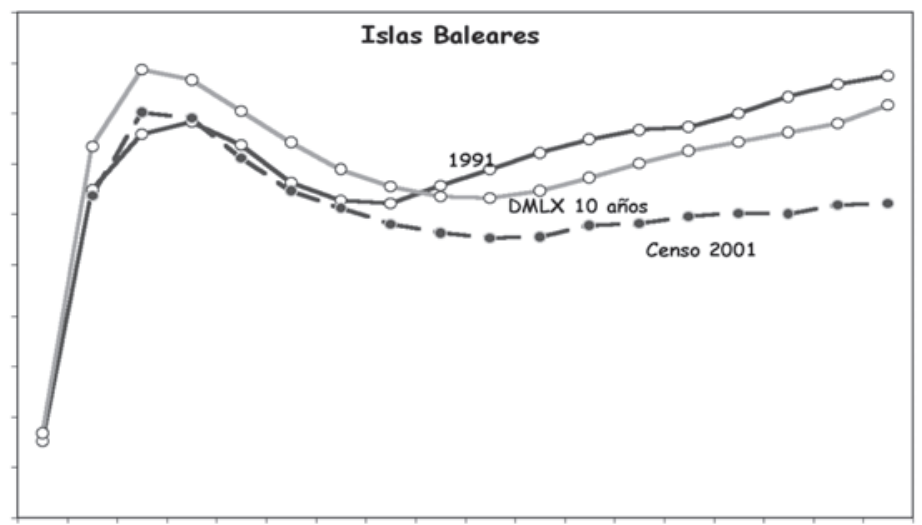


En Galicia parece ser que el nivel de conocimiento, bastante alto, haya alcanzado ya su máximo y no pueda superarse. El cambio previsto por el programa coincide en general con el resultado del censo de 2001 al anunciar un leve retroceso de la competencia entre la población adulta. El programa no preveía, en cambio, que el nivel de partida de los jóvenes, difícilmente superable, retrocediera, como ha sucedido realmente.

GRÁfICO 7. Contraste de la evolución «real» y prevista para hablar gallego en Galicia

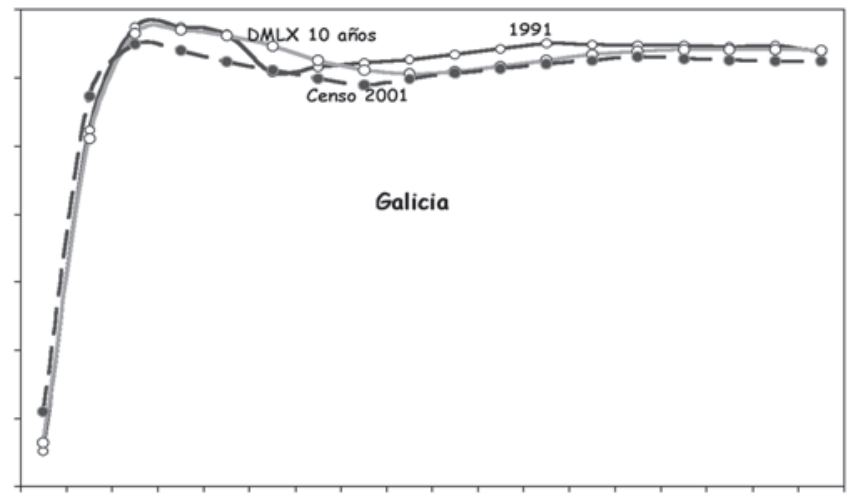

En el País Vasco, DMLX subestima el nivel de competencia de los escolares y de los jóvenes entre 10 y 24 años. El conocimiento del vasco aumenta poco a poco entre la población adulta y retrocede entre los más mayores, que arrastran todavía tendencias típicas del proceso de castellanización.

GRÁfICO 8. Contraste de la evolución «real» y prevista para hablar euskera en el País Vasco

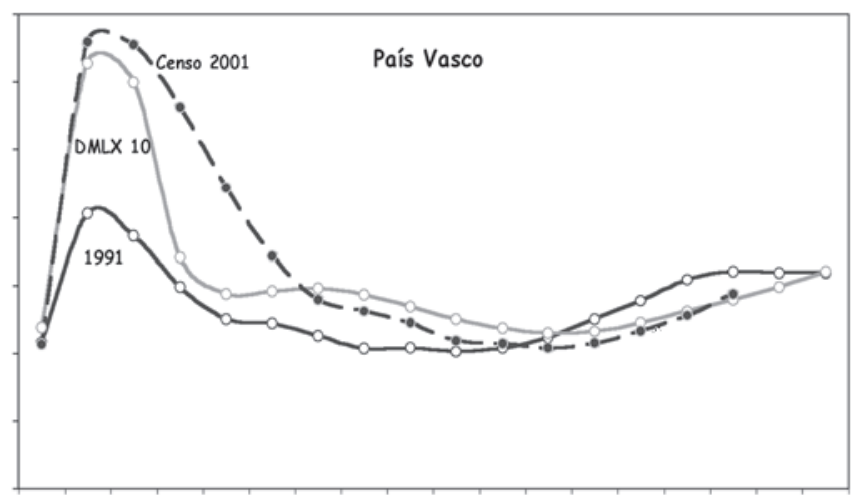


Por último, en Navarra, como en el País Vasco, el nivel de conocimiento previsto para los escolares está por debajo del resultado registrado en el Censo 2001. El conocimiento del euskera se mantiene en general estable en el resto de la población, sin observarse grandes diferencias entre lo real y lo proyectado.

GRÁFICO 9. Contraste de la evolución «real» y prevista para hablar euskera en Navarra

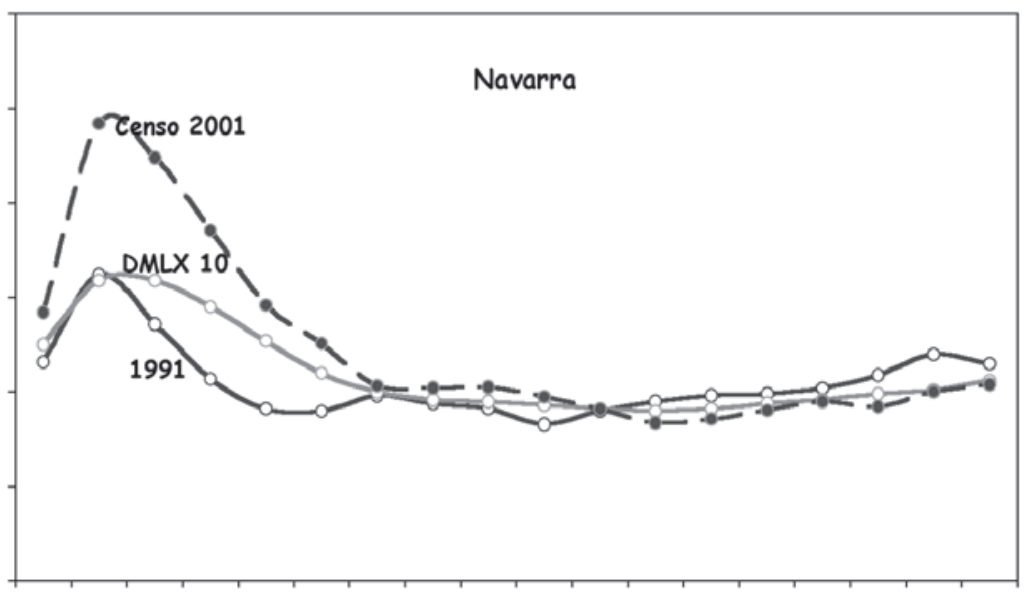

Las importantes diferencias entre la evolución proyectada por el programa DMLX y la evolución real o documentada nos advierten de la existencia de un tipo de cambio que no se puede prever. De modo que a los cambios que ya eran inherentes a los procesos demográficos y a la situación lingüística de partida, debemos añadir una serie de nuevos e inesperados acontecimientos que pueden llegar a producirse y que acabarán afectando la dinámica del cambio lingüístico y de la revitalización lingüística.

Este tipo de análisis permite, por otra parte, detectar tendencias extrañas y sorprendentes inexplicables por cualquier otro elemento que no sea el metodológico.

\section{DISCUSIÓN}

El objetivo último del análisis comparativo de la evolución del conocimiento oral de la lengua propia durante la década de los noventa, según el cambio documentado en el censo lingüístico y según el cambio previsto por el programa DMLX, reside en evaluar, de la manera más aséptica posible, el pro- 
greso de los diferentes procesos de normalización lingüística que se están llevando a cabo en seis comunidades bilingües. Dichos cambios pueden ser positivos, si la tendencia es al aumento de potenciales hablantes, o negativos, si en vez de ganar se pierden hablantes.

Por otra parte, hemos visto que ciertos cambios son previsibles porque responden a procesos y movimientos demográficos naturales como lo son los nacimientos y las defunciones, mientras que otros, de carácter coyuntural, pueden alterar el rumbo de determinados acontecimientos que van a influir en el desarrollo de la situación lingüística. Por ejemplo, un cambio de signo político conlleva generalmente cambios en la política lingüística.

El retroceso de la competencia lingüística entre la población adulta más mayor era previsible, puesto que esa tendencia se arrastraba del período anterior. Y en sentido contrario, el aumento del nivel de competencia entre los jóvenes escolares era también previsible, puesto que las nuevas generaciones pueden y deben aprender la lengua propia del territorio en la escuela. Estas dos tendencias opuestas aparecen bien ilustradas en todas las comunidades, excepto en Galicia, donde el nivel de conocimiento del gallego por los jóvenes era ya tan alto en los años 90 que difícilmente podía aumentar más. Lo que no era previsible era su retroceso, como así ha ocurrido.

El nivel de conocimiento de la población adulta que, en principio, no debería sufrir cambios drásticos, resulta sorprendente. Por una parte, si bien en la Comunidad Valenciana y, sobre todo, en las Islas Baleares, el cambio es negativo, la diferencia entre lo previsto y lo real es tan enorme que esa gran pérdida eventual de hablantes resulta más que sospechosa. Un cambio de signo político, como ocurrió en el gobierno autonómico de Valencia a mitad de los noventa, puede explicar una divergencia como la observada en esta comunidad, ${ }^{5}$ pero no la acaecida en la población balear. Es cierto que en estas dos comunidades el movimiento inmigratorio procedente del extranjero ha sido especialmente intenso, pero también lo es que en el censo de 2001 esta nueva realidad no quedó apenas reflejada. Las causas que explican esta diferencia son más de carácter político y social y, sobre todo, de carácter técnico y metodológico, dada la elevada tasa de inexhaustividad del censo, como ya hemos comentado más arriba.

En Cataluña, al contrario, el cambio es más que positivo y esa divergencia entre el cambio pronosticado y el cambio documentado del conocimiento de la población entre 15 y 59 años es semejante a la que se observa en los jóvenes entre 15 y 24 años del País Vasco. Quizá no sea una casualidad que justamente en estas dos comunidades hayan gobernado (o sigan gobernando) desde

5. Una encuesta realizada por la Academia Valenciana de la Lengua constata este descenso de catalanohablantes en la Comunidad Valenciana (AVL, 2005). 
inicios de la democracia hasta recientemente partidos nacionalistas que han dirigido y desarrollado políticas lingüísticas decididas, con objetivos concretos y medidas eficaces que han ido modificándose y adaptándose a la nueva realidad. Y tampoco debe ser una casualidad que sean las dos únicas comunidades en las que se haya modificado el plan inicial de normalización lingüística. En Cataluña, la Llei de política lingüística vino a remplazar, en 1998, la Llei de normalització lingüística de 1983 y, en el País Vasco entró en vigor en 1996 el Plan General de Promoción del Uso del Euskera. En ambos casos se estudiaron y evaluaron los logros conseguidos y las nuevas leyes o planes se orientaron para superar carencias y errores cometidos. En el resto de comunidades se sigue aplicando una Política Lingüística cuyos objetivos, a pesar de fijarse hace más de 20 años, todavía no se han logrado. En definitiva, si el cambio real es más positivo de lo que un programa informático pronostica, es porque se ha avanzado más y mejor de lo que se hubiera podido esperar en 10 años.

En Navarra y Galicia, comunidades que detentan el nivel de competencia más bajo y más alto respectivamente, el conocimiento de la lengua propia entre los adultos no cambia. En un caso porque ese nivel de partida ya era muy alto y en el otro porque era demasiado bajo. Pero mientras que en la comunidad de habla vasca, a pesar de que la lengua es oficial solo en una parte de Navarra, aumenta el nivel de competencia de los jóvenes escolares, en la de habla gallega retrocede. Esta tendencia a la baja no sorprende si se tiene en cuenta que en Galicia todavía no existe un programa donde la lengua vehicular de instrucción sea exclusivamente el gallego.

\section{REFERENCIAS BIBLIOGRÁFICAS}

ACAdÈmia Valenciana de la Llengua (2005): Llibre Blanc de l'ús del valencià I. Enquesta sobre la situació social del valencià 2004, València, Publicacions de l'Acadèmia Valenciana de la Llengua.

B AÑERES, J. y J. M. RoMANí (1994): «L'exhortation à la "normalisation" ou Ho volem tot en català (Nous voulons tout en catalan)», Lengas, 35: 27-43.

B Атіво, H. B. (2005): Language Decline and Death in Africa. Causes, Consequences and Challenges, Clevedon, Multilingual Matters.

Bobaljik, J. D., R. Pensalfini, L. Storto (eds.) (1996): Papers on Language Endangerment and the Maintenance of Linguistic Diversity, Cambridge, MAT, MIT Working Papers in Linguistics.

BRANCHADELL, A . (1987): «Normalització Lingüística: el concepte», Límits, 3 : 21-43. 
CARNIE, A. (1996): «Modern Irish: A case study in language revival failure», en Bobaljik, J. D., R. Pensalfini, L. Storto (eds.) (1996), 99-114.

Grenoble, L. A. y K. J. Whaley (2006): Saving languages, Cambridge, Cambridge University Press.

INSTITUT BALEAR D’EsTADÍSTICA. <http://www.caib.es/ibae/ibae.htm>.

InSTITUT D'ESTADÍSTICA DE CATALUNYA. <http://www.idescat.es/>.

INSTITUTO DE ESTADísTICA DE NAVARRA. <http://www.cfnavarra.es/estadistica>.

InSTITUTO GALEGO DE ESTADÍsTICA. <http://www.ige.xunta.es/>.

InSTITUTO VALENCIANO DE ESTADÍsTiCa. <http://www.ive.es/>.

Instituto VAsco DE Estadística. <http://www.eustat.es/>.

MARTí, F. et al. (2005): Words and Worlds. World Language Review, Clevedon, Multilingual Matters.

Slomanson, P. (1996): «Explaining and revising the failure of the Irish language revision», en Bobaljik, J. D., R. Pensalfini, L. Storto (eds.) (1996), 115-36.

SPOLSKY, B. (2004): Language policy, Cambridge, Cambridge University Press. UNESCO (2003): «Language Vitality and Endangerment». Disponible en pdf en la página de Endangered Languages, <http:// portal.unesco.org/culture/es/ev.phpURL_ID $=9105 \&$ URL_DO=DO_TOPIC \&URL_SECTION $=201 . \mathrm{ht} \mathrm{ml}>$.

VALlVERDÚ, F. (1998): Velles i noves qüestions sociolingüístiques, Barcelona, Edicions 62.

Vila Moreno, X. et al. (2005): Les dades lingüístiques del cens de l'any 2001: alguns dubtes $i$ limitacions, Barcelona, Institut d'Estudis Catalans (Xarxa CRUSCAT, 1). Disponible en pdf en la página de la Xarxa Cruscat. $<\mathrm{htttp}: / /$ www.demolinguistica.cat/web/index.php?option=com_content\&t ask=view\&id=27\&Itemid=59\&lang=ca_es $>$. 


\title{
EL MULTILINGÜISME \\ DES DEL BILINGÜISME. \\ LES REPRESENTACIONS \\ DELS ESTUDIANTS DE MAGISTERI \\ ENVERS LA DIVERSITAT LINGÜÍSTICA
}

\author{
Adela Costa \\ Consol Juan Asensio \\ Paulina Ribera Aragüete \\ Universitat de València
}

$\mathbf{L}$

A diversitat cultural i lingüística existent en la societat i en l'escola actual requereix un seguit de sabers, per part dels mestres, que encara s'estan construint. És a dir, aquesta situació encara és relativament nova i els professionals que ara treballen a les escoles han hagut d'afrontar-la aprenent i creant, a mesura que han estat necessàries, les maneres de fer adequades.

En aquest context, els estudiants de Magisteri han d'eixir de la Universitat preparats per a treballar en una escola diversa i multilingüe. Aquesta preparació implica, a més dels sabers lingüístics i didàctics, un treball sobre les representacions $i$ actituds dels estudiants envers la realitat del multilingüisme social i escolar. Les idees i actituds que els futurs mestres tinguen respecte d'aquests temes marcaran la seua manera de treballar quan comencen a exercir la seua professió i, d'alguna manera, seran les que transmetran als seus alumnes.

D'altra banda, els nostres estudiants formen part d'una societat bilingüe on la convivència de dues llengües no sempre ha estat harmoniosa. Aquesta situació ha generat i genera actituds i valoracions diverses entre els parlants. En el nostre treball hem partit d'aquest context real on es compaginen dues llengües situades en àmbits d'ús diferents $\mathrm{i}$ amb unes valoracions marcades socialment. Els nostres estudiants, per tant, han de reflexionar també sobre les seues actituds envers la realitat bilingüe d'aquest país com a punt de partida per analitzar les seues representacions sobre la societat multilingüe que s'està construint.

\section{OBJECTIUS I DISPOSITIU PER A RECOLLIR LES DADES}

En aquest treball hem volgut conéixer les actituds i les representacions dels nostres alumnes, tant pel que fa a la convivència de diverses llengües en la 
societat i en l'escola, com pel que fa a la valoració de la relació que s'hi produeix entre el castellà i el valencià. Dit d'una altra manera, hem volgut saber el que pensen els nostres estudiants sobre diversos aspectes relacionats amb la societat multilingüe en què vivim, amb l'escola multilingüe, amb l'educació plurilingüe... tot des de la perspectiva de la nostra societat bilingüe.

Tot açò ho hem concretat en els objectius següents:

- Conéixer les actituds dels estudiants de Magisteri envers la situació multilingüe de l'escola i de la societat actual.

- Conéixer la valoració que fan de la situació bilingüe pròpia del País Valencià en un context plurilingüe.

- Saber què pensen sobre el paper de l'escola en relació a la diversitat de llengües.

Com a dispositiu per a recollir les dades hem elaborat un qüestionari (vegeu quadre 1) que han emplenat, anònimament, cent estudiants de segon curs de les diferents titulacions de l'Escola de Magisteri «Ausiàs March» de la Universitat de València. El qüestionari consta de set apartats amb dues o tres alternatives en cadascun; els estudiants havien d'elegir una d'aquestes alternatives i fer-ne un breu comentari personal raonant la seua elecció.

Hem partit del supòsit que la procedència lingüística dels parlants pot condicionar-ne les respostes. En aquest sentit, a l'inici del qüestionari els hem demanat quina és la seua llengua primera i quina la que més utilitzen.

Dels diferents apartats que hi ha al qüestionari, uns es refereixen a les actituds cap al bilingüisme (A i B) i els altres $(\mathrm{C}, \mathrm{D}, \mathrm{E}, \mathrm{F}, \mathrm{G})$ a les actituds envers el multilingüisme i el plurilingüisme.

Les diferents alternatives de cada apartat responen a representacions socials, idees presents en la col-lectivitat, que manifesten actituds diferents respecte a un mateix aspecte del tema que és objecte d'aquest treball; es tracta d'expressions que podem escoltar habitualment en diferents àmbits socials. Els estudiants havien de triar aquella alternativa amb la qual se sentien més identificats.

En relació amb el bilingüisme, a l'apartat $\mathrm{A}$ les alternatives es refereixen a l'ús del valencià entre valencianoparlants i castellanoparlants i a l'aprenentatge del valencià per part dels castellanoparlants. Al B, a les actituds envers l'ensenyament del valencià i el castellà a l'escola.

Pel que fa al plurilingüisme, a l'apartat $\mathrm{C}$ els estudiants havien de valorar una llengua, bé per la seua utilitat, bé pel que representa com a signe d'identitat. Al D havien de triar entre dues opcions: si l'èxit de la comunicació ha de dependre més de nosaltres o més aviat dels que vénen de fora. A l'E havien de valorar si el fet d'aprendre valencià ajuda o dificulta l'aprenentatge d'altres llengües. A l'F havien de considerar si el manteniment de la llengua d'origen 
dels nouvinguts és o no competència de l'escola. Finalment, a l'apartat G, havien de dir si el sistema d'ensenyament ha de donar preferència al valencià o al castellà per tal d'integrar lingüísticament els nouvinguts.

\section{QÜESTIONARI}

CURS

\section{ESPECIALITAT}

Quina és la teua llengua primera?

Quina llengua uses amb més freqüència?

- De cadascun dels grups següents, tria l'expressió amb què més t'identifiques i comenta-la breument:

\section{A. Actitud favorable o no a l'aprenentatge del valencià}

1. És de mala educació parlar en valencià als castellanoparlants.

2. Si sempre es parla en castellà als castellanoparlants, mai no aprendran el valencià.

3. ¿A mí, por qué me tienen que obligar a aprender el valenciano?

B. Actitud envers l'ensenyament bilingüe castellà-valencià

1. Preferiria que els mestres no tinguérem l'obligació d'ensenyar el valencià.

2. És convenient que els xiquets valencians coneguen el valencià i el castellà en acabar l'escolarització obligatòria.

3. S'ha d'ensenyar el valencià a l'escola, perquè és la llengua pròpia del País.

C. Valoració d'una llengua en detriment d'altres: utilitat versus consciència de País

1. En un món globalitzat, per què perdre el temps aprenent llengües minoritàries com el valencià? L'anglès és el que interessa.

2. La llengua és el principal signe d'identitat d'un poble. La desaparició d'una llengua comporta la desaparició del poble com a tal.

\section{Actitud envers la realitat multilingüe de la nostra societat}

1. Cada vegada ens trobem amb més situacions en què hi ha immigrants i ens hem d'esforçar per comunicar-nos amb ells.

2. Els que vénen a viure ací són els que han d'aprendre a parlar com nosaltres.

E. Aprendre valencià, ajuda o dificulta l'aprenentatge d'altres llengües?

1. Saber valencià i castellà ajuda a aprendre altres llengües.

2. El fet de tenir un sistema escolar bilingüe és un entrebanc a l'hora de programar l'aprenentatge de llengües estrangeres.

F. El manteniment de la llengua d'origen és cosa de l'escola?

1. L'escola ha de procurar els mitjans per tal que els alumnes estrangers mantinguen la seua llengua d'origen.

2. És convenient que els alumnes estrangers mantinguen la seua llengua d'origen, però això no ho ha de fer l'escola, ho han de fer les famílies.

G. Utilitat versus ideologia pel que fa a l'aprenentatge del valencià i el castellà per part dels estrangers

1. Amb els alumnes estrangers cal donar prioritat al castellà perquè és el que els serà més útil. El valencià ja l'aniran aprenent.

2. És preferible que els alumnes estrangers aprenguen primer el valencià, perquè és la llengua pròpia d'aquest país. El castellà l'aprendran fàcilment després. 


\section{PRESENTACIÓ I ANÀLISI DE LES DADES}

Per a l'anàlisi de les dades, hem seguit el procediment següent:

En primer lloc, hem distingit les respostes en funció de la llengua primera dels estudiants (valencià-castellà). A continuació, hem classificat les dades quantitatives en funció de la llengua primera i en funció dels resultats totals. Després, hem fet una valoració qualitativa a partir dels comentaris dels estudiants extraient les idees clau, és a dir, aquelles que eren rellevants i significatives i que després han estat considerades en funció de la freqüència d'aparició.

Els resultats han estat els següents:

- Quina és la teua llengua primera?

$\begin{array}{lll}\text { Valencià } & 37 & 37 \% \\ \text { Castellà } & 63 & 63 \%\end{array}$

- Quina llengua uses amb més freqüència?

$\begin{array}{lll}\text { Valencià } & 38 & 38 \% \\ \text { Castellà } & 62 & 62 \%\end{array}$

En ser tan mínima la diferència entre la llengua primera i la més usada, no l'hem considerada significativa i, a l'hora d'obtenir els percentatges, hem pres la referència de la primera.

\section{A. Actitud favorable o no a l'aprenentatge del valencià}

1. És de mala educació parlar en valencià als castellanoparlants.

$\begin{array}{lcl}\mathrm{V} & 4 & 10,8 \% \\ \mathrm{C} & 6 & 9,5 \% \\ \text { Total } & 10 & 10 \%\end{array}$

2. Si sempre es parla en castellà als castellanoparlants, mai no aprendran el valencià.
$\mathrm{V}$
33
$89,2 \%$
C
53
$84,1 \%$
Total
86
$86 \%$

3. ¿A mí, por qué me tienen que obligar a aprender el valenciano?

$\begin{array}{lll}\mathrm{V} & 0 & \\ \mathrm{C} & 4 & 6,4 \% \\ \text { Total } & 4 & 4 \%\end{array}$


L'alternativa 2 ha estat elegida de manera majoritària amb un $86 \%$ del total, amb molt poca diferència entre valencianoparlants i castellanoparlants. Per contra, la tercera alternativa només ha estat triada per un $4 \%$, òbviament tots castellanoparlants. Pel que fa a l'alternativa majoritària, les idees que apareixen més repetides a l'hora d'argumentar la seua opció són:

- la pràctica i l'ús fan l'aprenentatge;

- la pràctica oral és més important que l'estudi de la gramàtica.

Alguns castellanoparlants manifesten que els valencianoparlants sovint canvien de llengua en parlar amb ells, tot i que saben que no tenen cap dificultat per a comprendre el valencià. D'altres, parlen de l'experiència pròpia: no poden aprendre si no se'ls parla en valencià i, en canvi, han aprés quan se'ls hi ha parlat. Observem, per tant, que els valencianoparlants canvien de llengua amb molta facilitat pel sol fet d'estar parlant amb un castellanoparlant. Així i tot, alguns valencianoparlants diuen que només estan disposats a canviar de llengua quan els altres no els entenen. Minoritàriament, apareixen expressions poc favorables a l'ús del valencià com ara «parlant castellà tots m'entenen», «parlar valencià a la gent de fora és una falta de respecte i una discriminació laboral i acadèmica».

\section{B. Actitud envers l'ensenyament bilingüe castellà-valencià}

1. Preferiria que els mestres no tinguérem l'obligació d'ensenyar el valencià.

$\begin{array}{lll}\mathrm{V} & 1 & 2,7 \% \\ \mathrm{C} & 6 & 9,5 \%\end{array}$

Total $\quad 7 \quad 7 \%$

2. És convenient que els xiquets valencians coneguen el valencià i el castellà en acabar l'escolarització obligatòria.

$\begin{array}{lll}\text { V } & 21 & 56,7 \% \\ \mathrm{C} & 47 & 74,6 \% \\ \text { Total } & 68 & 68 \%\end{array}$

3. S'ha d'ensenyar el valencià a l'escola, perquè és la llengua pròpia del País.

$\begin{array}{lcl}\text { V } & 15 & 40,5 \% \\ \text { C } & 9 & 14,9 \% \\ \text { Total } & 24 & 24 \%\end{array}$

Les tres alternatives reflecteixen una gradació pel que fa a l'ensenyament del valencià, des d'una opció contrària a l'obligació d'ensenyar valencià, fins 
una altra que en contempla la necessitat perquè és la llengua pròpia del País. L'opció 2 representa la postura intermèdia, és a dir, la conveniència que es coneguen les dues llengüies.

Només un 7\% del total preferirien que els mestres no tingueren l'obligació d'ensenyar valencià. Majoritàriament opten per l'opció intermèdia (68\%), amb una diferència entre els valencianoparlants i els castellanoparlants. Cal destacar que un $40 \%$ dels alumnes valencianoparlants trien l'alternativa 3, és a dir, l'obligació d'ensenyar valencià a l'escola perquè és la llengua pròpia del país.

Entre les raons més freqüents que aporten per justificar la postura majoritària, destaquen:

- són les llengües oficials;

- vivim en una societat bilingüe;

- conéixer les dues llengües proporciona més oportunitats per al futur i facilita l'aprenentatge d'altres llengües;

- necessitem el castellà per fer-nos entendre fora del País Valencià (aquesta idea l'expliciten alumnes valencianoparlants).

\section{Valoració d'una llengua en detriment d'altres: utilitat versus consciència de País}

1. En un món globalitzat, per què perdre el temps aprenent llengües minoritàries com el valencià? L'anglés és el que interessa.

$\begin{array}{lll}\mathrm{V} & 2 & 5,4 \% \\ \mathrm{C} & 9 & 14,2 \%\end{array}$

Total $11 \quad 11 \%$

2. La llengua és el principal signe d'identitat d'un poble. La desaparició d'una llengua comporta la desaparició del poble com a tal.

$\begin{array}{lll}\mathrm{V} & 35 & 94,6 \% \\ \mathrm{C} & 53 & 84,1 \%\end{array}$

Total $\quad 88 \quad 88 \%$

Les dues alternatives són contraposades. La primera rebutja l'aprenentatge de llengües minoritàries mentre que la segona defensa la necessitat de conservar-les en ser el principal signe d'identitat d'un poble.

Majoritàriament $(88 \%)$ trien la segona opció, amb molt poca diferència entre els valencianoparlants i els castellanoparlants. Molt sovint, en els comentaris apareix la idea de llengua associada a cultura, tradició, història, forma d'entendre el món, afectivitat, etc. 
Molts manifesten que les dues opcions no són contradictòries.

Algunes idees dels que trien l'opció minoritària són:

- val més conéixer la més útil. L'anglés obri portes;

- l'obsessió per mantenir llengües minoritàries és absurda.

\section{Actitud envers la realitat multilingüe de la nostra societat}

1. Cada vegada ens trobem amb més situacions en què hi ha immigrants i ens hem d'esforçar per comunicar-nos amb ells.

$\begin{array}{lll}\mathrm{V} & 9 & 24,3 \% \\ \mathrm{C} & 27 & 42,8 \% \\ \text { Total } & 36 & 36 \%\end{array}$

2. Els que vénen a viure ací són els que han d'aprendre a parlar com nosaltres.

$\begin{array}{lll}\mathrm{V} & 28 & 75,7 \% \\ \mathrm{C} & 32 & 50\urcorner 7 \% \\ \text { Total } & 60 & 60 \%\end{array}$

L'opció més triada ha estat la segona (60\%), és a dir, la que considera que els nouvinguts s'han d'adaptar a la societat on arriben; en canvi, el 36\% pensa que som nosaltres els que hem de fer l'esforç per comunicar-nos amb ells.

Cal destacar que no formulàvem quina era la llengua que haurien d'aprendre els nouvinguts -ja que ho fem en el darrer apartat; els estudiants, però, sí que la concreten en les seues respostes, amb diferències notables entre els castellanoparlants i els valencianoparlants, tal com podem observar en les raons que aporten:

- Valencianoparlants:

- si no aprenen valencià no poden participar plenament en la vida d'aquest País.

- Castellanoparlants:

- triaran aprendre castellà;

- han d'aprendre les dues llengües;

- no té sentit que aprenguen valencià quan els valencianoparlants no el parlen.

En general, s'observa una actitud favorable a l'esforç mutu. 


\section{E. Aprendre valencià, ajuda o dificulta l'aprenentatge d'altres llengües?}

1. Saber valencià i castellà ajuda a aprendre altres llengües.

$\begin{array}{lll}\mathrm{V} & 34 & 91,8 \% \\ \mathrm{C} & 57 & 90,4 \% \\ \text { Total } & 91 & 91 \%\end{array}$

2. El fet de tenir un sistema escolar bilingüe és un entrebanc a l'hora de programar l'aprenentatge de llengües estrangeres.

$\begin{array}{lll}\mathrm{V} & 3 & 8,2 \% \\ \mathrm{C} & 5 & 7,9 \% \\ \text { Total } & 8 & 8 \%\end{array}$

Davant la dicotomia que plantegem en aquest apartat, el $91 \%$ pensa que saber castellà i valencià afavoreix l'aprenentatge d'altres llengües, mentre que el $18 \%$ ho considera un entrebanc.

Els que trien l'opció 1, diuen que saber les dues llengües:

- predisposa a aprendre'n d'altres;

- fa que la ment estiga més preparada per a la diversitat;

- proporciona més bases sobre les quals estructurar els aprenentatges nous;

- ajuda a interioritzar les estructures gramaticals.

Aquells que ho consideren un entrebanc (opció 2) es refereixen a:

- la falta d'hores en el sistema educatiu;

- la procedència tan diversa de l'alumnat.

\section{F. El manteniment de la llengua d'origen és cosa de l'escola?}

1. L'escola ha de procurar els mitjans per tal que els alumnes estrangers mantinguen la seua llengua d'origen.

$\begin{array}{lcl}\mathrm{V} & 7 & 19 \% \\ \mathrm{C} & 15 & 23,8 \% \\ \text { Total } & 22 & 22 \%\end{array}$

2. És convenient que els alumnes estrangers mantinguen la seua llengua d'origen, però això no ho ha de fer l'escola, ho han de fer les famílies.

$\begin{array}{lll}\text { V } & 30 & 81 \% \\ \text { C } & 47 & 74,6 \% \\ \text { Total } & 77 & 77 \%\end{array}$


En aquest apartat donem per fet que s'ha de mantenir la llengua d'origen dels nouvinguts. L'alternativa que plantegem és si la responsabilitat de mantenir-la és de l'escola o no.

En aquest cas, el $77 \%$ dels estudiants considera que la responsabilitat no és de l'escola, atés que:

- l'escola ha de fer que aprenguen la llengua de la societat que els acull;

- l'escola no té mitjans per a mantindre totes les llengües de procedència; ja té prou feina amb el valencià, el castellà i l'anglés.

Fins i tot els que trien l'opció 1 (22\%) fan palesa en els seus comentaris la dificultat que açò suposaria per a l'escola i proposen:

- que es duguen a terme activitats en les llengües dels immigrants per tal de fomentar actituds de respecte i tolerància;

- que es faça en horari extraescolar.

\section{G. Utilitat versus ideologia pel que fa a l'aprenentatge del valencià i el castellà per part dels estrangers}

1. Amb els alumnes estrangers cal donar prioritat al castellà perquè és el que els serà més útil. El valencià ja l'aniran aprenent.

$\begin{array}{lll}\mathrm{V} & 10 & 27,1 \% \\ \mathrm{C} & 26 & 41,2 \% \\ \text { Total } & 36 & 36 \%\end{array}$

2. És preferible que els alumnes estrangers aprenguen primer el valencià, perquè és la llengua pròpia d'aquest país. El castellà l'aprendran fàcilment després.

$\begin{array}{lll}\mathrm{V} & 27 & 72,9 \% \\ \mathrm{C} & 32 & 50,7 \% \\ \text { Total } & 59 & 59 \%\end{array}$

Tenint en compte la situació sociolinguiística del País Valencià i també la formulació de les alternatives, en què es contraposa utilitat i ideologia, pot sorprendre que el 59\% del total, opte per donar prioritat a l'aprenentatge del valencià per als alumnes estrangers, que és la resposta amb més càrrega ideològica. Però observem que les raons que donen en triar aquesta opció són únicament de caràcter pragmàtic; entre elles destaquen:

- el castellà el sentiran en totes parts;

- l'escola és l'única oportunitat d'aprendre valencià, ja que al carrer no s'aprèn fàcilment. 
Els estudiants que elegeixen la resposta minoritària també donen raons de tipus utilitari:

- cal ser pràctic, el castellà permet integrar-se i desplaçar-se per Espanya.

Tant els uns com els altres expliciten en els seus comentaris que la conveniència d'una opció o altra està en funció del fet que el nouvingut visca en un poble valencianoparlant o en una ciutat, on la llengua predominant sol ser el castellà.

\section{CONCLUSIONS}

L'anàlisi de les respostes dels estudiants de la recerca, de les alternatives que han prioritzat en cada apartat i de les idees clau que ens han semblat més significatives ens ha portat a formular les conclusions següents:

En relació a la situació sociolingüística d'aquest país, majoritàriament tenen assumida la convivència de les dues llengües, valencià i castellà, com una cosa normal que no només no genera conflictes, sinó que és beneficiosa per a la seua formació lingüística. Queda molt clar també per als estudiants, que aquest bilingüisme ha de conviure en el context multilingüe en què ens trobem i que s'ha de mantindre dins d'una educació plurilingüe en les nostres escoles. Probablement en aquest sentit influeix el fet que han viscut ja l'ensenyament del valencià en la seua etapa escolar, i també la formació rebuda a l'Escola de Magisteri.

Pel que fa al paper de l'escola en aquesta nova etapa, la major part dels estudiants opina que l'escola ha de ser l'encarregada d'integrar lingüísticament els alumnes nouvinguts, tot fomentant actituds de respecte envers les diferents llengües d'origen. La integració, diuen, s'hauria de fer preferentment en valencià. Aquesta dada és rellevant perquè consideren que el valencià, una llengua minoritzada, ha de ser preferentment la llengua d'acollida i d'integració, és a dir, valoren el fet que no desaparega enmig d'una societat multilingüe i d'una educació que, necessàriament, ha de contemplar diverses llengües.

Hem observat que, en general s'aprecien diferències entre les respostes elegides pels valencianoparlants i els castellanoparlants. Aquestes són més significatives en els apartats B, D i G, és a dir, quan es fa referència, respectivament, a l'obligatorietat de l'ensenyament bilingüe valencià-castellà, a la comunicació amb els nouvinguts i a l'aprenentatge del valencià o el castellà per part dels estrangers. Com havíem pressuposat, sembla evident que la procedència lingüística influeix en les actituds que manifesten.

Certament, els resultats de la recerca denoten unes actituds molt favorables a la defensa del valencià, però cal plantejar-se si el que ha ocorregut és que els 
estudiants han respost allò que s'esperava que respongueren o si, com hem dit abans, les respostes han pogut estar molt influenciades per continguts que s'han treballat al llarg de la carrera o, fins i tot, pel fet que el qüestionari s'ha emplenat en hores de classe.

Un aspecte que ens ha resultat sorprenent és que, malgrat que en algun moment prenen opcions ideològiques, en general tenen una visió pragmàtica en relació als temes plantejats. Per exemple, en la valoració que fan del bilingüisme i de formar part d'una societat bilingüe, com ja hem comentat abans, juntament amb arguments que parlen de qüestions identitàries, n'apareixen d'altres que mostren una representació d'aquest fet com una cosa normal, com una característica més que conforma una societat determinada, sense la càrrega ideològica que, potser, es podria esperar si tenim en compte aspectes de la nostra història recent $\mathrm{i}$ que han configurat les actituds de generacions anteriors.

Tot això i alguns altres interrogants que se'ns han plantejat en aquest treball que presentem hauran de ser objecte de recerques posteriors.

\section{REFERÈNCIES BIBLIOGRÀFIQUES}

AreizAgA, E. (2003): «La interculturalidad en el aula de español como lengua estranjera», Textos de didáctica de la lengua y la literatura, 34: 27- 43.

BAKER, C. (1997): Fundamentos de educación bilingüe y bilingüismo, Madrid, Cátedra.

Costa, A., C. Juan, P. Ribera (2005): «Estudi sobre la formació cultural i multilingüe dels estudiants de Magisteri», Lenguaje y Textos, 23: 7-18.

Bourgain, D. (1990): «Diversité des répresentations sociales de l'écriture et diversification de ses approches didactiques», dins Schneuwly, B (ed.) (1990): Diversifier l'enseignement du français écrit, Lausanne, Delachaux-Niestlé, 289-296.

EtXevarRia, F. (2001): «Reptes de l'educació intercultural al País Basc», Articles de Didàctica de la llengua i la literatura, 23: 85-98.

GuAsch, O. (2001): «El plurilingüisme i la renovació de l'ensenyament de la llengua», Articles de Didàctica de la llengua i la literatura, 23: 9-21.

JoDELET, D. (1989): Les représentations sociales, París, PUF.

Millan, M. i O. Guasch (2004): «La formación del profesorado en las comunidades con dos lenguas oficiales», Textos de Didáctica de la lengua y la literatura, 37: 105-11.

Unamuno,V. (2004): Lengua, escuela y diversidad sociocultural, Barcelona, Graó.

DePARTAMENT D'Educació (2005): Pla per a la llengua i la cohesió social, Barcelona, Generalitat de Catalunya. 
CONSEll D'EuRopa (2001): Llengües modernes. Aprenentatge, ensenyament, avaluació. Un marc europeu comú de referència per a les llengües, Estrasburg, Consell d'Europa (Versió en català dels Departaments de Cultura i Educació de la Generalitat de Catalunya). 


\title{
LA RELACIÓN ENTRE EL APRENDIZAJE \\ DEL ESPAÑOL COMO LENGUA \\ EXTRANJERA Y LAS ACTITUDES \\ LINGÜÍSTICAS
}

\author{
CinZia di Franco \\ Universidad Antonio de Nebrija de Madrid \\ Università degli Studi di Palermo
}

\section{INTRODUCCIÓN}

$\mathbf{T}$ ODOS los hablantes de una lengua tienen una conciencia lingüística, es decir, son conscientes de cómo está estructurada su comunidad desde un punto de vista sociolingüístico. Dicho de otra manera, cada hablante de una determinada lengua es capaz de identificar a través de esa misma lengua a otros individuos.

Hoy en día, en cualquier sector, se advierte la necesidad de conocer las actitudes de los individuos que se encuentran en una determinada área de influencia, con el fin de obtener un punto de apoyo en la elección y adopción de ciertas políticas y/o estrategias de acción que permitan el logro de las metas y objetivos fijados.

En el ámbito de la enseñanza/aprendizaje de lenguas extranjeras (LES), es decir, dentro de un mundo lleno de diversos problemas e inquietudes a resolver, el conocimiento de las actitudes lingüísticas se considera desde siempre un factor básico que debe tomarse en cuenta a la hora de enfrentarse con los estudiantes para intentar administrar los recursos humanos de manera más adecuada.

En sociolingüística, las lenguas no se consideran solo instrumentos para transmitir significado, sino que se relacionan con las identidades de los grupos sociales o étnicos que las hablan. Por lo tanto, si hay una relación intensa entre lengua e identidad, esta relación debería manifestarse en las actitudes de los individuos hacia esas lenguas y sus usuarios (Appel y Muysken, 1996). A este propósito, Lambert, Gardner, Olton y Tunstall (1968) retoman la teoría de McGill sobre las tendencias etnográficas y las actitudes del aprendiz hacia el grupo de nativos de la lengua objeto (LO), sosteniendo que su motivación y actitud hacia dicha lengua van a influir en el éxito del aprendizaje. Un aprendiz gradualmente tenderá a adoptar unos rasgos del comportamiento que carac- 
terizan a los individuos de otro grupo lingüístico-cultural, o sea del grupo de nativos de la Lo de estudio. El éxito de la adquisición de la Lo dependerá de la actitud del aprendiz hacia ese grupo, exactamente:

His motivation to learn is thought to be determined by his attitudes and by his orientation toward learning a second language. The orientation is instrumental in form if the purposes of language study reflect the more utilitarian value of linguistic achievement, such as getting ahead in one's occupation, and is integrative if the student is oriented to learn more about the other cultural community as if he desired to become a potential member of the other group (1968: 473).

En relación con el concepto de motivación de tipo integrativo (orientada a conocer no solo la lengua, sino su cultura), opinamos que sin una correcta asimilación de ese binomio un estudiante nunca logrará alcanzar una correcta adquisición de la LE.

En este sentido conocer las actitudes de los estudiantes no es fundamental solo para programar un curso, sino para intervenir frente al posible fracaso debido a actitudes negativas e intentar modificarlas con el fin de no bloquear el proceso de aprendizaje de la LE. En pocas palabras, las actitudes lingüísticas hacen que sea fácil o difícil la adquisición de una LE. Por consiguiente, si ocurre un cambio de actitud en el aprendiz, se producirá un cambio lingüístico también. Dicho de otra manera, la actitud es directamente proporcional al éxito del aprendizaje de una LE. Si es positiva va a influir en el aprendizaje de manera positiva, mientras que si es negativa va a producir una forma de rechazo hacia la LO y, por lo tanto, va a comprometer la adquisición. La actitud positiva significa voluntad de aprender también una serie de estrategias que derivan de los parámetros culturales en los que se desarrolla una lengua. A este propósito, citamos a Bateman (2002: 318) quien afirma que «the study of another language will lead to positive attitudes toward the target culture and its members and a desire to interact with them».

El objetivo de este estudio preliminar es responder a las preguntas que suelen surgir a los profesores con respecto a sus estudiantes, como por ejemplo: ¿para qué han elegido estudiar español? Según ellos, ¿qué importancia tiene el español en el mundo?; ¿cómo consideran a los hispanohablantes?; ¿sienten atracción hacia la cultura española? Además, a un profesor, frente a una escasa motivación de sus estudiantes y/o al percibir una actitud negativa hacia la LO, le surge otra pregunta: ¿puedo ser tan incapaz de hacer un trabajo tan aparentemente natural de una manera tan imperfecta? No hay que olvidar que, independientemente del enfoque utilizado en su instrucción, cada profesor incluye sus pequeñas variaciones personales, que se basan en sus recuerdos de 
discente y en su experiencia como docente. Estas dos fuentes crean creencias y, por tanto, actitudes que orientan la actuación diaria en el aula. Este proceso afectará de manera muy directa a sus alumnos.

En esta comunicación se van a presentar los resultados de un estudio piloto, por el bajo número de informantes (10 sujetos universitarios), sobre la relación entre el aprendizaje del español como lengua extranjera $(E / l e)$ y las actitudes lingüísticas de los estudiantes italianos de E/le. ${ }^{1}$

\section{MÉTODO}

\subsection{Sujetos}

Los participantes son 10 sujetos, estudiantes de la carrera de Operador del Turismo Cultural de la Università degli Studi di Palermo, que se han seleccionado aleatoriamente. Son 8 mujeres y 2 hombres, de entre 20 y 29 años. La media de edad se sitúa en 24,4 , y una desviación típica de 3,06 . Hay un estudiante de tercer año, 5 de segundo y 4 de primero.

\subsection{Instrumentos de medida}

Para recoger los resultados se ha llevado a cabo una encuesta de tipo directo por un cuestionario (véase anexo), dividido en dos partes. La primera parte recoge simplemente los datos personales (encabezamiento), la segunda analiza las actitudes lingüísticas de los participantes (cuerpo) con respuestas cerradas, que, a veces, dejan un margen mínimo de abertura (otro: ). $\mathrm{Se}$ han utilizado preguntas de tipo dicotómico, apartados de elección múltiple y escalas de diferencial semántico. ${ }^{2}$ Se ha ideado el cuestionario utilizando la técnica de las escalas de actitud. Esta técnica no solo indaga la dirección, sino

1. La elaboración del material, es decir, la construcción del cuestionario, fue fundamental en este trabajo llevado a cabo en el curso de Sociopragmática y Pragmalingüística impartido por la profesora Ana María Cestero en el programa de Doctorado en Lingüística Aplicada a la Enseñanza del Español como lengua extranjera de la Universidad Antonio de Nebrija.

2. El diferencial semántico es una escala creada por Osgood et al. (1957). El investigador y su equipo se centraron en el estudio de las actitudes a través del lenguaje. De manera más específica, Osgood destacó el significado denotativo y el connotativo. El primero se refiere al significado del diccionario. El segundo concierne el significado que para cada persona tiene algo y es el significado que se evalúa en esta escala. El objetivo es encontrar una técnica cuantitativa que permita obtener una medida objetiva del significado psicológico de una serie de acontecimientos, objetos o personas, que para el individuo tienen un cierto sentido, por medio de una serie de escalas descriptivas de adjetivos bipolares. De esta manera, se puede establecer el grado de semejanza o disparidad entre conceptos. 
que proporciona información sobre la intensidad relativa con que se manifiesta esa actitud.

De manera específica, se investigó sobre cinco variables:

- Lenguas habladas y su grado de conocimiento.

- Razones, circunstancias y conveniencias.

- Importancia de las distintas lenguas y, concretamente, del español en el mundo.

- Uso de la lengua española (¿para qué?).

- Evaluación de la lengua y de los usuarios (cultura, comunidad española e hispanohablantes).

\subsection{Procedimiento}

El cuestionario se ha pasado a los sujetos durante los exámenes de la sesión otoñal del año académico 2003/2004, explicándoles lo que iban a hacer en líneas generales y subrayándoles que la compilación del cuestionario no tenía nada que ver con el éxito del examen.

\subsection{Análisis de los datos}

Los estudios más recientes sobre las actitudes lingüísticas se han desarrollado según una perspectiva mentalista, que considera las actitudes como un estadio interno y mental que puede dar lugar a ciertas formas de comportamiento. En realidad, esta concepción plantea serios problemas de investigación, porque no se pueden observar directamente los estadios mentales y, por lo tanto, los resultados de este tipo de investigación son muy cuestionables (Silva-Corvalán, 2001: 35). Por consiguiente, para ser más objetivos, en el presente estudio se ha optado por considerar datos cuantitativos y cualitativos.

\section{RESULTADOS Y DISCUSIÓN}

En esta sesión se presentan los datos, mostrando la frecuencia (fl) de cada variable.

En cuanto a los datos personales, no debe sorprender el hecho de que predominan las mujeres en esta pequeña muestra (8/10). Esta carrera pertenece al ámbito humanístico, en la Facultad de Filosofía y Letras.

Cabe advertir que vamos a presentar y discutir los resultados que afectan a las actitudes lingüísticas, dividiéndolos en 5 apartados, tal como eran las 5 variables analizadas. 


\subsection{Lenguas que habla y su grado de conocimiento}

En cuanto al número de lenguas conocidas, los datos revelan que todos los informantes conocen por lo menos dos LEs. Esto se debe a la tipología de estudios de los informantes. En la carrera de Turismo es normal que se estudien por lo menos dos lenguas. Además, hay tres casos en que se estudian tres lenguas y un caso -más raro- en que se estudian cuatro.

Con respecto al grado de conocimiento, el $50 \%$ de los informantes afirma que tiene un nivel de español intermedio. Un $30 \%$ tiene un nivel inicial y solo un $10 \%$ opina que tiene un nivel avanzado.

Más interesante es la pregunta 1c sobre la percepción del nivel de dificultad de la lengua española con respecto a otros idiomas (que son alemán, francés e inglés). El $60 \%$ de los sujetos ha respondido que el español les resulta de dificultad intermedia. El resto, el 40\%, lo han considerado fácil, confirmando el tópico que español e italiano (LM de todos los informantes) son muy similares. Sin embargo, el resultado del examen de los 4 sujetos informantes que tenían esta percepción resultó negativo. A este propósito, conviene recordar la afirmación de Arce (1984):

Es sabido que el español y el italiano son dos sistemas muy afines y su peligrosa afinidad y facilidad aparente se traducen en la mayor dificultad en su respectivo aprendizaje. Podríamos decir que se trata de dos de las lenguas más fáciles para aprenderlas mal y de las más difíciles para alcanzar su dominio desde una a otra (1984:109).

Es evidente que la cercanía de estas dos lenguas permite un avance más rápido en las primeras fases, pero potencia también una fosilización más estable que en otras lenguas.

Con respecto a la pregunta sobre lo que los estudiantes consideran más difícil a la hora de aprender español, véase el gráfico 1:

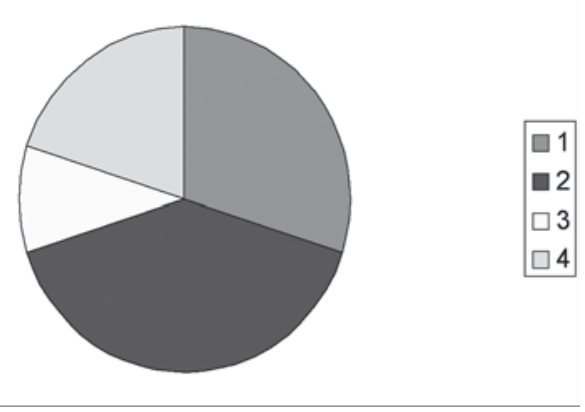

La mayor dificultad del español la encuentro en:

$1=$ pronunciación

2 = gramática

$3=$ vocabulario

$4=$ otras

(10\%: redacciones; $20 \%$ : hablar) 
La dificultad del español para los estudiantes reside en la gramática (40\%) y en la pronunciación (30\%). Siguiendo con la pregunta sobre lo que permite hacer el grado de conocimiento de $\mathrm{E} / \mathrm{le}$, un $80 \%$ responde que les permite comunicar suficientemente, mientras un $10 \%$ afirma que perfectamente, y el otro dice que no le permite comunicar. Esta pregunta y la sucesiva (tabla 1) son muy subjetivas y están muy bien relacionadas con la actitud:

\begin{tabular}{|c|c|c|c|c|}
\hline \multicolumn{6}{|l|}{ Cuando hablo español con nativos, me siento: } \\
\hline Satisfecho & Muy tenso & Frustrado & $\begin{array}{c}\text { Bien y con } \\
\text { ganas de } \\
\text { aprender más }\end{array}$ & Otras \\
\hline $10 \%$ & $30 \%$ & & $60 \%$ & \\
\hline
\end{tabular}

Los datos de la tabla 1 subrayan una actitud bastante positiva hacia E/le por más de la mitad (70\%) de los participantes.

En lo que se refiere a la pregunta sobre cómo han aprendido español, el $80 \%$ ha señalado que ha aprendido español gracias al profesor. Solo dos informantes han elegido más de una opción. Un $20 \%$ tiene una motivación de tipo integrativo, al referirse también al interés hacia la cultura. El 10\% ha aprendido gracias al contacto con los nativos. No hay otros sujetos que hayan tenido contactos con hispanohablantes. Este dato no debe sorprender. En la realidad siciliana e incluso en los pequeños pueblos de procedencia de los informantes, la mayoría de los jóvenes no están acostumbrados a viajar. En cuanto a la música, merece la pena comentar el resultado. No es muy relevante el porcentaje de estudiantes que ha aprendido español gracias a la música. Aunque la música española se está difundiendo muchísimo en Italia y mucha gente se ha acercado a su lengua y cultura por ella, la edad de nuestros informantes, que son jóvenes pero no adolescentes, es una época en que música y motivación al aprendizaje ya no tienen una relación muy fuerte.

En cuanto a las preguntas sobre el grado de dificultad de las cuatro habilidades (leer, escribir, hablar y escuchar), a través de los datos, aparece que la escritura, seguida por la escucha, son las destrezas consideradas más difíciles. A continuación, la lectura se percibe por la mayoría de los estudiantes como la más fácil. El único dato que sorprende es que el $40 \%$ de los informantes considera el habla como la habilidad más sencilla, dato que sorprende porque estos estudiantes tienen una gran dificultad a la hora de comunicar oralmente.

\subsection{Razones, circunstancias y conveniencias}

En este apartado se han utilizado las preguntas de tipo dicotómico (sí/no). En general, aparece y se confirma una actitud positiva por las respuestas de los 
informantes (90\%). Afirman que les gustaría una estancia en España para aprender la lengua y enfrentarse con la gente hispanohablante, valorando la importancia del español como lengua extranjera.

\subsection{Importancia de las distintas lenguas del mundo}

La tabla 2 muestra las respuestas de los sujetos:

\begin{tabular}{|c|c|c|c|c|c|c|c|}
\hline & Alemán & Árabe & Chino & Español & Francés & Inglés & Japonés \\
\hline $1^{\circ}$ & $\mathrm{x}$ & & & & & $\begin{array}{l}\text { X X X X X } \\
\text { X X X X }\end{array}$ & \\
\hline $2^{\circ}$ & $\mathrm{x} x$ & $\mathrm{x}$ & & $\mathrm{x} \times \mathrm{x}$ & $\mathrm{x} \times \mathrm{x}$ & $\mathrm{X}$ & \\
\hline $3^{\circ}$ & & X X X & & X X X X & $\mathrm{x} \times \mathrm{x}$ & & \\
\hline $4^{\circ}$ & $\mathrm{x} \times \mathrm{x}$ & $\mathrm{X}$ & & X X & $\mathrm{x} x$ & & $\mathrm{x} \mathrm{x}$ \\
\hline $5^{\circ}$ & $\mathrm{x} \times \mathrm{x}$ & $\mathrm{x} \times \mathrm{x}$ & $\mathrm{x} \mathrm{X}$ & $\mathrm{x}$ & & & $\mathrm{X}$ \\
\hline $6^{\circ}$ & & $\mathrm{x}$ & $\mathrm{X} \mathrm{X}$ & & $\mathrm{x} x$ & & $\mathrm{X} \times \mathrm{X} \times \mathrm{X}$ \\
\hline $7^{\circ}$ & $\mathrm{x}$ & $\mathrm{x}$ & $\mathrm{x} \times \mathrm{x} \times$ & X X & & & $\mathrm{X} x$ \\
\hline
\end{tabular}

Con respecto a estos datos, lo que más sorprende es la falta de conciencia de la importancia del español como segunda lengua hablada en el mundo e incluso de la difusión del chino por número de personas. Solo un $30 \%$ es consciente. El mismo $30 \%$ se vuelve a encontrar en las respuestas a la pregunta sucesiva, que afirman que en Italia aprender español no se considera necesario $(20 \%)$ o se considera extraño $(10 \%)$.

\subsection{Uso de la lengua}

Resulta evidente que casi en la totalidad el español se aprende para trabajar $(50 \%)$ y estudiar (50\%). Los estudiantes italianos tienden a acercarse al estudio del español a sabiendas de que se trata de una lengua extranjera muy parecida a su lengua materna (LM), que -según su percepción inicial- les permite aprobar los exámenes de LE más rápidamente y fácilmente en el nivel universitario. Sin embargo, después descubren que el español incluye unas reglas gramaticales complejas que no coinciden completamente con las del italiano.

\subsection{Evaluación de la lengua y sus usuarios}

Por último, se muestran y analizan los datos sobre la evaluación de la lengua y sus usuarios. En este apartado se han utilizado escalas de diferencial semántico. 
En cuanto a la primera pregunta del apartado (tabla 3), cabe advertir que los estudiantes equivocándose han elegido solo algunos de los adjetivos. Por consiguiente, se ha obtenido un cuadro parcial. Se confirma el tópico sobre los españoles que son acogedores y calientes. A este propósito, dudamos que los estudiantes sean conscientes del verdadero sentido del adjetivo «caliente». En general, se saca una buena percepción de los españoles por parte de los informantes y esto es un factor relevante, que ayuda a establecer una actitud de tipo positivo.

$$
\begin{array}{|ll|}
\hline \text { Los españoles son: } & \\
\text { Modernos ... tradicionales } & 2+5+6+4+7=24 / 5=4,8 \\
\text { Cívicos ... poco cívicos } & 1+1+1+3+1+3=10 / 6=1,6 \\
\text { Tolerantes ... poco tolerantes } & 1+2+4+3+1+4=15 / 6=2,5 \\
\text { Cultos ... poco cultos } & 1+2+1+2+1+1=8 / 6=1,3 \\
\text { Divertidos ... aburridos } & 1+1+1+1+1+1+1+1+1+1=10 / 10=1 \\
\text { Trabajadores ... perezosos } & 5+1+1+4+1+2=14 / 6=2,3 \\
\text { Acogedores ... poco acogedores } & 3+1+3+2+1+1=11 / 6=1,8 \\
\text { Calientes ... fríos } & 1+1+1+2+2+1+1+1+1+1=12 / 10=1,2 \\
\text { Extravertidos ... introvertidos } & 1+2+2+1+1+2+1+1=11 / 8=1,3
\end{array}
$$

Leyendo los datos sobre la percepción personal de los informantes hacia la cultura hispánica se vuelve a subrayar la actitud positiva. El $70 \%$ de los informantes considera España como un país bastante desarrollado, se declara «satisfecho» de las costumbres e iría a vivir a España. Con respecto a la lengua, se nota una valoración muy buena por la mayoría. Sin duda, los sujetos tienen una actitud positiva, corroborada por una motivación de tipo integrador (Cooper y Fishman, 1974). A través de sus respuestas, los estudiantes transmiten la perfecta conciencia de que hay que aprender toda una serie de estrategias que derivan de los parámetros culturales en los que se desarrolla el español.

\section{CONCLUSIÓN}

Los resultados de este estudio sobre las actitudes lingüísticas contribuyen a una mejor comprensión de la relación entre lengua e identidad de los estudiantes de la carrera de Turismo.

De hecho, se refleja la actitud positiva hacia el español, que lleva a estos estudiantes a elegirlo como L3. Además, esta tendencia está corroborada por las matriculaciones en los cursos. El inglés es la L2 obligatoria y luego tienen que elegir entre alemán, español y francés como L3. Ahora bien, el español es la lengua con el número más elevado de estudiantes entre las tres. 
Una de las limitaciones más evidentes de este estudio, lo repetimos, es el número muy reducido de informantes que forman la muestra. Además, hay que admitir que el cuestionario es demasiado extenso. De hecho, se habrían podido eliminar algunas preguntas que parecen muy similares entre ellas. En cuanto a las respuestas negativas, llevan a reflexiones que podrían generar un análisis de la realidad sociolingüística y de las competencias lingüísticas al mismo tiempo.

\section{REFERENCIAS BIBLIOGRÁFICAS}

ApPel, R. y P. MuYsKen (1996): Bilingüismo y contacto de lenguas, Barcelona, Ariel.

ARCE, J. (1984): «Italiano y español: Confrontación lingüística», en ARCE, J. et al. (eds.) (1984): Italiano y español. Estudios lingüísticos, Sevilla, Publicaciones de la Universidad de Sevilla, 109-126.

Bateman, B. E. (2002): «Promoting Openess toward Culture Learning: Ethnographic Interviews for Students of Spanish», The Modern Language Journal, 86, iii: 318-331.

COOPER, R. L. y J. A. Fishman (1974): «The study of language attitudes», International Journal of the Sociology of Language, 3: 5-19.

LAMBERT, W. E. et al. (1968): «A Study of the roles of attitudes and motivation in second-language learning», en FISHMAN, J. A. (ed.) (1968): Readings in the Sociology of Language, La Haya, Mouton, 473-491.

OsGood, C. et al. (1957): The Measurement of Meaning, Urbana, University of Illinois Press.

Silva-Corvalán, C. (2001): Sociolingüística y pragmática del español, Washington, D. C., Georgetown University Press, 34-36. 


\section{ANEXO \\ Cuestionario sociolingüístico}

\section{DATOS PERSONALES}

1. Edad:

2. Sexo:

3. Nacionalidad:

4. Lugar de residencia:

5. Nivel de estudios:

6. Profesión:

7. Lengua materna:

8. Años de estudio de español

1. Marca con una cruz una o varias de las opciones que se ofrecen:

a. Conozco __ lenguas extranjeras.

$\square 1$

$\square 2$

$\square 3$ o más

b. Mi nivel de dominio en esas lenguas es:

Lengua 1 (especificar cuál es)

$\square$ INICIAL $\square$ INTERMEDIO $\square$ AVANZADO

Lengua 2 (especificar cuál es)

$\square$ INICIAL $\square$ INTERMEDIO $\square$ AVANZADO

Lengua 3 (especificar cuál es)

$\square$ INICIAL $\square$ INTERMEDIO $\square$ AVANZADO

Lengua 4 (especificar cuál es)

$\square$ INICIAL $\square$ INTERMEDIO $\square$ AVANZADO

Otras

$\square$ INICIAL $\square$ INTERMEDIO $\square$ AVANZADO 
c. En relación con esas lenguas el español me parece
1. fácil
2. difícil
3. de dificultad intermedia

d. La mayor dificultad del español la encuentro en

1. pronunciación

2. gramática

3. vocabulario

4. otras

e. Mi dominio del español:

1. me permite comunicarme perfectamente

2. me permite comunicarme suficientemente

3. me permite comunicarme con muchas dificultades

4. no me permite comunicarme

f. Cuando hablo español con nativos, me siento

1. satisfecho

2. muy tenso

3. frustrado

4. bien y con ganas de aprender más

5. otras

g. He aprendido español gracias a:
1. el profesor
2. mis compañeros
3. mi interés por la cultura española
4. el contacto con los hispanohablantes
5. los programas de televisión en español
6. la música en español

2. Ordena las siguientes habilidades en español de mayor a menor dificultad: hablar, escribir, leer, escuchar:

$$
\begin{aligned}
& 1^{\circ} \\
& 2^{\circ} \\
& 3^{\circ} \\
& 4^{\circ}
\end{aligned}
$$


3. Pon un círculo en la respuesta que más se acerque a tu opinión:

a. ¿Es la primera vez que vienes a España a aprender español?

SÍ NO

b. ¿Volverás a España para seguir aprendiendo español?

SÍ NO

c. ¿Te ha gustado tu experiencia en España?

SÍ NO

d. ¿Admiras a las personas que hablan varias lenguas?

Sí NO

e. ¿En las sociedades actuales se valora más a las personas que hablan

varias lenguas?

SÍ NO

f. ¿Hablar español es importante hoy en día?

Sí NO

g. ¿Crees que es mejor que en cada país solo se hable una lengua y no varias?

SÍ NO

4. ¿Qué lenguas te parecen más importantes actualmente en el mundo? Ordena las siguientes lenguas de mayor a menor importancia: alemán, inglés, árabe, japonés, español, francés, chino:

$1^{\mathrm{a}}$
$2^{\mathrm{a}}$
$3^{\mathrm{a}}$
$4^{\mathrm{a}}$
$5^{\mathrm{a}}$
$6^{\mathrm{a}}$
$7^{\mathrm{a}}$

5. Marca con una cruz $(X)$ una o varias de las opciones que se ofrecen:

a. En mi país, aprender español:

$\square$ está muy valorado

$\square$ se considera interesante 
$\square$ es prestigioso

$\square$ no se considera muy necesario

$\square$ se considera extraño

b. Creo que el español es útil para:

$\square$ el trabajo

$\square$ el ocio / el tiempo libre

$\square$ los estudios

$\square$ integrarse en la sociedad de acogida

$\square$ otras (especificar cuáles)

c. Yo estudio español para o por:

$\square$ para mi trabajo

$\square$ por placer

$\square$ por mis estudios

$\square$ para integrarme

$\square$ otras (especificar cuáles)

6. Señala con una cruz $(X)$ el espacio más cercano a tu propia opinión:

Los españoles son:

$\begin{array}{lll}\text { modernos } & ------- & \text { tradicionales } \\ \text { cívicos } & ------- & \text { poco cívicos } \\ \text { tolerantes } & ------- & \text { poco tolerantes } \\ \text { cultos } & ------- & \text { poco cultos } \\ \text { divertidos } & ------- & \text { aburridos } \\ \text { trabajadores } & ------- & \text { perezosos } \\ \text { acogedores } & ------- & \text { poco acogedores } \\ \text { calientes } & ------- & \text { fríos } \\ \text { extravertidos } & ------- & \text { introvertidos }\end{array}$

7. Pon un círculo en el lugar que mejor refleje tu opinión

a. España es un país

$\square$ muy desarrollado $\square$ bastante desarrollado

$\square$ desarrollado $\quad \square$ poco desarrollado $\square$ nada desarrollado

b. Utilizo el español habitualmente

$\square$ nada $\quad \square$ muy poco $\quad \square$ bastante poco $\square$ algunas veces

$\square$ a menudo $\square$ con mucha frecuencia $\quad \square$ siempre 
8. Marca con una cruz $(X)$ la opción que mejor refleje tu opinión:

España es un país en el que, si pudiera...
a. viviría
b. viviría temporalmente
c. viviría cuando me jubile
d. no viviría

9. Indica tu grado de satisfacción con las siguientes costumbres españolas:

$1=$ insatisfactorio

2 = poco satisfactorio

$3=$ satisfactorio

$4=$ bastante satisfactorio

$5=$ muy satisfactorio

los horarios comerciales

los horarios de comidas

1

la familiaridad en el trato

con desconocidos

la «vida en la calle»

$\begin{array}{lllll}1 & 2 & 3 & 4 & 5 \\ 1 & 2 & 3 & 4 & 5\end{array}$

10. Señala con una cruz $(X)$ el espacio más cercano a tu propia opinión: La lengua española es:

$\begin{array}{lllllll}\text { fácil } & 1 & 2 & 3 & 4 & 5 & \text { difícil } \\ \text { agradable al oído } & 1 & 2 & 3 & 4 & 5 & \text { desagradable } \\ \text { clara } & 1 & 2 & 3 & 4 & 5 & \text { confusa } \\ \text { familiar } & 1 & 2 & 3 & 4 & 5 & \text { extraña } \\ \text { bonita } & 1 & 2 & 3 & 4 & 5 & \text { fea } \\ \text { interesante } & 1 & 2 & 3 & 4 & 5 & \text { aburrida }\end{array}$




\title{
EL ÁRABE COMO LENGUA FUENTE EN LOS PRÉSTAMOS LÉXICOS VIGENTES EN FRANCÉS MAGREBÍ
}

\author{
Dalila Fasla \\ Universidad de La Rioja
}

À vouloir à tout prix imposer un régime unitaire, nous risquons de nous retrouver désunis. La diversité s'est toujours révélée féconde. Pour pousser fort et dru, un arbre a besoin de plusieurs racines.

R. MIMOUNI

\section{MARCO TEÓRICO}

$\mathbf{L}$ A dimensión multilingüe de la comunidad magrebí tiene su origen en una situación de contacto de lenguas, hecho que permite identificar en la sincronía actual un fenómeno de poliglosia motivado por una superposición de pares diglósicos consecuente al uso de un conjunto de variedades con diferente distribución funcional $\left(\mathrm{A}_{1}, \mathrm{~A}_{2} \ldots\right.$, versus $\left.\mathrm{B}_{1}, \mathrm{~B}_{2} \ldots, \mathrm{B}_{\mathrm{n}}\right)(c f$. Fasla 2002, 2006, en prensa): así, frente a las diversas variedades de árabe y bereber, muestran también su vitalidad, aunque en grado variable, el francés, el español y el inglés. En este contexto definido por la pluralidad sociocultural, el uso del francés -como lengua hablada, escrita y leída- se mantiene en el sector educativo, económico y administrativo, a la vez que presenta una frecuencia significativa en los medios de comunicación; ${ }^{1}$ como ha señalado Quitout, en el

1. Aparte de su uso en los canales de televisión y en la radio, se publican diaria y semanalmente un buen número de periódicos y revistas en francés, v. gr., La Gazette du Maroc, La Nouvelle Tribune, La Vie Economique, L'Economiste, Le Matin du Sahara et Maghreb (Casablanca), Demain l'Algérie, Horizons, Jeune Indépendant, La Nouvelle République, Le Matin, Le Soir d'Algérie, Liberté (Argel), La Presse de Tunisie, Le Renouveau, Le Temps (Túnez); la abundancia de arabismos documentados en este tipo de publicaciones es justificada por los periodistas como una forma de acercarse a los hablantes bilingües: «les journalistes cherchent à se rapprocher de leur lectorat bilingue» (Kethiri, 2004: 249). El francés es también la lengua de expresión de muchos escritores magrebíes y goza asimismo de prestigio y aceptación como lengua de producción científica, junto con el inglés.

$C f$. la excelente síntesis de Ennaji sobre la situación sociolingüística del francés, centrada en las variedades habladas en Marruecos (2005: 97-110), que se estudian con detalle en Benzakour, Gaadi y Queffélec (2000: 85-114). El francés hablado en Argelia cuenta con la valiosa contribución de Queffélec et al. (2002: 36-37 y 118-121; cf. asimismo Dalache, 1981 y Morsly, 1984, 1993, 2004) y para la variante tunecina resulta especialmente representativa la monografía de Naffati y Queffélec (2004: 31-40 y 56-78); para una visión de conjunto sobre esta variedad diatópica hablada por la comunidad francófona magrebí, vid. la contribución clásica de Lanly $\left(1970^{2}\right)$ y Queffélec (1993), trabajo en el que se detalla el estado de la investigación a principios de los años noventa. 
caso concreto de Marruecos, «le français est la seule langue [...] qui puisse s'enorgueillir d'être à la fois lue, écrite et parlée. Il est la langue de toutes les promotions sociales et économiques [...]» (2001: 62). En cuanto a su valoración diafásica, no conviene olvidar que es la única variedad de esta comunidad cuyo uso se extiende tanto al registro formal como al ámbito coloquial o familiar (lengua A-B).

Esta situación de lenguas, sociedades y culturas en contacto ha dado lugar a numerosos fenómenos derivados de dicha situación, que pueden sistematizarse bien por su naturaleza propiamente lingüística o de acuerdo con su carácter sociocultural (v. gr., aculturación, code-switching, code-mixing, hibridación, interferencia, préstamo; $c f$. Fasla, 2006: $\S 2$ ). La realidad sociolingüística muestra que el fenómeno del préstamo se ha documentado históricamente entre todas las variedades implicadas en el contacto lingüístico, si bien presenta un elevado índice de frecuencia entre el árabe y el francés, como resultado de la consecuente simbiosis cultural entre la sociedad dominada y dominante: «[l'emprunt lexical] est vécu comme le résultat d'une coexistence de plus d'un siècle de deux communautés culturelles et linguistiques distinctes l'une de l'autre» (Kethiri, 2004: 248); por este motivo, conviene subrayar además que «el fenómeno de prestación-adopción se realiza en ambas direcciones [...], identificándose ambos sistemas lingüísticos (árabe y francés) con un doble papel de lengua fuente y lengua receptora en sucesivos periodos sincrónicos» (Fasla, en prensa: $\S \mathrm{I})^{2}$

El estudio del fenómeno del préstamo léxico que, en el caso que nos ocupa, tiene lugar en esta situación de lenguas en contacto directo ${ }^{3}$ y en un contexto de bilingüismo social, ha sido abordado en las últimas décadas desde diversas perspectivas metodológicas: así, frente al enfoque diacrónico predominante en la tradición europea, la lingüística norteamericana se ha basado en el análisis descriptivo de datos formales, actitud criticada inicialmente por Haugen (cf. 1950), como colaborador activo de la llamada revolución estructuralista en el estudio del préstamo lingüístico; en la misma línea se sitúa la contribución clásica de Weinreich, quien plantea el fenómeno de la interferencia léxica como

2. $C f$. el artículo de Derradji (1999) en el que se estudia este doble papel en el caso del francés magrebí; vid. asimismo Kethiri (2004: 249). En este sentido, llama especialmente la atención el papel del árabe como lengua fuente y la consiguiente dirección del préstamo, fenómeno que ha sido señalado por Amargui: «pourquoi une langue, en l'occurrence l'arabe marocain, malgré sa situation de langue dominée, fournit-elle des mots à une langue dominante? N'est-ce pas une situation paradoxale? Il est généralement admis que ce sont les langues dominantes qui alimentent les langues dominées en emprunts» (1995: 43; cf. Myers-Scotton, 2002: 238).

3. A diferencia del contacto indirecto, en el contacto directo de lenguas resultan especialmente productivos los fenómenos de hibridación documentados en la flexión de número, así como en los diferentes mecanismos de formación de palabras (vid. infra, 2.2-2.3). 
paso previo al préstamo (cf. [1953] 1974: 47-69; Haugen ([1957] 1972: 777778; Sala, 1988: esp. 141-185). ${ }^{4} \mathrm{Al}$ hilo de las causas del préstamo léxico aducidas en esta monografía fundacional sobre la lingüística de contacto, ofrecemos a continuación una descripción explicativa de los principales factores que han contribuido a la adopción de voces de origen árabe en la variedad de francés endógeno ${ }^{6}$ hablado en la comunidad magrebí:

(a) La necesidad de nombrar una nueva realidad, i. e., se adopta la voz de origen árabe para designar un referente ajeno a la cultura occidental, dado que el correspondiente término designativo no existe en la lengua receptora.

(b) La voz árabe se adopta para evitar posibles connotaciones derivadas del uso del término francés; en este caso, la prestación del arabismo y la vitalidad del propio término vigente en la lengua receptora constituye fuente de creación de dobletes semánticos formados por la voz de origen árabe y por el correspondiente sinónimo romance (v. gr., balek-attention; baraketbasta; ${ }^{7}$ boustan-palmeraie; doum-margaillon; ${ }^{8}$ flous-argent; $k l e b^{9}$-chien; riadjardin; toubib-médecin; wilaya-gouvernorat),${ }^{10}$ dobletes cuyo uso y vigencia

4. La trayectoria de ambas escuelas se recoge con detalle en Gómez Capuz (1998: 103-130 y 153).

5. Weinreich presenta las causas del préstamo léxico en función de la distinción entre hablantes monolingües y bilingües, distinción que también debe tenerse en cuenta en el caso de la comunidad magrebí; $c f$. asimismo el artículo de Castillo Fadic (2002: 476-482), en el que se revisan las principales teorías sobre las causas del préstamo léxico.

6. Como indica su propia denominación - vid., v. gr., Benzakour (2001: 82-86) y Kethiri (2004: 251) - esta variedad del francés se origina bajo la influencia de factores sociológicos internos a la propia comunidad lingüística y difiere del francés de referencia sobre todo en el nivel léxico, debido al fenómeno del préstamo en el contexto sociogeográfico señalado. En este sentido, resultan de vital importancia las aportaciones derivadas de la trayectoria de un ambicioso proyecto de investigación sobre el francés hablado y escrito en el Magreb (Inventaire des particularités lexicales du français au Maghreb, coordinado por A. Queffélec: $c f$. Benzakour, Gaadi y Queffélec, 2000; Queffélec et al., 2002; Naffati y Queffélec, 2004, referencias que recogen un significativo número de arabismos vigentes en francés marroquí, argelino y tunecino respectivamente). Todos los ejemplos recogidos en este trabajo han sido cotejados y extraídos de dichos repertorios y, en el apartado dedicado a su clasificación, se acompañan sistemáticamente de las correspondientes marcas diatópicas indicando su ámbito de uso: fA (francés argelino), $\mathrm{fM}$ (francés marroquí), $\mathrm{fMg}$ (francés magrebí), fT (francés tunecino). Vid. asimismo el repertorio de Duclos (1992), quien registra de forma sistemática el origen etimológico del término, aunque presenta el inconveniente de que en determinadas voces aduce como sinónimos simples variantes fonéticas de un mismo préstamo.

7. Cruce del italiano y el español ( $c f$. Duclos, 1992: s. v).

8. Voz tomada del español margallón ( $c f$. Duclos, 1992: s. v.), de uso preponderante en la ciudad de Orán.

9. «Attesté par le Petit Robert, sous sa forme clebs. Originellement cleb est le pluriel de kelb en arabe, mais le terme a été emprunté sous sa forme plurielle par le français, d'où cet usage au singulier qui est concurrencé par la forme singulier originelle [kelb]» (cf. Naffati y Queffélec, 2004: s. v. kelb, cleb).

10. Doblete de uso especialmente extendido en Argelia y Túnez. 
obedecen sobre todo a la influencia de la diversidad diastrática y diafásica.

(c) La prestación de la voz árabe está motivada para evitar la correspondiente construcción perifrástica en la lengua receptora (v. gr., baraket-c'est fini; doum-palmier-nain; hammam-bain public; hanout-petit magasin; médinaville arabe; mellah-quartier juif; naï-flûte traditionnelle; ramadan-mois du jeûne, mois saint), fenómeno históricamente documentado en otras situaciones de contacto linguiístico y consecuente prestación, como es el caso de los arabismos en iberorromance.

(d) Frente a las causas anteriormente citadas, basadas en fenómenos de carácter sociosemántico (designación, connotación, sinonimia, variación...), la adopción de determinadas voces de origen árabe puede responder también a factores etnolingüísticos, i. e., a la necesidad de preservar la identidad árabo-islámica, dado que en el caso que nos ocupa y a diferencia de otras situaciones de prestación-adopción, ${ }^{11}$ la lengua fuente (árabe) es una de las lenguas autóctonas.

\section{NIVELES DE ADAPTACIÓN LINGÜÍSTICA}

Como en todo proceso de prestación, los diferentes niveles del sistema receptor se muestran implicados en la adaptación lingüística de la voz tomada de la lengua fuente, fenómeno que se constata en la siguiente tipología:

\subsection{Adaptación morfonológica}

Frente a los términos no adaptados (extranjerismos), el corpus documentado permite distinguir:

(a) Préstamos adaptados al sistema morfonológico del francés, cuya ocasional variación fonética obedece a una diferente vitalidad sintópica (v. gr., iouiou, fA-youyou, $\mathrm{fMg}$ ); es importante recordar que el sistema fonético árabe presenta puntos de articulación inexistentes en francés, por lo que la adaptación se ve favorecida cuando los sonidos que conforman la voz prestada encuentran una

11. Como tendencia general, en los fenómenos de prestación-adopción, bien sea en contacto directo o diferido, la lengua receptora suele ser la variedad autóctona o materna (cuyo papel de lengua fuente resulta poco significativo) y la adopción del préstamo con frecuencia corre paralela a la necesidad de designar referentes que mantengan una cierta consonancia con la modernidad o con ciertas innovaciones tecnológicas. No obstante, en las variedades de francés y de árabe habladas en la comunidad magrebí se verifica la prestación en sentido bidireccional (y en contacto directo), dado que no solo se documentan arabismos en francés magrebí, sino que el árabe es, a su vez, lengua receptora de voces prestadas del francés en su papel de lengua fuente, como hemos señalado al comienzo de nuestra exposición. 
cierta correspondencia en la lengua receptora: ${ }^{12}$ «quand l'emprunt à l'arabe ne présente pas d'écart phonétique par rapport au français de référence, il s'intègre plus facilement (cf.tajine [...])» (Benzakour, 1995: 71).

(b) Préstamos en curso de adaptación, aún sometidos a variación fonética y que presentan, como consecuencia, una cierta inestabilidad de las grafías; de hecho, se documentan préstamos con tres o más variantes diferentes, lo cual indica generalmente que el proceso de adaptación aún no está concluido (v. gr., djellaba, djellab, jallabia, jellaba; harira, harrira, lahrira; macroud, macroute, makroud, makrout, maquroudh; madersa, madrassa, mdersa, médersa; r'bab, rabab, rebab, rebeb).

\subsection{Adaptación morfositáctica}

La integración de un préstamo en el sistema receptor es efectiva cuando la nueva palabra ha producido un rendimiento morfológico y semántico; como han señalado Poplack y Sankoff (1984: 100), en un estudio basado en Haugen, Bloomfield, Hyman y Lovins, «traditional as well as more recent studies of borrowing stressed that adaptations of foreign items of any linguistic level to the pattern of the recipient language, such as incorporation of verbal and nominal suffixes [(vid. infra, § 2.3)], assignment of gender... were indications that the forms had been integrated into that language».

En cuanto a la asignación de género, el término prestado mantiene casi siempre la marca de género de la lengua fuente, incluso en los casos de género ambiguo (v. gr., lel la delwa, lel la djellaba, le/ la djemiya, lel la henna), ${ }^{13}$ que pueden expresarse indistintamente en masculino o femenino; por otra parte, las diferentes marcas de femenino que se identifican en la morfología flexiva árabe se conservan generalmente en la adaptación del préstamo al sistema receptor, adaptación que en no pocos casos presenta además una vocal final de apoyo (v. gr., gallas, masc.; gallassa; fem. sing.; gallasate; fem. pl.; samsar, masc.; samsara; fem. sing; samsarate, fem. pl.).

La documentación de arabismos consignada en fuentes orales y escritas aporta datos concluyentes sobre la flexión de número; en este sentido, el plural francés prevalece generalmente sobre la formación del plural árabe, aunque pueden documentarse también casos que muestran la alternancia de las dos soluciones manteniéndose covigentes ambas formas (djebba, sing.; djebbas,

12. No existe una relación directa entre el uso más o menos extendido del préstamo y su mayor o menor grado de adaptación.

13. Este tipo de términos se registra en los repertorios consultados como sustantivos de género inestable; sobre el género del término henna en árabe y en francés estándar, vid. Naffati y Queffélec (2004: 98). 
djebbate, pl.; guerrab, sing.; guerrabs, guerraba, pl.; médersa, sing.; médersas, médersate, pl.; samsar, sing.; semsars, samssara, pl.; wilaya, sing.; wilayas, wilayate, pl.); otras veces se combinan las reglas de ambas lenguas, fenómeno que origina la formación de un plural híbrido (v. gr., dawr, sing.; adwars, pl.; habba, sing.; habbatas, pl.). No obstante, no faltan asimismo casos en los que coexisten, con similar frecuencia de uso, el plural francés, el plural árabe y la correspondiente forma híbrida (v. gr., daïra, sing.; daïras, dä̈rate, daïrates, pl.; wilaya, sing.; wilayas, wilayate, wilayates, $\mathrm{pl}$.).

\subsection{Adaptación morfoléxica}

La base léxica prestada interviene en la ulterior formación de un buen número de términos, resultantes de la anexión a dicha base de ciertos afijos y elementos compositivos tomados de la lengua receptora. Este fenómeno, que atestigua el rendimiento morfosemántico del préstamo, así como su integración plena en el sistema receptor, da lugar a una extensa tipología de términos híbridos que responde a diferentes mecanismos de formación de palabras, i. e., derivación por sufijación ${ }^{14}$ (v. gr., caïd-caïdal; Coran-coranique, coraniquement; couscous-couscoussier, ière; Islam-islamité; oud-oudiste; ramadan-ramadanesque, ramadanien, ienne, ramadanique), y composición ${ }^{15}$ (v. gr., fouta-blousa, minidjebba, pain diari, pain tabouna, supercaïd). Las formas truncadas son asimismo prueba del rendimiento morfosemántico del préstamo, aunque no siempre son indicadoras de un proceso de adaptación concluido (v. gr., por aféresis: alhamdoullah-hamdoullah; inchallah-challah), pues en ciertos casos, bien se trate de apócope o aféresis, constituyen una variante más de un préstamo en curso de adaptación.

La hibridación se extiende asimismo a la combinación sintagmática propia de las locuciones (avoir du flous «ser rico»; faire ä̈ mica «hacer vista gorda»; faire le ramadan «compartir el periodo de ayuno»; mettre un peu de zafran

14. El esquema derivativo predominante es base léxica ár. + afijo del sistema receptor; en los casos de derivación por prefijación resulta especialmente productivo el prefijo dé-.

Cuando la base léxica es un verbo, el fenómeno de hibridación es consecuente a la necesidad de adaptar el préstamo al correspondiente paradigma del tema de infinitivo de la lengua receptora (v. gr., barouder, derbouker, youyouter); en este sentido, «la elección de la primera conjugación [...] se justifica por el hecho de ser en la actualidad la única conjugación productiva en la que se integran nuevos verbos» (Gómez Capuz, 1998: 242, la cursiva es nuestra).

15. Las formaciones híbridas que se constatan con un mayor índice de frecuencia responden a esquemas de composición de diferente tipo: elemento compositivo + base léxica ár., sust. ár. + sust.fr., sust.fr. + adj. ár.; solo en casos aislados la adopción de términos compuestos tiene su origen directamente en la lengua fuente, por lo que estos préstamos no presentan hibridación (couscous madfoune, lit. «cuscús enterrado», i. e., la guarnición se coloca debajo de la sémola y se espolvorea todo con almendra tostada y canela; vid. infra, Anexo, s. v. couscous). 
«realzar»); este uso de la voz prestada, junto con el conjunto restante de fenómenos señalados (derivación, composición...), sin olvidar la formación de plurales híbridos, constituye una de las pruebas más representativas de la madurez (exploitation) del préstamo, como etapa implicada en la creatividad de la lengua receptora.

\section{CLASIFICACIÓN DE ARABISMOS VIGENTES EN FRANCÉS MAGREBÍ}

En línea con las bases teóricas de nuestro objeto de estudio, el caudal de arabismos vigente en las variedades locales del francés hablado en el Magreb puede sistematizarse conforme a diferentes criterios de clasificación:

\subsection{Según la variedad de árabe}

De acuerdo con las diferentes variedades que se identifican en cada modalidad sinfásica, el papel de lengua fuente queda básicamente representado por el árabe clásico (A) y por el dialectal (B); en este sentido, se distinguen dos tipos de términos: por una parte, préstamos cuyo ámbito designativo pertenece a la religión musulmana o a la ideología islámica, que proceden de la variedad clásica (v. gr., fatiha, hadith, ramadan); y, por otra, préstamos tomados del árabe dialectal (darija), que designan realidades cotidianas -denotadoras de pertenencia grupal- relacionadas con formas de organización social, con manifestaciones artísticas y culturales, así como con tradiciones gastronómicas y costumbres, bien sean de carácter extendido o particulares de cada región (v. gr., aïta, derbouka, dinar, harira, wilaya, youyou).

\subsection{Según la categoría gramatical}

\subsubsection{Sustantivos ${ }^{16}$}

El análisis onomasiológico del caudal de préstamos documentado permite su clasificación en campos semánticos de diferente productividad, cuya divergencia cuantitativa remite a una mayor o menor implicación e influencia de ciertas áreas socioculturales en la designación de referentes autóctonos y del sistema de valores tradicional, así como en el mantenimiento de la propia identidad étnica y cultural; en suma, salvo casos aislados (v. gr., kleb, toubib), el acervo de voces de origen árabe vigentes en francés magrebí hace referencia a una realidad geo-

16. Como puede comprobarse en otras situaciones de adopción, el sustantivo es la categoría que se presta con un mayor índice de frecuencia. 
sociológica determinada conjuntamente por la cultura magrebí y por el pensamiento islámico.

I. Administración: baladia (fA, fM), daïra (fA), wilaya (fMg).

II. Economía y comercio: dinar (fA, fT), dirham (fA, fM), flous $(\mathrm{fMg})$.

III. Enseñanza y educación: $m$ 'cid (fMg), médersa (fMg), taleb (fMg).

IV. Flora y fauna: boustan (fMg), doum (fA, fM), henna (fMg), kleb (fA, fT).

v. Hábitat, espacio urbano y rural: hammam (fMg), hanout (fA, fT), médina (fMg), mellah (fA, fM), riad (fM), zanka (fM).

VI. Gastronomía: bissara (fM), chorba (fMg), couscous (fMg), harira (fA, fM), kefta (fMg), lablabi (fT), makroud (fMg), tabouna (fMg), tajine (fMg), yoyo (fT), zafran (fMg).

VII. Indumentaria, vestimenta: burnous (fMg), djebba (fA, fT), djella$b a$ (fMg), fouta (fMg), hijab (fMg).

VIII. Organología, técnica vocal e instrumental, intérpretes y danzas: aïta (fM), azifet (fMg), bendir (fMg), chaâbi (fMg), dakka (fM), derbouka (fMg), dawr (fT), malouf (fMg), naï (fMg), oud (fMg), raï (fMg), rebab (fMg), tar (fA, fT), youyou (fMg).

IX. Política: baasiste (fA, fT), choura (fMg), hizb (fA).

X. Profesiones, cargos, oficios: atar (fMg), bransi (fT), cadhi (fMg), caïd (fMg), fernatchi (fM), gallas (fM), guerrab (fMg), négafa (fMg), samsar (fMg), toubib (fMg), wali (fMg).

XI. Religión (creencias, dogmas, ritos, cultos): baraka (fMg), Coran (fMg), fatiha (fMg), hadith $(\mathrm{fMg})$, omra $(\mathrm{fMg})$, ramadan $(\mathrm{fMg})$, sourate $(\mathrm{fMg})$, tawhid (fMg).

\subsubsection{Verbos}

Barouder (fMg), bédouiniser (se) (fMg), derbouker (fMg), gouler (fA), habouser (fMg), youyouter (fMg).

\subsubsection{Adjetivos}

Coranique (fMg), diari (fMg).

\subsubsection{Adverbios}

Bezef (fA), chouia (fMg), macache (fMg).

\subsubsection{Interjecciones ${ }^{17}$}

Akarbi (fMg), balek (fA), baraket (fA), bismillah (fMg), hamdoullah (fMg), inchallah (fMg), mektoub (fMg), ya (fMg), yalatif (fMg). 


\subsection{Según su extensión diatópica}

La valoración geolingüística y etnosociológica de los préstamos vigentes en francés magrebí permite, por último, su distribución en tres tipos:

(a) Préstamos comunes a la civilización arabo-islámica, cuyo ámbito referencial presenta un carácter litúrgico o ideológico ${ }_{1}^{18}$ por lo que en ciertos casos se trata asimismo de términos designativos de determinadas prendas de vestir, costumbres o tradiciones autóctonas (v. gr., fatiha, hadith, hijab, mektoub, ramadan, sourate, tawhid). La adopción de este tipo de préstamos, así como su vitalidad y vigencia se encuentra especialmente motivada, no solamente por la necesidad de nombrar nuevas realidades, hecho que constituye una causa universal, sino que tiene también su origen en uno de los objetivos básicos del proceso de arabización, i. e., la necesidad de preservar la identidad cultural de la sociedad árabo-islámica.

(b) Préstamos que designan realidades propias de la comunidad magrebí, pues remiten a un dominio referencial compartido: ciertas prendas de vestir (v. gr., djellaba, fouta $)^{19}$ se revelan como referentes comunes, así como algunos platos típicos de tradición extendida (v. gr., chorba, couscous, makroud, tajine), sin olvidar los términos designativos de ciertas manifestaciones artísticas o categorías musicológicas (v. gr., azifet, derbouka, naï, oud, rebab), presentes en la cultura magrebí.

(c) Préstamos que hacen referencia a una realidad sociocultural específica de cada dominio geográfico (marroquí, argelino, tunecino), i. e., denotan particularidades propias de cada marco sociocultural (v. gr., bissara, lablabi, yoyo) que pueden, no obstante, ser compartidas, en mayor o menor medida, con otro país magrebí. ${ }^{20}$

17. Algunos adverbios e interjecciones proceden de una reducción fraseológica originada en el proceso de prestación y adaptación al sistema receptor (v. gr., bismillah, hamdoullah, macache), si bien no se trata de un fenómeno sistemático ni exclusivo de dichas categorías (cf., v. gr., manarf< ma naref, ár. «je ne sais pas»).

18. No olvidemos que «el Islam constituye un elemento de adoctrinamiento ideológico y cultural» (Fasla, 2006: 8).

19. Como es evidente, nos referimos, en este caso, a prendas de vestir cuyo uso no obedece a un fundamento concerniente a la cultura árabo-islámica.

20. Así, por ejemplo, la gastronomía marroquí comparte elementos comunes con la de otras regiones magrebíes, pero posee un carácter propio, ya que es la única que no ha recibido influencias de la cocina turca. 


\section{CONCLUSIÓN}

Al hilo de esta clasificación diatópica derivada, a su vez, del estudio que precede, podemos concluir que este caso de prestación de arabismos ${ }^{21}$ constituye uno de los principales factores de mantenimiento del francés en la comunidad magrebí, dado que -como fenómeno consecuente a la situación de contacto descrita- ha permitido adaptar esta lengua a necesidades de designación absolutamente ajenas a la cultura francesa y, por extensión, a la cultura occidental ${ }^{22}$ de este modo, la adopción y adaptación de voces de origen árabe en esta variedad geográfica de francés permite nombrar realidades propias de un nuevo marco sociocultural, sometido a un cruce de ideologías que integra tres principios: tradición, identidad y modernidad.

\section{REFERENCIAS BIBLIOGRÁFICAS}

AmARgui, L. (1995): «Le français du Maroc et l'emprunt à l'arabe», en QuefFélec, A., F. BenZAKour y Y. CHERRAD-BENCHEFrA (eds.) (1995): Le français au Maghreb, Publications de l'Université de Provence, 43-52.

Benzakour, F. (1995): «Le français au Maroc. Processus néologique et problèmes d'intégration», en QuefFélec, A., F. BENZAKOuR y Y. CHERRADBEnCHEFRA (eds.) (1995): Le français au Maghreb, Publications de l'Université de Provence, 61-76.

- (2001): «Français de référence et français en usage au Maroc. Une adéquation illusoire: l'exemple de l'écart lexical», Cahiers de l'Institut de Linguistique de Louvain, 27/1-2: 75-87.

BENZAKour, F., D. GAADI y A. QuefFÉLEC (2000): Le français au Maroc. Lexique et contacts de langues, Bruselas, Duculot.

Castillo Fadic, M. N. (2002): «El préstamo léxico y su adaptación: un problema lingüístico y cultural», Onomazein, 7: 469-496.

DALACHE, D. (1981): «Quelques particularités du français employé en Algérie», Zielsprache Französich, 1: 18-24.

DERRADJI, Y. (1999): «Le français en Algérie: langue emprunteuse et empruntée», Le français en Afrique, 13: 72-82.

Duclos, J. (1992): Dictionnaire du français d'Algérie, París, Bonneton.

21. Los fenómenos de hibridación documentados reflejan la evolución histórica de dos sistemas en contacto directo y son, en buena medida, fruto del grado de competencia bilingüe que caracteriza a la comunidad francófona magrebí.

22. Como hemos señalado anteriormente y con independencia de su distribución geográfica, los préstamos consignados en los diferentes campos semánticos designan generalmente realidades que no presentan una correspondencia terminológica en el sistema lingüístico receptor. 
EnNAJI, M. (2005): «French», en Multilingualism, Cultural Identity and Education in Morocco, Nueva York, Springer, 97-110.

FASLA, D. (2002): «La comunidad poliglósica magrebí: code-switching e interferencia lingüística», en MUÑOZ NúÑEZ, Ma D. et al. (eds.) (2002): Actas del IV Congreso de Lingüística General, 5 vols., Universidad de Cádiz, III: 941-952.

- (2006): «Bilingüismo, poliglosia e identidad cultural en la sociedad marroquí», Actes del VII Congrés de Lingüística general, edición en CD-ROM, 1-11.

- (2007): «La situación lingüística del Magreb: lenguas en contacto, diglosia e identidad cultural», RSEL, 36/2.

Gómez CAPUZ, J. (1998): El préstamo lingüístico. Conceptos, problemas y métodos, Cuadernos de Filología, Anejo XXIX, Universidad de Valencia.

HAUgen, E. (1950): «The analysis of linguistic borrowing», Language, 26: 210-231.

- ([1957] 1972): «Language Contact», Actes du VIII Congrès International des Linguistes (Oslo 1957), Nendeln-Liechtenstein, Kraus, 771-785.

KethiRI, B. (2004): «Les professeurs de français en Algérie, vecteurs légitimes de la norme et l'emprunt aux idiomes locaux», Le français en Afrique, 19: 245-259.

Lanly, A. $\left(1970^{2}\right)$ : Le Français d'Afrique du Nord: étude linguistique, París, Bordas.

MorsLy, D. (1984): «La langue étrangère. Réflexion sur le statut de la langue française en Algérie», Le français dans le monde, 189: 22-26.

- (1993): «Les particularités lexicales du français parlé et écrit en Algérie», en LATin, D., A. QuefFÉlec y J. TABI-MANGA (eds.) (1993): Inventaire des usages de la francophonie: nomenclatures et méthodologies, París, John Libbey Eurotext, 177-182.

- (2004): «Langue française en Algérie: aménagement linguistique et mise en oeuvre des politiques linguistiques», Revue d'aménagement linguistique, 107: 171-183.

Myers-Scotton, C. (2002): «Lexical borrowing», en Contact Linguistics. Bilingual Encounters and Grammatical Outcomes, Oxford University Press, 234-245.

NAFFATI, H. y A. QuefFÉLEC (2004): Le français en Tunisie (Nice, UMR 60.39 du CNRS), Le français en Afrique, $\mathrm{n}^{\circ} 18$.

POPLACK, S. y D. SANKOFF (1984): «Borrowing: the synchrony of integration», Linguistics, 22: 99-135.

QuefFÉLEC, A. (1993): «Le français au Maghreb: problématique et état des recherches», en LATIN, D., A. QuefFÉleC y J. TABI-MANGA (eds.) (1993): Inventaire des usages de la francophonie: nomenclatures et méthodologies, París, John Libbey Eurotext, 163-168. 
QuefFÉLEC, A. et al. (2002): Le français en Algérie. Lexique et dynamique des langues, Bruselas, Duculot.

Quinsat, F. (1991): «Emprunts à l'arabe d'Afrique du Nord: mots argotiques, grossiers, péjoratifs ou familiers», Le Français Moderne, 59/2: 164-187.

Quitout, M. (2001): «L'arabe, le français, l'amazighe au Maroc: un patrimoine culturel national», Cahiers du Rifal, 22: 60-65.

SALA, M. (1988): El problema de las lenguas en contacto, Universidad Nacional Autónoma de México.

WeINREICH, U. ([1953] 1974): «Mechanisms and structural causes of interference», en Languages in Contact, Findings and Problems, La Haya, Mouton, 7-70. 


\section{ANEXO}

\section{GLOSARIO DE ARABISMOS: ${ }^{23}$}

Aïta. Forma musical árabe (vocal e instrumental) de carácter popular.

Akarbi. Palabra de honor.

Atar. Vendedor de especias y de plantas medicinales.

Azifet. Grupos de músicos.

Baasiste. Relativo a una doctrina que trata de conciliar el panarabismo con una forma de socialismo arabo-musulmán.

Baladia. Municipalidad.

Balek. ¡Cuidado!

Baraka. Bendición divina, suerte.

Baraket. ¡Basta ya!, es suficiente.

Barouder. Luchar, combatir.

Bédouiniser (se). Hacerse beduino.

Bendir. Tamboril de piel de cabrito u oveja.

Bezef. Mucho.

Bismillah. Lit. en el nombre de Dios.

Bissara. Puré de habas aderezado con comino y pimiento dulce.

Boustan. Palmeral.

Bransi. Fabricante de burnous.

Burnous. Abrigo o capa tradicional larga, con capucha y sin mangas.

Cadhi. Magistrado musulmán que desempeña funciones civiles, judiciales y religiosas.

Caïd. Funcionario del Ministerio del Interior.

Chaâbi. Tipo de música popular.

Chorba. Sopa hecha a base de trigo verde.

Chouia. Poco.

Choura. Asamblea consultativa.

Coran. Libro sagrado de los musulmanes sobre la doctrina del Islam.

Couscous. Plato tradicional hecho a base de sémola de trigo, garbanzos, carne, verdura, azafrán, cilantro y pimienta.

Daïra. Subdivisión administrativa territorial.

23. Conformado por los ejemplos allegados en los diferentes apartados de este trabajo. Por razones de espacio ofrecemos una definición sucinta y adaptada de los repertorios originales ya citados (i. e., Duclos, 1992; Benzakour, Gaadi y Queffélec, 2000; Queffélec et al., 2002; Naffati y Queffélec, 2004), en los que el lector podrá consultar asimismo las diferentes marcas gramaticales y sociolingüísticas; por otra parte, hemos excluido los derivados y compuestos dado que, al no tratarse en ningún caso de términos lexicalizados, su significado puede fácilmente deducirse del de sus elementos constituyentes. 
Dakka. Música folclórica típica de Marrakech.

Dawr. Canto tradicional árabe acompañado de poesía.

Delwa. Saco de piel de animal utilizado para transportar líquidos.

Derbouka. Tambor de barro cocido o de metal, cuya caja está revestida de una piel de cabra.

Derbouker. Tocar la derbouka o imitar su sonido.

Diari. Casero, hecho en casa.

Dinar. Unidad monetaria actual de Argelia y Túnez.

Dirham. Unidad monetaria actual de Marruecos.

Djebba. Túnica, vestido largo y amplio.

Djellaba. Traje largo de origen marroquí, con mangas y capucha.

Djemiya. Asociación, asamblea.

Doum. Palmera pequeña.

Fatiha. Primer capítulo del Corán.

Fernatchi. Encargado de atizar el fuego de la caldera de un hammam.

Flous. Dinero.

Fouta. Pareo largo de seda o de algodón.

Gallas. Portero de un hammam.

Gouler. Hablar, declarar.

Guerrab. Vendedor ambulante de agua que se transporta en un odre de piel de cabra.

Habouser. Destinar uno o varios bienes a una fundación generalmente de carácter religioso.

Hadith. Recopilación de actos y palabras del profeta Mohamed.

Hamboullah. Exclamación de alegría para dar gracias a Dios, sobre todo después de la comida.

Hammam. Baño público o privado.

Hanout. Tienda de comestibles situada en una zona rural.

Harira. Sopa tradicional consumida especialmente durante el ramadán, elaborada a base de legumbres, carne y especias.

Henna. Arbusto espinoso de cuyas hojas se obtiene una pasta para teñir el cabello, las manos y los pies.

$H i j a b$. Velo islámico que cubre la mayor parte del rostro femenino.

Hizb. Partido político.

Inchallah. Lit. y quiera Dios, si Dios quiere.

Kefta. Albóndigas de pequeño tamaño, fritas o en salsa.

Kleb. Perro.

Lablabi. Potaje de garbanzos con comino, ajo y pimentón.

M'cid. Escuela coránica de enseñanza primaria.

Macache. Nada.

Makroud. Fritura elaborada con patata cocida, huevo y especias. 
Malouf. Música clásica de origen arábigo-andaluza.

Médersa. Centro de enseñanza general y religiosa.

Médina. Parte antigua de una ciudad, construida conforme a los cánones del urbanismo árabe.

Mektoub. Lit. está escrito. Destino.

Mellah. Barrio judío.

Naï. Flauta tradicional.

Négafa. Mujer que prepara a la novia para el día de la boda.

Omra. Visita de los lugares santos del Islam.

Oud. Laúd árabe.

Raï. Música popular (vocal e instrumental) originaria del oeste argelino y especialmente extendida en la zona oriental de Marruecos.

Ramadan. Periodo de ayuno diurno (desde el alba hasta el crepúsculo) de un mes de duración.

Rebab. Instrumento de cuerda típico en la ejecución de música andalusí.

Riad. Jardín.

Samsar. Agente inmobiliario.

Sourate. Designación en árabe de cada uno de los capítulos del Corán.

Tabouna. Horno en el que se hace el pan redondo tradicional. Pan cocinado en este horno.

Tajine. Recipiente de barro cocido y, por extensión, plato en él cocinado, hecho a base de legumbres, huevos y carne.

Taleb. Estudiante de teología musulmana.

Tar. Tamboril provisto de pequeñas sonajas de cobre.

Tawhid. Doctrina del monoteísmo musulmán.

Toubib. Médico.

Wali. Protector de una ciudad o de una región.

Wilaya. Unidad administrativa que corresponde a una región.

Ya. Apelativo utilizado para dirigirse a alguien.

Yalatif. Lit. ¡Oh, Dios Clemente! Expresión utilizada para invocar la clemencia divina.

Youyou (onomat.). Grito emitido por las mujeres como muestra de alegría.

Youyouter. Emitir you-yous.

Yoyo. Dulce en forma de anillo bañado en sirope.

Zafran. Condimento culinario utilizado como colorante.

Zanka. Calle. 


\title{
VIEJOS PROBLEMAS DESDE NUEVOS ENFOQUES: LOS ARABISMOS EN EL ESPAÑOL MEDIEVAL DESDE LA PERSPECTIVA DE LA SOCIOLINGÜÍSTICA ${ }^{1}$
}

\author{
JaVier García González \\ Universidad Autónoma de Madrid
}

$\mathbf{E}$ N los últimos años la Sociolingüística ha desarrollado útiles herramientas metodológicas que pueden aportar nuevas perspectivas a un campo tradicional de estudio de la Historia de la lengua: la influencia árabe en el español. La propuesta metodológica del «Cambio Lingüístico Inducido por Contacto» (Contact-Induced Language Change), desarrollada y aplicada en estudios de contacto de lenguas en los últimos años, puede ayudar a analizar y comprender este proceso complejo, en el que interactuaron múltiples factores socioculturales e históricos y que se desarrolló a lo largo de un prolongado período de tiempo.

\section{CAMBIO LINGÜÍSTICO INDUCIDO POR CONTACTO (CLIC)}

En el CLIC (Thomason y Kaufman, 1988; Thomason, 2001) se plantean especialmente tres propuestas que son útiles para el estudio e interpretación de los arabismos: la distinción entre dos tipos de procesos de contacto (1.1), una tipología de predictores de clases y grados del cambio lingüístico (1.2), y, por último, una escala predictiva del préstamo (1.3).

1.1. Préstamo y deslizamiento, desplazamiento o abandono (shift) son los dos tipos de procesos o situaciones de contacto en el CLIC (Thomason y Kaufman, 1988: 65-146; Thomason, 2001: 66-76).

En los procesos de deslizamiento, desplazamiento o abandono de una lengua, el «aprendizaje imperfecto» tiene un papel esencial. El concepto de «aprendizaje imperfecto» no se refiere, en este caso, a un aprendizaje deficiente por

1. Este estudio se ha realizado dentro del proyecto Procesos de cambio lingüístico en situaciones de contacto (HUM2005-04374, MEC, I+D). 
parte de un grupo de hablantes no nativos de una L2 por falta de exposición o acceso a esa L2, o a falta de aptitud o mal aprendizaje, sino al mantenimiento y uso consciente o inconsciente de rasgos de su interlengua, en la que puede haber más o menos elementos transferidos de su L1. Si el grupo de hablantes no nativos tiene una relación de dominio, es una comunidad numerosa o tiene un alto grado de integración, los hablantes nativos de la L2 pueden imitar rasgos de la interlengua de estos hablantes no nativos que provienen de su L1. Los fenómenos históricos de contacto de substrato y superestrato son ejemplos de este tipo de situación de contacto. A diferencia de lo que suele ocurrir en el préstamo, los cambios en este proceso de contacto afectan básicamente a la pronunciación y a la morfosintaxis.

En el proceso de préstamo no interviene el factor de «aprendizaje imperfecto» de una L2. Las dos lenguas se mantienen, aunque en algunos casos de largo e intenso contacto puede producirse la «muerte» de la Lo (Lengua Objeto). Aunque puede haber préstamos fonéticos y gramaticales, si la duración del contacto es larga, los préstamos son básicamente léxicos. En este tipo de contacto no es imprescindible que exista un grupo bilingüe que actúe de puente entre las dos lenguas para que se produzcan los préstamos, pues estos pueden ser introducidos por hablantes con una competencia limitada o parcial de la LF (Lengua Fuente), por ejemplo solo en la lengua escrita (Thomason y Kaufman, 1988: 66-67), o solo con una «familiaridad pasiva» (Thomason, 2001: 139-142) o un conocimiento superficial de la LF; tampoco es necesario que sean introducidos en la LO por hablantes nativos de esta, pues pueden penetrar a través de hablantes no nativos, pero que la hablan y que son imitados por los hablantes nativos (Thomason, 2001: 68). Como veremos, estas consideraciones sobre los posibles grupos intermediarios son esenciales para explicar el tipo y el grado de contactos entre el árabe y el castellano medieval.

1.2. En segundo lugar, respecto de los factores que pueden ayudar a predecir cómo y en qué grado se puede producir un CLIC, estos pueden dividirse en dos bloques (Thomason, 2001: 60): factores lingüísticos y factores sociales.

Los tres factores lingüísticos básicos son la distancia tipológica entre la LF y la Lo, el grado en que se integran los rasgos o elementos en el sistema lingüístico, y, por último, la «marcación» (Universal Markedness) de los rasgos transferibles (los rasgos menos marcados tipológicamente o más congruentes suelen transferirse más fácilmente que los marcados; Thomason, 2001: 63).

Los dos factores o predictores sociales son más determinantes. La intensidad de contacto es un predictor que puede ser precisado por tres factores más específicos: la duración del contacto, el número de hablantes de la LF y de la LO, y la relación de dominio (socieconómico y político) entre los dos grupos. El otro factor o predictor social esencial es la actitud de los hablantes (Thomason, 
2001: 77-85), mucho más complicado de objetivar y el factor que produce resultados más difíciles de predecir, pero que es esencial, ya que la actitud, positiva o negativa, hacia un grupo influye en la actitud hacia su cultura, de la que forma parte la lengua; en la noción de actitud interactúan nociones como la identidad y la conciencia social y lingüística, el prestigio (abierto o encubierto), la motivación o la percepción de la distancia social entre los grupos.

1.3. Por último, en el CLIC se propone una escala predictiva de préstamos de cuatro grados de acuerdo con factores lingüísticos y esencialmente sociales (Thomason y Kaufman, 1988: 77-109; Thomason, 2001: 70-71). Los dos primeros grados de la escala, en los que, como trataré más adelante, podría inscribirse el contacto entre el árabe y el castellano medieval, son los siguientes:

1. Contacto casual (quienes toman los préstamos no necesitan tener competencia en la LF y/o hay pocos bilingües entre los hablantes de la LO). Se produce préstamo solo de vocabulario no básico, de palabras con significado léxico, generalmente sustantivos, pero también de algunos verbos, adjetivos y adverbios.

2. Contacto ligeramente más intenso (quienes toman los préstamos son bilingües con una razonable competencia en la LF, pero son una minoría entre los hablantes de la LO). Se produce préstamo de palabras con significado léxico, aunque también de palabras funcionales (conjunciones y adverbios), pero aún de vocabulario no básico. Aparece el préstamo estructural, pero solo de estructura «ligera», sin introducir rasgos o elementos que alteren las estructuras de la LO (nuevas funciones o restricciones funcionales en estructuras gramaticales ya existentes, o incremento del uso de un orden de las palabras anteriormente poco frecuente o raro). Aparece también el préstamo de rasgos fonológicos, como el de nuevos fonemas, pero solo incluidos en préstamos léxicos.

La escala se completa con otros grados de contacto:

3. Contacto más intenso (hay más bilingües y otros factores sociales favorecen el préstamo). Se produce préstamo de vocabulario no básico y también de básico, de clases cerradas, de más palabras funcionales y de morfemas. El préstamo gramatical es más intenso aunque moderado, sin llegar a producir cambios tipológicos importantes. La influencia en la pronunciación aumenta: se cambia la realización fonética de fonemas nativos, se pierden o añaden fonemas y se producen cambios en la colocación del acento o en la estructura silábica. 
4. Contacto intenso (bilingüismo muy extendido entre los hablantes de la LO y factores sociales que favorecen mucho los préstamos). El préstamo léxico es continuo e importante. Los préstamos gramaticales y fonológicos son abundantes y de todo tipo, llegando a préstamos estructurales que producen cambios tipológicos importantes, o a préstamos o pérdidas de categorías fonológicas y/o fonéticas completas.

Partiendo de este marco metodológico, a continuación pasaré a estudiar algunos aspectos de la influencia del árabe en el castellano de la alta Edad Media (711-1300). Me he centrado en esta etapa ya que, en mi opinión, es el período, más complejo en el largo contacto entre ambas lenguas, pues en él se desarrollan varios procesos de contacto y las posiciones (superordinada, subordinada) con respecto al otro grupo o lengua variaron a lo largo del tiempo. La situación, desde el punto de vista sociolingüístico, fue relativamente más estable en la Baja Edad Media, pues se mantuvo una posición social subordinada de los mudéjares y del árabe, que, a finales del período, se deterioró aún más, culminando con un proceso de «desarabización».

\section{LA INFLUENCIA DEL ÁRABE EN EL CASTELLANO DE LA ALTA EDAD MEDIA}

\subsection{Procesos de contacto}

El contacto entre el árabe y el castellano en la Alta Edad Media se produjo a través de varios procesos distintos: el contacto del árabe con las lenguas romances norteñas a través de los cristianos de al-Andalus, el contacto indirecto entre el castellano y el árabe antes de y durante la época de las Grandes Reconquistas, y, por último, el contacto directo del árabe y el castellano a través de los mudéjares. Este complejo haz de contactos tuvo como resultado una multiplicidad de vías de penetración de los arabismos en el castellano altomedieval. Describiré a continuación estos procesos teniendo en cuenta dos factores sociales: los grupos humanos que podrían haber actuado como punto de contacto entre ambas comunidades lingüísticas y culturales, y las actitudes frente al «otro».

2.1.1. Al abordar el primer proceso de contacto, encontramos que la situación sociolingüística de los cristianos andalusíes o mozárabes fue cambiante y compleja. El romandalusí ${ }^{2}$ fue una lengua en progresivo deslizamiento o desplazamiento hacia su desaparición desde sus comienzos. En una primera etapa (Corriente, 2004: 187), desde el siglo VIII hasta el siglo X, aunque se consolida,

2. Término más preciso propuesto por Corriente (2004: 186-187) frente al de mozárabe. 
por un lado, el haz dialectal romandalusí y en la sociedad andalusí surge el bilingüismo, por otro, se inicia un proceso lento pero progresivo de arabización, voluntario en gran medida, ya que los derechos de las minorías dimmíes (tributarios, «gentes del Libro» 0 «del Contrato») eran respetados y no existía presión para la aculturación (Glick, 1991: 222); la islamización, que llevaba aparejada generalmente la arabización lingüística y la aculturación, fue relativamente rápida (Benassar, 1989: 83-88), pues, partiendo de una situación muy minoritaria de los musulmanes hasta principios del siglo X, a comienzos del siglo XII el proceso de islamización se había completado por la conversión del $80 \%$ de la primitiva población indígena cristiana (Glick, 1991: 43-47). En una segunda etapa, que llegaría hasta los años finales del siglo XII o principios del siglo XIII, se produce una fractura social entre musulmanes y cristianos debido a las revueltas de finales del Califato, de la toma de Toledo (1085) por parte de los cristianos norteños y de las invasiones de almorávides (1086) y de almohades (1146) (Chejne, 1980: 55), lo que acelera el proceso de arabización y de desaparición del romandalusí. La arabización fue tan profunda que tras la conquista de Toledo la población mozárabe de Toledo estaba compuesta de hablantes de árabe monolingües (Glick, 1991: 233). Incluso en los siglos XIII y XIV las élites cultas cristianas de Toledo de origen mozárabe continuaban usando el árabe (Chejne, 1980: 345; Arié, 1993: 190).

Los cristianos andalusíes, desde el siglo IX hasta el siglo XIII, fueron los principales agentes comerciales de al-Andalus con Europa, Oriente y el norte peninsular (Glick, 1991: 157; Arié, 1993: 251). Esta será una de las más importantes vías de contacto con los romances norteños. La otra vía de contacto con estos romances serán las migraciones, pues desde el reinado de Alfonso III (866-910) existía un movimiento migratorio hacia el norte (Arié, 1993: 187), que aumentó con la caída del Califato y con las invasiones almorávides y almohades (siglos XI-XII). El flujo de emigrados y refugiados cristianos andalusíes se fue reduciendo conforme se producía el avance hacia el sur de los ejércitos cristianos durante las Grandes Reconquistas (finales del siglo XI-mediados del siglo XIII), pero aumentó el de aquellos que pasaban a depender de la nueva hegemonía cristiana.

Tanto los cristianos andalusíes que optaron o tuvieron oportunidad de emigrar hacia el norte, como los que pasaron a estar bajo dominio de los cristianos del norte se encontraron en una situación sociolinguiística compleja. En unos casos, eran cristianos ya hablantes monolingües de árabe, una contradicción para los esquemas de la época, pues, especialmente entre los cristianos norteños, los parámetros definitorios de grupo en la Edad Media peninsular eran, en primer lugar, la religión, pero también la lengua (Glick, 1991: 218-220); en otros casos conservaban, en mayor o menor grado, un romance (el romandalusí) que, aunque podría no plantear demasiados problemas para la intercomunicación o que, 
al menos, facilitaba un alto grado de intercomprensión, suponía una marcación social. Todo ello aceleró el proceso de desaparición del romandalusí, ya que el objetivo de este grupo social era la plena integración, por lo que no debió producirse «aprendizaje imperfecto». Los problemas de integración de estas nuevas minorías, especialmente de aquellos que habían permanecido en al-Andalus, fueron importantes: por un lado, debieron existir recelos y sospechas por parte sus correligionarios debido a su procedencia o al hecho de que habían preferido permanecer en una sociedad islámica, a lo que se unía el recuerdo de que, al menos en la época Omeya, habían mantenido un alto grado de fidelidad a los emires y califas, aportando, incluso, importantes contingentes de soldados o mercenarios a los ejércitos andalusíes; por otro lado, su mejor posición económica o sus habilidades (muchos integrantes de este grupo se habían especializado en la sociedad andalusí en la artesanía o el comercio), o su posesión de tierras cultivables, despertarían, también, la envidia y la codicia. Todo esto les llevó a sufrir empobrecimiento y segregación en las nuevas sociedades. ${ }^{3}$

2.1.2. El segundo proceso de contacto es el que se produce entre el árabe y el castellano medieval como lenguas fronterizas hasta el siglo XIII. Entre el árabe y el romance castellano no hubo contacto directo hasta fines del siglo XI, tras la caída del Califato y el comienzo de las Grandes Reconquistas. Aunque en la zona catalano-aragonesa el avance musulmán llegó hasta los Pirineos, los árabes no dominaron las zonas al norte del Sistema Central y gran parte de los contingentes bereberes asentados se retiraron a mediados del siglo VIII al sur del Sistema Central (Maíllo, 1994: 79-80; Maíllo, 2004: 30), por lo que se estableció la frontera en el centro y el oeste de la península mediante una línea imaginaria que partía de Medinaceli y continuaba casi en línea hasta llegar al Atlántico (Glick, 1991: 75-84). A esto hay que añadir que el concepto de frontera por parte de los árabes se basaba en el sistema de los $\underline{t} u g \bar{u} r$ («marcas»), grandes extensiones fronterizas indefinidas y flexibles (Manzano, 1991: 25-69). La Extremadura castellano-leonesa era, pues, una zona ni cristiana ni musulmana, independiente de los dos núcleos político-administrativos dominantes (Villar, 1986: 22), escenario de frecuentes correrías y enfrentamientos de los ejércitos musulmanes y cristianos (Maíllo, 1994: 84).

Frente a la tradicional idea de «desierto estratégico», un importante número de historiadores considera que esta zona no estuvo despoblada (Maíllo, 1994: 14; Pastor Díaz, 1996: 67-74). Terra depopulata significaría «sin señorío y no «sin población», por lo que repopulatio habría de entenderse, entonces, como «vuelta o integración en un señorío feudalización» (Glick, 1991: 113) o «formalización de una circunscripción administrativa» (Pastor Díaz,

3. Sobre la integración y actividades de los cristianos en la sociedad andalusí, véanse especialmente los trabajos de Chejne (1980), Glick (1991) y Arié (1993). 
1996: 132). Existen varios ejemplos de actividad en ciudades, monasterios y obispados antes de la repoblación oficial en estas zonas (Pastor Díaz, 1996: 124-136). Esta gran extensión de frontera al sur del Duero estuvo poblada entre los siglos VIII-XI por una gran diversidad de grupos humanos: restos de los bereberes que se habían establecido inicialmente la zona, huidos de las rebeliones andalusíes (muladíes, mozárabes y bereberes), desertores de ambos lados, campesinos que huían del dominio de los señores (Villar, 1986: 57-58; Glick, 1991: 114-115; Maíllo, 2004: 56-57); estos grupos se unieron a un substrato de población indígena tal vez en cierta medida arabizado ${ }^{4}$ (Villar, 1986: 50-51; Manzano, 1991: 172-173). A este complejo de grupos se fueron añadiendo los repobladores que, de forma espontánea u oficial, iban llegando a estas tierras (Villar, 1986: 62). Entre los siglos VIII y XI se desarrolla una expansión agraria en la zona por los pobladores ya establecidos, que se materializa en la creación de una malla de aldeas (Pastor Díaz, 1996: 62-66). Las crónicas musulmanas y cristianas de aquella época nos hablan de este complejo de grupos. Así, encontramos referencias a los ' $a^{\wedge}$ yam, grupo no árabe considerado por los cronistas árabes como distinto de los cristianos castellanos y leoneses (Villar, 1986: 23 y 68), o los «serranos» o «caballeros pardos», caballeros-villanos cristianos que vivían entre la margen izquierda del Duero y en el Sistema Central (Villar, 1986: 83; Maíllo, 1994: 44-46). El Fuero de Sepúlveda (1076) sería, más bien, un ejemplo de institucionalización de la vida de frontera, una legalización de una situación, más que un ordenamiento para atraer pobladores (Villar, 1986: 84-87). Pero, además, junto a estos grupos asentados existían otros que, aunque no establecidos en la zona, sí los encontramos en ella por diversas razones; entre ellos estarían los comerciantes y también los soldados de frontera, mercenarios, enaciados o espías fronterizos, adalides o guías, que tuvieron que actuar de intermediarios, estos últimos especialmente en el caso de los arabismos militares; finalmente, podría añadirse el grupo de los ganaderos trashumantes cristianos que atravesaban las fronteras hacia el sur en busca de pastos (Glick, 136-137).

Como vemos, encontramos entre los siglos VIII y XI la siguiente situación entre el Duero y el Sistema Central: una amplísima zona de frontera poblada por diversos grupos humanos y atravesada, como vía de paso, por ejércitos, ganaderos y mercaderes. Una situación social compleja y, también, lingüística, ya que debieron confluir hablantes de romance (en diferentes variedades), de árabe y de bereber. Esto puede llevar a plantear una cuestión en la que sería

4. Una posible prueba de una cierta arabización es la existencia de nombres arabizados de individuos no emigrados de al-Andalus, como el del conde cristiano de Gormaz, Abūl-Mundir a mediados del siglo x (Manzano, 1991: 161-163) o el de los embajadores del hijo del conde de Salamanca en la corte de al-Hakam II en el 971, Habì la Tawì la y Sa`āda (Maíllo, 1994: 34). 
necesario profundizar, pero que presento como una hipótesis sobre la que discutir: ¿esta compleja situación sociolingüística podría ser una de las causas, aunque no la única, de la frecuente aparición del artículo al- (y sus variantes asimiladas) en los arabismos de las lenguas romances del centro y occidente de la Península Ibérica?, y, aún más, ¿no sería posible plantear la existencia de un pidgin, una lengua de comunicación, en esta zona, y pensar que la aglutinación del artículo fuera una prueba de ello? Ejemplos de fenómenos parecidos pueden encontrarse en lenguas pidgin como el Chinook Jargon, de la costa noroeste de América, donde podemos encontrar la aglutinación del artículo francés: latab-p «mesa», lapipe «tabaco» (Holton, 1999; Thomason, 2001: 145). El paralelismo entre la conservación del artículo árabe y fenómenos parecidos en pidgins y criollos no es nueva, aunque se ha explicado este fenómeno como un resultado del bilingüismo árabe-romandalusí de los mozárabes (Noll, 1996).

Por último, para tener información sobre el importante factor social de la actitud, podemos acceder a lo que dicen o dejan traslucir las crónicas cristianas. En ellas se observa a lo largo de la Alta Edad Media una evolución (Barkai, 1991). ${ }^{5}$ Hasta la primera mitad del siglo XIII, muchas de las crónicas cristianas, pese a partir de una imagen negativa del «otro», presentan, en ocasiones, imágenes complejas, a veces incluso positivas; con excepción de algunas crónicas (como las de la época de Alfonso III o la Historia Silense) no hay, en general, una fuerte autoconciencia nacional; incluso después de la toma de Toledo (1085) las crónicas vacilan entre la «cruzada» o «guerra total» y la posibilidad aún de coexistencia entre musulmanes y cristianos en la Península Ibérica. Sin embargo, a partir de la victoria sobre los almohades de las Navas de Tolosa (1212), las crónicas presentan una mentalidad de «cruzada», de «guerra total», una fuerte autoconciencia nacional, y las imágenes de los musulmanes son generalmente muy negativas y cerradas, con generalizaciones estereotipadas. La mentalidad de «cruzada» o «guerra total» tardó más tiempo en desarrollarse en la Península Ibérica, en comparación con lo que sucedió en Europa, y cuando se formó, de todos modos, fue más moderada (Barkai, 1991: 292). En la crónicas del último cuarto del siglo XIII, tras finalizar la etapa de las Grandes Reconquistas (la época alfonsí), se encuentra una dualidad en la visión del «otro»: por un lado, la sociedad cristiana, puede acceder de manera directa al conocimiento de la lengua y de la cultura árabes, que poseen una fuerte atracción intelectual, pero, por otro, es una sociedad triunfante sobre el «otro», en la que domina el espíritu de «cruzada» y las imágenes y creencias negativas conformadas a lo largo de los siglos (García,

5. En este trabajo Barkai estudia también las crónicas musulmanas del período y realiza una interesante comparación entre las dos visiones del «otro». 
1993-1994). Finalmente, en este breve estudio de actitudes no hay que olvidar a los grupos fronterizos de lo que traté antes, pues en este caso nos encontramos con el hecho curioso de que en las crónicas musulmanas de los siglos XI y XII encontramos una cierta actitud de admiración hacia algunos de estos grupos, de los que se destaca el que sean valientes, emprendedores y sufridos (Maíllo, 1994: 45), pero en las crónicas cristianas son calificadas estas gentes fronterizas como «turba de réprobos, homicidas, maléficos, fornicarios, adúlteros, adivinos, odiosos ladrones, apóstatas execrados» (Villar, 1986: 78).

2.1.3. La última situación de contacto que trataré es la que se produjo en el caso de los mudéjares. Desde la toma de Toledo (1085) y Zaragoza (1118), la relación de dominio existente en la Península Ibérica se invirtió. Progresivamente, los reinos cristianos asumieron cada vez más importantes contingentes de población musulmana. Este grupo, políticamente derrotado, atravesó por variadas situaciones. Al principio, los cristianos del norte siguieron el ejemplo del trato que daban los musulmanes a sus minorías dimmíes, por lo que dieron cierta autonomía y mantuvieron cierto respeto por los nuevos súbditos (Chejne, 1980: 109). Sin embargo, frente a los musulmanes, que mantuvieron unas normas fijas de trato de las minorías, los cristianos mantuvieron modos y grados de tratamiento variables (Harvey, 1990: 55-67; Glick, 1991: 221-222). Varios factores influyeron en su situación: la presión internacional del espíritu de «cruzada» por parte del Papado y de Francia (Chejne, 1980: 113), las incursiones desde los restos de al-Andalus o el norte de África, y las sublevaciones de mudéjares en el siglo XIII. Esto ayudó a mantener la idea de amenaza y la visión del «otro» como enemigo. El acoso a la minoría mudéjar durante la Edad Media fue creciendo progresivamente, aunque en ocasiones, hubo cierta condescendencia con los mudéjares para retenerlos y evitar la pérdida demográfica y de mano de obra (Arié, 1993: 181-182). De todos modos, en el siglo XV los mudéjares pasaron a ser definitivamente una minoría separada, marcada y perseguida (Chejne, 1980: 109). Desde el comienzo de las Grandes Reconquistas las emigraciones y deportaciones hacia el sur, primero hacia alAndalus y luego hacia África, fueron constantes.

Aunque seguramente hubo resistencia a la aculturación, especialmente hasta el siglo XIII por la esperanza en un vuelco de la situación (Glick, 1991: 233), la pérdida del árabe entre los mudéjares fue progresiva. El árabe pasó a estar en una situación de deslizamiento o pérdida en favor de las lenguas romances. Sin embargo, no se produjo una influencia de su versión de la L2 (el castellano) en los hablantes nativos debido a factores sociales: su número (cada vez menor por las expulsiones y las emigraciones), su posición social subordinada y la actitud negativa de la mayoría romance y cristiana. Su influencia debe incluirse en el proceso general de préstamo del árabe en el castellano medieval, pese a ser un grupo subordinado. 


\subsection{Análisis de algunos datos}

De acuerdo con los datos, pueden establecerse dos etapas en la introducción de arabismos en el castellano altomedieval: ${ }^{6}$

1) En los arabismos de la primera etapa (siglos VIII-XI, antes de las Grandes Reconquistas) hay una importante cantidad de palabras accidentales y no integradas. De acuerdo con mis datos, de los 147 arabismos documentados por primera vez en esta etapa, al menos 48 (un $33,8 \%$ ) son dudosos. En otros casos, aunque el étimo árabe se encuentra identificado, son arabismos únicos, que solo aparecen una o dos veces y no continúan en el castellano (alchaz-alaz, habí, malfatana-mobatana, uma, almuctén, etc.). Junto a ellos, encontramos un conjunto de palabras con una característica común: su primera documentación, a veces única, aparece en esta época, y aunque algunas pueden aparecer esporádicamente, no vuelven a usarse de forma continuada hasta los siglos XIII o XIV; un caso prototípico de este tipo es atalaya, que aparece por primera vez en un documento mozárabe del siglo XI (Neuvonen, 1941: 68), posteriormente en un documento del año 1181 (CORDE), pero que a partir del siglo XIII tendrá un uso muy frecuente (265 apariciones, por ejemplo, en el CORDE, tanto en la forma atalaya como talaya) y una gran productividad (con derivados como atalayeros, atalear, atalayados), que demuestran su integración en el castellano. Un último grupo de arabismos no arraigados son arabismos desaparecidos, que se encuentran en los textos de forma más o menos continuada en esta época, pero dejan de usarse a lo largo de los siglos XII y XIII (adorra, tiraz, azeipha, melequi-meliki, alfetena, nubda-nubdua-annubta, etc.). Muchos de estos arabismos accidentales y dudosos se encuentran documentados en textos escritos por cristianos andalusíes emigrados, es decir, por hablantes de una lengua en abandono, el romandalusí. En definitiva, un número importante de arabismos de esta etapa pueden considerarse como préstamos espontáneos, casi de uso individual, no integrados. Esto se explicaría por un bajo grado de integración de los posibles grupos intermediarios y por la ausencia de un contacto directo.

Aunque el grupo más numeroso de arabismos de esta época son los referentes a vestidos y telas (44, un $29,9 \%$ del total), es el que tiene un porcenta-

6. Las fuentes usadas para este análisis han sido el estudio de Neuvonen (1941), el Léxico hispánico primitivo (siglos VII al XII) (Lapesa Melgar et al., 2003, Madrid, Fundación Ramón Menéndez Pidal-Real Academia Española), el Diccionario de arabismos y voces afines en Iberromance de Corriente (2003, $2^{\mathrm{a}}$ ed., Madrid, Gredos) y el Diccionario de la prosa castellana del Rey Alfonso X de Kasten y Nitti (2002, 3 vols., Nueva York, The Hispanic Seminary of Medieval Studies), así como el Corpus Diacrónico del Español de la RAE (CORDE), los fascículos publicados del Diccionario Histórico de la Real Academia Española y el Diccionario crítico etimológico castellano e hispánico de Corominas y Pascual (1980-1991, Madrid, Gredos). 
je más alto de casos dudosos (un 50\%). Por ello, puede afirmarse que el principal grupo en importancia es el de los arabismos pertenecientes a la administración, economía e instituciones sociales (40 casos, un 27,2\% del total), que tiene, además, un menor porcentaje de casos dudosos (20\%) y más ejemplos de arabismos integrados, como aldea, arrabal, barrio, alcalde, etc. La necesidad de este tipo de préstamos era grande por parte de los cristianos del norte y, también, de los pobladores de la Extremadura castellano-leonesa, ya que sus sociedades, menos estructuradas, necesitaban de modelos para su organización.

Los arabismos introducidos en esta época son sustantivos y algunos adjetivos (mezquino, azul). Un caso excepcional es el de la preposición hasta, ya que, pese a ser una palabra funcional, está documentada muy tempranamente (siglos X-XI) en multitud de variantes (adta, adte, asta, ata, hata) y tuvo un uso frecuentísimo desde sus comienzos, transformándose en el arabismo más usado en la Edad Media.

2) En la siguiente etapa (siglos XII-XIII, época de las Grandes Reconquistas), he encontrado 267 términos documentados por primera vez en esta etapa, casi el doble que los de la etapa anterior. Hay un importante número de arabismos pertenecientes a áreas temáticas muy concretas: la administración y economía (36), lo militar (32) y el campo y la agricultura (32), muchos de ellos integrados y considerados como propios; por ejemplo, un término tan cargado de connotaciones específicas como rebato (< ribát? «servicio militar prestado por los musulmanes acuartelados, en virtud de sus deberes religiosos, en rábida»), institución de ascetas guerreros introducida por los almorávides, penetra en el castellano y muy pronto crea derivados (arrebatamiento, arrebatar, (ar)rebatoso, rebatado, rebatosamient $(r) e$, (ar)rebatadamient $(r) e)$. Solo dos importantes grupos de arabismos no parecen integrados: los científicos (32 arabismos), por su carácter culto, y los referentes a lo árabe y musulmán, relativamente frecuentes (19 arabismos) dado el aumento de la población mudéjar, pero que no perdieron el rasgo más musulmán (por ejemplo, alfaquí). Hay que destacar la aparición de arabismos que se refieren a conceptos abstractos, cualidades o nociones (20 casos, como balde, tanda o fulano, etc.).

Las sociedades cristianas integraron en esta época aquellos préstamos que eran necesarios para continuar creando una organización social y económica, términos militares, por los continuos enfrentamientos, y los nombres de nuevos productos y técnicas, con los que entraron en contacto en sus avances hacia el sur y por los intercambios comerciales. Ciertos grupos pudieron actuar en este período como intermediarios entre ambas lenguas y culturas: por un lado, los soldados de frontera o los comerciantes en el caso de algunos términos, y, por otro, los fronterizos y los mudéjares, dos grupos que sufrían actitu- 
des negativas. En otros casos, sin embargo, los préstamos penetrarían a través de hablantes romances con un conocimiento superficial o una «familiaridad pasiva» del árabe. Es destacable el hecho de que encontramos en esta época cinco términos referentes a la «frontera» (alfaqueque, enaciado, exea, algarivo, truchimán), que solían tener connotaciones negativas, puesto que estos «mediadores» no eran admitidos en el esquema de una sociedad medieval en la que los grupos humanos debían ser claramente identificables (Glick 1991: 220).

\section{ALGUNAS CONCLUSIONES}

De acuerdo con la escala de préstamos del CLIC, el contacto del árabe con el castellano en la Alta Edad Media estaría situado en el punto 1 de la escala, en la fase de contacto casual, en la que los receptores de los préstamos no necesitan tener competencia en la LF y/o hay pocos bilingües entre los hablantes de la LO. Los préstamos se centraron casi exclusivamente en palabras con significado léxico pertenecientes al vocabulario no básico, pues no hay, por ejemplo, préstamos de partes del cuerpo, números, nociones temporales o espaciales, etc., y no hubo préstamo ni en la gramática ni en la pronunciación. El proceso podría, de todos modos, haber comenzado a llegar a los comienzos de la fase 2 (contacto ligeramente más intenso, préstamo de palabras funcionales y de estructura «ligera»), si tenemos en cuenta el préstamo de elementos como hasta. Evidentemente, la influencia en el léxico del árabe sobre el castellano medieval fue importante, pero el préstamo de vocabulario en la fase de contacto casual solo requiere una mínima presión cultural y social, puede producirse entre poblaciones separadas físicamente sin un bilingüismo extendido, también desde grupos subordinados a grupos superordinados (Thomason y Kaufman, 1988: 77), e incluso, sin una intermediación bilingüe, con tan solo una «familiaridad pasiva», una competencia parcial o un conocimiento superficial del árabe. De todos modos, dada la duración del contacto en este período de tiempo (siglos VIII-XIII, más de 500 años) debería haberse producido una mayor intensidad. Sin embargo, junto a factores estructurales como la distancia tipológica entre las dos lenguas, que puede alterar la escala de préstamos, influyeron en el proceso factores sociales como la ausencia de un fuerte bilingüismo y la existencia de actitudes negativas hacia el «otro» y hacia los posibles grupos intermediarios. 


\section{REFERENCIAS BIBLIOGRÁFICAS}

ARIÉ, R. (1993): España musulmana (siglos VIII-XV), Barcelona, Labor.

BARKAI, R. (1991): Cristianos y musulmanes en la España medieval (El enemigo en el espejo), $2^{\text {a }}$ ed., Madrid, Rialp.

Benassar, B. (1989): Historia de los españoles (siglos VI-XVII), vol. I, Barcelona, Crítica.

Chejne, A. G. (1980): Historia de España musulmana, $2^{\mathrm{a}}$ ed., Madrid, Cátedra.

CORRIENTE, F. (2004): «El elemento árabe en la historia lingüística peninsular», en CANO, R. (coord.) (2004): Historia de la lengua española, Barcelona, Ariel, 185-206.

GARCía GonZÁLEZ, J. (1993-1994): «El contacto de dos lenguas: los arabismos en el español medieval y en la obra alfonsí», Cahiers de Linguistique Hispanique Médievale, XVII-XIX: 335-365.

GLICK, TH. F. (1991): Cristianos y musulmanes en la España medieval (7111250), Madrid, Alianza.

Harvey, L. P. (1990): Islamic Spain, Chicago, The University of Chicago Press.

Holton, J. (1999): Chinook Jargon, San Leandro (California, EuA), Wawa Press.

Maíllo Salgado, F. (1994): Salamanca y los salmantinos en las Fuentes árabes, Salamanca, Centro de Estudios Salmantinos.

- (2004): De la desaparición de al-Andalus, Madrid, Abada.

Manzano Moreno, E. (1991): La frontera de al-Andalus en época de los Omeyas, Madrid, CSIC.

Neuvonen, E. K. (1941): Los arabismos en el siglo XIII, Helsinki, Imprenta de la Sociedad de Literatura Finesa.

Noll, V. (1996): «Der arabische Artikel al und das Iberoromanische», Romania arabica: 299-313.

PAstor, E. (1996): Castilla en el tránsito de la Antigüedad al feudalismo, Valladolid, Junta de Castilla y León.

Thomason, S. (2001): Language Contact. An Introduction, Edimburgo, Edinburgh University Press.

Thomason, S. y T. Kaufman (1988): Language Contact, Creolization and Genetic Linguistics, Berkeley-Los Ángeles-Oxford, University California Press.

Villar GarCía, L. M. (1986): La Extremadura castellano-leonesa, Valladolid, Junta de Castilla y León. 


\title{
UNA NUEVA APROXIMACIÓN AL CONCEPTO DE ORIENTACIÓN EN EL ÁMBITO DE APRENDIZAJE Y ENSEÑANZA DE SEGUNDAS LENGUAS Y SU APLICACIÓN EN EL MARCO UNIVERSITARIO ESPAÑOL
}

\author{
Susana Gómez MarTínez \\ Universidad de Valladolid
}

\section{INTRODUCCIÓN}

$\mathbf{M}$ IENTRAS que la adquisición de una primera lengua (L1) se produce de forma natural y tiene lugar para llevar a cabo una necesidad humana básica de comunicación, el aprendizaje de segundas lenguas (L2) constituye una ardua tarea que requiere mucho esfuerzo, especialmente en los contextos formales de aprendizaje. ${ }^{1}$

A pesar de que se ha destacado la aptitud hacia el aprendizaje de lenguas por ser uno de los factores individuales que tradicionalmente se han barajado como determinantes en el aprendizaje de una L2, las variables afectivas, tales como la actitud, las orientaciones, la ansiedad y la motivación, han demostrado ser al menos tan importantes como la aptitud lingüística en predecir el logro/éxito en una L2 (Gardner, 1985; Lasagabaster, 2003) o incluso más relevantes ( $c f$. Sasaki,1993). ${ }^{2}$

Teniendo en cuenta estos datos, la disposición afectiva del alumno va a servir como movilizador de los mecanismos cognitivos que garantizan la adquisi-

1. Krashen y Terrell (1983) realizan la distinción entre los términos «acquisition» y «learning» para diferenciar el proceso natural, sin esfuerzo e inconsciente de «adquirir» la lengua, frente al proceso artificial y consciente de «aprenderla» o estudiarla. Los estudiantes y usuarios de segundas lenguas «aprenden» $\mathrm{y}$ «adquieren» la L2 de una forma compleja en la que resulta imposible delimitar cuáles de sus conocimientos han sido adquiridos o aprendidos. De esta forma, seguiremos la idea propuesta por Ellis (1994) de utilizar los dos términos indistintamente y escribirlos con comillas cuando queramos utilizarlos con alguno de los sentidos anteriormente mencionados.

2. En su estudio, Sasaki (1993) observa cómo el impacto que tienen los factores individuales de naturaleza cognitiva resultan ser un $42 \%$ de la varianza en el nivel de competencia de los alumnos. El resto del diferencial se justifica por medio de elementos de carácter afectivo, principalmente relacionados con la motivación. 
ción de una L2 (Purcell y Suter, 1980; Sasaki, 1993; Moyer, 1999; Spolsky, 2000; Lorenzo, 2001). Este aspecto ya fue apuntado por Krashen en su hipótesis del filtro afectivo: «Those with attitudes more conducive to second language acquisition will not only seek and obtain more input, they will also have a lower or weaker filter. They will be more open to the input, and it will strike "deeper"» (Krashen, 1987: 31)

Teniendo en cuenta la indisociable relación entre motivación y aprendizaje y la gran repercusión que a su vez tienen sobre el nivel de éxito o fracaso obtenido en el aprendizaje de una L2, la motivación ha resultado ser una de las áreas del ámbito de enseñanza/aprendizaje de segundas lenguas que más interés ha despertado y que más profundamente se ha examinado, siendo varios los libros y cientos los artículos y capítulos de libros escritos durante las cuatro últimas décadas.

La motivación suele definirse como el mecanismo interno que mueve a las personas a conseguir algún objetivo y, en el caso del aprendizaje de segundas lenguas, la motivación tiene como objetivo o bien el dominio de una lengua o bien el manejo de la misma en un nivel inferior (McDonough, 1998: 219-220).

Aunque existe una asociación entre la idea de motivación y disfrute o placer en el aprendizaje de lenguas, los científicos behavioristas establecen una clara distinción dentro de la motivación entre el fin, objetivo o intención para el aprendizaje y el esfuerzo, trabajo y persistencia en la lucha para conseguir este fin. Dunkel (1948), por ejemplo, defiende que esta dicotomía es muy útil y directamente aplicable en el caso del aprendizaje de segundas lenguas, puesto que tanto los objetivos como el esfuerzo empleado en conseguir un determinado objetivo afectará al nivel de éxito o logro final.

Siguiendo esta línea, Gardner (1985) define el concepto «Motivation»a partir de la distinción entre «Orientation» $\mathrm{y}$ «Motivational Intensity»: «a combination of effort plus desire to achieve the goal of learning the language» (Gardner, 1985:10). De esta forma, la «orientación» corresponde a las razones por las que se estudia una L2 y la «Motivational Intensity» al esfuerzo y trabajo empleado en el proceso de aprendizaje. ${ }^{3}$

\section{ORIENTACIÓN INSTRUMENTAL VERSUS INTEGRADORA}

Varias han sido las propuestas apuntadas para definir el fin $\mathrm{u}$ orientaciones en el aprendizaje de segundas lenguas. Sin embargo, la distinción entre orien-

3. Varios estudios demuestran que es precisamente este último elemento de la motivación el que determina en gran medida la clave del éxito en el aprendizaje de segundas lenguas ( $c f$. GómezMartínez, 2000, 2001 y 2005; Fuertes-Olivera y Gómez-Martínez, 2004 y 2005). 
tación integradora e instrumental ha sido la más aceptada y la que más atención empírica ha recibido. ${ }^{4}$

Gardner define la «Orientación Integradora» como «those classes of reasons that suggest that the individual is learning a second language in order to learn about, interact with, or become closer to the second language community» (Gardner, 1985: 54). Los usuarios ${ }^{5}$ que presentan este tipo de orientación son personas con una predisposición afectiva e interpersonal positiva hacia el grupo de la lengua meta y hacia su cultura y formas de vida, con un deseo de interactuar y de familiarizarse o incluso de entrar a formar parte de ella: «a sincere and personal interest in the people and culture represented by the other language group» (Lambert, 1974: 98). Así pues, Dörnyei destaca como aspecto fundamental de la orientación integradora un «sort of a psychological and emotional identification» (Dörnyei, 2003: 5).

Esta postura contrasta con un fin más práctico que persigue la orientación instrumental: «the practical value and advantages of learning a new language» (Lambert, 1974: 98). Una recompensa material, cultural y/o personal con un objetivo más concreto y sobre todo utilitario: estudiar una L2 como requisito para entrar en la universidad, para solicitar un trabajo, para conseguir un buen puesto en el mundo laboral, para ascender en el mismo, para poder leer cualquier material en la lengua extranjera para poder viajar o sencillamente para conseguir un nivel social más elevado.

\subsection{Evaluación de la orientación integradora}

Basándose en la idea de que la identificación y el afecto positivo hacia los padres son importantes para la adquisición de una primera lengua (Mowrer, 1950), Gardner y Lambert (1972) defienden la orientación integradora como factor determinante de éxito en el aprendizaje de segundas lenguas (cf. «Sociolinguistic Model», Gardner, 1985).

The words, sounds, grammatical principles and the like that the language teacher tries to present are more than aspects of some linguistic code; they are integral parts of another culture. As a result, students' attitudes toward the

4. La motivación en el aprendizaje de segundas lenguas, definida como una «inherently complex enterprise» (Dörnyei, 2003: 2) está caracterizado por una variedad de aproximaciones teóricas al tema (véanse para una revisión Clément y Gardner, 2001; Dörnyei, $2001 a, 2001 b, 2003$; MacIntyre, 2002 ) que, lejos de sustituir a la propuesta de los científicos canadienses, sirven para complementarla (Oxford, 1996).

5. El término "usuario" está utilizado como término neutro para definir tanto al grupo que «usa» $\mathrm{y}$ «adquiere» una L2 en un contexto natural, como para aquellos que «usan», «adquieren» y/o «aprenden» una L2 en un contexto formal. 
specific language group are bound to influence how successful they will be in incorporating aspects of that language (Gardner, 1985: 6).

Gardner y Lambert (1972) basan su hipótesis de investigación en la idea de que aquellos estudiantes que presentan una orientación integradora, consiguen una competencia en la lengua mejor que aquellos cuya orientación es instrumental. Así pues, afirman que, «striving for a comfortable place in two cultures seems to be the best motivational basis for becoming bilingual» (Gardner y Lambert, 1972: 130). ${ }^{6}$

Entre los estudios empíricos más representativos que defienden la supremacía de la orientación integradora en el aprendizaje de segundas lenguas, destacamos los siguientes: Taylor et al. (1977); Clément, Smythe y Gardner (1978); Schumann (1978 y 1986); Desrochers y Gardner (1981); Gardner y Smythe, (1981); Gliksman, Gardner y Smythe (1982); Giles y Burne (1982); Strong (1984); Gardner, Lalonde y Moorcroft (1985); Lalonde y Gardner (1985); Ramage (1990); Gardner y Lysynchuk (1990); Crookes y Schmidt (1991); Gardner y MacIntyre, (1991); Tremblay, Goldberg y Gardner (1995); Gardner, Tramblay y Masgoret (1997); Gardner y Tremblay (1998). Muchos de estos estudios coinciden en que este tipo de orientación tiene éxito a largo plazo en el proceso de adquisición/aprendizaje de segundas lenguas y que además es la mejor forma para conseguir un dominio de los diferentes registros y la pronunciación como la de un hablante nativo: «integrative motivation typically underlies successful acquisition of a wide range of registers and a nativelike pronunciation» ( $c f$. Finegan, 1999: 568).

Sin embargo, frente a esta abrumadora cantidad de estudios que presentan la supremacía de la orientación integradora sobre la instrumental, existen otros estudios en los que la orientación integradora está negativamente correlacionada con los niveles de proficiencia en la lengua, tal y como demuestra Lukmani (1972), Oller, Hudson y Liu (1977), Chihara y Oller (1978).

El caso más extremo en relación a este aspecto lo presentan Oller, Baca y Vigil (1977) en un estudio sociolingüístico sobre la actitud que un grupo de mujeres inmigrantes de clase baja en California tenía hacia la cultura meta y su repercusión en el aprendizaje de la lengua. Los resultados demuestran que aquellas que evaluaron a los americanos de forma positiva, lograban un éxito menor que aquellas que los evaluaron de forma negativa. Esta idea les llevó a sugerir que algunos aprendices podían estar motivados por un deseo de mani-

6. Esta hipótesis se confirmaría en todos los estudios presentados en aquella época, con la excepción de los referidos al estudio llevado a cabo en Filipinas, donde la orientación instrumental estaba positivamente correlacionada con la competencia en inglés como segunda lengua (cf. Gardner y Lambert, 1972). 
pular a los hablantes de la lengua meta, lo que denominaron «Machiavellian Motivation» y que Oller y Perkins (1978) definen como una forma de control y triunfo sobre una comunidad que desprecian.

Sin embargo, tal y como sugiere Chambers (1999), extender estas conclusiones obtenidas en el contexto canadiense o en contextos semejantes donde el contacto con la otra lengua resulta inevitable (cf. Arratibel et al. 1998 y 2001; Arratibel, 1999) ${ }^{7}$ al resto de contextos es muy cuestionable pues, en el caso de los estudiantes de nuestra muestra o los cantoneses del estudio de Green (1999), su interacción con hablantes de la lengua meta o su contacto con la cultura es muy limitada y en ocasiones nula. Estamos pues no solo ante circunstancias muy diferentes, sino también ante naturalezas distintas, tal y como discutiremos más adelante.

\subsection{Evaluación de la orientación instrumental}

En menor cantidad, aunque no por ello menos importante, varios estudios demuestran la supremacía de la orientación instrumental sobre la integradora (cf. Lukmani, 1972; Burstal et al. 1974; Pierson y Fu, 1982; Kachru, 1986; Dörnyei, 1990; Gómez-Martínez, 2000, 2001, 2005; Lasagabaster, 2003, Fuertes-Olivera y Gómez-Martínez, 2004, 2005). ${ }^{8}$

Dörnyei, gran defensor de la orientación instrumental, basa su hipótesis en la naturaleza del estudiante de segundas lenguas en el contexto formal de aprendizaje en el aula de lenguas extranjeras. De esta forma, defiende que la motivación para aprender una lengua es muy diferente para los que «aprenden» y/o «adquieren» una «segunda» lengua que para aquellos que «aprenden» $\mathrm{y} / \mathrm{o}$ «adquieren» una lengua «extranjera», debido a las diferentes aproximaciones que se dan en las dos situaciones: mientras que el «aprendizaje» y/o «adquisición» de una «segunda» lengua implica el privilegio de un acceso directo a la lengua y cultura meta, el «aprendizaje» y/o «adquisición» de una lengua «extranjera» tiene lugar en un ambiente artificial donde el contacto con la lengua y cultura meta es muy limitado y en ocasiones inexistente. ${ }^{9}$ De esta forma,

7. Estudios realizados en la comunidad autónoma vasca que defienden que la orientación integradora es la que fomenta el uso del euskera y que además es la que ayuda al sujeto a interiorizar la lengua (Lasagabaster, 2003).

8. Hemos de tener en cuenta al comparar el número de estudios un hecho importante que destaca Dörnyei (2003) y es la situación única que define la situación en Canadá, donde coexisten la comunidad francófona y anglófona, es decir, dos de las lenguas más importantes del mundo, y el apoyo, promoción y esponsorización de la investigación en esta área.

9. El término "segunda lengua", "lengua segunda" o "L2" es el término neutro utilizado para definir tanto la lengua "segunda" (que se aprende y/o adquiere en contextos naturales) como la "extranjera" (que tiene lugar en contextos de aprendizaje formales). En este caso los términos están entrecomillados para destacar esta diferenciación. 
Dörnyei defiende que las razones instrumentales contribuyen de una forma más significativa a la motivación de los estudiantes de lenguas extranjeras, puesto que son más reales, están más a su alcance, son más cercanas a la situación que están viviendo y por consiguiente tienen mayor sentido para ellos ( $c f$. Dörnyei, 1990)..$^{10}$

En esta misma línea situamos algunas de nuestras contribuciones llevadas a cabo en el contexto universitario español. En ellas señalamos que la orientación instrumental es prácticamente la única que puede explicar en parte el éxito o fracaso de la mayoría de estudiantes que asisten a las clases de inglés instrumental en la universidad española ( $c f$. Gómez-Martínez, 2000, 2001, 2005; Fuertes-Olivera y Gómez-Martínez, 2004 y 2005). Los resultados obtenidos señalan que los estudiantes con una orientación instrumental demuestran índices más elevados de «Motivational Intensity», es decir, sus niveles de esfuerzo, trabajo y dedicación al estudio de la lengua meta son mayores: el grupo instrumental asiste más a clase, realiza su tarea con mayor asiduidad y lee más ( $c f$. Fuertes-Olivera y Gómez Martínez, 2004: 201). Teniendo en cuenta las circunstancias bajo las cuales tiene lugar el aprendizaje de segundas lenguas, esta preferencia por lo instrumental también puede ser debido a que la verdadera idea de «integración» en la cultura meta está lejos del alcance de la mayoría de nuestros estudiantes y algo que, salvo un número reducido que irá al extranjero como estudiantes Erasmus, está muy lejano o se podría considerar pero a largo plazo ( $c f$. Fuertes-Olivera y Gómez-Martínez, 2005).

A pesar de que este tipo de orientación parece encajar mucho mejor en el contexto que nos rodea, uno de los aspectos negativos que se ha observado es que este tipo de orientación no se mantiene en el tiempo y parece tener un efecto más a corto plazo.

Incluso el propio Gardner pone de manifiesto, en un estudio posterior con MacIntyre (1991), que los estudiantes con una motivación instrumental también logran su éxito en el aprendizaje de segundas lenguas; sin embargo, añade que, una vez desaparece el premio o el incentivo, los estudiantes no siguen intentándolo, mientras que aquellos con una orientación integradora mantendrán su interés más a largo plazo (Gardner y MacIntyre, 1991). La orientación instrumental pues parece «insufficient to account for the persistence needed in the laborious and time-consuming task of developing real competence in a new language» (Gardner y Lambert, 1972: 12).

Esta situación está muy bien ejemplificada por Lasagabaster en el contexto de la Comunidad Autónoma Vasca donde una persona que desee aprender euskera con fines meramente instrumentales (para lograr un empleo o mejorar su situación económica o laboral), pueda perder ese estímulo inicial una vez

10. Si bien defiende la supremacía de la orientación instrumental, también destaca que la orientación de tipo integrador puede ser necesaria para niveles más avanzados. 
logrado su objetivo. De esta forma, ilustra como personas que por ejemplo estudien euskera para conseguir un puesto en la administración pública (donde se precisa un perfil lingüístico determinado), terminen utilizando la lengua minoritaria muy esporádicamente o incluso puedan llegar a mostrarse reacios a usarla una vez logrado su objetivo laboral (Lasagabaster, 2003: 89).

\section{DELIMITACIÓN, COMBINACIÓN, DINAMISMO Y VARIEDAD DEL TIPO DE ORIENTACIONES}

La categorización entre las dos variedades de orientación se ha convertido en una regla lingüística (Green, 1999); sin embargo, varios son los estudios que discrepan ante esta distinción tan restrictiva ( $c f$. Gardner, 1985 y Au, 1988 para una revisión de los mismos) y ofrecen otra serie de perspectivas que complementan de forma muy positiva a la dicotomía anterior.

En primer lugar, tal y como apunta Lasagabaster (2003) la división entre los dos tipos de orientaciones no es siempre tan sencilla. Así, aprender una lengua para viajar al extranjero puede tener un fin integrador o instrumental: viajar para conocer otra cultura o viajar para conseguir méritos para tu trabajo y así conseguir una promoción, para extender un mercado floreciente, etc.

En segundo lugar, estas dos orientaciones no se oponen o representan alternativas necesariamente, sino que pueden darse en una misma persona ( $c f$. Burstall, 1975; Porter-Ladousse, 1981; Muchnick y Wolfe, 1982; Green, 1993; Brown, 2000; Lasagabaster, 2003). Un ejemplo claro sería el de aquella persona que quiere aprender euskera para poder integrarse en ciertas actividades culturales, al tiempo que es consciente de que dicha integración le puede favorecer personalmente y ayudarle a ascender en la escala social y a promocionar en su puesto de trabajo (Lasagabaster, 2003: 88-89).

Por otro lado, Dörnyei (2003: 18) defiende que la mayoría de las controversias e inconsistencias en los estudios realizados sobre la orientación se deben a que se ha estudiado de forma transversal y no se ha tenido en cuenta que las actitudes instrumentales e integradoras, aunque más o menos estables, tiene sus «ups and downs», se desarrollan y cambian a lo largo de los años. Así pues, al igual que Green, 1999, Dörnyei (2003) defiende que la orientación es dinámica, atraviesa diversas etapas de evolución y presenta un estado de continuo flujo y cambio que evoluciona con la madurez, experiencia y visión del mundo del estudiante de segundas lenguas.

Por último, además del clásico paradigma relativo a la orientación integradora vs instrumental, Crookes y Schmidt (1991) sugieren que se amplíe el abanico de los tipos de orientaciones para una descripción más detallada de los diferentes comportamientos que se observan durante el aprendizaje de una L2 
dependiendo del contexto donde se desarrolle. Del mismo modo, esta opinión también es compartida por Arratibel, quien, tras analizar a un grupo de adultos que aprendían euskera, observa que las diferentes orientaciones y su papel varían de un contexto a otro según las características de la muestra examinada, ya que las muestras con características especiales pueden también tener orientaciones especiales ( $c f$. Arratibel, 1999; Arratibel et al. 1998, 2001). ${ }^{11}$

\section{METODOLOGÍA Y RESULTADOS}

Los datos que vamos a analizar forman parte de los resultados obtenidos en un estudio más amplio realizado en la EUE de Estudios Empresariales de la Universidad de Valladolid durante el curso académico 2002-2003. La población sujeta a estudio la componen 352 estudiantes, muestra representativa de todos los alumnos matriculados en dicho centro y curso académico. Este grupo lo componen un $13,35 \%$ que estudiaba alguna de las dos modalidades de inglés empresarial impartidas en el centro (Inglés Empresarial I e Inglés Empresarial II) y un $86,65 \%$ que no estudiaba inglés (grupo +Ing y grupo -Ing respectivamente). ${ }^{12}$

El método de recogida de la información fue a través de un cuestionario de diseño propio en el que se midieron 88 variables que representaban, entre otras, las opiniones de los alumnos hacia el aprendizaje y uso del inglés como lengua extranjera. Los datos obtenidos se analizaron posteriormente con el programa SPSS.

Uno de los apartados fundamentales de este macroestudio era el análisis del tipo de orientación que caracterizaba a la muestra (vars. 59-69), para lo cual utilizamos una serie de afirmaciones que respondían a la pregunta «Estudio/estudiaría inglés para...» y que los alumnos baremarían del 1 al 5 siguiendo la escala de Likert. Dichas afirmaciones (ver tablas 1 y 2) representaban las variables que correspondían a los dos tipos de orientaciones clásica (instrumental e integradora) y fueron diseñadas de forma tal que midieran su intensidad pero que no se excluyeran entre sí.

Los resultados obtenidos nos ayudan, por un lado a confirmar estudios similares anteriores realizados en un mismo contexto (Gómez-Martínez, 2000

11. Los resultados de su estudio muestran cinco orientaciones motivacionales diferenciadas: la instrumental y la integrativa (las dos más parecidas a las mencionadas en la literatura) y la mixta, la de beneficio personal y la de transmisión, tres variedades que califica como originales de la población estudiada pues concuerdan con la realidad sociolingüística del contexto vasco (Arratibel et al. 1998: 158).

12. Algunos de los estudiantes pertenecientes a este último grupo estudiaban inglés fuera del centro, pero el porcentaje era muy bajo: tan solo un 3,3\% y un 2,6\% asistían a clases particulares y cursos multimedia respectivamente. 
y 2001; Fuertes-Olivera y Gómez-Martínez, 2004 y 2005) y, por otro, a ilustrar los puntos señalados en el apartado anterior de forma que podamos entender mejor el contexto que rodea a nuestra muestra.

Por un lado, tal y como vemos en las tablas 1 y 2 , ambos grupos (+Ing y -Ing) presentan una clara tendencia hacia un tipo de orientación instrumental más que integradora: los valores están en un $75 \%$ de los casos por encima de la media incluso en el caso del grupo -Ing, y es la variable que consideramos más instrumental («estudio/estudiaría inglés para mi futuro profesional», var. 60) la que consigue unos datos casi perfectos (Media 4,484,45; Mediana 5-5, Moda 5-5, Desviación típica 0,72-0,62 del grupo +Ing y -Ing respectivamente).${ }^{13}$ Estos resultados nos ayudan a confirmar estudios anteriores que defienden que las razones instrumentales son más significativas para este tipo de alumnado y están más a su alcance en un contexto de aprendizaje formal.

TABLA 1. Valores medios de la Orientación Instrumental

\begin{tabular}{|l|l|l|l|l|}
\hline \multicolumn{2}{|l|}{ VARIABLES INSTRUMENTALES } & \multicolumn{3}{l|}{ Valores de la media } \\
\hline $\mathrm{N}^{\circ}$ & Variable de análisis & +ING & -ING & +/- ING \\
\hline & Estudio/estudiaría inglés para... & & & \\
\hline 59 & Conseguir créditos para la carrera & $\mathbf{3 , 6 2}$ & 2,89 & $\mathbf{2 , 9 9}$ \\
\hline 60 & Mi futuro profesional & $\mathbf{4 , 5 5}$ & $\mathbf{4 , 4 8}$ & $\mathbf{4 , 4 9}$ \\
\hline 61 & $\begin{array}{l}\text { Entender Internet, revistas o cualquier texto } \\
\text { escrito en inglés }\end{array}$ & $\mathbf{3 , 9 6}$ & $\mathbf{3 , 6 7}$ & $\mathbf{3 , 7 1}$ \\
\hline 62 & Para viajar al extranjero & $\mathbf{4 , 1 7}$ & $\mathbf{4 , 1 1}$ & $\mathbf{4 , 1 2}$ \\
\hline 63 & Entender las canciones & $\mathbf{3 , 1 5}$ & 2,9 & 2,93 \\
\hline 64 & Ver las películas en versión original & $\mathbf{3 , 3 4}$ & 2,63 & 2,73 \\
\hline & Media tOTAL & $\mathbf{3 , 8 0}$ & $\mathbf{3 , 4 5}$ & $\mathbf{3 , 5 0}$ \\
\hline
\end{tabular}

TABLA 2. Valores medios de la Orientación Integradora

\begin{tabular}{|l|l|l|l|l|}
\hline \multicolumn{2}{|l|}{ VARIABLES INTEGRADORAS } & \multicolumn{3}{l|}{ Valores de la media } \\
\hline $\mathrm{N}^{\circ}$ & Variable de análisis & +ING & -ING & + +- ING \\
\hline & Estudiolestudiaría inglés para ... & & & \\
\hline 65 & $\begin{array}{l}\text { Vivir una temporada prolongada en un país } \\
\text { de habla inglesa }\end{array}$ & $\mathbf{3 , 6 4}$ & $\mathbf{3 , 3 7}$ & $\mathbf{3 , 4}$ \\
\hline
\end{tabular}




\begin{tabular}{|l|l|l|l|l|}
\hline \multicolumn{2}{|l|}{ VARIABLES INTEGRADORAS } & \multicolumn{3}{l|}{ Valores de la media } \\
\hline $\mathrm{N}^{\mathrm{N}}$ & Variable de análisis & $+\mathrm{ING}$ & -ING & +/- ING \\
\hline 66 & $\begin{array}{l}\text { Estudio/estudiaría inglés para ... } \\
\text { extranjero temporada prolongada en un país }\end{array}$ & $\mathbf{3 , 4 5}$ & $\mathbf{3 , 2 7}$ & $\mathbf{3 , 2 9}$ \\
\hline 67 & $\begin{array}{l}\text { Entender mejor las costumbres y estilos de } \\
\text { vida de países de habla inglesa }\end{array}$ & 2,89 & 2,79 & 2,81 \\
\hline 68 & $\begin{array}{l}\text { Tomar parte en actividades propias de los } \\
\text { países de habla inglesa }\end{array}$ & 2,72 & 2,5 & 2,53 \\
\hline 69 & $\begin{array}{l}\text { Integrarme y formar parte de la cultura } \\
\text { inglesa }\end{array}$ & 2,4 & 2,07 & 2,11 \\
\hline & MEDIA TOTAL & $\mathbf{3 , 0 2}$ & 2,80 & 2,88 \\
\hline
\end{tabular}

Por otro lado, en el análisis de correlación llevado a cabo con otra serie de variables sometidas a estudio, obtenemos datos altamente significativos entre la variable «meses de estancia en el extranjero» (var. 7) y dos variables integradoras («estudio/estudiaría inglés para tomar parte en actividades propias de los países de habla inglesa» -var. 69- y «estudio/estudiaría inglés para integrarme y formar parte de la cultura inglesa»-var. 70) con un índice de $r=0,66$ y de $r=0,71$ respectivamente en el grupo +Ing.

Estos resultados nos ayudan a confirmar los estudios mencionados anteriormente que defendían la importancia del contexto, circunstancias y posibilidades que tienen los usuarios de segundas lenguas a la hora de elegir su tipo de orientación.

En cuanto a la delimitación del tipo de orientación, las variables sometidas a análisis están divididas en lo que considero instrumental e integrador, coincidiendo con Lasagabaster en su afirmación de que algunas variables son difíciles de determinar, como es el caso de la variable 44 «viajar al extranjero» que podría considerarse indistintamente integradora o instrumental, dependiendo del objetivo que tenga en mente el viajante.

En lo que se refiere a la combinación de tipos de orientaciones, observamos cómo lógicamente las variables de cada tipo presentan entre sí valores de correlación altamente significativos (por encima de $r=0,5$ ). Así pues, la variable integradora «estudio/estudiaría inglés para vivir una temporada prolongada en un país de habla inglesa» (var. 65) presenta índices de correlación de $r=0,86$, $r=0,53, r=0,6, r=0,5$ con sus semejantes «estudio/estudiaría inglés para vivir una temporada en un país extranjero» (var. 66 ), «para entender mejor las costumbres y estilos de vida de países de habla inglesa (var. 67), «para tomar parte 
en actividades propias de los países de habla inglesa» (var. 68) y «para integrarme y formar parte de la cultura inglesa» (var. 69) respectivamente. ${ }^{14}$

Sin embargo, nuestros resultados apoyan la idea de que los dos tipos de orientaciones no son excluyentes sino complementarias y se pueden dar en una misma persona, tal y como ilustra el alto grado de correlación entre dos orientaciones que tradicionalmente se consideraban opuestas. De este modo, la variable claramente instrumental «estudio/estudiaría inglés para mi futuro profesional» (var. 60) presenta un índice de correlación de $r=0,52$ con la variable integradora «estudio/estudiaría inglés para vivir una temporada prolongada en un país extranjero» (var. 66).

Puesto que el estudio realizado no es longitudinal, no podemos ofrecer datos que apoyen la idea del dinamismo en la motivación, pero sí que conseguimos, en línea con los resultados de Arratibel, un abanico de tipo de orientaciones que duplican la dicotomía clásica que observábamos en estudios anteriores y que nos ayudan no solo a definir el contexto determinado de la población sujeta a estudio, sino también a poder encajar ciertas variables que eran complicadas de delimitar en la dicotomía clásica.

Para llegar a estos resultados, hemos realizado un análisis factorial de las variables sometidas a estudio.

Partimos de que el modelo que resulta del análisis de los datos, no es solo significativo en su conjunto $(\mathrm{Sig}=, 000)^{15}$, sino que a su vez el porcentaje que se explica en cada una de las variables es muy alto (por encima de 0,50 en todos los casos) ${ }^{16}$ y el porcentaje total explicado con estos cuatro modelos alcanza el $68,7 \%$ de la varianza total, es decir, alcanzamos a saber en un $68,7 \%$ por qué estudian o estudiarían la L2; los motivos que justifican el otro $31,3 \%$ restante lo desconocemos.

La matriz de componentes que observamos en la tabla 3, presenta los cuatro modelos que definen los perfiles de nuestros estudiantes.

\section{TABLA 3. Análisis factorial de la Orientación +/-Ing. Matriz de componentes rotados}

\begin{tabular}{|c|l|c|c|c|c|}
\hline \multirow{2}{*}{$\mathrm{N}^{\circ}$} & \multirow{2}{*}{ VARIABLE } & \multicolumn{4}{|l|}{ COMPONENTE } \\
\cline { 3 - 6 } & & 1 & 2 & 3 & 4 \\
\hline 59 & Para conseguir créditos para la carrera &, 035 &,- 077 &, 030 &, 897 \\
\hline 60 & Para mi futuro profesional &,- 071 &, 356 &, 334 &, 553 \\
\hline
\end{tabular}

14. Para una información detallada de todos los datos, $c f$. Gómez Martínez, 2005.

15. Los resultados del modelo son significativos en cuanto que la significación de la prueba de esfericidad de Bartlett es menor que 0,05 y es por lo tanto significativa.

16. Ver Gómez-Martínez (2005) para una información más detallada. 


\begin{tabular}{|l|l|c|c|c|c|}
\hline \multirow{2}{*}{$\mathrm{N}^{\circ}$} & \multirow{2}{*}{ VARIABLE } & \multicolumn{4}{l|}{ COMPONENTE } \\
\cline { 3 - 6 } 61 & 1 & 2 & 3 & 4 \\
\hline 62 & $\begin{array}{l}\text { Para entender Internet, revistas o cualquier } \\
\text { texto escrito en inglés }\end{array}$ &,- 083 &, 073 &, 804 &, 019 \\
\hline 63 & Para viajar al extranjero &, 047 &, 458 &, 574 &, 008 \\
\hline 64 & Para entender las canciones &, 255 &, 007 &, 751 &, 151 \\
\hline 65 & $\begin{array}{l}\text { Para vivir una temporada en un país de habla } \\
\text { inglesa }\end{array}$ &, 328 &, 080 &, 619 &, 113 \\
\hline 66 & Para vivir una temporada en un país extranjero &, 279 &, 889 &, 070 &, 043 \\
\hline 67 & $\begin{array}{l}\text { Para entender mejor las costumbres y estilos de } \\
\text { vida de países de habla inglesa }\end{array}$ &, 740 &, 287 &, 161 &,- 210 \\
\hline 68 & $\begin{array}{l}\text { Para tomar parte en actividades propias de los } \\
\text { países de habla inglesa }\end{array}$ &, 830 &, 296 &, 086 &, 042 \\
\hline 69 & $\begin{array}{l}\text { Para integrarme y formar parte de la cultura } \\
\text { inglesa }\end{array}$ &, 853 &, 095 &, 074 &, 106 \\
\hline
\end{tabular}

En esta tabla podemos observar cuatro perfiles que se pueden entender en un continuo imaginario y que va de los dos clásicos -perfil $\mathrm{n}^{\circ} 1$ claramente integrador y perfil $\mathrm{n}^{\circ} 4$ claramente instrumental- a dos perfiles adicionales, el perfil $n^{\circ} 2$ que define a un estudiante con una cierta influencia integradora, interesado en viajar, en conocer y un perfil $\mathrm{n}^{\circ} 3$ que define a un estudiante más orientado hacia el extremo instrumental. Este último grupo representa a un estudiante práctico y conocedor para quien el conocimiento de una nueva lengua supone una importante fuente de conocimiento y de puertas que se le pueden abrir en la vida. Es precisamente este último perfil el que consigue las cifras más representativas y el que, a mi forma de ver, mejor define a un estudiante universitario español que está lejos de entender la idea de integración, tiene un contacto muy reducido con la lengua y cultura meta, su futuro profesional está lejos en el tiempo, y sin embargo, busca un objetivo más real, más efectivo y más acorde con sus circunstancias y sus necesidades actuales.

\section{CONCLUSIONES}

Los resultados de este estudio nos ayudan a entender la evolución del concepto orientación desde la distinción clásica entre los dos únicos tipos -instru- 
mental e integradora- que resulta estática y restrictiva, hacia una perspectiva dinámica, más real, amplia y variada que responde con una mayor exhaustividad a la diversidad de contextos y circunstancias que rodean al uso de una L2 y a su proceso de aprendizaje y enseñanza.

La supremacía de la orientación integradora queda en tela de juicio en un mundo en el que el inglés es considerada la lengua internacional por excelencia y en el que sus usuarios tienen unas necesidades más prácticas que varían según sus circunstancias y el contexto en el que lo utilicen, aspectos que a su vez van a ayudar a definir el objetivo que persigue el usuario de una L2.

Estamos pues ante variedades de orientaciones que definen variedades de contextos. De este modo, es necesario valorar la orientación como una de las múltiples variables de un complejo modelo de factores individuales y circunstanciales que interactúan de una forma compleja y misteriosa en la adquisición $\mathrm{y}$ aprendizaje de segundas lenguas.

Sin embargo, y a pesar de que los datos que hemos analizado en este estudio corresponden a una situación particular, respetando la idiosincrasia propia de cada individuo, los resultados obtenidos no solo nos ofrecen una panorámica que se puede hacer extensible a muchos casos semejantes en la universidad española, sino, aún más importante, nos sirve a los docentes para poder entender mejor qué buscan y qué esperan nuestros alumnos de la clase, diseñar un currículo conforme a los datos obtenidos y poder dar respuesta a algunas de las muchas incógnitas que se nos presentan en el aula de lengua extranjera.

\section{REFERENCIAS BIBLIOGRÁFICAS}

Arratibel, N. (1999): Helduen euskalduntzean eragiten duten prozesu psikosozialak: motibazioaren errola, Tesis Doctoral, Universidad del País Vasco. ArRatiBel, N., M. L. LuQue y M. J. AzURMENDI (1998): «Aprendizaje y uso del euskera como lengua segunda -L2-: algunos aspectos psicosociolingüísticos», Revista de Psicología Social, (13) 2: 149-158.

Arratibel, N., M. J. Azurmendi e I. García (2001): Menpeko hizkuntzaren bizikemena, Bilbao, Udako Euskal Unibertsitatea.

Au, S. Y. (1988): «A Critical Appraisal of Gardner's Social Psychological Theory of Second Language Learning», Language Learning, 38: 75-100.

Brown, H. D. (2000): Principles of Language Learning and Teaching, Englewood Cliffs NJ, Prentice-Hall.

Burstall, C. (1975): «Factors Affecting Foreign Language Learning: A Consideration of Some Recent Findings», Language Teaching and Linguisitics, 8 (3): 25-39.

- et al. (1974): Primary French in the Balance, Windsor, NEFER. 
Chambers, G. N. (1999): Motivating Language Learners, Clevedon, Multilingual Matters.

Chimara, I. y J. W. Oller (1978): «Attitudes and Attained Proficiency in EFL: A Sociolinguistic Study of Adult Japanese Speakers», Language Learning, 28: 55-68.

Clément, R.; R. C. GARDNER (2001): «Second Language Mastery», en Robinson, W. P. y H. GiLEs (eds.) (2001): The New Handbook of Language and Social Psychology, Chichester, Inglaterra, Wiley \& Sons, 489-504.

Clément, R., P. C. Smythe y R. C. Gardner (1978): «Persistence in Second Language Study: Motivational Considerations», Canadian Modern Language Review, 34: 688-694.

Crookes, G. y R. W. Schmidt (1991): «Motivation: Reopening the Research Agenda», Language Learning, 41: 469-512.

Desrochers, A. y R. C. GARDNER (1981): Second Language Acquisition: An Investigation of a Bicultural Excursion Experience, Quebec, International Centre for Research on Bilingualism.

DöRNYEI, Z. (1990): «Conceptualising Motivation in Foreign Language Learning», Language Learning, 40: 45-78.

- (2001 a): Teaching and Researching Motivation, Harlow, Inglaterra, Longman.

- (2001 b): «New Themes and Approaches in L2 Motivation Research», Annual Review of Applied Linguistics, 21: 43-59.

- (ed.) (2003): Attitudes, Orientations, and Motivations in Language Learning: Advances Theory, Research, and Applications, Ann Arbor, Blackwell.

DunKel, H. (1948): Second Language Learning, Ginn, Boston.

Ellis, R. (1994): The Study of Second Language Acquisition, Oxford University Press.

Finegan, E. (1999): Language: Its Structure and Use, Harcourt Brace.

Fuertes-Olivera, P. A. y S. GÓMEZ-MARTínez (2004): «Empirical Assessment of Some Learning Factors Affecting Spanish Students of Business English», English for Specific Purposes, 23: 163-180.

- (2005): «The Acquisition of English as a Second Language: the Importance of Motivational Intensity» en GARRIDO, F. y J. Comesaña (eds.) (2005): Estudios de Filología Inglesa en honor de Antonio Garnica, Universidad de Sevilla, Secretariado de Publicaciones, 195-208.

GARDNER, R. (1985): Social Psychology and Second Language Learning: The Role of Attitude and Motivation, Londres, Edward Arnold.

Gardner, R. C., R. N. Lalonde y R. MoorCroft (1985): «The Role of Attitudes and Motivation in Second Language Learning: Correlational and Experimental Considerations», Language Learning, 35: 207-227. 
GArdner R. C. y W. E. LAmbert (1972): Attitudes and Motivation in Second Language Learning, Rowley, MA: Newbury.

GARDNER, R. C. y L. M. LYSYnChuK (1990): «The Role of Aptitude, Attitudes, Motivation and Language Use on Second Language Acquisition and Retention», Canadian Journal of Behavioural Science, 22: 254-270.

GARDNER, R. C. y P. D. MacIntyre (1991): «An Instrumental Motivation in Language Study: Who Says it isn't Effective?», Studies in Second Language Acquisition, n. ${ }^{\circ}$ 13: 266-272.

Gardner R. C. y P. C. Smythe (1981): «On the Development of the Attitude/Motivation Test Battery», Canadian Modern Language Review, 37: $510-525$.

Gardner, R. C. y P. F. TREMBlay (1998): «Specificity of Affective Variables and the Trait/State Conceptualization of Motivation in Second Language Acquisition», en Agnihotri, R., A. Khanna e I. Sachdev (eds.) (1998): Social Psychological Perspectives on Second Language Learning, Nueva Delhi, India, Sage.

Gardner, R. C., P. F. Tremblay y A. M. Masgoret (1997): «Towards a Full Model of Second language learning: an empirical investigation», Modern Language Journal, 81: 344-362.

GiLES, H. y J. BuRNE (1982): «An Intergroup Approach to Second Language Acquisition», Journal of Multicultural and Multilingual Development, 3: 17-40.

Gliksman, L., R. C. Gardner y P. C. Smythe (1982): «The Role of the Integrative Motive on Students' Participation in the French Classroom», Canadian Modern Language Review, 38: 625-647.

Gómez-Martínez, S. (2000): To What Extent are Orientation, Individual Effort, Instruction, Thinking in L1 and Grammar Translation Positive or Negative Factors in the Acquisition of English by Spanish Learners? A Study Based on a Sample of University Students in Spain. Proyecto de Investigación realizado en la Universidad de Essex, Reino Unido.

- (2001): External and Internal Factors Affecting Acquisition of English as a Second Language. A Research Study Based on a Sample of Spanish Students of English at the University of Valladolid. Proyecto de Investigación de Doctorado, Departamento de Lengua y Literatura Inglesa y Alemana, Universidad de Valladolid.

- (2005): La Teoría de la Multicompetencia y su aplicación en el marco universitario español: propuesta, diseño y estudio de un modelo de análisis aplicado a los estudiantes de Empresariales, Biblioteca Virtual Miguel de Cervantes. IsBN: 0-493-53941-7.

GreEN, C. F. (1993): «Learner Drives in Second Language Acquisition», International English Teaching Forum, 31 (1): 2-5. 
- (1999): «Categorising Motivational Drives in Second Language Acquisition», Language, Culture and Curriculum, vol. 12, no. 3: 265-279. Kachru, B. B. (1986): The Alchemy of English. The Spread, Functions and Models of Non-Native Englishes, Oxford, Pergamon Press Ltd.

Krashen, S. (1987): Principles and Practice in Second Language Acquisition, Prentice Hall International.

Krashen, S. y T. D. Terrell (1983): The Natural Approach, Pergamon.

LALONDE, R. N. y R. C. GARDNER (1985): «On the Predictive Validity of the Attitude/Motivation Test Battery», Journal of Multilingual and Multicultural Development, 6: 403-412.

LAMBERT, W. (1974): «Culture and language as factors in learning and educations», en ABoud, F. y R. D. MeADE (eds.) (1974): Cultural factors in learning and Education, Bellingham, Westerb Wasgubgtib State College, 91-122.

Lasagabaster, D. (2003): Trilingüismo en la enseñanza, Actitudes hacia la lengua minoritaria, la mayoritaria y la extranjera, Milenio.

Lorenzo, F. J. (2001): «Déficit de aprendizaje y déficit motivacional: investigando la hipótesis resultativa en el aula de idiomas», Cultura y Educación, 13 (2): 179-194.

LukMani, Y. (1972): «Motivation to Learn and Language Proficiency», Language Learning, 22: 261-73.

MacIntrre, P. D. (2002): «Motivation, anxiety and emotion in second language acquisition», en RoBINSON, P. (ed.) (2002): Individual differences in second language acquisition, Ámsterdam, Benjamins, 45-68.

McDonough, S. (1998): «Student Autonomy», en Johnson, K. y H. Johnson (eds.) (1998): Encyclopaedic Dictionary of Applied Linguistics, Londres, Blackwell, 306-308.

Mowrer, O. H. (1950): Learning theory and Personality Dynamics, Nueva York, Ronald Press.

Moyer, A. (1999): «Ultimate attainment in L2 Phonology. The Critical Factors of Age, Motivation, and Instruction», Studies in Second Language Acquisition, 21: 81-107.

Muchnick, A. y D. Wolfe (1982): «Attitudes and Motivations of American Students of Spanish». Canadian Modern Language Review, 38: 262-81.

Oller, J.W., L. BaCA y F. VigIL (1977): «Attitudes and Attained Proficiency in ESL: a Sociolinguistic Study of Mexican-Americans in the Southwest», Tesol Quarterly, 11: 173-183.

Oller, J. W., A. J. Hudson y P. F. Liu (1977): «Attitudes and Attained Proficiency in ESL: A Sociolinguistic study of Native Speakers of Chinese in the United States», Language Learning, 77: 1-27. 
Oller, J. y K. Perkins (1978): «Intelligence and Language Proficiency as Sources of Variance in Self-reported Affective Variables», Language Learning 28: 85-97.

Oxford, R. (1996): Language Learning: Pathways to the New Century, Honolulu, University of Hawai Press.

PIERSON, H. y G. S. Fu (1982): «Report on the Linguistic Attitudes Project in Hong Kong and its Relevance for Second Language Instruction», Language Learning and Communication, 1 (2): 121-232.

Porter-Ladousse, G. (1981): «From Needs to Wants: Motivation and the Language Learner», System, 10 (1): 29-37.

Purcell E. y R. Suter (1980): «Predictors of Pronunciation Accuracy: A Reexamination», Language Learning, 30: 271-287.

Ramage, K. (1990): «Motivational Factors and Persistence in Foreign Language Study», Language Learning, 40: 189-219.

SASAKI, M. (1993): «Relationships Among Second Language Proficiency, Foreign Language, Aptitude and Intelligence: A Structural Equation Modelling Approach», Language Learning, 43 (3): 313-344.

SchumanN, J. (1978): «The Acculturation Model for Second Language Acquisition», en GINGAS, R. (ed.) (1978): Second Language Acquisition and Foreign Language Teaching, Arlington, va, 27-50.

- (1986): «Research on the Acculturation Model for Second Language Acquisition», Journal of Multilingual and Multicultural Development, 7: 379-92.

SPOLSKY, B. (2000): «Language Motivation Revisited», Applied Linguistics, 21(2): 193-207.

Strong, M. (1984): «Integrative Motivation: Cause or Result of Successful SLA», Language Learning, 34: 1-14.

TAYlor, D. M., R. Meynard y E. Rheault (1977): «Threat to Ethnic Identity and Second Language Learning», en GILES, H. (1977): Language, ethnicity and intergroup relations, Academic Press, 99-118.

Tremblay, P. F., M. P. Goldberg y R. C. Gardner (1995): «Trait and State Motivation and the Acquisition of Hebrew Vocabulary», Canadian Journal of Behavioural Science, 27: 356-370. 


\title{
LA EXPRESIÓN DE FUTURO EN EL ESPAÑOL DE CATALUÑA. UN POSIBLE CASO DE CONFLUENCIA LINGÜÍSTICA
}

\author{
Cristina Illamola \\ Universitat de Barcelona
}

$\mathbf{L}$ A aplicación de nuevas disciplinas en el ámbito de la lingüística, tales como la sociología, el cognitivismo o la antropología, ha permitido profundizar en el estudio de fenómenos que hasta el momento solo habían sido explicados parcialmente. Concretamente, ello resulta de gran interés para los estudios de variación y contacto de lenguas en los que, aparte de los factores lingüísticos tradicionales, intervienen significativamente otros de índole cognitiva, sociocultural y pragmático-discursiva. Dado que los estudios de variación son resultado de esa concurrencia de disciplinas, en el presente trabajo se analiza la expresión de la futuridad en el español de Cataluña desde esa perspectiva, con el objetivo de validar la hipótesis de la confluencia de factores internos y externos en la expresión formal del futuro. Dicho en otras palabras, es necesario considerar, por un lado, la evolución cíclica de la forma sintética y las diferencias diatópicas y diafásicas entre la forma sintética y la analítica del futuro en español, y, por otro, la influencia del catalán sobre el español. ${ }^{1}$

En las zonas catalanohablantes la frecuencia de uso del futuro sintético (FS) y del futuro analítico (FA) para hablar de eventos venideros en español es opuesta al empleo que de estas mismas formas suele hacerse en el resto de zonas hispanohablantes. La idea parte del supuesto de que, pese a que en catalán también alternan dos estructuras -el FS y la perífrasis prospectiva «ANAR A + infinitivo»-, el menor rendimiento de la perífrasis en catalán y, por tanto, su menor grado de gramaticalización, parece incidir en la frecuencia de uso de la perífrasis «IR A + infinitivo» en el español hablado en Cataluña.

1. Dada la bidireccionalidad de esta cuestión, en este trabajo nos centraremos en la influencia que ejerce el catalán sobre el español hablado en Cataluña, aunque no se despreciará ninguna observación referente a la influencia del español sobre el catalán que ayude a esclarecer la hipótesis planteada. 


\section{INTRODUCCIÓN}

En español coexisten el futuro morfológico (No se lo diré, no te preocupes) y la perífrasis «IR A + infinitivo» (No se lo voy a decir, no te preocupes) ${ }^{2}$ como construcciones para expresar la futuridad, dado que, en determinados contextos, el verbo «IR» de la forma perifrástica ha perdido la noción etimológica de movimiento y ha adquirido nuevos matices de intencionalidad, de predicción, de certeza y de prospección (Melis, 2006). Diversos estudios confirman incluso la preferencia del FA en contextos prospectivos, tanto en zonas peninsulares como en zonas americanas, aunque más pronunciadamente en las últimas. ${ }^{3}$

En catalán, en cambio, en esos mismos contextos se emplea generalmente el futuro morfológico (No li diré res, no pateixis) y es esta la forma recomendada por la norma. De este modo, la perífrasis «ANAR A + infinitivo» aparece únicamente en enunciados con valor adlativo (Vaig a fer-li el sopar, perquè ha de marxar) y en los restantes usos, como por ejemplo en contextos prospectivos, el empleo del FA se considera antinormativo. ${ }^{4}$

En las siguientes páginas se intentará comprobar si el hecho de que en catalán se conserve el sentido etimológico de movimiento (Radatz, 2003: 63) y que, por tanto, no se hayan desarrollado los mismos valores de intencionalidad, certeza, predicción o deducción que en español ${ }^{5}$ influye en la expresión de la futuridad en el español hablado en Cataluña.

De todos modos, si bien la situación sociolingüística de Cataluña es idónea para hallar una justificación al uso particular de los futuros que en estas páginas se estudia, no pueden obviarse los recursos internos y la evolución histórica de cada lengua y considerar esa preferencia por los futuros morfológi$\cos$ en detrimento de la forma perifrástica únicamente consecuencia del contacto entre el español y el catalán. No puede ignorarse tampoco la posibilidad de que nos hallemos ante un momento de cambio en la distribución de las formas gramaticales que expresan tiempo de futuro en español, no tanto por influencia de otro sistema lingüístico, como por la propia evolución interna del español.

2. El empleo del presente de indicativo o del condicional con valores prospectivos no se ha considerado en este trabajo, pese a que son formas que, tanto en español como en catalán, coexisten con el futuro al describir eventos prospectivos.

3. Varias de estas investigaciones (Almeida y Díaz 1998; Matte Bon, 2006; Sedano, 2006; Company, 2006: §10) ponen de relieve las diferencias diafásicas entre FA y FS, considerando el FS más propio de contextos formales y el FA para los informales.

4. Pese a que todavía son pocos los estudios que contrastan FS y FA desde una perspectiva de contacto de lenguas, en las distintas zonas peninsulares, cabe destacar el trabajo de Ramírez-Parra y Blas Arroyo (citado en Blas Arroyo, 2005 y Radatz, 2003).

5. No nos detenemos en la comparación de valores entre español y catalán. Véanse Bosque y Demonte (1999), Solá et al., (2002) y Radatz (2003). 
En apoyo de la hipótesis de la interferencia del sistema verbal del catalán sobre el español, deben contrastarse las formas y valores perifrásticos de la construcción «IR A + infinitivo» en ambas lenguas. Sirva de ejemplo el siguiente cuadro comparativo:

FIGURA 1

\begin{tabular}{|l|c|c|}
\hline \multicolumn{1}{|c|}{ Valor de la perífrasis } & $\begin{array}{c}\text { Español } \\
\text { «IR A + INF» }\end{array}$ & $\begin{array}{c}\text { Catalán } \\
\text { «ANAR A + INF» }\end{array}$ \\
\hline (a) Movimiento: & Voy a comprar & Vaig a comprar \\
$\begin{array}{c}\text { (b) Intencionalidad plan- } \\
\text { ificación: }\end{array}$ & $\begin{array}{c}\text { El lunes voy a ir a ver } \\
\text { a mis padres }\end{array}$ & $\begin{array}{c}\text { El dilluns aniré a veure els } \\
\text { meus pares }\end{array}$ \\
(c) Futuro inmediato: & Te vas a caer \\
(d) Certeza: & Voy a aprobar
\end{tabular}

Para obtener una completa explicación del particular empleo de las formas verbales de futuro en el español hablado en esta zona bilingüe, se expone, en primer lugar, una descripción de la metodología empleada para la recopilación de los datos, y, en segundo lugar, se presentan los resultados obtenidos sobre los usos de las formas de futuro, contrastando los tres grupos lingüísticos que se pueden establecer dentro de la comunidad de habla catalana -bilingües, catalanohablantes y castellanohablantes.

Al final del trabajo se presentan unas conclusiones acerca de la validez de la hipótesis presentada a lo largo de estas páginas sobre la existencia de un mayor uso de las formas sintéticas del futuro en español debido a la convivencia de esta lengua con el catalán y de si, además del contacto lingüístico, confluyen otros factores, que constituyen causas internas del sistema.

\section{METODOLOGÍA}

El cuerpo de este estudio se basa en el análisis de los datos obtenidos después de la realización de una encuesta lingüística planteada para dar respuesta a las siguientes preguntas:

a) ¿en qué contextos pueden presentarse usos diferentes de las formas prospectivas entre el español peninsular y el español hablado en Cataluña? 
b) ¿existe una relación directa entre la adscripción lingüística del informante y la elección de FS o FA en los contextos mencionados?

c) ¿contribuyen los datos estadísticos a esclarecer si estamos ante un caso de confluencia lingüística?

Para ello, se ha diseñado una encuesta estructurada en dos bloques: uno más breve, que proporciona datos sociolingüísticos relativos al informante, es decir, la ficha sociolingüística; y otro que engloba los datos lingüísticos propiamente dichos, esto es, la encuesta lingüística.

Antes de completar la encuesta lingüística, el encuestado debe proporcionar datos personales e información relativa a variables sociolingüísticas tales como la edad, el sexo, la profesión, la lengua familiar, los hábitos de lectura, la lengua de escolarización, etc. Gracias a ello fue posible obtener la adscripción lingüística de los informantes, punto de partida de la clasificación de los resultados. ${ }^{7}$ De este modo, los 51 informantes que realizaron las encuestas se dividieron en dos grandes grupos: aquellos individuos que habitualmente residen fuera de las zonas catalanohablantes y cuyo contacto con el catalán, por tanto, es prácticamente inexistente (14); y aquellos pertenecientes a la comunidad de habla catalana (37). Este segundo conjunto de informantes se segmenta, a su vez, en tres subconjuntos, de ahí que el número de individuos sea mayor: los hablantes bilingües, con un total de 11 informantes; los catalanohablantes, con 14, y los castellanohablantes, con $12 .{ }^{8}$

En la segunda parte de la encuesta se incluye el cuestionario lingüístico propiamente dicho, que a su vez se divide en dos apartados bien diferenciados, puesto que el tipo de respuesta que se obtiene es distinta en cada uno de ellos: el primero consta de breves fragmentos incompletos que el informante debe completar eligiendo una respuesta entre múltiples opciones; el segundo, en cambio, contiene fragmentos extraídos de conversaciones orales y telefónicas reales, ${ }^{9}$ de narraciones y de textos periodísticos en los que el informante debe

6. Entendemos por «fenómeno de confluencia» la concurrencia de una interferencia a partir de una lengua dada y una determinada estrategia (Payrató, 1985: 29).

7. Concretamente, fueron las preguntas «¿Cuál considera que es su lengua habitual?»y «¿En qué lengua se siente más cómodo?» las que permitieron identificar a qué grupo lingüístico se adscribe cada informante, así como su identidad lingüística. En el caso de haber dos respuestas distintas, se tomó como referencia la lengua familiar.

8. Con esta clasificación hay que entender que si un individuo de la comunidad bilingüe ha sido clasificado como catalanohablante o castellanohablante no significa que no hable español o catalán, respectivamente, sino que ha sido el propio informante el que se ha adscrito como perteneciente a ese grupo.

9. Los fragmentos de conversaciones reales se han extraído del Corpus del español conversacional de Barcelona y su área metropolitana del grupo GRIESBA (Vila, 2001). 
rellenar los espacios en blanco escribiendo la forma verbal que crea más conveniente de un verbo que se proporciona entre paréntesis. ${ }^{10}$

\section{INTERPRETACIÓN DE LOS DATOS}

Visto el mecanismo de las encuestas, se presentan los resultados del análisis de los datos obtenidos a través de los cuestionarios. Teniendo en cuenta el objetivo de este estudio, los resultados que se examinan bajo este apéndice reflejan únicamente los datos relativos al FS y al FA, dejando de lado otras formas verbales que puedan haber ocurrido en las respuestas.

El análisis estadístico se ha centrado en la comparación de los distintos matices semánticos que adquiere la perífrasis «IR A + infinitivo» en los diferentes contextos. Concretamente, los gráficos y tablas que aparecen a continuación muestran los valores relativos y absolutos de los distintos contextos ordenados del siguiente modo: en primer lugar, se constata el valor intencional; a continuación, se inserta el valor de futuro inmediato; y, finalmente, se muestran los datos relativos al futuro con matices de certeza.

\subsection{Valor intencional del futuro}

Bajo este apéndice se analiza el total de FS y FA que se han producido en las preguntas de la encuesta cuyo valor básico era el de intencionalidad. Sirva de ejemplo de este valor el siguiente enunciado:

(1) Se acerca Semana Santa y todo el mundo quiere saber qué vas a hacer durante las vacaciones. ${ }^{11}$

La suma de todos los datos se ha llevado a cabo manteniendo la distinción intergrupal para poder extraer una comparación de los usos de las formas prospectivas en cada uno de los grupos lingüísticos de esta región bilingüe (véanse figuras 2 y 3 ).

10. Con el primer tipo de preguntas, se pretendía que el informante, a partir de un contexto seguido de 2, 3 o más respuestas, señalase los enunciados que él probablemente produciría en una situación similar. El segundo, por el contrario, permite más variedad en las respuestas. Téngase en cuenta, además, que una de las desventajas que supone este tipo de ejercicios es que el contexto no siempre resulta del todo esclarecedor y, en consecuencia, el informante puede hacer inferencias imposibles de predecir en la elaboración de las preguntas. También parece ser un obstáculo el proporcionar demasiadas opciones como respuesta para un mismo contexto, ya que se ha podido comprobar que, por un lado, el informante se confunde y concluye eligiendo la opción más diferente a todas o la que se sitúa en último lugar y, por otro, la encuesta deviene demasiado extensa.

11. Los ejemplos provienen de la encuesta que se diseñó para llevar a cabo este estudio. 
FIGURA 2. Valor intencional

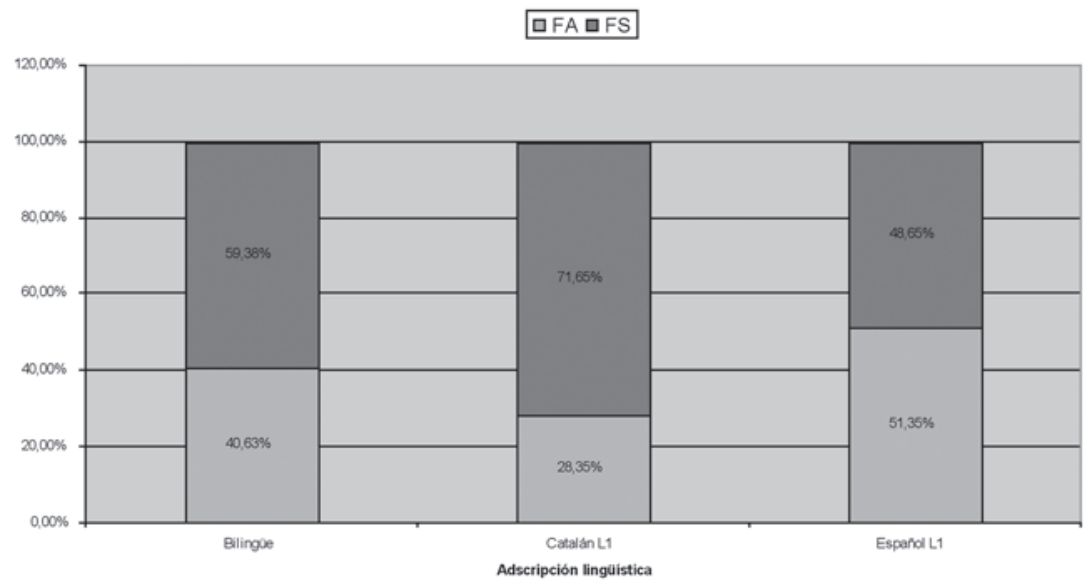

FIGURA 3. Valor intencional

\begin{tabular}{|l|c|c|c|c|c|c|}
\hline & $\begin{array}{c}\text { Futuro } \\
\text { analítico }\end{array}$ & $\begin{array}{c}\text { Cifras } \\
\text { absolutas }\end{array}$ & $\begin{array}{c}\text { Futuro } \\
\text { sintético }\end{array}$ & $\begin{array}{c}\text { Cifras } \\
\text { absolutas }\end{array}$ & $\begin{array}{c}\text { Total } \\
\text { general }\end{array}$ & $\begin{array}{c}\text { Total } \\
\text { absoluto }\end{array}$ \\
\hline Bilingüe & $40,63 \%$ & 39 & $59,38 \%$ & 57 & $100,00 \%$ & 96 \\
Catalán L1 & $28,35 \%$ & 36 & $71,65 \%$ & 91 & $100,00 \%$ & 127 \\
Español L1 & $51,65 \%$ & 57 & $48,65 \%$ & 54 & $100,00 \%$ & 111 \\
\hline $\begin{array}{l}\text { Total } \\
\text { general }\end{array}$ & $39,52 \%$ & 132 & $60,48 \%$ & 202 & $100,00 \%$ & 334 \\
\hline
\end{tabular}

Los datos muestran una gradación en la preferencia de uso según cada grupo lingüístico; esto es: si se toma como punto de referencia la frecuencia de aparición del Fs frente a la del FA, los catalanohablantes se sitúan en primer lugar con más del $70 \%$ de ocurrencias de FS en contextos intencionales, seguidos de los bilingües $(59,38 \%)$ y los castellanohablantes $(48,65 \%)$. Estos porcentajes ponen de manifiesto la elevada frecuencia de empleo del Fs por parte de los dos grupos lingüísticos cuya relación con el catalán parece mucho más estrecha que en los informantes castellanohablantes.

\subsection{Valor de futuro inmediato}

En cuanto a los usos de FS y FA con valor de inmediatez, los datos reflejan de nuevo la distinción intergrupal entre bilingües, informantes con el catalán como lengua propia y los que se adscriben como castellanohablantes. Igual 
que el apartado anterior, se incluye un enunciado de la encuesta a modo de ejemplo:

(2) Una madre advierte a su hijo: «bájate de ahí que te vas a caer».

\section{FIGURA 4. Valor de futuro inmediato}

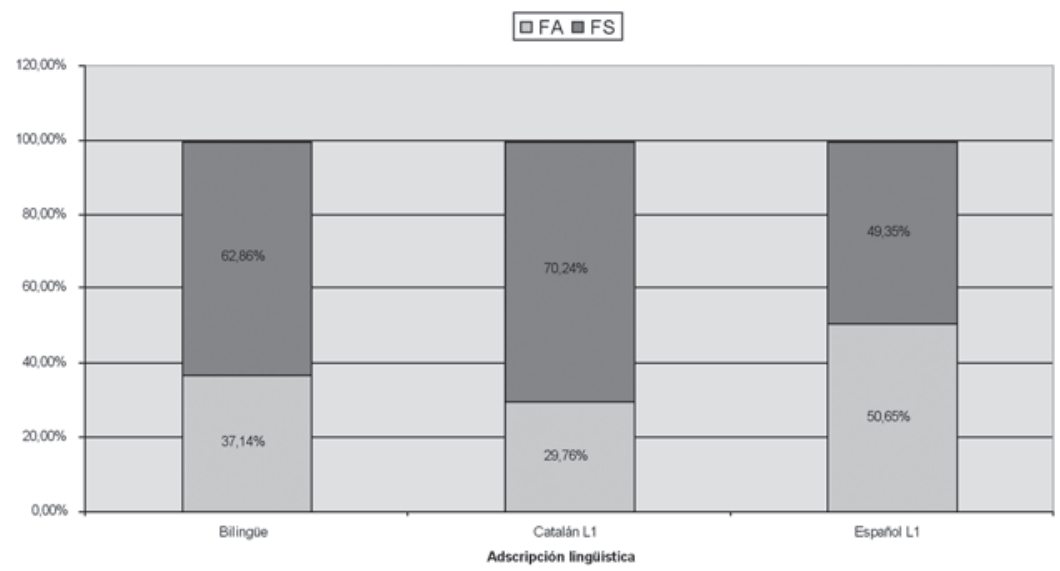

FiguRA 5. Valor de futuro inmediato

\begin{tabular}{|l|c|c|c|c|c|c|}
\hline & $\begin{array}{c}\text { Futuro } \\
\text { analítico }\end{array}$ & $\begin{array}{c}\text { Cifras } \\
\text { absolutas }\end{array}$ & $\begin{array}{c}\text { Futuro } \\
\text { sintético }\end{array}$ & $\begin{array}{c}\text { Cifras } \\
\text { absolutas }\end{array}$ & $\begin{array}{c}\text { Total } \\
\text { general }\end{array}$ & $\begin{array}{c}\text { Total } \\
\text { absoluto }\end{array}$ \\
\hline Bilingüe & $37,14 \%$ & 26 & $62,86 \%$ & 44 & $100,00 \%$ & 70 \\
Catalán L1 & $29,76 \%$ & 25 & $70,24 \%$ & 59 & $100,00 \%$ & 84 \\
Español L1 & $50,65 \%$ & 39 & $49,35 \%$ & 38 & $100,00 \%$ & 77 \\
\hline $\begin{array}{l}\text { Total } \\
\text { general }\end{array}$ & $38,96 \%$ & 90 & $61,04 \%$ & 141 & $100,00 \%$ & 231 \\
\hline
\end{tabular}

Una vez más, los datos corroboran la hipótesis planteada sobre la preferencia de los catalanohablantes por el FS comparado con la tendencia a emplear el FA de los castellanohablantes (véanse figuras 4 y 5). Asimismo, el grupo bilingüe se sitúa entre los dos polos de esta gradación en el uso de las formas prospectivas, pero con una clara preferencia por el FS.

En estos contextos, las ocurrencias de FA que produce el grupo catalanohablante difícilmente llegan a un 30\%, frente al 50\% del grupo castellanohablante. Resulta interesante resaltar que, aunque en estos contextos modales la preferencia por el FA y el FS en el grupo castellanohablante esté bastante equi- 
librado, los otros dos grupos muestran una clara preferencia por el FS: un $62,86 \%$, los bilingües y un $70,24 \%$, los catalanohablantes. Además, si comparamos la frecuencia de uso del futuro con valor de inmediatez con el de intencionalidad, observamos que los índices porcentuales de cada grupo son prácticamente similares (véase figura 6), hecho que corrobora la hipótesis del menor grado de aparición del FA en las zonas bilingües.

FIGURA 6

\begin{tabular}{|l|c|c|}
\hline & Valor futuro inmediato & Valor intencional \\
\cline { 2 - 3 } & Futuro analítico & Futuro analítico \\
\hline Bilingüe & $37,14 \%$ & $40,63 \%$ \\
Catalán L1 & $29,76 \%$ & $28,35 \%$ \\
Español L1 & $50,65 \%$ & $51,35 \%$ \\
\hline Total general & $38,96 \%$ & $39,52 \%$ \\
\hline
\end{tabular}

\subsection{Valor de futuro con matiz de certeza}

Los usos de FS y FA con valor de certeza aparecieron en contextos similares al ejemplo que aparece a continuación:

(3) Maite y Rosa son amigas de toda la vida. Maite hace tiempo que no ve a los hijos de Rosa y le gustaría verlos. Por eso Rosa le propone que se pase por su casa el domingo, que van a estar comiendo todos juntos.

Por lo que respecta a los datos, estos reflejan una mayor preferencia por el FA por parte de los hablantes que tienen el español como L1, seguidos de los bilingües y de los informantes que tienen el catalán como lengua propia, en último lugar. Es importante señalar también que, aunque en los tres grupos de hablantes establecidos el FS tiene unos índices muy elevados en este tipo de contextos, el FA sigue siendo la opción preferida por los informantes castellanohablantes, tal y como sucedía en el apartado anterior. Pese a ello, comparativamente, el valor de certeza presenta un porcentaje mucho menor que en los dos valores precedentes. 


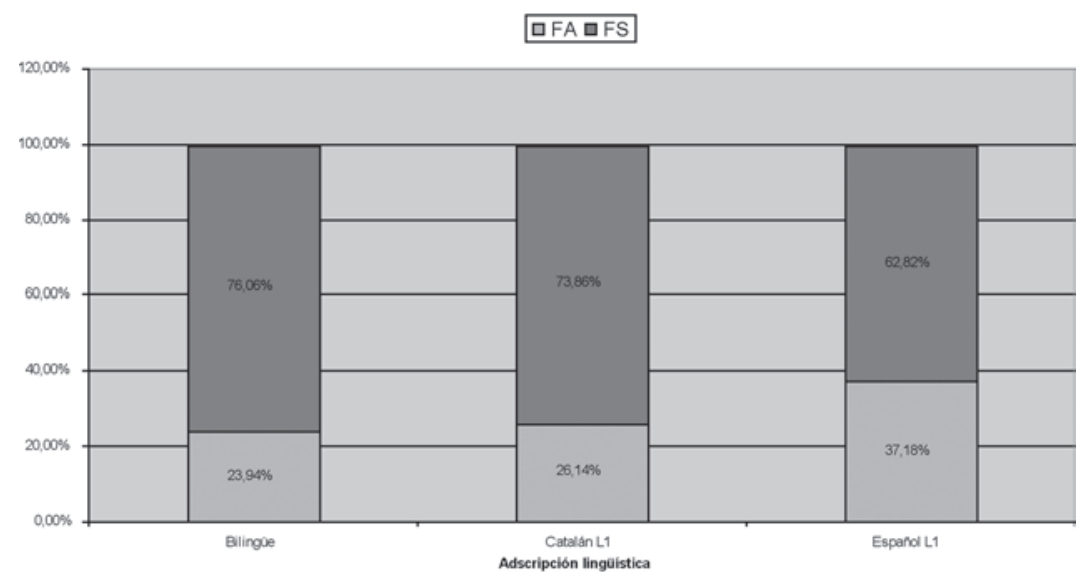

FIGURA 8. Valor de certidumbre

\begin{tabular}{|l|c|c|c|c|c|c|}
\hline & $\begin{array}{c}\text { Futuro } \\
\text { analítico }\end{array}$ & $\begin{array}{c}\text { Cifras } \\
\text { absolutas }\end{array}$ & $\begin{array}{c}\text { Futuro } \\
\text { sintético }\end{array}$ & $\begin{array}{c}\text { Cifras } \\
\text { absolutas }\end{array}$ & $\begin{array}{c}\text { Total } \\
\text { general }\end{array}$ & $\begin{array}{c}\text { Total } \\
\text { absoluto }\end{array}$ \\
\hline Bilingüe & $23,64 \%$ & 17 & $76,06 \%$ & 54 & $100,00 \%$ & 71 \\
Catalán L1 & $26,14 \%$ & 23 & $73,86 \%$ & 65 & $100,00 \%$ & 88 \\
Español L1 & $37,18 \%$ & 29 & $62,82 \%$ & 49 & $100,00 \%$ & 78 \\
\hline $\begin{array}{l}\text { Total gen- } \\
\text { eral }\end{array}$ & $29,11 \%$ & 69 & $70,89 \%$ & 168 & $100,00 \%$ & 237 \\
\hline
\end{tabular}

En el gráfico (véanse figuras 7 y 8 ) se aprecian dos claras tendencias entre los grupos lingüísticos, aunque con contrastes menos pronunciados que en los otros contextos expuestos: si bien los informantes con español como L1 muestran una alta preferencia por el FS (un 62,82\%), este grupo lingüístico sigue prefiriendo el FA (un $37,18 \%$ ) en mayor grado que los otros dos: en efecto, como indican los datos anteriores, los catalanohablantes emplean el FA en un $26,14 \%$ y los bilingües en un $23,94 \%$ de las ocurrencias. En esta ocasión, mientras los bilingües se distancian significativamente del grupo castellanohablante, el colectivo catalanohablante se aproxima a los usos de este último colectivo.

De todos modos, el cambio de posiciones entre bilingües y el grupo catalanohablante no corresponde a una diferencia de valores tan significativa como en los valores anteriores. Si bien en los contextos prospectivos con matiz de intencionalidad la diferencia en el empleo del FS y FA entre bilingües y cata- 
lanohablantes era de 12 puntos y en los de futuro inmediato, de 7,38 puntos, en el valor futuro de certeza la diferencia entre estos grupos es tan solo de 2,2 puntos. Esto puede deberse tal vez al tamaño de la muestra que se ha empleado para este estudio, por lo que cabría verificar si con una muestra que incluyese un número más elevado de informantes, el grupo catalanohablante seguiría manteniéndose en una posición intermedia y no en uno de los polos, como sí ocurría en los otros valores.

\section{CONCLUSIONES}

Hasta aquí se ha intentado mostrar de qué modo se expresa el concepto lingüístico de tiempo futuro en Cataluña a partir de los datos que ofrecen las encuestas lingüísticas realizadas a más de 50 informantes. Con el análisis se ha podido mostrar cómo el Fs predomina en contextos en los que en catalán no es posible emplear la perífrasis.

El gráfico que se incluye a continuación muestra los porcentajes globales de uso del FS y FA sin distinguir los tres valores considerados; a saber, futuro de intencionalidad, de inmediatez y de certeza. A partir de este gráfico (véanse figuras 9 y 10), puede concluirse que en Cataluña existe una preferencia por el FS en contextos en los que en el resto de zonas hispanohablantes se prefiere, generalmente, una forma analítica.

\section{FiguRA 9. Usos de FS y FA en el español de Cataluña}

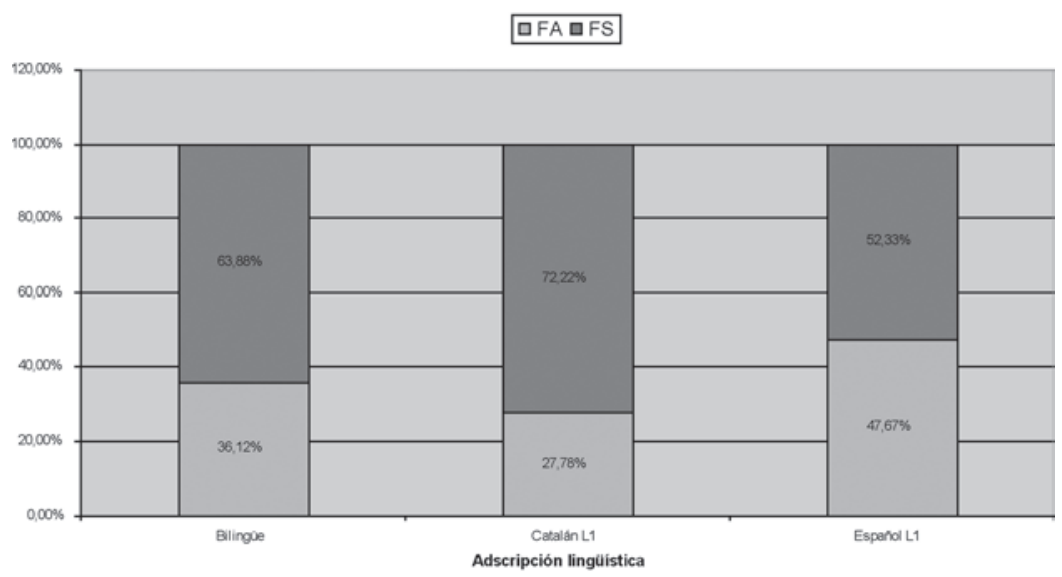


Figura 10. Uso de FS y FA

\begin{tabular}{|l|c|c|c|c|c|c|}
\hline & $\begin{array}{c}\text { Futuro } \\
\text { analítico }\end{array}$ & $\begin{array}{c}\text { Cifras } \\
\text { absolutas }\end{array}$ & $\begin{array}{c}\text { Futuro } \\
\text { sintético }\end{array}$ & $\begin{array}{c}\text { Cifras } \\
\text { absolutas }\end{array}$ & $\begin{array}{c}\text { Total } \\
\text { general }\end{array}$ & $\begin{array}{c}\text { Total } \\
\text { absoluto }\end{array}$ \\
\hline Bilingüe & $40,63 \%$ & 39 & $59,38 \%$ & 57 & $100,00 \%$ & 96 \\
Catalán L1 & $28,35 \%$ & 36 & $71,65 \%$ & 91 & $100,00 \%$ & 127 \\
Español L1 & $51,35 \%$ & 57 & $48,65 \%$ & 54 & $100,00 \%$ & 111 \\
\hline $\begin{array}{l}\text { Total gen- } \\
\text { eral }\end{array}$ & $39,52 \%$ & 132 & $60,48 \%$ & 202 & $100,00 \%$ & 334 \\
\hline
\end{tabular}

La preferencia por las formas analíticas por parte de los castellanohablantes, así como las diferencias diafásicas y diatópicas entre la forma sintética y la analítica, han sido ya tratadas en estudios anteriores (Sedano, 1994 y 2006; Almeida y Díaz, 1998; Blas Arroyo, 2005; Company, 2006; Melis, 2006). Por nuestra parte, el gráfico siguiente (veáse figura 11) recoge los datos relativos al uso de FS y FA que hacen los hablantes que no residen en la comunidad bilingüe catalana y nos permite llegar a la conclusión de que efectivamente, en las otras variedades de español, el FS parece hallarse en una fase de retroceso.

\section{FIGURA 11. FS y FA en las zonas de fuera de Cataluña}

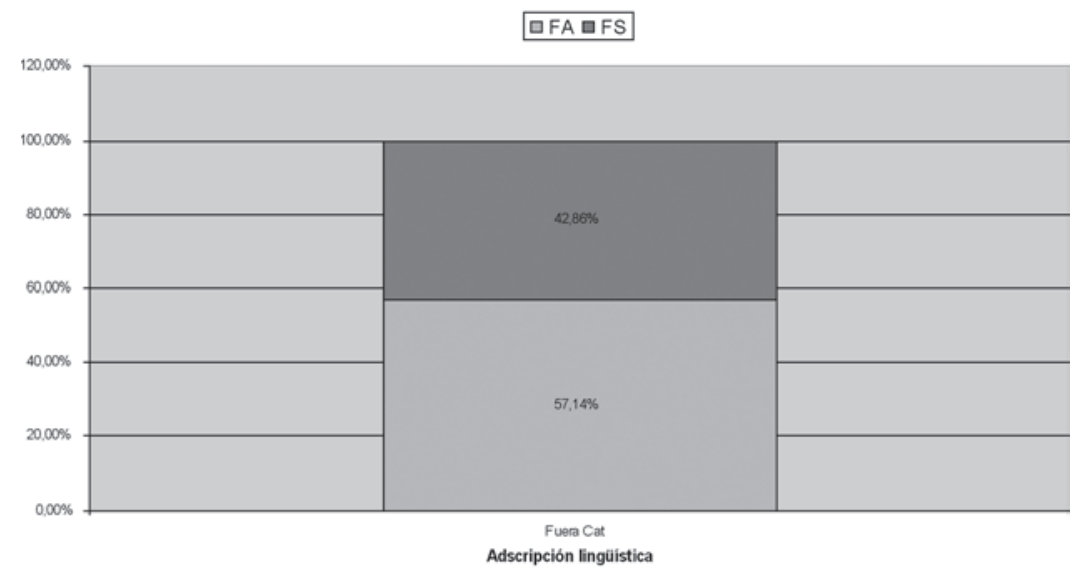

Por lo tanto, los datos de los que disponemos, presentados a lo largo de estas páginas, parecen validar la hipótesis de partida: el contacto con el catalán influye en el uso de las formas prospectivas en la variedad de español hablado en Cataluña. Esta influencia se materializa en un mayor uso del FS en esta variedad de español -en detrimento del futuro analítico-, en contextos en 
los que la forma perifrástica tiene valor intencional, de inmediatez y de futuridad con matices de certeza.

Ahora bien, no hay que descartar la posibilidad de que este bajo rendimiento de la construcción perifrástica en las zonas bilingües no se deba única y exclusivamente a la influencia del catalán, como se ha expuesto al principio de este trabajo. Quizás sea la confluencia de distintos factores lo que desemboca en un incremento del uso de las formas sintéticas: por un lado, la mencionada repercusión del catalán en la escasa productividad de los valores modales de la perífrasis; por otro, la evolución cíclica de las formas prospectivas en español desde la forma latina cantare habeo hasta la forma actual implica que no puede descartarse la posibilidad de que la tendencia sea nuevamente la simplificación hacia el FS (Melis, 2006), al menos en esta zona específica; en tercer lugar, es importante recordar que las diferencias diafásicas y diatópicas que existen entre el Fs y el FA, esto es, entre registro formal e informal, entre variedades peninsulares y americanas, respectivamente; $y$, finalmente, es preciso mencionar, además, que la proliferación de la construcción prospectiva en español se desarrolló de un modo productivo durante el siglo XIX, momento en que el contacto entre español y catalán empieza a ser socialmente más extenso, al darse entre un mayor número de individuos y, por tanto, no hay que excluir la posibilidad de un desarrollo independiente del FA al de otras zonas hispanohablantes.

Así pues, puede aventurarse que el empleo particular que se hace de las formas de futuro en el español que permanece en contacto con el catalán puede ser explicado como una manifestación de un fenómeno de confluencia lingüística que es preciso observar desde distintos puntos de vista, puesto que considerarlo un mero fenómeno de interferencia quizás simplificaría sobremanera este particular uso de las formas prospectivas. Con este estudio se pretende abrir una puerta a futuras investigaciones en las que se pueda ahondar en esta cuestión de un modo más exhaustivo y comprobar si ciertamente nos hallamos ante un cambio en la distribución de los valores del futuro en el español hablado en Cataluña.

\section{REFERENCIAS BIBLIOGRÁFICAS}

AlmeidA, M. y M. DíAz (1998): «Aspectos sociolingüísticos de un cambio gramatical: la expresión de futuro», Estudios filológicos, 33: 7-22.

Blas Arroyo, J. L. (2005): Sociolingüística del español, Madrid, Cátedra.

Bosque, I. y V. Demonte (eds.) (1999): Gramática descriptiva de la lengua española, Madrid, Espasa Calpe (Colección Real Academia Española, Colección Nebrija y Bello). 
Company Company, C. (dir.) (2006): Sintaxis Histórica, vols. 1 y 2, México, FCE.

Matte Bon, F. (2006): «Maneras de hablar del futuro en español. Entre gramática y pragmática. Futuro, ir a + infinitivo y presente de indicativo: análisis, usos valor profundo», RedELE, 6.

Melis, C. (2006): «Verbos de movimiento. La formación de los futuros perifrásticos», en COMPANy COMPANY, C. (dir.) (2006): Sintaxis Histórica, vol. 1 y 2, México, FCE, 875-968.

Payrató, Ll. (1985): La interferència lingüística. Comentaris i exemples català-castellà, Barcelona, Curial Edicions Catalanes / Publicacions de l'Abadia de Montserrat.

RADATZ, H. I. (2003): «La perífrasis vado + infinitivo en castellano, francés y catalán: por la misma senda - pero a paso distinto», en $\mathrm{PUSCH}, \mathrm{C}$. y A. WeSCH (ed.) (2003): Verbalperiphrasen im Katalanischen und anderen romanischen Sprachen im Lichte aktueller Grammatiktheorien. Akten des 18. Deutschen Katalanistentags, München 7-10 Oktober 2001, Hamburg Buske (Beihefte zu Romanistik in Geschichte und Gegenwart; 9), 61-75.

SedANO, M. (1994): «El futuro morfológico y la expresión ir a + infinitivo en el español hablado de Venezuela», Anuario Galego de Filoloxia, 21: 225-240.

- (2006): «Importancia de los datos cuantitativos en el estudio de las expresiones de futuro», Revista Signos, 39 (61): 283-296.

SolÀ, J. et al. (2002): Gramàtica del català contemporani, Barcelona, Empúries. Vila Pujol, M. R. (2001): Corpus del español conversacional de Barcelona y su área metropolitana, Barcelona, Universitat de Barcelona. 


\title{
EL PAPEL DE LA ESCUELA \\ ANTE LA INMIGRACIÓN \\ Y LA DIVERSIDAD LINGÜÍSTICA
}

\author{
Mercè Pujol Berchè \\ Université de Lille 3
}

\section{ALGUNAS CONSTATACIONES}

V

AMOS a empezar recordando algunas constataciones de especial interés. La población escolar extranjera se ha multiplicado por diez en una década (de 57.406 alumnos extranjeros en el curso $1995-96$ se ha pasado a 146.387 en el curso 2005-06) ( $c f$. Ministerio de Educación y Ciencia, 2006). El mayor incremento se ha producido en la Educación Secundaria Obligatoria puesto que de 2.490 alumnos en el curso 1995-96 se ha pasado a 146.387 en el curso 2005-2006, es decir que el alumnado extranjero se ha multiplicado por sesenta. El reparto de dicha población escolar no es la misma según se trate de centros públicos, concertados o privados. Así por ejemplo, el 33\% de niños españoles frecuentan una escuela concertada mientras que el porcentaje de niños extranjeros en esos mismos centros es del 4,2\%. Las escuelas públicas se concentran en España en barrios desfavorecidos y los niños emigrantes se concentran en barrios que presentaban ya una fuerte tasa de obreros y de emigración interna; en algunos de dichos barrios, el porcentaje de niños inmigrantes supera el $60 \%$ debido a la deserción de las familias autóctonas. La desigual distribución de la población escolar es debida, como sucede en otros países, a las condiciones económicas de los inmigrantes que tienden a vivir en zonas desfavorecidas. Pero en el caso concreto de España, esta segregación se debe también a las características específicas de los centros que componen el sistema educativo. Mientras que la mayoría de los escolares en Francia, Alemania o Suiza (países que han conocido a lo largo del siglo Xx fuertes aluviones de emigración), asisten a la escuela pública -mayoritaria en estos países-, los escolares españoles se distribuyen en tres tipos de centros diferentes. Los centros públicos administrados directamente por la administración, los centros privados que pueden tener orientación ideológica y la mayoría de las veces son confesionales y los centros concertados ${ }^{1}$ que también son privados pero que reciben subvenciones públicas.

1. Los centros concertados están obligados a cumplir ciertas normas como la gratuidad de la escolaridad (las otras actividades son de pago), el respeto a las creencias y deben ciertos criterios de matriculación como la proximidad, la presencia de hermanos en el centro y la renta de la familia. 
Se ha visto en los últimos años cómo las escuelas concertadas recibían por parte de la Administración cantidades importantes de dinero para su buen funcionamiento, sin que esta exigiera para dar el concierto, los requisitos imprescindibles que garanticen la igualdad para todos. El número de escuelas concertadas presentando la llamada diversidad es relativamente reducido, lo que favorece la segregación de clases sociales y la segregación lingüística. En un estudio llevado a cabo por Crespo Ubero $(2000)^{2}$ sobre los niños emigrantes en la comarca barcelonesa del Baix Llobregat Nord, se señalaba que en Martorell la escuela concertada no acogía ningún niño inmigrante, mientras que estos se concentraban en ciertas escuelas públicas. Como menciona Aja (1999), la situación es preocupante porque en algunos centros la población inmigrante escolar supera la tasa de la población inmigrante del mismo barrio. Para paliar la deserción de las familias autóctonas, las autoridades escolares disponen de normativas específicas. Así por ejemplo, la Generalitat de Catalunya publicó una, en el año 2002, según la cual se obligaba a un reparto equitativo de los niños extranjeros en los diferentes tipos de centro, pero dicha normativa, incluso otra posterior del año 2006, no siempre se cumple. La diversidad de clases sociales y de nacionalidades -la mezcla social- obedece a cuestiones políticas e ideológicas, así como al modelo de sociedad que se quiere construir: «juntos o separados». En el caso concreto de Cataluña existe el denominado «Pacto Nacional para la Educación» ( $c f$. Vila, Siqués y Roig, 2006) en el cual hay mecanismos de control para garantizar dicha mezcla social.

Los datos acabados de exponer permiten comprobar la existencia de la segregación social, es decir que en los llamados barrios desfavorecidos, la concentración de la clase obrera es mayor, sea ésta autóctona o extranjera. Esta segregación social se acompaña de la deserción de las familias autóctonas, que es una práctica de evitación, es decir de rechazo por parte de dichas familias de llevar a sus hijos a centros en los cuales la concentración de niños extranjeros es importante. Esto provoca la llamada segregación artificial (Aja, 1999) que tiene tres vertientes: la ubicación de las escuelas públicas mayoritariamente en barrios obreros, la deserción de los autóctonos y la no intervención de la administración educativa. Las concentraciones escolares artificiales pueden evitarse si la Administración ejerce un control sobre la elección de los alumnos y la distribución de todos los alumnos se hace de forma coherente. ${ }^{3}$ Esta segregación obedece a un modelo de «integración» de inmigrantes en el cual

2. Datos correspondientes al curso 1996-97, en los que según el Departament d'Educació de la Generalitat de Catalunya la población escolar extranjera era del 2\%, actualmente (curso 20062007) es del $11,7 \%$ ( $c f$. Generalitat de Catalunya, 2006).

3. Véase Carbonell et al. (2002) sobre el trabajo llevado a cabo al respecto en la ciudad de Vic, en Cataluña. 
no hay intereses comunes puesto que se aparta y se separa a los grupos. Todo ello trae consigo la guetorización, situación en la que es muy fácil la categorización de la población en general y la de los niños en particular.

La categorización consiste en segmentar el todo social en partes o subconjuntos definidos y estables y en retener solo uno de los componentes que constituyen la identidad de las personas o de los grupos haciendo de él el único signo de la misma. Cuando se categoriza, las identidades múltiples que caracterizan a todos los humanos se reducen a una, llegando incluso a lo despectivo y peyorativo. Y como una parte de nuestro saber social está organizado en torno a dichas categorizaciones, la comparación social resulta más fácil («nosotros tenemos todas las cualidades», «ellos tienen todos los defectos»). También resulta fácil la atribución de características que, conver-tidas en estables, justifican la categorización realizada o la parcelación establecida. Se ponen de manifiesto frases como «ellos hacen» y «nosotros hacemos». Formas discursivas como «los niños son difíciles, agresivos, poco inteligentes» son ilustraciones de categorizaciones. Se lleva a cabo asimismo una amalgama al referirnos a los niños extranjeros como «malos» desde el punto de vista educativo, sin embargo en las escuelas públicas ubicadas en zonas obreras, hay tanto alumnos «malos» como alumnos «buenos».

\section{LA FUNCIÓN DE LA ESCUELA Y LAS TAREAS ENCOMENDADAS}

La escuela es una de las instituciones más importantes de un país, forma parte de sus prioridades. Sus objetivos fundamentales son la transmisión de los conocimientos y los aprendizajes en general. También se le atribuyen funciones más específicas como la de enseñar a los alumnos a vivir en sociedad (civismo),${ }^{4}$ la de intentar que haya igualdad de oportunidades para todos, la de posibilitar la inserción profesional y la de transmitir los valores de una sociedad determinada. El problema es que cada vez hay menos trabajo, con lo cual la inserción es cada vez más difícil y que esta se consigue cuanto mayor es el número de diplomas (escuela y universidad se convierten en máquinas de diplomados). ${ }^{5} \mathrm{Si}$ antes había un rompecabezas ante la multiplicidad de funciones de la escuela, ahora el rompecabezas sigue existiendo pero hay piezas sobrantes, y cuando algo sobra, los últimos en llegar, es decir, los

$\overline{4 .}$ Véanse las discusiones actuales sobre la sustitución de las clases de religión por las de civismo o por las de educación para la cuidadanía.

5. Véanse a este respecto los acontecimientos ocurridos en Francia en noviembre de 2005 con los disturbios en los suburbios y meses más tarde (entre febrero y abril de 2006) el bloqueo de las universidades, signos de que los jóvenes protestan contra ciertos aspectos de la sociedad como la exclusión, el desempleo y la falta de oportunidades de ascensión social. 
inmigrantes, son los primeros en ser señalados. Se le pide a la escuela la integración de los alumnos extranjeros, sin embargo esto está en contradicción con el tipo de sociedad en la que vivimos puesto que, como se ha mencionado más arriba, existe la segregación por clase social. Nos hallamos ante la paradoja siguiente: la representación de la integración como formando parte del imaginario de la sociedad y la no integración existente en esa misma sociedad. El emigrante es percibido en el imaginario social como el símbolo de la «invasión», en todo caso es percibido como el causante de la inseguridad ciudadana y de la violencia. En este sentido, en una investigación sobre la respresentación de la emigración en la prensa escrita en España, hemos puesto de manifiesto (Pujol Berché, en prensa) que aparecen formas de polarización en los contrastes jugando con pares como «integraciónsegregación», «participación-guetorización», «convivencia-inseguridad», que los periódicos hablan incluso de «las políticas de segregación» y que se recurre a menudo al campo léxico de lo bélico con frases como «se promueve la lucha». En algunos periódicos incluso las noticias sobre emigración aparecen bajo títulos de sección como «el problema de los inmigrantes», es decir, que se problematiza la emigración y el inmigrante (sea éste adulto o niño) se vuelve una carga social ( $c f$. Van Dijk, 2003).

En una encuesta cuyos resultados se dieron a conocer en El Periódico de Catalunya se puso de manifiesto que en ciudades como Barcelona las tres preocupaciones principales de los ciudadanos eran la inmigración, la inseguridad y el paro; conceptos asociados alrededor de uno solo, la inmigración. A partir de ahí, la relación de causalidad que puede establecerse es fácil: la inmigración es la causa de la inseguridad y del paro. Lo mismo puede decirse de otra encuesta publicada esta vez por El País, cuyo titular rezaba: «La inmigración salta al primer puesto entre las preocupaciones ciudadanas», ${ }^{6}$ lo que pone en evidencia una relación causa-efecto al aludir que la principal preocupación ciudadana son los inmigrantes $\mathrm{o}$, dicho de otro modo, los emigrantes causan problemas, $\mathrm{o}$, en otras palabras, donde hay emigrantes hay inseguridad y delincuencia. La representación simbólica que generan dichas imágenes se vincula por lo tanto al conflicto y a la esfera de la criminalidad.

Volviendo nuevamente a la escuela, Charlot (2000) sugiere que la escuela integradora supone una cierta visión de la integración, de manera que un grupo social en la tradición de Durkheim puede ser considerado como integrado cuando sus miembros poseen una conciencia común, comparten las mismas creencias y prácticas y están en interacción. Los niños hijos de emigrantes mantienen rasgos culturales que no son los de la sociedad de residencia, con lo cual integrarlos es hacerles entrar en los valores de dicha sociedad y esta es,

$\overline{\text { 6. El País, }}$ 09/10/05. 
como se ha mencionado con anterioridad, una de las tareas de la escuela. Todo ello disimula cuatro presupuestos.

a) Los niños hijos de emigrantes deben pensarse a partir de sus orígenes, pero cabe preguntarse: ¿tenemos que pensar en términos de presente compartido o de futuro que construimos juntos?, ¿tenemos que reflexionar según los orígenes culturales, lingüísticos, raciales y/o religiosos, o partir de que todos somos iguales? El primer grupo de preguntas obedece a la visión de la sociedad según el modelo del «melting pot» propio de los Estados Unidos de América o incluso de Gran Bretaña, mientras que el segundo grupo de preguntas obedece más bien al modelo francés de la integración bajo el lema de «libertad, fraternidad e igualdad».

b) Integrar es hacer compartir valores comunes, ante lo cual nos podemos preguntar lo siguiente: ¿reposa nuestra sociedad en valores comunes?, ¿qué valores hay que enseñar? o ¿cada uno va a lo suyo? o, sencillamente, ¿lo que quieren los inmigrantes es lo mismo que quieren los autóctonos? Es decir, un trabajo, un coche, una vivienda. ¿Tenemos que pensar en términos de presente compartido o de futuro que construimos juntos?

c) La función de la escuela es inculcarles tales valores, pero cada vez dichos valores son más implícitos. Trabajar bien en la escuela para tener un buen empleo es algo que no se corresponde necesariamente con la realidad. Lo que transmite la escuela choca con la sociedad tal y como está concebida (consumición, gastos, diversión, dinero fácil de los créditos y préstamos, etc.) y tal y como funciona, a pesar de ello esto forma parte del imaginario social.

d) En cuanto la sociedad tiene un problema, sea de la índole que sea (drogas, accidentes de circulación, violencia doméstica, etc.), la escuela está en la mira de todos y nuevamente surgen preguntas como: ¿qué tareas damos a la escuela? Se piden muchas cosas a la escuela, algunas forman parte efectivamente de sus funciones aunque sin especificar cómo llevarlas a cabo, otras ni siquiera forman parte de las mismas.

Nos encontramos ante el reto de inmigración-integración-escuela. Para desafiarlo habrá que definir, en primer lugar, cada uno de los tres componentes para, posteriormente, construir una sociedad que respete dichos compromisos. Todos aquellos que forman la escuela (administración, docentes, padres ${ }^{7}$ y niños) deberían formar parte de la construcción de dicho proyecto.

7. Las familias de los niños emigrantes valoran la escuela, pero esta se aparta de ellos a causa de problemas lingüísticos, y por no tener un buen conocimiento sobre su funcionamiento. Los padres están preocupados por el éxito escolar, la socialización y la seguridad de sus hijos, como lo están el resto de las familias. La atención a la familia emigrante es fundamental para conocer, en el ámbito que nos ocupa, el lugar que ocupa la escuela en ella y la utilidad que se le otor- 
Los niños inmigrantes tienen los mismos problemas que los niños de medios populares, sean éstos españoles o no, posean o no el castellano y las otras lenguas de España. La escuela está concebida para los alumnos «teóricos», de las clases medias. Así, se ha comprobado que el fracaso escolar es una noción que aparece con la escolarización de masa y que se agudiza con la obligatoriedad hasta los 16 años. Esta última es una manera de esconder el paro masivo de los adolescentes y una formación profesional desvalorizada y a veces de poca calidad. Si se necesita que la mano de obra reproduzca mano de obra, habrá que decirlo explícitamente y habrá que darse los medios necesarios para ello en beneficio de todos: niños, profesores y sociedad. El fracaso de los niños inmigrantes es, en primer lugar, el fracaso de una clase social en relación a una enseñanza que no ha sido concebida para ella. Habría que decir en realidad, «los niños de obreros poco o nada cualificados sufren más las consecuencias del fracaso en la escuela que los demás». Lo que ocurre con la escuela y el fracaso de los niños inmigrantes y que ha ocurrido también en otros países como Francia es la llamada etnicisación de los problemas de fracaso escolar o de violencia en la escuela ( $c f$. Debardieux, 1997 y Barrère y Martucelli, 1997) y la creación de un estigma relacionado con la etnicidad (cf. Payet, 1997), es decir, que se señala a la emigración y a los niños emigrantes como causantes y a la vez como portadores del fracaso escolar.

Por otra parte, la no obligatoriedad de la escuela entre los 0 y los 3 y entre los 3 y los 6 años lleva a pautas de socialización diferentes según si los niños han ido o no a guarderías, jardines de infancia y a parvularios. Ambos periodos son evolutivamente cruciales para el desarrollo emotivo, motriz e intelectual de los niños. La no obligatoriedad de la educación infantil abre la puerta a dos posibles problemas. Por un lado, el no considerar como esencial (y por lo tanto obligatoria) la escolarización en unos años que son evolutivamente primordiales para el desarrollo de los niños y para su socialización, aspecto que yo designaría como psicosocial y psicolingüístico puesto que desde el punto de vista de la adquisición y desarrollo del lenguaje y, en consecuencia, de las lenguas, el niño recorre un largo camino entre su nacimiento y los 6 años de edad. Por otra, existe un aspecto económico, puesto que la mayor parte de las guarderías y de los parvularios son privados, ${ }^{8}$ de ahí se desprende que, por motivos económicos, los hijos de inmigrantes tengan un acceso relativamente restringido a los mismos. ${ }^{9}$

De la misma forma que se ha puesto de manifiesto que no ha habido por parte de los diferentes gobiernos centrales una política de inmigración y que

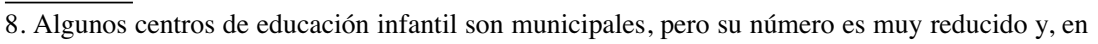
consecuencia, el acceso a los mismos resulta difícil.

9. La diferencia entre la tasa de escolarización en educación infantil entre la población autóctona y la población extranjera ha sido puesta en evidencia en estudios como el de Angulo (2003). 
hasta el año 2000 ninguno de los partidos políticos ha considerado la emigración como formando parte integrante de sus líneas de actuación, tampoco ha habido una política educativa por parte del Ministerio de Educación. Las diferentes comunidades autónomas han puesto en marcha distintas acciones. Así por ejemplo, las comunidades de Andalucía y de Murcia tienen las llamadas «leyes de solidaridad», la primera con un programa específico de acogida. Andalucía es en el curso 2005-06, la comunidad autónoma con mayor número de alumnado extranjero, lo que representa el 19,5\% del total en España. Cataluña que recibió durante ese mismo año escolar el 15\% del alumnado de origen extranjero tiene sus propios programas de inmersión y de acogida. La comunidad autónoma de Madrid con el 14,1\% tiene desde el año 2000 un programa específico llamado «compensación de las desigualdades» y desde el año 2003 se regulan las aulas de acogida denominadas «aulas de enlace».

\section{LA ESCUELA ANTE LA DIVERSIDAD LINGÜÍSTICA}

La escuela se encuentra en la actualidad en un contexto multilingüe complejo como la sociedad misma. Querer reducir esta complejidad a algo sencillo, lineal y fácil es llevarse a engaño. Los dos cambios sociológicos y demográficos más importantes en España, que se producen además en el contexto mundial de la globalización, son la inmigración y la mujer. Por otra parte, se sabe, con relación a la inmigración, que los diferentes indicadores de desarrollo humano (IDH) nos muestran que el mundo es más rico, pero al mismo tiempo más desigual, que no emigran los más pobres, sino aquellos que son físicamente más fuertes $\mathrm{y}$, entre ellos, se encuentran la clase media y la clase media-baja, que el nivel de formación de los inmigrantes es mayor que el de los españoles ${ }^{10}$ ( $c f$. Pujol Berché, 2003 y 2006). La sociedad está en un cambio profundo, constante y rapidísimo y la escuela, que forma parte de dicha sociedad, está inmersa en ese mismo cambio. Reflexionar sobre la escuela implica reflexionar sobre la sociedad, sobre el modelo de sociedad que se desea y sobre la diversidad, que es parte constituyente tanto de la sociedad como de la escuela.

Si observamos las prácticas lingüísticas en la sociedad, podemos constatar dos aspectos esenciales. Por una parte, la existencia de diversidad lingüística en España y, por otra, el hecho de que la lengua o lenguas del entorno son heterogéneas, presentan variedades diatópicas, diastráticas y diafásicas puesto que es algo que caracteriza a todas las lenguas, sin distinción. Si nos detenemos en

10. Las personas procedentes de América latina tienen un nivel de estudios mayor al de los españoles, mientras que las personas procedentes de Asia y de África tienen un nivel menor y las de Europa central tienen un nivel semejante al de los autóctonos. 
la observación de las prácticas lingüísticas de los niños fuera de la escuela, podemos observar los dos aspectos siguientes que se añaden obviamente a los anteriores, para enriquecerlos. En primer lugar, que muchos de los niños emigrantes son políglotas, sobre todo los africanos y los europeos del Este y, en segundo lugar, que las prácticas lingüísticas en el seno de las familias son múltiples. Estudios llevados a cabo en diferentes comunidades autónomas han puesto de manifiesto que en las escuelas madrileñas, por ejemplo, hay más de 200 lenguas ( $c f$. Broeder y Mijares, 2003) y que en las catalanas se pueden encontrar un número parecido ( $c f$. Gela, 2000). La escuela hace sin embargo que las lenguas y sobre todo la diversidad de prácticas lingüísticas de los inmigrantes (y de buena parte de los autóctonos) sean invisibles. Existe, como menciona Nussbaum (2004), una fractura enorme entre las prácticas lingüísticas exteriores y las que se enseñan en las aulas.

Se ha comprobado en países con una larga tradición de recepción de inmigrantes, como Francia, Suiza, Alemania u Holanda, que los niños y adolescentes tienden a eliminar toda diferencia lingüística, es decir que tienden a la asimilación lingüística. En el caso español, podemos destacar tres puntos importantes reflejados tanto en la LOGSE de 1990 como en la LOCE de 2002. El primero es que ambas leyes ignoran las lenguas de los emigrantes. En segundo lugar, dichas disposiciones no valoran ni siquiera el bagaje lingüístico de los niños hispanoamericanos puesto que a veces se les corrige su variedad diatópica para asimilarla a la peninsular que algunos maestros y profesores denominan «estándar». Por último, van en contra de la biodiversidad y de la diversidad lingüística. Estas tres observaciones confluyen en lo que podríamos calificar como posición ideológica fuerte. De ahí se desprende que la escuela mantiene un doble discurso: por una parte, afirma sobre el papel que todas las diferencias son un enriquecimiento y, por otra, sin embargo, lo olvida ocultándolo en sus acciones concretas. Es el llamado «discurso jacobino» puesto de manifiesto por Bourdieu (1979), que mantiene el discurso de la igualdad a costa de la diferencia. Se pone encima de la mesa la diversidad lingüística para que haya unas relaciones sociales más equilibradas, pero sin embargo se utiliza dicha diversidad como recurso para legitimar la exclusión social (cf. Martín Rojo, 2004).

Para que la escuela pueda poner en marcha un buen proyecto de diversidad lingüística es necesario saber qué bagaje lingüístico tienen los alumnos y para ello habrá que observar cómo desarrollan las lenguas en su entorno inmediato, es decir en el barrio y en la familia. Conocer en qué contextos naturales aprenden y cómo elaboran a partir de ahí los diversos conocimientos necesarios para vivir y desarrollarse dignamente. Luego tiene que haber permeabilidad entre el entorno y la escuela puesto que esta última es la que tiene que llevar a cabo, entre otras cosas, la enseñanza más formal. Tienen que valorarse las lenguas y las diferentes variedades de los niños emigrantes (aunque se 
alejen de la norma) puesto que los alumnos tienen experiencia como objetos de discurso (nos cuentan por ejemplo qué hacen por las mañanas antes de ir a la escuela). Todo ello constituyen signos de pertenencia a la comunidad, de intersubjetividad y de complicidad. En eso consiste la verdadera socialización en la segunda lengua.

Muy a menudo, sin embargo, la escuela considera a los niños cuyos padres han emigrado como «imperfectos», como «desequilibrados» con relación a los demás, puesto que se habla de «clases compensatorias» o de «carencias», como se puede comprobar en el siguiente artículo: «Para los alumnos que desconozcan la lengua y cultura españolas, o que presenten graves carencias $^{11}$ en conocimientos básicos, las Administraciones educativas desarrollarán programas específicos de aprendizaje con la finalidad de facilitar su integración en el nivel correspondiente $»^{12}$ (p. 45201). La pedagogía compensatoria no es otra cosa que la ayuda que se aporta a ciertas personas bajo ciertas condiciones cuando hay un desequilibrio y que se concede para estimularlas. De ahí deducimos que la imagen que se tiene del niño emigrante es la de alguien a quien le falta algo que hay que compensar puesto que «nosotros» (los nacidos en el lugar) lo tenemos y «ellos» (los forasteros) no. Se asimila siempre a los recién llegados con niños con dificultades de aprendizaje. En cambio, no se les considera como niños que tienen ya unos aprendizajes realizados, sobre todo, los que llegan y acceden a la ESO que, como se ha expuesto al principio de esta contribución, son los más numerosos. Estos alumnos, aparte de conocer ya una o más lenguas, han aprendido cosas y poseen ya cierta cultura escolar aunque esta sea diferente de la de la escuela española. Me parece importante poner de manifiesto que junto con la diversidad lingüística y la diversidad de prácticas de lenguaje existen competencias lingüísticas diversas, es decir que la heterogeneidad consiste también en el hecho de que el conocimiento (dominio) de las habilidades o destrezas lingüísticas (comprensión lectora, producción oral y escrita, comprensión auditiva e interacción) no es el mismo en todos los niños. Me parece que este aspecto es uno de los puntos cruciales de la enseñanza de lenguas que debería llevarse a cabo con los alumnos de secundaria sean éstos autóctonos o extranjeros y en este último caso, hayan seguido la escolaridad en España o se hayan incorporado tardíamente..$^{13}$

11. El subrayado es nuestro.

12. LOCE, 2002, sección $2^{\text {a }}$ del capítulo vII, título I, artículo 42.1.

13. Resultan reveladores los resultados obtenidos por el Instituto Nacional de Evaluación del Sistema Educativo (INECSE, 2004) llevados a cabo en sexto de primaria con pruebas estandarizadas, en las que se ponen de relieve que el $47 \%$ del alumnado no consigue un nivel aceptable y que un $16 \%$ obtiene resultados malos. Los resultados de las pruebas PISA (OCDE, 2002) en educación secundaria no son desgraciadamente más alentadores. 
Las lenguas de los inmigrantes son consideradas como menores, aunque estas sean el árabe o el chino. $\mathrm{Si}$, como hemos dicho con anterioridad, la escuela tiene que garantizar un puesto de trabajo, valdría la pena tener en consideración que el árabe o el chino son lenguas que ofrecen vías de trabajo interesantes de difusión, de exportación y de comercio, además de ser las lenguas de origen de los padres. Como menciona Skutnabb-Kangas (2000, al considerar como menores dichas lenguas o incluso al ocultarlas e ignorarlas estamos, en primer lugar, estigmatizando las lenguas de origen y, en segundo lugar, glorificando las lenguas de la colonización. De ese modo, racionalizamos todo aquello relacionado con las lenguas y hacemos creer que al aprender la lengua mayoritaria y dominante, el alumno ganará en todo.

Otro punto clave que cabe destacar es la falta de formación del profesorado en temas que podríamos considerar generales en la actualidad como el contacto de lenguas, el multilingüismo y la interculturalidad lo que lleva a veces a aberraciones, observadas en las clases, en las cuales el profesor corrige el léxico de un niño latinoamericano como algo extranjero y no procedente; siendo esto signo de etnocentrismo peninsular extremo y de ignorancia de la diversidad del español, dentro de su unidad..$^{14}$ A esta falta de formación del profesorado se añade otro hecho importante y es la presencia de profesorado poco experimentado puesto que se destina a profesores interinos acabados de diplomarse, a centros con una presencia importante de inmigrantes o a las aulas específicas concebidas para ellos.

$\mathrm{Si}$ anteriormente hemos mencionado que existe una contradicción entre las normativas de la administración escolar y lo que la escuela realiza, también podríamos señalar que existe contradicción interna en las propias disposiciones redactadas en los documentos de la administración escolar. Así pues, mientras que en las directrices se especifica la importancia de la lengua como vehículo de comunicación y de formación de individuos plurilingües, en los contenidos encontramos listados de reglas que no es otra cosa que la perpetuación de una enseñanza muy tradicional basada en el aprendizaje de la gramática considerada como eje central del razonamiento. Se constata de ese modo un clivaje entre aquello que consideramos más teórico como las aportaciones de la didáctica y las reglamentaciones generales y aquello más concreto como los contenidos que, sin embargo, no son otra cosa que la puesta en práctica de las directrices generales. Se crean barreras entre las lenguas del entorno, las variedades y las heterogeneidades de las mismas y la lengua «gramatical» de la escuela que se utiliza casi exclusivamente como herramienta de reflexión metalingüística, olvidando así que es ante todo un vehículo de comunicación y que tiene que ser útil para su propio aprendizaje y para llevar a cabo además

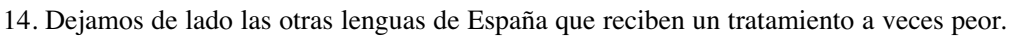


los diferentes aprendizajes escolares. La lengua o lenguas de la escuela son verdaderas herramientas de construcción de los conocimientos que deben aprenderse.

Podríamos resumir lo expuesto más arriba del siguiente modo. Las prácticas escolares no deberían deformar la lengua española y las otras lenguas del Estado motivo de aprendizaje. La escuela debería valorar lo que ya sabe el niño cuando llega a la misma y tomar en consideración todo su bagaje lingüístico, se aleje o no de lo normativo o de lo que algunos maestros y profesores consideran como tal. La escuela debería asimismo tener en cuenta que todos los aprendizajes requieren tiempo y enseñanza.

\section{CONCLUSIONES}

La institución educativa tiene un papel importante en la socialización de los individuos, pero no por ello tiene que resolver todos los problemas planteados en la sociedad, ni tampoco se le puede pedir que resuelva aquellos que no le incumben. De lo mencionado y expuesto con anterioridad, nos gustaría subrayar, en primer lugar, que las administraciones educativas del gobierno central y de las comunidaes autónomas deben garantizar la aplicación de la normativa en cuanto a la asignación de los alumnos a los diferentes centros educativos sin distinción de origen y evitar la deserción de las familias autóctonas de los centros públicos para impedir de ese modo la segregación artificial y la concentración escolar artificial.

En segundo lugar, nos gustaría exponer las siguientes propuestas que deberían ser lideradas, según nuestra opinión, por el Ministerio de Educación. La puesta en marcha de un plan real de acogida abandonando los modelos asistencialistas actuales que defina marcos normativos claros y que describa protocolos de actuación y de redes de centros, que evite todo tipo de propuestas compensatorias puesto que su punto de partida es la visión de los niños emigrantes como deficitarios de algo, y que aplique las directivas y los conocimientos que pone a nuestro alcance la didáctica de las lenguas, llegando al modelo comunicativo en la enseñanza de las lenguas. Debería asimismo poner en marcha un programa nacional de educación y un curriculum en el que estén presentes todas las lenguas motivo de aprendizaje que hagan visible la diversidad lingüística existente, es decir las variedades diatópicas del castellano, de las otras lenguas de España y de las lenguas de los inmigrantes, curriculum que permita tender puentes entre las prácticas reales de los niños llevadas a cabo en la familia y en el barrio y las prácticas educativas realizadas en el seno de la escuela, valorizando así los usos verbales de los niños a partir de las habilidades reales en contextos cotidianos. Una formación inicial del profesorado 
de calidad que tenga en cuenta la situación actual de la sociedad pluriétnica y de la escuela plurilingüe. Por último, pero no por ello menos importante, la evaluación de lo que se ha llevado a cabo en las diferentes comunidades autónomas hasta el momento actual y de lo existente en materia de emigración y lenguas.

\section{REFERENCIAS BIBLIOGRÁFICAS}

AJA, E. (1999): «La regulació de l'educació dels immigrants», en AJA, E., F. Carbonell y C. IoÉ (Colectivo IoÉ: C. Pereda, W. Actis de Prada, M. A.), J. FunES e I. VILA (eds.) (1999): La immigració estrangera a Espanya. Els reptes educatius, Barcelona, Fundació "La Caixa", 69-97.

Angulo, C. (2003): La población extranjera en España, Madrid, INE.

BARRÈre, A. y D. MARTUCELLI (1997): «L'école à l'épreuve de l'ethnicité», Les annales de la recherche urbaine, 75: 10-21.

Bourdieu, P. (1979): La distinction, París, Éditions de Minuit.

Broeder, P. y L. Mijares (2003): Plurilingüismo en Madrid, Madrid, Comunidad de Madrid, Ministerio de Educación y Deporte.

CARbonell, J., N. Simó y T. TORT (2002): Magribins a les aules: El model de Vic a debat. Vic, Eumo.

CHARlot, B. (2000): «L'intégration une mission pour l'école?», L'intégration une mission pour l'école?, Journée d'étude du 22 janvier 1997, París, Hachette, 17-48.

Crespo Ubero, R. (2000): «Educació i socialització dels fills immigrants», en Crespo Ubero, R., C. Delgado García y Ó. Pasqual Sorribes (2000): Pla intermunicipal d'integració dels immigrants estrangers del Baix Llobregat Nord, Barcelona, Diputació de Barcelona, Àrea de Benestar Social, col·lecció Serveis Socials, $n^{\circ} 16: 213-243$.

DebardieuX, E. (1997): «Insécurité et clivage sociale», Les annales de la recherche urbaine, 75: 45-60.

Gela (Grup d'Estudis de Llengües Amenaçades) (2000): La diversitsat lingüística, Quaderns ESO, Barcelona, Octaedro.

Generalitat de Catalunya (2006): Dades de l'inici de curs 2006-07. Barcelona, Departament d'Educació.

INECSE (2004): Aprender para el mundo de mañana. Resumen de resultados PISA 2003, Madrid, Ministerio de Educación y Ciencia.

Martín Rojo, M. L. (2004): «Dilemas ideológicos», Estudios de Sociolingüística, 5(2): 191-205.

Ministerio de EdUCACión y Ciencia (2006): Datos y cifras. Curso escolar 2006-07, Madrid, Ministerio de Educación y Ciencia. 
Nussbaum L. (2004): «Dilemas y desafíos de la educación lingüística», Estudios de Sociolingüística, 5(2): 207-217.

OCDE (2002): Conocimientos y destrezas para la vida. Primeros resultados del proyecto PISA 2000, Madrid, Ministerio de Educación y Ciencia.

PAYET, J. P. (1997): «'Le sale boulot'. Division morale du travail dans un collège de banlieue», Les annales de la recherche urbaine, 75: 70-82.

Pujol Berché, M. (2003): Del bilingüismo histórico al plurilingüismo: La inmigración en Cataluña, Perpiñán, Universidad de Perpiñán. Trabajo de investigación para la obtención de la Habilitation à diriger des recherches.

- (2006): «Política lingüística en España y población extranjera», en CASTILLO Lluch, M. y J. KabateK. (eds.) (2006): Las lenguas de España. Política lingüística, sociología del lenguaje e ideología desde la Transición hasta la actualidad, Madrid, Iberoamericana-Vervuert, 205-222.

- (2007): «Construcción de estereotipos: la imagen de la emigración latinoamericana transmitida por la prensa escrita en España», en VERGASA, V. (ed): ¿Verdades cansadas? Estereotipos e imágenes en relación con el mundo hispánico, Madrid, CSIC, col. Historia.

SkUtNABB-Kangas, T. (2000): Linguistics genocide in Education. Or worldwide diversity and human rights, Mahwah, NJ, Lawrence Erlbaum Associates.

VAn Disk, T. A. (2003): Racismo y discurso de las élites, Barcelona, Gedisa.

VILA, I., C. SIQués y T. RoIG (2006): Llengua, escola i immigració: un debat obert, Barcelona, Graó. 


\title{
TIPOLOGÍA DE ESTRATEGIAS \\ COMUNICATIVAS \\ ENTRE HABLANTES \\ EUSKALDUNIZADOS
}

\author{
Begoña Sarrionandia GURTUbay \\ Universidad del País Vasco
}

\section{INTRODUCCIÓN}

T

A definición del término estrategia comunicativa (EC) comporta una cierta complejidad, ya que su aplicación en diversos campos nos llevaría a una posible complicación conceptual. Así, en este trabajo se tratará de concertar en lo máximo posible la noción o nociones de estrategia dentro de una función comunicativa. De este modo, se dejarán al margen definiciones tales como estrategias de aprendizaje, puesto que la relación que el aprendizaje de una segunda lengua y su expresión comunicativa poseen podría tener como consecuencia una convergencia entre ambos campos teóricos, el aprendizaje y la comunicación en términos generales, lo cual no es intención de la autora del presente estudio. Dicho de otro modo, las EC constituyen un grupo de estrategias de aprendizaje.

Así, las definiciones varían en contenido, pero las características o rasgos que comparten son similares. Corder (1981) propone que las EC son una técnica sistematizada empleada por el hablante cuando se enfrenta a alguna dificultad. Por otra parte, Faerch y Kasper (1983b) las define como sistemas conscientemente planeados para la resolución de un problema cuando se trata de alcanzar un objetivo comunicativo. También se puede citar la descripción que Tarone (1977) realiza, y que define las EC como una tentativa mutua entre dos interlocutores en acordar un significado en situaciones en las que las estructuras requeridas para la comprensión del mensaje no son compartidas. Aparte de las definiciones apuntadas, existen otra serie de conceptualizaciones del término EC, mencionadas por autores como Kasper y Kellerman (1997), que las tratan como planes mentales implementados por el aprendiz de una segunda lengua en respuesta a un problema inminente en la comunicación.

Una vez clarificado el concepto de EC como un conjunto de habilidades o procesos internos que pone en marcha el aprendiz de una segunda lengua con el objeto de comunicarse de una forma exitosa, habría que explicar brevemente tres características que poseen una especial relevancia con el concepto de EC y que ayudan en mayor medida a una visión generalizada de esta parcela de la 
Lingüística Aplicada. Tales fenómenos son los de problematicidad, concienciación e intencionalidad. Aunque no se tratarán en su conjunto o individualmente, se ha de hacer una referencia puntual, puesto que ayudará a una comprensión global de la complejidad del tema referente a la competencia estratégica del hablante de una lengua ajena a la adquirida en la infancia.

En primer lugar se ha de destacar el fenómeno de la problematicidad. Este concepto se refiere a la noción de que las estrategias se adoptan en el momento en el que se percibe algún problema comunicativo. El hecho de producirse esta toma de conciencia puede parecer redundante, pero no lo es si tenemos en cuenta que las EC no son operaciones rutinarias durante el uso de una lengua nativa. El segundo criterio, la concienciación, puede relacionarse tanto a la concienciación por parte del hablante de que una EC se emplea para un determinado propósito, o de cómo una EC podría efectuar su efecto propuesto. En lo que concierne a este último punto, autores como Faerch y Kasper (1983a) han contestado que tienen que ver con los contextos situacionales o individuales. Por último, se cita el fenómeno de intencionalidad, en otras palabras, el hecho de que existe un control sobre la serie de EC, de tal modo que unas determinadas estrategias pueden ser seleccionadas dentro de la serie de EC existente, $\mathrm{y}$, al mismo tiempo, pueden ser deliberadamente aplicadas con unos efectos pretendidos.

\section{ESTUDIO}

Objetivos

1. Realización de una tipología de EC aplicada al euskera mediante la implantación de un taxonomía clasificatoria y la aplicación empírica de un método comprobable y comparable. Así, la investigación precisa de un número aceptable de ocurrencias, y de este modo colaborar en la sistematización de una taxonomía aplicada a la lengua vasca. En nuestro estudio se ha aplicado la taxonomía a aprendices de euskera que han adquirido un nivel intermedio.

2. El hablante con un nivel de competencia intermedio usa de un modo equilibrado tanto las estrategias reductivas como las productivas.

3. El hablante con un nivel de competencia intermedio utilizará con mayor frecuencia estrategias reductivas en actividades narrativas que en actividades descriptivas.

4. Definición de la efectividad comunicativa en una lengua adquirida, en nuestro caso el euskera, en hablantes cuya lengua materna es el castellano. La noción de éxito en funciones comunicativas resulta primordial dentro de las teorías de segunda adquisición de un idioma. Dicha efectividad se realizará 
considerando el uso de las denominadas estrategias más o menos exitosas que se verá reflejado en la taxonomía que se presenta para la clasificación de las EC, esto es, basadas en la lengua materna o en la lengua adquirida o segunda. Para ello, se ha intentado realizar un estudio del dominio de la lengua adquirida dependiendo de la EC seleccionada en hablantes con un nivel de competencia intermedio, por lo que se prevé que harán un uso equilibrado tanto de las EC basadas en la L1 como las EC basadas en la L2.

5. Comprobación de la situación del uso del euskera en hablantes euskaldunizados, esto es, verificar la competencia del hablante euskaldunberri (hablante cuya L2 sea el euskera) en una situación comunicativa ajena. Esta propuesta se puede considerar directamente relacionada con la anterior, puesto que se equipara normalmente grado de competencia y éxito.

6. Verificación de que el uso exitoso de EC basadas en la lengua materna previene la adquisición total de un segundo idioma, y consecuentemente ayuda a la conservación parcial del euskera.

\section{STATUS QUESTIONIS}

Con el objeto de seleccionar un método para la presente investigación, se han utilizado estudios empíricos de caso. Con el fin de detallar un método experimental se ha recogido la información detallada en Faerch y Kasper (1983a). Este estudio considera los recursos estratégicos que se ponen en marcha cuando el hablante intenta conservar el mensaje original. A su vez, recoge los estudios de caso realizados por Varadi (1983) y Tarone (1977). El primer autor utiliza el material proporcionado por 19 alumnos húngaros que poseen el inglés como segundo idioma. Los informantes ofrecen dos versiones escritas acerca de una breve historia en forma de cómic. La primera versión en húngaro, lengua nativa de los informantes, y la segunda versión en inglés. De este modo, (Varadi, 1983) consigue estrategias compensatorias no cooperativas. Por otra parte, (Tarone, 1977) utiliza como método de elicitación ejercicios orales. Así, un grupo de 9 hablantes húngaros con el inglés como lengua adquirida intentan describir oralmente una fotografía. Mediante esta actividad, el interlocutor consigue estrategias compensatorias cooperativas y estrategias de recuperación.

En un segundo trabajo de Varadi (1983) se recogen estrategias de reducción, tanto funcionales como formales, en un grupo de 16 aprendices húngaros con un nivel intermedio de inglés. El método utilizado es similar a los descritos anteriormente, oral en lengua materna (húngaro), y una segunda versión en inglés.

En último lugar, reseñar que en la investigación llevada a cabo por Faerch y Kasper (1983a), citada con anterioridad, se encuentra el trabajo de Bialys- 
tok $(1983 b)$, en el que se presenta un método de elicitación basado en la grabación y transcripción de los ejercicios orales de dos grupos de alumnos canadienses cuya segunda lengua es el francés. El primer grupo lo conforman 16 alumnos de bachiller, y el segundo grupo está compuesto por funcionarios canadienses inmersos en un programa especial de aprendizaje del francés como lengua segunda. Esta actividad oral presenta una novedad con respecto al resto de estudios, puesto que el investigador dispone de una lista con términos adecuados e inadecuados para la descripción de la historia. De este modo, se analizan las EC productivas y reductivas.

\section{MÉTODO}

\subsection{Participantes}

El experimento se llevó a cabo en el Instituto de Euskera de la Universidad de Deusto (Bilbao). Este centro de enseñanza de la lengua vasca es un organismo oficial dependiente del Instituto de Euskaldunización y Alfabetización de Adultos HABE (Viceconsejería de Cultura del Gobierno Vasco). Las razones que nos llevaron a la elección de este centro se deben a la experiencia de este centro en tareas de enseñanza de la lengua vasca (25 años), el prestigio de su profesorado (licenciados en Filología Vasca con varios años de experiencia profesional), y el gran número de alumnos, datos que avalan la calidad de los recursos educativos de este centro.

Los alumnos seleccionados estaban inmersos en un proceso de preparación para la obtención del título EGA (Euskara Gaitasun Agiria, Certificado de Competencia en Euskera), que se trata de la acreditación oficial de conocimiento del euskera más profusa en el País Vasco. Para la obtención de este título el candidato debe completar un proceso que abarca 12 niveles. Los componentes del estudio piloto se encontraban en la última fase de preparación del $7^{\circ}$ nivel. Dicho nivel se ha seleccionado puesto que, en opinión del profesorado consultado, se trata del nivel intermedio óptimo de competencia.

Para la selección del grupo de aprendices que conforman este estudio piloto se han desdeñado factores como la edad, sexo, motivación y actitud ante el idioma, ya que serían objeto de estudios más complejos. Para la elección de hablantes se ha consultado con los profesores encargados de cada grupo, teniendo en cuenta factores como asistencia diaria a clase y nivel de preparación.

En la lista definitiva se han incluido 4 grupos diferentes, dos con horario matinal y dos con horario vespertino. La totalidad la componen 23 alumnos. Este número de hablantes se considera una media aceptable para la obtención de una muestra comparable, considerando los trabajos realizados por otros investigadores. 


\subsection{Material y procedimientos}

La investigación se compone de dos tipos de actividades relacionadas con los canales de producción: un apartado escrito, que consta de dos ejercicios diferenciados, y un segundo ejercicio oral.

En la primera prueba escrita se ha utilizado el modelo de Varadi (1983), la descripción escrita de una breve historia en forma de cómic. El investigador dispone de una lista de términos adecuados e inadecuados relacionados con la historia. La primera versión se ha realizado en la lengua materna del hablante, el castellano, y, a continuación, una segunda versión en euskera, especificándose en las instrucciones de realización del ejercicio que no se traduzca la primera versión. Para cada versión el informante ha dispuesto de un tiempo de 15 minutos. El objetivo era el de tipificar las EC compensatorias no cooperativas.

Para el segundo ejercicio escrito el informante ha realizado una redacción sobre un tema concreto. Asimismo, se han obtenido dos versiones sobre el mismo tema en castellano y en euskera. El tiempo se ha limitado como en el primer ejercicio del apartado escrito, disponiendo el informante de 30 minutos para ambas versiones.

La actividad oral ha consistido en un resumen de 5 a 10 minutos sobre un artículo aparecido en una revista especializada en el aprendizaje del euskera. Antes de la realización de este ejercicio el informante oral ha recibido la instrucción de que debe relatar los datos más relevantes del artículo. Para la lectura del artículo el informante ha dispuesto de 20 minutos. El investigador ha podido intervenir en este ejercicio mediante preguntas, sin embargo, no podrá ayudar al informante, ni explicarle ningún término. Este último factor se enmarca en lo que diversos autores han denominado «actividad monitorizada», factor que ha sido desdeñado en el diseño de este estudio piloto. Esta actividad oral viene precedida por una conversación informal entre el investigador y el informante con el fin de elicitar una muestra de lenguaje natural. Así, el interlocutor participa en esta conversación, intercambia información con el hablante, y le comunica de forma oral las instrucciones necesarias para el segundo ejercicio oral.

Las versiones en lengua nativa se han utilizado con el fin de reflejar el significado pretendido por el hablante (Tarone, 1977), y de este modo, servirán como procedimiento para la identificación de las EC de reducción y de recuperación.

Todos los ejercicios orales han sido grabados y transcritos.

\subsection{Análisis y resultados}

El análisis de datos consiste en dos procesos diferenciados: identificación y clasificación de las EC, y análisis cuantitativo de los datos. 


\subsubsection{Identificación de las EC}

El primer objetivo de nuestra investigación era realizar una tipología de EC entre hablantes euskaldunizados, es decir, hablantes que se encuentran en un proceso de aprendizaje intermedio de la lengua vasca, por lo que realmente el estudio se refiere a la interlengua de los hablantes, según autores como Selinker. Es decir, utilizan un fenómeno particular de la interlengua denominado EC para solventar un problema comunicativo debido a su competencia intermedia del idioma. Por ello, la identificación de las EC reúne los criterios de problematicidad y de concienciación, el hablante experimenta un problema y trata de resolverlo mediante el uso de las EC, y además, es consciente del uso de las mismas. Un tercer criterio es el de la lexicalidad, por el que solo se han seleccionado las EC encaminadas a resolver problemas léxicos.

Por razones metodológicas, esta investigación solo se orientó al producto lingüístico, y, por este motivo, no se contó con la colaboración de los informantes en el proceso de identificación de las EC encontradas. Los comentarios de los sujetos que han intervenido en el estudio podrían haber ayudado en la identificación de nuevos casos de EC, pero, a nuestro juicio, podrían influir en los datos iniciales del experimento, y se ha observado que podría tratarse de un juicio basado en intuiciones que habrían deformado los resultados objetivos del estudio.

Como resultado del análisis, se han identificado un total de 520 EC.

\subsubsection{Clasificación de EC}

Las EC identificadas se han clasificado mediante una taxonomía adaptada de estudios de Tarone (1977) y Faerch y Kasper (1983b).

A. Estrategias de reducción

1. Estrategias formales de reducción

En este apartado se han incluido la anulación de reglas formales de las que el informante no se siente capacitado, de las que se siente inseguro o de las que no tiene un acceso rápido.

Badirudi jaboia hartu nahi duela (Parece que quiere coger el jabón) EC: Parece que queriendo coger el jabón

2. Estrategias funcionales de reducción

En este caso, se han tipificado las estrategias o tácticas utilizadas por el informante cuando evita referirse a ciertas partes del discurso o términos del habla. Esto es, el emisor renuncia o abandona ciertos tópicos.

Sobre todo, cuando ellos se pelean entre sí o desobedecen EC: 0 


\section{B. Estrategias de producción}

Estos recursos se activan cuando el hablante decide conservar el objetivo comunicativo original, compensando sus medios insuficientes o esforzándose en recuperar los términos requeridos.

a) Estrategias compensatorias

1. Estrategias no cooperativas

Estas estrategias no precisan de la presencia de un interlocutor.

- Basadas en la lengua materna

- «Code-switching» o alternancia de código: El hablante utiliza formas no pertenecientes al euskera.

EC: chivo expiatorio

- Adaptación del léxico nativo al léxico adquirido: Esta EC se refiere a aportaciones léxicas de la lengua materna que constituyen formas inexistentes en la L2. Se denomina comúnmente erderakazo (erdera, castellano en euskera).

EC: rebeldeak rebeldes

- Traducción literal: Traducción simultánea o siguiendo la sintaxis de la lengua nativa en la utilización de la segunda lengua.

La letra con sangre entra

EC: hitza odolaren bidez sartzen da

- Basadas en la lengua segunda

- Sustitución: El hablante reemplaza un término del léxico vasco por otro término perteneciente al mismo idioma. Acaban tomándote el pelo

EC: azkenean, adarra joko dizute (al final, te tomarán el pelo)

- Paráfrasis: El hablante se remite a un término de la L2 mediante la descripción o ejemplificación del mismo.

Intentan aprovecharse de los mayores para conseguir su objetivo EC: ... ama konbentsitzeko negar egiten hasten dira lortzeko (para convencer a la madre comienzan a llorar)

- Formación de palabras: El hablante se refiere a un término de la L2 utilizando una expresión de dicha L2.

- Reestructuración: El hablante desarrolla un plan léxico alternativo mediante el uso de sinónimos simples o complejos.

Ya que su mirada parece delatarle

EC: begiratzen ari da begi eder haiekin (está mirándole con esos hermosos ojos)

- Estrategias no lingüísticas

El hablante compensa su deficiencia utilizando medios no lingüísticos, tales como el gesto. 
2. Estrategias cooperativas

En este apartado se han incluido EC que precisan la presencia de un interlocutor.

- Alusiones directas: El hablante requiere explícitamente la intervención del interlocutor.

EC: Gero, orain, zenbat, ikasleen adina, ezta? (luego, ahora, cuántos, la edad de los alumnos ¿no?)

- Alusiones indirectas: El hablante requiere la intervención del interlocutor, pero indica la ayuda mediante tácticas gestuales o paralingüísticas.

b) Estrategias de recuperación

El hablante utiliza estas EC cuando se enfrenta a un problema de localización del término requerido, pero decide conservarlo en lugar de utilizar recursos compensatorios.

1. Pausa

El hablante espera recordar el término.

2. Campo semántico

El hablante identifica el campo semántico al que el término pertenece, por lo que recorre a dicho campo hasta localizar el término en cuestión.

EC: Gehienak lana aurkitu... bilatzeko (la mayoría para encontrar... buscar trabajo)

3. Uso de lenguas terceras

El hablante utiliza extranjerismos cuando desconoce su correspondencia exacta en la lengua segunda.

\subsubsection{Análisis cuantitativo}

\subsubsection{Tipología de EC}

Con el fin de corroborar las hipótesis y objetivos formulados anteriormente, los usos de EC se han tabulado en términos numéricos y sometidos a análisis estadísticos.

Así, se ha realizado una tabla clasificatoria con el fin de tipificar las EC. 
TABLA 1. Tipología de EC

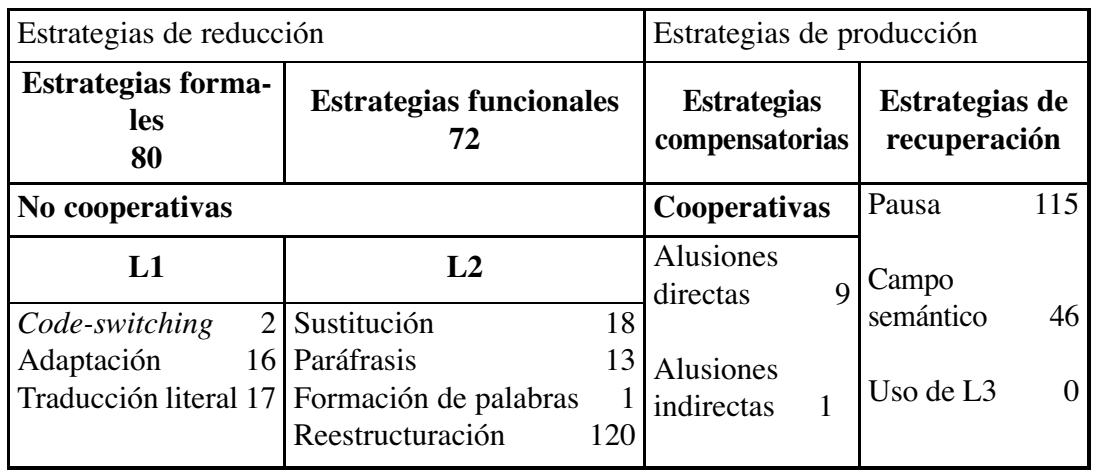

4.3.3.2. Uso de EC de reducción y de producción

En la segunda hipótesis de este estudio se mantenía que los hablantes euskaldunizados con un nivel de competencia intermedio harán un uso equilibrado de EC de reducción y de producción.

TABLA 2. Selección de EC

\begin{tabular}{|l|l|l|}
\hline Estrategias de reducción & 152 & $29,2 \%$ \\
\hline Estrategias de producción & 378 & $72,6 \%$ \\
\hline Total & 520 & $100 \%$ \\
\hline
\end{tabular}

En la Tabla 2 podemos observar que los hablantes euskaldunizados con un nivel de competencia intermedio hacen un uso más frecuente de estrategias de producción. Así, no se demuestra un equilibrio entre el uso de estrategias destinadas a evitar o abandonar el mensaje y las estrategias destinadas a preservar el mensaje. Este hecho se debe a que los hablantes cuentan con los suficientes recursos de elicitación, y no reducen o abandonan el mensaje puesto que son conscientes de que se trata de una prueba de su competencia lingüística en euskera, y tratan, por esta razón, de mantener el mensaje pretendido.

En cuanto al tipo de instrumento de recopilación de datos y la EC utilizada (Tabla 3), se observa que en la historia gráfica, un ejercicio guiado de carácter descriptivo, los hablantes hacen un uso equilibrado de estrategias reductivas y de estrategias productivas. Este hecho constata la hipótesis de que los hablantes con un nivel de competencia intermedio utilizan de manera equilibrada ambos tipos de estrategias, con lo que se puede afirmar que poseen un nivel de competencia lingüística óptimo, en otras palabras, la interlengua ofrecida por el grupo de hablantes resulta equilibrada. 
TABLA 3. Actividad escrita y selección de EC

\begin{tabular}{|l|c|c|}
\cline { 2 - 3 } \multicolumn{1}{c|}{} & $\begin{array}{c}\text { Historia gráfica } \\
\text { (descripción) }\end{array}$ & $\begin{array}{c}\text { Redacción } \\
\text { (narración) }\end{array}$ \\
\hline Estrategias de reducción & 109 & 43 \\
\hline $\begin{array}{l}\text { Estrategias de producción } \\
\text { compensatorias no cooperativas) }\end{array}$ & 92 & 95 \\
\hline Total & 201 & 138 \\
\hline
\end{tabular}

En el segundo ejercicio, denominado de redacción, de carácter narrativo, los hablantes utilizan en mayor frecuencia estrategias compensatorias de producción que estrategias reductivas. Se deduce, por lo tanto, que este grupo de hablantes posee recursos suficientes en la lengua adquirida como para mantener el mensaje pretendido.

En cuanto a la relación entre ambos ejercicios, se deduce que, aun contemplándose que los ejercicios narrativos resultan de una complejidad cognitiva mayor que los ejercicios denominados descriptivos, nuestro grupo de hablantes constata la posibilidad de que diversos factores (la enseñanza de la competencia estratégica en el aula, práctica de métodos de elicitación, enseñanza de destrezas, etc.) pueden determinar el grado de efectividad comunicativa en el aprendiz.

TABLA 4. Actividad oral y selección de EC

\begin{tabular}{|l|c|c|}
\hline & \multicolumn{2}{|c|}{ Conversación } \\
\hline Estrategias compensatorias cooperativas & 30 & $15,7 \%$ \\
\hline Estrategias de recuperación & 161 & $84,3 \%$ \\
\hline Total & 191 & $100 \%$ \\
\hline
\end{tabular}

La Tabla 4 demuestra que en el ejercicio oral, destinado a obtener las EC compensatorias cooperativas y las EC de recuperación (ambas EC de producción), los sujetos han utilizado en mayor frecuencia las estrategias de recuperación. Este dato se debe al hecho de que el hablante, a pesar de que es consciente de que el interlocutor es un hablante bilingüe castellano-euskera que toma parte activa en la conversación y puede cooperar en la búsqueda de una solución apropiada, intenta mantener la comunicación y utilizar estrategias exitosas o efectivas, por lo que titubea (115 pausas) o produce términos similares en la L2 (46 búsquedas en campo semántico). A partir de estos resul- 
tados se constata que nuestro grupo de hablantes hace uso de la intencionalidad estratégica y de la cooperación como recursos comunicativos estratégicos, lo que viene a reforzar la tesis, obtenida a partir de los resultados, de que los hablantes que conforman el estudio hacen un uso frecuente de estrategias discursivas de producción. Otros autores (Bialystok, 1990), hablan de táctica, esto es, las estrategias de recuperación no provocan cambios en la interlengua de estos alumnos.

\subsubsection{Uso de EC basadas en la L1 y la L2}

Con respecto al uso de EC basadas en la L1 y las EC basadas en la L2, el último objetivo del estudio es comprobar el grado de éxito o efectividad comunicativa en el grupo de hablantes que conforman nuestro estudio. Tal y como se ha mencionado con anterioridad, dicha efectividad se realizará considerando el uso de las denominadas estrategias más o menos exitosas que se verá reflejado en la taxonomía presentada para la clasificación de las EC, esto es, basadas en la lengua materna o en la lengua adquirida o segunda.

TABLA 5. Efectividad comunicativa

\begin{tabular}{|c|c|c|c|c|c|c|}
\hline \multicolumn{2}{|c|}{ L1 ESTRATEGIAS (- efectivas) } & \multicolumn{4}{c|}{ L2 ESTRATEGIAS (+ efectivas) } \\
\hline $\begin{array}{c}\text { Code-swit- } \\
\text { ching }\end{array}$ & $\begin{array}{c}\text { Adaptación } \\
\text { de la L1 a L2 }\end{array}$ & $\begin{array}{c}\text { Traducción } \\
\text { literal }\end{array}$ & Sustitución & Paráfrasis & $\begin{array}{c}\text { Formación } \\
\text { de palabras }\end{array}$ & Reestructuración \\
\hline 2 & 16 & 17 & 18 & 13 & - & 120 \\
\hline 35 & & \multicolumn{5}{|c|}{151} \\
\hline
\end{tabular}

La tabla clasificatoria demuestra que, exceptuando la reestructuración, se produce el fenómeno tal cual ha sido preconcebido. Los hablantes han utilizado equilibradamente tanto las EC L1 como las denominadas EC L2. Este hecho se corresponde con su nivel de competencia. Aparte de esto, sorprende la multitud de ocurrencias que suceden dentro de la estrategia considerada de mayor éxito comunicativo como la reestructuración. El empleo continuado de esta estrategia denota un gran nivel de adquisición de la L2 que estos estudiantes poseen, a pesar de que consideraciones iniciales no preveían tal grado de competencia comunicativa.

\section{CONSIDERACIONES FINALES}

La metodología empleada en la presente investigación ha permitido recopilar un corpus de producción oral y escrita en un grupo significativo de apren- 
dices de euskera con un nivel de competencia intermedio. Los métodos de elicitación mediante canales escritos y orales han ayudado a identificar y clasificar 530 EC. De este modo se han obtenido datos relevantes en el estudio de la competencia estratégica y comunicativa de hablantes de euskera como L2 cuya lengua materna es el castellano.

La selección de una taxonomía apropiada ha resultado de especial relevancia a la hora de someter el corpus a análisis cuantitativos, y, así, verificar los objetivos formulados al inicio de la investigación. Los resultados han demostrado la relación existente entre el tipo de ejercicio y la frecuencia de uso de las EC identificadas, la frecuencia de uso de EC en hablantes de euskera con un nivel de competencia intermedio cuya lengua materna es el castellano, así como la efectividad comunicativa en el grupo de hablantes seleccionado teniendo en cuenta la frecuencia de uso de las EC más o menos exitosas, esto es, basadas en la L2 o en la L1 de los sujetos objeto de estudio. Además, se ha conformado una taxonomía tipificadora de EC con el objeto de aplicarse a futuros estudios de investigación relacionados con la lengua vasca.

En este estudio no se han considerado sujetos con un nivel de competencia lingüística elemental y elevado, grupos que se considerarán en futuras investigaciones, sin embargo, se ha considerado el grupo de hablantes con un nivel intermedio, ya que estudios en esta dirección consideran este nivel de competencia como el grado óptimo de interlengua.

En suma, los resultados de nuestro estudio nos han permitido llegar a conclusiones acerca del uso de estudiantes de euskera cuya lengua nativa es el castellano, que han pretendido asentar una base sistematizadora en el campo de la enseñanza del euskera como L2.

\section{REFERENCIAS BIBLIOGRÁFICAS}

BiALYSTOK, E. (1983 a): «Some factors in the selection and implementation of communication strategies», en FAERCH C. y G. KASPER (eds.) (1983a).

- (1983 b): «Strategies in interlanguage learning and performance», en Davies, A., C. Criper y A. P. R. Howatt (ed.) (1984: 37-48).

- (1990): Communicative strategies, Oxford: Basil Blackwell.

CORDER, S. P. (1981): Error Analysis and Interlanguage, Oxford, Oxford University Press.

DAVIES, A., C. CRIPER y A. P. R. HowATt (eds.) (1984): Interlanguage: Proceedings of the Seminar in Honour of Pit Corder, Edimburgo, Edinburgh University Press.

FAERCH, C. y G. KASPER (1983 a): Strategies in Interlanguage Communication, Londres, Longman. 
- (1983 b): «On identifying communication strategies» en FAERCH, C. y G. KASPER (1983 $a$ : 210-238).

Kasper, G. y E. Kellerman (eds.) (1997): Communication Strategies: Psycholinguistic and Sociolinguistic Perspectives, Londres, Longman.

SARrionandia, B. (1999): Perfiles lingüísticos: modelo alternativo de evaluación de la competencia lingüística en euskera. Tesis Doctoral, Bilbao, Universidad de Deusto.

SLINKER, L. (1991): Rediscovering Interlanguage, Londres, Longman.

TARONE, E. (1977): «Conscious communication strategies in Interlanguage» en Brown, H., C. Yorio y R. Crymes (eds.) (1977): On Tesol '77, Washington DC, TESOL, 194-203.

VARADI, T. (1983): Strategies of Target Language Learner Communication: Message Adjustment, Timisoara, IRAL, 18: 59-71. 


\title{
CREENCIAS Y MODELOS \\ DE REPRESENTACIÓN \\ SOBRE LA ENSEÑANZA \\ DE LA PRONUNCIACIÓN EN E/LE
}

\author{
Lidia Usó ViciEdo \\ Universitat de Barcelona
}

\section{INTRODUCCIÓN}

D ESDE mediados de los años 70 existen líneas de investigación educativa que se han centrado en los procesos de pensamiento y creencias de los profesores y su implicación en la práctica docente, como resultado de las teorías cognitivas que ponen en relación cognición y acción (Clark y Yinger, 1979; Young, 1981; Elbaz, 1983; Clandinin, 1986; Clark y Peterson, 1986; Nespor, 1987; Gimeno y Pérez, 1987; Marrero, 1991; Pajares, 1992 y 1993; Kagan, 1992; Burns, 1992; Johnson, 1992; Richardson, 1996; Woods, 1996; Fang, 1996; Calderhead, 1996; Hsiao-Ching, 2000; Ballesteros, 2000; Borg, 2001; Palou, 2002; Gilbert, 2002; Borg, 2003; Forns, 2003; Anaya, 2004; Alfa, 2004). Marrero (1991) señala que el pensamiento del profesor afecta a la manera de planificar la enseñanza. Pajares (1992: 307) afirma que "few would argue that the beliefs teachers hold influence their perceptions and judgements, which, in turn, affect their behaviour in the classroom". Richardson (1996) destaca el carácter tácito de esta clase de conocimiento y el hecho de que se pueda reflejar en imágenes, rutinas, procedimientos y ritmos en la vida del aula. Borg (2001) sostiene que las creencias «guían» el pensamiento y el comportamiento de los profesores.

Por una parte, las creencias son un concepto que no resulta fácil de definir con exactitud. La antropología, la psicología social y la filosofía han contribuido a estudiar y a entender la naturaleza de las creencias y sus efectos en las acciones. Hay una gran congruencia entre estas tres disciplinas sobre la definición de las creencias consideradas mentalidades, premisas y proposiciones sobre el mundo que parecen ser verdaderas para el que las manifiesta y que guían sus decisiones, actitudes y acciones. Pero las creencias no son pensamientos que se limitan a lo que existe, sino que también pueden corresponder a valoraciones y juicios que se expresan con la formación de opiniones. Las personas pueden tener creencias de las que no son conscientes, o que han sido 
adquiridas sin demasiado procesamiento consciente como consecuencia de la observación, la imitación o la experiencia.

Según Van Dijk $(1998,2003)$, las creencias representan al mundo, lo interpretan en términos de categorías conceptuales socialmente adquiridas. En este sentido, las creencias constituyen el mundo según nosotros. Eso no significa que el mundo natural o social no exista independientemente de nuestras creencias, sino tan solo que las personas lo estructuran y experimentan en términos de sus creencias.

Para Cantero y de Arriba (1997) la conciencia del hombre es una representación parcial, un mapa de la realidad. La representación que tengamos del mundo -es decir, la conciencia- es lo que genera y gobierna toda nuestra conducta. Estos autores han llamado a esa representación o mapa «modelo del mundo» (MM). Así, en realidad, los seres humanos no actuamos directamente sobre el mundo sino a través de la representación que tenemos de él, de ese mapa que nos permite reducir la realidad a dimensiones manejables, ya que esta no podría ser representada en su totalidad debido a que la capacidad humana es limitada. Así, cada persona tiene un modelo del mundo particular, una representación del mundo diferente que habrá ido formando en el transcurso de su vida. Pero, a su vez, el modelo del mundo de cada individuo tiene bastante en común con el de los demás, dado que lo son de la misma realidad, por ello la comunicación es posible. Para estos autores el modelo del mundo es dinámico, manipulable y está en constante cambio. Lo manifestamos parcialmente a través de nuestros propios discursos y puede ser modificado en contacto con otros individuos, precisamente a través del discurso, de la interacción.

Moscovici (1961) habla de representaciones sociales (RS): construcciones simbólicas que se crean y recrean en el curso de las interacciones sociales; no tienen un carácter estático ni determinan inexorablemente las representaciones individuales. Este autor hace énfasis en la construcción social del conocimiento. En esta línea, Jodelet (1986) afirma que las representaciones sociales son imágenes «que condensan un conjunto de significados; sistemas de referencia que nos permiten interpretar lo que nos sucede, e incluso da un sentido a lo inesperado; categorías que sirven para clasificar las circunstancias, los fenómenos y a los individuos con quienes tenemos algo que ver...». Todo nuestro conocer es un «construir» representaciones sociales. Éstas se ubican en las mentes de los individuos. De nuevo aparece la imagen de la mente como morada, como espacio interno, donde habitan las representaciones que el individuo forja del mundo exterior. Así, las RS se conciben como estructuras ordenadas y jerarquizadas a partir de un grupo social específico y son compartidas por mentes individuales con ciertas variaciones.

Por otra parte, las teorías constructivistas de aprendizaje postulan que los alumnos llegan al aula con unas creencias ya formadas que influyen, de manera 
fundamental, en el qué y en el cómo aprenden. En esta línea, las recientes teorías cognitivas perciben el aprendizaje como un proceso activo y constructivo que estará influido por la mentalidad, las creencias y prejuicios de los individuos.

En todo este marco teórico la formación de profesores cobra especial relevancia en la medida en que esta pueda desestabilizar y hacer avanzar ese conocimiento aportado por los profesores al aula, es decir, su representación o modelo del mundo. El hecho de que hayan decidido voluntariamente seguir formándose podría ser ya el primer paso hacia el cambio. En la actualidad existe una línea de investigación sobre el crecimiento y desarrollo profesional de los profesores que aboga por el aprendizaje reflexivo y la interacción entre ellos como elementos clave en la elaboración y cambio de sus creencias (Schön, 1987; Hatton y Smith, 1995; Tillema, 2000; Conway, 2001; Gomez, 2002; Manouchehri, 2002; Sato y Kleinsasser, 2004; Warfield, Wood y Lehman, 2005; Carroll, 2005; So y Watkins, 2005).

Fundamentando estos estudios encontramos las perspectivas constructivistas de Piaget $(1932,1976)$ y Vygotsky $(1978,1981)$. Para Piaget el aprendiz juega un papel activo en la construcción del conocimiento y el entendimiento; para Vygotsky el aprendizaje se entiende como un proceso social, en el que los aprendices construyen significados de manera activa y continua interaccionando entre ellos en un determinado contexto social. En este sentido, los foros de debate virtuales se erigen como un vigoroso contexto de aprendizaje interactivo y social, al potenciar la interacción entre los participantes y la construcción de conocimiento con la ayuda del profesor (Jonassen et al., 1995; Sherry, 1996; Allan, 2004).

En el presente estudio trataremos de aproximarnos a lo que piensan un grupo de profesores de E/LE en formación sobre la enseñanza de la pronunciación, a partir de su participación en un foro de debate virtual. En concreto nos hemos planteado los siguientes objetivos:

1. Saber cuáles han sido las cuestiones o temas tratados por los informantes relacionados con la pronunciación.

2. Observar los temas que más interés han despertado en el debate, los más tratados.

3. Averiguar qué sistema de creencias tienen en mente los informantes sobre la enseñanza de la pronunciación e identificar posibles modelos de pensamiento o de representación diferentes a este respecto.

4. Finalmente, y en el caso de encontrar más de un modelo de pensamiento, observar cuál de ellos predomina entre los informantes y en qué medida se muestran los otros. 


\section{MÉTODO}

El corpus analizado consta de una muestra de 46 informantes, que han escogido la asignatura de Fonética Aplicada en el Máster de Formación de Profesores de Español como Lengua Extranjera que imparte anualmente el Departamento de Didàctica de la Llengua i la Literatura de la Universitat de Barcelona. En concreto, los informantes pertenecen a tres promociones del citado máster: a la promoción (2001/03), a la que hemos llamado A; a la promoción (2002/04), a la que hemos llamado B y a la promoción (2003/05), llamada C. Aún así, la muestra analizada pensamos que constituye un grupo homogéneo y cohesionado, por lo que se han analizado todos los informantes en conjunto.

En la Tabla 1 mostramos las características que le dan al grupo la cohesión y homogeneidad mencionada:

\section{TABLA 1. Características del grupo de informantes, muestra de estudio}

\begin{tabular}{|l|}
\hline - Alumnos que se están formando como profesores de E/LE. \\
\hline - La gran mayoría ejercen ya como profesores de E/LE, por tanto. \\
\hline - Son profesores que están preocupados por su formación y por la mejora de su \\
enseñanza. \\
\hline - Han escogido todos la versión semipresencial del máster. \\
\hline - Tienen todos una formación similar en Humanidades. \\
\hline - Todos han escogido la asignatura optativa de Fonética Aplicada. \\
\hline - El profesor ha sido el mismo en las tres promociones. \\
\hline - Los contenidos de la asignatura y la bibliografía facilitada también han sido los \\
mismos.
\end{tabular}

Para realizar este estudio hemos analizado las reflexiones de los informantes en sus participaciones en el foro de debate de la asignatura de Fonética Aplicada y en las tareas entregadas al profesor al finalizar el foro. En el foro los participantes reflexionaron y expresaron libremente sus opiniones acerca de 6 aspectos o temas relacionados con la enseñanza/aprendizaje de la pronunciación, propuestos por el profesor inicialmente, y sobre los que después reflexionarían por escrito en su tarea. A continuación, aportamos estas seis cuestiones: 
TABLA 2. Temas propuestos por el profesor para reflexionar en el foro

\begin{tabular}{|l|l|}
\hline Tema 1 & $\begin{array}{l}\text { ¿Nuestra labor es «corregir» la mala pronunciación de nuestros alum- } \\
\text { nos, como implica el propio término «corrección fonética»? ¿Pretende- } \\
\text { mos conseguir la «excelencia»? }\end{array}$ \\
\hline Tema 2 & ¿Por qué no funciona la corrección fonética tradicional? \\
\hline Tema 3 & ¿Hasta qué punto enseñar pronunciación es enseñar lengua oral? \\
\hline Tema 4 & ¿La pronunciación incluye la comprensión oral? \\
\hline Tema 5 & ¿Enseñar pronunciación es enseñar fonética? \\
\hline Tema 6 & $\begin{array}{l}\text { ¿Puede «enseñarse» la pronunciación, o más bien lo que podemos hacer } \\
\text { es procurar que los alumnos comiencen un proceso de adquisición fóni- } \\
\text { ca del idioma? }\end{array}$ \\
\hline
\end{tabular}

\section{RESULTADOS}

Respecto a los temas tratados, aparte de los propuestos por el profesor (ver método Tabla 2), los participantes han tratado espontáneamente 6 aspectos más relacionados con el tema de la pronunciación y que detallamos a continuación en la Tabla 3:

\section{TABLA 3. Temas nuevos surgidos en el debate}

\begin{tabular}{|l|l|}
\hline Tema 7 & $\begin{array}{l}\text { Sobre si la pronunciación implica la competencia fónica / la interlengua } \\
\text { fónica. }\end{array}$ \\
\hline Tema 8 & Sobre qué pronunciación del español enseñar. \\
\hline Tema 9 & Sobre la idea de imitar la forma de hablar de los nativos. \\
\hline Tema 10 & $\begin{array}{l}\text { Sobre los componentes emocionales y las barreras psicológicas que con- } \\
\text { lleva el hecho de hablar una LE / la apropiación de la LE. }\end{array}$ \\
\hline Tema 11 & $\begin{array}{l}\text { Sobre si el tema de la pronunciación preocupa a los estudiantes y/o pro- } \\
\text { fesores. }\end{array}$ \\
\hline Tema 12 & $\begin{array}{l}\text { Sobre los factores que obstaculizan el aprendizaje de la pronunciación (la } \\
\text { edad, el factor crítico, las interferencias y transferencias de la L1...). }\end{array}$ \\
\hline
\end{tabular}

En la Figura 1 podemos ver el número de informantes que ha tratado cada uno de los temas, tanto los propuestos por el profesor como los surgidos espontáneamente en el foro: 


\section{$\square$ Núm. alumnos}

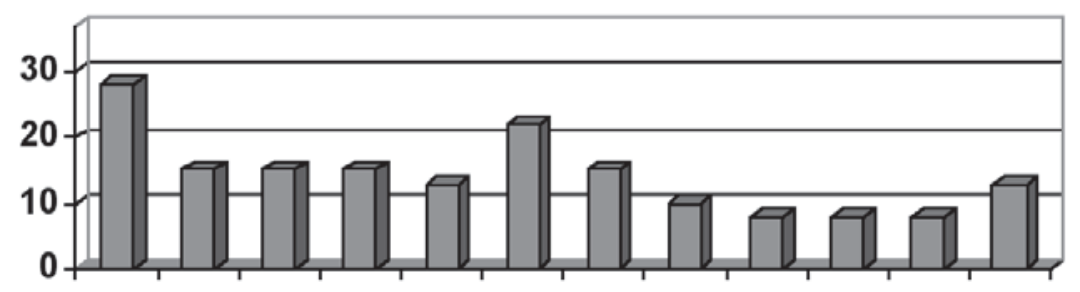

En relación con los sistemas de creencias que se han revelado en los discursos de los informantes, hemos encontrado cuatro modelos generales de pensamiento sobre la enseñanza de la pronunciación: uno «tradicional», que basa su enseñanza en la corrección; otro «comunicativo puro», que prioriza la inteligibilidad y eficacia de los discursos y rechaza la corrección fonética; y otros dos modelos híbridos a los que hemos llamado «comunicativo con corrección», por considerarla en caso de que la mala pronunciación afecte a la inteligibilidad o si nos lo piden los alumnos, y «falso comunicativo», modelo que al final se descubre tradicional y a favor de la corrección.

Seguidamente vemos en las Figuras 2, 3, 4 y 5 los cuatro modelos de pensamiento o de representación que predominan en los discursos de los participantes y que conformarían cuatro visiones bastante diferentes de la enseñanza de la pronunciación. 


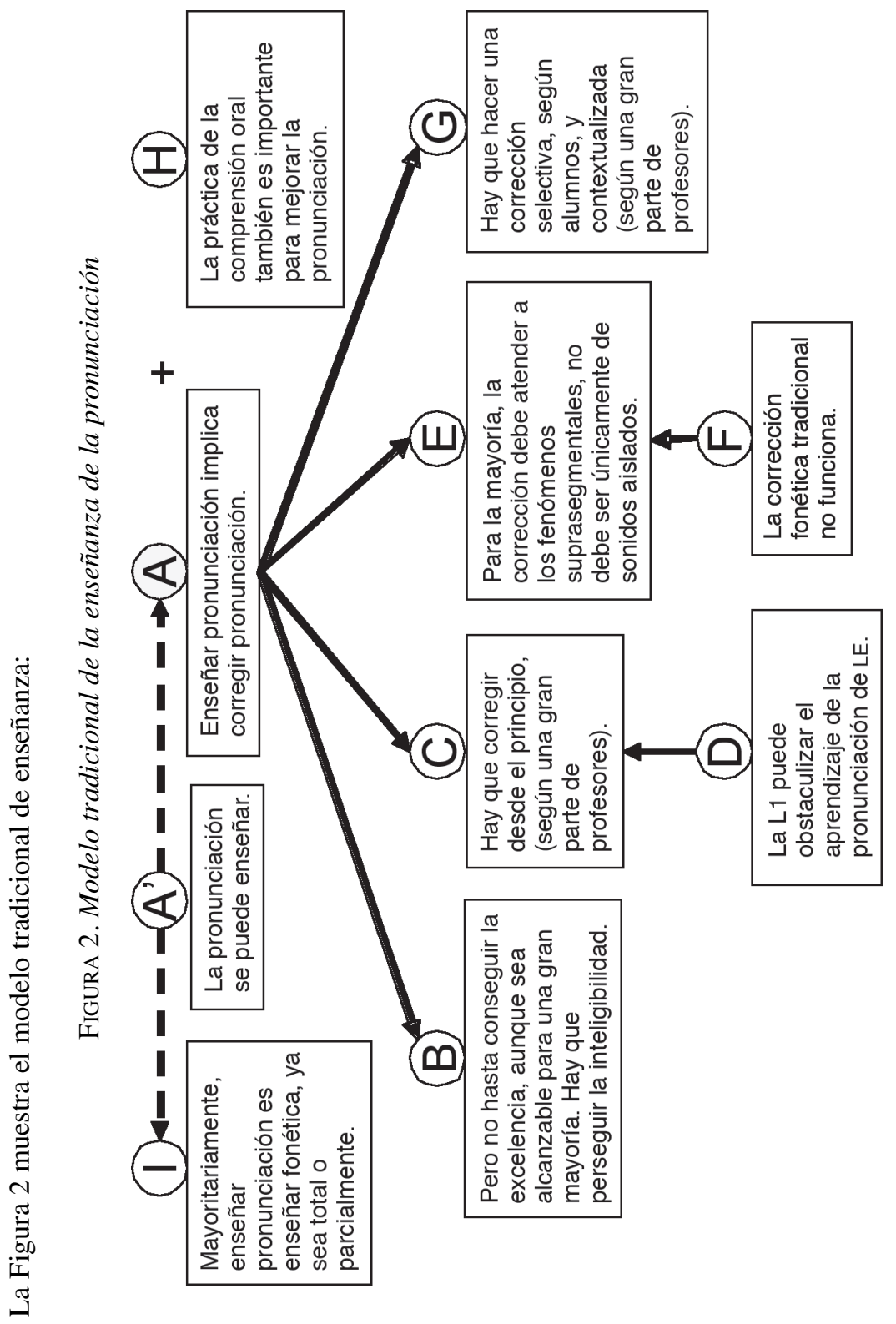




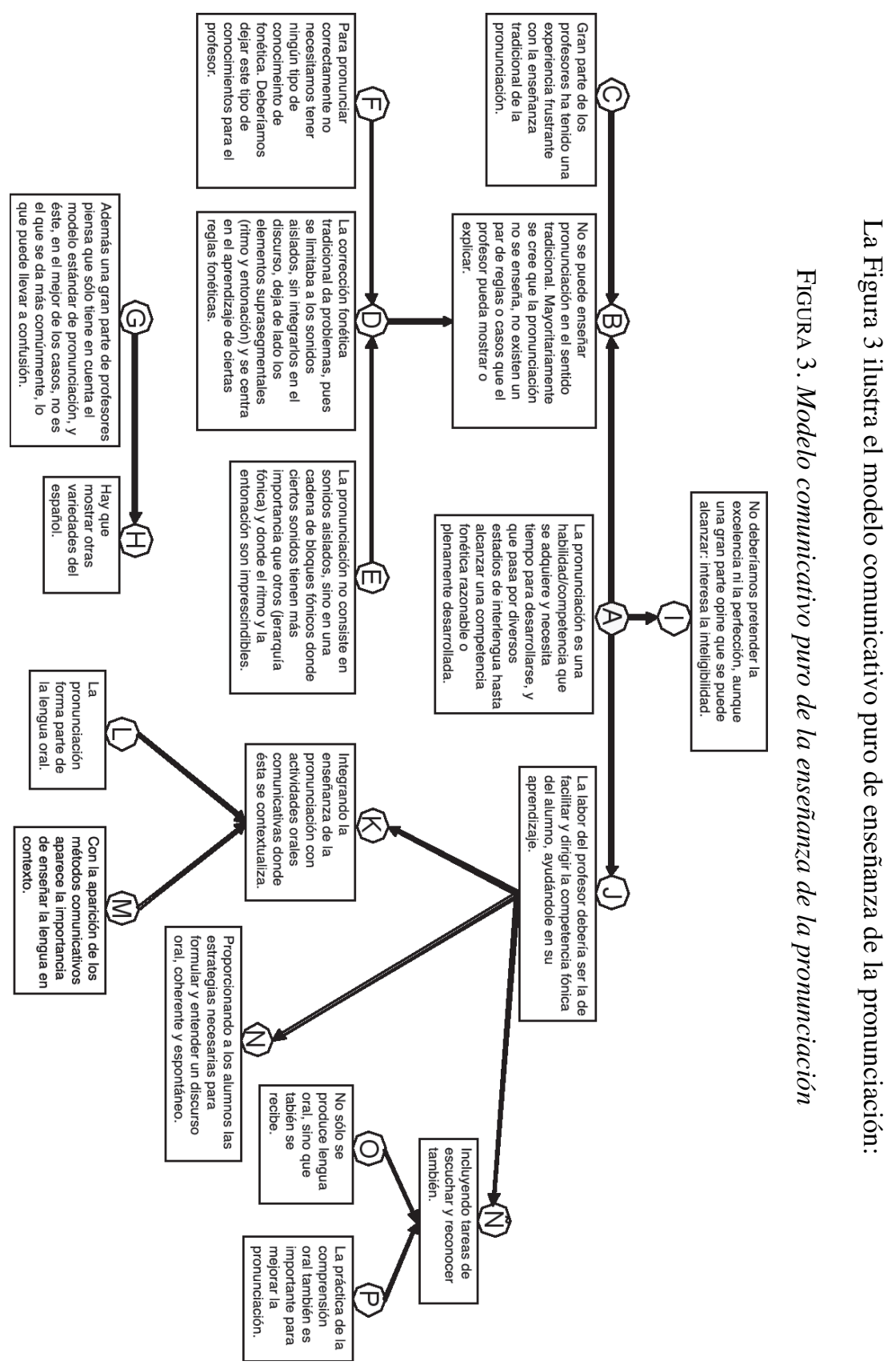




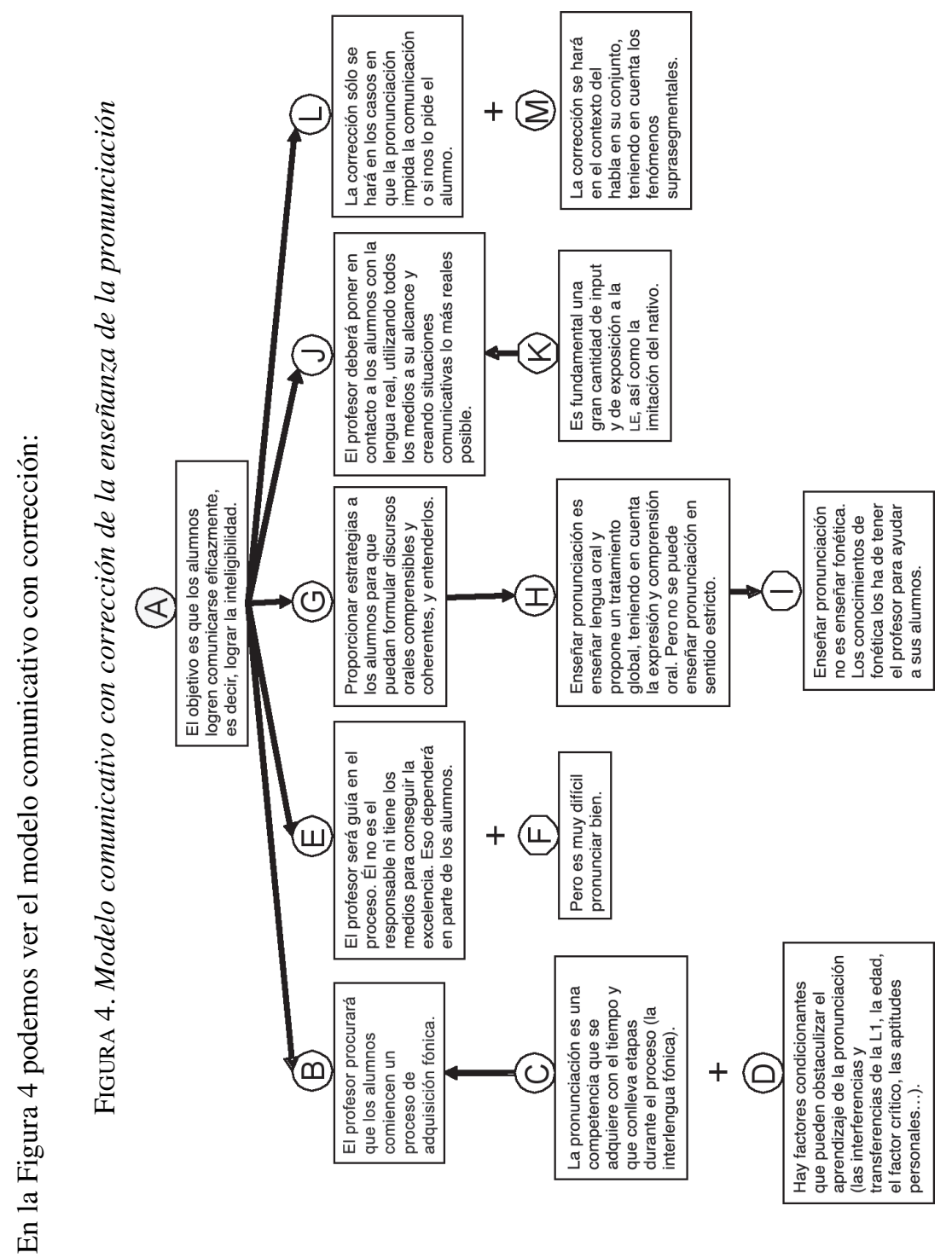



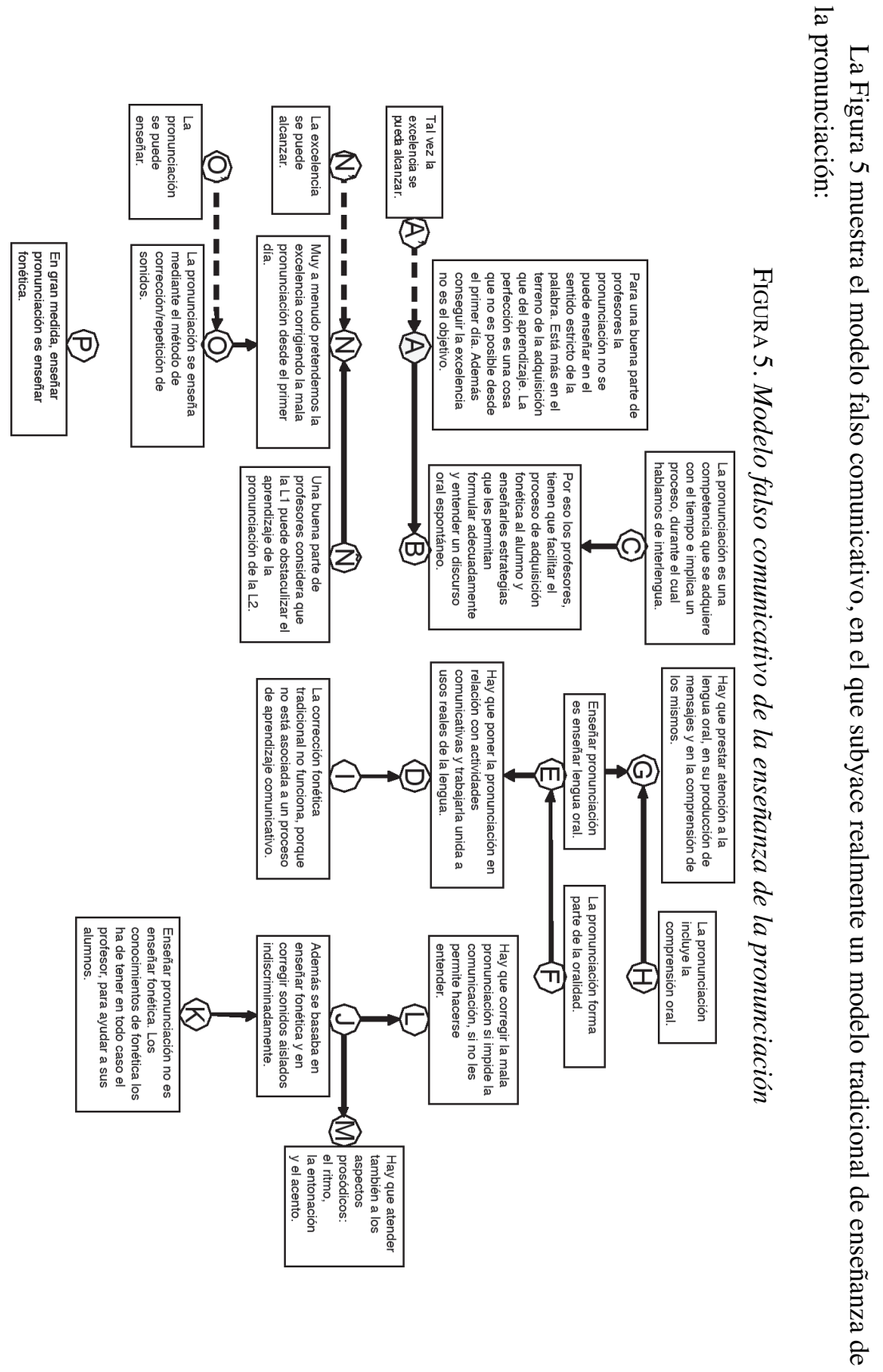
Finalmente, en la Figura 6 presentamos el porcentaje de informantes que ha manifestado tener implícito un modelo u otro de pensamiento sobre la enseñanza de la pronunciación:

FIGURA 6. Porcentaje de informantes según el modelo de enseñanza de pronunciación manifestado

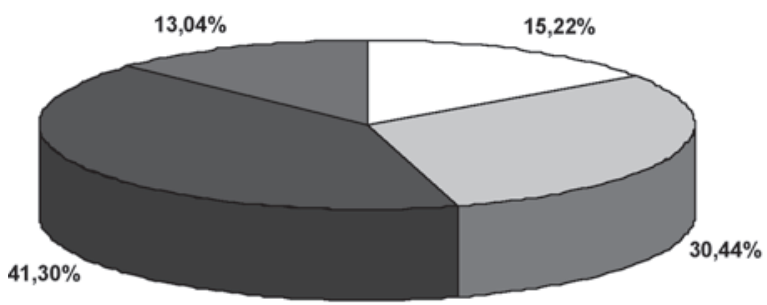

$\square$ Modelo tradicional

口Modelo falso

comunicativo

Modelo comunicativo + corrección

Modelo comunicativo puro

\section{CONCLUSIÓN}

En relación a los objetivos propuestos inicialmente, concluimos en primer lugar que, aunque el debate en el foro estaba semidirigido por las 6 cuestiones planteadas para reflexionar por el profesor, ha quedado patente su alta productividad, dada la proliferación de temas, que de hecho se han visto aumentados a 12. De los temas nuevos surgidos en el debate, el 7 y el 12 se trataban en los contenidos de la asignatura (ver Resultados Tabla 3). Los cuatro restantes han sido fruto de la interacción de los participantes, revelándose el foro de debate como fuente útil para potenciar el intercambio de ideas y el aprendizaje constructivista.

En segundo lugar, respecto a los temas que despertaron un mayor interés, destacan el 1 y el 6, de entre los propuestos por el profesor (ver Método Tabla 2), y el 7 y el 12, de entre los nuevos temas surgidos en el debate (ver Resultados Tabla 3).

En relación a los modelos de pensamiento o de representación sobre la enseñanza de la pronunciación que los profesores han revelado en sus discursos, hemos observado en primer lugar que los modelos de pensamiento individuales de los informantes se incluyen básicamente en cuatro modelos generales de representación: «tradicional», «falso comunicativo», «comunicativo con corrección» y «comunicativo puro» (ver resultados Figura 6). En nuestra opinión, estos modelos de pensamiento podrían constituir modelos de 
representación social (Moscovici, 1961; Jodelet, 1986), creados y compartidos, aunque con ciertas variaciones, por un grupo social cohesionado, los profesores de E/LE, al interaccionar para crear entendimiento, en última instancia, conocimiento.

En segundo lugar, podemos decir que básicamente estos cuatro modelos se engloban en dos grandes visiones o perspectivas de la enseñanza de la pronunciación: la comunicativa (el 54,34\%, incluyendo también los que se manifestaron a favor de la corrección) y la tradicional (el 45,66\%, si incluimos aquí dentro también los que revelaron un modelo falso comunicativo). A pesar de que parece predominar la visión comunicativa en este tema, cabe resaltar el alto porcentaje atribuido a la visión tradicional de la enseñanza de la pronunciación.

Cabe señalar también que la mayoría de los informantes $(86,96 \%)$ consideró la corrección fonética como herramienta útil en la enseñanza de la pronunciación. Consideramos que estos datos deberían tenerse en cuenta a la hora de tratar el tema de la pronunciación en los manuales de E/LE y de plantear actividades.

Para finalizar, si consideramos el análisis de los modelos de pensamiento identificados desde una perspectiva constructivista del aprendizaje, cabe resaltar que el $84,78 \%$ de los informantes hizo un discurso parcial o totalmente comunicativo, con ideas muy en la línea de los contenidos del máster (aunque el $30,44 \%$, correspondiente al modelo falso comunicativo, se revelara al final a favor de un modelo de pensamiento tradicional). En este sentido, podemos decir que el máster ha cumplido, a priori, con la función de aportar nuevo conocimiento. Esperemos que también haya servido para desestabilizar, en alguna medida, el sistema de creencias de los informantes, es decir, su modelo de pensamiento o representación.

\section{REFERENCIAS BIBLIOGRÁFICAS}

Alfa, N. (2004): Creencias de los aprendices griegos de E/LE sobre el aprendizaje y las características del español. Proyecto de Tesis doctoral, dirigido por M. Cambra, Universitat de Barcelona.

Allan, M. (2004): «A Peek into the Life of Online Learning Discussion Forums: Implications for Web-Based Distance Learning», International Review of Research in Open and Distance Learning, August, $<\mathrm{http}: / /$ www.irrodl.org/content/v5.2/allan.html>.

AnAYA, V. (2004): Libros de texto, pensamiento del profesor y directrices curriculares para E/LE en el sistema educativo francés. Proyecto de tesis doctoral, dirigido por M. Llobera, Universitat de Barcelona. 
Ballesteros, C. (2000): Percepciones, creencias y actuaciones de los profesores de lenguas propias durante los dos primeros años de funcionamiento de la enseñanza secundaria obligatoria (ESO). Un estudio de caso. Tesis doctoral inédita dirigida por M. Llobera, Universitat de Barcelona.

Borg, M. (2001): «Teachers' beliefs», English Language Teaching Journal, 55 (2): 186-188.

BORG, S. (2003): «Teacher cognition in language teaching. A review of research on what teachers think, know, believe, and do», Language Teaching, 36: 81-109.

BuRNS, A. (1992): «Teacher beliefs and their influence on classroom practice», Prospect, 7 (3): 56-66.

CAlderhead, J. (1996): «Teachers: Beliefs and Knowledge» en Berliner D. C. y R. C. CALFEE (eds.) (1996): Handbook of educational psychology, Prentice-Hall International, Londres, 709-725.

CAntero, F. J. y J. de Arriba (1997): Psicolingüística del discurso, Barcelona, Octaedro.

CARROLL, D. (2005): «Learning through interactive talk: A school-based mentor teacher study group as a context for professional learning», Teaching and Teacher Education, 21: 457-473.

Clandinin, D. J. (1986): Classroom Practice: Teacher Images in action, Londres, Falmer.

Clark, C. M. y P. L. Peterson (1986): «Teacher's thought processes», en Wittrock, M. C. (ed.) (1986): The Handbook of Research on Teaching, Nueva York, MacMillan.

Clark, C. M. y R. J. Yinger (1979): «Teachers' thinking», en Peterson, P. y H. J. WAlberG (eds.) (1979): Research on teaching, Berkeley, Ca., McCutchen.

CONWAY, P. F. (2001): «Anticipatory reflection while learning to teach: from a temporally truncated to a temporally distributed model of reflection in teacher education», Teaching and Teacher Education, 17: 89-106.

Elbaz, F. (1983): Teacher Thinking: A Study of Practical Knowledge, Londres, Croom and Helm.

FANG, Z. (1996): «A review of research on teacher beliefs and practices», Educational Research, 38 (1): 47-65.

FoRns, C. (2003): Creencias y actitudes de profesores y alumnos hispanos sobre su lengua y cultura. Un estudio de caso sobre residentes latinos en la ciudad de Chicago. Tesis doctoral inédita dirigida por M. Llobera, Universitat de Barcelona.

GILBERT, L. (2002): Com creuen els professors de traducció especialitzada que es forma un traductor? Proyecto de Tesis doctoral, dirigido por M. Llobera, Universitat de Barcelona. 
Gimeno, J. y A. PÉREZ (1987): El pensamiento psicopedagógico de los profesores. Informe de investigación, Madrid, CIDE.

Gomez, M. L. (2002): «The Role of Talk in Learning to Teach», Curriculum and Teaching, 17 (2): 37-53.

Hatton, N. y D. SMith (1995): «Reflection in teacher education: Towards definition and implementation», Teaching and Teacher education, 11 (1): 23-32.

HSIAO-CHING, S. (2000): «The interplay of a biology teacher's beliefs, teaching practices and gender-based student-teacher classroom interaction», Educational Research, 42 (1): 100-111.

JODELET, D. (1986): «La representación social: fenómenos, concepto y teoría» en Moscovici, S. (dir.) (1986): Psicología Social. Pensamiento y vida social. Psicología social y problemas sociales, II, Barcelona, Paidós, 469-495.

JOHNSON, K. (1992): «The relationship between teachers' beliefs and practices during literacy instruction for non-native speakers of English», Journal of Reading Behavior, 24 (1): 83-108.

JonASSEN, D., et al. (1995): "Constructivism and Computer-Mediated Communication in Distance Education», The American Journal of Distance Education, 9 (2):7-26.

KaGAN, D. (1992): «Implications of Research on Teacher Beliefs», Educational Psychologist, 27 (1): 65-90.

Manouchehri, A. (2002): «Developing teaching knowledge through peer discourse», Teaching and Teacher Education, 18: 715-737.

Marrero, J. (1991): «Teorías implícitas del profesorado y currículum», Cuadernos de Pedagogía, 197: 66-69.

Moscovici, S. (1979): El psicoanálisis, su imagen y su público, Huemal, Buenos Aires. (Trabajo original publicado en 1961).

NESPOR, J. (1987): «The role of beliefs in the practice of teaching», Journal of Curriculum Studies, 19 (4): 317-328.

PAJARES, F. (1992): «Teachers' Beliefs and Educational Research: Clearing up a Messy Construct», Review of Educational Research, 62 (3): 307-332.

- (1993): «Preservice Teacher's Beliefs: A Focus for Teacher Education», Action in Teacher Education, 15 (2): 45-54.

PAlou, J. (2002): L'ensenyament i l'aprenentatge del català com a primera llengua a l'escola. Creences i actuacions dels mestres amb relació a les activitats de llengua oral a l'etapa primària. Tesis doctoral inédita dirigida por M. Cambra, Universitat de Barcelona.

Piaget, J. (1932): The Language and Thought of the Child (2nd ed.) Londres, Routledge \& Kegan Paul.

- (1976): The grasp of consciousness: Action and concept in the young child, Cambridge, Harvard University Press. 
RichARDSON, V. (1996): «The role of attitudes and beliefs in learning to teach», en Sikula, J., T. J. Buttery y E. Guyton, (eds.) (1996): Handbook of Research on Teacher Education, Nueva York, MacMillan.

SATO, K. y R. KLEINSASSER (2004): «Beliefs, practices, and interactions of teachers in a Japanese high school English Department», Teaching and Teacher Education, 20: 797-816.

SHERRY, L. (1996): «Issues in Distance Learning», International Journal of Educational Telecommunications, 1 (4): 337-365.

SHön, D. A. (1987): Educating the reflective practitioner, San Francisco, Jossey-Bass.

So, W. P. y D. A. WATKINS (2005): «From beginning teacher education to professional teaching: A study of the thinking of Hong Kong primary science teachers», Teaching and Teacher Education, 21: 525-541.

Tillema, H. H. (2000): «Belief change towards self-directed learning in student teachers: immersion in practice or reflection on action», Teaching and Teacher Education, 16 (5/6): 575-591.

VAN DIJK, T. A. (1998): Ideología: Una aproximación multidisciplinaria, Barcelona, Gedisa.

- (2003): Ideología y discurso, Barcelona, Ariel.

Vigotsky, L. S. (1978): Mind in Society: The Development of Higher Psycological Process, Cambridge, Mass, Harvard University Press.

- (1981): «The genesis of higher mental functioning», en WERTSCH, J. V. (ed.) (1981): The concept of activity in Soviet psychology, Armonk, NY, Sharpe, 144-188.

Warfield, J., T. Wood y J. D. Lehman (2005): «Autonomy, beliefs and the learning of elementary mathematics teachers», Teaching and Teacher Education, 21: 439- 456.

Woods, D. (1996): Teacher Cognition in Language Teaching. Beliefs, decision-making and classroom practice, Cambridge, Cambridge University Press.

Young, R. E. (1981): «The epistemic discourse of teachers. An ethnografic study», Teaching and teacher education, 8 (2): 137-149. 


\title{
PROYECTO UNIVERSIDAD DE ALCALÁ: UNIVERSIDAD PARA LA INMIGRACIÓN
}

\author{
Carmen Valero Garcés \\ Universidad de Alcalá de Henares
}

\section{INTRODUCCIÓN}

$\mathbf{E}$ $\mathrm{N}$ la actualidad asistimos a un intenso debate sobre el fenómeno de la inmigración, en parte fruto de la percepción negativa que este genera en determinados sectores de la sociedad. Ahora bien, este fenómeno no es nuevo. Los movimientos de población han sido una constante histórica y se han producido desde los orígenes del hombre. De hecho, las investigaciones nos dicen que los primeros humanos no fueron europeos ni asiáticos o americanos sino africanos, y en algún momento del pasado a través de sucesivas oleadas migratorias se produjo el poblamiento de Eurasia a partir de individuos procedentes de África. Por otra parte, estos movimientos migratorios, a lo largo de miles y miles de años, han ido conformando los diferentes grupos étnicos y raciales actuales, así como las grandes civilizaciones históricas mediante una serie de mestizajes culturales.

España, como es lógico, no ha sido una excepción en esta cuestión y los flujos migratorios, tanto en un sentido como en otro, han sido numerosos a lo largo de su historia. Las migraciones no han cesado, pero sí ha habido importantes cambios en la dirección de estos movimientos de población y, sobre todo, en el contexto en que se han ido produciendo. España ha pasado de ser un país emisor de emigrantes a ser un país receptor de inmigrantes. Aunque los datos no están del todo claros, se estima que los ciudadanos no españoles en nuestro país oscilan entre el $6,5 \%$ y el 8,4 \% de la población lo que supone hasta un total de 3,5 millones de personas extranjeras. Nos hemos convertido por tanto en un país al que llegan miles de seres humanos que no entienden su nueva sociedad y a quienes apenas entendemos.

Estos aluviones migratorios de los últimos años han configurado en España, y en el Corredor del Henares -zona de actuación de la Universidad de Alcalá, fundamentalmente industrial y que comprende básicamente la zona norte de la Comunidad Autónoma de Madrid y la provincia de Guadalajara perteneciente a la Junta de Comunidades de Castilla-La Mancha- en particular, una nueva situación sociológica y demográfica que afecta de manera irreversible a toda la ciudadanía. Desde los aspectos laborales a los educativos se 
ven variados por los perfiles de una nueva convivencia que, día a día, toma cuerpo entre nosotros.

La Universidad de Alcalá (UAH), situada en este entorno de fuerte inmigración, ha querido asumir su responsabilidad social de facilitar la plena integración de estos recién llegados desarrollando el proyecto denominado Universidad para los Inmigrantes con el fin de facilitar el acceso de esta nueva población a nuestra cultura, a nuestras instituciones y a nuestra lengua y convertirse en ciudadanos de pleno derecho que contribuyan al desarrollo de este país. En las páginas que siguen me propongo describir brevemente dicho proyecto.

FIGURA 1

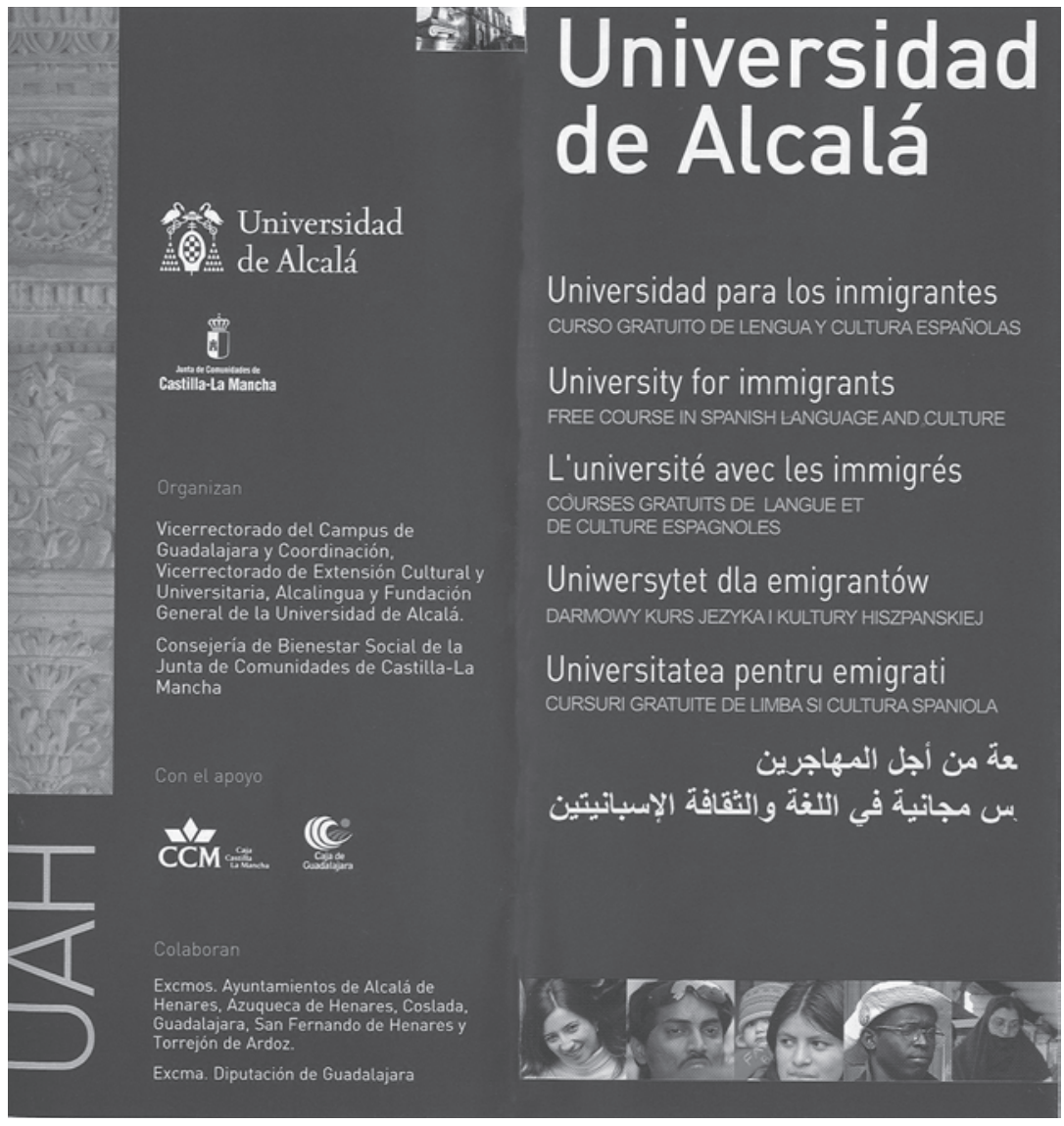




\section{OBJETIVOS}

El objetivo general del proyecto Universidad para los Inmigrantes, iniciado en la primavera de 2006, fue impulsar o poner en marcha una serie de actuaciones que facilitasen la integración social de las personas inmigrantes y el intercambio de experiencias y conocimientos entre los que están y los que llegan. Se trata de proyectos en su mayoría integrales en el sentido de que se busca la colaboración de la universidad con otros agentes sociales que están en contacto con dicha población: Ayuntamientos del Corredor del Henares (Alcalá de Henares, Guadalajara, Azuqueca, Torrejón de Ardoz, San Fernando y Coslada), Foros para la Inmigración, ONG y Asociaciones de Inmigrantes.

Los colaboradores de la UAH en este proyecto estamos convencidos de que sólo a través de la integración se podrán evitar problemas derivados de esta nueva realidad, entre los cuales figuran como los más graves la exclusión y marginación social originados por la falta de trabajo e interacción con la sociedad receptora. Pero hay que insistir en que la integración no debe ser exclusivamente laboral, sino también social y cultural. Por ello se planteó contribuir a mejorar las perspectivas de los inmigrantes de integrarse plenamente en la sociedad receptora con programas diversos para atender el mayor número posible de necesidades. Los programas planificados fueron de cuatro tipos fundamentalmente:

1. Enseñanza del español y formación en traducción e interpretación;

2. Programas de servicios;

3. Investigación; y

4. Programas culturales.

\section{PROGRAMAS}

Proporcionamos a continuación una breve descripción de algunos de estos programas.

\subsection{Programa de encuentros para la enseñanza de español a personas inmigrantes}

Objetivo principal: enseñar el español a la población inmigrante

Coordina: ALCALINGUA-UAH

Una de las consecuencias del fenómeno de la inmigración es que distintas culturas se ven obligadas a convivir sin que haya habido previamente una etapa de adaptación a las nuevas realidades y sin que, en muchos casos, exista la posi- 
bilidad de la comunicación, instrumento imprescindible para la convivencia, puesto que no comparten una lengua que lo haga posible. Es un hecho que la enseñanza del español a los grupos de población inmigrante facilita su integración y fomenta la convivencia intercultural, de ahí que sean muchos los ayuntamientos en el territorio nacional y las ONG o asociaciones de inmigrantes del más variado signo las que ofrecen clases de español. Sin embargo, son pocas las universidades, por no decir ninguna, que han acometido ese reto en sus aulas.

Desde la UAH se planteó un objetivo claro: enseñar el español a la población inmigrante. Sin embargo, hablar de enseñanza del español como segunda lengua a inmigrantes supone enfrentarse a una situación educativa muy especial, pues el objetivo del proceso de aprendizaje no es solo lingüístico sino, especialmente, sociocultural: el aprendizaje de la lengua no solo va a permitir la comunicación, sino que, por encima de todo, es el camino más eficaz hacia la integración. Es muy importante que tengamos esto en cuenta si queremos evitar que el fenómeno de la inmigración pueda convertirse en un problema por la marginación social de esta población. En consecuencia, se pretende formar lingüísticamente a todas estas personas, porque será el camino más seguro y certero para su integración.

La UAH contempló también el principal escollo para los inmigrantes que es el siguiente: al no disponer de tiempo ni de recursos económicos necesarios para inscribirse en escuelas o academias, acuden para su formación a ONG de diferentes características o a los servicios sociales de los ayuntamientos en las que, en muchas ocasiones, reciben una formación «de urgencia», impartida por colaboradores no expertos en la docencia de esta materia.

Por ello la UAH, en un primer momento, pretendió con este programa cubrir esta necesidad que tienen los inmigrantes de aprender español con clases gratuitas ofrecidas los fines de semana. Se analizaron también las necesidades y se planificaron cursos de español para personas inmigrantes en tres niveles de enseñanza: A, B y C, dividiéndose cada uno de ellos, a su vez, en dos niveles: A1, A2, B1, B2, C1 y C2, y desarrollando materiales adecuados: libros de texto, cuadernos de ejercicios y material audio (Serie Encuentros). El programa se puso en marcha en mayo de 2006.

\subsection{Programa de formación en traducción e interpretación en los servicios públicos}

Objetivos: Formación de traductores e intérpretes en lenguas de la inmigración Coordina: Grupo FITISPOS

Más allá del conocimiento de la lengua a un nivel que permita la comunicación en la vida cotidiana, el contacto con las instituciones exige de profesionales con un alto grado de competencia lingüística y cultural que hagan 
posible el intercambio de información de una a otra lengua. Atendiendo a esta necesidad se puso en marcha -ya en el año 2000- un programa pionero y único en nuestro país de formación de traductores e intérpretes en los servicios públicos. El objetivo principal era, y es, atender a la demanda creciente de profesionales que sirvan de enlace entre las instituciones y sus usuarios ante los nuevos retos que plantea la llegada de personas que hablan otras lenguas a nuestras escuelas, hospitales u oficinas del estado.

El programa consta de dos acciones formativas distintas para el curso 2006-2007:

I. Acción de postgrado: Máster Oficial en Comunicación Intercultural y Traducción e Interpretación en los Servicios Públicos, que se imparte en los pares de lenguas: árabe-español, alemán-español, francés-español, inglésespañol y rumano-español, al que se accede con el título de diplomado o licenciado y Máster en Traducción e Interpretación en los Servicios Públicos, en la combinación de lenguas árabe-español, polaco-español, rumanoespañol, ruso-español, chino-español y otras lenguas minoritarias, que se ofrece como Título Propio de la UAH y al que se accede igualmente con el título de diplomado o licenciado, pero que «excepcionalmente podrá eximirse de titulación oficial a personas que acrediten una notable experiencia profesional (mínimo 3 años) en ámbitos relacionados con la temática de la Acción Formativa» (ver <http://www2.uah.es/traduccion>). Ambos incluyen formación on line y presencial, prácticas en centros institucionales y memoria de Máster. Con estos tres aspectos se pretende preparar al alumno para trabajar en diferentes campos: con la formación online se pretende ponerles en contacto con las nuevas tecnologías; con las prácticas en instituciones, abrirles al mundo laboral; y con la Memoria de Máster, introducirles en la investigación. Nuestra experiencia demuestra que los tres componentes son necesarios hoy en día.

II. Acción de pregrado: Tres cursos de especialización, para los cuales no se precisa ninguna titulación especifica, únicamente el conocimiento de las dos lenguas de trabajo que elija el alumno. Cada curso se dedica a un aspecto relevante en las relaciones entre la población extranjera y las instituciones, a saber:

1. Curso sobre Comunicación Interlingüística (170 horas, online/no presencial).

2. Curso sobre Traducción e Interpretación en Hospitales y Centros de Salud (170 horas, en el par de lenguas elegido: árabe-español, inglésespañol, polaco-español, rumano-español, ruso-español, chino-español y otras lenguas minoritarias) 
3. Curso sobre Traducción e Interpretación Jurídico-Legal y Administrativa (170 horas, en el par de lenguas elegido: árabe-español, inglés-español, polaco-español, rumano-español, ruso-español, chino-español, y otras lenguas minoritarias).

Con dichos cursos se pretende atender a la demanda, por un lado, de personas que están únicamente interesadas en un aspecto de las relaciones (salud, educación, administración), y por otro, permitir el acceso a este tipo de educación especializada a personas que no cumplen los requisitos para acceder a estudios de postgrado (por poseer título extranjero no homologado -hecho frecuente entre los inmigrantes- o por carecer de estudios universitarios).

\section{PROGRAMAS DE SERVICIOS}

Con los programas de servicios se pretende promover la asistencia y asesoramiento a los inmigrantes con el fin de facilitar su acceso a los derechos y recursos sociales existentes, así como ofrecer una orientación laboral y facilitar la comunicación.

En la actualidad se halla en marcha, como ya hemos comentado:

\subsection{El servicio de traducción e interpretación}

Dicho servicio está formado por profesionales cualificados, que trabajan en las lenguas demandadas por los principales contingentes migratorios que llegan a nuestro entorno. Lo dirige la Dra. Carmen Valero, coordinadora del Grupo Fitispos desde su creación y dispone además de una bolsa de trabajo. Es un servicio cada vez más demandado por ayuntamientos, hospitales o delegaciones del Estado, e incluso entidades privadas como, por ejemplo, las compañías de seguros que solicitan la traducción de documentos oficiales, guías de servicios, folletos informativos, etc.

Otros servicios previstos son:

\subsection{Servicio de orientación laboral}

Dicho servicio está en fase de desarrollo. A través de un gabinete que asesorará y enseñará a los inmigrantes las técnicas de búsqueda de empleo:

Redacción de currículum.

Contestación a ofertas de empleo.

Entrevistas. 
Seguimiento de ofertas.

Pruebas psicotécnicas.

Búsqueda de empleo por Internet, etc.

\subsection{Servicio de asesoramiento jurídico}

Dicho servicio está en fase de desarrollo.

A través de un gabinete que asesorará a los inmigrantes en las cuestiones jurídicas que más les pueden afectar en su integración en la sociedad española.

\section{INVESTIGACIÓN SOBRE/CON LA INMIGRACIÓN}

La UAH, cumpliendo con uno de los fines específicos de la universidad, se ha marcado también como objetivo la investigación, y fomentar los estudios y análisis sobre la inmigración y sobre las experiencias en integración social.

Una actuación interesante prevista es la creación de un Archivo de Inmigración que albergue registros escritos, sonoros y visuales de los inmigrantes y de sus culturas. La Universidad para los Inmigrantes y los encuentros que organizarán y se han organizado ya en su seno proporcionarán un marco inmejorable para realizar estudios por parte de los investigadores de las áreas de Ciencias Sociales, Jurídicas, Filologías, etc., sobre este fenómeno de la inmigración que constituye una realidad necesitada de comprensión y respuestas.

En este sentido hay que hablar de nuevo del grupo FitisPos, hasta ahora el más activo y antiguo en relación con la formación e investigación con población inmigrante en la UAH, que inició sus trabajos ya en 1997 de la mano de la Dra. Carmen Valero Garcés, su coordinadora desde entonces.

\subsection{El grupo FiTiSPos: Investigación sobre la calidad en la comunicación con población extranjera}

Mientras llega el Archivo y otras actividades, podemos ya dar cuenta de algunas actuaciones del grupo FitisPos como son la realización de los siguientes proyectos:

1. Investigación sobre prevención y modos de vida saludables en relación con la población inmigrante. Diseño y elaboración de una Guía multilingüe de atención al menor (0-18 años) en español, inglés, francés, árabe, búlgaro, rumano, ruso y polaco, financiada por la Fundación Pfizer, en su convocatoria de Ayudas a Proyectos de Compromiso Social, 2005-2006.

2. Investigación sobre las primeras necesidades de atención al alumnado extranjero: Diseño y elaboración de una Guía multilingüe de atención al 
alumnado extranjero en los niveles de Primaria y Secundaria (español, árabe, inglés, rumano, búlgaro, polaco y ruso), financiado por la Consejería de Educación de la JCCM en su convocatoria de 2005-7.

3. La mediación intercultural en la atención sanitaria a población extranjera. Investigación y análisis de la problemática comunicativa interlingüística y propuestas de formación, financiado por el Ministerio de Educación y Ciencia (2004-7).

4. Investigación sobre la calidad de la comunicación con población extranjera en el Hospital General de Guadalajara, financiado por la Consejería de Sanidad de la Junta de Comunidades de Castilla-La Mancha (2003-4).

5. Investigación y análisis de la problemática interlingüística y propuestas de formación en el Hospital Ramón y Cajal de Madrid, financiado por la Universidad de Alcalá (2002-3, 2004-5).

6. Interculturalidad: Traducción, humor e inmigración. Documento multimedia (2002-3), financiado por la Universidad de Alcalá, la Fundación General de la Universidad, El Centro UNESCO de la Comunidad de Madrid, EMSI (Escuela de Mediadores de la Comunidad de Madrid) dependiente de Cruz Roja, y el Ayuntamiento de Alcalá de Henares.

7. Variedad lingüística en el área geográfica de la Universidad de Alcalá: Estudio preliminar de su perfil e incidencia en la comunidad, financiado por la Universidad de Alcalá (2001-2).

Los resultados de estos proyectos se han dado a conocer en publicaciones diversas (ofrim, Oralia, Pragmatics, Revista Clínica, etc. ) y en congresos nacionales e internacionales, como los dos organizados por el propio Grupo FitisPOS en 2002 y 2005, únicos en nuestro país dedicados a la T\&ISSPP y de proyección internacional. En abril de 2007 se celebrará el $V$ Congreso de Critical Link en Australia, en el cual la Dra. Valero participa como miembro del comité científico, y en la primavera de 2008 se celebrará en la UAH el III Congreso Internacional T\&ISSPP en nuestro país, organizado por el Grupo FITISPOS.

\subsection{El grupo FiTıSPOS: Creación de materiales multilingües}

El grupo FitisPos lleva también a cabo una intensa actividad de publicación de materiales multilingües y de formación. Los más recientes son:

Guía multilingüe de atención a mujeres embarazadas (español-árabe- búlgaro-francés-inglés-polaco-rumano-ruso) ISBN: 84-611-1567-8.

Guía multilingüe sobre pediatría (español- árabe- búlgaro- francésinglés- polaco- rumano- ruso). ISBN: 84-611-1566-X.

Guía multilingüe de atención al inmigrante en los servicios sociales (español-árabe-búlgaro-francés-inglés-polaco-rumano-ruso). IsBN: 84-611- 1568-6. 
Guía básica multilingüe de atención al paciente (español-árabe-búlgarofrancés-inglés-polaco-rumano-ruso). IsBN: 84-9836-020-X.

Formas de mediación intercultural: traducción e interpretación en los servicios públicos. Conceptos, datos, situaciones y práctica. C. Valero Garcés, Granada, Editorial COMARES/ Interlingua. IsBN: 84-609-3704-6.

Interculturalidad: Traducción, Humor e Inmigración. C. Valero Garcés (ed.), Alcalá de Henares, Fundación General de la Universidad, 2004. IsBN: 84-88754-18-3 (en CD).

Traducción como mediación entre lenguas y culturas / Translation as mediation or how to bridge linguistic and cultural gaps. Valero Garcés, C. (ed.), Alcalá de Henares, Servicio de Publicaciones de la UAH, 2005. ISBN: 84-8444-686-7 (en CD).

Traducción e interpretación en los servicios públicos. Contextualización, actualidad y futuro. Valero Garcés, C. (ed.), Granada, Comares, 2003. IsBN: 84-8444-686-7.

Discursos (dis)concordantes: modos y formas de comunicación y convivencia. Valero Garcés, C. y G. Mancho Barés (eds.), Universidad de Alcalá, Servicio de Publicaciones, 2003. IsBN: 84-8138-589-1.

Traducción en los Servicios Públicos: Nuevas Necesidades para Nuevas Realidades / Community Interpreting and Translating: New Needs for New Realities. Valero Garcés, C. y G. Mancho Barés (eds.), Alcalá de Henares, Servicio de Publicaciones, 2002. IsBN: 84-8138-637-5 (en CD).

\section{FigURA 2}
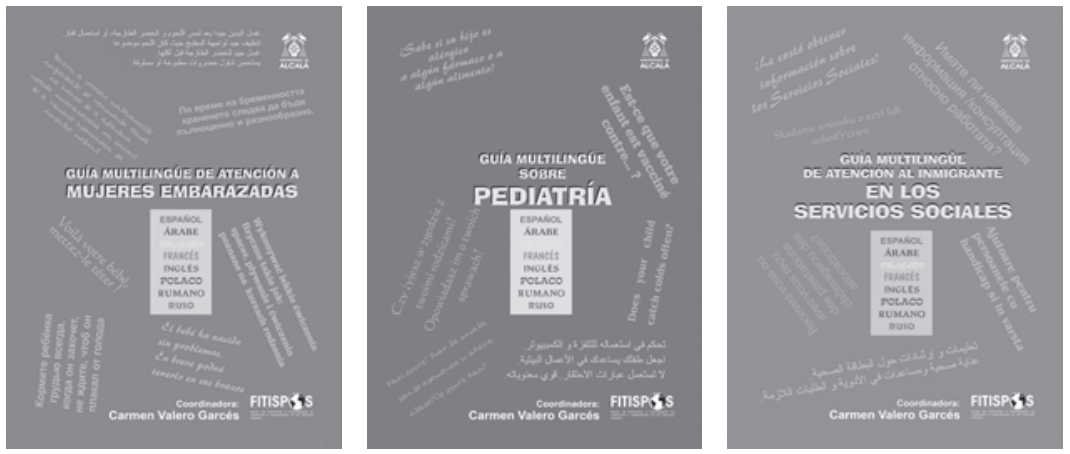

\section{PROGRAMAS CULTURALES}

El fenómeno de la inmigración ubica a las personas inmigrantes en situaciones de fuerte estrés al requerir de ellas un reajuste enorme en muchos de los 
ámbitos de su vida (familiar, laboral, etc.). Uno de los factores desencadenantes de este estrés psicológico es el fuerte choque cultural que padecen estas personas. Por ello el conocimiento de la cultura española por parte de los inmigrantes, junto con el aprendizaje del idioma (en aquellos que no sean hispanohablantes), es fundamental para tener un mayor éxito a la hora de lograr su integración. Es por ello que desde el principio se consideró conveniente ofertar cursos y programas en los que se aborde el estudio de la cultura española y de sus culturas. Asimismo, y dado que en la actualidad España se inserta en una realidad supranacional europea, resulta conveniente procurar para los inmigrantes el conocimiento legislativo de los dos grandes marcos de referencia donde se cifra su vida cotidiana. Por tanto se piensa en ofrecer también cursos sobre:

-La Constitución española;

-La Constitución Europea; y

-Otras leyes y estatutos que puedan ser de su incumbencia.

Dentro de este marco general, hemos organizando un Curso de Otoño (octubre-noviembre 2006), junto con la Universidad Carlos III y el Centro UNESCO de la Comunidad de Madrid, con el título Derechos humanos y religiones, dirigido a cualquier persona interesada en los derechos humanos y sensible a la actual y creciente afluencia de trabajadores de otros países que traen nuevas formas de concepción de la sociedad derivadas de costumbres, comportamientos y culturas en general diferentes a las mantenidas en España hasta el momento.

Los objetivos del curso son:

- Promover y estimular todas aquellas formas de mutuo conocimiento que favorezcan que los seres humanos convivan en paz aunque provengan de orígenes culturales distintos.

- Mostrar a la sociedad cuál es la realidad religiosa actual y la futura como parte de la cultura que aportan los nuevos ciudadanos que se incorporan a nuestra comunidad.

- Analizar en profundidad su relación con los Derechos Humanos y las leyes y costumbres de España.

- Iniciar acciones que aseguren un mutuo conocimiento de las comunidades en contacto con el fin de facilitar la convivencia pacífica y meditada.

Y tratará de temas tan sugerentes como:

- Los derechos humanos en el mundo actual: cumplimiento y transgresiones. 
- La cultura de los derechos humanos: Fundamentación filosófica y contextualización histórica.

- Religiones, laicidad, laicismo. El conflicto actual. Posibles respuestas.

- Los derechos humanos en las distintas confesiones religiosas: Judaísmo, Cristianismo, Islam.

- Diálogo entre religiones: Judaísmo, Islam, Iglesia Ortodoxa Rumana, y la Comunidad Hindú.

Para su impartición se cuenta con teólogos, especialistas en temas religiosos y representantes en España de otras religiones.

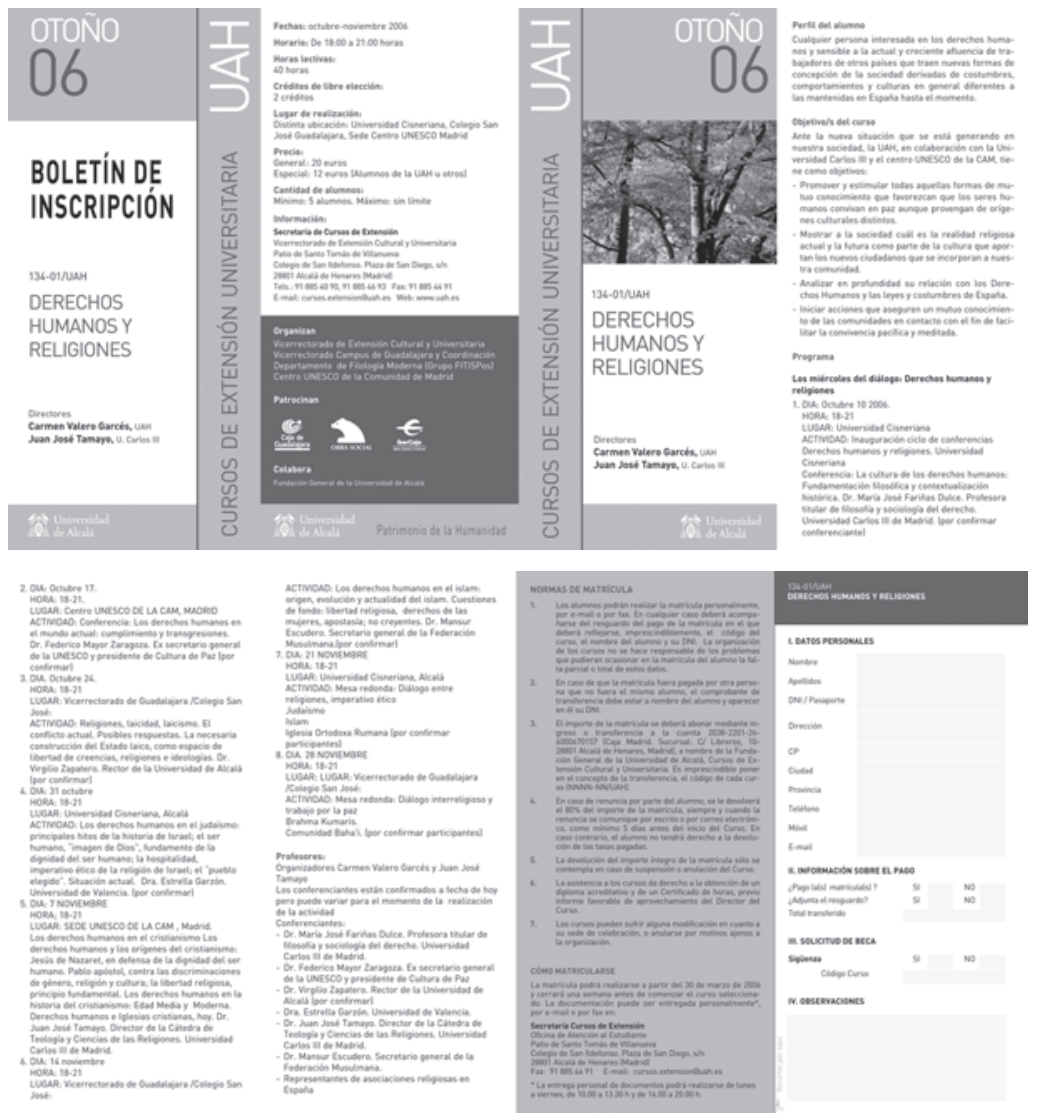

A dicho curso se unirán otras actividades cuyo fin será favorecer la educación intercultural. Un anticipo fueron las II Jornadas sobre Comunicación 
Intercultural, Traducción e Interpretación en los Servicios Públicos que bajo el título de «Hablando se entiende la gente», organizó el grupo Fitispos en junio 2006.

Los objetivos de las jornadas fueron:

- Aportar información y sensibilizar a los asistentes sobre la importancia del papel del mediador lingüístico y cultural en los servicios públicos.

- Comprender las modalidades y situaciones de traducción e interpretación que genera la comunicación intercultural, sobre todo en el contexto de la atención al inmigrante en servicios públicos (hospitales, juzgados, oficinas de empleo, ONG...).

- Conocer de primera mano la situación actual de la mediación lingüística y cultural en Madrid y el Corredor del Henares.

- Comprender los factores que intervienen en este tipo de mediación y conocer los requisitos para ejercer como mediador lingüístico y cultural.

- Analizar los recursos existentes.

- Buscar vías de colaboración para hacer más rápida y eficaz la comunicación entre unos y otros con el fin de favorecer la integración.

Y contaron con la participación de representantes de los Ministerios de Interior y de Justicia, de ayuntamientos de la zona, de hospitales de Madrid y del Corredor del Henares, así como de ONG y asociaciones de inmigrantes.

Dichas jornadas sirvieron como preludio a la clausura de la Acción Formativa de T\&ISSPP 2005-6, que concluyó con un acto titulado Homenaje a la Pala$b r a$, acto en el que se leyeron en los idiomas de los alumnos (español, árabe, búlgaro, inglés, francés, portugués, polaco, rumano, ruso) las palabras: amor, libertad, paz, vida, esperanza, amistad, comunicación, entendimiento, cooperación y armonía.

\section{CONCLUSIÓN}

En resumen, la UAH, a través de su programa Universidad para los Inmigrantes, ha puesto en marcha toda una acción novedosa y necesaria, acción que va dirigida no solo a las personas inmigrantes sino también y muy especialmente a la población de la sociedad receptora y en particular al propio personal y a sus estudiantes, algunos de los cuales son ya los hijos de familias inmigrantes. 


\title{
LOS ANGLICISMOS EN LAS LENGUAS ESPAÑOLA Y POLACA: UN ANÁLISIS CONTRASTIVO
}

\author{
MARTa WichereK \\ Universidad Jaguelónica de Cracovia
}

\section{PRELIMINAR}

$\mathbf{L}$ A aparición de lexemas, morfemas, estructuras gramaticales no heredados de su protolengua, sino incorporados por influencia de otros idiomas siempre ha estado presente en todas las lenguas. En teoría, se puede imaginar una comunidad enteramente aislada de las demás, que no tenga ningún contacto con el mundo externo, aunque, hoy en día, prácticamente no existen lugares a los que no hayan acudido personas de otras culturas. Este encuentro proporciona, por un lado, el mutuo intercambio de objetos e ideas cuyos nombres enriquecen el vocabulario de sus sistemas lingüísticos y, por el otro, puede afectar al nivel gramatical o, en ocasiones, incluso a su nivel fonológico.

Hasta el presente han surgido múltiples estudios dedicados a la problemática del préstamo realizados desde distintos puntos de vista. Sin embargo, pocas son las investigaciones contrastivas sobre esos mismos extranjerismos cuando se instalan en diferentes sistemas lingüísticos. En el presente trabajo, queremos llenar esta «laguna» al presentar algunas observaciones sobre la adaptación y el posterior funcionamiento de los mismos vocablos de procedencia anglosajona en dos lenguas distintas, pertenecientes a diferentes familias lingüísticas, como son el español y el polaco.

\section{FRECUENCIA}

A modo de introducción, hemos de destacar que entre todos los préstamos que contribuyen al enriquecimiento tanto de la lengua española como de la polaca, los anglicismos constituyen, actualmente, el grupo más numeroso. En los dos idiomas los vocablos de procedencia inglesa influyen en la aparición del vocabulario relacionado con campos semánticos como el deporte, la economía, la informática o la moda, por citar solo algunos de los más representativos en la actualidad. No obstante, es interesante notar que aunque los mismos 
campos léxicos se ven afectados por los anglicismos, estos no son iguales en las dos lenguas. Así, por ejemplo, en polaco no se utilizan vocablos tales como: glamour, kleenex, penalty, váter, feeling o heavy, ni siquiera en el lenguaje juvenil o jergal. En cambio, en la variante peninsular de la lengua española no se registran quiz («concurso»), (e)start («inicio») o business ('negocio', en polaco con la grafía biznes, ya aceptada por los diccionarios), palabras que funcionan en el polaco estándar. Vale la pena observar que estos elementos en polaco tienen sus equivalentes patrimoniales (konkurs, początek e interes, respectivamente); sin embargo, los polacos optan por utilizar las correspondientes palabras inglesas. En polaco también existen palabras de procedencia anglosajona que no poseen sinónimos patrimoniales, por ejemplo, strajk (del ing. strike) budét (del ing. budget), a los que en español equivalen vocablos de formantes latinos: huelga (de holgar y este del lat. tardío follicāre) y presupuesto (de presuponer y este de pre- y suponer del lat. supponĕre).

Por otro lado, un grupo relativamente numeroso de anglicismos presenta una diferencia significativa en cuanto a su frecuencia de uso: en polaco existen, pero se utilizan muy poco, sandwich, jersey, marines o córner, mientras que en español son muy frecuentes. En la situación inversa, es decir, ante los vocablos que tienen muy alto índice de frecuencia en polaco y más bajo en español, nos encontramos con casos como film, non-stop, mecz (ing. match) o plis (ing. please). Estas observaciones, obviamente, no valen para todos los anglicismos, puesto que hay muchas voces anglicadas de uso muy frecuente en ambas lenguas, por ejemplo, club, dólar, record o test. Sin embargo, vale la pena observar que la frecuencia se vincula de manera directa con el registro en que aparece el extranjerismo: cuanto más se utiliza, más posibilidad tiene de funcionar en la variante estándar, lo cual desempeña al mismo tiempo un papel nada desdeñable en el proceso de adaptación semántica a la lengua receptora (a lo que dedicaremos más atención en el apartado 5).

\section{ADAPTACIÓN FONOLÓGICA Y SU REPERCUSIÓN ORTOGRÁFICA}

Aunque no es imprescindible, los préstamos pueden sufrir numerosos cambios en su proceso de arraigo al nuevo sistema. El tipo y el número de estas adaptaciones dependen, naturalmente, de cada lengua en cuestión, pero todas ellas intentan facilitar el posterior funcionamiento de los extranjerismos en su nuevo entorno lingüístico.

Antes de que procedamos al análisis de las adaptaciones fonológicas practicadas en cada lengua, hemos de recordar que existen dos modos básicos de penetración de los préstamos en otros sistemas lingüísticos: o bien pueden llegar a otras lenguas por vía oral o bien lo hacen por vía gráfica (Mańczak- 
Wohlfeld, 1992: 25). Los vocablos que se introducen por vía gráfica suelen caracterizarse por mantener las mismas grafías tanto en la lengua receptora como en la prestataria. En cuanto a los anglicismos que han entrado en las lenguas por dicha vía, se pueden notar diferencias muy significativas, puesto que, a pesar del mismo significante, ni en la lengua española ni en la polaca se pronuncian de acuerdo con la realización fonética inglesa. Esto es especialmente visible a la hora de examinar los vocablos que poseen fonemas o grafemas inexistentes en polaco y/o en español. A modo de ejemplo, citemos elementos de muy distinta pronunciación según la lengua:

$$
\begin{aligned}
& \text { Squash - en pol. [skwóš], en esp. [eskwás] } \\
& \text { Sheriff - en pol. [ [éryf], en esp. [sérif] } \\
& \text { Walkman - en pol. [wokmen], en esp. [gwálman] } \\
& \text { Jersey - en pol. [dzérsei], en esp. [xerséi] } \\
& \text { Nylon - en pol. [ny̆lon], en esp. [náilon] }
\end{aligned}
$$

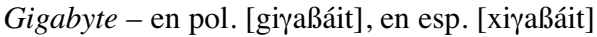

Un grupo numeroso que comparte la misma característica, es decir, cuando la realización fonética de un elemento se aleja considerablemente de su pronunciación en la lengua fuente, se da en el caso de formaciones siglares: las siglas $F B I, B B C$ o $C D$ en español se pronuncian como si fueran palabras españolas ([éfe bé í], [bé bé $\theta e ́]$ y [ $\theta$ é dé]), mientras que en polaco se sigue la pronunciación inglesa: [éf bí ái], [bí bí sí] y [sí dí], respectivamente. En cambio, los polacos pronuncian NATO, HIV o USA, de acuerdo con las pautas de la fonología polaca: [náto], [xíf] y [úsa] o [ú és á], respectivamente, mientras que en la lengua española estas formaciones han sido traducidas, originando las siglas: OTAN, VIH y EEUU, de muy distinta pronunciación en comparación con la inglesa: [ótan] y [úße í átfe], mientras que la sigla reduplicada EEUU se descifra siempre como [estáđos-uníđos].

La realización fonética de los extranjerismos puede causar problemas, especialmente a las personas que no conocen otros idiomas, pero incluso puede ejercer una influencia negativa en los aprendices de lenguas extranjeras. Nuestra propia experiencia docente nos indica, por ejemplo, que los alumnos polacos de Filología Hispánica no saben cómo leer los anglicismos no adaptados a nivel fonológico que aparecen en los textos españoles. Sorprendentemente, en la mayoría de los casos intentan mantener la pronunciación inglesa, aunque estos vocablos funcionan adaptados fonológicamente, en mayor o menor grado, en su lengua materna. Este fenómeno se puede observar muy bien, por ejemplo, a la hora de pronunciar los anglicismos que empiezan con - $r$ : las palabras round, ranking o rugby son pronunciadas por estos alumnos con una $r$ retrofleja, mientras que estos elementos en su 
lengua materna se pronuncian de acuerdo con las pautas fonológicas polacas.

Asimismo, si las lexías prestadas del inglés tienen carácter de citas también en la lengua polaca, los alumnos intentan pronunciarlas «a la inglesa», pronunciación que se aleja considerablemente de la española, y que resulta muy afectada. Por ejemplo, en la frase «La revista Time proclamó el blue jean como el fashion item que ejemplifica mejor la globalización cultural, puesto que ha conseguido otorgar un estatus upper class, aunque en los años 60 era considerada una prenda de baja estofa», los alumnos pronunciarían los vocablos mar-

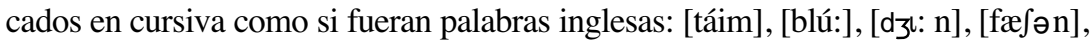
[áitem], [^рə] y [kla: s], respectivamente.

En el polo opuesto se encuentran los préstamos que llegan a una lengua dada por vía oral. En estos extranjerismos la adaptación consiste en la transcripción española o polaca de la pronunciación inglesa del vocablo y sin prestar atención a la grafía original. Es en este caso donde se observa más visiblemente el proceso de adaptación fonológica. Por perder el carácter foráneo, estas palabras no originan vacilaciones a la hora de encontrarlos en el texto. Tal es el caso de palabras inglesas como crawl, stress y shampoo, que en español se escriben crol, estrés y champú, y en polaco kraul, stres y szampon, respectivamente.

Con todo, hay anglicismos que pasan por adaptaciones en una de las lenguas, pero no en la otra, manteniéndose en esta segunda la grafía original inglesa. Por ejemplo, en la palabra whisky en español se sustituyen todos los fonemas ingleses por españoles, lo que provoca la escritura güisqui, mientras que en polaco se mantiene la grafía original (con la pronunciación [wíski]); en cambio, los polacos escriben keczup, mientras que los españoles, ketchup, con la pronunciación muy parecida: [két $\left.\int u p\right]$.

Vale la pena observar que no se puede indicar ninguna regla sobre cuándo los vocablos se someten a adaptaciones y cuándo no. Seguramente el factor que podría explicar este fenómeno no es la frecuencia, porque, por ejemplo, tanto en español como en polaco las dos lexías mencionadas, es decir, ketchup y güisqui, tendrán el mismo índice de frecuencia. Tampoco lo es la inexistencia de ciertos fonemas en una u otra lengua. Por ejemplo, el grafema $x$ en la lengua polaca aparece exclusivamente en las palabras cultas (por ejemplo, ex definitione, ex catedra), por lo tanto se podría suponer que en todos los casos donde aparezca esta letra se sustituiría por $k s$. Efectivamente, así es en el caso de klaxon y box (en pol. klakson y boks), aunque $x$ en otras palabras se mantiene, como por ejemplo, en fox-terrier. Paralelamente, en español tenemos güisqui, pero, al mismo tiempo, kleenex.

Concluyendo, hemos de poner de relieve que las adaptaciones fonológicas en las palabras de origen inglés -y más aún, las modificaciones ortográficas 
que conllevan- constituyen un verdadero desafío, sobre todo, para las personas que aprenden lenguas extranjeras. En la mayoría de los casos nos encontramos ante algún tipo de adaptación, lo que se deriva, entre otras razones, por la mayor complejidad del sistema vocálico inglés en comparación con el español o el polaco. Incluso cuando las lexías tienen la misma grafía en la lengua fuente y en la receptora, nos encontramos a menudo ante la correspondiente sustitución fonemática: basta comparar la pronunciación de bar en las tres lenguas analizadas, derby en polaco e inglés o $c l u b$ en español e inglés.

\section{ADAPTACIÓN MORFOLÓGICA}

Por lo que se refiere a la adaptación morfológica de los anglicismos en las dos lenguas analizadas, habría que destacar las siguientes como cuestiones más relevantes: a) la adscripción del género a los sustantivos prestados del inglés, b) la formación del plural, c) la adición del morfema verbal que permita la conjugación de los verbos de procedencia anglosajona, d) el funcionamiento de adjetivos y adverbios y e) la formación de palabras. Por el espacio limitado de nuestro artículo, nos limitaremos a presentar, exclusivamente, el primero de estos problemas, esto es, la adscripción del género a los anglicismos.

Como es sabido, en inglés no existe distinción de género mediante recursos morfológicos de tipo flexivo. En los procesos de pronominalización, generalmente se emplean pronombres masculinos para sustituir a referentes identificados como hombres, pronombres femeninos si hacen referencia a las mujeres, y en los demás casos se usa el neutro. Puesto que tanto en la lengua polaca como en la española el empleo de los géneros gramaticales depende de otros factores, todos los sustantivos prestados del inglés deben ser sometidos obligatoriamente al proceso de adscripción de género.

La mayor diferencia entre las dos lenguas receptoras consiste en el hecho de que en polaco hay tres géneros: al lado del masculino y el femenino existe también el neutro. Los sustantivos prestados del inglés que reciben en polaco el género neutro, son en su gran mayoría masculinos en español. Así, por ejemplo: el hobby $\rightarrow$ to $^{1}$ hobby, el bikini $\rightarrow$ to bikini, el güisqui $\rightarrow$ to whisky. Sin embargo, el vocablo party es en español femenino y en polaco, neutro.

¿Cuál puede ser la explicación de este hecho? Y, en general, ¿sobre qué base se adscribe el género en las lenguas analizadas? Dos factores son los factores principales que influyen en este proceso: el primero de carácter morfológico y el segundo de orden semántico.

1. Puesto que el polaco carece de artículos, para marcar el género se suele indicar el pro-nombre demostrativo correspondiente: ten para masculino, ta para femenino y to para neutro. 
El factor morfológico se manifiesta a través de la sufijación. Así pues, los elementos neutros en polaco en su gran mayoría terminan en $-y$ o $-i$ (véanse los ejemplos mencionados ut supra). De modo parecido, las lexías que terminan en inglés en -tion, pasan a la feminización, dada la equivalencia formal con el sufijo -ción/-sión en español y -cja/-sja en polaco, ambos marcas del género femenino. A modo de ejemplo citemos: en español deforestación (ing. deforestation) o en polaco repatriacja (del ing. repatriation) y en ambas lenguas macdonaldización / macdonaldyzacja (del ing. macdonaldization).

Otro factor que indudablemente influye en la adscripción del género depende del parasinónimo del vocablo prestado (Nymansson, 1995: 98). Es decir, si el anglicismo tiene su equivalente en la lengua prestataria, la mayoría de las veces adquiere el género de este. Por ejemplo: en español, la estrella $\rightarrow$ la (e)star o el sentimiento $\rightarrow$ el feeling; en polaco, ten korytarz $\rightarrow$ ten hall o ten dreszczowiec $\rightarrow$ ten thriller. Con todo, esta correlación no se ve confirmada en todos los casos, ya que hay elementos sinonímicos de diferente género. Por ejemplo: en español, la película $\rightarrow$ el film(e) o la plusmarca $\rightarrow$ el récord; en polaco, ta gotówka $\rightarrow$ ten cash o ta reklama $\rightarrow$ ten spot. Además, debemos recordar que no todos los elementos léxicos entablan relaciones de sinonimia, y por consiguiente, este procedimiento no puede considerarse como un mecanismo de adaptación universal.

Es interesante notar que el género prevaleciente entre todos los sustantivos de origen inglés en ambas lenguas es el masculino (el by-pass/ ten by-pass, el aerobic/ ten aerobik, el flash / ten flesz, etc.), mientras que los nombres femeninos se limitan, prácticamente, al llamado género natural (Nymansson, 1995: 96). Así, por ejemplo, la/ta miss o la/ta queen (a sumar a aquellos casos en que la feminización se ve impuesta por razones morfológicas). Al mismo tiempo, hay que observar que en español los sustantivos referidos a seres humanos marcan el género mediante el empleo del artículo correspondiente (el/la hippy, el/la fan o el/la punky), mientras que en polaco es imperiosa la adición del morfema femenino (hipiska, fanka y punkówa, respectivamente, hasta llegar a los casos extremos de supermenka, sportsmenka o barmanka).

Concluyendo, la adscripción del género de muchos anglicismos depende de su estructura morfológica o de su posición y funcionamiento en el sistema semántico de la lengua receptora. Pese a ello, hay casos en que dicha adscripción es, simplemente, arbitraria.

\section{ADAPTACIÓN SEMÁNTICA DE LOS ANGLICISMOS}

En primer lugar, hemos de observar que en todos los idiomas receptores el valor semántico de los extranjerismos es distinto del que poseen en su lengua 
materna. En la mayoría de los anglicismos que funcionan en español y en polaco opera un proceso de restricción del significado. No obstante, si comparamos los mismos vocablos de procedencia inglesa en ambas lenguas, notaremos que, pese a la existencia de un significado denotativo más o menos común, sus contextos de uso varían considerablemente. Así, los elementos que en una lengua pertenecen a la variedad estándar pueden aparecer marcados en la otra como propios de un registro culto o, por el contrario, coloquial. Comic (en polaco con la grafía komiks), disc jockey, drink o flirt son palabras estándares en polaco, y empleadas por cualquier miembro de esa comunidad idiomática. Sin embargo, en español son términos empleados preferentemente entre los jóvenes, y más difíciles de encontrar en el habla de otros genolectos. En cambio, las palabras anticipar o gay aparecen ya como ampliamente difundidas en el español peninsular, pero no así en polaco: se percibe el primero como un vocablo culto, mientras que el segundo pertenece al registro coloquial. De modo parecido, la palabra cash en español es un tecnicismo, mientras que en polaco se usa de forma cotidiana en el lenguaje familiar o coloquial.

Estas diferencias en el grado de adaptación semántica de los extranjerismos puede provocar también problemas entre los estudiantes de lenguas extranjeras (de nivel superior), así como entre los traductores e intérpretes. El hecho de que en las dos lenguas aparezcan los mismos elementos de procedencia extranjera no quiere decir que se utilicen en los mismos contextos. Por consiguiente, hay que actuar con sumo cuidado a la hora de emplear estos anglicismos en un discurso determinado.

\section{CONCLUSIONES}

Resumiendo, tanto en la lengua española como en la polaca, los anglicismos se someten a las adaptaciones de tipo fonológico, ortográfico, morfológico y semántico. Sin embargo, en las dos lenguas no se pueden determinar, $a$ priori, los resultados finales. Tan solo podemos hablar de ciertas tendencias, que pueden afectar a los anglicismos, aunque siempre encontraremos vocablos que escapen a tales reglas.

Nuestras observaciones han tenido como objetivo demostrar las diferencias más significativas concernientes a las adaptaciones y al posterior funcionamiento de las lexías anglicadas en las dos lenguas estudiadas, el español y el polaco. A este respecto, hemos visto cómo las palabras analizadas, aunque provengan de los mismos étimos, pueden desembocar en la misma, similar o muy distinta realización fonética, e, independientemente de su estructura, pueden adquirir distintos matices semánticos. Por último, subrayemos de nuevo cómo estas diferencias, de tipo diastrático y/o diafásico, son sumamente 
importantes en los procesos de aprendizaje de lenguas extranjeras o en la traducción de textos.

\section{REFERENCIAS BIBLIOGRÁFICAS}

MańCZAK-WOHLFELD, E. (1992): Analiza dekompozycyjna zapożyczef angielskich $w$ jezyku polskim, Cracovia, Wyd. Uniwersytetu Jagiellof skiego. NymANSSON, K. (1995): «Le genre grammatical des anglicismes contemporains en français», Cahiers de Lexicologie, 66: 95-113. 


\title{
INTRODUCCIÓN DE LA FRASEOLOGÍA EN LA CLASE DE ALEMÁN
}

\author{
$M^{\mathrm{a}}$ ISABel ANdúgar ANDreu \\ Universitat Jaume I
}

\section{INTRODUCCIÓN}

\section{¿Aprender refranes, frases hechas? ¿Por qué? ${ }^{1}$}

$\mathbf{E}$

${ }_{\mathrm{N}}$ primer lugar, porque la Fraseología es una parte importante de las lenguas y, como tal, en su proceso de aprendizaje, parece lógico acudir a ella.

En segundo lugar, por su complejidad, pues estas estructuras lingüísticas son mucho más complejas que otras y por ello, es necesario tener con ellas una consideración diferente. Son complejas doblemente: por su estructura y por su significado. Por su estructura, porque se trata de fórmulas fijadas, inamovibles, si no es intencionadamente. Por su significado, pues normalmente al lado de su significado literal aparece uno figurativo ${ }^{2}$. Y si no están claras a menudo en la lengua materna, ${ }^{3}$ mucho menos lo estarán en una lengua extranjera. ${ }^{4}$

En tercer lugar, porque surgen por doquier, en casi todas las lenguas y especialmente en la que nos ocupa, el alemán. Se encuentran tanto en diferentes medios de comunicación: periódicos, revistas, libros, pero también en cine y televisión; como en diferentes tipos de textos: literarios, periodísticos, publicitarios, ensayos, etc.

Si es importante el conocimiento de la Fraseología en cuanto a la comprensión, tanto más lo es en la expresión. Cuando introduce una estructura fraseológica, el hablante incorpora deliberadamente una función expresiva al mensaje,

* Por motivos de espacio, no se incluye aquí el material presentado en la versión oral, relacionado con cada una de las unidades fraseológicas: imágenes ilustrativas y dossier de ejercicios. Para minimizar la posible distorsión que este hecho pudiera provocar en la comprensión del artículo, se proporciona en la bibliografía adicional información de la documentación que sirvió de base. Y por supuesto, se intentará la publicación de este material en formato web en un futuro no muy lejano.

1. Existen más denominaciones, como ocurre en todas las lenguas, para estas expresiones. Refranes: Sprichtwörter; frases hechas: Redewendungen. Utilizaremos aquí estas, sin entrar en la cuestión taxonómica, pues entendemos que no es la finalidad del presente trabajo.

2. Wörtliche vs. figurative Bedeutung.

3. Muttersprache.

4. Fremdsprache.

5. Nachdruck. 
un condimento especial. Y de ahí que, un error o una simple variación léxica puedan provocar efectos diferentes o indeseados.

En definitiva, la Fraseología está en boca de todos, forma parte del componente más vivo del lenguaje. Además, los profesores pueden con ella no solo «Matar dos pájaros de un tiro», esto es enseñar Fraseología y, por tanto, lengua alemana (gramática, sintaxis, etc.), sino también «tres, cuatro, o cinco pájaros», y al mismo tiempo enseñar otros contenidos como Historia, Costumbres, ${ }^{6}$ etc.

Y, por supuesto, con la Fraseología se puede conseguir algo que es también decisivo en cualquier clase: aprender divirtiendo y despertar la fantasía.

Que toda traducción es una pequeña traición ya se ha dicho muchas veces. De antemano pedimos disculpas por las posibles inexactitudes en nuestras adaptaciones del alemán, que solo pretenden transmitir a nuestros lectores el significado de términos y citas en alemán de un modo sencillo.

\section{VALORACIÓN DE LA FRASEOLOGÍA EN LA FILOLOGÍA}

Tradicionalmente, la Fraseología ha ocupado un papel muy reducido en la enseñanza del alemán: se podía introducir un par de refranes en algún momento del proceso de enseñanza, pero, por lo general, no existía nunca una sistematización de este tipo de estructuras.

Es en los últimos años cuando por fin se pueden encontrar no solo listas, sino también metodologías, incluso específicas, para enseñar mediante la Fraseología, lo que representa un paso cualitativo importante. En los estudios filológicos actuales, las paremias ocupan ya el lugar que merecen en el estudio y aprendizaje de las lenguas. Como recuerdan Wotjak y Richter (1988: 7), «Die Phraseologismen, die noch vor relativ kurzer Zeit ein Stiefkind der Sprachwissenschaft war, ist in jüngerer Zeit zunehmend aus ihrem Schattendasein hinausgetretten». Es decir, las paremias, que habían sido hasta hace poco «hijastras» de la Filología, han ido saliendo progresivamente de la sombra; en definitiva, se ha dignificado su existencia. Por su parte, Kühn (1992), otro investigador relevante en el estudio de la fraseológica germanista, y creador del moderno concepto de Phraseodidaktik ${ }^{7}$ ha subrayado también que las paremias no solo no deberían ser calificadas como meras manifestaciones de un uso coloquial de la lengua, sino que, al mismo tiempo, hay que explicarlas en el proceso de producción de textos: «Redewendungen dürfen nicht als umgangssprachliche Schematwendungen abqualifiziert werden,

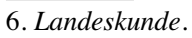

7. Literalmente: Fraseodidáctica. 
vielmehr gilt es, die besondere Gebrauchsweisen von Redewendungen in Texten herauszuarbeiten» (Kühn, 1996: 11).

\section{FINALIDADES DIDÁCTICAS DEL APRENDIZAJE DE LA FRASEOLOGÍA}

En general parece claro: cuantas más estructuras se aprendan, mayor será el dominio de un idioma. Pero con la Fraseología se debe tener cuidado, porque su uso no es tan sencillo como el del simple vocabulario: en cuanto se aprende el léxico, este se puede incluir fácilmente en el uso activo de la lengua sin demasiadas complicaciones, mientras que con la Fraseología se deben tener presentes muchos otros aspectos diferentes al mero significado literal. ${ }^{8}$

Para Wotjak (1996: 4) las finalidades didácticas del proceso de aprendizaje de la fraseología son principalmente tres:

1. el desarrollo ${ }^{9}$ de la competencia comunicativa, especialmente en la habilidad receptiva; ${ }^{10}$

2. la sensibilización sobre su amplitud de valores ${ }^{11}$ frente a palabras simples, y sobre preferencias de uso y restriciones; y

3. el dominio ${ }^{12}$ de algunos conocimientos elementales sobre el estado de las mismas y la presentación y hallazgo en los diccionarios.

Otras opiniones sostienen que al comienzo del proceso de aprendizaje es suficiente con el esfuerzo que supone entender las paremias. Ahora bien, como indican Bauer y Chlosta (1996 b: 98), no basta con enseñar solo el significado literal de la paremia ${ }^{13}$ sino que ésta debe mostrarse en contextos diferentes, teniendo siempre en cuenta los aspectos socioculturales así como los condicionantes diacrónicos o sincrónicos.

Por su parte, Elorduy y Fandrych (1996: 42) resumen la finalidad de una manera sencilla: el aprendiz ha de ser consciente de la idiosincrasia ${ }^{14}$ semántica, sintáctica y pragmática de las expresiones idiomáticas.

En definitiva, retomando las palabras de Kühn (1996: 16), la finalidad de la didáctica de la Fraseología puede resumirse a través de los tres términos

\footnotetext{
8. Wörtlicher Sinn.

9. die Weiterentwicklung.

10. die rezeptive Fertigkeit.

11. die Mehrwert.

12. das Aneignen.

13. Phraseologismus.

14. die Eigenart.
} 
siguientes: «erkennen, verstehen, verwenden». Esto es, lo que se pretende en primer lugar es que el aprendiz sea capaz de reconocer que se halla ante una estructura especial y, por tanto, apelar a su atención; en segundo lugar, que «comprenda», en un sentido amplio; y por último, que sea capaz de utilizar la paremia correctamente, y con esto habrá entendido el «cuándo», la situación pragmática en que puede utilizarse.

\section{DESTINATARIOS}

A la hora de introducir refranes en la enseñanza de idiomas, es necesario tener en cuenta algunos condicionantes. Entre los factores individuales relevantes destaca la $e d a d$, condicionante para cualquier aprendizaje, pero especialmente para el de una lengua extranjera, teniendo además en cuenta que el alemán no suele ser la primera, y que ya tienen otro o varios referentes asimilados, en cuanto lenguas extranjeras. ${ }^{15}$

La formación académica será también importante y, extendiéndolo al grupo, la homegeneidad o heterogeneidad de este a la hora de poder plantear las prácticas. Nos referimos tanto a la formación académica, cultural o científica, como a la formación en lenguas.

$\mathrm{Si}$ a esto se añade que, en cuanto a formación en lenguas, el alemán no suele ser la primera lengua extranjera, sino la segunda o tercera, conocer exactamente el perfil de aprendiz con el que se trabaja será muy importante para realizar con éxito nuestra tarea.

En una clase de idiomas además podemos encontrar personas con diferentes idiomas maternos. Mucho más importante será la procedencia si se trata de un curso internacional, pero también en una clase habitual hoy en día hay personas con diferentes lenguas, debido al progresivo proceso de mestizaje en que están inmersas nuestras sociedades.

Este factor también es importante ya que, debido a la idiosincrasia de las paremias y a su presencia en las demás lenguas, se puede contribuir al aprendizaje realizando comparaciones con las respectivas lenguas de los aprendices.

Como factor común al grupo, deberá tenerse en cuenta también el nivel de idioma en que se imparte la enseñanza. La Fraseología se puede aprender desde el primer día, porque se trata de estructuras que existen en todas las lenguas. Ahora bien, se asimilará mejor si se parte de un buen nivel idiomático,

15. Es además importante porque las paremias son estructuras que apenas están presentes en el corpus lingüístico en las primeras edades y van apareciendo y aumentando con la edad y otros condicionantes. 
porque en tal caso se podrá acceder al significado de las paremias -al menos literalmente- y se podrá trabajar con metodologías cada vez más adecuadas. Es decir, el nivel de idioma determinará los métodos de trabajo que podamos utilizar y, por tanto, la mayor o menor intensidad del aprendizaje.

En definitiva, la Fraseología se puede aprender desde el primer día, porque se trata de estructuras que existen en todas las lenguas. La cuestión es adaptar esa enseñanza al aprendiz, teniendo en cuenta todos los factores mencionados. Así, al mismo tiempo que se aprende otra parte del idioma, también se aprende esta. Y la experiencia nos dice que el reconocimiento de estas estructuras como comunes a otras lenguas y a la propia es particularmente grata.

\section{CORPUS}

\subsection{Corpus}

En la elección de un corpus significativo de Fraseología, y en particular uno de refranes, la mayoría de autores son prácticamente unánimes al elegir la denominada lista de Bauer, Chlosta y Grzybek, ${ }^{16}$ (referencias en Bauer y Chlosta, $1996 a$ : 22 y $1996 b$ : 100-101). Las razones fundamentales para su elección estriban en que se trata de una lista no demasiado extensa (sólo 57 refranes) y, por otro lado, en que nos encontramos, ciertamente, ante los refranes más frecuentes y utilizados en la lengua alemana. Además, su ordenación alfabética no se realiza a partir del primer término que aparece en el refrán, sino que se atiende a la voz considerada como más importante, tanto desde el punto de vista semántico como funcional (generalmente, un sustantivo o adjetivo). Ahora bien, los propios Bauer y Chlosta (1996 $a$ : 19-20) realizan una importante observación didáctica: se trata de una lista en la que los refranes se hallan descontextualizados y, por tanto, carecen de sentido completo, de manera que no se debe considerar como material preparado para enseñar. En definitiva, es un listado útil como para una primera aproximación, ${ }^{17}$ pero ha de desarrollarse didácticamente..$^{18}$

Como hemos señalado anteriormente, compartir una misma lengua materna favorece el proceso de aprendizaje de la Fraseología. Se puede tomar la

16. Data de 1994. El conocimiento de los mismos se ratificó en un 95\% mediante una encuesta realizada a 100 informantes, cuya lengua materna era el alemán.

17. Lernstoff für einen Einstieg.

18. Una propuesta diferente fue presentada por Elorduy y Fandryck (1996: 43), basada mediante la comparación de lenguas, mostrando diferente grado de paralelismo y diferenciación, de manera que facilite al aprendiz una primera incursión en este complejo campo. 
lista como base y aquellos que tienen una correspondencia en la materna no necesitarán mucha explicación. Ahora bien, puesto que no todos los refranes más conocidos en una lengua tienen correspondencia en otra, ni son usados en la misma medida en ambas, en muchos casos se necesitará también aclarar el sentido literal primero y después el figurativo. Evidentemente, se empleará más tiempo y medios en estos últimos que en aquellos que tienen un equivalente claro o cercano.

En cuanto a las frases hechas, la sistematización es menor. No se puede hablar de corpus concretos, sino más bien de diccionarios y manuales, donde la clasificación es simplemente alfabética.

Así pues, no hay un método único y suficientemente adecuado para cualquier situación, sino que su idoneidad dependerá especialmente del perfil del aprendiz, tal y como se ha apuntado antes. La comparación de lenguas puede ser usada para facilitar el aprendizaje, pero basarse en ella como único método de aprendizaje no es viable en ningún caso.

\subsection{Presentación de refranes}

Wotjak (1996: 9) sugiere presentar los refranes agrupados por campos de contenido fraseosemántico, introducidos por conceptos guía, en lugar de ofrecer una pura lista alfabética: «die Gruppierung in phraseosemantischen Begriffsfelder nach Leitbegriffen statt rein alfabetischer Auflistung». De ahí se deriva una cuestión importante: debemos tener en cuenta no solo cuántos refranes y cuáles deben ser aprendidos, sino también cómo se pueden presentar estos.

Con relación a la presentación didáctica de refranes, hay tres propuestas diferentes:

- elaborar listas de A-Z, es decir, alfabéticas puras;

- elaborar listas especiales; y

- presentar el «Mínimo paremiológico», sugerido por Mieder (1993: 17).

La elaboración de listas organizadas alfabéticamente es el método más usual de presentar los refranes. Un ejemplo de estas es la ya reseñada lista de Bauer, Chlosta y Gzybek, aunque a su vez también puede considerarse como un «mínimo paremiológico». Normalmente, las paremias en estas listas están mezcladas y, como ya hemos comentado, con frecuencia la letra inicial de la palabra más importante, normalmente un sustantivo, es la que determina su posición en la lista.

Otra posibilidad, más específica que la anterior, es presentar listas especiales. En este caso, se presentan las paremias organizadas en listas atendiendo a 
los siguientes criterios: 1 . Conceptos-guía léxicos $;{ }^{19}$ 2. Categorías semánticas; 3. Uso pragmático.

El «Mínimo paremiológico» fue propuesto por Mieder (1993: 17) y la lista consta de 27 refranes. Cabe destacar que no aparecen ordenados alfabéticamente y que seis de ellos no están incluidos en la lista de Bauer, Chlosta y Gzybek. En opinión de Mieder (1993) deberían ser utilizados ya desde los niveles iniciales del aprendizaje. ${ }^{20}$

En definitiva, la selección de los refranes tiene que reunir los más conocidos y frecuentes, por razones obvias de utilidad para el aprendiz. Cómo se muestren estos refranes será, por supuesto, importante, pero más importante será, según nuestra opinión, por medio de qué ejercicios se enseñen estas estrucuturas.

\section{DIDÁCTICA DE LA FRASEOLOGÍA}

En la mayoría de métodos de enseñanza de lengua alemana aparecen los refranes esporádicamente y sin conexión con la temática, completamente aislados y descontextualizados. Ello ocurre especialmente en los métodos para un primer nivel, pero también, desgraciadamente, en niveles superiores. Y eso cuando aparecen, pues muchas veces no se encuentra ni una sola expresión fraseológica en los métodos de aprendizaje.

Incluso en los manuales dedicados a la Fraseología los refranes aparecen descontextualizados. En este sentido, Kühn (1996: 10) ${ }^{21}$ los critica duramente y mantiene que «los refranes tienen que ser utilizados en textos específicos para cada grupo de aprendices, tienen que estar vinculados con la situación y los textos deben ser modelos típicos». Habitualmente se enseñan a través de ejercicios de reconocimiento y control, como una enumeración de vocabulario, lo cual lleva a Kühn (1996: 11) a subrayar «que enseñar refranes de este modo induce a aprenderlos de memoria como vocablos aislados y sin contexto».

En cualquier caso, este tipo de ejercicios se podría utilizar en los primeros niveles, cuando la competencia lingüística es limitada. En esos niveles, el hecho de reconocerlos en la lengua materna hace que se perciban, a la vez que elevados, asequibles. Más adelante no es aconsejable, porque no enseñan ningún uso comunicativo.

Para niveles intermedios o superiores de lengua se encuentran monografías que ponen en práctica diferentes estrategias y utilizan textos de todo tipo. Entre ellos, cabe destacar la de Wotjak y Richter (1988). Con la salvedad mencionada de que es necesario tener un nivel de idioma ya considerable.

19. Lexicalische Leitbegriffen.

20. Grundstufe.

21. Adressaten specifisch, situationangemessen und Textsorten typisch. 
En definitiva, siempre es mejor aprender la Fraseología integrada: no solo aprender las expresiones mecánicamente, su significado literal, sino entenderlas en un contexto pragmático y sociocultural. Y además, siempre que sea posible, cuando el nivel del alumnado y la situación lo permita, conviene trabajar con textos reales, como los que proporcionan la literatura o los medios de comunicación. Y en su defecto, preparar textos ad hoc, a fin de potenciar las destrezas comunicativas. El significado de los refranes sería extraído a partir de ejercicios sobre el texto y posteriormente podría ser reformulado convenientemente en otros tipos textuales.

En el presente trabajo, hemos seleccionado seis expresiones paremiológicas, a partir de las cuales plantearemos diversos ejercicios. Tres de ellas son refranes, Sprichwörter, ${ }^{22}$ y las otras tres, frases hechas, Redewendungen. ${ }^{23}$

Los refranes elegidos son los siguientes: a) Morgenstunde hat Gold im Munde; $b$ ) Der Apfel fällt nicht weit vom Stamm; c) Hunde die bellen beiben nicht. ${ }^{24}$

Las frases hechas elegidas son estas: d) Jemandem Honig um den Mund schmieren; e) Sich im siebten Himmel fühlen; f) Jemanden bis aufs letzte Hemd ausziehen..$^{25}$

La selección responde a la premisa mencionada anteriormente: la idoneidad de utilizar textos reales y, en los dos últimos casos, además, de actualidad.

Para tratar los aspectos léxicos, semánticos y pragmáticos de los refranes, se proponen ejercicios que desarrollan cada uno de ellos.

Los ejercicios que trabajan el léxico pueden ser ejercicios de aproximación: en un primer momento, es necesario entender las palabras que los integran. Como ejemplo, podemos utilizar ejercicios de preguntas concretas para obtener las informaciones que necesitamos, reacciones en cadena o juegos de asociaciones.

En este primer paso, se pueden trabajar aspectos morfosintácticos que se pueden relacionar con el contexto de aprendizaje: flexión nominal (determinantes, sustantivos, adjetivos), flexión verbal, sintaxis (nivel sintagmático y oracional), etc.

El mismo estilo de ejercicios serviría para desarrollar la competencia semántica. Normalmente sería el profesor el que explicara personalmente el

22. Los dos primeros aparecen tanto en la lista de Bauer, Chlosta y Grzybek -con los números 40 y 4 respectivamente-, como en el «mínimo paremiológico» de Mieder-números 15 y 8 . El último sólo aparece en Bauer, Chlosta y Grzybek -número 27.

24. Ofrecemos en primer lugar la expresión equivalente de cada uno de ellos, en segundo lugar el significado literal: a) A quien madruga, Dios le ayuda, literalmente: «La hora de la mañana tiene oro en la boca»; b) De tal palo, tal astilla, lit.: «La manzana no cae lejos del tronco»; c) Perro ladrador, poco mordedor, lit.: «Perros que ladran no muerden».

25. d) Dorarle la píldora a alguien, literalmente: «Untarle a alguién la boca con miel»; e) sentirselestar en el séptimo cielo; $f$ ) Perder hasta la camisa, lit.: «quitarle a alguien hasta la última camisa». 
significado del refrán o podría inducir la explicación y que fuera el alumnado el que la encontrara. En este paso se podría ayudar utilizando correspondencias en otros idiomas maternos. No obstante, sería más difícil con alumnado proveniente de diferentes países (cursos internacionales).

Consideramos los ejercicios que desarrollan la competencia pragmática los más importantes, porque enseñan a «utilizar» los refranes. Hay diferentes tipos: el clásico Multiple Choice (con o sin dibujos), la compleción de huecos ${ }^{26}$ (también con o sin dibujos), los ejercicios de coordinación, los juegos de coordinación, así como la utilización de otros juegos conocidos, como el Risiko-Spiel, etc.

Finalmente, se podría acabar promoviendo la creación de textos, en los que se emplearan los refranes. Los recursos podrían ser tanto literarios como materiales gráficos o audiovisuales.

Las frases hechas ofrecen la posibilidad de trabajar estas expresiones integradas en textos auténticos. La primera de las propuestas en este trabajo (Jemandem Honig um den Mund schmieren; e) sich im siebten Himmel fühlen) corresponde a una fábula transmitida por la tradición literaria occidental, que encontramos ya en Esopo: «la zorra y el cuervo». ${ }^{27}$ Las otras dos (Sich im siebten Himmel fühlen; Jemanden bis aufs letzte Hemd ausziehen) se han extraído de sendos textos actuales, en concreto de fragmentos de publicidad aparecidos en prensa alemana de gran difusión.

En el caso de los alumnos de niveles inferiores, tendríamos que hacer el trabajo de traducción para hacerles comprender los textos. El objetivo es que no se convierta en una actividad larga y aburrida, sino utilizar diferentes ejercicios, como los planteados más arriba, para ofrecer un trabajo fraccionado en sus sus partes léxica, semántica y pragmática. Por el contrario, con alumnos de un nivel intermedio superior no sería necesario ir paso por paso conscientemente, y, a partir de una lectura-aclaración, se podría parafrasear el texto, tanto oralmente como por escrito. ${ }^{28}$

La experiencia demuestra que cuando uno aprende Fraseología siempre se aprende algo más y esto es lo importante. Con este tipo de prácticas, no se aprenderá solo un refrán o una frase hecha, sino también conocimientos gramaticales, vocabulario, etc., es decir, no solo idioma, sino también cultura, ${ }^{29} \mathrm{y}$ todo aquello a lo que conduzca la fantasía del alumnado y la habilidad del profesorado.

Así pues, lo ideal es hacer un estudio global de Fraseología, esto es, ir de la comprensión al aprendizaje y de ahí, al uso. No debemos olvidar que la fina-

26. Lückentext.

27. Aparece también en Wotjak y Richter (1988: 96-97).

28. Un ejemplo bien preparado de Fraseología integrada nos los proporcionan G. Richter y M. Richter (1996: 62).

29. Landeskunde. 
lidad de la Didáctica de la Fraseología, Phraseodidaktik, es motivar un aprendizaje activo y no pasivo: en definitiva ser capaces de utilizar refranes y frases hechas correctamente al final del proceso.

\section{CONCLUSIÓN}

En nuestra opinión, los estudiantes que inician el estudio de una lengua extranjera, en este caso el alemán, no sólo deben iniciarse en el conocimiento de las paremias, sino que los enseñantes deben potenciar un uso consciente e intensivo de éstas. Para lograr el máximo aprovechamiento de estos materiales, generalmente marginados en el proceso de aprendizaje, es necesario tener en cuenta:

1. conectar con el momento de aprendizaje en que nos encontramos;

2. delimitar las estrategias que se van a trabajar, es decir, los niveles y las competencias que se quieren abordar; y por último y especialmente; y

3. ajustar el nivel de dificultad de la actividad al nivel del grupo.

Puede parecer complicado al principio, pero esta dificultad compensará con creces cuando aprendices y enseñantes adviertan que las paremias no sólo sirven para aprender mejor la lengua, sino que al mismo tiempo divierten y, sobre todo, despiertan las ganas y el interés por el aprendizaje.

En este trabajo, nos hemos limitado a recoger, elaborar y presentar unas cuantas ideas para lanzarlas a este vasto (que no desierto) campo.

A pesar de que

y que sin duda

$$
\text { Aller Anfang ist schwer, }
$$

Probieren geht über studieren.

Al final, cuando veamos que hemos conseguido nuestro objetivo, podremos concluir satisfechos:

Ende gut, alles gut..$^{30}$

30. Los equivalentes serían para el primer refrán «Todo comienzo es difícil»; para el segundo: «Probar va después de estudiar»; el tercero: «Bien está lo que bien acaba»; literalmente: «Final bueno, todo bueno». 


\section{REFERENCIAS BIBLIOGRÁFICAS}

BAuer, R. S. y C. Chlosta (1996 $a$ ): «Sprichtwörter: ein Problem für Fremdsprachelehrer wie lerner?!», $D a F, 2:$ 91-102.

— (1996 b): «Welche Übung macht den Meister? Von der Sprichtwortforschung zur Sprichtwortdidaktik», Fremdsprache Deutsch, 15: 16-24.

ElorduY, E. y C. FANDRYCH (1996): «Seltsame Vergleiche, komische Wendungen. Idiomatische Wendungen und Wortbildungen im Deutschunterricht in Mexiko», Fremdsprache Deutsch, 15: 42-46.

KüHN, P. (1996): «Redewendungen nur im Kontext!», Fremdsprache Deutsch, 15: $10-16$.

Mieder, W. (1979): Deutsche Sprichtwörter und Redensarten. Arbeitstexte für den Unterricht, Reclam, Stuttgart.

- (1993): «Deutsche Sprichwörter im amerikanischen Sprachunterricht», Die Unterrichtpraxis, 26,1: 13-21.

RichTER, G. y M. RichTER (1996): «Harte Nüsse- leicht geknackt? Ein bunter Übungsstraub», Fremdsprache Deutsch, 15: 58-62.

WotjaK, B. (1996): «Redewendungen und Sprichtwörter. Ein Buch mit sieben Siegeln? Einführung in den Themenschwerpunkt», Fremdsprache Deutsch, 15: 4-9.

WotJak, B. y M. Richter (1988): Sage und Schreibe: Deutsche Phraseologie in Text und Praxis, Leipzig, Langenscheidt.

\section{BIBLIOGRAFÍA ADICIONAL}

DeR SPIEGEL (1996): 42, 14. Oktober, 275. (Publicidad)

Drosdowski, G. y W. Scholze-Stubenrecht (eds.) (1992): Duden, 11, Manheim, Duden Verlag.

FrankFurter ALLGEMEINE MaGAZIN (1997): 38, 15. August, Woche, 11. (Publicidad)

FRIEDRICH, W. (1995): Moderne deutsche Idiomatik, Ismaning, Max Hueber Verlag.

GRIESBACH, H. y D. SchUlZ (eds.) (2000): 1000 deutsche Redensarten, Berlín, Langenscheidt.

HERZOG, A. (1981): Idiomatische Redewendungen von A-Z. Ein Übungsbuch für Anfänger und Fortgeschrittene, Leipzig, Langenscheidt.

KüHN, P. (1996): «Redewendungen nur im Kontext!», Fremdsprache Deutsch, 15: $10-16$.

KRÜGER-LORENZEN, K. (2001): Deutsche Redesarten und was dahinter steckt, Múnich, Heyne Verlag. 
MIEDER, W. (1979): Deutsche Sprichtwörter und Redensarten. Arbeitstexte für den Unterricht, Reclam, Stuttgart.

Wotjak, B. y M. Richter (1988): Sage und Schreibe: Deutsche Phraseologie in Text und Praxis, Leipzig, Langenscheidt. 
Junto a tres ponencias plenarias, el volumen incluye cincuenta artículos presentados durante el III Congreso Internacional sobre Lengua y Sociedad, que se celebró en la Universitat Jaume I en 2006, en los que se abordan las complejas relaciones entre el discurso y la sociedad desde diferentes perspectivas teóricas y metodológicas. De este modo, los estudios aparecen clasificados en cuatro bloques temáticos: a) Análisis del discurso (estrategias y tipologías); b) Estudios sobre (des)cortesía y construcción de la imagen en el discurso; c) Norma, usos y variación lingüística; y d) Multilingüismo, interculturalidad y contacto de lenguas.

JOSÉ LUIS BLAS ARROYO, catedrático de Lengua Española en el Departamento de Filología y Culturas Europeas de la Universitat Jaume I. Dedica su principal labor investigadora a temas de sociolingüística y contacto de lenguas, sobre los que ha publicado diversos libros y numerosos trabajos en revistas y monografías especializadas.

MANUELA CASANOVA ÁVALOS, profesora Titular de Escuela Universitaria en el Departamento de Filología y Culturas Europeas de la Universitat Jaume I. Ha desarrollado diversas investigaciones en el ámbito de la disponibilidad léxica en español, así como sobre la teoría y práctica del comentario de textos.

MÓNICA VELANDO CASANOVA, profesora contratada doctora en el Departamento de Filología y Culturas Europeas de la Universitat Jaume I, desarrolla su investigación en el campo de la diacronía de la lengua, con estudios sobre sintaxis, fraseología y normativa del español.

JAVIER VELLÓN LAHOZ, profesor del Departamento de Filología y Culturas Europeas de la Universitat Jaume I. Ha publicado numerosos trabajos sobre historia del teatro, y en los últimos años se ha especializado en el análisis del discurso, fundamentalmente de los lenguajes sociales (publicidad, textos audiovisuales, periodísticos y políticos).

\section{Col·lecció Estudis filològics /28}

